"Approved for public release; distribution is unlimited."

\title{
Ecological Evaluation of Proposed Dredged Material from Richmond Harbor
}
M. R. Pinza
J. Q. Word
J. A. Ward
D. K. Niyogi
H. L. Mayhew
N. P. Kohn
Battelle/Marine Sciences Laboratory
Sequim, Washington

October 1992

Prepared for

U.S. Army Corps of Engineers under a Related Services Agreement with the U.S. Department of Energy

Contract DE-AC06-76RLO 1830

Pacific Northwest Laboratory

Operated for the U.S. Department of Energy

by Battelle Memorial Institule 


\title{
DISCLAIMER
}

This report was prepared as an account of work sponsored by an agency of the United States Government. Neither the United States Government nor any agency thereof, nor Battelle Memorial Institute, nor any of their employees, makes any warranty, expressed or implied, or assumes any legal liability or responsibility for the accuracy, completeness, or usefulness of any information, apparatus, product, or process disclosed, or represents that its use would not infringe privately owned rights. Reference herein to any specific commercial product, process, or service by trade name, trademark, manufacturer, or otherwise does not necessarily constitute or imply its endorsement, recommendation, or favoring by the United States Government or any agency thereof, or Battelle Memorial Institute. The views and opinions of authors expressed herein do not necessarily state or reflect those of the United States Government or any agency thereof.

\author{
PACIFIC NORTHWEST LABORATORY \\ operated by \\ BATTELLE MEMORIAL INSTITUTE \\ for the \\ UNITED STATES DEPARTMENT OF ENERGY \\ under Contract DE-AC06-76RLO 1830
}

Printed in the United States of America

Available to DOE and DOE contractors from the

Office of Scientific and Technical Information, P.O. Box 62, Oak Ridge, TN 3783 t;

prices available from (615) 576-8401. FTS 626-8401.

Available to the public from the National Technical Information Service,

U.S. Department of Commerce, 5285 Port Royal Rd., Springfield, VA 22161. 
PNL-8389

UC-000

ECOLOGICAL EVALUATION OF PROPOSED DREDGED MATERIAL FROM RICHMOND HARBOR

M.R. Pinza

J.A. Ward

H.L. Mayhew

J.O. Word

D.K. Niyogi

N.P. Kohn

Battelle/Marine Sciences Laboratory

Sequim, Washington

October 1992

Prepared for the

U.S. Army Corps of Engineers

under a Related Services Agreement

with the U.S. Department of Energy

Contract DE-AC06-76RLO 1830

Pacific Northwest Laboratory

Richland, Washington 99352 



\section{SUMMARY}

Navigational channels in Richmond Harbor, California, are no longer wide or deep enough to accommodate large, deep draft vessels. Because this is a major West Coast port, dredging is proposed in four areas to deepen the channel to $-38 \mathrm{ft} \mathrm{MLLW}$ and to provide a tuming area between Potrero Reach and the Inner Harbor Channel. The Water Resources Development Act of 1989 (Public Law 99-662) authorized the U.S. Army Corps of Engineers (USACE), San Francisco District, to deepen and widen the navigational channels associated with Richmond Harbor. During the summer of 1991, Battelle/Marine Sciences Laboratory (MSL) was contracted by USACE to conduct sampling and testing of sediments proposed for dredging following the guidelines established in Section 103 of the Marine Protection, Research and Sanctuaries Act of 1972 (Public Law 92-532). This Public Law mandates that potentially harmful effects of dredged material be evaluated by chemical characterization, toxicity testing, and bioaccumulation testing.

The MSL collected sediment cores to a depth of $-40 \mathrm{ft}$ MLLW (-38 ft $+2 \mathrm{ft}$ overdepth) from 28 (12-in. core) and 30 (4-in. core) stations in Richmond Harbor representing the areas proposed for dredging. The sediment cores were allocated to six composite samples referred to as sediment treatments, which were then subjected to physical, chemical, toxicological, and bioaccumulation testing. Physical and chemical parameters included grain size, total organic carbon (TOC), total volatile solids (TVS), oil and grease, total petroleum hydrocarbons (TPH), polynuclear aromatic hydrocarbons (PAH), chlorinated pesticides, polychlorinated biphenyls (PCBs), priority poliutant metals, and butylitins. The results from the test treatments were compared to results from five reference treatments representative of potential in-bay and offshore disposal sites.

The results from physical and chemical analyses show that the majority of sediments were fine-grained, representative of silt and clay (Younger Bay Mud). The sediments with the higher proportion of fine grains also exhibited higher leveis for the remaining conventional parameters. Reference treatment R-AC demonstrated the highest levels of PAHs. Four of the test treatments showed higher PAH levels when compared to the remaining reference treatments. Three pesticides, 4,4'-DDD, 4,4'-DDE, and 4,4'-DDT, were detected in 3 test treatments at levels above all 5 reference treatments, and one PCB, aroclor 1254, was also detected in 20 of the Richmond Harbor sediment treatments at levels above all 5 reference treatments. Five test treatments consistently produced the highest levels for 5 of the 10 metals analyzed in this 
study (silver, arsenic, lead, zinc, and mercury). Three test treatments had the highest levels of tributyltin or dibutyltin concentrations compared to any of the reference treatments.

Solid-phase acute toxicity tests were conducted using the bentnose clam Macoma nasuta, the polychaete Nephtys caecoides, and the amphipod Rhepoxynius abronius to evaluate sediment toxicity. Toxicity tests designed to evaluate the suspended-particulate-phase were conducted using the mysid Holmesimysis sculpta, the speckled sanddab Citharichthys stigmaeus, and larvae of the mussel Mytilus edulis. Acute toxicity was noted in Rhepoxynius abronius for one test treatment when compared to either R-AM or R-BF. Three test treatments produced acute toxicity in N. caecoides when compared to R-PF, and two test treatments were acutely toxic when compared to R-OS.

Bioaccumulation potential was evaluated by exposing the $M$. nasuta and $N$. caocoides to solid-phase treatments for 28 days and then measuring the contaminants of concern present in their tissues. Bioaccumulation testing showed variable results depending on the reference treatment used for comparison. Four notable observations were found when comparing the levels of parameters in tissues of $M$. nasuta and $N$. caacoides in test treatments to reference treatments. First, elevated levels of PAH observed in $M$. nasuta and $N$. caecoides consisted mainly of the HPAH compounds fluoranthene, pyrene, and chrysene. Second, elevated levels of pesticides and PCBs were attributed to DDD, DDE, and aroclor 1254. Third, elevated levels of metals were limited to lead and arsenic. Finally, butyltins were not elevated in any test organism tissues relative to the reference treatments. The results generated from this study can be used by USACE to help make decisions regarding acceptable disposal options for the sediments from Richmond Harbor. 


\section{CONTENTS}

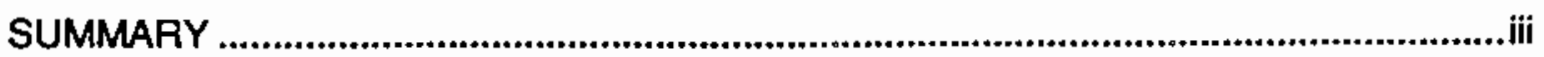

1.0 INTRODUCTION

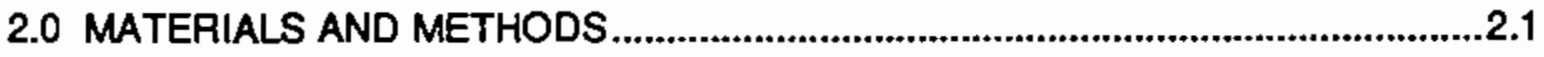

2.1 SEDIMENT AND TEST ORGANISM COLLECTION ...................................

2.1.1 Richmond Harbor Core Samples ...................................................2.1

2.1.2 Reference and Control Samples ................................................2.5

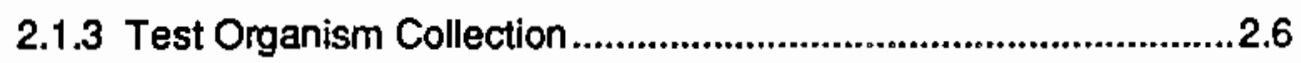

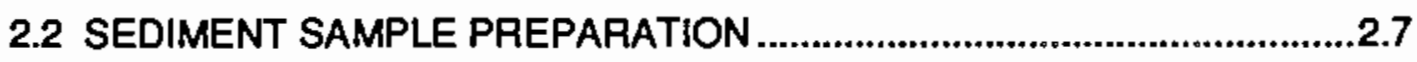

2.2.1 Laboratory Glassware and Equipment Preparation ......................2.7

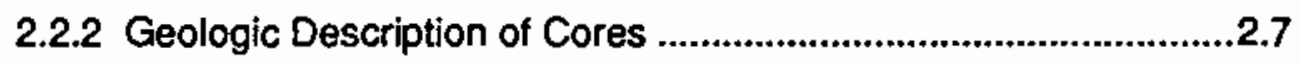

2.2.3 Preparation of Solid-Phase Samples ............................................ 2.8

2.2.4 Preparation of Suspended-Particulate Phase .............................2.9

2.3 TOXICOLOGICAL TESTING PROCEDURES .......................................2.10

2.3.1 10-Day Solid-Phase Flow-Through Test with

N. caecoides and $M$. nasuta ...................................................2.11

2.3.2 10-Day Solid-Phase Static Test with $R$. abronius ......................2.13

2.3.3 28-Day Solid-Phase Flow-Through Test with

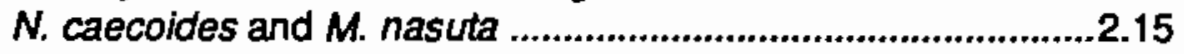

2.3.4 96-h Suspended-Particulate-Phase Static Test with

C. stigmaeus.

2.3.5 96-h Suspended-Particulate-Phase Static Test with

H. sculpta.

2.3.6 48-h Suspended-Particulate-Phase Static Test with Larval M. edulis. 
2.4 SEDIMENT AND TISSUE CHEMISTRY PROCEDURES

2.4.1 Conventional Sediment Measurements ................................2.20

2.4.2 Semivolatile Organic Compounds ........................................2.25

2.4.3 Chlorinated Pesticides and Polychlorinated Biphenyls ............2.25

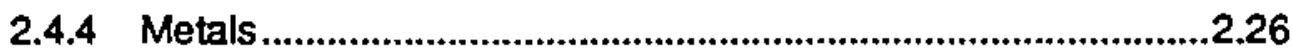

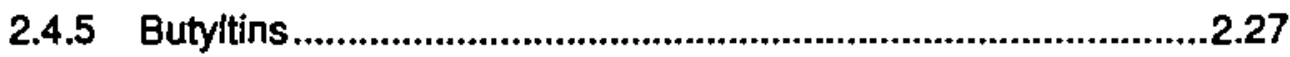

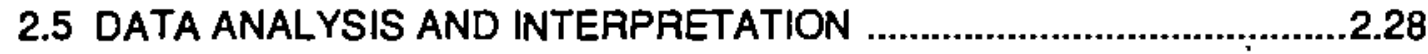

2.5.1 Randomization ................................................................2.28

2.5.2 Statistical Analysis of Solid-Phase Tests ..............................2.29

2.5.3 Statistical Analysis of SPP Tests .....................................2.29

2.5.4 Statistical Analysis of Bioaccumulation ................................2.30

2.6 QUALITY ASSURANCEIQUALITY CONTROL PROCEDURES .................................................................................2.30

2.6.1 Sediment Sampling. Tracking, and Storage.........................2.30

2.6.2 Sediment and Tissue Chemistry Quality Control Procedures ..2.31

2.6.3 Toxicological Testing Quality Control Procedures ..................2.33

3.0 RESULTS

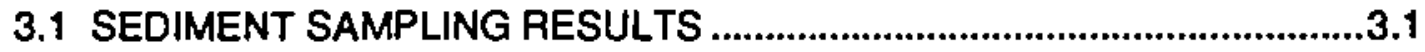

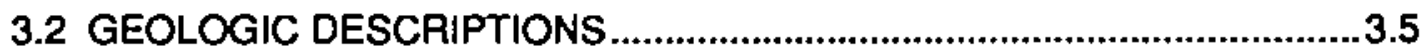

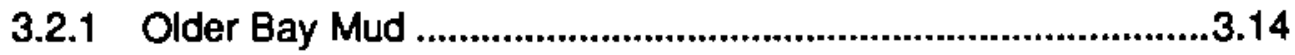

3.2.2 Younger Bay Mud ...............................................................15

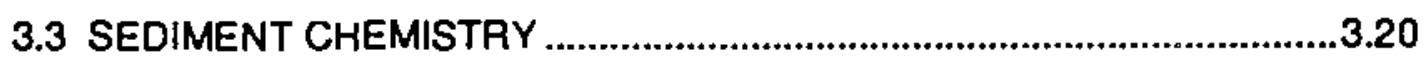

3.3.1 Conventional Sediment Measurements ...............................3.20

3.3.2 Polynuclear Aromatic Hydrocarbons ....................................3.35

3.3.3 Chlorinated Pesticides and Polychlorinated Biphenyls ............3.35 
3.3.4 Metals

.3 .39

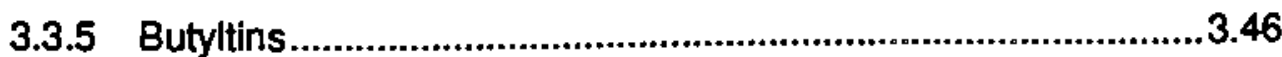

3.4 TOXICOLOGICAL TESTING RESULTS .................................................46

3.4.1 10-Day Flow-Through Solid-Phase Test with

$M$. nasuta and $N$. caecoides.

3.42 28-Day Flow-Through Solid-Phase Test with $M$. nasuta

and $N$. caecoides

3.4.3 10-Day Static Solid-Phase Test with R. abronius

3.4.4 96-h Static Suspended-Particulate-Phase Test

with C. stigmaeus

3.4.5 96-h Static Suspended-Particulate-Phase Test

with $H$. sculpta

3.4.6 48-h Static Suspended-Particulate-Phase Test with Larval M. edulis

3.5 TISSUE BIOACCUMULATION 3.59

3.5.1 Polynuclear Aromatic Hydrocarbon Bioaccumulation in $M$. nasuta 3.59

3.5.2 Pesticide and PCB Bioaccumulation in $M$. nasuta 3.65

3.5.3 Metals Bioaccumulation in $M$. nasuta. 3.65

3.5.4 Butyltin Bioaccumulation in M. nasuta 3.71

3.5.5 Polynuclear Aromatic Hydrocarton Bioaccumulation in N. caecoides

3.5.6 Pesticide and PCB Bioaccumulation in N. caecoides .3 .73

3.5.7 Metals Bioaccumulation in N. caecoides. 3.76

3.5.8 Butyltin Bioaccumulation in N. caecoides 3.78

4.0 DISCUSSION AND CONCLUSIONS 4.1

4.1 GEOLOGIC EVALUATIONS 4.1 
4.3.1 Comparison of Test Treatments to the Reference

Treatment R-AC

4.3.2 Comparison of Test Treatments to the Reference

Treatment R-AM

4.3.3 Comparison of Test Treatments to the Reference Treatment R-BF

4.3.4 Comparison of Test Treatments to the Reference Treatment R-OS

4.3.5 Comparison of Test Treatments to the Reference Treatment R-PF

4.4 CONCLUSIONS

4.4.1 Water Column

4.4.3 Bioaccumulation

APPENDIX A - MATERIALS AND METHODS USED FOR THE DESCRIPTION OF SEDIMENT CORES

APPENDIX B - GEOLOGIC ANALYSES DATA

APPENDIX C - SEDIMENT CHEMISTRY AND QUALITY ASSURANCE DATA C.1

APPENDIX D - BIOASSAY RESULTS FOR 10-DAY SOLID-PHASE TEST WITH MACOMA nasuta and NEPHTYS caecoides.

APPENDIX E - BIOASSAY RESULTS FOR 28-DAY SOLID-PHASE TEST WITH MACOMA nasuta ard NEPHTYS caecoides

APPENDIX F - BIOASSAY RESULTS FOR 10-DAY SOLID-PHASE STATIC TEST WITH 4-DAY REFERENCE TOXICANT TEST FOR RHEPOXYNIUS abronius 
APPENDIX G - BIOASSAY RESULTS FOR 96-HOUR SUSPENDED-PARTICULATEPHASE TEST AND 96-HOUR REFERENCE TOXICANT TEST FOR CITHARICHTHYS stigmaeus

APPENDIX H - BIOASSAY RESULTS FOR 96-HOUR SUSPENDED-PARTICULATEPHASE TEST AND 96+HOUR REFERENCE TOXICANT TEST FOR HOLMESIMYSIS SCUIpta H.1

APPENDIX 1 - BIOASSAY RESULTS FOR 48-HOUR SUSPENDED-PARTICULATEPHASE TEST AND. 48-HOUR REFERENCE TOXICANT TEST FOR MYTILUS edulis.

APPENDIX J - TISSUE CHEMISTRY AND QUALITY ASSURANCE DATA FOR MACOMA nasuta

APPENDIX K - TISSUE CHEMISTRY AND QUALITY ASSURANCE DATA FOR NEPTHYS caecoides K.1

APPENDIX L - STATISTICAL ANALYSIS OF BIOACCUMULATION IN MACOMA nasuta. L. 1

APPENDIX M - STATISTICAL ANALYSIS OF BIOACCUMULATION IN NEPHTYS caecoides 


\section{EIGURES}

$1.1 \quad$ Richmond Harbor Study Area ..........................................................................1.2

$1.2 \quad$ Richmond Harbor Sampling Stations................................................................. 1.3

2.1 Components of the 4-in. and 12-in. Vibratory-Hammer Coring Devices.............2.2

2.2 Richmond Harbor Composite Map .......................................................................

2.3 Flow-through Aquarium for $M$. nasuta and $N$. caecoides ................................2.12

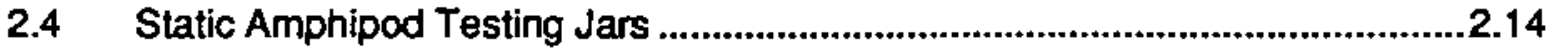

3.1 Richmond Harbor Composite Stations ................................................................

3.2 Compositing Scheme for TC-1 Through TC-5 …...............................................

3.3 Locations of R-AC and R-AM Reference Sampling Stations ..................................

3.4 Locations of R-BF Reference Sampling Stations .................................................8

3.5 Locations of R-PF Reference Sampling Station ...................................................9.

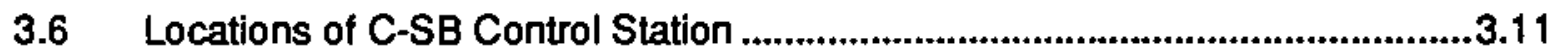

$3.7 \quad$ Locations of C-WB Control Station ..................................................................12

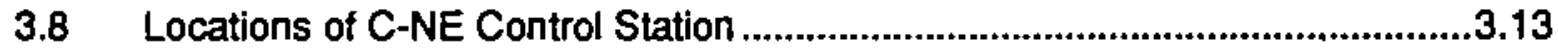

3.9 Geologic Cross Section Map of the Richmond Harbor Area .............................16

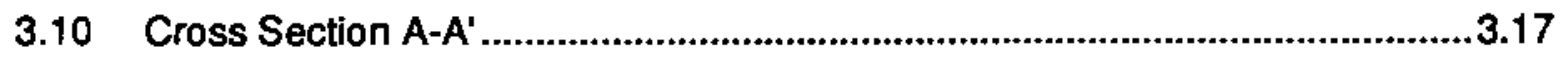

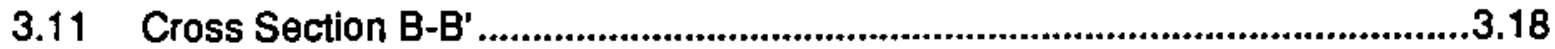

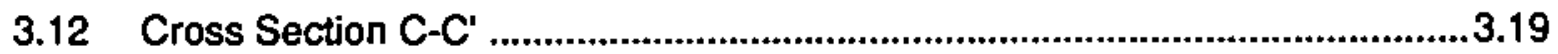

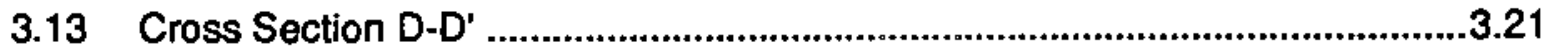

3.14 Cross Section E-E' Across the Richmond Harbor Inner Channel ....................3.22

3.15 Grain Size Distribution in Sediment Treatments ............................................3.29

3.16 Concentrations of TOC in Sediment Treatments ...........................................3.30 


\section{IABLES}

2.1 Analytical Chemistry Requirements for Richmond Harbor Sediment Treatments

2.2 Analytical Chemistry Requirements for Richmond Harbor Tissue Samples ....2.22

2.3 Grain Size Fractions Measured .................................................................2.23

2.4 Analytical Method and Corresponding Metal for Each Sample Matrix ............2.27

3.1 Information for 12-in. Core Sampling and Compositing .....................................3.3

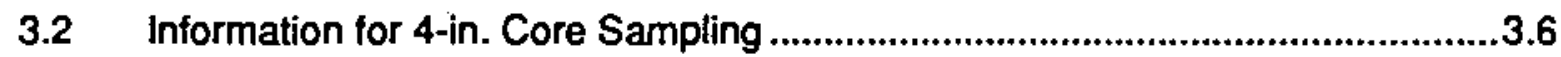

3.3 Information for Reference Sediment Sampling ...................................................10

3.4 Summary of Sediment Treatments for Testing ................................................23

3.5 Conventional Sediment Measurement Results ............................................26

3.6 Results of Dunn's Test for the 10-Day Solid-Phase Flow-Through

Test with $M$. nasuta

3.7 ANOVA Results for the 10-Day Solid-Phase Flow-Through Test

with $M$. nasuta

3.8 Results of Dunn's Test for the 10-Day Solid-Phase Flow-Through

Test with N. caecoides

3.9 ANOVA Results for the 10-Day Solid-Phase Flow-Through Test with $N$. caecoides

3.10 Results of Dunn's Test for the 28-Day Solid-Phase Flow-Through Test With $M$. nasuta and $N$. caocoides.

3.11 Results of Dunn's Test for the 10-Day Solid-Phase Static Test with $R$. abronius

3.12 ANOVA Results for the 10-Day Solid-Phase Flow-Through Test with $R$. abronius .3 .52

3.13 Percent Survival Results for the 96-h Static Suspended-Particulate-Phase Test with C. stigmaeus 
3.17 Unear Regression of TOC and Fine-Grained Sediment ....................................3.

3.18 Concentrations of TVS in Sediment Treatments ...........................................3.31

3.19 Linear Regression of TVS and Fine-Grained Sediment ...................................3.32

3.20 Linear Regression of TOC and TVS ..............................................................33

3.21 Concentrations of Oil and Grease in Sediment Treatments .............................3.33

3.22 Concentrations of TPH in Sediment Treatments ..............................................3.34

3.23 Linear Regression of TPH and Oil and Grease ............................................3.34

3.24 Concentrations of Total PAH in Sediment Treatments .....................................3.36

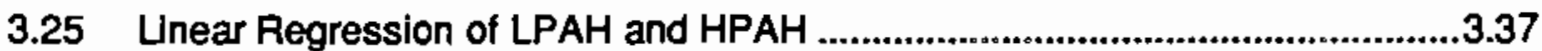

3.26 Concentrations of 4,4 -DDD in Sediment Treatments .......................................3.37

3.27 Concentrations of 4,4-DDE in Sediment Treatments .........................................3.38

3.28 Concentrations of 4,4'-DDT in Sediment Treatments .....................................3.38

3.29 Concentrations of Aroclor 1254 in Sediment Treatments ................................3.39

3.30 Concentrations of Silver in Sediment Treatments ...........................................40

3.31 Concentrations of Arsenic in Sediment Treatments ......................................3.41

3.32 Concentrations of Cadmium in Sediment Treatments ......................................41

3.33 Concentrations of Chromium in Sediment Treatments .................................3.42

3.34 Concentrations of Copper in Sediment Treatments ...........................................43

3.35 Concentrations of Mercury in Sediment Treatments ..........................................43

3.36 Concentrations of Nickel in Sediment Treatments ..........................................44

3.37 Concentrations of Lead in Sediment Treatments ...........................................45

3.38 Concentrations of Zinc in Sediment Treatments ..........................................45

3.39 Concentrations of Dibutyltin in Sediment Treatments......................................47

3.40 Concentrations of Tributyltin in Sediment Treatments .....................................4. 
3.14 T-Test and LC50 Determinations for the 96-h Static Suspended-Particulate Phase Test with C. stigmaeus

3.15 Percent Survival Results for the 96-h Static Suspended-Particulate Phase Test with H. sculpta

3.16 T-Test and LC50 Determinations for the 96-h Static Suspended-Particulate Phase Test with H. sculpta

3.17 Results of the 48-h Static Suspended-Particulate-Phase Test with $M$. edulis

3.18 T-Test and LC50 Determinations for the 48-h Static Suspended-Particulate Phase Test Based on Percent Survival with M. edulis

3.19 T-Test and EC50 Determinations for the 48-h Static Suspended-Particulate Phase Test Based on Percent Survival with $M$. edulis Larvae

3.20 Mean Low Molecular Weight PAH Concentrations in the Tissues of $M$. nasuta

3.21 Mean High Molecular Weight PAH Concentrations in the Tissues of $M$. nasuta

3.22 Low Molecular Weight PAHs in Tissues of M. nasuta That Are Significantly Different from Reference Tissue Concentrations Using Dunn's Test for Companison of All Means

3.23 High Molecular Weight PAHs in Tissues of M. nasuta That Are Significantly Different from Reference Tissue Concentrations Using Dunn's Test for Comparison of All Means

3.24 Mean Pesticide and PCB Concentrations in the Tissues of $M$. nasuta 3.66

3.25 Pesticides and PCBs in Tissues of $M$. nasuta That Are Significantly Different from Reference Tissue Concentrations Using Dunn's Test for Comparison of All Means

3.26 Mean Metals Concentrations in the Tissues of $M$. nasuta

3.27 Metals in Tissues of $M$. nasuta That Are Significantly Different from Reference Tissue Concentrations Using Dunn's Test for Comparison of All Means 
3.28 Mean Butyltin Concentrations in the Tissues of $M$. nasuta.

3.29 Butyltins in Tissue of $M$. nasuta That Are Signiticantly Different from Reference Tissue Concentrations Using Dunn's Test for Comparison of All Means

3.30 Mean Low and High Molecular Weight PAH Concentrations Detected in the Tissues of $N$. caecoides.

3.31 Low and High Molecular Weight PAHs in Tissues of $N$. caecoides That Are Significantly Different from Reference Tissue Concentrations Using

a Dunn's Test for Comparison of All Means

3.32 Pesticide and PCB Concentrations in the Tissues of $N$. caecoides .3 .75

3.33 Pesticides and PCBs in Tissues of $\boldsymbol{N}$. caecoides That Are Significantly Different from Reference Tissue Concentrations Using Dunn's Test for Comparison of All Means

3.34 Mean Metals Concentrations in the Tissues of $N$. caecoides 3.77

3.35 Metals in Tissues of $N$. caecoides That Are Significantly Different from Reference Tissue Concentrations Using Dunn's Test for Comparison of All Means

3.36 Mean Butyltin Concentrations in the Tissues of N. caecoides .3 .79

3.37 Butyltins in Tissues of $N$. caecoides That Are Significantly Different from Reference Tissue Concentrations Using Dunn's Test for Comparison of All Means

4.1 Summary of Geologic Descriptions

4.2 Summary of Significant Acute Toxicity and Bioaccumulation for Test Treatments Relative to the Reference R-AC

4.3 Summary of Significant Acute Toxicity and Bioaccumulation for Test Treatments Relative to the Reference R-AM

4.4 Summary of Significant Acute Toxicity and Bioaccumulation for Test Treatments Relative to the Reference R-BF.

4.5 Summary of Significant Acute Toxicity and Bioaccumulation for Test Treatments Relative to the Reference R-OS 4.10

4.6 Summary of Significant Acute Toxicity and Bioaccumulation for Test Treatments Relative to the Reference R-PF

4.7 FDA Action Limits 4.14 


\subsection{INTRODUCTION}

Richmond Harbor, a major West Coast port for shipping and petroleum refining, lies on the eastern shoreline of central San Francisco Bay near San Francisco, California (Figure 1.1). The currently authorized navigational depth of Richmond Harbor is - $35 \mathrm{ft}$ mean lower low water (MLLW). Because this depth will no longer accommodate large, deep draft vessels, a federal program is under way to widen channels and deepen the harbor to $-38 \mathrm{ft} \mathrm{MLLW.} \mathrm{The} \mathrm{proposed}$ dredging areas are the four major reaches of Richmond Harbor: the entrance channel, Potrero Reach, Inner Harbor Channel, and the Santa Fe Channel (Figure 1.2). Between the Potrero Reach and Inner Harbor Channel, a turning area is being considered that will allow ships to negotiate the turn into and out of the Inner Harbor Channel area. This deepening and widening program will remove an estimated 1.5 million cubic yards of dredged material.

The Water Resources Development Act of 1986 (Public Law 99-662) authorized the U.S. Army Corps of Engineers (USACE), San Francisco District, to be responsible for dredging and/ or disposal of Richmond Harbor sediments. Aquatic disposal (both in San Francisco Bay and ocean sites) is a preferred disposal option for suitable Richmond Harbor sediments. To gain authorization for aquatic disposal, the deepening program must evaluate sediment in accordance with Section 103 of the Marine Protection, Research, and Sanctuaries Act of 1972 (MPRSA), Public Law 92-532. To gain authorization for in-bay disposal, "The Corps must make determinations on the potential effects of dredged material into waters of the United States on the physical, chemical, and biological components of the aquatic environment in accordance with 40 CFR 230.11. Therefore, aquatic disposal should be divided into in-bay (Secton 404 of the Clean Water Act) and ocean (Section 103 of the MRPSA). This law stipulates that the proposed disposal of dredged material into open water will not result in potential environmental impacts. To comply with Section 103 and Section 404, the potentially harmful effects of the dredged material must be evaluated through chemical characterization, toxicity testing, and bioaccumulation testing prior to any dredging or disposal of material.

The USACE requested that Battelle/Marine Sciences Laboratory (MSL)(a) collect sediments and conduct chemical and biological evaluations under the guidelines established in

(a) The Battelle/Marine Sciences Laboratory is part of the Pacific Northwest Laboratory, which is operated for the U.S. Department of Energy by Battelle Memorial Institute. 


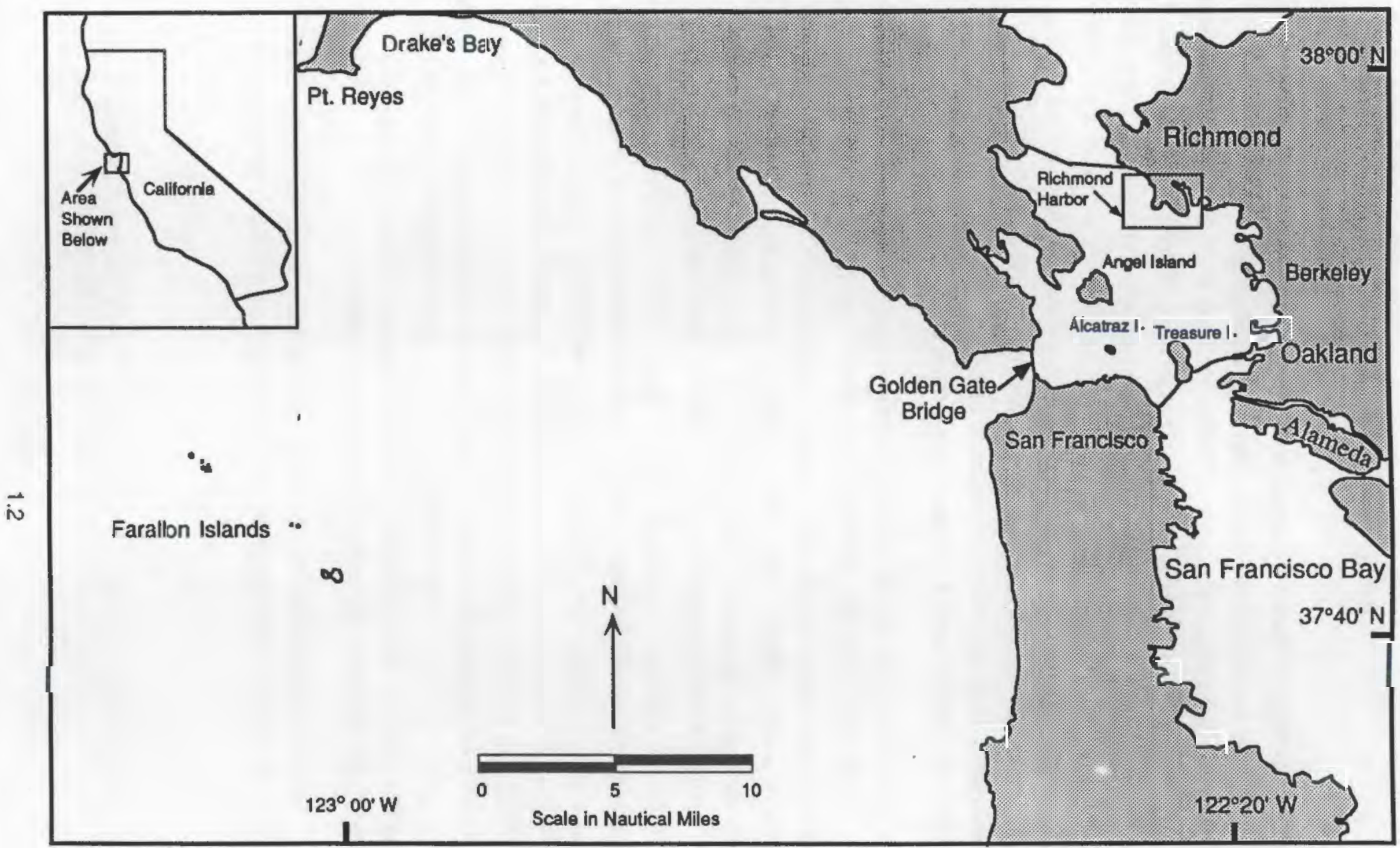

ElGURE 11. Richmond Harbor Study Area 


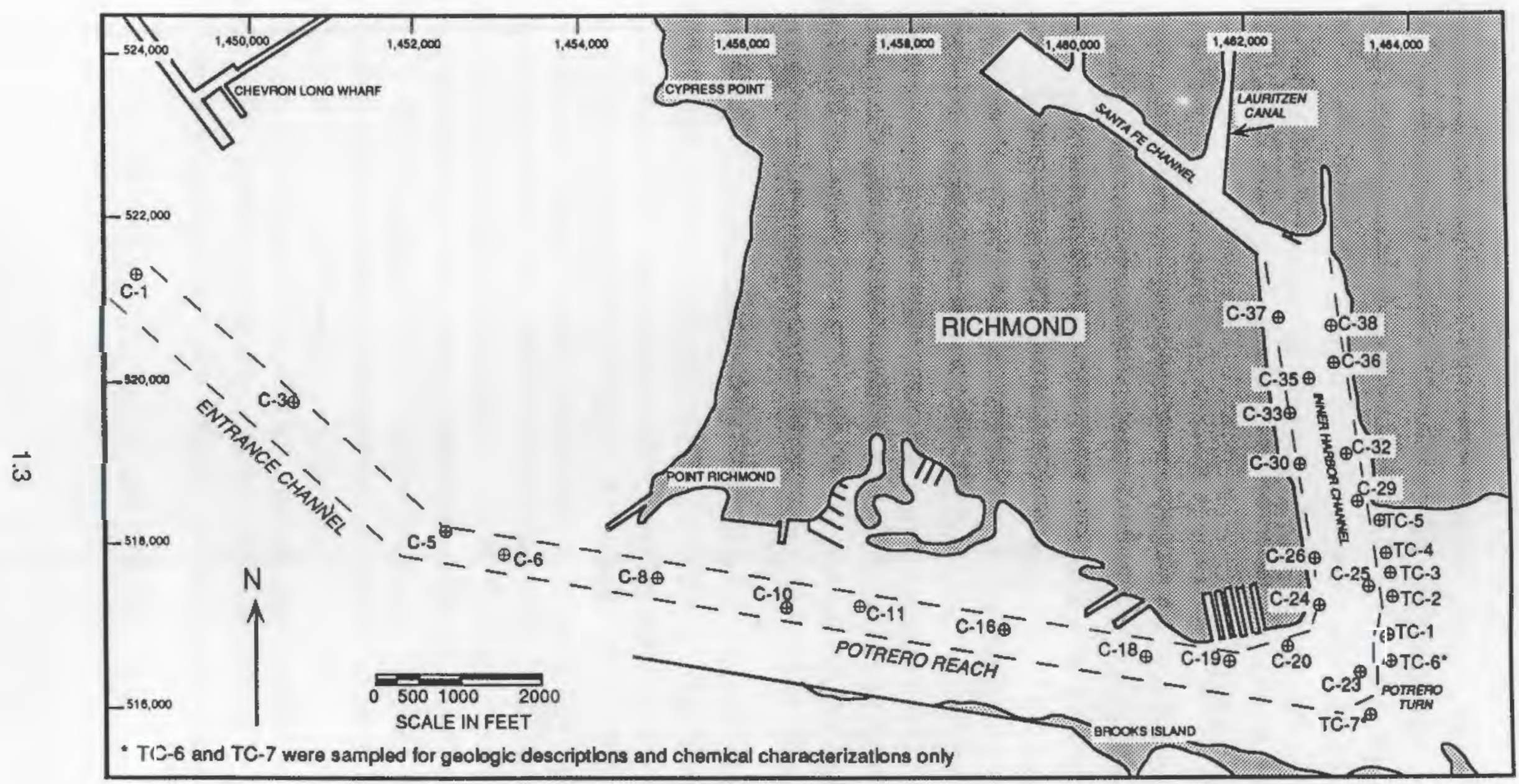

EIGURE 1.2. Richmond Harbor Sampling Stations 
Section 103. In 1989, the MSL conducted a detailed program to chemically characterize sediments proposed for dredging from Richmond Harbor. A total of 55 sediment treatments were subjected to characterization and testing. These sediment treatments were taken from sites in the entrance channel, Potrero Reach, the proposed tuming circle, the Inner Harbor Channel, and the Santa Fe Channel. The data from this sediment characterization is contained in Environmental Evaluations for Deepening of Richmond Harbor and Santa Fe Channels, Task 4: Chemistry Program (Brown et al. 1990).

The sediment characterization data contained in Brown et al. (1990) were used to plan the additional chemical and biological evaluations of Richmond Harbor sediments that are the subject of this report. Chemical characteristics were used to group sampling stations in the entrance channel, Potrero Reach, Inner Harbor Channel, and the proposed turning circle into representative composite samples for biological testing. The USACE excluded Santa Fe Channel sediments from further aquatic testing based on the levels of $4,4^{\prime}-D D T$ ( 130 to $470 \mu \mathrm{g} / \mathrm{kg}$ dry weight) as well as the presence of other chlorinated pesticides in sediment (4,4'-DDE, 4,4'-DDD, and dieldrin). The northernmost part of the Inner Harbor Channel, where the Santa Fe Channel enters it, was also excluded from further aquatic testing because the levels of pesticides at these sites appeared to be influenced by Santa Fe Channel sediments.

In June 1991, the MSL collected sediment cores (to a depth of $-38 \mathrm{ft} M L L W+2 \mathrm{ft}$ overdepth) from 28 (12-in. core) and 30 (4-in. core) stations in Richmond Harbor. Sediment from each of the 28 stations were combined into six composites (COMPs), subjected to physi$\mathrm{cal} / \mathrm{chemical}$ evaluation, and subjected to toxicological and bioaccumulation testing. Individual core samples from each of the 30 stations were described geologically. Samples from two additional stations located in the Potrero Turning Circle were also taken for geologic description and chemical characterization (Figure 1.2). In addition to the dredged material samples, sediment from five reference stations and three control stations was collected with a pipe dredge or a van Veen grab and tested concurrently with the Richmond Harbor sediments. The reference stations allowed the biological responses and contaminant levels of a proposed dredged sediment sample to be compared to those of a potential disposal area that is "...substantially free of contaminants and which...reflects conditions that would exist in the vicinity of the disposal site had no dredged-material disposal ever occurred...." The control sediments (native to the area) allowed validation of test results through evaluation of the health and normal response of the test organisms. 
After field collection, sediments were shipped to the MSL to begin chemical analysis and toxicological testing. All testing done by the MSL followed the protocols in the 1991 Implementation Manual Evaluation of Dredged Material Proposed for Ocean Disposal (USACE/EPA 1991) published jointly by USACE and the U.S. Environmental Protection Agency (EPA), hereinafter referred to as the 1991 implementation Manual. Chemical parameters included measurements of EPA priority pollutant metals, polynuclear aromatic hydrocarbons (PAHs), polychlorinated biphenyls (PCBs), chlorinated pesticides, butylins, and conventional parameters. The six COMPs were evaluated in solid-phase, bioaccumulation, and suspended-particulate-phase (SPP) tests. Three species of marine organisms (the juvenile sanddab Citharichthys stigmaeus, the mysid Holmesimysis sculpta and larvae of the mussel Mytilus edulis) were used in SPP tests to evaluate water column effects of dredged material disposai. Three species of marine organisms (the polychaete Nephtys caecoides, the bentnose clam Macoma nasuta, and the amphipod Rhepoxynius abronius) were exposed to solid-phase testing. The 28-day exposure of $M$. nasuta and $N$. caecoides to the solid phase of the dredged material was used to measure the bioaccumulation potential of sediment-bound contaminants. The tissues of these organisms were removed and measured for the same parameters as the sediments, with the exception of the conventional parameters. The toxicity and bioaccumulation results from test sediments were statistically compared to the reference sediments.

This report is intended to provide information required to address potential ecological effects from the proposed disposal of Richmond Harbor sediments in the ocean. This report is divided into five sections. Section 1.0 is the introduction containing a brief overview of the Richmond Harbor project. Section 2.0 describes the methods and materials used for sample collection, processing, biological testing, physical and chemical analyses of sediments and tissues, data analysis, and quality assurance requirements. Section 3.0 presents the results of geologic descriptions, biological testing, and physical and chemical analyses. Section 4.0 presents a discussion of the results and the conclusions. Section $\mathbf{5 . 0}$ lists the literature cited in support of this document. A series of appendixes contain detailed data listings for the following areas:

Appendix A Method of Geologic Description

Appendix B Geologic Core Data Logs

Appendix C Sediment Chemistry and Quality Assurance Data

Appendix D-I Toxicity Test Data

Appendix J-K Tissue Chemistry and Quality Assurance Data

Appendix L-M Bioaccumulation Results 


\subsection{MATERIALS AND METHODS}

\subsection{SEDIMENT AND TEST ORGANISM COLLECTION}

Sediment core samples were collected from 28 stations (12-in. core) and 30 stations (4in. core) in Richmond Harbor using vibratory-hammer core samplers designed by MSL and Manson Construction (Figure 2.1). The sediment samples were collected to $-40 \mathrm{ft}$ MLLW (38 ft Jlus $2 \mathrm{ft}$ overdepth). Specific locations of sediment sampling stations are shown in Figure 1.2. The 12-in. core sampler was used to collect the large volume of sediment needed for biological testing while minimizing contamination caused by excessive sample handling. The 4-in. core sampler was used to collect sediment needed for geologic descriptions and chemical characterizations at each station. In addition to the test sediment samples, reference and control sediment samples were collected to provide a comparison for sediment chemistry and biological testing. Five reference area sediment samples were collected using a pipe dredge sampler; three control samples were collected using either an MSL-designed sand dredge, modified Van Veen grab sampler, or shovel and bucket. Six species of marine organisms were required for biological testing; three of the species ( $N$. caecoides, $C$. stigmaeus, and $H$. sculpta) were collected from the northem California coast, and the remaining three species (M. nasuta, $R$. abronius, and $M$. edulis) were collected from Puget Sound in Washington State.

Navigation support for locating stations in Richmond Harbor was provided by Towill, Inc., of Concord, California, and included a survey vessel and operator. The surveyors used a laser/ range azimuth positioning system (EDM-Geodimeter AGA-120, Wild T-2 one second theodolite). Towill also provided MLLW corrected water depths at each station by measuring the actual depth with a recording fathometer (Raytheon DE719-E), measuring the distance to the water surface elevation from a known elevation above sea level, and calculated the difference between the water surface elevation and $0 \mathrm{ft}$ MLLW to provide for actual tidal heights.

\subsubsection{Bichmond Harbor Core Samples}

All stations were sampled to $-40 \mathrm{ft}$ MLLW using the 12-in. and 4-in. vibratory-hammer core samplers. The 12-in. core samples were taken at 28 stations and combined to form six COMPs (COMPs I through VI) (Figure 2.2). The 4 in. core samples were collected from 30 stations and used for geologic description and sediment chemistry. The six COMPs were submitted for chemical analyses and used for biological testing. The 4-in. cores were collected and stored in noncontaminating Lexan polycarbonate tubes that maintained the stratigraphic 


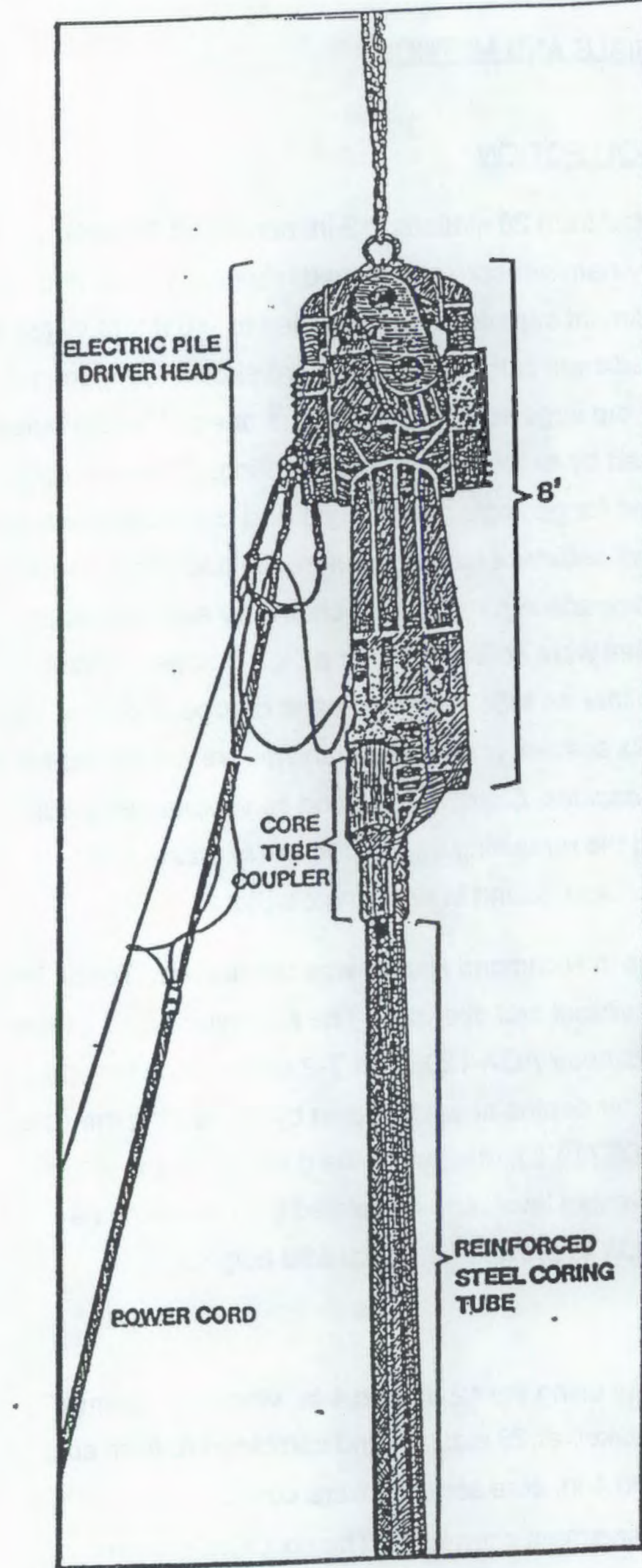

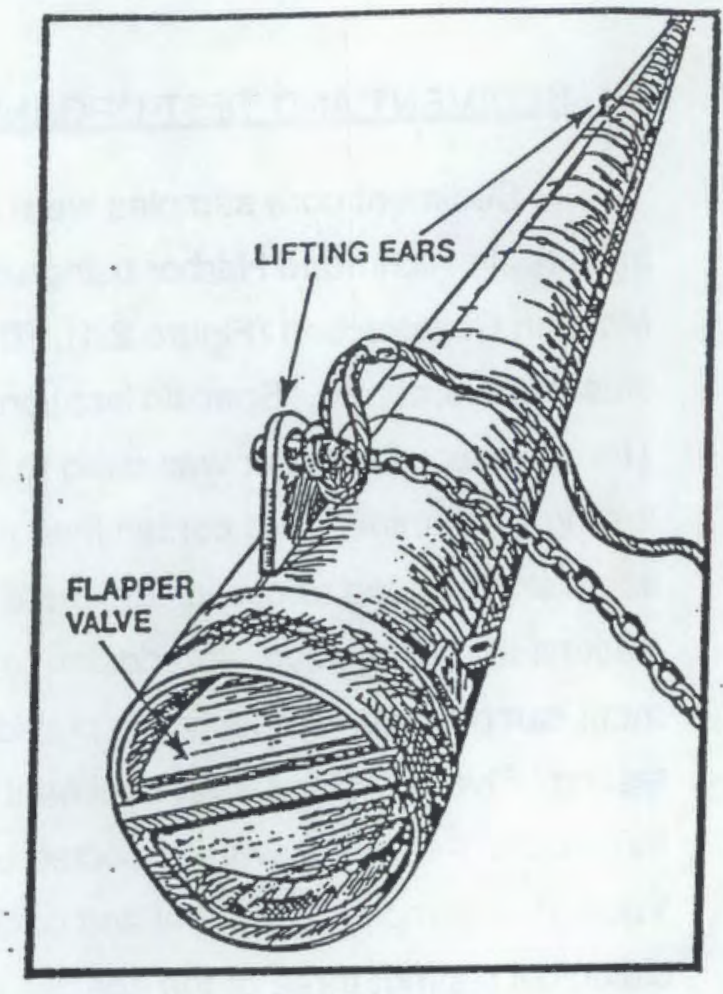

12-in. Coring Device

Vibratory-hammer Core FIGURE 2.1. Components of the 4-in. and 12-in. Vibratory-Hammer Coring Devices 


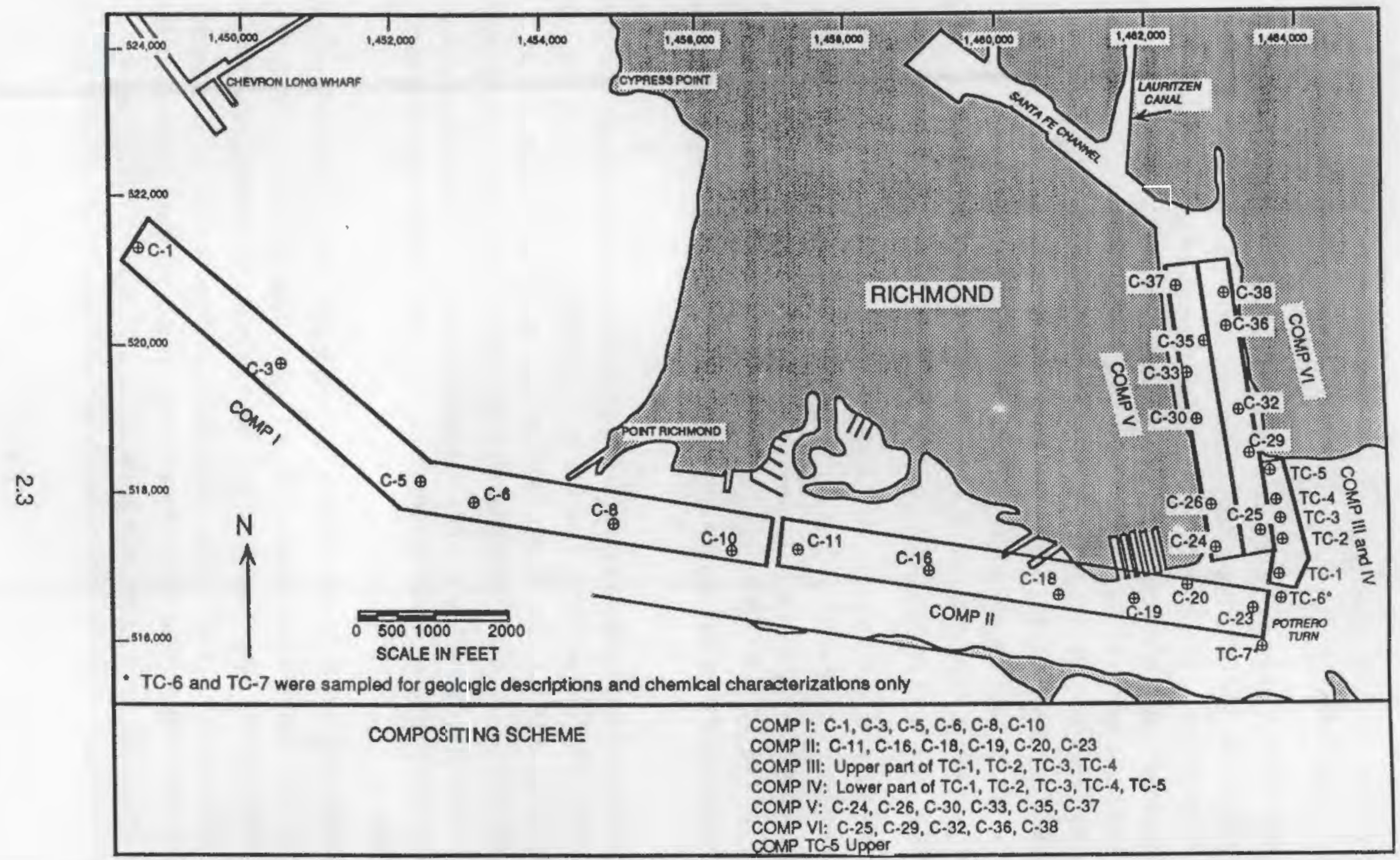

EIGURE22. Richmond Harbor Composite Map 
integrity of these sediments, which allowed a geologist to characterize the types of sediments composing each station.

Both the 12-in. and 4-in. core samplers were deployed from the Manson Construction derrick barge Vasa. The coring apparatus was attached to an electric vibratory hammer and suspended by a crane on the derrick barge. When the coring apparatus was positioned directly above the sampling station, the core was lowered through the water to the sediment surface. For harder-packed sediments, the vibratory hammer was engaged and driven through the sediment to project depth as indicated by the water surface level relative to calibrations ( $\mathrm{ft}$ ) on the outside of the core barrel. For soft sediment, the weight of the coring apparatus caused penetration through the sediment without vibration; if harder material was encountered, the vibratory hammer was engaged to project depth. The coring apparatus was then extracted from the sediment, detached from the vibratory hammer, and lowered onto the barge deck.

As each 12-in. core was placed horizontally on deck, the hinged door of the core barrel was opened, and the sediment was measured from the mudline downward to ensure that appropriate depth was reached. If the required core length was achieved, the sediment was marked at $-40 \mathrm{ft} \mathrm{MLLW.} \mathrm{If} \mathrm{the} \mathrm{required} \mathrm{core} \mathrm{length} \mathrm{was} \mathrm{not} \mathrm{achieved,} \mathrm{the} \mathrm{sediment} \mathrm{in} \mathrm{the} \mathrm{core}$ barrel was removed and the core sampler rinsed with seawater to prepare for a second coring attempt.

Once the core segments were measured, the appropriate amount of sediment for chemical and biological analyses was transferred from the core barrel to an epoxy-coated container using a stainless-steel spade. Each sample container was labeled with the project name, station or composite designation, contributing station(s), total vertical segment of contributing core in feet, and the sampling date(s). The containers were sealed and kept $\operatorname{cool}\left(\sim 4^{\circ} \mathrm{C}\right)$ in a freezer on board the sampling vessel until loaded into a refrigerated truck at the end of the sampling day.

Sediment was also collected to $-40 \mathrm{Ht}$ MLLW using the 4-in. core sampler. One core was collected per site. The core barrel was lined with a 3.125-in. (inner diameter) clear, steamcleaned Lexan core liner. When each core was brought on board, the liner was pulled from the barrel and the sediment was measured from the mudline downward to determine if appropriate depth ( $-40 \mathrm{H}$ MLLW) was reached. If the core achieved project depth, it was carefully carried to the cutting stand where it was capped, sealed, labeled, and if necessary, cut into shorter sections to fit in the freezer. If the required core length was not achieved, the sediment in the core 
barrel was emptied and the core sampler rinsed with seawater to prepare for a second coring attempt. Each core label included an arrow pointing to the top of the core, the station designation, core section indicator (e.g., Section 1 of 2 and Section 2 of 2), length interval from the mudline (e.g., 0 to $3 \mathrm{ft}$ ), and sampling date. When each 4-in. core was labeled and sealed, it was kept in a freezer on board the sampling vessel at $\sim 4^{\circ} \mathrm{C}$.

Detailed sampling records were maintained for each station. These included the station name, date, type of core (12-in. or 4-in.), replicate number, uncorrected water depth, tide height, corrected water depth, required core length, sampling time, total core collected, and comments. At the end of each sampling day, cores were off-loaded from the barge and stored in a refrigerated truck at the staging area. An inventory form was maintained daily as the core samples were placed onto the refrigerated truck for shipment to MSL. When sampling was completed, the inventory form was confirmed and recorded on the MSL chain-of-custody forms. The custody forms (three carbon copies) were signed by the field leader who kept one copy and sealed the others with the core samples.

\subsubsection{Beference and Control Samples}

Sediment samples from the five reference stations were collected with a pipe dredge deployed from the FV Cobra, a charter boat owned and operated by Bob Smith Sportfishing. Sampling locations were determined by LORAN C, variable fix and range radar systems, and visible ranges. The vessel's electronic navigation systems were verified at known fixed locations, such as the Golden Gate channel pilot buoy. Reference sampling records were maintained in a log book and consisted of station position, date, time, replicate, water depth, sediment type, and comments. All reference samples were kept in labeled coolers on board the sampling vessel until they were off-loaded to the refrigerated truck.

The control sediment sampling stations were located in Sequim Bay, Washington; West Beach, Whidbey Island, Washington; and Dillon Beach/Tomales Bay, California. The control sediment from Sequim Bay, Washington, was collected with a modified Van Veen grab sampler $\left(0.1 \mathrm{~m}^{2}\right)$ deployed from an $\mathrm{MSL}$ research vessel. West Beach sediment and the amphipod R. abronius, were collected with a srnall, MSL-designed anchor-dredge sampler. The dredge was deployed from MSL's 17-ft Boston Whaler in approximately $15 \mathrm{ft}$ of water. The West Beach sampling location was determined by reference to shoreline features. Dillon Beach control sediment was collected with a shovel by Brezina and Associates concurrently with the test organism N. caecoides. The Dillon Beach sediment was shipped overnight to the MSL, where it 
was stored at $4^{\circ} \pm 2^{\circ} \mathrm{C}$. The test organisms were also shipped to the MSL and maintained at proper holding conditions.

\subsubsection{Test Organism Collection}

Six species of marine organisms were used in Richmond Harbor toxicity tests:

- Bentnose clam (Macoma nasuta)

- Polychaete (Nephtys caecoides)

- Phoxocephalid amphipod (Rhepoxynius abronius)

- Juvenile flatfish (sanddab) (Citharichthys stigmaeus)

- Juvenile mysid shrimp (Holmesimysis sculpta)

- Larvae of bay mussel (Mytilus edulis)

All the organisms were wild-captured individuals collected either by a commercial supplier or by the MSL. Amphipods (R. abronius) were collected by MSL off West Beach, Whidbey Island, using the specially designed anchor dredge deployed from a 17-ft Boston Whaler. Sediment brought up with the dredge was sieved through a 2-mm mesh screen to remove large debris and predatory species. During sampling, the amphipods were kept in coolers partially filled with their native sediment and seawater and were delivered to a holding tank at the MSL at the end of the collection day. M. nasuta were collected from intertidal zones in Discovery Bay near Gardiner, Washington, by a commercial supplier using a shovel, sieve, and bucket. Until shipment, the clams were kept cool by placing them in large containers filled with sediment and seawater from the collection site.

Brezina and Associates (Dillon Beach, Califomia) supplied N. caecoides, C. stigmaeus, and $H$. sculpta individuals for toxicity testing. $N$. caecoides were collected from mud flats in Tomales Bay, California, using a shovel, bucket, and sieve and then placed into clean coolers containing sediment and seawater from the collection site. The $C$. stigmaeus were collected from Tomales Bay, California, in 12 to $15 \mathrm{ft}$ of water. C. stigmaeus were captured with a small trawl with a 0.25 -in. mesh net. After capture, the net was held close to the work boat so that a small dip net could be used to transfer the organisms into double plastic bags containing oxygen-saturated seawater. H. sculpta were collected by Brezina and Associates in Monterey Bay, California. They were captured with a plankton dip net and transferred to a holding container aboard the work boat where they were sorted by appropriate age and size class. After collection, the containers were supersaturated with oxygen $(22 \mathrm{ppm})$ and shipped overnight to MSL. 


\subsection{SEDIMENT SAMPLE PREPARATION}

Sediment used for biological testing was prepared within a 14-day holding period. During that period, the core samples were received at the MSL and inventoried against the chain-ofcustody form, processed for solid-phase and SPP testing, and biological tests initiated. The following sections describe equipment preparation, geologic descriptions of core samples, and preparation of sediments for solid-phase and SPP tests.

\subsubsection{Laboratory Glassware and Equipment Preparation}

All glassware, stainless-steel utensils, plastic, laboratory containers, and equipment went through stringent cleaning procedures to avoid contaminating sediment samples. Glassware, including test containers, aquaria, and sediment transfer equipment, was washed with warm, soapy water, rinsed five times with deionized water, then soaked in a $5 \%$ reagent grade nitric acid bath for a minimum of $4 \mathrm{~h}$. After soaking, glassware was rinsed with deionized water five times and allowed to dry. Titanium tools, PVC, Nalgene, and other plastic items such as funnels were also washed and soaked in acid baths in the same manner as glassware.

Stainless-steel bowls, spoons, spatulas, and other utensils were washed with warm, soapy water, rinsed five times with deionized water, and allowed to air dry. They were then rinsed with methylene chloride under a fume hood and allowed to evaporate under the hood before use.

Rubber stoppers and other porous materials were washed with warm, soapy water and rinsed five times with deionized water. These items were then "seasoned" by continuous soaking in, or exposure to, $0.45-\mu \mathrm{m}$-filtered seawater for at least 2 days prior to use.

Large pieces of laboratory equipment such as the epoxy-coated mixer used to mix sediment and epoxy-coated boards used to hold cores for geologic descriptions were washed with a mild soap solution and thoroughly rinsed with tap water followed by deionized water.

Equipment used to determine water quality parameters, such as $\mathrm{pH}$, dissolved oxygen, temperature, and refractometers were calibrated according to the manufacturer's specifications and intemal MSL procedures.

\subsubsection{Geologic Description of Cores}

A geologic characterization of each Richmond Harbor sampling station was conducted by an MSL geologist on the 4-in. Lexan-lined core. The Lexan core tube maintains the strati- 
graphic integrity of the sediment. All core sections from one station were removed from storage and the Lexan tube cut longitudinally with a circular saw. A linoleum knife was used to split the core open to expose the sediment stratigraphy. The geologist measured and described the entire core from mudline to bottom, recording data on a core data log. The geologic characterization protocol (Appendix A) was consistent with American Society for Testing Materials (ASTM) Method D2488-84 (ASTM 1984).

\subsubsection{Preparation of Solid-Phase Samples}

Sediment samples prepared for solid-phase testing and used for chemical and biological evaluation were collected with the 12-in. vibratory-hammer core (test sediment representing dredged material), a sand dredge sampler at the reference sites (existing environment of a disposal site without dredged material), and an amphipod dredge or shovel for the control sediment (environment of a benthic test organism).

Test sediment collected with the 12-in. vibratory-hammer core was used for biological testing and came from stations that were combined to yield six COMPs. The location of the 28 Richmond Harbor sampling stations and the determination of the stations designated to each composite were established prior to field sampling. Individual stations comprising a composite with a specific volume of sediment were placed in the appropriate pre-labeled bucket. The prelabeled buckets with COMPs I through VI were then sent back to the MSL for processing.

Test sediment collected with the 4-in. vibratory-hammer core were analyzed separately for 30 individual sampling stations. These samples were collected in Lexan cores that were capped, labeled, and divided into smaller sections for shipment to MSL. At MSL, the cores were split in a longitudinal direction and placed on an epoxy-coated table for geologic description.

The procedure for homogenizing the 4-in. cores and the six COMPs created from the 12 in cores varied according to sediment type. Compacted clay sediments were separated into smaller pieces with a stainless-steel grater and then mixed either with stainless-steel spoons or a mixer coated with a special epoxy paint. Silt, soft clay, and sandy sediments were mixed with stainless-steel spoons in stainless-steel bowls until uniform consistency and color were visible throughout the sediment. Minimal amounts of $0.45-\mu \mathrm{m}$-filtered seawater were added as needed to achieve a homogeneous consistency. Once a sediment sample was thoroughly homogenized, it was referred to as a sediment treatment indicating that all the necessary sample processing was completed and the sediment could be chemically analyzed and used in testing. Sample aliquots for chemical analyses were placed in clean, labeled containers appropriate for 
the parameters to be measured. Solid-phase sediment treatments not used immediately for solid-phase testing or SPP preparation were returned to the labeled, epoxy-coated metal buckets and stored at $4^{\circ} \mathrm{C}$.

The reference and control sediments were maintained at $4^{\circ} \mathrm{C}$ until sieved. To perform the sieving process, sediments were placed onto stacked screens, with mesh diameters of 0.5 to $1.0 \mathrm{~mm}$, set on top of a sieving stand. This sieving stand was designed to empty directly into a $55 \mathrm{gal}$, pre-cleaned aquarium containing approximately $15 \mathrm{gal}$ of filtered seawater. A Simms Geyser submersible pump was placed in the aquarium to recirculate the water. Organisms collected during the sieving process were discarded because they could influence the results of the test. Small debris such as shells or wood chips were placed into the collection aquarium to preserve the physical nature of the sediment. The sieved sediment was then allowed to settle ovemight at $4^{\circ} \mathrm{C}$. After settling, the overlying water was siphoned off and the sediment was transferred to an epoxy-coated mixer that was operated for 5 to $10 \mathrm{~min}$ or until a homogenous sediment mixture was achieved. At the end of the mixing period, the sediment was transferred to the 55-gal aquarium and stored at $4^{\circ} \mathrm{C}$ until needed for testing. Between sieving of reference sediments, all equipment was thoroughly rinsed with $0.45-\mu \mathrm{m}$-filtered seawater to avoid potential cross-contamination between samples.

\subsubsection{Preparation of Suspended-Particulate Phase}

- The SPP of sediment COMPs was used to evaluate water column effects of suspendedparticulate-phase materials for open water dredged material disposal. The SPP is the liquid that remains after intermixing sediment with seawater and allowing heavier particles to settle to the bottom. Because SPP preparation does not involve filtration, this phase contains suspended particles as well as dissolved constituents. The SPP tests evaluate effects caused by both the physical presence of the suspended particles and the chemical toxicity of contaminants associated with the particles or dissolved fractions. The process is intended to approximate exposure conditions created as a result of materials being discharged through the water column during dredged material disposal operations.

The first step of SPP preparation was to create a 4:1 (volume.volume) water to sediment slurry in 1-L glass jars with Teflon-lined lids. The jars were marked at $200-\mathrm{mL}$ and $400-\mathrm{mL}$ increments. Seawater was added to the 200 - $\mathrm{mL}$ mark and homogenized sediment was added until the water was displaced to the 400 - $\mathrm{mL}$ mark. The jar was filled to $1 \mathrm{~L}$ with filtered seawater. A set of 12 jars containing sediment and water were placed on a shaker table and agitated for $30 \mathrm{~min}$ at a shaking rate of 120 to $150 \mathrm{cycles} / \mathrm{min}$. After shaking, the slurry was poured into 
500-mL Teflon containers with tightly fitting lids, which were then placed in a centrifuge and spun for 10 to $15 \mathrm{~min}$ at approximately $1750 \mathrm{rpm}$. The 10-min centrifugation was allowed by the 1991 Implementation Manual and was necessary to ensure that test organisms would be visible at the first observation after exposure to SPP test treatments. After centrifugation, the supernatant was poured into clean, 10-gal aquaria for use in the SPP tests as soon as possible while the remaining sludge mixture was discarded. If SPP was not used immediately, the aquaria were stored at $4^{\circ} \mathrm{C}$. The Teflon jars were rinsed after each use, and the above process was continued until an adequate amount of SPP was produced. Between different sediment SPP preparations, all glass and Teflon containers were appropriately cleaned according to procedures described in Section 2.2.1.

\subsection{IOXICOLOGICAL TESTING PROCEDURES}

Solid-phase, SPP, toxicity, and bioaccumulation tests were performed on each composite at the MSL in Sequim, Washington. These tests were designed to assess distinct ecological effects of proposed aquatic disposal of dredged material from the Richmond Harbor Project.

The solid-phase tests were used to assess the acute toxicity and bioaccumulation potential of dredged material after settling at an aquatic disposal site. Three species of marine organisms were exposed to the sediment from the Richmond Harbor sampling stations, reference area sediment, and control sediment. Two acute toxicity tests were conducted: 1) a 10day solid-phase flow-through acute toxicity test using the polychaete N. caecoides, and 2) a 10day solid-phase static test using the amphipod $R$. abronius. The bioaccumulation test was a 28day exposure of $N$. caecoides and $M$. nasuta. The purpose of the 28-day test was to assess the potential for bioaccumulation of contaminants from the sediment into the tissues of the organisms. The test treatments and procedures were similar to the 10-day test except they involved a longer exposure period, larger test population, and depuration process for surviving $M$. nasuta and $N$. caecoides.

The SPP tests were used to assess the potential effects of discharging dredged material through the water column during disposal operations. The SPP tests evaluate 1) effects caused by the physical presence of suspended particles, 2) toxicity of chemical contaminants associated with the particles, or 3 ) the chemical contaminants after they have dissolved into the water column. Three marine species were used in these tests: mysids (H. sculpta), juvenile sanddabs (C. stigmaeus), and larvae of the bay mussel ( $M$. edulis). The SPP treatments were 
prepared as described in Section 2.2.4. For each SPP treatment, there were four replicates of each of the four SPP concentrations: $0 \%$ (seawater), $10 \%, 50 \%$, and $100 \%$ (SPP).

The MSL facilities provided the required conditions for flow-through solid-phase tests, static solid-phase tests, and static SPP tests. Laboratory equipment included a controlledtemperature environment, flow-through seawater supply, lighting control, and air supply.

\subsubsection{0-Day Solid-Phase Flow-Through Test with N. caecoides and M. nasuta}

Prior to testing, $\boldsymbol{N}$. caecoides were held in their native sediment in shallow trays covered with well-aerated $15^{\circ} \mathrm{C}$ seawater from a gravity-fed flow-through system. $M$. nasuta were held in large water tables or holding tanks containing clean sediment with flow-through $15^{\circ} \mathrm{C}$ seawater. Temperature, $\mathrm{pH}$, dissolved oxygen (DO), and salinity of water in each holding tank were monitored daily. The organisms were not fed during the holding period.

The flow-through bioaccumulation test using $M$. nasuta and $N$. caecoides was conducted in 10-gal aquaria placed in random positions on water tables. Figure 2.3 shows the system used for flow-through tests. Each aquarium was filled with approximately $8 \mathrm{~L}$ of sand-filtered seawater via the flow-through system. Sediment was then added to a depth of $3 \mathrm{~cm}$ by measuring the required amount $(3870 \mathrm{~mL})$ into a glass container and pouring the sediment into the aquaria. The sediment was washed with seawater to distribute the sediment evenly over the bottom of the aquaria. The flow-through system was initiated and aquaria were allowed to fill to a total volume of approximately $36 \mathrm{~L}$. For $4 \mathrm{~h}$, suspended materials in the aquaria settled and the flow-through system was adjusted and calibrated to deliver $125 \pm 10 \mathrm{~mL} / \mathrm{min}$ of seawater flow to each aquarium. The system operated ovemight before the organisms were added.

To initiate the test, $25 \mathrm{M}$. nasuta and $40 \mathrm{~N}$. caecoides were collected from the holding tanks and placed in each aquarium. The label on each test aquaria included initiation time/date and the initials of the person who placed the organisms in each chamber. Water quality parameters (noted below) were measured daily in at least one replicate of each sediment treatment and recorded on water quality data sheets. (Water quality data are provided in Appendixes D through I). The water quality parameters and ranges established for the tests were

$\begin{array}{ll}\text { Dissolved Oxygen } & \geq 4.0 \mathrm{mg} / \mathrm{L} \\ \text { pH } & \text { ambient } \pm 0.5 \text { units } \\ \text { Salinity } & \text { ambient } \pm 2.0 \% \\ \text { Temperature } & 15.0^{\circ} \mathrm{C} \pm 2.0^{\circ} \mathrm{C} \\ \text { Flow Rates } & 125 \pm 10 \mathrm{~mL} / \mathrm{min} .\end{array}$




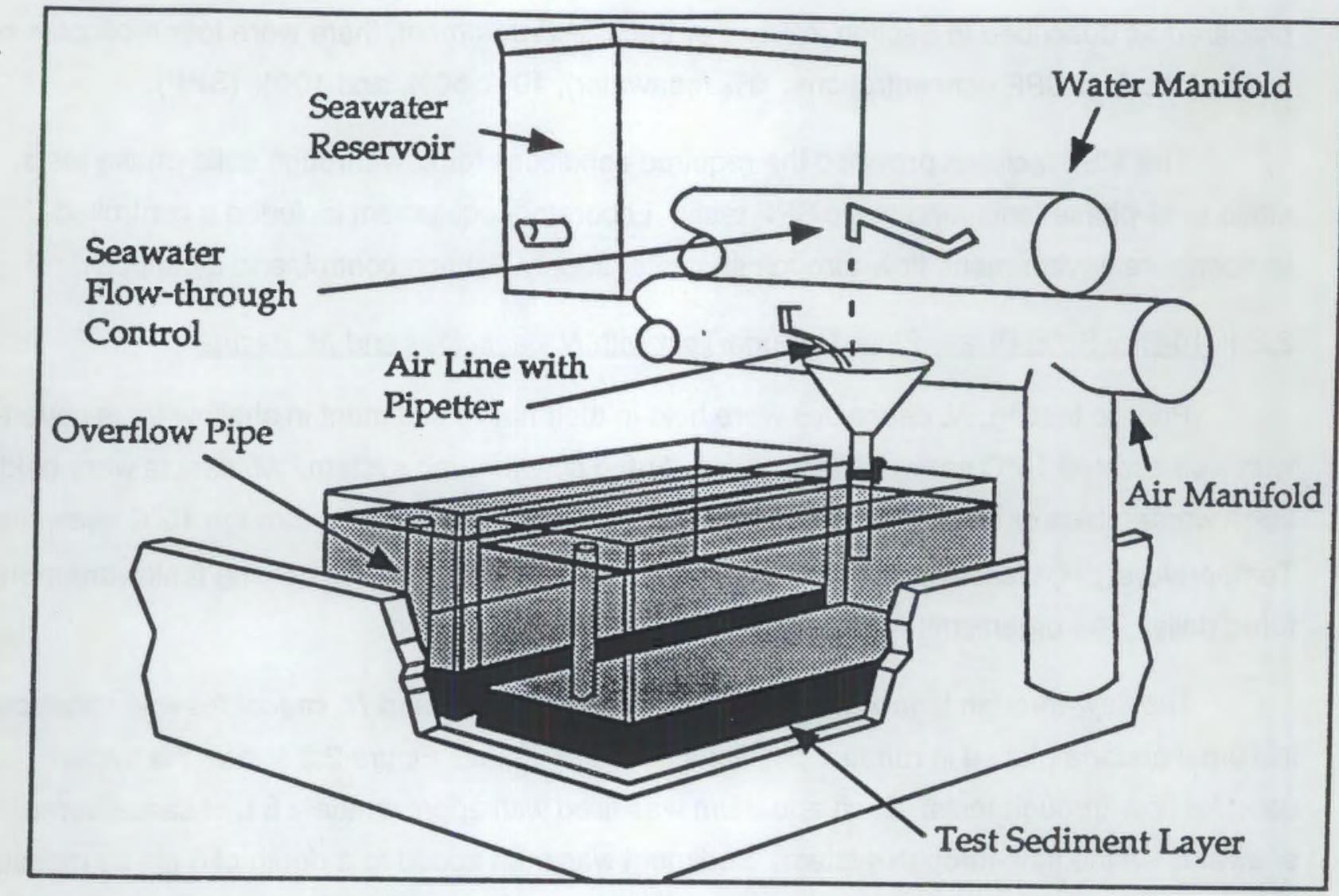

EIGURE 2.3. Flow-Through Aquarium for M. nasuta, N. caecoides

Daily observations of test animal behavior were made and recorded on data forms for each test. The number of $M$. nasuta on the sediment surface and those with their siphons exposed was noted, as well as the number of $N$. caecoides on the sediment surface and those with only their heads exposed. In addition to daily observations of behavior, the number of dead organisms in each aquaria was recorded on daily observation forms. Dead organisms were removed from the aquaria and incinerated; no replacement of dead organisms occurred during testing. If and when a dead $\boldsymbol{N}$. caecoides was removed, the specimen was identified as a whole animal or a portion of the animal (head or tail).

At the end of the 10-day test, water quality measurements were performed in all replicates and the contents of each aquarium were gently passed through a $1.0-\mathrm{mm}$ Nytex screen to recover the $N$. caecoides and $M$. nasuta. The organisms were placed in glass baking dishes 
labeled with the sediment treatment number and the number of dead versus live of each species was determined. Death was determined by observing whether the $N$. caecoides reacted to gentle probing; if there was no movement, the organism was considered dead. Death in the $M$. nasuta was determined by observations; those which were unresponsive and those with gaping shells were considered dead. The mortality data were recorded on the termination forms and at least $10 \%$ of the mortality counts were confirmed by a second observer.

\subsubsection{0-Day Solid-Phase Static Test with R. abronius}

The amphipods were held in a large holding tank containing their native sediment with flowing $15^{\circ} \mathrm{C}$ seawater. Organisms were not fed during the holding period, which was less than 2 weeks before test initiation.

The R. abronius test was conducted in 1-qt Mason jars (Figure 2.4) placed in random positions on a water table maintained at $15^{\circ} \mathrm{C}$. Prior to test initiation, test sediment was added to the jars to a depth of $2 \mathrm{~cm}$ and slowly filled with $0.45-\mu \mathrm{m}$-filtered seawater to a volume of 750 $\mathrm{mL}$. The jars were aerated and placed on the water table overnight to stabilize temperature to test conditions. After settling, initial water quality parameters were measured in each container and recorded on water quality forms.

Tests were initiated by adding $20 R$. abronius to each test container. The amphipods were gently sieved from the holding tank into clean seawater and counted into small transfer containers. The number of organisms was then confirmed by a second observer before being transferred into the test container. The date and time of initiation were recorded on data forms. $R$. abronius were observed daily during the test, and the number of organisms floating on the surface, swimming in the jar, or on the sediment surface was recorded on observation forms. Amphipods floating on the surface were gently pushed below the water surface with a pipette tip and observations were made as to whether they burrowed below the sediment or returned to the surface.

Water temperature, salinity, $\mathrm{pH}$, and DO were measured daily in one replicate of each sediment treatment and in all containers at initiation and termination of the test. Acceptable ranges for water quality parameters during the experiment were

$\begin{array}{ll}\text { Dissolved Oxygen } & \geq 4.0 \mathrm{mg} / \mathrm{L} \\ \mathrm{pH} & \text { ambient } \pm 0.5 \text { units } \\ \text { Salinity } & \text { ambient } \pm 2.0 \% \\ \text { Temperature } & 15^{\circ} \mathrm{C} \pm 2.0^{\circ} \mathrm{C} .\end{array}$




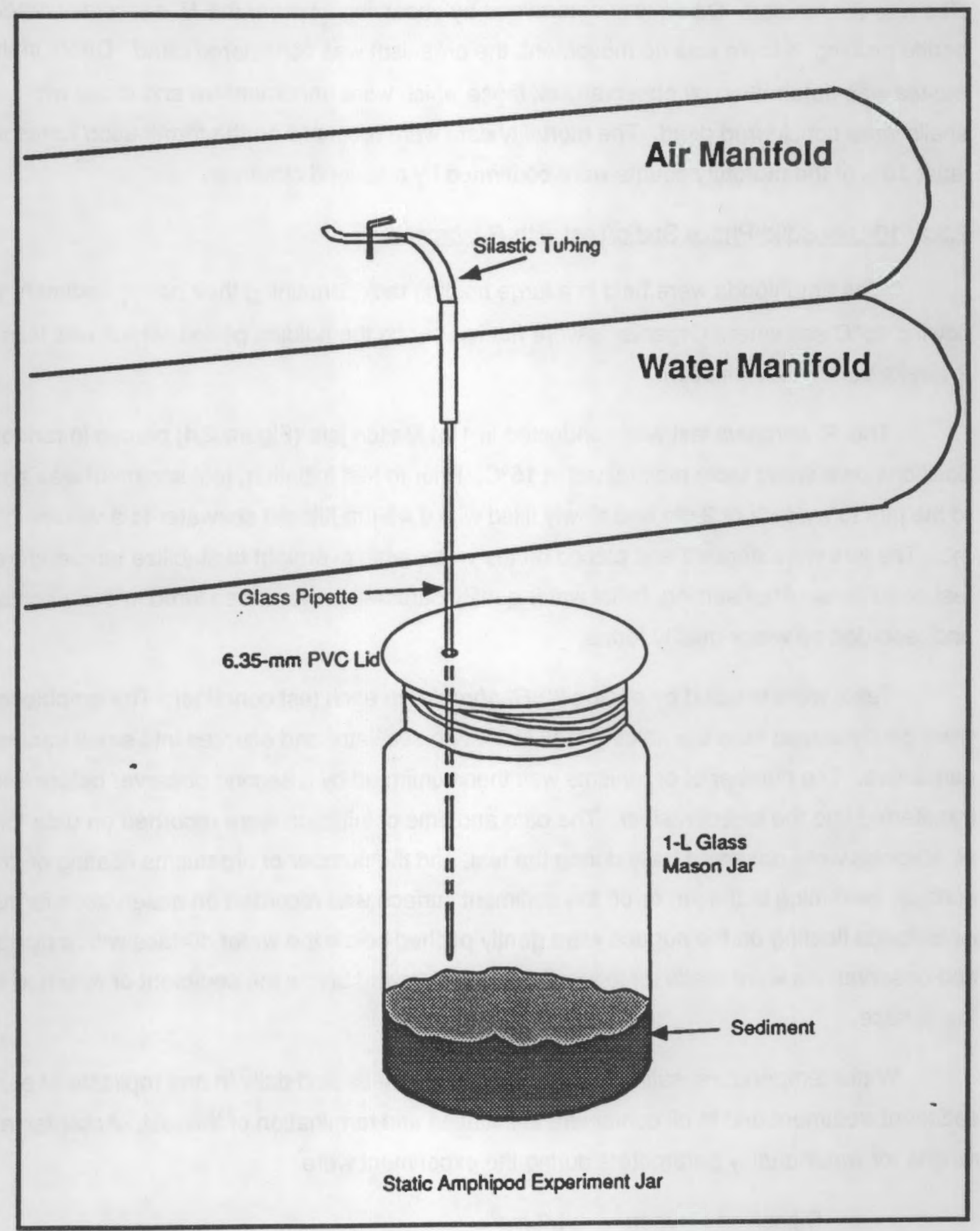

EIGURE2.4. Static Amphipod Testing Jars 
At the end of the test (Day 10), the contents of each jar were sieved through a $0.5-\mathrm{mm}$ Nytex screen to collect the $R$. abronius. The organisms were placed in clean seawater in a glass dish labeled with the sediment treatment and replicate number. The number of live versus dead organisms was determined (if necessary, they were examined under a dissecting microscope). The presence or absence of body parts recovered at the end of the test was also noted. If a $R$. abronius did not respond to gentle probing after several minutes of observation, it was considered dead. At least $10 \%$ of the mortality counts were confirmed by a second observer.

A 96-h reference toxicant test was also conducted to establish the health and expected response of the test organism. The reference toxicant test was conducted in the same manner as the solid-phase test. $R$. abronius were exposed to a seawater control plus four concentrations of cadmium chloride $(0.5,1.0,2.0$, and $4.0 \mathrm{mg} / \mathrm{L}$ as $\mathrm{Cd})$. There were three replicates of each treatment.

\subsubsection{8-Day Solid-Phase Flow-Through Test with $N$. caecoides and M. nasuta}

The procedure for conducting the 28-day, solid-phase flow-through test with $N$. caecoides and $M$. nasuta was identical to that of the 10-day test with three exceptions: 1) the number of organisms was increased to $25 \mathrm{M}$. nasuta and $40 \mathrm{~N}$. caecoides because more individuals were needed to produce enough tissue for chemical analysis; 2) the exposure period was increased from 10 to 28 days; and 3) the surviving test organisms were depurated (void the digestive track) and tissues were sampled for chemical analysis. The ranges for water quality parameters as well as the test conditions, such as temperature and flow rate, were the same in the 28-day test as for the 10-day test. Water quality parameters were measured and mortality of the test organisms was monitored at the same frequency for both tests.

When the 28-day test was terminated, the living $M$. nasuta and $N$. caecoides were collected for chemical evaluation of bioaccumulation. To ensure that tissue chemistry results would not be biased by contaminants associated with sediment grains in the digestive tract, the test organisms were allowed to depurate for $48 \mathrm{~h}$ following the 28-day exposure. The surviving $N$. caecoides from each test aquarium were placed in another flow-through 10-gal aquarium with approximately 2 in. of clean sediment in the bottom. This sediment layer is necessary for $N$. caecoides because they require sediment to surround their tissues in order to survive. The animals were not fed during the depuration period. The surviving $M$. nasuta were contained in a glass baking dish (without sediment) and placed in the depuration aquarium containing the $N$. 
caecoides from the same sediment treatment and replicate. After $48 \mathrm{~h}$ of depuration, the $M$. nasuta shells were cieaned with a scrub brush and the tissues were removed using titanium knives. The tissues were placed in pre-cleaned jars and submitted for chemical analysis. The N. caecoides were gently washed in clean seawater to remove extemal sediment grains and put in containers for chemical analysis.

\subsubsection{6-h Suspended-Particulate-Phase Static Test with C. stigmaeus}

The test chambers for the SPP test using $C$. stigmaeus were 10-gal aquaria randomly positioned on the water tables, with 20 to 24 aquaria per table. Test temperature was maintained by a circulating water bath on the water table. Aeration was provided through a glass pipette connected by silastic tubing to an overhead air manifold. Aquaria were labeled with a sediment treatment code, concentration, and replicate number. The volume of test material in each aquarium was $16 \mathrm{~L}$. To obtain the $100 \%$ SPP treatment, $16 \mathrm{~L}$ of $100 \%$ SPP was added directly to the aquarium; the $0 \%$ SPP treatment was $16 \mathrm{~L}$ of $0.45-\mu \mathrm{m}$-filtered Sequim Bay seawater. To prepare the $10 \%$ and $50 \%$ SPP concentrations, appropriate volumes of $100 \%$ SPP and $0.45-\mu \mathrm{m}$-filtered Sequim Bay dilution water were mixed directly in the test aquaria.

After SPP preparation and placement of containers on the water table, aeration was started and initial water quality parameters were measured in alt replicates. Ten $C$. stigmaeus were then netted from the holding tanks and added to each test container. The test population for each concentration was $\mathbf{4 0}$ individuals (160 individuals per SPP treatment). Initiation time and date were documented on test containers and data record forms. C. stigmaeus were not fed during the 96-h exposure. After initiation, $\mathrm{DO}, \mathrm{pH}$, salinity, and temperature were measured daily in at least one replicate. Acceptable ranges for the water quality parameters during the experiment were

$\begin{array}{ll}\text { Dissolved Oxygen } & \geq 4.0 \mathrm{mg} / \mathrm{L} \\ \mathrm{pH} & \text { ambient } \pm 0.5 \text { units } \\ \text { Salinity } & \text { ambient } \pm 2.0 \% \\ \text { Temperature } & 15.0^{\circ} \mathrm{C} \pm 2.0^{\circ} \mathrm{C} .\end{array}$

Observations of $C$. stigmaeus activity and behavior in each test container were made at test initiation and at $4,24,48$, and $72 \mathrm{~h}$. An organism was considered dead if it did not respond to gentle probing. Dead organisms were removed and preserved in Davidson's fixative for potential histopathological analysis. 
Before termination of the test at $96 \mathrm{~h}$, water quality parameters were measured in all replicates. At $96 \mathrm{~h}$, the number of live versus dead organisms was determined for each test container. As a quality control check, a second observer confirmed at least $10 \%$ of the mortality counts. Additionally, $C$. stigmaeus from SPP treatments exhibiting a toxicological effect (either through mortality or behavioral abnormalities) were also preserved for potential histopathological analysis.

\subsubsection{6-h Suspended-Particulate-Phase Static Test with $H$. sculota}

Prior to testing, $H$. sculpta were held for at least $48 \mathrm{~h}$ in flow-through aquaria maintained at test temperature $\left(15^{\circ} \mathrm{C}\right) . H$. sculpta were fed finely ground, flaked fish food twice a day, and water quality parameters in the holding tanks were monitored daily.

The test containers for the $H$. sculpta test were 2-L glass baking dishes placed in random positions on water tables. Test temperature was maintained by immersing these containers in a circulating water bath. Aeration was provided through a pipette connected by silastic tubing to an overhead air manifold. Appropriate volumes of $100 \%$ SPP and $0.45-\mu \mathrm{m}$-filtered Sequim Bay dilution water were added to clean, $1 \mathrm{gal}$ jars to make $0 \%, 10 \%, 50 \%$, and $100 \%$ SPP concentrations for the $H$. sculpta test. A total of $3000 \mathrm{~mL}$ was prepared for each dilution to achieve the test volume of $1000 \mathrm{~mL}$ in each replicate. The test containers were labeled with a sediment treatment code, concentration, and replicate number.

After the concentrations were prepared and placed on the water table, each container was gently aerated and water quality was measured in all replicates of each sediment treatment. $H$. sculpta were then removed from the holding tanks using a wide-bore pipette. To initiate the test, 10 individuals were added to each container to produce a test population of 40 individuals per concentration (160 individuals per treatment). The test initiation time and date were documented on data forms. After test initiation, water quality parameters were measured daily in one replicate of each sediment treatment. Acceptable water quality parameters for this test were

$\begin{array}{ll}\text { Dissolved Oxygen } & \geq 4.0 \mathrm{mg} / \mathrm{L} \\ \text { pH } & \text { ambient } \pm 0.5 \text { units } \\ \text { Salinity } & \text { ambient } \pm 2.0 \% \\ \text { Temperature } & 15.0^{\circ} \mathrm{C} \pm 2.0^{\circ} \mathrm{C} .\end{array}$

Observations of test organisms were made at test initiation and at 4, 24, 48, and $72 \mathrm{~h}$ using a light table to enhance visibility of the $H$. sculpta. During the $96-h$ exposure, $H$. sculpta 
were fed small amounts of ground, flaked fish food at $4,24,48$, and $72 \mathrm{~h}$. Excess food was removed with a small pipette before daily observations using extra caution not to disturb test animals. Molted exoskeletons and any particulates from the SPP solution that had precipitated were aiso removed.

Prior to test termination, water quality parameters were measured in all replicates. At 96 $h$, the number of live versus dead animals was determined for each test container. An organism was considered dead if it did not respond to gentle probing. As a quality control check, a second observer confimed surviving test organisms in at least $10 \%$ of the mortality counts.

A 96-h reference toxicant test was also conducted to establish the health and expected response of the test organisms. The reference toxicant test was conducted in the same manner as the SPP tests. H. sculpta were exposed to a seawater control plus four concentrations of zinc chloride $(0.25,0.50,1.0$, and $2.0 \mathrm{mg} / \mathrm{L}$ as $\mathrm{Zn})$. There were three replicates of each treatment.

\subsubsection{8-h.Suspended-Panticulate-Phase_Static Test with Larval $M$. edulis}

Prior to testing, adult $M$. edulis were held in flow-through holding tanks at ambient temperature. The test chambers for the bivalve larvae test were 1-qt Mason jars in which dilutions of SPP for the bivalve test $(0 \%, 10 \%, 50 \%$, and $100 \%)$ were directly prepared. The dilution water consisted of ofishore Strait of Juan de Fuca seawater filtered at $20 \mu \mathrm{m}$. This offshore water was collected to reduce the risk of using nearshore water that might have algal blooms. Algal blooms may or may not affect the mussels but the precaution was taken. The final volume of test material in each container was $750 \mathrm{~mL}$. Test chambers containing SPP were placed in random positions on a water table and aerated. Once the containers had reached test temperature $\left(16^{\circ} \mathrm{C} \pm 2^{\circ} \mathrm{C}\right)$, initial water quality parameters were measured in all replicates.

Adult $M$. edulis were induced to spawn by placing individuals in seawater that was quickly warmed to $20^{\circ} \mathrm{C}$. Broodstock musseis were maintained in $20^{\circ} \mathrm{C}$ seawater for $45 \mathrm{~min}$ during which time DO levels were monitored. If no spawning öccurred within $1 \mathrm{~h}$, adult mussels were removed from the water and allowed to air dry for approximately 15 min and then returned to the $20^{\circ} \mathrm{C}$ seawater.

Most adults spawned within an hour and were removed from the $20^{\circ} \mathrm{C}$ holding container and placed in individual baking dishes for the collection of gametes. Sperm from up to three males was pooled and passed through $35-\mu \mathrm{m}$ mesh to remove debris. The sperm pool was 
then introduced to containers of egg suspension and allowed to fertilize. The egg suspensions were mixed frequently using a perforated plunger over a period of 90 to $140 \mathrm{~min}$, at which time development of the embryos was assessed. The egg suspensions with a high percentage of embryo development were pooled into a common stock for use in the test. The pooled egg

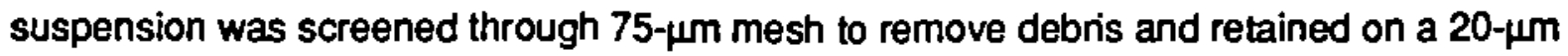
screen to rinse away excess sperm. The eggs were rinsed from the $20-\mu \mathrm{m}$ screen into a clean container and diluted with seawater.

To estimate fertilization success and embryo density, a $1-\mathrm{mL}$ sample was removed from the container (after thorough mixing) and diluted to $100 \mathrm{~mL}$ with seawater. Three, $1-\mathrm{mL}$ samples were removed from this 100:1 suspension, and the number of developing embryos and non-fertilized eggs was scored using a Sedgewick-Rafter counting chamber on a compound microscope at low magnification. The mean number of embryos from the replicate counts was multiplied by 100 (to correct for the dilution factor) to estimate the density of embryos in the egg stock. The resulting density of embryos/mL was used to calculate percent fertilization and the amount of embryo stock to add to each test container.

To initiate the test, an appropriate amount of bivalve embryo stock solution was pipetted into each test container to yield a density of $25 \mathrm{embryos} / \mathrm{mL}$ in the containers of test material. A perforated piunger was used to thoroughly mix the contents of the stock container before removing each aliquot with the pipette. The test initiation date and time were recorded on data record forms. Each subsample was placed in a labeled vial, fixed with $1 \mathrm{~mL}$ of $50 \%$ formalin, and scored for the number of fertilized eggs.

Water quality parameters were measured in one replicate of each dilution $24 \mathrm{~h}$ after test initiation. Acceptable ranges for water quality parameters during the experiment were

$\begin{array}{ll}\text { Dissolved Oxygen } & 24.0 \mathrm{mg} / \mathrm{L} \\ \mathrm{pH} & \text { ambient } \pm 0.5 \text { units } \\ \text { Salinity } & \text { ambient } \pm 2.0 \% \\ \text { Temperature } & 16.0^{\circ} \mathrm{C} \pm 2.0^{\circ} \mathrm{C} .\end{array}$

The bivalve test was terminated after 48 to $72 \mathrm{~h}$, when development of D-shaped larvae predominated in control containers. Final water quality measurements were recorded for all replicates. Each chamber was then homogenized with the perforated plunger, and a $10-\mathrm{mL}$ aliquot was removed with a calibrated pipette and placed in a labeled vial containing $1 \mathrm{~mL}$ of $50 \%$ formalin. Samples were scored for the appearance of normal D-shaped larvae, abnormally 
developed larvae, blastula-stage larvae, and total number of larvae. At least $10 \%$ of the counts were confirmed by a second observer.

A 48-h reference toxicant test was also conducted to establish the health and expected response of the test organisms. The reference toxicant test was set up and conducted in the same manner as the SPP tests. $M$. edulis larvae were exposed to a seawater control plus four concentrations of copper sulfate $(1,4,16$, and $64 \mu \mathrm{g} / \mathrm{L}$ as $\mathrm{Cu})$ with two replicates per treatment.

\subsection{SEDIMENT AND TISSUE CHEMISTRY PROCEDURES}

Richmond Harbor sediment treatments were analyzed for conventional and chemical parameters. Conventional parameters included grain size, total organic carbon (TOC), total volatile solids (TVS), oil and grease, total petroleum hydrocartons (TPH), and percent solids. Chemical analyses included PAHs, chlorinated pesticides, PCBs, metals, and butyltins. Table 2.1 shows the analytical parameters measured for the Richmond Harbor sediment treatments. $N$. caecoides and $M$. nasuta were analyzed for the same set of PAHs, chlorinated pesticides PCBs, metals, and butyltins as shown in Table 2.2.

The following sections briefly describe the methods used for analysis of sediments and tissues for the required physical and chemical parameters. Analyses followed established EPA procedures where applicable. Quality control samples included method blanks, matrix spike (MS) and matrix spike duplicate (MSD) analyses, standard reference materials (SRMs), and analytical replicates. The MS, MSD, and SRMs were used as measurements of analytical accuracy. The analytical replicates, MS, and MSD were used to evaluate analytical precision. Accuracy is defined in terms of bias (how close the measurement is to the true value) and precision (how variable the measurements are when repeated).

\subsubsection{Conventional Sediment Measurements}

Conventional sediment measurements consist of grain size, TOC, TVSs, oil and grease, TPHs, and percent solids. The procedures for each of these analyses are discussed in the following paragraphs.

Grain size analysis was conducted by Soil Technology, Inc., Bainbridge Island, Washington. Sixteen grain size fractions were detemined by a combination of sieve and pipette techniques from the Puget Sound Estuary Program (PSEP) Protocols for Measuring Selected Environmental Variables in Puget Sound (PSEP 1986). These methods are consistent with 
IABLE2.1. Analytical Chemistry Requirements for Richmond Harbor Sediment Treatments

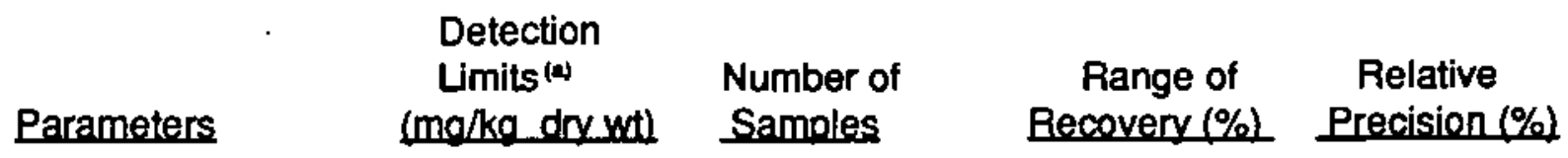

Sediment

Conventionals

TOC

Oil and Grease

$0.1 \%$

20

20

Grain Size

Total Volatile Solids
NA

$0.1 \%$
57

57

57

57

57

NA(O)
$50-150$
$50-150$
NA

NA
10

20

20

NA

10

\section{Metals}

\begin{tabular}{|c|c|c|c|c|}
\hline $\mathrm{Ag}$ & 1.0 & 57 & $75-125$ & 20 \\
\hline As & 1.0 & 57 & NA & 20 \\
\hline $\mathrm{Cd}$ & 0.1 & 57 & $75-125$ & 2 \\
\hline $\mathrm{Cr}$ & 1.0 & 57 & NA & 20 \\
\hline $\mathrm{Cu}$ & 1.0 & 57 & NA & \\
\hline $\mathrm{Hg}$ & 0.02 & 57 & $75-125$ & \\
\hline $\mathrm{Ni}$ & 1.0 & 57 & NA & 2 \\
\hline $\mathrm{Pb}$ & 1.0 & 57 & NA & 20 \\
\hline $\mathrm{Se}$ & 0.5 & 57 & $75-125$ & \\
\hline $\mathrm{Zn}$ & 1.0 & 57 & NA & 2 \\
\hline
\end{tabular}

\section{Organic}

Compounds

\begin{tabular}{|c|c|c|c|}
\hline $\begin{array}{l}\text { Butyltins } \\
\text { PCBs (c) } \\
\text { PAHs (d) } \\
\text { Pesticides (o) }\end{array}$ & $\begin{array}{l}0.01 \\
0.02 \\
0.02 \\
0.002\end{array}$ & $\begin{array}{l}57 \\
57 \\
57 \\
57\end{array}$ & $\begin{array}{l}40-120 \\
40-120 \\
40-120 \\
40-120\end{array}$ \\
\hline
\end{tabular}

(a) Target detection limits; all efforts were made to reach lowest practical detection limits.

(b) NA Not applicable.

(c) Reported as aroclor equivalents 1242, 1248, 1254, and 1260 and total PCB. Analyzed using EPA Method 8080.

(d) All compounds on EPA Method 610 list. Analyzed using Method 8270 in SIM mode.

(e) All compounds on EPA Method 608 list. Analyzed using Method 8080. 
IABLE 22. Analytical Chemistry Requirements for Richmond Harbor Tissue Samples

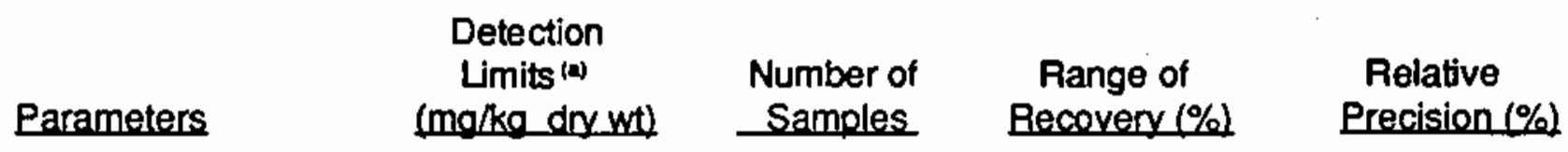

\section{Metals}

$\begin{array}{lllcl}\mathrm{Ag} & 1.0 & 145 & 75-125 & 20 \\ \mathrm{As} & 1.0 & 145 & \text { NA(b) } & 20 \\ \mathrm{Cd} & 0.1 & 145 & 75-125 & 20 \\ \mathrm{Cr} & 1.0 & 145 & 75-125 & 20 \\ \mathrm{Cu} & 1.0 & 145 & \mathrm{NA} & 20 \\ \mathrm{Hg} & 0.02 & 145 & 75-125 & 20 \\ \mathrm{Ni} & 1.0 & 145 & 75-125 & 20 \\ \mathrm{~Pb} & 1.0 & 145 & \mathrm{NA} & 20 \\ \mathrm{Se} & 0.5 & 145 & 75-125 & 20 \\ \mathrm{Zn} & 1.0 & 145 & \mathrm{NA} & 20\end{array}$

Organic

Compounds

$\begin{array}{lllll}\text { Butyltins } & 0.01 & 145 & 40-120 & 30 \\ \text { PCBs (c) } & 0.02 & 150 & 40-120 & 30 \\ \text { PAHs }^{(d)} & 0.02 & 150 & 40-120 & 30 \\ \text { Pesticides }^{(0)} & 0.002 & 150 & 40-120 & 30\end{array}$

(a) Target detection lirnits; all efforts were made to reach lowest practical detection limits.

(b) NA Not applicable.

(c) Reported as aroclor equivalents 1242, 1248, 1254, and 1260 and total PCB. Analyzed using EPA Method 8080.

(d) All compounds on EPA Method 610 list. Analyzed using Method 8270 in SIM mode.

(e) All compounds on EPA Method 608 list. Aralyzed using Method 8080.

ASTM D421 (ASTM 1978) and D422 (ASTM 1972) (with the substitution of the No. 100 Sieve for the No. 140 sieve). An additional measurement for salt content was performed and each grain size fraction was corrected for this salt measurement. Table 2.3 presents the fractions measured.

Approximately $25 \mathrm{~g}$ of each sediment sample was analyzed for total solids while another 10- to 100-g aliquot was weighed for grain size analysis. To separate the coarser sand and gravel fraction from the silt/clay fraction, sediment was washed with distilled water through a 
IABLE2.3. Grain Size Fractions Measured

\begin{tabular}{ccc} 
Grain Size (um) & Phi & \multicolumn{2}{c}{ Screen Number } \\
\cline { 3 - 3 } 4750 & & 4 \\
2000 & -2 & 10 \\
850 & -1 & 20 \\
425 & 0 & 40 \\
250 & 1.5 & 60 \\
149 & 2 & 100 \\
75 & 3 & 200 \\
62.5 & 3.75 & 230 \\
48 & 4 & NA(1) \\
31.2 & 4.5 & NA \\
23 & 5 & NA \\
15.6 & 5.5 & NA \\
7.8 & 6 & NA \\
3.9 & 7 & NA \\
1.9 & 8 & NA \\
0.9 & 9 & NA \\
0.4883 & 10 & NA
\end{tabular}

(a) NA Not applicable.

63.5- $\mu \mathrm{m}$ (4.0 phi) sieve into a 1-L graduated cylinder. The coarse fraction was dried, weighed, and shaken through a nest of sieves to yield the required seven coarse subfractions. Any material still passing the final 63.5- $\mu \mathrm{m}$ sieve was added to the previous fines in the 1-L graduated cylinder. The silt/clay fraction was then subdivided by a pipette technique based on Stoke's Law of differential settling velocities for different sized particles. The silt/clay fraction was disassociated by a dispersant (sodium hexametaphosphate) in distilled water in a 1-L graduated cylinder. At specified time intervals and specified depths below the surface, 20-mL aliquots were withdrawn from the graduated cylinder, delivered to a preweighed container, and dried at $90^{\circ} \pm 2^{\circ} \mathrm{C}$ to a constant weight. Triplicate analysis of three samples was performed as a quality control measure. Other quality control measures, such as spikes, SRMs, or minimum detection limits, do not apply to grain size analysis.

Analysis of TOC was performed by Global Geochem in Canoga Park, California. Total organic carbon is the amount of non-volatile, partially volatile, volatile, and particulate organic carbon compounds in a sample. Each sediment treatment was dried and ball milled to a fine powder. Before combustion, inorganic carbon in the sample was removed by acidification. The 
TOC in sediment was then determined by measuring the carbon dioxide released during combustion of the sample (PSEP 1986; SW846 Method 9060, EPA 1986) and reported as percent of dry weight. Quality control measures inctuded three method blanks and one triplicate analysis per batch (three batches).

Total oil and grease and TPH analyses were pertormed by Twin City Testing in St. Paul, Minnesota. Total oil and grease includes vegetable oils, animal fats, soaps, waxes, and any other carbon-hydrogen material extractable by the solvent Freon. Total petroleum hydrocarbons comprise the nonpolar mineral fraction of total oil and grease that is not removed by silica gel absorption. Infrared spectrophotometry (IR) was used to determine concentrations of oil and grease (Method 413.2, EPA 1979) and petroleum hydrocarbons (Method 418.1, EPA 1979). A 20-g aliquot of sample was dried with anhydrous sodium sulfate and extracted with Freon. For total oil and grease, sample extracts were scanned from 4000 to $600 \mathrm{~cm}^{-1}$ on an IR and the peak height measured at $2930 \mathrm{~cm}^{-1}$. This wavelength represents the $-\mathrm{CH}_{2}$ configurations of hydrocarbons and was the standard used to determine oil and grease. For TPHs, silica gel was added to the extract to remove the more polar animal- and vegetable-based oils. The extract was then shaken, allowed to sette, removed, and scanned the same way as the oil and grease sample. The relationship of peak height to oil concentration was determined by regressing the peak height versus a known concentration of fuel oil. Quality control measures included one blank, an MS and MSD, and one analytical triplicate per batch. Three batches were performed for the oil and grease and TPH.

Analysis of TVSs was performed at the MSL. Total volatile solids are a measure of the fraction of total solids that are lost on ignition at a higher temperature. The TVS is used as an estimate for the amount of organic matter in the total solids. Operationally, TVS is defined by the combustion temperature and does not always represent the organic content of a sample; more volatile organic material may be lost during drying, and inorganic material may be lost during combustion. To pertorm TVS analysis, the MSL followed PSEP (1986). First, the sample was oven dried to constant weight and then removed, weighed, and combusted at $550^{\circ} \mathrm{C}$. The sample was cooled in a desiccator and then reweighed. The amount of sample lost during ignition was then defined as the volatile solids fraction. Quality control measures included two method blanks (one per batch) and three sets of triplicate analysis.

Sediment treatments used for determination of percent solids were prepared in one of two ways. (Each laboratory pertorms a percent solids analysis to determine a sample dry 
weight; different laboratories may use one of the two methods.) Pre-weighed wet samples are either freeze-dried over a period of 4 days or dried in an oven at $110^{\circ} \mathrm{C}$ for at least $8 \mathrm{~h}$, and cooled in a desiccator. The ratio of dry weight to wet weight is multiplied by 100 to determine the percent solids.

\subsubsection{Semivolatile Organic Compounds}

Analyses for 16 PAHs in the Richmond Harbor sediment treatments and tissues were performed by the MSL in Sequim, Washington. The semivolatile organic compounds were analyzed in Richmond Harbor sediments (EPA Method 9270). These compounds were extracted using a slightly modified NOAA Status and Trends Method (NOAA 1985). The modification involved multiple extractions on an ambient roller using methylene chloride as the extraction solvent. A portion of the sediment extract was then analyzed by gas chromatography/mass spectroscopy in the Selective lon Mode (GC/MS SIM) following EPA SW-846 Method 8270 (1986). Tissue extracts were run through gel permeation chromatography (GPC) prior to analysis to remove any additional interferences.

Quality control measures included at least one method blank and one MS/MSD per batch. An MS and MSD solution consisting of all 16 PAH compounds was added to each sample (sediment and tissue) to assess the accuracy and precision of the measurement. The SRM was used to assess the accuracy of the measurement. This SRM was National institute of Science and Technology (NIST) SRM 1941. The SRM for the tissues was the NIST 1974.

\subsubsection{Chlorinated Pesticides and Polychlorinated Biphenyls}

The PCB and pesticide analyses for Richmond Harbor sediment and tissue samples were performed by the MSL in Sequim, Washington. Chlorinated pesticides and PCBs in sediments and tissues were quantified by gas chromatography/electron capture detection (GC/ ECD) following EPA SW-846 Method 8080 (1986).

Chlorinated pesticides and PCBs were extracted simultaneously with the PAH compounds using the ambient roller technique as described for PAHs (NOAA 1985). The procedure involved a multiple methylene chloride extraction. A portion of the methylene chioride extract was solvent exchanged to hexane, and interferences were removed by passing the extract through a column packed with $10 \mathrm{~g}$ of $2 \%$ deactivated alumina and $20 \mathrm{~g}$ of $2 \%$ deactivated silica following standard MSL procedures. Most samples required an additional cleanup treatment using high performance liquid chromatography (HPLC) to remove other interferences. Analyti- 
cal quantification was performed using GC/ECD analysis. Tetrachlorometaxylene (TCMX) and Octachloronaphthalene $(\mathrm{OCN})$ were added to each sample before extraction to assess extraction efficiency.

Quality control measures included a method blank with each batch. An MS solution consisting of either a subset of pesticides or one arocior was also added to the appropriate samples before extraction. The MS/MSD analyses and blanks were conducted with each batch to assess accuracy and precision of the measurement.

\subsubsection{Metals}

Sediment and tissue metals analyses were performed by the Pacific Northwest Laboratory (PNL) in Richland, Washington, and the MSL in Sequim, Washington. In addition, tissue samples were analyzed for selected metals using inductively coupled plasma mass spectrometry (ICP/MS) by Skiddaway Institute of Oceanography in Savannah, Georgia. Ten metals were measured in sediments and tissues: silver (Ag), arsenic (As), cadmium (Cd), chromium (Cr), copper (Cu), mercury ( $\mathrm{Hg})$, nickel (Ni), lead (Pb), selenium (Se), and zinc (Zn). Sediment samples, $M$. nasuta tissue, and $N$. cascoides tissue were analyzed using a combination of four different methods: 1) energy-diffusive $x$-ray fluorescence (XRF), following the method of Sanders (1987); 2) Zeeman graphite-furnace atomic absorption spectroscopy (GFA.A), following EPA SW-846 Method 7000 (1986) and the method of Bloom and Crecelius (1984); 3) coldvapor atomic absorption spectroscopy (CVAA) according to EPA SW-846 Method 7471 (1986) and the method of Bloom and Crecelius (1983); and 4) ICP/MS. The analytical methods for each sample matrix and corresponding metals for which each method was used are presented in Table 2.4.

To prepare sediment and tissues for analysis, samples were freeze-dried and blended in a Spex mixer-mill. Approximately $5 \mathrm{~g}$ of mixed sample was ground in a ceramic ball mill. The XRF analysis was performed on a $0.5-g$ aliquot of dried, ground material pressed into a pellet with a diameter of $2 \mathrm{~cm}$. For GFAA, CVAA, and ICP/MS analyses, $0.2-$ to $0.5-\mathrm{g}$ aliquots of dried homogenous sample went through an acid digestion process to separate and isolate the metals from the matrix.

Quality control measures for metals analyses included analysis of blanks (not applicable to XRF technique), MS and MSD, and triplicate analyses for each batch of up to 20 samples, and analysis of at least 1 SRM sample per 20 samples. The SRMs for sediment were SRM 1646, obtained from the NIST, and BEST-1 and PACS-1, obtained from the National Research 
IABLE 2.4. Analytical Method and Corresponding Metal for Each Sample Matrix

$\mathrm{XB}$
$\mathrm{As}$
$\mathrm{Cr}$
$\mathrm{Cu}$
$\mathrm{Ni}$
$\mathrm{Pb}$
$\mathrm{Se}$
$\mathrm{Zn}$

Sediment

XBF GFAA CVAA

$\frac{\text { N. caecoides Tissue }}{\text { XRE }}$

As $\quad \mathrm{Hg}$

$\mathrm{Cu}$

Se

$\mathrm{Zn}$

$\begin{array}{lll}\mathrm{Ag} & \mathrm{Hg} & \mathrm{As} \\ \mathrm{Cd} & & \mathrm{C} \\ & & \mathrm{Zn}\end{array}$

Council of Canada (NRCC). The tissue SRMs included an oyster tissue, 1566a, obtained from NRCC.

\subsubsection{Butylitins}

Butyltins in sediment and $M$. nasuta tissue were analyzed at the MSL in Sequim, Washington, and butyltins in N. caecoides samples were analyzed at Battelle Ocean Sciences in Duxbury, Massachusetts. Butyitin compounds in sediment and tissues were analyzed using gas chromatographyfflame photometric detection (GC/FPD) following the methods of Unger et al. (1986).

Wet samples were extracted with methylene chloride and tropolone. For sediment, tripentyltin was added before extraction as a surrogate compound to assess extraction efficiency. For tissues, tripropyltin was added before extraction as a surrogate compound to assess extraction efficiency. The mono, di-, tri-, and tetrabutyltin compounds extracted from the sediment and tissues were derivatized to a less volatile, more thermally stable form (nonionic nhexyl/or n-pentyl derivatives).

The extracts were passed through a florisil liquid chromatography column for cleanup and the butylitins were quantified by GC/FPD. Concentrations were reported in $\mu \mathrm{g} / \mathrm{kg}$ dry weight of di-, tri- and tetra-butyltin species as tin. The recently certified reference material for butylitins, NRCC SRM PACS-1, was analyzed with Richmond Harbor sediment. Sंelected sediment and tissue samples were spiked with di- and tributyltins prior to extraction to assess the accuracy of the procedure. Method blanks, one set of MS/MSD and one set of triplicates were analyzed with each batch of samples extracted. 


\subsection{DATA ANALYSIS AND INTERPRETATION}

Several statistical analyses were conducted to determine the magnitude and significance of toxicity and bioaccumulation in test treatments relative to reference treatments. Each statistical test is based on a completely random design that allows unbiased comparison between treatments. The 1991 Implementation Manual recommends Dunnett's Test for comparing test treatments to a single reference treatment. However, the Richmond Hartor experiments were conducted with multiple reference treatments because a single reference most representative of a potential disposal site had not been selected. In this case, Dunn's Test, a modification of Tukey's Honestly Significant Difference (HSD) Test (Dunn 1961), is appropriate for multiple reference comparisons and it was used to compare the test treatments to all the reference treatments. The alpha level was expanded to 0.1 for both bioaccumulation and toxicity comparisons in order to increase the comparison-wise error rate, which decreases confidence limits around the means and enhances the likelihood of detecting significant differences between treatments. This implies that the test is statistically less conservative, meaning that it is more likely to detect a significant difference than comparisons at $\alpha=0.05$. Comparisons conducted at $\alpha=0.05$ are less sensitive to differences in means, resulting in fewer significant difterences. Test design and specific statistical analysis procedures are discussed in the following sections.

Concentrations of contaminants of concem in the tissues of $M$. nasuta and $N$. caecoides were also compared to the Food and Drug Administration (FDA) action levels for poisonous and deleterious substances in fish and shellish for human food. These action limits are the levels above which the FDA can take legal action, and are based on human health as well as economic considerations" (USACERPA 1991). Procedures for evaluating levels are outlined in the 1991 Implementation Marual.

\subsubsection{Randomization}

All solid phase and SPP toxicity tests were designed as completely random tests. Organisms were randomly allocated to treatments, and treatments were randomly positioned on water tables. To dețermine the randomization, a random number table was generated for each toxicity test using the discrete uniform random number generator in the Lotus 123 spreadsheet software. For the SPP tests, $C$. stigmaeus and $H$. sculpta individuals and $M$. edulis larvae were randomly allocated to SPP replicates for all concentrations. Special care was taken with $C$. stigmaeus individuals to eliminate bias caused by variable mobility of the fish (otherwise, easily caught fish would be used eartier than more mobile fish). 


\subsubsection{Statistical Analysis of Solid-Phase Tests}

Solid-phase toxicity of all sediment treatments was compared by analysis of variance (ANOVA) tests on the arcsine square-root of the proportion of organisms surviving the test. The arcsine square-root transformation stabilizes the within-class variances to meet the assumptions of the ANOVA. All treatments were compared using Dunn's Test with an experiment-wise error rate of $\alpha=0.10$. Dunn's Test is similar to Tukey's HSD Test, which had been used for previous projects, but Dunn's modification accommodates larger numbers of treatments and unbalanced replicates. Both Dunn's and Tukey's HSD Tests are multiple-range comparisons that provide information about how each sediment treatment compares to all other treatments. These statistical methods allow comparison of a test treatment to more than one reference treatment when all are tested concurrently. Toxicity of the treatment was considered significant if it was statistically different from one or more reference treatments and if the survival in the treatment was $210 \%$ lower than the reference treatment for the test organism (20\% lower than reference for R. abronius).

\subsubsection{Statistical Analysis of SPP Tests}

Two statistical tests are presented in the 1991 Implementation Manual for the interpretation of SPP tests. The first test is a one-sided t-test between survival in control replicates and survival in the $100 \%$ SPP replicates. This test is pertormed only when survival in the $100 \%$ SPP is less than control (0\% SPP) survival and when control survival is greater than $90 \%(70 \% \mathrm{M}$. edulis test) indicating test validity. Prior to conducting the t-test, angular transformation (arcsine of the square root) of the proportion surviving in test replicates is performed to reduce possible heterogeneity of variance between control and 100\% SPP mean survivals. The second test required by the 1991 Implementation Manual is an LC50 calculation, the concentration of SPP that is lethal to $50 \%$ of the individuals tested. The LC50 values for these tests were calculated using the Trimmed Spearman-Karber method (Hamilton 1977). The Spearman-Karber estimator is appropriate only if there is increasing mortality with increasing concentration and if $50 \%$ or greater mortality is observed in test solutions when normalized to control survival. If $50 \%$ mortality doès not occur in the $100 \%$ SPP dilutions for any treatments, then LC50 values are reported as $>100 \%$ SPP. The same method was used to calculate EC50 values (the concentration where $50 \%$ of the test individuals show a certain effect) for the bivalve SPP test and LC50 values for all reference toxicant tests. 


\subsubsection{Statistical Analysis of Bioaccumulation}

Before statistical analysis of $M$. nasuta and $N$. caecoides tissue concentrations, a visual inspection of the tissue chemistry data was performed. If visual inspection showed that a compound was undetected in al of the replicate samples in a test treatments or that the mean tissue concentration in the reference treatments was greater than that in the test treatments, no further analysis was performed. If the detected concentration of a compound exceeded that of any reference treatment, statistical analysis was performed. In all cases, detection limits were used in numerical calculations when a compound was undetected.

Treatments where contaminants of concem were detected were compared to all reference treatments using ANOVA and Dunn's Test for comparison of all means. Analytical detection limit values were used for replicates where the compound was not detected. If all replicates of a test treatment were flagged with $U$ (analyte was not present above the level of associated value) or $\mathrm{J}$ [analyte detected below method detection limits (MDL), but above instrument detection limit (IOL)] qualifications by the analytical laboratory, the treatment was not analyzed. Significant bioaccumulation of a contaminant was determined by the statistical grouping yielded by Dunn's Test at $\alpha=0.10$.

\subsection{QUALITY ASSURANCE/QUALITY CONTROL (OA/OC) PROCEDURES}

The QAOC procedures followed for these studies were consistent with the 1991 Implementation Manual and the EPA protocols (PSEP 1986). The procedures followed were documented by PNL's Quality Engineening Division as a QA Plan. A member of PNL's quality engineering staff was present throughout each phase of these studies to ensure that accepted procedures were followed. The PNL Laboratory Record Books (LRB) were assigned to each portion of the study and served as records of day-to-day activities during the research. All entries in the LR8s were signed, dated, and reviewed by the project manager. The following discussion summarizes QAOC procedures followed for the three main portions of this study: sediment sampling, tracking, and storage; sediment and tissue chemistry; and toxicological testing (all QAOC evaluations are contained in Appendixes $\mathrm{C}, \mathrm{J}$, and K).

\subsubsection{Sediment Sampling. Tracking and Storage}

To locate the sampling points within the harbor the vessel's navigation systems required an accuracy of $\pm 10 \mathrm{ft}$. All core liners were made of noncontaminating lexan and were steam cleaned before use. The sample stations were labeled with the appropriate locations, date, time 
collected, and core sections. After collection, all samples were kept at $\sim 4^{\circ} \mathrm{C}$ in a refrigerated storage container. The detailed sampling information was recorded daily on core logs.

To ensure the integrity of samples from the time of collection through sample analysis, sample custody procedures were followed. All sediment samples were accompanied by chainof-custody forms from the time of collection to receipt at MSL. After sample selection and compositing, a new set of custody forms was initiated for the sediment subsamples requiring chemical analyses. These accompanied the samples to the appropriate laboratory where the forms were signed and returned to the MSL project manager. Custody forms were also initiated for all tissue samples upon completion of the biological testing. These forms accompanied the samples to the appropriate laboratory for chemical analyses.

All sediment collected for this study was stored in glass containers, cellulose acetate butyrate containers, or steel drums lined with 9-C-4-A-phenolic epoxy, a noncontaminating coating. Sediment cores and grab samples were stored at $-4^{\circ} \mathrm{C}$ prior to biological testing. Subsamples for chemicat analyses were obtained prior to biological testing. These subsamples were stored frozen until chemical analyses were performed. Samples for organic analyses were stored frozen for a period not exceeding 2 months (PSEP 1986; EPAUSACE 1991). Samples for metals were freeze-dried upon receipt at the laboratory and held for a period not exceeding 6 months (PSEP 1986; EPAUSACE 1991).

Tissue samples were frozen immediately upon completion of the bioaccumulation tests. Samples for organic analyses were stored in EPA certified precleaned glass jars with Teflonlined lids, and held up to 2 months prior to analysis. Tissue samples for metals analyses were stored in precleaned plastic jars and held up to 6 months prior to analysis.

\subsubsection{Sediment and Tissue Chemistry Quality Control Procedures}

Chemical testing procedures require that specific QANC protocols be followed. OAOC guidelines specific to this project are provided by the PNL Quality Engineening Division as a QA Plan. These guidelines include the following:

- analysis of a method blank with each batch of samples

- replicate analysis on at least $5 \%$ of the samples (triplicate analyses where possible) to assess analytical precision

- analysis of matrix spikes on $10 \%$ of the samples (where applicable) with appropriate compounds to assess accuracy 
- analysis of SRMs at a frequency of $5 \%$, if available for the analytes of interest and sample matrix

- archival of alt instrument printouts (e.g., raw data and chromatograms from AA and GC analyses) for future review.

In actual practice, some of the specific guidelines listed in the QA Plan for analytical precision and accuracy were modified to apply to the most current methods employed by laboratories. The guidelines for detection limits, range of recovery, and relative precision are listed in Table 2.1 for sediments and in Table 2.2 for tissues.

Measurements of accuracy can be determined by analyzing MS of known concentrations and SRMs that have been certified for the presence of specific parameters. The MS were analyzed for metals and organic parameters and are generally made up of a subset of the analytes of interest. Percent recoveries were calculated based on the differences between the amount spiked and the amount recovered in the sample. Metal spikes were analyzed at a frequency of $5 \%$ and organic compound spikes were generally analyzed at $5 \%$. In sediment, SRMs were analyzed for metals and organic compounds; in tissues, SRMs were analyzed for metals oniy.

Surrogate compounds were added in known amounts to samples analyzed for PCBs, pesticides, PAHs, and butyltins. Surrogate compounds are added to samples prior to extraction and their recoveries are a measurement of the efficiency or procedural accuracy of the analysis.

Measurements of precision were obtained through replicate analysis of selected sediment treatments. Analysis of replicates shows the precision and repeatability of the results. The measurements of precision are the industrial statistic (I-stat) and relative percent difference (RPD) for duplicate analyses, and the relative standard deviation (RSD) for triplicate analyses. The fstat is defined as the absolute value of the difference between duplicate measurements divided by the sum of the duplicates. The RPD is defined as the absolute value of the difference between two duplicate measurements, divided by the mean of the duplicates, multiplied by 100. The RSD is defined as the sample standard deviation, divided by the mean, multiplied by 100. All instrument printouts and other raw data generated using MSL analytical instruments are filed at MSL for future reference. Copies of data generated by offsite analytical facilities are maintained at the MSL. 


\subsubsection{Iexicological Testing Quality Control Procedures}

Appropriate procedures for organism care were maintained from collection through testing. Organisms shipped to MSL were gradually equilibrated to ambient surroundings and kept in their native sediment whenever possible. Animals were fed, if necessary, before biological testing. Information on the collecting and handling of each test specles is included in Section 2.1.3.

Selection of species was consistent with the 1991 implementation Manual and involved the use of juvenile forms, burrowing invertebrates, deposit foeding organisms, and a larval (planktonic) form. Representatives of all test organisms were taxonomically identified by qualified experts at MSL before use in testing.

Native control sediments were included in all bioassays to validate the test through organism survival. Reference toxicant tests were also included to measure the relative sensitivity of the test organisms. Reference toxicant tests are trequently conducted at MSL and results from these tests were used in comparison to previous studies.

During testing, water quality parameters were measured to ensure that acceptable experimental conditions were maintained. These conditions included a stable temperature $\left( \pm 2.0^{\circ} \mathrm{C}\right)$, minimum DO of $4.0 \mathrm{mg} / \mathrm{L}$, and $14 \mathrm{~h}$ of light per day. Salinity was allowed to vary $\pm 2.0 \%$, and $\mathrm{pH}$ was allowed to vary \pm 0.5 units within each test container during the testing period. These limits and values are consistent with those outlined in the 1991 Implementation Manual. Water quality instruments were calibrated according to the manufacturer's specification or PNL protocols.

All data generated on spreadsheets for use in this report received a $100 \%$ data validation by technically qualified staff members. Manipulation of data within the spreadsheets was rechecked with hand calculations. These calculations were documented directly on the spreadsheet to assure data traceability. In addition, the report received a technical review, editorial review, and OAOC review. 



\subsection{BESULTS}

This section presents the results from sediment sampling, geologic descriptions, sediment chemistry, toxicological testing, and tissue chemistry. Complete appendixes containing all data generated in support of the Richmond Harbor Program are included in this report.

\subsection{SEDIMENT SAMPLING RESULTS}

Richmond Harbor sediment was collected from June 17 through June 20, 1991. Reference sediment was collected on June 17 and 18,1991 . All sediment samples were collected following the procedures described in Section 2.1.

The 12-in. core samples were collected from 28 stations in Richmond Harbor to a project depth of $-40 \mathrm{ft}$ MLLW (Figure 1.2). Based on Brown et al. (1990), sediment obtained from stations presumed to be similar were combined to form six sediment composites that were thoroughly mixed in the laboratory, subsampled for chemistry, and used in biological and bioaccumulation testing (Figure 3.1). Because these stations were similar, composites eliminated the need to perform biological testing at individual stations. Table 3.1 provides field sampling information for the 12-in. core samples including station designation and location, collection data; core length, contribution to composites (gal), and composite number. Approximately 4 to $10 \mathrm{gal}$ of sediment from individual stations was combined with sediment from other stations to form the six COMPs. The amount of sediment contributed from each station was dependent on the length of core collected. COMPs I, II, V, and VI were composited as planned; however, COMPs III and IV provided some noteworthy exceptions that require explanation.

Originally, COMPs III and IV were to be made from the appropriate sections of cores taken from the Potrero Reach tuming circle and stations TC-I through TC-5. COMP III was to comprise the upper sections of the 12-in. cores from stations TC-1 through TC-5 and COMP IV was to comprise the lower sections of those same 12-in. cores; the division between the two was to be based on grain-size characteristics. When the core sample from Station TC-5 was examined in the field, however, the upper section appeared different from the other tuming circle stations. Consequently this section was kept separate and given the designation TC-5 Upper Comp. Because of this, COMP III actually comprises the upper sections of the 12-in. cores from stations TC- 1 through TC-4. Figure 3.2 shows TC-1 through TC-5 and their respective contributions to COMPs III and IV. 


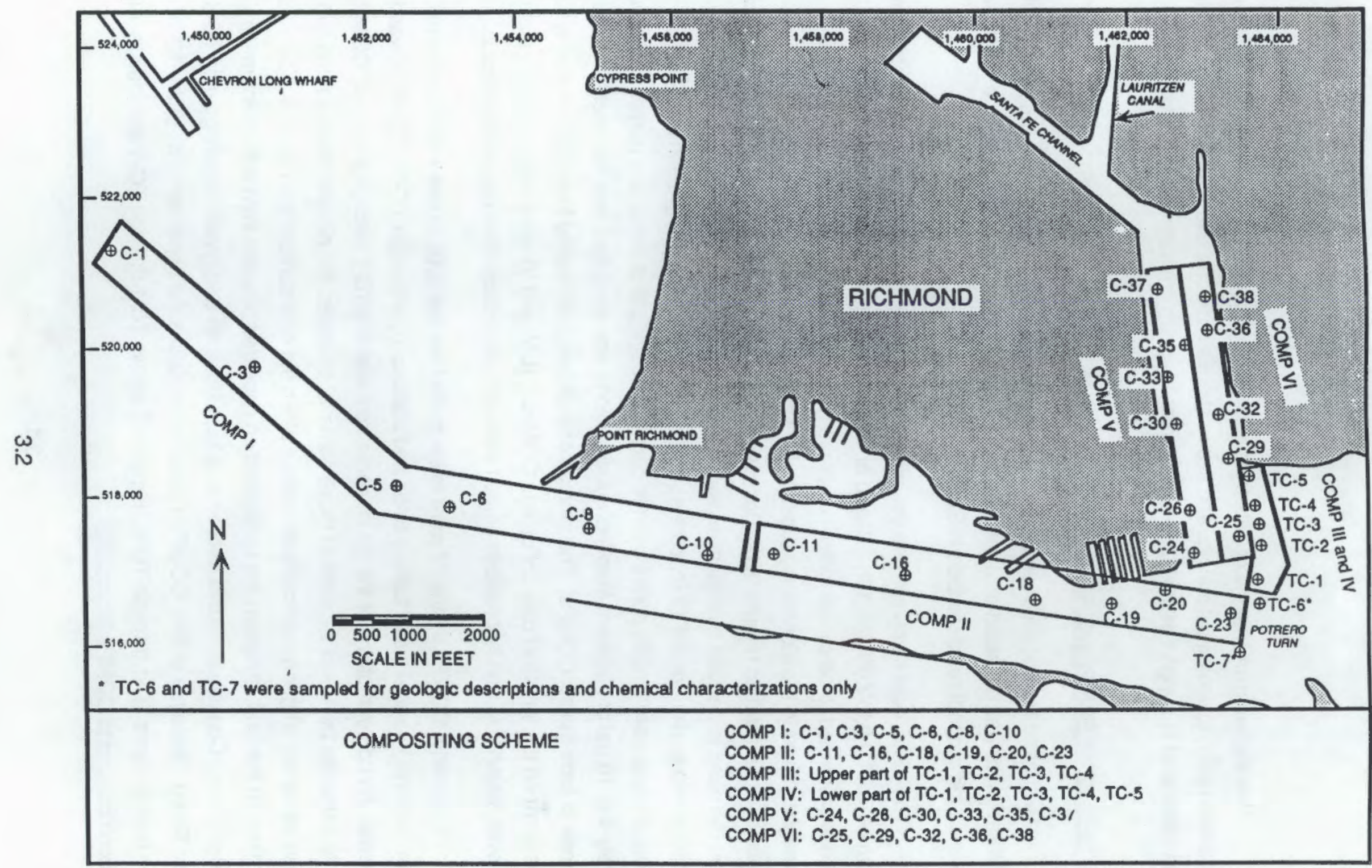

ElGURE 3.1. Richmond Harbor Composite Stations 
Table 3.1. Information for 12-in. Core Sampling and Compositing, Richmond Harbor Program

\begin{tabular}{|c|c|c|c|c|c|c|c|c|c|c|}
\hline Station & Bequicate & $\begin{array}{c}\text { Date } \\
\text { collected }\end{array}$ & $\begin{array}{l}\text { Callfomia Stat } \\
\text { Coordlnates } \\
\text { East }(X)\end{array}$ & $\begin{array}{l}\text { te Plane } \\
\text { (Zone Iii) } \\
\text { Northen. }\end{array}$ & $\begin{array}{l}\text { Mudine } \\
\text { Depth } \\
\text { Givilm }\end{array}$ & $\begin{array}{l}\text { RCore } \\
\text { Required } \\
\text { 10-40it }\end{array}$ & $\begin{array}{r}\text { ACore } \\
\text { Collected }\end{array}$ & $\begin{array}{l}\text { Volume of } \\
\text { contribution } \\
\text { (oal) }\end{array}$ & Composite & Comments \\
\hline$c-1$ & 1 & $06-17-91$ & 1449390.19 & 520987.69 & 36.4 & 3.6 & 7.0 & 4.5 & 1 & \\
\hline $\mathrm{cos}$ & 1 & $06-17-91$ & 1450547.70 & 519752.43 & 36.0 & 4.0 & 6.0 & 5.0 & i & \\
\hline C.5 & 1 & $06-17-91$ & 1452379.27 & 518120.72 & 36.4 & 3.6 & 3.8 & 4.0 & I & \\
\hline C-6 & 1 & $06-17-91$ & 1453053.81 & 517926.61 & 36.3 & 3.7 & 6.0 & 4.2 & 1 & \\
\hline C-6 & 1 & $06-17-91$ & 1454896.38 & 517590.35 & 36.4 & 3.6 & 5.7 & 5.0 & I & \\
\hline$C-10$ & 1 & $08-17-91$ & 1456429.14 & 517299.72 & 36.0 & 4.0 & 4.0 & 5.0 & i & \\
\hline C-29 & 1 & 06-18-91 & 1463334.18 & 518492.92 & 35.0 & 5.0 & 9.5 & 7.0 & VI & \\
\hline C-32 & 1 & $06-18-91$ & 1463210.48 & 519097.77 & 35.3 & 4.7 & 9.0 & $6.0-7.0$ & VI & \\
\hline C-36 & 1 & $06-18-91$ & 1463135.69 & 520210.61 & 36.1 & 3.9 & 9.0 & 6.0 & VI & \\
\hline C-38 & 1 & $06-18-91$ & 1463113.00 & 520633.38 & 36.1 & 3.9 & 7.0 & 8.0 & VI & \\
\hline C-37 & 1 & $06-18-91$ & 1482458.57 & 520383.62 & 36.1 & 3.9 & 10.0 & 6.0 & v & \\
\hline G-35 & 1 & $06-18-91$ & 1462806.17 & 520008.19 & 36.2 & 3.8 & 8.0 & 6.0 & V & \\
\hline C.33 & 1 & $06-18-91$ & 1462559.19 & 519573.38 & 35.0 & 5.0 & 9.0 & 7.0 & v & \\
\hline C-30 & 1 & 06-18-91 & 1462643.87 & 518940.33 & 35.3 & 4.7 & 7.0 & 7.0 & v & \\
\hline C-28 & 1 & $06-18-91$ & 1462783.48 & 517802.54 & 36.1 & 3.9 & 7.5 & 6.0 & v & \\
\hline C-24 & 1 & 06-18-91 & 1462868.10 & 517210.83 & 36.0 & 4.0 & 7.0 & 6.0 & v & \\
\hline C-25 & 1 & $06-18-91$ & 1463471.95 & 517427.14 & 35.0 & 5.0 & 5.0 & 7.0 & VI & \\
\hline$c-23$ & 1 & 08-18-91 & 1463292.49 & 516419.86 & 32.8 & 7.2 & 12.0 & 10.0 & II & \\
\hline$G-11$ & 1 & 06-19-91 & 1457318.48 & 517260.14 & 37.3 & 2.7 & 8.5 & 7.0 & II & \\
\hline C-16 & 1 & $06-19-91$ & 1459062.57 & 516947.11 & 36.2 & 3.8 & 4.0 & 7.0 & II & \\
\hline$C-18$ & 1 & 06-19-91 & 1460733.61 & 616591.21 & 36.1 & 3.9 & 7.0 & 7.0 & II & $\begin{array}{l}\text { Penetrated to } 48 \mathrm{ft} \text { to retain } \\
\text { sediment; collected sediment } \\
\text { from-36.1 to }-40.0 \mathrm{ftMLLW} \text {. }\end{array}$ \\
\hline$C-19$ & 1 & $06-19-91$ & 1461734.38 & 516529.59 & 35.9 & 4.1 & 6.6 & 7.0 & II & \\
\hline$c-20$ & 1 & $06-19-91$ & 1462470.03 & 516699.50 & 36.2 & 3.8 & 3.8 & 7.0 & II & \\
\hline TC-5 & 1 & $06-19-91$ & 1463563.33 & 518188.03 & 21.9 & 18.1 & 18.0 & $30.0 \quad \mathrm{Y}$ & Upper Comp & Taken from mudline to $-36.5 \mathrm{~h} \mathrm{MLLW}$ \\
\hline TC-5 & 1 & $06-19-91$ & 1463563.33 & 518168.03 & 21.9 & 18.1 & 18.0 & 10.0 & IV & Taken from -36.3 to $-40.0 \mathrm{ft}$ MLLW \\
\hline TC-1 & 1 & 06-19-91 & 1463670.78 & 516888.25 & 11.3 & 28.7 & 30.0 & 10.0 & IV & Taken from -21.3 to $-40.0 \mathrm{ft}$ MLLW \\
\hline TC-1 & 1 & 08-19-91 & 1463670.78 & 516866.25 & 11.3 & 28.7 & 30.0 & 10.0 & III & Taken from -11.3 to $-21.3 \mathrm{th}$ MLLW \\
\hline TC-2 & 1 & $06-20-91$ & 1463762.30 & 617300.30 & 11.5 & 28.5 & 38.0 & 10.0 & III & Taken from -11.5 to -14.5 h MLLW \\
\hline TC-2 & 1 & 06-20-91 & 1463762.30 & 517300.30 & 11.5 & 28.5 & 38.0 & 15.0 & IV & Taken from -14.5 to $-40.0 \mathrm{~h} \mathrm{MLLW}$ \\
\hline TC-4 4 & 1 & 06-20-91 & 1463881.45 & 517852.69 & 6.2 & 33.6 & 34.5 & 10.0 & III & Taken from -6.2 to $-23.2 \mathrm{ft}$ MLLW \\
\hline $\mathrm{TC}_{-4}$ & 1 & 06-20-91 & 1463681.45 & 517852.69 & 6.2 & 33.8 & 34.5 & 10.0 & IV & Taken from -23.2 to $-40 \mathrm{ft} \mathrm{MLLW}$ \\
\hline TCO 3 & 1 & 06-20-91 & 1463728.93 & 517605.20 & 8.5 & 31.5 & 37.5 & 10.0 & III & Taken from -8.5 to $-24.0 \mathrm{ft}$ MLLW \\
\hline $\operatorname{TC} 3$ & 1 & $06-20-91$ & 1463728.93 & 517605.20 & 8.5 & 31.5 & 37.5 & 10.0 & IV & Taken from -24.0 to $-40.0 \mathrm{f}$ MLLW \\
\hline
\end{tabular}




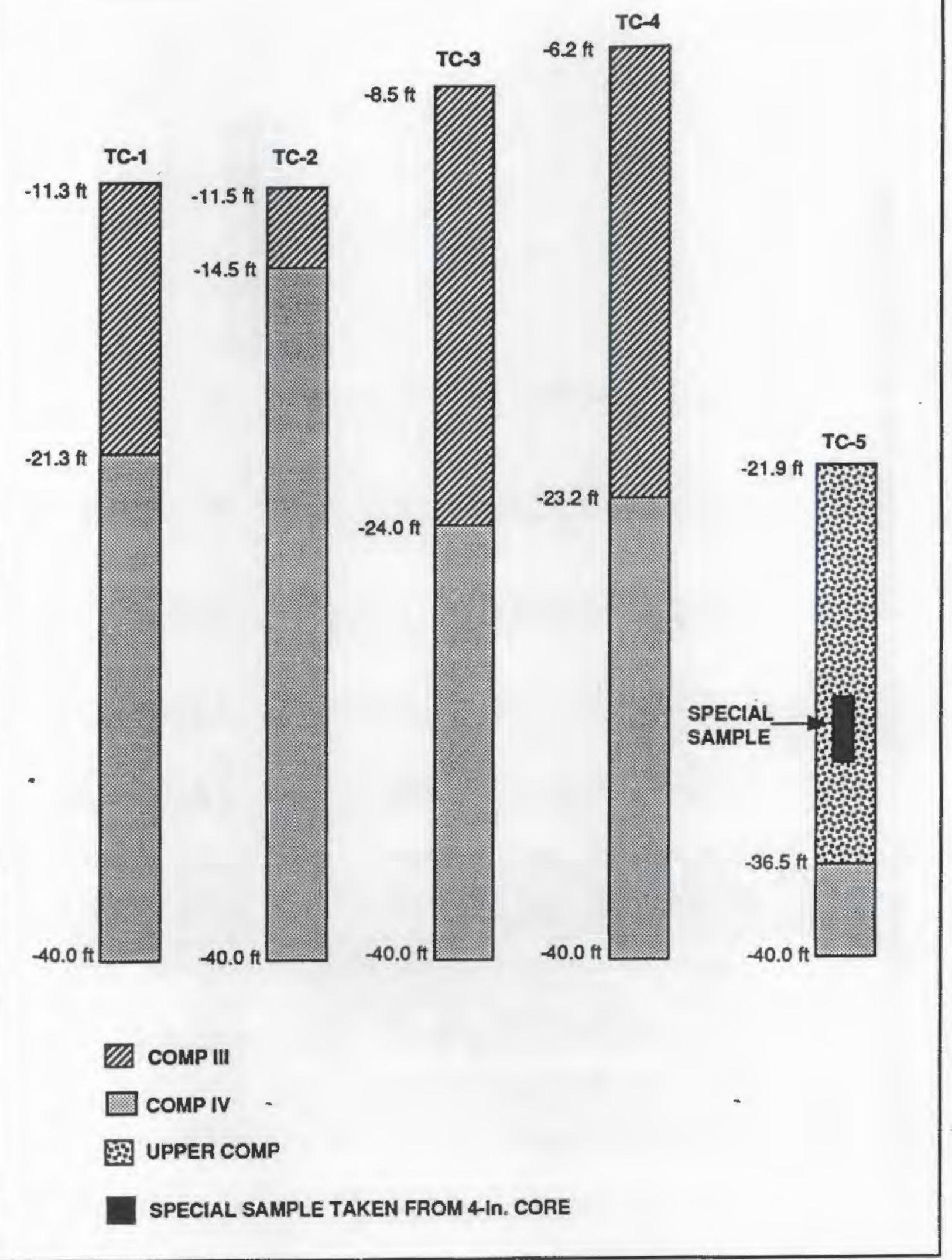

ElGURE 3.2. Compositing Scheme for TC-1 Through TC-5, Richmond Harbor Program 
The 4-in. core samples were also collected from the 28 stations in Richmond Harbor with 2 additional stations in the Potrero Reach maneuvering area (Table 3.2). All cores from each station were geologically described and chemically evaluated to document sediment type and chemical contaminant levels at each station. The additional two stations, TC-6 and TC-7, were sampled exclusively with the 4-in. core sampler because biological testing was not required. Examination of the 4-in. core in the laboratory also revealed Station TC-5 had a small section that appeared to have different grain-size characteristics from the remaining core. This portion, referred to as TC-5 Special, was subjected to separate chemical analysis independent from TC-5.

Reference sediment was collected from three in-bay areas and two offshore areas. The three in-bay reference areas had multiple sampling sites. The Alcatraz Island environs (R-AM) consisted of eight sites evenly spaced at 0.5-nautical mile $(\mathrm{nm})$ intervals around Alcatraz Island (Figure 3.3), four sites within the boundaries of the Alcatraz Island disposal site (R-AC) (Figure 3.3), and four sites within the Bay Farm Borrow Area (R-BF) (Figure 3.4).

Sediment collected from individual sites within a reference area was composited to produce a homogeneous sample. The two offshore reference areas were the deep, off-shelf reference area (R-OS) and the Point Reyes Fine reference area (R-PF) (Figure 3.5). These reference composites consisted of three replicate samples collected and combined to obtain the required volume of sediment needed for testing. Complete reference sediment sampling information is provided in Table 3.3 .

Control sediment for use in solid-phase toxicity tests was collected from Sequim Bay, Washington (Figure 3.6); West Beach, Washington (Figure 3.7); and Tomales Bay, California, (Figure 3.8) as described in Section 2.1.3. Sequim Bay control sediment (C-SB) was used as an experimental control in all toxicity tests as well as the native control for M. nasuta. West Beach control sediment (C-WB) was the native sediment for the amphipod $R$. abronius. Native sediment for $N$. caecoides (C-NE) and C. stigmaeus (C-SD) was collected from Tomales Bay, California.

\subsection{GEOLOGIC DESCRIPTIONS}

The following sections provide a description of the geology of the Richmond Harbor sediment based on the characterization of 30 sediment cores collected June 17 through 20 , 1991. Twenty-three short core samples (< $7 \mathrm{ft})$ were collected from the Richmond Harbor 
Table 3.2. Information for 4-in. Core Sampling, Richmond Harbor Program

\begin{tabular}{|c|c|c|c|c|c|c|c|}
\hline Station & Replicate & $\begin{array}{r}\text { Date } \\
\text { Collected }\end{array}$ & $\begin{array}{l}\text { Callomias } \\
\text { Coordinates } \\
\text { East }(X)\end{array}$ & $\begin{array}{l}\text { Plane } \\
\text { one III) } \\
\text { Northn }\end{array}$ & $\begin{array}{l}\text { Mudine } \\
\text { Depth } \\
\text { (-nMUM }\end{array}$ & $\begin{array}{c}\text { ACoro } \\
\text { Required } \\
\text { re-40\#MLW }\end{array}$ & $\begin{array}{l}\text { Ficore } \\
\text { collected }\end{array}$ \\
\hline C-1 & 1 & $08-17-91$ & 1449390.19 & 520987.69 & 36.4 & 3.6 & 4.5 \\
\hline$C-3$ & 1 & $08-17-91$ & 1450547.70 & 519752.43 & 36.0 & 4.0 & 4.0 \\
\hline C.5 & 1 & $06-17-91$ & 1452379.27 & 518120.72 & 36.4 & 3.6 & 3.6 \\
\hline C-6 & 1 & $08-17-91$ & 1453053.81 & 517926.81 & 36.3 & 3.7 & 4.7 \\
\hline$C-8$ & 1 & $06-17-91$ & 1454896.38 & 517590.35 & 38.4 & 3.6 & 8.0 \\
\hline C.10 & 1 & $06-17-91$ & 1456429.14 & 517239.72 & 36.0 & 4.0 & 4.7 \\
\hline$C-29$ & 1 & $06-16-91$ & 1463334.18 & 518492.92 & 35.0 & 5.0 & 7.0 \\
\hline C-32 & 1 & $06-18-91$ & 1463210.48 & 519097.77 & 35.3 & 4.7 & 7.5 \\
\hline C-36 & 1 & $06-18-91$ & 1483135.69 & 520210.61 & 36.1 & 3.9 & 8.5 \\
\hline C-38 & 1 & $06-18-91$ & 1463113.00 & 520633.36 & 38.1 & 3.9 & 6.9 \\
\hline C-37 & 1 & $06-16-91$ & 1462458.57 & 520383.62 & 36.1 & 3.9 & 6.7 \\
\hline C-35 & 1 & $06-16-91$ & 1462806.17 & 520008.19 & 36.2 & 3.8 & 6.5 \\
\hline C-33 & 1 & $06-18-91$ & 1462559.19 & 519573.36 & 35.0 & 5.0 & 6.0 \\
\hline C-30 & 1 & $06-18-91$ & 1462643.87 & 518940.33 & 35.3 & 4.7 & 6.0 \\
\hline C-26 & 1 & $06-18-91$ & 1462783.48 & 517802.54 & 36.1 & 3.9 & 4.5 \\
\hline C-24 & 1 & $06-18-91$ & 1462888.10 & 517210.83 & 36.0 & 4.0 & 4.6 \\
\hline C-25 & 1 & $06-18-91$ & 1463471.95 & 517427.14 & 35.0 & 5.0 & 6.0 \\
\hline C-23 & 1 & $06-18-91$ & 1463292.49 & 516419.86 & 32.8 & 7.2 & 7.2 \\
\hline C.11 & 1 & 06-19-91 & 1457318.48 & 517260.14 & 37.3 & 2.7 & 2.7 \\
\hline C-16 & 1 & 06-19-91 & 1459062.57 & 516947.11 & 36.2 & 3.8 & 4.5 \\
\hline C-18 & 1 & $06-19-91$ & 1460733.61 & 516591.21 & 36.1 & 3.9 & 4.5 \\
\hline C.19 & 1 & $06-19-91$ & 1461734.38 & 516529.59 & 35.9 & 4.1 & 6.0 \\
\hline C-20 & 1 & $06-19-91$ & 1462470.03 & 516699.50 & 36.2 & 3.8 & 7.0 \\
\hline TC-5 & 1 & $06-19-91$ & 1463563.33 & 518188.03 & 21.9 & 18.1 & 15.0 \\
\hline TC-7 & 1 & $06-19-91$ & 1483615.40 & 516336.91 & 11.0 & 29.0 & 35.0 \\
\hline TC-6 & 1 & $06-19-91$ & 1463754.99 & 516496.57 & 6.0 & 34.0 & 39.0 \\
\hline TC-1 & 1 & $06-19-91$ & 1463870.76 & 516868.25 & 11.3 & 28.7 & 25.0 \\
\hline TC-2 & 1 & $06-20-91$ & 1463762.30 & 517300.30 & 11.5 & 28.5 & 21.5 \\
\hline TC-4 & 1 & $06-20-91$ & 1463681.45 & 517852.69 & 6.2 & 33.8 & 32.5 \\
\hline TC-3 & 1 & $06-20-91$ & 1463728.93 & 517605.20 & 8.5 & 31.5 & 26.0 \\
\hline
\end{tabular}




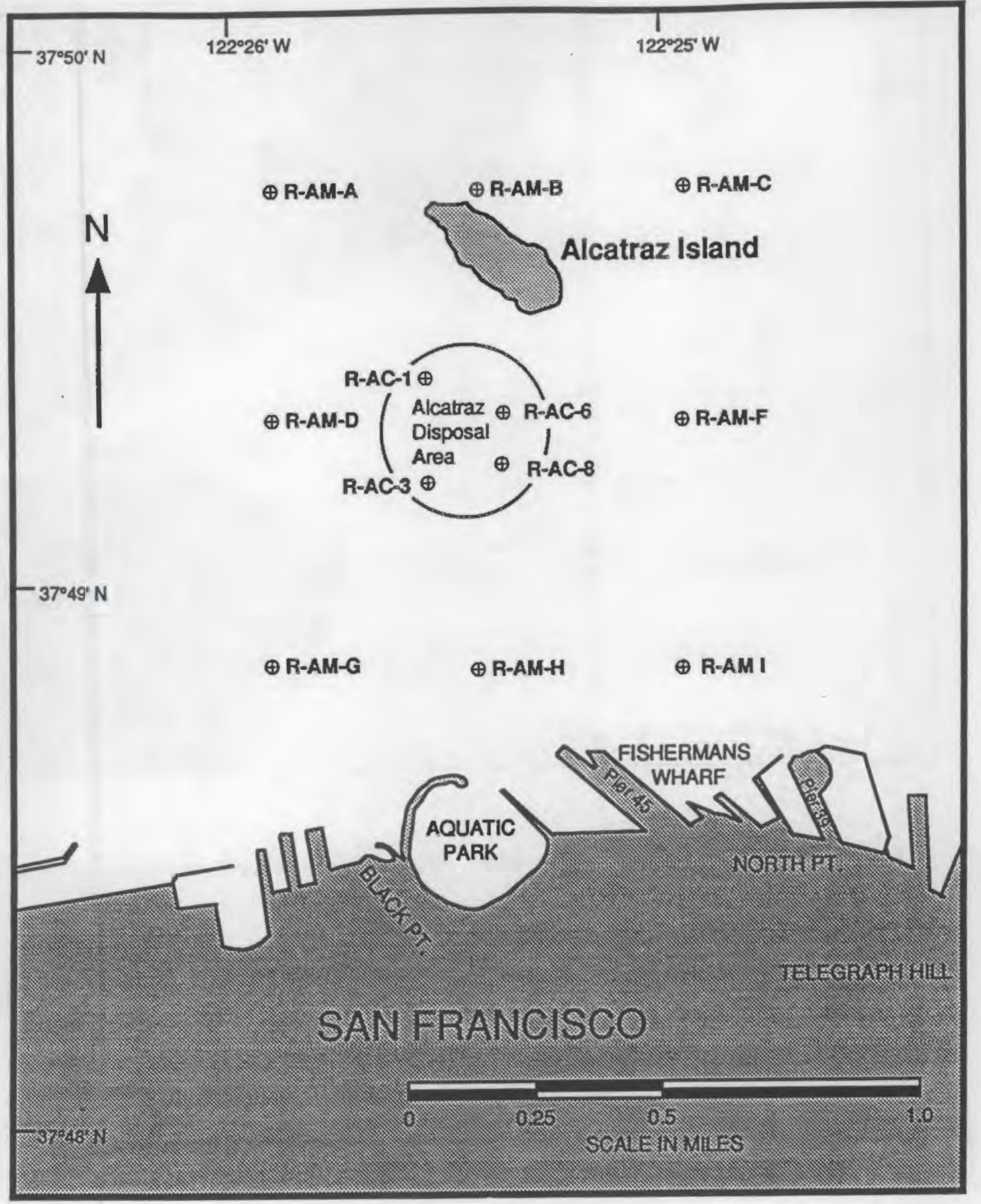

FlGURE 3,3. Locations of R-AC and R-AM Reference Sampling Stations, Richmond Harbor Program 


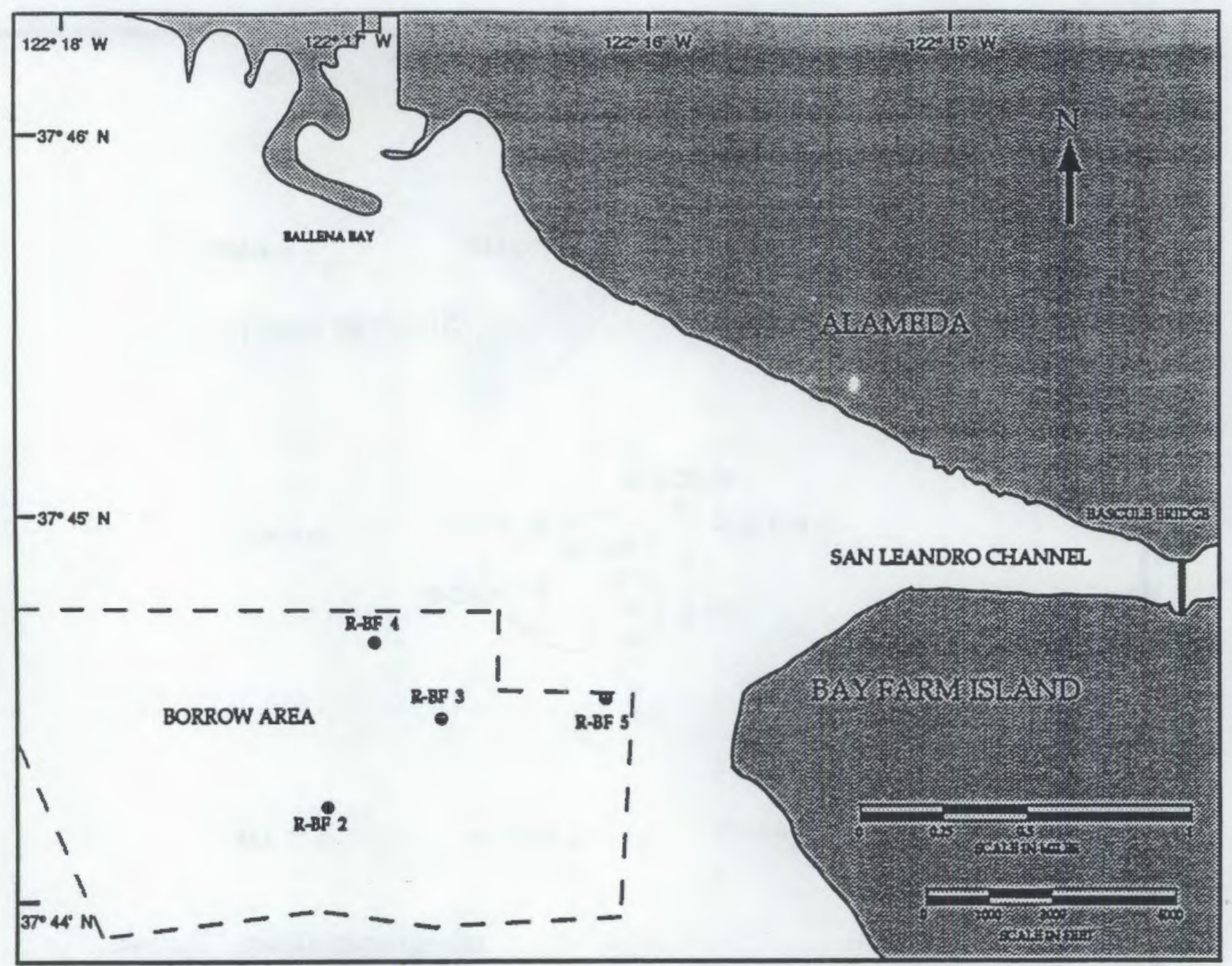

EIGURE 3.4. Locations of R-BF Reference Sampling Stations, Richmond Harbor Program

channel, and seven long core samples (15 to $39 \mathrm{ft}$ ) were collected from the proposed turning basin (Potrero Reach). Sample station locations are presented in Figure 1.2. The core samples were geologically described according to ASTM Procedure D2488-84: "Standard Practice for Description and Identification of Soils (Visual-Manual Procedure)." The following sediment characteristics were logged: dry strength of silt/clay, dilatancy of silt/clay, toughness of silt/clay, plasticity of silt/clay, sediment type (i.e., engineering classification), color, consistency (i.e., firmness), cementation, sedimentary structure, reaction with hydrochloric acid, maximum particle size, and odor. In addition, other diagnostic features such as the presence of root traces, mollusk shells, and/or related detritus were noted. A detailed description of the materials and methods used for describing the sediment cores is given in Appendix A. Detailed cores logs collected during Richmond Harbor sampling are provided in Appendix B. 


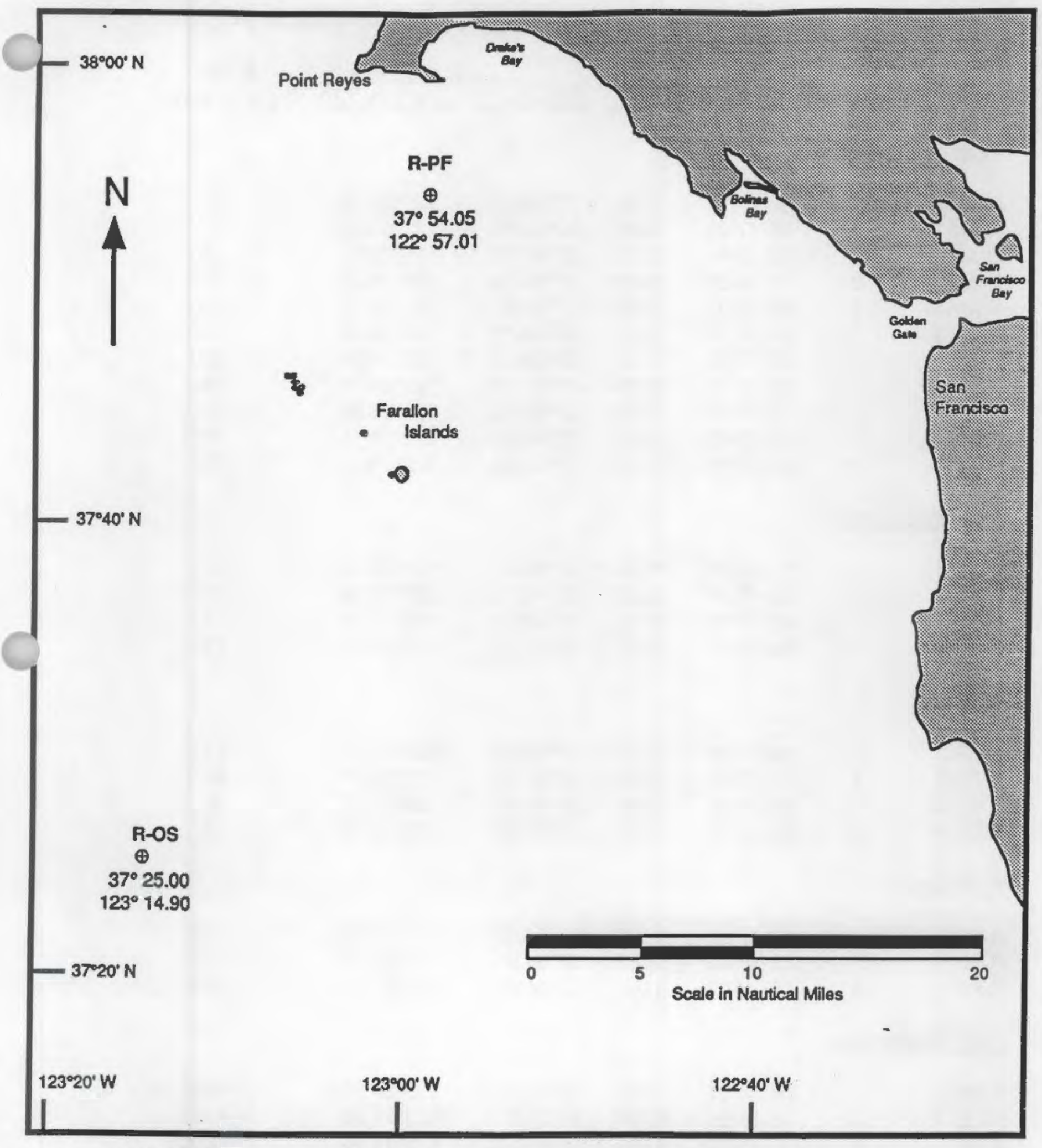

ElGURE 3.5. Location of R-PF Referençe Sampling Station, Richmond Harbor Program 
IABLE 3.3. Information for Reference Sediment Sampling, Richmond Harbor Program

Date

Station Beplicate Sampled Time Latitude(N) Longitude (W) (-ftMLLW)

Alcatraz-Environs

$\begin{array}{lllllll}\text { R-AM-A } & 1 & 06-17-91 & 1240 & 37^{\circ} 49.81 & 122^{\circ} 25.86 & 54 \\ \text { R-AM-B } & 1 & 06-17-91 & 1300 & 37^{\circ} 49.72 & 122^{\circ} 25.43 & 64 \\ \text { R-AM-B } & 2 & 06-17-91 & 1310 & 37^{\circ} 49.73 & 123^{\circ} 25.48 & 50 \\ \text { R-AM-B } & 3 & 06-17-91 & 1330 & 37^{\circ} 49.72 & 122^{\circ} 25.38 & 77 \\ \text { R-AM-C } & 1 & 06-17-91 & 1355 & 37^{\circ} 49.87 & 122^{\circ} 25.07 & 70 \\ \text { R-AM-F } & 1 & 06-17-91 & 1415 & 37^{\circ} 49.13 & 122^{\circ} 24.29 & 84 \\ \text { R-AM-F } & 1 & 06-17-91 & 1440 & 37^{\circ} 49.35 & 122^{\circ} 24.84 & 82 \\ \text { R-AM-I } & 1 & 06-17-91 & 1503 & 37^{\circ} 48.98 & 122^{\circ} 24.73 & 78 \\ \text { R-AM-H } & 1 & 06-17-91 & 1529 & 37^{\circ} 48.89 & 122^{\circ} 25.50 & 48 \\ \text { R-AM-G } & 1 & 06-17-91 & 1542 & 37^{\circ} 48.83 & 122^{\circ} 26.13 & 72 \\ \text { R-AM-D } & 1 & 06-17-91 & 1615 & 37^{\circ} 49.35 & 122^{\circ} 25.95 & 71\end{array}$

Alcatraz-Disposal

$\begin{array}{lllllll}\text { R-AC-1 } & 1 & 06-17-91 & 1640 & 37^{\circ} 49.27 & 122^{\circ} 25.33 & 54 \\ \text { R-AC-3 } & 1 & 06-17-91 & 1700 & 37^{\circ} 49.12 & 122^{\circ} 25.30 & 80 \\ \text { R-AC-6 } & 1 & 06-17-91 & 1715 & 37^{\circ} 49.18 & 122^{\circ} 25.10 & 76 \\ \text { R-AC-8 } & 1 & 06-17-91 & 1730 & 37^{\circ} 49.14 & 122^{\circ} 25.09 & 68\end{array}$

Bay Farm

$\begin{array}{lllllll}\text { R-BF-2 } & 1 & 06-17-91 & 1845 & 37^{\circ} 44.23 & 122^{\circ} 17.11 & 31 \\ \text { R-BF-3 } & 1 & 06-17-91 & 1905 & 37^{\circ} 44.48 & 122^{\circ} 16.76 & 34 \\ \text { R-BF-4 } & 1 & 06-17-91 & 1925 & 37^{\circ} 44.67 & 122^{\circ} 16.97 & 30 \\ \text { R-BF-5 } & 1 & 06-17-91 & 1945 & 37^{\circ} 44.57 & 122^{\circ} 16.19 & 33\end{array}$

\section{Point Reyes}

$\begin{array}{lllllll}\text { R-PF } & 1 & 06-18-91 & 1105 & 37^{\circ} 54.05 & 122^{\circ} 57.00 & 222 \\ \text { R-PF } & 2 & 06-18-91 & 1123 & 37^{\circ} 54.05 & 122^{\circ} 57.01 & 222 \\ \text { R-PF } & 3 & 06-18-91 & 1140 & 37^{\circ} 54.02 & 122^{\circ} 57.01 & 223\end{array}$

Deep Offshore Site

$\begin{array}{lllllll}\text { R-OS } & 1 & 06-18-91 & 1550 & 37^{\circ} 25.03 & 123^{\circ} 14.84 & 4200 \text { est } \\ \text { R-OS } & 2 & 06-18-91 & 1700 & 37^{\circ} 24.87 & 123^{\circ} 14.96 & 4192 \\ \text { R-OS } & 3 & 06-18-91 & 1820 & 37^{\circ} 24.98 & 123^{\circ} 14.90 & 4200\end{array}$




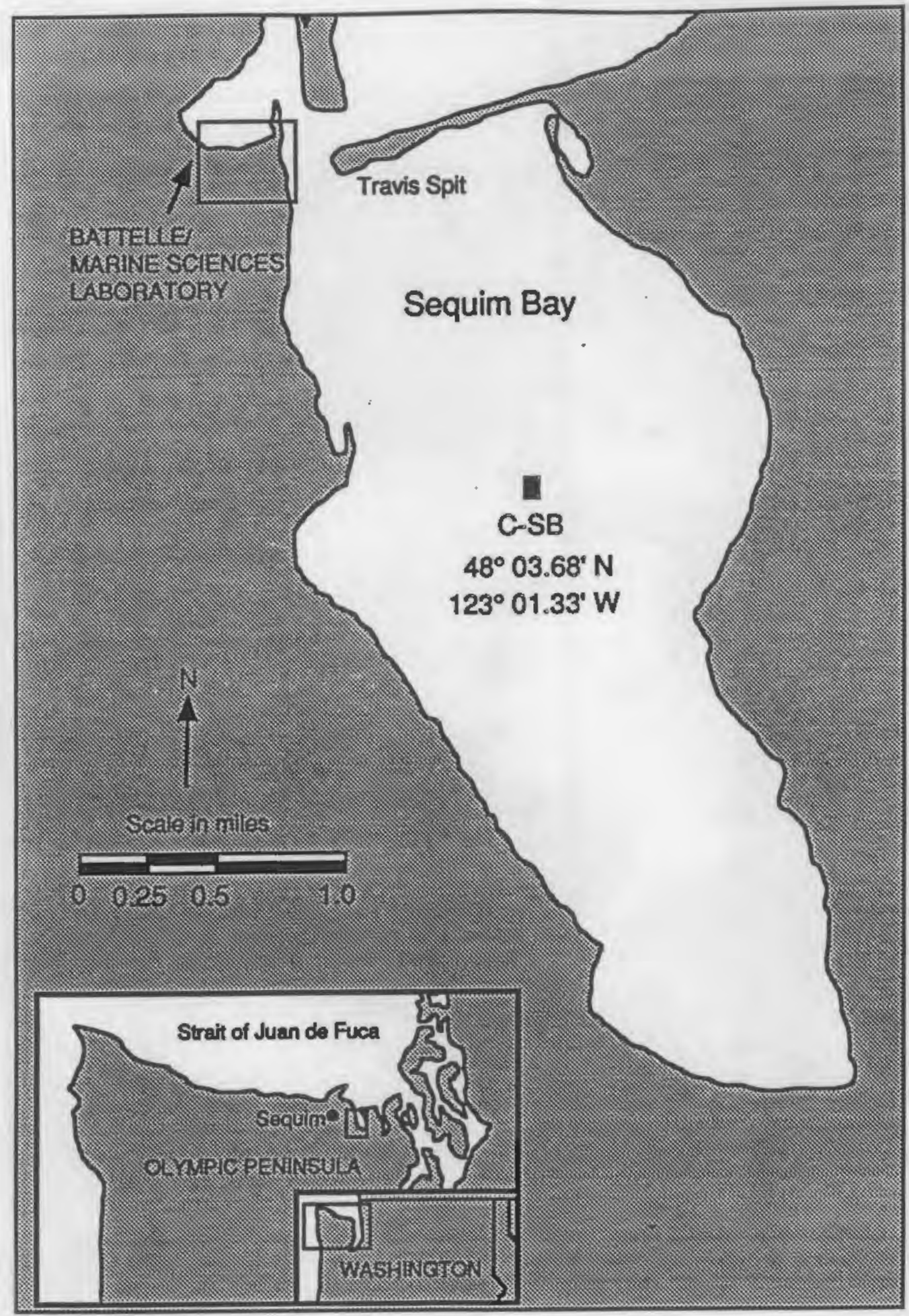

ElGURE 3.6. Location of C-SB Control Station, Fichmond Harbor Program 


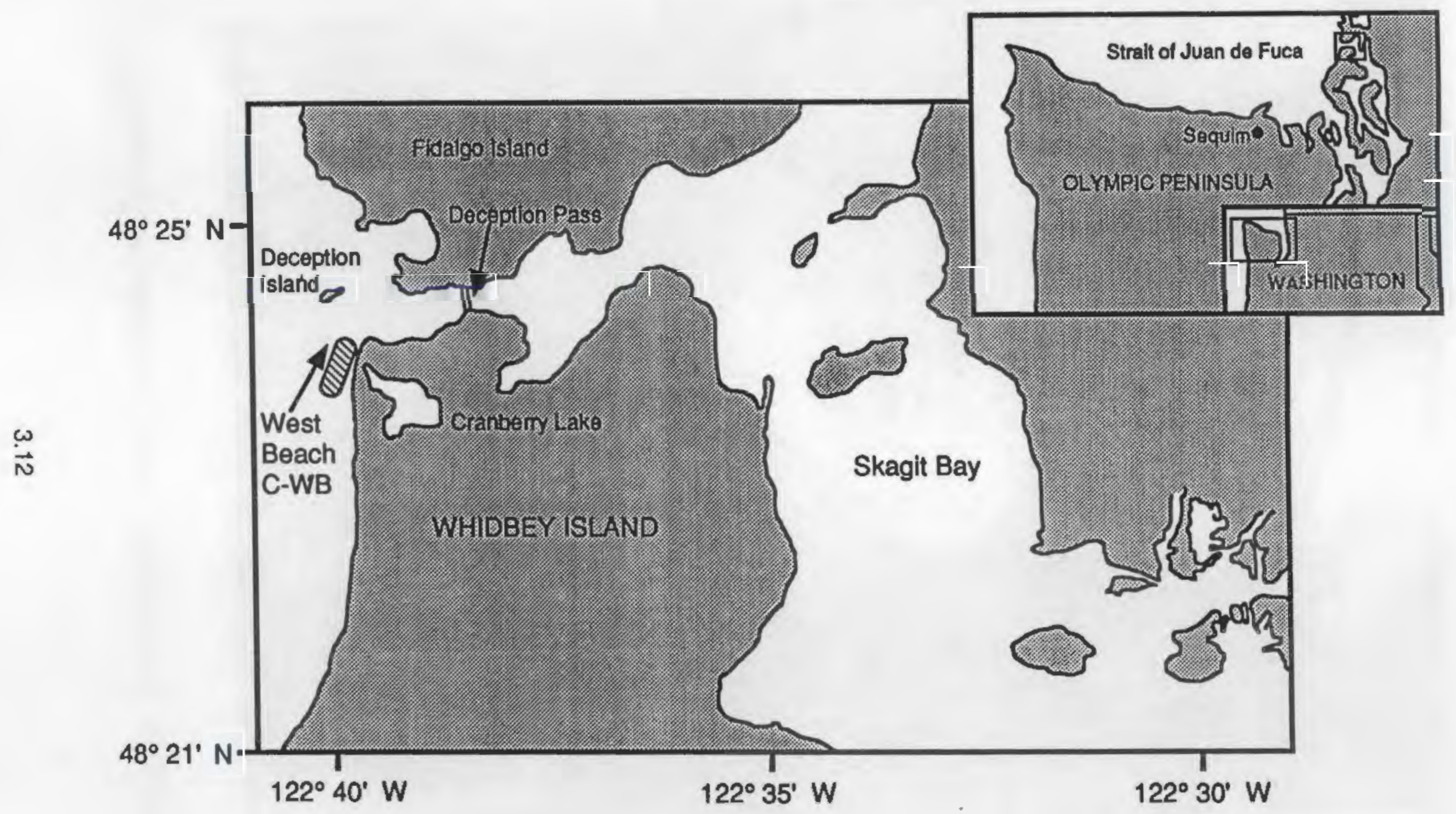

EIGURE 3.7. Location of C-WB Control Station, Richmond Harbor Program 


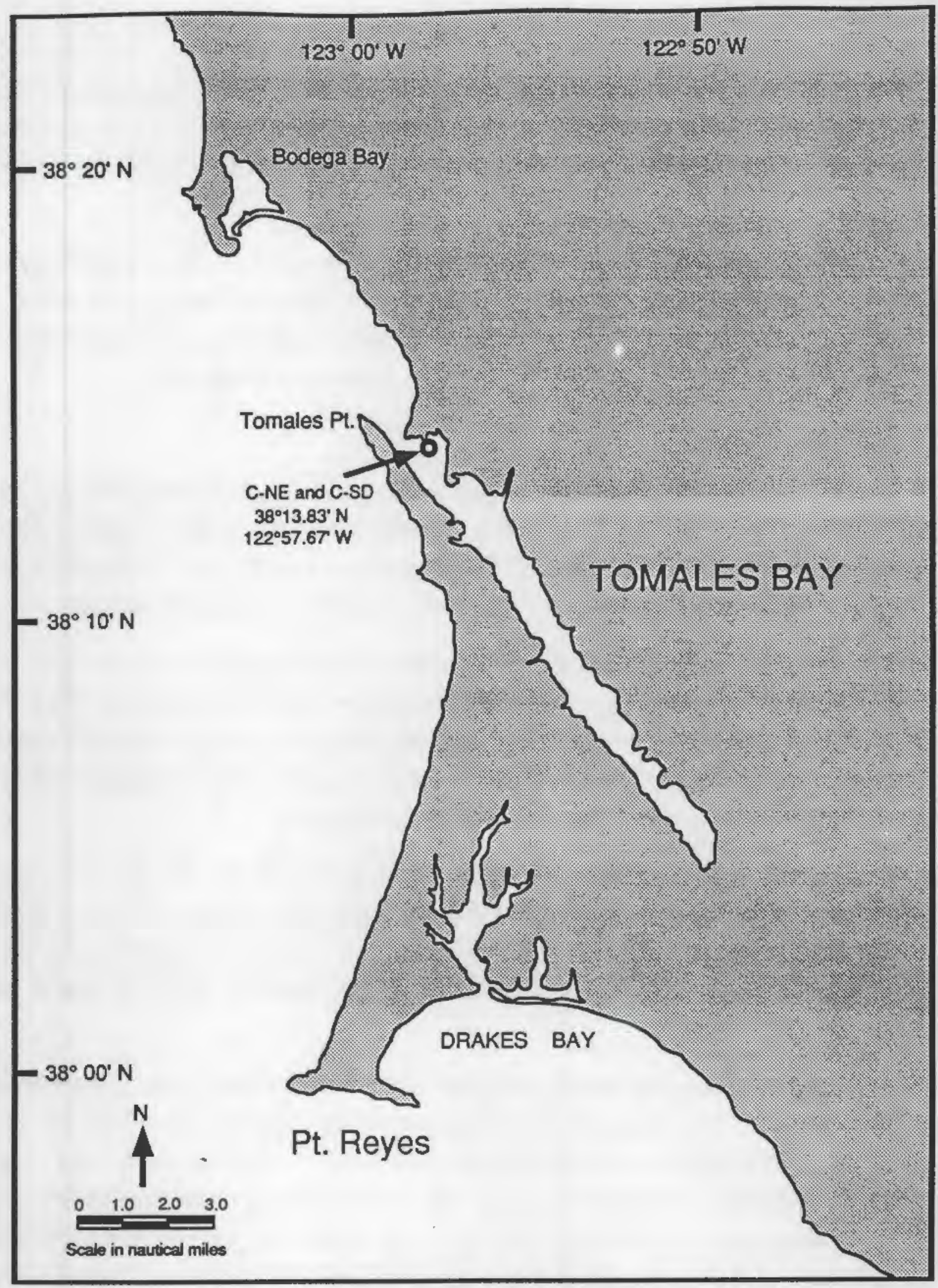

EIGURE 3,8. Location of C-NE Control Station, Richmond Harbor Program 
Two geologic units have been identified in the Richmond Harbor Program area: Older Bay Mud (OBM) and Younger Bay Mud (YBM) (USACE 1975a). The firm to hard OBM sediments include both estuarine and terrestrial deposits; the soft, dark YBM sediments are marine deposits.

The OBM and YBM are distinguished from each other on the basis of consistency and color. The OBM sediments are firm to hard in consistency and are various shades of red, brown, yellow, or gray; whereas the YBM sediments are generally very soft in consistency and dark gray to black in color. The OBM and YBM are described in detail below.

\subsubsection{Older Bay Mud}

The OBM unit consists of a wide range of deposits ranging from loose pebbly sands to stiff, cohesive silty clays. The OBM unit was probably deposited during the last glacial period when sea level resided as much as $335 \mathrm{ft}$ below its present level (USACE 1975b, 1979). Some of the unit may have been deposited during previous glacial and interglacial periods.

The terrestrial sediments of the OBM unit are various shades of red, yellow, and brown; implying deposition in oxidizing environments such as rivers, streams, and deltas. The presence of deeply penetrating root traces also suggests deposition in a terrestrial environment. The marine portions of the OBM unit consist of fine-grained deposits that are olive and gray in color, indicating a low energy, chemically reducing environment.

The high degree of compaction and consolidation of the OBM implies that this unit is much older than the overlying YBM unit. The highly oxidized and weathered nature of the OBM, in combination with the presence of root traces, calcium-carbonate, and iron oxide nodules, suggest the OBM unit locally underwent subaerial alteration where portions of the bay lay above sea level.

In the Richmond Harbor Program area, the OBM is composed primarily of estuarine deposits of clay to silty or sandy clay with occasional lenses and thin beds of sand. The OBM sediments are firm to hard in consistency and brown or gray in color and have no odor. Traces of organic matter were observed in 10 cores. Four to $6 \mathrm{ft}$ of silty sand was encountered at $-32 \mathrm{ft}$ MLLW in cores from the turning basin stations TC-1 through TC-4. The sand unit was green to brown in color, contained rounded and angular pebbles, and exhibited stratification and graded bedding. Nodules of calcium carbonate were observed in samples from stations C-29, C-32, C-35, C-36, C-38, and TC-3, which are all located within the Inner Harbor Channel. Nodules of 
iron oxide were observed in samples from stations $\mathrm{C}-18, \mathrm{C}-19, \mathrm{C}-25, \mathrm{C}-37, \mathrm{TC}-1, \mathrm{TC}-2$, and TC-4, which are located in the Potrero Reach (and the proposed turning basin). These iron oxide areas appear to have experienced post-depositional subaerial alteration.

\subsubsection{Younger Bay Mud (YBM)}

The YBM forms a continuous blanket across the harbor bottom, except where it has been removed by dredging. The YBM was deposited as sea level rose following the last ice age, which ended approximately 12,000 years ago (Bariy 1983). The YBM unit is also present above sea level inland from the present bay (USACE 1975a), suggesting that either sea level was higher at times in the past or recent uplift (i.e., tectonic) of the land surface has occurred.

The YBM unit consists mostly of very soft to soft silty clays and clayey silts with minor amounts of organic matter, fine sand, and shell fragments (USACE 1975a). The YBM sediments are dark gray to black in color. The dark color and odor of hydrogen sulfide are consistent with deposition in chemically reducing conditions. Shells and shell fragments were commonly observed in YBM sediments, and a concentrated layer of oyster shells was identified at stations TC-3 and TC-4 at approximately $-20 \mathrm{ft}$ MLLW. A layer of silty to gravelly sand was identified at stations $\mathrm{C}-6$ and $\mathrm{C}-10$ at approximately $-40 \mathrm{ft}$ MLLW. The sand layer contains shells and was laminated or cross-laminated at Station TC-6, consistent with deposition in a deltaic environment. The thickness and extent of the sand layer is unknown.

The USACE (1975a) subdivided the YBM into a Semi-Consolidated Bay Mud member overlain by a Soft Bay Mud member. The firmness of the YBM unit increases slightly with depth, probably as a result of compaction beneath the weight of overlying sediments. The primary unit identified at the Richmond Harbor area is the Soft Bay Mud member; however, the Semi-Consolidated Bay Mud member was tentatively identified at stations TC-2 and TC-3.

Geologic cross sections representing the composite areas shown in Figure 3.9 are constructed from sediment sample core logs that depict the distribution of the OBM and YBM in the Richmond Harbor Program area. Figure 3.10 shows an east/west cross section representing the geology of the entrance channel. As seen in the figure, the OBM was not encountered west of Station C-16. Figures 3.11 and 3.12 show north/south cross sections representing the Inner Harbor Channel. In contrast to the entrance channel, Inner Harbor Channel cross sections consisted primarily of OBM. The OBM was encountered at approximately -39 to $-40 \mathrm{ft}$ MLLW; the overlying YBM was generally less than $5 \mathrm{ft}$ thick, which may have accumulated since the channel was last dredged. The YBM increases dramatically in the turning circle portion of 


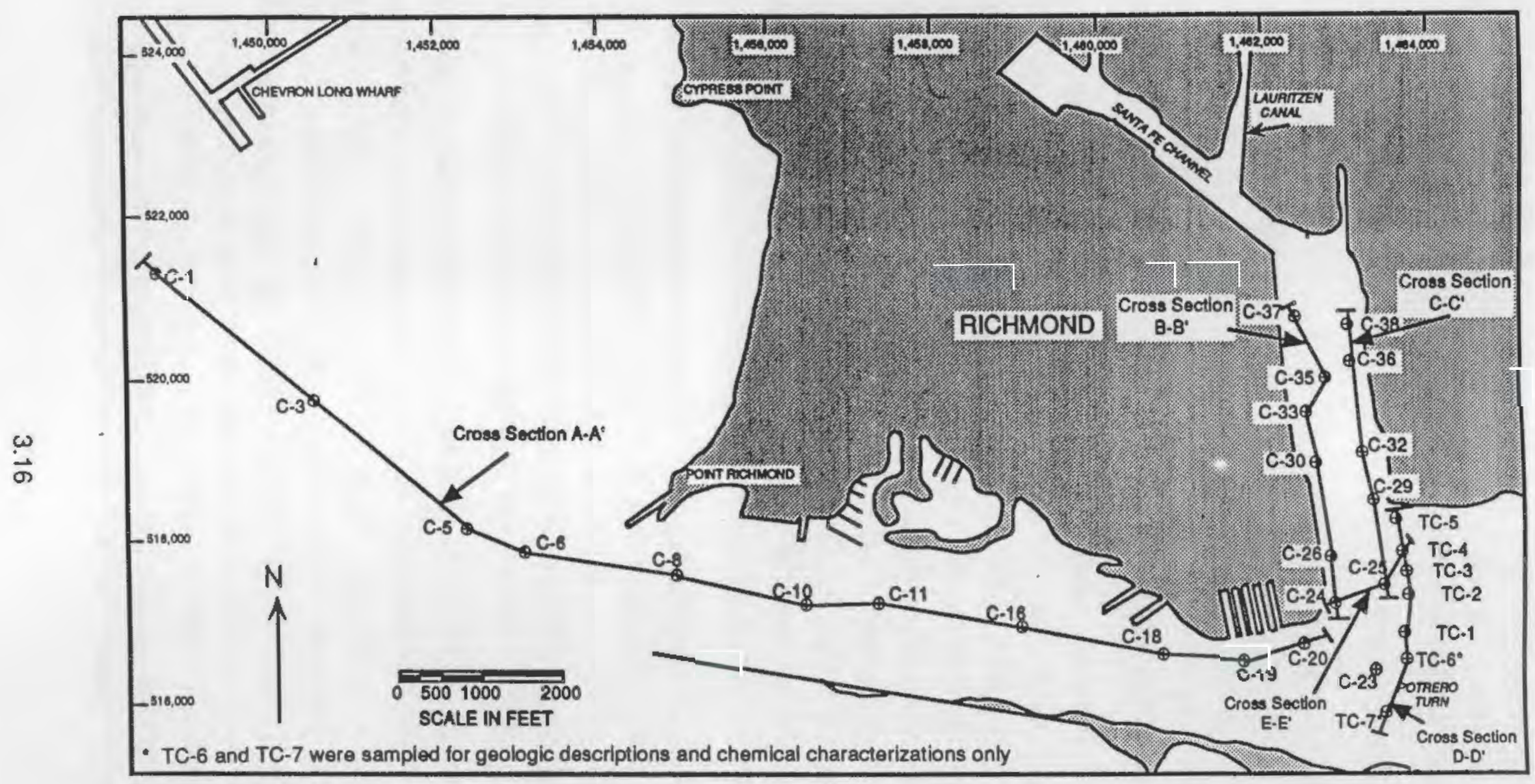

ElGURE 3.9. Geologic Cross Section Map of the Richmond Harbor Area 


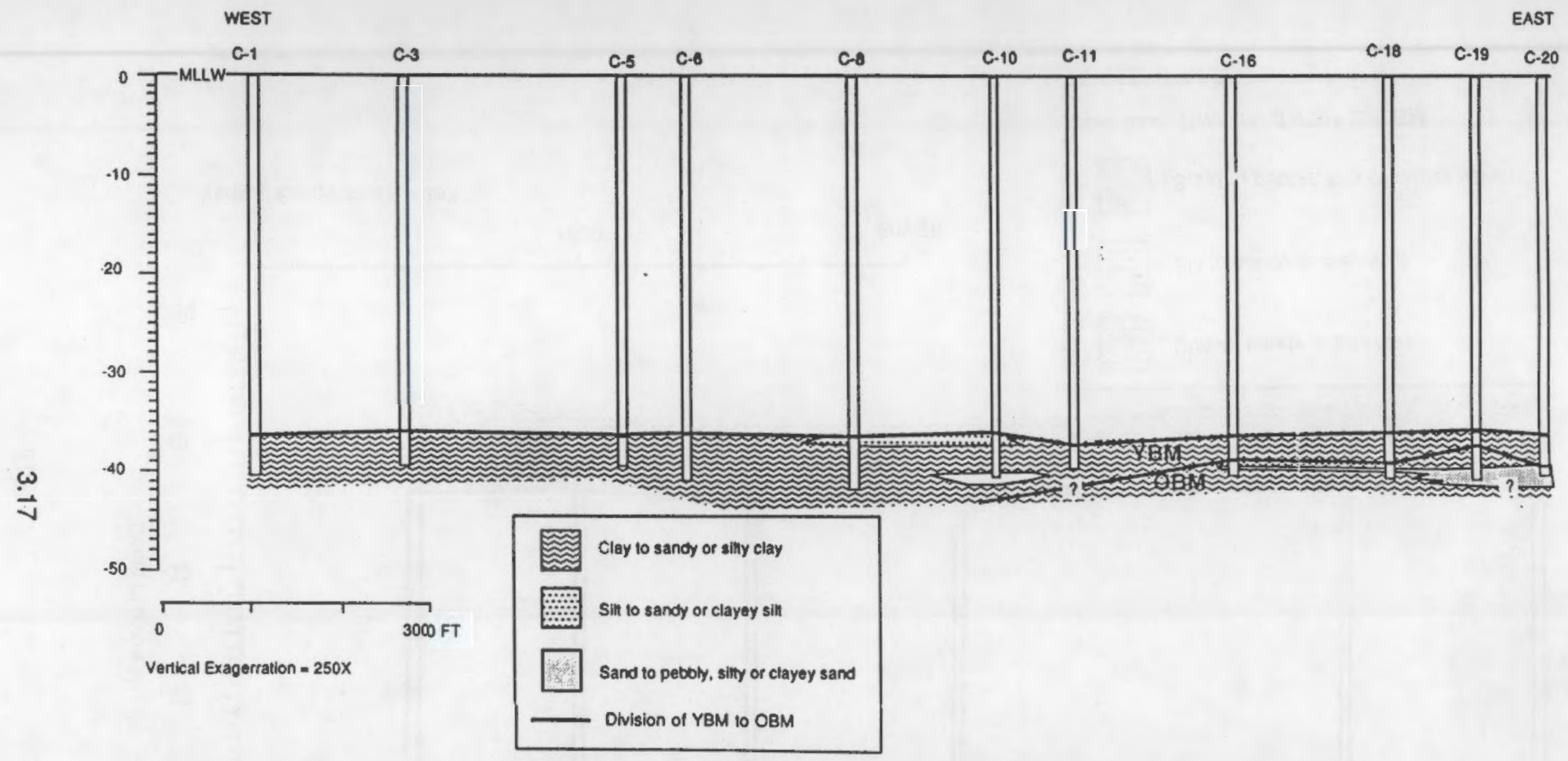

ElGURE 3.10. Cross Section A-A', Richmond Harbor Program 


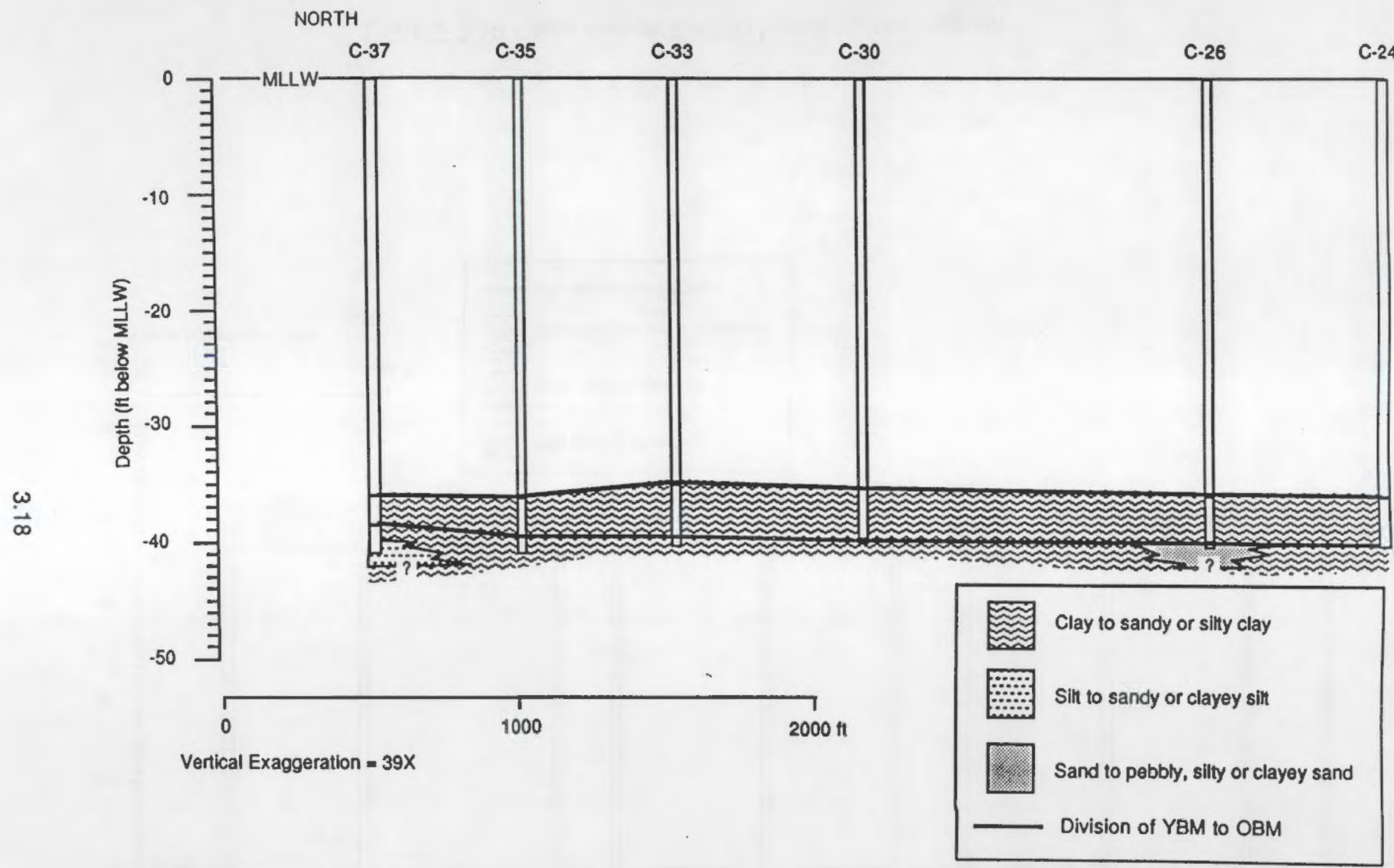

EIGURE 3.11. Cross Section B-B', Richmond Harbor Program 


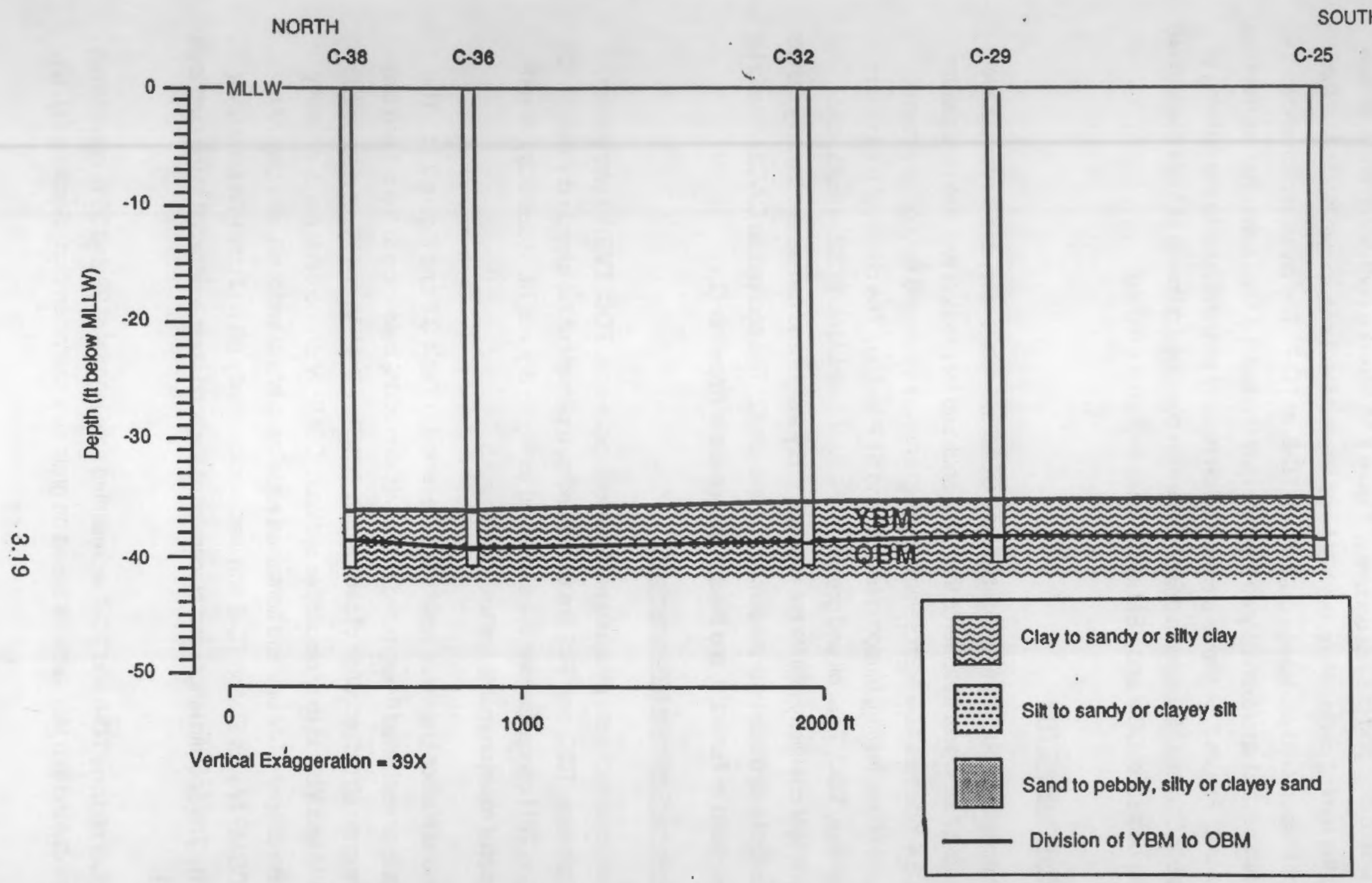

EIGURE 3.12. Cross Section C-C', Richmond Harbor Program 
the channel where dredging has not occurred. Figure 3.13 shows a north/south cross section representing the turning circle. Here, the YBM was the dominant unit, shown by the fact that OBM was not encountered at stations $\mathrm{C}-23, \mathrm{C}-24, \mathrm{TC}-6$, or TC-7. The cross section shows the YBM has a thickness of approximately $40 \mathrm{ft}$, which may represent a filled paleochannel downcut into the OBM unit. Figure 3.14 shows a cross section roughly perpendicular to the opening of the Inner Harbor Channel. Stations in this cross section consisted primarily of YBM down to -40 $\mathrm{ft}$ MLLW. The contact of OBM and YBM in this cross section is irregular.

\subsection{SEDIMENT CHEMISTRY}

Forty-three individual sediment samples, 6 COMPs, 5 references, and 3 controls, were composited into 57 sediment treatments that were analyzed for physical and chemical parameters. Table 3.4 indicates how each sediment treatment was evaluated through sediment chemistry, solid-phase testing, bioaccumulation, and SPP testing. The chemical parameters included grain size, TOC, TVS, oil and grease, TPH, PAH, pesticides, PCBs, metals, and butyltins. Sediment chemistry results are reported in dry weight and complete chemistry results and quality control information are presented in Appendix $C$. The acceptable QAQC criteria for sediments are listed in Table 2.1 and the summaries are in Appendix C.

\subsubsection{Conventional Sediment Measurements}

Conventional sediment measurements include grain size, TOC, TVS, oil and grease, and TPH. Grain size, TOC, and TVS are expressed as a percent of the sample dry weight. Oil and grease and TPH concentrations are expressed as $\mathrm{mg} / \mathrm{kg}$ dry weight. A summary of sediment conventional measurements is shown in Table 3.5.

Richmond Harbor grain size results are presented in Table 3.5 and Figure 3.15. The majority of stations contained fine-grained sediments with $\geq 50 \%$ belonging to the silt and clay fractions. The grain size distribution of sediment in COMPS I, II, III, V, and VI represented a mixture of OBM and YBM in their respective stations. COMP IV on the other hand, primarily represented the deeper OBM unit and contained equal amounts of sand, silt, and clay. An exception in COMP IV was Station TC-2 and was predominantly silt and clay (the sand layer began at $36 \mathrm{ft}$ ). The specific length and placement of the sand layer is depicted in the core logs in Appendix B.

Individual stations TC- 6 and TC-7 represented core lengths of 39 and $35 \mathrm{ft}$, respectively. Each core was divided into four sections based on grain size characteristics. Sections (1), (2), 


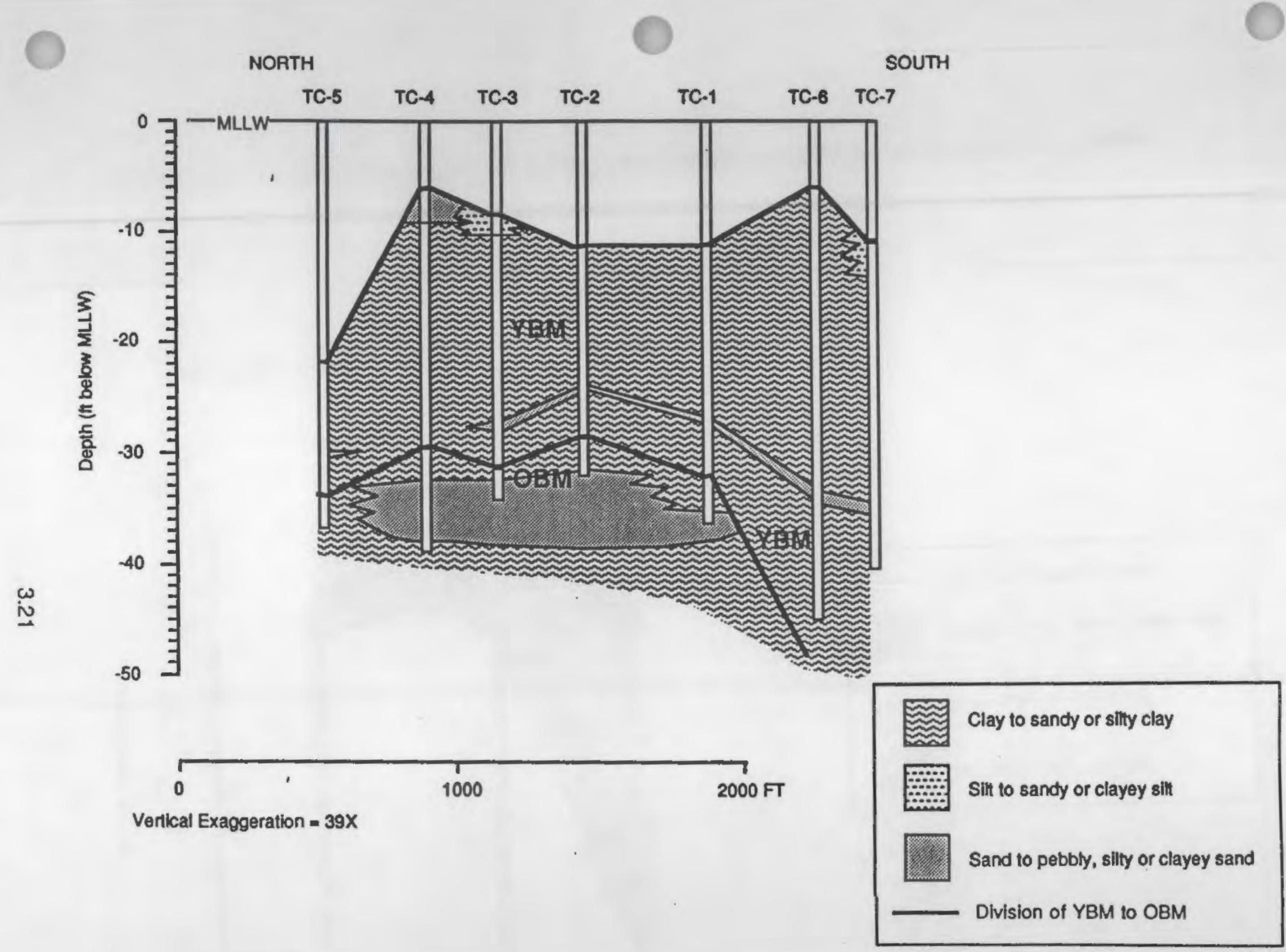

ElGURE 3,13. Cross Section D-D', Richmond Harbor Program 


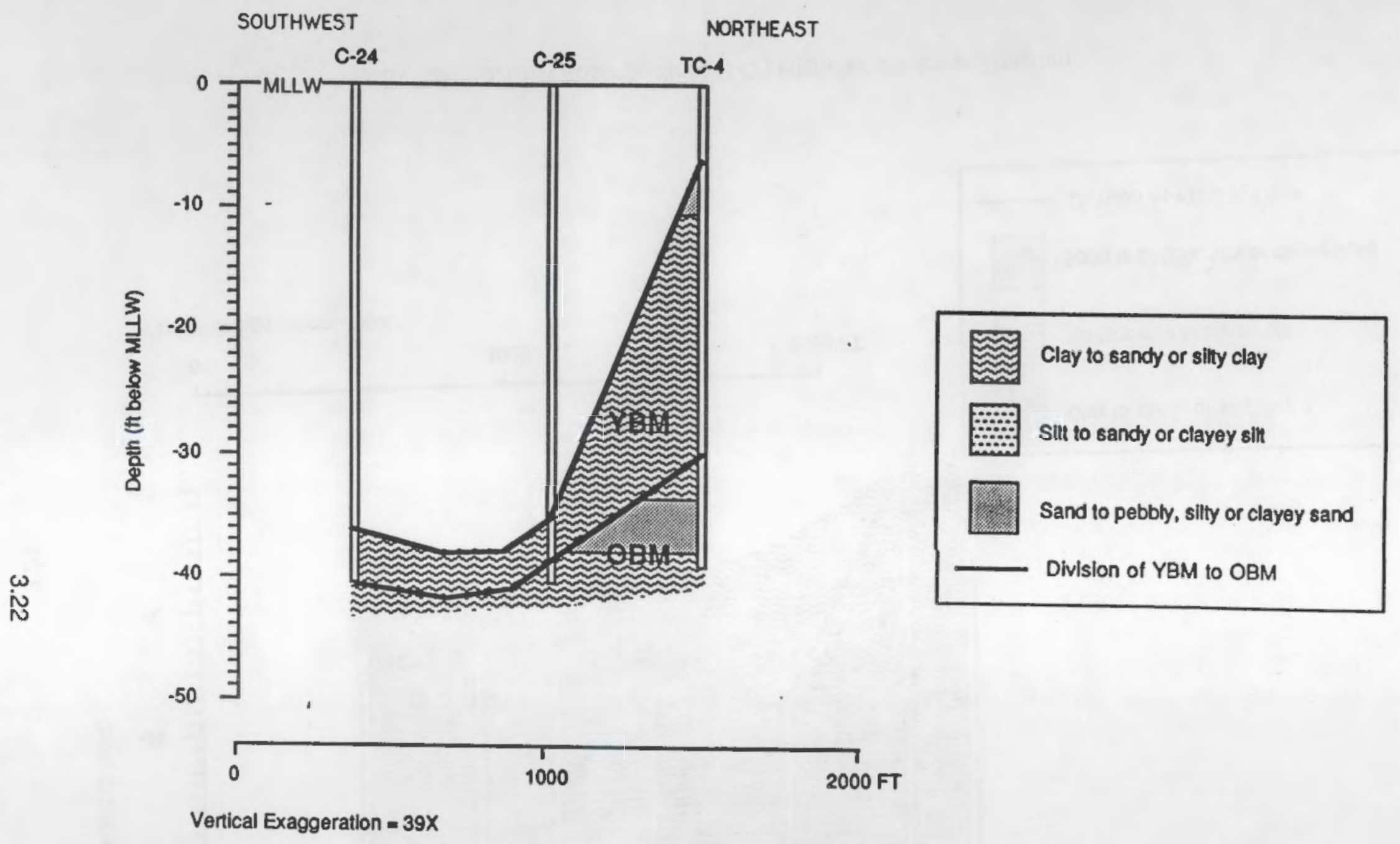

ElGURE 3.14. Cross Section E-E' Across the Richmond Harbor Inner Channel, Richmond Harbor Program 
Iable 3.4. Summary of Sediment Treatments for Testing, Richmond Harbor Program

Sediment

Ireatment

\section{COMP I}

C.1

C-3

C-5

C-6

C- 8

C-10

\section{COMP \|}

\section{C-11}

\section{C-16}

C-18

C-19

C-20

C-23

COMP III

TC-1 Upper

TC-2 Upper

TC-3 Upper

TC-4 Upper

TC-5 Upper Comp

TC-5 Upper

TC-5 Special Sample

\section{Mudline \\ (-At) M니는}

NA(a)

36.4

36.0

36.4

36.3

36.4

36.0

NA

37.3

36.2

36.1

35.9

36.2

32.8

NA

11.3

11.5

8.5

6.2

NA

21.9

NA
Sediment Solid-Phase SPP Chemistry Testing Iesting

Mudiline to $-40 \mathrm{ft}$ MLLW from $12-\mathrm{in}$. core sections of $\mathrm{C}-1, \mathrm{C}-3, \mathrm{C}-5, \mathrm{C}-6, \mathrm{C}-8, \mathrm{C}-10$ Mudline to $-40 \mathrm{ft}$ MLLW from 4-in. core Mudline to $-40 \mathrm{ft}$ MLLW from 4 -in. core Mudline to $-40 \mathrm{ft}$ MLLW from 4 -in. core Mudline to $-40 \mathrm{ft}$ MLLW from 4-in. core Mudline to $-40 \mathrm{ft}$ MLLW from 4-in. core Mudline to $-40 \mathrm{ft}$ MLLW from 4-in. core

Mudline to $-40 \mathrm{ft}$ MLLW from 12-in. core sections of C-11, C-16, C-18, C-19, C-20, C-23 Mudline to $-40 \mathrm{ft}$ MLLW from 4-in. core Mudline to $-40 \mathrm{ft}$ MLLW from 4-in. core Mudline to $-40 \mathrm{ft}$ MLLW from 4-in. core Mudline to $-40 \mathrm{ft}$ MLLW from 4-in. core Mudline to $-40 \mathrm{ft}$ MLLW from 4-in. core Mudline to $-40 \mathrm{ft}$ MLLW from 4-in. core

YES

YES

YES

YES

YES

YES

YES

YES

YES

NO

NO

NO

NO

NO

NO

YES

YES

NO

NO

NO

NO

NO

NO

Taken from upper 12-In. core

sections of TC-1, TC-2, TC-3, TC-4

Mudline to $-21.3 \mathrm{ft} \mathrm{MLLW} \mathrm{from} \mathrm{4-in.} \mathrm{core}$

Mudline to $-15.3 \mathrm{ft}$ MLLW from 4-in. core

Mudline to $-24.3 \mathrm{ft}$ MLLW from 4-in. core

Mudline to $-17.0 \mathrm{ft}$ MLLW from 4-in. core

YES

YES

YES

YES

YES

YES

NO

NO

NO

NO

NO

NO

YES

NO

NO

NO

NO

NO

NO

Upper Comp taken from Mudline to $-36.5 \mathrm{ft}$ MLLW YES of a 12-in. core

Mudline to $-34.0 \mathrm{ft}$ MLLW from 4-in. core

Sample taken from $-30.2 \mathrm{ft}$ to $32.7 \mathrm{ft}$ MLLW of a 4-in. core
YES

YES

YES

YES

YES

YES

YES

YES

NO

NO

NO

NO

YES

NO

NO

NO

NO

YES YES

NO

NO

NO 
IABLE 3.4. (contd)

\begin{tabular}{|c|c|c|c|c|c|}
\hline $\begin{array}{l}\text { Sediment } \\
\text { Ireatment }\end{array}$ & $\begin{array}{r}\text { Mudline } \\
(-f t=M L L W)\end{array}$ & Description & $\begin{array}{l}\text { Sediment } \\
\text { Chemistry }\end{array}$ & $\begin{array}{l}\text { Solid-Phase } \\
\text { Testing }\end{array}$ & $\begin{array}{l}\text { SPP } \\
\text { Iesting }\end{array}$ \\
\hline COMP IV & NA & $\begin{array}{l}\text { Taken from lower } 12 \text {-in. core } \\
\text { sections of TC-1, TC-2, TC-3, TC-4, TC-5 }\end{array}$ & YES & YES & YES \\
\hline TC-1 Lower & . $\quad 11.3$ & $21.3 \mathrm{ft} \mathrm{to}-36.5 \mathrm{ft}$ MLLW from 4 -in. core & YES & NO & NO \\
\hline TC-2 Lower & 11.5 & $15.3 \mathrm{ft}$ to $-32.1 \mathrm{ft} \mathrm{MLLW}$ from 4 -in. core & YES & NO & NO \\
\hline TC-3 Lower & 8.5 & 24.3 to $-34.3 \mathrm{ft} \mathrm{MLLW} \mathrm{from} 4$-in. core & YES & NO & NO \\
\hline TC-4 Lower & 6.2 & 17.0 to $-38.8 \mathrm{ft} \mathrm{MLLW}$ from 4 -in. core & YES & NO & NO \\
\hline TC-5 Lower & 21.9 & $36.5 \mathrm{ft}$ to $-39.6 \mathrm{ft} \mathrm{MLLW} \mathrm{from} \mathrm{4-in.} \mathrm{core}$ & YES & NO & NO \\
\hline COMP V & NA & $\begin{array}{l}\text { Mudline to }-40 \mathrm{ft} \text { MLLW from } 12-\mathrm{in} \text {. cores } \\
\text { from } \mathrm{C}-24, \mathrm{C}-26, \mathrm{C}-30, \mathrm{C}-33, \mathrm{C}-35, \mathrm{C}-37\end{array}$ & YES & YES & YES \\
\hline C-24 & 36.0 & Mudline to $-40 \mathrm{ft}$ MLLW from 4-in. core & YES & NO & NO \\
\hline C-26 & 36.1 & Mudline to $-40 \mathrm{ft}$ MLLW from 4-in. core & YES & NO & NO \\
\hline C-30 & 35.3 & Mudline to $-40 \mathrm{ft}$ MLLW from 4-in. core & YES & NO & NO \\
\hline C-33 & 35.0 & Mudline to $-40 \mathrm{ft}$ MLLW from 4-in. core & YES & NO & NO \\
\hline C-35 & 36.2 & Mudline to $-40 \mathrm{ft}$ MLLW from 4-in. core & YES & NO & NO \\
\hline $\mathrm{C}-37$ & 36.1 & Mudline to $-40 \mathrm{ft}$ MLLW from 4-in. core & YES & NO & NO \\
\hline COMP VI & NA & $\begin{array}{l}\text { Mudline to }-40 \mathrm{ft} \text { MLLW from } 12 \text {-in. cores } \\
\text { from C-25, C-29, C-32, C-36, C-38 }\end{array}$ & YES & YES & YES \\
\hline C-25 & 35.0 & Mudline to $-40 \mathrm{ft}$ MLLW from 4-in. core & YES & NO & NO \\
\hline C-29 & 35.0 & Mudline to $-40 \mathrm{ft}$ MLLW from 4 -in. core & YES & NO & NO \\
\hline C-32 & 35.3 & Mudline to $-40 \mathrm{ft}$ MLLW from 4-in. core & YES & NO & NO \\
\hline C-36 & 36.1 & Mudline to $-40 \mathrm{ft} \mathrm{MLLW}$ from 4 -in. core & YES & NO & NO \\
\hline $\mathrm{C}-38$ & 36.1 & Mudline to $-40 \mathrm{ft}$ MLLW from 4-in. core & YES & NO & NO \\
\hline TC-6 (1) & 6.0 & Mudline to $-9.0 \mathrm{ft}$ MLLW from 4-in. core & YES & NO & NO \\
\hline TC-6 (2) & 9.0 & Mudline to $-32.0 \mathrm{ft} \mathrm{MLLW} \mathrm{from} \mathrm{4-in.} \mathrm{core}$ & YES & NO & NO \\
\hline TC-6 (3) & 32.0 & Mudline to $-33.5 \mathrm{ft} \mathrm{MLLW} \mathrm{from} \mathrm{4-in.} \mathrm{core}$ & YES & NO & NO \\
\hline TC-6 (4) & 33.5 & Mudline to $-40.0 \mathrm{ft} \mathrm{MLLW} \mathrm{from} \mathrm{4-in.} \mathrm{core}$ & YES & NO & NO \\
\hline
\end{tabular}




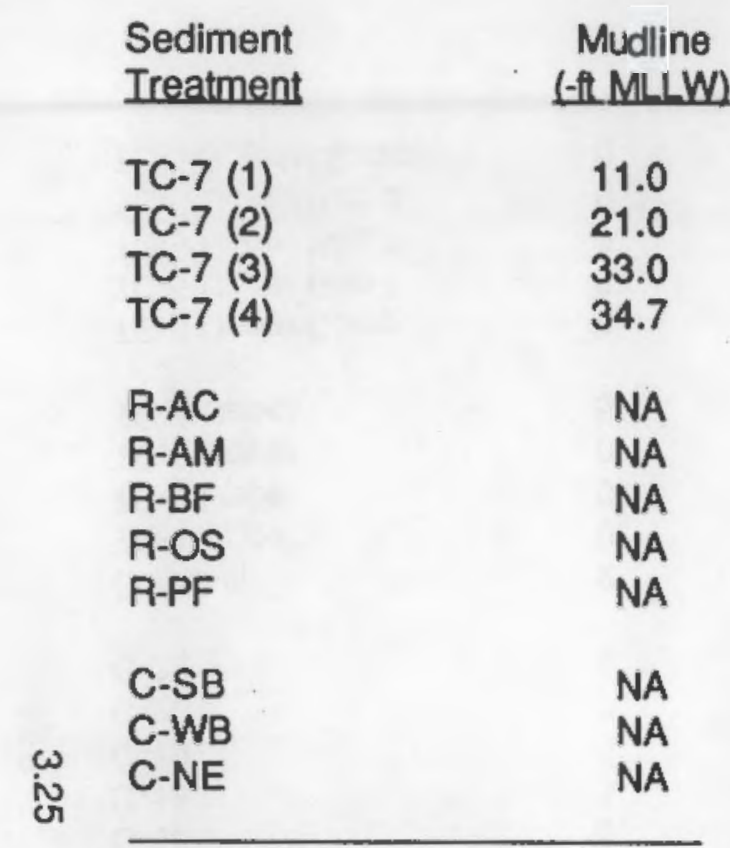

(a) NA Not applicable. 
IABLE 3.5. Conventional Sediment Measurement Results (grain size, TOC, and TVS in percent dry weight; Oil and Grease and TPH in mg/kg diry weight)

\begin{tabular}{|c|c|c|c|c|c|c|c|c|}
\hline $\begin{array}{l}\text { Sediment } \\
\text { Ireatment }\end{array}$ & $\begin{array}{l}\text { Gravel } \\
22000 \text { um }\end{array}$ & $\begin{array}{l}\text { Sand } \\
625 \text { - } \\
2000 \text { um }\end{array}$ & $\begin{array}{l}\text { Sin } \\
3.9 \\
625 \text { um }\end{array}$ & $\begin{array}{c}\text { Clay } \\
\leq 3.9 \text { um }\end{array}$ & IOC & IVS & Oil and Grease & $\mathrm{IPH}$ \\
\hline $\begin{array}{l}\text { COMPI } \\
\text { C-1 } \\
\text { C-3 } \\
\text { C-5 } \\
\text { C-6 } \\
\text { C-8 } \\
\text { C-10 }\end{array}$ & $\begin{array}{l}0 \\
0 \\
0 \\
0 \\
0 \\
0 \\
0\end{array}$ & $\begin{array}{r}9 \\
23 \\
12 \\
5 \\
4 \\
1 \\
4\end{array}$ & $\begin{array}{l}45 \\
42 \\
44 \\
51 \\
46 \\
41 \\
45\end{array}$ & $\begin{array}{l}46 \\
35 \\
44 \\
44 \\
50 \\
58 \\
51\end{array}$ & $\begin{array}{l}0.99 \\
0.80 \\
0.93 \\
1.01 \\
1.09 \\
1.18 \\
1.08\end{array}$ & $\begin{array}{l}6.10 \\
4.75 \\
5.52 \\
5.68 \\
6.12 \\
6.55 \\
5.90\end{array}$ & $\begin{array}{r}63.22 \\
91.26 \\
89.17 \\
144.92 \\
108.89 \\
132.45 \\
151.75\end{array}$ & $\begin{array}{r}41.39 \\
68.41 \\
65.03 \\
92.66 \\
88.21 \\
104.76 \\
115.92\end{array}$ \\
\hline $\begin{array}{l}\text { COMP II } \\
\text { C-11 } \\
\text { C-16 } \\
\text { C-18 } \\
\text { C-19 } \\
\text { C-20 } \\
\text { C-23 }\end{array}$ & $\begin{array}{l}0 \\
0 \\
0 \\
3 \\
0 \\
7 \\
0\end{array}$ & $\begin{array}{r}8 \\
1 \\
25 \\
13 \\
20 \\
28 \\
3\end{array}$ & $\begin{array}{l}44 \\
41 \\
34 \\
39 \\
49 \\
29 \\
45\end{array}$ & $\begin{array}{l}48 \\
58 \\
41 \\
45 \\
31 \\
36 \\
52\end{array}$ & $\begin{array}{l}0.73 \\
1.14 \\
0.59 \\
0.81 \\
0.28 \\
0.67 \\
0.74\end{array}$ & $\begin{array}{l}5.49 \\
6.46 \\
3.98 \\
4.73 \\
3.38 \\
4.66 \\
4.54\end{array}$ & $\begin{array}{r}118.30 \\
99.86 \\
92.04 \\
124.58 \\
42.91 \\
103.58 \\
66.91\end{array}$ & $\begin{array}{l}91.00 \\
76.06 \\
74.71 \\
95.91 \\
27.30 \\
78.82 \\
46.08\end{array}$ \\
\hline $\begin{array}{l}\text { COMP III } \\
\text { TC-1 Upper } \\
\text { TC-2 Upper } \\
\text { TC-3 Upper } \\
\text { TC-4 Upper }\end{array}$ & $\begin{array}{l}2 \\
0 \\
0 \\
0 \\
5\end{array}$ & $\begin{array}{r}11 \\
3 \\
8 \\
6 \\
12\end{array}$ & $\begin{array}{l}54 \\
57 \\
49 \\
65 \\
57\end{array}$ & $\begin{array}{l}33 \\
40 \\
43 \\
29 \\
26\end{array}$ & $\begin{array}{l}0.68 \\
0.79 \\
0.90 \\
0.59 \\
0.54\end{array}$ & $\begin{array}{l}3.65 \\
3.96 \\
5.19 \\
3.03 \\
2.87\end{array}$ & $\begin{array}{r}44.06 \\
90.29 \\
132.78 \\
37.83 \\
73.52\end{array}$ & $\begin{array}{l}26.74 \\
34.60 \\
79.16 \\
19.54 \\
16.77\end{array}$ \\
\hline $\begin{array}{l}\text { TC-5 Upper Comp } \\
\text { TC-5 Upper Rep } 1 \\
\text { TC-5 Upper Rep } 2 \\
\text { TC-5 Upper Rep } 3 \\
\text { TC-5 Special Sample }\end{array}$ & $\begin{array}{l}0 \\
0 \\
0 \\
0 \\
0\end{array}$ & $\begin{array}{r}10 \\
8 \\
8 \\
8 \\
5\end{array}$ & $\begin{array}{l}43 \\
45 \\
44 \\
43 \\
45\end{array}$ & $\begin{array}{l}47 \\
47 \\
48 \\
49 \\
50\end{array}$ & $\begin{array}{l}0.91 \\
0.93 \\
0.94 \\
0.96 \\
1.07\end{array}$ & $\begin{array}{l}5.00 \\
5.14 \\
5.09 \\
5.09 \\
5.65\end{array}$ & $\begin{array}{r}311.19 \\
297.24 \\
230.74 \\
418.34 \\
18.83\end{array}$ & $\begin{array}{r}281.16 \\
256.11 \\
189.60 \\
350.10 \\
10.99\end{array}$ \\
\hline
\end{tabular}


IABLE 3.5. (contd)

\begin{tabular}{|c|c|c|c|c|c|c|c|c|c|}
\hline & Sediment & Gravel & $\begin{array}{l}\text { Sand } \\
\approx .5-\end{array}$ & $\begin{array}{l}\text { Sit } \\
3.9\end{array}$ & Clay & & & & \\
\hline & Ireatment & 22000 um & 2000 um & $62.5 \mathrm{um}$ & $\leq 3.94 m$ & IOC & TVS & Oilland Grease & $\mathrm{IPH}$ \\
\hline & COMP IV & 3 & 26 & 43 & 28 & 0.39 & 3.32 & 19.06 & 10.50 \\
\hline & TC-1 Lower & 7 & 21 & 39 & 33 & 0.43 & 3.00 & 9.80 & 5.67 \\
\hline & TC-1 Lower Dup & $N M(a)$ & NM & NM & NM & 0.42 & MM & NM & NM \\
\hline & TC-2 Lower & 3 & 9 & 47 & 41 & 0.60 & 3.45 & 24.30 & 13.27 \\
\hline & TC-3 Lower & 12 & 48 & 22 & 18 & 0.26 & 2.07 & 13.03 & 8.58 \\
\hline & TC-3 Lower Dup & NM & NM & NM & NM & 0.28 & NM & NM & NM \\
\hline & TC-4 Lower & 3 & 30 & 40 & 27 & 0.25 & 2.22 & 14.14 & 8.10 \\
\hline & TC-5 Lower & 3 & 30 & 39 & 28 & 0.41 & 2.50 & 24.65 & 7.79 \\
\hline & COMPV & 1 & 2 & 34 & 63 & 1.08 & 6.38 & 186.23 & 141.25 \\
\hline & $C-24$ & 0 & 2 & 39 & 59 & 0.79 & 4.96 & 76.55 & 54.99 \\
\hline & C-26 & 1 & 6 & 37 & 56 & 1.01 & 5.93 & 138.15 & 107.13 \\
\hline & C-30 & 0 & 3 & 38 & 59 & 1.06 & 6.26 & 218.95 & 174.70 \\
\hline$\omega$ & C-30 Dup & NM & NM & NM & NM & 1.06 & NM & NM & NM \\
\hline N & C-33 & 0 & 3 & 37 & 60 & 0.92 & 6.06 & 100.39 & 83.05 \\
\hline & C-35 & 0 & 5 & 41 & 54 & 0.84 & 5.52 & 151.47 & 119.79 \\
\hline & C-37 & 0 & 16 & 41 & 43 & 0.60 & 4.77 & 263.31 & 150.44 \\
\hline & COMP VI & 0 & 3 & 36 & 61 & 1.03 & 6.52 & 252.06 & 185.70 \\
\hline & C-25 & 0 & 16 & 41 & 43 & 0.49 & 4.06 & 76.89 & 63.25 \\
\hline & C-29 & 0 & 6 & 51 & 43 & 0.57 & 4.61 & 91.93 & 72.97 \\
\hline & C-29 Dup & NM & NM & NM & NM & 0.59 & NM & NM & NM \\
\hline & C-32 & 0 & 2 & 54 & 44 & 0.60 & 4.74 & 167.80 & 140.78 \\
\hline & C-32 Dup & NM & NM & NM & NM & 0.60 & NM & NM & NM \\
\hline & C-36 & 0 & 5 & 40 & 55 & 0.89 & 5.62 & 223.76 & 180.06 \\
\hline & $C-38$ & 1 & 6 & 45 & 48 & 0.59 & 4.65 & 118.09 & 101.70 \\
\hline & TC-6 (1) & 2 & 11 & 50 & 37 & 0.79 & 4.48 & 37.60 & 25.13 \\
\hline & TC-6 (2) & 0 & 3 & 61 & 36 & 0.71 & 3.56 & 27.74 & 14.43 \\
\hline & TC-6 (3) & 1 & 77 & 11 & 11 & 0.15 & 1.53 & 5.64 & 2.63 \\
\hline & TC-6 (4) & 0 & 10 & 45 & 45 & 0.56 & 3.50 & 15.57 & 9.01 \\
\hline
\end{tabular}


IABLE 3.5. (contd)

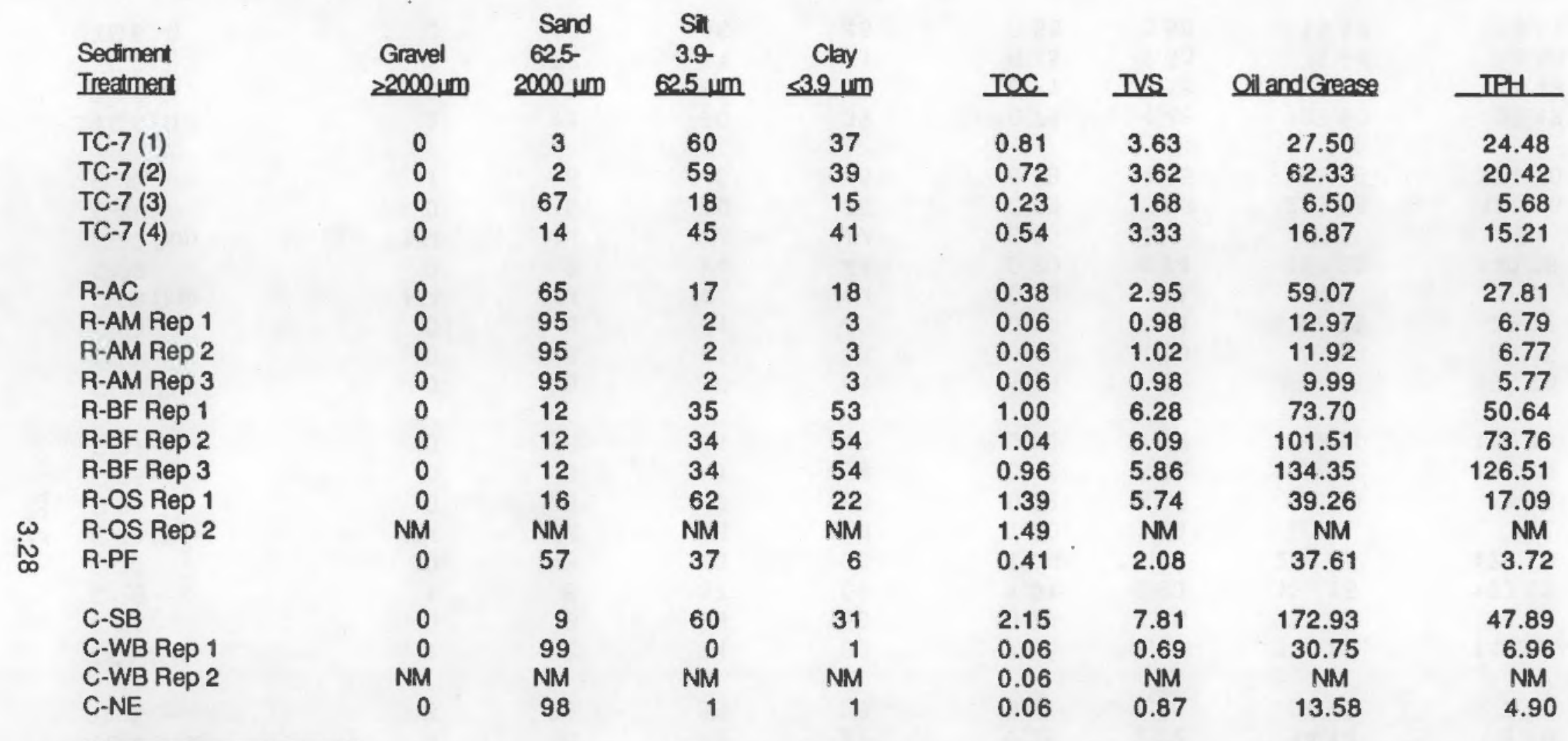

(a) NA Not measured. 


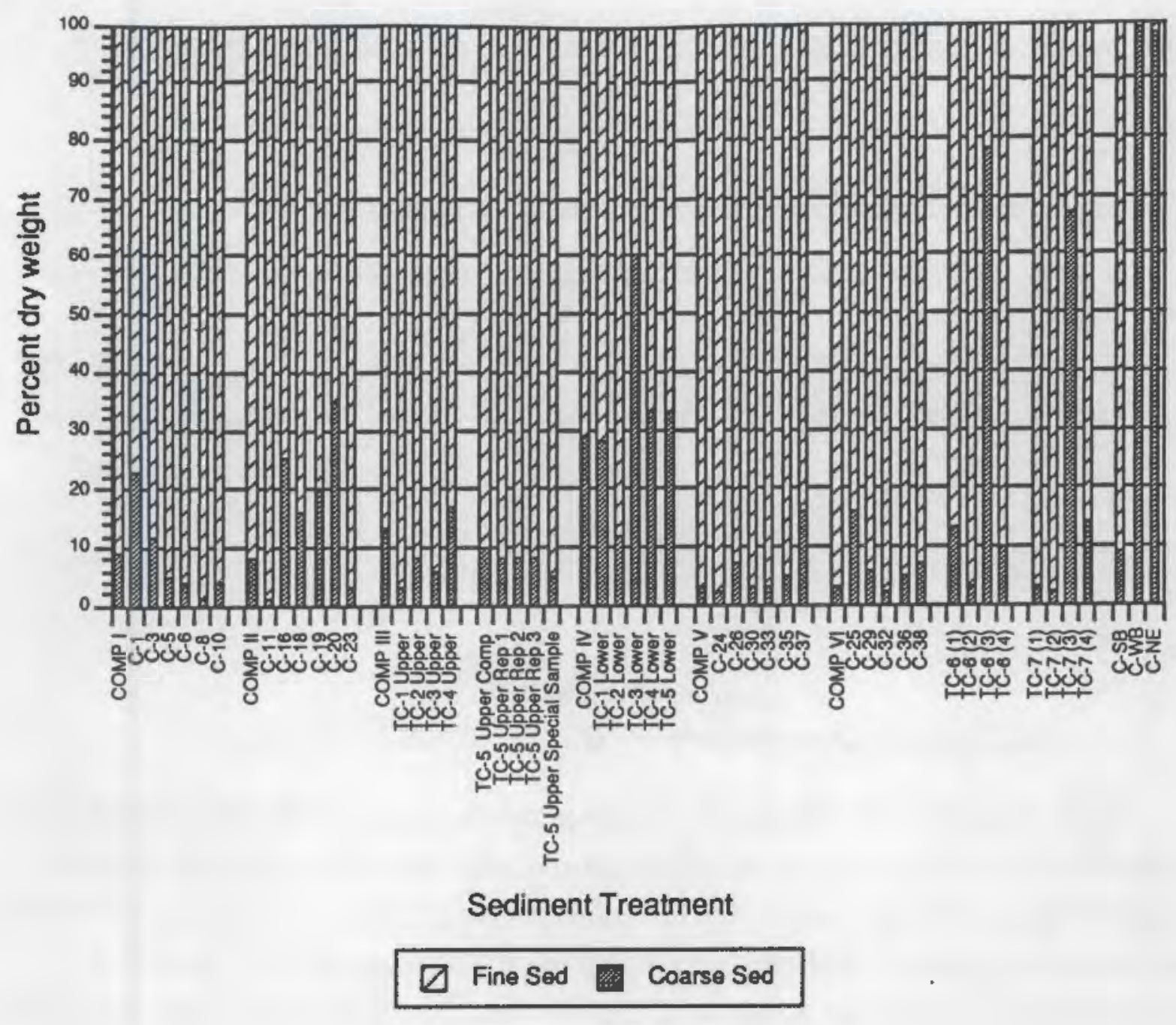

EIGURE 3.15. Grain Size Distribution in Sediment Treatments

and (4) at both stations were categorized as silt and/or clay, while section (3) consisted of a layer of sand and mollusk shells.

The reference treatments were primarily sand $(\geq 57 \%)$ with the exception of R-BF, which was $12 \%$ sand and $88 \%$ silt and clay, and R-OS, which was $16 \%$ sand and $84 \%$ silt and clay. Control treatments C-NE and C-WB were $\geq 98 \%$ sand, while C-SB was $9 \%$ sand and $91 \%$ silt and clay material.

The QAVQC requirements were met for grain size analysis and are acceptable,for use in analysis. A detailed QAOC summary is presented in Appendix $C$. 


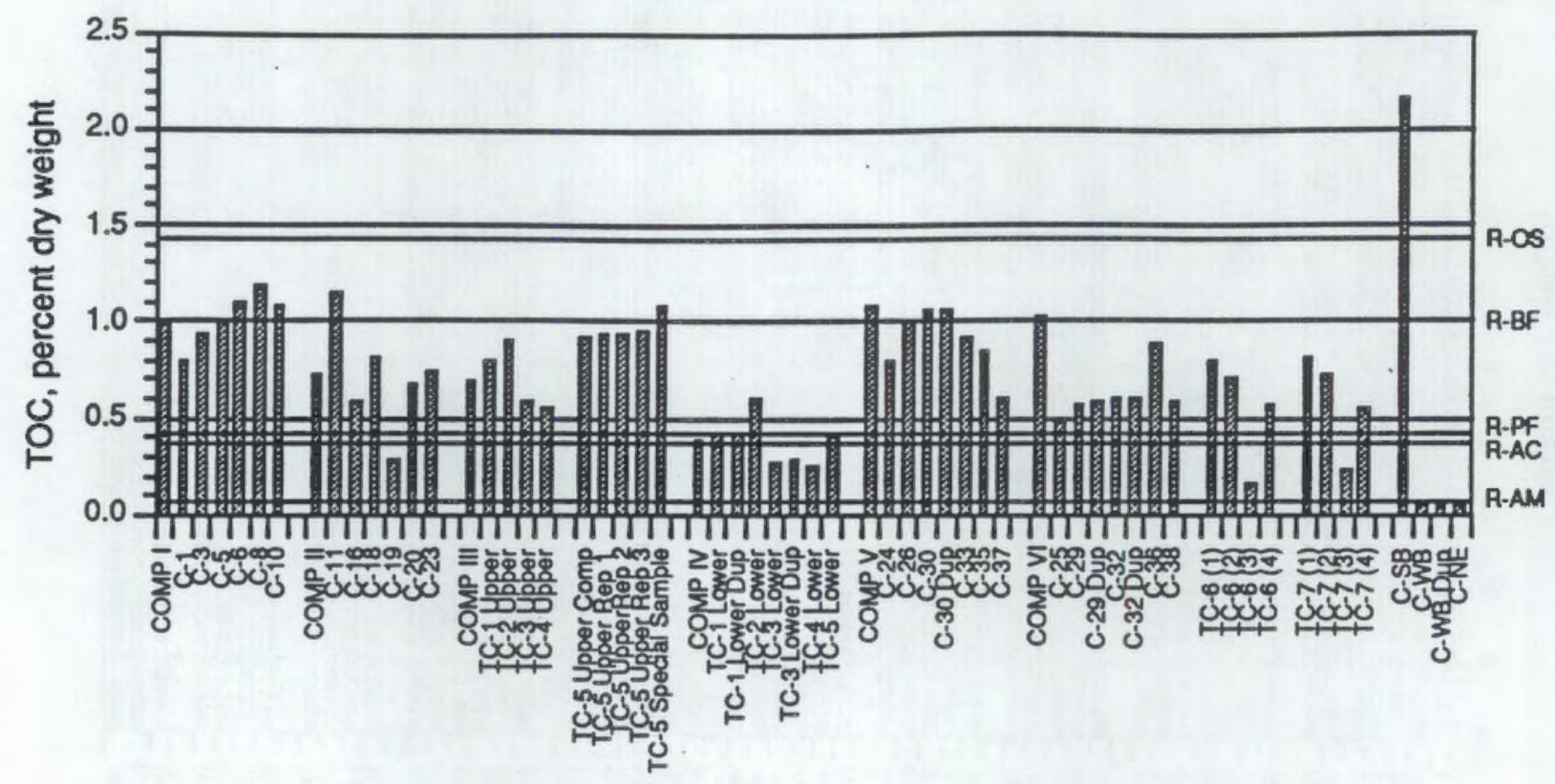

Sediment Treatment

EIGURE 3.16. Concentrations of TOC in Sediment Treatments

The concentrations of TOC in the control treatments ranged from $0.06 \%$ at C-WB and CNE to $2.15 \%$ at C-SB (Figure 3.16). All of the test treatments and reference treatments contained TOC values within this range. The test treatments with the higher TOC values were also predominantly fine-grained, as shown by the linear regression relationship in Figure 3.17.

Treatments with more than $50 \%$ fine-grained sediment had more than $0.50 \%$ TOC. The notable exception was treatment C-SB, which had a TOC content twice as high as expected from the linear regression. This occurrence has been documented with this control treatment in previous studies at MSL

The QAVC requirements were met for TOC analysis and are acceptable for use in analysis. A detailed QAQC summary is presented in Appendix C.

All test and reference treatments were within the TVS range of $0.69 \%$ to $7.81 \%$ established by the control treatments C-WB and C-SB (Figure 3.18). The same pattern observed between fine grain size and TOC was applicable to fine sediments and TVS as illustrated in Figure 3.19. Sediment treatments with higher TVS values come from fine-grained sediment stations. Control treatment C-SB is the one exception, containing higher TVS values than predicted based on percent grain size. 


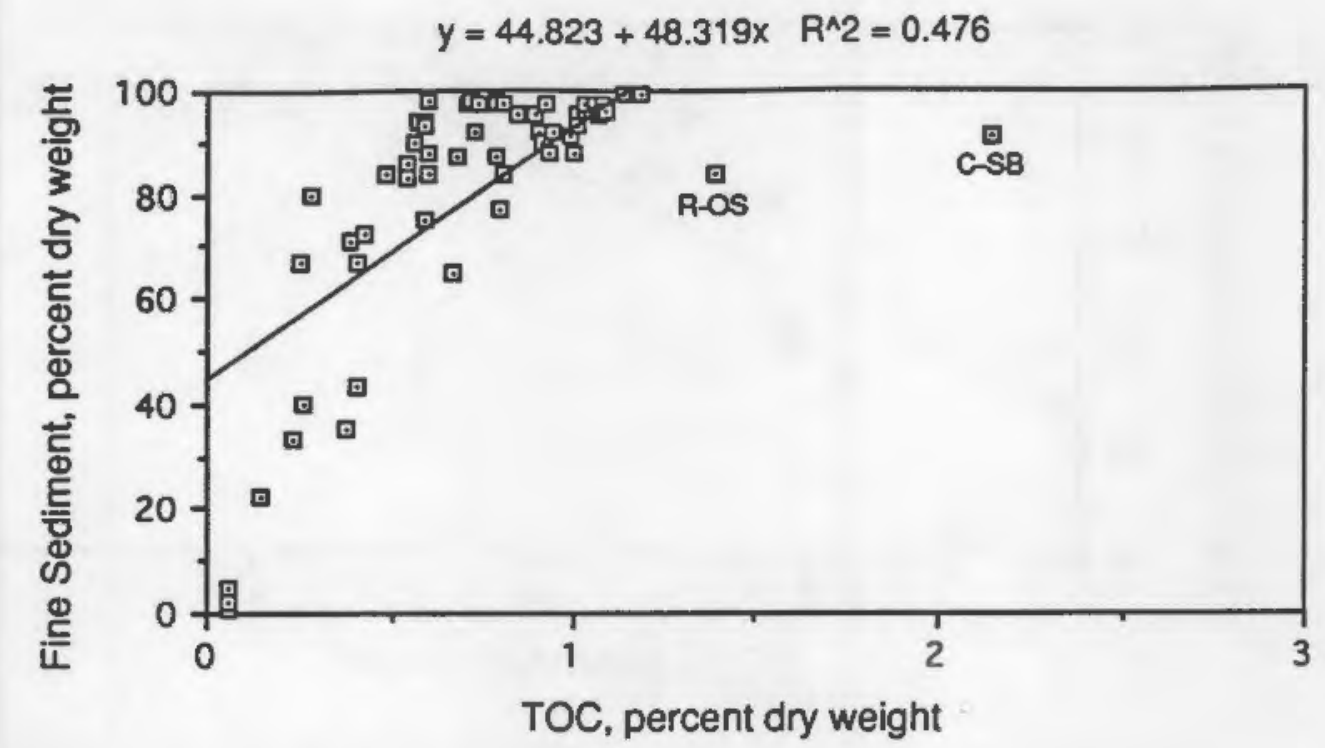

ElGURE 3.17. Linear Regression of TOC and Fine-Grained Sediment

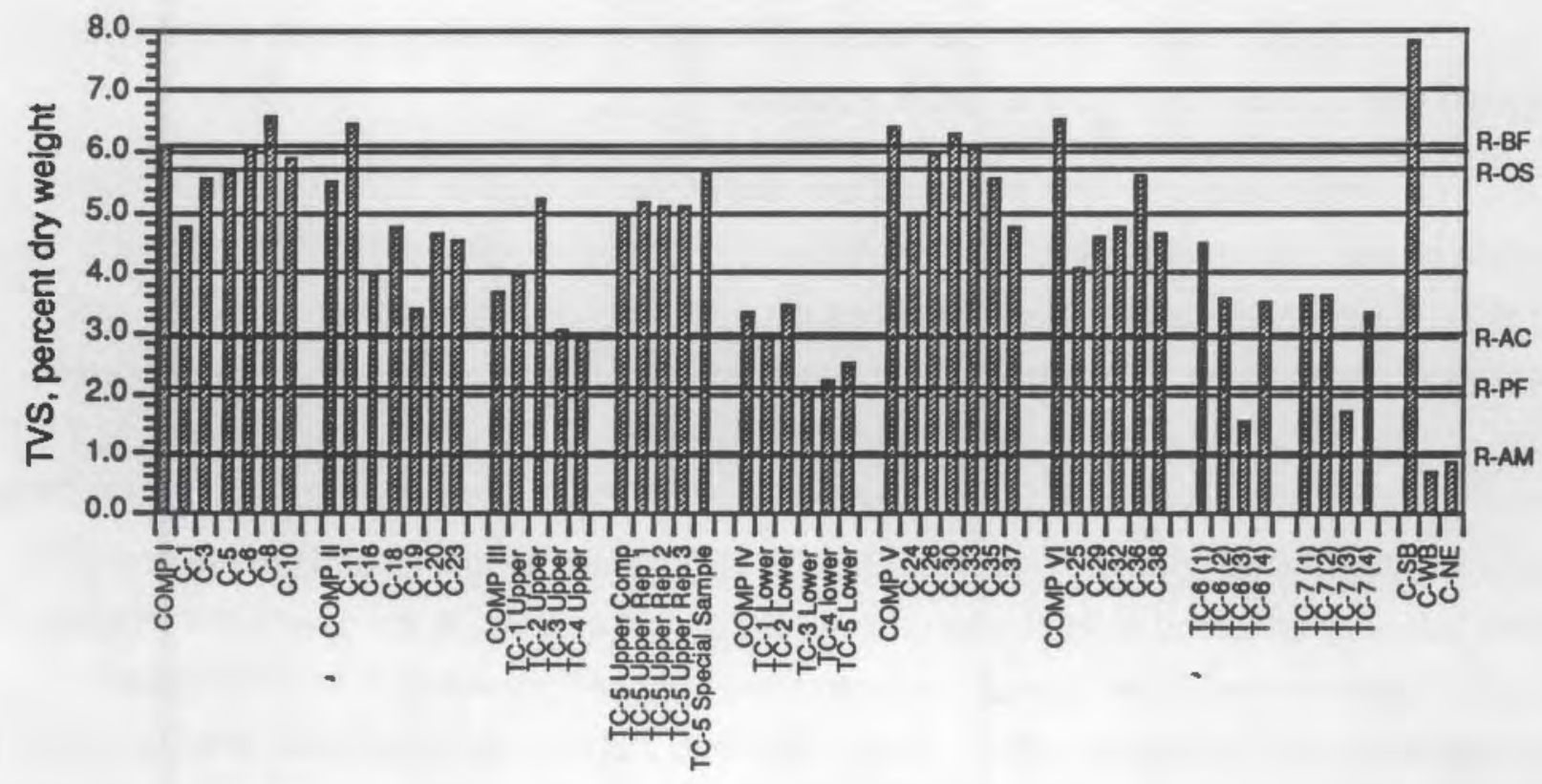

Sediment Treatment

EIGURE 3.18. Concentrations of TVS in Sediment Treatments 


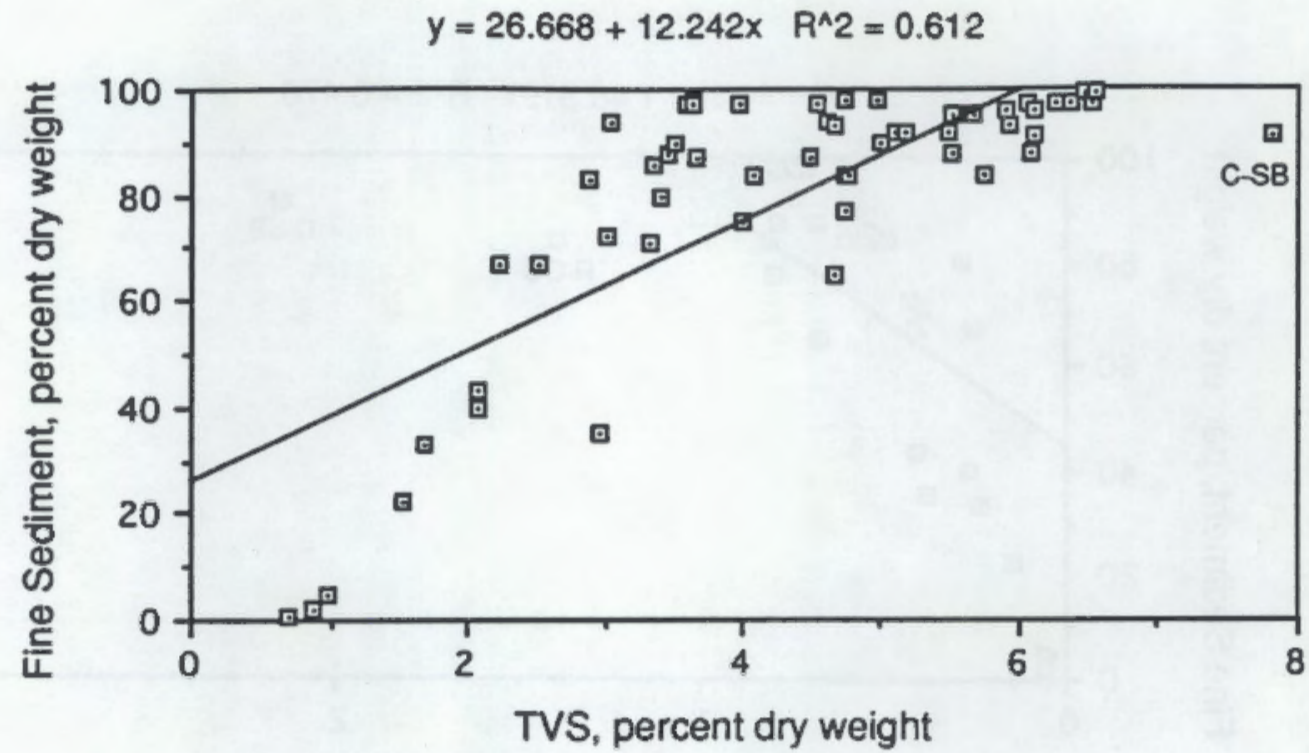

FIGURE 3.19. Linear Regression of TVS and Fine-Grained Sediment

A positive correlation is also observed for TVS and TOC in Figure 3.20. Generally, as the percentage of TOC increased, so did the percentage of TVS. Two exceptions, R-OS and CSB, had higher amounts of TVS then predicted by the TOC content.

The QAVC requirements were met for TVS and are acceptable for use in analysis. A detailed QAOC summary is presented in Appendix C.

Oil and grease and TPH concentrations are shown in Figures 3.21 and 3.22. Oil and grease concentrations in the test treatments ranged from $5.64 \mathrm{mg} / \mathrm{kg}$ at TC-6(3) to $418.34 \mathrm{mg} /$ $\mathrm{kg}$ at TC-5 Upper Rep 3. The concentrations of oil and grease in the reference and control treatments ranged from $9.99 \mathrm{mg} / \mathrm{kg}$ at R-AM Rep 3 to $172.93 \mathrm{mg} / \mathrm{kg}$ at C-SB. The concentrations of TPH in the test treatments ranged from $2.63 \mathrm{mg} / \mathrm{kg}$ at TC-6(3) to $350.10 \mathrm{mg} / \mathrm{kg}$ at TC-5 Upper Rep. 3. In the reference and control treatments, TPH ranged from $3.72 \mathrm{mg} / \mathrm{kg}$ at R-PF to $126.51 \mathrm{mg} / \mathrm{kg}$ at R-BF Rep 3. Test treatment TC-6(3) had the lowest oil and grease and TPH levels, possibly attributed to its coarse grain size (sand) in contrast to the other sediment treatments. Treatments with the highest concentrations of oil and grease also had the highest concentrations of TPH (Figure 3.23). The exception to this correlation is C-SB, which contains a high TOC value and substantially more oil and grease relative to TPH, suggesting that the TOC is not petroleum based. 
$y=1.4000+4.0615 x \quad R^{\wedge} 2=0.823$

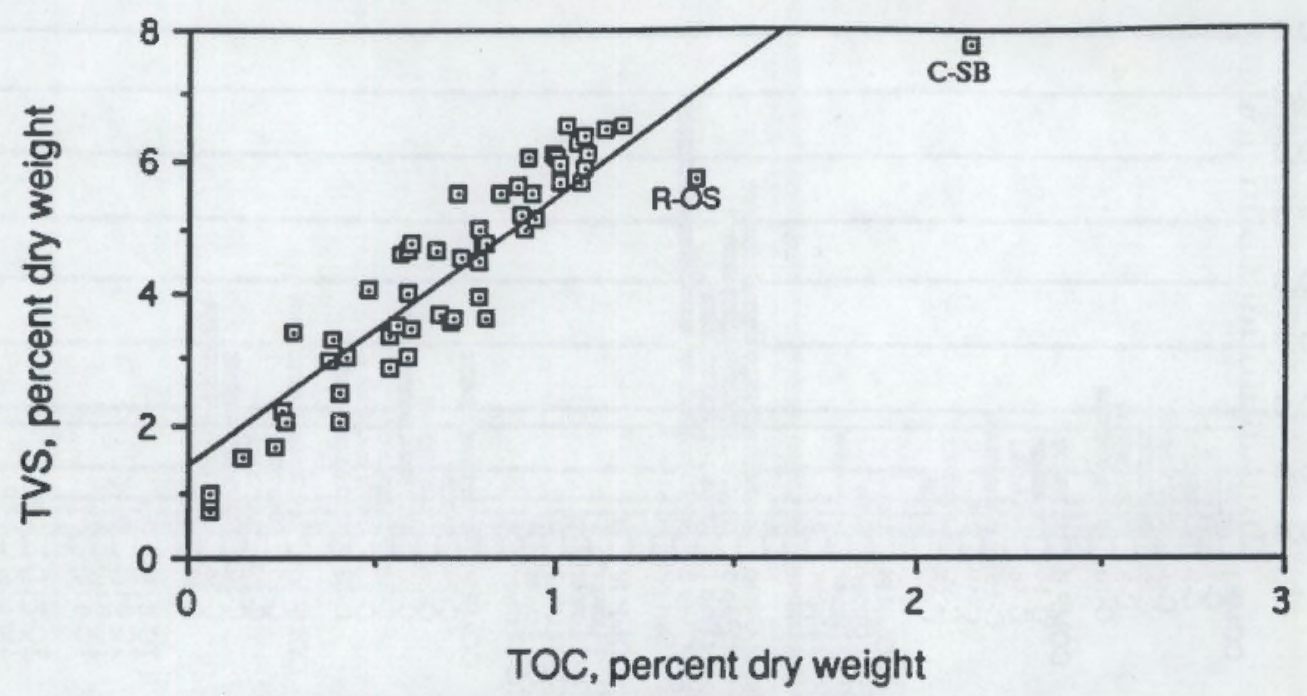

ElGURE 3.20. Linear Regression of TOC and TVS

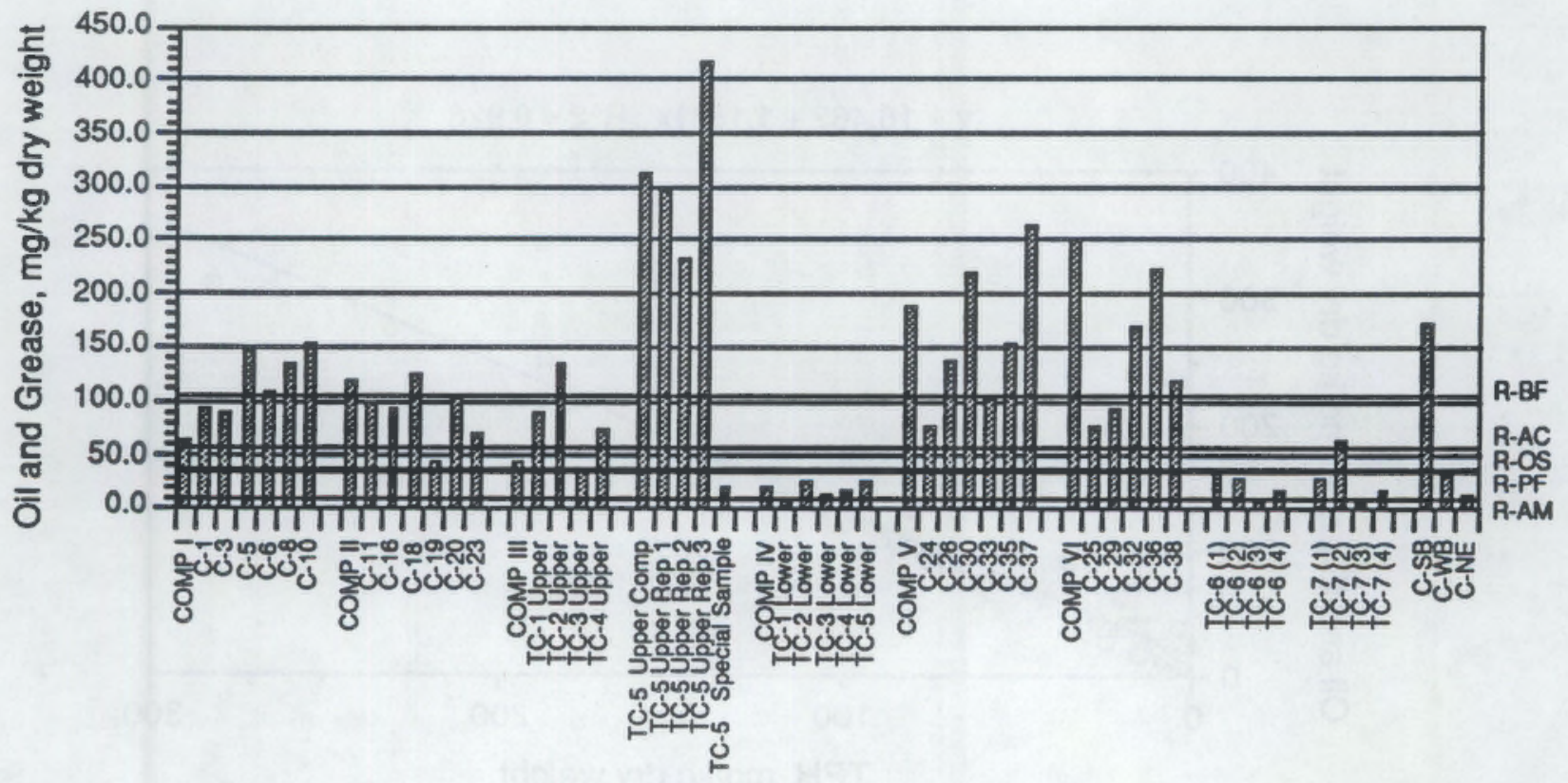

Sediment Treatment

FIGURE 3.21. Concentrations of Oil and Grease in Sediment Treatments 


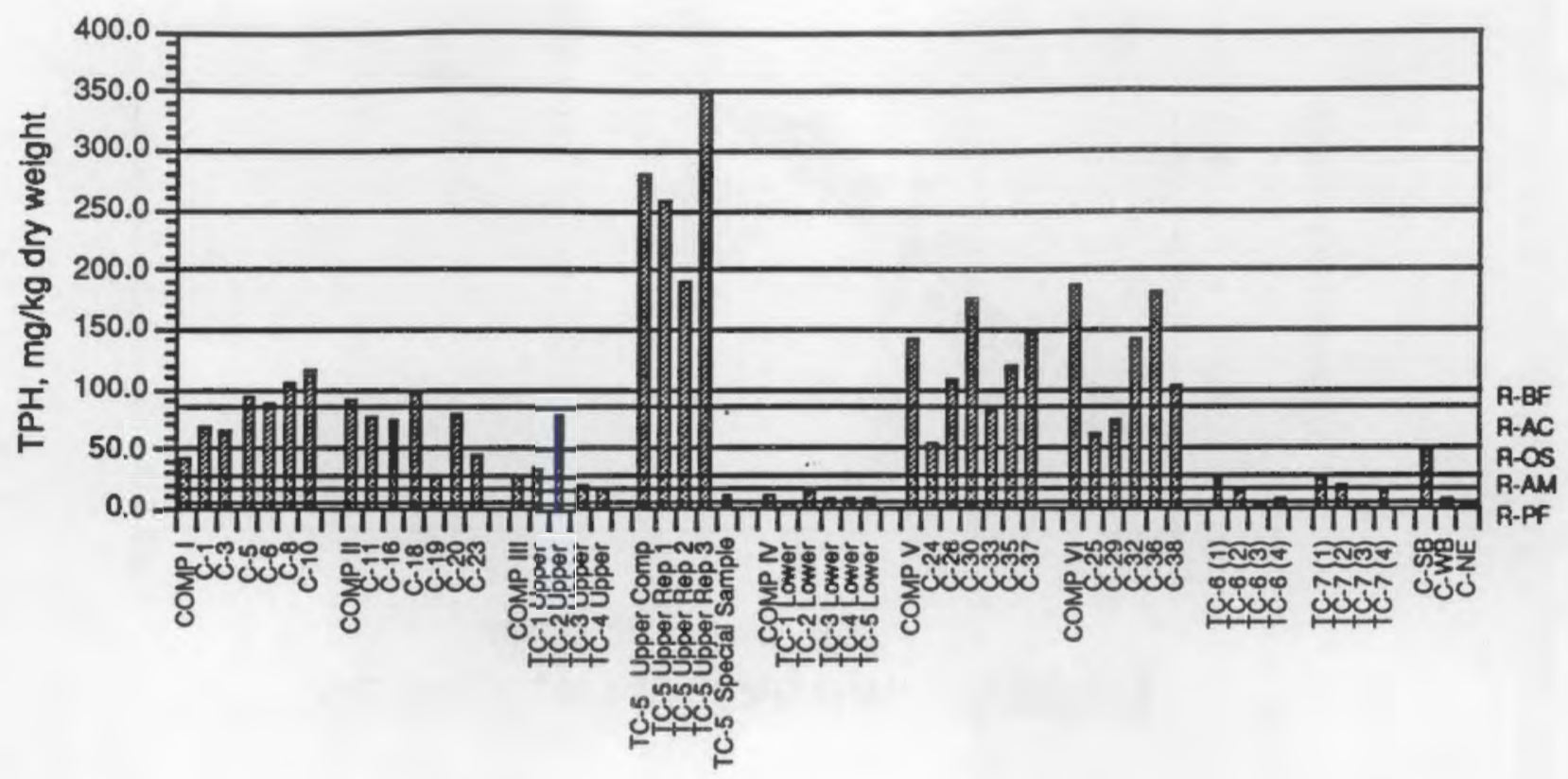

Sediment Treatment

FIGURE 3.22. Concentrations of TPH in Sediment Treatments

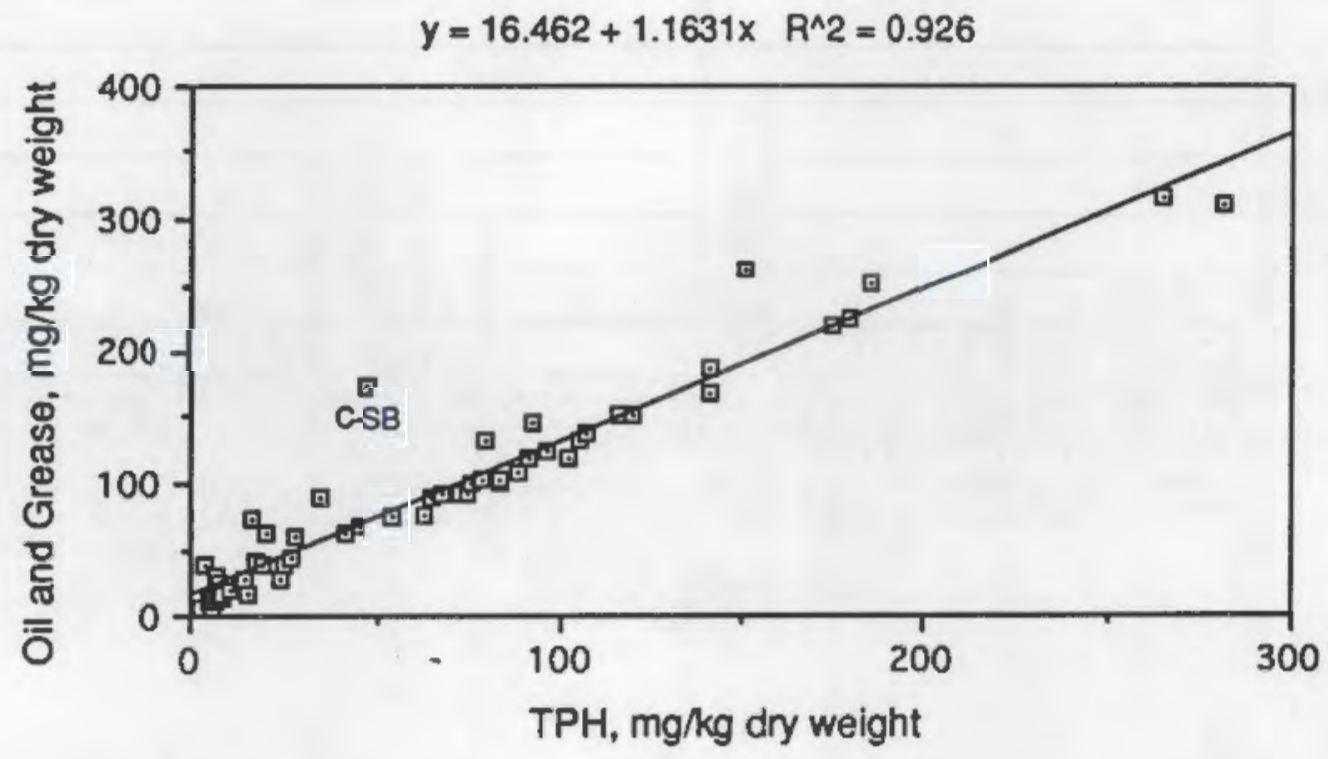

FIGURE 3.23. Linear Regression of TPH and Oil and Grease 
The QAVCC requirements were met for oil and grease and TPH with the exception of some MS/MSD results. Overall analytical performance was acceptable and those data are appropriate for use in analysis. A detailed QAQC summary is presented in Appendix C.

\subsubsection{Polynuclear Aromatic Hydrocarbons}

Sixteen PAH compounds were analyzed in Richmond Harbor sediment treatments. The results and quality control data are reported in two groups based on molecular weight. The low molecular weight compounds (LPAH) are naphthalene, acenaphthylene, acenaphthene, fluorene, phenanthrene, and anthracene. The high molecular weight compounds (HPAH) are chrysene, fluoranthene, pyrene, benzo(a)anthracene, benzo(b)- and benzo(k)fluoranthene, benzo(a)pyrene, indeno(1,2,3-c,d)pyrene, dibenzo(a,h)anthracene, and benzo(g,h,i)perlyene.

The results of LPAH and HPAH are shown in Figure 3.24. Concentrations of LPAHs ranged from 10.9 to $810.27 \mu \mathrm{g} / \mathrm{kg}$ dry weight, while concentrations of HPAHs ranged from 0 to $5696.86 \mu \mathrm{g} / \mathrm{kg}$ dry weight. Complete results of PAH analysis, quality control data, and a quality control summary are contained in Appendix C, Tables 1 through 6 . HPAHs comprised a greater fraction of total PAH in $\mathbf{4 6}$ out of the $\mathbf{5 7}$ sediment treatments. The 11 sediment treatments where LPAHs were higher included the COMP IV treatments, TC-3 Lower, TC-6 and TC-7, and control treatments C-WB and C-NE. Most of the higher LPAH treatments contained $>10 \%$ coarser grain size fractions and were representative of the deeper cores. Figure 3.25 is a linear regression comparing the LPAHs to the total HPAHs. Reference treatment R-AC had a substantially higher contribution of HPAH than expected.

The QAVC requirements were met for $\mathrm{PAH}$ with the exception of a few MS/MSD and surrogate recoveries. The overall QAVC results are acceptable for use in analysis, though the estimates of pyrene concentrations may be high for selected stations. A detailed QAQC summary is presented in Appendix C.

\subsubsection{Chlorinated Pesticides and Polychlorinated Biphenyls}

Three pesticides were detected in sediment treatments from Richmond Harbor as shown in Figures 3.26, 3.27, and 3.28. These three compounds were found at the highest concentrations in test treatments C-38 (4,4'-DDD), C-36 (4,4'-DDE), and COMP VI (4,4'-DDT). (Note that sediment treatments $\mathrm{C}-38$ and $\mathrm{C}-36$ are two of the stations comprising COMP VI.) Reference treatment R-BF had the highest 4,4'-DDD, 4,4'-DDE, and 4,4'-DDT levels of any reference treatment, with values of $8.0 \mu \mathrm{g} / \mathrm{kg}, 1.6 \mu \mathrm{g} / \mathrm{kg}$, and $7.3 \mu \mathrm{g} / \mathrm{kg}$, respectively. Aroclor 1254 was 


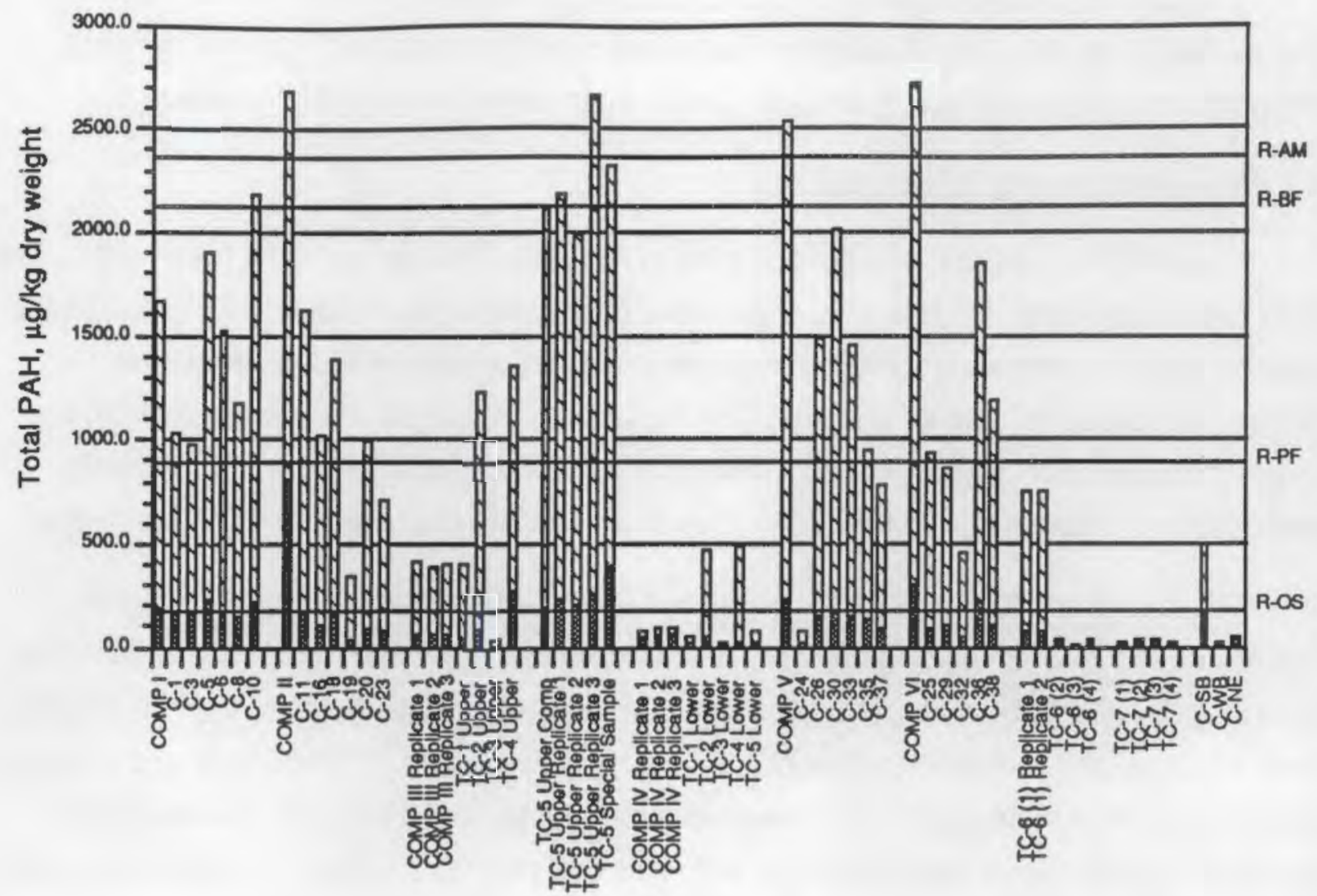

Sediment Treatment

\section{Б HPAH $\square$ LPAH}

EIGURE 3.24. Concentrations of Total PAH in Sediment Treatments (Reference treatment R-AC had a concentration of $6304.43 \mu \mathrm{g} / \mathrm{kg}$, which is above the vertical axis of the figure.)

the only detected PCB in the Richmond Harbor sediment treatments (Figure 3.29). Detected concentrations ranged from $6.0 \mu \mathrm{g} / \mathrm{kg}$ at $\mathrm{R}-\mathrm{AC}$ to $64 \mu \mathrm{g} / \mathrm{kg}$ at TC-7(4). The two test treatments with the highest levels of pesticides and PCBs had predominantly fine-grained sediments with relatively high TOC, oil and grease, and TPH.

The OACC requirements were met for the majority of $\mathrm{PCB}$ and pesticides analyzed, indicating these data are acceptable for use in analysis, though the levels reported for the pesticides Endrin, 4,4'-DDT, 4,4'-DDD, and 4,4'-DDE may be overestimated. A detailed QAVC summary is presented in Appendix C. 


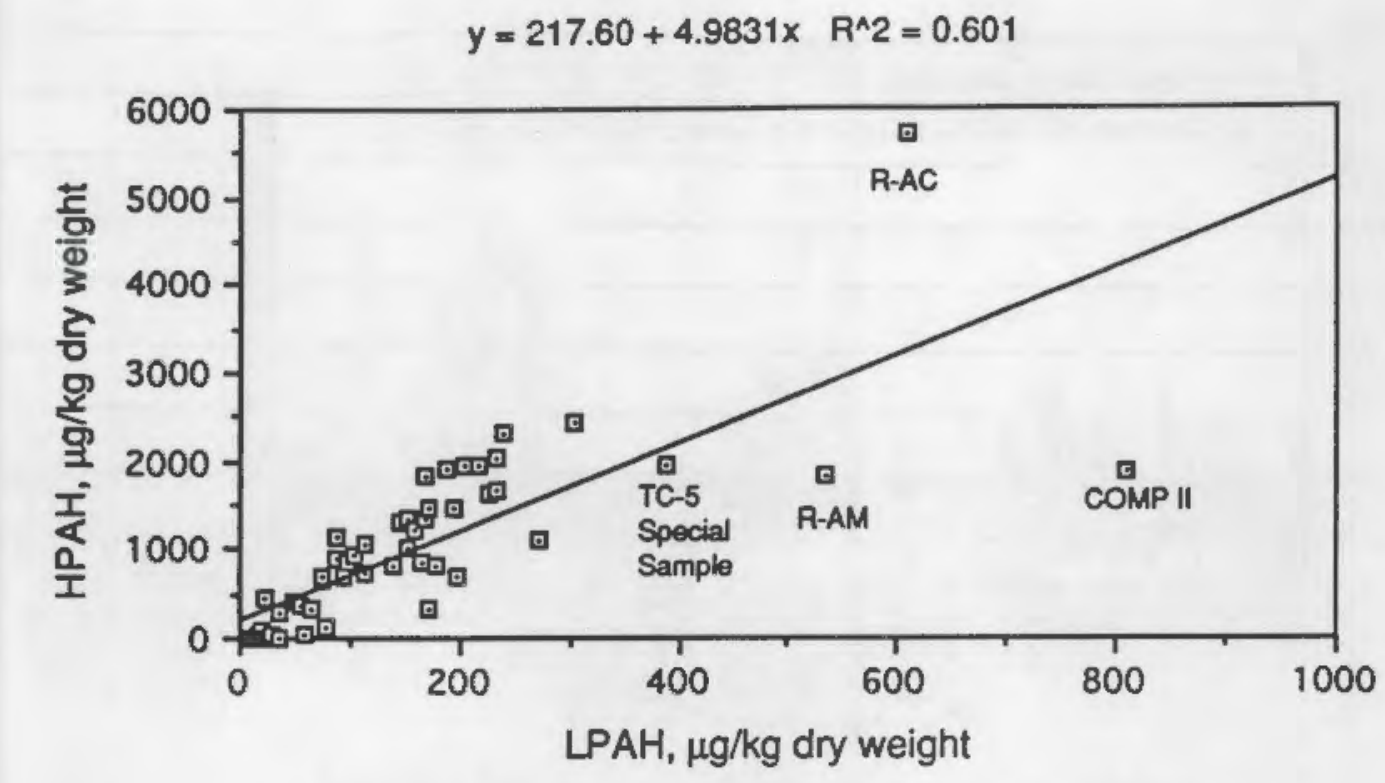

EIGURE 3.25. Linear Regression of LPAH and HPAH

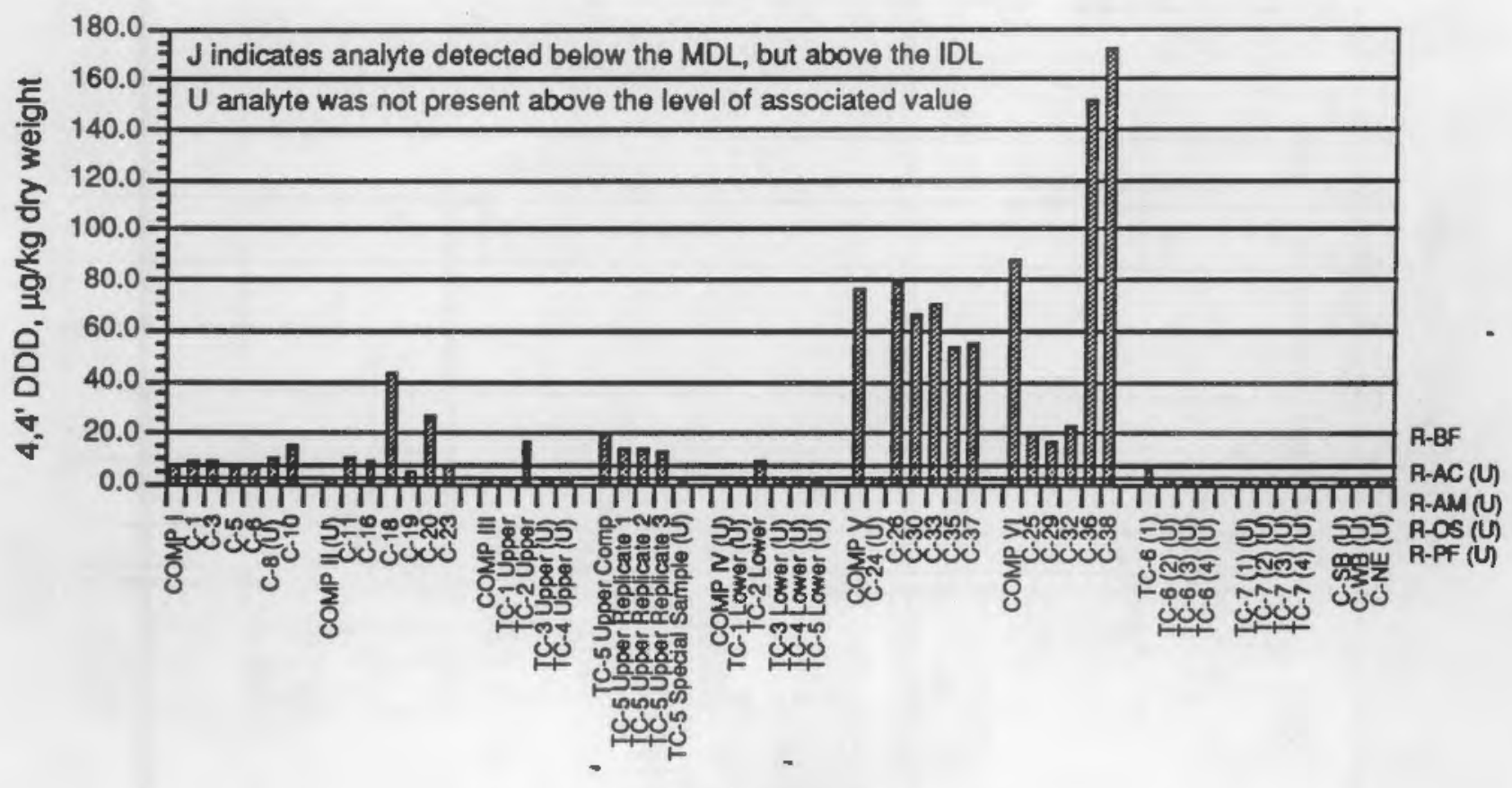

Sediment Treatment

EIGURE 3.26. Concentrations of 4,4'-DDD in Sediment Treatments 


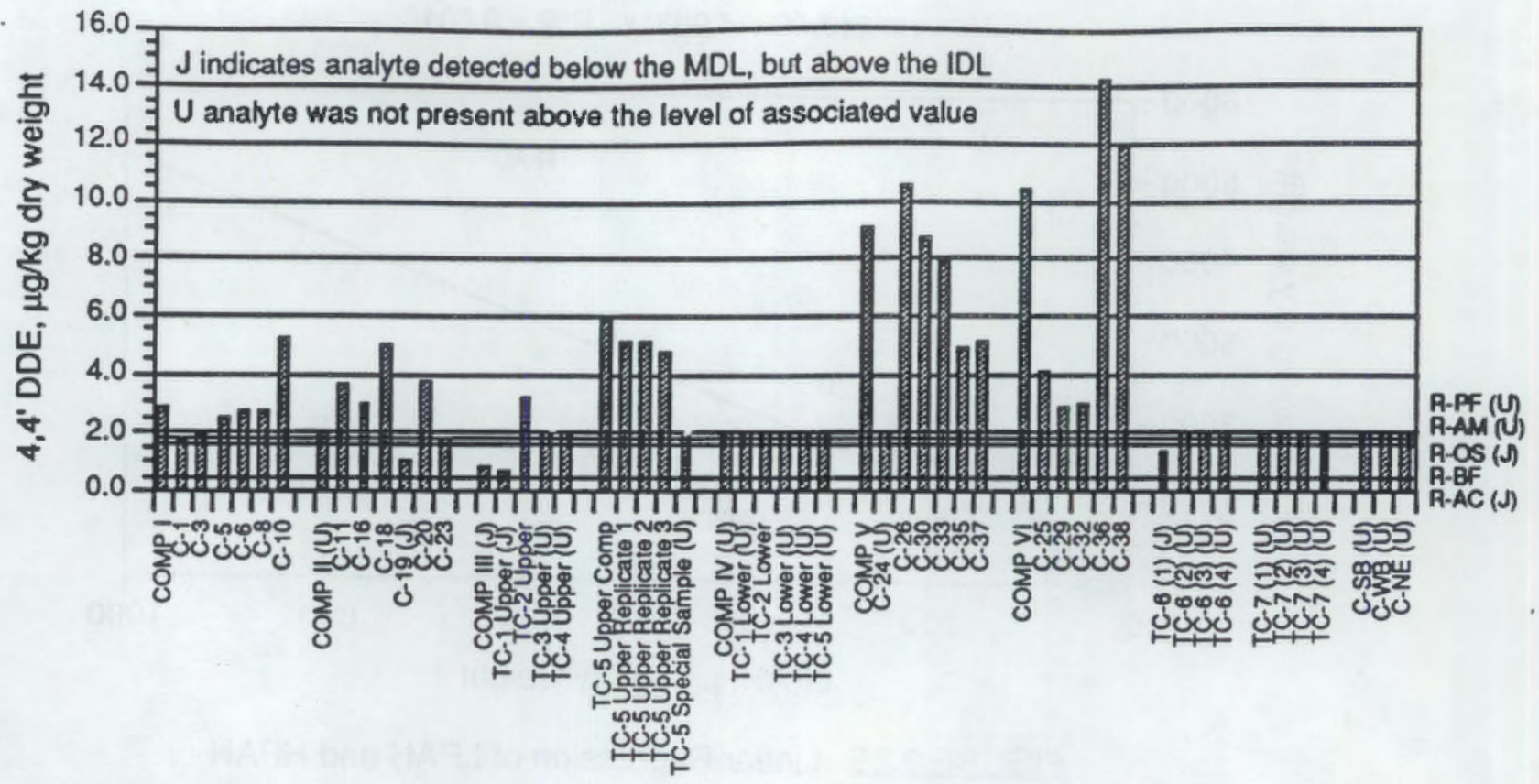

Sediment Treatment

ElGURE 3.27. Concentrations of 4,4'-DDE in Sediment Treatments

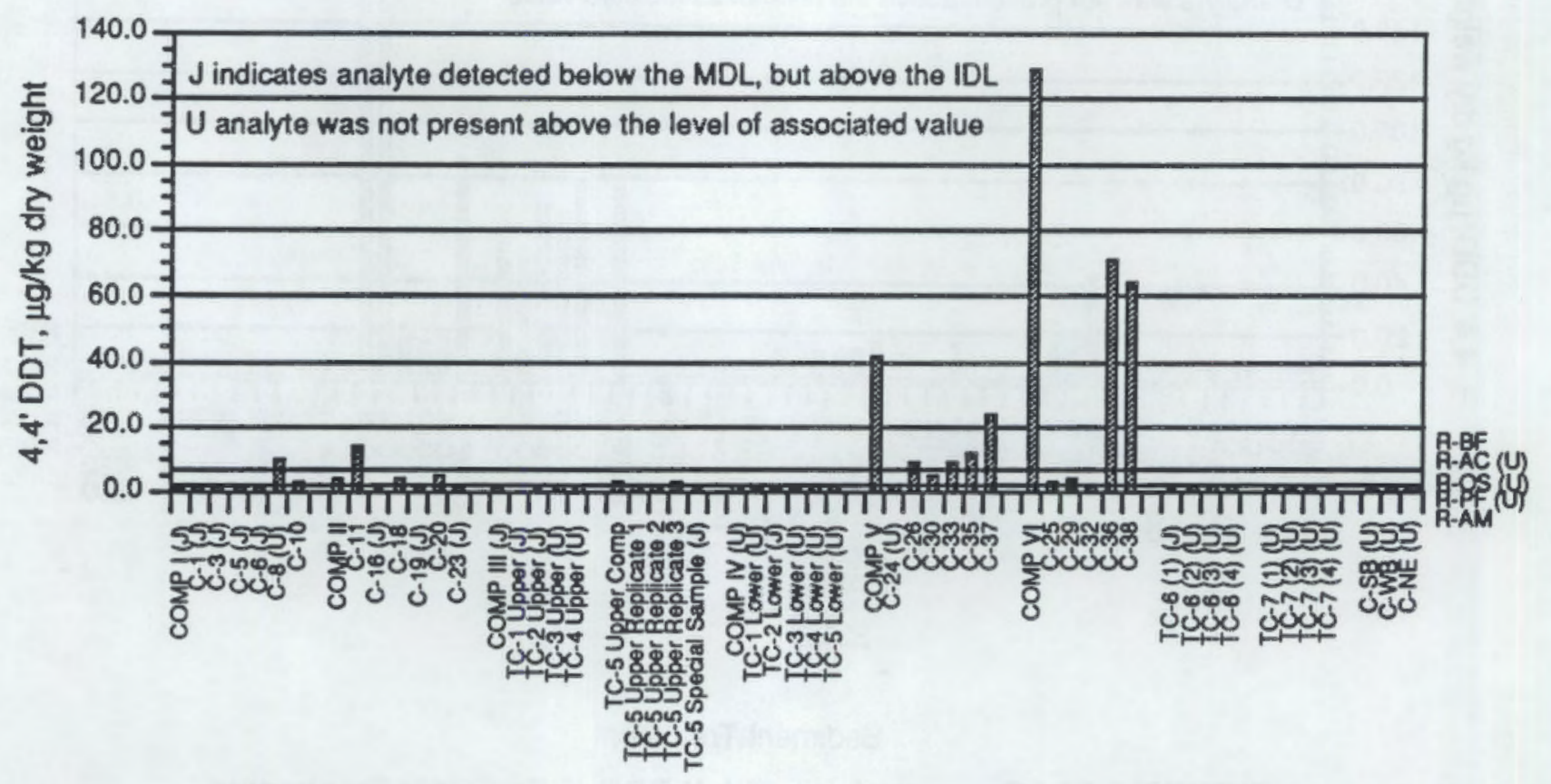

Sediment Treatment

FIGURE 3.28. Concentrations of 4,4'-DDT in Sediment Treatments 


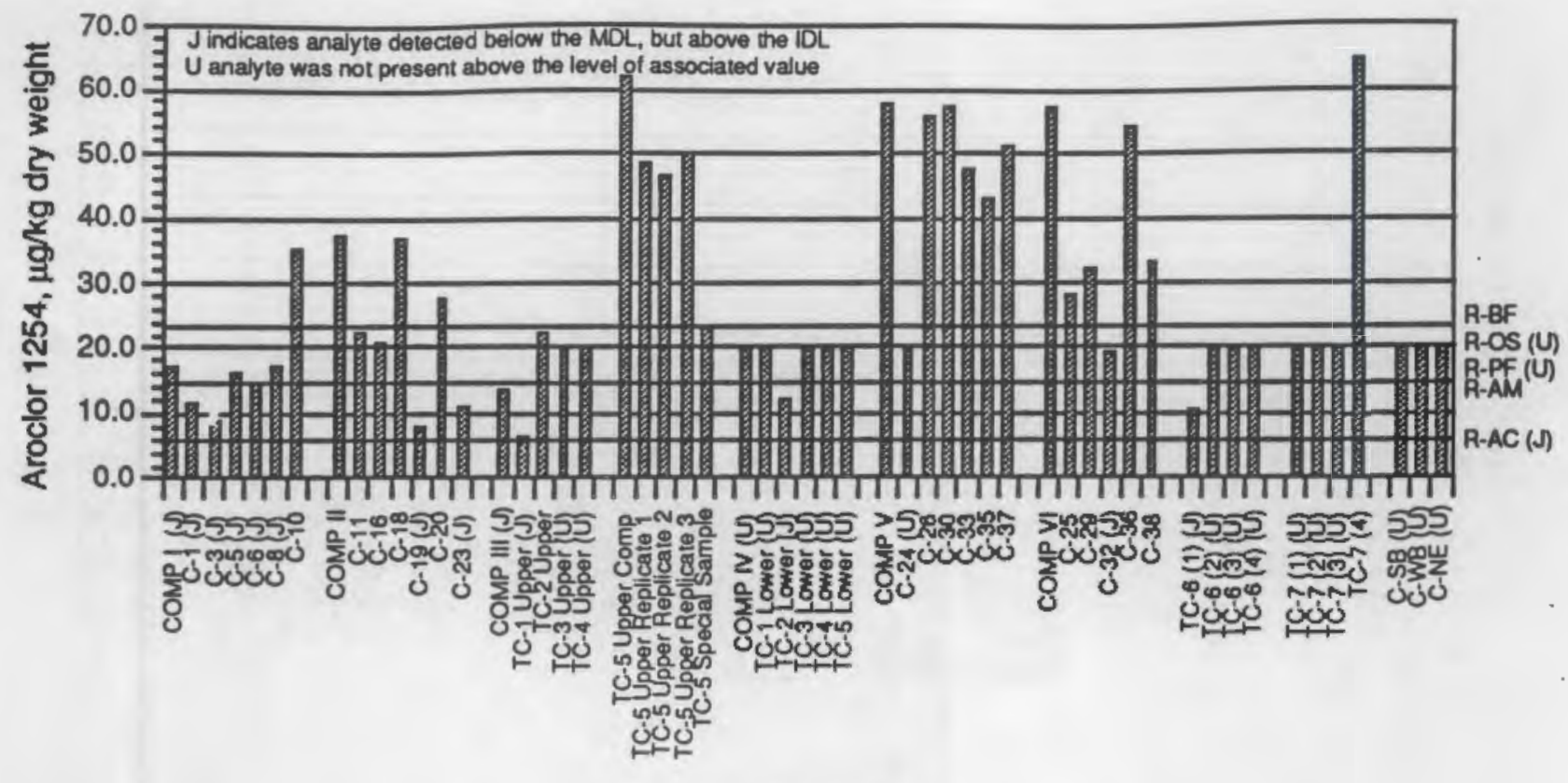

Sediment Treatment

EIGURE 3.29. Concentrations of Aroclor 1254 in Sediment Treatments

\subsubsection{Metals}

Ten metals were measured in sediments from Richmorid Harbor. These are reported in $\mathrm{mg} / \mathrm{kg}$ (ppm) dry weight. Complete results, quality control data, and a quality control summary are contained in Appendix C, Tables 14 and 15. Figures 3.30 through 3.38 provide a comparison of metals concentrations in test treatments and reference treatments. Comparison with metals concentrations in typical shale soil is also provided because these metals are ubiquitous in the natural environment. The metals concentrations in shale soil are reported by Krauskopf (1967).

Concentrations of silver $(\mathrm{Ag})$ in the reference treatments ranged from $0.033 \mathrm{mg} / \mathrm{kg}$ at R-AM to $0.501 \mathrm{mg} / \mathrm{kg}$ at R-OS. Concentrations in the test treatments ranged from $0.078 \mathrm{mg} / \mathrm{kg}$ in TC-6(3) to $1.299 \mathrm{mg} / \mathrm{kg}$ in TC-5 Special Sample. A 40-fold difference was observed between the reference treatment (R-AM) and the test treatment (TC-5 Special Sample). Six test treatments had values higher than R-OS (Figure 3.30). Three test treatments, two reference treatments, and two control treatments had Ag values below that of typical shale soil $(0.1 \mathrm{mg} / \mathrm{kg}$ dry weight) (Krauskopf 1967). 


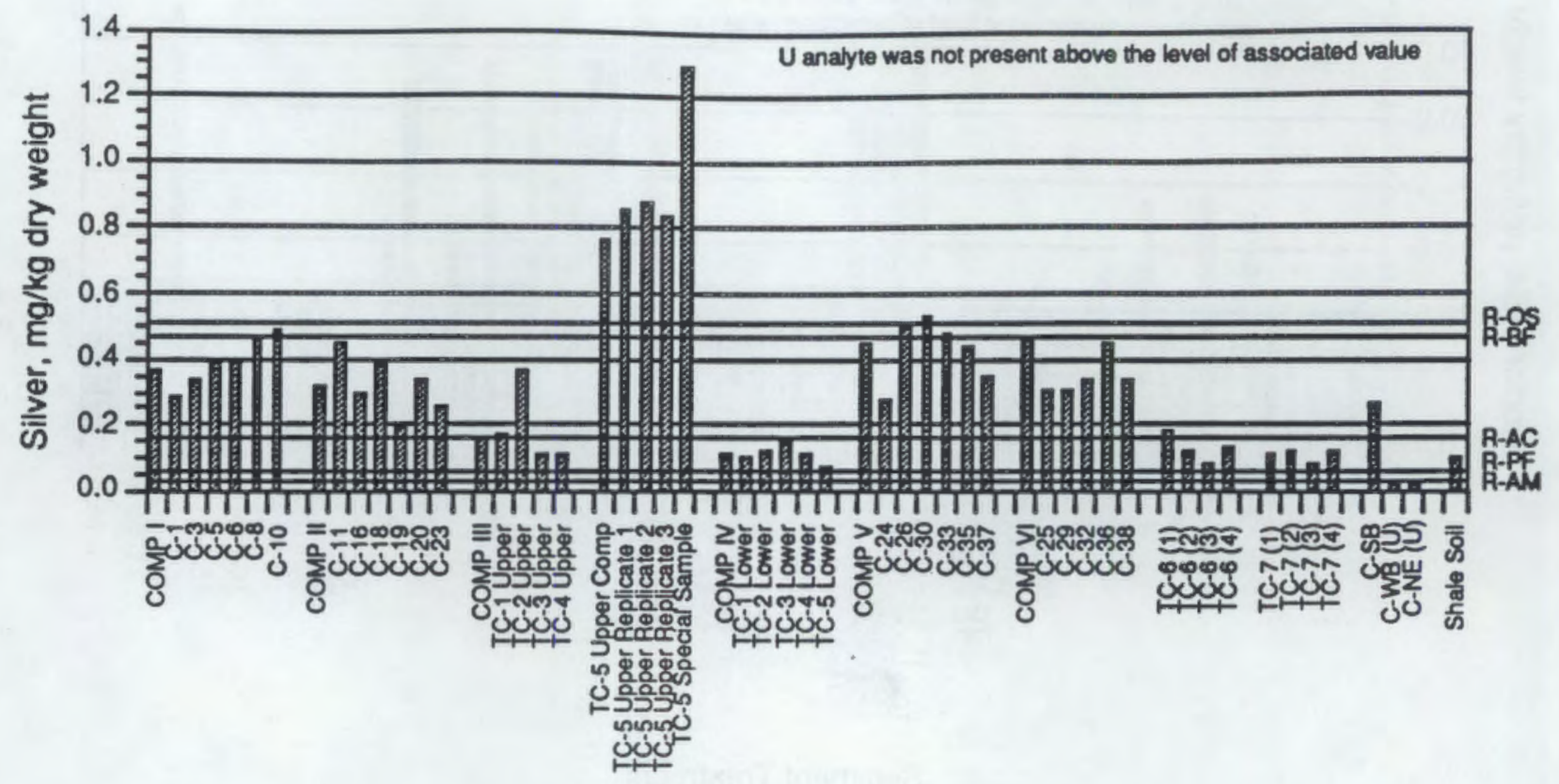

Sediment Treatment

FlGURE 3.30. Concentrations of Silver in Sediment Treatments

Concentrations of arsenic (As) in the sediment treatments are presented in Figure 3.31. The As concentrations for the references ranged from $4.01 \mathrm{mg} / \mathrm{kg}$ at $\mathrm{R}-\mathrm{OS}$ to $10.25 \mathrm{mg} / \mathrm{kg}$ at RAC. Concentrations in the test treatments ranged from $5.91 \mathrm{mg} / \mathrm{kg}$ at $T C-7(3)$ to $24.80 \mathrm{mg} / \mathrm{kg}$ at TC-5 Special Sample. A sixfold difference was observed between the reference treatment (ROS) and test treatment (TC-5 Special Sample). Ten test treatments had values below that of R$\mathrm{AC}$, and two test treatments, $\mathrm{TC}-6(3)$ and $\mathrm{TC}-7(3)$, had values below the $6.6 \mathrm{mg} / \mathrm{kg}$ found in shale soil (Krauskopf 1967).

Cadmium (Cd) concentrations ranged from $0.055 \mathrm{mg} / \mathrm{kg}$ at $\mathrm{R}-\mathrm{AM}$ to $2.297 \mathrm{mg} / \mathrm{kg}$ at RPF; all test treatments were within this range (Figure 3.32). The shale soil value for $\mathrm{Cd}$ is 0.3 $\mathrm{mg} / \mathrm{kg} ; 15$ test treatments, 3 references, and 2 controls were below this value (Krauskopf 1967).

Concentrations of chromium $(\mathrm{Cr})$ in the reference treatments ranged from $172 \mathrm{mg} / \mathrm{kg}$ at R-OS to $438 \mathrm{mg} / \mathrm{kg}$ at R-AC. Concentrations of $\mathrm{Cr}$ in test treatments ranged from $156 \mathrm{mg} / \mathrm{kg}$ at C-19 to $320 \mathrm{mg} / \mathrm{kg}$ at TC-1 Lower (Figure 3.33). A twofold difference was observed between the reference treatment (R-OS) and the test treatment (TC-1 Lower). All test, reference, and control treatments were above the shale soil $\mathrm{Cr}$ concentration of $100 \mathrm{mg} / \mathrm{kg}$ (Krauskopf 1967). 


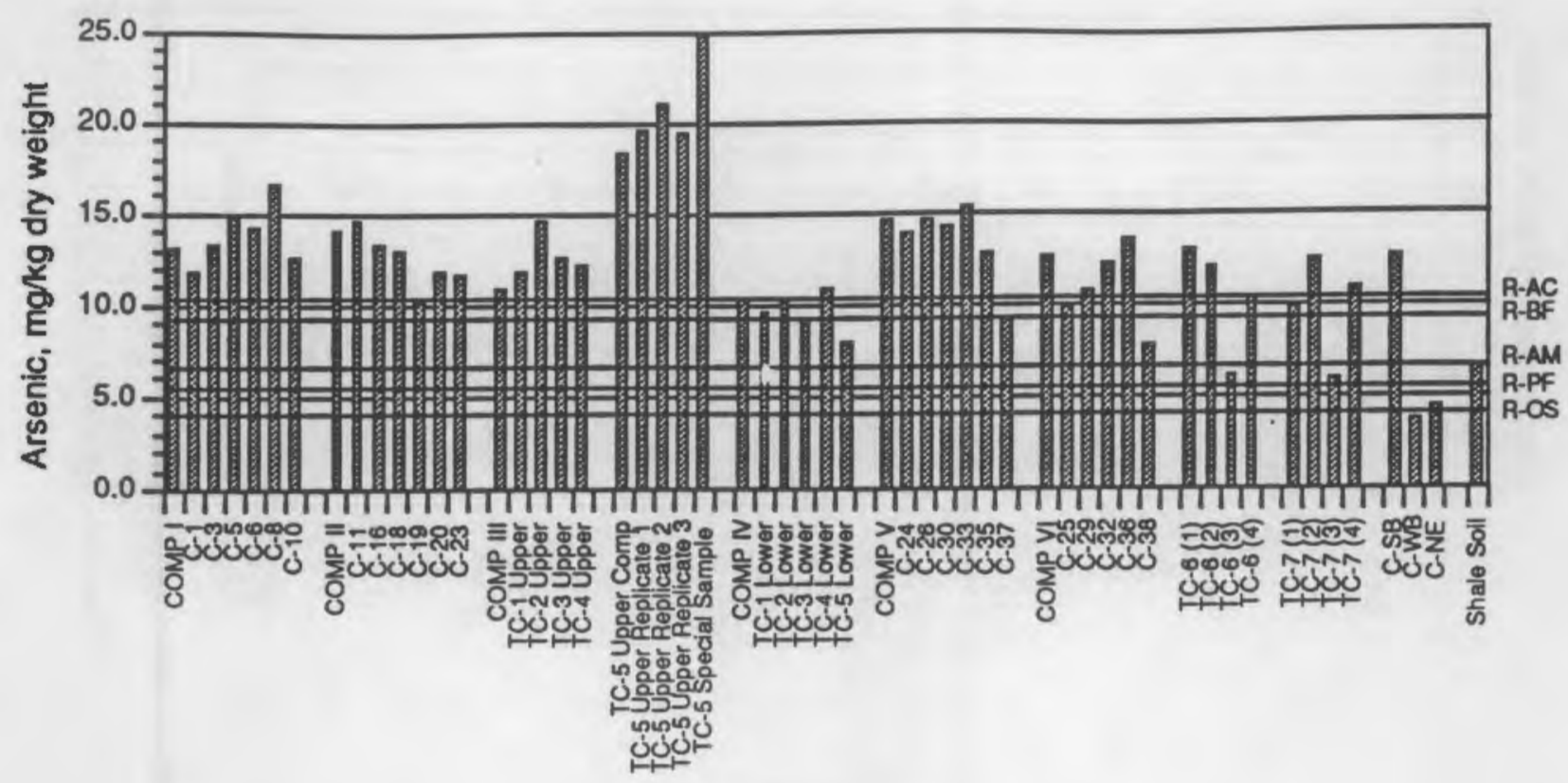

Sediment Treatment

FIGURE 3.31. Concentrations of Arsenic in Sediment Treatments

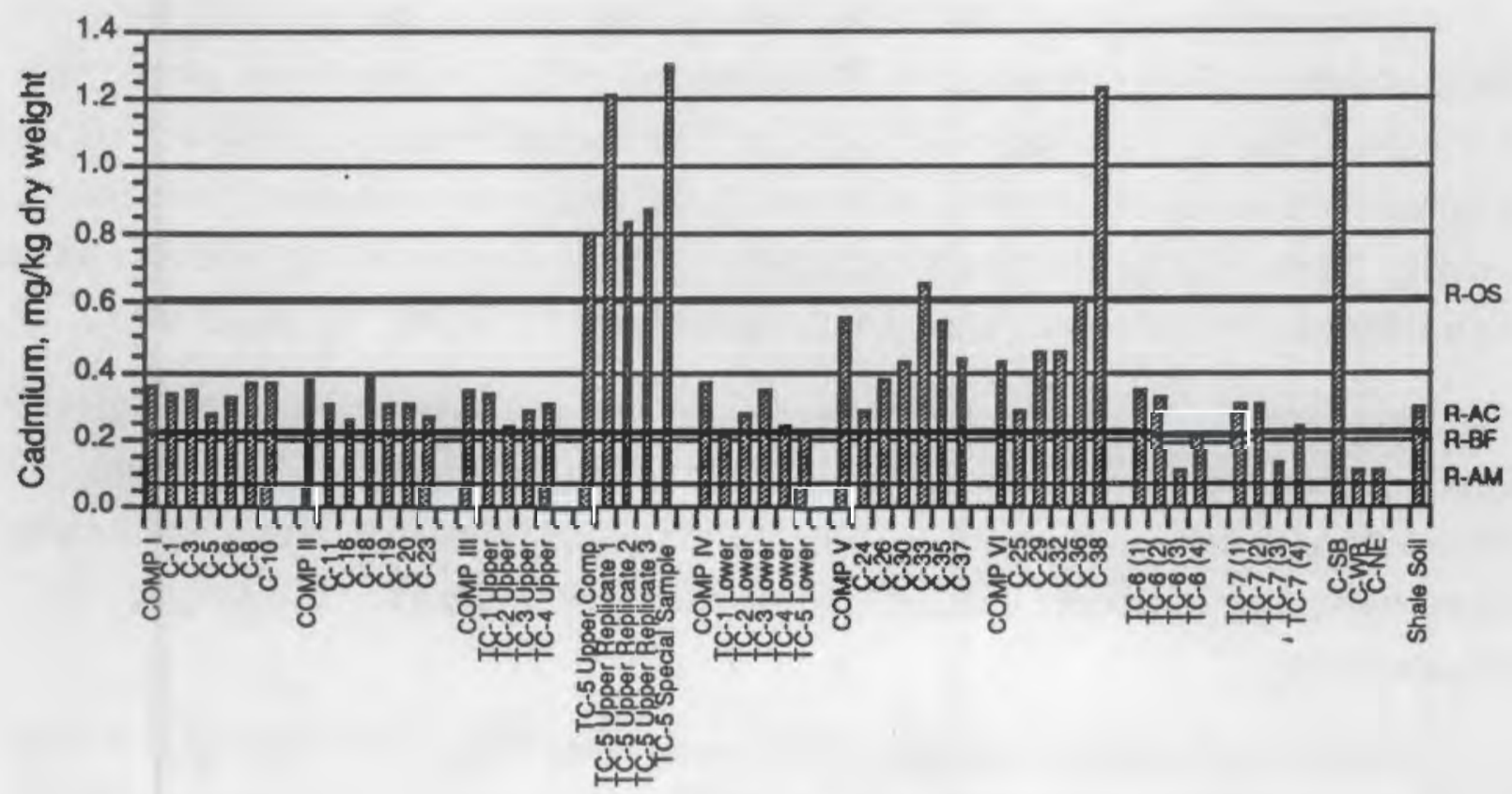

Sediment Treatment

EIGURE 3,32. Concentrations of Cadmium in Sediment Treatments (Reference treatment R-PF had a concentration of $2.297 \mathrm{mg} / \mathrm{kg}$, which is above the vertical axis of the figure.) 


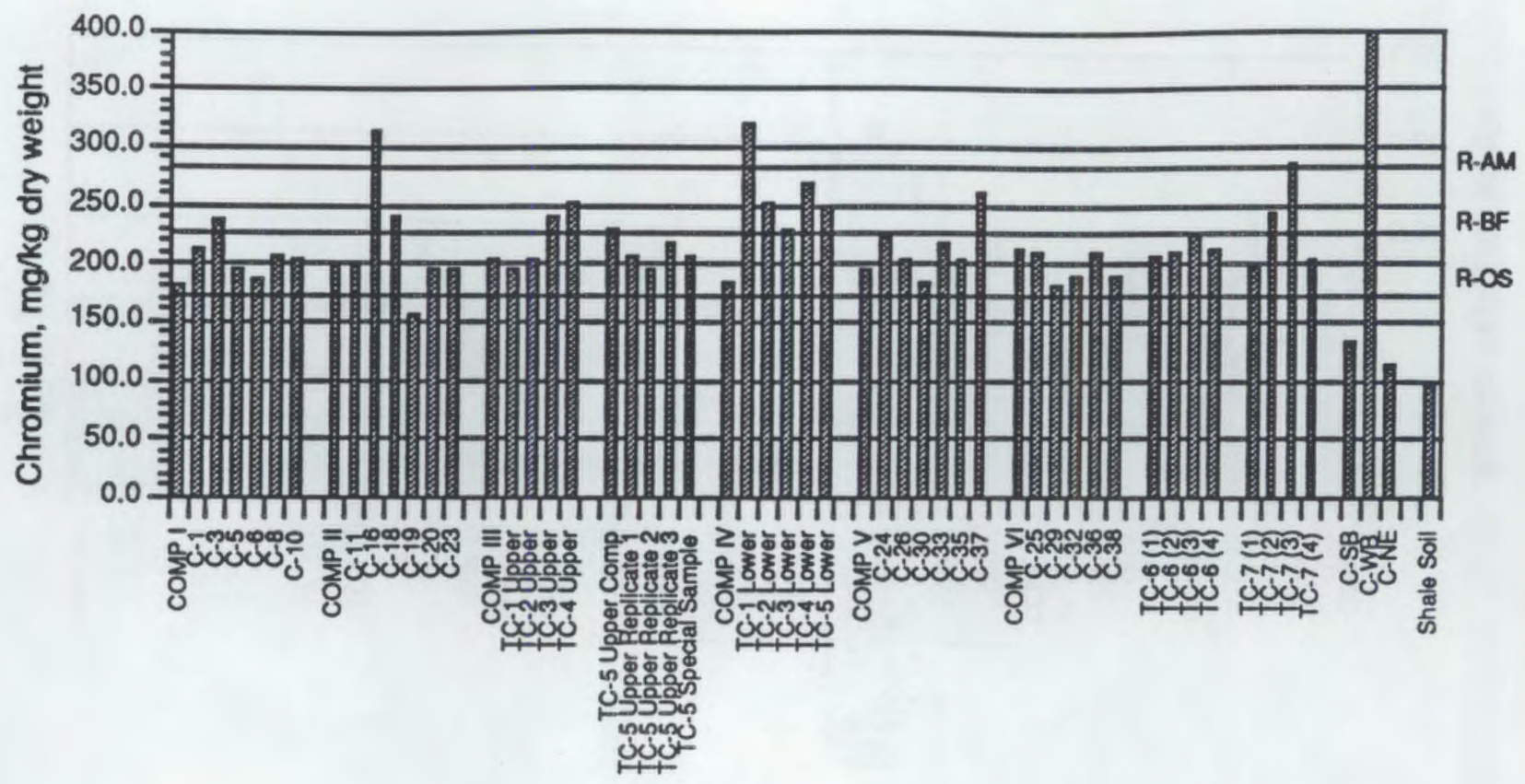

Sediment Treatment

ElGURE 3.33. Concentrations of Chromium in Sediment Treatments (Reference treatments R-PF and R-AC had concentrations of 411.0 and $438.0 \mathrm{mg} / \mathrm{kg}$, which are above the vertical axis of the figure.)

Concentrations of copper $(\mathrm{Cu})$ in the reference treatments ranged from $10.7 \mathrm{mg} / \mathrm{kg}$ (R$A M)$ to $56.1 \mathrm{mg} / \mathrm{kg}$ (R-BF) (Figure 3.34). Concentrations of $\mathrm{Cu}$ in test treatments ranged from $16.2 \mathrm{mg} / \mathrm{kg}$ at treatment TC-6(3) to $96.4 \mathrm{mg} / \mathrm{kg}$ at TC-5 Special Sample. A ninefold difference was observed between the reference treatment (R-AM) and the test treatment (TC-5 Special Sample). Twenty-four test treatments exceeded the Cu concentration of R-BF and twenty-three test treatments exceeded the Cu concentration of shale soil (57 mg/kg) (Krauskopf 1967).

Mercury $(\mathrm{Hg})$ concentrations in test treatments ranged from $0.052 \mathrm{mg} / \mathrm{kg}$ at TC-7(1) to $1.431 \mathrm{mg} / \mathrm{kg}$ at TC-5 Special Sample (Figure 3.35). Twelve test treatments exceeded the highest reference treatment, which was R-BF $(0.427 \mathrm{mg} / \mathrm{kg})$. Fourteen Richmond Harbor test treatments and one reference treatment exceeded the shale soil $\mathrm{Hg}$ value of $0.4 \mathrm{mg} / \mathrm{kg}$ (Krauskopf 1967).

Nickel ( $\mathrm{Ni}$ ) concentrations in the reference treatments ranged from $45.2 \mathrm{mg} / \mathrm{kg}$ at R-AM to $116.4 \mathrm{mg} / \mathrm{kg}$ at R-BF (Figure 3.36). Concentrations of $\mathrm{Ni}$ in test treatments ranged from 46.1 $\mathrm{mg} / \mathrm{kg}$ at TC-6(3) to $130.9 \mathrm{mg} / \mathrm{kg}$ at C-33. A threefold difference was observed between the reference treatment (R-AM) and the test treatment (C-33). Thirty-nine sediment treatments and one reference treatment had Ni values above that of shale soil (95 mg/kg) (Krauskopf 1967). 


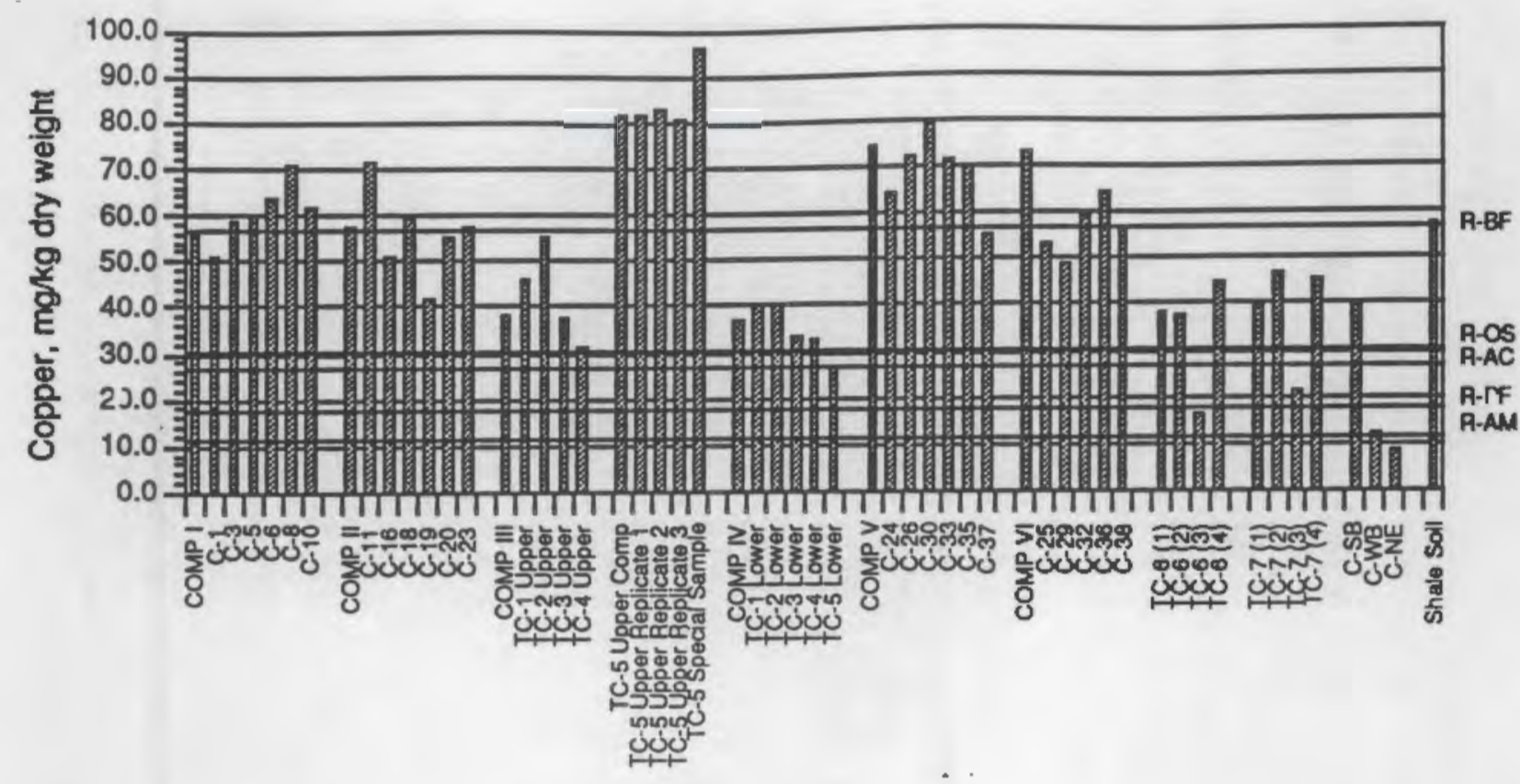

Sediment Treatment

FIGURE 3.34. Concentrations of Copper in Sediment Treatments

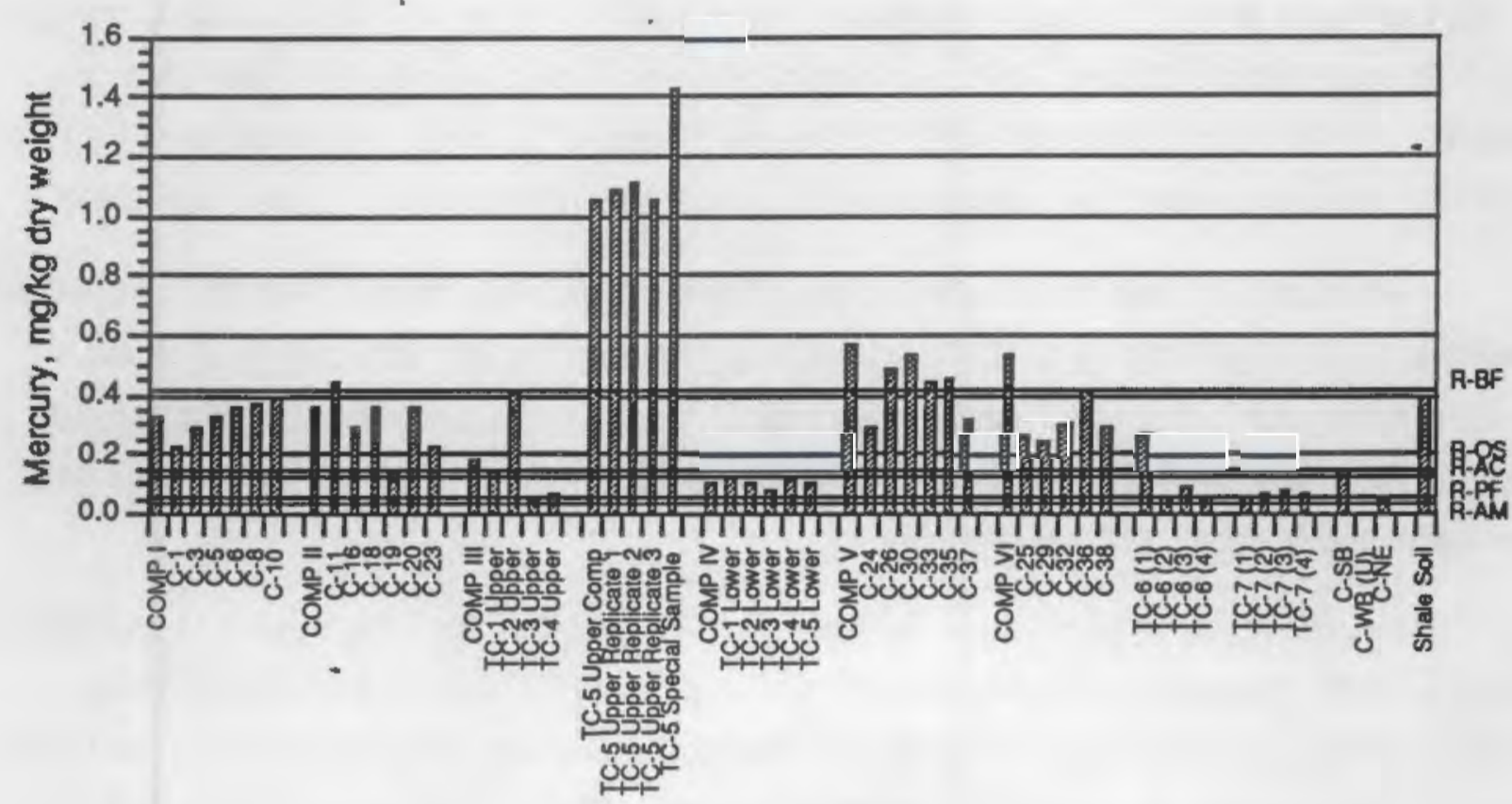

Sediment Treatment

FIGURE 3.35. Concentrations of Mercury in Sediment Treatments 


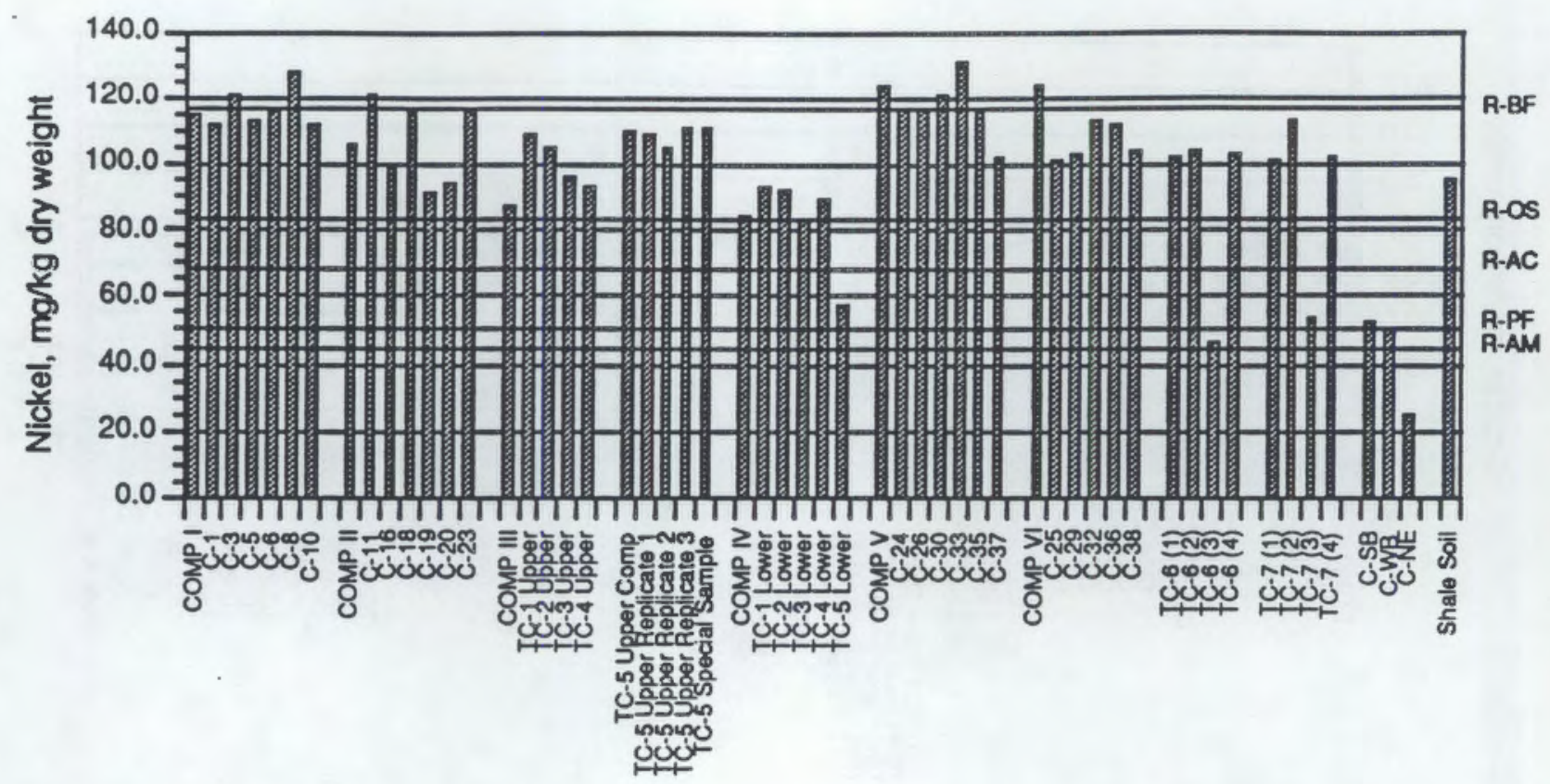

Sediment Treatment

FIGURE 3.36. Concentrations of Nickel in Sediment Treatments

Concentrations of lead $(\mathrm{Pb})$ in the reference treatments ranged from $7.1 \mathrm{mg} / \mathrm{kg}$ at $\mathrm{R}-\mathrm{PF}$ to $36.4 \mathrm{mg} / \mathrm{kg}$ at R-BF. The test treatments ranged from $8.3 \mathrm{mg} / \mathrm{kg}$ at TC-6(3) to $62.1 \mathrm{mg} / \mathrm{kg}$ at TC-5 Special Sample (Figure 3.37). A ninefold difference was observed between reference treatment (R-PF) and test treatment (TC-5 Special Sample). All but 17 test treatments had $\mathrm{Pb}$ concentrations exceeding the typical shale soil concentration of $20 \mathrm{mg} / \mathrm{kg}$ (Krauskopf 1967).

Selenium (Se) was detected in 12 test treatments with concentrations ranging from 0.82 $\mathrm{mg} / \mathrm{kg}$ at C-26 to $1.44 \mathrm{mg} / \mathrm{kg}$ at TC-5 Upper Comp. Selenium was undetected in all of the references except R-OS, which had a value of $2.57 \mathrm{mg} / \mathrm{kg}$, the highest Se value of any treatment. All of the sediment treatments with detected values of Se were above the typical shale soil value of $0.6 \mathrm{mg} / \mathrm{kg}$ (Krauskopf 1967).

Concentrations of zinc $(\mathrm{Zn})$ in the references ranged from $35.1 \mathrm{mg} / \mathrm{kg}$ (R-AM) to 139.1 $\mathrm{mg} / \mathrm{kg}$ (R-BF). The test treatments ranged from $35.2 \mathrm{mg} / \mathrm{kg}$ [TC-6(3)] to $260 \mathrm{mg} / \mathrm{kg}$ (TC-5 Special Sample) (Figure 3.38). A sevenfold difference was observed between reference treatment (R-AM) and test treatment (TC-5 Special Sample). Six test treatments, three references, and two controls had values below the concentration of $\mathrm{Zn}$ typically found in shale soil $(80 \mathrm{mg} /$ kg) (Krauskopf 1967). 


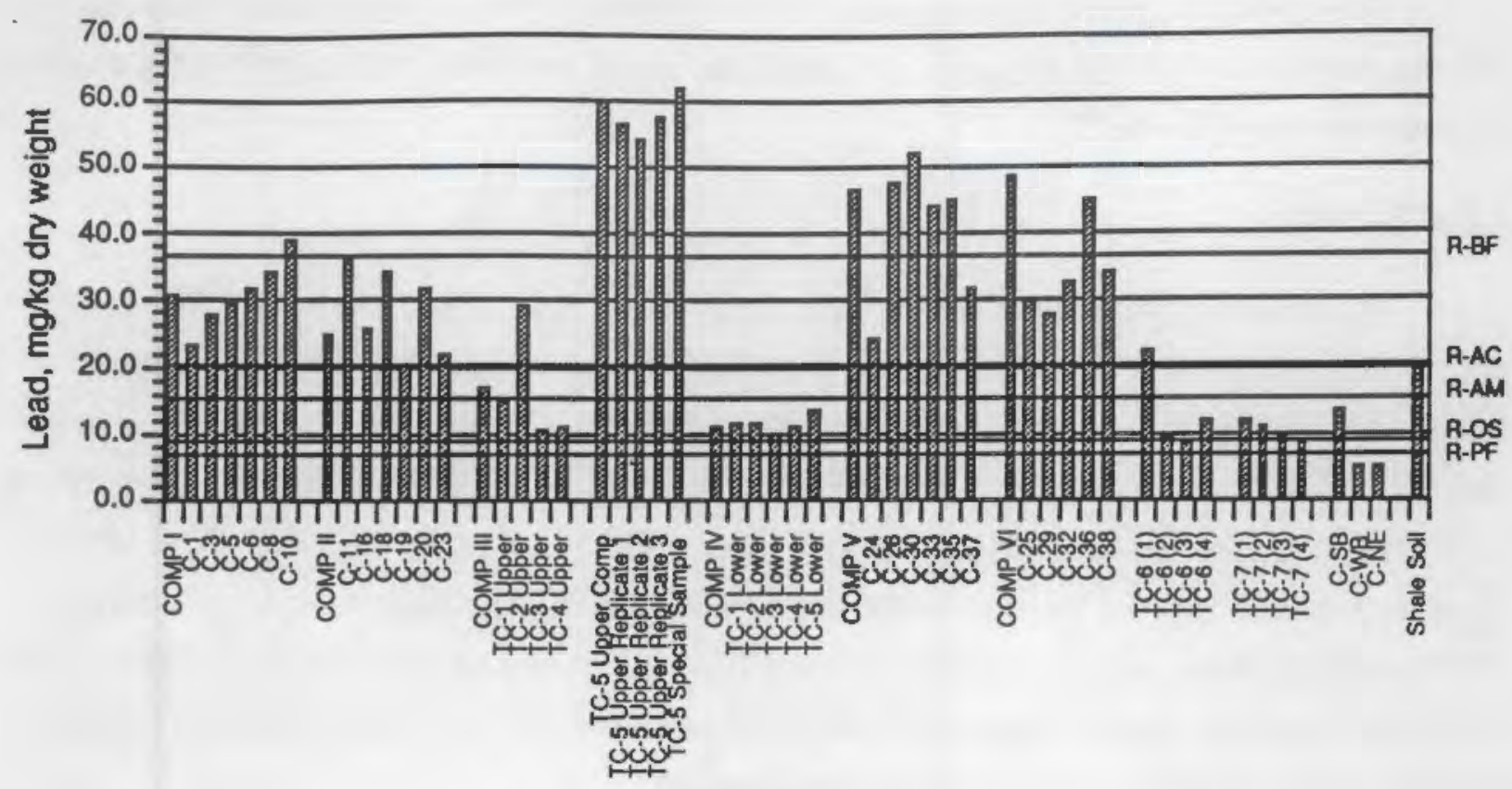

Sediment Treatment

FIGURE 3.37. Concentrations of Lead in Sediment Treatments

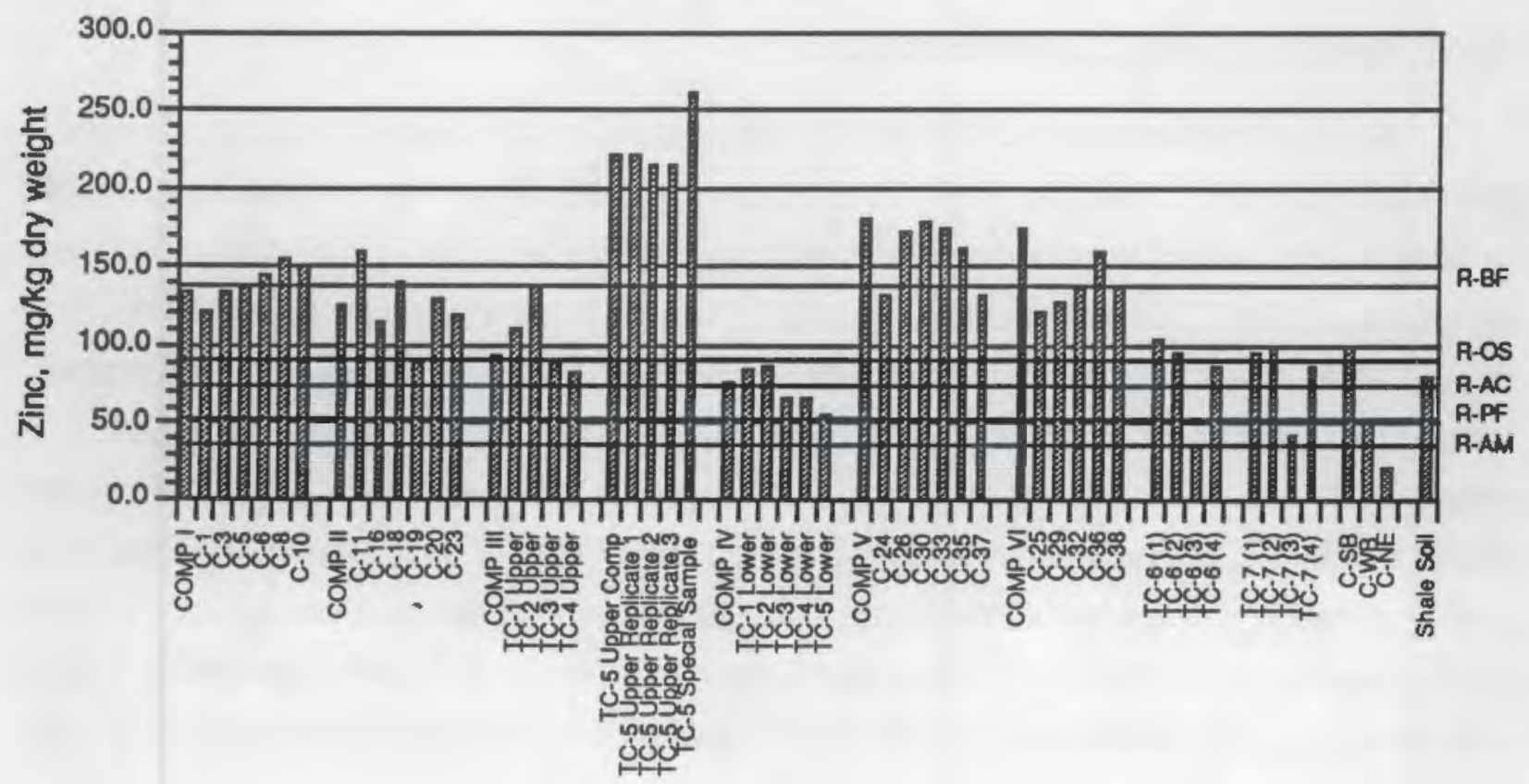

Sediment Treatment

FIGURE 3.38. Concentrations of Zinc in Sediment Treatments 
The QAVC requirements were met for the majority of metals analyzed. The overall QA QC results show that these data are acceptable for use in analysis. A detailed QAQC summary is presented in Appendix C.

\subsubsection{Butyltins}

Monobutyltin (MBT) concentrations were detected at TC-5 Upper Rep 3 at $4(\mathrm{~J}) \mu \mathrm{g} / \mathrm{kg}$ and at $19 \mu \mathrm{g} / \mathrm{kg}$ in TC-5 Special Sample. Monobutyltin was undetected in control and reference treaimen.s. Dibutyltin (DBT) concentrations ranged from $0.3 \mu \mathrm{g} / \mathrm{kg}$ at TC-1 lower, TC-4 lower, and TC-7(3) to $11.4 \mu \mathrm{g} / \mathrm{kg}$ at TC-5 Upper Rep 3 (Figure 3.39), a 38-fold difference. Dibutyltins concentrations in references ranged from $0.5(\mathrm{~J})$ at R-OS to $5.4 \mu \mathrm{g} / \mathrm{kg}$ at R-AC. TC-5 Upper Reps 1,3 , and C-16 were the only test treatments with DBT values above R-AC. Tributyltin (TBT) concentrations ranged from $0.3 \mu \mathrm{g} / \mathrm{kg}$ at TC-4 Upper to $23.5 \mu \mathrm{g} / \mathrm{kg}$ at C-16 (Figure 3.40), a 78-fold difference. References $\mathrm{R}-\mathrm{BF}$ and $\mathrm{R}-\mathrm{AC}$ were the only two references with detected levels of TBT (1.9 $\mu \mathrm{g} / \mathrm{kg}$ and $16.2 \mu \mathrm{g} / \mathrm{kg}$, respectively).

The QAVCC requirements were met for the majority of butyltins analyzed. The QAQC results show that these data are acceptable for use in data analysis. A detailed QAQC summary is presented in Appendix C.

\subsection{IOXICOLOGICALTESTING RESULTS}

Solid-phase tests were conducted to evaluate the toxicity of seven Richmond Harbor test treatments (COMPS I through VI and TC-5 Upper Comp) relative to five reference treatments. In addition, two control treatments were used to validate the tests through examination of test organism survival. The solid-phase tests conducted with these sediments were a 10-day flowthrough solid-phase test with the polychaete $N$. caecoides and the bentnose clam $M$. nasuta (acute toxicity), a 28-day flow-through solid-phase test with $N$. caecoides and $M$. nasuta (bioaccumulation exposure), and a 10-day static solid-phase test with the amphipod $R$. abronius (acute toxicity). The 10-day tests were considered valid if $90 \%$ or greater survival of test organisms occurred in native control treatment. After the tests were inspected for validity, the data were evaluated by ANOVA and Dunn's Modification to Tukey's HSD Test to determine if significant differences occurred between test treatments when compared to the five reference treatments (Section 2.5.2).

Suspended-particulate-phase tests were conducted concurrently with the solid-phase tests and included three marine species: the mysid shrimp H. sculpta, juvenile speckled 


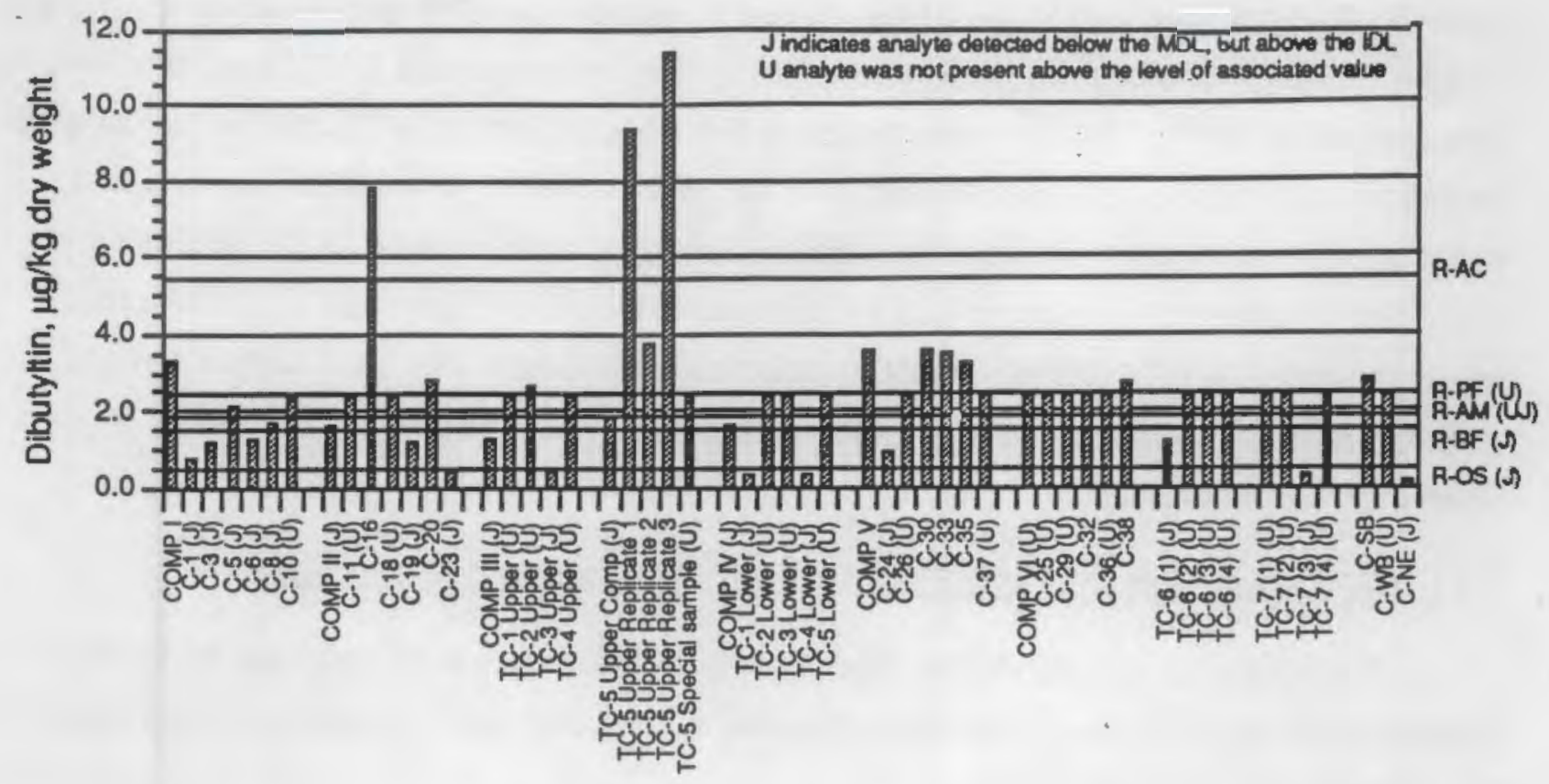

Sediment Treatment

FIGURE 3.39. Concentrations of Dibutyltin in Sediment Treatments

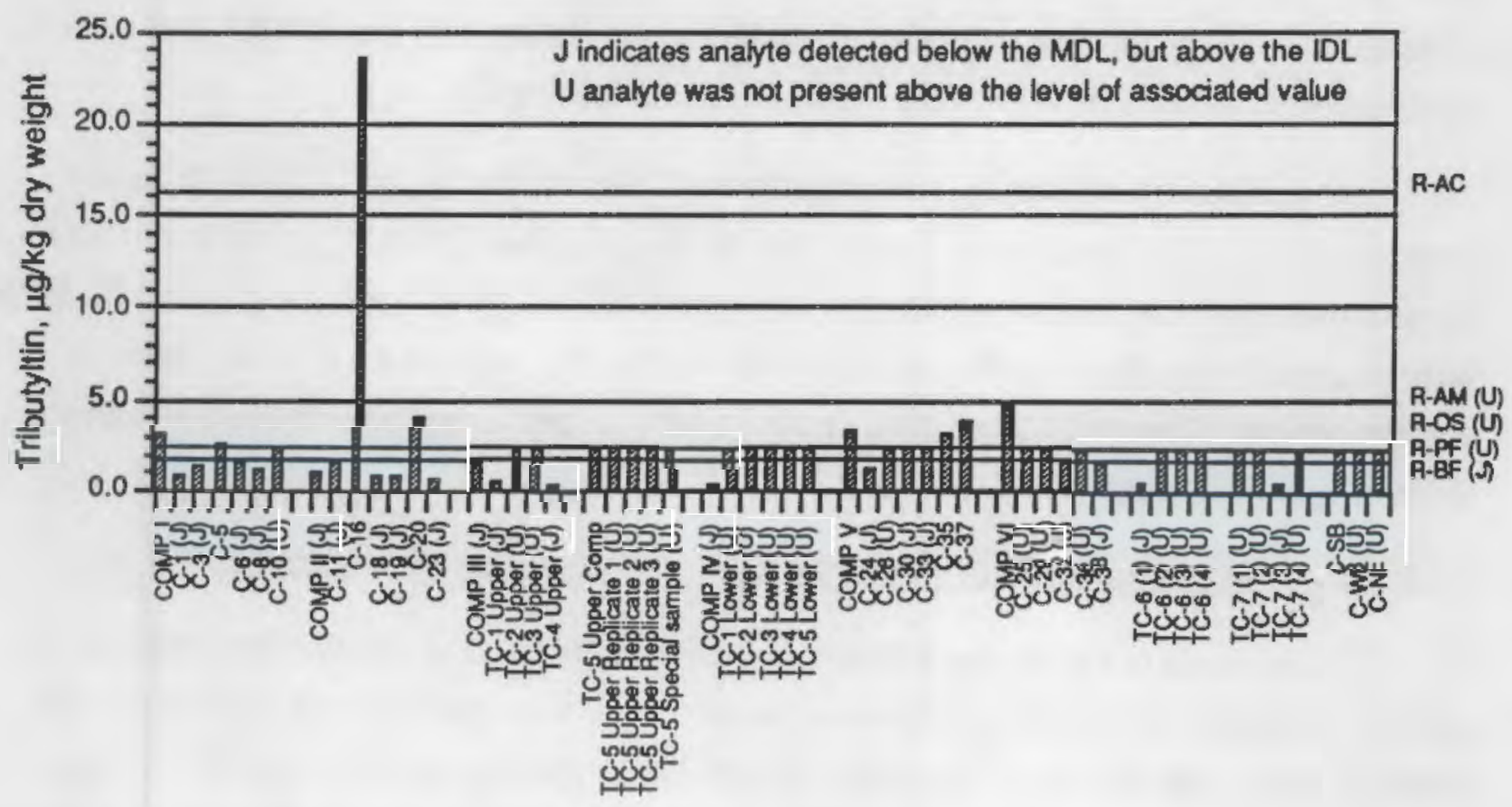

Sediment Treatment

FlGURE 3.40. Concentrations of Tributyltin in Sediment Treatments 
sanddab $C$. stigmaeus, and larvae of the mussel $M$. edulis. The SPP tests were conducted with COMPs I through VI and TC-5 Upper Comp, using four concentrations [0\% (seawater), 10\%, $50 \%$, and $100 \%$ SPP]. The SPP preparation is described in Section 2.2 .3 and the toxicological testing procedures are discussed in Section 2.4.2. For each SPP test, control survival and water quality results were evaluated to validate the test. Survival values for the controls and $100 \%$ SPP treatments were compared using an independent, two-sample t-test. If the result was significant $(\alpha=0.1$ ), and at least $50 \%$ reduction in survival of the $100 \%$ SPP relative to control was noted, LC50 and/or EC50 estimates were determined using the Trimmed Spearman-Karber method.

\subsubsection{0-Day Flow-Through Solid-Phase Test with $M$. nasuta and $N$. caecoides}

The 10-day $M$. nasuta and $N$. caecoides solid-phase tests were validated by $100 \%$ survival of $M$. nasuta in the native control treatment C-SB, and $95 \%$ survival of $N$. caecoides in the native control treatment $\mathrm{C}-\mathrm{NE}$.

Mean survival of $M$. nasuta was $96 \%$ or greater in the seven Richmond Harbor test treatments and five reference treatments. The ANOVA and Dunn's Test showed no significant differences between test and reference treatments for the proportion (arcsine square-root transformation) of organisms surviving. Summary of the results from the ANOVA and Dunn's Modification to Tukey's HSD Test are shown in Tables 3.6 and 3.7.

Mean survival of $N$. caecoides ranged from $73 \%$ in COMP IV to $100 \%$ in the control treatment C-SB. The results from Dunn's Test for the proportion surviving (arcsine square-root transformation) (Table 3.8) showed test treatments COMP IV, TC-5 Upper Comp, and COMP III were statistically significantly different from R-BF and R-OS, and had a $>10 \%$ difference in percent survival. The ANOVA results indicate statistically significant differences between the 12 test and reference treatments (Table 3.9).

\subsubsection{8-Day Flow-Through Solid-Phase Test with $M$. nasuta and $N$. caecoides}

The purpose of the 28-day solid-phase test using M. nasuta and $N$. caecoides was to provide results associated with the bioaccumulation potential of specific test treatments. The results of the $M$. nasuta and $N$. caecoides 28-day toxicological tests are presented in Table 3.10 and Appendix E. The tests were validated for both species by $M$. nasuta survival of $95 \%$ in the control treatment C-SB and N. caecoides survival of $95 \%$ in the control treatment C-NE. 
IABLE 3.6. Results of Dunn's Test for the 10-Day Solid-Phase Flow-Through Test with $M$. nasuta

\begin{tabular}{lcc}
$\begin{array}{l}\text { Sediment } \\
\text { Ireatment }\end{array}$ & $\begin{array}{c}\text { Mean Percent } \\
\text { Survival }\end{array}$ & $\begin{array}{c}\text { Statistical } \\
\text { Grouping(b) }\end{array}$ \\
\cline { 2 - 3 } COMP IV & 97.6 & $\mathrm{~A}$ \\
COMP II & 96.0 & $\mathrm{~A}$ \\
R-PF & 98.0 & $\mathrm{~A}$ \\
R-AM & 98.0 & $\mathrm{~A}$ \\
R-BF & 98.0 & $\mathrm{~A}$ \\
R-OS & 99.0 & $\mathrm{~A}$ \\
COMP VI & 99.0 & $\mathrm{~A}$ \\
R-AC & 99.0 & $\mathrm{~A}$ \\
COMP III & 99.0 & $\mathrm{~A}$ \\
COMP I & 100.0 & $\mathrm{~A}$ \\
TC-5 Upper Comp & 100.0 & A \\
COMP V & 100.0 & A \\
C-SB & 100.0 & NA \\
C-NE & 99.0 & NA
\end{tabular}

(a) NA Control treatments not included in statistical analysis.

(b) All of the test and reference were not statistically significant from each other as denoted by the common letter $A$ in the statistical grouping column.

IABLE 3.7. ANOVA Results for the 10-Day Solid-Phase Flow-Through Test with $M$. nasuta

\begin{tabular}{|c|c|c|c|c|c|}
\hline $\begin{array}{l}\text { Source } \\
\text { Yariation }\end{array}$ & $\begin{array}{l}\text { Sum of } \\
\text { Squares }\end{array}$ & $d f^{(a)}$ & $\begin{array}{l}\text { Mean } \\
\text { Square }\end{array}$ & E-Ratio & $\begin{array}{c}\text { Significance } \\
\text { Level }\end{array}$ \\
\hline $\begin{array}{l}\text { Between Groups } \\
\text { Within Groups }\end{array}$ & $\begin{array}{l}0.088 \\
0.614\end{array}$ & $\begin{array}{l}11 \\
48\end{array}$ & $\begin{array}{l}0.008 \\
0.013\end{array}$ & 0.626 & 0.7 \\
\hline
\end{tabular}

(a) d.t. Degrees of freedom. 
IABLE 3.8. Results of Dunn's Test for the 10-Day Solid-Phase Flow-Through Test with $N$. caecoides

\begin{tabular}{l} 
Sediment \\
Ireatment \\
COMP IV \\
TC-5 Upper Comp \\
COMP III \\
COMP II \\
R-AC \\
COMP VI \\
COMP V \\
R-AM \\
COMP I \\
R-BF \\
R-OS \\
R-PF \\
C-SB \\
C-NE \\
\hline
\end{tabular}

\begin{tabular}{|c|c|}
\hline $\begin{array}{l}\text { Mean Percent } \\
\text { Survival }\end{array}$ & $\begin{array}{l}\text { Statistical } \\
\text { Grouping }\end{array}$ \\
\hline 73.0 & A \\
\hline 79.0 & A \\
\hline 79.0 & $A B$ \\
\hline 89.0 & $A B C$ \\
\hline 91.0. & $A B C$ \\
\hline 91.0 & $A B C$ \\
\hline 93.0 & $A B C$ \\
\hline 93.0 & $A B C$ \\
\hline 91.0 & $A B C$ \\
\hline 92.0 & $A B C$ \\
\hline 95.0 & $B C$ \\
\hline 97.4 & C \\
\hline 100.0 & $N^{(b)}$ \\
\hline 97.0 & NA \\
\hline
\end{tabular}

(a) Test treatments COMP IV and TC-5 Upper Comp were statistically signficant from $\mathrm{R}-\mathrm{OS}$ because they do not have a letter $\mathrm{B}$ or $\mathrm{C}$ in the statistical grouping column; test treatments Comp IV, TC-5 Upper Comp, and Comp III were statistically significant from R-PF because they do not have a letter $C$ in the statistical grouping column.

(b) NA Control treatments not included in statistical analysis.

TABLE 3.9. ANOVA Results for the 10-Day Solid-Phase Flow-Through Test with $N$. caecoides

\begin{tabular}{|c|c|c|c|c|c|}
\hline $\begin{array}{l}\text { Source } \\
\text { Variation }\end{array}$ & $\begin{array}{l}\text { Sum of } \\
\text { Squares }\end{array}$ & d.f. & $\begin{array}{l}\text { Mean } \\
\text { Square }\end{array}$ & E-Ratio & $\begin{array}{c}\text { Significance } \\
\text { Leyel }\end{array}$ \\
\hline $\begin{array}{l}\text { Between Groups } \\
\text { Within Groups }\end{array}$ & $\begin{array}{l}0.817 \\
0.908\end{array}$ & $\begin{array}{l}11 \\
48\end{array}$ & $\begin{array}{l}0.074 \\
0.019\end{array}$ & 3.924 & 0.0004 \\
\hline
\end{tabular}

(a) d.f. Degrees of freedom. 
IABLE 3.10. Results of the 28-Day Solid-Phase Flow-Through Test with $M$. nasuta and $N$. caecoides

$\begin{array}{lcc}\begin{array}{l}\text { Sediment } \\ \text { Ireatment }\end{array} & \begin{array}{c}\text { Mean Percent } \\ \text { Survival of M. nasuta }\end{array} & \begin{array}{c}\text { Mean Percent } \\ \text { Survival of } N \text {. caecoides }\end{array} \\ \text { COMP I } & 92.0 & 89.0 \\ \text { COMP II } & 89.6 & 93.5 \\ \text { COMP III } & 92.8 & 88.5 \\ \text { TC-5 Upper Comp } & 84.0 & 85.0 \\ \text { COMP IV } & 84.8 & 77.0 \\ \text { COMP V } & 90.4 & 90.5 \\ \text { COMP VI } & 87.2 & 96.5 \\ \text { R-AC } & 91.2 & 92.0 \\ \text { R-AM } & 89.6 & 94.5 \\ \text { R-BF } & 88.8 & 82.5 \\ \text { R-OS } & 91.2 & 97.5 \\ \text { R-PF } & 89.6 & 97.5 \\ \text { C-SB } & 95.0 & 95.0 \\ \text { C-NE } & 90.0 & 95.0\end{array}$

\subsubsection{0-Day Static Solid-Phase Test with $R$. abronius}

Results of the 10-day $R$. abronius test were validated by a $100 \%$ mean survival in the control treatment C-WB. Mean percent survival for the 10-day $R$. abronius test ranged from $58 \%$ in COMP III to $100 \%$ in C-WB. The ANOVA and Dunn's Test results (Tables 3.11 and 3.12) showed a significant difference in COMP III. COMP III had $>10 \%$ reduction in percent survival when compared to the reference treatments R-BF and R-AM.

The results of the $R$. abronius reference toxicant test using a $C d$ standard were analyzed using the Trimmed Spearman-Karber method (Section 2.5.3). The LC50 was estimated at 1.09 $\mathrm{mg} / \mathrm{L}$, indicating that a $50 \%$ decrease in survival was expected at that concentration. This LC50 is similar to those estimated during previous tests, suggesting that the $R$. abronius used for Richmond Harbor testing showed a similar sensitivity to $\mathrm{Cd}$.

\subsubsection{6-h Static Suspended-Particulate-Phase Test with C. stigmaeus}

The 96-h $C$. stigmaeus SPP test was validated by greater than $90 \%$ mean survival in control treatments (Table 3.13). Greater than $90 \%$ mean survival was found in all $100 \%$ SPP treatments except for the sediment from TC-5 Upper Comp, which averaged $23 \%$ survival. The C. stigmaeus used in TC-5 Upper Comp were preserved in the event that a histopathological 
IABLE 3.11. Results of Dunn's Test for the 10-Day Solid-Phase Static Test with $R$. abronius

\begin{tabular}{lcc}
$\begin{array}{l}\text { Sediment } \\
\text { Ireatment }\end{array}$ & $\begin{array}{c}\text { Mean Percent } \\
\text { Survival of } R_{\text {, abronius }}\end{array}$ & $\begin{array}{c}\text { Statistical } \\
\text { Grouping }\end{array}$ \\
\cline { 2 - 3 } COMP III & 58.0 & \\
R-OS & 66.0 & $\mathrm{~A}$ \\
R-AC & 75.0 & $\mathrm{AB}$ \\
COMP IV & 76.0 & $\mathrm{AB}$ \\
COMPI & 77.0 & $\mathrm{AB}$ \\
COMP II & 80.0 & $\mathrm{AB}$ \\
R-BF & 82.0 & $\mathrm{AB}$ \\
TC-5 Upper Comp & 82.0 & $\mathrm{AB}$ \\
COMP VI & 83.0 & $\mathrm{AB}$ \\
COMP V & 87.0 & $\mathrm{AB}$ \\
R-BF & 88.0 & $\mathrm{AB}$ \\
R-AM & 90.0 & $\mathrm{~B}$ \\
C-SB & 88.0 & $\mathrm{~B}$ \\
C-WB & 100.0 & $\mathrm{NA}(\mathrm{a})$ \\
& & $\mathrm{NA}$
\end{tabular}

(a) NA Not applicable.

IABLE 3.12. ANOVA Results for the 10-Day Solid-Phase Static Test with $R$. abronius

$\begin{array}{llllll}\begin{array}{l}\text { Source } \\ \text { Variation }\end{array} & \begin{array}{c}\text { Sum of } \\ \text { Squares }\end{array} & \text { d.f. }{ }^{\text {(a) }} & \begin{array}{c}\text { Mean } \\ \text { Square }\end{array} & \text { E-Batio } & \begin{array}{l}\text { Significance } \\ \text { Level }\end{array} \\ \text { Between Groups } & 0.719 & 11 & 0.065 & 2.451 & 0.0161 \\ \text { Within Groups } & 1.281 & 48 & 0.027 & & \end{array}$

(a) d.t. Degrees of freedom 
IABLE 3.13. Percent Survival Results for the 96-h Static Suspended-Particulate-Phase Test with $C$. stigmaeus

\begin{tabular}{|c|c|c|}
\hline $\begin{array}{l}\text { Sediment } \\
\text { Ireatment }\end{array}$ & $\begin{array}{c}\% \text { SPP } \\
\text { Concentration }\end{array}$ & $\begin{array}{l}\text { Mean } \\
\text { Percent } \\
\text { Survival }\end{array}$ \\
\hline $\begin{array}{l}\text { COMP I } \\
\text { COMP I } \\
\text { COMP } 1 \\
\text { COMP I }\end{array}$ & $\begin{array}{r}0 \\
10 \\
50 \\
100\end{array}$ & $\begin{array}{l}95 \\
98 \\
95 \\
98\end{array}$ \\
\hline $\begin{array}{l}\text { COMP II } \\
\text { COMP II } \\
\text { COMP II } \\
\text { COMP II }\end{array}$ & $\begin{array}{r}0 \\
10 \\
50 \\
100\end{array}$ & $\begin{array}{l}95 \\
95 \\
93 \\
93\end{array}$ \\
\hline $\begin{array}{l}\text { COMP III } \\
\text { COMP III } \\
\text { COMP III } \\
\text { COMP III }\end{array}$ & $\begin{array}{r}0 \\
10 \\
50 \\
100\end{array}$ & $\begin{array}{r}93 \\
98 \\
95 \\
100\end{array}$ \\
\hline $\begin{array}{l}\text { TC-5 Upper Comp } \\
\text { TC-5 Upper Comp } \\
\text { TC-5 Upper Comp } \\
\text { TC-5 Upper Comp }\end{array}$ & $\begin{array}{r}0 \\
10 \\
50 \\
100\end{array}$ & $\begin{array}{r}100 \\
100 \\
50 \\
23\end{array}$ \\
\hline $\begin{array}{l}\text { COMP IV } \\
\text { COMP IV } \\
\text { COMP IV } \\
\text { COMP IV }\end{array}$ & $\begin{array}{r}0 \\
10 \\
50 \\
100\end{array}$ & $\begin{array}{l}98 \\
90 \\
95 \\
90\end{array}$ \\
\hline $\begin{array}{l}\text { COMP V } \\
\text { COMP V } \\
\text { COMP V } \\
\text { COMP V }\end{array}$ & $\begin{array}{r}0 \\
10 \\
50 \\
100\end{array}$ & $\begin{array}{l}98 \\
93 \\
98 \\
93\end{array}$ \\
\hline $\begin{array}{l}\text { COMP VI } \\
\text { COMP VI } \\
\text { COMP VI } \\
\text { COMP VI }\end{array}$ & $\begin{array}{r}0 \\
10 \\
50 \\
100\end{array}$ & $\begin{array}{l}95 \\
95 \\
98 \\
98\end{array}$ \\
\hline
\end{tabular}


examination will be necessary. Water quality data parameters (Appendix G, Table G.3) remained within the targeted range during testing. Table 3.14 presents the t-test comparisons of control treatments to $100 \%$ SPP for each sediment, and shows that only one composite (TC-5 Upper Comp) had a significant difference in survival between the $0 \%$ and $100 \%$ SPP tests. Using the Trimmed Spearman-Karber method, an LC50 of 75.4\% SPP was calculated for this test treatment.

A reference toxicant test conducted with $\mathrm{Cu}$ was run concurrently with the SPP treatments. Results are p.esented in Appendix G. An LC50 value of $1.23 \mathrm{mg} / \mathrm{L} \mathrm{Cu}$ was calculated using the Trimmed Spearman-Karber method and is comparable to other tests that have been conducted with $C$. stigmaeus and $\mathrm{Cu}$ at the MSL.

\subsubsection{6-h Static Suspended-Particulate-Phase Test with H. sculpta}

The 96-h H. sculpta SPP test was validated by greater than $90 \%$ mean survival in all control treatments (0\% SPP) (Table 3.15). Survival in all 100\% SPP treatments remained at or above $85 \%$. Water quality data (Appendix $\mathrm{H}$, Table H.3) show that all measured parameters remained within acceptable ranges during the test. Table 3.16 presents $t$-test and $L C 50$ values for this test and shows that survival between the control and $100 \%$ SPP dilutions was not statistically significantly different for any of the test treatments. Because of the high survival in all SPP treatments, LC50 values were not calculable and were reported as greater than $100 \%$ SPP.

IABLE 3.14. T-Test and LC50 Determinations for the 96-h Static Suspended-ParticulatePhase Test with $C$. stigmaeus

\begin{tabular}{|c|c|c|c|c|c|}
\hline $\begin{array}{l}\text { Sediment } \\
\text { Ireatment }\end{array}$ & $\begin{array}{l}\text { Table } \\
\text { t-value }\end{array}$ & d.f. $^{(a)}$ & $\begin{array}{c}\text { Calculated } \\
\text { t-yalue }\end{array}$ & Significant(b) & $\begin{array}{l}\text { LC50 as } \\
\text { PercentSPP }\end{array}$ \\
\hline COMP I & 2.447 & 6 & $N A^{(c)}$ & NO & $>100^{(d)}$ \\
\hline COMP II & 2.447 & 6 & 0.447 & No & $>100$ \\
\hline COMP III & 2.447 & 6 & NA & NO & $>100$ \\
\hline TC-5 Upper Comp & 2.447 & 6 & 10.333 & YES & 75.4 \\
\hline COMP IV & 2.447 & 6 & 1.567 & NO & $>100$ \\
\hline COMP V & 2.447 & 6 & 0.926 & NO & $>100$ \\
\hline COMP VI & 2.447 & 6 & NA & NO & $>100$ \\
\hline
\end{tabular}
(a) d.f. Degrees of freedom.
(b) $\alpha=0.05$ for two sample t-test comparison of $0 \%$ and $100 \%$ SPP.
(c) NA Not applicable.
(d) Test organism survival was $>50 \%$ in all concentrations. 
IABLE 3.15. Percent Survival Results for the 96-h Static Suspended-Particulate-Phase Test with H. sculpta

\begin{tabular}{|c|c|c|}
\hline $\begin{array}{l}\text { Sediment } \\
\text { Ireatment }\end{array}$ & $\begin{array}{c}\% \text { SPP } \\
\text { Concentration }\end{array}$ & $\begin{array}{l}\text { Mean } \\
\text { Percent } \\
\text { Survival }\end{array}$ \\
\hline $\begin{array}{l}\text { COMP I } \\
\text { COMP I } \\
\text { COMP I } \\
\text { COMP I }\end{array}$ & $\begin{array}{r}0 \\
10 \\
50 \\
100\end{array}$ & $\begin{array}{r}100 \\
90 \\
100 \\
98\end{array}$ \\
\hline $\begin{array}{l}\text { COMP \| } \\
\text { COMP \| } \\
\text { COMP \| } \\
\text { COMP \| }\end{array}$ & $\begin{array}{r}0 \\
10 \\
50 \\
100\end{array}$ & $\begin{array}{r}100 \\
100 \\
75 \\
95\end{array}$ \\
\hline $\begin{array}{l}\text { COMP III } \\
\text { COMP III } \\
\text { COMP III } \\
\text { COMP III }\end{array}$ & $\begin{array}{r}0 \\
10 \\
50 \\
100\end{array}$ & $\begin{array}{r}100 \\
95 \\
90 \\
98\end{array}$ \\
\hline $\begin{array}{l}\text { TC-5 Upper Comp } \\
\text { TC-5 Upper Comp } \\
\text { TC-5 Upper Comp } \\
\text { TC-5 Upper Comp }\end{array}$ & $\begin{array}{r}0 \\
10 \\
50 \\
100\end{array}$ & $\begin{array}{r}98 \\
100 \\
98 \\
95\end{array}$ \\
\hline $\begin{array}{l}\text { COMP IV } \\
\text { COMP IV } \\
\text { COMP IV } \\
\text { COMP IV }\end{array}$ & $\begin{array}{r}0 \\
10 \\
50 \\
100\end{array}$ & $\begin{array}{r}93 \\
100 \\
98 \\
98\end{array}$ \\
\hline $\begin{array}{l}\text { COMP V } \\
\text { COMP V } \\
\text { COMP V } \\
\text { COMP V }\end{array}$ & $\begin{array}{r}0 \\
10 \\
50 \\
100\end{array}$ & $\begin{array}{l}93 \\
98 \\
98 \\
85\end{array}$ \\
\hline $\begin{array}{l}\text { COMP VI } \\
\text { COMP VI } \\
\text { COMP VI } \\
\text { COMP VI }\end{array}$ & $\begin{array}{r}0 \\
10 \\
50 \\
100\end{array}$ & $\begin{array}{l}95 \\
88 \\
90 \\
90\end{array}$ \\
\hline
\end{tabular}


IABLE3.16. T-Test and LC50 Determinations for the 96-h Static Suspended-ParticulatePhase Test with $H$. sculpta

\begin{tabular}{|c|c|c|c|c|c|}
\hline $\begin{array}{l}\text { Sediment } \\
\text { Ireatment }\end{array}$ & $\begin{array}{c}\text { Table } \\
\text { t-value }\end{array}$ & d.fer & $\begin{array}{c}\text { Calculated } \\
\text { t-value }\end{array}$ & Significant(b) & $\begin{array}{l}\text { LC50 as } \\
\text { Percent SPP }\end{array}$ \\
\hline COMP I & 2.447 & 6 & 1.000 & NO & $>100(9)$ \\
\hline COMP II & 2.447 & 6 & 1.732 & NO & $>100$ \\
\hline COMP III & 2.447 & 6 & 1.000 & NO & $>100$ \\
\hline TC-5 Upper Comp & 2.447 & 6 & 0.447 & NO & $>100$ \\
\hline COMP IV & 2.447 & 6 & $N^{(d)}$ & NO & $>100$ \\
\hline COMP V & 2.447 & 6 & 0.701 & NO & $>100$ \\
\hline COMP VI & 2.447 & 6 & NA & NO & $>100$ \\
\hline
\end{tabular}

(a) d.f. Degrees of freedom.

(b) $\alpha=0.05$ for two sample t-test comparison of 0 and $100 \%$ SPP.

(c) Test organism survival was $>50 \%$ in alt concentrations.

(d) NA Not applicable.

The H. sculpta reference toxicant test using zinc chloride $\left(\mathrm{ZnCl}_{2}\right)$ was analyzed using the Trimmed Spearman-Karber method. The LC50 was estimated at $0.19 \mathrm{mg} / \mathrm{L}$ of $\mathrm{Zn}$, meaning that a $50 \%$ decrease in survival could be expected at this concentration. This value is comparable to previous LC50 values determined for this species with $\mathrm{Zn}$ as a reference toxicant.

\subsubsection{8-h_Static Suspended-Particulate-Phase Test with Laval $M$, edulis}

Water quality data for the bivalve SPP bioaccumulation test (Appendix I, Table I.2) show that all measured parameters remained within the acceptable range during testing. The results presented in Table 3.17 display the mean percent survival and the mean percent nomal development for all treatments. Mean survival was greater than $84 \%$ in all control treatments. Table 3.18 presents the results of the independent, two sample t-tests comparing the survivals in the $0 \%$ and $100 \%$ SPP concentrations. Only one test treatment, COMP I, produced a significant difference in survival in the $100 \%$ SPP $(72.6 \%)$. Because of the high survival in all SPP treatments, LC50 values were not calculable and are reported as greater than $100 \%$ SPP.

The mean percent of live larvae with fully developed shells was generally between $50 \%$ and $65 \%$ for al concentrations of the SPP treatments except for TC-5 Upper Comp, which was $2.2 \%$ (Table 3.17). The remainder of larvae were normal, but were incompletely developed, probably caused by early termination of the test. A criterion for normal versus abnormal development is not provided for mussels in ASTM (1978). The results of this test did meet the crite- 
IABLE 3.17. Results of the 48-h Static Suspended-Particulate-Phase Test with $M$. edulis

\begin{tabular}{|c|c|c|c|}
\hline $\begin{array}{l}\text { Sediment } \\
\text { Ireatment }\end{array}$ & $\begin{array}{c}\% \text { SPP } \\
\text { concentration }\end{array}$ & $\begin{array}{l}\text { Mean } \\
\text { Percent } \\
\text { Sunvival }\end{array}$ & $\begin{array}{c}\text { Mean } \\
\text { Percent } \\
\text { Eully Developed }\end{array}$ \\
\hline $\begin{array}{l}\text { COMP } 1 \\
\text { COMP } 1 \\
\text { COMP } 1 \\
\text { COMP } 1\end{array}$ & $\begin{array}{r}0 \\
10 \\
50 \\
100\end{array}$ & $\begin{array}{l}96.9 \\
83.9 \\
75.0 \\
72.6\end{array}$ & $\begin{array}{l}64.5 \\
56.4 \\
55.1 \\
49.7\end{array}$ \\
\hline $\begin{array}{l}\text { COMP II } \\
\text { COMP II } \\
\text { COMP \| } \\
\text { COMP II }\end{array}$ & $\begin{array}{r}0 \\
10 \\
50 \\
100\end{array}$ & $\begin{array}{l}84.4 \\
82.1 \\
68.4 \\
95.7\end{array}$ & $\begin{array}{l}60.9 \\
60.3 \\
52.9 \\
54.6\end{array}$ \\
\hline $\begin{array}{l}\text { COMP III } \\
\text { COMP III } \\
\text { COMP III } \\
\text { COMP III }\end{array}$ & $\begin{array}{r}0 \\
10 \\
50 \\
100\end{array}$ & $\begin{array}{l}92.0 \\
78.4 \\
94.7 \\
83.5\end{array}$ & $\begin{array}{l}61.7 \\
56.6 \\
65.3 \\
54.7\end{array}$ \\
\hline $\begin{array}{l}\text { TC-5 Upper Comp } \\
\text { TC-5 Upper Comp } \\
\text { TC-5 Upper Comp } \\
\text { TC-5 Upper Comp }\end{array}$ & $\begin{array}{r}0 \\
10 \\
50 \\
100\end{array}$ & $\begin{array}{l}93.8^{(2)} \\
85.5 \\
74.7 \\
76.0\end{array}$ & $\begin{array}{l}64.0^{(b)} \\
54.8 \\
48.4 \\
2.2\end{array}$ \\
\hline $\begin{array}{l}\text { COMP IV } \\
\text { COMP IV } \\
\text { COMP IV } \\
\text { COMP IV }\end{array}$ & $\begin{array}{r}0 \\
10 \\
50 \\
100\end{array}$ & $\begin{array}{l}87.2 \\
88.4 \\
82.7 \\
85.2\end{array}$ & $\begin{array}{l}60.3 \\
58.9 \\
55.9 \\
54.9\end{array}$ \\
\hline $\begin{array}{l}\text { COMP V } \\
\text { COMP V } \\
\text { COMP V } \\
\text { COMP V }\end{array}$ & $\begin{array}{r}0 \\
10 \\
50 \\
100\end{array}$ & $\begin{array}{l}89.1 \\
76.8 \\
83.0 \\
84.6\end{array}$ & $\begin{array}{l}59.0 \\
56.7 \\
56.0 \\
57.9\end{array}$ \\
\hline $\begin{array}{l}\text { COMP VI } \\
\text { COMP VI } \\
\text { COMP VI } \\
\text { COMP VI }\end{array}$ & $\begin{array}{r}0 \\
10 \\
50 \\
100\end{array}$ & $\begin{array}{l}92.6 \\
82.9 \\
80.3 \\
78.7\end{array}$ & $\begin{array}{l}65.9 \\
56.1 \\
57.7 \\
49.3\end{array}$ \\
\hline
\end{tabular}

(a) Used mean control survival of COMP I, COMP III, and COMP VI to estimate control survival for TC-5 Upper Comp.

(b) Used mean control of fully developed larvae of COMP I, COMP III, and COMP VI to estimate control of fully developed larvae for TC-5 Upper Comp. 
IABLE 3.18. T-Test and LC50 Determinations for the 48-h Static SuspendedParticulate-Phase Test Based on Percent Survival with $M$. edulis

$\begin{array}{lccccc}\begin{array}{l}\text { Sediment } \\ \text { Ireatment }\end{array} & \begin{array}{c}\text { Table } \\ \text { t-value }\end{array} & \text { d.f. }^{(\text {a) }} & \begin{array}{c}\text { Calculated } \\ \text { t-value }\end{array} & \text { Significant(b) } & \begin{array}{c}\text { LC50 as } \\ \text { Eercent SPP }\end{array} \\ \text { COMP I } & 2.571 & 5 & 4.202 & \text { YES } & >100^{(c)} \\ \text { COMP II } & 2.571 & 5 & \text { NA }^{(d)} & \text { NO } & >100 \\ \text { COMP III } & 2.571 & 5 & 1.419 & \text { NO } & >100 \\ \text { TC-5 Upper Comp } & 2.571 & 5 & 1.543^{(0)} & \text { NO } & >100 \\ \text { COMP IV } & 2.447 & 6 & 0.222 & \text { NO } & >100 \\ \text { COMP V } & 2.447 & 6 & 0.319 & \text { NO } & >100 \\ \text { COMP VI } & 2.447 & 6 & 2.778 & \text { NO } & >100\end{array}$
(a) d.f. Degree of freedom.
(b) $\alpha=0.05$ for two sample t-test comparison of $0 \%$ and $100 \%$ SPP.
(c) Test organism survival was $>50 \%$ in all concentrations.
(d) NA Not applicable.
(e) Used mean control survival of COMP I, COMP III, COMP VI to estimate control survival for TC-5 Upper Comp.

IABLE3.19. T-Test and EC50 Determinations for the 48-h Static SuspendedParticulate-Phase Test Based on the Proportion of Normal $M$. edulis Larvae

\begin{tabular}{|c|c|c|c|c|c|}
\hline $\begin{array}{l}\text { Sediment } \\
\text { Ireatment }\end{array}$ & $\begin{array}{l}\text { Table } \\
\text { t-value }\end{array}$ & d.f. $f^{(a)}$ & $\begin{array}{c}\text { Calculated } \\
\text { t-value }\end{array}$ & Significance ${ }^{(b)}$ & $\begin{array}{l}\text { LC50 as } \\
\text { Percent SPP }\end{array}$ \\
\hline COMP I & 2.571 & 5 & 4.416 & YES & $>100^{(c)}$ \\
\hline COMP II & 2.571 & 5 & 1.058 & NO & $>100$ \\
\hline COMP ill & 2.571 & 5 & 1.853 & NO & $>100$ \\
\hline TC-5 Upper Comp ${ }^{(d)}$ & 2.571 & 5 & 46.794 & YES & $>57.7$ \\
\hline COMP IV & 2.447 & 6 & 1.031 & NO & $>100$ \\
\hline COMP V & 2.447 & 6 & 0.280 & NO & $>100$ \\
\hline COMP VI & 2.447 & 6 & 5.200 & YES & $>100$ \\
\hline
\end{tabular}

(a) d.t. Degrees of freedom.

(b) $\alpha=0.05$ for two sample t-test comparison of $0 \%$ and $100 \%$ SPP.

(c) Normal development was $>50 \%$ in all concentrations relative to controls.

(d) Used mean control of fully developed larvae of COMP I, COMP III, and COMP VI to estimate control of fully developed larvae for TC-5 Upper Comp. 
rion of $60 \%$ normal development for hard-shelled clams. Table 3.19 shows that two treatments (COMP I and COMP VI) produced significant differences in percent of fully developed larval between the $0 \%$ and $100 \%$ SPP concentrations. No EC50 values were calculable because of the high percent normal development in the $100 \%$ SPP concentrations relative to the controls. The test treatment TC-5 Upper Comp produced the lowest percentage (2.2) of fully developed larvae and generated an EC50 of $57.7 \%$.

A reference toxicant test was also conducted using M. edulis larvae. An LC50 value of $14.5 \mathrm{mg} / \mathrm{L}$ for Cu reduced the percent survival of larvae to $50 \%$ compared to controls calculated by the Trimmed Spearman-Karber method. Using the same method, an EC50 value of 6.60 $\mathrm{mg} / \mathrm{L} \mathrm{Cu}$ was determined based on the reduction of normal larval development in the Cu solutions compared to controls. These values are within the range of LC50s and EC50s estimated during other tests at the MSL, indicating that the larvae tested showed comparable sensitivity.

\subsection{IISSUE BIOACCUMULATION}

M. nasuta and $N$. caecoides were tested in a 28-day solid phase test using COMPs I through VI and TC-5 Upper Comp to evaluate the bioaccumulation potential of these sediment treatments. The tissue of $M$. nasuta and $N$. caecoides were analyzed for PAHs, pesticides, PCBs, metals, and butyltins. Complete tissue chemistry results in wet and dry weight, quality control data, and quality control summaries for these tests are presented in Appendixes $\mathrm{J}$ and $K$. The tissue chemistry results, summanized in the following section, were used in a statistical evaluation that consisted of Dunn's Test for comparison of all means of test treatments relative to reference treatments (Appendixes $L$ and $M$ ). Dunn's Test is a conservative model that uses an experiment-wise error rate (0.1), allowing comparisons of all possible treatment combinations and denotes significant differences among test and reference treatments. During statistical analysis, test treatments were omitted from statistical comparisons if all replicate values for a compound were undetected. Reference treatments were used regardless of whether the values were detected or undetected. When needed, the detection limit value was used in place of -undetected values.

\subsubsection{Polynuclear Aromatic Hydrocarbon Bioaccumulation in M, nasuta}

Tables 3.20 and 3.21 present the mean concentrations of LPAH and HPAH compounds for test, reference, and control treatments as well as background tissue information. The back- 
IABLE 3.20. Mean Low Molecular Weight PAH Concentrations in the Tissues of $M$. nasuta

Sediment

Ireatment

COMP I

COMP II

COMP III

TC-5 Upper Comp

COMP IV

COMP V

COMP VI

R-AC

R-AM

R-BF

R-OS

R-PF

C-NE

C-SB

Background

\begin{tabular}{c}
\hline Napthalene \\
13.14 \\
12.72 \\
11.41 \\
20.96 \\
13.96 \\
15.27 \\
21.09
\end{tabular}

15.50

15.55

15.69

12.43

13.35

12.15

10.49

9.57 (concentrations in $1 \mathrm{~g} / \mathrm{kg}$ dry weight)

Eluorene Ehenanthrene Anthracene

5.12

$6.17 \mathrm{UJ}(\mathrm{b})$

$4.19 \mathrm{~J}$

6.54

4.75

5.46

$5.93 \mathrm{UJ}$

11.70

7.26

5.16

$5.04 \mathrm{UJ}$

5.30

15.08

12.65

10.14

27.88

9.98

16.48

16.02

$3.54 \mathrm{~J}^{(\text {(a) }}$

$2.42 \mathrm{~J}$

$3.20 \mathrm{UJ}$

6.11

$4.75 \mathrm{UJ}$

4.83

5.09

111.96

46.04

14.02

10.89

11.17

45.51

18.15

3.39

$2.61 \mathrm{UJ}$

$3.55 \mathrm{UJ}$

$4.70 \mathrm{~J}$

15.78

10.43

14.91
$1.19 \mathrm{~J}$

$3.73 \mathrm{UJ}$

$3.72 \mathrm{UJ}$

(a) J Analyte detected below method detection limit (MDL), but above instrument detection limit.

(b) U Analyte was not present above the level of associated value.

ground tissues were taken from $M$. nasuta that were kept in clean sediment and then allowed to depurate prior to subsampling the tissue for chemical analysis. These tissues were chemically analyzed to determine if $M$. nasuta were exposed to contaminants prior to testing.

Resuits of Dunn's Test for LPAH and HPAH are summarized in Table 3.22 and 3.23, respectively. The LPAH table indicates that test treatment TC-5 Upper Comp had significantly higher levels of phenanthrene in tissues of $M$. nasuta relative to R-OS, R-PF, and R-BF. TC-5 Upper Comp also produced significant elevations of anthracene in tissues of $M$. nasuta relative to R-OS.

Examination of the results for the HPAH statistical evaluation produced six observations: 1) none of the $M$. nasuta tissues exposed to the test treatments had concentrations of HPAHs elevated above R-AC or R-AM, 2) five test treatments (COMPS I, II, V, VI, and TC-5 Upper Comp) had significantly higher tissue concentrations of fluoranthene, pyrene, chrysene, benzo(b)-fluoranthene, benzo(k)fluoranthene, and benzo(a)pyrene compared to R-OS and $R-P F, 3$ ) in addition to these compounds, pyrene was elevated in three test treatments when 
IABLE 3.21. Mean High Molecular Weight PAH Concentrations in the Tissues of M. nasuta

\begin{tabular}{|c|c|c|c|c|c|c|c|c|c|}
\hline $\begin{array}{l}\text { Sediment } \\
\text { Ireatment }\end{array}$ & $\begin{array}{c}\text { Fluor- } \\
\text { anthene }\end{array}$ & Pyrene & $\begin{array}{c}\text { Benzo(a) } \\
\text { anthracene }\end{array}$ & Chrysene & $\begin{array}{l}\text { Benzo(b) } \\
\text { fluor- } \\
\text { anthene }\end{array}$ & $\begin{array}{l}\text { Benzo(k) } \\
\text { fluor } \\
\text { anthene }\end{array}$ & $\begin{array}{c}\text { Benzo(a) } \\
\text { pyrene }\end{array}$ & $\begin{array}{r}\text { Indeno } \\
(1,2,3-c) \\
\text { pyrene }\end{array}$ & $\begin{array}{c}\text { Benzo } \\
\text { (g,h,i) } \\
\text { perylene }\end{array}$ \\
\hline $\begin{array}{l}\text { COMP I } \\
\text { COMP II } \\
\text { COMP III } \\
\text { TC-5 Upper } \\
\text { COMP IV } \\
\text { COMP V } \\
\text { COMP VI }\end{array}$ & $\begin{array}{r}36.02 \\
25.42 \\
11.38 \\
\text { np } 154.17 \\
8.00 \\
41.63 \\
34.97\end{array}$ & $\begin{array}{r}61.42 \\
48.89 \\
10.51 \\
267.23 \\
5.55 \\
146.49 \\
149.63\end{array}$ & $\begin{array}{c}10.84 \\
6.99 \\
3.52 \mathrm{UJ} \\
44.94 \\
5.47 \mathrm{UJ} \\
18.76 \\
17.54\end{array}$ & $\begin{array}{r}15.97 \\
11.70 \\
4.47 \\
69.35 \\
4.36 \\
26.50 \\
24.73\end{array}$ & $\begin{array}{c}24.51 \\
21.01 \\
7.52 \mathrm{UJ} \\
80.93 \\
8.00 \mathrm{UJ} \\
57.06 \\
55.03\end{array}$ & $\begin{array}{c}16.15 \\
14.28 \\
4.44 \mathrm{UJ} \\
61.72 \\
6.87 \mathrm{UJ} \\
37.37 \\
38.39\end{array}$ & $\begin{array}{c}15.68 \\
14.57 \\
4.37 \mathrm{UJ} \\
62.08 \\
8.00 \mathrm{U} \\
35.83 \\
34.79\end{array}$ & $\begin{array}{c}9.20 \\
9.00 \\
8.33 \mathrm{U} \\
22.49 \\
9.60 \mathrm{U} \\
14.35 \\
13.35\end{array}$ & $\begin{array}{l}10.98 \\
11.24 U \text { (a) J(b) } \\
9.84 U \\
27.07 \\
13.02 U \\
18.17 \\
16.81\end{array}$ \\
\hline $\begin{array}{l}\text { R-AC } \\
\text { R-AM } \\
\text { R-BF } \\
\text { R-OS } \\
\text { R-PF }\end{array}$ & $\begin{array}{r}1124.66 \\
287.09 \\
45.69 \\
12.31 \\
9.81\end{array}$ & $\begin{array}{r}2614.47 \\
316.09 \\
48.62 \\
8.67 \\
7.62\end{array}$ & $\begin{array}{c}242.06 \\
115.81 \\
12.73 \\
3.86 \mathrm{UJ} \\
6.95 \mathrm{UJ}\end{array}$ & $\begin{array}{r}299.76 \\
182.84 \\
22.25 \\
5.19 \\
3.83\end{array}$ & $\begin{array}{c}327.48 \\
75.95 \\
32.63 \\
4.41 \mathrm{UJ} \\
6.97 \mathrm{UJ}\end{array}$ & $\begin{array}{c}244.02 \\
86.86 \\
17.58 \\
3.66 \mathrm{UJ} \\
6.15 \mathrm{UJ}\end{array}$ & $\begin{array}{c}358.85 \\
105.19 \\
21.31 \\
3.72 \mathrm{UJ} \\
5.91 \mathrm{UJ}\end{array}$ & $\begin{array}{c}102.38 \\
29.82 \\
10.74 \\
5.29 \mathrm{UJ} \\
10.01 \mathrm{U}\end{array}$ & $\begin{array}{c}105.28 \\
30.42 \\
17.30 \\
7.26 \mathrm{UJ} \\
13.58 \mathrm{U}\end{array}$ \\
\hline $\begin{array}{l}\text { C-NE } \\
\text { C-SB } \\
\text { Background }\end{array}$ & $\begin{array}{l}17.00 \\
24.06 \\
70.10\end{array}$ & $\begin{array}{l}10.93 \\
14.18 \\
48.54\end{array}$ & $\begin{array}{l}2.82 \mathrm{~J} \\
2.78 \mathrm{~J} \\
6.29 \mathrm{~J}\end{array}$ & $\begin{array}{r}8.60 \\
6.87 \\
22.06\end{array}$ & $\begin{array}{c}2.68 \mathrm{~J} \\
6.87 \\
10.75\end{array}$ & $\begin{array}{l}1.24 \mathrm{~J} \\
4.23 \\
6.69\end{array}$ & $\begin{array}{l}0.89 \mathrm{~J} \\
6.14 \mathrm{UJ} \\
5.16 \mathrm{UJ}\end{array}$ & $\begin{array}{l}5.28 \mathrm{UJ} \\
8.00 \mathrm{UJ} \\
6.97 \mathrm{UJ}\end{array}$ & $\begin{array}{c}7.29 \mathrm{UJ} \\
10.86 \mathrm{UJ} \\
11.63 \mathrm{U}\end{array}$ \\
\hline
\end{tabular}

(a) $U$ Analyte was not present above the level of associated value.

(b) $\mathrm{J}$ Analyte detected beiow method detection limits (MDL), but above instrument detection limit (IDL). 
IABLE3.22. Low Molecular Weight PAHs in Tissues of M. nasuta That Are Significantly Different from Reference Tissue Concentrations Using Dunn's Test for Comparison of All Means

Sediment Treatment and

Mean Tissue Concentration (1ta/kodry weight).

B-AC

B-AM

B-BE

R-OS

B-PE

Napthalene

15.50

15.55

15.69

12.43

13.35

None are significantly elevated

Eluorene

11.70

7.26

5.16

$5.04 U^{(x)}$ J 501

5.30

None are significantly elevated

Phenanthrene

TC-5 Upper Comp 27.88

Anthracene

TC-5 Upper Comp 6.11
111.96

...(c)

45.51

18.15

3.39

14.02

10.89

11.17

S(4)

$\mathrm{S}$

$\mathrm{S}$

(a) U Analyte was not present above the level of associated value.

(b) J Analyte detected below method detection limits (MDL), but above instrument detection limit (IDL).

(c) - Not significantly elevated $(\alpha=0.1)$.

(d) S Significant $(\alpha=0.1)$.

compared to R-BF, 4) test treatments COMP I, TC-5 Upper Comp, COMP V, and COMP VI showed elevated levels of benzo(a)anthracene relative to R-OS and R-PF, 5) test treatments COMP V, TC-5 Upper Comp, and COMP VI showed elevated levels of pyrene when compared to R-BF, R-OS, and R-PF, and 6) COMP V, VI, and TC-5 Upper Comp had elevated levels of indeno( $(1,2,3-c)$ pyrene and benzo(g,h,i)perylene relative to R-OS. Results of ANOVA and Dunn's Test companing mean tissue concentrations and statistical groupings for individual compounds are presented in Appendix $L$. 
IABLE 3.23. High Molecular Weight PAHs in Tissues of $M$. nasuta That Are Significantly Different from Reference Tissue Concentrations Using Dunn's Test for Comparison of all Means

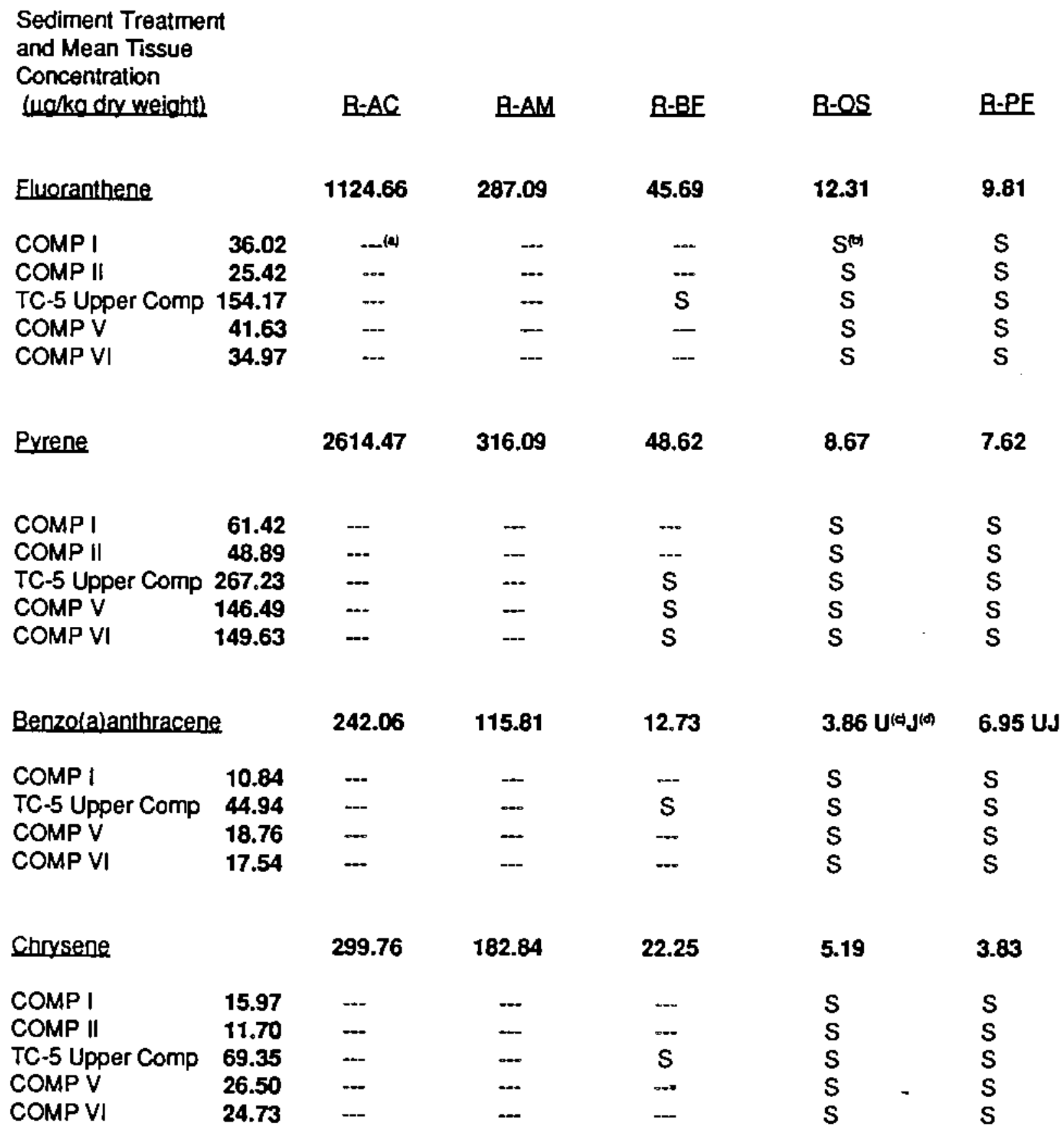


IABLE 3.23. (contd)

Sediment Treatment

and Mean Tissue

Concentration

(ug/kadry weight)

Benzo(b)fluoranthene

B-AC B-AM

B-BE

B-OS

B-PE

327.48

75.95

32.63

4.41 UJ

$6.97 \mathrm{UJ}$

COMP 1

COMP II

TC-5 Upper Comp

COMP V

24.51

21.01

80.93

COMP VI

57.06

55.03

Benzo(k)fluoranthene

244.02

86.86

17.58

$3.66 \mathrm{UJ}$

$6.15 \mathrm{UJ}$

COMP I

COMP II

TC-5 Upper Comp

COMPV

16.15

14.28
61.72

$\begin{array}{cc}-- & \cdots \\ -- & - \\ - & s \\ \cdots & \cdots\end{array}$

COMP VI

37.37

38.39

$\cdots$
$\cdots$
$\cdots$

Benzolajpyrene

$358.85 \quad 105.19$

21.31

3.72 UJ

5.91 UJ

COMP I

COMP II

15.68

14.57

$--$

-..

-..

$\cdots$

TC-5 Upper Comp

62.08

$-$

$\ldots$

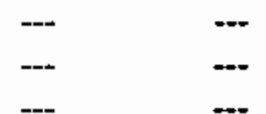

COMP VI

35.83

34.79

Indeno(1.2.3-c)pyrene

102.38

29.82

10.74

$5.29 \mathrm{UJ}$

$10.01 U$

TC-5 Upper Comp

COMP V

22.49

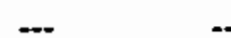

$S$

-..

$\mathrm{S}$

COMP VI

13.35

$-\cdots$

$-$

$\mathrm{S}$

$\mathrm{S}$

$\mathrm{S}$

$\mathrm{S}$

Benzo(ahil)erylene

105.28

30.42

17.30

$7.26 \mathrm{UJ}$

$13.58 \mathrm{U}$

TC-5 Upper Comp
COMP V

COMP VI

27.07

18.17
16.81

$\begin{array}{ll}-- & - \\ \cdots & \cdots \\ \cdots & \cdots\end{array}$

$\stackrel{S}{S}$

(a) -.. Not significantly elevated $(\alpha=0.1)$.

(b) S Significant $(\alpha=0.1)$.

(c) U Analyte was not present above the level of associated value.

(d) J Analyte detected below method detection limits (MDL), but above instrument detection limit (IDL). 
The QAVC requirements were met for the majority of PAHs analyzed in $M$. nasuta tissues. The overall results of QAQC results indicate that these data are acceptable for use in analysis. A detailed QAVC summary is presented in Appendix J.

\subsubsection{Pesticide and PCB Bioaccumulation in $M$, nasuta}

Chlorinated pesticide and PCB mean tissue concentrations are presented in Table 3.24. Based on detectable or estimated concentrations, 8 of the 18 pesticide compounds and 1 PCB (aroclor 1254) were used in a statistical analysis. Table 3.25 shows the results of Dunn's $\because \epsilon s t$. Except for COMP IV, pesticide levels of 4,4'-DDD and 4,4'-DDE in tissues of $M$. nasuta test treatments were all statistically significant when compared to at least one reference treatment. COMPs $V$ and $V I$ were significantly higher than all reference treatments for 4,4'-DOD and 4,4'DDE, and COMP VI was significantly higher than R-AM and R-BF for dieldrin. Alpha, delta, and gamma BHC, 4,4'-DDT and endosulfan II were not statistically different between sediment and reference treatments. Arocior 1254 concentrations in the tissues of $M$. nasuta test treatments showed significant differences when compared to reference treatments; six test treatments were significantly higher than at least two reference treatments (R-OS and R-PF). Complete $M$. nasuta tissue chemistry data in both wet and dry weight pesticide and $\mathrm{PCB}$ concentrations, quality control data, and quality control summaries are contained in Appendix J.

The QAQC requirements were met for the majority of pesticides and PCBs analyzed. The results of QAOC evaluations show that these data are acceptable for use in analysis. A detailed QAQC summary is presented in Appendix $\mathrm{J}$.

\subsubsection{Metals Bioaccumulation in $M$. nasuta}

Mean metals concentrations in the tissues of $M$. nasuta, expressed in $\mathrm{mg} / \mathrm{kg}$ dry weight, are presented in Table 3.26. This table also shows the ratio or fold factor of the lowest metals concentrations to the highest concentrations for all sediment treatments (including control and background). These ratios ranged from 1.2 to 2.6 for each of the 10 metals evaluated. All of the metals concentrations were detectable and were used in the statistical analysis.

The results of Dunn's Test are summarized in Table 3.27. Lead was the only metal that was statistically significantly different in comparison to the reference treatments. Test treatments TC-5 Upper Comp, COMP V, and COMP VI had significantly higher lead concentrations when compared to the reference treatments R-OS and R-PF. 
IABLE 3.24. Mean Pesticide and PCB Concentrations in the Tissues of $M$. nasuta

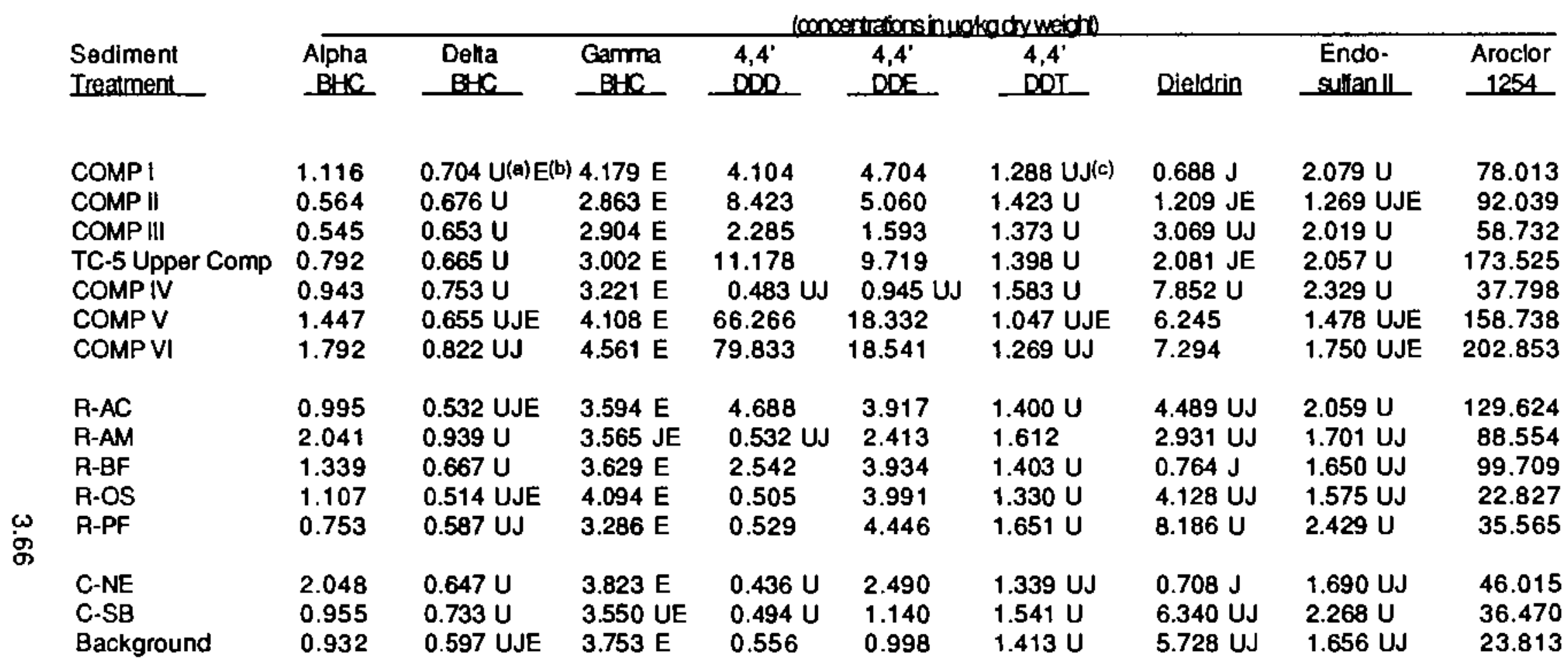

(a) U The analyte was not present above the level of associated value.

(b) $E$ Value is an estimate; analyte not detected on confirmation column.

(c) J Analyte detected below method detection limits (MDL), but above instrument detection limit (IDL). 
IABLE 3.25. Pesticides and PCBs in Tissues of $M$. nasuta That Are Significantly Different from Reference Tissue Concentrations Using Dunn's Test for Comparison of All Means

Sediment Treatment

and Mean Tissue

Concentration

(mokodry weight)

$-\mathrm{B}-\mathrm{AC}$

B-AM

B-BE B-OS

B-PE

Alpha BHC

0.995

2.041

$1.339 \quad 1.107$

0.753

None are significantly elevated

Delta BHC

$0.532 U^{(a)} J^{(b)} E^{(c)}$

$0.939 \mathrm{U}$

$0.667 U$

0.514 UJE

0.667 UJ

None are significantly elevated

Gamma BHC

$3.594 \mathrm{E}$

$3.565 \mathrm{JE}$

$3.629 \mathrm{E}$

$4.094 \mathrm{E}$

$3.286 \mathrm{E}$

None are significantly elevated

4.4. DDD

COMP I

COMP ॥

COMP III

TC-5 Upper Comp

COMP V

COMP VI

4.4. DDE

COMP I

COMP \|

COMP III

TC-5 Upper Comp

COMP V

COMP VI
4.104

8.423

2.285

11.178

66.266

79.833
4.688

\begin{tabular}{l}
$\cdots$ \\
$\cdots$ \\
$\cdots$ \\
$\cdots$ \\
\hline
\end{tabular}

3.917

4.704

5.060

1.593

9.719

18.332

18.541

4.4. DDI

None are significantly elevated
0.532 UJ

2.542

0.505

0.529

$S^{(0)}$
$S$
$S$
$S$
$S$
$S$

$\cdots$

$\cdots$

...

S

S

S

2.413

3.934

3.991

4.446

S
S
-
S
S
S

--
--
S
S
S

\begin{tabular}{l}
-- \\
\hdashline.- \\
S \\
S
\end{tabular}

\begin{tabular}{l}
$\cdots$ \\
- \\
\hline$S$ \\
S \\
S
\end{tabular}

$1.651 \mathrm{U}$ 
TABLE 3.25. (contd)

Sediment Treatment
and Mean Tissue
Concentration
(mokgon weight)

Dieldrin

COMP V

COMP VI

Endosulfan
B-AC R-AM

$4.489 \mathrm{UJ}$

2.931 UJ

$0.764 \mathrm{~J}$

B-OS

R-PE

B-BE

\subsection{UJ}

$8.186 \mathrm{U}$

S

s

7.294

$2.059 \mathrm{U}$

$1.701 \mathrm{UJ}$

$1.650 \mathrm{UJ}$

$1.575 \mathrm{UJ}$

$2.429 U$

None are significantly elevated

Aroclor 1254

129.624

88.554

99.709

22.827

35.565

COMP I

COMP \|

78.013

92.039

$\cdots$

$--$

$\cdots$

$\cdots$

58.732

--

S

S

$S$

COMP HI

$\begin{array}{lr}\text { TC-5 Upper Comp } 173.525 \\ \text { COMP IV } & \mathbf{3 7 . 7 9 8}\end{array}$

COMP V

158.738

COMP VI

202.853

$\bar{s}$

S

-

s

S

$\begin{array}{ll}S & S \\ S & - \\ S & S \\ S & S\end{array}$

(a) U Analyte was not present above the level of associated value.

(b) I Analyte detected below method detection limits (MDL), but above instrument detection limit (IDL).

(c) E Value is an estimate; analyte not detected on contirmation volume.

(d) - Not significantly elevated $(\alpha=0.1)$.

(e) S Signiticant $(\alpha=0.1$ ).

The QANC requirements were met for the majority of the metals analyzed with the exception of 8 out of 40 replicate comparisons. The results of QAQC evaluations show that these data are acceptable for use in analysis. A detailed QAQC summary is presented in Appendix J.

The results of individual ANOVA and Dunn's Tests for metals are presented in Appendix $L$. These tables show $M$. nasuta metals levels in test treatments relative to the reference treatments. 
IABLE 3.26. Mean Metals Concentrations in the Tissues of $M$. nasuta

\begin{tabular}{|c|c|c|c|c|c|c|c|c|c|c|}
\hline Sediment & & & & & & $\mathrm{N}$ & & & & \\
\hline Ireaiment & $\Delta$ & As & cd & $a$ & Eu & $\mathrm{Ha}$ & $\mathrm{NI}$ & $E b$ & $\underline{\mathrm{Se}}$ & Zn \\
\hline COMP I & 0.457 & 31.6 & 0.168 & 2.44 & 20.26 & 0.086 & 4.17 & 1.67 & 1.75 & 99.8 \\
\hline COMP II & 0.476 & 29.8 & 0.182 & 1.89 & 18.79 & 0.071 & 4.56 & 1.81 & 1.44 & 107.2 \\
\hline COMP ॥॥ & 0.535 & 33.5 & 0.237 & 2.59 & 19.62 & 0.065 & 5.45 & 1.55 & 1.50 & 123.1 \\
\hline TC-5 Upper Comp & 0.234 & 33.2 & 0.265 & 2.51 & 17.90 & 0.102 & 5.41 & 2.13 & 1.53 & 127.4 \\
\hline COMP IV & 0.510 & 29.2 & 0.160 & 2.62 & 18.19 & 0.054 & 5.26 & 1.42 & 1.26 & 104.7 \\
\hline COMP V & 0.351 & 31.5 & 0.223 & 2.24 & 19.25 & 0.105 & 5.57 & 2.14 & 1.75 & 135.1 \\
\hline COMP VI & 0.622 & 30.5 & 0.213 & 2.14 & 21.72 & 0.094 & 5.60 & 2.32 & 1.57 & 122.1 \\
\hline A-AC & 0.468 & 28.4 & 0.194 & 2.38 & 17.54 & 0.065 & 5.13 & 1.84 & 1.76 & 115.9 \\
\hline R-AM & 0.305 & 28. & 0.253 & 2.26 & 17.66. & 0.0 & 4.54 & & 1.67 & 133.0 \\
\hline R-BF & 0.243 & 28.3 & 0.259 & 1.95 & 17.54 & 0.101 & 5.17 & 2.03 & 1.60 & 126.4 \\
\hline R-OS & 0.502 & 27.0 & 0.222 & 2.71 & 14.70 & 0.066 & 5.62 & 1.22 & 1.65 & 96.9 \\
\hline R-PF & 0.363 & 29.1 & 0.338 & 2.96 & 16.45 & 0.076 & 4.83 & 1.20 & 1.43 & 122.0 \\
\hline C-SB & 0.399 & 30.5 & 0.189 & 1.58 & 21.34 & 0.070 & 3.81 & 1.50 & 1.69 & 114.6 \\
\hline C-NE & 0.312 & 30.1 & 0.295 & 1.77 & 19.94 & 0.102 & 4.58 & 1.44 & 1.69 & 134.8 \\
\hline Background & 0.869 & 30.2 & 0.319 & 2.61 & 23.30 & 0.071 & 3.49 & 2.39 & 1.44 & 132.6 \\
\hline Ratto(a) & 2.6 & 1.2 & 2.1 & 1.6 & 1.5 & 1.9 & 1.5 & 1.9 & 1.4 & 1.4 \\
\hline
\end{tabular}

(a) The highest observed value divided by the lowest observed value. 
IABLE 3.27. Metals in Tissues of $M$. nasuta That Are Significantly Different from Reference Tissue Concentrations Using Dunn's Test for Comparison of All Means

Sediment Treatment

and Mean Tissue

Concentration

(mo/kg dry weiaht)

Silver

None are significantly elevated

Arsenic

None are significantly elevated

Cadmium

None are significantly elevated

Chromium

None are significantly elevated

Cepper

None are significantly elevated

Mercury

None are significantly elevated

Nickel

None are significantly elevated

Lead

TC-5 Upper Comp 2.13

COMP V

2.14

COMP VI

2.32

Selenium

None are significantly elevated

Zinc

None are significantly elevated

$\begin{array}{lllll}\text { B-AC } & \text { B-AM } & \text { B-BE } & \text { B-OS } & \text { B-PF } \\ 0.468 & 0.305 & 0.243 & 0.502 & 0.363\end{array}$

28.4

28.7

28.3

27.0

29.1

$\begin{array}{lllll}0.194 & 0.253 & 0.259 & 0.222 & 0.338\end{array}$

$\begin{array}{lllll}2.38 & 2.26 & 1.95 & 2.71 & 2.96\end{array}$

$\begin{array}{lllll}17.54 & 17.66 & 17.54 & 14.70 & 16.45\end{array}$

$\begin{array}{lllll}0.065 & 0.084 & 0.101 & 0.066 & 0.076\end{array}$

5.13

4.54

5.17

5.62

\subsection{3}

1.84

1.62

2.03

1.22

1.20

- (4) - $\quad-$

- $\quad \cdots \quad$ -

$S^{(0)}$

S

$-$

1.76

1.67

1.60

1.65

1.43

115.9

133.0

126.4

96.9

122.0

(a) - Not significantly elevated $(\alpha=0.1)$

(b) S Significantly elevated $(\alpha=0.1)$ 


\subsubsection{Butyltin Bioaccumulation in M, nasuta}

Mean butyltin concentrations ( $\mu \mathrm{g} / \mathrm{kg}$ dry weight) in $M$. nasuta tissues exposed to test, reference, and control treatments are summarized in Table 3.28. Tributyltin concentrations ranged from $38.6 \mu \mathrm{g} / \mathrm{kg}$ (COMP I) to $94 \mu \mathrm{g} / \mathrm{kg}$ (C-NE), a two-fold difference. Dibutyltin concentrations ranged from undetected at $2.5 \mu \mathrm{g} / \mathrm{kg}$ (COMP I) to $11.9 \mu \mathrm{g} / \mathrm{kg}$ (R-AC), a five-fold difference. Table 3.29 presents the results obtained from Dunn's Test and shows no significant increase in butyltin concentrations between test and reference treatments. The ANOVA and Dunn's Test results for comparison of mean butyltins in $M$. nasuta tissues are presented in Appendix L.

The QAOCC requirements were met for the majority of butyltins analyzed. Although $M$. nasuta tissues exposed to sediment composites were not statistically significantly different from the reference treatments, butyltin levels in the tissues were consistently higher across all test treatments when compared to previous studies at the MSL. Further examination of these data showed that all tissue samples (inciuding reference and control) exposed to the MSL filtered

IABLE 3.28. Mean Butyltin Concentrations in the Tissues of $M$. nasuta

Sediment

Ireatment

COMP I

COMP ॥

COMP III

TC-5 Upper Comp

COMP IV

COMP V

COMP VI

R-AC

R-AM

R-BF

R-OS

R-PF

C-NE

C-SB

Background (concentrations in $\mu \mathrm{o} / \mathrm{kg}$ dry weight)

Iributyltin Dibutyltin

38.6

58.8

53.8

53.5

56.9

55.4

45.9

$2.5 U^{(4)}$

6.8

4.8

10.1

9.6

6.4

4.8

77.5

73.7

67.4

48.2

45.1

11.9

10.1

7.0

9.4

$2.7 \mathrm{U}$

94.0

50.1

14.4
11.0

4.9

$2.5 \mathrm{U}$

(a) U Analyte was not present above the level of associated value. 
IABLE 3.29. Butyltins in Tissues of $M$. nasuta That Are Significantly Different from Reference Tissue Concentrations Using Dunn's Test for Comparison of All Means

Sediment Treatment

and Mean Tissue

Concentration

(uo/ko dry weightl

R-AC B-AM B-BF B-OS B-PF

Iributyltin

$\mathbf{7 7 . 5}$

73.7

67.4

48.2

45.1

None are significantly elevated

Dibutyltin

11.9

10.1

7.0

9.4

$2.7 U^{(1)}$

None are significantly elevated

(a) $U$ Analyte was not present above the level of associated value.

seawater system showed relatively high levels of tributyltin when compared to background tissue samples held in raw seawater. This suggests a possible source of TBT contamination associated with the seawater system, which to date, has not been resolved. For this reason, the bioaccumulation of butyltins in the tissues of $M$. nasuta is inconclusive for the Richmond Harbor COMPs. Sediment chemistry data, however, suggest the possibility for bioaccumulation of TBT after exposure to sediment from the TC-5 Upper Comp and COMP II. The presence of elevated butyltin levels in the tissue of $M$. nasuta exposed to these COMPs would not affect conclusions regarding their suitability for ocean disposal because other contaminants were present at significant levels in the tissues of test organisms exposed to these COMPs when compared to a given reference. A detailed QAVC summary is presented in Appendix K.

\subsubsection{Polynuclear Aromatic Hydrocarbon Bioaccumulation in N. caecoides}

Mean detectable concentrations ( $\mu \mathrm{g} / \mathrm{kg}$ dry weight) of PAHs in the tissues of $N$. caecoides are presented in Table 3.30. Five of the 16 PAH compounds had detectable concentrations that were subsequently used in a statistical comparison.

The results of Dunn's Test are summarized in Table 3.31 and show no significant elevations of PAH in the tissues of $N$. caecoides for any test treatments relative to the reference treatment R-AC. This table shows that only four PAHs, phenanthrene, fluoranthene, pyrene, and chrysene were significantly elevated in $N$. caecoides tissues from test treatments relative to one or more reference treatments. TC-5 Upper Comp was the only test treatment with signifi- 
IABLE 3.30. Mean Low and High Molecular Weight PAH Concentrations Detected in the Tissues of $N$. caecoides

Sediment

Ireatment

COMP I

COMP II

COMP III

TC-5 Upper Comp

COMP IV

COMP V

COMP VI

R-AC

R-AM

R-BF

R-OS

R-PF

C-NE

C-SB

Background (concentrations in $40 / \mathrm{kg}$ dry weight)

\begin{tabular}{|c|c|c|c|c|}
\hline Napthalene & Phenanthrene & Fluoranthene & Pyrene & Chrysene \\
\hline 48.87 & 22.32 & 21.21 & 58.74 & 13.29 \\
\hline 19.58 & 19.18 & 21.37 & 67.48 & 14.62 \\
\hline $14.39 \mathrm{~J}(\mathrm{a})$ & 15.41 & $12.02 \mathrm{~J}$ & 19.65 & $5.88 \mathrm{~J}$ \\
\hline $24.65 \mathrm{~J}$ & 56.60 & 210.17 & 491.66 & 87.64 \\
\hline $26.54 \mathrm{~J}$ & 20.38 & $12.64 \mathrm{~J}$ & $15.45 \mathrm{~J}$ & $4.75 \mathrm{~J}$ \\
\hline 16.93 & 20.04 & 28.44 & 188.07 & 25.62 \\
\hline $27.85 \mathrm{~J}$ & 20.85 & 28.51 & 191.61 & 25.47 \\
\hline 29.86 & 319.66 & 1948.85 & 5907.89 & 318.76 \\
\hline 48.08 & 58.10 & 125.61 & 273.46 & 51.78 \\
\hline 31.55 & 25.06 & 29.11 & 55.70 & 19.10 \\
\hline 23.43 & 15.84 & $11.15 \mathrm{~J}$ & $13.73 \mathrm{~J}$ & $7.48 U^{(b)} J$ \\
\hline 19.86 & 23.07 & 18.54 & 19.74 & $6.52 \mathrm{~J}$ \\
\hline 24.55 & 24.49 & 14.71 & 16.61 & $5.81 \mathrm{~J}$ \\
\hline 18.81 & 16.17 & 22.88 & 27.33 & $8.76 \mathrm{~J}$ \\
\hline 15.55 & 18.00 & 10.38 & 10.98 & 5.30 \\
\hline
\end{tabular}

(a) J Analyte detected below method detection limit (MDL), but above instrument detection limit.

(b) U Analyte was not present above the level of associated value.

cantly higher phenanthrene, fluoranthene, pyrene, and chrysene relative to R-BF, R-OS, and R$\mathrm{PF}$ and higher concentrations of fluoranthene and pyrene relative to R-AM. Results of ANOVA and Dunn's Test comparing mean $N$. caecoides tissue concentrations and statistical groupings for individual PAHs are presented in Appendix M. These tables show the relationship of $N$. caecoides tissue levels between each test and reference treatment.

The QAOC requirements were met for the majority of PAHs analyzed. In a few cases, the detection limit was elevated because of limited sample amounts. The results of QAOC evaluations show that these data are acceptable for use in analysis. A detailed QAOC summary is presented in Appendix K.

\subsubsection{Pesticide and PCB Bioaccumulation in N. caecoides}

Chiorinated pesticide and $\mathrm{PCB}$ analysis of $N$. caocoides tissues are presented in Table 3.32. Only two pesticides $\left(4,4^{\prime}-\mathrm{DDE}\right.$ and $4,4^{\prime}-\mathrm{DDD}$ ) and one PCB (aroclor 1254) were found at 
IABLE3.31. Low and High Molecular Weight PAHs in Tissues of $N$. caecoides That Are Significantly Different from Reference Tissue Concentrations Using Dunn's Test for Comparison of All Means

Sedimemt Treatment and Mean Tissue Concentration (110/kodn weight)

B-AC

B-AM

B-BF B-OS

B-PF

Naphthalene

29.86

48.08

31.55

23.43

19.86

None are significantly elevated

Phenanthrene

TC-5 Upper Comp

Eluoranthene

COMP I
COMP II
TC-5 Upper Comp
COMP V
COMP VI

Byrene

COMP I

COMP II

TC-5 Upper Comp

COMPV

COMP VI

Chrysene

COMP I

COMP II

TC-5 Upper Comp

COMP V

COMP VI

\subsection{6}

56.60

1948.85

21.21

21.37

210.17

28.44

28.51

5907.89

$\begin{array}{ll}\mathbf{5 8 . 7 4} & -- \\ 67.48 & -- \\ 491.66 & - \\ 188.07 & -- \\ 191.61 & --\end{array}$

318.76

13.29

14.62

87.64

25.62

25.47
58.10

$-\ldots(4)$

125.61

$\begin{array}{ll}\cdots & \cdots \\ -\cdots & s \\ -\cdots & \cdots\end{array}$

273.46

$\bar{s}$

51.78

$\begin{array}{lll}- & - & s \\ - & \bar{s} & s \\ - & - & s \\ - & - & S\end{array}$

$55.70 \quad 13.73 \mathrm{~J}$

$\mathrm{s}$

23.07

$S$

18.54

$29.11 \quad 11.15$ Jण

$$
\begin{aligned}
& \cdots \\
& \hdashline \\
& \text { S } \\
& \text { S }
\end{aligned}
$$

19.74

$\mathrm{S}$
$\mathrm{S}$
$\mathrm{S}$
$\mathrm{S}$
$\mathrm{S}$

$\begin{array}{ll}\text { S } & \text { S } \\ \text { S } & \text { S } \\ \text { S } & \text { S } \\ \text { S } & \text { S } \\ \text { S } & \text { S }\end{array}$
(a) -- Not significant $(\alpha=0.1)$.
(b) S Significant ( $\alpha=0.1$ ).
(c) J Analyte detected below method detection limits (MDL), but above instrument detection limit (IDL).
(d) U Analyte was not present above the level of associated value. 
IABLE 3.32. Mean Pesticide and PCB Concentrations in the Tissues of $N$. caecoides

Sediment

Ireatment

COMP I

COMP $\|$

COMP III

TC-5 Upper Comp

COMP IV

COMP V

COMP VI

R-AC

R-AM

R-BF

R-OS

R-PF

C-NE

C-SB

Background (concentrations in $\mu \mathrm{g} / \mathrm{kg}$ dry weight).

4.4'-DDE 4.4'-DDD Ároclor 1254

12.70

14.58

5.88

23.27

$2.81 U^{(a) j(a)}$

40.41

37.33

10.02

5.08

9.40

7.94

8.86

4.59

4.08

3.04
5.97

12.97

2.19

18.80

$2.95 \mathrm{U}$

76.11

105.48

5.91

$1.94 \mathrm{U}$

2.78

$1.73 \mathrm{U}$

$1.42 \mathrm{U}$

$1.12 \mathrm{U}$

$1.31 \mathrm{U}$

$0.56 \mathrm{U}$
93.82

172.22

75.53

410.42

$125.01 \mathrm{UJ}$

317.81

362.74

186.47

96.74

151.91

$73.75 \mathrm{U}$

$60.21 \mathrm{U}$

(a) U Analyte was not present above the level of associated value.

(b) J Analyte detected below method detection limits (MDL), but above instrument detection limit (IDL).

detectable levels that allowed statistical evaluation. Table 3.33 shows the results of the statistical analysis. Test treatments COMP I, COMP II, TC-5 Upper Comp, COMP V, and COMP VI had significantly higher concentrations of 4,4'-DDE, 4,4'-DDD and aroclor 1254 when compared to one or more of the reference treatments. COMP IV was the only test treatment with lower leveis of 4,4-DDE, 4,4'-DDD, and aroclor 1254 than all five reference treatments. Results of ANOVA and Dunn's Test comparing mean $N$. caecoides tissue concentrations and statistical groupings for individual pesticides and PCBs are presented in Appendix M.

The QAOC requirements were met for the majority of pesticides and PCBs analyzed. Detection limit goals were met for pesticides, but were exceeded in 11 of 75 PCB samples. Higher PCB detection limits were a result of the limited quantity of tissue available for analysis. The results of QAVQC evaluations show that these data are acceptable for use in analysis. $A$ detailed QA/QC summary is presented in Appendix J. 
IABLE 3.33. Pesticides and PCBs in Tissues of $N$. caecoides That Are Significantly Different from Reference Tissue Concentrations Using Dunn's Test for Comparison of All Means

Sediment Treatment
and Mean Jissue
Concentration
(uokedod weightl)

4.4-ГDE

COMP 1

COMP ॥

TC-5 Upper Comp

COMP V

COMP V1

4.4-DDD

COMP I

COMP If

TC-5 Upper Comp

COMP V

COMP VI

12.70

14.58

23.27

40.41

37.33

10.02

$--($ )
---
S
S

5.91

$1.94 U^{(m)}$

96.74
2.78

$1.73 \mathrm{U}$

\begin{tabular}{ll}
- & \\
\hline$S$ & $S$ \\
$S$ & $S$ \\
$S$ & $S$
\end{tabular}

151.91

S
S

B-OS

B-PE

7.94

8.86

..-
S
S

$S$
$S$
$S$

$\cdots$
$\mathrm{S}$
$\mathrm{S}$

$1.42 \mathrm{U}$

-
$S$
$S$

S
S
S

$73.75 \mathrm{U}$

$60.21 \mathrm{U}$

S
S
S

$\mathrm{S}$
$\mathrm{S}$
$\mathrm{S}$
$\mathrm{S}$

(a) - Not significantly elevated $(\alpha=0.1)$.

(b) S Significant $(\alpha=0.1$ ).

(c) $U$ Analyte was not present above the level of associated value.

\subsubsection{Metals Bioaccumulation in N. caecoides}

Mean metals concentrations in the tissues of $N$. caecoides, expressed in $\mathrm{mg} / \mathrm{kg}$ dry weight, are presented in Table 3.34. This table also shows the comparison between the lowest concentrations and the highest concentrations for all sediment treatments (including control and background). 
IABLE 3.34. Mean Metals Concentrations in the Tissues of $N$. caecoides

\begin{tabular}{|c|c|c|c|c|c|c|c|c|c|c|}
\hline \multirow{2}{*}{$\begin{array}{l}\text { Sediment } \\
\text { Ireatment }\end{array}$} & \multicolumn{10}{|c|}{ (concentrations in $\mathrm{mg} / \mathrm{kg}$ ols wejoht) } \\
\hline & AQ & As & Cd & CI & $\mathrm{Cu}$ & $\mathrm{Ha}$ & $\mathrm{Ni}$ & $\mathrm{B}$ & Se & Zn \\
\hline $\begin{array}{l}\text { COMP I } \\
\text { COMP II } \\
\text { COMP III } \\
\text { TC-5 Upper Comp } \\
\text { COMP IV } \\
\text { COMP V } \\
\text { COMP VI }\end{array}$ & $\begin{array}{l}0.033 \\
0.048 \\
0.030 \\
0.047 \\
0.024 \\
0.030 \\
0.035\end{array}$ & $\begin{array}{l}34.7 \\
31.1 \\
28.1 \\
35.8 \\
28.2 \\
31.1 \\
32.8\end{array}$ & $\begin{array}{l}1.17 \\
1.11 \\
1.04 \\
0.97 \\
1.12 \\
1.08 \\
1.17\end{array}$ & $\begin{array}{l}0.77 \\
0.67 \\
0.85 \\
1.16 \\
0.69 \\
0.73 \\
0.89\end{array}$ & $\begin{array}{l}14.16 \\
13.82 \\
11.16 \\
11.55 \\
11.49 \\
11.84 \\
13.20\end{array}$ & $\begin{array}{l}0.080 \\
0.075 \\
0.079 \\
0.064 \\
0.069 \\
0.065 \\
0.069\end{array}$ & $\begin{array}{l}4.65 \\
5.78 \\
5.70 \\
5.48 \\
5.48 \\
3.76 \\
4.88\end{array}$ & $\begin{array}{l}1.05 \\
0.96 \\
0.74 \\
1.26 \\
0.62 \\
1.12 \\
1.24\end{array}$ & $\begin{array}{l}1.76 \\
1.45 \\
1.36 \\
2.04 \\
1.59 \\
1.88 \\
1.68\end{array}$ & $\begin{array}{l}200.7 \\
203.1 \\
194.9 \\
193.1 \\
189.4 \\
190.9 \\
201.6\end{array}$ \\
\hline $\begin{array}{l}\text { R-AC } \\
\text { R-AM } \\
\text { R-BF } \\
\text { R-OS } \\
\text { R-PF }\end{array}$ & $\begin{array}{l}0.038 \\
0.056 \\
0.031 \\
0.041 \\
0.029\end{array}$ & $\begin{array}{l}28.5 \\
23.5 \\
29.6 \\
24.1 \\
25.6\end{array}$ & $\begin{array}{l}1.17 \\
1.18 \\
0.95 \\
1.16 \\
1.11\end{array}$ & $\begin{array}{l}0.77 \\
0.84 \\
0.91 \\
0.86 \\
0.89\end{array}$ & $\begin{array}{l}13.21 \\
12.07 \\
10.80 \\
11.86 \\
11.88\end{array}$ & $\begin{array}{l}0.062 \\
0.078 \\
0.084 \\
0.074 \\
0.078\end{array}$ & $\begin{array}{l}5.44 \\
5.56 \\
4.41 \\
5.33 \\
5.30\end{array}$ & $\begin{array}{l}0.96 \\
0.62 \\
1.07 \\
0.62 \\
1.44\end{array}$ & $\begin{array}{l}1.72 \\
1.57 \\
1.46 \\
1.87 \\
1.48\end{array}$ & $\begin{array}{l}204.5 \\
196.7 \\
186.0 \\
182.1 \\
186.4\end{array}$ \\
\hline $\begin{array}{l}\text { C-SB } \\
\text { C-NE } \\
\text { Background }\end{array}$ & $\begin{array}{l}0.034 \\
0.035 \\
\text { NM(a) }\end{array}$ & $\begin{array}{r}27.1 \\
24.8 \\
\text { NM }\end{array}$ & $\begin{array}{l}0.99 \\
1.15 \\
\text { NM }\end{array}$ & $\begin{array}{r}0.94 \\
0.71 \\
\text { NM }\end{array}$ & $\begin{array}{c}12.22 \\
13.45 \\
\text { NM }\end{array}$ & $\begin{array}{r}0.047 \\
0.069 \\
\text { NM }\end{array}$ & $\begin{array}{r}5.04 \\
3.87 \\
\text { NM }\end{array}$ & $\begin{array}{l}0.67 \\
0.62 \\
\text { NM }\end{array}$ & $\begin{array}{l}1.92 \\
1.43 \\
\text { NM }\end{array}$ & $\begin{array}{c}186.6 \\
173.0 \\
\text { NM }\end{array}$ \\
\hline Ratio(b) & 2.3 & 1.5 & 1.2 & 1.7 & 1.3 & 1.8 & 1.5 & 2.0 & 1.5 & 1.2 \\
\hline
\end{tabular}


The results of the Dunn Test are summarized in Table 3.35. This table shows that As was the only metal that exhibited significant differences between test and reference treatments. These test treatments were COMP I, TC-5 Upper Comp, and COMP VI relative to reference treatments R-AM, R-OS and R-PF.

Mean tissue concentrations are shown with the ANOVA and Dunn Test results for each metal in Appendix M. These tables show $N$. caecoides metals levels in the test treatments relative to each other and to the reference treatments. The statistical groupings show treatments that were similar as well as those that were different.

The QANOC requirements were met for metals analyzed in $N$. caecoides tissues. The results of QAOC evaluations show that these data are acceptable for use in analysis. A detailed QAVCC summary is presented in Appendix K.

\subsubsection{Butyltin Bioaccumulation in N. caecoides}

Mean butyltin concentrations ( $\mu \mathrm{g} / \mathrm{kg}$ dry weight) in $N$. caecoides tissues exposed to test, reference, and control treatments are summarized in Table 3.36. Tributyltin was detected in nine treatments (two test, three reference, and two control), dibutyltin was detected in three treatments (three test and four reference). These two compounds were then used in the statistcal analysis comparing sediment to reference treatments.

Table 3.37 presents the results of Dunn's Test for butyltin concentrations in $\mathbf{N}$. caecoides. This table shows that no test treatments had significantly higher concentrations of butyltins compared to any of the reference treatments. The ANOVA and Dunn's Test results for comparison of mean butyltins in N. caecoides tissues are presented in Appendix M. These tables show how the reference treatments compare to each other as well as to test treatments.

The QANOC requirements were met for the majority of butyltins analyzed. Most of the samples showed elevated target detection limits beyond $10 \mu \mathrm{g} / \mathrm{kg}$ wet weight. This was attributed to the limited tissue available for extraction. The overall results of QADC results indicate that these data are acceptable for use in analysis. A detailed QAVOC summary is presented in Appendix K. 
IABLE 3,35. Metals in Tissues of $N$. caecoides That Are Significantly Different from Reference Tissue Concentrations Using Dunn's Test for Comparison of All Means

Sediment Treatment

and Mean Tissue

Concentration

(mg/kg dry weight)

R-AM

B-BE

B-OS

B-PE

Siker

0.038

0.056

0.031

0.041

0.029

None are significantly elevated

Arsenic

28.5

23.5

29.6

24.1

25.6

COMP I

34.7

-...(a)

$S^{\text {(x) }}$

$\ldots$

$s$

$\cdots$

COMP VI

32.8

Cadmium

None are significantly elevated

Chromium

None are significantly elevated

Copper

None are significantly elevated

Mercury

None are significantly elevated

Nickel

None are significantly elevated

Lead

None are significantly elevated

Selenium

None are significantly elevated

Zinc

$\cdots$

$--$

1.17

$S$

S

$\ldots$

1.18

0.95

1.16

1.11

0.77

0.84

0.91

0.86

0.89

13.21

12.07

10.80

11.86

11.88

0.062

0.078

0.084

0.074

0.078

5.44

5.56

4.41

5.33

5.30

0.96

0.62

1.07

0.62

1.44

1.72

1.57

1.46

1.87

1.48

204.5

196.7

186.0

182.1

186.4

None are significantly elevated

(a)--- Not significantly elevated $(\alpha=0.1)$.

(b) S Significant $(\alpha=0.1)$. 
IABLE 3.36. Mean Butyltin Concentrations in the Tissues of N. caecoides

\begin{tabular}{|c|c|c|}
\hline \multirow{2}{*}{$\begin{array}{l}\text { Sediment } \\
\text { Ireatment }\end{array}$} & \multicolumn{2}{|c|}{ (concentrations in $\mu \mathrm{g} / \mathrm{ko}$ dry weight) } \\
\hline & Iributyltin & Dibutyltin \\
\hline COMP I & 171.81 & $69.13 U^{(m)}(\mathrm{s}(\mathrm{t})$ \\
\hline COMP \| & 114.37 UJ & $82.46 \mathrm{U}$ \\
\hline COMP III & $181.74 \mathrm{UJ}$ & $97.59 \mathrm{U}$ \\
\hline TC-5 Upper Comp & $112.39 \mathrm{UJ}$ & $93.57 \mathrm{U}$ \\
\hline COMP IV & $139.00 \mathrm{UJ}$ & $66.00 \mathrm{UJ}$ \\
\hline COMP V & 97.50 & 49.64 \\
\hline COMP V! & 99.35 & 61.96 \\
\hline R-AC & 76.81 & $77.57 \mathrm{UJ}$ \\
\hline R-AM & 119.03 & $45.31 \mathrm{UJ}$ \\
\hline R-BF & $146.92 \mathrm{UJ}$ & 57.00 \\
\hline R-OS & 105.77 & $78.53 \mathrm{U}$ \\
\hline R-PF & 88.79 & 51.51 UJD \\
\hline C-NE & 111.94 & $55.57 \mathrm{U}$ \\
\hline C-SB & 105.94 & 55.70 UJD \\
\hline Backg & NM(0) & NM \\
\hline
\end{tabular}
(a) U Analyte was not present above the level of associated value.
(b) $J$ Analyte detected below method detection limits (MDL), but above
(c) NM Not measured. instrument detection limit (IDL).

IABLE 3.37. Butyltins in Tissues of N. caecoides That Are Significantly Different from Reference Tissue Concentrations Using Dunn's Test for Comparison of All Means

Sediment Treatment and Mean Tissue Concentration (ug/kg dry weight)

\begin{tabular}{lcccc} 
B-AC & B-AM & B-BE & B-OS & B-PE \\
\cline { 5 - 6 } 76.81 & 119.03 & $146.92 U^{(4) J}$ & 105.77 & 88.79 \\
& - & & & - \\
77.57 UJ & 45.31 UJ & 57.00 & $78.53 \mathrm{U}$ & $51.51 \mathrm{UJ}$
\end{tabular}

None are significantly elevated

(a) U Analyte was not present above the level of associated value.

(b) J Analyte detected below method detection limits (MDL), but above instrument detection limit (IDL). 


\subsection{DISCUSSIONAND CONCLUSIONS}

The following section presents a discussion of the results pertinent to the Richmond Harbor project including geologic evaluations, sediment chemistry results, and toxicological and bioaccumulation potential. Test treatments are statistically compared to reference treatments to determine if significant differences occur. For the purposes of this discussion, the term "signiffcant acute toxicity" indicates that the test treatment does not comply with the benthic bioassay criteria for ocean disposal defined under CFR 40, Section 227.13 (c). The primary comparisons are acute toxicity and bioaccumulation potential. Sediment chemistry results are to be used in support of toxicity tests and bioaccumulation results in order to evaluate appropriate disposal options.

\subsection{GEOLOGIC EVALUATIONS}

Geologic evaluations were performed on sediment cores representing the material proposed for dredging. These evaluations determined the proportion of Older Bay Mud (OBM) and Younger Bay Mud (YBM) within dredging prisms, and provide USACE with the information needed to estimate the quantity of material that is suitable or unsuitable for unconfined openwater disposal. Table 4.1 shows that most of the test treatments were composed of YBM, which is generally a clay or silty clay material often mixed with sand. The OBM was prevalent only at stations C-19 (COMP II), C-29 (COMP VI), 'ं-33 (COMP V), and C-38 (COMP VI), where it typically exhibited a high plasticity, suggesting that it is more cohesive than the YBM.

\subsection{SEDIMENT CHEMISTRY}

According to the 1991 Implementation Manual, sediment chemistry results are intended to provide information about chemical contaminants of concem that could potentially cause toxicity or bioaccumulation. Section 3.3 presents the sediment chemistry results of the 57 sediment treatments and shows these treatments compared to reference treatment contarninant levels. For the conventional parameters, the majority of sediments were predominantly finegrained (silt and clay) and were representative of YBM. The sediment treatments with a higher proportion of fine-grained sediments representative of YBM also exhibited higher levels of TOC, TVS, oil and grease, and TPH than OBM sediments. 
TABLE 4.1. Summary of Geologic Descriptions

\begin{tabular}{|c|c|c|c|c|}
\hline $\begin{array}{l}\text { Sediment } \\
\text { Ireatment }\end{array}$ & $\begin{array}{l}\text { Mudline } \\
\text { ftMLLWW }\end{array}$ & $\begin{array}{r}\text { Sediment } \\
\mathrm{YBM}^{(a)}\end{array}$ & $\begin{array}{l}\text { Thickness, ft } \\
\text { OBM(b) }\end{array}$ & Physical Description (to $-40 \mathrm{ft})$ \\
\hline C-1 & 36.4 & 4.2 & 0.0 & Clayey sand with shell fragments \\
\hline C-3 & 36.0 & 3.6 & 0.0 & Silty clay \\
\hline C-5 & 36.4 & 3.3 & 0.0 & Silty day with sand \\
\hline C-6 & 36.3 & 4.7 & 0.0 & Clayey sand with gravelly sand \\
\hline C-8 & 36.4 & 5.5 & 0.0 & Silts and fine sands; clay \\
\hline C-10 & 36.0 & 4.6 & 0.0 & Silts and fine sands; clay; silty sands \\
\hline C-11 & 37.3 & 2.5 & 0.0 & Clayey sand \\
\hline C-16 & 36.2 & 2.8 & 1.9 & YBM-clay; OBM-clayey sand \\
\hline C-18 & 36.1 & 2.7 & 1.6 & YBM-clayey sand; OBM-clay with silts \\
\hline C-19 & 35.9 & 1.8 & 3.2 & YBM-clayey sand; OBM-sandy days \\
\hline C-20 & 36.2 & 3.3 & 1.0 & YBM-clayey sand; OBM-sandy silt \\
\hline C-23 & 32.8 & 6.9 & 0.0 & High plasticity clay \\
\hline C-24 & 36.0 & 4.3 & 0.0 & Clayey sand \\
\hline C-25 & 35.0 & 3.7 & 1.6 & YBM-clay; OBM-clay with iron oxides \\
\hline C-26 & 36.1 & 3.7 & 0.8 & YBM-clay; OBM-clayey sand \\
\hline C-29 & 35.0 & 3.2 & 7.3 & YBM-clay; OBM-high plasticity clay \\
\hline C-30 & 35.3 & 4.5 & 0.2 & YBM-clay; OBM-clayey sand \\
\hline C-32 & 35.3 & 3.4 & 2.1 & YBM-clay; OBM-high plasticity clay \\
\hline C-33 & 35.0 & 4.5 & 5.9 & YBM-clay; OBM-high plasticity clay \\
\hline C-35 & 36.2 & 3.3 & 1.7 & YBM-clay; OBM-high plasticity clay \\
\hline C-36 & 36.1 & 3.4 & 1.4 & YBM-clay; OBM-high plasticity clay \\
\hline C-37 & 36.1 & 3.0 & 1.9 & YBM-clay; OBM-clay with silty sands \\
\hline C-38 & 36.1 & 2.4 & 2.5 & YBM-clay; OBM-high plasticity clay \\
\hline TC-1 & 11.3 & 20.9 & 4.3 & YBM-clay; OBM-clayey sands \\
\hline TC-2 & 11.5 & 17.3 & 3.3 & YBM-clay; OBM-high plasticity clay \\
\hline TC-3 & 8.5 & 22.3 & 3.5 & YBM-clay; OBM-clay with gravelly sanc \\
\hline$T C-4$ & 6.2 & 23.3 & 9.5 & YBM-clay; OBM-gravelly sands \\
\hline TC-5 & 21.9 & 12.2 & 2.9 & YBM-clay; OBM-clay \\
\hline TC-6 & 6.2 & 38.8 & 0.0 & High plasticity clays \\
\hline TC-7 & 11.0 & 29.5 & 0.0 & High plasticity clays \\
\hline
\end{tabular}

(a) YBM - Younger Bay Mud.

(b) OBM - Older Bay Mud. 
The majority of sediment treatments had detectable levels of PAH. Reference treatment R-AC had the highest detectable level of total PAHs. COMP II, TC-5 Upper Rep 3, COMP V, and COMP VI had lower levels of PAH compared to R-AC and higher PAH levels relative to the remaining four reference treatments (R-AM, R-BF, R-PF, and R-OS). The results of pesticide analysis showed that three pesticides, 4,4' DDD, 4,4' DDE, and 4,4' DDT, were found at detectable levels in sediments. Test treatments C-38 and C-36 exhibited the highest levels of 4,4'DDD and 4,4'-DDE, while COMP VI had substantially higher levels of 4,4'-DDT. Aroclor 1254 was the only detectable PCB in the sediment treatments of which TC- 5 Upper Comp produced the highest level. The results of the metals analyses showed that TC-5 Upper Comp, TC-5 Upper Rep 3, and TC-5 Special Sample produced consistently higher levels of Ag, As, Cd, Cu, $\mathrm{Hg}, \mathrm{Pb}$, and $\mathrm{Zn}$ relative to the other sediment treatments. The remaining three metals showed varying levels of $\mathrm{Cr}$ and $\mathrm{Ni}$ among the test treatments and $\mathrm{Se}$ was undetected for most of the test treatments. The results for butyltin analyses showed the highest DBT fevels were found at TC-5 Upper Rep 3, TC-5 Upper Rep 1, and C-16; C-16 had much higher levels of TBT than any other test or reference treatments.

\subsection{TOXICOLOGY AND BIOACCUMULATION POTENTIAL}

The Richmond Harbor test treatments (COMPs) that resulted in significant acute toxicity or bioaccumulation are discussed in this section. The conclusions generated from the acute toxicity results vary depending on the reference treatment to which the results are compared. However, four observations were consistently noted for the comparison of test to reference treatments. First, acute 10-day toxicity for $N$. caecoldes was shown for COMP IV and TC-5 Upper Comp when compared to R-OS, and for COMP III, TC-5 Upper Comp, and COMP IV when compared to R-PF. Second, acute 10-day toxicity was also observed for $R$. abronius in relation to R-AM and R-BF. Third, C. stigmaeus displayed acute toxicity to the SPP derived from TC-5 Upper Comp (calculated LC50 of 75.4\%). These tissues were preserved in the event that a histopathological examination was necessary. Fourth, acute toxicity was not observed in the 10-day $M$. nasuta test relative to any reference treatment.

The conclusions generated from the bioaccumulation results also vary depending on the reference treatment to which the results are compared. However, five observations were consistently noted for the comparison of test to reference treatments. First, elevated levels of LPAHs in the tissues of $M$. nasuta were due to phenanthrene and anthracene; elevated levels of HPAHs were due to the presence of 9 of the 10 PAH compounds. Second, elevated levels of 
LPAHs in the tissues of $N$. caecoides were due to phenanthrene; significantly elevated levels of HPAHs were due to the presence of fluoranthene, pyrene, and chrysene. Third, elevated levels of pesticides and PCBs in the tissues of $M$. nasuta were from 4,4'-DDD, 4,4'-DDE, dieldrin, and aroclor 1254; tissues of $N$. caecoides exhibited elevated levels of 4,4'-DDD, 4,4'-DDE, and aroclor 1254. Although the levels of 4,4'-DDT were elevated in the test sediments, it was not detected at a significant level in the tissues of $M$. nasuta or $N$. caecoides. However, 4,4-DDD and 4,4'-DDE were present at significant levels in the tissues of both organisms. The reason for non-significant 4,4'-DDT levels in tissues ,s unknown; however, the ratios of 4,4'-DDD to 4,4DDE do not suggest metabolism of 4,4'-DDT by test organisms in tissues. Fourth, butyltins were not elevated in test organism tissue relative to the references. Finally, elevated levels of metals in tissues were limited to $\mathrm{Pb}$ in $M$. nasuta and As in $N$. caecoides. What follows is a comparison of toxicological and bioaccumulation data for the test treatment tissues of $M$. nasuta and $N$. caecoides relative to each reference.

\subsubsection{Comparison of Test Treatments to the Beference Treatment B-AC}

Table 4.2 summarizes the acute toxicity, bioaccumulation results, and the ratio of the test treatment concentrations relative to the Alcatraz Island dredged material disposal site, reference treatment $R-A C$. No significant acute toxicity to test organisms was observed for any test treatments relative to $\mathrm{R}-\mathrm{AC}$.

Elevated levels of pesticides (4,4'-DDD and 4,4'-DDE) and PCBs (aroclor 1254) were observed in the tissues of $M$. nasuta and $N$. caecoides exposed to test treatments TC-5 Upper COMP, COMP V, and COMP VI relative to R-AC. Metals, butyltins, and PAHs in tissues of $M$. nasuta and $N$. caecoides were not elevated in any test treatment when compared to R-AC.

Comparison of test treatment data to the reference R-AC produced nine "responses," where a response is defined as significant acute toxicity or elevated tissue levels of PAHs, pesticides, PCBs, metals, or butyltins relative to the reference treatments. Reference treatment R-AC produced the lowest observable number of responses of any reference treatment in this study.

\subsubsection{Comparison of Test Jreatments to the Reference TreatmentR-AM}

Table 4.3 provides the acute toxicity, bioaccumulation results, and the ratio of the highest treatment concentrations relative to the environs samples near the Alcatraz island dredged material disposal site, reference treatment R-AM. Significant acute toxicity was observed only in test treatment COMP III for $R$. abronius. 
IABLE 4.2. Summary of Significant Acute Toxicity and Bioaccumulation for Test Treatments Relative to the Reference R-AC

Sediment

Ireatment

COMP I

COMP ॥

COMP III

TC-5 Upper Comp ---

COMP IV

COMP V

COMP VI
M. nasuta Bioaccumulation

BAH RCB PESI Metals Butyltins

$\cdots$

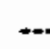$$
-
$$$$
\cdots \quad 2.5(b) \quad \cdots
$$$$
\begin{array}{ccccc}
- & \ldots & \ldots & \ldots & \ldots
\end{array}
$$$$
\begin{array}{ccccc}
-. & \ldots & 12.9(b) & \ldots & \ldots
\end{array}
$$$$
\begin{array}{lllll}
\cdots & 1.6(b) & 17.0(b) & \ldots &
\end{array}
$$

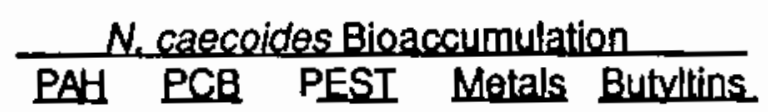

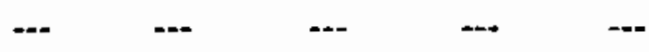

$\begin{array}{lllll}-- & -- & -\cdots & --\end{array}$

$\begin{array}{lllll}\cdots & -- & -- & - & -\end{array}$

$\begin{array}{lllll}\ldots & 2.2(b) & 2.3^{(b)} & \ldots & \ldots\end{array}$

$\begin{array}{lllll}- & - & \ldots & \ldots & \ldots\end{array}$

$\begin{array}{llllll}-. & -. & 12.9(b) & \ldots & \end{array}$

$\begin{array}{cccc}\cdots & 1.9(\mathrm{~b}) & 17.8(\mathrm{~b}) & -\end{array}$

is (a) Not significant.

(b) Value represents the highest ratio of a test treatment relative to the reference R-AC. 
IABLE 4.3. Summary of Significant Acute Toxicity and Bioaccumulation for Test Treatments Relative to the Reference R-AM

Sediment Ireatment

$M$ nasuta Bioaccumulation RAH RCB RESI Metals Butyltins

$\frac{N \text { caecoides Bioaccumulation }}{\mathrm{PAH}} \mathrm{PCB}$ PESI Metals Butultins.

COMP 1

COMP ॥

COMP III

$\cdots$

$\cdots+$

-.. 7.7 (b)

$\cdots$

$9.3(b)$

$\cdots$

$\cdots$

Phe(c)

TC-5 Upper Comp -.-

COMP IV

COMP V

COMP VI

$\begin{array}{llllll}\cdots & \cdots & 1.8(0) & 124.56(b) & \ldots & \ldots\end{array}$

‥ $2.3($ b) 89.0 (b) $\quad \ldots \quad$..-

$\begin{array}{lllll}\cdots & \cdots & 2.5(b) & 1.5(b) & \ldots\end{array}$

$\begin{array}{lllll}-- & \ldots & 6.7(b) & \ldots & -\end{array}$

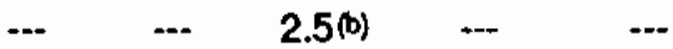

$\begin{array}{llll}\ldots & 2.0(b) & 12.4(b) & \ldots\end{array}$

-.. $\quad$-..-

1.8 (b) $\quad 4.2$ (b) $\quad 9.7$ (b) $\quad 1.5$ (b) $\quad$---

$\begin{array}{lllll}\cdots & -. & \ldots & \ldots & \ldots\end{array}$

$\begin{array}{lllll}-- & 3.3(b) & 39.0(b) & --- & --\end{array}$

$\ldots \quad 3.7$ (b) $\quad 54.0$ (b) $\quad 1.4($ b) $\quad$-.-

(a) Not significant.

(b) Value represents the highest ratio of a test treatment relative to the reference R-AM.

(c) Rhe is the 10-day static Rhepoxynius abronius test. 
Significantly elevated levels of pesticides $\left(4,4^{\prime}-D D D\right.$ and $\left.4,4^{\prime}-D D E\right)$ were observed in tissues of $M$. nasuta for COMP I, COMP II, COMP III, TC-5 Upper Comp, COMP V, and COMP $V I$ when compared to R-AM. Significantly elevated levels of dieldrin were observed on tissues of $M$. nasuta for COMP VI. The concentrations of Aroclor 1254 in M. nasuta tissues exposed to TC-5 Upper Comp, COMP V, and COMP VI were approximately twice those observed in tissues exposed to R-AM. There was no evidence of bioaccumulation potential for PAHs, metals, or butylitins in the tissues of $M$. nasuta.

Elevated levels of PAHs, PCBs, pesticides, and the metal As were observed in $N$. caecoides tissues exposed to one or more of the test treatments when compared to R-AM. Fluoranthene and pyrene were elevated in the tissues of $N$. caecoides for TC-5 Upper Comp. Aroclor 1254 was elevated in the tissues of $N$. caecoides for TC- 5 Upper Comp, COMP V, and COMP VI. 4,4'-DDE and 4,4'-DDD were elevated in tissues of N. caecoides for COMP I, COMP II, TC-5 Upper Comp, COMP V, and COMP VI. Arsenic was found at elevated levels in the tissues of $N$. caecoides for at least one or more of the following test treatments: COMP I, TC-5 Upper Comp, and COMP VI. No significant bioaccumulation of butyltirls was observed in $N$. caecoides relative to R-AM.

Comparison of the acute toxicity and bioaccumulation results of test treatments relative to R-AM produced 22 responses. This was the second lowest observed number of responses relative to all references ( $\mathrm{R}-\mathrm{BF}$ also had 22 responses).

\subsubsection{Comparison of Test Treatments to the Reference Treatment B-BE}

Table 4.4 presents the results of acute toxicity, bioaccumulation results, and the ratio of test treatment concentrations relative to the Bay Farm Borrow Pit, reference treatment R-BF. Significant acute toxicity was observed with $R$. abronius exposed to COMP III relative to R-BF.

Significantly elevated levels of PAHs, PCBs, and pesticides were observed in the tissues of $M$. nasuta exposed to test treatments TC-5 Upper Comp, COMP V, and COMP VI. There was no evidence of bioaccumulation potential for metals or butyltins in the tissues of $M$. nasuta

Significantly elevated levels of PAHs, pesticides, and PCBs were also observed in the tissues of $N$. caecoides exposed to one or more of the following test treatments: COMP II, TC-5 Upper Comp, COMP V, and COMP VI relative to R-BF. There was no evidence of elevated levels of metals or butyltins in N. caecoides tissues relative to R-BF. Comparison of acute toxicity and bioaccumulation results of test treatments to the reference R-BF produced 22 responses. 
IABLE 4.4. Summary of Significant Acute Toxicity and Bioaccumulation for Test Treatments Relative to the Reference R-BF

\begin{tabular}{|c|c|c|c|c|c|c|c|c|c|c|c|}
\hline \multirow{2}{*}{$\begin{array}{l}\text { Sediment } \\
\text { Treatment }\end{array}$} & \multirow[b]{2}{*}{ Acute Toxicity } & \multicolumn{5}{|c|}{$M$ nasuta Bioaccumulation } & \multicolumn{5}{|c|}{ N. caecoides Bioaccumulation } \\
\hline & & PAH & $\mathrm{PCB} F$ & PESI & Metals & Butyllins. & $\mathrm{EAH}$ & $\mathrm{PCB}$ & PESI & Metals & Butulins \\
\hline СOMP I & --(a) & -- & -- & -- & -. & -. & -. & -. & -. & -- & -- \\
\hline COMP & -.- & -.- & -.. & -.. & -.- & $\ldots$ & $\ldots$ & $\ldots$ & $4.7(0)$ & ... & --- \\
\hline COMP III & Rhe(c) & -.- & -. & -.- & $\ldots$ & $\ldots$ & -.. & ..- & -. & $\ldots$ & $\ldots$ \\
\hline TC-5 Uppe & Comp --. & $5.5(b)$ & $1.7(0)$ & $4.4(b)$ & -.- & ..- & $8.8(0)$ & 2.7 (b) & $6.8(b)$ & $\ldots$ & .. \\
\hline COMP IV & $\cdots$ & -- & $\cdots$ & $\ldots$ & --- & -. & $\cdots$ & --- & $\cdots$ & $\cdots$ & $\ldots$ \\
\hline COMP V & $-\cdots$ & $3.0(0)$ & $1.6(0)$ & $24.0(\mathrm{~b})$ & -.- & $\ldots$ & $3.4(b)$ & $2.1(b)$ & $27.0(\mathrm{~b})$ & $\ldots$ & ..- \\
\hline COMP VI & -.. & $3.1(0)$ & $2.0(0)$ & $31.0(\mathrm{~b})$ & $\ldots$ & ... & $3.4(0)$ & $2.4(b)$ & $38.0(b)$ & ... & ... \\
\hline
\end{tabular}

$\stackrel{\infty}{\infty}$ (a) Not significant.

(b) Value represents the highest ratio of a test treatment relative to the reference R-BF.

(c) Rhe is the 10-day static Rhepoxynius abronius test. 


\subsubsection{Comparison of Test Treatments to the Reference Treatment R-OS}

Table 4.5 summarizes the acute toxicity, bioaccumulation results, and the ratio of test treatment concentrations relative to the off-shelf reference site, R-OS. Significant acute toxicity was noted in N. caecoides exposed to test treatments TC-5 Upper Comp and COMP IV.

Significantly elevated levels of LPAH, HPAH, PCBs, pesticides, and the metal Pb were noted in the tissues of $M$. nasuta when compared to R-OS. Tissue levels of PAHs were elevated above R-OS for the following test treatments: COMP I, CCMP II, TC-5 Upper Comp, COMP V, and COMP VI. The PCB aroclor 1254 was elevated in all test treatments. Pesticides were elevated in all test treatments except for COMP IV. Lead was significantly elevated in the tissue of $M$. nasuta for TC-5 Upper Comp, COMP V, and COMP VI when compared to R-OS. There was no evidence of significantly elevated levels of butyltins in the tissues of $M$. nasuta.

Significantly elevated levels of PAHs, pesticides, PCBs, and the metal As were observed in the tissues of $N$. caecoides when compared to R-OS. Tissue levels of PAHs were elevated in test treatments COMP I, COMP II, TC-5 Upper Comp, COMP V, and COMP VI. Tissue levels of PCBs were elevated in COMP II, TC-5 Upper Comp, COMP V, and COMP VI. Pesticide tissue levels were elevated in $N$. caecoides for COMP II, TC-5 Upper Comp, COMP V, and COMP VI. Arsenic was significantly elevated for test treatments COMP I, TC-5 Upper Comp, and COMP VI. There was no evidence of significantly elevated levels of butyltins in tissues of $N$. caecoides relative to R-OS.

Comparison of acute toxicity and bioaccumulation results of test treatments to the reference R-OS produced 41 responses. References R-OS and R-PF had the highest total observed responses of all references.

\subsubsection{Comparison of Test Treatments to the Reference Treatment R-PF}

Table 4.6 summarizes acute toxicity, bioaccumulation results, and the ratio of test treatment concentrations relative to the Point Reyes reference treatment, R-PF. Significant acute toxicity was observed for $N$. caecoides exposed to test treatments COMP III, TC-5 Upper Comp, and COMP IV.

Significantly elevated levels of contaminants were observed in tissues of $M$. nasuta exposed to all test treatments except COMP IV relative to R-PF. Tissue levels of PAHs were elevated above R-PF for one or more of the following test treatments: COMP I, COMP II, TC-5 
IABLE 4.5. Summary of Significant Acute Toxicity and Bioaccumulation for Test Treatments Relative to the Reference R-OS

\begin{tabular}{|c|c|c|c|c|c|c|c|c|c|c|c|}
\hline \multirow{2}{*}{$\begin{array}{l}\text { Sediment } \\
\text { Ireatment }\end{array}$} & \multirow[b]{2}{*}{ Acute Toxicity } & \multicolumn{5}{|c|}{$M$ nasuta Bioaccumulation } & \multicolumn{5}{|c|}{ N caecoides Bioaccumulation } \\
\hline & & $\mathrm{EAH}$ & $\mathrm{PCB}$ & PEST & Metals & Butyltins & $\mathrm{BAH}$ & $\mathrm{PCB}$ & PESI & Metals & Butyltins \\
\hline COMP I & --(a) & $7.1(b)$ & $3.4(0)$ & 8.1 (b) & --- & $\ldots$ & $4.3(b)$ & $\ldots$ & -- & 1.4 (b) & $\ldots$ \\
\hline COMP \| & $\ldots$ & $5.6(b)$ & $4.0(0)$ & $16.7^{(b)}$ & --. & $\cdots$ & 4.9 (b) & 2.3 (b) & 7.5 (b) & -.- & $\ldots$ \\
\hline COMP III & $\ldots$ & -.- & $2.6($ b) & $4.5(b)$ & ..- & --. & $\ldots$ & --- & ..- & ..- & $\ldots$ \\
\hline TC-5 Upper Comp & p Nep(c) & $30.8(b)$ & $7.6(0)$ & $22.0(\mathrm{~b})$ & 1.7 (b) & -- & $36.0(b)$ & 5.6 (b) & 10.9 (b) & $1.5(b)$ & -.. \\
\hline COMP IV & Nep & -- & $1.7(0)$ & --- & .. & $\cdots$ & -- & $\cdots$ & -- & $\cdots$ & --- \\
\hline COMP V & $\cdots$ & 16.9(b) & $7.0(0)$ & $120.0(b)$ & 1.75 (b) & $\cdots$ & $13.7^{\text {(b) }}$ & 4.3(b) & $44.0($ b) & $\cdots$ &.- \\
\hline COMP VI & $\ldots$ & 17.3 (b) & $8.9(0)$ & 158.0 (b) & $1.9(b)$ & $\ldots$ & $14.0(b)$ & 4.9 (b) & c1.0(b) & 1.4 (b) & ... \\
\hline
\end{tabular}

$+\quad$ (a) Not significant.

D (b) Value represents the highest ratio of a test treatment relative to the reference R-OS.

(c) Nep is the 10-day flow-through Nephtys caecoides static toxicity test. 
IABLE_4.6. Summary of Significant Acute Toxicity and Bioaccumulation for Test Treatments Relative to the Reference R-PF

Sediment

Ireatment

COMP I

COMP ॥

COMP III

TC-5 Upper Comp Nep

COMP IV

COMP V

COMP VI$$
--\cdot
$$

Nep

$\cdots$

$-\cdot$
$M$ nasuta.Bioaccumulation

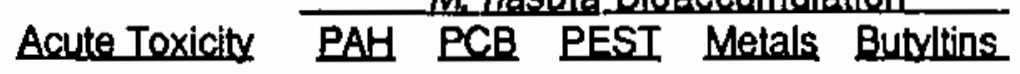

$$
- \text { - (a) }
$$

Nep(c)
8.1 (b) 2.2 (b) 8.6 (b) $\quad \ldots \quad \ldots$

6.4(b) 2.6(b) 17.7(b) -.. -

... $1.6(\mathrm{~b}) \quad 4.8$ (b) $\quad \ldots \quad$-..

35. (b) $^{4.9(\mathrm{~b})} 23.5^{(\mathrm{b})} \quad 1.8^{(\mathrm{b})} \quad$---

$\begin{array}{llll}-- & -- & -- & --\end{array}$

19.2(b) 4.5 (b) 127.0 (b) 1.8 (b) ---

19.6 (b) 5.7 (b) 168.0 (b) 1.9 (b) $\quad \ldots$
$N$ caecoides Bioaccumulation PAH PCB PESI Metals Butyltins

3.0 (b) $\quad \ldots \quad 4.2$ (b) 1.4 (b) $\quad \ldots$

3.4 (b) 2.9 (b) 9.1 (b) $\quad \ldots$

25.0 (b) 6.8 (b) $13.2^{(b)} \quad 1.4$ (b)

(a) Not significant.

$\therefore$ (b) Value represents the highest ratio of a test treatment relative to the reference R-PF.

- (c) Nep is the 10-day flow-through Nephtys caecoides static toxicity test. 
Upper Comp, COMP V, and COMP VI. Pesticides and the PCB aroclor 1254 were significantly elevated in M. nasuta tissues exposed to all test treatments except COMP IV. Lead was present in the tissue of $M$. nasuta at significantly elevated concentrations for test treatments TC5 Upper Comp, COMP V, and COMP VI. There was no evidence of significantly elevated leveis of butyltins in the tissues of $M$. nasuta for any test treatment.

Significantly elevated levels of contaminants were also observed in the tissues of $N$. caecoides relative to tissues exposed to the reference R-PF. Tissue levels of PAHs were elevated above R-PF for one or more of the following test treatments: COMP I, COMP II, TC-5 Upper Comp, COMP V, and COMP VI. Pesticides and PCBs were significantly elevated in tissues of $N$. caecoides for COMP I, COMP II, TC-5 Upper Comp, COMP V, and COMP Vi. Arsenic was significantly elevated in test treatments COMP $l$ and TC-5 Upper Comp. There was no evidence of significant elevation of butyltins relative to R-PF.

Comparison of test treatment acute toxicity and bioaccumulation to the reference R-PF produced 41 responses. This was the highest total observed and equal to the responses observed in R-OS.

\subsection{CONCLUSIONS}

The tiered approach to evaluating potential impacts of ocean disposal of dredged material is presented in the 1991 Implementation Manual. This approach consists of a series of activities (tests) and decision modules (determination of compliance) that aid in interpreting physical, chemical, and biological data related to the evaluation of proposed dredged sediment. In this study, water column toxicity, deposited sediment toxicity, and deposited sediment bioaccumulation potential were evaluated. The following summarizes the tests conducted using the determination of compliance definitions provided by the 1991 Implementation Manual.

\subsubsection{Water Column}

Estimates of toxicity in the water column were evaluated by exposing three marine species (H. sculpta, C. stigmaeus, and $M$. edulis) to three concentrations of SPP and a seawater-only control. The SPP tests showed acute toxicity and a calculable LC50 of $75.4 \%$ SPP in the $C$. stigmaeus test for TC-5 Upper Comp. Under 1991 Implementation Manual guidelines, the limiting permissible concentration for dissolved plus suspended contaminants (represented by the SPP) cannot exceed $0.01 \%$ of the acutely toxic concentration at the boundaries of the 
disposal site after allowing $4 \mathrm{~h}$ for initial mixing. This means that a concentration greater than $0.75 \%$ SPP would have to be present at the boundary of the disposal site after initial mixing to exceed the acutely toxic concentration if the dredge material was composed of sediment from TC-5 Upper Comp.

\subsubsection{Deposited Sediment Toxicity}

Deposited sediment toxicity was determined by exposing three species of manine organisms ( $M$. nasuta, $N$. caecoides, and $R$. abronius) to test sediment treatments. The 1991 Implementation Manual guidelines concerning determination of compliance for deposited sediment toxicity are based on whether the mortality of organisms exposed to test sediments (dredged material) is statistically significantly different from reference and whether test organism mortality in test treatments exceeds the reference treatment by $20 \%$ ( $R$. abronius) or $10 \%$ (other species). If mortality in test treatments is statistically significantly different from the reference mortality and exceeds the reference by the above percentages, the test material does not comply with the benthic bioassay criteria of Section 227.13(c) and Appendix A of the 1991 Implementation Manual.

The toxicological test conducted by the MSL showed only two tests ( $N$. caecoides and $R$. abronius) where significant acute toxicity was observed when COMPs were statistically compared to the five reference treatments via Dunn's Test at $\alpha=0.10$. Test treatments producing significant toxicity in $R$. abronius were COMP III relative to the references R-AM and R-BF. Test treatments producing significant toxicity in N. caecoides were COMP III relative to R-PF and TC5 Upper Comp and COMP IV relative to both R-OS and R-PF. Based on these tests, sediment treatments COMP III, TC-5 Upper Comp, and COMP IV do not comply with the benthic bioassay criteria of Section 227.13(c) and Appendix A of the 1991 implementation Manual.

\subsubsection{Bioaccumulation}

The potential for bioaccumulation of contaminants was evaluated through 28-day solidphase flow-through tests with $M$. nasuta and $N$. caecoides. The concentrations of contaminants were compared to existing Food and Drug Administration (FDA) limits, and also compared through Dunn's Test to determine whether statistically significant levels of contaminants were present $(\alpha=0.10)$ relative to reference treatments. The tissue chemistry results were compared to existing FDA action limits shown in Table 4.7 and showed no evidence of bioaccumulation that would exceed FDA limits. However, statistically significant elevations of contaminants were present in the tissues of $M$. nasuta and $N$. caecoides when compared to the five references. In 
IABLE 4.7. FDA Action Limits

Substance

Action Level.ppom (wet wt)

M. nasuta

N. caecoides

Metals

Methyl Mercury

Pesticldes
1.0 ---(a)

0.3

0.3

0.3

5.0

1.0

0.3

0.3

0.5

0.3

0.3

0.25

0.1

12.0

5.0
.01

$-$

.005

002

.002

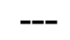

.0007

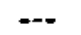

$\ldots$

$-$

.01

.05

Industrlal Chemicals

PCBs

Dioxin
2.0

25.0
.03

.2

(a) -- Compound was not included in analysis.

most cases, the PAH, pesticide, and PCB levels were at least twice that observed in a given reference. Elevated metals concentrations were at levels less than twice that observed in tissues exposed to reference treatments. Statistical analysis of butyltin concentrations showed no evidence of significant increases in tissue concentrations for test sediments relative to reference tissues. This result was in contrast to the relatively high levels of butyltins noted in some of the sediment cores contributing to the COMPs.

Companison of test treatment data to the reference R-AC produced the fewest toxicological and bioaccumulation responses (9); comparison to the reference R-OS and R-PF produced the most ( 41 each). The references $\mathrm{B}-\mathrm{AM}$ and $\mathrm{R}-\mathrm{BF}$ produced 22 responses each. Again, the significance of the comparisons is dependent upon the reference to which the test treatments 
are compared. According to the 1991 Implementation Manual, further evaluation of the test sediments and the proposed dredged material they represent may be necessary to determine whether these materials can be disposed of in the ocean. These evaluations may take the form of numerical modeling, case-specific testing. or other management action as defined by the 1991 Implementation Manual and developed by the District Engineer and Regional Administrator. The summary results presented in Tables 4.1 through 4.6 should aid in this decision and policy making. 
. 


\subsection{REFERENCES}

ASTM (American Society for Testing and Materials). 1972. Standard Method for Particle-Size Analysis of Soils. D422, American Society for Testing and Materials, Philadelphia, Pennsylvania.

ASTM (American Society for Testing and Materiais). 1978. Standard_Method for Dry Preparation of Soil Samples for Particle-Size Analysis_and Determination of Soil Constants. D421, American Society for Testing and Materials, Philadelphia, Pennsylvania.

ASTM (American Society for Testing and Materials). 1984. Standard Practice for Description and Identification of Soils. D2488-84, American Society for Testing and Materials, Philadelphia, Pennsylvania, pp. 293-302.

Barry, R. G 1983. Late-Plejstocene Climatology: Late_Quatemary Environments of the United States. University of Minnesota Press, Minneapolis.

Bloom, N. S., and E. A Crecelius. 1983. "Determination of Mercury in Seawater at SubNanogram per Liter Levels." Marine Chemistry 14:49-59.

Bloom, N. S., and E. A Crecelius. 1984. "Distribution of Silver, Mercury, Lead, Copper and Cadmium in Central Puget Sound Sediments." Marine Chemistry 21:377-390.

Brown, B., N. P. Kohn, J. A. Ward, and B. N. Bjomstad. 1990. Environmental Eyaluations for Deepening of Richmond Harbor and Santa Fe Channels. PNL-7614, Pacific Northwest Laboratory, Richland, Washington.

Dunn, O. J. 1961. "Multiple Comparison Among Means." Joumal of the American Statistical Association 56:52-64.

EPA (see U.S. Environmental Protection Agency).

Hamilton, M. A. R. C. Russo, R. V. Thurston. 1977. "Trimmed Spearman-Karber Method for Estimating Median Lethal Concentrations in Toxicity Bioassays. "Environmental Scjence Iechnology 11(7):714-533.

Krauskopf, K 1967. Introduction te Geechemistry. McGraw-Hill International Series in the Earth and Planetary Sciences, McGraw-Hill, New York.

NOAA (National Oceanic and Atmospheric Administration). 1985. Standard Analytical Procedures of the NOAA National Analytical Facility. 1985-6: Extractable Toxic Compounds (Second Edition). NOAA Technical Memorandum NMFS F/NWC-92. Washington, D.C. p. 121.

PSEP (Puget Sound Estuary Program). 1986. Becommended Protocols for Measuring Selected Environmental Variables in Puget Sound. Volumes 1 and 2. Prepared by Tetra Tech, Inc. for the Puget Sound Estuary Program, Bellevue, Washington.

Sanders, R. W. 1987. Energy Dispersive X-Ray Fluorescene Spectoscopy. PNL-SOP: PNLSP-19.

Unger, M. A., W. G. Macintyre, J. Greaves, and R. J. Huggett. 1986. 'GC Determination of Butyltins in Natural Waters by Flame Photometric Detection of Hexyl Derivatives with Mass Spectrometric Confirmation." Chemosphere 15(4):461-470. 
U.S. Army Corps of Engineers (USACE). 1975a. Dredge Disposal Study: San Francisco Bay and Estuary. U. S. Army Corps of Engineers, San Francisco District, San Francisco, California.

U.S. Army Corps of Engineers (USACE). 1975b. Maintenance Dredging: Existing Navigation Erojects. San Francisco Bay Region, California: U. S. Army Corps of Engineers, San Francisco District. Final Composite Environment Statement, San Francisco, California.

U.S. Environmental Protection Agency (EPA). 1979. Test Methods for Evaluating Solid Waste: Physical/Chemical_Methods. EPA-600 4-79-020 Methods 413.2, 418.1, Environmental Monitoring and Support Laboratory, Cincinnati, Ohio.

U.S. Environmental Protect,on Agency (EPA). 1986. Test Methods for Evaluating Solid Waste: Physical/Chemica[Methods. EPA-955-001-00000, U.S. Environmental Protection Agency, Government Printing Office, Washington, D.C.

U.S. Army Corps of Engineers/U.S. Environmental Protection Agency (USACE/EPA). 1991. Evaluation of Dredged Material Proposed for Ocean Disposal (Testing Manual). EPA-68-C80105. U.S. Environmental Protection Agency, Office of Marine and Estuarine Protection, Washington, DC. 


\section{APPENDIX A}

MATERIALS AND METHODS USED FOR IHE DESCRIPTION OF SEDIMENT CORES 
APPENDIX A

MATERIALS AND METHODS USED FOR

THE DESCRIPTION OF SEDIMENT CORES

\section{A.1 MATERIALS}

The following is a checklist of items and materials used for the examination and description of sediment cores.

- ASTM Procedure D 2488-84

- Stainless-steel knife

- Hand lens (10X magnification)

- $\quad 10 \mathrm{~N}$ Hydrochloric acid (HCl)

- Ruler (scaled in 0.1-foot increments)

- 8 lank log forms (see Figure A.1)

- Clipboard

- AGI Data Sheets

- Munsell Color Charts

In addition, the charts and/or reference materials listed in Table A.1, and included in this appendix, are used for the description of specific sediment characteristics.

\section{A.2 METHODS}

Descriptions of the physical, chemical, and biological features preserved in sediments aid in the interpretation of the types of geologic processes active both during and after the sediment was deposited. A total of 17 sediment characteristics, outlined in ASTM (1984), are commonly used to describe inorganic soils. These are listed in Table A.2.

Moisture condition was not routinely logged because of the saturated nature of the sediments. Furthermore, since particles were rarely larger than coarse sand, neither were angularity, particle shape, range in particle size, and hardness logged. For this reason, these sediment characteristics were not included in the $\log$ form used for the description of Richmond Harbor Program sediments (Figure A.I). However, in the few instances where these characteristics did apply, they were described under the "COMMENTS" column. 
Core Data Log

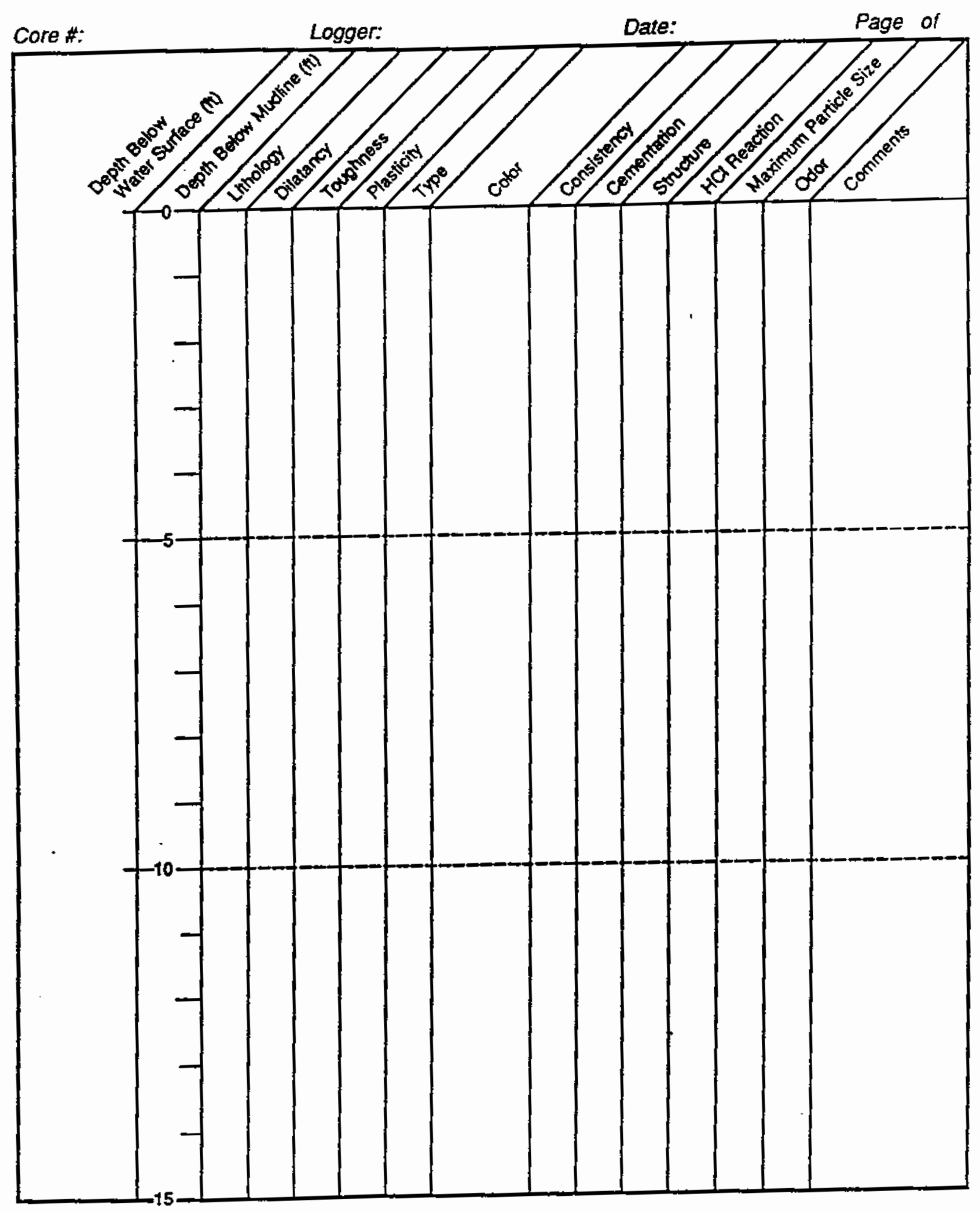

FIGURE A.1. Log Form Used to Record Sediment Descriptions 
IABLE A.1. Charts and Other Reference Materials Used to Provide Standardized Descriptions of Sediment Characteristics.

CHART/REFERENCE

- Percentage

Estimate Chart

- Roundness Scale

- Sorting Chart

- Particle Shape

- Munsell Soil Color Charts

- Unified Soil Classification System

- Grain-size Scales

- Lithologic Symbols
PURPOSE

Estimate percentage of individual particles or constituents

Roundness of sand and coarser particles

Estimate of grading

Reference to describe particle shape

Soil color

Method for designating sediment type

Range of particle sizes; maximum particle size

Graphic patterns for lithologic log
FIGURE \#

A. 2

A. 3 A

A. 3B

A. 4

A. 5

A. 6, A.7

A. 8 , A. 9

A.10, A.11

TABLE A.2. Sediment characteristics identified in ASTM Procedure D2488-84.

1) angularity *

2) particle shape *

3) color

4) odor

5) moisture condition

6) $\mathrm{HCl}$ reaction

7) consistency (i.e., firmness)

8) cementation *

9) structure
10) sediment classification type (i.e., lithology)

11) range of particle sizes *

12) maximum particle size

13) hardness *

14) dry strength **

15) dilatancy

16) toughness **

17) plasticity **

\footnotetext{
* Applies to coarse-grained sediment (sand and larger particles)

** Applies to fine-grained sediment of mostly silt and/or clay Features not generally logged for this study are underlined
} 
The definition of "soil" from the engineers standpoint (ASTM 1984), includes any unconsolidated sediment. The geologic definition of soil is slightly different and restricts soils to those sedimentary deposits that have undergone alteration near the land's surface by either physical, chemica1, and/or biological processes; therefore, in a strict sense, not all sediments are soils. For the purposes of this discussion, however, "soils" and "sediments" will be used synonymously.

It is sometimes helpful to provide an estimate of the relative proportions of different constituents in sediments (e.g. light-versus dark-colored minerals). This is made easier and more accurate by using a percentage estimate chart, which provides a graphic reference with varying concentrations of a particular constituent (Figure A.2).

The criteria used to describe each of the 17 sediment characteristics identified in ASTM (1984) are discussed below.
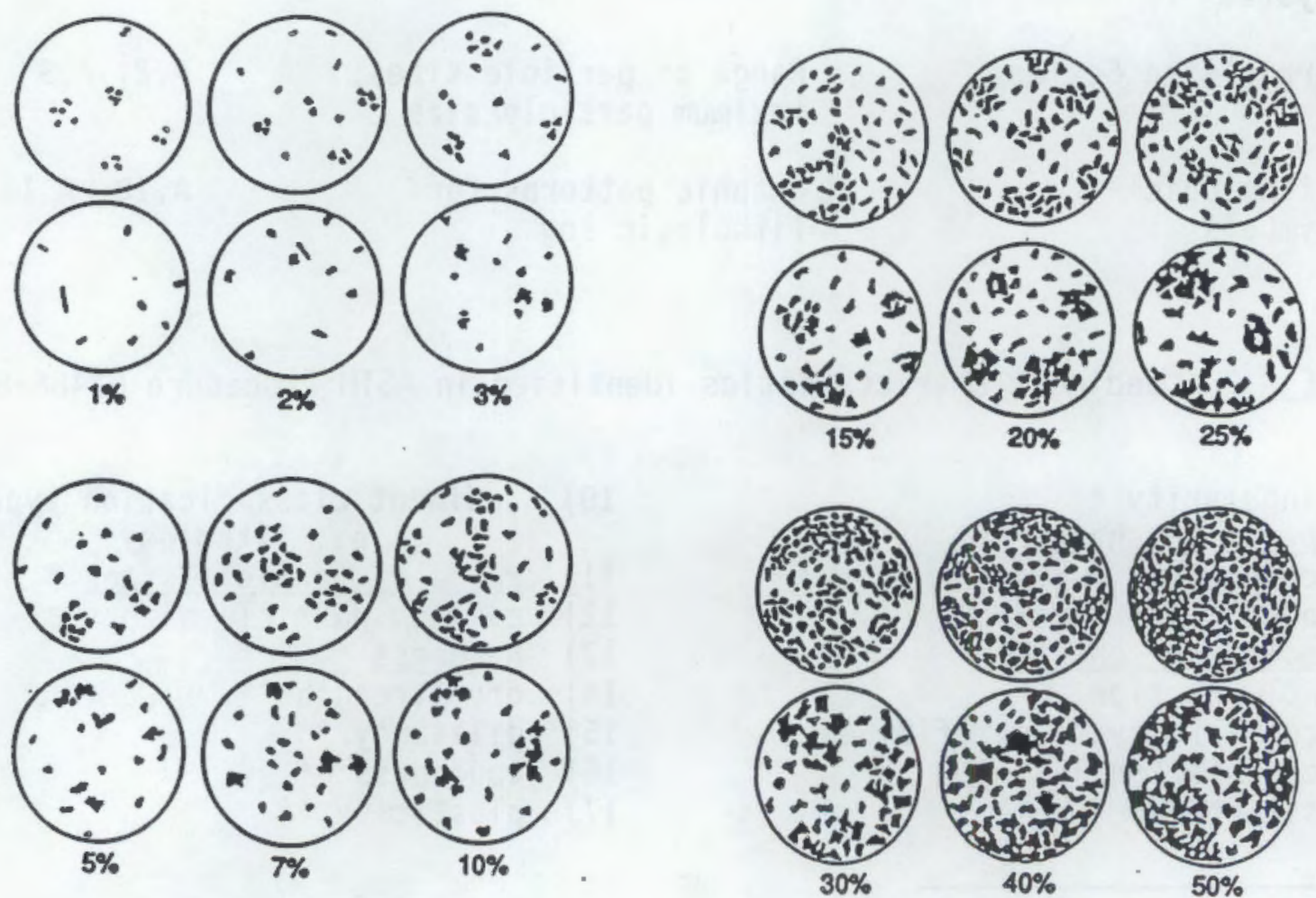

FIGURE A.2. Comparison Chart Used to Estimate the Percentages of Constituents (from AGI 1982) 


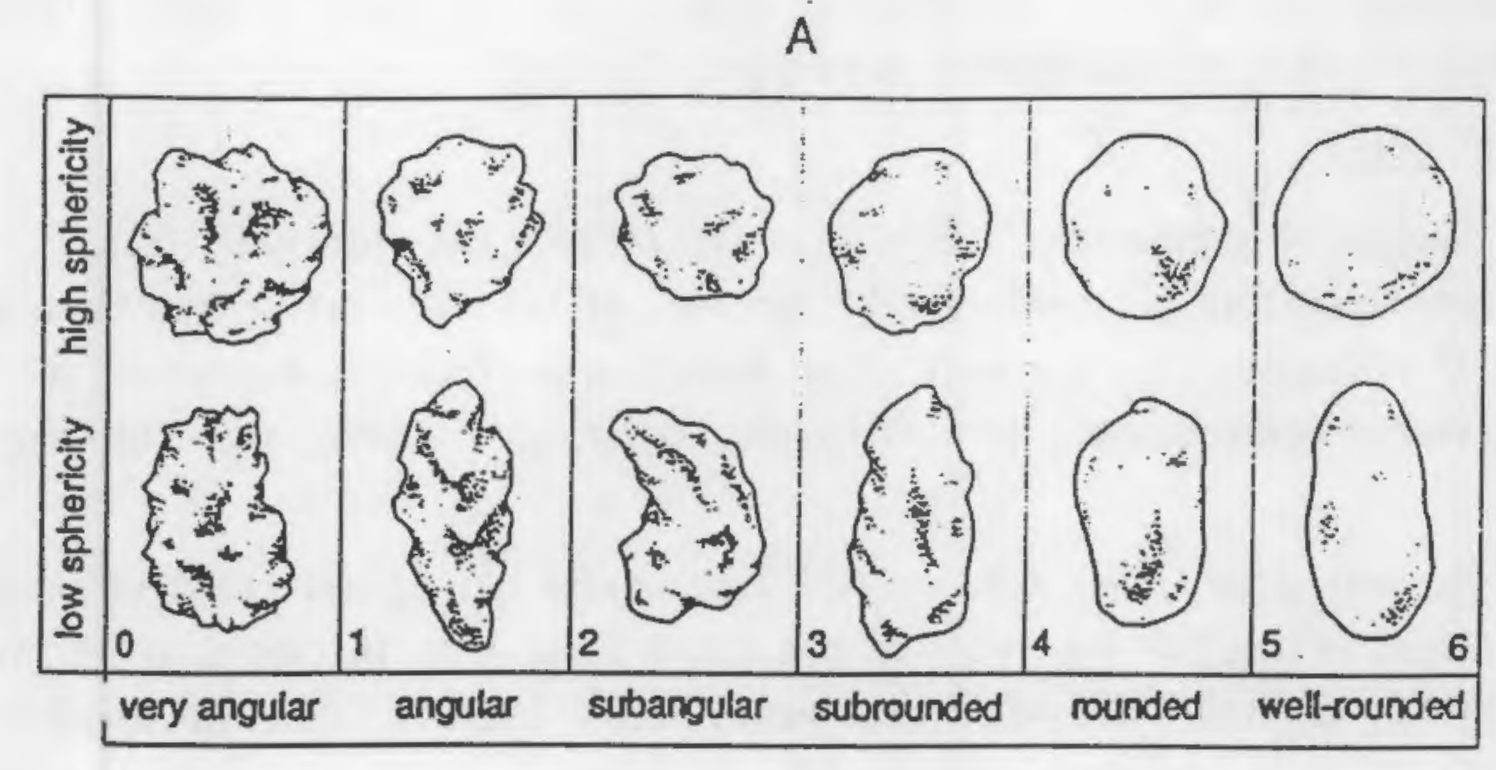

B
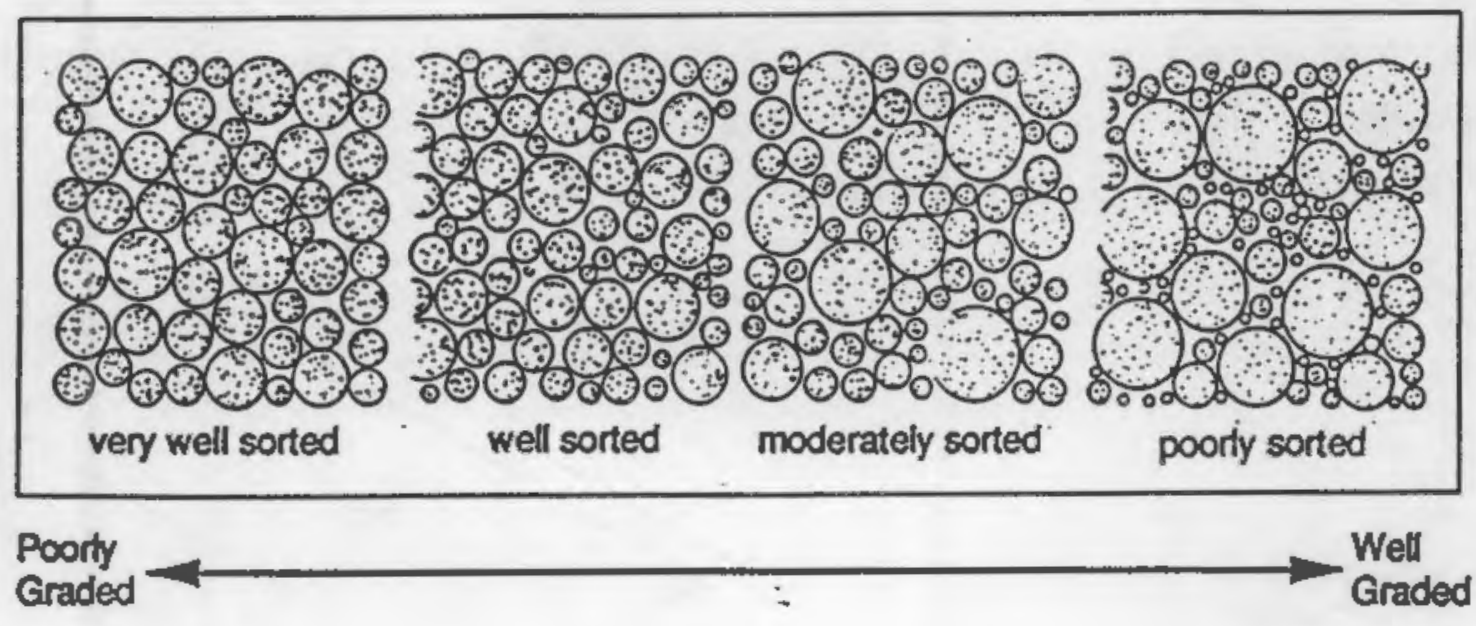

FIGURE A.3. Charts Used to Visually Estimate (A) Roundness/Sphericity and (B) Sorting/Grading 


\section{A.2.1 Angularity}

The angularity of sedimentary particles is a reflection of the sedimentary environment and the amount of time that has elapsed before deposition and burial. A chart showing how to classify the angularity of sedimentary particles is presented in Figure A.3A. A range of angularity may be stated, such as: subrounded to rounded.

\section{A.2.2 Shape}

Shapes of sedimentary particles often reflect the internal characteristics (e.g., preferential parting) of the material or sometimes the type of sedimentary environment. For example gravel clasts deposited in high-energy environments, such as beaches and river bottoms, are often worn flat.

According to Figure A.4, gravel-sized clasts may be described in one of four ways. First, if the ratio of the clast's width to thickness is $>3$, it is classified as flat. Second, if the ratio of the clast's length to width is $>3$, the clast is elongate. Third, if both criteria apply the clast is both flat and elongate. And last, if none of the criteria apply, then shape is not mentioned. Indicate the fraction of the clasts that have the shape, such as: one-third of gravel clasts are flat. Particle shape did not apply to most of the sediments logged during this project and the few pebbles that were observed were neither flat nor elongate.

$W=$ Width
$T=$ Thickness
$L=$ Length

Flat: $W / T>3$

Elongated: $L W>3$

Flat and Elongated: meets both criteria

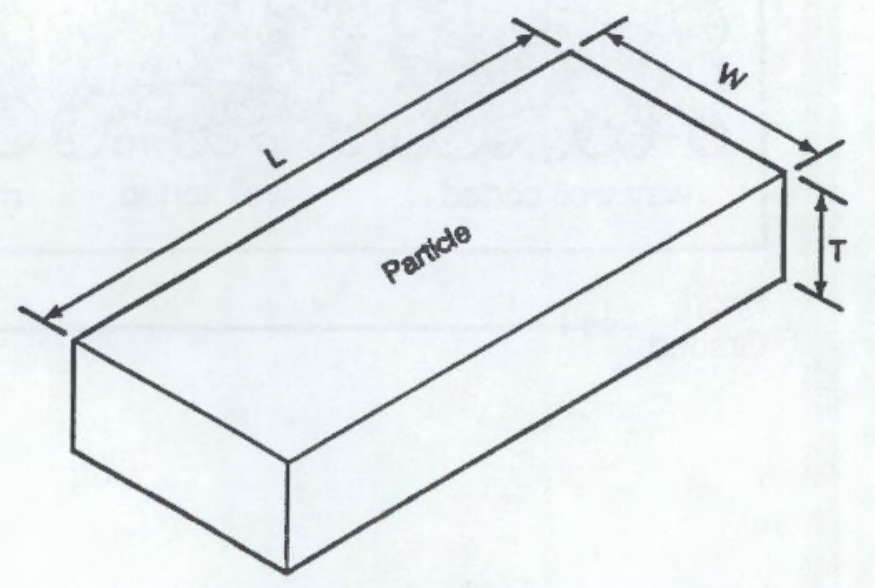

FIGURE A.4. Criteria Used to Describe Particle Shape of Pebbles and Large Gravels (From ASTM 1984) 


\section{A.2.3 Color}

Color may be useful in identifying materials of similar geologic origin. For example, color was often a useful criteria for differentiating Younger Bay Mud from 01der Bay Mud. Sediment color was determined by comparing the wet sediment with standard sediment colors given in Munsell (1975). The advantage to using the Munsell soil color system is that it provides a consistent, standardized method for describing color and subjectivity is minimized.

The Munsell color notation consists of three simple variables that combine to describe all colors known in the Munsell soil color system. The three variables are: hue, value, and chroma (Figure A.5). The hue notation indicates the relation of the sediment color with respect to red, yellow, green, blue and purple; the value notation indicates its lightness, and the chroma notation indicates its strength (i.e., intensity).

Color can be described either by the Munsell notation (e.g. 5YR 5/3; hue $=5 Y R$, value $=5$, chroma $=3$ ) or by its equivalent color name (e.g. reddish brown). Both the color name and Munsell notation were recorded on core logs (see Appendix B). Only rarely was there not a reasonable match between the true color of the core sediment and one of the colors on a Munsell color chart.

\section{A.2.4 $\underline{\text { Odor }}$}

Odors may indicate the presence of contaminants or be the result of the geochemical environment. Odors most frequently noted were that of petroleum hydrocarbons and the smell of rotten eggs (an indication of the presence of hydrogen sulfide). Both of these odors were restricted to the Younger Bay Mud unit. Petroleum odors may be the result of contamination of the sediments by shipping spills or industrial waste, or perhaps are derived from decaying organic matter present in these sediments. Hydrogen sulfide is a common natural by-product in chemically reducing environments such as the 0 akl and Harbor estuary. 

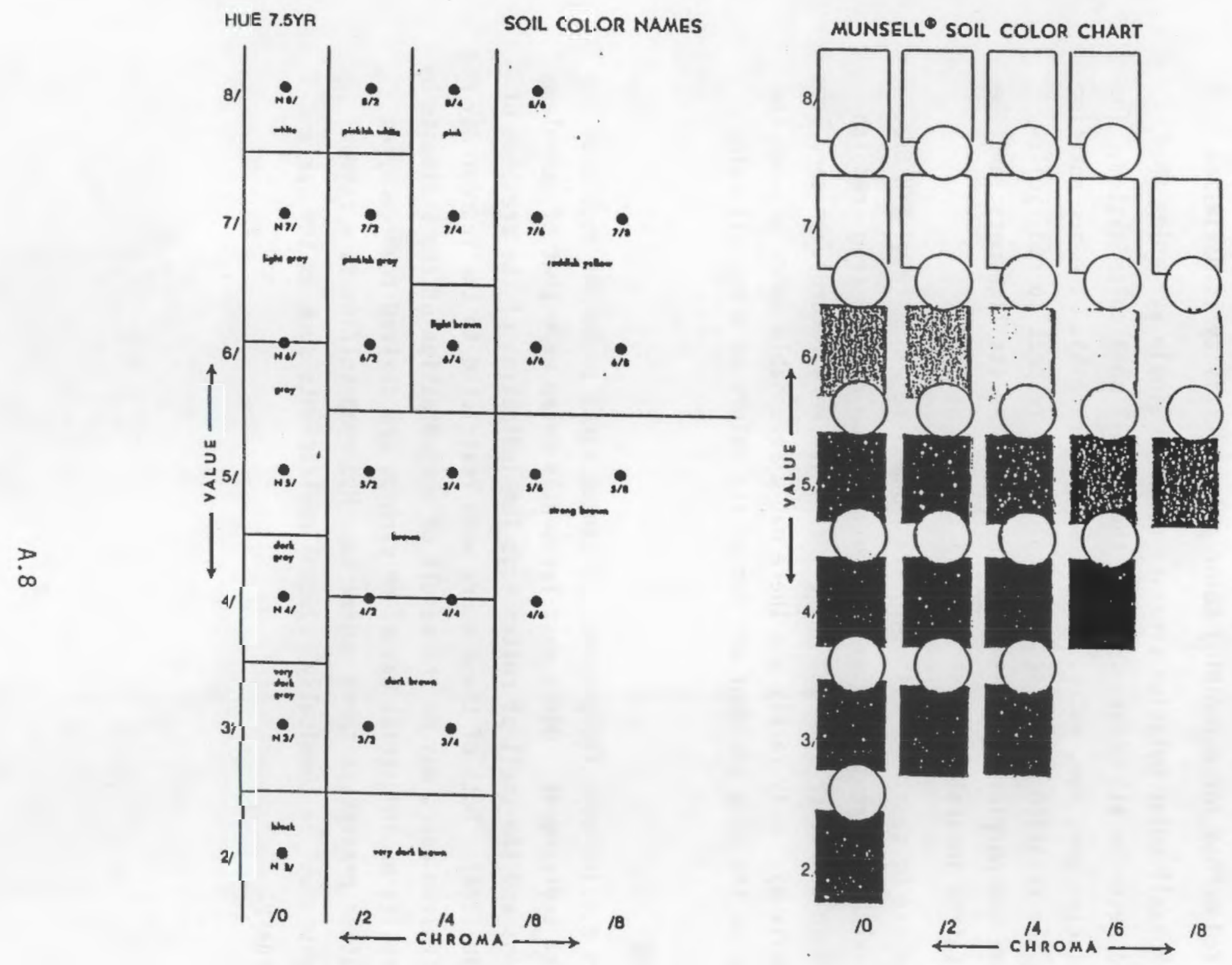

7.5YR

EIGURE A.5. Example of a Page from the Munsell Soll Color for Hue 7.5YR 


\section{A.2.5 Moisture Condition}

Moisture condition is described as either dry, moist, or wet according to the following criteria:

DRY Absence of moisture, dry to the touch

MOIST Damp but no visible water

WET Visible free water, usually soil is below water table (i.e., saturated)

All the sediments logged for this project were taken from below sea level and did not lose any significant moisture between the time they were drilled and logged. Therefore, they are all classified as wet.

\section{A.2.6 $\mathrm{HCl}$ Reaction}

The reaction (i.e., effervescence) of sedimentary material, as a result of adding hydrochloric acid, is an indication of the presence of calcium carbonate. Calcium carbonate in sediments may be derived from a variety of sources including: 1) physical disintegration of preexisting carbonate rocks (e.g., limestone, marble), 2) biogenic precipitation (e.g., shell, bone), and 3) soil development. In the last example, calcium carbonate concentrations, often referred to as caliche or calcrete, may accumulate over time near the land's surface in arid climates. Where calcium carbonate concentrations occur in combination with other evidence for soil development, such as root traces and oxidation, then a pedogenic (soil forming) origin is favored. Criteria for describing the reaction with $10 \mathrm{~N} \mathrm{HCl}$ are as follows:

NONE No visible reaction

WEAK Some reaction, with bubbles forming slowly

STRONG Violent reaction, with bubbles forming immediately

A solution of $10 \mathrm{~N} \mathrm{HCl}$ is obtained by slowly adding one part of concentrated hydrochloric acid to three parts of distilled water. 


\section{A.2.7 Consistency}

Consistency is a measure of the firmness or consolidation of sedimentary material. In general, there is a direct relationship between consistency and age of the deposit (i.e., older deposits are usually more firm because of compaction and/or cementation). Consistency is most applicable to fine-grained sediments and least applicable on sediments that contain significant amounts of gravel. The criteria used to determine consistency are as follows:

VERY SOFT Penetrometer penetrates soil greater than $4 \mathrm{~cm}$

SOFT Penetrometer penetrates soil 2.0 to $4.0 \mathrm{~cm}$

FIRM Penetrometer penetrates soil 0.25 to $2.0 \mathrm{~cm}$

HARD Penetrometer penetrates soil less than $0.25 \mathrm{~cm}$

The penetrometer used for sediment core descriptions consists of a 6 -in. nail spike attached to a clay brick for a total mass of $2.0 \mathrm{~kg}$; the nail spike is marked in centimeter increments to quantify the amount of soil penetration.

\section{A.2.8 Cementation}

Often sedimentary particles are held together with a binding cement. Three common natural cements are calcium carbonate (1ime), silica, and iron-oxide compounds. Particles cemented with calcium carbonate effervesce in the presence of hydrochloric acid (see Section A.2.6 above). Sediments cemented with iron oxide are usually some shade of red, yellow, or brown. Usually there is a relationship between consistency (Section A.2.7) and cementation, in that strongly cemented deposits are also hard to very hard. Criteria used to describe the degree of cementation are:

WEAK Crumbles or breaks with handling or light finger pressure MODERATE Crumbles or breaks with considerable finger pressure STRONG Will not crumble or break with finger pressure

\section{A.2.9 Structure}

Structures are features that originate within the layers of sediment or at the sediment/water interface in response to various physical, biologic and/or chemical processes. Structures may be classified into two categories: 
primary and secondary. Primary structures form as the sediment is being deposited (e.g., lamination, stratification). Secondary structures form after deposition, often as a result of compaction or other stresses (e.g., fissured, slickensided), biologic activity (e.g., root traces, mottling), and soil development (e.g., homogeneous, blocky, mottled). The following are some common structures observed in sedimentary deposits.

\section{PRIMARY STRUCTURES}

STRATIFIED Alternating layers of varying material or color with layers at least $6 \mathrm{~mm}$ thick

LAMINATED Alternating layers of varying material or color with the layers less than $6 \mathrm{~mm}$ thick

LENSED Inclusion of small pockets of different sediment type, such as small lenses of sand scattered through a mass of clay. (This type of structure may also be secondary).

\section{SECONDARY STRUCTURES}

FISSURED Breaks along definite planes of fracture with little resistance to fracturing

SLICKENSIDED Fracture planes appear polished or glossy, sometimes striated

BLOCKY Cohesive soil that can be broken down into small angular lumps which resist further breakdown

MOTTLED Variation in color of sediments as represented by localized spots or blotches of color or shades of color

HOMOGENEOUS Same color and appearance throughout

\section{A.2.10 Sediment Classification Type}

The classification method used in this study is the Unified Soil Classification System, which consists of a two-letter designation for most soils (i.e., unconsolidated sediments). A simplified version of the Unified Soil Classification System is presented in Figure A.6, while a more-detailed breakdown is presented in Figure A.7. 


\begin{tabular}{|c|c|c|c|c|}
\hline \multicolumn{3}{|c|}{ Major Divisions } & $\begin{array}{c}\text { Group } \\
\text { Symbols }\end{array}$ & Description \\
\hline \multirow{8}{*}{ 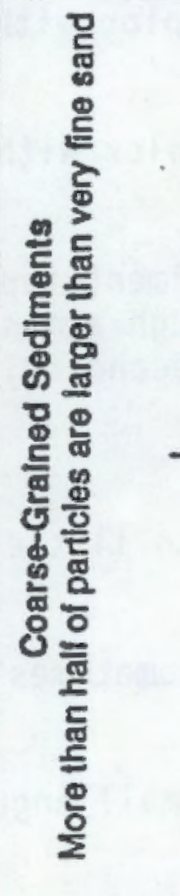 } & \multirow{4}{*}{$250 \%$ Gravel } & \multirow{2}{*}{$\begin{array}{c}\text { Clean } \\
\text { Gravels }\end{array}$} & GW & $\begin{array}{l}\text { Well-graded (i.e., poorly sorted) gravels, } \\
\text { gravel-sand mixtures, little or no fines }\end{array}$ \\
\hline & & & GP & $\begin{array}{l}\text { Poorly graded (i.e., well sorted) gravels, } \\
\text { gravel-sand mixtures, little or no fines }\end{array}$ \\
\hline & & \multirow{2}{*}{$\begin{array}{c}\text { Gravels } \\
\text { with } \\
\text { Fines }\end{array}$} & GM & Sity gravels, gravel-sand-silt mixtures \\
\hline & & & GC & Clayey gravels, gravel-sand-clay mixtures \\
\hline & \multirow{4}{*}{$250 \%$ Gravel } & \multirow{2}{*}{$\begin{array}{l}\text { Clean } \\
\text { Sands }\end{array}$} & sw & Well-graded sands, gravelly sands, little or no fines \\
\hline & & & SP & Poorly graded sands, gravelly sands, little or no fines \\
\hline & & \multirow{2}{*}{$\begin{array}{l}\text { Sands } \\
\text { with } \\
\text { Fines }\end{array}$} & SM & Sitty sands, sand-silt mixtures \\
\hline & & & SC & Clayey sands, sand-clay mixtures \\
\hline \multirow{4}{*}{ 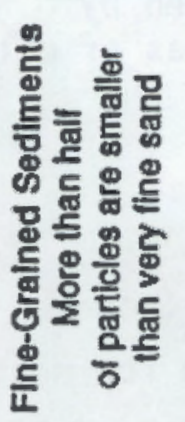 } & \multirow{4}{*}{$\begin{array}{l}\text { Silts and } \\
\text { Clays }\end{array}$} & \multirow{2}{*}{$\begin{array}{l}\text { Low } \\
\text { Liquid } \\
\text { Limit }\end{array}$} & ML & $\begin{array}{l}\text { Sitts and very fine sands, silty or clayey fine sands, } \\
\text { or clayey sitts, writh slight plasticity }\end{array}$ \\
\hline & & & $\mathrm{CL}$ & $\begin{array}{l}\text { Clays of low to medium plasticity, gravelly clays, } \\
\text { sandy clays, sity clays, lean clays }\end{array}$ \\
\hline & & \multirow{2}{*}{$\begin{array}{c}\text { High } \\
\text { Liquid } \\
\text { Limit }\end{array}$} & MH & Silts or fine sandy silts with moderate plasticity \\
\hline & & & $\mathrm{CH}$ & Clays of high plasticity, fat clays \\
\hline
\end{tabular}

FIGURE A.6. Abbreviated Form of the Unified Soil Classification System (From AGI 1982) 

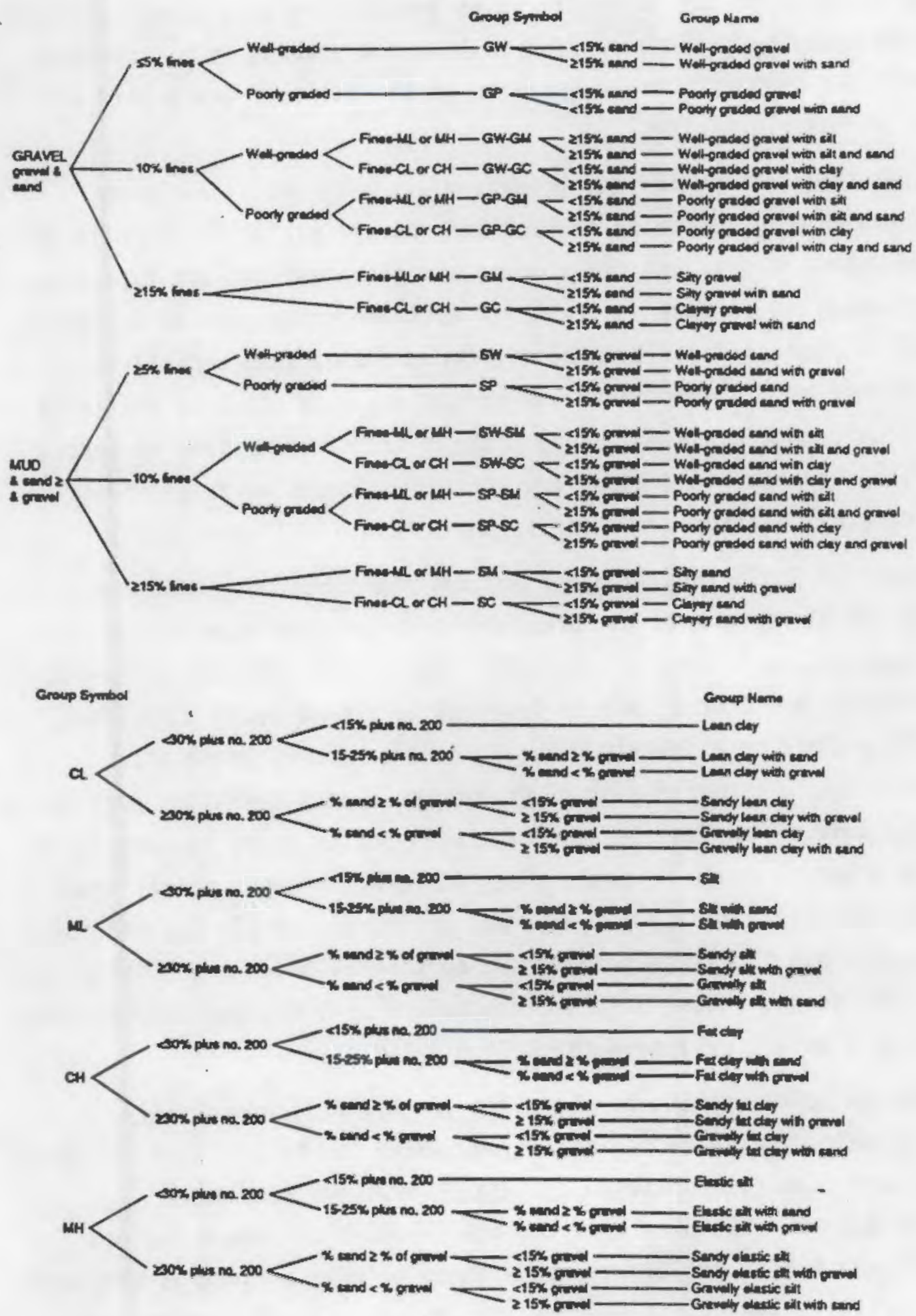

FIGURE A.7. Detailed Flow Chart For the Classification of Coarse- and Fine-
Grained Soils Using the Unified Soil CTassification System 
According to the Unified Soil Classification System, coarse-grained sediments are classified based on grain-size distribution and grading (i.e., sorting), while fine-grained sediments are classified on the basis of grain size and liquid limit versus plasticity.

Particle-size distribution may be determined with precision using laboratory methods (e.g., sieving of sand and coarser particles; pipette or hydrometer analysis of silt and clay). Because these methods are expensive and time-consuming, it is more desirable to estimate grain size using rapid visual-manual techniques described below. For example, sand and coarser particles are most easily identified via comparison with standard charts of grain size (Figures A.8 and A.9). Fine-grained soils, consisting of mostly silt and/or clay, on the other hand, are identified based on manual tests of their dry strength, dilatancy, toughness, and plasticity (Figure A.10).

In the Unified Soil Classification System, the first letter of the sediment-type symbol represents the predominant grain-size interval, be it gravel (G), sand (S), silt (M), or clay (C). For coarse-grained sediments, the first letter (i.e., G or S) may be followed by a descriptor of grading, either W (well graded) or P (poorly graded), or a secondary grain-size descriptor $(M$ or $C)$. The definition of grading is opposite that of sorting, a common geologic term. For example, a clean, well-sorted sand, consisting of particles over a narrow range in grain size, is referred to as poorly graded in the Unified Soil Classification System and would receive the designation "SP". The relationship between grading and sorting is shown graphically in Figure A.3B. The second letter in the fine-grained soil designation consists of either L (low liquid limit) or $\mathrm{H}$ (high liquid limit).

The lithology column on the geologic log (Figure A.1) essentially represents a graphic display of sediment type, which can be utilized for quick easy reference and comparison between different cores and thus make interpretations easier. Examples of lithologic symbols in common use are presented in Figure A.11. Additional symbols may be used as long as they are graphically representative of the feature and are specifically defined and identified in a key that accompanies lithologic logs. 


\begin{tabular}{|c|c|c|c|c|c|c|c|}
\hline \multicolumn{3}{|c|}{ Grade Limits } & \multirow[b]{2}{*}{ inches } & \multirow{2}{*}{$\begin{array}{c}\text { U.S. } \\
\text { Standard } \\
\text { Sieve Series }\end{array}$} & \multirow{2}{*}{\multicolumn{3}{|c|}{ Grade Name }} \\
\hline phi & $\mathrm{mm}$ & $\mathrm{mm}$ & & & & & \\
\hline-12 & $4096-$ & $-\quad--$ & 161.3 & $-\quad-$ & 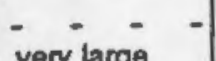 & & \multirow{11}{*}{ GRAVEL } \\
\hline-11 & $2048-$ & $-\quad--$ & 80.6 & $-\quad-$ & $\overline{l a r c e}^{-}-\overline{-}$ & & \\
\hline-10 & $1024-$ & --- & 40.3 & 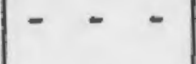 & $-\overline{\text { medium }}-\overline{-}$ & Boulders & \\
\hline-9 & $512-$ & $-\quad--$ & 20.2 & $-\quad-\quad-$ & $\overline{\text { small }}^{-}-$ & & \\
\hline 8 & $256=$ & $-\quad--$ & 10.1 & -- & large & & \\
\hline-7 & $128-$ & $-\quad--$ & 5.0 & $-\quad--$ & $\overline{\text { small }}-\overline{-}$ & Cobbles & \\
\hline-6 & $64-$ & $-\quad--$ & 2.52 & $63 \mathrm{~mm}-$ & very coarse & \multirow{5}{*}{ Pebbles } & \\
\hline .5 & $32-$ & $-\quad-$ & 1.26 & $31.5 \mathrm{~mm}$ & $\overline{\text { coarse }}-\overline{-}$ & & \\
\hline-4 & $16-$ & $-\quad-\quad-$ & 0.63 & $16 \mathrm{~mm}-$ & ${ }_{\text {medium }}^{-}-$ & & \\
\hline-3 & 8- & $-\quad-\quad-$ & 0.32 & $8 \mathrm{~mm}-$ & $\operatorname{line}^{-}--$ & & \\
\hline-2 & $4-$ & $-\quad-\quad-$ & 0.16 & No. 5 - & very fine & & \\
\hline-1. & $-2-$ & & 0.08 & No. $10-$ & very coarse & \multirow{5}{*}{ Sand } & \multirow{5}{*}{ SAND } \\
\hline 0 & $1-$ & $-\quad-$ & 0.04 & No. 18 - & $\overline{c o s}_{\text {corse }}-\overline{-}$ & & \\
\hline+1 & $1 / 2-$ & $0.500-$ & - & No. 35 - & $-\overline{m e d i u m}^{-}-$ & & \\
\hline+2 & $.^{1 / 4}-$ & $0.250-$ & - & No. 60 - & $\overline{f i n e}^{-}--$ & & \\
\hline+3 & $1 / 8$ & $0.125-$ & - & No. 120 & ${ }_{\text {very fine }}^{-}-$ & & \\
\hline & $1 / 16-$ & 0.062 & & - No. $230-$ & coarse & \multirow{4}{*}{ Sith } & \multirow{8}{*}{ MUD } \\
\hline+5 & $1 / 32-$ & $0.031-$ & - & $-\quad-$ & - $\overline{\text { medium }}^{-}-$ & & \\
\hline+6 & $1 / 64-$ & $0.016-$ & - & -- & $\overline{f i n e}^{-}--$ & & \\
\hline+7 & $1 / 128-$ & $0.008-$ & $-\quad-$ & -- & - very fine & & \\
\hline+8 & $1 / 256-$ & $0.004-$ & -- & -- & coarse & \multirow{4}{*}{ Clay Size } & \\
\hline+9 & $1 / 512-$ & $0.002-$ & -- & $-\cdot-$ & medium & & \\
\hline+10 & $1 / 1024$ & $0.001-$ & - & $-\quad-$ & fine -- & & \\
\hline+11 & $1 / 2048$ & $0.0005-$ & $-\quad-$ & $-\quad-$ & very fine & & \\
\hline 12 & $-1 / 4096-$ & $-0.00025-$ & & & & & \\
\hline
\end{tabular}

FIGURE A.8. Grain-size Scale Used to Determine Sedimentary Particle Size 


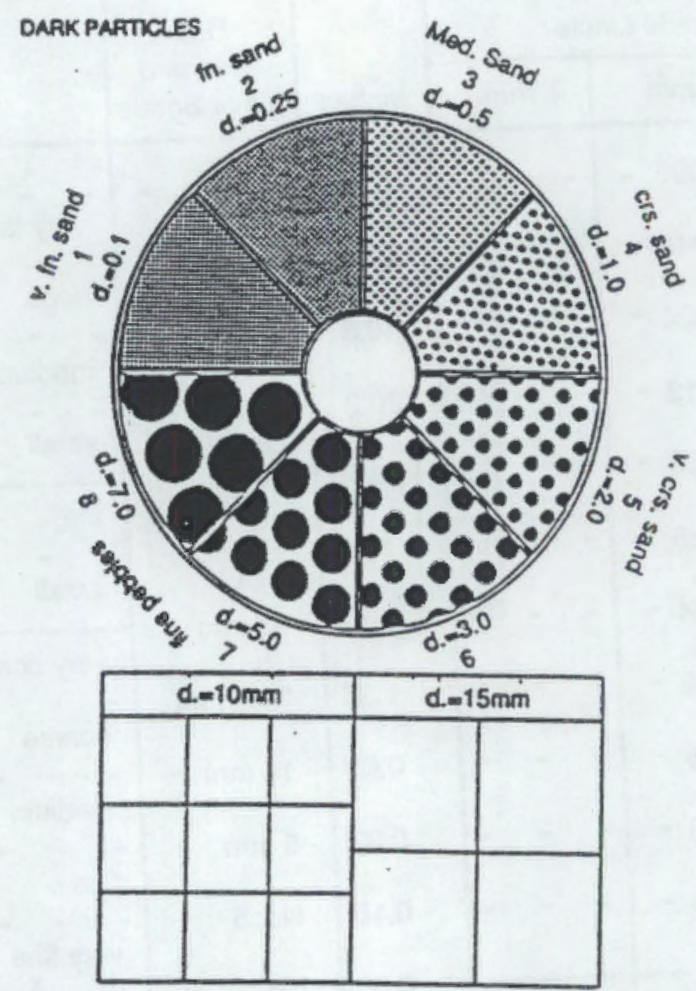

FIGURE A.9. Comparison Chart Used to Distinguish Among Sand to Pebble-size Particles (From AGI 1982). For larger particles, refer to

Figure A.8; for smaller particles, refer to Sections A.2.13 and A.2.16 in this Appendix

\begin{tabular}{|c|c|c|c|c|}
\hline \multirow{2}{*}{$\begin{array}{l}\text { Sediment } \\
\text { Type }\end{array}$} & Dry Strength & Duatancy & \multirow{2}{*}{ 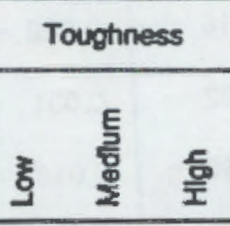 } & \multirow{2}{*}{ 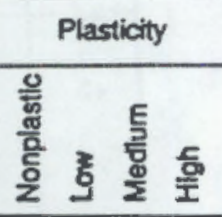 } \\
\hline & 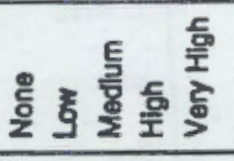 & 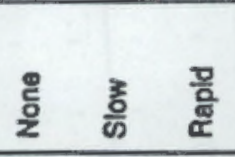 & & \\
\hline $\begin{array}{l}\text { ML } \\
\text { (SHY) }\end{array}$ & & & & \\
\hline $\begin{array}{c}\text { MH } \\
\text { (Elastio Silt) }\end{array}$ & & & & \\
\hline$\underset{\text { (2an Clay) }}{C}$ & & & & \\
\hline $\begin{array}{c}\mathrm{CH} \\
\text { (Fat Clay) }\end{array}$ & & & & \\
\hline
\end{tabular}

FIGURE A.10. Identification of Inorganic Fine-grained Soils From Manual Tests 


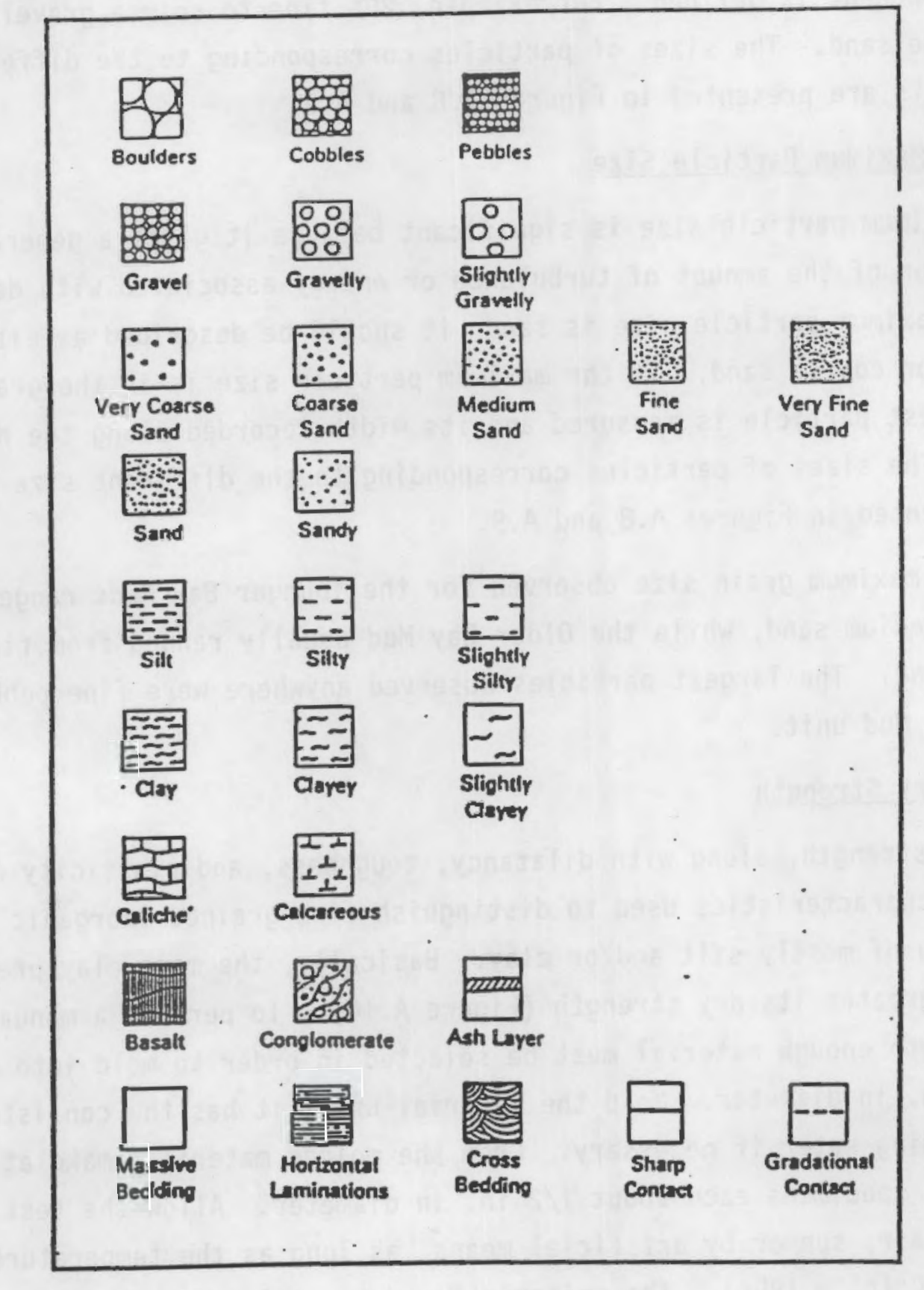

FIGURE A.11. Lithologic Symbols Used on Core Log Forms 


\section{A.2.11 Range of Particle Sizes}

For gravel- and sand-sized particles, the range of particle sizes within each component is defined. For example, $20 \%$ fine to coarse grave1, $40 \%$ fine to coarse sand. The sizes of particles corresponding to the different size components are presented in Figures A.8 and A.9.

\section{A.2.12 Maximum Particle Size}

Maximum particle size is significant because it gives a general indication of the amount of turbulence or energy associated with deposition. If the maximum particle size is sand, it should be described as either fine, medium, or coarse sand. If the maximum particle size is in the gravel range, the largest particle is measured and its width recorded along the narrowest axis. The sizes of particles corresponding to the different size components are presented in Figures A.8 and A.9.

The maximum grain size observed for the Younger Bay Muds ranged from silt to medium sand, while the 01der Bay Mud usually ranged from fine sand to coarse sand. The largest particles observed anywhere were fine pebbles in the Older Bay Mud unit.

\section{A.2.13 Dry Strength}

Dry strength, along with dilatancy, toughness, and plasticity are physical characteristics used to distinguish fine-grained inorganic soils, consisting of mostly silt and/or clay. Basically, the more clay present in a soil the greater its dry strength (Figure A.10). To perform a manual test of dry strength enough material must be selected in order to mold into a ball about 1 in. in diameter. Mold the material until it has the consistency of putty, adding water if necessary. From the molded material, make at least three test specimens each about $1 / 2$ in. in diameter. Allow the test specimens to dry in air, sun or by artificial means, as long as the temperature does not exceed $60^{\circ} \mathrm{C}$ (ASTM 1984). The criteria for determining dry strength are as follows:

NONE The dry specimen crumbles into powder with mere pressure of handling

LOW The dry specimen crumbles into powder with light finger pressure 
MEDIUM The dry specimen breaks into pieces or crumbles with considerable finger pressure

HIGH The dry specimen cannot be broken with finger pressure. Specimen will break into pieces between thumb and a hard surface

VERY HIGH The dry specimen cannot be broken between the thumb and a hard surface

Dry strength was determined for Richmond Harbor Program rores by sampling selected intervals and allowing the samples to air dry overnight. Dry strength was determined the next day and noted in the comments column of the geologic log.

\section{A.2.14 Dilatancy}

Dilatancy is a measure of how easily a soil gives up water when shaken. For example, some clays have the ability to absorb and retain large amounts of water into their crystal lattice. "Fat" clays tend to retain their water even under stress whereas "lean" clays and silt tend to release water when shaken.

To test for dilatancy select enough material to mold into a ball about $1 / 2$ in. in diameter. Mold the material, adding water if necessary, until it has a soft, but not sticky consistency. Smooth the soil ball in the palm of the hand with a blade of a knife or small spatula. Shake horizontally, striking the side of the hand vigorously against the other several times. Note the reaction of water appearing on the surface of the soil. Squeeze the sample by closing the hand or pinching the soil between the fingers, and note the reaction. Specimens with high dilatancy will quickly yield water when shaken and absorb water when squeezed. The criteria for describing dilatancy are:

NONE No visible change in the specimen

SLOW Water appears slowly on the surface of the specimen during shaking and does not disappear or disappears slowly upon squeezing

RAPID Water appears quickly on the surface of the specimen during shaking and disappears quickly upon squeezing 
The range of dilatancy for the different fine-grained sediment types is shown in Figure A.10. From this figure it is apparent that dilatancy decreases with decreasing grain size.

\section{A.2.15 Toughness}

After completion of the dilatancy test, shape the same specimen into an elongated pat and roll by hand on a smooth surface or between the palms into a thread about $1 / 8 \mathrm{in.}(3 \mathrm{~mm})$ in diameter. (If the sample is too wet to roll easily, it should be spread into a thin layer and allowed to lose some water by evaporation.) Fold the sample threads and reroll repeatedly until the thread crumbles at a diameter of about $1 / 8 \mathrm{in}$. The thread will crumble at a diameter of $1 / 8 \mathrm{in}$. when the soil is near the plastic limit. Note the pressure required to roll the thread near the plastic limit. Also, note the strength of the thread. After the thread crumbles, the pieces should be lumped together and kneaded until the lump crumbles. Note the toughness of the material during kneading and classify into one of the following categories.

LOW Only slight pressure is required to roll the thread near the plastic limit. The thread and lump are weak and soft

MEDIUM Medium pressure is required to roll the thread to near the plastic limit. The thread and lump have medium stiffness.

HIGH Considerable pressure is required to roll the thread to near the plastic limit. The thread and the lump have very high stiffness.

The range of toughness for the different fine-grained sediment types is shown in Figure A.10. From this figure it is apparent that toughness increases with a decrease in particle size.

\section{A.2.16 Plasticity}

On the basis of observations made during the toughness test, describe the plasticity of the material according to the following criteria:

NONPLASTIC A 1/8 in. thread cannot be rolled at any water content

LOW The thread can barely be rolled and the lump cannot be formed when drier than the plastic limit. 
MEDIUM The thread is easy to roll and not much time is required to reach the plastic limit. The thread cannot be rerolled after reaching the plastic limit. The lump crumbles when drier than the plastic limit.

HIGH It takes considerable time rolling and kneading to reach the plastic limit. The thread can be rerolled several times after reaching the plastic limit. The lump can be formed without crumbling when drier than the plastic limit.

The range of plasticity for the different fine-grained sediment types is shown in Figure A.10. From this figure it is apparent that an increase in plasticity accompanies a decrease in grain size. 


\section{A.3 REFERENCES}

American Geological Institute. 1982. AGI Data Sheets for Geology in the Field, Laboratory, and Office: American Geological Institute. Falls Church, Virginia.

American Society for Testing and Materials (ASTM). 1984. Standard Practice for description and identification of soils (Visual-manual procedure):

Procedure D2488-84. American Society for Testing and Materials.

Philadelphia, Pennsylvania, Pp. 293-302.

Compton, R. R. 1962.. Manual of Field Geology. John Wiley and Sons, New York, p. 378.

Last, G. V., and T. L. Liikala. 1987. A Field Guide for Well-site Geologists: Cable-tool Drilling. PNL-6392. Pacific Northwest Laboratory, Richland, Washington.

Munsel1. 1975. Munsell Soil Color Charts. Macbeth, A Division of Kollmorgen Co. Baltimore, Maryland, 7 charts.

Tucker, M. E. 1982. The Field Description of Sedimentary Rocks. John Wiley and Sons, New York, p. 112. 
APPENDIX B

GEOLOGIC ANALYSES DATA 


\section{Core Data Log}

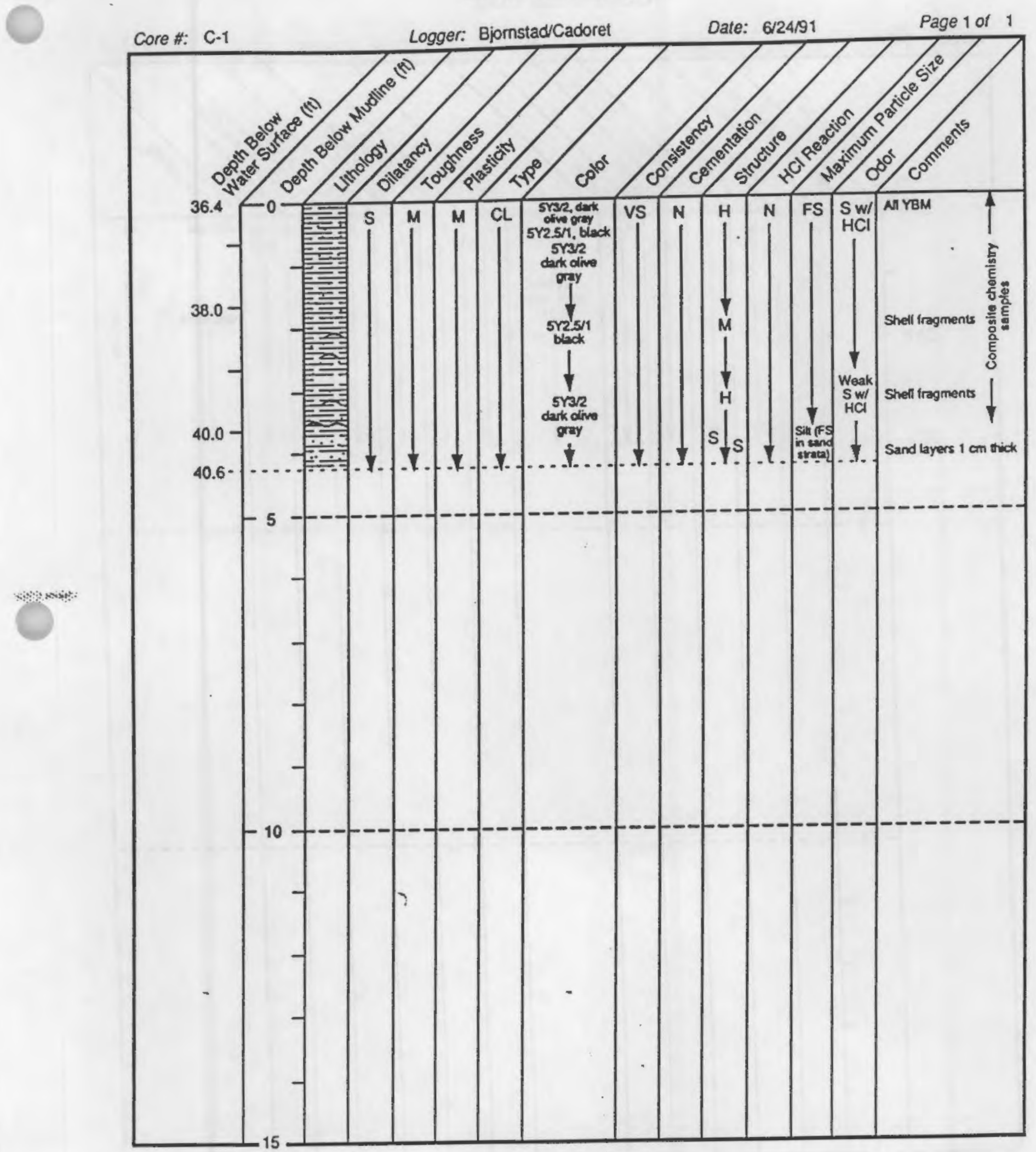


Core Data Log

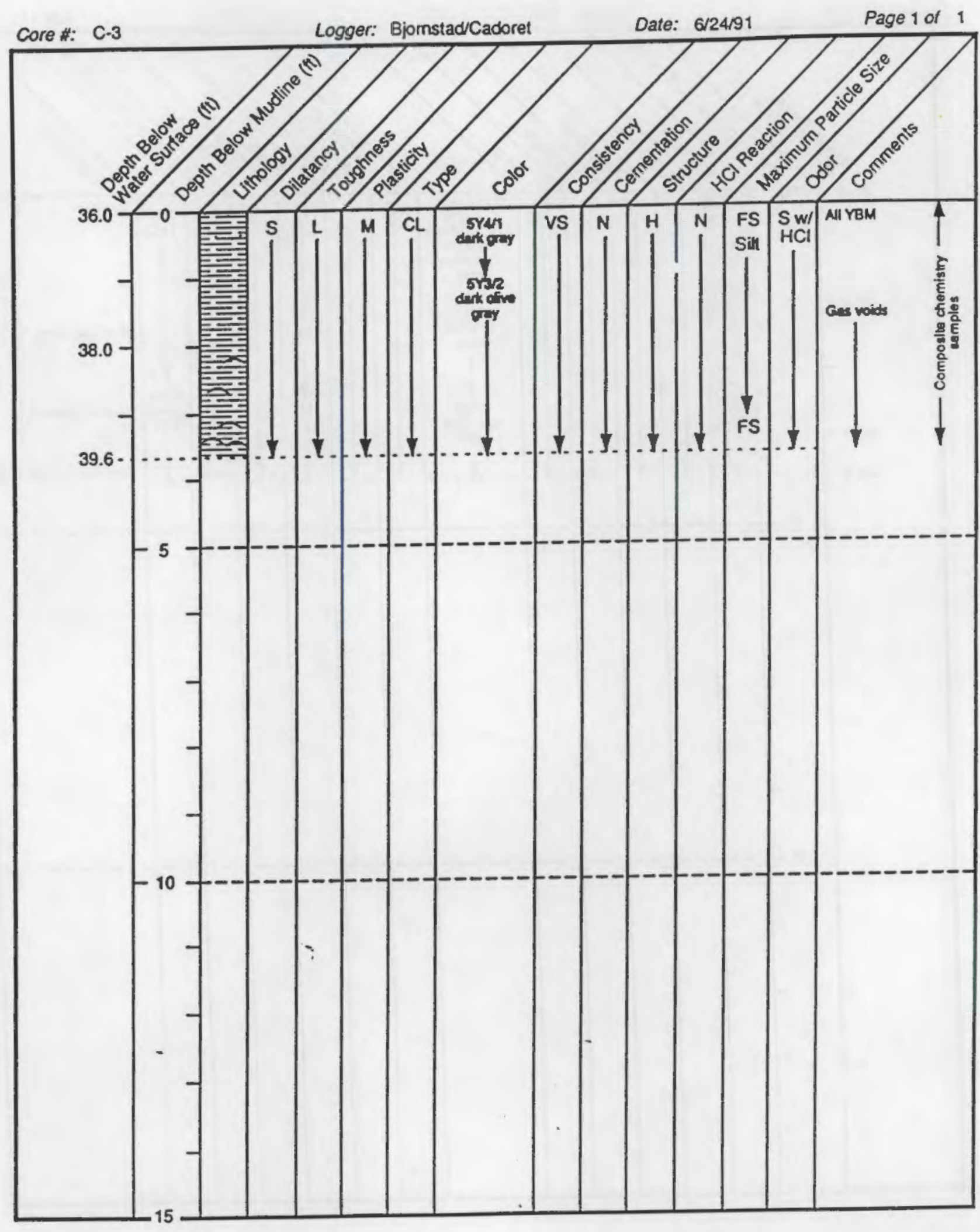


Core Data Log

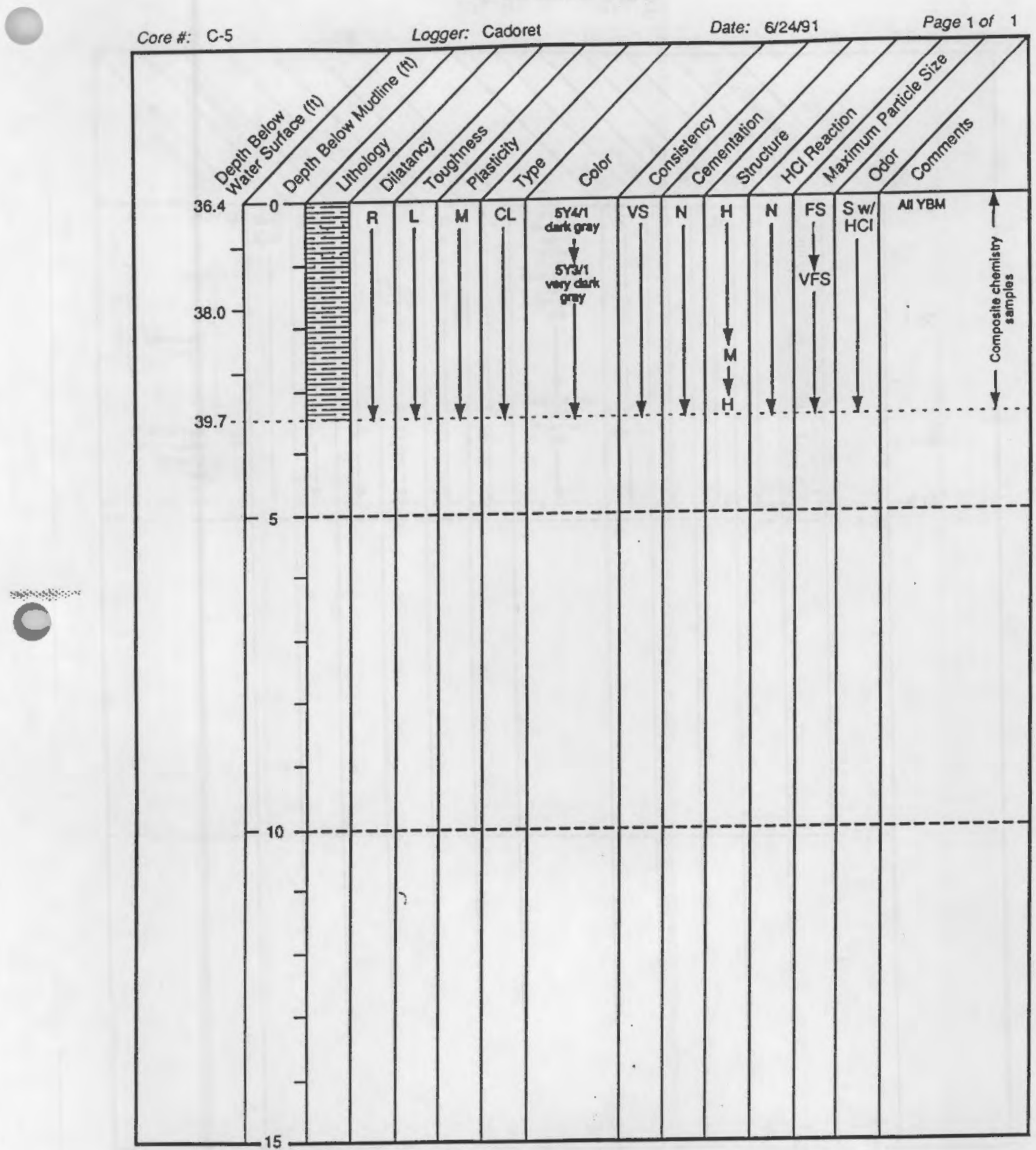




\section{Core Data Log}

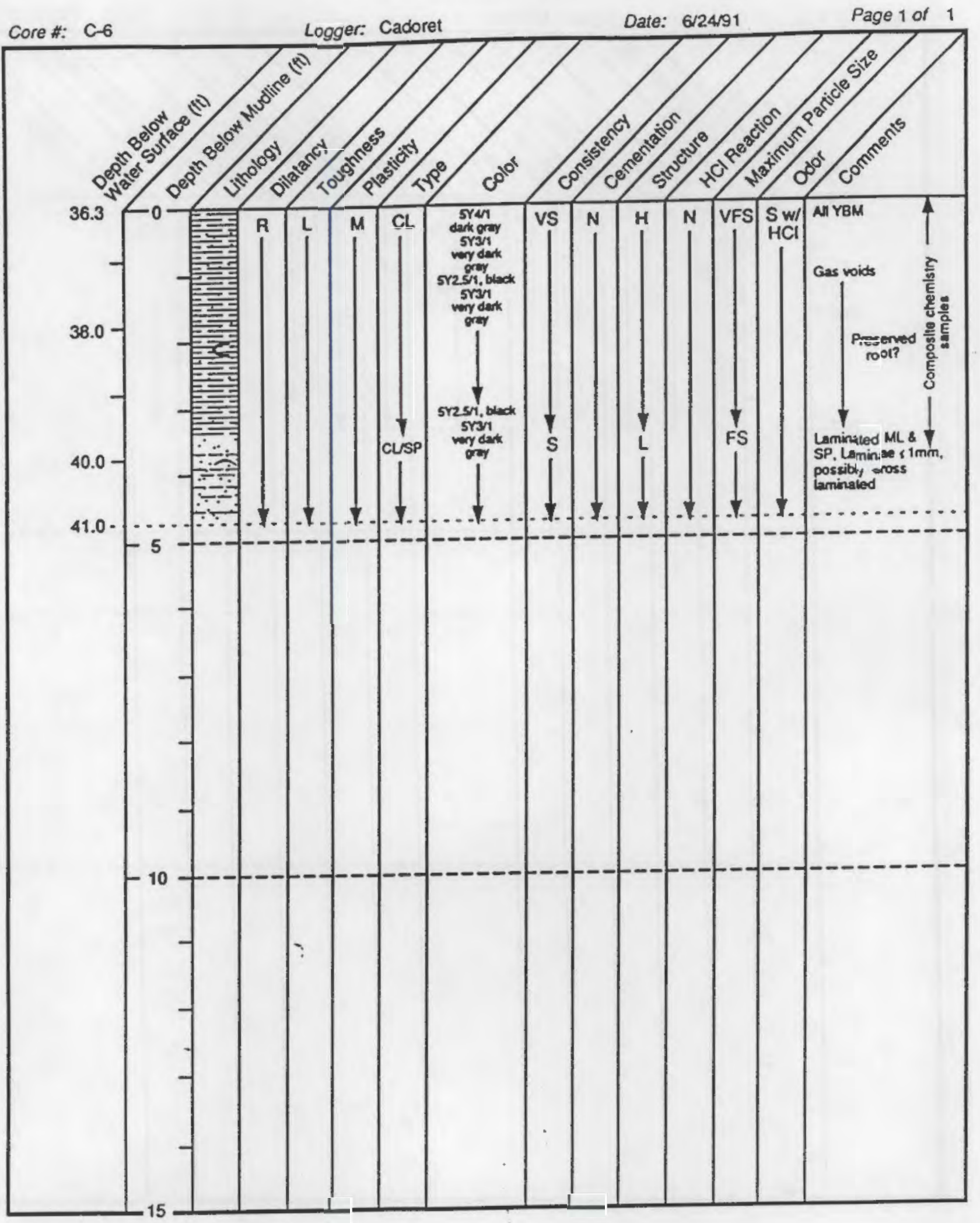




\section{Core Data Log}

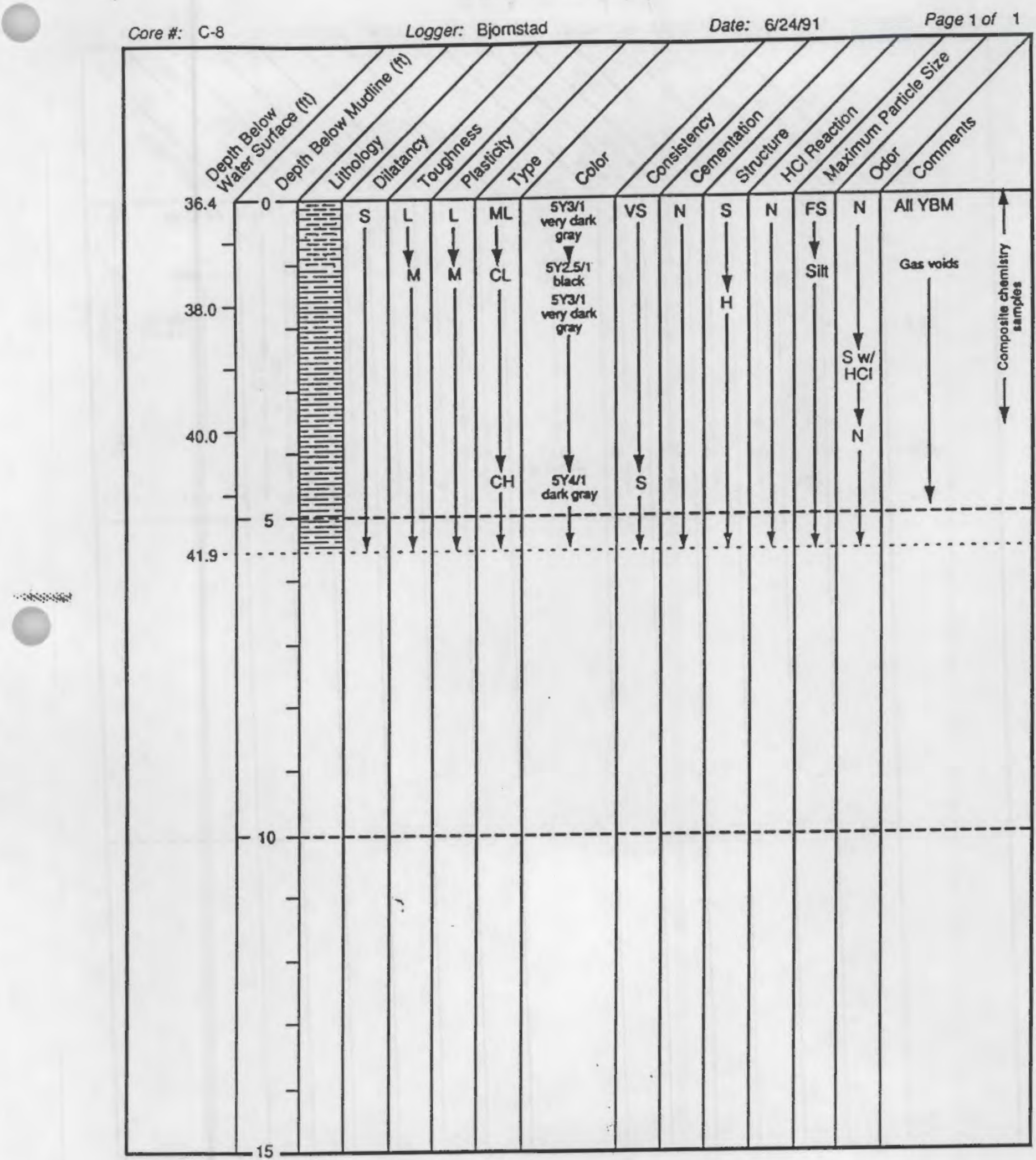


Core Data Log

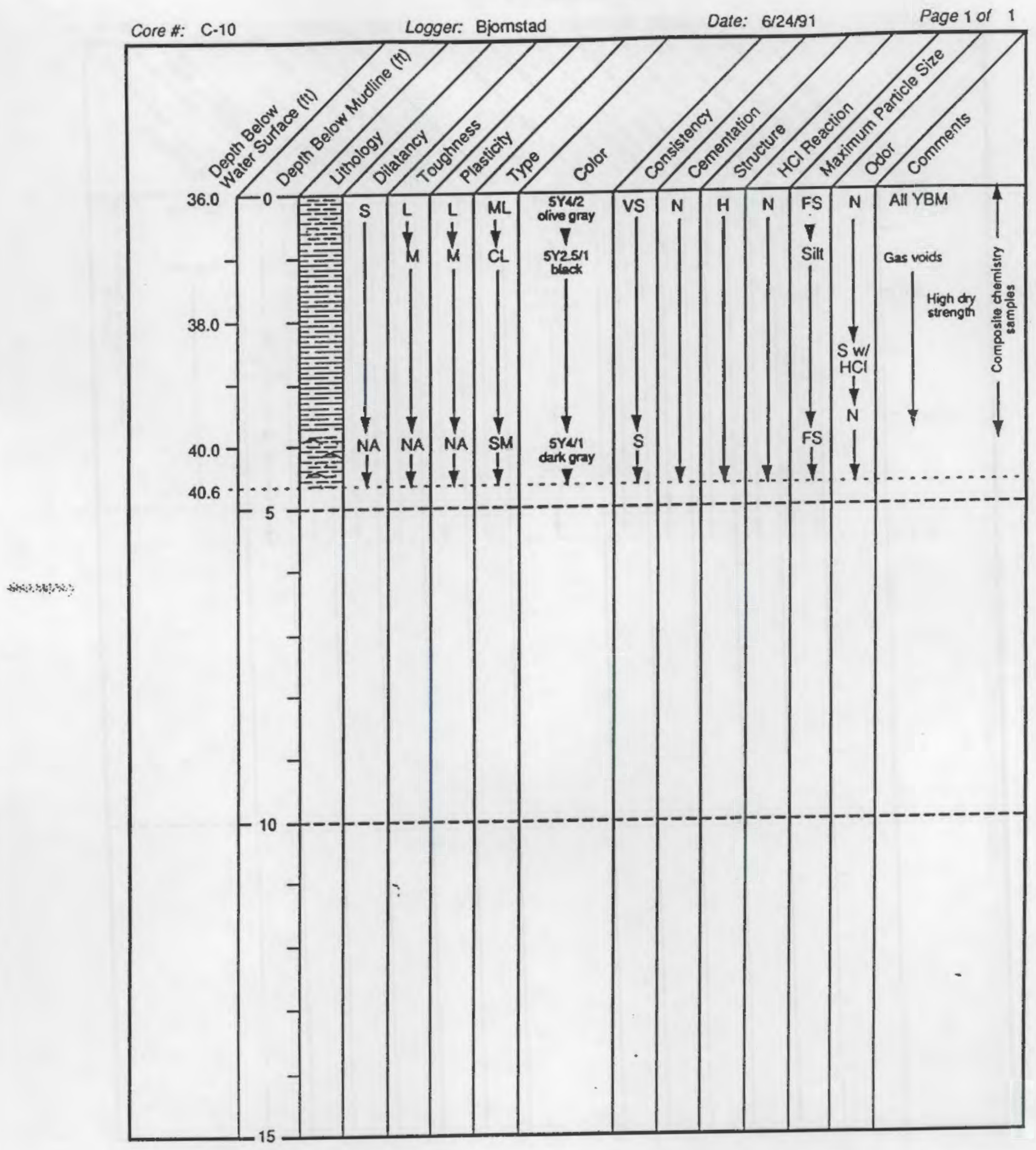


Core Data Log

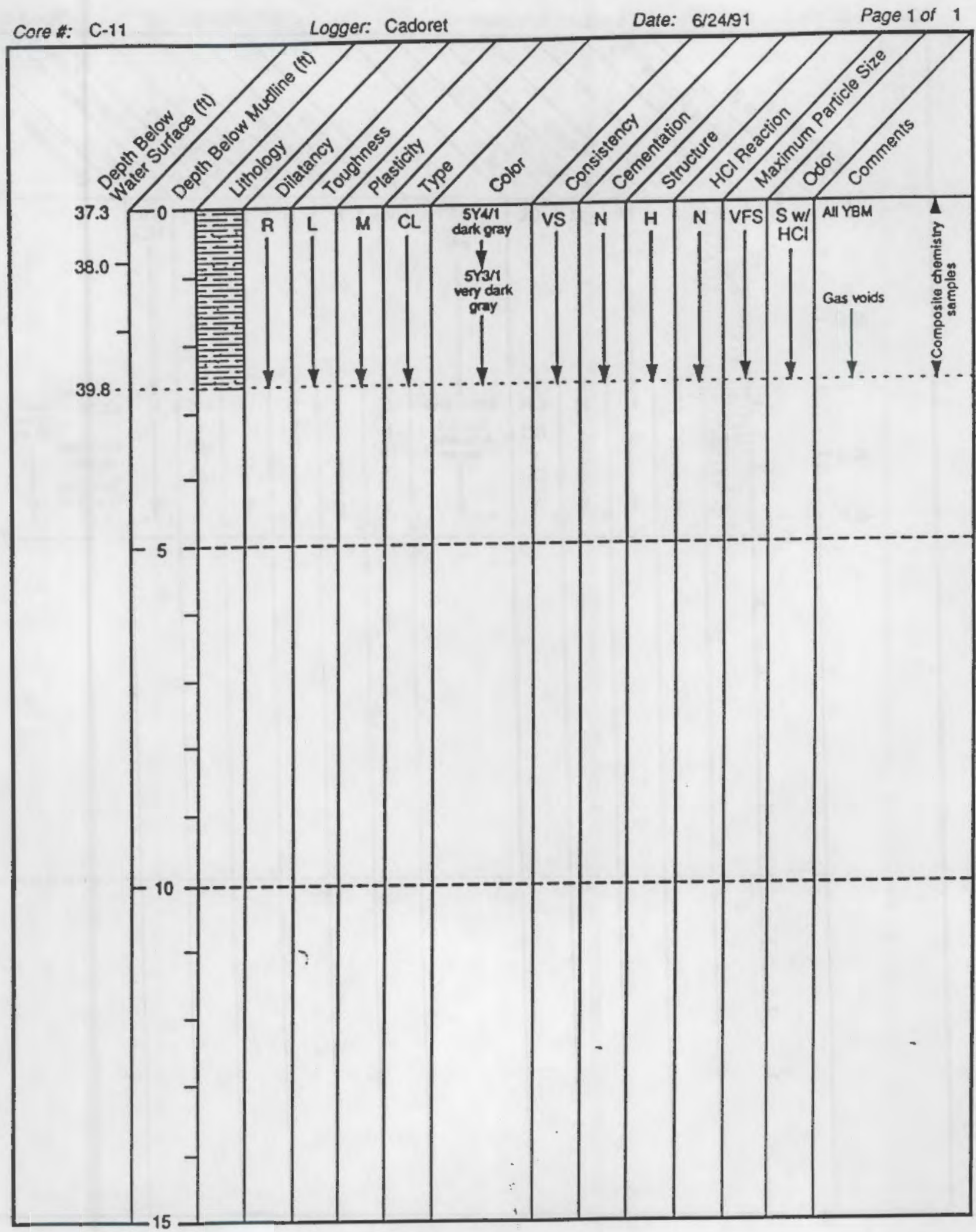


Core Data Log

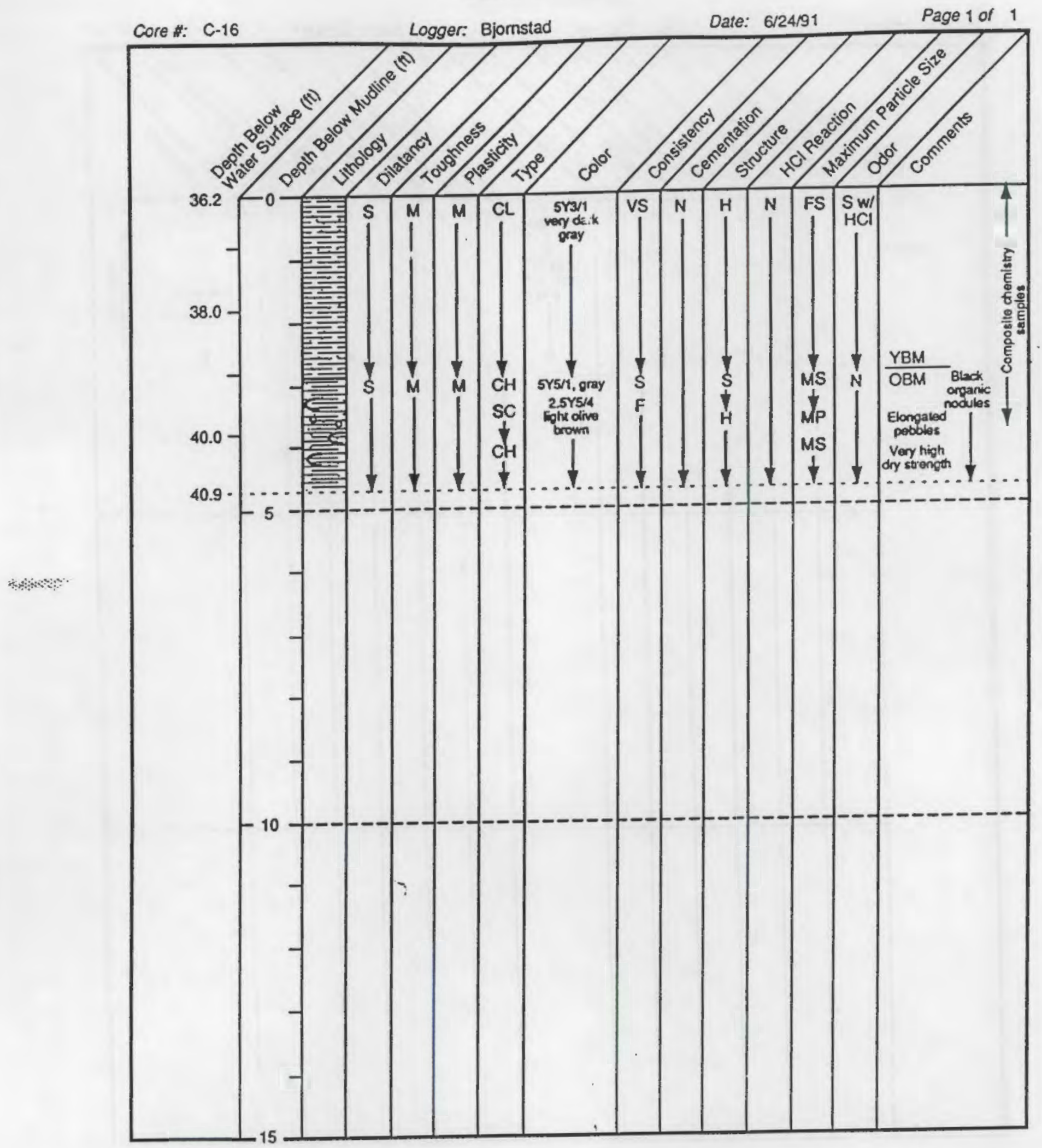

B. 8 


\section{Core Data Log}

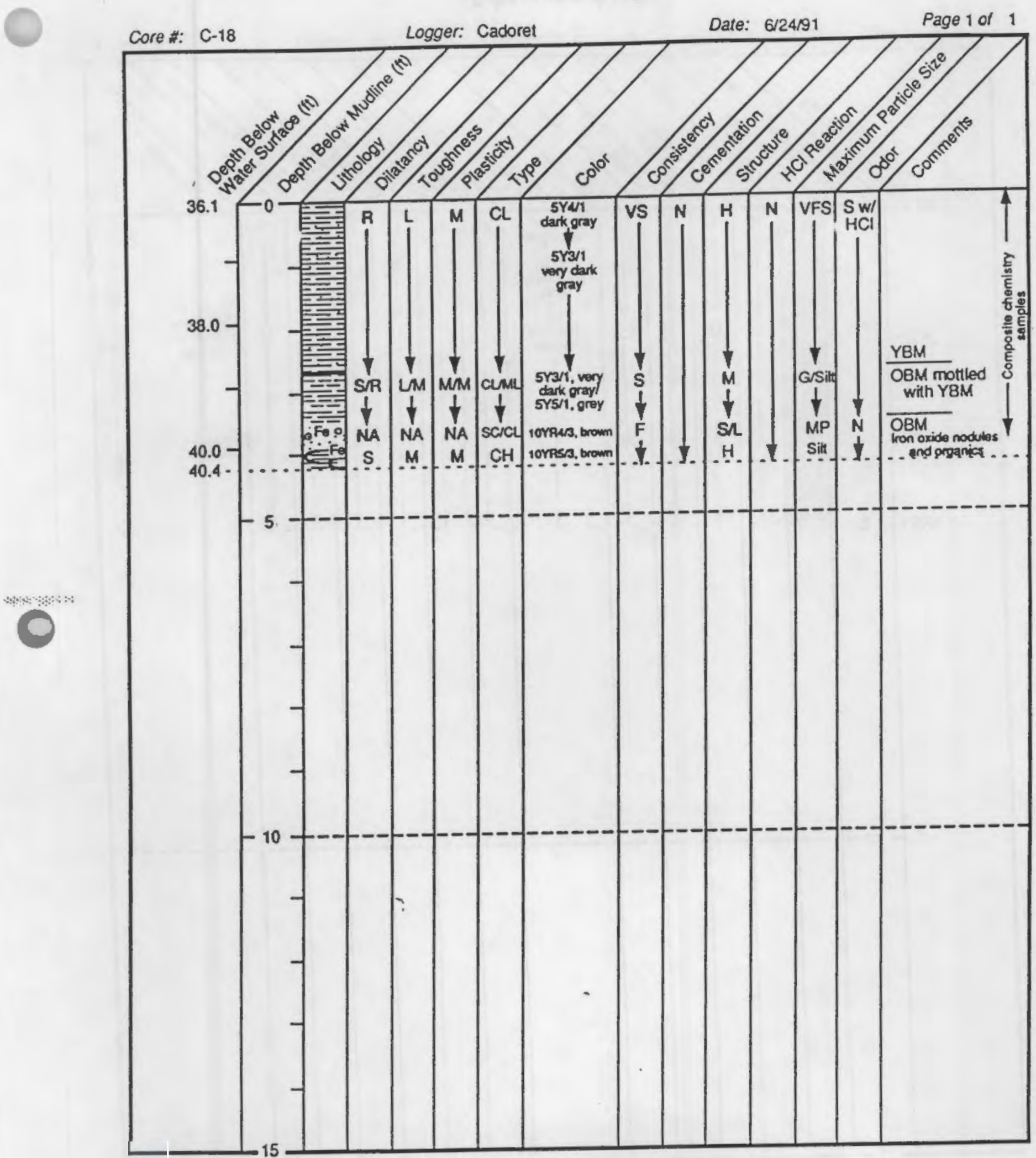




\section{Core Data Log}

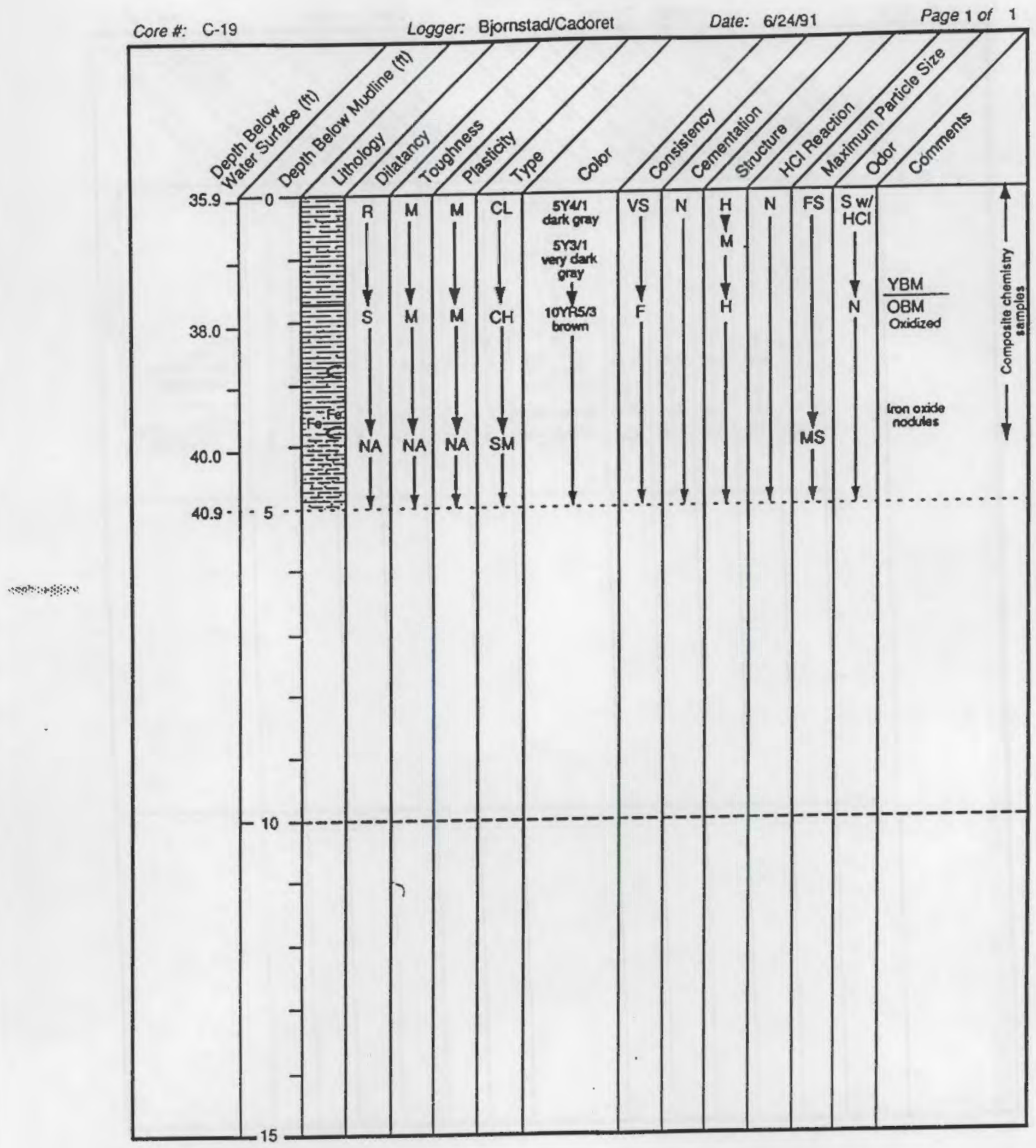




\section{Core Data Log}

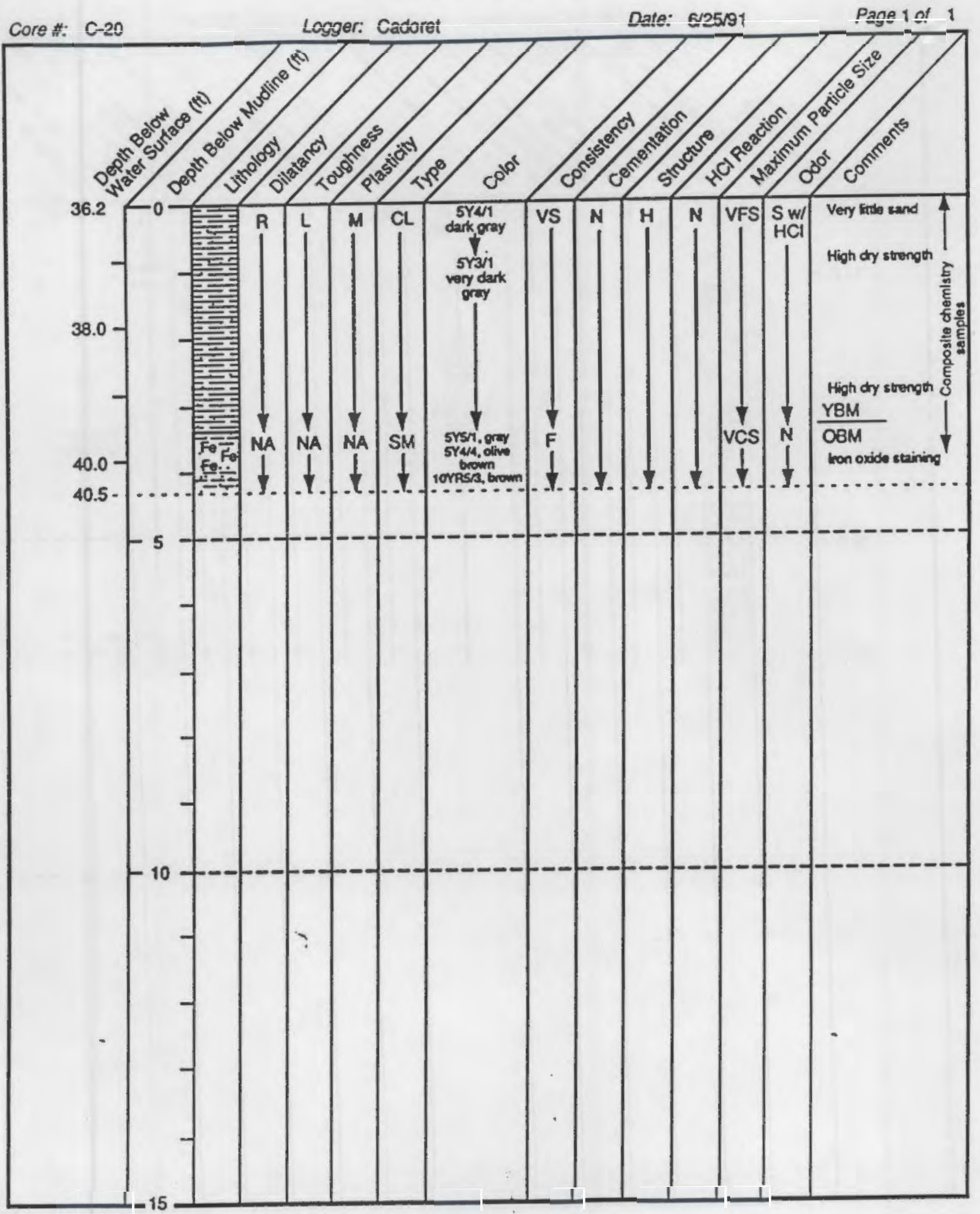


Core Data Log

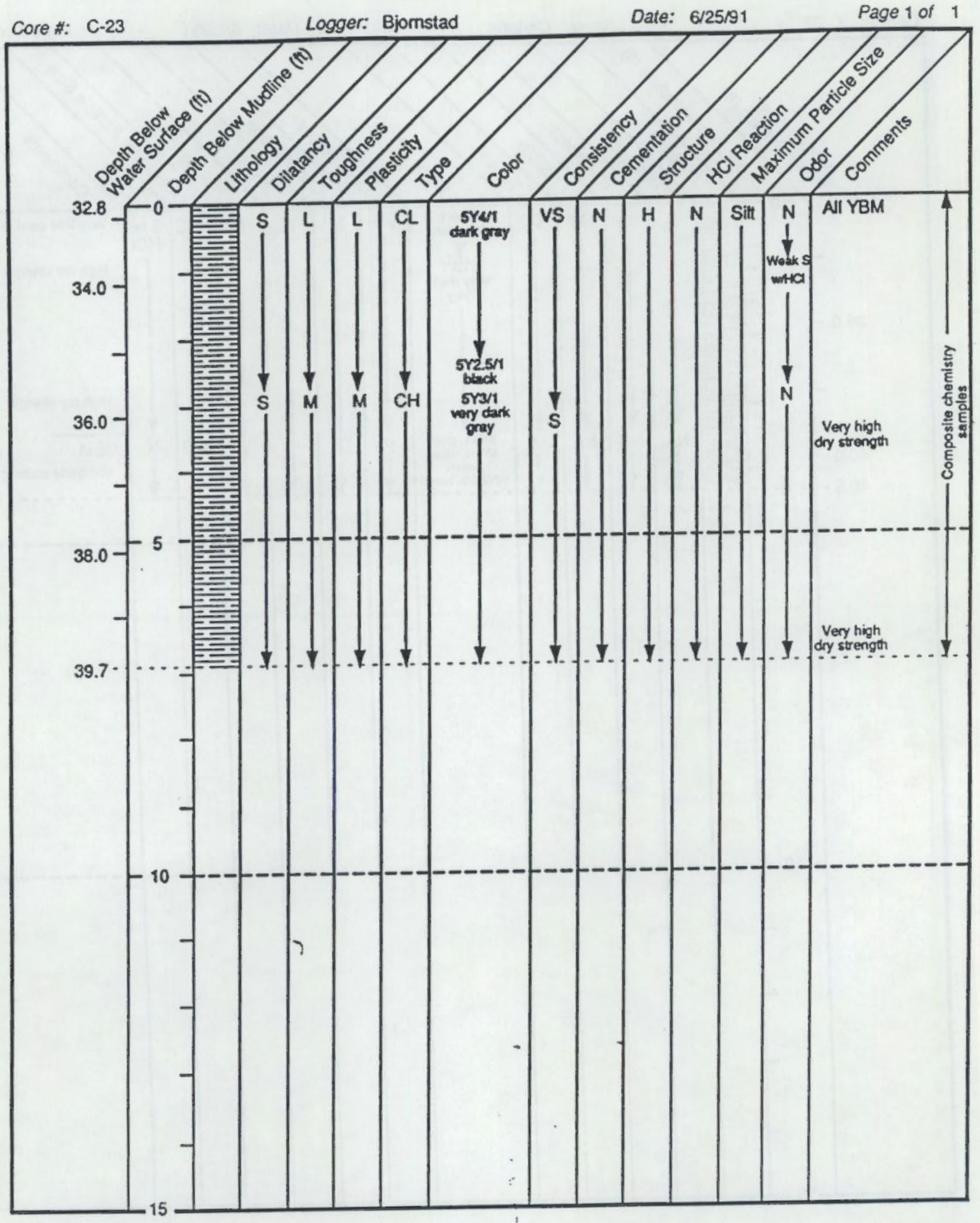




\section{Core Data Log}

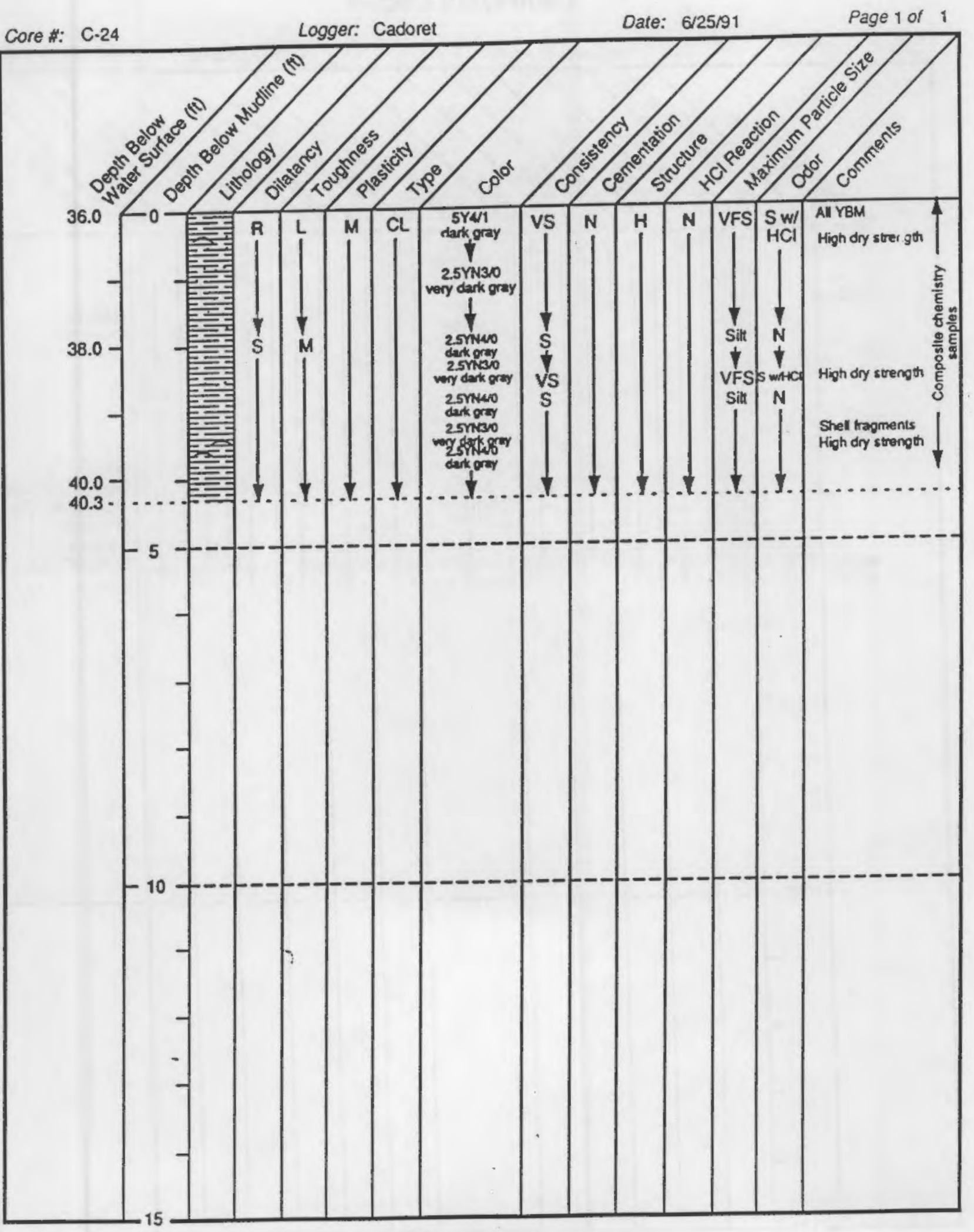




\section{Core Data Log}

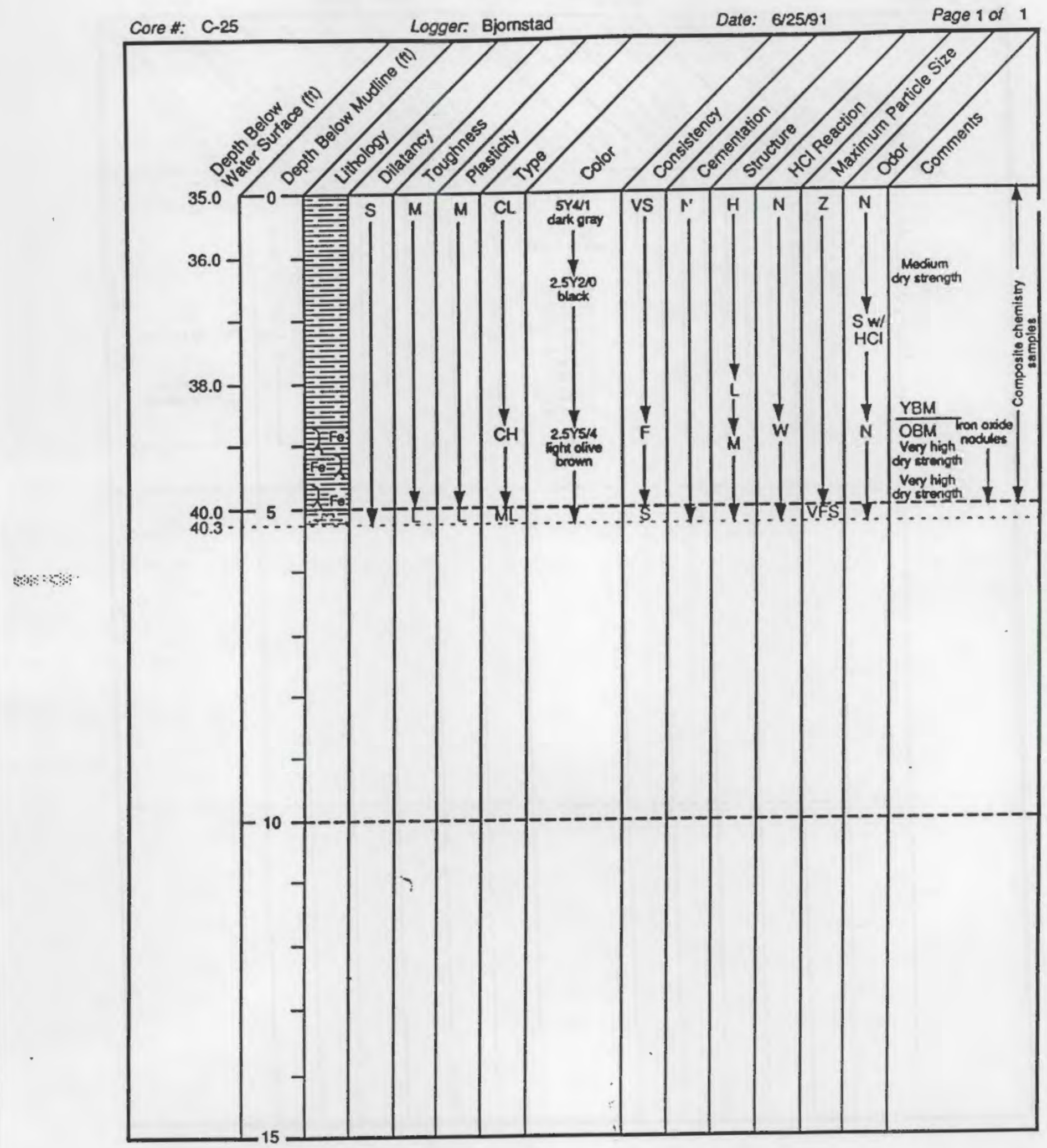


Core Data Log

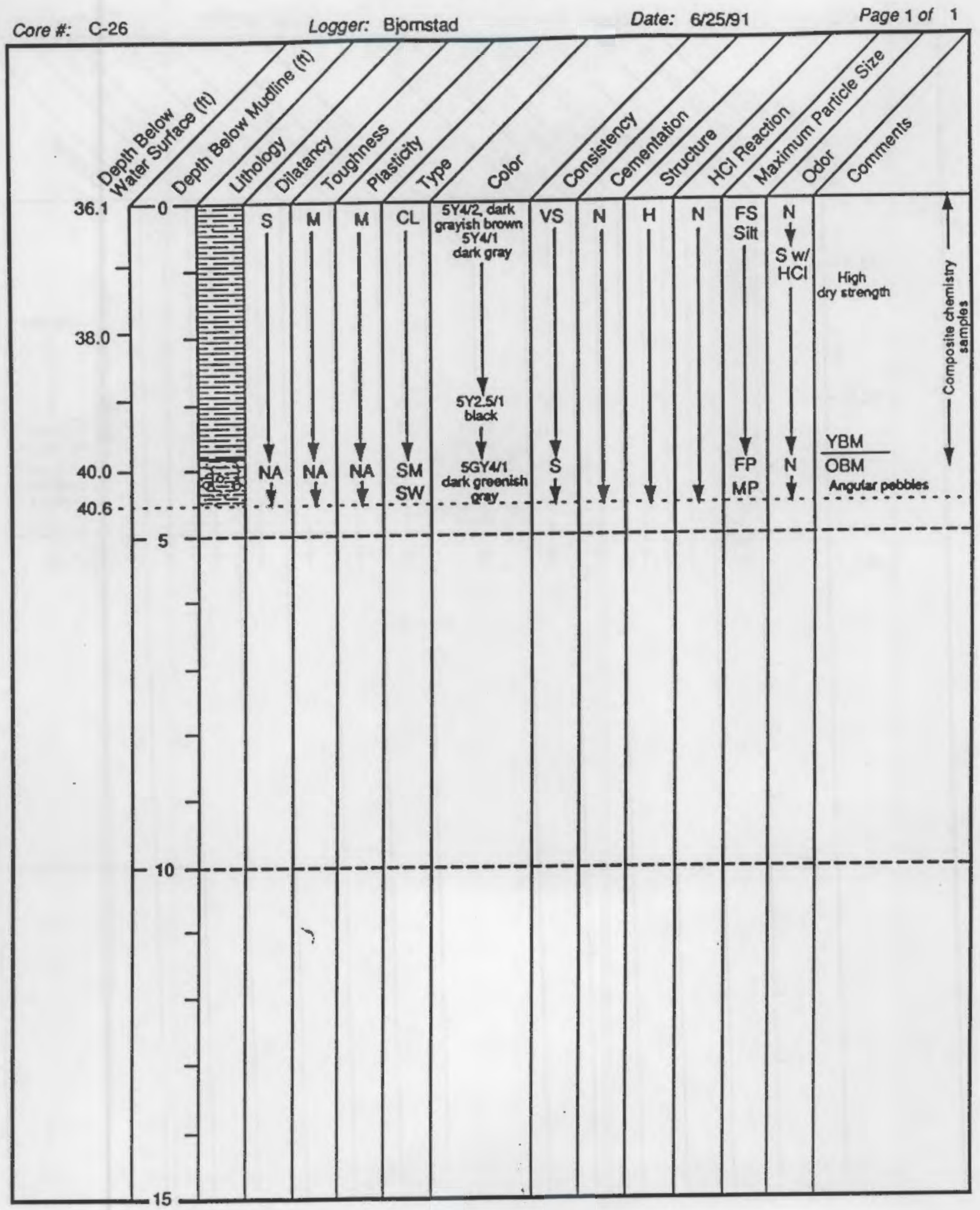


Core Data Log

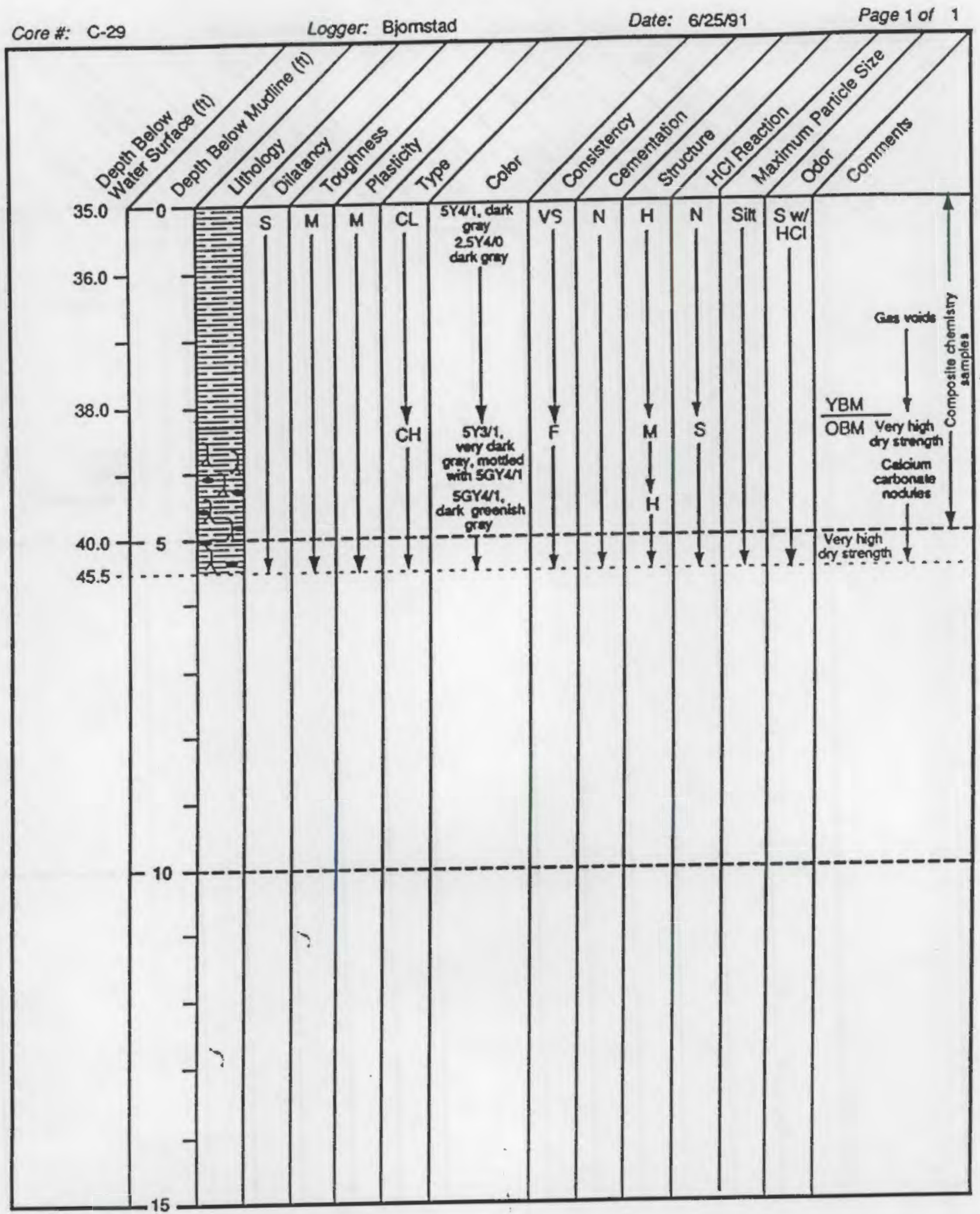




\section{Core Data Log}

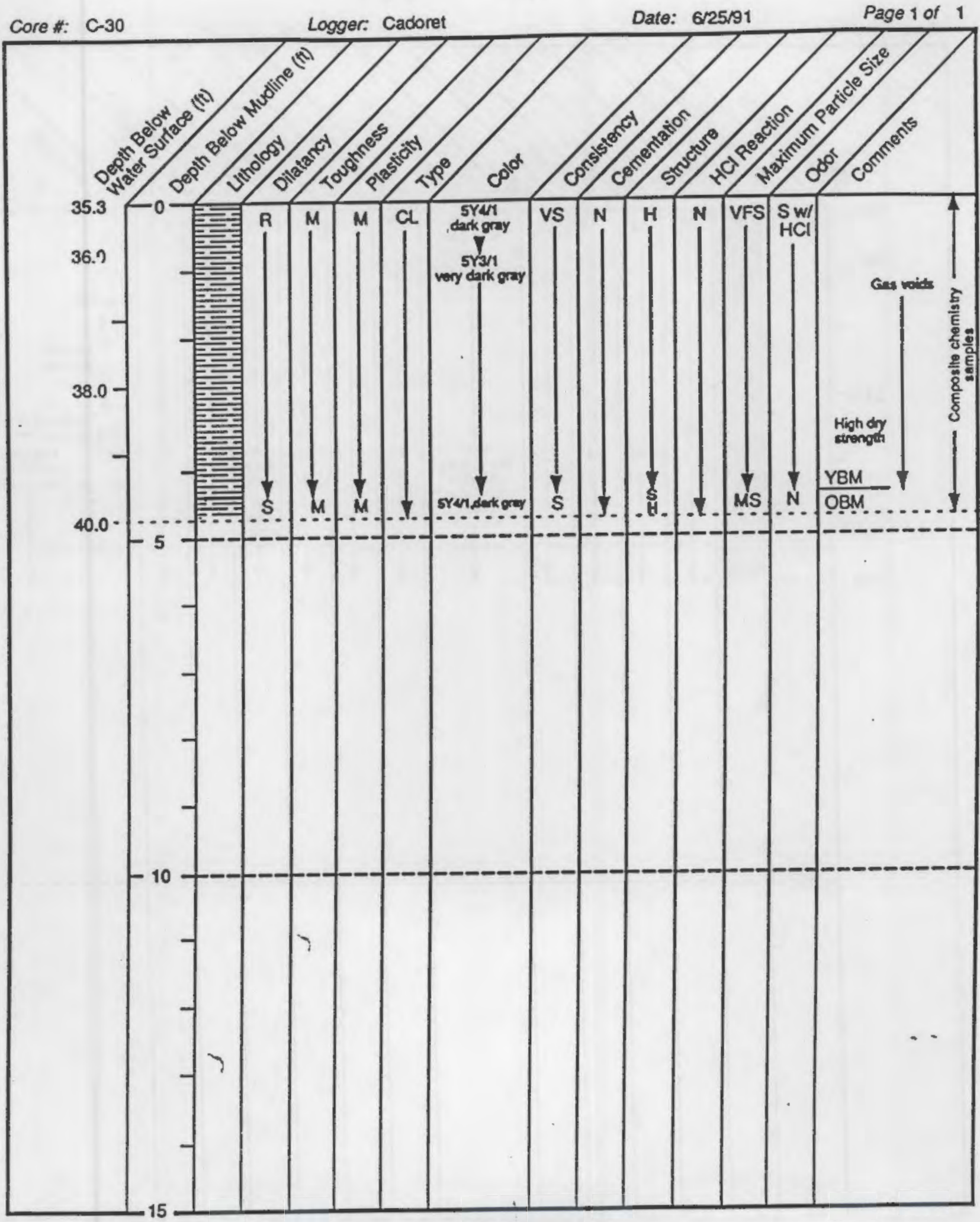




\section{Core Data Log}

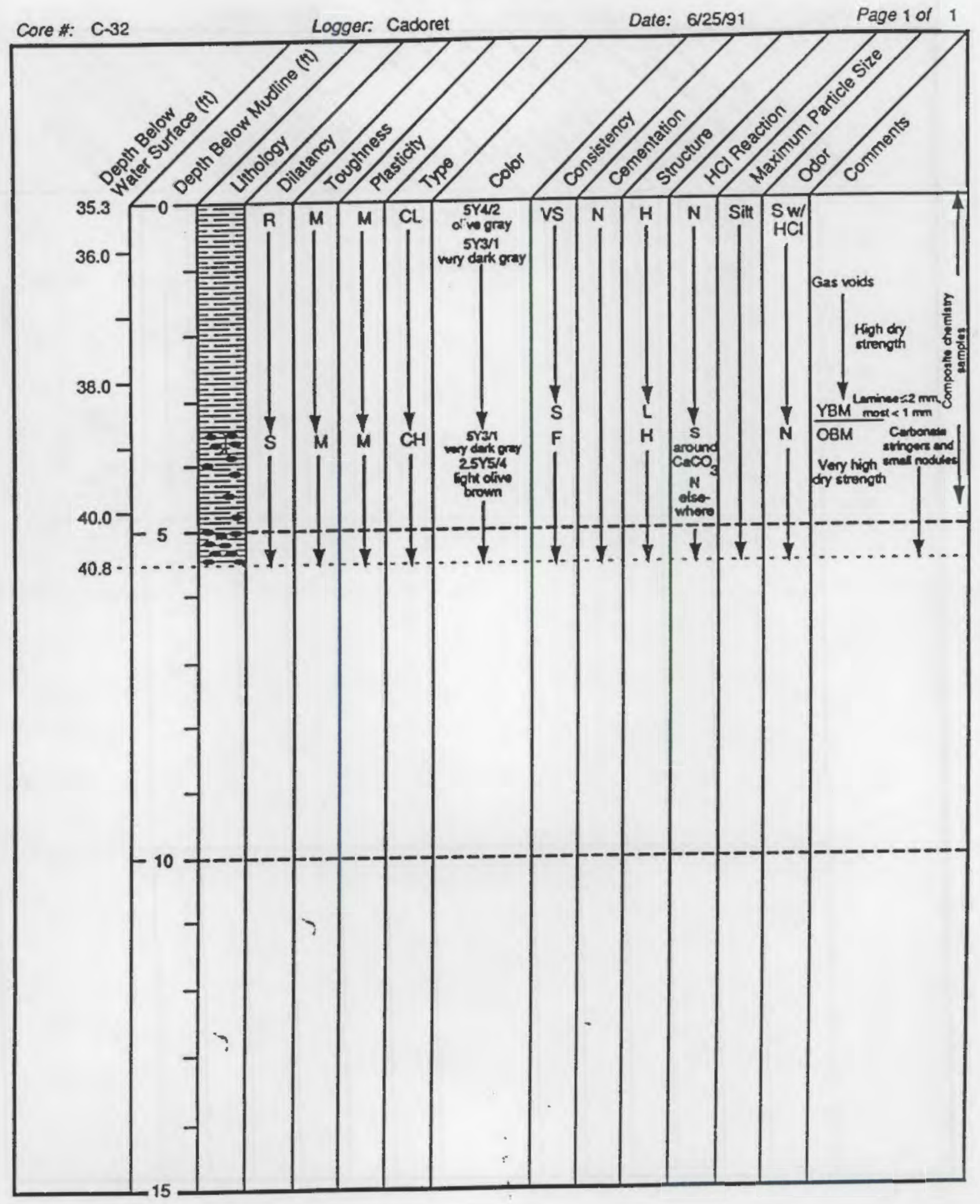




\section{Core Data Log}

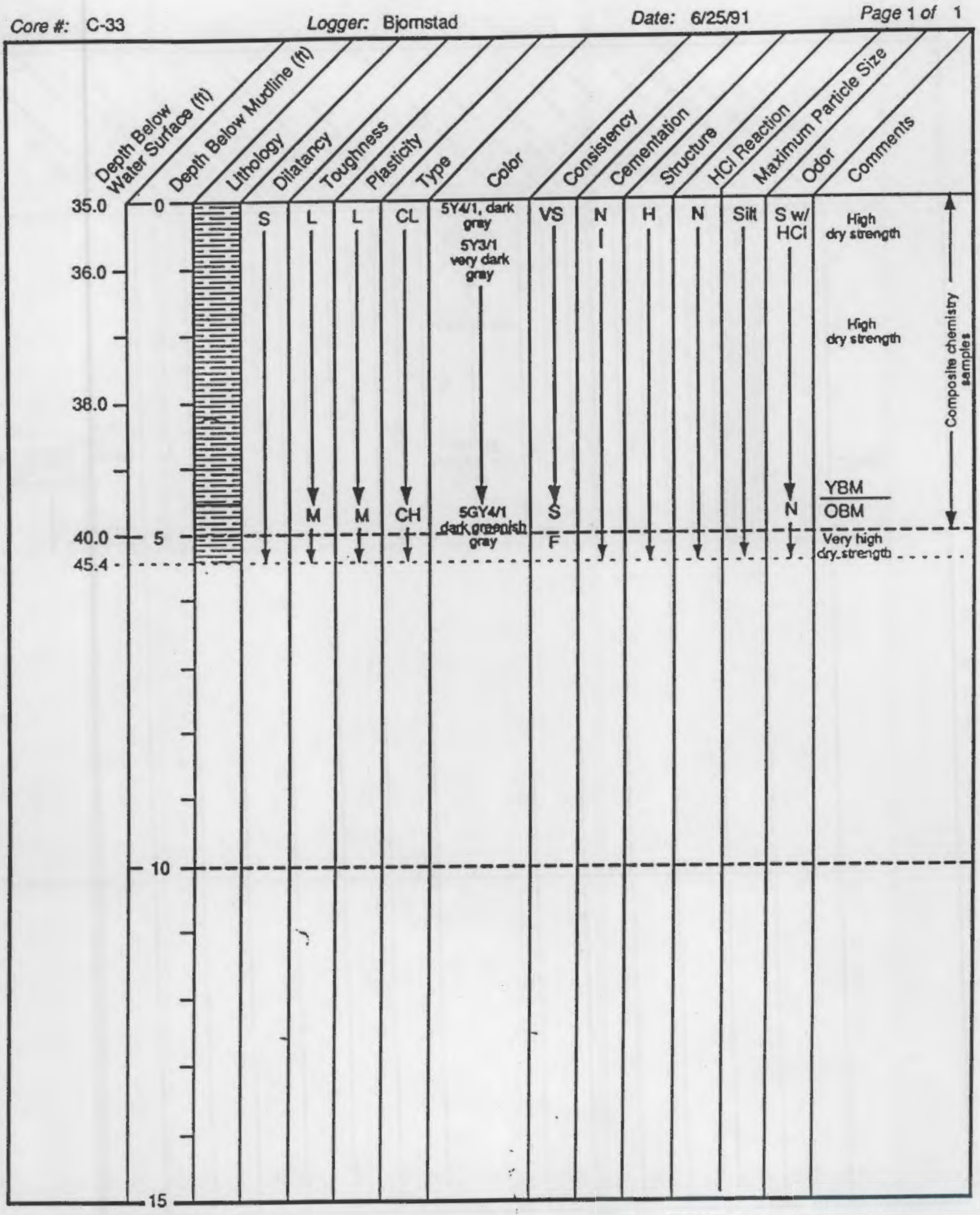


Core Data Log

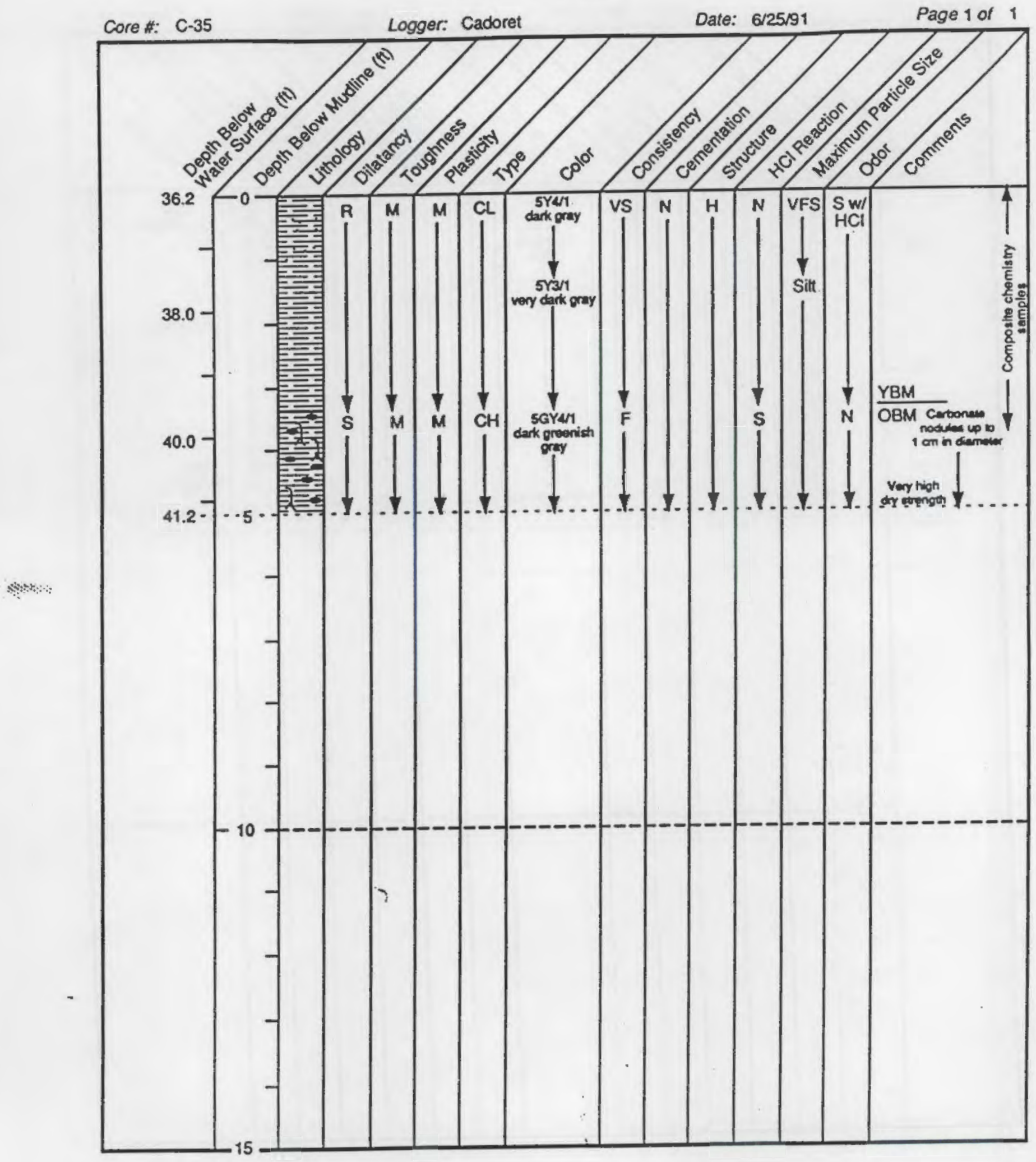




\section{Core Data Log}

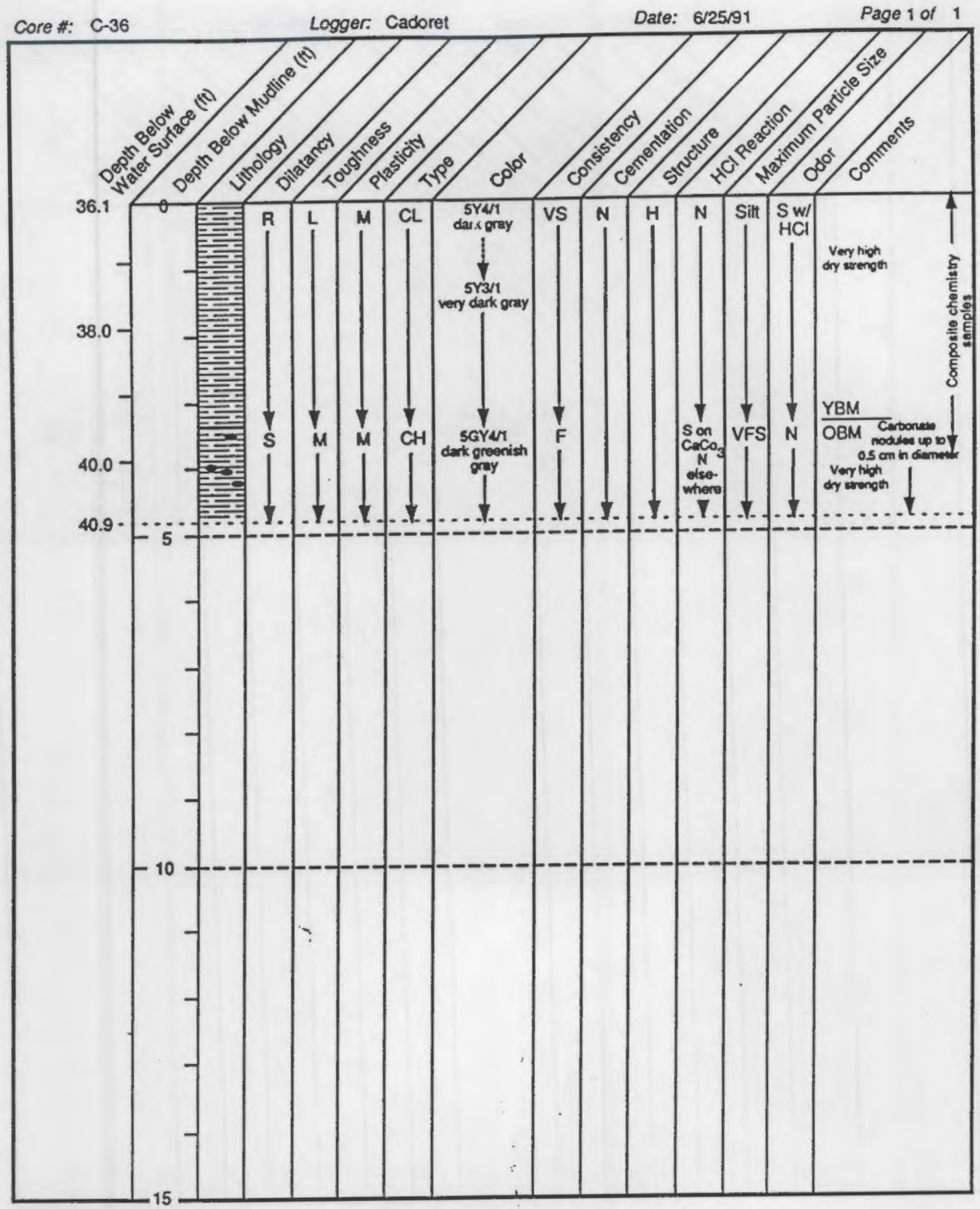


Core Data Log

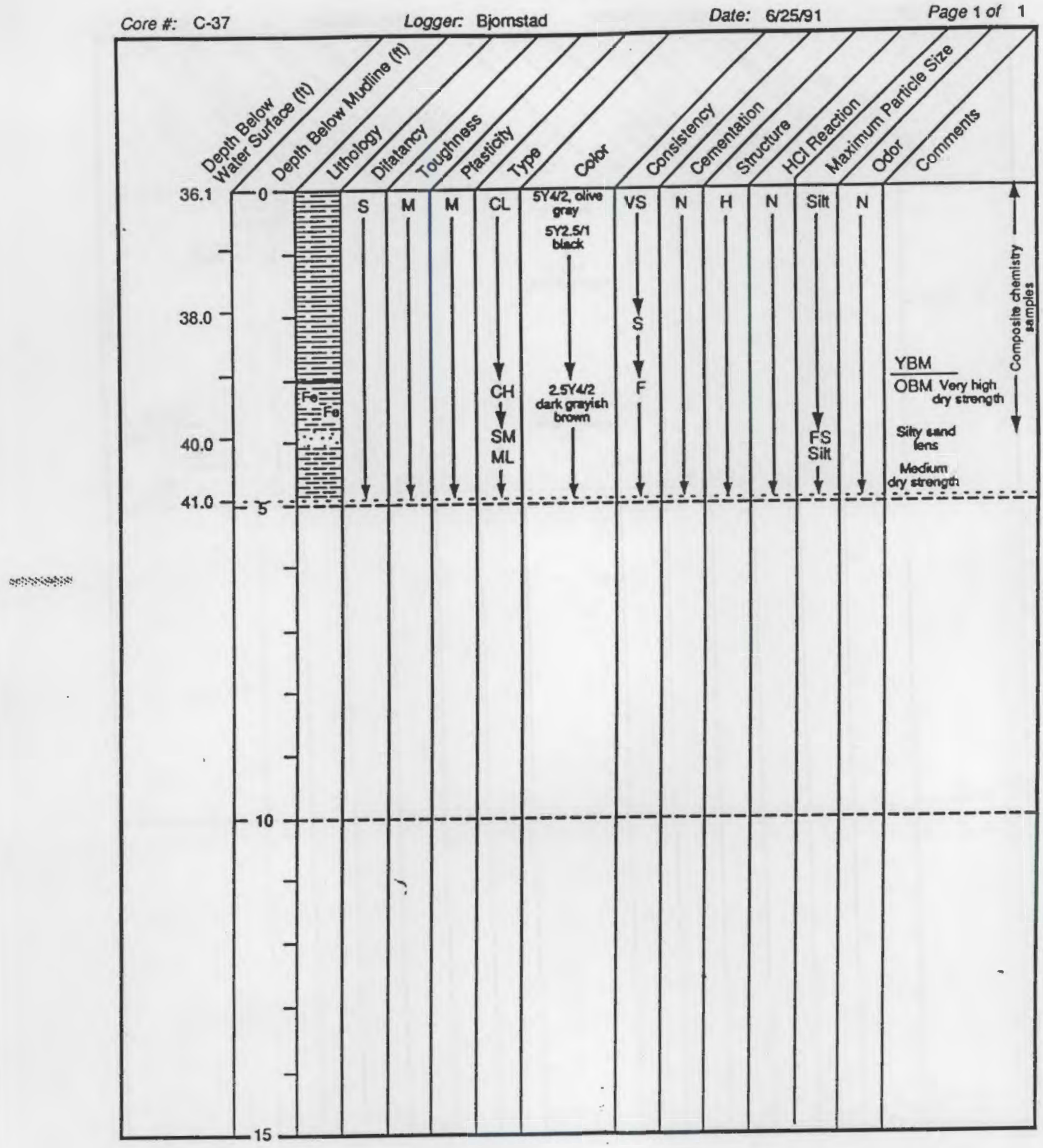




\section{Core Data Log}

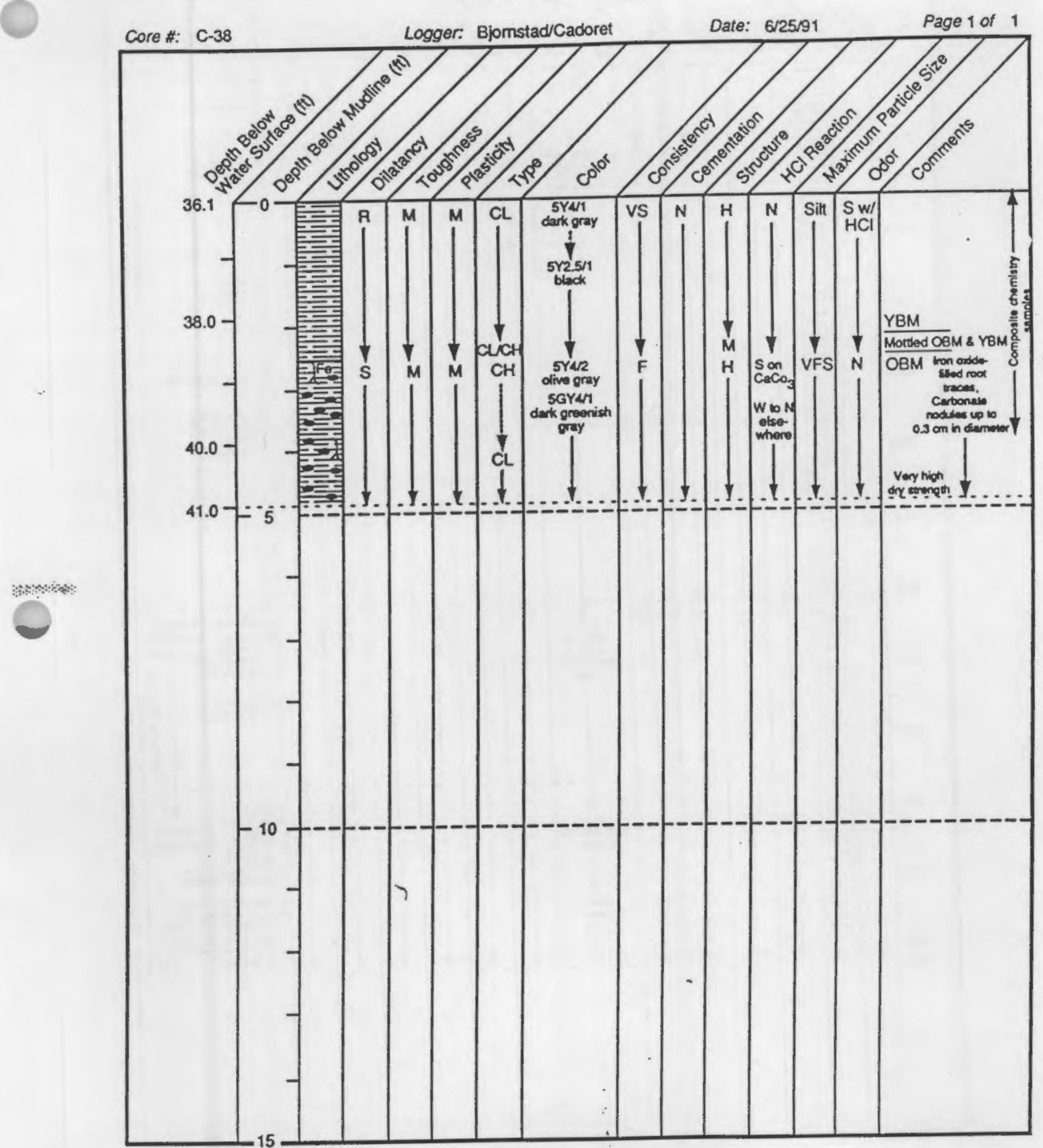


Core Data Log

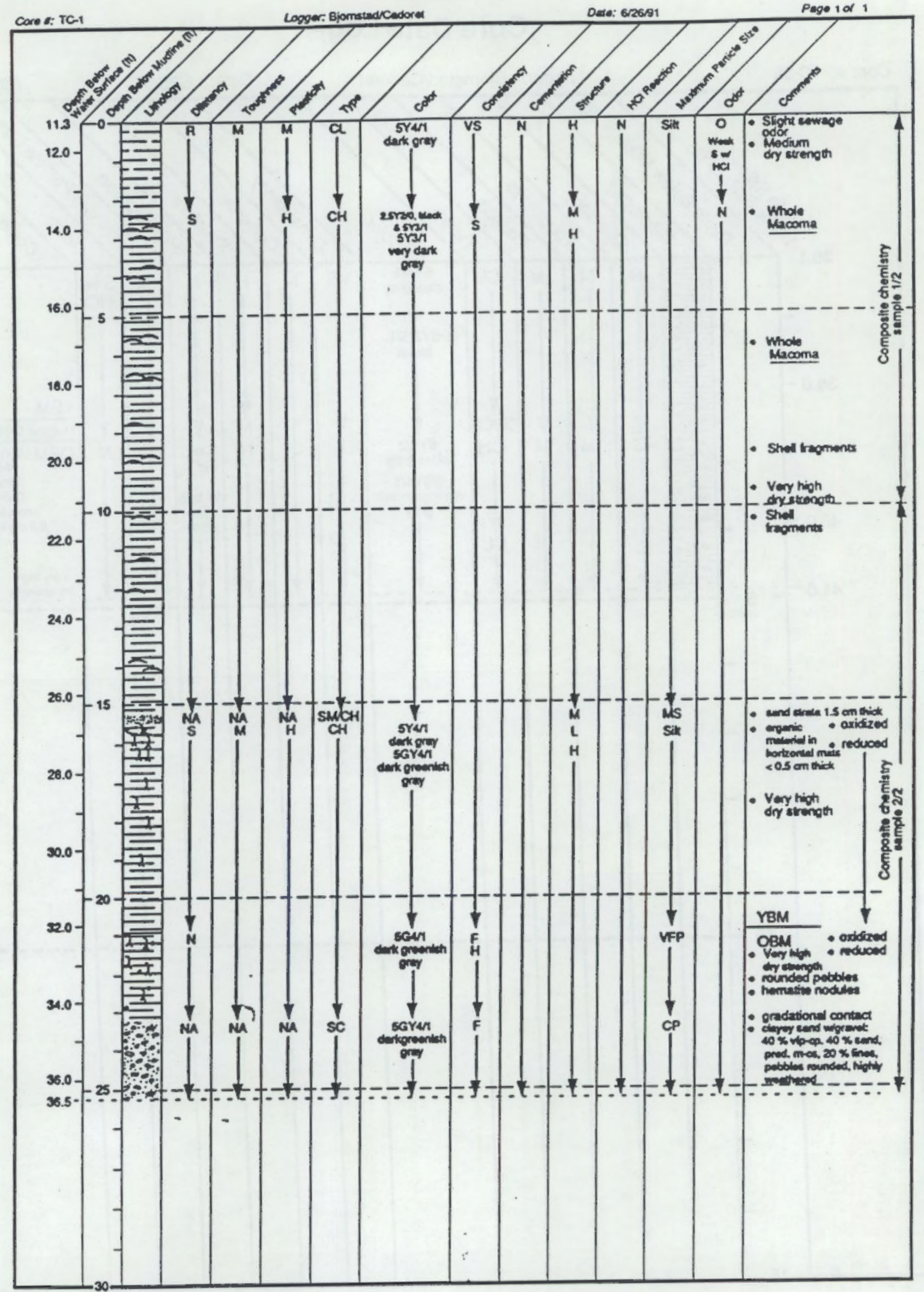


Core Data Log

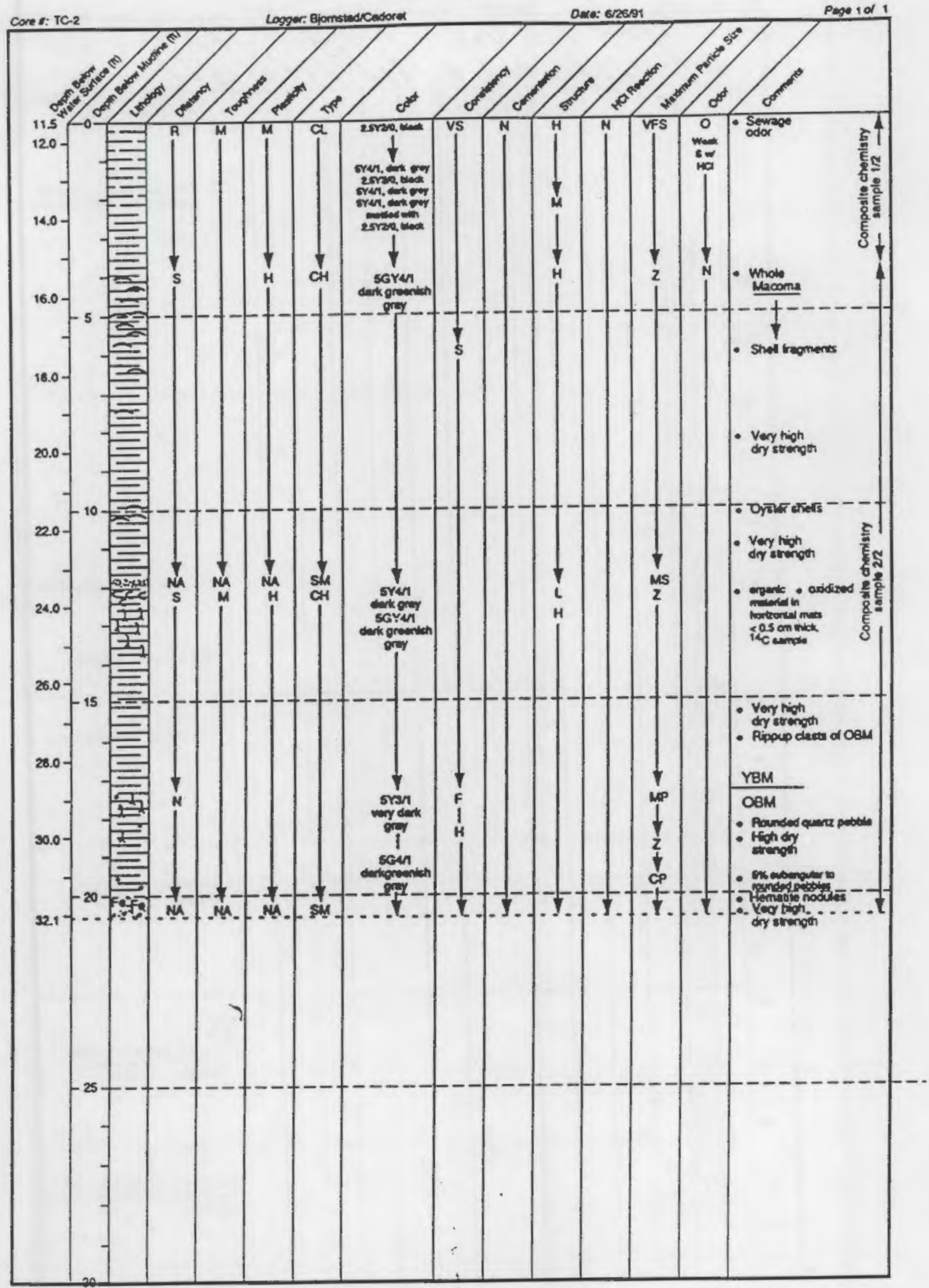




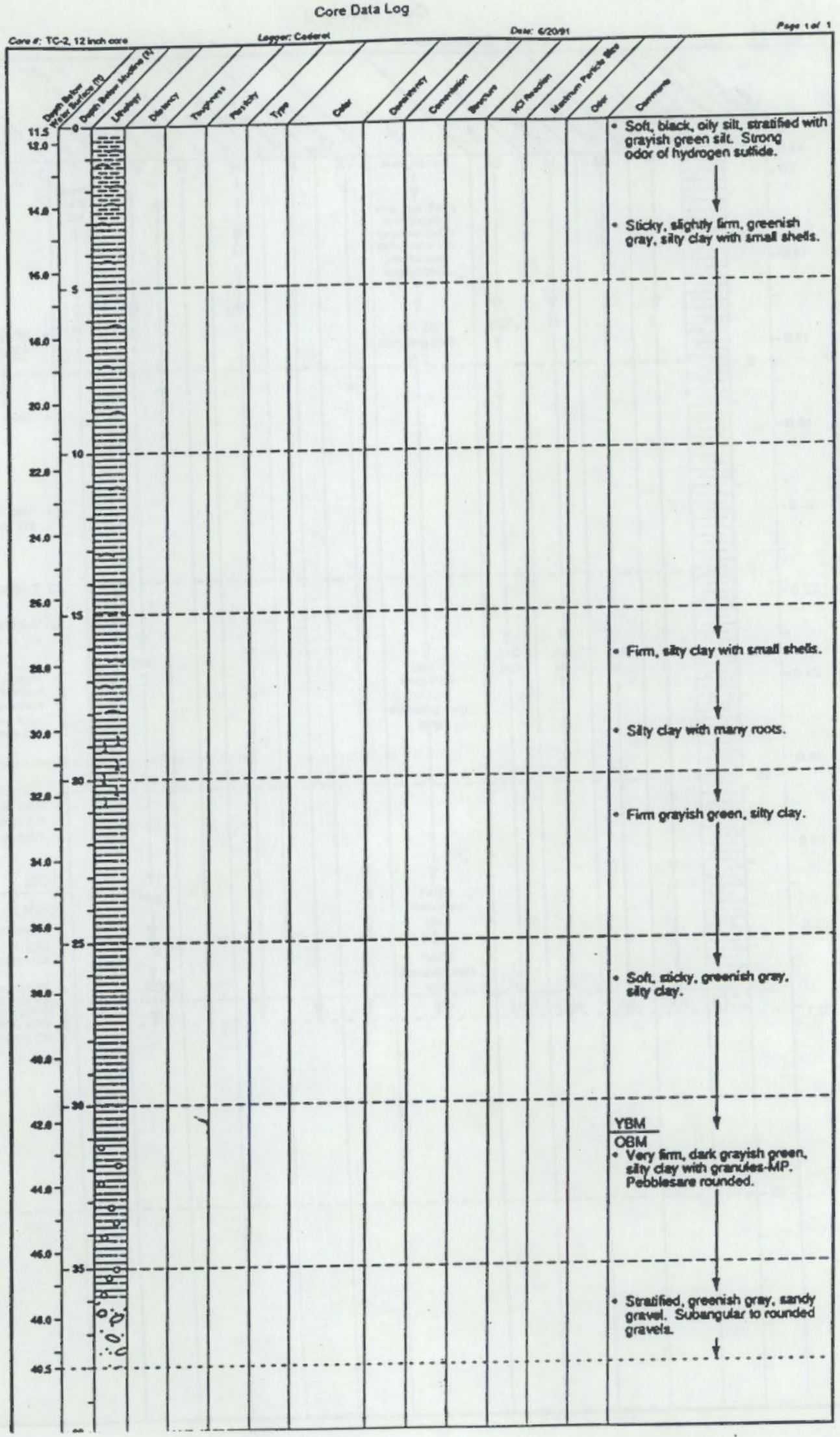


Core Data Log

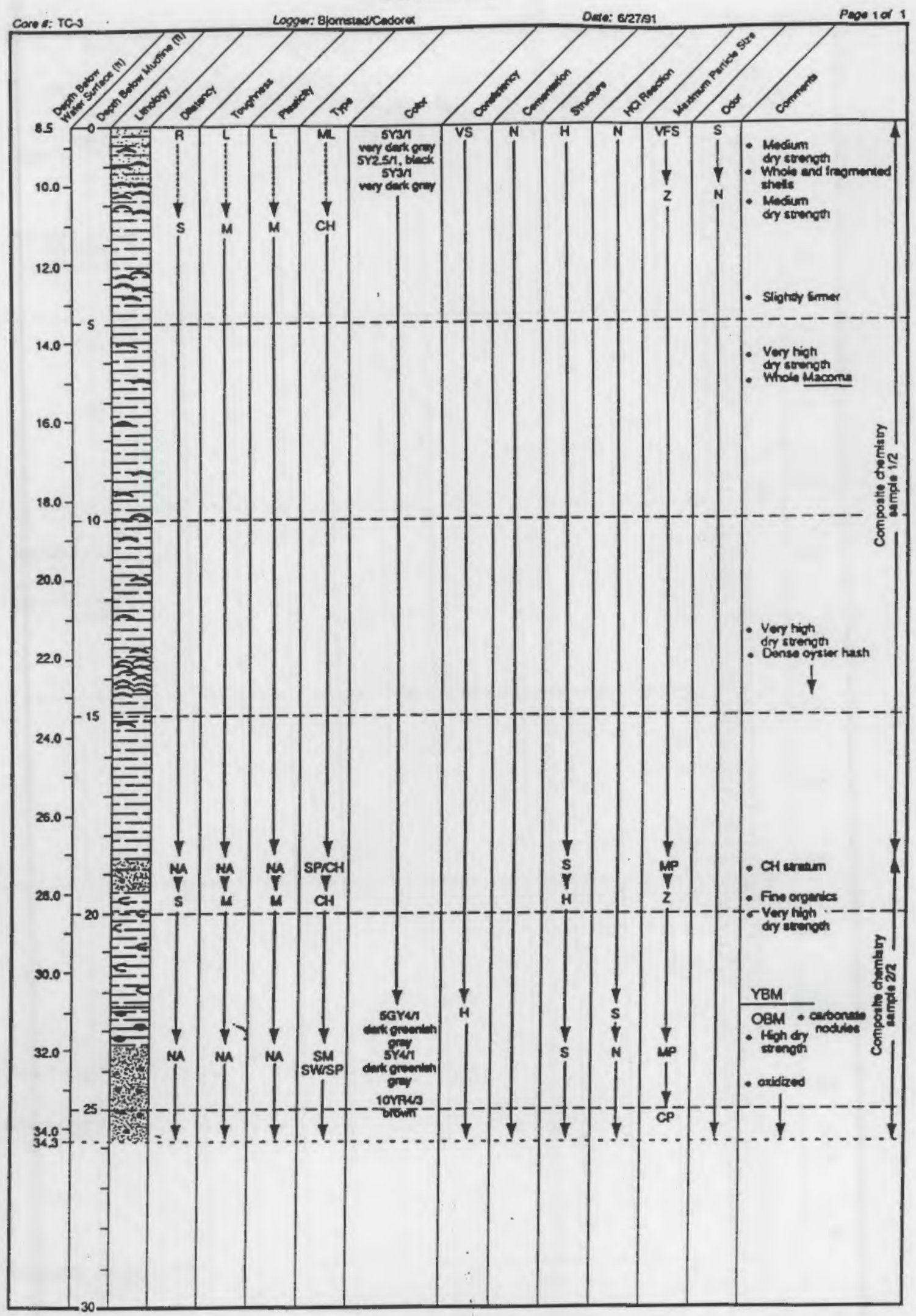


Core Data Log

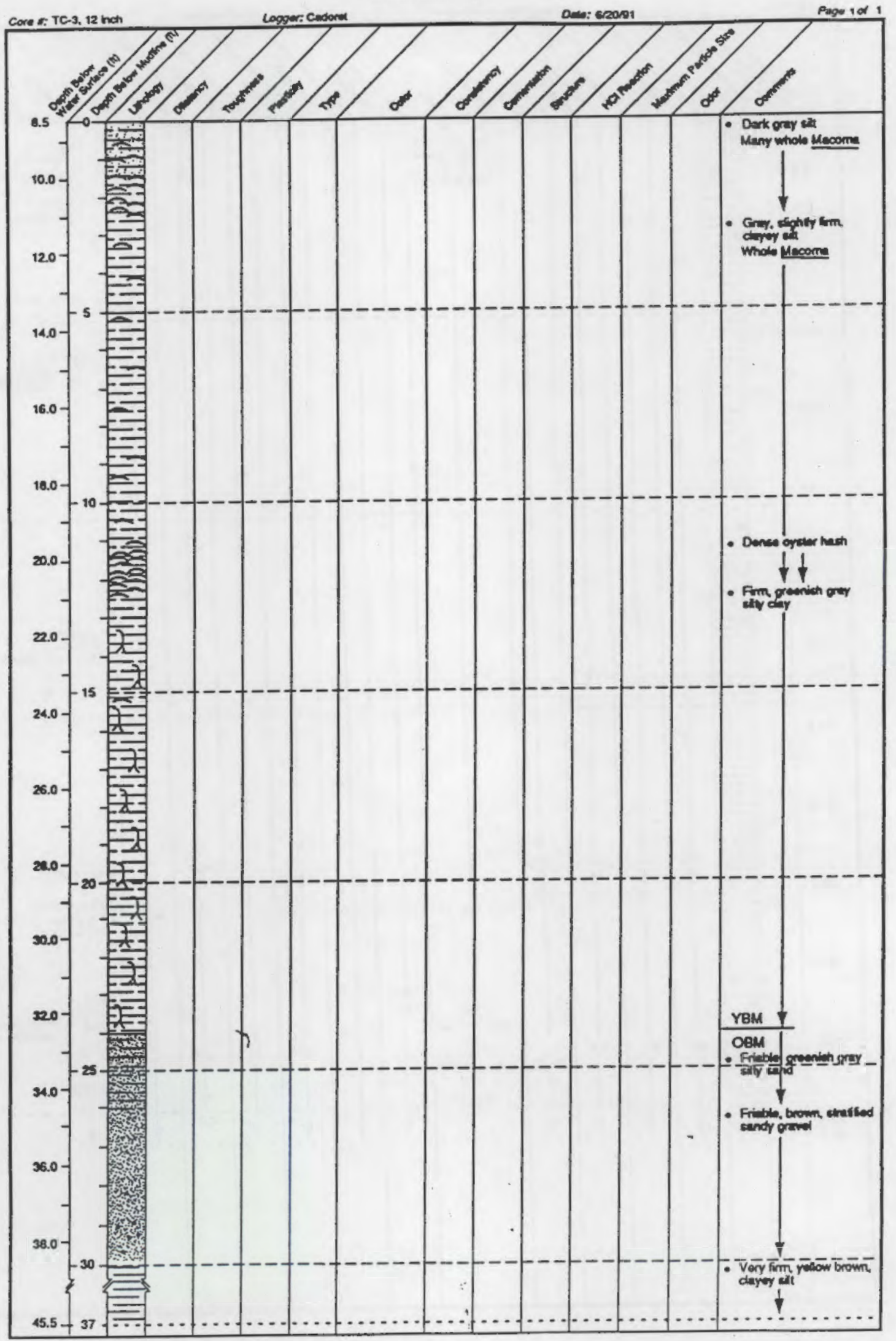




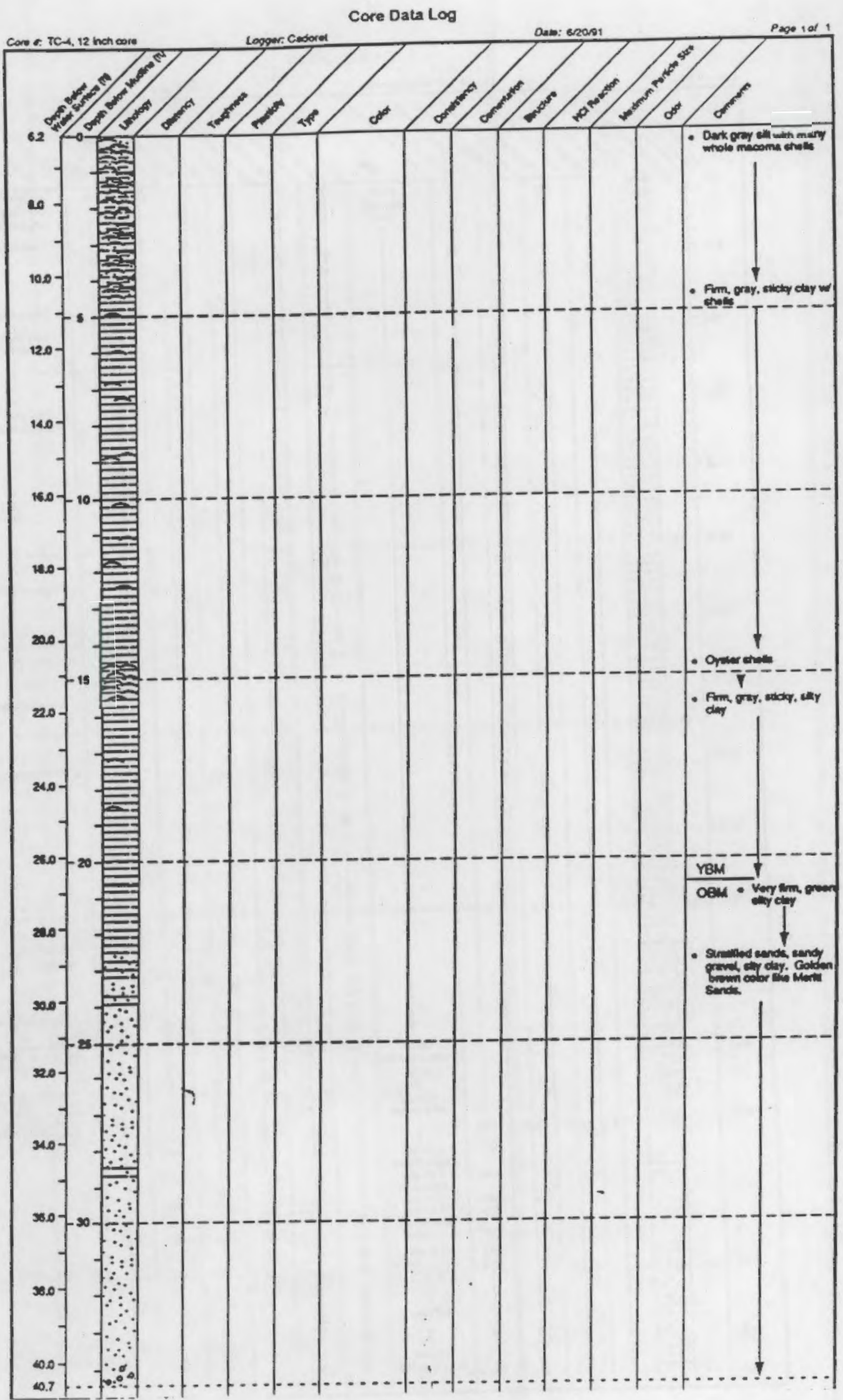




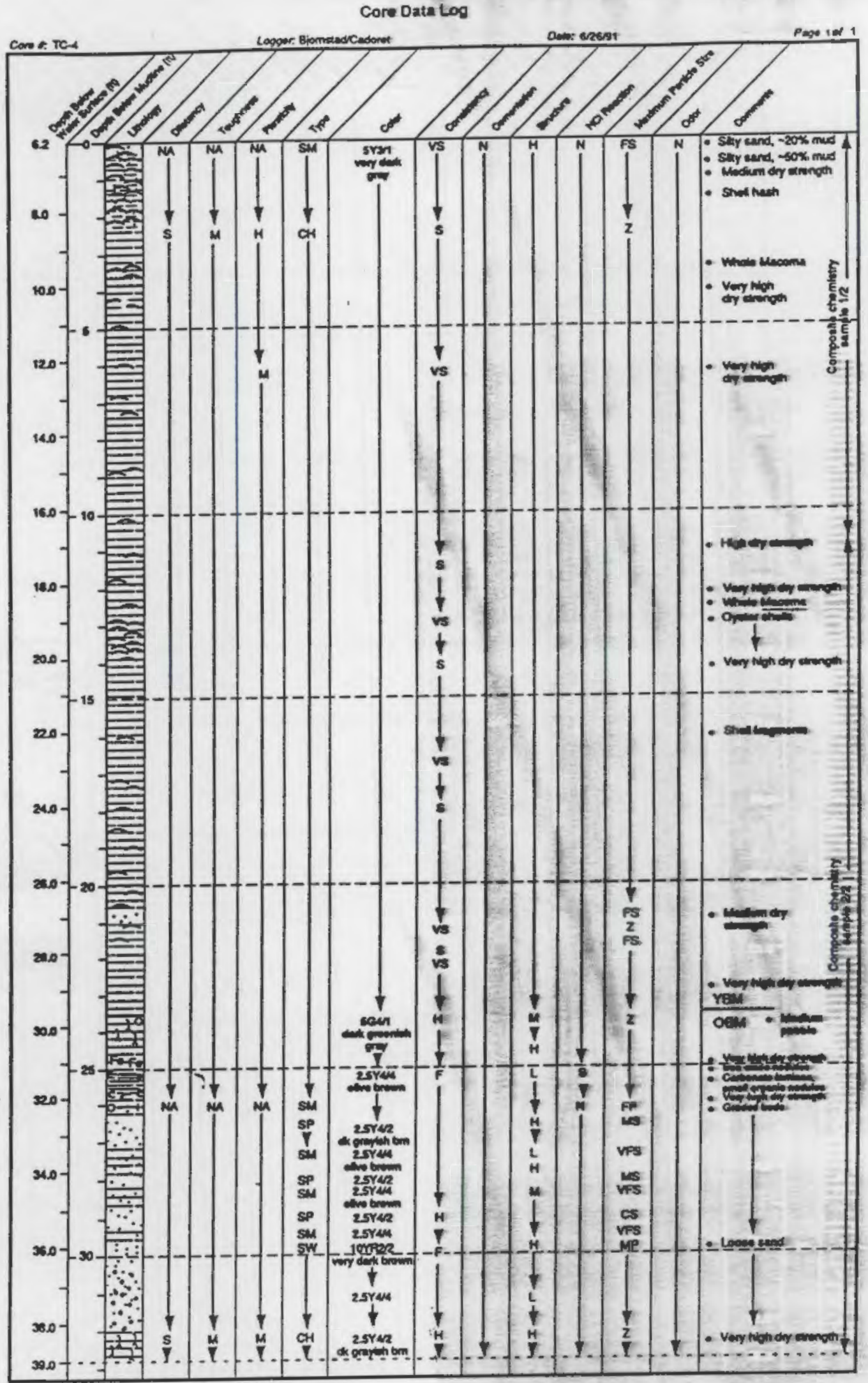




\section{Core Data Log}

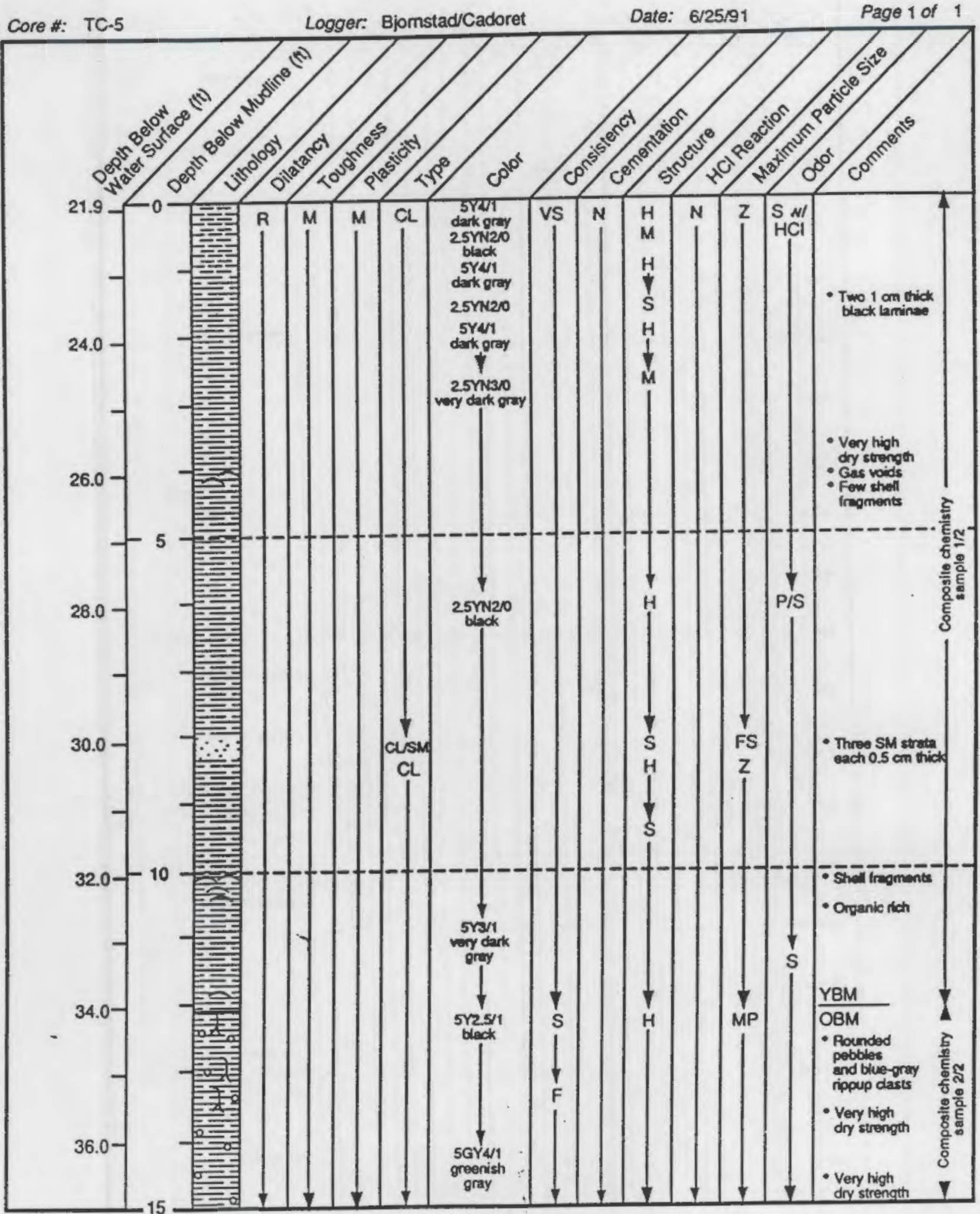




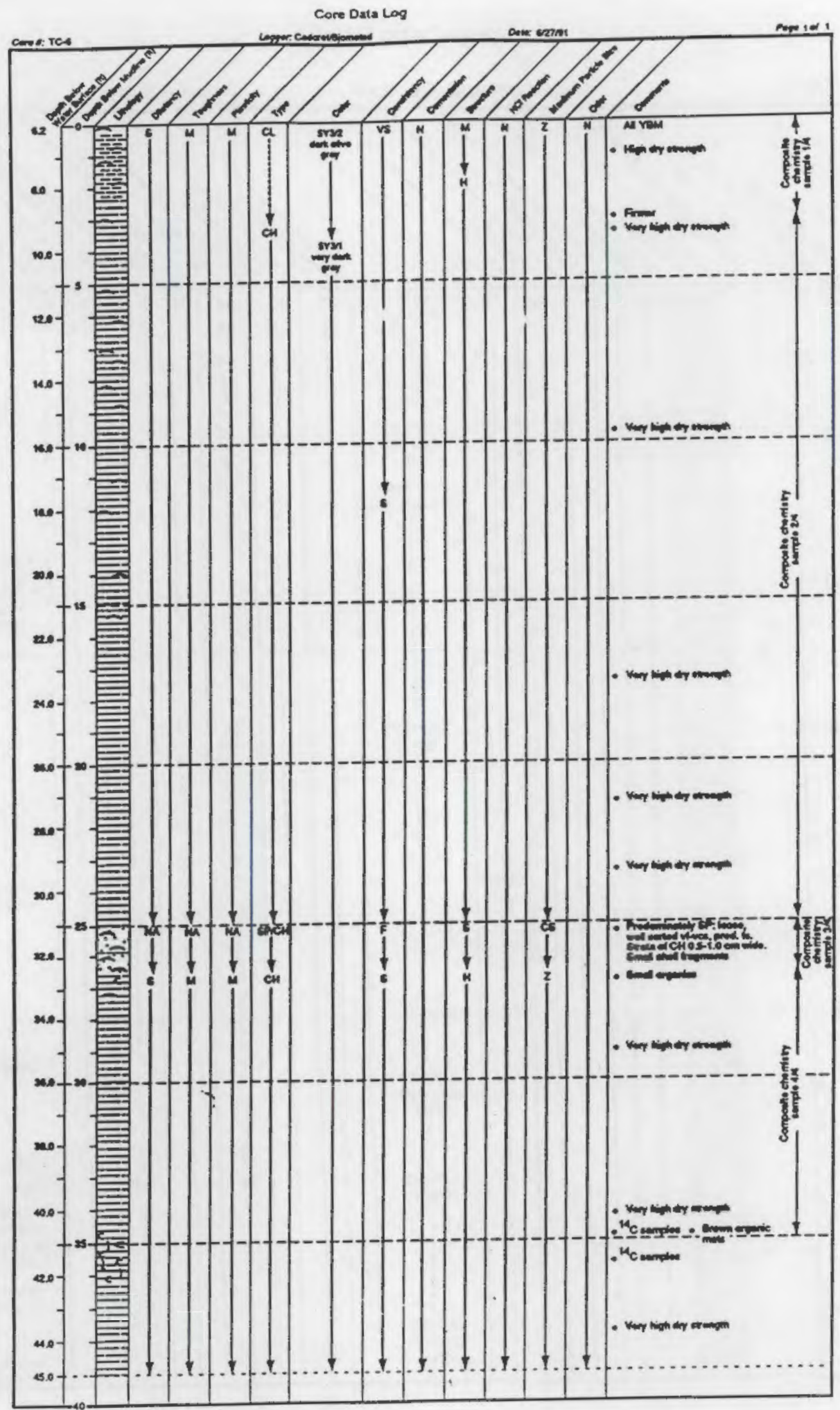


Core Data Log

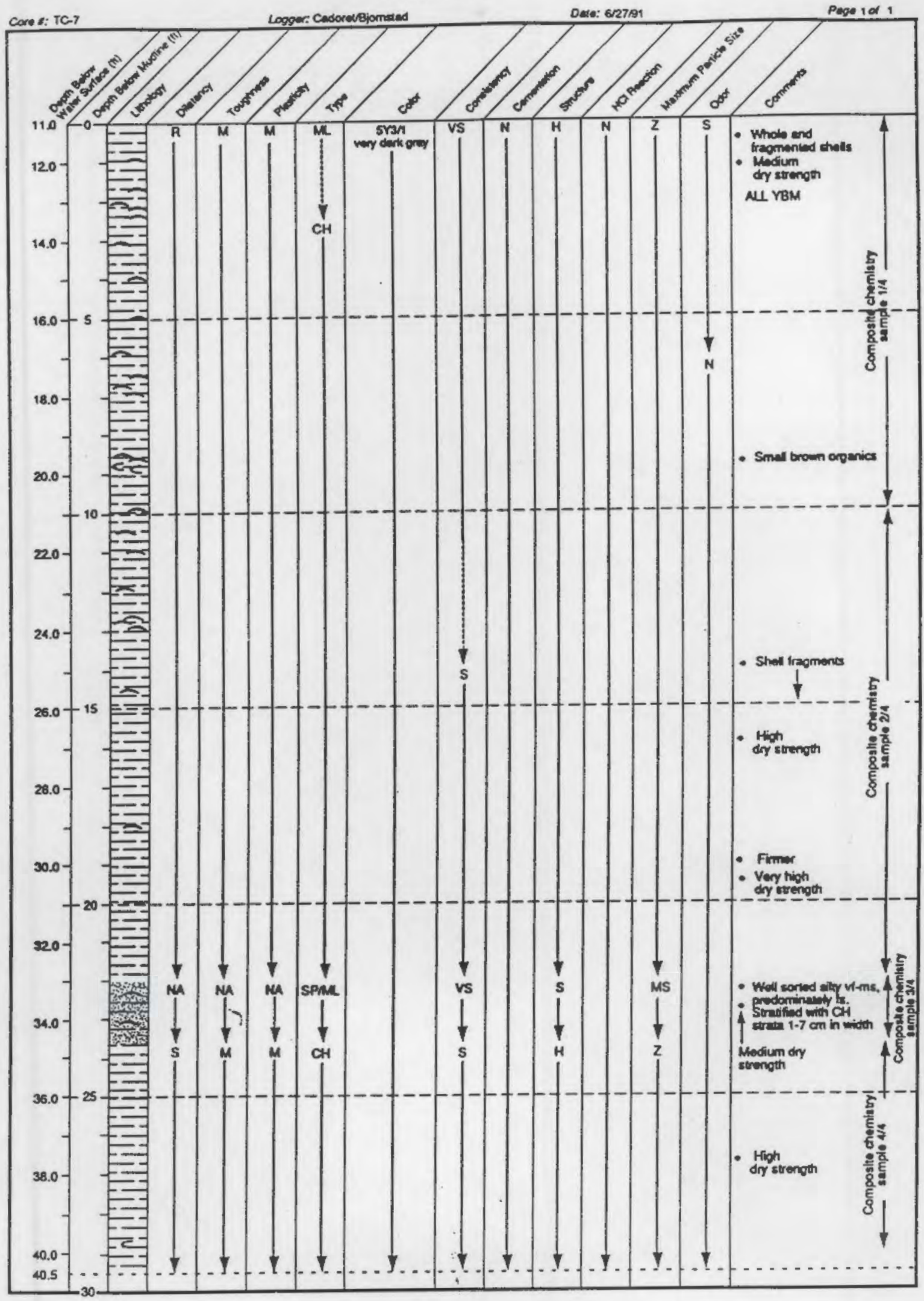


APPENDIX C

\section{SEDIMENT CHEMISTRY AND QUALITY ASSURANCE DATA}




\section{QA/QC SUMMARY}

PROG RAM: Richmond Harbor Program

PARAMETER: Grain Size

LABORATORY: Soil Technologies, Inc.

MATRIX: Sediment

SAMPLE NUMBER: 57

QA/QC REQUIREMENTS

$\begin{array}{ccccc}\begin{array}{c}\text { Reference } \\ \text { Method }\end{array} & \begin{array}{c}\text { Range of } \\ \text { Recovery }\end{array} & \begin{array}{c}\text { Relative } \\ \text { Precision }\end{array} & \begin{array}{c}\text { Detection } \\ \text { LImit (dry wt) }\end{array} \\ \begin{array}{c}\text { ASTM D421 } \\ \text { \& D422 }\end{array} & \text { NA } & \text { NA } & \text { NA }\end{array}$

HOLDING TIMES NOT APPLICABLE

DETECTION LIMITS NOT APPLICABLE

METHOD BLANKS NOT APPLICABLE

MATRIX SPIKES NOT APPLICABLE

SRMs NOT APPLICABLE

REPLICATES Three samples were analyzed in triplicate (TC-5 Upper Comp, R-BF, and RAM) with each extraction batch. Precision was measured by Relative Standard Deviation (RSDs) between replicates. Comparison of sand, silt, and clay summations resulted in RSD values ranging from $0 \%$ to $2 \%$.

SURROGATES NOT APPLICABLE

ADDITIONAL INFORMATION

All samples were corrected for the quantity of salt and dispersant contained in the fluid collected during analyses of the pipette fraction. This consisted of extracting a 20-mL aliquot of the seawater/dispersant mixture, evaporative drying, weighing of the residual material remaining, and subtraction and correction of all fractions measured by pipette. The salt/dispersant mass was reported with the raw data. 


\section{QA/QC SUMMARY}

PROGRAM:

PARAMETER:

LABORATORY:

MATRIX:

SAMPLE NUMBER:
Richmond Harbor Program

Total Organic Carton (TOC)

Global Geochemistry Corporation

Sediment

57

\section{QA/QC REQUIREMENTS}

\section{Reference \\ Method}

5310

$\begin{array}{ccc}\begin{array}{c}\text { Range } \\ \text { of Recovery }\end{array} & \begin{array}{c}\text { Relative } \\ \text { Precision }\end{array} & \begin{array}{c}\text { Detection } \\ \text { Limit (dry wt) }\end{array} \\ \text { NA } & \pm 10 \% & 0.1 \%\end{array}$

HOLDING TIMES

Holding times have not been set for TOC analyses of sediments. All samples were freeze dried upon receipt at the laboratory. Samples were analyzed within 2 months of laboratory sample receipt, which is consistent with recommendations for other organic analyses.

DETECTION LIMITS Detection limits were acceptable $(<0.1 \%)$.

METHOD BLANKS Three method blanks were analyzed. Blank contamination was at levels less than $0.01 \%$, ranging from $0.006 \%$ to $0.009 \%$. These values are less than $1 / 10$ the target detection limits of $0.1 \%$ and do not require blank correction.

\section{MATRIX SPIKES Not applicable.}

SRMs

REPLICATES

SURROGATES
One standard reference material, MESS-1, obtained from the National Research Council of Canada (NRCC) was analyzed in triplicate. Although not certified for TOC, frequent analyses at MSL indicated an estimated value of $2.3 \%$. Values obtained ranged from $2.29 \%$ to $2.33 \%$, indicating acceptable accuracy for this method.

Three samples were analyzed in triplicate (TC-5 Upper Comp, R-AM, and R-BF). Precision was measured by Relative Standard Deviation (RSD) between replicates. The RSDs for the replicates ranged from $0 \%$ to $4 \%$, indicating acceptable precision for the method.

Seven samples were also analyzed in duplicate. Relative percent differences ranged from $0 \%$ to $7 \%$, indicating acceptable analytical precision for this method.

Not applicable. 


\section{QA/QC SUMMARY}

PROGRAM:

PARAMETER:

LABORATORY:

MATRIX:

SAMPLES
Richmond Harbor Program

Total Volatile Solids (TVS)

Battelle/Marine Sciences Laboratory

Sediment

57

QA/QC REQUIREMENTS

\section{Reference \\ Method}

MSL-M-2

\author{
Range \\ of Recovery
}

NA
Relative

Precislon

$\pm 10 \%$

$0.1 \%$

HOLDING TIMES Holding times have not been set for TVS analyses on sediments. Samples were held frozen or freeze dried and analyzed within 2 months of sample receipt at the laboratory.

DETECTION LIMITS Detection limits were acceptable for all samples (<0.1\%)

METHOD BLANKS Two method blanks were analyzed with these samples and they were measured at $0.0013 \%$ and $0.0014 \%$ in each blank. These levels were below the method detection limit and do not require blank correction or affect sample results.

MATRIX SPIKES

SRMS

REPLICATES

SURROGATES
NOT APPLICABLE

NOT APPLICABLE

Three samples were analyzed in triplicate (TC-5 Upper Comp, R-AM, and R-BF). Precision was measured by Relative Standard Deviation (RSD) between replicates. The RSDs for the triplicates ranged from $1 \%$ to $3 \%$, indicating acceptable precision of the method.

NOT APPLICABLE 


\section{OA/OC SUMMARY}

PROGRAM:

PARAMETER:

LABORATORY:

MATRIX:

SAMPLES NUMBER:

QA/QC REQUIREMENTS
Richmond Harbor Program

Oil and Grease/Total Petroleum Hydrocarbons (TPHs)

Twin City Testing

Sediment

$\begin{array}{lcccc}\text { Reference } & \begin{array}{c}\text { Range of } \\ \text { Method }\end{array} & \begin{array}{c}\text { Relative } \\ \text { Recovery }\end{array} & \begin{array}{c}\text { Detection } \\ \text { Preclsion }\end{array} & \begin{array}{c}\text { Limit (dry wt) } \\ \text { Llm }\end{array} \\ \text { Oil and Grease } & 413.2 & 50 \%-150 \% & \pm 20 \% & 20 \mathrm{mg} / \mathrm{kg} \\ \text { TPH } & 418.1 & 50 \%-150 \% & \pm 20 \% & 20 \mathrm{mg} / \mathrm{kg}\end{array}$

HOLDING TIMES

Holding times have not been set for oil and grease in sediment. All samples were held frozen and analyzed within 2 months of laboratory receipt, which is consistent with recommendations for other organic analyses.

DETECTION LIMITS

METHOD BLANKS
Detection limits were acceptable for all samples ( $<20 \mathrm{ppm})$

Three oil and grease method blanks were analyzed with the samples. Oil and grease levels in the method blanks ranged from 3.31 to $7.14 \mathrm{mg} / \mathrm{kg}$. Two method blanks were analyzed for TPH analyses with levels ranging from 0.47 to $5.34 \mathrm{mg} / \mathrm{kg}$. Blank levels were in most cases, less than $1 / 5$ the target detection limit goals. Blank corrections were not required.

Three blank spikes were analyzed with each extraction batch. The spiking solution was consistent with EPA Method 413.2 (EPA 1991) and was spiked into samples of clean sand that were extracted and analyzed. Recoveries for both oil and grease and TPH ranged from $89 \%$ to $154 \%$. All values were within the range of recovery except for the recovery of one TPH spike. Spike recovery data indicated acceptable accuracy of the method.

Three sets of matrix spike/matrix spike duplicate samples (COMP I, COMP III, and COMP IV) were analyzed with the samples. Matrix spike recoveries ranged from $31 \%$ to $131 \%$ with two spike recoveries outside of the OC goals. Relative Percent Differences (RPDs) between the recoveries ranged from $9 \%$ to $45 \%$, with RPDs for two of the three sets of spike duplicates exceeding the precision goal of $20 \%$.

Blank spikes tended to be more reproducible than actual matrix spikes, indicating somewhat reduced accuracy resulting from sediment matrix effects. 
REPLICATES

SRMS

SURROGATES
Three samples were analyzed in triplicate (TC-5 Upper Comp. R-BF, and R-AM). Relative Standard Deviation (RSD) between replicates ranged from $9 \%$ to $46 \%$. Four out of the six RSD values calculated exceeded the QC goal for precision.

NOT APPLICABLE

NOT APPLICABLE 


\title{
OA/OC SUMMARY
}

\author{
PROGRAM: \\ PARAMETER: \\ Richmond Harbor Program \\ LABORATORY: \\ Polynuclear Aromatic Hydrocarbons (PAHs) \\ MATRIX: \\ Battelle/Marine Sciences Laboratory \\ SAMPLE NUMBER: 57
}

QA/OC REQUIREMENTS

$\begin{array}{cccc}\begin{array}{c}\text { Reference } \\ \text { Method }\end{array} & \begin{array}{c}\text { Range } \\ \text { of Recovery }\end{array} & \begin{array}{c}\text { Relative } \\ \text { Precision }\end{array} & \begin{array}{c}\text { Detection } \\ \text { Llmit (dry wt) }\end{array} \\ 8270 & 40 \% \cdot 120 \% & \pm 30 \% & 20 \mu \mathrm{g} / \mathrm{kg}\end{array}$

HOLDING TIMES

The following is a list of $O C$ extraction and analysis dates for the three batches of sediment samples analyzed for PAHs:

\begin{tabular}{|c|c|c|}
\hline & Extraction Date & GC Analysis Date \\
\hline atch A: & $10 / 30 / 91$ & $11 / 25 / 91$ \\
\hline Batch B: & $9 / 18 / 91$ & $11 / 13 / 91-11 / 15 / 91$ \\
\hline Batch C: & $11 / 05 / 91$ & $12 / 25 / 91-12 / 30 / 91$ \\
\hline Batch D (reruns): & $01 / 30 / 92$ & $02 / 27 / 92$ \\
\hline
\end{tabular}

Samples were kept frozen until used in extraction. Batch A, Batch $C$, and Batch $D$ exiracts were analyzed within the EPA recommended 40-day (EPA 1986) holding time. However, due to instrument problems, Batch B was not analyzed for up to 57 days. Matrix spikes and surrogate compounds were added to all samples at the time of extraction. Recoveries of matrix spike and surrogates indicate that $n$ serious bias was introduced for Batch B PAH analyses.

DETECTION LIMITS The achieved detection limits for all PAH compounds were much lower than the target detection limit goals of $<20 \mu \mathrm{g} / \mathrm{kg}$ and are acceptable.

METHOD BLANKS Four method blanks were analyzed (one with each extraction batch). Two LPAHs (naphthalene and phenanthrene) were present in all method blanks. Three HPAHs (fluoranthene, pyrene, and benzo(ghi)-perylene) were present in two of the four method blanks. Levels of naphthalene and phenanthrene in Blank A were approximately two times the target detection limit. The remaining three blanks were approximately $1 / 2$ the target detection limits of $20 \mu \mathrm{g} / \mathrm{kg}$. All sample values associated with Blank A were flagged with a " $B$ " to note possible blank contamination. The HPAH contaminants in the blanks were less than the target detection limits and were not flagged with a " $B$ ". 


\section{MATRIX SPIKES}

SRMs

REPLICATES

SURROGATES
Three samples (COMP 1, COMP III, and COMP IV) were spiked in duplicate with all sixteen PAH compounds. These spikes were measured to assess the accuracy of the method. Recoveries for LPAH compounds ranged from $19 \%$ to $93 \%$. All recoveries for Batch $B$ and Batch $C$ were within the QANCC requirements. Recovery for all PAH compounds in Batch A spike duplicate were consistently below the bwer $C \mathrm{C}$ limit of $40 \%$. Since surrogate recoveries for this sample were acceptable, the most probable explanation is that the sample was inadvertently spiked low and should not affect the quality of samples analyzed with this batch.

The HPAH spike recoveries ranged from $36 \%$ to $209 \%$ with the majority of the recoveries within the QANC requirements. However, pyrene recoveries were high (172\% and $209 \%)$ for both spikes in Batch C. These recoveries suggest that the pyrene values associated with Batch $C$ may be biased high.

One SRM compound, 1941 (NIST) was analyzed with each extraction batch. Values were within $30 \%$ of the certified mean value.

Four samples (COMP III, COMP IV, TC-5 Upper Comp, and R-BF) were analyzed in triplicate. Precision of the method was measured by determining the Relative Standard Deviation (RSD). The LPAH replicate analyses showed acceptable precision with RSD ranging from $5 \%$ to $26 \%$. The HPAH RSDs ranged from $4 \%$ to $30 \%$, again, indicating acceptable precision of the method.

Three radiolabelled surrogates (naphthalene d8, acenapthalene $\mathrm{d10}$, and perylene d12) were added to samples prior to extraction to assess the efficiency of the method. Naphthalene recoveries ranged from $1 \%$ to $82 \%$. The QANC Plan does not require re-extraction unless recoveries are below $20 \%$. One sample had a recovery less than $20 \%$ for naphthalene and was subsequently re-extracted producing a naphthalene d8 recovery of $1 \%$; a second re-extraction was not required. Re-extractions were not required for acenapththene and perylene, which had recoveries of $38 \%$ to $80 \%$ and $37 \%$ to $138 \%$, respectively. 


\section{QA/QC SUMMARY}

PROGRAM:

PARAMETER:

LABORATORY:

MATRIX:

SAMPLE NUMBER:
Richmond Harbor Program

Chlorinated Pesticides and Polychlorinated Biphenyls (PCBs)

Battelle/Marine Sciences Laboratory

Sediment

57

QA/QC REQUIREMENTS

$\begin{array}{cccc}\begin{array}{c}\text { Reference } \\ \text { Method }\end{array} & \begin{array}{c}\text { Range } \\ \text { of Recovery }\end{array} & \begin{array}{c}\text { Relative } \\ \text { Precision }\end{array} & \begin{array}{c}\text { Detection } \\ \text { Limit_dry wht) }\end{array} \\ 8080 & 40 \%-120 \% & \pm 30 \% & 20 \mu \mathrm{g} / \mathrm{kg}\end{array}$

HOLDING TIMES The following is a list of extraction dates and GC nun dates for the three batches of sediment samples analyzed for PCB/Pesticides:

$\begin{array}{lll} & \text { Extraction Date } & \text { Analysis Date } \\ \text { Batch A: } & 10 / 30 / 91 & 11 / 25 / 91 \\ \text { Batch B: } & 09 / 18 / 91 & 11 / 13 / 91-11 / 15 / 91 \\ \text { Batch C: } & 11 / 05 / 91 & 12 / 25 / 91-12 / 30 / 91 \\ \text { Batch D (re-runs): } & 01 / 30 / 92 & 02 / 27 / 92\end{array}$

Samples were frozen until used in extractions. Batch $A$, Batch $C$, and Batch D extracts were analyzed within the EPA recommended 40-day (EPA 1986) holding time. However, Batch $B$ was not analyzed for 57 days. Matrix spikes and surrogate compounds were added to all samples at the time of extraction. Matrix spike recoveries were somewhat elevated (see below). indicating extract evaporation may have occurred during the longer holding time and the values associated with this batch may be biased high.

DETECTION LIMITS All PCB detection limits were within the detection limit goals. Detection limits for six of the pesticides were elevated (10 $\mu \mathrm{g} / \mathrm{kg}$ ) in three samples (C8, R-BF Rep. 2 and 3) due to matrix interferences. Detection limits for toxaphene were below the target detection limit of $30 \mu \mathrm{g} / \mathrm{kg}$.

METHOD BLANKS

Six method blanks were analyzed for the pesticide and $P C B$ samples.

Pesticides and PCBs were not detected in any of the sediment samples.

MATRIX SPIKES Three samples (COMP I, COMP III, and COMP IV) were spiked in duplicate to assess the accuracy of the method. A portion of the samples were spiked with 19 pesticides and a separate aliquot of these samples were spiked with aroclor 1254. One pesticide spike duplicate for Batch A was lost after extraction; therefore, only a matrix spike is available for that batch. 
SRMS

REPLICATES
Pesticide recoveries (excluding endrin) for COMP I and COMP IV ranged from $73 \%$ to $172 \%$. All but 6 of 21 recovery measurements for Batch $A$ and Batch $C$ spikes were within the QANCC requirements. Batch $B$ had higher recoveries for all pesticides ranging from $131 \%$ to $219 \%$ (excluding endrin). The sample results for Batch B may also be elevated, atthough surrogate recoveries for these samples were not significantly higher than the other batches.

Endrin recoveries for all matrix spikes were high, ranging from $257 \%$ to $548 \%$. No corrective action was taken.

The PCB spike recoveries ranged from $74 \%$ to $125 \%$. One recovery value for the spike from Batch A exceeded the OAVOC requirements. This indicates acceptable accuracy of the method. Relative percent differences (RPDs) between the spike and spike duplicates ranged from $8 \%$ to $38 \%$ with one RPD value from Batch $C$ slightly exceeding the precision goal of $\pm 30 \%$, indicating acceptable precision of the method.

One SRM, 1941 (NIST), was analyzed with each batch of samples for pesticides. Pesticide values are reported for this SRM; however, they are not certified and are considered consensus values and were obtained from only one laboratory using a different method. Three pesticides consensus values ( $4,4^{\prime}-$-DDT, 4, $4^{\prime}$-DDD, and 4,4'-DDE) were elevated above the target consensus values. These elevated SRM values indicate that the accuracy of the pesticide analyses may be biased high. However, these consensus values are not certified and in themselves may be biased low.

Consensus values were not provided for aroclor concentrations.

Three samples (TC-5 Upper Comp, R-AM, and R-BF) were analyzed in triplicate to assess precision as measured by the Relative Standard Deviation (RSD). Only one pesticide was detected in one set of triplicates and a value of $5 \%$ was obtained indicating acceptable precision of the measurement. Aroclor precision was measured in all three sets of triplicates. The RSDs ranged from $4 \%$ to $37 \%$ with only the RSD value from Batch $B$ exceeding the precision goal.

Two surnogate compounds were added to all samples prior to analyses, tetrachloro-metaxylene (TCMX) and octachloronaphthalene (OCN). All recoveries were within the QAVC requirements with the exception of two TCMX values of $30.5 \%$ and $129 \%$ and one sample with an OCN recovery of $24.9 \%$. Because no pesticides or PCBs were detected in these samples and the recovery was greater than $20 \%$, re-extraction was not required. 


\section{OA/QC SUMMARY}

PROGRAM:

PARAMETER:

LABORATORY:

MATRIX:

SAMPLE NUMBER
Richmond Harbor Program

Metals (Ag, As, Cd, Cr, Cu, $\mathrm{Hg}, \mathrm{Ni}, \mathrm{Pb}, \mathrm{Se}$, and $\mathrm{Zn}$ )

Battelie/Marine Sciences Laboratory

Sediment

57

OA/OC REOUIREMENTS

$\begin{array}{cccc}\text { QA/QC } & \text { Range of } & \text { Relative } & \text { Detection } \\ \text { Document } & \text { Recevery } & \text { Precision Limits (dry w) }\end{array}$

$\begin{array}{lc}\text { Arsenic } & \text { PNL-SP-19 } \\ \text { Cadmium } & \text { MSL-M-33 } \\ \text { Chromium } & \text { PNL-SP-19 } \\ \text { Copper } & \text { PNL-SP-19 } \\ \text { Lead } & \text { PNL-SP-19 } \\ \text { Mercury } & \text { MSL-M-11 } \\ \text { Nickel } & \text { PNL-SP-19 } \\ \text { Selenium } & \text { MSL-M-33 } \\ \text { Silver } & \text { MSL-M-33 } \\ \text { Zinc } & \text { PNL-SP-19 }\end{array}$

$\begin{array}{cc}\text { NA } & \pm 20 \% \\ 75 \%-125 \% & \pm 20 \% \\ \text { NA } & \pm 20 \% \\ \text { NA } & \pm 20 \% \\ \text { NA } & \pm 20 \% \\ 75 \%-125 \% & \pm 20 \% \\ \text { NA } & \pm 20 \% \\ 75 \%-125 \% & \pm 20 \% \\ 75 \%-125 \% & \pm 20 \% \\ \text { NA } & \pm 20 \%\end{array}$

$1.0 \mathrm{mg} / \mathrm{kg}$

$0.1 \mathrm{mg} / \mathrm{kg}$

$1.0 \mathrm{mg} / \mathrm{kg}$

$1.0 \mathrm{mg} / \mathrm{kg}$

$1.0 \mathrm{mg} / \mathrm{kg}$

$0.02 \mathrm{mg} / \mathrm{kg}$

$1.0 \mathrm{mg} / \mathrm{kg}$

$0.5 \mathrm{mg} / \mathrm{kg}$

$1.0 \mathrm{mg} / \mathrm{kg}$

$1.0 \mathrm{mg} / \mathrm{kg}$

\section{HOLDING TIMES}

All metals were analyzed within the recommended holding times specitied by EPAUSACE (1991). Samples were immediately freeze dried, digested, and analyzed within the 6 month recommended holding times for metals in sediments.

\section{DETECTION LIMITS All detection limit goals were met.}

\author{
METHOD BLANKS
}

Three method blanks were digested with the samples. Two of the three blanks were analyzed by GFAA for $\mathrm{Ag}$ and $\mathrm{Cd}$. Blanks did not produce values for $\mathrm{Ag}$ but low levels of $\mathrm{Cd}$ were detected All values associated with the blanks corrected for Cd levels. (NOTE: Blank amount was less than $10 \%$ of any sample value and does not affect the results.) All three method blanks were analyzed in duplicate for $\mathrm{Hg}$. Low levels of $\mathrm{Hg}$ were detected in method blanks; all values were corrected for $\mathrm{Hg}$ blank levels. (NOTE: Method blanks are not requested for $\mathrm{As}, \mathrm{Cr}, \mathrm{Cu}, \mathrm{Ni}, \mathrm{Pb}$, Se, and Zn due to the method of analysis XRF, which precludes the use of method blanks.)

Three sarmples (COMP I, COMP III, COMP IV) were spiked in duplicate to assess the accuracy of the method. Matrix spikes were appropriate for $\mathrm{Ag}, \mathrm{Cd}$, and $\mathrm{Hg}$. Recoveries ranged from $80 \%$ to $111 \%$ and were within the QAVC requirements, which indicated acceptable accuracy of the method. Relative Percent Differences (RPDs) between spike and spike duplicate recoveries ranged from $1 \%$ to $9 \%$ and were within the precision requirements. 
SRMS

REPLICATES

SURROGATES
SRM 1646, an estuarine sediment (obtained from NIST), was analyzed for all metals with the exception of $\mathrm{Ag}$ and $\mathrm{Se}$ (1646 is not certified for these metals). Three separate aliquots of this sample were analyzed to assess accuracy of the measurement. $\mathrm{Cd}, \mathrm{Cr}$, and Ni were out of the certified range but were within the QAQC requirements. A second SRM, BEST-1, a marine sediment (obtained from the NRCC) was analyzed for $\mathrm{Hg}$. All measurements were below the certified range but were within the $\mathrm{QANC}$ requirements.

Three samples (TC-5 Upper Comp, R-AM, and R-BF) were analyzed in triplicate to assess precision of the method as measured by Relative Standard Deviation. (RSD). The RSD values ranged from $0 \%$ to $39 \%$. Four out of thirty measurements exceeded QAOC requirements, indicating acceptable precision for the methods.

Not Applicable 


\section{QA/QC SUMMARY}

PROGRAM:

PARAMETER:

LABORATORY:

MATRIX:

SAMPLES NUMBER:
Richmond Hartor Program

Butyitins

Battelle/Marine Sciences Laboratory

Sediment

57

\section{QA/QC REQUIREMENTS}

\begin{tabular}{lcccc} 
Monobutyltin & $\begin{array}{c}\text { Reference } \\
\text { Method }\end{array}$ & $\begin{array}{c}\text { Range } \\
\text { of Recovery }\end{array}$ & $\begin{array}{c}\text { Relative } \\
\text { Precision }\end{array}$ & $\begin{array}{c}\text { Detection } \\
\text { Limit_dry wt) }\end{array}$ \\
\cline { 2 - 2 } & - & $\pm 30 \%$ & $10 \mu \mathrm{g} / \mathrm{kg}$ \\
Dibutyltin & $M S L-M-4$ & $40 \%-120 \%$ & $\pm 30 \%$ & $10 \mu \mathrm{g} / \mathrm{kg}$ \\
Tributyltin & $M S L-M-4$ & $40 \%-120 \%$ & $\pm 30 \%$ & $10 \mu \mathrm{kg}$
\end{tabular}

HOLDING TIMES

DETECTION LIMITS

METHOD BLANKS

MATRIX SPIKES

SRMs

Holding times have not been established for butytin compounds in sediment. Samples were frozen until used for extraction. Analyses were performed within 2 months of sample receipt at the laboratory, which is consistent with recommendations for other organic analyses.

Detection limit goals $(1 \mu \mathrm{g} / \mathrm{kg})$ were met.

Five method blanks were analyzed. Butylins were undetected in ail method blanks with the exception of dibutyltin in the blank from Batch $D$. The value detected was less than 1/5 the target detection limit and does not require correction for blank contamination or affect the quality of sample data.

Three butyltin compounds, mono-, di-, and tributyltin were spiked for three samples (COMP I, COMP III, and COMP IV). Tri- and dibutyltin matrix spike recoveries ranged from $54 \%$ to $120 \%$ and were within the QAQC requirements.

The RPD values between spike duplicates ranged from $1 \%$ to $39 \%$, with all but one value within the QAQC requirements.

Standard Reference Material (SRM) PACS-1, obtained from the National Research Council of Canada (NRCC), was analyzed to assess the accuracy of butyltin methods. (Note: As required by the NRCC, these values are reported after being corrected for surrogate recoveries.) All but one tributyltin recovery were within the certified values. Dibutyltin recoveries were more variable and were not within the certified ranges. The MSL's past experience has resulted in recoveries similar to those reported here; therefore, no corrective action was taken. The variability of the analyses indicates that the measurements are either not precise or the SRM itself is non-homogeneous. 
REPLICATES

SURROGATES
Three samples (TC-5 Upper Comp, R-AM, and R-BP) were analyzed in triplicate. Precision was measured by Relative Standard Deviation (RSD) and ranged from $0 \%$ to $49 \%$ with one out of six measurements exceeding QAVC requirements.

One compound, tripentyltin, was added prior to extraction as a surrogate to assess the efficiency of the method. Surrogate recoveries ranged from $53 \%$ to $134 \%$. All values were within the QA/OC requirements, with the exception of one sample, C-19, which had a recovery of $134 \%$. The tri- and dibutyttin values associated with the elevated recoveries were undeterted.

\section{ADDITIONAL INFORMATION}

The current compound used as a surrogate for butyltin analyses is tripentyltin. All pentyttin recoveries were within the QAVC requirements. A few samples that initially exceeded these goals were re-extracted and analyzed.

The surrogate compound used in the past was tripropyltin. This compound is significantly more volatile than tributyltin and recoveries have been consistently low. For this reason, use of the new surrogate compound tripentyltin was initiated. Recem experiments in the laboratory have shown that the recoveries of the tripentyltin more accurately reflect the behavior of butyltin compounds. 
TABLE C.1. Total Polynuclear Aromatic Hydrocarbons (PAHs) Found in Sediment Treatments, Richmond Harbor Program

\begin{tabular}{|c|c|c|c|c|}
\hline $\begin{array}{l}\text { Sediment } \\
\text { Ireatment }\end{array}$ & $\begin{array}{l}\text { Analytical } \\
\text { Batch } \\
\end{array}$ & $\begin{array}{l}\text { Low Mol ecular } \\
\text { Weight PAHS }\end{array}$ & $\begin{array}{l}\text { High Molecular } \\
\text { Weight PAHs } \\
\end{array}$ & $\begin{array}{l}\text { Total } \\
\text { PAHs } \\
\end{array}$ \\
\hline $\begin{array}{l}\text { COMP I } \\
C-1 \\
C-3 \\
C-5 \\
C-6 \\
C-8 \\
c-10\end{array}$ & $\begin{array}{l}\text { C } \\
A \\
A \\
A \\
A \\
A \\
A\end{array}$ & $\begin{array}{l}193.41 \\
164.93 \\
176.70 \\
234.61 \\
169.78 \\
152.83 \\
216.82\end{array}$ & $\begin{array}{r}1474.86 \\
867.91 \\
792.78 \\
1661.51 \\
1357.69 \\
1023.63 \\
1962.23\end{array}$ & $\begin{array}{r}1668.27 \\
1032.84 \\
969.48 \\
1896.12 \\
1527.47 \\
1176.46 \\
2179.05\end{array}$ \\
\hline $\begin{array}{l}\text { COMP II } \\
C-11 \\
C-16 \\
C-18 \\
C-19 \\
C-20 \\
C-23\end{array}$ & $\begin{array}{l}\text { A } \\
B \\
B \\
B \\
B \\
B \\
B\end{array}$ & $\begin{array}{l}810.27 \\
170.16 \\
103.84 \\
159.83 \\
35.79 \\
86.59 \\
70.06\end{array}$ & $\begin{array}{r}1873.60 \\
1454.24 \\
915.55 \\
1223.22 \\
302.48 \\
896.51 \\
636.31\end{array}$ & $\begin{array}{r}2683.87 \\
1624.40 \\
1019.39 \\
1383.05 \\
338.27 \\
983.10 \\
706.01\end{array}$ \\
\hline $\begin{array}{l}\text { COMP II I Replicate l } \\
\text { COMP II Replicate } 2 \\
\text { COMP II I Replicate } 3 \\
\text { TC-1 Upper } \\
\text { TC-2 Upper } \\
\text { TC-3 Upper } \\
\text { TC-4 Upper }\end{array}$ & $\begin{array}{l}B \\
B \\
B \\
B \\
B \\
C \\
B\end{array}$ & $\begin{array}{l}67.80 \\
59.51 \\
62.03 \\
56.62 \\
87.16 \\
15.44 \\
272.22\end{array}$ & $\begin{array}{r}348.10 \\
321.22 \\
345.73 \\
346.40 \\
1142.23 \\
26.89 \\
1077.98\end{array}$ & $\begin{array}{r}415.90 \\
380.73 \\
407.76 \\
403.02 \\
1229.39 \\
42.33 \\
1350.20\end{array}$ \\
\hline $\begin{array}{l}\text { TC-5 Upper Comp } \\
\text { TC-5 Upper Replicate } 1 \\
\text { TC-5 Upper Rep Ticate } 2 \\
\text { TC-5 Upper RepTicate } 3 \\
\text { TC-5 Special Sample }\end{array}$ & $\begin{array}{l}A \\
C \\
C \\
C \\
C\end{array}$ & $\begin{array}{l}187.25 \\
231.61 \\
206.55 \\
258.96 \\
387.85\end{array}$ & $\begin{array}{l}1923.65 \\
1948.80 \\
1783.67 \\
2397.28 \\
1940.39\end{array}$ & $\begin{array}{l}2110.90 \\
2180.41 \\
1990.22 \\
2656.24 \\
2328.24\end{array}$ \\
\hline $\begin{array}{l}\text { COMP IV Replicate } 1 \\
\text { COMP IV Replicate } 2 \\
\text { COMP IV Replicate } 3 \\
\text { TC -1 Lower } \\
\text { TC }-2 \text { Lower } \\
\text { TC-3 Lower } \\
\text { TC }-4 \text { Lower } \\
\text { TC-5 Lower }\end{array}$ & $\begin{array}{l}\text { A } \\
\text { A } \\
\text { A } \\
B \\
B \\
C \\
C \\
\text { B }\end{array}$ & $\begin{array}{l}55.47 \\
54.19 \\
63.96 \\
16.22 \\
50.10 \\
13.38 \\
22.07 \\
18.64\end{array}$ & $\begin{array}{r}30.31 \\
36.00 \\
28.37 \\
37.58 \\
425.10 \\
2.42 \\
461.79 \\
62.34\end{array}$ & $\begin{array}{r}85.78 \\
90.19 \\
92.33 \\
53.80 \\
475.20 \\
15.80 \\
483.86 \\
80.98\end{array}$ \\
\hline
\end{tabular}


IABLE C.1. (contd)

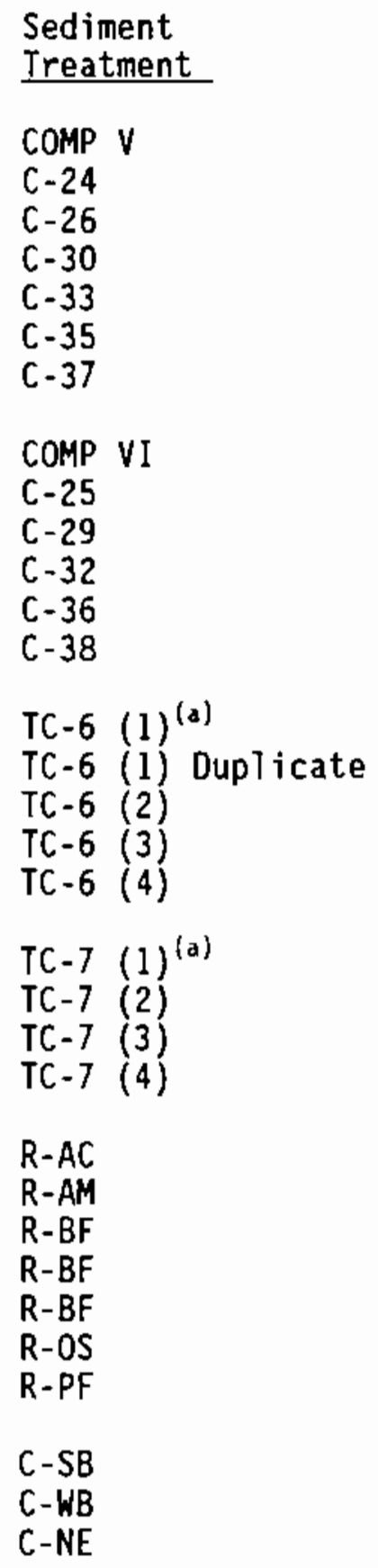

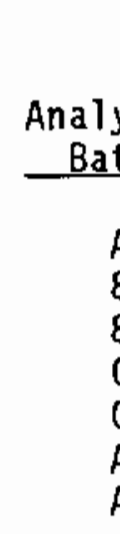

$(\mu \mathrm{g} / \mathrm{kg}$ dry weight $)$

\begin{tabular}{ccc}
\hline $\begin{array}{c}\text { Total } \\
\text { Low Molecular }\end{array}$ & Total & \\
Height Molecular & Total \\
Weight PAHs & PAHs \\
\cline { 2 - 3 }
\end{tabular}

$\begin{array}{lrrr}\text { A } & 238.53 & 2295.80 & 2534.33 \\ 8 & 27.97 & 54.94 & 82.91 \\ 8 & 150.56 & 1325.97 & 1476.53 \\ \text { C } & 168.93 & 1842.32 & 201 . .25 \\ \text { C } & 144.86 & 1312.68 & 1457.54 \\ \text { A } & 138.51 & 814.98 & 953.49 \\ \text { A } & 94.50 & 681.07 & 775.57\end{array}$

$\begin{array}{lrrr}\text { A } & 305.46 & 2417.28 & 2722.74 \\ \text { B } & 96.52 & 836.88 & 933.40 \\ \text { A } & 111.75 & 749.52 & 861.27 \\ \text { A } & 51.23 & 407.67 & 458.90 \\ \text { B } & 225.99 & 1616.25 & 1842.24 \\ \text { B } & 111.81 & 1072.42 & 1184.23 \\ & & & \\ \text { C } & 73.36 & 681.77 & 755.13 \\ \text { C } & 78.54 & 667.93 & 746.47 \\ \text { C } & 23.54 & 18.97 & 42.51 \\ \text { C } & 10.90 & 2.24 & 13.14 \\ \text { C } & 21.60 & 19.67 & 41.27 \\ \text { C } & & & \\ \text { C } & 12.58 & 11.28 & 23.86 \\ \text { C } & 25.65 & 15.42 & 41.07 \\ \text { C } & 36.75 & 0.00 & 36.75 \\ & 21.18 & 6.29 & 27.47\end{array}$

$\begin{array}{lrrr}\text { A } & 607.57 & 5696.86 & 6304.43 \\ \text { B } & 534.55 & 1838.62 & 2373.17 \\ \text { A } & 226.76 & 2460.25 & 2687.01 \\ \text { A } & 170.46 & 1846.26 & 2016.72 \\ \text { A } & 212.43 & 1494.49 & 1706.92 \\ \text { A } & 77.44 & 114.67 & 192.11 \\ \text { A } & 198.28 & 699.31 & 897.59 \\ \text { A } & 169.97 & 328.57 & 498.54 \\ \text { A } & 18.75 & 6.34 & 25.09 \\ \text { A } & 35.00 & 12.77 & 47.77\end{array}$

(a) Stations TC-6 and TC-7 were split into four separate core sections which were composited, subsampled for chemistry, and used for geologic descriptions. 
IABLE.C.2. Low Molecular Weight Polynuclear Aromatic Hydrocarbons (LPAHs) in Sediment, Richmond Harbor Program

\begin{tabular}{|c|c|c|c|c|c|c|c|}
\hline \multirow[b]{2}{*}{$\begin{array}{l}\text { Sediment } \\
\text { Ireatment }\end{array}$} & \multirow[b]{2}{*}{$\begin{array}{l}\text { Analytical } \\
\text { Batch } \\
\end{array}$} & \multicolumn{6}{|c|}{ LPAHs $(\mu \mathrm{g} / \mathrm{kg}$ dry weight) } \\
\hline & & $\begin{array}{l}\text { Naphtha- } \\
\text { lene } \\
\end{array}$ & $\begin{array}{l}\text { Acenaph- } \\
\text { thylene }\end{array}$ & $\begin{array}{l}\text { Acenaph- } \\
\text { thene } \\
\end{array}$ & Fluorene & $\begin{array}{l}\text { Phenan- } \\
\text { threne }\end{array}$ & $\begin{array}{l}\text { Anthra- } \\
\text { cene } \\
\end{array}$ \\
\hline $\begin{array}{l}\text { Target } D L \text { (a) } \\
\text { Achieved DL (High) } \\
\text { Achieved DL (Low) }\end{array}$ & & $\begin{array}{l}20.0 \\
8.88\end{array}$ & $\begin{array}{l}20.0 \\
9.75 \\
2.41\end{array}$ & $\begin{array}{r}20.0 \\
14.89 \\
3.03\end{array}$ & $\begin{array}{r}20.0 \\
13.05 \\
2.49\end{array}$ & $\begin{array}{l}20.0 \\
20.0\end{array}$ & $\begin{array}{l}20.0 \\
6.61 \\
2.02\end{array}$ \\
\hline $\begin{array}{l}\text { COMP I } \\
C-1 \\
C-3 \\
C-5 \\
C-6 \\
C-8 \\
C-10\end{array}$ & $\begin{array}{l}\text { C } \\
A \\
A \\
A \\
A \\
A \\
B\end{array}$ & $\begin{array}{l}40.34 \mathrm{~B}^{(\mathrm{b})} \\
31.77 \mathrm{~B}^{35.90 \mathrm{~B}} \\
38.76 \mathrm{~B} \\
26.83 \mathrm{~B} \\
36.82 \mathrm{~B} \\
36.09\end{array}$ & $\begin{array}{c}9.24 \\
7.38 \\
7.30 \mathrm{U} \\
10.08 \\
9.42 \\
6.30 \\
11.41\end{array}$ & $\begin{array}{c}13.26 \\
10.79 \\
12.53 \\
12.07 \\
8.87 \\
9.40 \\
12.44 \mathrm{U}\end{array}$ & $\begin{array}{l}9.42 \\
7.88 \mathrm{U}(\mathrm{c}) \\
9.17 \mathrm{U} \\
12.25 \\
9.91 \\
7.75 \\
10.91 \mathrm{U}\end{array}$ & 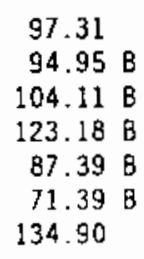 & $\begin{array}{l}23.84 \\
20.04 \\
24.16 \\
38.27 \\
27.36 \\
21.17 \\
34.42\end{array}$ \\
\hline $\begin{array}{l}\text { COMP II } \\
\text { C-11 } \\
\text { C-16 } \\
\text { C-18 } \\
C-19 \\
C-20 \\
C-23\end{array}$ & $\begin{array}{l}A \\
B \\
B \\
B \\
B \\
B \\
B\end{array}$ & $\begin{array}{c}143.498 \\
28.79 \\
20.19 \\
29.73 \\
7.72 \\
17.13 \\
9.01\end{array}$ & $\begin{array}{r}117.28 \\
8.73 \\
5.20 \\
7.52 \\
3.04 \mathrm{U} \\
8.45 \mathrm{U} \\
3.73 \mathrm{U}\end{array}$ & $\begin{array}{r}119.23 \\
7.65 \\
5.89 \mathrm{U} \\
5.99 \\
4.64 \mathrm{U} \\
12.91 \mathrm{U} \\
3.73 \mathrm{U}\end{array}$ & $\begin{array}{c}123.40 \\
9.58 \\
5.39 \\
8.50 \\
4.07 \mathrm{U} \\
11.32 \mathrm{U} \\
5.28\end{array}$ & $\begin{array}{c}160.188 \\
93.53 \\
60.72 \\
88.40 \\
23.82 \\
55.74 \\
46.08\end{array}$ & $\begin{array}{r}146.69 \\
21.68 \\
12.34 \\
19.69 \\
4.25 \\
13.72 \\
9.69\end{array}$ \\
\hline $\begin{array}{l}\text { COMP II I Replicate } 1 \\
\text { COMP II Replicate } 2 \\
\text { COMP III Replicate } 3 \\
\text { TC-1 Upper } \\
\text { TC-2 Upper } \\
\text { TC-3 Upper } \\
\text { TC-4 Upper }\end{array}$ & $\begin{array}{l}\text { B } \\
B \\
B \\
B \\
B \\
C \\
B\end{array}$ & $\begin{array}{c}23.20 \\
20.07 \\
13.55 \\
16.13 \\
8.88 \mathrm{U} \\
6.67 \\
24.71\end{array}$ & $\begin{array}{l}4.77 \mathrm{U} \\
4.01 \mathrm{U} \\
7.15 \mathrm{U} \\
3.81 \mathrm{U} \\
9.75 \mathrm{U} \\
2.41 \mathrm{U} \\
20.89\end{array}$ & $\begin{array}{r}7.28 \mathrm{U} \\
6.13 \mathrm{U} \\
10.92 \mathrm{U} \\
5.82 \mathrm{U} \\
14.89 \mathrm{U} \\
3.26 \mathrm{U} \\
8.82\end{array}$ & $\begin{array}{r}6.38 \mathrm{U} \\
5.37 \mathrm{U} \\
9.57 \mathrm{U} \\
5.10 \mathrm{U} \\
13.05 \mathrm{U} \\
2.94 \mathrm{U} \\
12.49\end{array}$ & $\begin{array}{r}36.68 \\
34.26 \\
41.10 \\
33.90 \\
73.58 \\
8.77 \\
172.95\end{array}$ & $\begin{array}{r}7.92 \\
5.18 \\
7.38 \\
6.59 \\
13.58 \\
2.35 \\
32.36\end{array}$ \\
\hline $\begin{array}{l}\text { TC-5 Upper Comp } \\
\text { TC-5 Upper Repl icate } 1 \\
\text { TC-5 Upper Repl icate } 2 \\
\text { TC-5 Upper Repl icate } 3 \\
\text { TC-5 Special Sample }\end{array}$ & $\begin{array}{l}A \\
C \\
C \\
C \\
C\end{array}$ & $\begin{array}{l}33.06 \mathrm{~B} \\
36.62 \\
33.47 \\
37.33 \\
30.28\end{array}$ & $\begin{array}{r}10.94 \\
11.31 \\
8.84 \\
11.43 \\
8.87\end{array}$ & $\begin{array}{l}9.58 \mathrm{U} \\
11.88 \\
10.75 \\
11.81 \\
19.19 \times(\mathrm{d})\end{array}$ & $\begin{array}{l}16.92 \\
23.63 \\
21.91 \\
24.02 \\
51.83\end{array}$ & $\begin{array}{r}96.72 \mathrm{~B} \\
108.92 \\
97.46 \\
133.87 \\
223.55\end{array}$ & $\begin{array}{l}29.61 \\
39.25 \\
34.12 \\
40.50 \\
54.13\end{array}$ \\
\hline $\begin{array}{l}\text { COMP IV Replicate } 1 \\
\text { COMP IV Replicate } 2 \\
\text { COMP IV Replicate } 3 \\
\text { TC-1 Lower } \\
\text { IC-2 Lawer } \\
\text { TC-3 Lower } \\
\text { TC-4 Lower } \\
\text { TC-5 Lower }\end{array}$ & $\begin{array}{l}\text { A } \\
A \\
A \\
B \\
B \\
C \\
C \\
B\end{array}$ & $\begin{array}{r}32.63 \mathrm{~B} \\
31.40 \mathrm{~B} \\
36.43 \mathrm{~B} \\
5.46 \\
11.87 \\
8.88 \\
12.95 \\
9.43\end{array}$ & $\begin{array}{l}3.76 \mathrm{U} \\
4.05 \mathrm{U} \\
4.94 \mathrm{U} \\
4.84 \mathrm{U} \\
2.86 \mathrm{U} \\
3.40 \mathrm{U} \\
6.53 \mathrm{U} \\
7.16 \mathrm{U}\end{array}$ & $\begin{array}{r}5.42 \mathrm{U} \\
5.84 \mathrm{U} \\
7.13 \mathrm{U} \\
7.39 \mathrm{U} \\
4.37 \mathrm{U} \\
4.60 \mathrm{U} \\
8.83 \mathrm{U} \\
10.93 \mathrm{U}\end{array}$ & $\begin{array}{l}4.72 \mathrm{U} \\
5.09 \mathrm{U} \\
6.21 \mathrm{U} \\
6.47 \mathrm{U} \\
3.83 \mathrm{U} \\
4.15 \mathrm{U} \\
7.96 \mathrm{U} \\
9.58 \mathrm{U}\end{array}$ & $\begin{array}{l}22.84 \mathrm{~B} \\
22.79 \mathrm{~B} \\
27.53 \\
10.76 \\
30.82 \\
4.50 \mathrm{X} \\
9.12 \\
9.21\end{array}$ & $\begin{array}{l}3.53 U \\
3.80 U \\
4.64 U \\
4.47 U \\
7.41 \\
3.32 U \\
6.38 U \\
6.61 U\end{array}$ \\
\hline $\begin{array}{l}\text { COMP V } \\
C-24 \\
C-26 \\
C-30 \\
C-33 \\
C-35 \\
C-37\end{array}$ & $\begin{array}{l}A \\
B \\
B \\
C \\
C \\
A \\
A\end{array}$ & $\begin{array}{l}70.648 \\
10.35 \\
31.06 \\
37.99 \\
45.04 \\
30.708 \\
31.838\end{array}$ & $\begin{array}{r}11.96 \\
5.47 \mathrm{U} \\
7.08 \\
10.74 \\
9.35 \\
6.53 \\
7.34 \mathrm{U}\end{array}$ & $\begin{array}{r}13.35 \mathrm{U} \\
8.35 \mathrm{U} \\
7.76 \mathrm{U} \\
12.97 \mathrm{U} \\
10.08 \mathrm{U} \\
8.08 \mathrm{U} \\
10.60 \mathrm{U}\end{array}$ & $\begin{array}{r}11.63 \mathrm{U} \\
7.32 \mathrm{U} \\
8.39 \\
11.69 \mathrm{U} \\
9.09 \mathrm{U} \\
6.84 \mathrm{U} \\
9.23 \mathrm{U}\end{array}$ & $\begin{array}{l}110.69 \mathrm{~B} \\
17.62 \\
80.28 \\
85.21 \\
59.63 \\
66.58 \mathrm{~B} \\
44.04 \mathrm{~B}\end{array}$ & $\begin{array}{r}45.24 \\
5.05 \mathrm{~L} \\
23.75 \\
34.99 \\
30.84 \\
19.78 \\
18.63\end{array}$ \\
\hline $\begin{array}{l}\text { COMP VI } \\
C-25 \\
C-29 \\
C-32 \\
C-36 \\
C-38\end{array}$ & $\begin{array}{l}\text { A } \\
\text { B } \\
A \\
A \\
B \\
B\end{array}$ & $\begin{array}{l}89.54 \mathrm{~B} \\
23.59 \\
33.32 \mathrm{~B} \\
20.35 \mathrm{~B} \\
32.82 \\
19.59\end{array}$ & $\begin{array}{c}16.81 \\
5.40 \mathrm{U} \\
5.39 \\
4.28 \mathrm{U} \\
10.43 \\
8.90\end{array}$ & $\begin{array}{r}13.64 \\
8.24 \mathrm{U} \\
5.84 \\
6.18 \mathrm{U} \\
22.23 \\
9.39 \mathrm{U}\end{array}$ & $\begin{array}{r}13.18 \\
7.23 \mathrm{U} \\
5.19 \\
5.38 \mathrm{u} \\
17.74 \\
8.23 \mathrm{U}\end{array}$ & $\begin{array}{r}124.978 \\
58.73 \\
46.608 \\
30.88 \quad 8 \\
105.87 \\
59.42\end{array}$ & $\begin{array}{l}47.32 \\
14.20 \\
15.41 \\
10.06 \\
35.90 \\
23.90\end{array}$ \\
\hline
\end{tabular}


TABLE C.2. (contd)

\begin{tabular}{|c|}
\hline $\begin{array}{l}\text { Sediment } \\
\text { Treatment }\end{array}$ \\
\hline $\begin{array}{l}\text { TC-6 (1) } \\
\text { TC-6 (1) Duplicate } \\
\text { TC-6 (2) } \\
\text { TC-6 (3) } \\
\text { TC-6 (4) }\end{array}$ \\
\hline $\begin{array}{l}\text { TC-7 (1) } \\
\text { TC }{ }^{(e)}(2) \\
\text { TC }-7 \text { (3) } \\
\text { TC-7 (4) }\end{array}$ \\
\hline $\begin{array}{l}R-A C \\
R-A M \\
R-B F \text { Repl icate } 1 \\
R-B F \text { Repl icate } 2 \\
R-B F \text { Repl icate } 3 \\
R-O S \\
R-P F\end{array}$ \\
\hline $\begin{array}{l}C-S B \\
C-W B \\
C-N E\end{array}$ \\
\hline
\end{tabular}

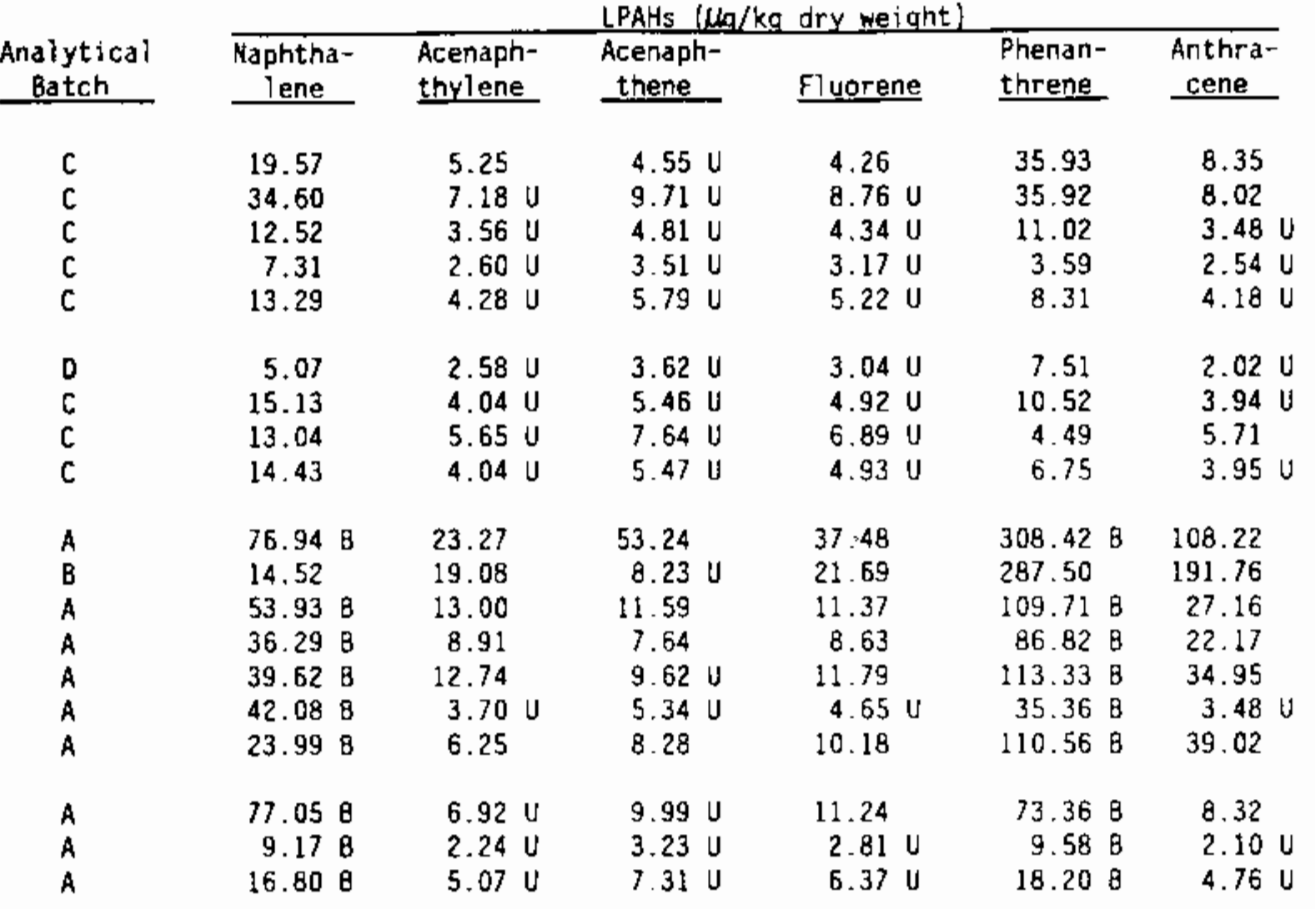

(a) DL Detection 1 imits.

(b) B Analyte detected above target detection 1 imit in blank associated with batch of samples.

(c) U The analyte was not present above the level of the associated value.

(d) $X$ Indicates relative intensities of the primary/confirmation ion vary by greater than $\mathbf{2} 20 \mathrm{x}$ of these masses in the reference mass spectrum due to interferences to the confirmation ion (qualifies analyte data).

(e) Stations TC-6 and TC-7 were $s p l$ it into four separate core sections which were composited, subsampled for chemistry, and used for geologic descriptions. 
TABLE C.3. High Molecular Weight Polynuclear Aromatic Hydrocarbons (HPAHs) in Sediment, Richmond Harbor Program

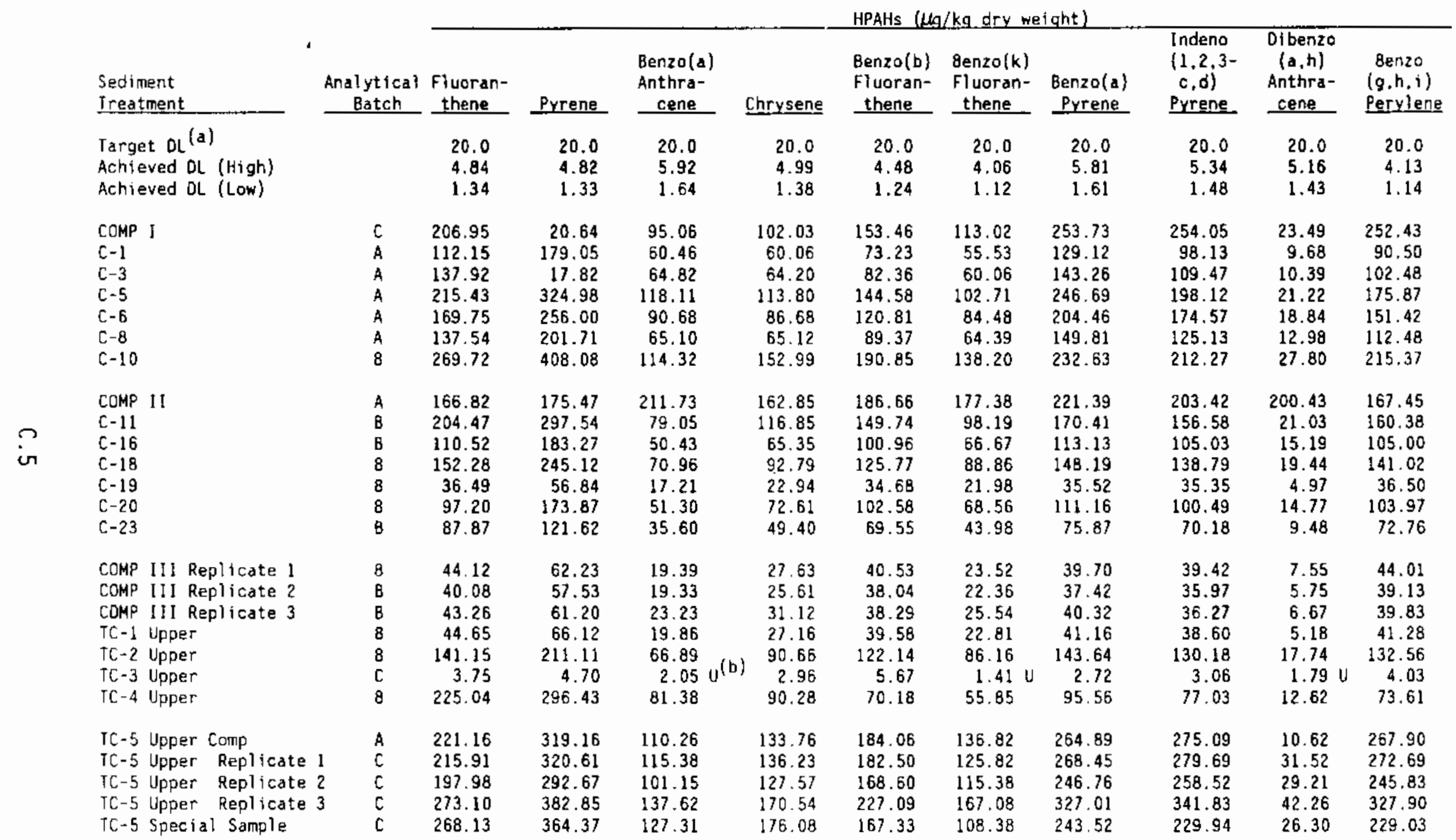


TABLE C.3. (contd)

\begin{tabular}{|c|c|c|c|c|c|c|c|c|c|c|c|}
\hline \multirow[b]{2}{*}{$\begin{array}{l}\text { Sediment } \\
\text { Ireatment }\end{array}$} & \multirow[b]{2}{*}{$\begin{array}{c}\text { Analytical } \\
\text { 8atch } \\
\end{array}$} & \multicolumn{10}{|c|}{ HPAHs $(\mu \mathrm{g} / \mathrm{kg}$ dry weight $)$} \\
\hline & & $\begin{array}{l}\text { Fluoran- } \\
\text { thene } \\
\end{array}$ & Pyrene & $\begin{array}{l}\text { Benzo(a) } \\
\text { Anthra- } \\
\text { cene } \\
\end{array}$ & Chrysene & $\begin{array}{l}\text { Benzo(b) } \\
\text { Fluoran- } \\
\text { thene }\end{array}$ & $\begin{array}{l}\text { Benzo(k) } \\
\text { Fluoran- } \\
\text { thene } \\
\end{array}$ & $\begin{array}{l}\text { Benzo (a) } \\
\text { Pyrene }\end{array}$ & $\begin{array}{l}\text { indeno } \\
(1,2,3- \\
\text { c,d) } \\
\text { Pyrene } \\
\end{array}$ & $\begin{array}{l}\text { Dibenzo } \\
(a, h) \\
\text { Anthra- } \\
\text { cene } \\
\end{array}$ & $\begin{array}{l}\text { Benzo } \\
(g . h, i) \\
\text { Perylene }\end{array}$ \\
\hline $\begin{array}{l}\text { COMP IV Replicate } 1 \\
\text { COMP IV Replicate } 2 \\
\text { COMP IV Replicate } 3 \\
\text { TC-1 Lower } \\
\text { TC-2 Lower } \\
\text { TC-3 Lower } \\
\text { TC-4 Lower } \\
\text { TC-5 Lower }\end{array}$ & $\begin{array}{l}\text { A } \\
\text { A } \\
\text { A } \\
8 \\
8 \\
\text { C } \\
\text { C } \\
B\end{array}$ & $\begin{array}{r}6.90 \\
7.18 \\
7.50 \\
4.91 \\
55.81 \\
2.37 \mathrm{U} \\
6.55 \\
6.41\end{array}$ & $\begin{array}{r}9.96 \\
10.64 \\
11.13 \\
6.78 \\
82.16 \\
2.42 \\
8.11 \\
10.09\end{array}$ & $\begin{array}{c}3.42 \mathrm{U} \\
3.68 \mathrm{U} \\
4.49 \mathrm{U} \\
2.78 \mathrm{U} \\
24.22 \\
2.90 \mathrm{U} \\
5.57 \mathrm{U} \\
4.11 \mathrm{U}\end{array}$ & $\begin{array}{l}2.96 \\
3.05 \\
3.49 \mathrm{U} \\
4.69 \\
34.61 \\
2.44 \mathrm{U} \\
7.14 \\
5.46\end{array}$ & $\begin{array}{c}6.29 \\
6.74 \\
5.80 \\
7.94 \\
49.46 \\
2.20 \mathrm{U} \\
7.38 \\
8.06\end{array}$ & $\begin{array}{l}2.21 \mathrm{U} \\
2.38 \mathrm{U} \\
2.91 \mathrm{U} \\
1.79 \mathrm{U} \\
29.40 \mathrm{U} \\
1.99 \mathrm{U} \\
4.20 \\
4.91\end{array}$ & $\begin{array}{l}3.42 \mathrm{U} \\
3.68 \mathrm{U} \\
4.50 \mathrm{U} \\
3.50 \\
48.51 \\
2.85 \mathrm{U} \\
5.47 \mathrm{U} \\
8.42\end{array}$ & $\begin{array}{l}3.12 \mathrm{U} \\
3.58 \\
4.11 \mathrm{U} \\
3.82 \\
46.29 \\
2.62 \mathrm{U} \\
6.27 \\
8.49\end{array}$ & $\begin{array}{l}3.07 \mathrm{U} \\
3.31 \mathrm{U} \\
4.03 \mathrm{U} \\
1.82 \mathrm{U} \\
6.70 \mathrm{U} \\
2.53 \mathrm{U} \\
4.86 \mathrm{U} \\
2.70 \mathrm{U}\end{array}$ & $\begin{array}{r}4.20 \\
4.81 \\
3.94 \\
5.94 \\
47.94 \\
2.03 \mathrm{U} \\
6.34 \\
10.50\end{array}$ \\
\hline $\begin{array}{l}\text { COMP V } \\
C-24 \\
C-26 \\
C-30 \\
C-33 \\
C-35 \\
C-37\end{array}$ & $\begin{array}{l}A \\
B \\
B \\
C \\
C \\
A \\
A\end{array}$ & $\begin{array}{r}199.15 \\
7.37 \\
149.88 \\
180.72 \\
111.50 \\
77.36 \\
54.74\end{array}$ & $\begin{array}{r}376.52 \\
9.27 \\
273.08 \\
312.15 \\
214.71 \\
141.17 \\
137.27\end{array}$ & $\begin{array}{r}141.71 \\
3.56 \\
70.70 \\
106.36 \\
75.22 \\
48.30 \\
35.77\end{array}$ & $\begin{array}{r}166.43 \\
5.64 \\
99.08 \\
126.20 \\
94.84 \\
53.66 \\
46.48\end{array}$ & $\begin{array}{r}248.80 \\
11.82 \\
150.44 \\
188.69 \\
139.80 \\
89.22 \\
80.41\end{array}$ & $\begin{array}{r}182.37 \\
2.03 \mathrm{U} \\
101.04 \\
136.11 \\
106.93 \\
64.81 \\
59.72\end{array}$ & $\begin{array}{r}361.27 \\
4.97 \\
161.85 \\
258.08 \\
189.04 \\
128.45 \\
106.00\end{array}$ & $\begin{array}{r}306.40 \\
5.09 \\
149.03 \\
261.06 \\
182.36 \\
105.38 \\
79.31\end{array}$ & $\begin{array}{c}40.46 \\
2.06 \mathrm{~V} \\
20.11 \\
32.48 \\
23.65 \\
13.09 \\
10.62\end{array}$ & $\begin{array}{r}272.69 \\
7.22 \\
150.76 \\
240.47 \\
174.63 \\
93.54 \\
70.75\end{array}$ \\
\hline $\begin{array}{l}\text { COMP VI } \\
C-25 \\
C-29 \\
C-32 \\
C-36 \\
C-38\end{array}$ & $\begin{array}{l}A \\
B \\
A \\
A \\
B \\
B\end{array}$ & $\begin{array}{r}227.53 \\
97.98 \\
76.96 \\
41.75 \\
149.83 \\
90.70\end{array}$ & $\begin{array}{r}409.19 \\
165.54 \\
144.60 \\
85.31 \\
339.76 \\
207.34\end{array}$ & $\begin{array}{r}150.70 \\
49.30 \\
50.77 \\
24.85 \\
89.52 \\
57.21\end{array}$ & $\begin{array}{r}165.86 \\
63.56 \\
53.69 \\
28.12 \\
142.53 \\
99.07\end{array}$ & $\begin{array}{r}266.02 \\
88.83 \\
75.25 \\
42.32 \\
198.38 \\
138.43\end{array}$ & $\begin{array}{r}186.45 \\
64.51 \\
55.56 \\
28.94 \\
150.26 \\
102.07\end{array}$ & $\begin{array}{r}380.34 \\
104.02 \\
110.75 \\
58.45 \\
197.90 \\
138.35\end{array}$ & $\begin{array}{r}313.44 \\
93.92 \\
90.66 \\
48.03 \\
162.99 \\
111.16\end{array}$ & $\begin{array}{r}42.09 \\
13.34 \\
11.06 \\
7.43 \\
29.73 \\
22.71\end{array}$ & $\begin{array}{r}275.66 \\
95.88 \\
80.22 \\
42.47 \\
155.35 \\
105.38\end{array}$ \\
\hline $\begin{array}{l}T C-6(1) \text { (C) } \\
\text { TC-6 (1) Dupl icate } \\
\text { TC-6 (2) } \\
\text { TC-6 (3) } \\
\text { TC-6 (4) }\end{array}$ & $\begin{array}{l}c \\
C \\
C \\
c \\
C\end{array}$ & $\begin{array}{l}67.05 \\
66.40 \\
3.27 \\
1.81 \mathrm{U} \\
5.06\end{array}$ & $\begin{array}{r}94.84 \\
94.84 \\
4.42 \\
2.24 \\
5.25\end{array}$ & $\begin{array}{r}42.42 \\
40.27 \\
3.03 \mathrm{U} \\
2.22 \mathrm{U} \\
3.65 \mathrm{~J}\end{array}$ & $\begin{array}{r}45.82 \\
45.02 \\
3.14 \\
1.87 \mathrm{U} \\
3.08 \mathrm{~J}\end{array}$ & $\begin{array}{l}66.65 \\
63.66 \\
4.90 \\
1.68 \mathrm{U} \\
5.32\end{array}$ & $\begin{array}{l}49.35 \\
49.64 \\
2.09 \mathrm{U} \\
1.52 \mathrm{U} \\
2.51 \mathrm{U}\end{array}$ & $\begin{array}{r}105.65 \\
104.64 \\
2.98 \mathrm{U} \\
2.18 \mathrm{U} \\
3.59 \mathrm{U}\end{array}$ & $\begin{array}{r}100.86 \\
96.78 \\
2.74 \mathrm{U} \\
2.00 \mathrm{U} \\
3.29 \mathrm{U}\end{array}$ & $\begin{array}{r}11.12 \\
10.46 \\
2.65 \mathrm{U} \\
1.93 \mathrm{U} \\
3.19 \mathrm{U}\end{array}$ & $\begin{array}{l}98.01 \\
96.22 \\
3.24 \\
1.55 \mathrm{U} \\
4.04\end{array}$ \\
\hline $\begin{array}{l}T C-7(1)^{(C)} \\
T C-7(2) \\
T C-7(3) \\
T C-7(4)\end{array}$ & $\begin{array}{l}D \\
C \\
C \\
C\end{array}$ & $\begin{array}{l}2.28 \\
3.62 \\
3.94 \mathrm{U} \\
3.08\end{array}$ & $\begin{array}{l}2.85 \\
4.59 \\
3.93 \mathrm{U} \\
3.21\end{array}$ & $\begin{array}{l}1.14 \mathrm{U} \\
3.44 \mathrm{U} \\
4.82 \mathrm{U} \\
3.45 \mathrm{U}\end{array}$ & $\begin{array}{l}2.19 \\
2.90 \mathrm{U} \\
4.06 \mathrm{U} \\
2.90 \mathrm{U}\end{array}$ & $\begin{array}{l}2.60 \\
4.38 \\
3.66 \mathrm{U} \\
2.62 \mathrm{U}\end{array}$ & $\begin{array}{l}0.72 \mathrm{U} \\
2.37 \mathrm{U} \\
3.31 \mathrm{U} \\
2.37 \mathrm{U}\end{array}$ & $\begin{array}{l}0.93 \mathrm{U} \\
3.38 \mathrm{U} \\
4.73 \mathrm{U} \\
3.39 \mathrm{U}\end{array}$ & $\begin{array}{l}0.96 \mathrm{U} \\
3.11 \mathrm{U} \\
4.35 \mathrm{U} \\
3.11 \mathrm{U}\end{array}$ & $\begin{array}{l}0.94 \mathrm{U} \\
3.00 \mathrm{U} \\
4.21 \mathrm{U} \\
3.01 \mathrm{U}\end{array}$ & $\begin{array}{l}1.36 \\
2.83 \\
3.37 \mathrm{U} \\
2.41 \mathrm{U}\end{array}$ \\
\hline
\end{tabular}


TABLE C.3. (contd)

HPAHs (Ha/kg dry weight)

\begin{tabular}{l} 
Sediment \\
Ireatment \\
$R-A C$ \\
$R-A M$ \\
$R-B F$ Replicate 1 \\
$R-B F$ Replicate 2 \\
$R-B F$ Replicate 3 \\
$R-O S$ \\
$R-P F$ \\
$C-S B$ \\
$C-H B$ \\
$C-N E$ \\
\hline
\end{tabular}

\begin{tabular}{|c|c|c|c|c|c|c|c|c|c|c|}
\hline \multirow[b]{2}{*}{$\begin{array}{c}\text { Analytical } \\
\text { Batch } \\
\end{array}$} & \multirow[b]{2}{*}{$\begin{array}{l}\begin{array}{l}\text { Fluoran- } \\
\text { thene }\end{array} \\
\end{array}$} & \multicolumn{9}{|c|}{ HPAHs $(\mu \mathrm{q} / \mathrm{kg}$ dry weight) } \\
\hline & & Pyrene & $\begin{array}{l}\text { Benzo(a) } \\
\text { Anthra- } \\
\text { cene } \\
\end{array}$ & Chrysene & $\begin{array}{l}\text { Benzo(b) } \\
\text { Fluoran- } \\
\text { thene }\end{array}$ & $\begin{array}{l}\text { Benzo(k) } \\
\text { Fluoran- } \\
\text { thene } \\
\end{array}$ & $\begin{array}{l}\text { Benzo(a) } \\
\text { Pyrene }\end{array}$ & $\begin{array}{l}\text { Indeno } \\
(1,2,3- \\
c, d) \\
\text { Pyrene }\end{array}$ & $\begin{array}{l}\text { Dibenzo } \\
\text { (a,h) } \\
\text { Anthra- } \\
\text { cene } \\
\end{array}$ & $\begin{array}{l}\text { Benzo } \\
(g, h, 1) \\
\text { Pervlene }\end{array}$ \\
\hline $\begin{array}{l}A \\
B \\
A \\
A \\
A \\
A \\
A\end{array}$ & $\begin{array}{r}767.53 \\
321.65 \\
254.72 \\
189.46 \\
171.40 \\
15.54 \\
102.54\end{array}$ & $\begin{array}{r}1424.27 \\
436.79 \\
371.85 \\
272.33 \\
247.03 \\
22.15 \\
150.06\end{array}$ & $\begin{array}{r}350.58 \\
198.52 \\
145.00 \\
104.23 \\
93.49 \\
5.52 \\
84.61\end{array}$ & $\begin{array}{r}320.57 \\
231.57 \\
146.66 \\
113.04 \\
103.15 \\
9.68 \\
79.14\end{array}$ & $\begin{array}{r}407.72 \\
101.18 \\
240.57 \\
187.99 \\
139.80 \\
18.72 \\
41.17\end{array}$ & $\begin{array}{c}305.36 \\
139.51 \\
171.82 \\
124.69 \\
99.85 \\
2.18 \mathrm{U} \\
49.36\end{array}$ & $\begin{array}{r}843.65 \\
192.71 \\
393.61 \\
293.95 \\
232.94 \\
12.70 \\
98.56\end{array}$ & $\begin{array}{r}658.76 \\
106.12 \\
373.38 \\
285.61 \\
203.53 \\
14.52 \\
46.47\end{array}$ & $\begin{array}{c}55.72 \\
23.93 \\
37.67 \\
28.90 \\
20.15 \\
3.02 \mathrm{U} \\
9.27\end{array}$ & $\begin{array}{r}562.70 \\
86.64 \\
324.97 \\
246.06 \\
183.15 \\
15.84 \\
38.13\end{array}$ \\
\hline $\begin{array}{l}A \\
A \\
A\end{array}$ & $\begin{array}{r}70.84 \\
2.85 \\
5.13\end{array}$ & $\begin{array}{r}60.43 \\
3.49 \\
7.64\end{array}$ & $\begin{array}{r}21.24 \\
2.04 \mathrm{U} \\
4.61 \mathrm{U}\end{array}$ & $\begin{array}{r}47.30 \\
1.58 \mathrm{U} \\
3.58 \mathrm{U}\end{array}$ & $\begin{array}{r}34.66 \\
1.49 \mathrm{U} \\
3.37 \mathrm{~J}\end{array}$ & $\begin{array}{l}19.08 \\
1.32 \mathrm{U} \\
2.98 \mathrm{U}\end{array}$ & $\begin{array}{c}25.01 \mathrm{X}^{(\mathrm{d})} \\
2.04 \mathrm{U} \\
4.61 \mathrm{U}\end{array}$ & $\begin{array}{l}25.23 \\
1.86 \mathrm{~V} \\
4.21 \mathrm{U}\end{array}$ & $\begin{array}{l}5.65 \mathrm{U} \\
1.83 \mathrm{U} \\
4.14 \mathrm{U}\end{array}$ & $\begin{array}{l}24.78 \\
1.35 \mathrm{U} \\
3.05 \mathrm{U}\end{array}$ \\
\hline
\end{tabular}

(a) DL Detection limt

(b) U The analyte was not present above the level of the associated value.

(c) Stations TC-6 and TC-7 were split Into four separate core sectlons which were composited, subsampled for chemistry. and used for geologic description.

(d) $x$ Indicates relative intensities of the primary/confirmation ion vary by greater

than $\pm 20 \%$ of these masses in the reference mass spectrum due to interferences

to the confimation ion (qualifies analyte data). 
TABLE C.4. Quality Control Data for Low Molecular Weight Polynuclear Aromatic Hydrocarbons (LPAHs) in Sediment, Richmond Harbor Program

Sediment
Treatment

Method Blanks

Blank

Blank

Blank

Blank

Matrix Spikes

\begin{tabular}{|c|c|c|c|c|c|c|}
\hline \multirow[b]{2}{*}{$\begin{array}{l}\text { Analytical } \\
\text { Batch }\end{array}$} & \multicolumn{6}{|c|}{ LPAHs ( $\mu \mathrm{g} / \mathrm{kg}$ dry weight) } \\
\hline & $\begin{array}{l}\text { Naphtha= } \\
\text { lene } \\
\end{array}$ & $\begin{array}{l}\text { Acenaph- } \\
\text { thylene }\end{array}$ & $\begin{array}{l}\text { Acenaph- } \\
\text { thene }\end{array}$ & Fluprene & $\begin{array}{l}\text { Phenan- } \\
\text { threne }\end{array}$ & $\begin{array}{l}\text { Anthra- } \\
\text { cene }\end{array}$ \\
\hline
\end{tabular}

$\begin{array}{lrlllll}A & 40.67 & 5.71 \mathrm{U}^{(\mathrm{a})} & 9.73 & 7.17 \mathrm{U} & 52.25 & 5.36 \mathrm{U} \\ \mathrm{B} & 9.21 & 4.93 \mathrm{U} & 7.54 \mathrm{U} & 6.61 \mathrm{U} & 10.25 & 4.56 \mathrm{U} \\ \mathrm{C} & \mathrm{i2.23} & 5.88 \mathrm{U} & 7.96 \mathrm{U} & 7.17 \mathrm{U} & 5.81 & 5.75 \mathrm{U} \\ \mathrm{D} & 7.28 & 2.15 \mathrm{U} & 3.02 \mathrm{U} & 2.53 \mathrm{U} & 3.21 & 1.68 \mathrm{U}\end{array}$

\begin{tabular}{|c|c|c|c|c|c|c|c|}
\hline $\begin{array}{l}\text { COMP I } \\
\text { COMP I MS } \\
\text { Concentration Recovered } \\
\text { Anount Spiked } \\
\text { Percent Recovery }\end{array}$ & $\begin{array}{l}c \\
c\end{array}$ & $\begin{array}{r}40.34 \\
111.27 \\
70.93 \\
178.00 \\
407\end{array}$ & $\begin{array}{r}9.24 \\
101.38 \\
92.14 \\
178.00 \\
527\end{array}$ & $\begin{array}{r}13.26 \\
99.00 \\
85.74 \\
178.00 \\
48 \%\end{array}$ & $\begin{array}{r}9.42 \\
105.77 \\
96.35 \\
178.00 \\
54 \%\end{array}$ & $\begin{array}{r}97.31 \\
172.36 \\
75.05 \\
178.00 \\
42 \%\end{array}$ & $\begin{array}{r}23.84 \\
135.54 \\
111.70 \\
178.00 \\
63 \%\end{array}$ \\
\hline $\begin{array}{l}\text { COHP I } \\
\text { COMP I MSD } \\
\text { Concentration Recovered } \\
\text { Amount Spiked } \\
\text { Percent Recovery }\end{array}$ & $\begin{array}{l}C \\
C\end{array}$ & $\begin{array}{l}40.34 \\
88.64 \\
48.30 \\
196.00 \\
25 \times(b)\end{array}$ & $\begin{array}{r}9.24 \\
109.44 \\
100.20 \\
196.00 \\
51 x\end{array}$ & $\begin{array}{r}13.26 \\
105.77 \\
92.51 \\
196.00 \\
47 x\end{array}$ & $\begin{array}{r}9.42 \\
123.75 \\
114.33 \\
196.00 \\
58 \%\end{array}$ & $\begin{array}{r}97.31 \\
228.4 \\
131.09 \\
196.00 \\
67 \%\end{array}$ & $\begin{array}{r}23.84 \\
179.21 \\
155.37 \\
196.00 \\
79 \%\end{array}$ \\
\hline $\begin{array}{l}\text { MS/MSD RPD } \\
\text { MS/MSD I-STAT }\end{array}$ & & $\begin{array}{l}47 \%^{(c)} \\
0.24\end{array}$ & $0.01^{1 x}$ & 0.01 & $0.04^{7 x}$ & $0.23^{457^{(c)}}$ & $0.12^{23 x^{(c)}}$ \\
\hline $\begin{array}{l}\text { COMP III Replicate } 1 \\
\text { COMP III MS Replicate } 1 \\
\text { Concentration Recovered } \\
\text { Amount Spiked } \\
\text { Percent Recovery }\end{array}$ & $\begin{array}{l}B \\
B\end{array}$ & $\begin{array}{r}23.20 \\
143.58 \\
120.38 \\
218.34 \\
55 x\end{array}$ & $\begin{array}{r}4.77 \mathrm{v} \\
150.77 \\
150.77 \\
218.34 \\
69 x\end{array}$ & $\begin{array}{r}7.28 \mathrm{U} \\
160.98 \\
160.98 \\
218.34 \\
74 x\end{array}$ & $\begin{array}{r}6.38 \mathrm{U} \\
183.27 \\
183.27 \\
218.34 \\
84 \%\end{array}$ & $\begin{array}{r}36.68 \\
239.78 \\
203.10 \\
218.34 \\
937\end{array}$ & $\begin{array}{r}7.92 \\
172.51 \\
164.59 \\
218.34 \\
757\end{array}$ \\
\hline $\begin{array}{l}\text { COMP III Replicate } 1 \\
\text { COMP III MSO Replicate } 1 \\
\text { Concentration Recovered } \\
\text { Amount Spiked } \\
\text { Percent Recovery }\end{array}$ & $\begin{array}{l}\text { B } \\
\text { B }\end{array}$ & $\begin{array}{r}23.20 \\
152.43 \\
129.23 \\
218.34 \\
597\end{array}$ & $\begin{array}{r}4.77 \\
140.26 \\
140.26 \\
218.34 \\
647\end{array}$ & $\begin{array}{c}7.28 \\
156.18 \\
156.18 \\
218.34 \\
72 \%\end{array}$ & $\begin{array}{c}6.38 \mathrm{U} \\
175.42 \\
175.42 \\
218.34 \\
80 x\end{array}$ & $\begin{array}{r}36.68 \\
231.09 \\
194.41 \\
218.34 \\
89 \%\end{array}$ & $\begin{array}{r}7.92 \\
153.49 \\
145.57 \\
218.34 \\
67 \%\end{array}$ \\
\hline $\begin{array}{l}\text { MS/MSD RPD } \\
\text { MS/HSD I-STAT }\end{array}$ & & 0.04 & $0.04^{7 x}$ & 0.02 & $0.02^{4 \%}$ & $0.02^{4 \%}$ & $\begin{array}{l}12 \% \\
0.06\end{array}$ \\
\hline $\begin{array}{l}\text { COHP IV Replicate } 1 \\
\text { COHP IV MS Replicate } 1 \\
\text { Concentration Recovered } \\
\text { Amount Spiked } \\
\text { Percent Recovery }\end{array}$ & $\begin{array}{l}\text { A } \\
\text { A }\end{array}$ & $\begin{array}{c}32.63 \\
118.308^{(d)} \\
85.67 \\
145.00 \\
59 \%\end{array}$ & $\begin{array}{r}3.76 \mathrm{U} \\
112.21 \\
112.21 \\
145.00 \\
77 \%\end{array}$ & $\begin{array}{r}5.42 \mathrm{U} \\
109.07 \\
109.07 \\
145.00 \\
75 \%\end{array}$ & $\begin{array}{r}4.72 \mathrm{U} \\
112.98 \\
112.98 \\
145.00 \\
78 \%\end{array}$ & $\begin{array}{c}22.84 \mathrm{~B} \\
132.46 \mathrm{~B} \\
109.62 \\
145.00 \\
76 \%\end{array}$ & $\begin{array}{r}3.53 \mathrm{U} \\
123.96 \\
123.96 \\
145.00 \\
85 \%\end{array}$ \\
\hline $\begin{array}{l}\text { COMP IV Replicate } 1 \\
\text { COMP IV MSO Replicate } 1 \\
\text { Concentration Recovered } \\
\text { Amount Spiked } \\
\text { Percent Recovery }\end{array}$ & $\begin{array}{l}\text { A } \\
\text { A }\end{array}$ & $\begin{array}{l}32.63 \\
62.25 \mathrm{~B} \\
29.62 \\
145.00 \\
20 x^{(b)}\end{array}$ & $\begin{array}{c}3.76 \mathrm{U} \\
26.34 \\
26.34 \\
145.00 \\
18 x^{(b)}\end{array}$ & $\begin{array}{l}5.42 \mathrm{U} \\
29.29 \\
29.29 \\
145.00 \\
20 \%(\mathrm{~b})\end{array}$ & $\begin{array}{r}4.72 \mathrm{U} \\
28.15 \\
28.15 \\
145.00 \\
\quad 19 x^{(b)}\end{array}$ & $\begin{array}{l}22.848 \\
75.258 \\
52.41 \\
145.00 \\
36 \%(b)\end{array}$ & $\begin{array}{r}3.53 \mathrm{~b} \\
37.20 \\
37.20 \\
145.00 \\
26 x^{(b)}\end{array}$ \\
\hline $\begin{array}{l}\text { MS/HSD RPD } \\
\text { MS/HSD I-STAT }\end{array}$ & & 0.49 & $\begin{array}{l}124 \%^{(c)} \\
0.62\end{array}$ & $\begin{array}{l}115 \%^{(c)} \\
0.58\end{array}$ & $\begin{array}{l}120 \%^{(c)} \\
0.60^{(c)}\end{array}$ & $\begin{array}{l}71 \%^{(c)} \\
0.35\end{array}$ & $\begin{array}{l}108 \%^{(c)} \\
0.54\end{array}$ \\
\hline
\end{tabular}


IABLE C.4. (contd)

\begin{tabular}{|c|c|c|c|c|c|c|c|}
\hline \multirow[b]{2}{*}{$\begin{array}{l}\text { Sediment } \\
\text { Treatment } \\
\end{array}$} & \multirow[b]{2}{*}{$\begin{array}{l}\text { Analytical } \\
\text { Batch } \\
\end{array}$} & \multicolumn{6}{|c|}{ LPAHs $(\mu \mathrm{g} / \mathrm{kg}$ dry weight) } \\
\hline & & $\begin{array}{l}\text { Naphtha- } \\
\text { lene }\end{array}$ & $\begin{array}{l}\text { Acenaph- } \\
\text { thylene }\end{array}$ & $\begin{array}{l}\text { Acenaph- } \\
\text { thene }\end{array}$ & Fluorene & $\begin{array}{l}\text { Phenan- } \\
\text { threne }\end{array}$ & $\begin{array}{l}\text { Anthra- } \\
\text { cene } \\
\end{array}$ \\
\hline \multicolumn{8}{|c|}{ Standard Reference Material } \\
\hline $\begin{array}{l}\text { Certified } \\
\text { value }\end{array}$ & & $\mathrm{NC}^{(\mathrm{e})}$ & NC & NC & HC & $\begin{array}{l}577.0 \\
\pm 59.0\end{array}$ & $\begin{array}{l}202.0 \\
\pm 42.0\end{array}$ \\
\hline SRM 1941-1 & A & $N_{A}(f)$ & NA & NA & NA & 385.43 & 131.38 \\
\hline SRM 1941-2 & B & MA & NA & NA & NA & 525.82 & 153.03 \\
\hline SRH 1941-3 & B & NA & NA & NA & NA & 521.61 & 150.67 \\
\hline SRM 1941-4 & C & NA & NA & NA & NA & 538.58 & 207.35 \\
\hline
\end{tabular}

Analytica) Duplicates

\begin{tabular}{|c|c|c|c|c|c|c|c|c|}
\hline $\begin{array}{l}\mathrm{TC}-6(1)^{(g)} \\
\mathrm{TC}-6(1)\end{array}$ & $\begin{array}{l}\text { Duplicate } 1 \\
\text { Dupl icate } 2\end{array}$ & C & $\begin{array}{l}19.57 \\
34.60\end{array}$ & $\begin{array}{l}5.25 \\
7.18 U\end{array}$ & $\begin{array}{l}4.55 \mathrm{U} \\
9.71 \mathrm{U}\end{array}$ & $\begin{array}{l}4.26 \\
8.76 \mathrm{U}\end{array}$ & $\begin{array}{l}35.93 \\
35.92\end{array}$ & $\begin{array}{l}8.35 \\
8.02\end{array}$ \\
\hline RPD & & & & NA & NA & NA & $0 \%$ & 007 \\
\hline
\end{tabular}

Analytical Replicates

\begin{tabular}{|c|c|c|c|c|c|c|c|c|}
\hline $\begin{array}{l}\text { COMP } \\
\text { COMP } \\
\text { COMP } \\
\text { RSD }\end{array}$ & $\begin{array}{l}\text { II Replicate } 1 \\
\text { III Replicate } 2 \\
\text { III Replicate } 3\end{array}$ & $\begin{array}{l}B \\
B \\
B\end{array}$ & $\begin{array}{r}23.20 \\
20.07 \\
13.55 \\
26 \%\end{array}$ & $\begin{array}{l}4.77 \mathrm{U} \\
4.01 \mathrm{U} \\
7.15 \mathrm{U} \\
\text { NA }\end{array}$ & $\begin{array}{c}7.28 \mathrm{U} \\
6.13 \mathrm{U} \\
10.92 \mathrm{U} \\
\text { NA }\end{array}$ & $\begin{array}{l}6.38 \mathrm{U} \\
5.37 \mathrm{U} \\
9.57 \mathrm{U} \\
\text { NA }\end{array}$ & $\begin{array}{r}36.68 \\
34.26 \\
41.10 \\
9 \%\end{array}$ & $\begin{array}{l}7.92 \\
5.18 \\
7.38 \\
21 \%\end{array}$ \\
\hline $\begin{array}{r}\text { COMP } \\
\text { COMP } \\
\text { COMP } \\
\text { RSD }\end{array}$ & $\begin{array}{l}\text { IV Replicate } 1 \\
\text { IV Repi icate } 2 \\
\text { IV Replicate } 3\end{array}$ & $\begin{array}{l}A \\
A \\
A\end{array}$ & $\begin{array}{c}32.63 \mathrm{~B} \\
31.40 \mathrm{~B} \\
36.43 \mathrm{~B} \\
8 \%\end{array}$ & $\begin{array}{l}3.76 \mathrm{U} \\
4.05 \mathrm{U} \\
4.94 \mathrm{U} \\
\text { NA }\end{array}$ & $\begin{array}{l}5.42 \mathrm{U} \\
5.84 \mathrm{U} \\
7.13 \mathrm{U} \\
\mathrm{NA}\end{array}$ & $\begin{array}{l}4.72 \mathrm{U} \\
5.09 \mathrm{U} \\
6.21 \mathrm{U} \\
\text { NA }\end{array}$ & $\begin{array}{c}22.84 \mathrm{~B} \\
22.79 \mathrm{~B} \\
27.53 \mathrm{~B} \\
11 \%\end{array}$ & $\begin{array}{l}3.53 \mathrm{U} \\
3.80 \mathrm{U} \\
4.64 \mathrm{U} \\
\text { NA }\end{array}$ \\
\hline $\begin{array}{r}\text { TC }-5 \\
\text { TC }-5 \\
\text { TC }-5 \\
\text { RSO }\end{array}$ & $\begin{array}{l}\text { Upper Replicate } \\
\text { Upper Replicate } 2 \\
\text { Upper Replicate } 3\end{array}$ & $\begin{array}{l}\mathrm{C} \\
\mathrm{C} \\
\mathrm{C}\end{array}$ & $\begin{array}{r}36.62 \\
33.47 \\
37.33 \\
6 \%\end{array}$ & $\begin{array}{r}11.31 \\
8.84 \\
11.43 \\
14 \%\end{array}$ & $\begin{array}{r}11.88 \\
10.75 \\
11.81 \\
6 \%\end{array}$ & $\begin{array}{r}23.63 \\
21.91 \\
24.02 \\
5 \%\end{array}$ & $\begin{array}{r}108.92 \\
97.46 \\
133.87 \\
16 \%\end{array}$ & $\begin{array}{r}39.25 \\
34.12 \\
40.50 \\
9 \%\end{array}$ \\
\hline $\begin{array}{r}R-8 F \\
R-8 F \\
R-8 F \\
R S D\end{array}$ & $\begin{array}{l}\text { Replicate } 1 \\
\text { Replicate } 2 \\
\text { Replicate } 3\end{array}$ & $\begin{array}{l}A \\
A \\
A\end{array}$ & $\begin{array}{c}53.93 \mathrm{~B} \\
36.29 \mathrm{~B} \\
39.62 \mathrm{~B} \\
22 \%\end{array}$ & $\begin{array}{c}13.00 \\
8.91 \\
12.74 \\
20 \%\end{array}$ & $\begin{array}{c}11.59 \\
7.64 \\
9.62 \mathrm{U} \\
\mathrm{NA}\end{array}$ & $\begin{array}{r}11.37 \\
8.63 \\
11.79 \\
16 \%\end{array}$ & $\begin{array}{r}109.718 \\
86.828 \\
113.338 \\
147\end{array}$ & $\begin{array}{r}27.16 \\
22.17 \\
34.95 \\
23 \%\end{array}$ \\
\hline
\end{tabular}

(a) U The analyte was not present above the level of the associated value.

(b) Recovery outside quality control range (40\%-120\%).

(c) Value exceeds relative precision allowance of $30 \%$.

(d) B Analyte detected above target detection limit in blank associated with batch samples.

(e) NC Not certified.

(f) NA Not applicable.

(g) Stations TC-6 and TC-7 were split inte four separate core sections which were composited, subsampled for chemistry, and used for geologic descriptions. 
TABLE C.5. Quality Control Data for High Molecular Weight Polynuclear Aromatic Hydrocarbons (HPAHs) in Sediment, Richmond Harbor Program

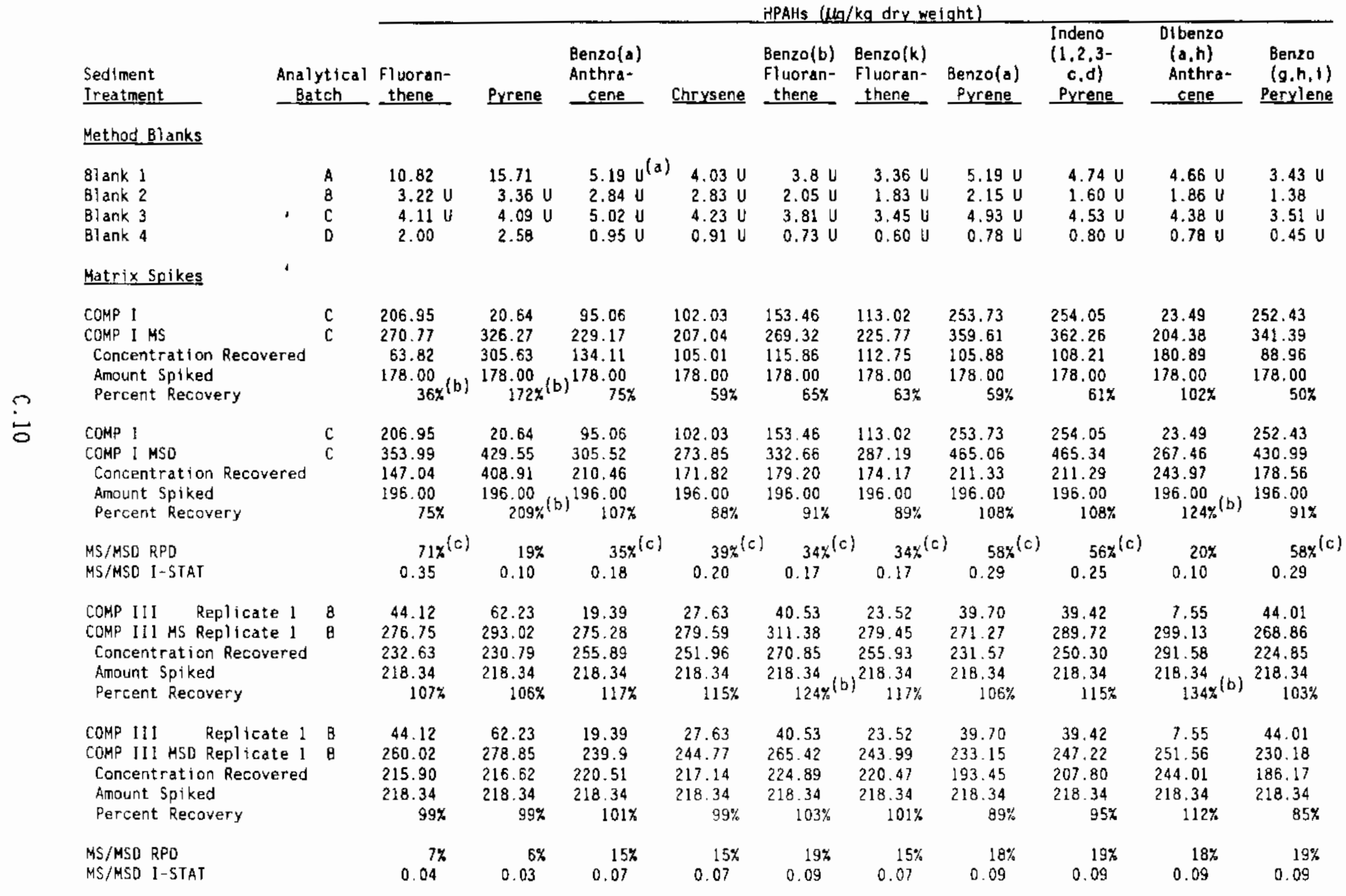




\section{TABLE C.5. (contd)}

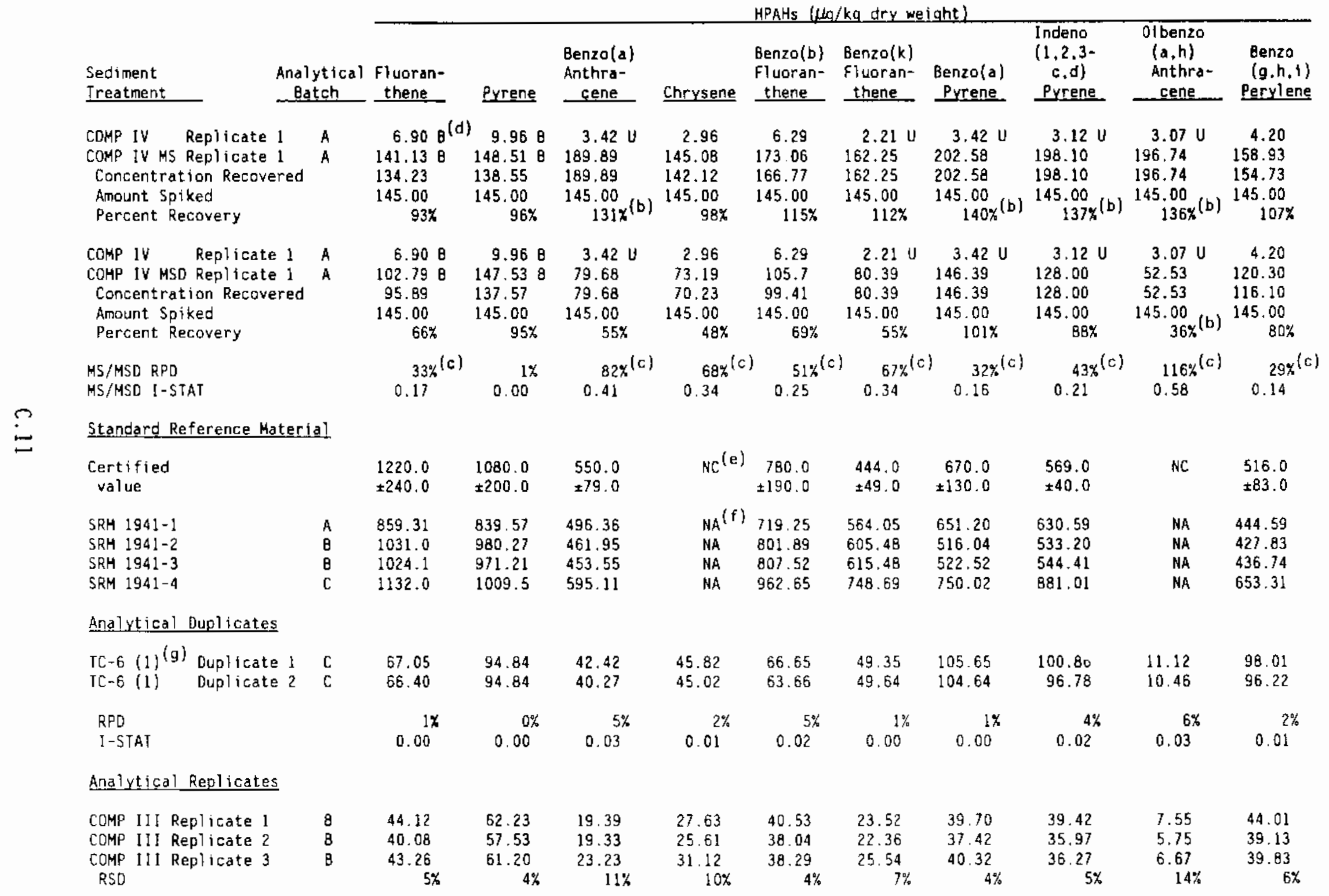


IABLE C.5. (contd)

\begin{tabular}{|c|c|c|c|c|c|c|c|c|c|c|c|}
\hline \multirow[b]{2}{*}{$\begin{array}{l}\text { Sediment } \\
\text { Ireatment } \\
\end{array}$} & \multirow[b]{2}{*}{$\begin{array}{c}\text { Analytical } \\
\text { Batch } \\
\end{array}$} & \multicolumn{10}{|c|}{ HPAHs $(\mu \mathrm{g} / \mathrm{kg}$ dry meight $)$} \\
\hline & & $\begin{array}{l}\begin{array}{l}\text { Fluoran- } \\
\text { thene }\end{array} \\
\end{array}$ & Pyrene & $\begin{array}{l}\text { Benzo (a) } \\
\text { Anthra- } \\
\text { cene } \\
\end{array}$ & Chrysene & $\begin{array}{l}\text { Benzo(b) } \\
\text { Fivoran- } \\
\text { thene }\end{array}$ & $\begin{array}{l}\text { Benzo(k) } \\
\text { Fluoran- } \\
\text { thene }\end{array}$ & $\begin{array}{l}\text { Benzo(a) } \\
\text { Pyrene } \\
\end{array}$ & $\begin{array}{c}\text { Indeno } \\
(1,2,3- \\
c, d) \\
\text { Pyrene } \\
\end{array}$ & $\begin{array}{c}\text { Dibenzo } \\
\text { (a.h) } \\
\text { Anthra- } \\
\text { cene } \\
\end{array}$ & $\begin{array}{r}\text { Eenzo } \\
(9, h, 1) \\
\text { Perylene }\end{array}$ \\
\hline COMP IV Replicate 1 & A & $6.90 \mathrm{~B}$ & $9.96 \mathrm{~B}$ & $3.42 \mathrm{U}$ & 2.96 & 6.29 & $2.21 \mathrm{U}$ & $3.42 \mathrm{U}$ & $3.12 \mathrm{U}$ & $3.07 \mathrm{U}$ & 4.20 \\
\hline COMP IV Replicate 2 & A & $7.18 \mathrm{~B}$ & 10.648 & $3.68 \mathrm{U}$ & 3.05 & 6.74 & $2.38 \mathrm{U}$ & $3.68 \mathrm{U}$ & 3,58 & $3.31 \mathrm{U}$ & 4.81 \\
\hline $\begin{array}{l}\text { COMP IV Replicate } 3 \\
\text { RSD }\end{array}$ & A & $\begin{array}{c}7.508 \\
4 \%\end{array}$ & $\begin{array}{c}11.13 \mathrm{~B} \\
6 \%\end{array}$ & $\begin{array}{l}4.49 U \\
N A\end{array}$ & $\begin{array}{l}3.49 \mathrm{U} \\
\mathrm{NA}\end{array}$ & 5.80 & $\begin{array}{l}2.91 \mathrm{U} \\
\text { NA }\end{array}$ & $\begin{array}{l}4.50 \mathrm{U} \\
\mathrm{NA}\end{array}$ & 4.11 U & $\begin{array}{l}4.03 \mathrm{U} \\
\mathrm{NA}\end{array}$ & $\begin{array}{l}3.94 \\
10 \%\end{array}$ \\
\hline rC-5 Upper Replicate & c & 215.91 & 320,61 & 115.38 & 36.23 & 182.50 & 125.82 & 268.45 & 279 & 31.52 & 272.69 \\
\hline TC-5 Upper Replicate & $\mathrm{c}$ & 197.98 & 29 & 101.15 & 127.57 & 168.60 & 115.38 & 246.76 & 258.52 & 29.21 & 245.83 \\
\hline IC-5 Upper Replicate & $c$ & 273.10 & 382.85 & 137.62 & 170.54 & 227.09 & 167.08 & 327.01 & 341.83 & 42.26 & 327.90 \\
\hline RSD & & $17 \%$ & $14 \%$ & $16 \%$ & $16 \%$ & $16 \%$ & $20 \%$ & $15 \%$ & $15 \%$ & $20 \%$ & $15 \%$ \\
\hline R-8F Replicate 1 & A & $254.72 \mathrm{~B}$ & $371.85 \mathrm{~B}$ & 145 & 146.66 & 240.57 & 171.82 & 393.61 & 373.38 & 37.67 & 324.97 \\
\hline R-BF Replicate 2 & A & 189.468 & $272.33 \mathrm{~B}$ & 104.23 & 113.04 & 187.99 & 124.69 & 293.95 & 285.61 & 28.90 & 246.06 \\
\hline R-BF Replicate 3 & A & $171.40 \mathrm{~B}$ & $247.03 \mathrm{~B}$ & 93.49 & 103.15 & 139.80 & 99.85 & 232.94 & 203.53 & 20.15 & 183.15 \\
\hline RSD & & $21 x$ & $22 \%$ & $24 \%$ & $19 \%$ & $27 \%$ & $28 \%$ & $26 \%$ & $3 \mathrm{C}^{\circ \%}$ & $30 \%$ & $28 \%$ \\
\hline
\end{tabular}

(a) U The analyte was not present above the level of the associated value.

(b) Recovery outside quality control range (40-120\%).

(c) Value exceeds relative precision allowance of $30 \%$.

(d) B Analyte detected above target range in blank associated with batch samples.

(e) NC Not certified.

(f) NA Not applicable.

(g) Stations IC-6 and TC-7 were split into four separate core sections which were composited, subsampled for chemistry. and used for geologic descriptions. 
IABLE C.6. Surrogate Recoveries for Polynuclear Aromatic Hydrocarbons (PAHs) Including Quality Control Data for Sediment, Richmond Harbor Program

Sediment
Ireatment

COMP I

C-1

$\mathrm{C}-3$

C-5

C-6

C-8

$\mathrm{C}-10$

COMP II

C -11

C -16

$\mathrm{C}-18$

$\mathrm{C}-19$

$\mathrm{C}-20$

C -23

COMP III Replicate I COMP III Replicate 2 COMP III Replicate 3

TC-1 Upper

TC-2 Upper

TC-3 Upper

TC-4 Upper

TC-5 Upper Comp

TC-5 Upper Replicate 1

TC-5 Upper Replicate 2

TC-5 Upper Replicate 3

TC-5 Special Sample

COMP IV Replicate I

COMP IV Replicate 2

COMP IV Replicate 3

TC-1 Lower

TC-2 Lower

TC-3 Lower

TC-4 Lower

TC-5 Lower

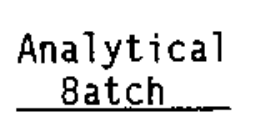

C

A

A

A

A

A

B

A

B

B

B

B

8

8

B

B

B

B

B

C

B

A

C

$\mathrm{C}$

C

C

A

A

A

B

B

C

C

B
Surrogate Percent_Recoveries

\begin{tabular}{|c|c|c|}
\hline $\begin{array}{l}\text { Naph- } \\
\text { thalene } \\
\text { d8 } \\
\end{array}$ & $\begin{array}{l}\text { Acenaph- } \\
\text { thalene } \\
\text { dlo } \\
\end{array}$ & $\begin{array}{c}\text { Perylene } \\
\quad \text { d12 }\end{array}$ \\
\hline 62 & 68 & 108 \\
\hline 70 & 80 & 110 \\
\hline 44 & 49 & 62 \\
\hline 49 & 62 & 86 \\
\hline 48 & 62 & 92 \\
\hline 44 & 49 & 63 \\
\hline 60 & 66 & 96 \\
\hline
\end{tabular}

44

60

71

61

45

$39^{(a)}$

$39^{(a)}$

51

64

72

65

55

55

55

87

79

94

88

87

83

92

71

81

42

76

$1^{(a)}$

41

67

\section{3}

82

90

83

90

80

82

65

$52 \quad 65$

113

107

102

118

59

$30^{(2)}$

65

74

93

65

70

74

40

62

49

70

82 $128^{(a)}$
$132^{(a)}$
$126^{(a)}$
82
92
88
98
78 
TABLE C.6. (contd)

Sediment

Treatment

COMP V

$\mathrm{C}-24$

$C-26$

$C-30$

$\mathrm{C}-33$

$C-35$

C -37

COMP VI

$C-25$

C. 29

C -32

C -36

C -38

TC-6 (1) (b) Duplicate 1

TC-6 (1) Duplicate 2

TC -6 (2)

TC -6 (3)

TC -6 (4)

TC-7 $(1)^{(b)}$

TC-7 (2)

$\mathrm{TC}-7$ (3)

TC-7 (4)

$\mathrm{R}-\mathrm{AC}$

$\mathrm{R}-\mathrm{AM}$

$R-B F$

$R-B F$

$R-B F$

$R-O S$

$R-P F$

C-SB

$C-W B$

$\mathrm{C}-\mathrm{NE}$

\begin{tabular}{|c|c|c|}
\hline $\begin{array}{l}\text { Naph- } \\
\text { thalene } \\
\text { d8 } \\
\end{array}$ & $\begin{array}{l}\text { Acenaph- } \\
\text { thatene } \\
\text { dlo } \\
\end{array}$ & $\begin{array}{c}\begin{array}{c}\text { Perylene } \\
\mathrm{d} 12\end{array} \\
\end{array}$ \\
\hline $\begin{array}{l}62 \\
73 \\
54 \\
59 \\
60 \\
44 \\
50\end{array}$ & $\begin{array}{l}67 \\
77 \\
62 \\
66 \\
64 \\
51 \\
56\end{array}$ & $\begin{array}{c}138^{(a)} \\
86 \\
80 \\
107 \\
95 \\
71 \\
70\end{array}$ \\
\hline $\begin{array}{l}65 \\
66 \\
45 \\
35^{(a)} \\
55 \\
52\end{array}$ & $\begin{array}{l}72 \\
67 \\
56 \\
38^{(a)} \\
57 \\
65\end{array}$ & $\begin{array}{c}132^{(\mathrm{a})} \\
88 \\
81 \\
40 \\
77 \\
94\end{array}$ \\
\hline
\end{tabular}

$\begin{array}{llll}\mathrm{C} & 73 & 76 & 121^{(a)} \\ \mathrm{C} & 75 & 78 & 116 \\ \mathrm{C} & 72 & 75 & 101 \\ \mathrm{C} & 46 & 50 & 69 \\ \mathrm{C} & 68 & 71 & 99\end{array}$

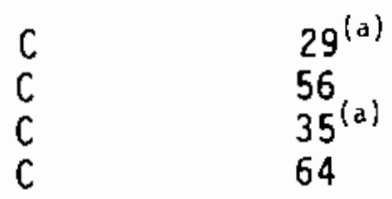

$39^{(a)}$

60

44

66

$37^{(a)}$

85

61

82

$\begin{array}{lllr}\text { A } & 62 & 72 & 123^{(a)} \\ \text { B } & 59 & 61 & 89 \\ \text { A } & 62 & 71 & 109 \\ \text { A } & 43 & 55 & 98 \\ \text { A } & 41 & 48 & 74 \\ \text { A } & 49 & 62 & 116 \\ \text { A } & 53 & 61 & 98 \\ \text { A } & 5 B & 72 & 119 \\ \text { A } & 36^{(a)} & 47 & 78 \\ \text { A } & 44 & 59 & 92\end{array}$


IABLE C.6. (contd)

Sediment

Treatment

Qual ity Control Data

Method Blanks

B] ank 1

Blank 2

Blank 3

Blank 4

Matrix Spikes

COMP I MS

COMP I MSD

MS/MSD RPO

MS/MSD I-STAT

COMP III MS Replicate 1

COMP III MSD Replicate I

MS/MSD RPD

MS/MSD I -STAT

COMP IV MS Replicate 1

COMP IV MSD Replicate 1

MS/MSD RPD

MS/MSD I -STAT

Analytical Duplicates

TC-6 (1)

TC-6 (1) Dupl icate

RPD

I -STAT

Analytical Triplicates

COMP III Replicate I

COMP III Replicate 2

COMP III Replicate 3

RSD
Analytical

Batch

\begin{tabular}{|c|c|c|}
\hline & & \\
\hline $\begin{array}{l}\text { Naph- } \\
\text { thalene } \\
\text { d8 } \\
\end{array}$ & $\begin{array}{l}\text { Acenaph- } \\
\text { thalene } \\
\text { d10 } \\
\end{array}$ & $\begin{array}{c}\text { Perylene } \\
\text { d12 } \\
\end{array}$ \\
\hline
\end{tabular}


IABLE C.6. (contd)

Sediment

Ireatment

COMP IV Replicate I

COMP IV Replicate 2

COMP IV Rep]icate 3

RSD

TC-5 Upper Replicate 1

TC-5 Upper Replicate 2

TC-5 Upper Replicate 3

RSD

R-BF Replicate 1

R-BF Replicate 2

R-BF Replicate 3

RSD

Surrogate Percent Recoveries

\begin{tabular}{|c|c|c|}
\hline $\begin{array}{l}\text { Naph- } \\
\text { thalene } \\
\text { d8 } \\
\end{array}$ & $\begin{array}{l}\text { Acenaph- } \\
\text { thalene } \\
\text { d10 }\end{array}$ & $\begin{array}{c}\text { Perylene } \\
\mathrm{d} 12\end{array}$ \\
\hline $\begin{array}{l}65 \\
70 \\
74\end{array}$ & $\begin{array}{l}72 \\
76 \\
80\end{array}$ & $\begin{array}{l}128^{(a)} \\
132^{(a)} \\
126^{(a)}\end{array}$ \\
\hline 6 & 5 & 2 \\
\hline $\begin{array}{l}58 \\
55 \\
59\end{array}$ & $\begin{array}{l}70 \\
65 \\
74\end{array}$ & $\begin{array}{l}107 \\
102 \\
118\end{array}$ \\
\hline 4 & 6 & 8 \\
\hline $\begin{array}{l}62 \\
43 \\
41\end{array}$ & $\begin{array}{l}71 \\
55 \\
48\end{array}$ & $\begin{array}{r}109 \\
98 \\
74\end{array}$ \\
\hline 24 & 20 & 19 \\
\hline
\end{tabular}

Analytical

Batch

A

A

A

A

.

$(-100$

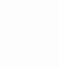

c

C

C

$A$
$A$
$A$

\section{.}


TABLE C.7. Sediment Chlorinated Pesticide Results (alphabetical, Aldrin - DDT), Richmond Harbor Program

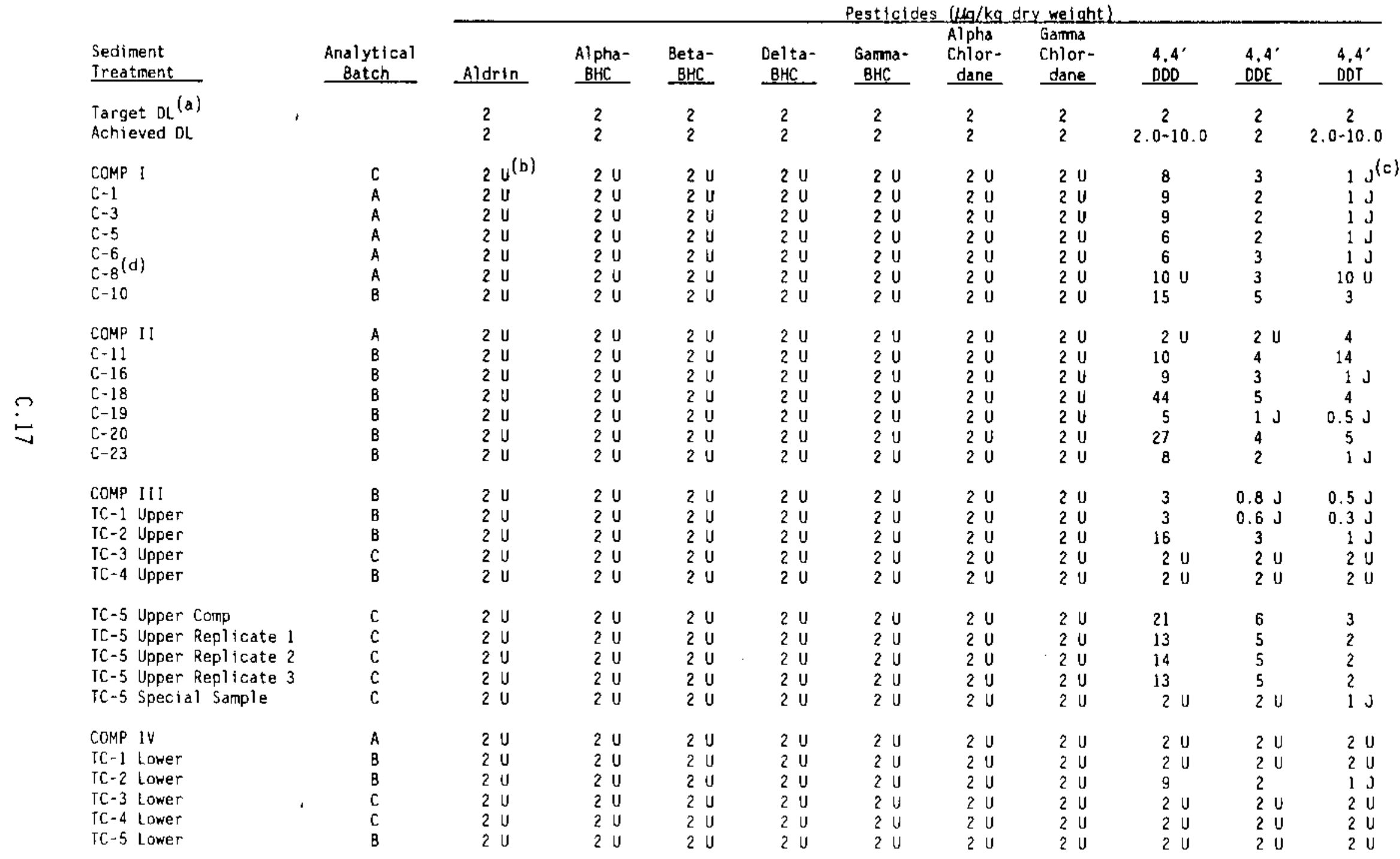


IABLE C.7. (contd)

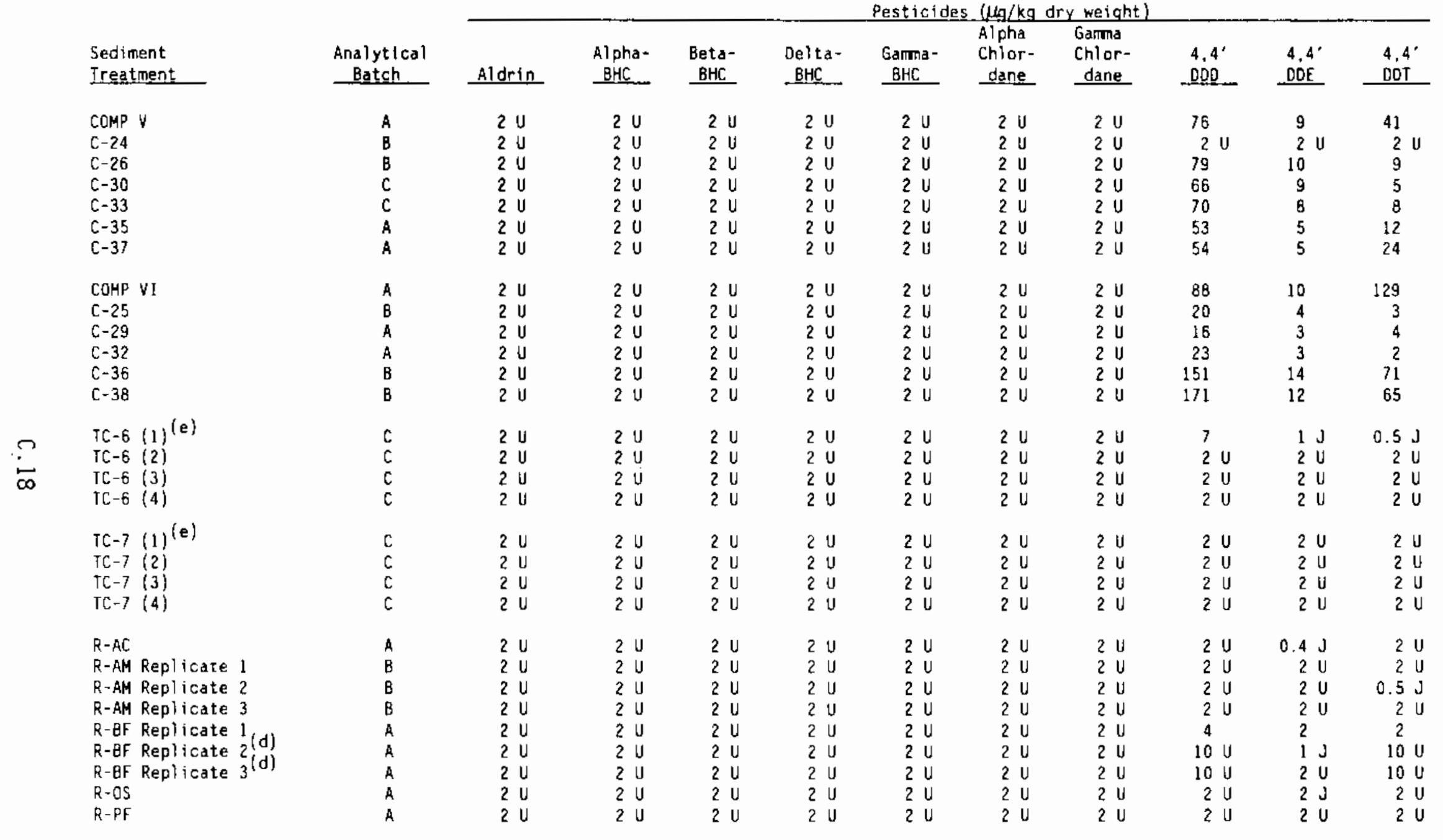


IABLE C.7. (contd)

\begin{tabular}{|c|c|c|c|c|c|c|c|c|c|c|c|}
\hline \multirow[b]{2}{*}{$\begin{array}{l}\text { Sediment } \\
\text { Ireatment }\end{array}$} & \multirow[b]{2}{*}{$\begin{array}{l}\text { Analytical } \\
\text { Batch }\end{array}$} & \multicolumn{10}{|c|}{ Pesticides ( $\mu_{\mathrm{g}} / \mathrm{kg}$ dry wetght) } \\
\hline & & Aldrín & $\begin{array}{l}\text { Alpha- } \\
\text { BHC } \\
\end{array}$ & $\begin{array}{l}\text { Beta- } \\
\text { BHC }\end{array}$ & $\begin{array}{l}\text { Del ta- } \\
\text { 배C }\end{array}$ & $\begin{array}{l}\text { Gamna- } \\
\text { BHC }\end{array}$ & $\begin{array}{l}\text { Alpha } \\
\text { Chlor- } \\
\text { dane }\end{array}$ & $\begin{array}{l}\text { Gaama } \\
\text { Chlor- } \\
\text { dane } \\
\end{array}$ & $\begin{array}{r}4.4^{\prime} \\
D 00 \\
\end{array}$ & $\begin{array}{l}4,4^{\prime} \\
\text { DOE } \\
\end{array}$ & $\begin{array}{l}4,4^{\prime} \\
\text { ODT }\end{array}$ \\
\hline $\begin{array}{l}\mathrm{C}-\mathrm{SB} \\
\mathrm{C}-\mathrm{WB} \\
\mathrm{C}-\mathrm{NE}\end{array}$ & $A$ & $\begin{array}{l}2 u \\
2 u \\
2 U\end{array}$ & $\begin{array}{l}2 \mathrm{U} \\
2 \mathrm{U} \\
2 \mathrm{U}\end{array}$ & $\begin{array}{l}2 u \\
2 u \\
2 u\end{array}$ & $\begin{array}{l}2 \mathrm{U} \\
2 \mathrm{U} \\
2 \mathrm{U}\end{array}$ & $\begin{array}{l}2 u \\
2 u \\
2 u\end{array}$ & $\begin{array}{ll}2 u \\
2 u \\
2 u\end{array}$ & $\begin{array}{l}2 \mathrm{U} \\
2 \mathrm{U} \\
2 \mathrm{u}\end{array}$ & $\begin{array}{l}2 \mathrm{U} \\
2 \mathrm{U} \\
2 \mathrm{u}\end{array}$ & $\begin{array}{l}2 \mathrm{U} \\
2 \mathrm{U} \\
2 \mathrm{u}\end{array}$ & $\begin{array}{ll}2 & U \\
2 & U \\
2 & U\end{array}$ \\
\hline
\end{tabular}

(a) OL Detection limit.

(b) $U$ the analyte was not present above the level of the associated value.

(c) J Analyte detected below method detection limit (MOL), but above instrument detection limit (IOL),

(d) Elevated detection 1 imits due to matrix spike interference.

(e) Stations TC-6 and TC-7 were split into four separate core sections which were composited, subsampied for chemistry, and used for geologic descriptions. 
IABLE_. 8 . Sediment Chlorinated Pesticide Results (alphabetical, Dieldrin - Toxaphene), Richmond Harbor Program

\begin{tabular}{|c|c|c|c|c|c|c|c|c|c|c|}
\hline & & & & & Pesticlde & $g / \mathrm{kg} \mathrm{d}$ & ght & & & \\
\hline $\begin{array}{l}\text { Sediment } \\
\text { Ireatment } \\
\end{array}$ & $\begin{array}{l}\text { Analytical } \\
\text { Batch }\end{array}$ & Dieldrin & $\begin{array}{c}\text { Endo } \\
\text { Sulfan } \\
1 \\
\end{array}$ & $\begin{array}{c}\text { Endo } \\
\text { Sulfan } \\
\text { I I }\end{array}$ & $\begin{array}{c}\text { Endo } \\
\text { Sulfan } \\
\text { Sulfate } \\
\end{array}$ & Endrin & $\begin{array}{c}\text { Endrin } \\
\text { Alde- } \\
\text { hyde } \\
\end{array}$ & $\begin{array}{l}\text { Hepta- } \\
\text { chlor }\end{array}$ & $\begin{array}{l}\text { Hepta- } \\
\text { chlor } \\
\text { epaxide }\end{array}$ & $\begin{array}{l}\text { Toxa- } \\
\text { Phene }\end{array}$ \\
\hline $\begin{array}{l}\text { Target DL (a) } \\
\text { Achieved } \mathrm{OL}\end{array}$ & & $\begin{array}{l}2 \\
2\end{array}$ & $\begin{array}{l}2 \\
2\end{array}$ & $2.0^{2}-10.0$ & $\begin{array}{c}2 \\
2.0-10.0\end{array}$ & $\frac{2}{2.0-10.0}$ & $\frac{2}{2.0-10.0}$ & $\begin{array}{l}2 \\
2\end{array}$ & $\begin{array}{l}2 \\
2\end{array}$ & $\begin{array}{l}30 \\
20\end{array}$ \\
\hline $\begin{array}{l}\text { COMP I } \\
C-1 \\
C-3 \\
C-5 \\
C-6 \\
C-8(C) \\
C-10\end{array}$ & $\begin{array}{l}\text { C } \\
A \\
A \\
A \\
A \\
A \\
B\end{array}$ & $\begin{array}{ll}2 & U^{(b)} \\
2 & U \\
2 & U \\
2 & U \\
2 & U \\
2 & U \\
2 & U\end{array}$ & $\begin{array}{ll}2 & U \\
2 & U \\
2 & U \\
2 & U \\
2 & U \\
2 & U \\
2 & U\end{array}$ & $\begin{array}{rl}2 & U \\
2 & U \\
2 & U \\
2 & U \\
2 & U \\
10 & U \\
2 & U\end{array}$ & $\begin{array}{rl}2 & U \\
2 & U \\
2 & U \\
2 & U \\
2 & U \\
10 & U \\
2 & U\end{array}$ & $\begin{array}{rr}2 & U \\
2 & U \\
2 & U \\
2 & U \\
2 & U \\
10 & U \\
2 & U\end{array}$ & $\begin{array}{rl}2 & U \\
2 & U \\
2 & U \\
2 & U \\
2 & U \\
10 & U \\
2 & U\end{array}$ & $\begin{array}{ll}2 & U \\
2 & U \\
2 & U \\
2 & U \\
2 & U \\
2 & U \\
2 & U\end{array}$ & $\begin{array}{ll}2 & U \\
2 & U \\
2 & U \\
2 & U \\
2 & U \\
2 & U \\
2 & U\end{array}$ & $\begin{array}{ll}20 & \mathrm{U} \\
20 \mathrm{U} \\
20 \mathrm{U} \\
20 \mathrm{U} \\
20 \mathrm{U} \\
20 \mathrm{U} \\
20 \mathrm{U}\end{array}$ \\
\hline $\begin{array}{l}\text { COMP II } \\
C-11 \\
c-16 \\
c-18 \\
c-19 \\
c-20 \\
c-23\end{array}$ & $\begin{array}{l}A \\
B \\
B \\
B \\
B \\
B \\
B\end{array}$ & $\begin{array}{ll}2 & U \\
2 & U \\
2 & U \\
2 & U \\
2 & U \\
2 & U \\
2 & U\end{array}$ & $\begin{array}{ll}2 & U \\
2 & U \\
2 & U \\
2 & U \\
2 & U \\
2 & U \\
2 & U\end{array}$ & $\begin{array}{ll}2 & \mathrm{U} \\
2 & \mathrm{U} \\
2 & \mathrm{U} \\
2 & \mathrm{U} \\
2 & \mathrm{U} \\
2 & \mathrm{U} \\
2 & \mathrm{U}\end{array}$ & $\begin{array}{ll}2 & U \\
2 & U \\
2 & U \\
2 & U \\
2 & U \\
2 & U \\
2 & U\end{array}$ & $\begin{array}{ll}2 & \mathrm{U} \\
2 & \mathrm{U} \\
2 & \mathrm{U} \\
2 & \mathrm{U} \\
2 & \mathrm{U} \\
2 & \mathrm{U} \\
2 & \mathrm{U}\end{array}$ & $\begin{array}{ll}2 & U \\
2 & U \\
2 & U \\
2 & U \\
2 & U \\
2 & U \\
2 & U\end{array}$ & $\begin{array}{ll}2 & U \\
2 & U \\
2 & U \\
2 & U \\
2 & U \\
2 & U \\
2 & U\end{array}$ & $\begin{array}{ll}2 & U \\
2 & U \\
2 & U \\
2 & U \\
2 & U \\
2 & U \\
2 & U\end{array}$ & $\begin{array}{ll}20 & U \\
20 & U \\
20 U \\
20 U \\
20 U \\
20 U \\
20 U\end{array}$ \\
\hline $\begin{array}{l}\text { COMP } 11 \mathrm{I} \\
\text { TC-1 Upper } \\
\text { TC-2 Upper } \\
\text { TC-3 Upper } \\
\text { TC-4 Upper }\end{array}$ & $\begin{array}{l}B \\
B \\
B \\
C \\
B\end{array}$ & $\begin{array}{ll}2 & \mathrm{U} \\
2 & \mathrm{U} \\
2 & \mathrm{U} \\
2 & \mathrm{U} \\
2 & \mathrm{U}\end{array}$ & $\begin{array}{ll}2 & U \\
2 & U \\
2 & U \\
2 & U \\
2 & U\end{array}$ & $\begin{array}{ll}2 & \mathrm{U} \\
2 & \mathrm{U} \\
2 & \mathrm{U} \\
2 & \mathrm{U} \\
2 & \mathrm{U}\end{array}$ & $\begin{array}{ll}2 & U \\
2 & U \\
2 & U \\
2 & U \\
2 & U\end{array}$ & $\begin{array}{ll}2 & \mathrm{U} \\
2 & \mathrm{U} \\
2 & \mathrm{U} \\
2 & \mathrm{U} \\
2 & \mathrm{U}\end{array}$ & $\begin{array}{ll}2 & U \\
2 & U \\
2 & U \\
2 & U \\
2 & U\end{array}$ & $\begin{array}{ll}2 & U \\
2 & U \\
2 & U \\
2 & U \\
2 & U\end{array}$ & $\begin{array}{ll}2 & \mathrm{U} \\
2 & \mathrm{U} \\
2 & \mathrm{U} \\
2 & \mathrm{U} \\
2 & \mathrm{U}\end{array}$ & $\begin{array}{ll}20 & U \\
20 & U \\
20 & U \\
20 & U \\
20 & U\end{array}$ \\
\hline $\begin{array}{l}\text { TC-5 Upper Comp } \\
\text { TC-5 Upper Replicate } 1 \\
\text { TC-5 Upper Replicate } 2 \\
\text { TC-5 Upper Replicate } 3 \\
\text { TC-5 Special Sample }\end{array}$ & $\begin{array}{l}\mathrm{C} \\
\mathrm{C} \\
\mathrm{C} \\
\mathrm{C} \\
\mathrm{C}\end{array}$ & $\begin{array}{ll}2 & \mathrm{U} \\
2 & \mathrm{U} \\
2 & \mathrm{U} \\
2 & \mathrm{U} \\
2 & \mathrm{U}\end{array}$ & $\begin{array}{ll}2 & U \\
2 & U \\
2 & U \\
2 & U \\
2 & U\end{array}$ & $\begin{array}{ll}2 & U \\
2 & U \\
2 & U \\
2 & U \\
2 & U\end{array}$ & $\begin{array}{ll}2 & \mathrm{U} \\
2 & \mathrm{U} \\
2 & \mathrm{U} \\
2 & \mathrm{U} \\
2 & \mathrm{U}\end{array}$ & $\begin{array}{ll}2 & \mathrm{U} \\
2 & \mathrm{U} \\
2 & \mathrm{U} \\
2 & \mathrm{U} \\
2 & \mathrm{U}\end{array}$ & $\begin{array}{ll}2 & U \\
2 & U \\
2 & U \\
2 & U \\
2 & U\end{array}$ & $\begin{array}{ll}2 & U \\
2 & U \\
2 & U \\
2 & U \\
2 & U\end{array}$ & $\begin{array}{ll}2 & U \\
2 & U \\
2 & U \\
2 & U \\
2 & U\end{array}$ & $\begin{array}{l}20 \mathrm{U} \\
20 \mathrm{U} \\
20 \mathrm{U} \\
20 \mathrm{U} \\
20 \mathrm{U}\end{array}$ \\
\hline $\begin{array}{l}\text { COMP IV } \\
\text { TC-1 Lower } \\
\text { TC-2 Lower } \\
\text { TC-3 Lower } \\
\text { TC-4 lower } \\
\text { TC-5 Lower }\end{array}$ & $\begin{array}{l}A \\
B \\
B \\
C \\
C \\
B\end{array}$ & $\begin{array}{ll}2 & \mathrm{U} \\
2 & \mathrm{U} \\
2 & \mathrm{U} \\
2 & \mathrm{U} \\
2 & \mathrm{U} \\
2 & \mathrm{U}\end{array}$ & $\begin{array}{ll}2 & \mathrm{U} \\
2 & \mathrm{U} \\
2 & \mathrm{U} \\
2 \mathrm{U} \\
2 \mathrm{U} \\
2 \mathrm{U}\end{array}$ & $\begin{array}{ll}2 & U \\
2 & U \\
2 & U \\
2 & U \\
2 & U \\
2 & U\end{array}$ & $\begin{array}{ll}2 & \mathrm{U} \\
2 & \mathrm{U} \\
2 & \mathrm{U} \\
2 & \mathrm{U} \\
2 & \mathrm{U} \\
2 & \mathrm{U}\end{array}$ & $\begin{array}{ll}2 & \mathrm{U} \\
2 & \mathrm{U} \\
2 & \mathrm{U} \\
2 & \mathrm{U} \\
2 & \mathrm{U} \\
2 & \mathrm{U}\end{array}$ & $\begin{array}{ll}2 & \mathrm{U} \\
2 & \mathrm{U} \\
2 & \mathrm{U} \\
2 & \mathrm{U} \\
2 & \mathrm{U} \\
2 & \mathrm{U}\end{array}$ & $\begin{array}{ll}2 & U \\
2 & U \\
2 & U \\
2 & U \\
2 & U \\
2 & U\end{array}$ & $\begin{array}{ll}2 & U \\
2 & U \\
2 & U \\
2 & U \\
2 & U \\
2 & U\end{array}$ & $\begin{array}{ll}20 & \mathrm{U} \\
20 & \mathrm{U} \\
20 \mathrm{U} \\
20 \mathrm{U} \\
20 \mathrm{U} \\
20 \mathrm{U}\end{array}$ \\
\hline
\end{tabular}


IABLE C.8. (contd)

\begin{tabular}{|c|c|c|c|c|c|c|c|c|c|c|}
\hline & & & & & Pesticide & $\mathrm{kg} / \mathrm{kg} \mathrm{dry}$ & (ght) & & & \\
\hline $\begin{array}{l}\text { Sediment } \\
\text { Treatment }\end{array}$ & $\begin{array}{l}\text { Analytical } \\
\text { Batch } \\
\end{array}$ & Dieldrin & $\begin{array}{c}\text { Endo } \\
\text { Sulfan } \\
1 \\
\end{array}$ & $\begin{array}{c}\text { Endo } \\
\text { Sulfan } \\
\text { II }\end{array}$ & $\begin{array}{c}\text { Endo } \\
\text { Sulfan } \\
\text { Sulfate } \\
\end{array}$ & Endrin & $\begin{array}{l}\text { Endrin } \\
\text { Alde- } \\
\text { hyde }\end{array}$ & $\begin{array}{l}\text { Hepta- } \\
\text { chior }\end{array}$ & $\begin{array}{l}\text { Hepta- } \\
\text { chlor } \\
\text { epoxtde }\end{array}$ & $\begin{array}{l}\text { Toxa- } \\
\text { phene }\end{array}$ \\
\hline $\begin{array}{l}\text { COHP V } \\
C-24 \\
C-26 \\
C-30 \\
C-33 \\
C-35 \\
C-37\end{array}$ & $\begin{array}{l}A \\
B \\
B \\
C \\
C \\
A \\
A\end{array}$ & $\begin{array}{ll}2 & U \\
2 & U \\
2 & U \\
2 & U \\
2 & U \\
2 & U \\
2 & U\end{array}$ & $\begin{array}{ll}2 & U \\
2 & U \\
2 & U \\
2 & U \\
2 & U \\
2 & U \\
2 & U\end{array}$ & $\begin{array}{ll}2 & \mathrm{U} \\
2 & \mathrm{U} \\
2 & \mathrm{U} \\
2 & \mathrm{U} \\
2 & \mathrm{U} \\
2 & \mathrm{U} \\
2 & \mathrm{U}\end{array}$ & $\begin{array}{ll}2 & U \\
2 & U \\
2 & U \\
2 & U \\
2 & U \\
2 & U \\
2 & U\end{array}$ & $\begin{array}{ll}2 & U \\
2 & U \\
2 & U \\
2 & U \\
2 & U \\
2 & U \\
2 & U\end{array}$ & $\begin{array}{ll}2 & U \\
2 & U \\
2 & U \\
2 & U \\
2 & U \\
2 & U \\
2 & U\end{array}$ & $\begin{array}{ll}2 & U \\
2 & U \\
2 & U \\
2 & U \\
2 & U \\
2 & U \\
2 & U\end{array}$ & $\begin{array}{ll}2 & U \\
2 & U \\
2 & U \\
2 & U \\
2 & U \\
2 & U \\
2 & U\end{array}$ & $\begin{array}{l}20 \mathrm{U} \\
20 \mathrm{U} \\
20 \mathrm{U} \\
20 \mathrm{U} \\
20 \mathrm{U} \\
20 \mathrm{U} \\
20 \mathrm{U}\end{array}$ \\
\hline $\begin{array}{l}\text { COMP VI } \\
C-25 \\
C-29 \\
C-32 \\
C-36 \\
c-38\end{array}$ & $\begin{array}{l}A \\
B \\
A \\
A \\
B \\
B\end{array}$ & $\begin{array}{ll}2 & u \\
2 & u \\
2 & u \\
2 & u \\
2 & u \\
2 & 0\end{array}$ & $\begin{array}{ll}2 & U \\
2 & U \\
2 & U \\
2 & U \\
2 & U \\
2 & U\end{array}$ & $\begin{array}{ll}2 & U \\
2 & U \\
2 & U \\
2 & U \\
2 & U \\
2 & U\end{array}$ & $\begin{array}{ll}2 & U \\
2 & U \\
2 & U \\
2 & U \\
2 & U \\
2 & U\end{array}$ & $\begin{array}{ll}2 & U \\
2 & U \\
2 & U \\
2 & U \\
2 & U \\
2 & U\end{array}$ & $\begin{array}{ll}2 & U \\
2 & U \\
2 & U \\
2 & U \\
2 & U \\
2 & U\end{array}$ & $\begin{array}{ll}2 & U \\
2 & U \\
2 & U \\
2 & U \\
2 & U \\
2 & U\end{array}$ & $\begin{array}{ll}2 & U \\
2 & U \\
2 & U \\
2 & U \\
2 & U \\
2 & U\end{array}$ & $\begin{array}{l}20 \mathrm{U} \\
20 \mathrm{U} \\
20 \mathrm{U} \\
20 \mathrm{U} \\
20 \mathrm{U} \\
20 \mathrm{U}\end{array}$ \\
\hline $\begin{array}{l}\text { IC-6 (1) } \\
\text { TC-6 (d) } \\
\text { TC-6 (3) } \\
\text { TC-6 (4) }\end{array}$ & $\begin{array}{l}\mathrm{C} \\
\mathrm{C} \\
\mathrm{C} \\
\mathrm{C}\end{array}$ & $\begin{array}{ll}2 & U \\
2 & U \\
2 & U \\
2 & U\end{array}$ & $\begin{array}{ll}2 & U \\
2 & U \\
2 & U \\
2 & 0\end{array}$ & $\begin{array}{ll}2 & \mathrm{U} \\
2 & \mathrm{U} \\
2 & \mathrm{U} \\
2 & \mathrm{U}\end{array}$ & $\begin{array}{ll}2 & U \\
2 & U \\
2 & U \\
2 & U\end{array}$ & $\begin{array}{ll}2 & \mathrm{U} \\
2 & \mathrm{U} \\
2 & \mathrm{U} \\
2 & \mathrm{U}\end{array}$ & $\begin{array}{ll}2 & \mathrm{U} \\
2 & \mathrm{U} \\
2 & \mathrm{U} \\
2 & \mathrm{U}\end{array}$ & $\begin{array}{ll}2 & U \\
2 & U \\
2 & U \\
2 & U\end{array}$ & $\begin{array}{ll}2 & U \\
2 & U \\
2 & U \\
2 & U\end{array}$ & $\begin{array}{l}20 \mathrm{U} \\
20 \mathrm{U} \\
20 \mathrm{U} \\
20 \mathrm{U}\end{array}$ \\
\hline $\begin{array}{ll}\text { TC-7 } & (1)^{(d)} \\
\text { TC-7 } & (2) \\
T C-7 & (3) \\
T C-7 & (4)\end{array}$ & $\begin{array}{l}c \\
C \\
C \\
C\end{array}$ & $\begin{array}{ll}2 & U \\
2 & u \\
2 & u \\
2 & u\end{array}$ & $\begin{array}{ll}2 & U \\
2 & U \\
2 & U \\
2 & U\end{array}$ & $\begin{array}{ll}2 & U \\
2 & U \\
2 & U \\
2 & U\end{array}$ & $\begin{array}{ll}2 & U \\
2 & U \\
2 & U \\
2 & U\end{array}$ & $\begin{array}{ll}2 & U \\
2 & U \\
2 & U \\
2 & U\end{array}$ & $\begin{array}{ll}2 & \mathrm{U} \\
2 & \mathrm{U} \\
2 & \mathrm{U} \\
2 & \mathrm{U}\end{array}$ & $\begin{array}{ll}2 & \mathrm{U} \\
2 & \mathrm{U} \\
2 & \mathrm{U} \\
2 & \mathrm{U}\end{array}$ & $\begin{array}{ll}2 & U \\
2 & U \\
2 & U \\
2 & U\end{array}$ & $\begin{array}{l}20 \mathrm{U} \\
20 \mathrm{U} \\
20 \mathrm{U} \\
20 \mathrm{U}\end{array}$ \\
\hline $\begin{array}{l}\text { R-AC } \\
\text { R-AH Replicate } 1 \\
\text { R-AH Replicate } 2 \\
\text { R-AM Replicate } 3 \\
\text { R-BF Replicate } 1(\mathrm{c}) \\
\text { R-BF Replicate } 2 \text { (c) } \\
\text { R-BF Replicate } 3(\mathrm{C}) \\
\text { R-OS } \\
\text { R-PF }\end{array}$ & $\begin{array}{l}A \\
B \\
B \\
B \\
A \\
A \\
A \\
A \\
A\end{array}$ & $\begin{array}{ll}2 & U \\
2 & U \\
2 & U \\
2 & U \\
2 & U \\
2 & U \\
2 & U \\
2 & U \\
2 & U\end{array}$ & $\begin{array}{ll}2 & U \\
2 & U \\
2 & U \\
2 & U \\
2 & U \\
2 & U \\
2 & U \\
2 & U \\
2 & U\end{array}$ & $\begin{array}{rr}2 & \mathrm{U} \\
2 & \mathrm{U} \\
2 & \mathrm{U} \\
2 & \mathrm{U} \\
2 & \mathrm{U} \\
10 & \mathrm{U} \\
10 & \mathrm{U} \\
2 & \mathrm{U} \\
2 & \mathrm{U}\end{array}$ & $\begin{array}{rl}2 & U \\
2 & U \\
2 & U \\
2 & U \\
2 & U \\
10 & U \\
10 & U \\
2 & U \\
2 & U\end{array}$ & $\begin{array}{rr}2 & \mathrm{U} \\
2 & \mathrm{U} \\
2 & \mathrm{U} \\
2 & \mathrm{U} \\
2 & \mathrm{U} \\
10 & \mathrm{U} \\
10 & \mathrm{U} \\
2 & \mathrm{U} \\
2 & \mathrm{U}\end{array}$ & $\begin{array}{rr}2 & \mathrm{U} \\
2 & \mathrm{U} \\
2 & \mathrm{U} \\
2 & \mathrm{U} \\
2 & \mathrm{U} \\
10 & \mathrm{U} \\
10 & \mathrm{U} \\
2 & \mathrm{U} \\
2 & \mathrm{U}\end{array}$ & $\begin{array}{ll}2 & \mathrm{U} \\
2 & \mathrm{U} \\
2 & \mathrm{U} \\
2 & \mathrm{U} \\
2 & \mathrm{U} \\
2 & \mathrm{U} \\
2 & \mathrm{U} \\
2 & \mathrm{U} \\
2 & \mathrm{U}\end{array}$ & $\begin{array}{ll}2 & U \\
2 & U \\
2 & U \\
2 & U \\
2 & U \\
2 & U \\
2 & U \\
2 & U \\
2 & U\end{array}$ & $\begin{array}{l}20 \mathrm{U} \\
20 \mathrm{U} \\
20 \mathrm{U} \\
20 \mathrm{U} \\
20 \mathrm{U} \\
20 \mathrm{U} \\
20 \mathrm{U} \\
20 \mathrm{U} \\
20 \mathrm{U}\end{array}$ \\
\hline
\end{tabular}


IABLE C.8. (contd)

\begin{tabular}{|c|c|c|c|c|c|c|c|c|c|c|}
\hline \multirow[b]{2}{*}{$\begin{array}{l}\text { Sediment } \\
\text { Ireatment }\end{array}$} & \multirow[b]{2}{*}{$\begin{array}{l}\text { Analytical } \\
\text { Batch }\end{array}$} & \multirow{2}{*}{\multicolumn{2}{|c|}{$\begin{array}{c}\text { Endo } \\
\text { Sul fan } \\
1 \\
\end{array}$}} & \multirow[b]{2}{*}{$\begin{array}{c}\text { Endo } \\
\text { Sulfan } \\
\text { II }\end{array}$} & \multirow[b]{2}{*}{$\begin{array}{c}\text { Endo } \\
\text { Sulfan } \\
\text { Sulfate } \\
\end{array}$} & & \\
\hline & & & & & & Endrin. & $\begin{array}{l}\text { Endrin } \\
\text { Alde- } \\
\text { hyde }\end{array}$ & $\begin{array}{l}\text { Hepta- } \\
\text { chlor }\end{array}$ & $\begin{array}{l}\text { Hepta- } \\
\text { chlor } \\
\text { epoxide }\end{array}$ & $\begin{array}{l}\text { Toxa- } \\
\text { phene }\end{array}$ \\
\hline $\begin{array}{l}C-S B \\
C-N B \\
C-N E\end{array}$ & $\begin{array}{l}A \\
A \\
A\end{array}$ & $\begin{array}{ll}2 & \mathrm{U} \\
2 & \mathrm{U} \\
2 & \mathrm{U}\end{array}$ & $\begin{array}{l}2 \mathrm{U} \\
2 \mathrm{U} \\
2 \mathrm{U}\end{array}$ & $\begin{array}{ll}2 & U \\
2 & U \\
2 & U\end{array}$ & $\begin{array}{ll}2 & U \\
2 & U \\
2 & U\end{array}$ & $\begin{array}{ll}2 & U \\
2 & U \\
2 & U\end{array}$ & $\begin{array}{ll}2 & U \\
2 & U \\
2 & U\end{array}$ & $\begin{array}{ll}2 & U \\
2 & U \\
2 & U\end{array}$ & $\begin{array}{l}2 \mathrm{U} \\
2 \mathrm{U} \\
2 \mathrm{U}\end{array}$ & $\begin{array}{l}20 U \\
20 U \\
20 U\end{array}$ \\
\hline
\end{tabular}

(a) DL Detection limit.

(b) $U$ The analyte was not present above the level of the associated value.

(c) Elevated detection limits due to matrix interference.

(d) Stations TC-6 and TC-7 were split into four separate core sections which were composited, subsampled for chemistry. and used for geologic descriptions. 
TABLE C.9. Quality Control Data for Sediment Chlorinated Pesticide Analysis (alphabetical, Aldrin - 4, 4'DDT), Richmond Harbor Program

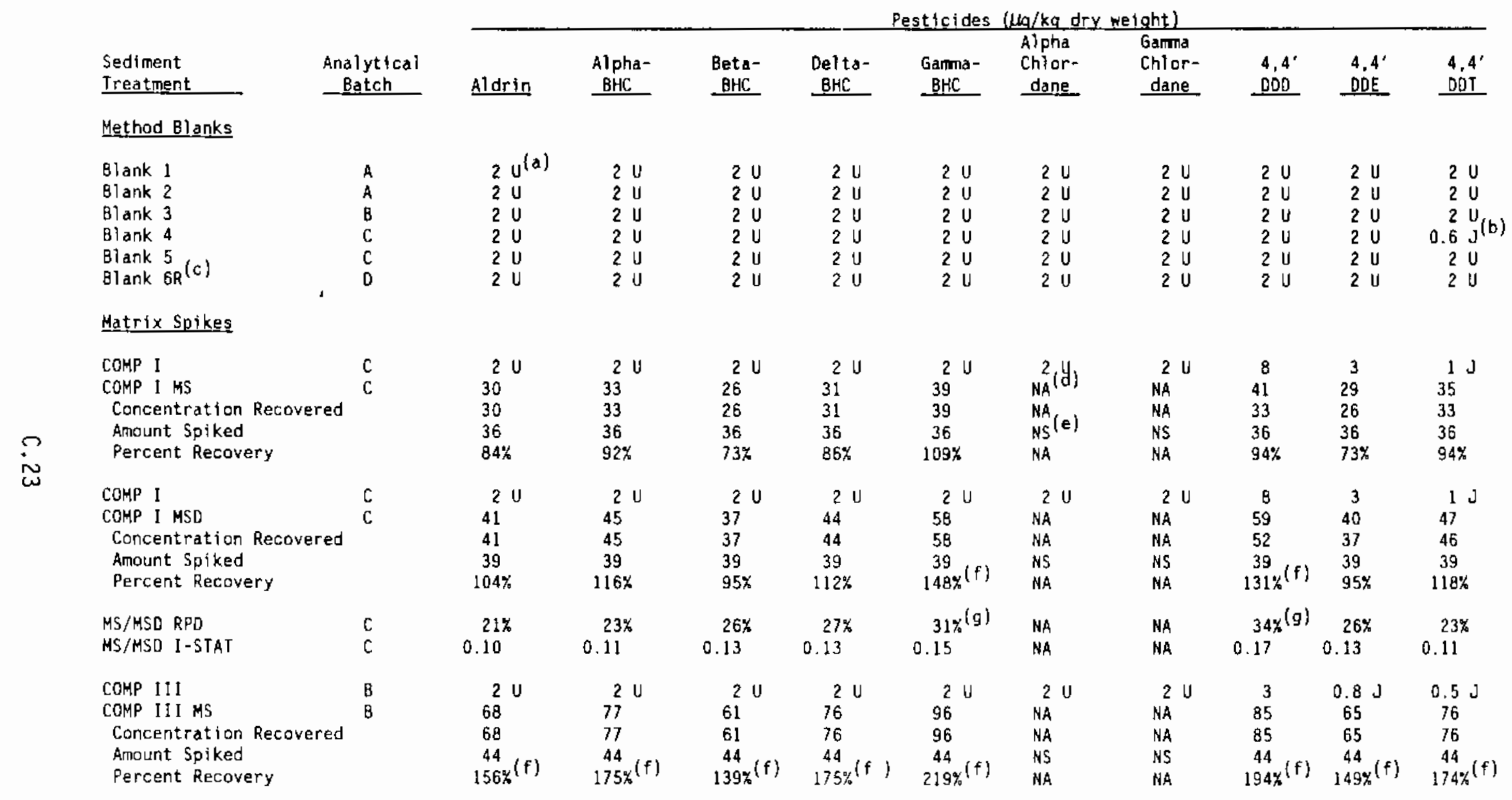


TABLE C.9. (contd)

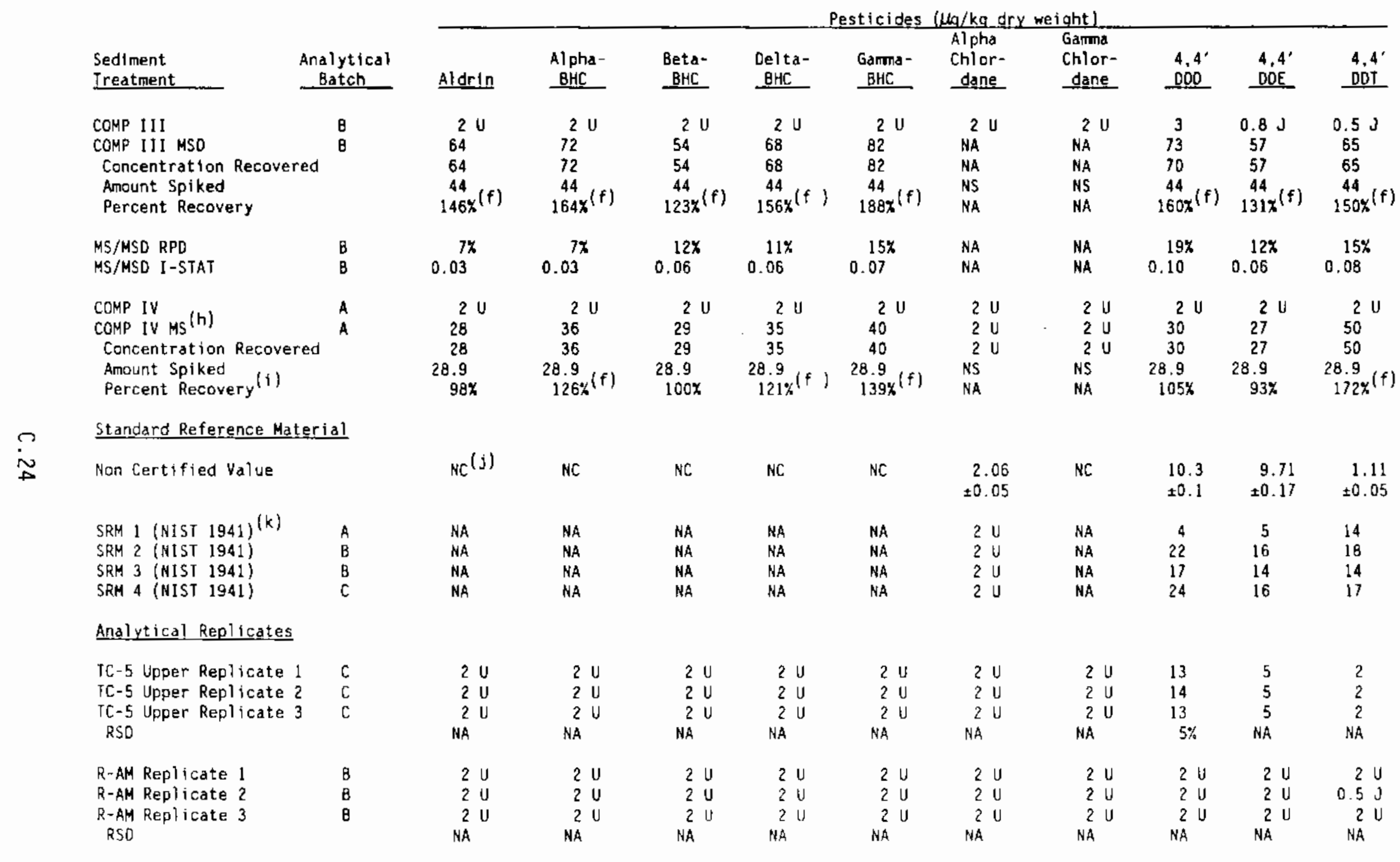


IABLE C.9. (contd)

\begin{tabular}{|c|c|c|c|c|c|c|c|c|c|c|c|}
\hline \multirow[b]{2}{*}{$\begin{array}{l}\text { Sediment } \\
\text { Ireatment }\end{array}$} & \multirow[b]{2}{*}{$\begin{array}{c}\text { Analytical } \\
\text { Batch } \\
\end{array}$} & & \multicolumn{9}{|c|}{ Pesticides $(\mu \mathrm{g} / \mathrm{kg}$ dry weight $)$. } \\
\hline & & Aldrin & $\begin{array}{l}\text { Alpha- } \\
\text { BHC }\end{array}$ & $\begin{array}{l}\text { Beta- } \\
\text { BHC }\end{array}$ & $\begin{array}{l}\text { Defta- } \\
\text { BHC }\end{array}$ & $\begin{array}{l}\text { Garma - } \\
\text { BHC }\end{array}$ & $\begin{array}{l}\text { Alpha } \\
\text { Chlor- } \\
\text { dane }\end{array}$ & $\begin{array}{l}\text { Garma } \\
\text { Chlor- } \\
\text { dane } \\
\end{array}$ & $\begin{array}{r}4.4^{\circ} \\
000 \\
\end{array}$ & $\begin{array}{r}4,4^{\prime} \\
D O E \\
\end{array}$ & $\begin{array}{r}4,4^{\prime} \\
00 I^{-} \\
\end{array}$ \\
\hline $\begin{array}{l}\text { R-BF Replicate } 1 \\
\text { R-BF Replicate } 2(k) \\
\text { R-BF Replicate } 3(k) \\
\text { RSO }\end{array}$ & $\begin{array}{l}A \\
A\end{array}$ & $\begin{array}{rl}2 & U \\
2 & U \\
2 & U \\
N A & \end{array}$ & $\begin{array}{rl}2 & U \\
2 & U \\
2 & U \\
N A\end{array}$ & $\begin{array}{rl}2 & U \\
2 & U \\
2 & U \\
N A\end{array}$ & $\begin{array}{rl}2 & U \\
2 & U \\
2 & U \\
\text { NA } & \end{array}$ & $\begin{array}{rl}2 & U \\
2 & U \\
2 & U \\
N A & \end{array}$ & $\begin{array}{rl}2 & U \\
2 & U \\
2 & U \\
N A\end{array}$ & $\begin{array}{rl}2 & U \\
2 & U \\
2 & U \\
\text { NA }\end{array}$ & $\begin{array}{l}4 \\
10 U \\
10 U \\
\text { NA U }\end{array}$ & $\begin{array}{rr}2 \\
1 & J \\
2 & U \\
N A & \end{array}$ & $\begin{array}{l}2 \\
10 U \\
10 U \\
N A\end{array}$ \\
\hline
\end{tabular}

(a) U The analyte was not present above the level of the associated value.

(b) J Analyte detected below method detection limit (MOL) but above instrument detection 1 imit (IDL).

(c) $R$ Sample was reanalyzed.

(d) NA Not applicable.

(e) NS Not spiked.

(f) Recovery outside quality control range $(40 \%-120 \%)$.

(g) Value exceeds relative precision range of $30 \%$.

(h) Matrix spike duplicate was lost during processing.

(i) Recoveries outside of range are attributed to probable response factor errors caused by using

(j) NC Not certified.

or (k) Elevated detection limits due to matrix interference. 
IABLE C.10. Quality Control Data for Sediment Chlorinated Pesticide Analysis (alphabetical, Dieldrin-Toxaphene), Richmond Harbor Program

\begin{tabular}{|c|c|c|c|c|c|c|c|c|c|c|}
\hline \multirow[b]{2}{*}{$\begin{array}{l}\text { Sediment } \\
\text { Ireatment }\end{array}$} & \multirow[b]{2}{*}{$\begin{array}{l}\text { Analytical } \\
\text { Batch }\end{array}$} & \multicolumn{9}{|c|}{ Pesticides $(\mu \mathrm{kg} / \mathrm{kg}$ dry weight) } \\
\hline & & Dieldrin & $\begin{array}{c}\text { Endo } \\
\text { Sul fan } \\
\text { I } \\
\end{array}$ & $\begin{array}{c}\text { Endo } \\
\text { Su\}fan } \\
\text { II } \\
\end{array}$ & $\begin{array}{l}\text { Endo } \\
\text { Sulfan } \\
\text { Sulfate }\end{array}$ & Endrin (a) & $\begin{array}{l}\text { Endrin } \\
\text { Alde- } \\
\text { hyde }\end{array}$ & $\begin{array}{l}\text { Hepta- } \\
\text { chlor }\end{array}$ & $\begin{array}{l}\text { Hepta- } \\
\text { chlor } \\
\text { epoxide }\end{array}$ & $\begin{array}{l}\text { Toxa- } \\
\text { phene }\end{array}$ \\
\hline
\end{tabular}

\section{Method Blanks}

\section{Blank 1}

Blank 2

81 ank 3

Blank 4

Blank 5

Blank $6 R(c)$

Matrix Spikes

\section{COMP}

COMP I MS

Concentration Recovered

o Amount Splked

COMP I MSD

Concentration Recovered

Amount Spiked

Percent Recovery

\section{MS/MSD RPD}

MS/MSO I-STAT

COMP $I$ II

COMP III MS

Concentration Recovered

Amount Spiked

Percent Recovery

$\begin{array}{lll}2 \mathrm{U} & 2 \mathrm{U} \\ 2 \mathrm{U} & 2 \mathrm{U} \\ 2 \mathrm{U} & 2 \mathrm{U} \\ 2 \mathrm{U} & 2 \mathrm{U} \\ 2 \mathrm{U} & 2 \mathrm{U} \\ 2 \mathrm{U} & 2 \mathrm{U}\end{array}$

$\begin{array}{ll}2 & U \\ 2 & U \\ 2 & U \\ 2 & U \\ 2 & U \\ 2 & U\end{array}$

$\begin{array}{ll}2 & U \\ 2 & U \\ 2 & U \\ 2 & U \\ 2 & U \\ 2 & U\end{array}$

$\begin{array}{llll}2 & U & 2 & U \\ 2 & U & 2 & U \\ 2 & U & 2 & U \\ 2 & U & 2 & U \\ 2 & U & 2 & U \\ 2 & U & 2 & U\end{array}$

$\begin{array}{ll}2 & U \\ 2 & U \\ 2 & U \\ 2 & U \\ 2 & U \\ 2 & U\end{array}$

$20 \mathrm{U}$

$20 \mathrm{U}$

$20 \mathrm{U}$

20

$20 \mathrm{U}$

$\begin{array}{ll}2 u & \\ 29 & \\ 29 & \\ 36 & \\ 82 \% & \\ 2 U & \\ 43 & \\ 43 & \\ 39 & \\ 108 \% & \\ 27 \% & \\ 0.14 & \\ 2 u & \\ 68 & \\ 68 & \\ 44 & \\ 156 \% & \\ & \end{array}$

$\begin{array}{lr}2 \mathrm{U} & 2 \\ 28 & 28 \\ 28 & 28 \\ 36 & 36 \\ 79 \% & 78\end{array}$

$\begin{array}{ll}2 \mathrm{U} & \\ 28 & \\ 28 & \\ 36 & 29 \\ 78 \mathrm{x} & \end{array}$

$\begin{array}{lc}2 U & 2 U \\ 29 & 143 \\ 29 & 143 \\ 36 & 36 \\ 80 \% & 401 \%(f)\end{array}$

$\begin{array}{llll}2 . U & 2 U & 2 U & 20(\text { U) } \\ 18 & 28 & 27 & \text { NA } \\ 18 & 28 & 27 & \text { NA } \\ 36 & 36 & 36 & \text { NS }(e) \\ 51 \% & 79 \% & 75 \% & \text { NA } \\ & & & \\ 2 U & 2 U & 2 U & 20 U \\ 24 & 39 & 38 & \text { NA } \\ 24 & 39 & 38 & \text { NA } \\ 39 & 39 & 39 & \text { NS } \\ 62 \% & 99 \% & 96 \% & \text { NA } \\ & & & \\ 20 \% & 22 \% & 24 \% & \text { NA } \\ 0.10 & 0.11 & 0.12 & \text { NA }\end{array}$

39
39
39
$100 \%$
$23 \%$
12
20
60
60
44
$1387^{(f)}$

2 U
41
41
39
$103 \%$
$28 \%$
0.14
$2 u$
62
62
44
$141 \%(f)$

$\begin{array}{cc}2 U & 2 U \\ 41 & 215 \\ 41 & 215 \\ 39 & 39 \\ 105 \% & 548 \%(f) \\ & \\ 27 \% & 31 \%^{(g)} \\ 0.13 & 0.15\end{array}$

$2 \mathrm{U}$
39
39
44
$89 \%$

$2 \mathrm{U}$
57
57
44
$130 \%(f)$

$2 \mathrm{U}$
59
59
44
$135 \%$


TABLE C.10. (contd)

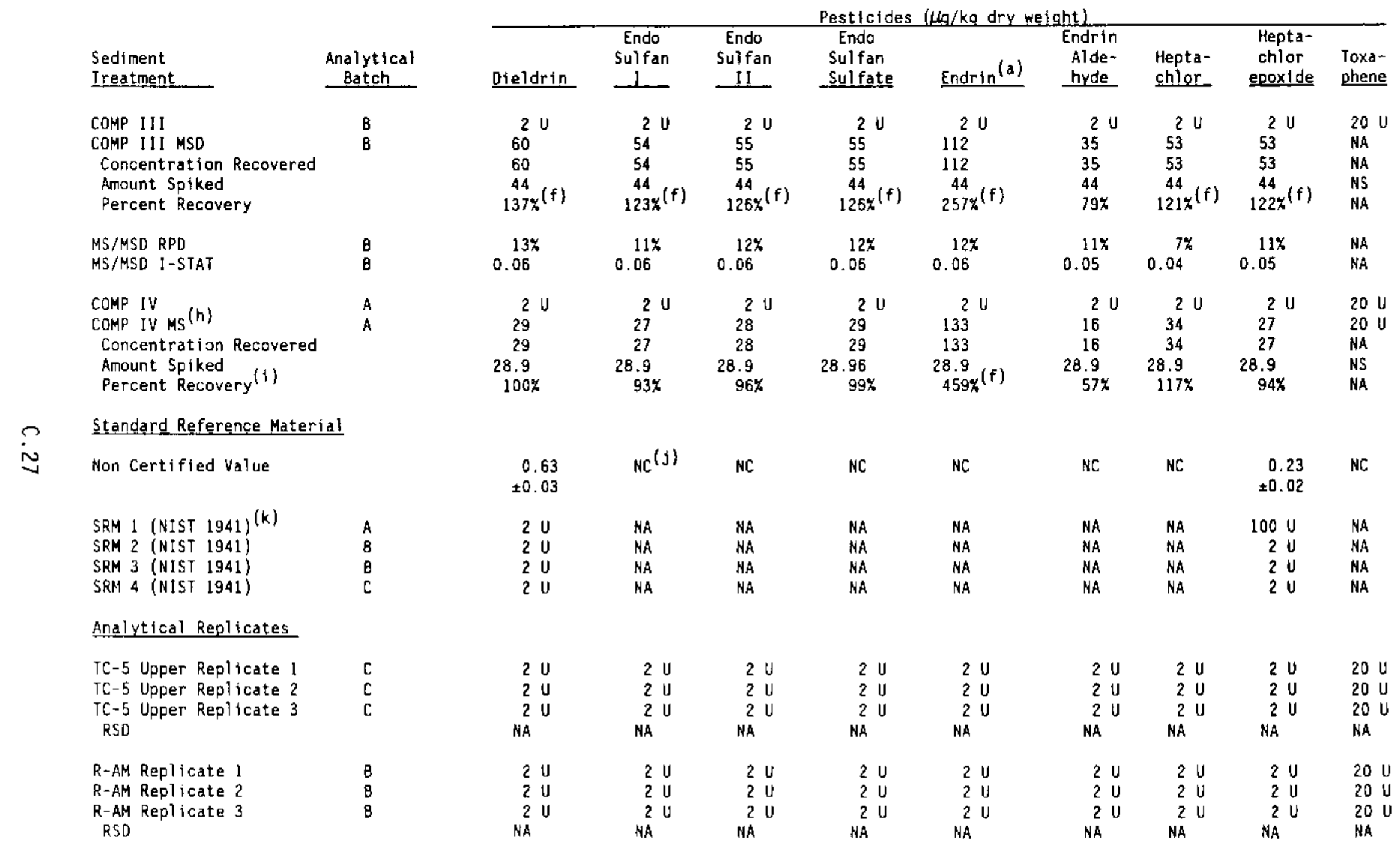


TABLE C.10. (contd)

\begin{tabular}{|c|c|c|c|c|c|c|c|c|c|c|}
\hline \multirow[b]{2}{*}{$\begin{array}{l}\text { Sediment } \\
\text { Ireatment }\end{array}$} & \multirow[b]{2}{*}{$\begin{array}{c}\text { Analytical } \\
\text { Batch }\end{array}$} & \multicolumn{9}{|c|}{ Pesticides ( $\mu_{\mathrm{k}} / \mathrm{kg}$ dry weight) } \\
\hline & & Dieldrin & $\begin{array}{l}\text { Endo } \\
\text { Sulfan } \\
\text { I } \\
\end{array}$ & $\begin{array}{c}\text { Endo } \\
\text { Sul fan } \\
\text { II } \\
\end{array}$ & $\begin{array}{c}\text { Endo } \\
\text { Sulfan } \\
\text { Sulfate } \\
\end{array}$ & Endrin (a) & $\begin{array}{l}\text { Endrin } \\
\text { Alde- } \\
\text { hyde } \\
\end{array}$ & $\begin{array}{l}\text { Kepta- } \\
\text { chlor }\end{array}$ & $\begin{array}{l}\text { Hepta- } \\
\text { chlor } \\
\text { epoxide }\end{array}$ & $\begin{array}{l}\text { Toxa- } \\
\text { phene }\end{array}$ \\
\hline $\begin{array}{l}\text { R-BF Replicate } 1 \\
\text { R-BF Replicate } 2(k) \\
\text { R-AF Replicate } 3(k) \\
\text { RSD }\end{array}$ & $\begin{array}{l}A \\
A \\
A\end{array}$ & $\begin{array}{rr}2 & U \\
2 & U \\
2 & U \\
N A\end{array}$ & $\begin{array}{rl}2 & U \\
2 & U \\
2 & U \\
\text { HA }\end{array}$ & $\begin{array}{l}2 \mathrm{U} \\
10 \mathrm{U} \\
10 \mathrm{U} \\
\mathrm{NA}\end{array}$ & $\begin{array}{l}2 \mathrm{U} \\
10 \mathrm{U} \\
10 \mathrm{U} \\
\mathrm{NA}\end{array}$ & $\begin{array}{l}2 \mathrm{U} \\
10 \mathrm{U} \\
10 \mathrm{U} \\
\mathrm{NA}\end{array}$ & $\begin{array}{rl}2 & U \\
10 U \\
10 U \\
\text { NA }\end{array}$ & $\begin{array}{rl}2 & U \\
2 & U \\
2 & U \\
\text { NA }\end{array}$ & $\begin{array}{rl}2 & U \\
2 & U \\
2 & U \\
N A & \end{array}$ & $\begin{array}{l}20 \mathrm{U} \\
20 \mathrm{U} \\
20 \mathrm{U} \\
\mathrm{NA}\end{array}$ \\
\hline
\end{tabular}

(a) Analyte amount in standard mixture is believed to be incorrect.

(b) $U$ The analyte was not present above the level of the associated value.

(c) R Sample was reanalyzed.

(d) NA Not applicable.

(e) NS Not spiked.

(f) Recovery outside quality control range $(40 \%-120 \%)$.

(g) Value exceeds relative precision range of $30 \%$.

(h) Matrix spike duplicate was lost during processing.

(i) Recoveries outside of range are attributed to probable response factor errors caused by using

calibration standards from a different source than that used for the soiking solution.

(j) NC Not certified.

(k) Elevated detection 1 imits due to Matrix interference. 
IABLE C.11. Sediment Polychlorinated Biphenyls (PCBs) Results, Richmond Harbor Program

Sediment

Treatment

Target $\mathrm{DL}^{(\mathrm{a})}$

Achieved DL

COMP I

$\mathrm{C}-1$

C -3

$c-5$

C-6

C-8

C -10

COMP II

$C-11$

$\mathrm{C}-16$

$c-18$

$C-19$

$\mathrm{C}-20$

C -23

COMP III

TC-1 Upper

TC-2 Upper

TC-3 Upper

TC-4 Upper

TC-5 Upper Comp

TC-5 Upper

TC-5 Upper

TC-5 Upper

TC-5 Special Sample

COMP IV

TC-1 Lower

$\mathrm{TC}-2$ Lower

TC-3 Lower

TC-4 Lower

TC-5 Lower

COMP $V$

$\mathrm{C}-24$

C -26

C -30

C -33

C -35

C -37

\begin{tabular}{|c|c|c|c|c|}
\hline \multirow[b]{2}{*}{$\begin{array}{l}\text { Analytical } \\
\text { Batch } \\
\end{array}$} & \multicolumn{4}{|c|}{ PCBs $(\mu \mathrm{q} / \mathrm{kg}$ dry weight) } \\
\hline & $\begin{array}{l}\text { Arocior } \\
1242\end{array}$ & $\begin{array}{l}\text { Arocior } \\
1248\end{array}$ & $\begin{array}{l}\text { Aroclor } \\
1254 \\
\end{array}$ & $\begin{array}{l}\text { Arocior } \\
1260 \\
\end{array}$ \\
\hline & $\begin{array}{l}20 \\
20\end{array}$ & $\begin{array}{l}20 \\
20\end{array}$ & $\begin{array}{l}20 \\
20\end{array}$ & $\begin{array}{l}20 \\
20\end{array}$ \\
\hline
\end{tabular}

$\begin{array}{lllll}\mathrm{C} & 20 \mathrm{U}^{(b)} & 20 \mathrm{U} & 17 \mathrm{~J}^{(c)} & 20 \mathrm{U} \\ \mathrm{A} & 20 \mathrm{U} & 20 \mathrm{U} & 12 \cdot \mathrm{J} & 20 \mathrm{U} \\ \mathrm{A} & 20 \mathrm{U} & 20 \mathrm{U} & 9 \mathrm{~J} & 20 \mathrm{U} \\ \mathrm{A} & 20 \mathrm{U} & 20 \mathrm{U} & 16 \mathrm{~J} & 20 \mathrm{U} \\ \mathrm{A} & 20 \mathrm{U} & 20 \mathrm{U} & 14 \mathrm{~J} & 20 \mathrm{U} \\ \mathrm{A} & 20 \mathrm{U} & 20 \mathrm{U} & 17 \mathrm{~J} & 20 \mathrm{U} \\ \mathrm{B} & 20 \mathrm{U} & 20 \mathrm{U} & 35 & 20 \mathrm{U}\end{array}$

$\begin{array}{rrrrr}\mathrm{A} & 20 \mathrm{U} & 20 \mathrm{U} & 37.1 & 20 \mathrm{U} \\ \mathrm{B} & 20 \mathrm{U} & 20 \mathrm{U} & 22 & 20 \mathrm{U} \\ \mathrm{B} & 20 \mathrm{U} & 20 \mathrm{U} & 21 & 20 \mathrm{U} \\ \mathrm{B} & 20 \mathrm{U} & 20 \mathrm{U} & 37 & 20 \mathrm{U} \\ \mathrm{B} & 20 \mathrm{U} & 20 \mathrm{U} & 8 \mathrm{~J} & 20 \mathrm{U} \\ \mathrm{B} & 20 \mathrm{U} & 20 \mathrm{U} & 27 & 20 \mathrm{U} \\ \mathrm{B} & 20 \mathrm{U} & 20 \mathrm{U} & 11 \mathrm{~J} & 20 \mathrm{U}\end{array}$

B $20 \mathrm{U}$

B $20 \mathrm{U}$

B $20 \mathrm{U}$

C $20 \mathrm{U}$

B $20 \mathrm{U}$

C $20 \mathrm{U}$

C $20 \mathrm{U}$

C $\quad 20 \mathrm{U}$

C $\quad 20 \mathrm{U}$

C $20 \mathrm{U}$

A $20 \mathrm{U}$

B $20 \mathrm{U}$

B $20 \mathrm{U}$

C $20 \mathrm{U}$

C $20 \mathrm{U}$

B $20 \mathrm{U}$

A $20 \mathrm{U}$

B $20 \mathrm{U}$

B $20 \mathrm{U}$

C $20 \mathrm{U}$

C $20 \mathrm{U}$

A $20 \mathrm{U}$

A $20 \mathrm{~V}$
$20 \mathrm{U}$

$20 \mathrm{U}$

$20 \mathrm{U}$

$20 \mathrm{U}$

$20 \mathrm{U}$

$20 \mathrm{U}$

$20 \mathrm{U}$

$20 \mathrm{U}$

$20 \mathrm{U}$

$20 \mathrm{U}$

$20 \mathrm{U}$

$20 \mathrm{U}$

$20 \mathrm{U}$

$20 \mathrm{U}$

$20 \mathrm{U}$

$20 \mathrm{U}$

$20 \mathrm{U}$

$20 \mathrm{U}$

$20 \mathrm{U}$

$20 \mathrm{U}$

$20 \mathrm{U}$

$20 \mathrm{~V}$

$20 \mathrm{~V}$

\section{3}

$7 \mathrm{~J}$

22

$20 \mathrm{U}$

$20 \mathrm{U}$

62

49

47

50

23

$20 \mathrm{U}$

$20 \mathrm{U}$

$12 \mathrm{~J}$

$20 \mathrm{U}$

$20 \mathrm{U}$

$20 \mathrm{U}$

58

$20 \mathrm{U}$

55

57

48

43

51
$20 \mathrm{~V}$

$20 \mathrm{U}$

$20 \mathrm{U}$

$20 \mathrm{U}$

$20 \mathrm{U}$

$20 \mathrm{U}$

$20 \mathrm{U}$

$20 \mathrm{U}$

$20 \mathrm{U}$

$20 \mathrm{U}$

$20 \mathrm{U}$

$20 \mathrm{U}$

$20 \mathrm{U}$

$20 \mathrm{U}$

$20 \mathrm{U}$

$20 \mathrm{U}$

$20 \mathrm{U}$

$20 \mathrm{U}$

$20 \mathrm{U}$

$20 \mathrm{U}$

$20 \mathrm{~V}$

$20 \mathrm{~V}$

$20 \mathrm{~V}$ 
IABLE C.11. (contd)

Sediment

Ireatment

COMP VI

$\mathrm{C}-25$

C -29

C -32

$\mathrm{C}-36$

C -38
$\mathrm{TC}-6(1)^{(d)}$

TC-6 (2)

TC-6 (3)

TC -6 (4)

TC $-7(1)^{(d)}$

TC -7 (2)

TC -7 (3)

TC -7 (4)

$R-A C$

R-AM Replicate 1

R-AM Replicate 2

R-AM Replicate 3

R-BF Replicate 1

R-BF Replicate 2

R-BF Replicate 3

$R-0 S$

$\mathrm{R}-\mathrm{PF}$

C-SB

$C-W B$

C-NE

\begin{tabular}{|c|c|c|c|c|}
\hline \multirow[b]{2}{*}{$\begin{array}{l}\text { Analytical } \\
\text { Batch } \\
\end{array}$} & \multicolumn{4}{|c|}{ PCBs $(\mu \mathrm{g} / \mathrm{kg}$ dry weight) } \\
\hline & $\begin{array}{l}\text { Aroclor } \\
1242 \\
\end{array}$ & $\begin{array}{l}\text { Aroclor } \\
1248 \\
\end{array}$ & $\begin{array}{l}\text { Aroctor } \\
1254\end{array}$ & $\begin{array}{c}\text { Aroclor } \\
1260 \\
\end{array}$ \\
\hline $\begin{array}{l}A \\
B \\
A \\
A \\
B \\
B\end{array}$ & $\begin{array}{ll}20 & U \\
20 & U \\
20 & U \\
20 & U \\
20 & U \\
20 & U\end{array}$ & $\begin{array}{ll}20 & U \\
20 & U \\
20 & U \\
20 & U \\
20 & U \\
20 & U\end{array}$ & $\begin{array}{l}57 \\
28 \\
32 \\
19 \\
54 \\
33\end{array}$ & $\begin{array}{ll}20 & U \\
20 & U \\
20 & U \\
20 & U \\
20 & U \\
20 & U\end{array}$ \\
\hline $\begin{array}{l}C \\
C \\
c \\
C\end{array}$ & $\begin{array}{l}20 \mathrm{U} \\
20 \mathrm{U} \\
20 \mathrm{U} \\
20 \mathrm{U}\end{array}$ & $\begin{array}{l}20 \mathrm{U} \\
20 \mathrm{U} \\
20 \mathrm{U} \\
20 \mathrm{U}\end{array}$ & $\begin{array}{ll}11 & J \\
20 & U \\
20 & U \\
20 & U\end{array}$ & $\begin{array}{l}20 \mathrm{U} \\
20 \mathrm{U} \\
20 \mathrm{U} \\
20 \mathrm{U}\end{array}$ \\
\hline $\begin{array}{l}C \\
C \\
c \\
C\end{array}$ & $\begin{array}{l}20 \mathrm{U} \\
20 \mathrm{U} \\
20 \mathrm{U} \\
20 \mathrm{U}\end{array}$ & $\begin{array}{l}20 \mathrm{U} \\
20 \mathrm{U} \\
20 \mathrm{U} \\
20 \mathrm{U}\end{array}$ & $\begin{array}{l}20 \mathrm{U} \\
20 \mathrm{U} \\
20 \mathrm{U} \\
64\end{array}$ & $\begin{array}{ll}20 & U \\
20 & U \\
20 & U \\
20 & U\end{array}$ \\
\hline
\end{tabular}

$\begin{array}{lllll}A & 20 \mathrm{U} & 20 \mathrm{U} & 6 \mathrm{~J} & 20 \mathrm{U} \\ \mathrm{B} & 20 \mathrm{U} & 20 \mathrm{U} & 14 \mathrm{~J} & 20 \mathrm{U} \\ \mathrm{B} & 20 \mathrm{U} & 20 \mathrm{U} & 21 \mathrm{U} & 20 \mathrm{U} \\ \mathrm{B} & 20 \mathrm{U} & 20 \mathrm{U} & 10 \mathrm{~J} & 20 \mathrm{U} \\ \mathrm{A} & 20 \mathrm{U} & 20 \mathrm{U} & 23 \mathrm{U} \\ \mathrm{A} & 20 \mathrm{U} & 20 \mathrm{U} & 19 \mathrm{~J} & 20 \mathrm{U} \\ \mathrm{A} & 20 \mathrm{U} & 20 \mathrm{U} & 26 \mathrm{U} & 20 \mathrm{U} \\ \mathrm{A} & 20 \mathrm{U} & 20 \mathrm{U} & 20 \mathrm{U} & 20 \mathrm{U} \\ \mathrm{A} & 20 \mathrm{U} & 20 \mathrm{U} & 20 \mathrm{U} & 20 \mathrm{U} \\ \mathrm{A} & 20 \mathrm{U} & 20 \mathrm{U} & 20 \mathrm{U} & 20 \mathrm{U} \\ \mathrm{A} & 20 \mathrm{U} & 20 \mathrm{U} & 20 \mathrm{U} & 20 \mathrm{U} \\ \mathrm{A} & 20 \mathrm{U} & 20 \mathrm{U} & 20 \mathrm{U} & 20 \mathrm{U}\end{array}$

(a) DL Detection limit.

(b) $U$ The analyte was not present above the level of the associated value.

(c) 3 Analyte detected below method detection limit (MDL) but above instrument detection limits (IDL).

(d) Stations TC-6 and TC-7 were split into four separate core sections which were composited, subsampled for chemistry, and used for geologic descriptions. 
IABLE C.12. Quality Control Data for Polychlorinated Biphenyl (PCB) Results, Richmond Harbor Program

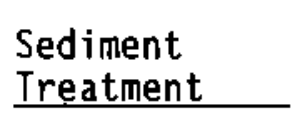

Method Blanks

Blank 1

Blank 2

Blank 3

Blank 4

BTank 5

Blank $6 R^{(b)}$

Matrix Spikes

\begin{tabular}{|c|c|c|c|c|c|}
\hline $\begin{array}{l}\text { COMP I } \\
\text { COMP I MS } \\
\text { Concentration Recovered } \\
\text { Amount Spiked } \\
\text { Percent Recovery }\end{array}$ & $\begin{array}{l}\mathrm{C} \\
\mathrm{C}\end{array}$ & $\begin{array}{l}20 \text { U } \\
N A^{(d)} \\
N A \\
N S^{(e)} \\
N A\end{array}$ & $\begin{array}{l}20 U \\
168 \\
168 \\
226 \\
74 \%\end{array}$ & $\begin{array}{l}17 \mathrm{~J}^{(\mathrm{C})} \\
\text { NA } \\
\text { NA } \\
\text { NS } \\
\text { NA }\end{array}$ & $\begin{array}{l}20 \mathrm{U} \\
\text { NA } \\
\text { NA } \\
\text { NS } \\
\text { NA }\end{array}$ \\
\hline $\begin{array}{l}\text { COMP I } \\
\text { COMP I MSD } \\
\text { Concentration Recovered } \\
\text { Amount Spiked } \\
\text { Percent Recovery }\end{array}$ & $\begin{array}{l}\mathrm{C} \\
\mathrm{C}\end{array}$ & $\begin{array}{l}20 U \\
\text { NA } \\
\text { NA } \\
\text { NS } \\
\text { NA }\end{array}$ & $\begin{array}{l}20 U \\
114 \\
114 \\
123 \\
93 \%\end{array}$ & $\begin{array}{l}\text { 17 J } \\
\text { NA } \\
\text { NA } \\
\text { NS } \\
\text { NA }\end{array}$ & $\begin{array}{l}20 \text { U } \\
\text { NA } \\
\text { NA } \\
\text { NS } \\
\text { NA }\end{array}$ \\
\hline $\begin{array}{l}\text { MS/MSD RPD } \\
\text { MS/MSD I-STAT }\end{array}$ & $\begin{array}{l}B \\
B\end{array}$ & $\begin{array}{l}\text { NA } \\
\text { NA }\end{array}$ & $\begin{array}{l}22 \% \\
0.11\end{array}$ & $\begin{array}{l}\text { NA } \\
\text { NA }\end{array}$ & $\begin{array}{l}\text { NA } \\
\text { NA }\end{array}$ \\
\hline $\begin{array}{l}\text { COMP II I } \\
\text { COMP II MS } \\
\text { Concentration Recovered } \\
\text { Amount Spiked } \\
\text { Percent Recovery }\end{array}$ & $\begin{array}{l}B \\
B\end{array}$ & $\begin{array}{l}20 \text { U } \\
\text { NA } \\
\text { NA } \\
\text { NS } \\
\text { NA }\end{array}$ & $\begin{array}{l}20 U \\
244 \\
244 \\
207 \\
118 \%\end{array}$ & $\begin{array}{l}13 \\
\text { NA } \\
\text { NA } \\
\text { NS } \\
\text { NA }\end{array}$ & $\begin{array}{l}20 U \\
\text { NA } \\
\text { NA } \\
\text { NS } \\
\text { NA }\end{array}$ \\
\hline $\begin{array}{l}\text { COMP III } \\
\text { COMP I I MSD } \\
\text { Concentration Recovered } \\
\text { Amount Spiked } \\
\text { Percent Recovery }\end{array}$ & $\begin{array}{l}B \\
B\end{array}$ & $\begin{array}{l}20 U \\
\text { NA } \\
\text { NA } \\
\text { NS } \\
\text { NA }\end{array}$ & $\begin{array}{l}20 U \\
263 \\
263 \\
229 \\
115 \%\end{array}$ & $\begin{array}{l}13 \mathrm{~J} \\
\text { NA } \\
\text { NA } \\
\text { NS } \\
\text { NA }\end{array}$ & $\begin{array}{l}20 \text { U } \\
\text { NA } \\
\text { NA } \\
\text { NS } \\
\text { NA }\end{array}$ \\
\hline $\begin{array}{l}\text { MS/MSD RPD } \\
\text { MS/MSD I-STAT }\end{array}$ & $\begin{array}{l}\text { B } \\
\text { B }\end{array}$ & $\begin{array}{l}\text { NA } \\
\text { NA }\end{array}$ & $0.01^{2 \%}$ & $\begin{array}{l}\text { NA } \\
\text { NA }\end{array}$ & $\begin{array}{l}\text { NA } \\
\text { NA }\end{array}$ \\
\hline
\end{tabular}

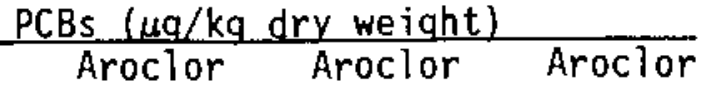

\begin{tabular}{cllll} 
Analytical Aroclor & Aroclor & Aroclor & Aroclor \\
Batch & 1242 & 1248 & 1254 & 1260 \\
\hline
\end{tabular}


TABLE C.12. (contd)

\begin{tabular}{|c|c|c|c|c|c|}
\hline \multirow[b]{2}{*}{$\begin{array}{l}\text { Sediment } \\
\text { Ireatment }\end{array}$} & \multirow[b]{2}{*}{$\begin{array}{c}\text { Analytical } \\
\text { Batch } \\
\end{array}$} & \multicolumn{4}{|c|}{ PCBs ( $\mu \mathrm{g} / \mathrm{kg}$ dry wejght) } \\
\hline & & $\begin{array}{l}\text { Aroclor } \\
1242 \\
\end{array}$ & $\begin{array}{l}\text { Aroclor } \\
1248\end{array}$ & $\begin{array}{l}\text { Aroclor } \\
1254\end{array}$ & $\begin{array}{l}\text { Aroclor } \\
1260\end{array}$ \\
\hline $\begin{array}{l}\text { COMP IV } \\
\text { COMP IV MS } \\
\text { Concentration Recovered } \\
\text { Amount Spiked } \\
\text { Percent Recovery }\end{array}$ & $\begin{array}{l}A \\
A\end{array}$ & $\begin{array}{l}20 U \\
\text { NA } \\
\text { NA } \\
\text { NS } \\
\text { NA }\end{array}$ & $\begin{array}{l}20 \mathrm{U} \\
155 \\
155 \\
130 \\
120 \%\end{array}$ & $\begin{array}{l}20 \text { U } \\
\text { NA } \\
\text { NA } \\
\text { NS } \\
\text { NA }\end{array}$ & $\begin{array}{l}20 \\
\text { NA } \\
\text { NA } \\
\text { NS } \\
\text { NA }\end{array}$ \\
\hline $\begin{array}{l}\text { COMP IV } \\
\text { COMP IV MSD } \\
\text { Concentration Recovered } \\
\text { Amount Spiked } \\
\text { Percent Recovery }\end{array}$ & A & $\begin{array}{l}20 U \\
\text { NA } \\
\text { NA } \\
\text { NS } \\
\text { NA }\end{array}$ & $\begin{array}{l}20 \mathrm{U} \\
198 \\
198 \\
158 \\
125 \%(f)\end{array}$ & $\begin{array}{l}20 \text { U } \\
\text { NA } \\
\text { NA } \\
\text { NS } \\
\text { NA }\end{array}$ & $\begin{array}{l}20 \text { U } \\
\text { NA } \\
\text { NA } \\
\text { NS } \\
\text { NA }\end{array}$ \\
\hline $\begin{array}{l}\text { MS/MSD RPD } \\
\text { MS/MSD I-STAT }\end{array}$ & $\begin{array}{l}A \\
A\end{array}$ & $\begin{array}{l}\text { NA } \\
\text { NA }\end{array}$ & 0.02 & $\begin{array}{l}\text { NA } \\
\text { NA }\end{array}$ & $\begin{array}{l}\text { NA } \\
\text { NA }\end{array}$ \\
\hline
\end{tabular}

\section{Standard Reference Material}

No certified values provided for PCBs

\section{Analytical Replicates}

$\begin{array}{llllll}\text { TC-5 Upper } & \mathrm{C} & 20 \mathrm{U} & 20 \mathrm{U} & 49 & 20 \mathrm{U} \\ \text { TC-5 Upper } & \mathrm{C} & 20 \mathrm{U} & 20 \mathrm{U} & 47 & 20 \mathrm{U} \\ \text { TC-5 Upper } & \mathrm{C} & 20 \mathrm{U} & 20 \mathrm{U} & 50 & 20 \mathrm{U} \\ \text { RSD } & & \text { NA } & \text { NA } & 4 \% & \text { NA } \\ \text { R-AM Replicate 1 } & \mathrm{B} & 20 \mathrm{U} & 20 \mathrm{U} & 14 \mathrm{~J} & 20 \mathrm{U} \\ \text { R-AM Replicate 2 } & \mathrm{B} & 20 \mathrm{U} & 20 \mathrm{U} & 21 & 20 \mathrm{U} \\ \text { R-AM Replicate 3 } & 8 & 20 \mathrm{U} & 20 \mathrm{U} & 10 \mathrm{~J} & 20 \mathrm{U} \\ \text { RSD } & & \text { NA } & \text { NA } & 37 \%(g) & \text { NA } \\ \text { R-BF Replicate 1 } & \mathrm{A} & 20 \mathrm{U} & 20 \mathrm{U} & 23 & 20 \mathrm{U} \\ \text { R-BF Replicate 2 } & \mathrm{A} & 20 \mathrm{U} & 20 \mathrm{U} & 19 \mathrm{~J} & 20 \mathrm{U} \\ \text { R-BF Replicate 3 } & \mathrm{A} & 20 \mathrm{U} & 20 \mathrm{U} & 26 & 20 \mathrm{U} \\ \text { RSD } & & \text { NA } & \text { NA } & 15 \% & \text { NA }\end{array}$

(a) $U$ The analyte was not present above the level of the associated value.

(b) $R$ Sample was reanalyzed.

(c) J Analyte detected below method detection limit (MDL) but above instrument detection limits (IDL).

(d) NA Not applicable.

(e) NS Not spiked.

(f) Recovery outside quality control range (40\%-120\%).

(g) Value exceeds relative precision range of $30 \%$. 
TABLE C.13. Surrogate Recoveries for ChTorinated Pesticides and Polychlorinated Biphenyls (PCBs) in Sediment, Richmond Harbor Program

Sediment

Treatment

\section{COMP I}

$\mathrm{C}-1$

C-3

C -5

$C-6$

C-8

C -10

COMP II

$C-11$

$C-16$

C -18

C -19

C -20

C -23

COMP III

TC-1 Upper

TC-2 Upper

TC-3 Upper

TC-4 Upper

TC-5 Upper Comp

TC-5 Upper

TC-5 Upper

TC-5 Upper

TC-5 Special Sample

COMP IV

TC-I Lower

TC-2 Lower

TC - 3 Lower

TC-4 Lower

TC-5 Lower

COMP V

C -24

C -26

C -30

C -33

C -35

C -37
Analytical

Batch

C

A

A

A

A

A

B

A

B

B

B

B

B

B

B

B

B

C

B

C

C

C

C

C

A

B

B

C

C

B

A

$B$

B

C

C

A

A
Surrogate

Percent Recovery

\begin{tabular}{lr}
\hline TCX & OCN \\
92.0 & 93.9 \\
97.6 & 109.4 \\
62.2 & 65.2 \\
84.4 & 85.3 \\
80.7 & 86.7 \\
61.7 & 67.8 \\
94.2 & 93.1
\end{tabular}

99.1

90.5

104.2

94.8

97.3

89.1

97.7

97.5

113.2

92.8

83.9

110.0

91.1

88.5

84.9

92.3

77.2

93.6

86.6

100.8

82.2

89.8

105.2

91.3

105.2

89.7

85.2

82.6

73.4

70.1
107.5

75.1

92.8

89.2

95.2

89.5

100.9

96.3

99.5

80.2

87.9

78.7

97.3

99.9

93.7

101.0

82.2

104.9

87.2

96.1

88.7

101.2

100.3

99.8

104.7

89.5

92.1

87.3

76.6

74.9 
IABLE C.13. (contd)

\section{Sediment \\ Treatment}

CONP VI

$\mathrm{C}-25$

$\mathrm{C}-29$

C -32

$\mathrm{C}-36$

C -38

TC $-6(1)^{(a)}$

TC -6 (2)

TC -6 (3)

TC -6 (4)

$\mathrm{TC}-7(1)^{(\mathrm{a})}$

TC -7 (2)

TC -7 (3)

TC -7 (4)

R-AC

R-AM Replicate 1

R-AM Replicate 2

R-AM Replicate 3

R-BF Replicate 1

R-BF Replicate 2

R-BF Replicate 3

$R-O S$

$\mathrm{R}-\mathrm{PF}$

C-SB

$C-W B$

C-NE

\section{Analytical \\ Batch}

A

B

A

A

B

B

C

C

C

C

C

C

C

C

A

B

B

B

A

A

A

A

A

A
A
A

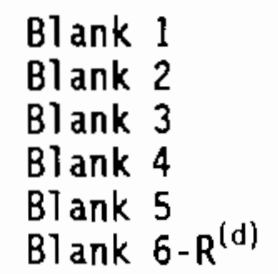

\section{Quality Control Data}

\section{Method Blanks}

A
A
B
C
C
D
Surrogate

Percent Recovery

TCX

94.8

92.8

73.4

49.4

86.2

102.3

98.0

97.0

69.3

94.5

$30.5^{(b)}$

83.8

67.3

87.2

89.4

86.1

88.6

86.0

85.9

75.9

67.7

84.4

79.6

94.6

70.9

77.6

OCN

106.4

90.8

84.3

51.8

81.8

89.7

97.3

99.8

67.5

95.2

$24.9^{(b)}$

82.5

75.6

91.5

92.1

94.4

115.2

102.1

92.9

91.6

71.4

100.0

82.2

98.5

85.6

86.9

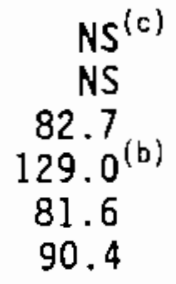

NS

NS

$94.0^{\circ}$

77.5

87.1

118.5 
TABLE C.13. (contd)

Sediment

Treatment

Matrix Spikes

COMP I MS

COMP I MSD

MS/MSD RPD

MS/MSD I-STAT

COMP III MS

COMP III MSD

MS/MSD RPD

MS/MSD I-STAT

COMP IV MS

COMP IV MSD
Analytical

Batch

C

B

B

A

A
Surrogate

Percent Recovery

OCN

62.5

76.9

61.2

74.9

20.7

.1

20.1

.1

99.7

82.5

101.6

92.4

$19 \quad 9$

$.09 \quad .05$

98.1

98.1

109.0

109.0

0
0

0

MS/MSD I-STAT

Standard Reference Material

No certified values provided for PCBs

Analytical Replicates

TC-5 Upper

TC-5 Upper

TC-5 Upper

RSD

R-AM Replicate 1

R-AM Replicate 2

R-AM Replicate 3

RSD
C
C

B

B

B
88.5

84.9

92.3

4

86.1

88.6

86.0

2
99.9

93.7

101.0

4

94.4

115.2

102.1

10 
IABLE C.13. (contd)

Sediment

Treatment

R-BF Replicate 1

R-BF Replicate 2

R-BF Replicate 3

RSD
Anatytical
Batch

A

A

A
Surrogate

Percent Recovery

\begin{tabular}{ll}
\hline TCX & OCN \\
85.9 & 92.9 \\
75.9 & 91.6 \\
67.7 & 71.4
\end{tabular}

12

(a) Stations TC-6 and TC-7 were split into four separate core sections which were composited, subsampled for chemistry, and used for geologic descriptions.

(b) Recovery outside quality control range (40\%-120\%).

(c) NS Not spiked; sample inadvertantly not spiked.

(d) $R$ Sample was reanalyzed. 
TABLE C.14. Sediment Metals Results, Richmond Harbor Program

\begin{tabular}{|c|c|c|c|c|c|c|c|c|c|c|c|}
\hline $\begin{array}{l}\text { Sediment } \\
\text { Ireatiment }\end{array}$ & $\begin{array}{c}\text { Analytical } \\
\text { Batch }\end{array}$ & \multicolumn{10}{|c|}{$1 / \mathrm{kg} \mathrm{dr}$} \\
\hline $\begin{array}{l}\text { Target } \mathrm{OL}(\mathrm{a}) \\
\text { Achieved } \mathrm{OL}\end{array}$ & & $\begin{array}{l}1.000 \\
0.019\end{array}$ & $\begin{array}{l}1.00 \\
1.00\end{array}$ & $\begin{array}{l}0.100 \\
0.012\end{array}$ & $\begin{array}{l}1.0 \\
1.0\end{array}$ & $\begin{array}{l}1.0 \\
1.0\end{array}$ & $\begin{array}{r}0.02 \\
0.0003\end{array}$ & $\begin{array}{l}1.0 \\
1.0\end{array}$ & $\begin{array}{l}1.0 \\
1.0\end{array}$ & $\begin{array}{l}0.50 \\
0.50\end{array}$ & $\begin{array}{l}1.0 \\
1.0\end{array}$ \\
\hline $\begin{array}{l}\text { COMP } 11 \\
c-11 \\
c-16 \\
c-18 \\
c-19 \\
c-20 \\
c-23\end{array}$ & $\begin{array}{l}A \\
B \\
B \\
8 \\
8 \\
8 \\
8\end{array}$ & $\begin{array}{l}0.314 \\
0.448 \\
0.293 \\
0.389 \\
0.195 \\
0.337 \\
0.251\end{array}$ & $\begin{array}{l}14.00 \\
14.50 \\
13.20 \\
12.90 \\
10.20 \\
11.90 \\
11.60\end{array}$ & $\begin{array}{l}0.380 \\
0.306 \\
0.257 \\
0.396 \\
0.308 \\
0.311 \\
0.268\end{array}$ & $\begin{array}{l}197.0 \\
202.0 \\
315.0 \\
240.0 \\
156.0 \\
196.0 \\
196.0\end{array}$ & $\begin{array}{l}57.4 \\
71.3 \\
50.8 \\
59.4 \\
42.0 \\
55.1 \\
57.2\end{array}$ & $\begin{array}{l}0.358 \\
0.439 \\
0.293 \\
0.356 \\
0.140 \\
0.357 \\
0.230\end{array}$ & $\begin{array}{r}105.5 \\
120.6 \\
99.4 \\
115.6 \\
91.3 \\
94.1 \\
115.4\end{array}$ & $\begin{array}{l}24.9 \\
36.0 \\
25.9 \\
33.9 \\
20.1 \\
31.5 \\
21.6\end{array}$ & $\begin{array}{l}0.82 U \\
0.93 \\
0.77 U \\
0.81 U \\
0.80 U \\
0.80 U \\
0.78 U\end{array}$ & $\begin{array}{r}124.5 \\
159.4 \\
114.3 \\
139.3 \\
90.0 \\
129.1 \\
119.7\end{array}$ \\
\hline $\begin{array}{l}\text { TC-5 Upper Comp } \\
\text { TC-5 Upper Replicate } 1 \\
\text { TC-5 Upper Replicate } 2 \\
\text { TC-5 Upper Replicate } 3 \\
\text { TC-5 Special Sample }\end{array}$ & $\begin{array}{l}A \\
C \\
C \\
C \\
C\end{array}$ & $\begin{array}{l}0.769 \\
0.856 \\
0.880 \\
0.840 \\
1.299\end{array}$ & $\begin{array}{l}18.20 \\
19.50 \\
21.00 \\
19.40 \\
24.80\end{array}$ & $\begin{array}{l}0.799 \\
1.209 \\
0.835 \\
0.871 \\
1.294\end{array}$ & $\begin{array}{l}230.0 \\
207.0 \\
194.0 \\
218.0 \\
206.0\end{array}$ & $\begin{array}{l}81.2 \\
81.1 \\
82.7 \\
80.4 \\
96.4\end{array}$ & $\begin{array}{l}1.048 \\
1.081 \\
1.110 \\
1.047 \\
1.431\end{array}$ & $\begin{array}{l}110.4 \\
108.9 \\
105.0 \\
110.7 \\
111.2\end{array}$ & $\begin{array}{l}60.0 \\
56.2 \\
53.8 \\
57.2 \\
62.1\end{array}$ & $\begin{array}{l}1.44 \\
0.83 \mathrm{U} \\
0.82 \mathrm{U} \\
0.85 \\
0.84 \mathrm{U}\end{array}$ & $\begin{array}{l}220.0 \\
220.0 \\
214.0 \\
214.0 \\
260.0\end{array}$ \\
\hline $\begin{array}{l}\text { COMP IV } \\
\text { TC-1 Lower } \\
\text { TC-2 Lower } \\
\text { TC-3 Lower } \\
\text { TC-4 Lower } \\
\text { TC-5 Lower }\end{array}$ & $\begin{array}{l}A \\
B \\
B \\
C \\
C \\
B\end{array}$ & $\begin{array}{l}0.110 \\
0.103 \\
0.121 \\
0.159 \\
0.107 \\
0.075\end{array}$ & $\begin{array}{r}10.27 \\
9.58 \\
10.25 \\
9.22 \\
10.86 \\
7.85\end{array}$ & $\begin{array}{l}0.362 \\
0.211 \\
0.276 \\
0.347 \\
0.237 \\
0.217\end{array}$ & $\begin{array}{l}184.0 \\
320.0 \\
253.0 \\
229.0 \\
269.0 \\
248.0\end{array}$ & \begin{tabular}{l|}
36.5 \\
40.1 \\
40.2 \\
33.2 \\
32.3 \\
26.5
\end{tabular} & $\begin{array}{l}0.101 \\
0.119 \\
0.103 \\
0.077 \\
0.116 \\
0.105\end{array}$ & $\begin{array}{l}84.6 \\
93.1 \\
91.8 \\
83.5 \\
89.5 \\
57.2\end{array}$ & $\begin{array}{l}11.1 \\
11.5 \\
11.3 \\
10.0 \\
10.8 \\
13.1\end{array}$ & $\begin{array}{l}0.77 \mathrm{U} \\
0.98 \\
0.79 \mathrm{U} \\
0.75 \mathrm{U} \\
0.81 \mathrm{U} \\
0.78 \mathrm{U}\end{array}$ & $\begin{array}{l}76.1 \\
84.4 \\
87.1 \\
65.9 \\
66.0 \\
55.2\end{array}$ \\
\hline $\begin{array}{l}\text { COMP V } \\
C-24 \\
C-26 \\
C-30 \\
C-33\end{array}$ & $\begin{array}{l}\text { A } \\
B \\
B \\
C \\
C\end{array}$ & $\begin{array}{l}0.448 \\
0.279 \\
0.500 \\
0.527 \\
0.483\end{array}$ & $\begin{array}{l}14.50 \\
13.80 \\
14.60 \\
14.20 \\
15.40\end{array}$ & $\begin{array}{l}0.556 \\
0.291 \\
0.379 \\
0.428 \\
0.655\end{array}$ & $\begin{array}{l}196.0 \\
223.0 \\
205.0 \\
184.0 \\
217.0\end{array}$ & $\begin{array}{l}74.4 \\
64.3 \\
72.4 \\
79.0 \\
71.5\end{array}$ & $\begin{array}{l}0.562 \\
0.295 \\
0.486 \\
0.529 \\
0.437\end{array}$ & $\begin{array}{l}123.5 \\
117.1 \\
117.0 \\
121.1 \\
130.9\end{array}$ & $\begin{array}{l}46.4 \\
24.1 \\
47.6 \\
52.1 \\
44.1\end{array}$ & $\begin{array}{l}0.83 \mathrm{U} \\
0.83 \\
0.82 \\
0.82 \mathrm{U} \\
0.84 \mathrm{U}\end{array}$ & $\begin{array}{l}179.3 \\
130.8 \\
172.0 \\
178.0 \\
173.5\end{array}$ \\
\hline
\end{tabular}


TABLE C.14. (contd)

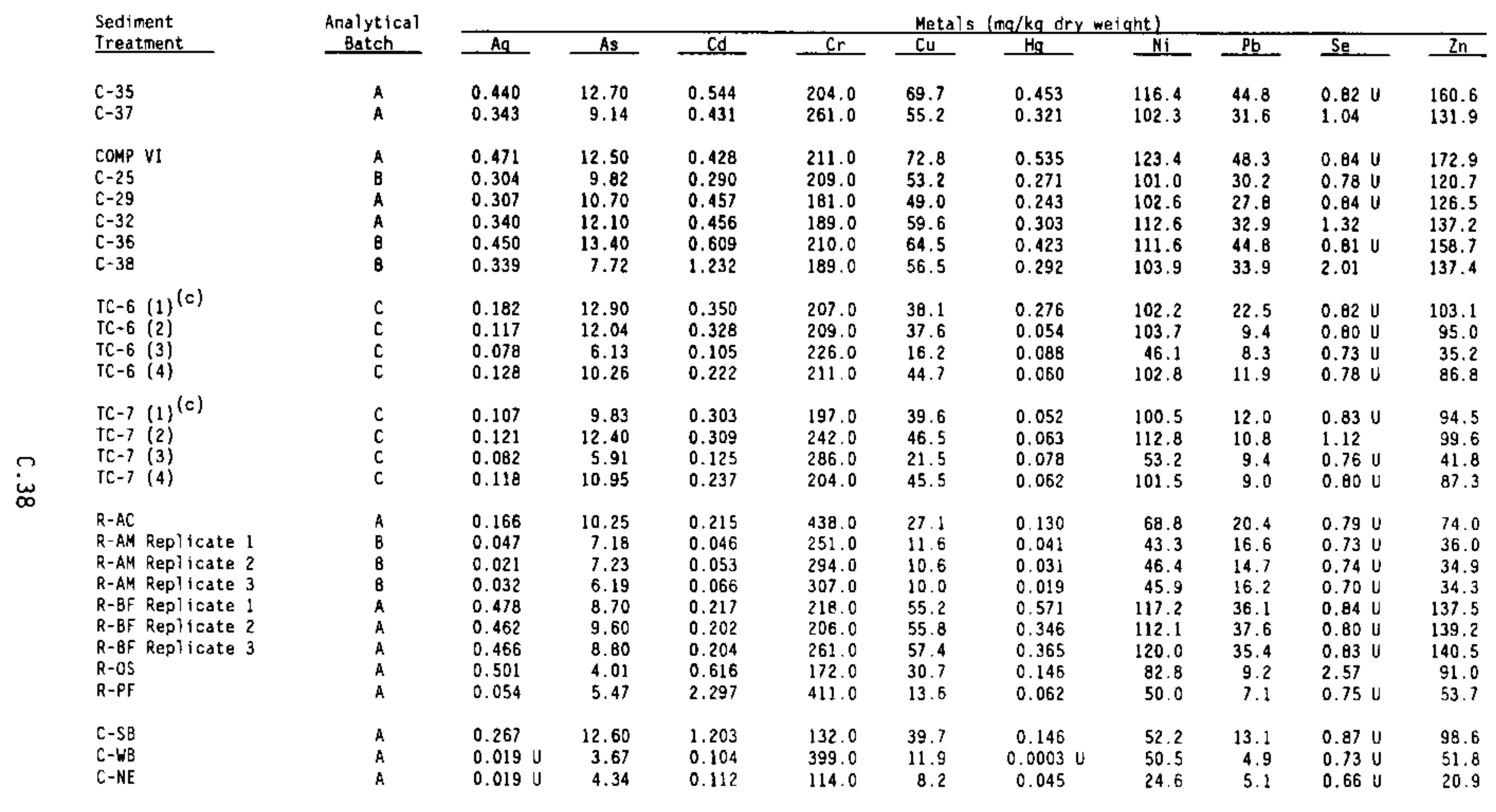

(a) DL Oetection himit.

(b) U The analyte was not present above the level of the associated value

(c) TC-6 and TC-7 were split into four separate core sect fons which were composited. subsampled for chemistry, and used for geologic descriptions. 
IABLE C.15. Quality Control Data for Sediment Metals Analyses, Richmond Harbor Program

Sediment

Anajytical

Ireatment

Batch

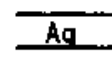

Method Blanks

Blank 1

Blank 1 Duplicate

Blank 2

Biank 2 Duplicate

Blank 3

Blank 3 Duplicate

$\begin{array}{lccc}A & 0.019 u^{(a)} & \text { NM(b) } & 0.012 \\ A & \text { NH } & \text { NM } & \text { NM } \\ 8 & 0.019 \mathrm{UH} & \text { NM } & 0.013 \\ B & \text { NH } & \text { NM } & \text { NM } \\ C & \text { HH } & \text { NM } & \text { NM } \\ C & \text { NH } & \text { NM } & \text { HM }\end{array}$

\section{Matrix Spikes}

comp

COMP I MS

Concentration Recovered

Spike Amount

Percent Recovery

COMP I

COMP I MSO

Concentration Recovered

Spike Amount

Percent Recovery

MS/MSD RPD

MS/MSD I-Stat

COMP III

COMP III MS

Concentration Recovered

Spike Amount

Percent Recovery

COMP III

COMP III MSD

Concentration Recovered

Spike Amount

Percent Recovery

$\begin{array}{clc}0.362 & \text { NA }(c) & 0.351 \\ 2.439 & \text { NA } & 2.254 \\ 2.077 & \text { NA } & 1.903 \\ 2.000 & \text { NS }(d) & 2.000 \\ 104 \% & \text { NA } & 95 \% \\ & & \\ 0.362 & \text { NA } & 0.351 \\ 2.539 & \text { NA } & 2.357 \\ 2.177 & \text { NA } & 2.006 \\ 2.000 & \text { NS } & 2.000 \\ 109 \% & \text { NA } & 100 \% \\ & & \\ 5 \% & \text { NA } & 5 \% \\ 0.02 & \text { NA } & 0.03 \\ & & \\ 0.160 & \text { NA } & 0.342 \\ 2.250 & \text { NA } & 2.296 \\ 2.090 & \text { NA } & 1.954 \\ 2.000 & \text { HS } & 2.000 \\ 105 \% & \text { HA } & 98 \% \\ & & \\ 0.160 & \text { NA } & 0.342 \\ 2.383 & \text { NA } & 2.235 \\ 2.223 & \text { NA } & 1.893 \\ 2.000 & \text { NS } & 2.000 \\ 111 \% & \text { NA } & 95 \% \\ 6 \% & \text { NA } & 3 \% \\ 0.03 & \text { NA } & 0.02\end{array}$

MS/MSD RPO

0.03

C
C
C
C
B
B

B
B


IABLE C.15. (contd)

\begin{tabular}{|c|c|c|c|c|c|c|c|c|c|c|c|}
\hline \multirow{2}{*}{$\begin{array}{l}\text { Sediment } \\
\text { Ireatment }\end{array}$} & \multirow{2}{*}{$\begin{array}{c}\text { Analytical } \\
\text { Bateh } \\
\end{array}$} & \multicolumn{10}{|c|}{ Metals $(\mathrm{mg} / \mathrm{kq}$ dry weight $)$} \\
\hline & & $\mathrm{Ag}$ & $\overline{A S}$ & cd & $\mathrm{Cr}$ & $\mathrm{Cu}$ & $\mathrm{Hq}$ & $\mathrm{Ni}$ & $\mathrm{Pb}$ & Se & 2n \\
\hline $\begin{array}{l}\text { COMP IV } \\
\text { COMP IV HS } \\
\text { Concentration Recovered } \\
\text { Spike Amount } \\
\text { Percent Recovery }\end{array}$ & $\begin{array}{l}\text { A } \\
\text { A }\end{array}$ & $\begin{array}{l}0.110 \\
2.307 \\
2.197 \\
2.000 \\
110 x\end{array}$ & $\begin{array}{l}\text { MA } \\
\text { MA } \\
\text { MA } \\
\text { HS } \\
\text { MA }\end{array}$ & $\begin{array}{l}0.362 \\
2.441 \\
2.079 \\
2.000 \\
104 x\end{array}$ & $\begin{array}{l}\text { NA } \\
\text { NA } \\
\text { NA } \\
\text { NS } \\
\text { NA }\end{array}$ & $\begin{array}{l}\text { NA } \\
\text { NA } \\
\text { NA } \\
\text { NS } \\
\text { NA }\end{array}$ & $\begin{array}{l}0.101 \\
0.951 \\
0.850 \\
0.988 \\
86 \%\end{array}$ & $\begin{array}{l}\text { NA } \\
\text { NA } \\
\text { NA } \\
\text { NS } \\
\text { NA }\end{array}$ & $\begin{array}{l}\text { KA } \\
\text { MA } \\
\text { NA } \\
\text { HS } \\
\text { HA }\end{array}$ & $\begin{array}{l}\text { NA } \\
\text { HA } \\
\text { HA } \\
\text { HS } \\
\text { HA }\end{array}$ & $\begin{array}{l}\text { HA } \\
\text { NA } \\
\text { HA } \\
\text { NS } \\
\text { NA }\end{array}$ \\
\hline $\begin{array}{l}\text { COMP IV } \\
\text { COMP IV MSD } \\
\text { Concentration Recovered } \\
\text { Spike Anount } \\
\text { Percent Recovery }\end{array}$ & $\hat{A}$ & $\begin{array}{l}0.110 \\
2.239 \\
2.129 \\
2.000 \\
106 x\end{array}$ & $\begin{array}{l}\text { MA } \\
\text { HA } \\
\text { NA } \\
\text { NS } \\
\text { HA }\end{array}$ & $\begin{array}{l}0.362 \\
2.497 \\
2.135 \\
2.000 \\
107 \%\end{array}$ & $\begin{array}{l}\text { NA } \\
\text { NA } \\
\text { NA } \\
\text { NS } \\
\text { NA }\end{array}$ & $\begin{array}{l}\text { NA } \\
\text { NA } \\
\text { NA } \\
\text { NS } \\
\text { NA }\end{array}$ & $\begin{array}{r}0.101 \\
0.891 \\
0.790 \\
0.990 \\
80 \%\end{array}$ & $\begin{array}{l}\text { NA } \\
\text { NA } \\
\text { NA } \\
\text { NS } \\
\text { NA }\end{array}$ & $\begin{array}{l}\text { NA } \\
\text { NA } \\
\text { NA } \\
\text { NS } \\
\text { NA }\end{array}$ & $\begin{array}{l}\text { NA } \\
\text { NA } \\
\text { NA } \\
\text { NS } \\
\text { NA }\end{array}$ & $\begin{array}{l}\text { NA } \\
\text { HA } \\
\text { HA } \\
\text { MS } \\
\text { NA }\end{array}$ \\
\hline $\begin{array}{l}\text { MS/MSD RPD } \\
\text { MS/MSD I-Stat }\end{array}$ & & 0.02 & $\begin{array}{l}\text { NA } \\
\text { NA }\end{array}$ & $0.01^{3 x}$ & $\begin{array}{l}\text { NA } \\
\text { NA }\end{array}$ & $\begin{array}{l}\text { NA } \\
\text { NA }\end{array}$ & 0.04 & $\begin{array}{l}\text { NA } \\
\text { HA }\end{array}$ & $\begin{array}{l}\text { NA } \\
\text { NA }\end{array}$ & $\begin{array}{l}\text { KA } \\
\text { HA }\end{array}$ & $\begin{array}{l}\text { NA } \\
\text { NA }\end{array}$ \\
\hline \multicolumn{12}{|l|}{ Standard Reference Material } \\
\hline Certified Value 1646 & & $\mathrm{NC}^{(e)}$ & $\begin{array}{l}11.6 \\
\pm 1.3\end{array}$ & $\begin{array}{r}0.36 \\
\pm 0.07\end{array}$ & $\begin{array}{l}76.0 \\
\pm 3.0\end{array}$ & $\begin{array}{l}18.0 \\
\pm 3.0\end{array}$ & $\begin{array}{r}0.063 \\
\pm 0.012\end{array}$ & $\begin{array}{l}32.0 \\
\pm 3.0\end{array}$ & $\begin{array}{l}28.2 \\
\pm 1.8\end{array}$ & $\mathrm{NC}$ & $\begin{array}{r}138.0 \\
\pm 6.0\end{array}$ \\
\hline $\begin{array}{lll}\text { SRM } & 1646 \text { Repl icate } 1 \\
\text { SRM } 1646 \text { Duplicate } \\
\text { SRM } 1646 \text { Replicate } 2 \\
\text { SRM } 1646 \text { Replicate } 3\end{array}$ & $\begin{array}{l}A \\
A \\
B \\
C\end{array}$ & $\begin{array}{l}\text { NA } \\
\text { NA } \\
\text { NA } \\
\text { NA }\end{array}$ & $\begin{array}{r}10.5 \\
\mathrm{HM} \\
11.8 \\
11.7\end{array}$ & $\begin{array}{l}0.604 \\
\mathrm{NM} \\
0.404 \\
0.395\end{array}$ & $\begin{array}{r}87.0 \\
\text { NH } \\
88.0 \\
90.0\end{array}$ & $\begin{array}{r}21.3 \\
\text { NH } \\
20.6 \\
21.3\end{array}$ & $\begin{array}{l}0.067 \\
0.064 \\
0.066 \\
0.063\end{array}$ & $\begin{array}{r}37.6 \\
\text { NM } \\
38.1 \\
37.3\end{array}$ & $\begin{array}{r}31.7 \\
\text { NM } \\
29.5 \\
30.5\end{array}$ & $\begin{array}{l}\text { NA } \\
\text { NA } \\
\text { HA } \\
\text { KA }\end{array}$ & $\begin{array}{r}134.0 \\
\text { NH } \\
135.6 \\
135.9\end{array}$ \\
\hline Certified Value 8EST-1 & & NC & NC & NC & NC & NC & $\begin{array}{r}0.092 \\
\pm 0.009\end{array}$ & NC & HC & NC & HC \\
\hline $\begin{array}{l}\text { BEST-1 Replicate } 1 \\
\text { BEST-1 Duplicate } \\
\text { BEST-1 Replicate } 2 \\
\text { BEST-1 Replicate } 3\end{array}$ & $\begin{array}{l}A \\
A \\
B \\
C\end{array}$ & $\begin{array}{l}\text { NA } \\
\text { HA } \\
\text { NA } \\
\text { NA }\end{array}$ & $\begin{array}{l}\text { NA } \\
\text { MA } \\
\text { NA } \\
\text { NA }\end{array}$ & $\begin{array}{l}\text { KA } \\
\text { KA } \\
\text { HA } \\
\text { NA }\end{array}$ & $\begin{array}{l}\text { NA } \\
\text { NA } \\
\text { NA } \\
\text { NA }\end{array}$ & $\begin{array}{l}\text { NA } \\
\text { NA } \\
\text { NA } \\
\text { NA }\end{array}$ & $\begin{array}{l}0.079 \\
0.079 \\
0.082 \\
0.081\end{array}$ & $\begin{array}{l}\text { NA } \\
\text { NA } \\
\text { NA } \\
\text { NA }\end{array}$ & $\begin{array}{l}\text { NA } \\
\text { KA } \\
\text { MA } \\
\text { NA }\end{array}$ & $\begin{array}{l}\text { NA } \\
\text { NA } \\
\text { NA } \\
\text { NA }\end{array}$ & $\begin{array}{l}\text { NA } \\
\text { NA } \\
\text { HA } \\
\text { HA }\end{array}$ \\
\hline \multicolumn{12}{|l|}{ Analytical Ouplicates } \\
\hline $\begin{array}{l}\text { IC-5 Upper Comp } \\
\text { TC-5 Upper Comp Duplicate } \\
\text { RPD } \\
\text { I-Stat }\end{array}$ & $\begin{array}{l}\text { A } \\
\text { A }\end{array}$ & $\begin{array}{l}\text { NA } \\
\text { NA } \\
\text { NA } \\
\text { HA }\end{array}$ & $\begin{array}{l}\text { HA } \\
\text { NA } \\
\text { HA } \\
\text { NA }\end{array}$ & $\begin{array}{l}\text { KA } \\
\text { NA } \\
\text { KA } \\
\text { KA }\end{array}$ & $\begin{array}{l}\text { NA } \\
\text { NA } \\
\text { NA } \\
\text { NA }\end{array}$ & $\begin{array}{l}\text { NA } \\
\text { NA } \\
\text { NA } \\
\text { NA }\end{array}$ & $\begin{array}{c}1.048 \\
1.075 \\
3 \% \\
0.01\end{array}$ & $\begin{array}{l}\text { NA } \\
\text { NA } \\
\text { NA } \\
\text { NA }\end{array}$ & $\begin{array}{l}\text { NA } \\
\text { NA } \\
\text { NA } \\
\text { NA }\end{array}$ & $\begin{array}{l}\text { NA } \\
\text { NA } \\
\text { NA } \\
\text { NA }\end{array}$ & $\begin{array}{l}\text { NA } \\
\text { NA } \\
\text { NA } \\
\text { NA }\end{array}$ \\
\hline
\end{tabular}


IABLE C.15. (contd)

\begin{tabular}{|c|c|c|c|c|c|c|c|c|c|c|c|}
\hline \multirow{2}{*}{$\begin{array}{l}\text { Sediment } \\
\text { Ireatment }\end{array}$} & \multirow{2}{*}{$\begin{array}{c}\text { Analytical } \\
\text { Batch }\end{array}$} & \multicolumn{10}{|c|}{ Metals (mg/kg dry weight) } \\
\hline & & $\overline{\mathrm{Ag}}$ & As & Cd & $\mathrm{Cr}$ & $\mathrm{Cu}$ & $\mathrm{Ha}$ & $\mathrm{Ni}$ & $\mathrm{Pb}$ & $\mathrm{Se}$ & $Z n$ \\
\hline $\begin{array}{l}\text { TC-5 Special Sample } \\
\text { TC-5 Special Ouplicate } \\
\text { RPD } \\
\text { I-Stat }\end{array}$ & $\begin{array}{l}\mathrm{C} \\
\mathrm{C}\end{array}$ & $\begin{array}{l}\text { NA } \\
\text { NA } \\
\text { NA } \\
\text { NA }\end{array}$ & $\begin{array}{l}\text { NA } \\
\text { NA } \\
\text { NA } \\
\text { NA }\end{array}$ & $\begin{array}{l}\text { NA } \\
\text { NA } \\
\text { NA } \\
\text { NA }\end{array}$ & $\begin{array}{l}\text { NA } \\
\text { NA } \\
\text { NA } \\
\text { NA }\end{array}$ & $\begin{array}{l}\text { NA } \\
\text { NA } \\
\text { NA } \\
\text { NA }\end{array}$ & $\begin{array}{l}1.431 \\
1.412 \\
1 \% \\
0.01\end{array}$ & $\begin{array}{l}\text { NA } \\
\text { HA } \\
\text { HA } \\
\text { HA }\end{array}$ & $\begin{array}{l}\text { NA } \\
\text { NA } \\
\text { NA } \\
\text { HA }\end{array}$ & $\begin{array}{l}\text { NA } \\
\text { NA } \\
\text { NA } \\
\text { NA }\end{array}$ & $\begin{array}{l}\text { NA } \\
\text { NA } \\
\text { NA } \\
\text { NA }\end{array}$ \\
\hline $\begin{array}{l}\text { TC-1 Lower } \\
\text { TC-1 Lower Duplícate } \\
\text { RPD } \\
\text { I-Stat }\end{array}$ & $\begin{array}{l}B \\
B\end{array}$ & $\begin{array}{l}\text { NA } \\
\text { NA } \\
\text { NA } \\
\text { NA }\end{array}$ & $\begin{array}{l}\text { HA } \\
\text { HA } \\
\text { HA } \\
\text { HA }\end{array}$ & $\begin{array}{l}\text { NA } \\
\text { NA } \\
\text { NA } \\
\text { NA }\end{array}$ & $\begin{array}{l}\text { NA } \\
\text { HA } \\
\text { NA } \\
\text { NA }\end{array}$ & $\begin{array}{l}\text { NA } \\
\text { NA } \\
\text { NA } \\
\text { NA }\end{array}$ & $\begin{array}{c}0.119 \\
0.120 \\
1 \% \\
0.00\end{array}$ & $\begin{array}{l}\text { NA } \\
\text { NA } \\
\text { NA } \\
\text { NA }\end{array}$ & $\begin{array}{l}\text { NA } \\
\text { NA } \\
\text { HA } \\
\text { HA }\end{array}$ & $\begin{array}{l}\text { NA } \\
\text { NA } \\
\text { NA } \\
\text { NA }\end{array}$ & $\begin{array}{l}\text { NA } \\
\text { NA } \\
\text { NA } \\
\text { NA }\end{array}$ \\
\hline $\begin{array}{l}\text { COMP VI } \\
\text { COMP VI Duplicate } \\
\text { RPD } \\
\text { I-Stat }\end{array}$ & A & $\begin{array}{l}\text { NA } \\
\text { NA } \\
\text { NA } \\
\text { NA }\end{array}$ & $\begin{array}{l}\text { NA } \\
\text { HA } \\
\text { NA } \\
\text { NA }\end{array}$ & $\begin{array}{l}\text { MA } \\
\text { NA } \\
\text { NA } \\
\text { MA }\end{array}$ & $\begin{array}{l}\text { NA } \\
\text { NA } \\
\text { NA } \\
\text { NA }\end{array}$ & $\begin{array}{l}\text { HA } \\
\text { HA } \\
\text { HA } \\
\text { NA }\end{array}$ & $\begin{array}{c}0.535 \\
0.544 \\
2 \% \\
0.01\end{array}$ & $\begin{array}{l}\text { NA } \\
\text { NA } \\
\text { NA } \\
\text { NA }\end{array}$ & $\begin{array}{l}\text { NA } \\
\text { NA } \\
\text { NA } \\
\text { NA }\end{array}$ & $\begin{array}{l}\text { NA } \\
\text { NA } \\
\text { NA } \\
\text { NA }\end{array}$ & $\begin{array}{l}\text { NA } \\
\text { NA } \\
\text { NA } \\
\text { NA }\end{array}$ \\
\hline Analytical Replicates & & & & & & & & & & & \\
\hline $\begin{array}{l}\text { TC-5 Upper Repl Icate } 1 \\
\text { TC-5 Upper Repl icate } 2 \\
\text { TC-5 Upper Replicate } 3 \\
\text { RSD }\end{array}$ & $\begin{array}{l}\mathrm{C} \\
\mathrm{C} \\
\mathrm{C}\end{array}$ & $\begin{array}{l}0.856 \\
0.880 \\
0.840 \\
2 \%\end{array}$ & $\begin{array}{r}19.50 \\
21.00 \\
19.40 \\
4 \%\end{array}$ & $\begin{array}{l}1.209 \\
0.835 \\
0.871 \\
\quad 21 \%(f)\end{array}$ & $\begin{array}{r}207.0 \\
194.0 \\
218.0 \\
6 \%\end{array}$ & $\begin{array}{l}81.1 \\
82.7 \\
80.4 \\
1 \%\end{array}$ & $\begin{array}{l}1.081 \\
1.110 \\
1.047 \\
3 \%\end{array}$ & $\begin{array}{l}108.9 \\
105.0 \\
110.7 \\
3 \%\end{array}$ & $\begin{array}{l}56.2 \\
53.8 \\
57.2 \\
3 \%\end{array}$ & $\begin{array}{l}0.83 \mathrm{U} \\
0.82 \mathrm{U} \\
0.85 \\
\text { HA }\end{array}$ & $\begin{array}{r}220.0 \\
214.0 \\
214.0 \\
2 \%\end{array}$ \\
\hline $\begin{array}{l}\text { R-AM Replicate } 1 \\
\text { R-AM Replicate } 2 \\
\text { R-AM Replicate } 3 \\
\text { RSD }\end{array}$ & $\begin{array}{l}8 \\
8 \\
8\end{array}$ & $\begin{array}{l}0.047 \\
0.021 \\
0.032 \\
394\end{array}$ & $\begin{array}{r}7.18 \\
7.23 \\
6.19 \\
97\end{array}$ & $\begin{array}{r}0.046 \\
0.053 \\
0.066 \\
18 \%\end{array}$ & $\begin{array}{r}251.0 \\
294.0 \\
307.0 \\
10 \%\end{array}$ & $\begin{array}{l}11.6 \\
10.6 \\
10.0 \\
8 \%\end{array}$ & $\begin{array}{l}0.041 \\
0.031 \\
0.019 \\
36 \%\end{array}$ & $\begin{array}{l}43.3 \\
46.4 \\
45.9 \\
4 \%\end{array}$ & $\begin{array}{r}16.6 \\
14.7 \\
16.2 \\
6 \%\end{array}$ & $\begin{array}{l}0.73 \mathrm{U} \\
0.74 \mathrm{U} \\
0.70 \mathrm{U} \\
\text { NA }\end{array}$ & $\begin{array}{r}36.0 \\
34.9 \\
34.3 \\
2 \%\end{array}$ \\
\hline $\begin{array}{l}\text { R-BF Replicate } 1 \\
\text { R-BF Replicate } 2 \\
\text { R-BF Replicate } 3 \\
\text { RSD }\end{array}$ & $\begin{array}{l}\hat{A} \\
\hat{A} \\
\hat{A}\end{array}$ & $\begin{array}{r}0.478 \\
0.462 \\
0.466 \\
2 \%\end{array}$ & $\begin{array}{r}8.70 \\
9.60 \\
8.80 \\
5 \%\end{array}$ & $\begin{array}{r}0.217 \\
0.202 \\
0.204 \\
4 \%\end{array}$ & $\begin{array}{r}218.0 \\
206.0 \\
261.0 \\
13 \%\end{array}$ & $\begin{array}{l}55.2 \\
55.8 \\
57.4 \\
2 \%\end{array}$ & $\begin{array}{l}0.571 \\
0.346 \\
0.365 \\
29 \%\end{array}$ & $\begin{array}{r}117.2 \\
112.1 \\
120.0 \\
3 \%\end{array}$ & $\begin{array}{r}36.1 \\
37.6 \\
35.4 \\
3 \%\end{array}$ & $\begin{array}{l}0.84 \mathrm{U} \\
0.80 \mathrm{U} \\
0.83 \mathrm{U} \\
\mathrm{NA}\end{array}$ & $\begin{array}{r}137.5 \\
139.2 \\
140.5 \\
1 \%\end{array}$ \\
\hline
\end{tabular}

(a) U The analyte was not present above the level of the associated value

(b) NM Not measured, no blank or duplicate data avallable; samples were analyzed by XRF.

(c) NA Not applicable.

(d) NS Not spiked.

(e) NC Not certified, but previous analysis has determined $0.1 \mathrm{mg} / \mathrm{kg}$ to be a good estimate.

(f) Value exceeds relative prectsion range of $20 \%$. 
IABLE C.16. Sediment Total Organic Carbon (TOC) and Total Volatile Solids (TVS) Results, Richmond Harbor Program

\begin{tabular}{|c|c|c|c|}
\hline $\begin{array}{l}\text { Sediment } \\
\text { Ireatment }\end{array}$ & $\begin{array}{c}\text { Analytical } \\
\text { Batch } \\
\end{array}$ & $\begin{array}{c}\text { TOC } \\
\text { (percent dry weight) }\end{array}$ & $\begin{array}{c}\text { TVS } \\
\text { (percent dry weight) }\end{array}$ \\
\hline $\begin{array}{l}\text { Target } \mathrm{DL}(\mathrm{a}) \\
\text { Achieved } \mathrm{DL}\end{array}$ & & $\begin{array}{l}0.1 \\
0.006\end{array}$ & 0.1 \\
\hline $\begin{array}{l}\text { COMP I } \\
\text { C-1 } \\
C-3 \\
C-5 \\
C-6 \\
C-8 \\
C-10\end{array}$ & $\begin{array}{l}\text { C } \\
A \\
A \\
A \\
A \\
A \\
B\end{array}$ & $\begin{array}{l}0.99 \\
0.80 \\
0.93 \\
1.01 \\
1.09 \\
1.18 \\
1.08\end{array}$ & $\begin{array}{l}6.10 \\
4.75 \\
5.52 \\
5.68 \\
6.12 \\
6.55 \\
5.90\end{array}$ \\
\hline $\begin{array}{l}\text { COMP II } \\
C-11 \\
C-16 \\
c-18 \\
c-19 \\
c-20 \\
c-23\end{array}$ & $\begin{array}{l}\text { A } \\
\text { B } \\
B \\
B \\
B \\
B \\
B\end{array}$ & $\begin{array}{l}0.73 \\
1.14 \\
0.59 \\
0.81 \\
0.28 \\
0.67 \\
0.74\end{array}$ & $\begin{array}{l}5.49 \\
6.46 \\
3.98 \\
4.73 \\
3.38 \\
4.66 \\
4.54\end{array}$ \\
\hline $\begin{array}{l}\text { COMP II I } \\
\text { TC-1 Upper } \\
\text { TC-2 Upper } \\
\text { TC-3 Upper } \\
\text { TC-4 Upper }\end{array}$ & $\begin{array}{l}B \\
B \\
B \\
C \\
B\end{array}$ & $\begin{array}{l}0.68 \\
0.79 \\
0.90 \\
0.59 \\
0.54\end{array}$ & $\begin{array}{l}3.65 \\
3.96 \\
5.19 \\
3.03 \\
2.87\end{array}$ \\
\hline $\begin{array}{l}\text { TC-5 Upper Comp } \\
\text { TC-5 Upper Replicate } 1 \\
\text { TC-5 Upper Replicate } 2 \\
\text { TC-5 Upper Replicate } 3 \\
\text { TC-5 Special Sample }\end{array}$ & $\begin{array}{l}A \\
C \\
C \\
C \\
C\end{array}$ & $\begin{array}{l}0.91 \\
0.93 \\
0.94 \\
0.96 \\
1.07\end{array}$ & $\begin{array}{l}5.00 \\
5.14 \\
5.09 \\
5.09 \\
5.65\end{array}$ \\
\hline $\begin{array}{ll}\text { COMP IV } \\
\text { TC-1 Lower } \\
\text { TC-1 Lower Duplicate } \\
\text { TC-2 Lower } \\
\text { TC-3 Lower } \\
\text { TC-3 Lower Duplicate } \\
\text { TC }-4 \text { Lower } \\
\text { TC }-5 \text { Lower }\end{array}$ & $\begin{array}{l}A \\
B \\
B \\
B \\
C \\
C \\
C \\
B\end{array}$ & $\begin{array}{l}0.39 \\
0.43 \\
0.42 \\
0.60 \\
0.26 \\
0.28 \\
0.25 \\
0.41\end{array}$ & $\begin{array}{l}3.32 \\
3.00 \\
\mathrm{NM}^{(\mathrm{b})} \\
3.45 \\
2.07 \\
\mathrm{NM} \\
2.22 \\
2.50\end{array}$ \\
\hline
\end{tabular}


TABLE C.16. (contd)

\begin{tabular}{|c|c|c|c|}
\hline $\begin{array}{l}\text { Sediment } \\
\text { Ireatment }\end{array}$ & $\begin{array}{l}\text { Analytical } \\
\text { Batch } \\
\end{array}$ & $\begin{array}{c}\text { TOC } \\
\text { (percent dry weight) }\end{array}$ & $\begin{array}{c}\text { TVS } \\
\text { (percent dry weight) }\end{array}$ \\
\hline $\begin{array}{l}\text { COMP V } \\
\text { C-24 } \\
C-26 \\
C-30 \\
C-30 \text { Dupl icate } \\
C-33 \\
C-35 \\
C-37\end{array}$ & $\begin{array}{l}\text { A } \\
\text { B } \\
B \\
C \\
C \\
C \\
A \\
\text { A }\end{array}$ & $\begin{array}{l}1.08 \\
0.79 \\
1.01 \\
1.06 \\
1.06 \\
0.92 \\
0.84 \\
0.60\end{array}$ & $\begin{array}{l}6.38 \\
4.96 \\
5.93 \\
6.26 \\
N M \\
6.06 \\
5.52 \\
4.77\end{array}$ \\
\hline $\begin{array}{l}\text { COMP VI } \\
\text { C-25 } \\
\text { C-29 } \\
\text { C-29 Dupl icate } \\
\text { C-32 } \\
C-32 \text { Dupl icate } \\
C-36 \\
C-38\end{array}$ & $\begin{array}{l}\text { A } \\
B \\
A \\
A \\
A \\
A \\
B \\
B\end{array}$ & $\begin{array}{l}1.03 \\
0.49 \\
0.57 \\
0.59 \\
0.60 \\
0.60 \\
0.89 \\
0.59\end{array}$ & $\begin{array}{r}6.52 \\
4.06 \\
4.61 \\
\text { NM } \\
4.74 \\
\text { NM } \\
5.62 \\
4.65\end{array}$ \\
\hline $\begin{array}{l}\text { TC-6 }(1)^{(c)} \\
\text { TC-6 (2) } \\
\text { TC-6 (3) } \\
\text { TC-6 (4) }\end{array}$ & $\begin{array}{l}C \\
C \\
C \\
C\end{array}$ & $\begin{array}{l}0.79 \\
0.71 \\
0.15 \\
0.56\end{array}$ & $\begin{array}{l}4.48 \\
3.56 \\
1.53 \\
3.50\end{array}$ \\
\hline $\begin{array}{l}\text { TC-7 (1) } \\
\text { TC-7 (c) } \\
\text { TC-7 (2) } \\
\text { TC-7 (4) }\end{array}$ & $\begin{array}{l}c \\
c \\
c \\
c\end{array}$ & $\begin{array}{l}0.81 \\
0.72 \\
0.23 \\
0.54\end{array}$ & $\begin{array}{l}3.63 \\
3.62 \\
1.68 \\
3.33\end{array}$ \\
\hline $\begin{array}{l}\text { R-AC } \\
\text { R-AM Replicate } 1 \\
\text { R-AM Replicate } 2 \\
\text { R-AM Replicate } 3 \\
\text { R-BF Replicate } 1 \\
\text { R-BF Replicate } 2 \\
\text { R-BF Replicate } 3 \\
\text { R-OS } \\
\text { R-OS Duplicate } \\
\text { R-PF }\end{array}$ & $\begin{array}{l}A \\
B \\
B \\
B \\
A \\
A \\
A \\
A \\
A \\
A\end{array}$ & $\begin{array}{l}0.38 \\
0.06 \\
0.06 \\
0.06 \\
1.00 \\
1.04 \\
0.96 \\
1.39 \\
1.49 \\
0.41\end{array}$ & $\begin{array}{l}2.95 \\
0.98 \\
1.02 \\
0.98 \\
6.28 \\
6.09 \\
5.86 \\
5.74 \\
\text { NM } \\
2.08\end{array}$ \\
\hline
\end{tabular}


IABLE C.16. (contd)

Sediment

Ireatment

\section{C-SB}

$C-W B$

C-WB Duplicate

C-NE
Analytical

Batch

A

A

A

A
TOC

(percent dry weight) (percent dry weight)

2.15

0.06

0.06

0.06
7.81

0.69

$\mathrm{NM}$

0.87

(a) DL Detection limit.

(b) NM Not measured; duplicate analys is performed by ARI for TOC only; TVS was analyzed by the MSL.

(c) TC-6 and TC-7 were split into four separate core sections which were composited, subsampled for chemistry, and used for geologic descriptions. 
IABLE C.17. Quality Control Data Total Organic Carbons (TOC) and Total Volatile Solids (TVS) AnaTyses, Richmond Harbor Program

Sediment

Treatment

Method Blanks

Blank 1

Blank 2

Blank 3
Analytical Batch
TOC

(percent dry weight) (percent dry weight)

Standard Reference Materials

Estimated value

MESS-1 Replicate 1

MESS-1 Replicate 2

MESS-1 Replicate 3
A $\quad 0.007$

B $\quad 0.006$

C $\quad 0.009$
0.0013

0.0014

$\mathrm{NM}^{(\mathrm{a})}$

Analytical Duplicates

$\begin{array}{llll}\text { TC-1 Lower } & \text { B } & 0.43 & \text { NM } \\ \text { TC-1 Lower Duplicate } & \text { B } & 0.42 & \text { NM } \\ \text { RPD } & & 2 \% & \text { NM } \\ \text { I-Stat } & & 0.01 & \text { NM } \\ \text { TC-3 Lower } & C & 0.26 & \text { NM } \\ \text { TC-3 Lower Duplicate } & \text { C } & 0.28 & \text { NM } \\ \text { RPD } & & 7 \% & \text { NM } \\ \text { I-Stat } & & 0.04 & \text { NM } \\ & & & \text { NM } \\ \text { C-30 } & C & 1.06 & \text { NM } \\ \text { C-30 Duplicate } & \text { C } & 1.06 & \text { NM } \\ \text { RPD } & & 0 \% & \text { NM } \\ \text { I-Stat } & & 0.00 & \text { NM } \\ \text { C-29 } & & 0.57 & \text { NM } \\ \text { C-29 Duplicate } & \text { A } & 0.59 & \text { NM } \\ \text { RPD } & \text { A } & 3 \% & \text { NM } \\ \text { I-Stat } & & 0.02 & \text { NM } \\ \text { C-32 } & & 0.60 & \text { NM } \\ \text { C-32 Duplicate } & \text { A } & 0.60 & \text { NM } \\ \text { RPD } & \text { A } & 0.00 & \text { NM } \\ \text { I-Stat } & & & \text { NM } \\ \text { R-0S } & & 1.39 & \text { NM } \\ \text { R-0S Duplicate } & \text { A } & 1.49 & \text { NM } \\ \text { RPD } & & 0.03 & \end{array}$


TABLE C.17. (contd)

\begin{tabular}{|c|c|c|c|}
\hline $\begin{array}{l}\text { Sediment } \\
\text { Treatment }\end{array}$ & $\begin{array}{l}\text { Analytical } \\
\quad \text { Batch } \\
\end{array}$ & $\begin{array}{c}\text { TOC } \\
\text { (percent dry weight) }\end{array}$ & $\begin{array}{c}\text { TVS } \\
\text { (percent dry weight) }\end{array}$ \\
\hline $\begin{array}{l}\text { C-WB } \\
\text { C-WB Duplicate } \\
\text { RPD } \\
\text { I-Stat }\end{array}$ & $\begin{array}{l}A \\
A\end{array}$ & $\begin{array}{l}0.06 \\
0.06 \\
0 \% \\
0.00\end{array}$ & $\begin{array}{l}\text { NM } \\
\text { NM } \\
\text { NM } \\
\text { NM }\end{array}$ \\
\hline
\end{tabular}

Analytical Replicates

$\begin{array}{lccc}\text { TC-5 Upper Replicate 1 } & \text { C } & 0.93 & 5.14 \\ \text { TC-5 Upper Replicate 2 } & \text { C } & 0.94 & 5.09 \\ \text { TC-5 Upper Replicate 3 } & \text { C } & 0.98 & 5.09 \\ \text { RSD } & & 3 \% & 1 \% \\ \text { R-AM Replicate 1 } & 8 & 0.06 & 0.98 \\ \text { R-AM RepIicate 2 } & 8 & 0.06 & 1.02 \\ \text { R-AM Replicate 3 } & \text { B } & 0.06 & 0.98 \\ \text { RSD } & & 0 \% & 2 \% \\ \text { R-BF Replicate 1 } & \text { A } & 1.00 & 6.28 \\ \text { R-BF Replicate 2 } & \text { A } & 1.04 & 6.09 \\ \text { R-BF Replicate 3 } & \text { A } & 0.96 & 5.86 \\ \text { RSD } & & 4 \% & 3 \%\end{array}$

\footnotetext{
(a) NM Not measured; TVS analyzed in two batches.

(b) MESS-1 is not certified for TOC, but frequent analyses at MSL indicate an est imated value of $2.3 \%$.

(c) NC Not certified.

(d) NA Not applicable.
} 


\section{TABLE C.18. Sediment $0 i 1$ and Grease and Total Petroleum Hydrocarbons (TPHs) Results, Richmond Harbor Program}

Sediment

Treatment

Target $\mathrm{OL}^{(\mathrm{a})}$

Achieved DL Low

Achieved OL High

COMP I

$\mathrm{C}-1$

$\mathrm{C}-3$

$\mathrm{C}-5$

C-6

C-8

$C-10$

COMP II

C-11

$c-16$

C-18

C -19

$\mathrm{C}-20$

$\mathrm{C}-23$

COMP III

TC-1 Upper

TC-2 Upper

TC-3 Upper

IC-4 Upper

TC-5 Upper Comp

TC-5 Upper Replicate 1

TC-5 Upper Replicate 2

TC-5 Upper Replicate 3

TC-5 Special Sample

COMP IV

TC-1 Lower

TC-2 Lower

TC-3 Lower

TC-4 Lower

TC-5 Lower

COMP $V$

$\mathrm{C}-24$

$\mathrm{C}-26$

C -30

$\mathrm{C}-33$

$\mathrm{C}-35$

$\mathrm{C}-37$

COMP VI

$\mathrm{C}-25$

$\mathrm{C}-29$

$\mathrm{C}-32$

C -36

$\mathrm{C}-38$

TC-6 (1) (b)

TC-6 (2)

TC-6 (3)

TC -6 (4)
Anal ytica] Batch

$0 i l$ and 6rease
(mg/kg dry weight)

20.00

0.5

1.29

63.22

91.26

89.17

144.92

108.89

132.45

151.75

118.30

99.86

93.04

124.58

42.91

103.58

68.91

44.06

90.29

132.78

37.83

73.52

311.19

297.24

230.74

418.34

18.83

19.06

9.80

24.30

13.03

14.14

24.65

186.23

76.55

138.15

218.95

100.39

151.47

263.31

252.06

76.69

91.93

167.80

223.76

118.09

37.60

27.74

5.64

15.57

TPHs
$\frac{(\mathrm{mg} / \mathrm{kg} \text { dry weight) }}{20.00}$
0.5
1.29

41.39

68.41

65.03

92.66

88.21

104.76

115.92

91.00

76.06

74.71

95.91

27.30

78.82

46.08

26.74

34.60

79.16

19.54

16.77

281.16

256.11

189.60

350.10

10.99

10.50

5.67

13.27

8.58

8. 10

7.79

141.25

54.99

107.13

174.70

83.05

119.79

150.44

185.70

63.25

72.97

140.78

180.06

101.70

25.13

14.43

2.63

9.01
Petroleum Fraction ( $x$ ) 
IABLE C.18. (contd)

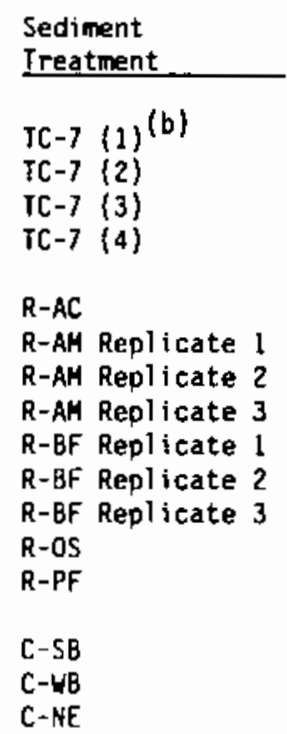

Sediment

IC-7 (1) (b)

IC-7 (2)

IC -7 (3)

C-NE

\section{Anajytical Batch}

$\mathrm{C}$
$\mathrm{C}$
$\mathrm{C}$
$\mathrm{C}$

A

8

8

A

A

A

A

$\begin{array}{lr}\text { A } & 172.93 \\ \text { A } & 30.75 \\ \text { A } & 13.5 B\end{array}$

59.07

12.97

11.92

9.99

73.70

101.51

134.35

39.26

37.61
TPHs
$(\mathrm{mo} / \mathrm{kg}$ dry weight)

Petrol eum (ma/ko dry weight)

24.48

20.42

5.68

15.21

27.81

6.79

6.77

5.77

50.64

73.76

126.51

17.09

3.72

47.89

6.96

4.90
Fraction (q)

89
33
87
90

47
52
57
58
69
73
94
44
10

28
23
36

87

47

52

58

69

73

94

10

$2 \mathrm{~B}$

36

(a) DL Detection $1 \mathrm{imit}$.

(b) Stations TC-6 and TC-7 were split into four separate core sections which were composited, subsampled for chemistry. and used for geologic descriptions. 
TABLE_.19. Quality Control Data for Sediment $0 i 1$ and Grease and Total Petroleum Hydrocarbons (TPHs) Analyses, Richmond Harbor Program

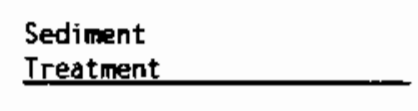

Method Blanks

Blank 1

Blank 2

Blank 3

\section{Blank Spikes}

\section{Biank}

Biank MS

Concentration Recovered Anount Spiked

Percent Recovery

Blank

Blank MS

Concentration Recovered

Anount Spiked

Percent Recovery

Blank

Blank MS

Concentration Recovered

Arrount Spiked

Percent Recovery
$0 i t$ and Grease
$(\mathrm{mg} / \mathrm{kg}$ dry weicht)

7.14

6.57

3.31

Total Petroleum

Hydrocarbons

(mq/kg dry weight)

Petroleum Fraction (z)

Matrix Spikes

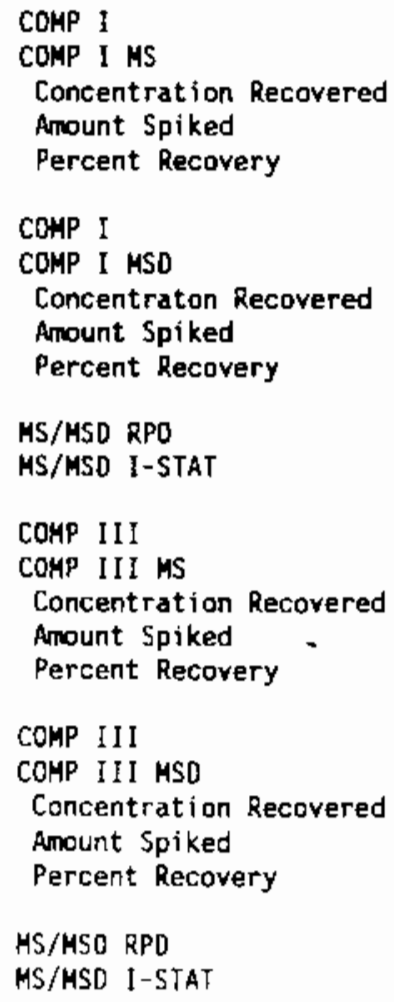

A

A

$\begin{array}{cc} & 24.65 \\ & 24.00 \\ & 103 \% \\ 8 & \\ 8 & 0.00 \mathrm{U} \\ & 27.72 \\ & 27.72 \\ & 26.00 \\ & 107 \% \\ \mathrm{C} & \\ \mathrm{C} & 0.00 \mathrm{U} \\ & 35.94 \\ & 35.94 \\ & 23.90 \\ & 150 \mathrm{x}\end{array}$

B

$B$

B

8

$B$

$\begin{array}{cc} & 59.60 \\ & 787 \\ \text { B } & \\ & 44.06 \\ & 71.67 \\ & 27.61 \\ & 51.40 \\ & 54 \% \\ & 377^{(\mathrm{e})} \\ & 0.19\end{array}$

63.22

162.47

99.25

75.70

$131 \%$

63.22

144.02

80.80

77.80

$104 \%$

$23 x^{(e)}$

0.12

44.06

44.06

$\begin{array}{lr}\text { NM }^{(a)} & 0 \\ 5.34 & 81 \\ 0.47 & 14\end{array}$

$\begin{array}{cl}0.00 \mathrm{U} & 0 \\ 21.31 & 86 \\ 21.31 & \mathrm{NA} \\ 24.00 & \mathrm{NA} \\ 89 \% & \mathrm{NA}\end{array}$

$0.00 \mathrm{U}$

$23.62 \quad 85$

23.62 NA

$26.00 \quad$ NA

$\begin{array}{lr}0.00 \mathrm{U} & 0 \\ 36.79 & 102 \\ 36.79 & \text { NA } \\ 23.90 & \text { NA } \\ 154 \mathrm{X}^{(\mathrm{d})} & \text { NA }\end{array}$

41.39

138.05

96.66

75.70

$128 \%$

41.39

125.89

84.50

77.80

$109 \%$

65

85

NA

NA

NA

65

B7

NA

NA

NA

$16 \%$ NA

NA

26.74

73.35

46.61

59.60

$78 \%$

26.74

56.49

29.75

51.40

$58 \%$

$0^{30 x^{(e)}}$

0

4




\section{TABLE C.19. (contd)}

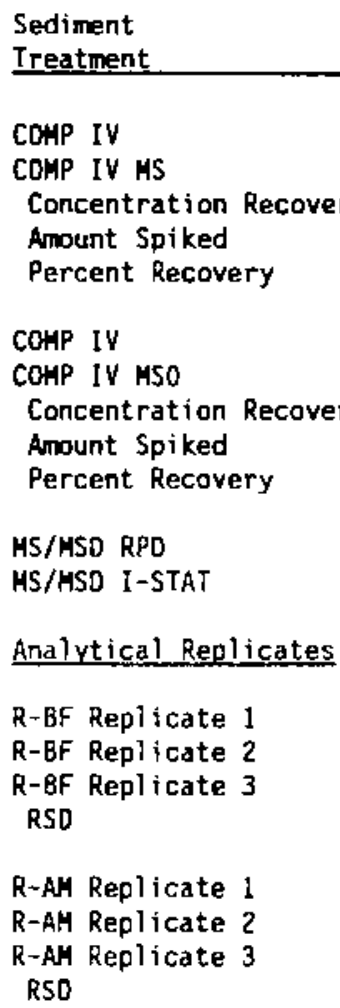

TC-5 Upper Replicate 1 TC-5 Upper Replicate 2 TC-5 Upper Replicate 3 RSD
Analytical

Oil and Grease
Total Petroleum
Hydrocarbons (ma/kg dry weight)

Petroleum

Batch

(mo/kg dry weight)

A

19.06

39.18

20.12

64.60

$$
31 x(d)
$$

10.50

32.07

21.57

64.60

$33 x^{(d)}$

Fraction ( $x$ )

A

19.06
61.75
42.69
55.40
$77 x$
$85 x^{(e)}$
0.42

10.50

50.27

39.77

55.40

$72 x$

55

82

NA

NA

NA

55

81

NA

NA

NA

NA

NA

$\begin{array}{ll}73 x^{(e)} & \text { NA } \\ 0.37 & \text { NA }\end{array}$

50.64

73.76

101.51

134.35

$29 x^{(e)}$

126.51 $46 x^{(e)}$

69

A
12.97
11.92
9.99
$13 x$

6.79

6.77

5.77

$9 x$

73

94

8
8
$B$

297.24

230.74

418.34

$30 x(e)$

256.11

189.60

350.10

$30 x(e)$

52
57
58
$5 x$

86

82

c

\section{$30 x$}

(a) NH Hot measured; septa put on colum upside dom, no blank information available.

(b) U The analyte was not present above the level of the associated value.

(c) NA Not applicable.

(d) Recovery outside quality control range (50x-150x).

(e) Value exceeds relative precision range of $20 \%$. 
TABLE C.20. Sediment Butyltin Results, Richmond Harbor Program

\begin{tabular}{|c|c|c|c|c|c|c|}
\hline \multirow[b]{2}{*}{$\begin{array}{l}\text { Sediment } \\
\text { Treatment }\end{array}$} & \multirow[b]{2}{*}{$\begin{array}{l}\text { Analytical } \\
\text { Batch } \\
\end{array}$} & \multirow{2}{*}{$\begin{array}{l}\text { Tripentyltin } \\
\text { Surragate } \\
\text { Recovery }(y) \\
\end{array}$} & \multicolumn{4}{|c|}{ Butyltin Species $(\mu \mathrm{g} / \mathrm{kg}$ dry weight) } \\
\hline & & & $\begin{array}{l}\text { Tetra- } \\
\text { butyltin }\end{array}$ & $\begin{array}{c}\text { Tri- } \\
\text { butyltin }\end{array}$ & $\begin{array}{c}\text { Di- } \\
\text { butyltin }\end{array}$ & $\begin{array}{c}\text { Mono- } \\
\text { butylitin } \\
\end{array}$ \\
\hline $\begin{array}{l}\text { Farget } O{ }^{(a)} \\
\text { Achieved OL }\end{array}$ & & & $\begin{array}{r}10.0 \\
2.4\end{array}$ & $\begin{array}{r}10.0 \\
2.5\end{array}$ & $\begin{array}{r}10.0 \\
2.4\end{array}$ & $\begin{array}{r}10.0 \\
5.1\end{array}$ \\
\hline COMP I & D & 97.43 & $1.2 J^{(b)}$ & 3.1 & 3.3 & $5.1 u^{(c)}$ \\
\hline$c-1$ & A & 78.14 & $2.4 \mathrm{U}$ & $0.8 \mathrm{~J}$ & $0.8 \mathrm{~J}$ & 5.10 \\
\hline$\varepsilon-3$ & A & 84.84 & $2.4 \mathrm{U}$ & $1.4 \mathrm{~J}$ & $1.2 \mathrm{~J}$ & S.IU \\
\hline$\varepsilon-5$ & A & 78.14 & $2.4 \mathrm{U}$ & 2.6 & $2.1 \mathrm{~J}$ & $5.1 \mathrm{u}$ \\
\hline C-6 & A & 79.04 &. $.4 \mathrm{U}$ & $1.5 \mathrm{~J}$ & $1.3 \mathrm{~J}$ & $5.1 \mathrm{U}$ \\
\hline$c-8$ & A & 79.47 & $2.4 \mathrm{U}$ & $1.3 \mathrm{~J}$ & $1.7 \mathrm{~J}$ & $5.1 \mathrm{U}$ \\
\hline$c-10$ & 8 & 82.12 & $2.4 \mathrm{U}$ & $2.5 \mathrm{U}$ & $2.4 \mathrm{U}$ & $5.1 \mathrm{U}$ \\
\hline COMP II & A & 66.68 & $2.4 \mathrm{~V}$ & $1.0 \mathrm{~J}$ & $1.6 \mathrm{~J}$ & $5.1 \mathrm{U}$ \\
\hline$c-11$ & B & 93.41 & $2.4 \mathrm{U}$ & $1.5 \mathrm{~J}$ & $2.4 \mathrm{U}$ & 5.10 \\
\hline$c-16$ & $B$ & 73.04 & $2.4 \mathrm{U}$ & 23.5 & 7.8 & $5.1 \cup$ \\
\hline$c-18$ & B & 83.48 & $2.4 \mathrm{U}$ & $0.9 \mathrm{~J}$ & $2.4 \mathrm{U}$ & $5.1 \cup$ \\
\hline$c-19$ & B & $134.27^{(d)}$. & $2.4 \mathrm{U}$ & $0.8 \mathrm{~J}$ & $1.2 \mathrm{~J}$ & $5.1 \mathrm{U}$ \\
\hline$c-20$ & B & 86.98 & $2.4 \mathrm{U}$ & 4.1 & 2.8 & $5.1 \mathrm{u}$ \\
\hline$C-23$ & 8 & 66.67 & $2.4 \mathrm{U}$ & $0.7 \mathrm{~J}$ & $0.5 \mathrm{~J}$ & $5.1 \cup$ \\
\hline COMP III & 0 & 79.17 & $0.4 \mathrm{~J}$ & $1.6 \mathrm{~J}$ & $1.3 \mathrm{~J}$ & $5.1 \mathrm{U}$ \\
\hline TC-1 Upper & 8 & 70.96 & $2.4 \mathrm{U}$ & $0.5 \mathrm{~J}$ & $2.4 \mathrm{U}$ & $5.1 \mathrm{U}$ \\
\hline TC- 2 Upper & 8 & 73.62 & $2.4 \mathrm{U}$ & $2.5 \mathrm{U}$ & $2.6 \mathrm{U}$ & $5.1 u$ \\
\hline TC-3 Upper & c & 78.40 & $2.4 \mathrm{U}$ & $2.5 \mathrm{U}$ & $0.4 \mathrm{~J}$ & $5.1 \mathrm{U}$ \\
\hline TC-4 Upper & $B$ & 69.40 & $2.4 \mathrm{U}$ & $0.3 \mathrm{~J}$ & $2.4 \mathrm{U}$ & 5.10 \\
\hline TC-5 Upper Comp & $\mathrm{E}$ & 87.25 & $2.0 \mathrm{U}$ & 2.3 & $1.9 \mathrm{~J}$ & $4.2 \mathrm{U}$ \\
\hline TC-5 Upper Replicate 1 & 0 & 91.54 & $2.4 \mathrm{U}$ & $2.5 \mathrm{U}$ & 9.3 & $5.1 \mathrm{U}$ \\
\hline TC-5 Upper Replicate 2 & D & 91.65 & $2.4 \mathrm{U}$ & $2.5 \mathrm{U}$ & 3.7 & 5.10 \\
\hline TE-5 Upper Repíicat 3 & D & 75.52 & $2.4 \mathrm{~J}$ & $2.5 \mathrm{U}$ & 11.4 & $4.0 \mathrm{~J}$ \\
\hline TC-5 Special sample $e^{(e)}$ & $\mathrm{E}$ & 58.72 & $2.4 \mathrm{~J}$ & $2.5 \mathrm{U}$ & $2.4 \mathrm{U}$ & 19.0 \\
\hline COMP IV & D & 88.44 & $0.4 \mathrm{~J}$ & $0.4 \mathrm{~J}$ & $1.6 \mathrm{~J}$ & $5.1 \mathrm{~J}$ \\
\hline IC-1 Lower & B & 68.41 & $2.4 \mathrm{U}$ & $2.5 \mathrm{U}$ & $0.3 \mathrm{~J}$ & $5.1 \mathrm{U}$ \\
\hline TC-2 Lower & 8 & 65.01 & $2.4 \mathrm{U}$ & $2.5 \mathrm{U}$ & $2.4 \mathrm{U}$ & $5.1 \mathrm{U}$ \\
\hline TC-3 Lower & c & 85.01 & $2.4 \mathrm{U}$ & $2.5 \mathrm{U}$ & $2.4 \mathrm{U}$ & $5.1 \mathrm{U}$ \\
\hline TC-4 Lower & c & 74.79 & $2.4 \mathrm{U}$ & $2.5 \mathrm{U}$ & $0.3 \mathrm{~J}$ & 5.10 \\
\hline TC-5 Lower & B & 63.31 & $2.4 \mathrm{U}$ & $2.5 \mathrm{U}$ & $2.4 \mathrm{~V}$ & $5.1 \mathrm{U}$ \\
\hline COMP V & A & 74.51 & $2.4 \mathrm{U}$ & 3.4 & 3.6 & $5.1 \mathrm{U}$ \\
\hline$c-24$ & $B$ & 67.03 & $2.4 \mathrm{U}$ & $1.3 \mathrm{~J}$ & $0.9 \mathrm{~J}$ & $5.1 \mathrm{U}$ \\
\hline$C-26$ & $B$ & 74.40 & $2.4 \mathrm{U}$ & $2.5 \mathrm{U}$ & $2.4 \mathrm{U}$ & $5.1 \mathrm{U}$ \\
\hline$c-30$ & C & 102.40 & $2.4 \mathrm{U}$ & $2.4 \mathrm{~J}$ & 3.6 & $5.1 \mathrm{U}$ \\
\hline$c-33$ & c & 89.50 & $2.4 \mathrm{U}$ & $2.5 \mathrm{~J}$ & 3.5 & $5.1 \mathrm{U}$ \\
\hline$c-35$ & A & 79.32 & $2.4 \mathrm{U}$ & 3.2 & 3.2 & $5.1 \mathrm{U}$ \\
\hline$C-37$ & A & 99.98 & $2.4 \mathrm{U}$ & 3.9 & $2.4 U$ & $5.1 \mathrm{U}$ \\
\hline COMP VI & A & 75.77 & $2.4 \mathrm{U}$ & 4.7 & $2.4 \mathrm{U}$ & $5.1 \mathrm{U}$ \\
\hline$c-25$ & B & 74.61 & $2.4 \mathrm{U}$ & $2.5 \mathrm{U}$ & $2.4 \mathrm{U}$ & $5.1 \mathrm{U}$ \\
\hline$c-29$ & $B$ & 63.67 & $2.4 \mathrm{U}$ & $2.5 \mathrm{U}$ & $2.4 \mathrm{U}$ & $5.1 \mathrm{U}$ \\
\hline$c-32$ & A & 94.12 & $2.4 \mathrm{U}$ & $1.6 \mathrm{~J}$ & 2.4 & $5.1 \mathrm{U}$ \\
\hline$c-36$ & $B$ & 72.50 & $2.4 \mathrm{U}$ & $2.5 \mathrm{U}$ & $2.4 U$ & 5.14 \\
\hline$c-38$ & 8 & 69.47 & $0.3 \mathrm{~J}$ & $1.6 \mathrm{~J}$ & 2.7 & $5.1 \mathrm{U}$ \\
\hline $\operatorname{TC}-6(1)^{(f)}$ & C & 70.85 & $2.4 U$ & $0.6 \mathrm{~J}$ & $1.2 \mathrm{~J}$ & $5.1 \mathrm{U}$ \\
\hline TC-6 (2) & $\mathrm{C}$ & 74.26 & $2.4 \mathrm{U}$ & $2.5 \mathrm{U}$ & $2.4 \mathrm{U}$ & $5.1 \mathrm{U}$ \\
\hline$T C-6(3)$ & C & 53.38 & $2.4 \mathrm{U}$ & $2.5 \mathrm{U}$ & $2.4 U$ & $5.1 \mathrm{U}$ \\
\hline$T C-6(4)$ & $c$ & 82.91 & $2.4 \mathrm{~V}$ & $2.5 \mathrm{U}$ & $2.4 U$ & $5.1 \mathrm{U}$ \\
\hline
\end{tabular}




\section{IABLE C.20. (contd)}

Sediment
Treatment
TC-7 (1) (f)
TC-7 (2)
TC-7 (3)
TC-7 (4)
R-AC
R-AM Replicate 1
R-AM Replicate 2
R-AM Replicate 3
R-BF Repiicate 1
R-8F Replicate 2
R-BF Replicate 3
R-OS
R-PF
C-SB
C-WB
C-NE

Analytical
Batch

Tripentyitin

Surrogate

Recovery (X)

C
C
C
C

93.95

83.80

79.93

79.14

87.27

56.93

71.09

66.38

70.65

71.92

69.45

70.23

63.68

87.08

59.98

63.68
Butyltin Species ( $\mu \mathrm{g} / \mathrm{kg}$ dry weight)

\begin{tabular}{cccc}
\hline Tetra- & Tri- & Di- & Mono- \\
butyltin & butyltin & butyltin & butyltin
\end{tabular}

$2.4 \mathrm{U}$

$2.4 \mathrm{U}$

$2.5 \mathrm{U}$

$2.5 \mathrm{U}$

$2.4 \mathrm{U}$

$2.4 \mathrm{U}$

$0.3 \mathrm{~J}$

$2.4 \mathrm{U}$

$5.1 \mathrm{~V}$

$5.1 \mathrm{U}$

$5.1 \mathrm{U}$

$2.4 \mathrm{U}$

2. $5 \mathrm{U}$

$5.1 \mathrm{U}$

$0.7 \mathrm{~J}$

$0.3 \mathrm{~J}$

16.2

$2.5 \mathrm{U}$

$2.5 \mathrm{U}$

$2.5 \mathrm{U}$

$2.4 \mathrm{U}$

$2.4 \mathrm{~V}$

$2.4 \mathrm{U}$

$1.9 \mathrm{~J}$

$1.9 \mathrm{~J}$

$1.9 \mathrm{~J}$

$2.5 \mathrm{U}$

$2.4 \mathrm{U}$

$2.4 \mathrm{~V}$

$2.5 \mathrm{~V}$

5.4

$0.7 \mathrm{~J}$

5.16

$2.4 \mathrm{U}$

$2.4 \mathrm{U}$

$5.1 \mathrm{U}$

$5.1 \mathrm{U}$

$5.1 \mathrm{U}$

$1.3 \mathrm{~J}$

$5.1 \mathrm{U}$

$1.6 \mathrm{~J}$

$1.6 \mathrm{~J}$

$0.5 \mathrm{~J}$

$5.1 \mathrm{U}$

$5.1 \mathrm{U}$

$5.1 \mathrm{U}$

$2.4 \mathrm{U}$

$5.1 \mathrm{U}$

$2.1 \mathrm{U}$
$2.4 \mathrm{U}$
$2.4 \mathrm{U}$

2.2
$2.5 \mathrm{U}$
$2.5 \mathrm{U}$

2.8

$2.4 \mathrm{~V}$

$4.4 \mathrm{U}$

$2.4 \mathrm{U}$

$0.2 \mathrm{~J}$

$5.1 \mathrm{U}$

$5.1 \mathrm{U}$

(a) DL Detection limit.

(b) J Analyte detected below method detection limit (MOL) but above instrument detection limit (IDL).

(c) If The analyte was not present above the level of the associated value.

(d) Recovery outside quality control range (40x-120x).

(e) Sample had interference in the chromatogram; the internal standard was altered to give approximate numbers for this sample.

(f) Stations IC- 6 and TC-7 were split into four separate core sections which were composited. subsampled for chemistry. and used for geologic descriptions.

(g) Replicate 1 broke during extraction as noted by analyst. sample was then re-extracted and rerun with Batch $D$. 


\section{TABLE C.21. Quality Control Data for Sediment Butyltin Analysis, Richmond Harbor Program}

Sediment

Treatment

Method Blanks

Blank 1

Blank 2

Blank 3

Blank 4

Blank 5

Matrix Soikes

\begin{tabular}{|c|c|c|c|c|c|}
\hline \multirow[b]{2}{*}{$\begin{array}{l}\text { Analytical } \\
\text { Batch }\end{array}$} & \multirow{2}{*}{$\begin{array}{l}\text { Tripentyltin } \\
\text { Surrogate } \\
\text { Recovery }(x)\end{array}$} & \multicolumn{4}{|c|}{ Butyltin Species ( $\mu / \mathrm{kg}$ dry weight) } \\
\hline & & $\begin{array}{l}\text { Tetra- } \\
\text { butyitin }\end{array}$ & $\begin{array}{c}\text { Tri- } \\
\text { butyltin }\end{array}$ & $\begin{array}{c}0 i- \\
\text { butyltin }\end{array}$ & $\begin{array}{c}\text { Mono- } \\
\text { butyltin }\end{array}$ \\
\hline
\end{tabular}

$2.4 \mathrm{U}^{(\mathrm{a})}$
$2.4 \mathrm{U}$
$2.4 \mathrm{U}$
$2.4 \mathrm{U}$
$2.1 \mathrm{U}$

$2.5 \mathrm{U}$

$2.5 \mathrm{U}$

$2.5 \mathrm{U}$

$2.5 \mathrm{U}$

$2.1 \mathrm{U}$
$2.4 \mathrm{U}$
$2.4 \mathrm{U}$
$2.4 \mathrm{U}$
$3.4 \mathrm{U}$
$2.1 \mathrm{U}$

$5.1 \mathrm{U}$

$5.1 \mathrm{U}$

$5.1 \mathrm{U}$

$5.1 \mathrm{U}$

$4.4 \mathrm{U}$

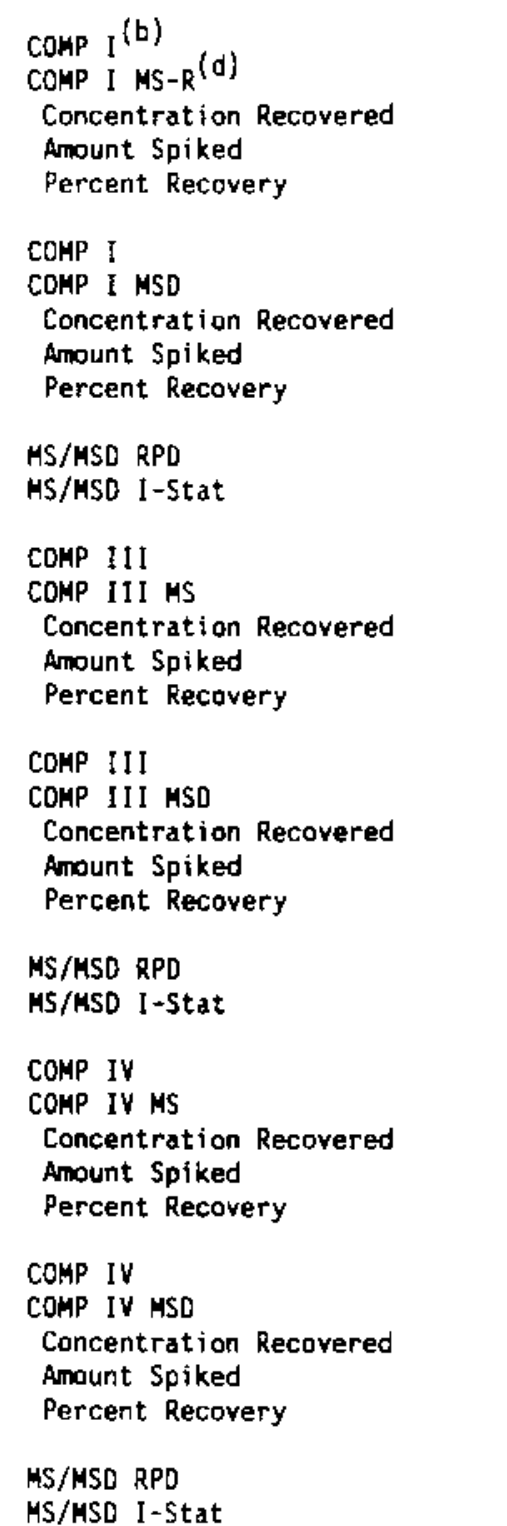

\begin{tabular}{|c|c|c|c|c|c|}
\hline \multirow{5}{*}{$\begin{array}{l}D \\
D\end{array}$} & 97.43 & $1.2 \mathrm{~J}^{(\mathrm{c})}$ & 3.1 & 3.3 & $5.1 \mathrm{U}$ \\
\hline & 86.41 & 94.9 & 140.9 & 165 & 57.3 \\
\hline & ${ }_{N A}(e)$ & 93.7 & 137.8 & 161.7 & 57.3 \\
\hline & $\mathrm{NS}^{(t)}$ & 203.2 & 203.3 & 203.3 & 203.2 \\
\hline & NA & $46 x$ & $68 \%$ & $80 \%$ & $287^{(9)}$ \\
\hline \multirow{7}{*}{$\begin{array}{l}D \\
D\end{array}$} & 97.43 & $1.2 \mathrm{~J}$ & 3.1 & 3.3 & $5.1 \mathrm{U}$ \\
\hline & 146.71 & 98.1 & 186.6 & 245.1 & 82.2 \\
\hline & NA & 96.9 & 183.5 & 241.8 & 82.2 \\
\hline & NS & 200.8 & 200.8 & 200.8 & 200.8 \\
\hline & NA & $48 \%$ & $91 \%$ & $120 \%$ & $41 \%$ \\
\hline & NA & $5 x$ & $30 \%$ & $41 z^{(h)}$ & $37 \%^{(h)}$ \\
\hline & NA & 0.02 & 0.15 & 0.20 & 0.18 \\
\hline \multirow{5}{*}{$\begin{array}{l}D \\
D\end{array}$} & 79.17 & $0.4 \mathrm{~J}$ & $1.6 \mathrm{~J}$ & $1.3 \mathrm{~J}$ & $5.1 \mathrm{U}$ \\
\hline & 85.19 & 60.5 & 105.7 & 145.7 & 60.2 \\
\hline & NA & 60.1 & 104.1 & 144.4 & 60.2 \\
\hline & NS & 172.1 & 172.1 & 172.1 & 172.1 \\
\hline & NA & $35 x^{(g)}$ & $60 \%$ & $84 x$ & $35 \%(g)$ \\
\hline \multirow{7}{*}{$\begin{array}{l}0 \\
0\end{array}$} & 79.17 & $0.4 \mathrm{~J}$ & $1.6 \mathrm{~J}$ & $1.3 \mathrm{~J}$ & $5.1 \mathrm{U}$ \\
\hline & 75.06 & 70.0 & 101.0 & 120.0 & 42.5 \\
\hline & NA & 69.6 & 99.4 & 118.7 & 42.5 \\
\hline & NS & 164.2 & 164.2 & 164.2 & 164.2 \\
\hline & NA & $42 x$ & $61 \%$ & $72 \%$ & $26 x^{(g)}$ \\
\hline & NA & $19 x$ & $0 x$ & $15 \%$ & $30 x$ \\
\hline & NA & 0.10 & 0.00 & 0.07 & 0.15 \\
\hline \multirow{5}{*}{$\begin{array}{l}0 \\
0\end{array}$} & 88.44 & $0.4 \mathrm{~J}$ & $0.4 \mathrm{~J}$ & $1.6 \mathrm{~J}$ & $5.1 \mathrm{~V}$ \\
\hline & 83.99 & 57.2 & 90.1 & 126.6 & 43.8 \\
\hline & NA & 56.8 & 89.7 & 125.0 & 43.8 \\
\hline & NS & 146.8 & 146.8 & 146.8 & 196.8 \\
\hline & NA & $398^{(g)}$ & $61 x$ & $85 \%$ & $30 x^{(g)}$ \\
\hline \multirow{7}{*}{$\begin{array}{l}0 \\
D\end{array}$} & 88.44 & $0.4 \mathrm{~J}$ & $0.4 \mathrm{~J}$ & $1.6 \mathrm{~J}$ & $5.1 \mathrm{U}$ \\
\hline & 80.81 & 43.1 & 83.7 & 125.4 & 42.8 \\
\hline & NA & 42.7 & 83.3 & 123.8 & 42.8 \\
\hline & NS & 154.3 & 154.3 & 154.3 & 154.3 \\
\hline & NA & $28 x^{(9)}$ & 547 & $80 x$ & $28 x^{(9)}$ \\
\hline & NA & $337^{(h)}$ & $12 \%$ & $6 x$ & $7 \%$ \\
\hline & NA & 0.17 & 0.06 & 0.03 & 0.04 \\
\hline
\end{tabular}




\section{TABLE C.21. (contd)}

\begin{tabular}{|c|c|c|c|c|c|c|}
\hline \multirow[b]{2}{*}{$\begin{array}{l}\text { Sediment } \\
\text { Ireatment }\end{array}$} & \multirow[b]{2}{*}{$\begin{array}{l}\text { Analytical } \\
\text { Batch } \\
\end{array}$} & \multirow{2}{*}{$\begin{array}{l}\text { Tripentyltin } \\
\text { Surrogate } \\
\text { Recovery }(x)\end{array}$} & \multicolumn{4}{|c|}{ Butyltin Species $(\mu \mathrm{g} / \mathrm{kg}$ dry weight) } \\
\hline & & & $\begin{array}{l}\text { Tetra- } \\
\text { butyltin }\end{array}$ & $\begin{array}{c}\text { Tri- } \\
\text { butyltin }\end{array}$ & $\begin{array}{c}\text { Di- } \\
\text { butyltin }\end{array}$ & $\begin{array}{c}\text { Mono- } \\
\text { butyltin }\end{array}$ \\
\hline $\begin{array}{l}\text { TC-5 Upper Comp } \\
\text { IC-5 Upper Comp HS } \\
\text { Concentration Recovered } \\
\text { Amount Spiked } \\
\text { Percent Recovery }\end{array}$ & $\begin{array}{l}E \\
E\end{array}$ & $\begin{array}{r}87.25 \\
92.14 \\
\text { HA } \\
\text { HS } \\
\text { NA }\end{array}$ & $\begin{array}{l}2.0 \mathrm{U} \\
15.1 \\
15.1 \\
19.0 \\
80 x\end{array}$ & $\begin{array}{r}2.3 \\
18.8 \\
16.5 \\
19.0 \\
87 x\end{array}$ & $\begin{array}{l}1.9 \mathrm{~J} \\
15.9 \\
14.0 \\
19.0 \\
74 \mathrm{x}\end{array}$ & $\begin{array}{c}4.2 \mathrm{U} \\
9.7 \\
9.7 \\
19.0 \\
51 \mathrm{x}\end{array}$ \\
\hline \multicolumn{7}{|c|}{ Standard Reference Material } \\
\hline Certified Value & & $N C^{(i)}$ & NC & $\begin{array}{l}1270 \\
\pm 220\end{array}$ & $\begin{array}{l}1160 \\
\pm 180\end{array}$ & $\begin{array}{l}280 \\
\pm 17\end{array}$ \\
\hline $\begin{array}{l}\operatorname{PACS}(j) \\
\operatorname{PACS}(j) \\
\operatorname{PACS}(j) \\
\operatorname{PACS}(j)\end{array}$ & $\begin{array}{l}8 \\
C \\
D \\
E\end{array}$ & $\begin{array}{l}\text { NA } \\
\text { NA } \\
\text { NA } \\
\text { NA }\end{array}$ & $\begin{array}{l}\text { NA } \\
\text { NA } \\
\text { NA } \\
\text { NA }\end{array}$ & $\begin{array}{l}1287.9 \\
1912.6 \\
1089.7 \\
1059.9\end{array}$ & $\begin{array}{r}1124.7 \\
2017.9 \\
133.3 \\
848.3\end{array}$ & $\begin{array}{r}395.6 \\
456.1 \\
246.3 \\
56.7\end{array}$ \\
\hline \multicolumn{7}{|l|}{ Analytical Replicates } \\
\hline $\begin{array}{l}\text { TC-5 Upper Replicate } 1 \\
\text { TC-5 Upper Replicate } 2 \\
\text { TC-5 Upper Replicate } 3 \\
\text { RSD }\end{array}$ & $\begin{array}{l}0 \\
0 \\
0\end{array}$ & $\begin{array}{r}91.54 \\
91.65 \\
75.52 \\
11 x\end{array}$ & $\begin{array}{l}2.4 \mathrm{U} \\
2.4 \mathrm{U} \\
2.4 \mathrm{U} \\
\mathrm{NA}\end{array}$ & $\begin{array}{l}2.5 \mathrm{U} \\
2.5 \mathrm{U} \\
2.5 \mathrm{U} \\
\mathrm{NA}\end{array}$ & $\begin{array}{l}9.3 \\
3.7 \\
11.4 \\
49 x^{(h)}\end{array}$ & $\begin{array}{l}5.1 \mathrm{U} \\
5.1 \mathrm{U} \\
4.0 \mathrm{~J} \\
\text { NA }\end{array}$ \\
\hline $\begin{array}{l}\text { R-AM Replicate } 1 \text { (k) } \\
\text { R-AM Replicate } 2 \\
\text { R-AM Replicate } 3 \\
\text { RSO }\end{array}$ & $\begin{array}{l}0 \\
8 \\
8\end{array}$ & $\begin{array}{r}96.72 \\
71.09 \\
66.38 \\
21 x\end{array}$ & $\begin{array}{l}0.3 \mathrm{~J} \\
2.4 \mathrm{U} \\
2.4 \mathrm{U} \\
\text { NA }\end{array}$ & $\begin{array}{l}2.5 \mathrm{U} \\
2.5 \mathrm{U} \\
2.5 \mathrm{U} \\
\mathrm{NA}\end{array}$ & $\begin{array}{l}0.7 \mathrm{~J} \\
2.4 \mathrm{U} \\
2.4 \mathrm{U} \\
\text { NA }\end{array}$ & $\begin{array}{l}5.1 \mathrm{U} \\
5.1 \mathrm{U} \\
5.1 \mathrm{U} \\
\text { NA }\end{array}$ \\
\hline $\begin{array}{l}\text { R-BF Replicate } 1 \\
\text { R-8F Replicate } 2 \\
\text { R-8F Replicate } 3 \\
\text { RSO }\end{array}$ & $\begin{array}{l}A \\
A \\
A\end{array}$ & $\begin{array}{r}70.65 \\
71.92 \\
69.45 \\
2 x\end{array}$ & $\begin{array}{l}2.4 \mathrm{U} \\
2.4 \mathrm{U} \\
2.4 \mathrm{U} \\
\text { NA }\end{array}$ & $\begin{array}{c}1.9 \mathrm{~J} \\
1.9 \mathrm{~J} \\
1.9 \mathrm{~J} \\
0 \mathrm{x}\end{array}$ & $\begin{array}{c}1.3 \mathrm{~J} \\
1.6 \mathrm{~J} \\
1.6 \mathrm{~J} \\
12 \%\end{array}$ & $\begin{array}{cc}5.1 & U \\
5.1 & U \\
5.1 & U \\
\text { NA } & \end{array}$ \\
\hline
\end{tabular}

NOTE: There is no SRH for Batch A. Surrogate was out of range; therefore, rerun with Batch 0 .

(a) U The analyte was not present above the level of the associated value.

(b) Original spikes lost during extraction: new set rerun with Batch $D$.

(c) J Analyte detected below method detection limit (MDL) but above instrument detection limit (IDL).

(d) $R$ Matrix spike and matrix spike dupl icate had surrogates out of range. spikes were re-extracted and rerun with Batch 0 .

(e) NA Not applicable.

(f) NS Not spiked.

(g) Recovery outside quality control range (40x-120\%).

(h) Value exceeds relative precision range of $30 \%$.

(i) NC Not certified.

(j) Standard reference materials detected and certified values are corrected for surrogate propyltin recovery.

(k) Replicate 1 broke during extraction as noted by analyst, sample was then re-extracted and run with Batch $D$. 
TABLE C.22. Summary of Sediment Grain Size Including Quality Control Data, Richmond Harbor Program

\begin{tabular}{|c|c|c|c|c|c|}
\hline \multirow[b]{2}{*}{$\begin{array}{l}\text { Sediment } \\
\text { Ireatment }\end{array}$} & \multirow[b]{2}{*}{$\begin{array}{c}\text { Analytical } \\
\text { Batch } \\
\end{array}$} & \multicolumn{4}{|c|}{ Total Percent } \\
\hline & & $\begin{array}{c}\text { Gravel } \\
>2000 \mu \mathrm{m}\end{array}$ & $\begin{array}{l}\text { Sand } \\
62.5- \\
2000 \mu \mathrm{m}\end{array}$ & $\begin{array}{r}\text { Silt } \\
3.9- \\
62.5 \mu \mathrm{m} \\
\end{array}$ & $\begin{array}{c}\text { Clay } \\
\leq 3.9 \mu \mathrm{m} \\
\end{array}$ \\
\hline $\begin{array}{l}\text { COMP I } \\
C-1 \\
C-3 \\
C-5 \\
C-6 \\
C-8 \\
C-10\end{array}$ & $\begin{array}{l}\mathrm{C} \\
\mathrm{A} \\
\mathrm{A} \\
\mathrm{A} \\
\mathrm{A} \\
\mathrm{A} \\
\mathrm{B}\end{array}$ & $\begin{array}{l}0 \\
0 \\
0 \\
0 \\
0 \\
0 \\
0\end{array}$ & $\begin{array}{r}9 \\
23 \\
12 \\
5 \\
4 \\
1 \\
4\end{array}$ & $\begin{array}{l}45 \\
42 \\
44 \\
51 \\
46 \\
41 \\
45\end{array}$ & $\begin{array}{l}46 \\
35 \\
44 \\
44 \\
50 \\
58 \\
51\end{array}$ \\
\hline $\begin{array}{l}\text { COMP II } \\
\text { C-11 } \\
\text { C-16 } \\
\text { C-18 } \\
C-19 \\
C-20 \\
C-23\end{array}$ & $\begin{array}{l}\mathrm{A} \\
\mathrm{B} \\
\mathrm{B} \\
\mathrm{B} \\
\mathrm{B} \\
\mathrm{B} \\
8\end{array}$ & $\begin{array}{l}0 \\
0 \\
0 \\
3 \\
0 \\
7 \\
0\end{array}$ & $\begin{array}{r}8 \\
1 \\
25 \\
13 \\
20 \\
28 \\
3\end{array}$ & $\begin{array}{l}44 \\
41 \\
34 \\
39 \\
49 \\
29 \\
45\end{array}$ & $\begin{array}{l}48 \\
58 \\
41 \\
45 \\
31 \\
36 \\
52\end{array}$ \\
\hline $\begin{array}{ll}\text { COMP III } \\
\text { TC-1 Upper } \\
\text { TC-2 Upper } \\
\text { TC-3 Upper } \\
\text { TC-4 Upper }\end{array}$ & $\begin{array}{l}\mathrm{B} \\
\mathrm{B} \\
\mathrm{B} \\
\mathrm{C} \\
8\end{array}$ & $\begin{array}{l}2 \\
0 \\
0 \\
0 \\
5\end{array}$ & $\begin{array}{r}11 \\
3 \\
8 \\
6 \\
12\end{array}$ & $\begin{array}{l}54 \\
57 \\
49 \\
65 \\
57\end{array}$ & $\begin{array}{l}33 \\
40 \\
43 \\
29 \\
26\end{array}$ \\
\hline $\begin{array}{l}\text { TC-5 Upper Comp } \\
\text { TC-5 Upper RepIicate } 1 \\
\text { TC-5 Upper RepTicate } 2 \\
\text { TC-5 Upper Replicate } 3 \\
\text { TC-5 Special Sample }\end{array}$ & $\begin{array}{l}A \\
C \\
C \\
C \\
C\end{array}$ & $\begin{array}{l}0 \\
0 \\
0 \\
0 \\
0\end{array}$ & $\begin{array}{r}10 \\
8 \\
8 \\
8 \\
5\end{array}$ & $\begin{array}{l}43 \\
45 \\
44 \\
43 \\
45\end{array}$ & $\begin{array}{l}47 \\
47 \\
48 \\
49 \\
50\end{array}$ \\
\hline $\begin{array}{l}\text { COMP IV } \\
\text { TC-1 Lower } \\
\text { TC-2 Lower } \\
\text { TC-3 Lower } \\
\text { TC-4 Lower } \\
\text { TC }-5 \text { Lower }\end{array}$ & $\begin{array}{l}A \\
B \\
B \\
C \\
C \\
B\end{array}$ & $\begin{array}{r}3 \\
7 \\
3 \\
12 \\
3 \\
3\end{array}$ & $\begin{array}{r}26 \\
21 \\
9 \\
48 \\
30 \\
30\end{array}$ & $\begin{array}{l}43 \\
39 \\
47 \\
22 \\
40 \\
39\end{array}$ & $\begin{array}{l}28 \\
33 \\
41 \\
18 \\
27 \\
28\end{array}$ \\
\hline $\begin{array}{l}\text { COMP V } \\
C-24 \\
C-26 \\
C-30 \\
C-33 \\
C-35 \\
C-37\end{array}$ & $\begin{array}{l}A \\
8 \\
B \\
C \\
C \\
A \\
A\end{array}$ & $\begin{array}{l}1 \\
0 \\
1 \\
0 \\
0 \\
0 \\
0\end{array}$ & $\begin{array}{r}2 \\
2 \\
6 \\
3 \\
3 \\
5 \\
16\end{array}$ & $\begin{array}{l}34 \\
39 \\
37 \\
38 \\
37 \\
41 \\
41\end{array}$ & $\begin{array}{l}63 \\
59 \\
56 \\
59 \\
60 \\
54 \\
43\end{array}$ \\
\hline
\end{tabular}


TABLE C.22. (contd)

Sediment

Ireatment

\section{COMP VI}

$C-25$

$c-29$

C -32

$\mathrm{C}-36$

$c-38$

TC-6 (1) $(\mathrm{a})$

IC -6 (2)

TC -6 (3)

TC-6 (4)

TC-7 (1) (a)

TC -7 (2)

IC -7 (3)

TC-7 (4)

$\mathrm{R}-\mathrm{AC}$

R-AM Replicate 1

R-AM Replicate 2

R-AM Replicate 3

R-BF Replicate 1

R-BF Replicate 2

R-BF Replicate 3

$R-0 S$

$\mathrm{R}-\mathrm{PF}$

C-SB

$C-W 8$

C-NE
Total Percent

Sand silt

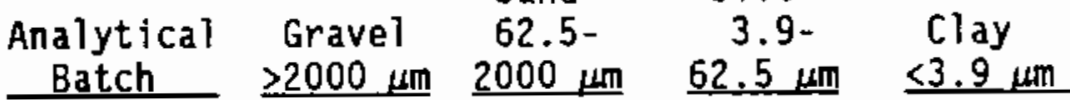

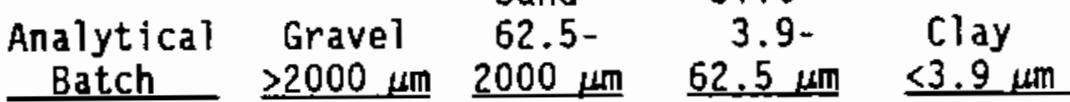

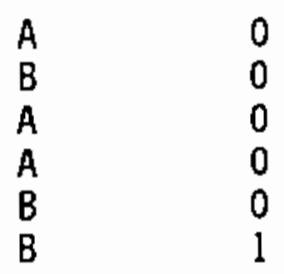

3
16
6
2
5
6

36

61

0
0
0
0
0
1

C $\quad 2$

11

3

77

10

\section{1}

51

54

40

45

43

43

44

55

48

$\begin{array}{ll}c & 1 \\ C & 0\end{array}$

50

37

$61 \quad 36$

11

45

11

45

C $\quad 0$

C $\quad 0$

60

37

$\begin{array}{lll}\text { C } & 0 & 67\end{array}$

C

14

39

15

41

A $\quad 0 \quad 65$

B $\quad 0$

18

65

95

95

12

12

12

16

57

59

18

45

17

2

2

2
35

34

34

62

37

60

99

98

3

3

53

54

54

22

$\begin{array}{rrrrr}\text { A } & 0 & 9 & 60 & 31 \\ \text { A } & 0 & 99 & 0 & 1 \\ \text { A } & 0 & 98 & 1 & 1\end{array}$

Quality Control Data

Analytical Replicates

TC-5 Upper Replicate 1

TC -5 Upper Replicate 2 -

TC-5 Upper Replicate 3 RSD

$\begin{array}{cllcc}C & 0 & 8 & 45 & 47 \\ C & 0 & 8 & 44 & 48 \\ C & 0 & 8 & 43 & 49 \\ & 0 \% & 0 \% & 2 \% & 2 \%\end{array}$

R-BF Replicate 1

R-BF Replicate 2

R-BF Replicate 3

$\begin{array}{clccc}\mathrm{A} & 0 & 12 & 35 & 53 \\ \mathrm{~A} & 0 & 12 & 34 & 54 \\ \mathrm{~A} & 0 & 12 & 34 & 54 \\ & 0 \% & 0 \% & 2 \% & 1 \%\end{array}$


IABLE C.22. (contd)

Sediment

Ireatment

\begin{tabular}{|c|c|c|c|c|}
\hline \multirow[b]{2}{*}{$\begin{array}{l}\text { Analytical } \\
\text { Batch } \\
\end{array}$} & \multicolumn{4}{|c|}{ Total Percent } \\
\hline & $\begin{array}{c}\text { Gravel } \\
>2000 \quad \mu m\end{array}$ & $\begin{array}{c}\text { Sand } \\
62.5- \\
2000 \mathrm{\mu m} \\
\end{array}$ & $\begin{array}{r}\text { Silt } \\
3.9- \\
62.5 \mathrm{\mu m} \\
\end{array}$ & $\begin{array}{c}\text { Clay } \\
\leq 3.9 \mu \mathrm{m}\end{array}$ \\
\hline $\begin{array}{l}B \\
B \\
B\end{array}$ & $\begin{array}{l}0 \\
0 \\
0 \\
0 \%\end{array}$ & $\begin{array}{c}95 \\
95 \\
95 \\
0 \%\end{array}$ & $\begin{array}{l}2 \\
2 \\
2 \\
0 \%\end{array}$ & $\begin{array}{l}3 \\
3 \\
3 \\
0 \%\end{array}$ \\
\hline
\end{tabular}

(a) Stations TC-6 and TC-7 were split into four separate core sections which were composited, subsampled for chemistry, and used for geologic descriptions. 
IABLE C.23. Sediment Grain Size Results (percent dry weight), Richmond Harbor Program

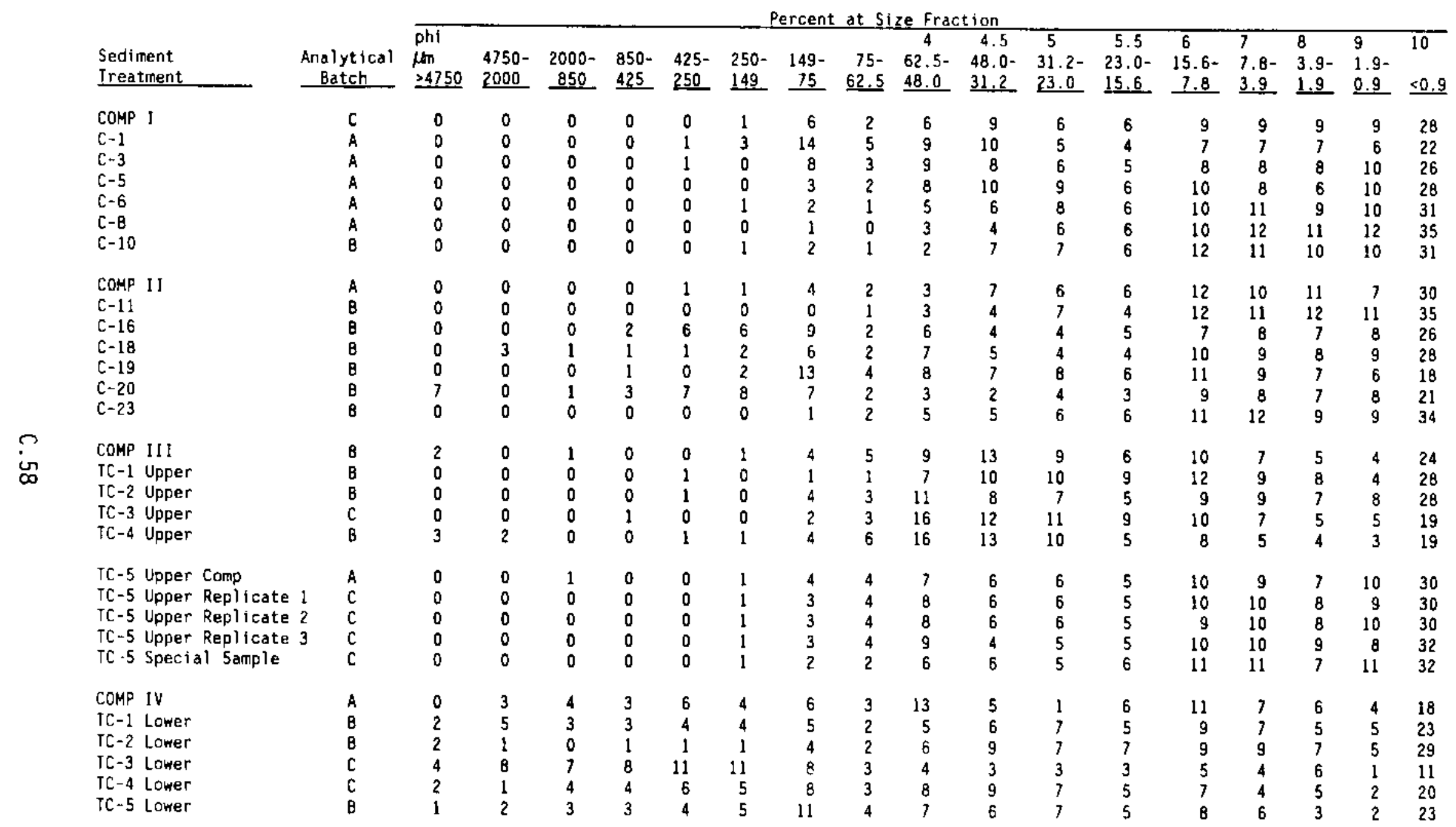




\section{IABLE C.23. (contd)}

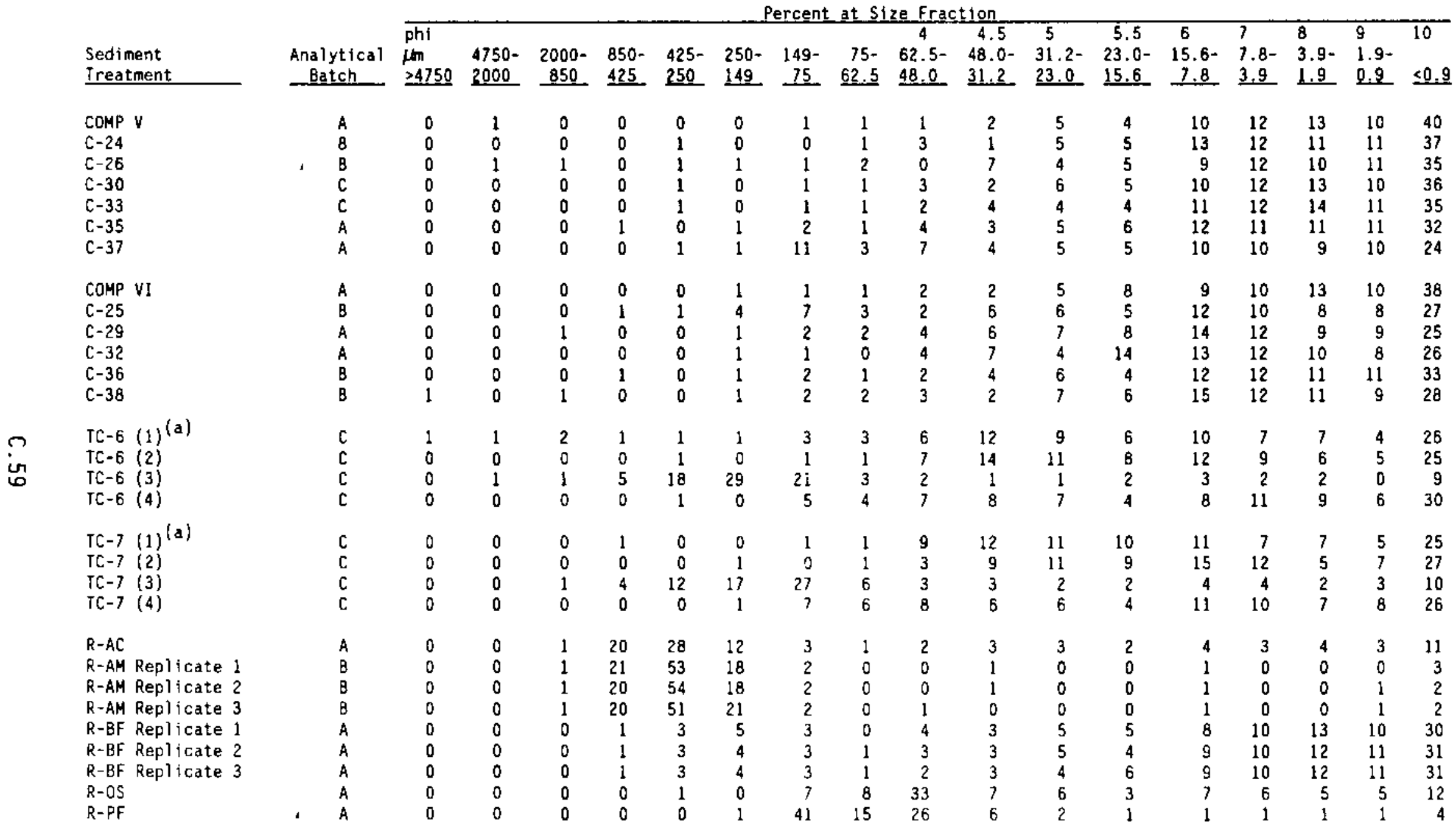




\section{IABLE C.23. (contd)}

Sediment Ireatment.

C-SB

$\mathrm{C}-\mathrm{WB}$

C-NE
Percent at Size fraction

Analytical ph

$$
\text { phi }
$$

4750- 2000 Batch

A $\quad 0$

A

were split into four separate core sections which were composited, subsampled for chemistry. and used for geologic descriptions. 


\section{IABLE C.24. Quality Control Data for Sediment Grain Size, Richmond Harbor Program}

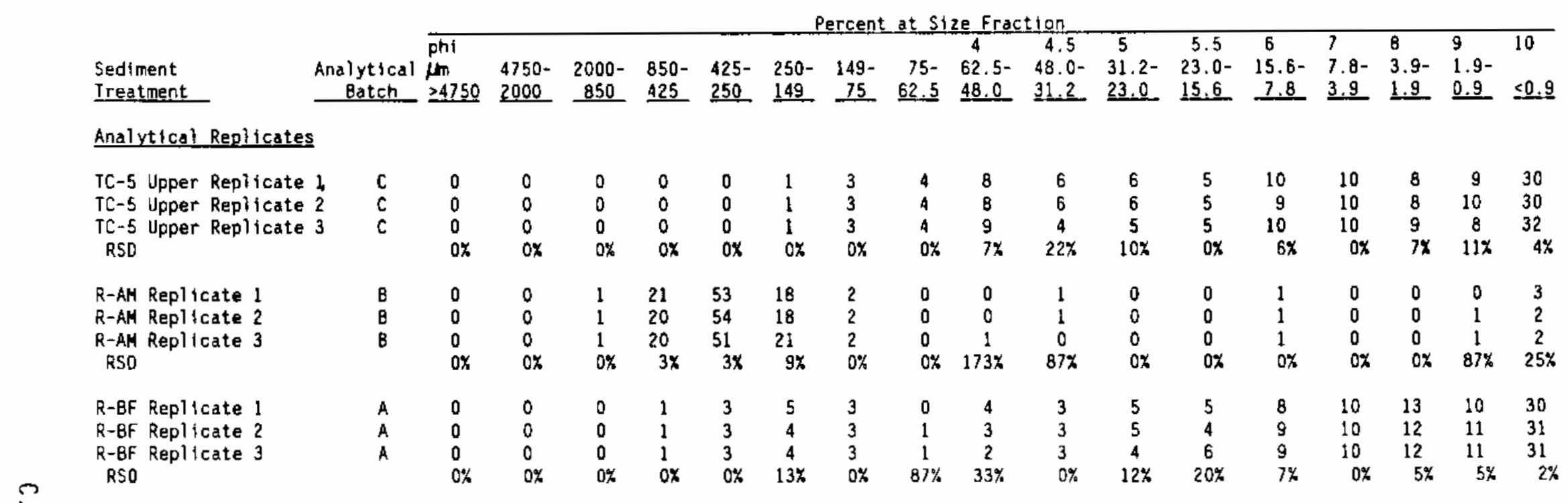




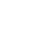


APPENDIX D

BIOASSAY RESULTS FOR 10-DAY SOLID-PHASE TEST WITH MACOMA nasuta AND NEPHTYS caecoides 
TABLE D.1. Test Results for 10-Day M. nasuta Solid-Phase Test, Richmond Harbor Program

\begin{tabular}{|c|c|c|c|c|}
\hline \multirow[b]{2}{*}{$\begin{array}{l}\text { Sediment } \\
\text { Ireatment }\end{array}$} & \multirow[b]{2}{*}{ Replicate } & \multicolumn{2}{|c|}{ M. nasuta } & \multirow{2}{*}{$\begin{array}{c}\text { Mean } \\
\text { Proportion } \\
\text { Survivine }\end{array}$} \\
\hline & & $\underline{\text { Live }}{ }^{(a)}$ & $\begin{array}{l}\text { Dead } \\
\text { or Missing }\end{array}$ & \\
\hline COMP I & 1 & 20 & 0 & \\
\hline COMP I & 2 & 20 & 0 & \\
\hline COMP I & 3 & 20 & 0 & 1.00 \\
\hline COMP I & 4 & 20 & 0 & \\
\hline COMP I & 5 & 20 & 0 & \\
\hline СОMP II & 1 & 20 & 0 & \\
\hline СОMP II & 2 & 20 & 0 & \\
\hline СОMP II & 3 & 16 & 4 & 0.96 \\
\hline COMP II & 4 & 20 & 0 & \\
\hline COMP I I & 5 & 20 & 0 & \\
\hline COMP I I I & 1 & 20 & 0 & \\
\hline COMP III & 2 & 19 & 1 & \\
\hline COMP III & 3 & 20 & 0 & 0.99 \\
\hline COMP III & 4 & 20 & 0 & \\
\hline COMP III & 5 & 20 & 0 & \\
\hline TC-5 Upper Comp & 1 & 20 & 0 & \\
\hline TC-5 Upper Comp & 2 & 20 & 0 & \\
\hline TC-5 Upper Comp & 3 & 20 & 0 & 1.00 \\
\hline TC-5 Upper Comp & 4 & 20 & 0 & \\
\hline TC-5 Upper Comp & 5 & 20 & 0 & \\
\hline COMP IV & 1 & 19 & 1 & \\
\hline COMP IV & 2 & 20 & 0 & \\
\hline COMP IV & 3 & 20 & 0 & 0.97 \\
\hline COMP IV & 4 & 20 & 0 & \\
\hline COMP IV & 5 & 18 & 2 & \\
\hline COMP V & I & 20 & 0 & \\
\hline COMP V & 2 & 20 & 0 & \\
\hline COMP V & 3 & 20 & 0 & 1.00 \\
\hline COMP V & 4 & 20 & 0 & \\
\hline COMP V & 5 & 20 & 0 & \\
\hline COMP VI & 1 & 20 & 0 & \\
\hline COMP VI & 2 & 20 & 0 & \\
\hline COMP VI & 3 & 20 & 0 & 0.99 \\
\hline COMP VI & 4 & 20 & 0 & \\
\hline COMP VI & 5 & 19 & 1 & \\
\hline
\end{tabular}

D. 1 
IABLE D.1. (contd)

Sediment

Treatment

$\mathrm{R}-\mathrm{AC}$

$\mathrm{R}-\mathrm{AC}$

$\mathrm{R}-\mathrm{AC}$

$\mathrm{R}-\mathrm{AC}$

$\mathrm{R}-\mathrm{AC}$

R-AM

R-AM

R-AM

R-AM

R-AM

$\mathrm{R}-\mathrm{BF}$

$R-B F$

$R-B F$

$R-B F$

$\mathrm{R}-\mathrm{BF}$

$\mathrm{R}-\mathrm{OS}$

$\mathrm{R}-\mathrm{OS}$

$R-O S$

$\mathrm{R}-0 \mathrm{~S}$

$\mathrm{R}-\mathrm{OS}$

$R-P F$

$\mathrm{R}-\mathrm{PF}$

$R-P F$

$R-P F$

$\mathrm{R}-\mathrm{PF}$

$C-S B$

$C-S B$

$C-S B$

$C-S B$

C-SB

C-NE

$\mathrm{C}-\mathrm{NE}$

C $-N E$

C-NE

C-NE

\begin{tabular}{|c|c|}
\hline \multicolumn{2}{|c|}{ M. nasuta } \\
\hline$\underline{L i v e}^{(a)}$ & $\begin{array}{c}\text { Dead } \\
\text { or Missi }\end{array}$ \\
\hline $\begin{array}{l}20 \\
20 \\
19 \\
20 \\
20\end{array}$ & $\begin{array}{l}0 \\
0 \\
1 \\
0 \\
0\end{array}$ \\
\hline
\end{tabular}

20

19

20

19

20

19

20

20

19

20

20

20

20

20

19

19

20

20

20

19

20

20

20

20

20

20

20

19

20

20
Mean

Proportion

Surviving

0.99

0.98

0.98

0.99

0.98

1.00

0.99

(a) Survival based on initial exposure of 20 individuals per replicate. 
IABLE D.2. Rank Order Based on Mean Proportion Surviving for 10-Day M. nasuta Solid-Phase Test, Richmond Harbor Program

Sediment

Treatment

COMP II
COMP IV
$R-B F$
$R-A M$
$R-P F$
$R-A C$
$R-O S$
COMP VI
COMP II I
$C-N E$
COMP V
TC-5 Upper Comp
$C-S B$
COMP I

Mean

Proportion

Surviving
0.96
0.97
0.98
0.98
0.98
0.99
0.99
0.99
0.99
0.99
1.00
1.00
1.00
1.00 
IABLE D.3. Daily Observation of $M$. nasuta on Sediment Surface During 10-Day Solid-Phase Test, Richmond Harbor Program

Sediment

Treatment

COMP 1

COMP I

COMP I

COMP I

COMP I

COMP II

COMP II

COMP II

COMP II

COMP II

COHP III

COMP III

COHP III

COMP III

COMP III

TC-5 Upper Comp

TC-5 Upper Comp

TC-5 Upper Comp

TC-5 Upper Comp

TC-5 Upper Comp

COMP IV

COMP IV

COMP IV

COMP IV

COHP IV

COMP $V$

COMP $V$

COMP $V$

COMP V

COMP V

COMP VI

СOMP VI

COMP VI

COMP VI

COMP VI

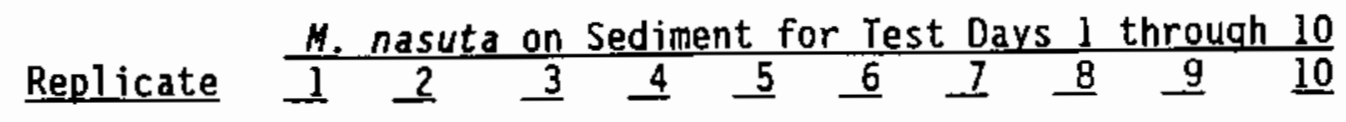

1
2
3
4
5

3

2

$\begin{array}{ll}2 & 0 \\ 0 & 0\end{array}$

$\begin{array}{llllllll}2 & 1 & 1 & 2 & 2 & 2 & 2 & 2 \\ 0 & 0 & 0 & 0 & 0 & 0 & 0 & 0 \\ 2 & 0 & 1 & 2 & 2 & 1 & 2 & 0 \\ 0 & 0 & 0 & 0 & 0 & 0 & 0 & 0 \\ 0 & 0 & 0 & 0 & 0 & 0 & 0 & 0\end{array}$

1
2
3
4
5

$\begin{array}{llllllllll}7 & 3 & 2 & 2 & 2 & 2 & 1 & 2 & 2 & 2 \\ 0 & 0 & 0 & 0 & 0 & 0 & 0 & 0 & 0 & 1 \\ 5 & 7 & 4 & 3 & 3 & 3 & 3 & 2 & 2 & 2 \\ 4 & 2 & 2 & 2 & 1 & 1 & 0 & 0 & 1 & 1 \\ 1 & 1 & 1 & 1 & 0 & 0 & 0 & 0 & 0 & 0\end{array}$

1
2
3
4
5

$\begin{array}{llllllllll}2 & 3 & 1 & 1 & 2 & 2 & 2 & 2 & 2 & 2 \\ 1 & 2 & 1 & 1 & 1 & 1 & 1 & 1 & 1 & 0 \\ 5 & 3 & 4 & 3 & 2 & 3 & 2 & 2 & 2 & 3 \\ 4 & 2 & 3 & 1 & 1 & 1 & 1 & 1 & 1 & 1 \\ 3 & 3 & 3 & 3 & 4 & 3 & 3 & 2 & 3 & 2\end{array}$

1
2
3
4
5

$\begin{array}{llllllllll}2 & 2 & 3 & 3 & 3 & 3 & 2 & 0 & 1 & 2 \\ 1 & 0 & 1 & 1 & 2 & 1 & 0 & 0 & 0 & 0 \\ 4 & 3 & 2 & 0 & 2 & 1 & 1 & 1 & 1 & 2 \\ 3 & 0 & 1 & 1 & 2 & 2 & 1 & 1 & 1 & 1 \\ 5 & 2 & 2 & 2 & 1 & 0 & 0 & 0 & 0 & 0\end{array}$

$\begin{array}{lllllllllll}1 & 4 & 2 & 1 & 1 & 1 & 1 & 0 & 0 & 0 & 0 \\ 2 & 4 & 4 & 3 & 2 & 3 & 2 & 2 & 0 & 1 & 1 \\ 3 & 9 & 4 & 0 & 1 & 1 & 0 & 0 & 0 & 0 & 1 \\ 4 & 5 & 2 & 3 & 3 & 1 & 2 & 3 & 1 & 3 & 2 \\ 5 & 3 & 1 & 1 & 2 & 2 & 1 & 1 & 0 & 1 & 2\end{array}$

$\begin{array}{lllllllllll}1 & 0 & 0 & 0 & 0 & 0 & 0 & 0 & 0 & 0 & 1 \\ 2 & 0 & 0 & 0 & 1 & 1 & 1 & 0 & 0 & 0 & 0 \\ 3 & 2 & 2 & 0 & 1 & 1 & 1 & 1 & 1 & 1 & 1 \\ 4 & 0 & 0 & 1 & 1 & 1 & 0 & 0 & 0 & 0 & 0 \\ 5 & 0 & 0 & 0 & 0 & 0 & 0 & 0 & 0 & 0 & 0\end{array}$

$\begin{array}{lllllllllll}1 & 0 & 0 & 0 & 0 & 0 & 0 & 0 & 0 & 0 & 0 \\ 2 & 3 & 2 & 2 & 2 & 1 & 2 & 2 & 0 & 1 & 1 \\ 3 & 1 & 0 & 1 & 1 & 0 & 1 & 1 & 0 & 0 & 0 \\ 4 & 4 & 4 & 3 & 4 & 3 & 5 & 6 & 6 & 5 & 2 \\ 5 & 1 & 2 & 2 & 2 & 3 & 2 & 1 & 2 & 3 & 2\end{array}$ 
IABLE D.3. (contd)

Sediment

Treatment

$R-A C$

$\mathrm{R}-\mathrm{AC}$

$\mathrm{R}-\mathrm{AC}$

$\mathrm{R}-\mathrm{AC}$

$\mathrm{R}-\mathrm{AC}$

$\begin{array}{ll}R-A M & 1 \\ R-A M & 2 \\ R-A M & 3 \\ R-A M & 4 \\ R-A M & 5\end{array}$

$R-B F$

$R-B F$

$R-B F$

$R-B F$

$\mathrm{R}-\mathrm{BF}$

R-OS

$\mathrm{R}-\mathrm{OS}$

$\mathrm{R}-\mathrm{OS}$

$\mathrm{R}-\mathrm{OS}$

R-OS

R-PF

$R-P F$

$R-P F$

$R-P F$

$R-P F$

C-SB

$C-S B$

$\mathrm{C}-\mathrm{SB}$

$C-S B$

C-SB

$\mathrm{C}-\mathrm{NE}$

C-NE

$\mathrm{C}-\mathrm{NE}$

C-NE

C-NE
Replicate

1
2
3
4
5

1
2
3
4
5

1
2
3
4
5

1
2
3
4
5

1
2
3
4
5

1
2
3
4
5

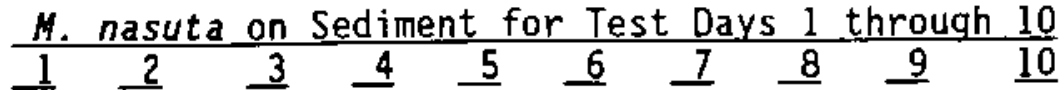

$\begin{array}{llllllllll}2 & 1 & 1 & 1 & 1 & 1 & 2 & 2 & 0 & 0\end{array}$

$\begin{array}{llllllllll}1 & 1 & 1 & 1 & 1 & 1 & 0 & 0 & 0 & 0\end{array}$

$\begin{array}{llllllllll}0 & 0 & 0 & 0 & 1 & 0 & 0 & 0 & 0 & 0\end{array}$

$\begin{array}{llllllllll}1 & 0 & 0 & 0 & 0 & 0 & 0 & 0 & 0 & 0 \\ 0 & 0 & 0 & 0 & 0 & 0 & 0 & 0 & 1 & 0\end{array}$

$\begin{array}{llllllllll}0 & 0 & 0 & 0 & 0 & 1 & 0 & 0 & 2 & 2 \\ 1 & 2 & 2 & 1 & 3 & 2 & 2 & 2 & 5 & 5 \\ 1 & 1 & 0 & 0 & 2 & 2 & 1 & 2 & 2 & 1 \\ 2 & 0 & 2 & 1 & 1 & 1 & 0 & 1 & 2 & 1 \\ 0 & 0 & 0 & 1 & 2 & 3 & 3 & 3 & 6 & 6\end{array}$

$\begin{array}{llllllllll}2 & 0 & 0 & 0 & 0 & 0 & 0 & 0 & 0 & 0\end{array}$

$\begin{array}{llllllllll}0 & 0 & 0 & 0 & 0 & 0 & 0 & 0 & 0 & 0\end{array}$

$\begin{array}{llllllllll}0 & 0 & 0 & 0 & 0 & 1 & 0 & 0 & 1 & 1\end{array}$

$\begin{array}{llllllllll}2 & 2 & 1 & 1 & 1 & 1 & 1 & 0 & 0 & 0 \\ 0 & 0 & 0 & 0 & 0 & 0 & 0 & 0 & 1 & 1\end{array}$

$\begin{array}{llllllllll}1 & 0 & 0 & 0 & 0 & 0 & 0 & 0 & 0 & 1\end{array}$

$\begin{array}{llllllllll}2 & 0 & 0 & 0 & 0 & 0 & 0 & 0 & 0 & 0 \\ 3 & 1 & 1 & 2 & 2 & 2 & 1 & 0 & 0 & 0\end{array}$

$\begin{array}{llllllllll}1 & 1 & 1 & 1 & 1 & 2 & 1 & 1 & 0 & 0 \\ 0 & 0 & 0 & 0 & 0 & 0 & 0 & 0 & 0 & 0\end{array}$

$\begin{array}{llllllllll}0 & 0 & 0 & 0 & 0 & 2 & 0 & 0 & 0 & 0\end{array}$

$\begin{array}{llllllllll}0 & 0 & 0 & 0 & 0 & 0 & 0 & 0 & 0 & 0 \\ 0 & 0 & 0 & 1 & 0 & 0 & 0 & 0 & 0 & 0\end{array}$

$\begin{array}{llllllllll}0 & 0 & 1 & 0 & 0 & 0 & 0 & 0 & 0 & 0 \\ 0 & 0 & 0 & 0 & 0 & 0 & 0 & 0 & 0 & 0\end{array}$

$\begin{array}{llllllllll}0 & 0 & 0 & 0 & 0 & 0 & 0 & 0 & 0 & 0\end{array}$

$\begin{array}{llllllllll}1 & 0 & 1 & 1 & 1 & 0 & 0 & 0 & 0 & 0 \\ 0 & 0 & 1 & 1 & 0 & 1 & 0 & 0 & 1 & 1\end{array}$

$\begin{array}{llllllllll}1 & 1 & 1 & 2 & 1 & 1 & 2 & 0 & 1 & 2 \\ 1 & 1 & 0 & 1 & 1 & 2 & 2 & 2 & 1 & 4 \\ 1 & 1 & 0 & 2 & 2 & 2 & 4 & 4 & 5 & 6 \\ 2 & 2 & 0 & 0 & 1 & 3 & 2 & 1 & 2 & 2 \\ 1 & 1 & 1 & 0 & 2 & 2 & 1 & 0 & 1 & 2\end{array}$ 
TABLE D.4. Daily Observations of M. nasuta Siphons Exposed During 10-Day Solid-Phase Test, Richmond Harbor Program

Sed iment

Ireatment

COMP I
COMP I
COMP I
COMP I
COMP I
COMP II
COMP II
COMP II
COMP II
COMP II
COMP III
COMP III
COMP III
COMP III
COMP III

TC-5 Upper Comp
TC-5 Upper Comp
TC-5 Upper Comp
TC-5 Upper Comp
TC-5 Upper Comp

COMP IV

COMP IV

COMP IV

COMP IV

COMP IV

COMP $V$

COMP $V$

COMP $V$

COMP $V$

COMP $V$

COMP VI

COMP VI

COMP VI

COMP VI

COMP VI
M. nasuta Siphons Exposed Test Days 1 through 10

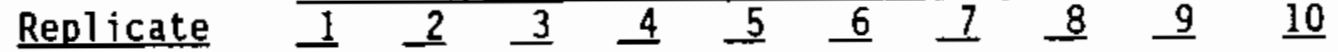

$\begin{array}{llllllllll}21 & 8 & 8 & 6 & 7 & 7 & 4 & 4 & 4 & 6\end{array}$

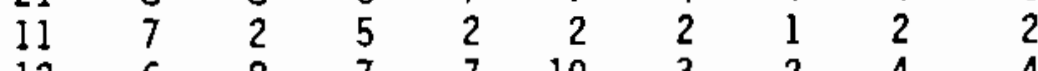

$\begin{array}{llllllllll}12 & 6 & 8 & 7 & 7 & 10 & 3 & 2 & 4 & 4\end{array}$

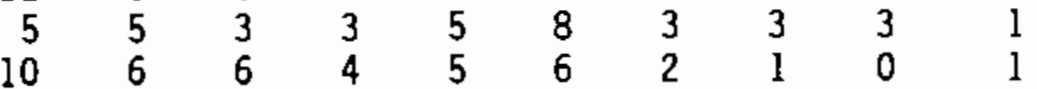

$\begin{array}{llllllllll}13 & 19 & 13 & 11 & 14 & 10 & 9 & 8 & 8 & 9\end{array}$

$\begin{array}{lllllllllll}7 & 7 & 6 & 8 & 9 & 12 & 4 & 1 & 2 & 3\end{array}$

$\begin{array}{rrrrrrrrrr}23 & 21 & 13 & 14 & 11 & 13 & 10 & 4 & 3 & 3\end{array}$

$\begin{array}{rrrrrrrrrr}13 & 12 & 13 & 11 & 9 & 11 & 9 & 10 & 6 & 7 \\ 14 & 8 & 7 & 4 & 6 & 3 & 1 & 3 & 2 & 4\end{array}$

$\begin{array}{llllllllll}21 & 12 & 8 & 7 & 10 & 11 & 6 & 0 & 3 & 2\end{array}$

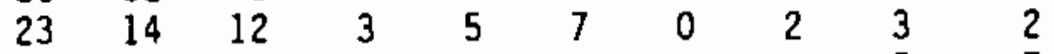

$\begin{array}{llllllllll}31 & 22 & 19 & 11 & 14 & 14 & 8 & 8 & 5 & 7\end{array}$

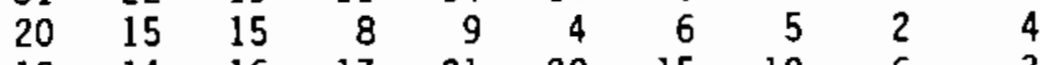

$\begin{array}{llllllllll}19 & 14 & 16 & 17 & 21 & 20 & 15 & 10 & 6 & 3\end{array}$

$\begin{array}{llllllllll}13 & 11 & 11 & 9 & 12 & 9 & 9 & 5 & 6 & 5\end{array}$

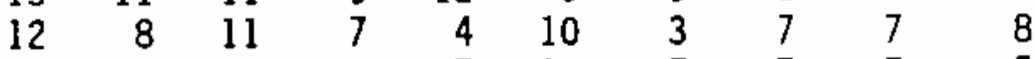

$\begin{array}{llllllllll}20 & 22 & 13 & 9 & 7 & 10 & 7 & 7 & 7 & 5\end{array}$

$\begin{array}{llllllllll}14 & 12 & 11 & 10 & 10 & 7 & 3 & 5 & 3 & 4\end{array}$

$\begin{array}{llllllllll}18 & 13 & 13 & 8 & 9 & 7 & 2 & 3 & 3 & 2\end{array}$

$\begin{array}{llllllllll}24 & 16 & 18 & 21 & 11 & 5 & 5 & 5 & 5 & 3\end{array}$

$\begin{array}{llllllllll}21 & 10 & 14 & 13 & 11 & 6 & 2 & 2 & 3 & 3\end{array}$

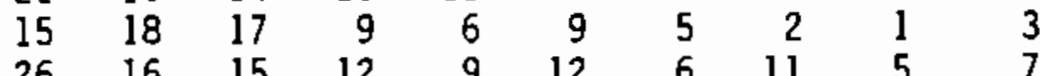

$\begin{array}{rrrrrrrrrrr}4 & 26 & 16 & 15 & 12 & 9 & 12 & 6 & 11 & 5 & 7 \\ 5 & 22 & 12 & 17 & 12 & 10 & 9 & 4 & 7 & 5 & 6\end{array}$

$\begin{array}{llllllllll}8 & 12 & 5 & 7 & 5 & 3 & 0 & 3 & 0 & 3\end{array}$

$\begin{array}{llllllllll}13 & 6 & 7 & 8 & 5 & 6 & 0 & 0 & 3 & 2\end{array}$

$\begin{array}{llllllllll}12 & 7 & 9 & 7 & 6 & 6 & 1 & 2 & 3 & 2\end{array}$

$\begin{array}{llllllllll}7 & 9 & 8 & 9 & 6 & 7 & 2 & 2 & 3 & 3\end{array}$

$\begin{array}{llllllllll}2 & 2 & 3 & 2 & 1 & 1 & 0 & 2 & 0 & 1\end{array}$

$\begin{array}{llllllllll}11 & 10 & 12 & 9 & 7 & 4 & 4 & 3 & 4 & 2\end{array}$

$\begin{array}{rrrrrrrrrr}7 & 4 & 4 & 4 & 5 & 4 & 1 & 2 & 3 & 3\end{array}$

$\begin{array}{llllllllll}10 & 6 & 10 & 8 & 5 & 7 & 4 & 3 & 1 & 3\end{array}$

$\begin{array}{llllllllll}11 & 7 & 9 & 8 & 9 & 7 & 8 & 6 & 6 & 7\end{array}$

$\begin{array}{llllllllll}9 & 6 & 10 & 8 & 6 & 7 & 5 & 4 & 5 & 6\end{array}$ 
TABLE D.4. (contd)

Sediment

Treatment

Replicate

M. nasuta Siphons Exposed Test Days 1 through 10

$R-A C$
$R-A C$
$R-A C$
$R-A C$
$R-A C$

$R-A M$

R-AM

R-AM

R-AM

R-AM

$R-B F$

$R-B F$

$R-B F$

$R-B F$

$\mathrm{R}-\mathrm{BF}$

R-OS

R-OS

$\mathrm{R}-\mathrm{OS}$

$\mathrm{R}-\mathrm{OS}$

R-OS

$R-P F$

R-PF

R-PF

$R-P F$

R-PF

C-SB

C-SB

C-SB

C-SB

C-SB

C-NE

C-NE

C-NE

C-NE

C-NE

1
2
3
4
5

$12 \quad 1$

$\begin{array}{rrrrrrrrrr}12 & 11 & 9 & 10 & 7 & 5 & 1 & 3 & 5 & 2 \\ 6 & 6 & 4 & 7 & 4 & 7 & 5 & 11 & 1 & 9\end{array}$

$\begin{array}{rrrrrrrrrr}8 & 9 & 6 & 14 & 8 & 7 & 2 & 1 & 2 & 2\end{array}$

$\begin{array}{rrrrrrrrrr}9 & 11 & 4 & 9 & 6 & 5 & 4 & 3 & 2 & 4 \\ 14 & 10 & 10 & 9 & 5 & 8 & 1 & 4 & 3 & 4\end{array}$

1
2
3
4
5

1
2
3
4
5

1
2
3
4
5

1
2
3
4
5

1
2
3
4
5

1
2
3
4
5

$\begin{array}{rrrrrrrrrr}5 & 3 & 1 & 4 & 3 & 4 & 0 & 0 & 1 & 3 \\ 14 & 10 & 15 & 12 & 14 & 10 & 8 & 8 & 13 & 10 \\ 12 & 5 & 8 & 3 & 5 & 5 & 1 & 6 & 2 & 4 \\ 7 & 4 & 4 & 3 & 1 & 2 & 2 & 2 & 4 & 2 \\ 15 & 8 & 11 & 8 & 5 & 12 & 14 & 10 & 15 & 16\end{array}$

$\begin{array}{rrrrrrrrrr}9 & 7 & 5 & 12 & 6 & 3 & 1 & 2 & 1 & 2 \\ 6 & 5 & 7 & 4 & 3 & 4 & 1 & 1 & 2 & 1 \\ 12 & 3 & 5 & 6 & 5 & 6 & 3 & 4 & 2 & 4 \\ 7 & 10 & 11 & 6 & 6 & 5 & 6 & 1 & 1 & 2 \\ 9 & 5 & 7 & 5 & 6 & 4 & 3 & 4 & 4 & 3\end{array}$

$\begin{array}{rrrrrrrrrr}8 & 6 & 6 & 8 & 10 & 5 & 4 & 3 & 5 & 3 \\ 10 & 2 & 3 & 4 & 4 & 6 & 6 & 3 & 2 & 1 \\ 2 & 3 & 5 & 4 & 3 & 4 & 2 & 0 & 1 & 4 \\ 9 & 9 & 5 & 7 & 4 & 8 & 3 & 4 & 4 & 3 \\ 18 & 15 & 9 & 9 & 10 & 7 & 3 & 4 & 3 & 4\end{array}$

$\begin{array}{rrrrrrrrrr}10 & 7 & 6 & 6 & 6 & 6 & 3 & 3 & 0 & 4 \\ 7 & 2 & 7 & 2 & 4 & 2 & 3 & 2 & 4 & 3 \\ 10 & 10 & 8 & 5 & 4 & 3 & 1 & 2 & 3 & 5 \\ 5 & 5 & 1 & 2 & 2 & 3 & 5 & 1 & 6 & 3 \\ 6 & 5 & 3 & 5 & 3 & 7 & 1 & 3 & 0 & 5\end{array}$

$\begin{array}{llllllllll}6 & 9 & 6 & 8 & 8 & 3 & 3 & 3 & 1 & 3 \\ 2 & 1 & 5 & 3 & 3 & 5 & 2 & 1 & 2 & 1 \\ 1 & 2 & 3 & 1 & 3 & 2 & 2 & 0 & 1 & 1 \\ 9 & 2 & 4 & 3 & 4 & 6 & 1 & 1 & 0 & 3 \\ 5 & 3 & 4 & 3 & 5 & 6 & 3 & 5 & 0 & 4\end{array}$

$\begin{array}{rrrrrrrrrr}6 & 0 & 3 & 5 & 4 & 6 & 4 & 5 & 3 & 3 \\ 9 & 6 & 8 & 8 & 6 & 7 & 6 & 10 & 6 & 8\end{array}$

$\begin{array}{llllllllll}7 & 8 & 8 & 6 & 11 & 12 & 5 & 7 & 11 & 8\end{array}$

$\begin{array}{rrrrrrrrrr}11 & 10 & 5 & 2 & 8 & 8 & 8 & 2 & 2 & 3 \\ 4 & 3 & 5 & 2 & 3 & 5 & 2 & 3 & 3 & 8\end{array}$ 
TABLE D.5. Daily Observations of $M$. nasuta Dead and Removed During 10-Day Solid-Phase Test, Richmond Harbor Program

Sediment

Treatment

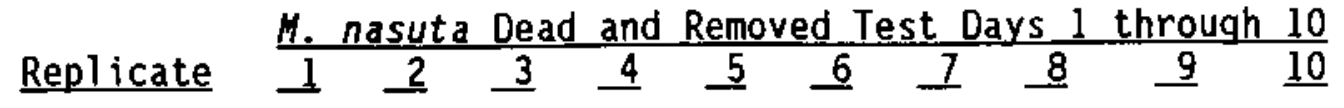

COMP I

COMP I

COMP I

COMP I

COMP I

$\begin{array}{lllllllllll}1 & 0 & 0 & 0 & 0 & 0 & 0 & 0 & 0 & 0 & 0 \\ 2 & 0 & 0 & 0 & 0 & 0 & 0 & 0 & 0 & 0 & 0 \\ 3 & 0 & 0 & 0 & 0 & 0 & 0 & 0 & 0 & 0 & 0 \\ 4 & 0 & 0 & 0 & 0 & 0 & 0 & 0 & 0 & 0 & 0 \\ 5 & 0 & 0 & 0 & 0 & 0 & 0 & 0 & 0 & 0 & 0\end{array}$

COMP II

COMP II

COMP II

COMP II

COMP II

1
2
3
4
5

COMP III

COMP II I

COMP II I

COMP II I

COMP II I

$\begin{array}{llllllllll}0 & 0 & 0 & 0 & 0 & 0 & 0 & 0 & 0 & 0\end{array}$

$\begin{array}{llllllllll}0 & 0 & 0 & 0 & 0 & 0 & 0 & 0 & 0 & 0\end{array}$

$\begin{array}{llllllllll}0 & 0 & 1 & 0 & 0 & 0 & 0 & 0 & 0 & 1\end{array}$

$\begin{array}{llllllllll}0 & 0 & 0 & 0 & 0 & 0 & 0 & 0 & 0 & 0\end{array}$

$\begin{array}{llllllllllll}\text { TC - } 5 \text { Upper Comp } & 1 & 0 & 0 & 0 & 0 & 0 & 0 & 0 & 0 & 0 & 0 \\ \text { TC-5 Upper Comp } & 2 & 0 & 0 & 0 & 0 & 0 & 0 & 0 & 0 & 0 & 0 \\ \text { TC-5 Upper Comp } & 3 & 0 & 0 & 0 & 0 & 0 & 0 & 0 & 0 & 0 & 0 \\ \text { TC-5 Upper Comp } & 4 & 0 & 0 & 0 & 0 & 0 & 0 & 0 & 0 & 0 & 0 \\ \text { TC-5 Upper Comp } & 5 & 0 & 0 & 0 & 0 & 0 & 0 & 0 & 0 & 0 & 0\end{array}$

COMP IV

COMP IV

COMP IV

COMP IV

COMP IV

$\begin{array}{lllllllllll}1 & 0 & 0 & 0 & 0 & 0 & 0 & 0 & 0 & 0 & 0 \\ 2 & 0 & 0 & 0 & 0 & 0 & 0 & 0 & 0 & 1 & 0 \\ 3 & 0 & 0 & 0 & 0 & 0 & 0 & 0 & 0 & 0 & 0 \\ 4 & 0 & 0 & 0 & 0 & 0 & 0 & 0 & 0 & 0 & 0 \\ 5 & 0 & 0 & 0 & 0 & 0 & 0 & 0 & 0 & 0 & 0\end{array}$

COMP $V$

COMP $V$

COMP V

COMP V

COMP V

$\begin{array}{lllllllllll}1 & 0 & 0 & 0 & 0 & 0 & 1 & 0 & 0 & 0 & 0 \\ 2 & 0 & 0 & 0 & 0 & 0 & 0 & 0 & 0 & 0 & 0 \\ 3 & 0 & 0 & 0 & 0 & 0 & 0 & 0 & 0 & 0 & 0 \\ 4 & 0 & 0 & 0 & 0 & 0 & 0 & 0 & 0 & 0 & 0 \\ 5 & 0 & 0 & 0 & 0 & 0 & 0 & 0 & 0 & 0 & 1\end{array}$

COMP VI

COMP VI

COMP VI

COMP VI

COMP VI

$\begin{array}{lllllllllll}1 & 0 & 0 & 0 & 0 & 0 & 0 & 0 & 0 & 0 & 0 \\ 2 & 0 & 0 & 0 & 0 & 0 & 0 & 0 & 0 & 0 & 0 \\ 3 & 0 & 0 & 0 & 0 & 0 & 0 & 0 & 0 & 0 & 0 \\ 4 & 0 & 0 & 0 & 0 & 0 & 0 & 0 & 0 & 0 & 0 \\ 5 & 0 & 0 & 0 & 0 & 0 & 0 & 0 & 0 & 0 & 0\end{array}$

$\begin{array}{lllllllllll}1 & 0 & 0 & 0 & 0 & 0 & 0 & 0 & 0 & 0 & 0 \\ 2 & 0 & 0 & 0 & 0 & 0 & 0 & 0 & -0 & 0 & 0 \\ 3 & 0 & 0 & 0 & 0 & 0 & 0 & 0 & 0 & 0 & 0 \\ 4 & 0 & 0 & 0 & 0 & 0 & 0 & 0 & 0 & 0 & 0 \\ 5 & 0 & 0 & 0 & 0 & 0 & 0 & 0 & 0 & 0 & 0\end{array}$ 
IABLE D.5. (contd)

Sediment

Treatment

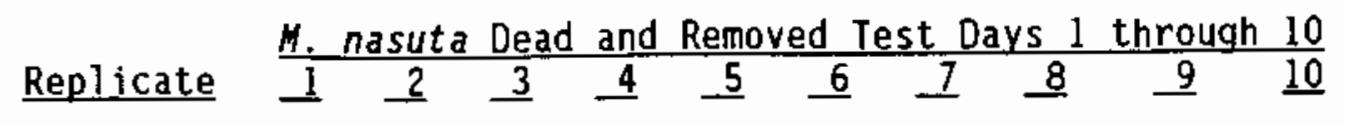

$\mathrm{R}-\mathrm{AC}$

$\mathrm{R}-\mathrm{AC}$

$\mathrm{R}-\mathrm{AC}$

$\mathrm{R}-\mathrm{AC}$

$R-A C$

R-AM

R-AM

R-AM

R-AM

R-AM

R-BF

$R-B F$

$R-B F$

$R-B F$

$\mathrm{R}-\mathrm{BF}$

R-OS

R-OS

R-OS

R-OS

R-OS

$R-P F$

R-PF

R-PF

R-PF

R-PF

C-SB

C-SB

C-SB

C-SB

C-SB

C-NE

C-NE

C-NE

C-NE

C-NE

$\begin{array}{lllllllllll}1 & 0 & 0 & 0 & 0 & 0 & 0 & 0 & 0 & 0 & 0 \\ 2 & 0 & 0 & 0 & 0 & 0 & 0 & 0 & 0 & 0 & 0 \\ 3 & 0 & 0 & 0 & 0 & 0 & 0 & 0 & 1 & 0 & 0 \\ 4 & 0 & 0 & 0 & 0 & 0 & 0 & 0 & 0 & 0 & 0 \\ 5 & 0 & 0 & 0 & 0 & 0 & 0 & 0 & 0 & 0 & 0\end{array}$

$\begin{array}{lllllllllll}1 & 0 & 0 & 0 & 0 & 0 & 0 & 0 & 0 & 0 & 0 \\ 2 & 0 & 0 & 0 & 0 & 1 & 0 & 0 & 0 & 0 & 0 \\ 3 & 0 & 0 & 0 & 0 & 0 & 0 & 0 & 0 & 0 & 0 \\ 4 & 0 & 0 & 0 & 1 & 0 & 0 & 0 & 0 & 0 & 0 \\ 5 & 0 & 0 & 0 & 0 & 0 & 0 & 0 & 0 & 0 & 0\end{array}$

$\begin{array}{lllllllllll}1 & 0 & 0 & 0 & 0 & 0 & 0 & 0 & 0 & 1 & 0 \\ 2 & 0 & 0 & 0 & 0 & 0 & 0 & 0 & 0 & 0 & 0 \\ 3 & 0 & 0 & 0 & 0 & 0 & 0 & 0 & 0 & 0 & 0 \\ 4 & 0 & 0 & 0 & 0 & 0 & 0 & 0 & 0 & 0 & 0 \\ 5 & 0 & 0 & 0 & 0 & 0 & 0 & 0 & 0 & 0 & 0\end{array}$

$\begin{array}{lllllllllll}1 & 0 & 0 & 0 & 0 & 0 & 0 & 0 & 0 & 0 & 0 \\ 2 & 0 & 0 & 0 & 0 & 0 & 0 & 0 & 0 & 0 & 0 \\ 3 & 0 & 0 & 0 & 0 & 0 & 0 & 0 & 0 & 0 & 0 \\ 4 & 0 & 0 & 0 & 0 & 0 & 0 & 0 & 0 & 0 & 0 \\ 5 & 0 & 0 & 0 & 0 & 0 & 0 & 1 & 0 & 0 & 0\end{array}$

$\begin{array}{lllllllllll}1 & 0 & 0 & 0 & 0 & 0 & 0 & 0 & 0 & 0 & 0 \\ 2 & 0 & 0 & 0 & 0 & 0 & 0 & 0 & 0 & 0 & 0 \\ 3 & 0 & 0 & 0 & 0 & 0 & 0 & 0 & 0 & 0 & 0 \\ 4 & 0 & 0 & 0 & 0 & 0 & 0 & 0 & 0 & 0 & 0 \\ 5 & 0 & 0 & 0 & 1 & 0 & 0 & 0 & 0 & 0 & 0\end{array}$

$\begin{array}{lllllllllll}1 & 0 & 0 & 0 & 0 & 0 & 0 & 0 & 0 & 0 & 0 \\ 2 & 0 & 0 & 0 & 0 & 0 & 0 & 0 & 0 & 0 & 0 \\ 3 & 0 & 0 & 0 & 0 & 0 & 0 & 0 & 0 & 0 & 0 \\ 4 & 0 & 0 & 0 & 0 & 0 & 0 & 0 & 0 & 0 & 0 \\ 5 & 0 & 0 & 0 & 0 & 0 & 0 & 0 & 0 & 0 & 0\end{array}$

$\begin{array}{lllllllllll}1 & 0 & 0 & 0 & 0 & 0 & 0 & 0 & 0 & 0 & 0 \\ 2 & 0 & 0 & 0 & 0 & 0 & 0 & 0 & 0 & 0 & 0 \\ 3 & 0 & 0 & 0 & 0 & 0 & 0 & 1 & 0 & 0 & 0 \\ 4 & 0 & 0 & 0 & 0 & 0 & 0 & 0 & 0 & 0 & 0 \\ 5 & 0 & 0 & 0 & 0 & 0 & 0 & 0 & 0 & 0 & 0\end{array}$ 
IABLE D.6. Water Quality Sumary for 10-Day M. nasuta/N. caecoides Solid-Phase Test, Richmond Harbor Program

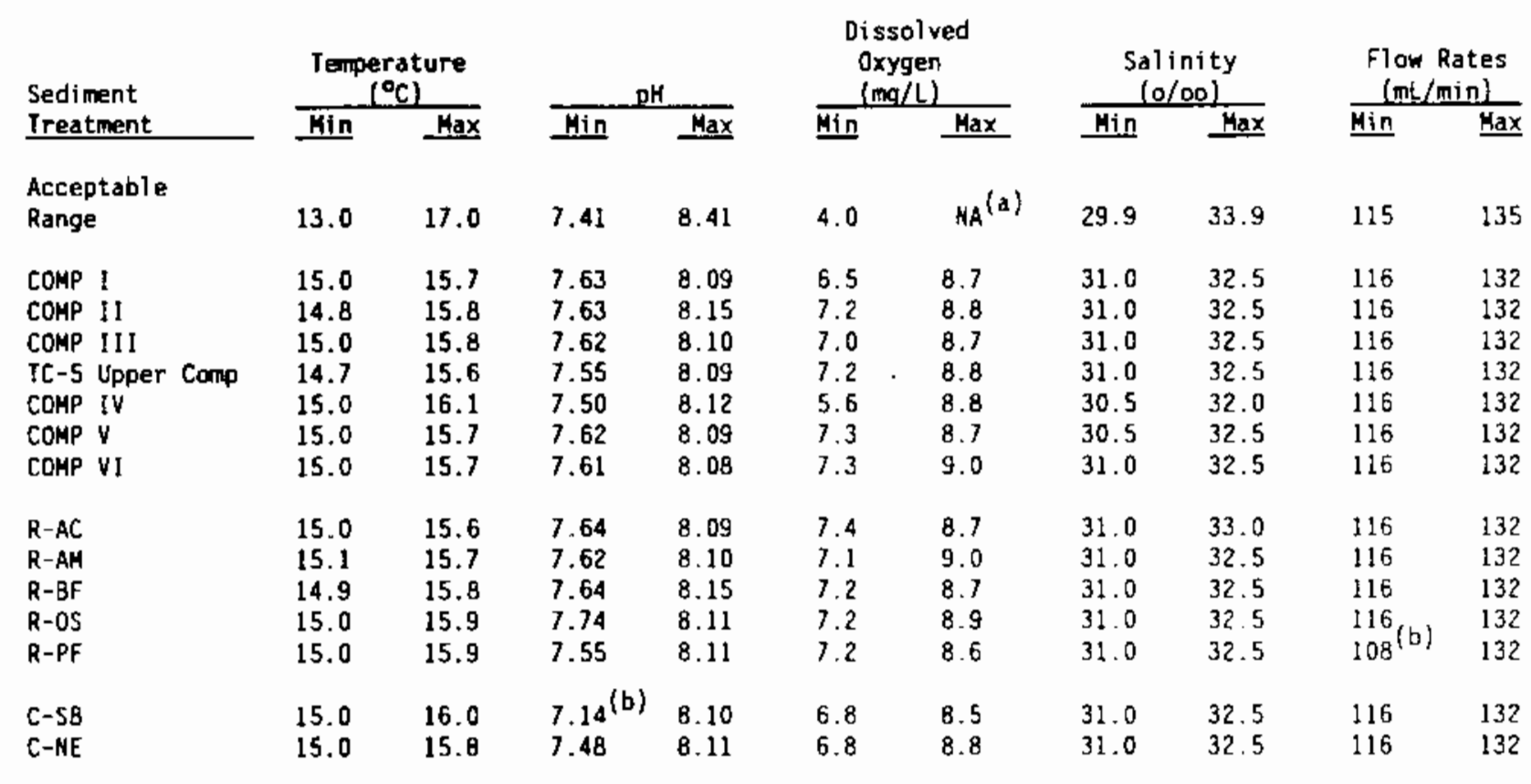

(a) Not applicable.

(b) Data point out of range. 
IABLE 0.7. Test Results for 10-Day N. caecoides Solid-Phase Test, Richmond Harbor Program

\begin{tabular}{|c|c|c|c|c|}
\hline \multirow[b]{2}{*}{$\begin{array}{l}\text { Sediment } \\
\text { Ireatment }\end{array}$} & \multirow[b]{2}{*}{ Replicate } & \multicolumn{2}{|c|}{ N. caecoides } & \multirow{2}{*}{$\begin{array}{c}\text { Mean } \\
\text { Proportion } \\
\text { Surviving }\end{array}$} \\
\hline & & Live $^{(a)}$ & $\begin{array}{c}\text { Dead } \\
\text { or Missing }\end{array}$ & \\
\hline $\begin{array}{l}\text { COMP I } \\
\text { COMP I } \\
\text { COMP I } \\
\text { COMP I } \\
\text { COMP I }\end{array}$ & $\begin{array}{l}1 \\
2 \\
3 \\
4 \\
5\end{array}$ & $\begin{array}{l}19 \\
17 \\
16 \\
19 \\
20\end{array}$ & $\begin{array}{l}1 \\
3 \\
4 \\
1 \\
0\end{array}$ & 0.91 \\
\hline $\begin{array}{l}\text { COMP II } \\
\text { COMP II } \\
\text { COMP II } \\
\text { COMP II } \\
\text { COMP II }\end{array}$ & $\begin{array}{l}1 \\
2 \\
3 \\
4 \\
5\end{array}$ & $\begin{array}{l}17 \\
18 \\
18 \\
17 \\
19\end{array}$ & $\begin{array}{l}3 \\
2 \\
2 \\
3 \\
1\end{array}$ & 0.89 \\
\hline $\begin{array}{l}\text { COMP II } \\
\text { COMP II } \\
\text { COMP II } \\
\text { COMP III } \\
\text { COMP III }\end{array}$ & $\begin{array}{l}1 \\
2 \\
3 \\
4 \\
5\end{array}$ & $\begin{array}{r}18 \\
18 \\
18 \\
16 \\
9\end{array}$ & $\begin{array}{r}2 \\
2 \\
2 \\
4 \\
11\end{array}$ & 0.79 \\
\hline $\begin{array}{l}\text { TC-5 Upper Comp } \\
\text { TC-5 Upper Comp } \\
\text { TC-5 Upper Comp } \\
\text { TC-5 Upper Comp } \\
\text { TC-5 Upper Comp }\end{array}$ & $\begin{array}{l}1 \\
2 \\
3 \\
4 \\
5\end{array}$ & $\begin{array}{l}14 \\
15 \\
14 \\
18 \\
18\end{array}$ & $\begin{array}{l}6 \\
5 \\
6 \\
2 \\
2\end{array}$ & 0.79 \\
\hline $\begin{array}{l}\text { COMP IV } \\
\text { COMP IV } \\
\text { COMP IV } \\
\text { COMP IV } \\
\text { COMP IV }\end{array}$ & $\begin{array}{l}1 \\
2 \\
3 \\
4 \\
5\end{array}$ & $\begin{array}{l}17 \\
15 \\
13 \\
12 \\
16\end{array}$ & $\begin{array}{l}3 \\
5 \\
7 \\
8 \\
4\end{array}$ & 0.73 \\
\hline $\begin{array}{l}\text { COMP V } \\
\text { COMP V } \\
\text { COMP V } \\
\text { COMP V } \\
\text { COMP V }\end{array}$ & $\begin{array}{l}1 \\
2 \\
3 \\
4 \\
5\end{array}$ & $\begin{array}{l}19 \\
18 \\
18 \\
19 \\
19\end{array}$ & $\begin{array}{l}1 \\
2 \\
2 \\
1 \\
1\end{array}$ & 0.93 \\
\hline $\begin{array}{l}\text { COMP VI } \\
\text { COMP VI } \\
\text { COMP VI } \\
\text { COMP VI } \\
\text { COMP VI }\end{array}$ & $\begin{array}{l}1 \\
2 \\
3 \\
4 \\
5\end{array}$ & $\begin{array}{l}17 \\
19 \\
20 \\
17 \\
18\end{array}$ & $\begin{array}{l}3 \\
1 \\
0 \\
3 \\
2\end{array}$ & 0.91 \\
\hline
\end{tabular}


IABLE D.7. (contd)

Sediment

Ireatment

$\mathrm{R}-\mathrm{AC}$

$R-A C$

$R-A C$

$R-A C$

$\mathrm{R}-\mathrm{AC}$

R-AM

R-AM

R-AM

R-AM

R-AM

$R-B F$

$R-B F$

$R-B F$

$R-B F$

$R-B F$

$\mathrm{R}-\mathrm{OS}$

$R-0 S$

R-OS

R-OS

R-OS

$R-P F$

$R-P F$

$R-P F$

$R-P F$

R-PF

C-SB

$C-S B$

C-SB

C-SB

C-SB

C-NE

C-NE

$\mathrm{C}-\mathrm{NE}$

$\mathrm{C}-\mathrm{NE}$

C-NE

Live $^{(a)}$
19
18
17
19
18

19

18

18

19

19

17

17

19

19

20

20

20

19

17

19

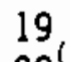

$29^{(b)}$

19

20

20

20

20

20

20

20

18

19

20

18

20
Mean

Proportion

Surviving

0.91

3
1
2

0.93

0.92

0.95

0.97

1.00

0.95

(a) Survival based on initial exposure of 20 individuals per replicate.

(b) Based on exposure of 30 individuals. 
IABLE D.8. Rank Order Based on Mean Proportion Surviving for 10-Day N. caecoides Solid-Phase Test, Richmond Harbor Program

\section{Sediment \\ Treatment}

COMP IV
COMP II
TC-5 Upper Comp
COMP II
R-AC
COMP I
COMP VI
R-BF
R-AM
COMP V
R-OS
C-NE
R-PF
C-SB

Mean

Proportion

Surviving

0.73
0.79
0.79
0.89
0.91
0.91
0.91
0.92
0.93
0.93
0.95
0.95
0.97
1.00 


\section{IABLE D.9. (contd)}

Sediment

Treatment

R-AC

R-AC

R-AC

R-AC

R-AC

R-AM

R-AM

R-AM

R-AM

R-AM

$R-B F$

$\mathrm{R}-\mathrm{BF}$

$R-B F$

$R-B F$

$\mathrm{R}-\mathrm{BF}$

R-OS

R-OS

R-OS

R-OS

R-OS

$R-P F$

$R-P F$

$R-P F$

$R-P F$

R-PF

C-SB

C-SB

$C-S B$

$C-S B$

C-SB

$\mathrm{C}-\mathrm{NE}$

$\mathrm{C}-\mathrm{NE}$

$\mathrm{C}-\mathrm{NE}$

$\mathrm{C}-\mathrm{NE}$

$\mathrm{C}-\mathrm{NE}$

$N$. Caecoides on Sediment Test Days 1 through 10

Replicate

1
2
3
4
5

$\begin{array}{llllllllll}0 & 0 & 0 & 0 & 1 & 0 & 0 & 0 & 0 & 0\end{array}$

$\begin{array}{llllllllll}0 & 0 & 0 & 0 & 0 & 0 & 0 & 0 & 0 & 0\end{array}$

$\begin{array}{llllllllll}0 & 0 & 0 & 0 & 1 & 0 & 0 & 0 & 0 & 0\end{array}$

$\begin{array}{llllllllll}0 & 1 & 1 & 0 & 0 & 0 & 0 & 0 & 0 & 0 \\ 0 & 1 & 1 & 0 & 0 & 0 & 0 & 0 & 1 & 0\end{array}$

1
2
3
4
5

$\begin{array}{llllllllll}0 & 0 & 0 & 0 & 0 & 0 & 0 & 0 & 0 & 0 \\ 0 & 0 & 0 & 0 & 0 & 0 & 0 & 0 & 0 & 0\end{array}$

$\begin{array}{llllllllll}0 & 0 & 0 & 0 & 0 & 0 & 0 & 0 & 0 & 0 \\ 0 & 0 & 0 & 1 & 0 & 0 & 0 & 0 & 0 & 0\end{array}$

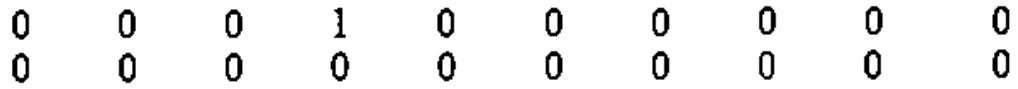

$\begin{array}{llllllllll}0 & 1 & 0 & 1 & 0 & 0 & 0 & 0 & 0 & 0\end{array}$

1
2
3
4

$\begin{array}{llllllllll}0 & 2 & 1 & 0 & 0 & 0 & 0 & 0 & 0 & 0\end{array}$

$\begin{array}{llllllllll}1 & 1 & 1 & 1 & 2 & 2 & 0 & 0 & 0 & 0\end{array}$

$\begin{array}{llllllllll}0 & 0 & 0 & 0 & 0 & 0 & 0 & 0 & 0 & 0\end{array}$

$\begin{array}{llllllllll}0 & 0 & 0 & 0 & 0 & 0 & 0 & 0 & 0 & 0 \\ 0 & 0 & 0 & 0 & 0 & 0 & 0 & 0 & 0 & 0\end{array}$

$\begin{array}{lllllllllll}1 & 0 & 0 & 0 & 0 & 2 & 0 & 0 & 0 & 0 & 0 \\ 2 & 0 & 0 & 0 & 0 & 0 & 0 & 0 & 0 & 0 & 0 \\ 3 & 0 & 0 & 1 & 0 & 0 & 0 & 0 & 0 & 0 & 0 \\ 4 & 2 & 1 & 1 & 1 & 0 & 0 & 0 & 0 & 0 & 0 \\ 5 & 1 & 0 & 0 & 0 & 0 & 0 & 0 & 0 & 0 & 0\end{array}$

$\begin{array}{lllllllllll}1 & 1 & 0 & 1 & 0 & 0 & 1 & 0 & 0 & 0 & 0 \\ 2 & 2 & 0 & 0 & 0 & 0 & 0 & 0 & 0 & 0 & 0 \\ 3 & 0 & 0 & 0 & 0 & 0 & 0 & 0 & 0 & 0 & 0 \\ 4 & 0 & 0 & 1 & 0 & 0 & 0 & 0 & 0 & 0 & 0 \\ 5 & 0 & 0 & 0 & 0 & 0 & 0 & 0 & 0 & 0 & 0\end{array}$

$\begin{array}{lllllllllll}1 & 0 & 0 & 0 & 0 & 0 & 0 & 0 & 0 & 0 & 0 \\ 2 & 1 & 0 & 0 & 0 & 0 & 0 & 0 & 0 & 0 & 0 \\ 3 & 0 & 0 & 0 & 0 & 0 & 0 & 0 & 0 & 0 & 0 \\ 4 & 0 & 1 & 0 & 0 & 0 & 0 & 0 & 0 & 0 & 0 \\ 5 & 1 & 1 & 0 & 0 & 0 & 0 & 0 & 0 & 0 & 0\end{array}$

$\begin{array}{lllllllllll}1 & 0 & 0 & 0 & 1 & 0 & 0 & 0 & 0 & 0 & 0 \\ 2 & 0 & 1 & 0 & 1 & 0 & 1 & 0 & 0 & 0 & 0 \\ 3 & 0 & 0 & 0 & 0 & 0 & 0 & 0 & 0 & 0 & 0 \\ 4 & 1 & 1 & 1 & 0 & 1 & 0 & 0 & 0 & 0 & 0 \\ 5 & 0 & 0 & 0 & 0 & 0 & 0 & 0 & 0 & 0 & 0\end{array}$ 
TABLE D.10. Daily Observations of N. caecoides Dead and Removed During 10-Day Solid-Phase Test, Richmond Harbor Program

Sediment

Ireatment

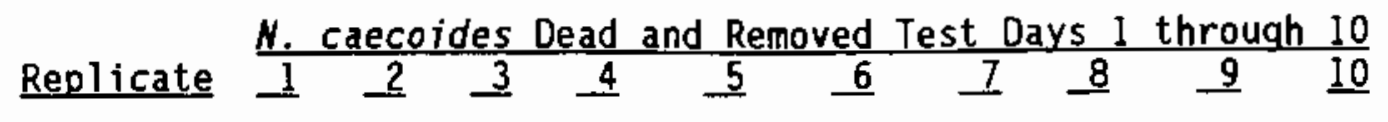

COMP I
COMP I
COMP I
COMP I
COMP I
COMP II
COMP II
COMP II
COMP II
COMP II
COMP II
COMP II
COMP II
COMP II
COMP II

TC-5 Upper Comp

TC-5 Upper Comp 2

TC-5 Upper Comp 3

TC-5 Upper Comp 4

TC-5 Upper Comp 5

$\begin{array}{lllllllllll}I & 0 & 0 & 1 & 0 & 0 & 0 & 0 & 0 & 0 & 0 \\ 2 & 0 & 0 & 0 & 0 & 0 & 0 & 0 & 0 & 0 & 0 \\ 3 & 0 & 0 & 0 & 0 & 0 & 0 & 0 & 0 & 0 & 0 \\ 4 & 0 & 0 & 0 & 0 & 0 & 0 & 0 & 0 & 0 & 0 \\ 5 & 0 & 0 & 0 & 0 & 0 & 0 & 0 & 0 & 0 & 0\end{array}$

$\begin{array}{lllllllllll}1 & 0 & 0 & 0 & 0 & 0 & 0 & 0 & 0 & 0 & 0 \\ 2 & 0 & 0 & 0 & 0 & 0 & 0 & 0 & 0 & 0 & 0 \\ 3 & 0 & 0 & 0 & 0 & 0 & 0 & 0 & 0 & 0 & 0 \\ 4 & 0 & 0 & 0 & 0 & 0 & 0 & 0 & 0 & 0 & 0 \\ 5 & 0 & 0 & 0 & 0 & 0 & 0 & 0 & 0 & 0 & 0\end{array}$

$\begin{array}{lllllllllll}1 & 0 & 0 & 0 & 0 & 0 & 0 & 1 & 0 & 0 & 0 \\ 2 & 0 & 0 & 0 & 0 & 0 & 0 & 0 & 0 & 0 & 0 \\ 3 & 0 & 0 & 0 & 0 & 0 & 0 & 0 & 0 & 0 & 0 \\ 4 & 0 & 0 & 1 & 0 & 0 & 0 & 0 & 0 & 0 & 0 \\ 5 & 0 & 0 & 0 & 0 & 0 & 0 & 0 & 0 & 0 & 0\end{array}$

COMP IV

COMP IV

COMP IV

COMP IV

COMP IV

$\begin{array}{lllllllllll}1 & 0 & 0 & 0 & 0 & 0 & 0 & 0 & 0 & 0 & 0 \\ 2 & 0 & 0 & 0 & 0 & 0 & 0 & 0 & 0 & 0 & 0 \\ 3 & 0 & 0 & 0 & 0 & 0 & 0 & 1 & 0 & 0 & 0 \\ 4 & 0 & 0 & 0 & 0 & 0 & 0 & 0 & 0 & 0 & 0 \\ 5 & 0 & 0 & 0 & 0 & 0 & 0 & 0 & 0 & 0 & 0\end{array}$

COMP $V$

COMP V

COMP V

COMP V

COMP V

COMP VI

COMP VI

COMP VI

COMP VI

COMP VI

$\begin{array}{lllllllllll}1 & 0 & 0 & 0 & 0 & 0 & 0 & 0 & 0 & 0 & 0 \\ 2 & 0 & 0 & 0 & 0 & 0 & 0 & 0 & 0 & 0 & 0 \\ 3 & 0 & 0 & 0 & 0 & 0 & 0 & 0 & 0 & 0 & 0 \\ 4 & 0 & 0 & 0 & 0 & 0 & 0 & 0 & 0 & 0 & 0 \\ 5 & 0 & 0 & 0 & 0 & 0 & 0 & 0 & 0 & 0 & 0\end{array}$

$\begin{array}{lllllllllll}1 & 0 & 0 & 1 & 0 & 0 & 0 & 0 & 0 & 0 & 0 \\ 2 & 0 & 0 & 0 & 0 & 0 & 0 & 0 & 0 & 0 & 0 \\ 3 & 0 & 0 & 0 & 0 & 0 & 0 & 0 & 0 & 0 & 0 \\ 4 & 0 & 0 & 0 & 0 & 0 & 0 & 0 & 0 & 0 & 0 \\ 5 & 0 & 0 & 1 & 0 & 0 & 0 & 1 & 0 & 0 & 0\end{array}$


TABLE D.10. (contd)

Sediment

Treatment

N. caecoides Dead and Removed Test Days 1 through 10

$\mathrm{R}-\mathrm{AC}$

$R-A C$

$\mathrm{R}-\mathrm{AC}$

$\mathrm{R}-\mathrm{AC}$

$\mathrm{R}-\mathrm{AC}$

Replicate $\stackrel{N \text {. caecoides Dead and }}{1} \underline{2} \stackrel{3}{4}$

$1 \quad 0 \quad 00000$

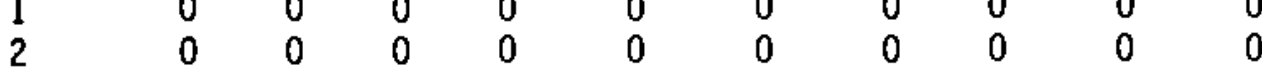

$\begin{array}{lllllllllll}3 & 0 & 0 & 0 & 0 & 0 & 0 & 0 & 0 & 0 & 0\end{array}$

$\begin{array}{lllllllllll}4 & 0 & 0 & 1 & 0 & 0 & 0 & 0 & 0 & 0 & 0 \\ 5 & 0 & 0 & 1 & 0 & 0 & 0 & 0 & 0 & 1 & 0\end{array}$

R-AM
R-AM

$\begin{array}{lllllllllll}1 & 0 & 0 & 0 & 0 & 0 & 0 & 0 & 0 & 0 & 0 \\ 2 & 0 & 0 & 0 & 0 & 0 & 0 & 0 & 0 & 0 & 0 \\ 3 & 0 & 0 & 0 & 1 & 0 & 0 & 0 & 0 & 0 & 0 \\ 4 & 0 & 0 & 0 & 0 & 0 & 0 & 0 & 0 & 0 & 0 \\ 5 & 0 & 0 & 0 & 1 & 0 & 0 & 0 & 0 & 0 & 0\end{array}$

$R-A M$

$\mathrm{R}-\mathrm{AM}$

$R-B F$

$\mathrm{R}-\mathrm{OS}$

$\mathrm{R}-\mathrm{OS}$

$\mathrm{R}-\mathrm{OS}$

$\mathrm{R}-\mathrm{OS}$

$\mathrm{R}-\mathrm{OS}$

$R-P F$

$R-P F$

$R-P F$

$R-P F$

$R-P F$

$C-S B$

$C-S B$

$C-S B$

$C-S B$

C-SB

C-NE

C-NE

$\mathrm{C}-\mathrm{NE}$

C-NE

$\mathrm{C}-\mathrm{NE}$

\section{$\begin{array}{llll}0 & 0 & 0 & 0\end{array}$}

$\begin{array}{llll}0 & 0 & 0 & 0\end{array}$

$\begin{array}{llll}0 & 0 & 0 & 0\end{array}$

$\begin{array}{lllll}3 & 0 & 0 & 0 & 0 \\ 4 & 0 & 0 & 0 & 0 \\ 5 & 0 & 0 & 0 & 0\end{array}$

0

$\begin{array}{lllll}0 & 0 & 0 & 0 & 0 \\ 2 & 0 & 0 & 0 & 0 \\ 0 & 0 & 0 & 0 & 0 \\ 0 & 0 & 0 & 0 & 0 \\ 0 & 0 & 0 & 0 & 0\end{array}$

$\begin{array}{lllll}1 & 0 & 0 & 0 & 0 \\ 2 & 0 & 0 & 0 & 0 \\ 3 & 0 & 0 & 1 & 0 \\ 4 & 0 & 0 & 1 & 0 \\ 5 & 0 & 0 & 0 & 0\end{array}$

$\begin{array}{lllll}1 & 0 & 0 & 1 & 0 \\ 2 & 0 & 0 & 0 & 0 \\ 3 & 0 & 0 & 0 & 0 \\ 4 & 0 & 0 & 0 & 0 \\ 5 & 0 & 0 & 0 & 0\end{array}$

$\begin{array}{lllll}1 & 0 & 0 & 0 & 0 \\ 2 & 0 & 0 & 0 & 0 \\ 3 & 0 & 0 & 0 & 0 \\ 4 & 0 & 0 & 0 & 0 \\ 5 & 0 & 0 & 0 & 0\end{array}$

1
2
3
4
5

$\begin{array}{lllll}0 & 0 & 0 & 1 & 0 \\ 0 & 0 & 0 & 1 & 0\end{array}$

0

$\begin{array}{llllll}3 & 0 & 0 & 0 & 0 & 0 \\ 4 & 0 & 0 & 1 & 0 & 1\end{array}$

$\begin{array}{llll}0 & 0 & 1 & 0 \\ 0 & 0 & 0 & 0\end{array}$

1

$\begin{array}{lll}0 & 0 & 0 \\ 0 & 0 & 0\end{array}$

$\begin{array}{ll}0 & 0 \\ 0 & 0 \\ 0 & 0 \\ 0 & 0 \\ 0 & 0\end{array}$ 

APPENDIX E

BIOASSAYRESULTS FOR 28-DAY SOLID-PHASE TEST WITH MACOMA nasuta and NEPHTYS caecoides 
IABLE.E.1. Test Results for 28-Day M. nasuta Solid-Phase Test, Richmond Harbor Program

\begin{tabular}{|c|c|c|c|c|}
\hline \multirow[b]{2}{*}{$\begin{array}{l}\text { Sediment } \\
\text { Ireatment }\end{array}$} & \multirow[b]{2}{*}{ Replicate } & \multicolumn{2}{|c|}{ M. nasuta } & \multirow{2}{*}{$\begin{array}{c}\text { Mean } \\
\text { Proportion } \\
\text { Survivine }\end{array}$} \\
\hline & & Live ${ }^{(a)}$ & $\begin{array}{c}\text { Dead } \\
\text { or Missing }\end{array}$ & \\
\hline $\begin{array}{ll}\text { COMP } & \text { I } \\
\text { COMP } & \text { I } \\
\text { COMP } & \text { I } \\
\text { COMP } & \text { I } \\
\text { COMP } & \text { I }\end{array}$ & $\begin{array}{l}1 \\
2 \\
3 \\
4 \\
5\end{array}$ & $\begin{array}{l}24 \\
25 \\
22 \\
22 \\
22\end{array}$ & $\begin{array}{l}1 \\
0 \\
3 \\
3 \\
3\end{array}$ & 0.92 \\
\hline $\begin{array}{l}\text { COMP II } \\
\text { COMP II } \\
\text { COMP II } \\
\text { COMP II } \\
\text { COMP II }\end{array}$ & $\begin{array}{l}1 \\
2 \\
3 \\
4 \\
5\end{array}$ & $\begin{array}{l}22 \\
22 \\
23 \\
23 \\
22\end{array}$ & $\begin{array}{l}3 \\
3 \\
2 \\
2 \\
3\end{array}$ & 0.90 \\
\hline $\begin{array}{l}\text { COMP I I I } \\
\text { COMP I I } \\
\text { COMP I I } \\
\text { COMP II I } \\
\text { COMP II I }\end{array}$ & $\begin{array}{l}1 \\
2 \\
3 \\
4 \\
5\end{array}$ & $\begin{array}{l}25 \\
22 \\
24 \\
23 \\
22\end{array}$ & $\begin{array}{l}0 \\
3 \\
1 \\
2 \\
3\end{array}$ & 0.93 \\
\hline $\begin{array}{l}\text { TC-5 Upper Comp } \\
\text { TC-5 Upper Comp } \\
\text { TC -5 Upper Comp } \\
\text { TC-5 Upper Comp } \\
\text { TC -5 Upper Comp }\end{array}$ & $\begin{array}{l}1 \\
2 \\
3 \\
4 \\
5\end{array}$ & $\begin{array}{l}22 \\
21 \\
24 \\
17 \\
21\end{array}$ & $\begin{array}{l}3 \\
4 \\
1 \\
8 \\
4\end{array}$ & 0.84 \\
\hline $\begin{array}{l}\text { COMP IV } \\
\text { COMP IV } \\
\text { COMP IV } \\
\text { COMP IV } \\
\text { COMP IV }\end{array}$ & $\begin{array}{l}1 \\
2 \\
3 \\
4 \\
5\end{array}$ & $\begin{array}{l}19 \\
19 \\
24 \\
20 \\
24\end{array}$ & $\begin{array}{l}6 \\
6 \\
1 \\
5 \\
1\end{array}$ & 0.85 \\
\hline $\begin{array}{l}\text { COMP V } \\
\text { COMP V } \\
\text { COMP V } \\
\text { COMP V } \\
\text { COMP V }\end{array}$ & $\begin{array}{l}1 \\
2 \\
3 \\
4 \\
5\end{array}$ & $\begin{array}{l}24 \\
19 \\
22 \\
23 \\
25\end{array}$ & $\begin{array}{l}1 \\
6 \\
3 \\
2 \\
0\end{array}$ & 0.90 \\
\hline $\begin{array}{l}\text { COMP VI } \\
\text { COMP VI } \\
\text { COMP VI } \\
\text { COMP VI } \\
\text { COMP VI }\end{array}$ & $\begin{array}{l}1 \\
2 \\
3 \\
4 \\
5\end{array}$ & $\begin{array}{l}20 \\
23 \\
21 \\
21 \\
24\end{array}$ & $\begin{array}{l}5 \\
2 \\
4 \\
4 \\
1\end{array}$ & 0.87 \\
\hline
\end{tabular}

E. 1 
TABLE E.1. (contd)

Sediment

Treatment

$\mathrm{R}-\mathrm{AC}$

$\mathrm{R}-\mathrm{AC}$

$\mathrm{R}-\mathrm{AC}$

$\mathrm{R}-\mathrm{AC}$

$\mathrm{R}-\mathrm{AC}$

$\mathrm{R}-\mathrm{AM}$

$\mathrm{R}-\mathrm{AM}$

$\mathrm{R}-\mathrm{AM}$

$\mathrm{R}-\mathrm{AM}$

$R-A M$

$R-B F$

$R-B F$

$R-B F$

$R-B F$

$R-B F$

$R-O S$

$\mathrm{R}-\mathrm{OS}$

$\mathrm{R}-\mathrm{OS}$

$\mathrm{R}-\mathrm{OS}$

R-OS

R-PF

$R-P F$

$R-P F$

$R-P F$

$R-P F$

C-SB

$\mathrm{C}-\mathrm{SB}$

$C-S B$

$\mathrm{C}-\mathrm{SB}$

C-SB

C-NE

$\mathrm{C}-\mathrm{NE}$

$\mathrm{C}-\mathrm{NE}$

$\mathrm{C}-\mathrm{NE}$

$\mathrm{C}-\mathrm{NE}$

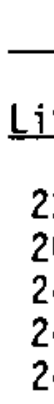

21

24

21

22

24

20

23

25

23

20

22

23

24

23

22

21

24

22

24

21

$\begin{array}{ll}25 & 0 \\ 24 & 1 \\ 24 & 1 \\ 22 & 3 \\ 24 & 1\end{array}$

25

19

23

23

22
Mean

Proportion

Surviving

0.91

0.90

0.89

0.91

0.90

0.95

0.90

(a) Survival based on initial exposure of 25 individuals per replicate. 
IABLE E.2. Rank Order Based on Mean Proportion Surviving 28-Day M. nasuta Solid-Phase Test, Richmond Harbor Program

Sediment
Ireatment
TC-5 Upper Comp
COMP IV
COMP VI
R-BF
COMP II
C-NE
R-AM
R-PF
COMP V
R-AC
R-OS
COMP I
COMP III
C-SB

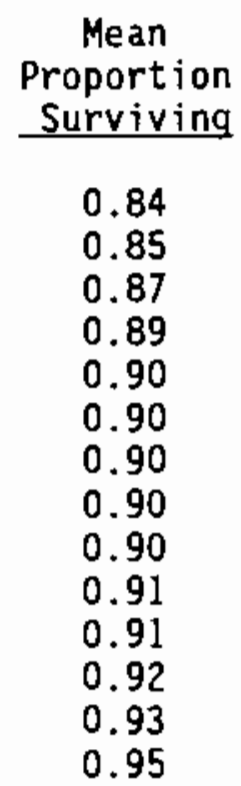



TABLE E.3. DaiTy Observations of M. nasuta on Sediment Surface During 28-Day Solid-Phase Test,
Richmond Harbor Program

Sediment Treatment

$M$ nosuta on Sediment Test Days 1 through 28

COMP I

COMP I

COMP I

COMP I

COMP 1

COMP II

COMP II

COMP II

COMP II

COMP II

COMP III

COMP III

COMP III

COMP III

$m$

COMP III Repilicate

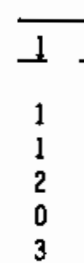

TC-5 upper Comp

IC-5 Upper Comp

TC-5 Upper Comp

TC-5 Upper Comp

TC-5 Upper Comp

COMP IV

COMP IV

COMP IV

COMP IN

COHP IV

COMP $V$

COMP $V$

COMP $V$

COMP $V$

COMP $V$

$\begin{array}{llllllllllllllllllllllllllllll}1 & 1 & 0 & 1 & 0 & 1 & 0 & 0 & 0 & 0 & 1 & 0 & 0 & 0 & 0 & 0 & 0 & 0 & 0 & 0 & 0 & 0 & 0 & 0 & 0 & 0 & 0 & 0 \\ 1 & 1 & 1 & 0 & 0 & 0 & 0 & 0 & 0 & 0 & 0 & 0 & 0 & 0 & 0 & 0 & 0 & 0 & 0 & 0 & 0 & 0 & 0 & 0 & 0 & 0 & 0 & 0 \\ 2 & 3 & 2 & 2 & 1 & 1 & 1 & 1 & 0 & 0 & 0 & 0 & 0 & 2 & 0 & 0 & 0 & 0 & 0 & 2 & 0 & 1 & 0 & 0 & 0 & 0 & 0 & 0 \\ 0 & 2 & 0 & 0 & 0 & 0 & 0 & 0 & 0 & 0 & 0 & 0 & 0 & 0 & 0 & 0 & 0 & 0 & 0 & 0 & 0 & 0 & 0 & 0 & 0 & 1 & 0 & 0 \\ 3 & 4 & 1 & 2 & 2 & 2 & 1 & 2 & 2 & 3 & 2 & 2 & 3 & 2 & 1 & 1 & 0 & 1 & 1 & 1 & 1 & 1 & 0 & 0 & 0 & 0 & 2 & 0 \\ 6 & 5 & 2 & 2 & 3 & 3 & 3 & 3 & 4 & 2 & 2 & 2 & 2 & 1 & 1 & 1 & 1 & 1 & 0 & 2 & 1 & 1 & 1 & 0 & 0 & 0 & 0 & 0 \\ 3 & 3 & 1 & 1 & 0 & 1 & 0 & 1 & 0 & 0 & 0 & 1 & 0 & 1 & 1 & 0 & 0 & 0 & 0 & 1 & 0 & 0 & 0 & 0 & 0 & 1 & 1 & 1 \\ 3 & 4 & 1 & 1 & 0 & 1 & 0 & 1 & 1 & 1 & 1 & 1 & 1 & 2 & 1 & 0 & 1 & 0 & 0 & 2 & 0 & 1 & 0 & 0 & 1 & 1 & 1 & 0 \\ 3 & 3 & 1 & 1 & 2 & 1 & 1 & 1 & 1 & 1 & 1 & 1 & 1 & 1 & 0 & 0 & 0 & 0 & 0 & 1 & 1 & 1 & 1 & 1 & 1 & 0 & 0 & 0 \\ 1 & 3 & 0 & 1 & 1 & 1 & 1 & 1 & 1 & 1 & 1 & 1 & 1 & 1 & 0 & 0 & 0 & 0 & 0 & 1 & 0 & 1 & 1 & 0 & 2 & 1 & 2 & 0 \\ & & & & & & & & & & & & & & & & & & & & & & & & & & & \\ 0 & 0 & 0 & 0 & 1 & 0 & 0 & 0 & 0 & 0 & 0 & 0 & 0 & 0 & 0 & 0 & 0 & 0 & 0 & 0 & 0 & 0 & 0 & 0 & 0 & 1 & 0 & 0 \\ 6 & 7 & 5 & 3 & 5 & 3 & 4 & 4 & 3 & 2 & 1 & 1 & 1 & 2 & 1 & 1 & 1 & 1 & 1 & 3 & 0 & 0 & 0 & 0 & 1 & 0 & 0 & 0 \\ 4 & 2 & 2 & 2 & 0 & 1 & 0 & 1 & 0 & 0 & 0 & 1 & 1 & 0 & 0 & 0 & 0 & 0 & 0 & 0 & 0 & 0 & 0 & 0 & 0 & 0 & 0 & 0 \\ 7 & 4 & 3 & 1 & 1 & 2 & 2 & 2 & 2 & 0 & 0 & 0 & 0 & 1 & 1 & 0 & 0 & 0 & 0 & 1 & 1 & 1 & 0 & 0 & 0 & 0 & 0 & 0 \\ 0 & 2 & 2 & 2 & 1 & 2 & 2 & 2 & 1 & 1 & 2 & 2 & 2 & 4 & 2 & 2 & 2 & 1 & 1 & 6 & 1 & 2 & 1 & 0 & 2 & 1 & 1 & 0\end{array}$

$\begin{array}{rrrrrr}7 & 10 & 5 & 3 & 3 & 2 \\ 4 & 2 & 2 & 1 & 1 & 1 \\ 2 & 3 & 0 & 1 & 0 & 2 \\ 17 & 14 & 8 & 3 & 3 & 3 \\ 14 & 11 & 6 & 4 & 2 & 2\end{array}$

$\begin{array}{ll}2 & 2 \\ 1 & 1 \\ 1 & 1 \\ 1 & 3 \\ 1 & 0\end{array}$

$\begin{array}{lllllll}1 & 1 & 0 & 1 & 1 & 1 & 0 \\ 1 & 2 & 0 & 0 & 0 & 0 & 0 \\ 0 & 0 & 0 & 0 & 0 & 0 & 0 \\ 2 & 3 & 3 & 3 & 2 & 3 & 3 \\ 1 & 2 & 1 & 1 & 1 & 4 & 1\end{array}$

$\begin{array}{lllllll}0 & 0 & 0 & 0 & 0 & 0 & 0 \\ 0 & 0 & 0 & 0 & 0 & 0 & 0\end{array}$

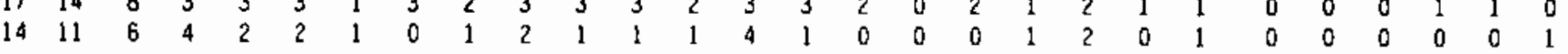

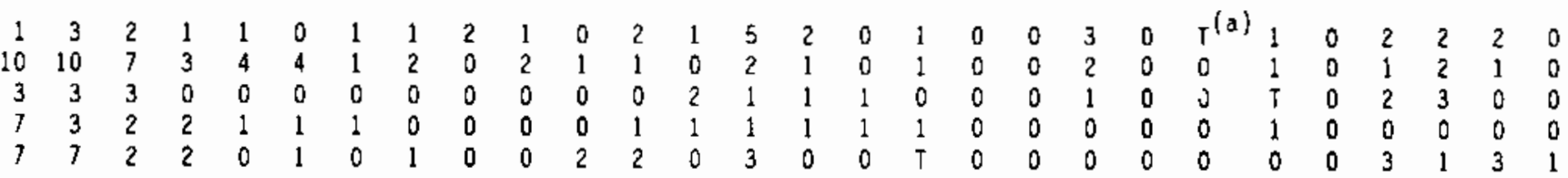

$\begin{array}{lllllllllllllllllllllllllllll}1 & 4 & 1 & 0 & 0 & 0 & 0 & 0 & 0 & 0 & 0 & 1 & 0 & 3 & 1 & 1 & 0 & 0 & 1 & 2 & 0 & 1 & 1 & 0 & 3 & 1 & 1 & 1 \\ 1 & 2 & 1 & 1 & 1 & 1 & 1 & 0 & 0 & 0 & 0 & 0 & 0 & 0 & 0 & 0 & 0 & 0 & 0 & 1 & 0 & 0 & 0 & 0 & 1 & 0 & 0 & 0 \\ 6 & 4 & 2 & 2 & 2 & 2 & 1 & 0 & 2 & 2 & 2 & 2 & 2 & 3 & 2 & 1 & 0 & 0 & 1 & 2 & 1 & 1 & 1 & 1 & 1 & 1 & 2 & 1 \\ 2 & 2 & 2 & 2 & 2 & 2 & 2 & 0 & 0 & 0 & 0 & 0 & 0 & 1 & 0 & 0 & 2 & 0 & 0 & 1 & 0 & 1 & 1 & 0 & 1 & 1 & 1 & 0 \\ 0 & 0 & 0 & 0 & 0 & 0 & 0 & 0 & 0 & 0 & 0 & 0 & 0 & 1 & 0 & 0 & 0 & 0 & 0 & 1 & 0 & 0 & 0 & 0 & 0 & 0 & 0 & 0\end{array}$


TABLE E.3. (contd)

Sediment

Ireatment

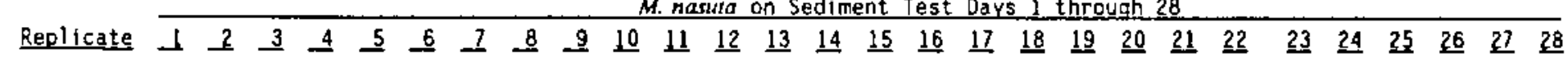

COMP V

COMP VI

COMP VI

$\mathrm{R}-\mathrm{AC}$

$R-A C$

$R-A C$

$R-A C$
$R-A C$

$\stackrel{m}{\text { in }}$

$R-A M$
$R-A M$

$R-A M$

R-AH

$R-B F$
$R-B F$
$R-B F$
$R-B F$
$R-B F$

$R-O S$
$R-O S$
$R-O S$
$R-O S$
$R-O S$
$R-P F$
$R-P F$
$R-P F$
$R-P F$
$R-P F$
$C-S B$
$C-S B$
$C-S B$
$C-S B$
$C-S B$

$\begin{array}{llllllllllllllllllllllllllllll}5 & 0 & 0 & 0 & 0 & 0 & 0 & 0 & 0 & 0 & 0 & 0 & 0 & 0 & 0 & 0 & 1 & 0 & 0 & 3 & 0 & 0 & 0 & 0 & 0 & 0 & 0 & 0 \\ 2 & 3 & 1 & 1 & 0 & 1 & 0 & 0 & 0 & 0 & 0 & 0 & 1 & 1 & 1 & 0 & 0 & 0 & 0 & 0 & 0 & 0 & 0 & 0 & 0 & 0 & 0 & 0 \\ 0 & 1 & 0 & 0 & 0 & 0 & 0 & 0 & 0 & 0 & 1 & 0 & 0 & 1 & 1 & 1 & 0 & 0 & 0 & 2 & 0 & 0 & 0 & 0 & 1 & 1 & 1 & 0 \\ 3 & 4 & 0 & 0 & 0 & 0 & 0 & 0 & 0 & 0 & 0 & 0 & 0 & 2 & 1 & 0 & 0 & 0 & 0 & 1 & 0 & 0 & 0 & 0 & 1 & 0 & 0 & 0 \\ 0 & 0 & 0 & 0 & 0 & 0 & 0 & 0 & 0 & 0 & 0 & 0 & 0 & 0 & 0 & 0 & 0 & 0 & 0 & 0 & 0 & 0 & 0 & 0 & 0 & 0 & 0 & 0\end{array}$

$\begin{array}{llllllllllllllllllllllllllll}0 & 2 & 1 & 1 & 0 & 0 & \mathrm{~T} & 0 & 0 & 0 & 0 & 0 & 0 & 4 & 2 & 0 & 1 & 1 & 1 & 0 & 0 & 1 & 0 & T & 0 & 1 & 1 & 1\end{array}$ $\begin{array}{llllllllllllllllllllllllllll}11 & 0 & 0 & 1 & 0 & 5 & 0 & 0 & 0 & 0 & 5 & 0 & 0 & 4 & 5 & 0 & 1 & 1 & 1 & 0 & 0 & 1 & 0 & 1 & 0 & 1 & 1 & 1\end{array}$ $\begin{array}{llllllllllllllllllllllllllllll}3 & 0 & 0 & 0 & 0 & 1 & 0 & 0 & 0 & \mathrm{~T} & \mathrm{~T} & 0 & \mathrm{~T} & 1 & 0 & 0 & 0 & 0 & 0 & 1 & 0 & 0 & 0 & 0 & 1 & 0 & 0 & 0 \\ 0 & 0 & 0 & 0 & 0 & 0 & 0 & 0 & 0 & 0 & 0 & 0 & 0 & 2 & 0 & 0 & 0 & 0 & 0 & 0 & 0 & 0 & 0 & 0 & 0 & 0 & 0 & 0\end{array}$ $\begin{array}{llllllllllllllllllllllllllll}0 & 0 & 0 & 0 & 0 & 0 & 0 & 0 & 0 & 0 & 0 & 0 & 0 & 2 & 1 & 0 & 0 & 0 & 0 & 1 & 0 & 0 & 0 & 0 & 1 & 0 & 0 & 0 \\ 2 & 2 & 2 & 2 & 0 & 0 & 0 & 0 & 0 & 0 & 0 & 0 & 0 & 0 & 0 & 0 & 0 & 0 & 0 & 1 & 0 & 0 & 0 & 0 & 0 & 0 & 0 & 0\end{array}$ 1
2
3
4
5 $\begin{array}{llll}1 & 3 & 1 & 2 \\ 2 & 5 & 3 & 3 \\ 0 & 0 & 0 & 1 \\ 11 & 2 & 1 & 1\end{array}$

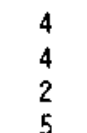

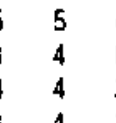
$\begin{array}{llll}5 & 7 & 6 & 8 \\ 6 & 6 & 6 & 0 \\ 1 & 1 & 2 & 0\end{array}$

$\begin{array}{lllllllllllllll}6 & 5 & 5 & 4 & 5 & 4 & 5 & 3 & 5 & 5 & 4 & 6 & 2 & 3 & 2 \\ 6 & 5 & 7 & 5 & 4 & 4 & 8 & 2 & 5 & 4 & 4 & 4 & 2 & 4 & 3 \\ 3 & 2 & 0 & 1 & 0 & 0 & 3 & 3 & 4 & 3 & 4 & 4 & 3 & 3 & 1 \\ 3 & 2 & 0 & 2 & 1 & 1 & 2 & 0 & 1 & 1 & 2 & 3 & 7 & 4 & 4 \\ 3 & 3 & 1 & 3 & 4 & 3 & 3 & 3 & 3 & 2 & 2 & 2 & 2 & 0 & 2\end{array}$
$\begin{array}{rrrrrrrrrrrrrrrrrrrrrrrrrrrrrrr}8 & 11 & 3 & 4 & 1 & 2 & 1 & 0 & 1 & 1 & 1 & 1 & 1 & 1 & 1 & 2 & 0 & 0 & 0 & 0 & 0 & 0 & 0 & 0 & 0 & 0 & 0 & 0 \\ 2 & 2 & 1 & 1 & 1 & 1 & 1 & 0 & 1 & 2 & 2 & 0 & 0 & 0 & 0 & 0 & 0 & 0 & 0 & 0 & 0 & 0 & 0 & 0 & 0 & 0 & 0 & 0 \\ 4 & 3 & 0 & 3 & 0 & 0 & 0 & 0 & 0 & 0 & 0 & 0 & 5 & 0 & 0 & 0 & 0 & 0 & 0 & 0 & 0 & 0 & 0 & 0 & 0 & 0 & 0 & 0 \\ 1 & 2 & 0 & 1 & 0 & 1 & 0 & 0 & 0 & 0 & 0 & 1 & 0 & 1 & 1 & 0 & 0 & 0 & 0 & 1 & 0 & 1 & 0 & 0 & 1 & 1 & 1 & 1 \\ 0 & 1 & 0 & 0 & 0 & 0 & 0 & 0 & 0 & 0 & 0 & 0 & 0 & 0 & 0 & 0 & 0 & 0 & 0 & 0 & 0 & 0 & 0 & 0 & 1 & 1 & 1 & 0\end{array}$ $\begin{array}{llllllllllllllllllllllllllll}4 & 4 & 2 & 1 & 2 & 1 & 2 & 0 & 1 & 0 & 1 & 1 & 1 & 2 & 2 & 1 & 1 & 1 & 1 & 2 & 1 & 1 & 1 & 1 & 1 & 0 & 0 & 0\end{array}$ $\begin{array}{llllllllllllllllllllllllllll}2 & 2 & 0 & 1 & 1 & 2 & 1 & 1 & 1 & 0 & 0 & 0 & 0 & 0 & 0 & 0 & 0 & 0 & 0 & 0 & 0 & 0 & 0 & 0 & 0 & 0 & 0 & 0\end{array}$

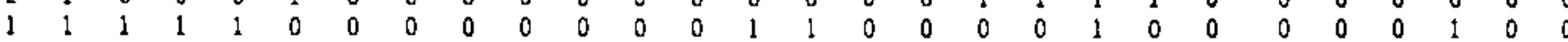
$\begin{array}{lllllllllllllllllllllllllllll}4 & 1 & 1 & 1 & 1 & 1 & 0 & 0 & 0 & 0 & 0 & 0 & 0 & 0 & 1 & 1 & 0 & 0 & 0 & 0 & 1 & 0 & 0 & 0 & 0 & 0 & 1 & 0 & 0 \\ 5 & 1 & 0 & 0 & 0 & 0 & 0 & 0 & 0 & 0 & 0 & 0 & 0 & 0 & 0 & 0 & 0 & 0 & 0 & 0 & 0 & 0 & 0 & 0 & 0 & 0 & 1 & 0 & 0\end{array}$

1
2
3
4
5

$\begin{array}{llllllllllllllllllllllllllll}0 & 2 & 0 & 0 & 0 & 1 & 1 & 0 & 0 & 0 & 1 & 2 & 2 & 2 & 2 & 0 & 2 & 2 & 0 & 5 & 1 & 3 & 2 & 2 & 3 & 1 & 1 & 1 \\ 0 & 0 & 0 & 0 & 0 & 0 & 0 & 1 & 0 & 0 & 0 & 0 & 0 & 0 & 0 & 0 & 0 & 0 & 0 & 0 & 0 & 0 & 1 & 0 & 2 & 0 & 2 & 0 \\ 1 & 1 & 1 & 0 & 0 & 0 & 0 & 0 & 0 & 1 & 2 & 2 & 1 & 3 & 1 & 1 & 2 & 1 & 1 & 2 & 1 & 1 & 2 & 2 & 2 & 0 & 1 & 0 \\ 0 & 0 & 0 & 0 & 0 & 0 & 0 & 0 & 0 & 0 & 0 & 0 & 0 & 2 & 0 & 0 & 0 & 0 & 0 & 1 & 1 & 1 & 1 & 0 & 0 & 0 & 0 & 0 \\ 0 & 1 & 0 & 0 & 0 & 1 & 1 & 0 & 0 & 0 & 1 & 1 & 1 & 1 & 0 & 1 & 0 & 1 & 0 & 0 & 0 & 0 & 1 & 0 & 2 & 1 & 4 & 1\end{array}$

$\begin{array}{lllllllllllllllllllllllllllll}1 & 0 & 0 & 0 & 0 & 0 & 0 & 0 & 0 & 0 & 0 & 0 & 0 & 0 & 0 & 0 & 0 & 0 & 0 & 0 & 0 & 0 & 0 & 0 & 0 & 0 & 0 & 0 \\ 0 & 0 & 0 & 0 & 0 & 0 & 0 & T & 0 & 0 & 0 & 0 & 0 & 0 & 0 & 0 & 0 & 0 & 0 & 0 & 0 & 0 & 1 & 0 & 1 & 0 & 0 & 0 \\ 1 & 1 & 0 & 1 & 0 & 1 & 0 & 0 & 0 & 4 & 0 & 0 & 0 & 1 & 0 & 0 & 0 & 0 & 0 & 0 & 0 & 0 & 0 & 0 & 0 & 0 & 0 & 0 \\ 0 & 0 & 0 & 0 & 0 & 0 & 0 & 0 & 0 & 0 & 0 & 0 & 0 & 5 & 1 & 0 & 1 & 1 & 0 & 3 & 0 & 0 & 0 & 0 & 1 & 2 & 0 & 0 \\ 1 & 1 & 0 & 1 & 0 & 0 & 0 & 0 & 0 & 0 & 0 & 0 & 0 & 1 & 1 & 0 & 1 & 0 & 0 & 0 & 0 & 0 & 0 & 0 & 0 & 0 & 0 & 0\end{array}$




\section{IABLE E.3. (contd)}

Sediment Ireatment

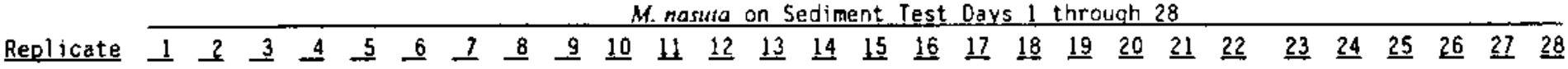

$\mathrm{C}-\mathrm{NE}$

C-NE
C-NE
C-NE

C-NE
C-NE
C-NE

$\begin{array}{lllllllllllllllllllllllllllllllllll}1 & 1 & 0 & 1 & 0 & 1 & 2 & 1 & 1 & 2 & 0 & 1 & 1 & 0 & 0 & 0 & 0 & 0 & 0 & 0 & 3 & 0 & 0 & 1 & 0 & 0 & 0 & 1 & 0 \\ 2 & 0 & 6 & 5 & 1 & 2 & 4 & 4 & 7 & 6 & 5 & 6 & 4 & 4 & 8 & 5 & 5 & 4 & 7 & 6 & 7 & 3 & 3 & 3 & 5 & 5 & 5 & 3 & 4 \\ 3 & 1 & 3 & 3 & 3 & 2 & 2 & 2 & 2 & 3 & 1 & 5 & 2 & 3 & 3 & 3 & 3 & 3 & 4 & 3 & 2 & 3 & 2 & 2 & 3 & 4 & 4 & 4 & 5 \\ 4 & 0 & 1 & 1 & 1 & 0 & 2 & 0 & 3 & 3 & 1 & 2 & 1 & 0 & 4 & 5 & 3 & 1 & 0 & 3 & 4 & 3 & 2 & 3 & 2 & 3 & 4 & 5 & 3 \\ 5 & 1 & 4 & 2 & 3 & 4 & 4 & 4 & 3 & 3 & 6 & 3 & 4 & 2 & 6 & 5 & 4 & 4 & 4 & 4 & 4 & 3 & 4 & 4 & 2 & 3 & 1 & 4 & 1\end{array}$

(a) T Too turbid to make accurate observation. 
TABLE E.4: Daily Observations of M. nasuta Siphons Exposed During 28-Day Solid-Phase Test, Richmond Harbor Program

Sediment Ireatment

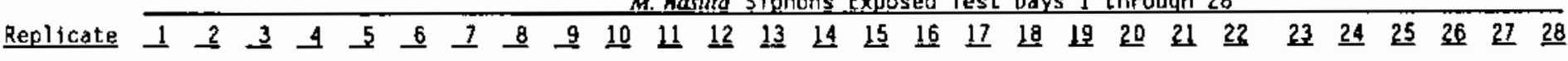

COMP ]

COMP 1

COMP I

COMP I

CONP 1

COMP 11

COHP II

COHP II

COMP II

COHP II

COHP III

CONP III

COHP III

COMP III

$m$

COMP III

TC-5 Upper Comp TC-5 Upper Comp TC-5 Upper Comp TC-5 Upper Comp TC-5 upper Comp

COHP IV

COMP IV

COHP IV

COMP IV

COMP IV

COMP $V$

COMP

COMP

COMP $\checkmark$

COMP $V$

$\begin{array}{rrrrrrrrrrrrrrrrrrrrrrrrrrrrrrrrrr}12 & 5 & 4 & 7 & 5 & 7 & 3 & 5 & 1 & 0 & 4 & 1 & 1 & 0 & 0 & 1 & 3 & 0 & 0 & 0 & 0 & 0 & 0 & 2 & 0 & 0 & 0 & 1 \\ 5 & 3 & 2 & 6 & 2 & 2 & 1 & 2 & 1 & 1 & 0 & 5 & 1 & 0 & 0 & 1 & 0 & 0 & 0 & 0 & 0 & 0 & 1 & 0 & 0 & 0 & 0 & 0 \\ 6 & 3 & 4 & 7 & 4 & 4 & 6 & 3 & 2 & 2 & 3 & 3 & 5 & 0 & 1 & 1 & 4 & 2 & 1 & 2 & 2 & 5 & 3 & 1 & 1 & 0 & 0 & 1 \\ 9 & 4 & 2 & 5 & 2 & 4 & 1 & 3 & 1 & 4 & 6 & 5 & 2 & 0 & 0 & 1 & 0 & 0 & 0 & 0 & 0 & 3 & 0 & 1 & 0 & 1 & 1 & 3 \\ 9 & 11 & 1 & 5 & 7 & 4 & 0 & 3 & 5 & 6 & 4 & 5 & 4 & 4 & 3 & 1 & 2 & 1 & 1 & 1 & 0 & 0 & 0 & 0 & 0 & 0 & 0 & 1\end{array}$

$\begin{array}{rrrrrrrrrrrrrrrrrrrrrrrrrrrrrr}7 & 9 & 6 & 10 & 7 & 8 & 7 & 8 & 7 & 6 & 7 & 4 & 5 & 2 & 2 & 4 & 4 & 3 & 1 & 1 & 3 & 2 & 2 & 0 & 0 & 0 & 0 & 0 \\ 8 & 6 & 4 & 3 & 2 & 2 & 1 & 1 & 0 & 1 & 2 & 2 & 1 & 0 & 1 & 0 & 1 & 0 & 1 & 1 & 1 & 1 & 1 & 0 & 0 & 0 & 0 & 2 \\ 4 & 10 & 4 & 7 & 5 & 11 & 6 & 4 & 2 & 3 & 3 & 4 & 4 & 1 & 2 & 2 & 1 & 1 & 1 & 1 & 1 & 1 & 0 & 0 & 0 & 0 & 0 & 1 \\ 10 & 7 & 2 & 5 & 4 & 4 & 3 & 2 & 2 & 2 & 3 & 2 & 1 & 1 & 1 & 2 & 2 & 0 & 0 & 0 & 0 & 1 & 1 & 0 & 0 & 0 & 0 & 1 \\ 7 & 5 & 7 & 4 & 1 & 5 & 1 & 3 & 1 & 2 & 3 & 1 & 0 & 0 & 0 & 1 & 1 & 0 & 0 & 0 & 0 & 0 & 1 & 0 & 0 & 0 & 1 & 1\end{array}$

$\begin{array}{rrrrrrrrrrrrrrrrrrrrrrrrrrrrr}6 & 5 & 5 & 12 & 10 & 3 & 2 & 2 & 2 & 1 & 2 & 0 & 2 & 0 & 0 & 0 & 0 & 0 & 2 & 0 & 0 & 2 & 0 & 1 & 0 & 1 & 0 & 1 \\ 16 & 14 & 7 & 12 & 9 & 6 & 5 & 6 & 4 & 3 & 4 & 7 & 3 & 1 & 1 & 4 & 2 & 1 & 2 & 1 & 0 & 1 & 2 & 0 & 0 & 0 & 1 & 1 \\ 8 & 3 & 7 & 9 & 6 & 9 & 3 & 9 & 3 & 4 & 2 & 2 & 3 & 1 & 0 & 0 & 1 & 0 & 0 & 0 & 0 & 1 & 1 & 0 & 0 & 0 & 0 & 0 \\ 17 & 16 & 13 & 9 & 9 & 9 & 3 & 9 & 6 & 3 & 8 & 3 & 6 & 2 & 5 & 4 & 1 & 1 & 1 & 0 & 1 & 1 & 2 & 0 & 0 & 0 & 0 & 0 \\ 1 & 9 & 3 & 8 & 5 & 7 & 4 & 4 & 6 & 5 & 8 & 4 & 3 & 4 & 2 & 2 & 7 & 1 & 5 & 0 & 2 & 2 & 0 & 1 & 1 & 3 & 0 & 1\end{array}$

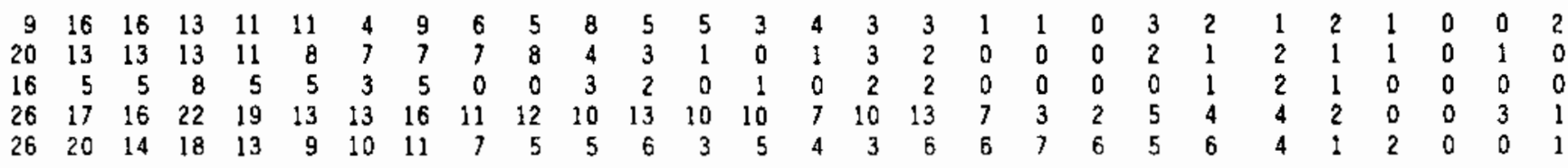

$\begin{array}{lllllllllllllllllllllllllllllllll}7 & 6 & 4 & 12 & 10 & 5 & 7 & 8 & 3 & 3 & 6 & 6 & 6 & 4 & 1 & 1 & 4 & 2 & 4 & 0 & 2 & T^{(a)} & 2 & 2 & 1 & 0 & 2 & 0\end{array}$

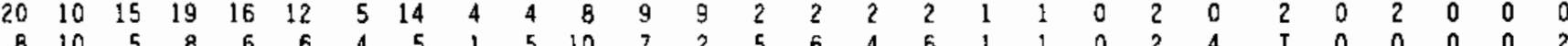
$\begin{array}{lllllllllllllllllllllllllllll}14 & 11 & 11 & 10 & 6 & 7 & 4 & 4 & 3 & 6 & 3 & 5 & 6 & 1 & 0 & 2 & 1 & 2 & 1 & 0 & 0 & 1 & 0 & 0 & 0 & 0 & 0 & 0\end{array}$ $\begin{array}{llllllllllllllllllllllllllllll}28 & 20 & 13 & 17 & 9 & 11 & 4 & 9 & 7 & 10 & 14 & 10 & 4 & 8 & 9 & 1 & \mathrm{~T} & 3 & 3 & 1 & 9 & 2 & 2 & 0 & 3 & 0 & 2 & 3\end{array}$

$\begin{array}{rrrrrrrrrrrrrrrrrrrrrrrrrrrrrrrrrrr}7 & 5 & 6 & 6 & 3 & 6 & 2 & 6 & 3 & 4 & 3 & 4 & 1 & 2 & 3 & 0 & 5 & 2 & 2 & 3 & 7 & 3 & 2 & 4 & 2 & 2 & 2 & 1 \\ 6 & 8 & 5 & 10 & 6 & 8 & 5 & 1 & 3 & 0 & 2 & 4 & 0 & 0 & 1 & 0 & 0 & 2 & 1 & 0 & 1 & 1 & 1 & 0 & 0 & 0 & 0 & 0 \\ 12 & 11 & 13 & 6 & 6 & 7 & 3 & 6 & 3 & 5 & 6 & 2 & 4 & 3 & 3 & 2 & 3 & 4 & 5 & 2 & 3 & 3 & 3 & 2 & 1 & 1 & 0 & 2 \\ 10 & 8 & 8 & 11 & 12 & 6 & 3 & 2 & 3 & 4 & 3 & 4 & 2 & 0 & 1 & 0 & 4 & 0 & 0 & 0 & 1 & 2 & 1 & 0 & 1 & 0 & 1 & 3 \\ 8 & 4 & 3 & 5 & 2 & 3 & 1 & 0 & 3 & 0 & 2 & 4 & 0 & 0 & 0 & 0 & 1 & 0 & 0 & 0 & 1 & 1 & 2 & 1 & 0 & 0 & 0 & 4\end{array}$




\section{TABLE E.4. (contd)}

Sediment

\section{Ireatment}

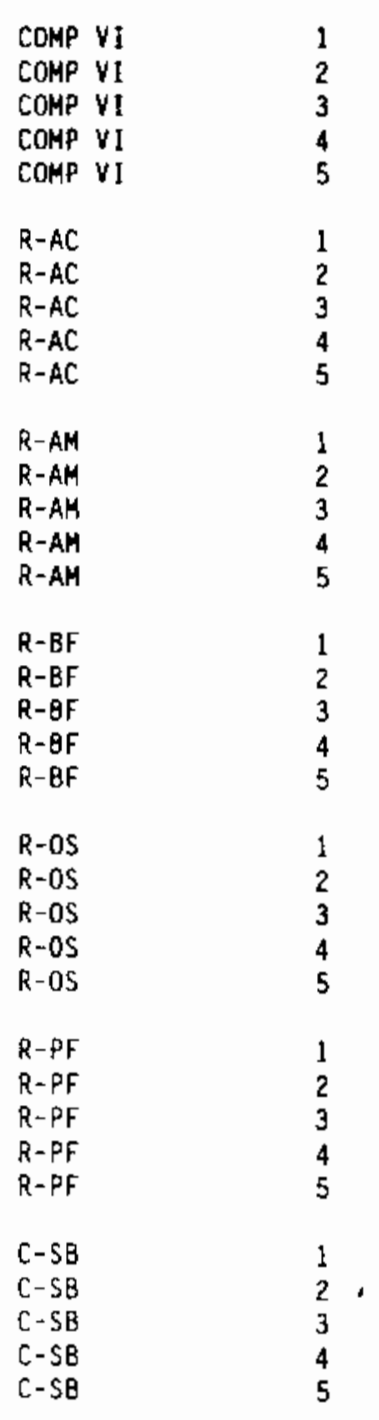

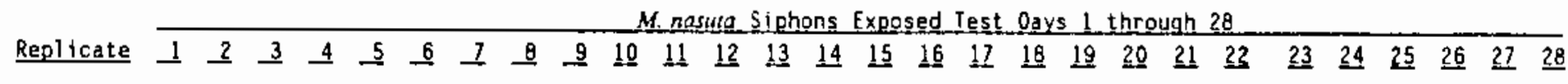

$\begin{array}{rrrlllllllllllllllllllllllll}9 & 4 & 6 & 9 & 5 & 4 & 2 & 5 & 0 & 2 & 1 & 0 & 1 & 0 & 0 & 3 & 1 & 0 & 2 & 0 & 0 & 3 & 1 & 1 & 0 & 0 & 1 & 0 \\ 16 & 5 & 4 & 6 & 6 & 6 & 2 & 2 & 3 & 2 & 5 & 6 & 2 & 5 & 2 & 2 & 4 & 1 & 1 & 1 & 2 & 4 & 1 & 1 & 1 & 0 & 1 & 0 \\ 3 & 4 & 7 & 8 & 4 & 4 & 0 & 1 & 2 & 1 & 2 & 4 & 2 & 0 & 0 & 0 & 4 & 2 & 0 & 0 & 2 & 2 & 1 & 0 & 0 & 0 & 0 & 0 \\ 14 & 9 & 4 & 3 & 0 & 1 & 1 & 1 & 4 & 3 & 4 & 4 & 1 & 5 & 2 & 2 & 1 & 1 & 0 & 0 & 1 & 2 & 0 & 0 & 0 & 0 & 0 & 0 \\ 10 & 6 & 5 & 6 & 3 & 5 & 2 & 2 & 2 & 1 & 4 & 3 & 2 & 1 & 2 & 2 & 2 & 0 & 0 & 0 & 0 & 1 & 0 & 0 & 0 & 1 & 0 & 0\end{array}$

$\begin{array}{rrrrrrrrrrrrrrrrrrrrrrrrrrrrr}8 & 10 & 6 & 11 & 4 & 4 & 1 & 3 & 3 & 4 & 7 & 3 & 5 & 0 & 2 & 1 & 4 & 2 & 1 & 0 & 0 & 5 & 1 & 1 & 0 & 0 & 1 & 4 \\ 28 & 13 & 11 & 10 & 6 & 9 & 2 & 8 & 8 & 3 & 9 & 2 & 4 & 1 & 4 & 6 & 3 & 4 & 3 & 0 & 0 & 2 & 0 & 0 & 0 & 0 & 0 & 0 \\ 10 & 4 & 6 & 9 & 5 & 6 & 2 & 2 & 2 & 1 & 1 & 2 & 1 & 2 & 3 & 3 & 2 & 1 & 0 & 0 & 0 & 2 & 0 & 0 & 0 & 1 & 0 & 0 \\ 4 & 4 & 3 & 8 & 7 & 8 & 8 & 5 & 5 & 5 & 5 & 6 & 5 & 1 & 1 & 1 & 4 & 1 & 2 & 0 & 1 & 2 & 2 & 0 & 0 & 0 & 0 & 0 \\ 8 & 7 & 11 & 13 & 9 & 5 & 2 & 2 & 1 & 1 & 3 & 4 & 2 & 0 & 3 & 6 & 1 & 2 & 3 & 1 & 0 & 1 & 2 & 0 & 0 & 0 & 0 & 0\end{array}$

$\begin{array}{llllllllllllllllllllllllllll}9 & 7 & 6 & 6 & 5 & 5 & 6 & 9 & 9 & 15 & 12 & 15 & 12 & 9 & 6 & 5 & 11 & 10 & 7 & 6 & 14 & 9 & 5 & 6 & 2 & 2 & 1 & 5\end{array}$ $\begin{array}{rrrrrrrrrrrrrrrrrrrrrrrrrrrrrr}5 & 8 & 3 & 9 & 8 & 12 & 13 & 8 & 8 & 12 & 12 & 13 & 12 & 10 & 7 & 11 & 5 & 5 & 6 & 4 & 4 & 6 & 5 & 7 & 4 & 2 & 4 & 3 \\ 1 & 0 & 7 & 1 & 1 & 6 & 5 & 5 & 3 & 2 & 13 & 4 & 1 & 4 & 2 & 2 & 3 & 3 & 2 & 0 & 1 & 3 & 2 & 1 & 0 & 0 & 0 & 2\end{array}$ $\begin{array}{rrrrrrrrrrrrrrrrrrrrrrrrrrrrrr}20 & 2 & 4 & 7 & 4 & 7 & 3 & 6 & 2 & 3 & 6 & 6 & 7 & 4 & 4 & 1 & 0 & 1 & 1 & 0 & 0 & 2 & 1 & 0 & 0 & 5 & 1 & 4 \\ 9 & 7 & 9 & 8 & 6 & 7 & 3 & 3 & 8 & 4 & 12 & 6 & 5 & 7 & 4 & 2 & 5 & 3 & 3 & 2 & 4 & 6 & 4 & 4 & 1 & 1 & 0 & 2\end{array}$

\section{$\stackrel{m}{\infty}$}

$\begin{array}{rrrrrrrrrrrrrrrrrrrrrrrrrrrrrrr}14 & 14 & 5 & 9 & 6 & 8 & 3 & 2 & 1 & 2 & 2 & 4 & 3 & 1 & 4 & 4 & 5 & 0 & 1 & 1 & 0 & 1 & 1 & 0 & 0 & 0 & 0 & 0 \\ 4 & 5 & 3 & 4 & 1 & 2 & 1 & 0 & 2 & 4 & 2 & 2 & 0 & 0 & 0 & 1 & 2 & 0 & 0 & 0 & 0 & 2 & 0 & 0 & 0 & 0 & 1 & 0 \\ 10 & 0 & 1 & 11 & 1 & 3 & 0 & 0 & 0 & 1 & 2 & 1 & 4 & 0 & 0 & 0 & 1 & 0 & 0 & 0 & 0 & 0 & 0 & 0 & 0 & 0 & 0 & 0 \\ 5 & 2 & 1 & 2 & 1 & 3 & 1 & 1 & 2 & 3 & 2 & 1 & 0 & 0 & 1 & 1 & 2 & 1 & 2 & 0 & 3 & 2 & 1 & 2 & 0 & 1 & 3 & 4 \\ 2 & 0 & 1 & 2 & 0 & 3 & 1 & 1 & 2 & 2 & 3 & 3 & 3 & 0 & 1 & 0 & 6 & 1 & 0 & 0 & 0 & 0 & 0 & 1 & 0 & 0 & 0 & 0 \\ 8 & 6 & 7 & 5 & 5 & 6 & 2 & 1 & 2 & 3 & 4 & 8 & 3 & 3 & 5 & 5 & 2 & 5 & 3 & 2 & 1 & 4 & 3 & 1 & 0 & 0 & 0 & 2 \\ 4 & 6 & 3 & 4 & 3 & 3 & 1 & 1 & 0 & 0 & 1 & 2 & 0 & 0 & 0 & 0 & 1 & 0 & 0 & 0 & 0 & 1 & 1 & 0 & 2 & 1 & 0 & 2 \\ 9 & 2 & 3 & 3 & 3 & 6 & 0 & 2 & 2 & 1 & 2 & 3 & 2 & 1 & 2 & 0 & 2 & 0 & 2 & 1 & 1 & 0 & 0 & 0 & 0 & 0 & 0 & 0 \\ 7 & 5 & 2 & 4 & 3 & 3 & 1 & 2 & 2 & 0 & 2 & 1 & 0 & 1 & 1 & 2 & 0 & 0 & 0 & 0 & 3 & 0 & 0 & 0 & 0 & 0 & 0 & 0 \\ 7 & 7 & 2 & 4 & 1 & 2 & 1 & 1 & 0 & 2 & 2 & 3 & 2 & 1 & 1 & 0 & 0 & 0 & 0 & 1 & 1 & 0 & 3 & 0 & 0 & 2 & 0 & 0\end{array}$

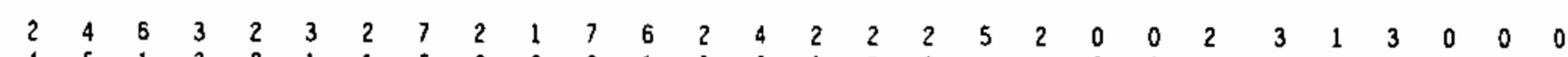

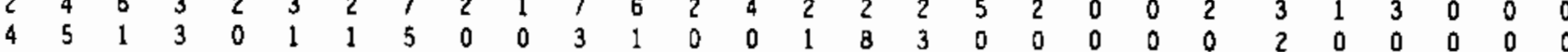
$\begin{array}{llllllllllllllllllllllllllllll}6 & 1 & 11 & 2 & 3 & 6 & 0 & 1 & 0 & 2 & 4 & 6 & 5 & 3 & 1 & 3 & 6 & 1 & 1 & 1 & 4 & 3 & 4 & 2 & 1 & 0 & 0 & 1\end{array}$ $\begin{array}{rrrrrrrrrrrrrrrrrrrrrrrrrrrrr}5 & 6 & 1 & 5 & 5 & 6 & 4 & 2 & 2 & 3 & 4 & 4 & 4 & 1 & 1 & 3 & 5 & 2 & 1 & 1 & 4 & 3 & 3 & 0 & 0 & 0 & 0 & 0 \\ & & 1 & 5 & & 0 & & 4 & 6 & 11 & 8 & 4 & 4 & 3 & 2 & 1 & 2 & 2 & 0 & 0 & 0 & 2 & 2 & 0 & 0 & 1 & 1 & 4\end{array}$

$\begin{array}{llllllllllllllllllllllllllll}13 & 1 & 1 & 6 & 2 & 3 & 2 & 2 & 3 & 2 & 2 & 2 & 2 & 0 & 1 & 1 & 2 & 1 & 0 & 0 & 0 & 0 & 0 & 0 & 0 & 0 & 0 & 0\end{array}$ $\begin{array}{llllllllllllllllllllllllllllll}6 & 2 & 2 & 5 & 4 & 2 & 0 & 1 & 1 & 0 & 1 & 0 & 0 & 0 & 1 & 2 & 2 & 1 & 1 & 1 & 0 & 0 & 1 & 0 & 0 & 0 & 0 & 0 \\ 2 & 2 & 0 & 4 & 4 & 2 & 1 & 0 & 1 & 5 & 1 & 3 & 0 & 0 & 0 & 0 & 2 & 0 & 0 & 0 & 0 & 0 & 1 & 0 & 0 & 0 & 0 & 0\end{array}$ $\begin{array}{llllllllllllllllllllllllllllll}4 & 3 & 3 & 5 & 2 & 3 & 2 & 2 & 4 & 5 & 5 & 2 & 2 & 0 & 1 & 2 & 5 & 2 & 3 & 3 & 2 & 3 & 2 & 4 & 0 & 1 & 1 & 3 \\ 2 & 4 & 3 & 4 & 2 & 1 & 0 & 0 & 1 & 1 & 2 & 1 & 2 & 0 & 0 & 3 & 0 & 0 & 0 & 0 & 0 & 1 & 1 & 0 & 0 & 0 & 1 & 0\end{array}$ 


\section{TABLE E.4. (contd)}

Sediment

M. nastua Siphons Exposed Test Days 1 through 28

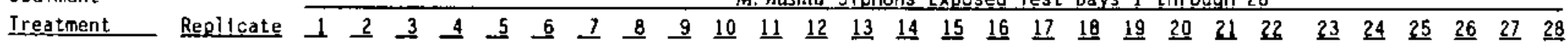

C-NE

$\mathrm{C}-\mathrm{NE}$

$\mathrm{C}-\mathrm{NE}$

$\mathrm{C}-\mathrm{NE}$

C-NE

$\begin{array}{lllllllllllllllllllllllllllllll}1 & 2 & 3 & 2 & 1 & 4 & 3 & 1 & 2 & 0 & 1 & 3 & 0 & 0 & 0 & 0 & 0 & 0 & 0 & 0 & 0 & 2 & 0 & 0 & 0 & 0 & 2 & 0\end{array}$ $\begin{array}{rrrrrrrrrrrrrrrrrrrrrrrrrrrrrrrrrr}5 & 8 & 6 & 10 & 6 & 9 & 7 & 12 & 10 & 10 & 10 & 8 & 11 & 5 & 7 & 3 & 11 & 4 & 2 & 6 & 3 & 0 & 0 & 0 & 1 & 1 & 3 & 2\end{array}$ $\begin{array}{lllllllllllllllllllllllllllll}4 & 0 & 8 & 2 & 2 & 8 & 4 & 3 & 5 & 3 & 7 & 8 & 2 & 4 & 4 & 1 & 3 & 4 & 6 & 1 & 6 & 3 & 3 & 4 & 3 & 2 & 0 & 2 \\ 4 & 3 & 6 & 6 & 7 & 7 & 7 & 3 & 7 & 6 & 6 & 7 & 0 & 6 & 8 & 4 & 2 & 3 & 6 & 5 & 4 & 4 & 0 & 2 & 4 & 5 & 3 & 1\end{array}$

(a) T Too turbid to make accurate observation. 
IABLE E.5. Daily Observations of M. nasuta Dead and Removed During 28-0ay Solid-Phase Test,
Richmond Harbor Program

Sediment Ireatment

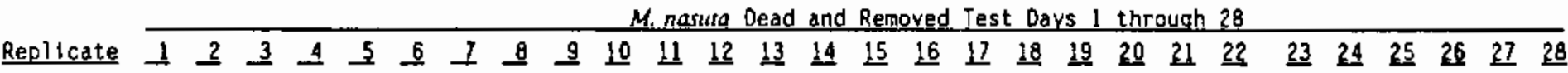

comp I

COMP I

COMP I

COMP I

COMP I

COMP II

COMP II

COMP 11

COMP I

COMP II

COMP III

COMP II I

COMP III

COMP III

in

COMP 111

TC-5 Upper Comp

TC-5 Upper Comp

TC-5 Upper Comp

TC-5 Upper Comp

IC - 5 Upper Comp

$\begin{array}{lllllllllllllllllllllllllllllll}0 & 0 & 0 & 0 & 0 & 0 & 0 & 0 & 0 & 1 & 0 & 0 & 0 & 0 & 0 & 0 & 0 & 0 & 0 & 0 & 0 & 0 & 0 & 0 & 0 & 0 & 0 & 0 \\ 0 & 0 & 0 & 0 & 0 & 0 & 0 & 0 & 0 & 0 & 0 & 0 & 0 & 0 & 0 & 0 & 0 & 0 & 0 & 0 & 0 & 0 & 0 & 0 & 0 & 0 & 0 & 0 \\ 0 & 0 & 0 & 0 & 0 & 0 & 0 & 0 & 0 & 1 & 0 & 0 & 0 & 0 & 0 & 0 & 0 & 0 & 0 & 1 & 0 & 0 & 0 & 0 & 0 & 0 & 0 & 0 \\ 0 & 0 & 0 & 0 & 0 & 0 & 0 & 0 & 0 & 0 & 0 & 0 & 0 & 0 & 0 & 0 & 0 & 0 & 0 & 0 & 0 & 0 & 0 & 0 & 0 & 1 & 0 & 0 \\ 0 & 0 & 0 & 0 & 0 & 0 & 0 & 0 & 0 & 0 & 0 & 0 & 0 & 1 & 0 & 0 & 0 & 0 & 0 & 0 & 0 & 0 & 1 & 0 & 0 & 0 & 0 & 0\end{array}$

$\begin{array}{lllllllllllllllllllllllllllllll}0 & 0 & 0 & 0 & 0 & 0 & 1 & 0 & 0 & 0 & 0 & 0 & 1 & 0 & 0 & 0 & 0 & 0 & 0 & 0 & 0 & 0 & 1 & 0 & 0 & 0 & 0 & 0 \\ 0 & 0 & 0 & 0 & 0 & 0 & 0 & 0 & 0 & 0 & 0 & 0 & 0 & 0 & 0 & 0 & 0 & 0 & 0 & 0 & 0 & 0 & 0 & 0 & 0 & 0 & 0 & 1 \\ 0 & 0 & 1 & 0 & 0 & 0 & 0 & 0 & 0 & 0 & 0 & 0 & 0 & 0 & 0 & 0 & 0 & 0 & 0 & 1 & 0 & 0 & 0 & 0 & 0 & 0 & 0 & 0 \\ 0 & 0 & 0 & 0 & 0 & 0 & 0 & 0 & 0 & 0 & 0 & 0 & 0 & 1 & 0 & 0 & 0 & 0 & 0 & 0 & 0 & 0 & 0 & 0 & 1 & 0 & 0 & 0 \\ 0 & 0 & 0 & 0 & 0 & 0 & 0 & 1 & 0 & 0 & 0 & 0 & 0 & 0 & 0 & 0 & 0 & 0 & 0 & 0 & 0 & 0 & 0 & 0 & 0 & 0 & 0 & 0\end{array}$

COMP IV

COHP IV

COMP IV

COMP IV

COMP IV

$\begin{array}{lll}0 & 0 & 0 \\ 0 & 0 & 0 \\ 0 & 0 & 0 \\ 0 & 0 & 0\end{array}$

0
0
0
0

$\begin{array}{ll}0 & 0 \\ 0 & 0 \\ 0 & 0 \\ 0 & 0\end{array}$

$\begin{array}{ll}0 & 0 \\ 1 & 0 \\ 0 & 0 \\ 0 & 0\end{array}$

$\begin{array}{ll}0 & 0 \\ 0 & 0 \\ 0 & 0 \\ 0 & 0\end{array}$

$\begin{array}{lll}0 & 0 & 0 \\ 0 & 0 & 0 \\ 0 & 1 & 0 \\ 0 & 0 & 0\end{array}$

$\begin{array}{llllllll}0 & 0 & 0 & 0 & 0 & 0 & 0 & 0 \\ 0 & 0 & 0 & 0 & 0 & 1 & 0 & 0 \\ 0 & 0 & 0 & 0 & 0 & 0 & 0 & 0 \\ 0 & 0 & 0 & 0 & 1 & 0 & 0\end{array}$

$\begin{array}{lllllll}0 & 0 & 0 & 0 & 0 & 0 & 0 \\ 0 & 0 & 0 & 0 & 0 & 0 & 0\end{array}$

COMP $V$

COMP V

COMP $V$

COMP $V$

COMP $V$

$\begin{array}{llllllllllllllllllllllllllllll}0 & 0 & 0 & 0 & 0 & 0 & 0 & 0 & 0 & 0 & 0 & 0 & 0 & 0 & 0 & 0 & 0 & 1 & 0 & 0 & 0 & 0 & 0 & 1 & 0 & 0 & 0 & 0 \\ 0 & 0 & 0 & 0 & 0 & 0 & 0 & 0 & 0 & 2 & 0 & 0 & 0 & 0 & 0 & 0 & 0 & 0 & 0 & 0 & 0 & 0 & 0 & 0 & 0 & 0 & 0 & 1 \\ 0 & 0 & 0 & 0 & 0 & 0 & 0 & 0 & 0 & 0 & 0 & 0 & 0 & 0 & 0 & 0 & 0 & 0 & 0 & 0 & 0 & 0 & 0 & 0 & 0 & 0 & 0 & 1 \\ 0 & 0 & 0 & 0 & 0 & 0 & 0 & 0 & 0 & 1 & 0 & 0 & 0 & 0 & 1 & 1 & 0 & 0 & 0 & 0 & 1 & 1 & 0 & 1 & 0 & 1 & 1 & 0 \\ 0 & 0 & 0 & 1 & 0 & 0 & 0 & 0 & 0 & 0 & 0 & 0 & 0 & 1 & 0 & 0 & 0 & 0 & 1 & 0 & 0 & 1 & 0 & 0 & 0 & 0 & 0 & 0\end{array}$

$\begin{array}{lllllllllllllllllllllllllllllllllllll}0 & 0 & 0 & 0 & 0 & 0 & 0 & 0 & 1 & 0 & 0 & 0 & 0 & 0 & 0 & 1 & 1 & 0 & 0 & 1 & 0 & 1 & (a) & 1 & 0 & 0 & 0 & 0 & 0\end{array}$

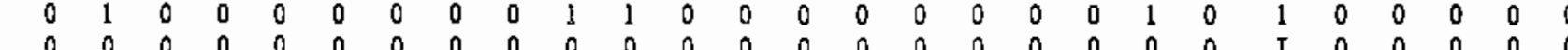
$\begin{array}{llllllllllllllllllllllllllllll}0 & 0 & 0 & 1 & 0 & 0 & 0 & 0 & 0 & 0 & 0 & 1 & 0 & 0 & 0 & 0 & 1 & 0 & 0 & 0 & 0 & 0 & 1 & 0 & 0 & 0 & 0 & 0\end{array}$

$\begin{array}{llllllllllllllllllllllllllllllllllll}0 & 0 & 0 & 0 & 0 & 0 & 0 & 0 & 0 & 0 & 0 & 0 & 0 & 0 & 0 & 0 & 0 & 0 & 0 & 0 & 0 & 0 & 0 & 0 & 0 & 0 & 0 & 0 \\ 0 & 0 & 0 & 0 & 0 & 0 & 0 & 0 & 0 & 0 & 0 & 0 & 0 & 0 & 0 & 0 & 0 & 0 & 0 & 0 & 0 & 0 & 0 & 0 & 1 & 0 & 0 & 0 \\ 0 & 0 & 0 & 0 & 0 & 0 & 0 & 0 & 0 & 0 & 0 & 0 & 0 & 0 & 0 & 0 & 0 & 0 & 0 & 1 & 0 & 0 & 0 & 0 & 0 & 0 & 1 & 0 \\ 0 & 0 & 0 & 0 & 0 & 0 & 0 & 0 & 0 & 0 & 0 & 0 & 0 & 0 & 0 & 0 & 1 & 0 & 0 & 0 & 0 & 0 & 0 & 0 & 0 & 0 & 0 & 0 \\ 0 & 0 & 0 & 0 & 0 & 0 & 0 & 0 & 0 & 0 & 0 & 0 & 0 & 0 & 0 & 0 & 0 & 0 & 0 & 0 & 0 & 0 & 0 & 0 & 0 & 0 & 0 & 0\end{array}$


IABLE E.5. (contd)

Sediment

M. nasura Dead and Removed Test Days 1 through 28

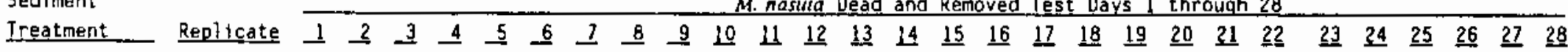

COMP $V$

COHP VI

COHP VI

COMP VI

$R-A C$
$R+A C$

$R+A C$
$R-A C$

$\mathrm{R}-\mathrm{AC}$

$\mathrm{R}-\mathrm{AC}$

R-AM

R-AM

R-AM

$R-A M$

$\mathrm{T}$
$\vdots$

$R-B F$
$R-B F$
$R-B F$

$R-B F$
$R-B F$

R-OS

R-OS

$R-O S$
$R-O S$

$R-O S$
$R-O S$

$R-P F$

$R-P F$

$R-P F$
$R-P F$

$R-P F$

C-SB

C-SB

$C-S B$

C-SB

$\begin{array}{llllllllllllllllllllllllllllll}0 & 0 & 0 & 0 & 0 & 0 & 0 & 0 & 0 & 0 & 0 & 0 & 0 & 0 & 0 & 0 & 1 & 0 & 0 & 1 & 0 & 0 & 0 & 1 & 0 & 0 & 0 & 1 \\ 0 & 0 & 0 & 0 & 0 & 0 & 0 & 0 & 0 & 0 & 0 & 0 & 0 & 0 & 1 & 0 & 0 & 0 & 0 & 0 & 1 & 0 & 0 & 0 & 0 & 0 & 0 & 0 \\ 0 & 0 & 0 & 0 & 0 & 0 & 0 & 0 & 0 & 0 & 0 & 0 & 0 & 0 & 0 & 0 & 0 & 1 & 1 & 1 & 1 & 0 & 0 & 0 & 0 & 0 & 0 & 0 \\ 0 & 0 & 0 & 0 & 0 & 0 & 0 & 0 & 0 & 0 & 0 & 0 & 0 & 0 & 0 & 1 & 0 & 0 & 0 & 1 & 0 & 0 & 0 & 0 & 1 & 0 & 0 & 0 \\ 0 & 0 & 0 & 0 & 0 & 0 & 0 & 0 & 0 & 0 & 0 & 0 & 0 & 0 & 0 & 0 & 0 & 0 & 0 & 0 & 0 & 0 & 0 & 0 & 0 & 0 & 0 & 1\end{array}$

$\begin{array}{llllllllllllllllllllllllllllll}0 & 0 & 0 & 0 & 0 & 0 & 0 & 0 & 0 & 0 & 0 & 0 & 0 & 0 & 1 & 0 & 0 & 0 & 0 & 0 & 0 & 0 & 0 & 0 & 0 & 0 & 0 & 1 \\ 0 & 1 & 0 & 0 & 0 & 0 & 0 & 0 & 0 & 0 & 1 & 0 & 0 & 0 & 0 & 0 & 0 & 0 & 0 & 1 & 0 & 0 & 0 & 0 & 1 & 0 & 0 & 0 \\ 0 & 0 & 0 & 0 & 0 & 0 & 0 & 0 & 0 & 0 & T & 0 & 0 & 0 & 0 & 0 & 0 & 0 & 0 & 0 & 1 & 0 & 0 & 0 & 0 & 0 & 0 & 0 \\ 0 & 0 & 0 & 0 & 0 & 0 & 0 & 0 & 0 & 0 & 0 & 0 & 0 & 0 & 0 & 0 & 0 & 0 & 0 & 0 & 0 & 0 & 0 & 0 & 1 & 0 & 0 & 0 \\ 0 & 0 & 0 & 0 & 0 & 0 & 0 & 0 & 0 & 0 & 0 & 0 & 0 & 0 & 0 & 0 & 0 & 0 & 0 & 0 & 0 & 0 & 0 & 0 & 0 & 0 & 0 & 0\end{array}$

$\begin{array}{llllllllllllllllllllllllllllllll}0 & 0 & 0 & 0 & 0 & 0 & 0 & 0 & 0 & 0 & 0 & 0 & 0 & 0 & 0 & 0 & 0 & 0 & 0 & 1 & 0 & 0 & 0 & 0 & 3 & 0 & 0 & 0 \\ 0 & 0 & 0 & 0 & 0 & 0 & 0 & 0 & 0 & 0 & 0 & 0 & 0 & 0 & 0 & 0 & 0 & 0 & 0 & 0 & 0 & 0 & 0 & 0 & 1 & 0 & 0 & 0\end{array}$ $\begin{array}{lllllllllllllllllllllllllllllll}0 & 0 & 0 & 0 & 0 & 0 & 0 & 0 & 0 & 0 & 0 & 0 & 0 & 0 & 0 & 0 & 0 & 0 & 0 & 0 & 0 & 1 & 0 & 0 & 0 & 0 & 1 & 0\end{array}$ $\begin{array}{lllllllllllllllllllllllllllll}0 & 0 & 0 & 0 & 0 & 0 & 0 & 0 & 0 & 0 & 0 & 0 & 0 & 0 & 0 & 0 & 0 & 0 & 0 & 2 & 0 & 0 & 0 & 0 & 0 & 0 & 0 & 0 \\ 0 & 0 & 0 & 0 & 0 & 0 & 0 & 0 & 0 & 0 & 0 & 0 & 0 & 0 & 0 & 0 & 0 & 0 & 0 & 0 & 0 & 1 & 0 & 0 & 0 & 0 & 0 & 0\end{array}$

$\begin{array}{lllllllllllllllllllllllllllllll}0 & 0 & 1 & 2 & 0 & 0 & 1 & 0 & 0 & 0 & 0 & 0 & 0 & 0 & 0 & 1 & 0 & 0 & 0 & 0 & 0 & 0 & 0 & 0 & 0 & 0 & 0 & 0\end{array}$ $\begin{array}{lllllllllllllllllllllllllllll}0 & 0 & 0 & 0 & 0 & 0 & 0 & 0 & 0 & 0 & 0 & 0 & 0 & 0 & 0 & 0 & 0 & 0 & 0 & 0 & 0 & 0 & 0 & 0 & 0 & 0 & 0 & 0\end{array}$ $\begin{array}{lllllllllllllllllllllllllllllll}0 & 0 & 0 & 0 & 0 & 0 & 0 & 0 & 0 & 0 & 0 & 0 & 0 & 0 & 0 & 0 & 0 & 0 & 0 & 0 & 1 & 0 & 0 & 1 & 0 & 0 & 0 & 0 \\ 0 & 0 & 0 & 0 & 0 & 0 & 0 & 0 & 0 & 0 & 0 & 0 & 2 & 0 & 0 & 0 & 1 & 0 & 0 & 0 & 0 & 0 & 0 & 0 & 0 & 0 & 0 & 0\end{array}$

$\begin{array}{lllllllllllllllllllllllllllll}0 & 0 & 0 & 0 & 0 & 0 & 1 & 0 & 0 & 0 & 0 & 0 & 0 & 0 & 0 & 1 & 0 & 0 & 0 & 0 & 0 & 0 & 0 & 0 & 1 & 0 & 0 & 0\end{array}$ $\begin{array}{llllllllllllllllllllllllllllll}0 & 0 & 0 & 0 & 0 & 1 & 0 & 0 & 1 & 0 & 0 & 0 & 0 & 0 & 0 & 0 & 0 & 0 & 0 & 0 & 0 & 0 & 0 & 0 & 0 & 0 & 0 & 0\end{array}$

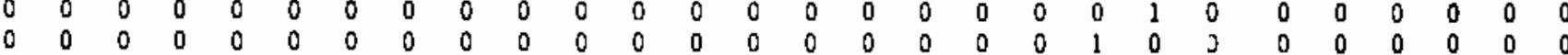
$\begin{array}{lllllllllllllllllllllllllll}0 & 0 & 0 & 0 & 0 & 0 & 0 & 0 & 0 & 0 & 0 & 0 & 0 & 0 & 0 & 0 & 0 & 0 & 0 & 0 & 0 & 0 & 1 & 0 & 1 & 0 & 1\end{array}$

$\begin{array}{lllllllllllllllllllllllllllllll}0 & 0 & 0 & 0 & 0 & 0 & 0 & 0 & 0 & 0 & 0 & 0 & 0 & 0 & 0 & 0 & 0 & 0 & 0 & 0 & 0 & 0 & 1 & 0 & 2 & 0 & 0 & 1\end{array}$ $\begin{array}{llllllllllllllllllllllllllllllll}0 & 0 & 0 & 0 & 0 & 0 & 0 & 0 & 0 & 0 & 0 & 0 & 0 & 0 & 0 & 0 & 0 & 0 & 0 & 0 & 0 & 0 & 0 & 0 & 0 & 0 & 0 & 0 \\ 0 & 1 & 0 & 0 & 0 & 0 & 0 & 0 & 0 & 0 & 0 & 0 & 0 & 0 & 0 & 0 & 0 & 0 & 0 & 1 & 0 & 0 & 0 & 0 & 1 & 0 & 0 & 0\end{array}$ $\begin{array}{lllllllllllllllllllllllllllllll}0 & 0 & 0 & 0 & 0 & 0 & 0 & 0 & 0 & 0 & 0 & 0 & 0 & 0 & 0 & 0 & 0 & 0 & 0 & 0 & 0 & 0 & 1 & 0 & 0 & 0 & 0 & 0\end{array}$

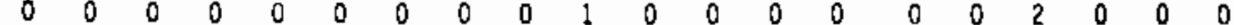
$\begin{array}{llllllllllllllllllllllllllllll}0 & 0 & 0 & 0 & 0 & 0 & 0 & 0 & 0 & 0 & 0 & 0 & 0 & 0 & 0 & 0 & 0 & 0 & 0 & 0 & 0 & 0 & 0 & 0 & 0 & 0 & 0 & 0 \\ 0 & 0 & 0 & 0 & 0 & 0 & 0 & 0 & 0 & 0 & 0 & 0 & 0 & 0 & 0 & 0 & 0 & 0 & 0 & 0 & 0 & 0 & 1 & 0 & 0 & 0 & 0 & 0 \\ 0 & 0 & 0 & 0 & 0 & 0 & 0 & 0 & 0 & 0 & 0 & 0 & 0 & 0 & 0 & 0 & 0 & 0 & 0 & 0 & 0 & 0 & 1 & 0 & 0 & 0 & 0 & 0 \\ 0 & 0 & 0 & 0 & 0 & 0 & 0 & 0 & 0 & 0 & 0 & 0 & 0 & 0 & 0 & 0 & 0 & 0 & 1 & 0 & 0 & 0 & 0 & 1 & 0 & 0 & 0 & 0 \\ 0 & 0 & 1 & 1 & 0 & 0 & 0 & 0 & 0 & 0 & 0 & 0 & 0 & 0 & 0 & 0 & 1 & 0 & 0 & 0 & 0 & 0 & 0 & 0 & 0 & 0 & 0 & 0\end{array}$ 
IABLEE.5. (contd)

Sediment

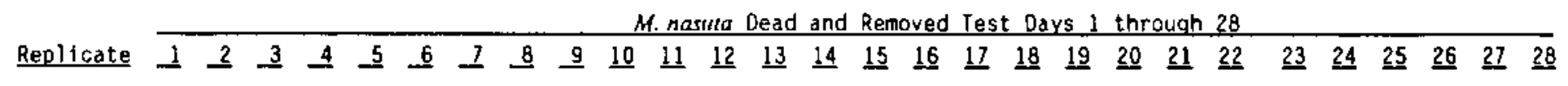

Treatment

$\begin{array}{llllllllllllllllllllllllllllllllllllll}C-N E & 1 & 0 & 0 & 0 & 0 & 0 & 0 & 0 & 0 & 0 & 0 & 0 & 0 & 0 & 0 & 0 & 0 & 0 & 0 & 0 & 0 & 0 & 0 & 0 & 0 & 0 & 0 & 0 & 0 \\ C-N E & 2 & 0 & 0 & 1 & 0 & 0 & 0 & 0 & 0 & 0 & 0 & 0 & 0 & 0 & 0 & 0 & 0 & 0 & 0 & 0 & 2 & 1 & 0 & 0 & 0 & 1 & 0 & 0 & 0 \\ \text { C-NE } & 3 & 0 & 0 & 0 & 0 & 0 & 0 & 0 & 0 & 0 & 0 & 0 & 0 & 0 & 0 & 0 & 0 & 0 & 0 & 1 & 0 & 0 & 0 & 0 & 0 & 0 & 0 & 0 & 0 \\ \text { C-NE } & 4 & 0 & 0 & 0 & 0 & 0 & 0 & 0 & 0 & 0 & 0 & 0 & 0 & 0 & 0 & 0 & 0 & 0 & 0 & 0 & 0 & 0 & 0 & 0 & 0 & 0 & 0 & 0 & 0 \\ \text { C-NE } & 5 & 0 & 0 & 0 & 0 & 0 & 0 & 0 & 0 & 0 & 0 & 0 & 1 & 0 & 0 & 0 & 0 & 0 & 0 & 0 & 0 & 0 & 0 & 1 & 0 & 1 & 0 & 0 & 0\end{array}$

(a) T Too turbid to make accurate observation. 
TABLE E.6. Water Quality Summary for 28-Day M. nasuta/N. caecoides Solid-Phase Test, Richmond Harbor Program

\begin{tabular}{|c|c|c|c|c|c|c|c|c|c|c|}
\hline \multirow{2}{*}{$\begin{array}{l}\text { Sediment } \\
\text { Iredtment }\end{array}$} & \multicolumn{2}{|c|}{$\begin{array}{c}\text { Temperature } \\
\left({ }^{\circ} \mathrm{C}\right)\end{array}$} & \multicolumn{2}{|c|}{$\mathrm{pH}$} & \multicolumn{2}{|c|}{$\begin{array}{l}\text { Dissolved } \\
\text { Oxygen } \\
\text { (mg/L) }\end{array}$} & \multicolumn{2}{|c|}{$\begin{array}{c}\text { Salinity } \\
(0 / 00)\end{array}$} & \multicolumn{2}{|c|}{$\begin{array}{c}\text { Flow Rates } \\
\text { (ml/min) }\end{array}$} \\
\hline & Min & $\operatorname{Max}$ & Min & $\operatorname{Max}$ & Hin & $\operatorname{Max}$ & Min & Max & Min & $\operatorname{Max}$ \\
\hline $\begin{array}{l}\text { Acceptable } \\
\text { Range }\end{array}$ & 13.0 & 17.0 & 7.51 & 8.51 & 4.0 & $\mathrm{NA}^{(\mathrm{a})}$ & 29.6 & 33.6 & 115 & 135 \\
\hline $\begin{array}{l}\text { COMP I } \\
\text { COMP II } \\
\text { COMP II } \\
\text { TC-5 Upper Comp } \\
\text { COMP IV } \\
\text { COMP V } \\
\text { COMP VI }\end{array}$ & $\begin{array}{l}15.1 \\
14.8 \\
14.9 \\
14.9 \\
15.0 \\
15.0 \\
14.9\end{array}$ & $\begin{array}{l}16.0 \\
16.3 \\
16.4 \\
15.9 \\
16.0 \\
16.0 \\
16.5\end{array}$ & $\begin{array}{l}7.67 \\
7.66 \\
7.67 \\
7.60 \\
7.67 \\
7.66 \\
7.66\end{array}$ & $\begin{array}{l}8.27 \\
8.26 \\
8.30 \\
8.28 \\
8.32 \\
8.30 \\
8.27\end{array}$ & $\begin{array}{l}7.3 \\
7.0 \\
7.2 \\
5.4 \\
7.0 \\
7.0 \\
7.2\end{array}$ & $\begin{array}{l}8.8 \\
8.7 \\
8.9 \\
8.9 \\
8.6 \\
8.8 \\
8.7\end{array}$ & $\begin{array}{l}30.0 \\
30.5 \\
30.5 \\
30.5 \\
30.0 \\
30.0 \\
30.0\end{array}$ & $\begin{array}{l}32.5 \\
32.5 \\
33.0 \\
32.5 \\
32.5 \\
32.5 \\
32.5\end{array}$ & $\begin{array}{l}116 \\
116 \\
116 \\
116 \\
116 \\
112 \\
116\end{array}$ & $\begin{array}{l}133 \\
134 \\
133 \\
140 \\
132 \\
140^{(b)} \\
133\end{array}$ \\
\hline $\begin{array}{l}R-A C \\
R-A M \\
R-B F \\
R-O S \\
R-P F\end{array}$ & $\begin{array}{l}14.9 \\
14.9 \\
14.9 \\
15.0 \\
14.9\end{array}$ & $\begin{array}{l}16.4 \\
15.9 \\
16.0 \\
16.2 \\
16.3\end{array}$ & $\begin{array}{l}7.71 \\
7.69 \\
7.66 \\
7.71 \\
7.59\end{array}$ & $\begin{array}{l}8.29 \\
8.30 \\
8.29 \\
8.31 \\
8.29\end{array}$ & $\begin{array}{l}7.0 \\
6.8 \\
6.0 \\
6.8 \\
7.0\end{array}$ & $\begin{array}{l}8.6 \\
9.0 \\
8.7 \\
8.8 \\
8.9\end{array}$ & $\begin{array}{l}30.0 \\
30.0 \\
30.0 \\
30.0 \\
30.0\end{array}$ & $\begin{array}{l}32.5 \\
32.5 \\
32.5 \\
32.5 \\
32.5\end{array}$ & $\begin{array}{l}116 \\
116 \\
116 \\
116 \\
116\end{array}$ & $\begin{array}{l}133 \\
132 \\
132 \\
132 \\
133\end{array}$ \\
\hline $\begin{array}{l}\mathrm{C}-\mathrm{SB} \\
\mathrm{C}-\mathrm{NE}\end{array}$ & $\begin{array}{l}15.0 \\
14.8\end{array}$ & $\begin{array}{l}16.4 \\
15.9\end{array}$ & $\begin{array}{l}7.68 \\
7.70\end{array}$ & $\begin{array}{l}8.33 \\
8.29\end{array}$ & $\begin{array}{l}6.8 \\
7.2\end{array}$ & $\begin{array}{l}8.9 \\
8.9\end{array}$ & $\begin{array}{l}30.0 \\
30.0\end{array}$ & $\begin{array}{l}32.5 \\
32.5\end{array}$ & $\begin{array}{l}116 \\
116\end{array}$ & $\begin{array}{l}133 \\
144\end{array}$ \\
\hline
\end{tabular}

(a) NA Mot applicable.

(b) Oata point out of range. 
IABLE E.7. Test Results for 28-Day N. caecoides Solid-Phase Test, Richmond Harbor Program

\begin{tabular}{|c|c|c|c|c|}
\hline \multirow[b]{2}{*}{$\begin{array}{l}\text { Sediment } \\
\text { Ireatment }\end{array}$} & \multirow[b]{2}{*}{ Replicate } & \multicolumn{2}{|c|}{ N. caecoides } & \multirow{2}{*}{$\begin{array}{c}\text { Mean } \\
\text { Proportion } \\
\text { Surviving }\end{array}$} \\
\hline & & Live & $\begin{array}{c}\text { Dead } \\
\text { or Missing }\end{array}$ & \\
\hline $\begin{array}{ll}\text { COMP } & \text { I } \\
\text { COMP } & \text { I } \\
\text { COMP } & \text { I } \\
\text { COMP } & \text { I } \\
\text { COMP } & \text { I }\end{array}$ & $\begin{array}{l}1 \\
2 \\
3 \\
4 \\
5\end{array}$ & $\begin{array}{l}34 \\
38 \\
40 \\
31 \\
35\end{array}$ & $\begin{array}{l}6 \\
2 \\
0 \\
9 \\
5\end{array}$ & 0.89 \\
\hline $\begin{array}{l}\text { COMP II } \\
\text { COMP II } \\
\text { COMP II } \\
\text { COMP II } \\
\text { COMP II }\end{array}$ & $\begin{array}{l}1 \\
2 \\
3 \\
4 \\
5\end{array}$ & $\begin{array}{l}37 \\
36 \\
39 \\
35 \\
40\end{array}$ & $\begin{array}{l}3 \\
4 \\
1 \\
5 \\
0\end{array}$ & 0.94 \\
\hline $\begin{array}{l}\text { COMP II I } \\
\text { COMP III } \\
\text { COMP II I } \\
\text { COMP II I } \\
\text { COMP II }\end{array}$ & $\begin{array}{l}1 \\
2 \\
3 \\
4 \\
5\end{array}$ & $\begin{array}{l}35 \\
39 \\
34 \\
35 \\
34\end{array}$ & $\begin{array}{l}5 \\
1 \\
6 \\
5 \\
6\end{array}$ & 0.89 \\
\hline $\begin{array}{l}\text { TC-5 Upper Comp } \\
\text { TC-5 Upper Comp } \\
\text { TC-5 Upper Comp } \\
\text { TC-5 Upper Comp } \\
\text { TC-5 Upper Comp }\end{array}$ & $\begin{array}{l}1 \\
2 \\
3 \\
4 \\
5\end{array}$ & $\begin{array}{l}29 \\
32 \\
36 \\
36 \\
37\end{array}$ & $\begin{array}{r}11 \\
8 \\
4 \\
4 \\
3\end{array}$ & 0.85 \\
\hline $\begin{array}{l}\text { COMP IV } \\
\text { COMP IV } \\
\text { COMP IV } \\
\text { COMP IV } \\
\text { COMP IV }\end{array}$ & $\begin{array}{l}1 \\
2 \\
3 \\
4 \\
5\end{array}$ & $\begin{array}{l}34 \\
32 \\
30 \\
28 \\
30\end{array}$ & $\begin{array}{r}6 \\
8 \\
10 \\
12 \\
10\end{array}$ & 0.77 \\
\hline $\begin{array}{l}\text { COMP V } \\
\text { COMP V } \\
\text { COMP V } \\
\text { COMP V } \\
\text { COMP V }\end{array}$ & $\begin{array}{l}1 \\
2 \\
3 \\
4 \\
5\end{array}$ & $\begin{array}{l}33 \\
37 \\
36 \\
38 \\
37\end{array}$ & $\begin{array}{l}7 \\
3 \\
4 \\
2 \\
3\end{array}$ & 0.91 \\
\hline $\begin{array}{l}\text { COMP VI } \\
\text { COMP VI } \\
\text { COMP VI } \\
\text { COMP VI } \\
\text { COMP VI }\end{array}$ & $\begin{array}{l}1 \\
2 \\
3 \\
4 \\
5\end{array}$ & $\begin{array}{l}36 \\
33 \\
35 \\
37 \\
32\end{array}$ & $\begin{array}{l}4 \\
7 \\
5 \\
3 \\
8\end{array}$ & 0.87 \\
\hline
\end{tabular}


TABLE E.7. (contd)

Sediment

Treatment

$R-A C$

$R-A C$

$\mathrm{R}-\mathrm{AC}$

$R-A C$

$\mathrm{R}-\mathrm{AC}$

R-AM

R-AM

R-AM

$R-A M$

R-AM

$R-B F$

$R-B F$

$R-B F$

$R-B F$

$\mathrm{R}-\mathrm{BF}$

$\mathrm{R}-\mathrm{OS}$

$R-0 S$

R-OS

R-OS

R-OS

$R-P F$

$R-P F$

$R-P F$

$R-P F$

$R-P F$

$C-S B$

C-SB

C-SB

C-SB

C-SB

$\mathrm{C}-\mathrm{NE}$

$C-N E^{-}$

$\mathrm{C}-\mathrm{NE}$

$\mathrm{C}-\mathrm{NE}$

$C-N E$

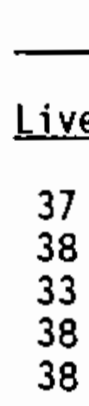

N. caecoides

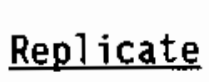

1

2

3

4

5

1

2

3

4
5

5

1
2
3
4
5

1

3

4
5

1

2

4

5

1

2

3

5

1

2

3

4

37

40

40

35

37

34

30

34

30

37

39

38

40

39

39

38

40

39

40

38

38

39

37

40

36

38

38

38

39
Mean

Proportion

or Missing Surviving

3

2

0.92

2

0.83

10

3

0.98

37

0.95

5

3

6

10

6

3

0.98

I

1

2

0

2

0

1

0

2

1

3

0
4

0.95

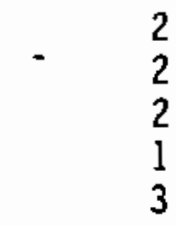

0.95

(a) Survival based on initial exposure of 40 individuals per replicate. 
TABLE E.8. Rank Order Based on Mean Proportion Surviving 28-Day N. caecoides Solid-Phase Test, Richmond Harbor Program

Sediment
Ireatment
COMP IV
R-BF
TC-5 Upper Comp
COMP VI
COMP III
COMP I
COMP V
R-AC
COMP II
R-AM
C-NE
C-SB
R-PF
R-OS

Mean

Proportion

Surviving

0.77

0.83

0.85

0.87

0.89

0.89

0.91

0.92

0.94

0.95

0.95

0.95

0.98

0.98 
IABLE E.9. Daily Observations of $N$. caecoides on Sediment Surface During 28-Day Solid-Phase Test, Richmond Harbor Program

Sediment

Treatment

$N$ caecoides on Sediment Test Days 1 through 28

COMP I

COMP I

COMP :

COHP I

COMP I Replicate 1

COMP II

COMP II

COMP II

COMP II

COMP II

COMP 111

COMP III

COMP III

m CONP 111

TC-5 Upper Comp

TC-5 Upper Comp

TC-5 Upper Comp

IC-5 Upper Comp

TC-5 Upper Comp

COMP IV

COMP IV

COMP IV

COMP IV

COMP IV

COMP $V$

COMP $V$

COMP $V$

COMP V

COMP V

\begin{tabular}{|c|c|c|c|c|c|c|c|c|c|c|c|c|c|c|c|c|c|c|c|c|c|c|c|c|c|c|c|}
\hline$\underline{1}$ & 2 & $\underline{3}$ & 4 & 5 & $\underline{6}$ & 7 & 8 & 9 & 10 & 11 & $\underline{12}$ & 13 & 14 & 15 & $\underline{16}$ & 17 & $\underline{1 B}$ & $\underline{19}$ & $\underline{20}$ & $\underline{21}$ & 22 & $\underline{23}$ & $\underline{24}$ & 25 & $\underline{26}$ & 27 & $\underline{2 B}$ \\
\hline 0 & 2 & 3 & 0 & 0 & 0 & 0 & 0 & 0 & 0 & 0 & 0 & 0 & 0 & 0 & 0 & 0 & 0 & 0 & 0 & 0 & 0 & 0 & 0 & 0 & 0 & 0 & \\
\hline 0 & 0 & 0 & 0 & 0 & 0 & 0 & 0 & 0 & 0 & 0 & 0 & 0 & 0 & 0 & 0 & 0 & 0 & 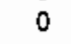 & & 0 & & & & 0 & 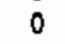 & & 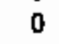 \\
\hline 0 & 1 & 0 & 0 & 0 & 0 & 0 & 0 & 0 & 0 & 0 & 0 & 0 & 0 & 0 & 0 & 0 & 0 & 0 & 0 & 0 & 0 & 0 & 0 & 0 & 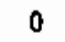 & u & 0 \\
\hline 0 & 3 & 3 & 3 & 1 & 1 & 0 & 0 & 1 & 1 & 0 & 0 & 0 & 0 & 0 & 0 & 0 & 0 & 0 & 0 & 0 & 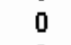 & 0 & 0 & 0 & 0 & 0 & 0 \\
\hline 0 & 1 & 0 & 1 & 1 & 0 & 0 & 0 & 0 & 0 & 0 & U & 0 & 0 & 0 & 0 & 0 & 0 & 0 & 0 & 0 & 0 & 0 & 0 & 0 & 0 & 0 & 0 \\
\hline
\end{tabular}

COMP VJ

СOMP VI

COMP VI

COMP VI

COMP VI

$\begin{array}{lllllllllllllllllllllllllllllll}1 & 1 & 1 & 1 & 2 & 1 & 2 & 0 & 0 & 0 & 0 & 0 & 0 & 0 & 0 & 0 & 0 & 0 & 0 & 0 & 0 & 0 & 0 & 0 & 0 & 0 & 0 & 0 \\ 0 & 0 & 0 & 0 & 0 & 0 & 0 & 0 & 0 & 0 & 0 & 0 & 0 & 0 & 0 & 0 & 0 & 0 & 0 & 0 & 0 & 0 & 0 & 0 & 0 & 0 & 0 & 0 \\ 0 & 0 & 0 & 0 & 0 & 0 & 0 & 0 & 0 & 0 & 0 & 0 & 0 & 0 & 0 & 0 & 0 & 0 & 0 & 0 & 0 & 0 & 0 & 0 & 0 & 0 & 0 & 0 \\ 1 & 1 & 0 & 0 & 0 & 0 & 0 & 0 & 0 & 0 & 0 & 0 & 0 & 0 & 0 & 0 & 0 & 0 & 0 & 0 & 0 & 0 & 0 & 0 & 0 & 0 & 0 & 0 \\ 0 & 0 & 0 & 0 & 0 & 1 & 0 & 0 & 0 & 0 & 0 & 0 & 0 & 0 & 0 & 0 & 0 & 0 & 0 & 0 & 0 & 0 & 0 & 0 & 0 & 0 & 0 & 0\end{array}$

$\begin{array}{lllllllllllllllllllllllllllllllll}1 & 2 & 0 & 1 & 2 & 1 & 1 & 0 & 0 & 0 & 0 & 0 & 0 & 0 & 0 & 0 & 0 & 0 & 0 & 0 & 0 & 0 & 0 & 0 & 0 & 0 & 0 & 0\end{array}$ $\begin{array}{lllllllllllllllllllllllllllllll}0 & 0 & 1 & 1 & 1 & 1 & 1 & 1 & 0 & 0 & 0 & 0 & 0 & 0 & 0 & 0 & 0 & 0 & 0 & 0 & 0 & 0 & 0 & 0 & 0 & 0 & 0 & 0 & 0\end{array}$ $\begin{array}{llllllllllllllllllllllllllllll}0 & 3 & 4 & 1 & 1 & 1 & 0 & 0 & 0 & 0 & 0 & 0 & 0 & 0 & 0 & 0 & 0 & 0 & 0 & 0 & 0 & 0 & 0 & 0 & 0 & 0 & 0 & 0\end{array}$ $\begin{array}{llllllllllllllllllllllllllll}0 & 3 & 4 & 1 & 1 & 1 & 1 & 0 & 0 & 0 & 0 & 0 & 0 & 0 & 0 & 0 & 0 & 0 & 0 & 0 & 0 & 0 & 0 & 0 & 1 & 0 & 0 & 0 \\ 1 & 2 & 2 & 0 & 0 & 0 & 0 & 0 & 0 & 0 & 0 & 0 & 0 & 0 & 0 & 0 & 0 & 0 & 0 & 0 & 0 & 0 & 0 & 0 & 0 & 0 & 0 & 0\end{array}$

$\begin{array}{lllllllllllllllllllllllllllll}2 & 3 & 0 & 1 & 0 & 0 & 1 & 0 & 0 & 0 & 0 & 0 & 0 & 0 & 0 & 0 & 0 & 0 & 0 & 0 & 0 & 0 & 0 & 0 & 0 & 0 & 0 & 0\end{array}$

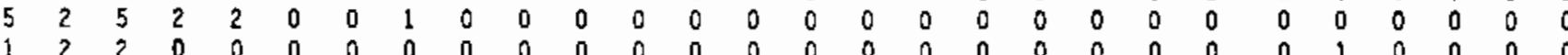
$\begin{array}{llllllllllllllllllllllllllll}2 & 3 & 1 & 1 & 1 & 1 & 0 & 0 & 0 & 0 & 0 & 0 & 0 & 0 & 0 & 0 & 0 & 0 & 0 & 0 & 0 & 0 & 0 & 1 & 0 & 0 & 0 & 0 \\ 0 & 0 & 0 & 0 & 0 & 1 & 0 & 0 & 0 & 0 & 0 & 0 & 1 & 0 & 0 & 0 & 0 & 0 & 0 & 0 & 0 & 0 & 0 & 0 & 0 & 0 & 0 & 0\end{array}$

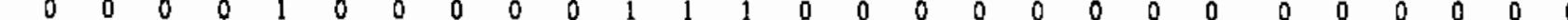

$\begin{array}{lllllllllllllllllllllllllllllllll}0 & 0 & 0 & 4 & 1 & 1 & 1 & 0 & 0 & 0 & 0 & 0 & 0 & 0 & 0 & 0 & 0 & 0 & 0 & 0 & 0 & T^{(a)} & 0 & 0 & 0 & 0 & 0 & 0\end{array}$ $\begin{array}{llllllllllllllllllllllllllllllll}2 & 1 & 2 & 0 & 0 & 0 & 0 & 0 & 0 & 0 & 0 & 0 & 0 & 0 & 0 & 0 & 0 & 0 & 0 & 0 & 0 & 0 & 0 & 1 & 0 & 0 & 0 & 0 \\ 0 & 0 & 1 & 1 & 0 & 0 & 0 & 0 & 0 & 0 & 0 & 0 & 0 & 0 & 0 & 0 & 0 & 0 & 0 & 0 & 0 & 0 & T & 0 & 0 & 0 & 0 & 0\end{array}$ $\begin{array}{llllllllllllllllllllllllllll}0 & 1 & 1 & 1 & 2 & 0 & 1 & 0 & 2 & 0 & 1 & 0 & 0 & 0 & 0 & 0 & 0 & 0 & 0 & 0 & 0 & 0 & 0 & 0 & 0 & 0 & 0 & 0\end{array}$ $\begin{array}{lllllllllllllllllllllllllllllll}1 & 1 & 1 & 1 & 1 & 1 & 1 & 0 & 0 & 0 & 0 & 0 & 0 & 0 & 0 & 0 & 0 & 0 & 0 & 0 & 0 & 0 & 0 & 0 & 0 & 0 & 0 & 0\end{array}$ $\begin{array}{llllllllllllllllllllllllllll}0 & 1 & 2 & 2 & 2 & 1 & 1 & 1 & 1 & 0 & 0 & 0 & 0 & 0 & 0 & 0 & 0 & 0 & 0 & 0 & 0 & 0 & 0 & 0 & 0 & 0 & 0 & 0\end{array}$ $\begin{array}{llllllllllllllllllllllllllll}0 & 2 & 1 & 1 & 0 & 0 & 1 & 0 & 1 & 0 & 0 & 0 & 0 & 0 & 0 & 0 & 0 & 0 & 0 & 0 & 0 & 0 & 0 & 0 & 0 & 0 & 0 & 0\end{array}$

$\begin{array}{llllllllllllllllllllllllllllll}1 & 0 & 1 & 0 & 0 & 0 & 0 & 0 & 0 & 0 & 0 & 0 & 0 & 0 & 0 & 0 & 1 & 0 & 0 & 0 & 0 & 0 & 0 & 0 & 0 & 0 & 0 & 0 \\ 0 & 2 & 4 & 0 & 1 & 1 & 0 & 0 & 0 & 0 & 0 & 0 & 0 & 0 & 0 & 0 & 0 & 0 & 0 & 0 & 0 & 0 & 0 & 0 & 0 & 0 & 0 & 0 \\ 0 & 1 & 0 & 0 & 0 & 0 & 0 & 0 & 0 & 0 & 0 & 0 & 0 & 0 & 0 & 0 & 0 & 0 & 0 & 0 & 0 & 0 & 0 & 0 & 0 & 0 & 0 & 0 \\ 1 & 1 & 1 & 1 & 1 & 0 & 0 & 0 & 0 & 0 & 0 & 0 & 0 & 0 & 0 & 0 & 0 & 0 & 0 & 0 & 0 & 0 & 0 & 0 & 0 & 0 & 0 & 0 \\ 0 & 2 & 1 & 0 & 0 & 0 & 0 & 0 & 0 & 0 & 0 & 0 & 0 & 0 & 0 & 0 & 0 & 0 & 0 & 0 & 0 & 0 & 0 & 0 & 0 & 0 & 0 & 0\end{array}$




\section{IABLE E.9. (contd)}

Sediment

Ireatment

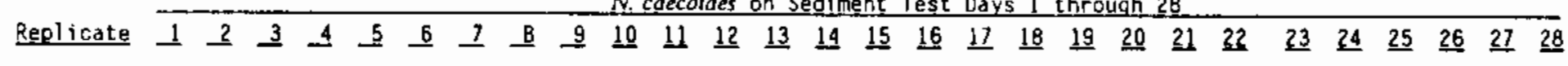

$\begin{array}{lllllllllllllllllllllllllllllllllllllll}R-A C & 1 & 3 & 1 & 0 & 1 & 1 & 0 & T & 0 & 0 & 0 & 0 & 0 & 0 & 0 & 0 & 0 & 0 & 0 & 0 & 0 & 0 & 0 & 0 & T & 0 & 0 & 0 & 0 \\ R-A C & 2 & 0 & 0 & 0 & 1 & 0 & 0 & 0 & 0 & 0 & 0 & 0 & 0 & 0 & 0 & 0 & 0 & 0 & 0 & 0 & 0 & 0 & 0 & 0 & 0 & 0 & 0 & 0 & 0 \\ R-A C & 3 & 0 & 2 & 3 & 0 & 0 & 0 & 0 & 0 & T & T & T & 0 & T & 0 & 0 & 0 & 0 & T & 0 & 0 & 0 & 0 & 0 & 0 & 0 & 0 & 0 & 0 \\ R-A C & 4 & 0 & 0 & 0 & 0 & 0 & 0 & 0 & 0 & 0 & 0 & 0 & 0 & 0 & 0 & 0 & 0 & 0 & 0 & 0 & 0 & 0 & 0 & 0 & 0 & 0 & 0 & 0 & 0 \\ R-A C & 5 & 1 & 0 & 1 & 0 & 0 & 0 & 0 & 0 & 0 & 0 & 0 & 0 & 0 & 0 & 0 & 0 & 0 & 0 & 0 & 0 & 0 & 0 & 0 & 0 & 0 & 0 & 0 & 0\end{array}$

\section{$R-A M$}

R-AM

$\begin{array}{llllllllllllllllllllllllllllllllll}3 & 0 & 1 & 1 & 1 & 0 & 0 & 0 & 0 & 0 & 0 & 0 & 0 & 0 & 0 & 0 & 0 & 0 & 0 & 0 & 0 & 0 & 0 & 0 & 0 & 0 & 0 & 0\end{array}$

R-AH

R-AH

$\begin{array}{llllllllllllllllllllllllllllllll}0 & 0 & 0 & 0 & 0 & 0 & 0 & 0 & 0 & 0 & 0 & 0 & 0 & 0 & 0 & 0 & 0 & 0 & 0 & 0 & 0 & 0 & 0 & 0 & 0 & 0 & 0 & 0\end{array}$ $\begin{array}{lllllllllllllllllllllllllllllll}0 & 0 & 0 & 1 & 0 & 0 & 0 & 0 & 0 & 0 & 0 & 0 & 0 & 0 & 0 & 0 & 0 & 0 & 0 & 0 & 0 & 0 & 0 & 0 & 0 & 0 & 0 & 0\end{array}$ $\begin{array}{llllllllllllllllllllllllllll}0 & 1 & 2 & 0 & 0 & 0 & 0 & 0 & 0 & 0 & 0 & 0 & 0 & 0 & 0 & 0 & 0 & 0 & 0 & 0 & 0 & 0 & 0 & 0 & 0 & 0 & 0 & 0 \\ 0 & 1 & 1 & 1 & 0 & 0 & 0 & 0 & 0 & 0 & 0 & 0 & 0 & 0 & 0 & 0 & 0 & 0 & 0 & 0 & 0 & 0 & 0 & 0 & 0 & 0 & 0 & 0\end{array}$

R-BF

$R-B F$

$R-B F$

$m$

R-BF

$\begin{array}{lllllllllllllllllllllllllllllllll}0 & 0 & 0 & 0 & 0 & 0 & 0 & 0 & 0 & 0 & 1 & 0 & 0 & 0 & 0 & 0 & 0 & 0 & 0 & 0 & 0 & 0 & 0 & 0 & 0 & 0 & 0 & 0\end{array}$ $\begin{array}{lllllllllllllllllllllllllllllll}3 & 0 & 0 & 0 & 1 & 1 & 0 & 1 & 0 & 0 & 0 & 0 & 0 & 0 & 0 & 0 & 0 & 0 & 0 & 0 & 0 & 0 & 0 & 0 & 0 & 0 & 0 & 0 \\ 0 & 2 & 2 & 0 & 0 & 0 & 0 & 0 & 0 & 0 & 0 & 0 & 0 & 0 & 0 & 0 & 0 & 0 & 0 & 0 & 0 & 0 & 0 & 0 & 0 & 0 & 0 & 0\end{array}$ $\begin{array}{lllllllllllllllllllllllllllll}1 & 2 & 1 & 0 & 1 & 0 & 1 & 0 & 0 & 0 & 0 & 0 & 0 & 0 & 0 & 0 & 0 & 0 & 0 & 0 & 0 & 0 & 0 & 0 & 0 & 0 & 0 & 0 \\ 0 & 1 & 0 & 0 & 0 & 0 & 0 & 0 & 0 & 0 & 0 & 0 & 0 & 0 & 0 & 0 & 0 & 0 & 0 & 0 & 0 & 0 & 0 & 0 & 0 & 0 & 0 & 0\end{array}$

$R-O S$
$R-O S$

$R-O S$
$R-O S$

$R-05$

$\begin{array}{llllllllllllllllllllllllllllllll}1 & 0 & 0 & 0 & 0 & 0 & 0 & 0 & 0 & 0 & 0 & 0 & 0 & 0 & 0 & 0 & 0 & 0 & 0 & 0 & 0 & 0 & 0 & 0 & 0 & 0 & 0 & 0 \\ 0 & 0 & 1 & 0 & 0 & 0 & 0 & 0 & 0 & 0 & 0 & 0 & 0 & 0 & 0 & 0 & 0 & 0 & 0 & 0 & 0 & 0 & 0 & 0 & 0 & 0 & 0 & 0 \\ 0 & 0 & 0 & 0 & 0 & 0 & 0 & 0 & 0 & 0 & 0 & 0 & 0 & 0 & 0 & 0 & 0 & 0 & 0 & 0 & 0 & 0 & 0 & 0 & 0 & 0 & 0 & 0 \\ 0 & 0 & 0 & 0 & 0 & 0 & 0 & 0 & 0 & 0 & 0 & 0 & 0 & 0 & 0 & 0 & 0 & 0 & 0 & 0 & 0 & 0 & 0 & 0 & 0 & 0 & 0 & 0 \\ 0 & 1 & 0 & 0 & 0 & 0 & 0 & 0 & 0 & 0 & 0 & 0 & 0 & 0 & 0 & 0 & 0 & 0 & 0 & 0 & 0 & 0 & 0 & 0 & 0 & 0 & 0 & 0\end{array}$

$R-P F$

$R-P F$
$R-P F$

$R-P F$
$R-P F$

$R-P F$

$C-S B$

$C-S B$

C-SB

C-SB

$\begin{array}{lllllllllllllllllllllllllllllll}0 & 0 & 1 & 0 & 0 & 0 & 0 & 0 & 0 & 0 & 0 & 0 & 0 & 0 & 0 & 0 & 0 & 0 & 0 & 0 & 0 & 0 & 0 & 0 & 0 & 0 & 0 & 0 \\ 0 & 0 & 0 & 0 & 0 & 0 & 0 & 0 & 0 & 0 & 0 & 0 & 0 & 0 & 0 & 0 & 0 & 0 & 0 & 0 & 0 & 0 & 0 & 0 & 0 & 0 & 0 & 0 \\ 0 & 0 & 1 & 0 & 0 & 0 & 0 & 0 & 0 & 0 & 0 & 0 & 0 & 0 & 0 & 0 & 0 & 0 & 0 & 0 & 0 & 0 & 0 & 0 & 0 & 0 & 0 & 0 \\ 0 & 0 & 0 & 0 & 0 & 0 & 0 & 0 & 0 & 0 & 0 & 0 & 1 & 0 & 0 & 1 & 0 & 0 & 0 & 0 & 0 & 0 & 0 & 0 & 0 & 0 & 0 & 0 \\ 0 & 0 & 0 & 0 & 1 & 1 & 0 & 0 & 0 & 0 & 0 & 0 & 0 & 0 & 0 & 0 & 0 & 0 & 0 & 0 & 0 & 0 & 0 & 0 & 0 & 0 & 0 & 0 \\ 0 & 0 & 0 & 0 & 0 & 0 & 0 & 0 & 0 & 0 & 0 & 0 & 0 & 0 & 0 & 0 & 0 & 0 & 0 & 0 & 0 & 0 & 0 & 0 & 0 & 0 & 0 & 0 \\ 0 & 0 & 0 & 0 & 0 & 0 & 0 & 1 & 0 & 0 & 0 & 0 & 0 & 0 & 0 & 0 & 0 & 0 & 0 & 0 & 0 & 0 & 0 & 0 & 0 & 0 & 0 & 0 \\ 0 & 1 & 0 & 1 & 1 & 0 & 0 & 0 & 0 & 0 & 0 & 0 & 0 & 0 & 0 & 0 & 0 & 0 & 0 & 0 & 0 & 0 & 0 & 0 & 0 & 0 & 0 & 0 \\ 0 & 0 & 0 & 0 & 0 & 0 & 0 & 0 & 0 & 0 & 1 & 0 & 0 & 0 & 0 & 0 & 0 & 0 & 0 & 0 & 0 & 0 & 0 & 0 & 0 & 0 & 0 & 0 \\ 1 & 1 & 1 & 0 & 0 & 0 & 0 & 0 & 0 & 0 & 0 & 0 & 0 & 0 & 0 & 0 & 0 & 0 & 0 & 0 & 0 & 0 & 0 & 0 & 0 & 0 & 0 & 0\end{array}$


IABLE E.9. (contd)

Sediment

Ireatment

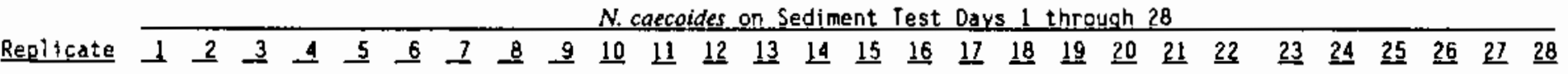

$\begin{array}{ll}C-N E & 1 \\ C-M E & 2 \\ C-H E & 3 \\ C-N E & 4 \\ C-N E & 5\end{array}$

$\begin{array}{llllllllllllllllllllllllllllll}1 & 0 & 0 & 0 & 0 & 0 & 0 & 0 & 0 & 0 & 0 & 0 & 0 & 0 & 0 & 0 & 0 & 0 & 0 & 0 & 0 & 0 & 0 & 0 & 0 & 0 & 0 & 0 \\ 0 & 0 & 0 & 0 & 0 & 0 & 0 & 0 & 0 & 0 & 0 & 0 & 0 & 0 & 0 & 0 & 0 & 0 & 0 & 0 & 0 & 0 & 0 & 0 & 0 & 0 & 0 & 0 \\ 0 & 1 & 1 & 0 & 0 & 0 & 0 & 0 & 0 & 0 & 0 & 0 & 0 & 0 & 0 & 0 & 0 & 0 & 0 & 0 & 0 & 0 & 0 & 0 & 0 & 0 & 0 & 0 \\ 0 & 0 & 0 & 0 & 0 & 0 & 0 & 0 & 0 & 0 & 0 & 0 & 0 & 0 & 0 & 0 & 0 & 0 & 0 & 0 & 0 & 0 & 0 & 0 & 0 & 0 & 0 & 0 \\ 0 & 0 & 2 & 2 & 0 & 0 & 0 & 0 & 0 & 0 & 0 & 0 & 0 & 0 & 0 & 0 & 0 & 0 & 0 & 0 & 0 & 0 & 0 & 0 & 0 & 0 & 0 & 0\end{array}$

(a) T Too turbid to make accurate abservation. 
IABLE E.10. Daily Observations of $N$. caecoides Dead and Removed During 28-Day Solid-Phase Test, Richmond Harbor Program

Sediment Ireatment

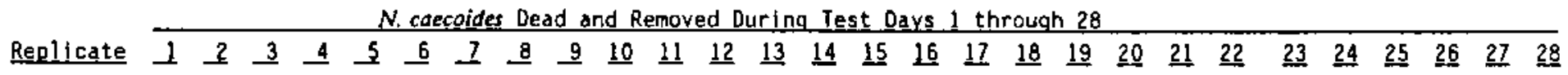

COHP I

comp I

COMP I

COMP I

COMP II

COMP $\|$

COMP II

COMP II

COMP 11

COMP III

COMP II!

COMP III

COMP III

ì

COMP III

TC-5 Upper Comp IC-5 Upper Comp IC-5 Upper Comp IC-5 Upper Comp TC-5 Upper Comp

COMP IV

COMP IV

COMP IV

COMP IV

COMP $V$

COMP V

COMP $V$

COMP $V$

COMP $V$

COMP VI

COMP VI

COMP VI

COMP VI

COMP VI

$\begin{array}{llllllllllllllllllllllllllllll}0 & 0 & 2 & 0 & 0 & 0 & 0 & 0 & 0 & 0 & 0 & 0 & 0 & 0 & 0 & 0 & 0 & 0 & 0 & 0 & 0 & 0 & 0 & 0 & 0 & 0 & 0 & 0 \\ 0 & 0 & 0 & 0 & 0 & 0 & 0 & 0 & 0 & 0 & 0 & 0 & 0 & 0 & 0 & 0 & 0 & 0 & 0 & 0 & 0 & 0 & 0 & 0 & 0 & 0 & 0 & 0 \\ 0 & 0 & 0 & 0 & 0 & 0 & 0 & 0 & 0 & 0 & 0 & 0 & 0 & 0 & 0 & 0 & 0 & 0 & 0 & 0 & 0 & 0 & 0 & 0 & 0 & 0 & 0 & 0 \\ 0 & 0 & 0 & 1 & 0 & 1 & 0 & 0 & 0 & 1 & 0 & 0 & 0 & 0 & 0 & 0 & 0 & 0 & 0 & 0 & 0 & 0 & 0 & 0 & 0 & 0 & 0 & 0 \\ 0 & 0 & 0 & 1 & 1 & 0 & 0 & 0 & 0 & 0 & 0 & 0 & 0 & 0 & 0 & 0 & 0 & 0 & 0 & 0 & 0 & 0 & 0 & 0 & 0 & 0 & 0 & 0\end{array}$

$\begin{array}{lllllllll}0 & 0 & 1 & 0 & 0 & 0 & 2 & 0 & 0 \\ 0 & 0 & 0 & 0 & 0 & 0 & 0 & 0 & 0 \\ 0 & 0 & 0 & 0 & 0 & 0 & 0 & 0 & 0 \\ 0 & 0 & 0 & 0 & 0 & 0 & 0 & 0 & 0 \\ 0 & 0 & 0 & 0 & 0 & 0 & 0 & 0 & 0\end{array}$

$\begin{array}{lll}0 & 0 \\ 0 & 0 \\ 0 & 0 \\ 0 & 0 & 0\end{array}$

$\begin{array}{ll}0 & 0 \\ 0 & 0 \\ 0 & 0 \\ 0 & 0 \\ 0 & 0\end{array}$

$\begin{array}{llllllllll}0 & 0 & 0 & 0 & 0 & 0 & 0 & 0 & 0\end{array}$

$\begin{array}{llllll}0 & 0 & 0 & 0 & 0 & 0\end{array}$ $\begin{array}{lllllllllllllllllllllllllllll}0 & 0 & 0 & 0 & 0 & 0 & 0 & 0 & 0 & 0 & 0 & 0 & 0 & 0 & 0 & 0 & 0 & 0 & 0 & 0 & 0 & 0 & 0 & 0 & 0 & 0 & 0\end{array}$ $\begin{array}{lllllllllllllllllllllllllllllllll}0 & 0 & 0 & 0 & 1 & 1 & 0 & 0 & 0 & 0 & 0 & 0 & 0 & 0 & 0 & 0 & 0 & 0 & 0 & 0 & 0 & 0 & 0 & 0 & 0 & 0 & 0 & 0 \\ 0 & 0 & 0 & 0 & 1 & 0 & 0 & 1 & 0 & 0 & 0 & 0 & 0 & 0 & 0 & 0 & 0 & 0 & 0 & 0 & 0 & 0 & 0 & 0 & 0 & 0 & 0 & 0\end{array}$ $\begin{array}{lllllllllllllllllllllllllllll}0 & 0 & 0 & 0 & 1 & 0 & 0 & 0 & 0 & 0 & 0 & 0 & 0 & 0 & 0 & 0 & 0 & 0 & 0 & 0 & 0 & 0 & 0 & 0 & 0 & 0 & 0 & 0\end{array}$ $\begin{array}{lllllllllllllllllllllllllllllll}0 & 0 & 3 & 0 & 0 & 0 & 1 & 0 & 0 & 0 & 0 & 0 & 0 & 0 & 0 & 0 & 0 & 0 & 0 & 0 & 0 & 0 & 0 & 0 & 0 & 0 & 0 & 0\end{array}$

$\begin{array}{lllllllllllllllllllllllllllllll}0 & 0 & 0 & 0 & 0 & 0 & 1 & 0 & 0 & 0 & 0 & 0 & 0 & 0 & 0 & 0 & 0 & 0 & 0 & 0 & 0 & 0 & 0 & 0 & 0 & 0 & 0 & 0\end{array}$ $\begin{array}{llllllllllllllllllllllllllllll}0 & 0 & 1 & 0 & 0 & 0 & 0 & 0 & 0 & 0 & 0 & 0 & 0 & 0 & 0 & 0 & 0 & 0 & 0 & 0 & 0 & 0 & 0 & 0 & 0 & 0 & 0 & 0\end{array}$ $\begin{array}{lllllllllllllllllllllllllllllll}0 & 0 & 0 & 0 & 0 & 0 & 0 & 0 & 0 & 0 & 0 & 0 & 0 & 0 & 0 & 0 & 0 & 0 & 0 & 0 & 0 & 0 & 0 & 0 & 0 & 0 & 0 & 0\end{array}$ $\begin{array}{llllllllllllllllllllllllllllll}0 & 0 & 0 & 0 & 0 & 0 & 0 & 0 & 0 & 0 & 0 & 0 & 1 & 0 & 0 & 0 & 0 & 0 & 0 & 0 & 0 & 0 & 0 & 0 & 0 & 0 & 0 & 0 \\ 0 & 0 & 0 & 0 & 0 & 0 & 0 & 0 & 0 & 0 & 0 & 0 & 0 & 1 & 0 & 0 & 0 & 0 & 0 & 0 & 0 & 0 & 0 & 0 & 0 & 0 & 0 & 0\end{array}$ $\begin{array}{llllllllllllllllllllllllllllllll}0 & 0 & 0 & 2 & 0 & 0 & 1 & 0 & 0 & 0 & 0 & 0 & 0 & 0 & 0 & 0 & 0 & 0 & 0 & 0 & 0 & \text { T(a) } & 0 & 0 & 0 & 0 & 0 & 0\end{array}$ $\begin{array}{lllllllllllllllllllllllllllll}0 & 0 & 0 & 1 & 0 & 0 & 0 & 0 & 0 & 0 & 0 & 0 & 0 & 0 & 0 & 0 & 0 & 0 & 0 & 0 & 0 & 0 & T & 0 & 0 & 0 & 0 & 0\end{array}$ $\begin{array}{lllllllllllllllllllllllllllll}0 & 0 & 0 & 0 & 1 & 0 & 1 & 0 & 1 & 0 & 0 & 0 & 0 & 0 & 0 & 0 & 0 & 0 & 0 & 0 & 0 & 0 & 0 & 0 & 0 & 0 & 0 & 0 \\ 0 & 0 & 0 & 0 & 1 & 0 & 0 & 0 & 0 & 0 & 0 & 0 & 0 & 0 & 0 & 0 & 1 & 0 & 0 & 0 & 0 & 0 & 0 & 0 & 0 & 0 & 0 & 0\end{array}$ $\begin{array}{llllllllllllllllllllllllllllllll}0 & 0 & 0 & 1 & 0 & 0 & 0 & 0 & 0 & 0 & 0 & 0 & 0 & 0 & 0 & 0 & 0 & 0 & 0 & 0 & 0 & 0 & 0 & 0 & 0 & 0 & 0 & 0\end{array}$ $\begin{array}{lllllllllllllllllllllllllllllllllll}0 & 0 & 0 & 0 & 0 & 0 & 0 & 0 & 0 & 0 & 0 & 0 & 0 & 0 & 0 & 0 & 0 & 0 & 0 & 0 & 0 & 0 & 0 & 0 & 0 & 0 & 0 & 0\end{array}$ $\begin{array}{lllllllllllllllllllllllllllll}0 & 0 & 0 & 1 & 1 & 0 & 0 & 0 & 0 & 0 & 0 & 0 & 0 & 0 & 0 & 0 & 0 & 0 & 0 & 0 & 0 & 0 & 0 & 0 & 0 & 0 & 0 & 0\end{array}$

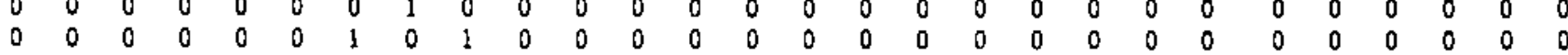
$\begin{array}{lllllllllllllllllllllllllllllllll}0 & 0 & 0 & 0 & 0 & 0 & 0 & 0 & 0 & 0 & 0 & 0 & 0 & 0 & 0 & 0 & T & 0 & 0 & 0 & 0 & 0 & 0 & 0 & 0 & 0 & 0 & 0\end{array}$ $\begin{array}{llllllllllllllllllllllllllllllllll}0 & 0 & 2 & 0 & 0 & 0 & 0 & 0 & 0 & 0 & 0 & 0 & 0 & 0 & 0 & 0 & 0 & 0 & 0 & 0 & 0 & 0 & 0 & 0 & 0 & 0 & 0 & 0 \\ 0 & 0 & 0 & 0 & 0 & 0 & 0 & 0 & 0 & 0 & 0 & 0 & 0 & 0 & 0 & 0 & 0 & 0 & 0 & 0 & 0 & 0 & 0 & 0 & 0 & 0 & 0 & 0\end{array}$ $\begin{array}{llllllllllllllllllllllllllllll}0 & 0 & 0 & 0 & 0 & 0 & 0 & 0 & 0 & 0 & 0 & 0 & 0 & 0 & 0 & 0 & 0 & 0 & 0 & 0 & 0 & 0 & 0 & 0 & 0 & 0 & 0 & 0\end{array}$ $\begin{array}{llllllllllllllllllllllllllll}0 & 0 & 1 & 0 & 0 & 0 & 0 & 0 & 0 & 0 & 0 & 0 & 0 & 0 & 0 & 0 & 0 & 0 & 0 & 0 & 0 & 0 & 0 & 0 & 0 & 0 & 0 & 0\end{array}$ 
TABLE E.10. (contd)

Sediment

Freatment.

Replicate 1 . caecoides Dead and Removed During. Test Days t through 28

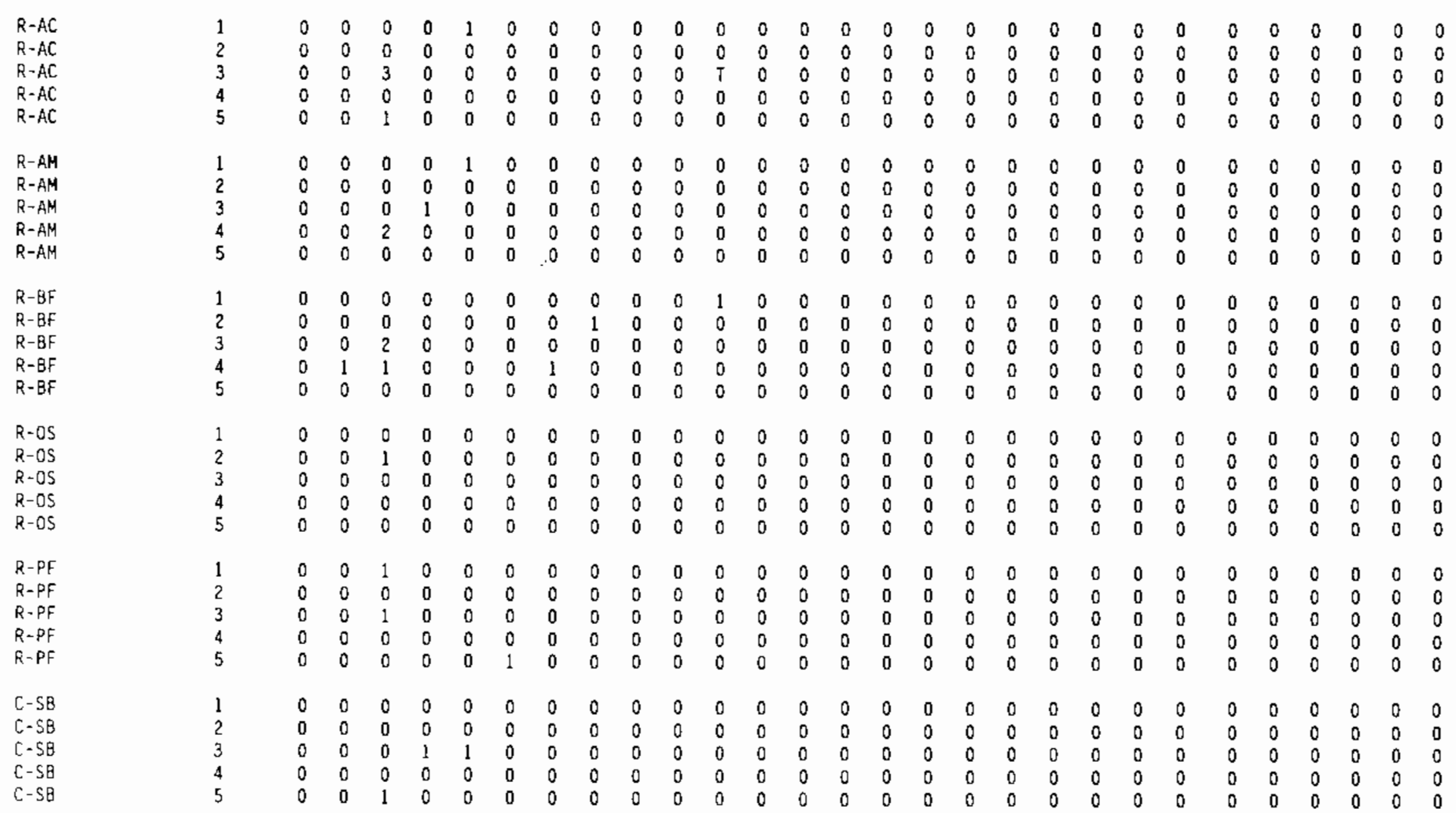


TABLE E.10. (contd)

Sediment

Ireatment

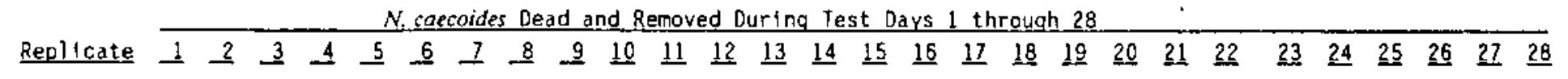

$\begin{array}{ll}C-N E & 1 \\ C-N E & 2 \\ C-N E & 3 \\ C-N E & 4 \\ C-N E & 5\end{array}$

$\begin{array}{llllllllllllllllllllllllllllll}0 & 0 & 0 & 0 & 0 & 0 & 0 & 0 & 0 & 0 & 0 & 0 & 0 & 0 & 0 & 0 & 0 & 0 & 0 & 0 & 0 & 0 & 0 & 0 & 0 & 0 & 0 & 0 \\ 0 & 0 & 0 & 0 & 0 & 0 & 0 & 0 & 0 & 0 & 0 & 0 & 0 & 0 & 0 & 0 & 0 & 0 & 0 & 0 & 0 & 0 & 0 & 0 & 0 & 0 & 0 & 0 \\ 0 & 0 & 1 & 0 & 0 & 0 & 0 & 0 & 0 & 0 & 0 & 0 & 0 & 0 & 0 & 0 & 0 & 0 & 0 & 0 & 0 & 0 & 0 & 0 & 0 & 0 & 0 & 0 \\ 0 & 0 & 0 & 0 & 0 & 0 & 0 & 0 & 0 & 0 & 0 & 0 & 0 & 0 & 0 & 0 & 0 & 0 & 0 & 0 & 0 & 0 & 0 & 0 & 0 & 0 & 0 & 0 \\ 0 & 0 & 1 & 2 & 0 & 0 & 0 & 0 & 0 & 0 & 0 & 0 & 0 & 0 & 0 & 0 & 0 & 0 & 0 & 0 & 0 & 0 & 0 & 0 & 0 & 0 & 0 & 0\end{array}$

(a) T Too turbid to make accurate observation. 


\section{APPENDIX F}

BLASSAY RESULTS EOR 10-DAY SOLID PHASE STATIC TEST WITH 4-DAY REFEBENCE TOXICANT TEST FOR RHEPOXYNIUS abroniuS 
IABLE F.1. Test Results for 10-Day R. abronius Solid-Phase Static Test, Richmond Harbor Program

\begin{tabular}{|c|c|c|c|c|}
\hline \multirow[b]{2}{*}{$\begin{array}{l}\text { Sediment } \\
\text { Ireatment }\end{array}$} & \multirow[b]{2}{*}{ Replicate } & \multicolumn{2}{|c|}{ R. abronius } & \multirow{2}{*}{$\begin{array}{c}\text { Mean } \\
\text { Proportion } \\
\text { Surviving }\end{array}$} \\
\hline & & $\underline{\operatorname{Live}^{(a)}}$ & $\begin{array}{l}\text { Dead } \\
\text { or Missing }\end{array}$ & \\
\hline $\begin{array}{l}\text { COMP I } \\
\text { COMP } \\
\text { COMP I } \\
\text { COMP I } \\
\text { COMP I }\end{array}$ & $\begin{array}{l}1 \\
2 \\
3 \\
4 \\
5\end{array}$ & $\begin{array}{l}13 \\
14 \\
17 \\
19 \\
14\end{array}$ & $\begin{array}{l}7 \\
6 \\
3 \\
1 \\
6\end{array}$ & 0.77 \\
\hline $\begin{array}{l}\text { COMP II } \\
\text { COMP II } \\
\text { COMP II } \\
\text { COMP II } \\
\text { COMP II }\end{array}$ & $\begin{array}{l}1 \\
2 \\
3 \\
4 \\
5\end{array}$ & $\begin{array}{l}19 \\
14 \\
16 \\
18 \\
13\end{array}$ & $\begin{array}{l}1 \\
6 \\
4 \\
2 \\
7\end{array}$ & 0.80 \\
\hline $\begin{array}{l}\text { COMP II I } \\
\text { COMP I I I } \\
\text { COMP II I } \\
\text { COMP II I } \\
\text { COMP II I }\end{array}$ & $\begin{array}{l}1 \\
2 \\
3 \\
4 \\
5\end{array}$ & $\begin{array}{r}9 \\
17 \\
13 \\
12 \\
7\end{array}$ & $\begin{array}{r}11 \\
3 \\
7 \\
8 \\
13\end{array}$ & 0.58 \\
\hline $\begin{array}{l}\text { TC-5 Upper Comp } \\
\text { TC-5 Upper Comp } \\
\text { TC-5 Upper Comp } \\
\text { TC-5 Upper Comp } \\
\text { TC-5 Upper Comp }\end{array}$ & $\begin{array}{l}1 \\
2 \\
3 \\
4 \\
5\end{array}$ & $\begin{array}{l}18 \\
17 \\
13 \\
15 \\
19\end{array}$ & $\begin{array}{l}2 \\
3 \\
7 \\
5 \\
1\end{array}$ & 0.82 \\
\hline $\begin{array}{l}\text { COMP IV } \\
\text { COMP IV } \\
\text { COMP IV } \\
\text { COMP IV } \\
\text { COMP IV }\end{array}$ & $\begin{array}{l}1 \\
2 \\
3 \\
4 \\
5\end{array}$ & $\begin{array}{l}16 \\
15 \\
18 \\
14 \\
13\end{array}$ & $\begin{array}{l}4 \\
5 \\
2 \\
6 \\
7\end{array}$ & 0.76 \\
\hline $\begin{array}{l}\text { COMP } V \\
\text { COMP } V \\
\text { COMP } V \\
\text { COMP } V \\
\text { COMP } V\end{array}$ & $\begin{array}{l}1 \\
2 \\
3 \\
4 \\
5\end{array}$ & $\begin{array}{l}18 \\
18 \\
18 \\
17 \\
16\end{array}$ & $\begin{array}{l}2 \\
2 \\
2 \\
3 \\
4\end{array}$ & 0.87 \\
\hline $\begin{array}{l}\text { COMP VI } \\
\text { COMP VI } \\
\text { COMP VI } \\
\text { COMP VI } \\
\text { COMP VI }\end{array}$ & $\begin{array}{l}1 \\
2 \\
3 \\
4 \\
5\end{array}$ & $\begin{array}{l}16 \\
16 \\
16 \\
16 \\
19\end{array}$ & $\begin{array}{l}4 \\
4 \\
4 \\
4 \\
1\end{array}$ & 0.83 \\
\hline
\end{tabular}


TABLE F.1. (contd)

\begin{tabular}{|c|c|c|c|c|}
\hline \multirow[b]{2}{*}{$\begin{array}{l}\text { Sediment } \\
\text { Ireatment }\end{array}$} & \multirow[b]{2}{*}{ Replicate } & \multicolumn{2}{|c|}{ R. abronius } & \multirow{2}{*}{$\begin{array}{c}\text { Mean } \\
\text { Proportion } \\
\text { Surviving }\end{array}$} \\
\hline & & $\underline{\text { Live }}{ }^{(a)}$ & $\begin{array}{c}\text { Dead } \\
\text { or Missing }\end{array}$ & \\
\hline $\begin{array}{l}R-A C \\
R-A C \\
R-A C \\
R-A C \\
R-A C\end{array}$ & $\begin{array}{l}1 \\
2 \\
3 \\
4 \\
5\end{array}$ & $\begin{array}{l}12 \\
14 \\
17 \\
17 \\
15\end{array}$ & $\begin{array}{l}8 \\
6 \\
3 \\
3 \\
5\end{array}$ & 0.75 \\
\hline $\begin{array}{l}\text { R-AM } \\
\text { R-AM } \\
\text { R-AM } \\
\text { R-AM } \\
\text { R-AM }\end{array}$ & $\begin{array}{l}1 \\
2 \\
3 \\
4 \\
5\end{array}$ & $\begin{array}{l}19 \\
20 \\
16 \\
17 \\
18\end{array}$ & $\begin{array}{l}1 \\
0 \\
4 \\
3 \\
2\end{array}$ & 0.90 \\
\hline $\begin{array}{l}R-B F \\
R-B F \\
R-B F \\
R-B F \\
R-B F\end{array}$ & $\begin{array}{l}1 \\
2 \\
3 \\
4 \\
5\end{array}$ & $\begin{array}{l}18 \\
19 \\
16 \\
17 \\
18\end{array}$ & $\begin{array}{l}2 \\
1 \\
4 \\
3 \\
2\end{array}$ & 0.88 \\
\hline $\begin{array}{l}R-O S \\
R-O S \\
R-O S \\
R-O S \\
R-O S\end{array}$ & $\begin{array}{l}1 \\
2 \\
3 \\
4 \\
5\end{array}$ & $\begin{array}{r}15 \\
18 \\
15 \\
4 \\
14\end{array}$ & $\begin{array}{r}5 \\
2 \\
5 \\
16 \\
6\end{array}$ & 0.66 \\
\hline $\begin{array}{l}R-P F \\
R-P F \\
R-P F \\
R-P F \\
R-P F\end{array}$ & $\begin{array}{l}1 \\
2 \\
3 \\
4 \\
5\end{array}$ & $\begin{array}{l}18 \\
19 \\
14 \\
16 \\
15\end{array}$ & $\begin{array}{l}2 \\
1 \\
6 \\
4 \\
5\end{array}$ & 0.82 \\
\hline $\begin{array}{l}C-S B \\
C-S B \\
C-S B \\
C-S B \\
C-S B\end{array}$ & $\begin{array}{l}1 \\
2 \\
3 \\
4 \\
5\end{array}$ & $\begin{array}{l}18 \\
19 \\
14 \\
18 \\
19\end{array}$ & $\begin{array}{l}2 \\
1 \\
6 \\
2 \\
1\end{array}$ & 0.88 \\
\hline $\begin{array}{l}C-W B \\
C-W B \\
C-W B \\
C-W B \\
C-W B\end{array}$ & $\begin{array}{l}1 \\
2 \\
3 \\
4 \\
5\end{array}$ & $\begin{array}{l}20 \\
20 \\
20 \\
20 \\
20\end{array}$ & $\begin{array}{l}0 \\
0 \\
0 \\
0 \\
0\end{array}$ & 1.00 \\
\hline
\end{tabular}

(a) Survival based on initial exposure of 20 individuals per replicate. 
TABLE F.2. Rank Order Based on Mean Proportion Surviving 10-Day $R$. abronius Solid-Phase Static Test, Richmond Harbor Program

Sediment
Ireatment
COMP III
R-OS
R-AC
COMP IV
COMP I
COMP II
IC-5 Upper Comp
R-PF
COMP VI
COMP V
R-BF
C-SB
R-AM
C-WB

Mean

Proportion

Surviving

0.58

0.66

0.75

0.76

0.77

0.80

0.82

0.82

0.83

0.87

0.88

0.88

0.90

1.00 


\section{TABLE F.3. Water Quality Sunmary for 10-Day R. abronius Solid-Phase Static Test, Richmond Harbor Program}

\begin{tabular}{|c|c|c|c|c|c|c|c|c|}
\hline \multirow{2}{*}{$\begin{array}{l}\text { Sediment } \\
\text { Treatment }\end{array}$} & \multicolumn{2}{|c|}{$\begin{array}{c}\text { Temperature } \\
\left({ }^{\circ} \mathrm{C}\right)\end{array}$} & \multicolumn{2}{|c|}{$\mathrm{pH}$} & \multicolumn{2}{|c|}{$\begin{array}{l}\text { Dissolived } \\
\text { Oxygen } \\
(\mathrm{mg} / \mathrm{l})\end{array}$} & \multicolumn{2}{|c|}{$\begin{array}{c}\text { Salinity } \\
(0 / 00)\end{array}$} \\
\hline & Hin & $\max$ & Min & $\overline{\operatorname{Max}}$ & Min & $\operatorname{Max}$ & Min & Max \\
\hline $\begin{array}{l}\text { Acceptable } \\
\text { Range }\end{array}$ & 13.0 & 17.0 & 7.64 & 8.64 & 4.0 & $N A^{(a)}$ & 29.8 & 33.8 \\
\hline COHP I & 14.9 & 15.4 & 7.86 & 8.34 & 7.3 & 7.9 & 31.5 & 32.5 \\
\hline COHP II & 14.9 & 15.4 & 7.81 & 8.30 & 7.2 & 7.9 & 31.5 & 32.5 \\
\hline COMP III & 14.8 & 15.4 & 7.78 & 8.26 & 7.3 & 8.0 & 30.0 & 32.0 \\
\hline TC-5 Upper Comp & 14.9 & 15.4 & 8.00 & 8.46 & 7.3 & 7.9 & 31.0 & 32.0 \\
\hline COMP IV & 14.9 & 15.6 & 7.72 & 8.25 & 7.2 & 8.0 & 30.0 & 32.0 \\
\hline COMP V & 14.8 & 15.4 & 7.67 & 8.33 & 7.1 & 7.9 & 31.5 & 33.0 \\
\hline COMP VI & 14.8 & 15.6 & 7.77 & 8.33 & 7.3 & 7.9 & 31.5 & 32.5 \\
\hline$R-A C$ & 14.8 & 15.4 & 7.73 & 8.24 & 7.4 & 8.0 & 32.0 & 33.0 \\
\hline R-AM & 14.8 & 15.4 & 7.73 & 8.21 & 7.4 & 8.1 & 31.5 & 32.5 \\
\hline$R-B F$ & 15.0 & 15.4 & 7.73 & 8.23 & 7.1 & 7.9 & 31.5 & 32.5 \\
\hline $\mathrm{R}-\mathrm{OS}$ & 14.9 & 15.5 & 7.81 & 8.29 & 7.3 & 8.0 & 32.0 & 33.0 \\
\hline$R-P F$ & 14.8 & 15.7 & 7.73 & B. 19 & 7.1 & 8.0 & 32.0 & 32.5 \\
\hline C-SB & 14.8 & 15.3 & B. 01 & B. $B 8^{(b)}$ & 7.4 & 7.9 & 32.0 & 32.5 \\
\hline$C-4 B$ & 14.8 & 15.5 & 7.88 & 8.46 & 7.0 & 8.1 & 31.5 & 32.5 \\
\hline
\end{tabular}

(a) NA Not applicable.

(b) Data point out of range. 
TABLE F.4. Daily Observations of $R$. abronius on Sediment Surface During 10-Day Solid-Phase Static Test, Richmond Harbor Program

Sediment Treatment Repl
1
2
3
5

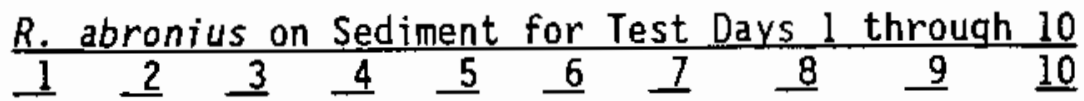

$\begin{array}{ll}\text { COMP I } & 1 \\ \text { COMP I } & 2 \\ \text { COMP I } & 3 \\ \text { COMP I } & 4 \\ \text { COMP I } & 5 \\ \text { COMP II } & \\ \text { COMP II } & 2 \\ \text { COMP II } & 3 \\ \text { COMP II } & 4 \\ \text { COMP II } & 5 \\ \text { COMP II } & \\ \text { COMP II } & 2 \\ \text { COMP II } & 3 \\ \text { COMP III } & 4 \\ \text { COMP III } & 5\end{array}$

TC-5 Upper Comp
TC-5 Upper Comp
TC-5 Upper Comp
TC-5 Upper Comp
TC-5 Upper Comp

$\begin{array}{ll}\text { COMP IV } & 1 \\ \text { COMP IV } & 2 \\ \text { COMP IV } & 3 \\ \text { COMP IV } & 4 \\ \text { COMP IV } & 5\end{array}$

$\begin{array}{ll}\text { COMP } V & \\ \text { COMP V } & 2 \\ \text { COMP V } & 3 \\ \text { COMP V } & 4 \\ \text { COMP } V & 5\end{array}$

COMP VI

COMP VI

COMP VI

COMP VI

COMP VI

$\begin{array}{lllllllllll}1 & 1 & 1 & 1 & 0 & 1 & 0 & 0 & 0 & 0 & 0 \\ 2 & 0 & 0 & 0 & 0 & 0 & 0 & 2 & 2 & 1 & 1 \\ 3 & 0 & 0 & 0 & 0 & 0 & 0 & 0 & 0 & 0 & 0 \\ 4 & 0 & 0 & 0 & 0 & 0 & 0 & 0 & 0 & 0 & 0 \\ 5 & 0 & 0 & 2 & 2 & 3 & 3 & 2 & 0 & 0 & 0\end{array}$

$\begin{array}{lllllllllll}1 & 0 & 0 & 0 & 0 & 0 & 1 & 1 & 1 & 1 & 0 \\ 2 & 1 & 2 & 1 & 0 & 1 & 0 & 0 & 1 & 1 & 1 \\ 3 & 0 & 0 & 0 & 0 & 0 & 1 & 1 & 1 & 1 & 1 \\ 4 & 0 & 0 & 0 & 0 & 0 & 0 & 0 & 0 & 0 & 0 \\ 5 & 0 & 0 & 0 & 0 & 0 & 0 & 0 & 0 & 0 & 0\end{array}$

$\begin{array}{lllllllllll}1 & 0 & 0 & 0 & 0 & 0 & 0 & 0 & 0 & 0 & 0 \\ 2 & 0 & 0 & 0 & 0 & 0 & 0 & 0 & 0 & 0 & 0 \\ 3 & 1 & 0 & 1 & 1 & 0 & 1 & 1 & 1 & 1 & 1 \\ 4 & 1 & 0 & 1 & 1 & 1 & 1 & 1 & 1 & 1 & 0 \\ 5 & 0 & 0 & 0 & 0 & 2 & 0 & 0 & 1 & 0 & 1\end{array}$

$\begin{array}{lllllllllll}1 & 1 & 0 & 0 & 0 & 0 & 1 & 1 & 1 & 2 & 2 \\ 2 & 0 & 0 & 0 & 0 & 0 & 0 & 0 & 0 & 0 & 0 \\ 3 & 0 & 1 & 0 & 1 & 1 & 0 & 1 & 0 & 0 & 1 \\ 4 & 0 & 0 & 0 & 0 & 0 & 0 & 0 & 0 & 0 & 1 \\ 5 & 0 & 0 & 0 & 0 & 0 & 0 & 0 & 0 & 0 & 0\end{array}$

$\begin{array}{lllllllllll}1 & 0 & 0 & 0 & 0 & 0 & 0 & 0 & 0 & 0 & 0 \\ 2 & 0 & 0 & 0 & 0 & 0 & 1 & 0 & 0 & 0 & 0 \\ 3 & 0 & 0 & 0 & 0 & 1 & 0 & 0 & 0 & 0 & 2 \\ 4 & 0 & 0 & 0 & 0 & 0 & 1 & 0 & 1 & 0 & 0 \\ 5 & 0 & 0 & 0 & 0 & 0 & 0 & 0 & 2 & 0 & 0\end{array}$.

$\begin{array}{lllllllllll}1 & 0 & 1 & 0 & 0 & 0 & 0 & 0 & 0 & 0 & 0 \\ 2 & 0 & 0 & 0 & 2 & 1 & 1 & 0 & 0 & 0 & 0 \\ 3 & 0 & 0 & 0 & 0 & 0 & 0 & 0 & 0 & 0 & 0 \\ 4 & 0 & 0 & 0 & 0 & 0 & 0 & 0 & 0 & 0 & 0 \\ 5 & 0 & 0 & 0 & 0 & 0 & 0 & 0 & 0 & 0 & 1 \\ 1- & 0 & 0 & 2 & 1 & 1 & 2 & 0 & 0 & 0 & 0 \\ 2 & 1 & 0 & 0 & 0 & 0 & 0 & 0 & 0 & 0 & 0 \\ 3 & 0 & 0 & 0 & 0 & 0 & 0 & 0 & 0 & 0 & 0 \\ 4 & 0 & 0 & 1 & 1 & 1 & 2 & 1 & 1 & 0 & 0 \\ 5 & 0 & 0 & 0 & 0 & 0 & 0 & 0 & 0 & 0 & 0\end{array}$


TABLE F.4. (contd)

Sediment

Treatment

$\mathrm{R}-\mathrm{AC}$

$R-A C$

$\mathrm{R}-\mathrm{AC}$

$R-A C$

R-AC

R-AM

R-AM

R-AM

R-AM

R-AM

$R-B F$

$R-B F$

$R-B F$

$\mathrm{R}-\mathrm{BF}$

$\mathrm{R}-\mathrm{BF}$

$R-O S$

R-OS

$\mathrm{R}-\mathrm{OS}$

$R-0 S$

R-OS

$R-P F$

$R-P F$

$R-P F$

$R-P F$

$R-P F$

C-SB

$C-S B$

C-SB

$C-S B$

C-SB

$C-W B$

$C-W B$

$C-W B$

$C-W B$

C-WB

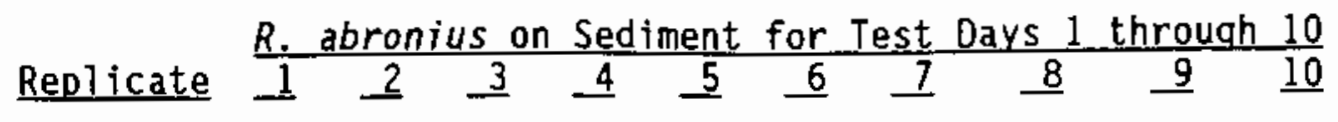

$\begin{array}{lllllllllll}1 & 0 & 0 & 0 & 1 & 2 & 3 & 3 & 3 & 2 & 4 \\ 2 & 0 & 0 & 0 & 1 & 1 & 1 & 1 & 1 & 0 & 0 \\ 3 & 0 & 0 & 1 & 0 & 2 & 1 & 0 & 1 & 0 & 0 \\ 4 & 0 & 0 & 0 & 0 & 1 & 0 & 1 & 0 & 0 & 0 \\ 5 & 0 & 0 & 1 & 0 & 0 & 0 & 0 & 0 & 0 & 0\end{array}$

$\begin{array}{lllllllllll}1 & 0 & 2 & 2 & 1 & 1 & 1 & 1 & 1 & 1 & 1 \\ 2 & 0 & 0 & 0 & 0 & 0 & 0 & 1 & 1 & 1 & 1 \\ 3 & 0 & 0 & 0 & 0 & 0 & 0 & 2 & 3 & 3 & 4 \\ 4 & 1 & 2 & 2 & 2 & 3 & 3 & 3 & 3 & 2 & 2 \\ 5 & 0 & 0 & 0 & 0 & 0 & 0 & 0 & 1 & 0 & 0\end{array}$

$\begin{array}{lllllllllll}1 & 0 & 0 & 0 & 0 & 0 & 0 & 0 & 0 & 0 & 0 \\ 2 & 0 & 0 & 0 & 0 & 0 & 0 & 0 & 0 & 0 & 0 \\ 3 & 0 & 2 & 1 & 0 & 0 & 0 & 0 & 0 & 0 & 0 \\ 4 & 1 & 0 & 0 & 1 & 1 & 1 & 1 & 1 & 1 & 0 \\ 5 & 0 & 0 & 0 & 0 & 0 & 0 & 0 & 0 & 0 & 0\end{array}$

$\begin{array}{lllllllllll}1 & 1 & 1 & 1 & 1 & 1 & 0 & 1 & 0 & 0 & 0 \\ 2 & 0 & 0 & 0 & 1 & 0 & 0 & 0 & 1 & 1 & 1 \\ 3 & 0 & 0 & 1 & 0 & 0 & 0 & 0 & 0 & 0 & 0 \\ 4 & 1 & 0 & 2 & 4 & 3 & 5 & 6 & 7 & 7 & 6 \\ 5 & 0 & 0 & 0 & 0 & 0 & 0 & 0 & 0 & 0 & 0\end{array}$

$\begin{array}{lllllllllll}1 & 0 & 0 & 0 & 0 & 0 & 0 & 0 & 0 & 0 & 0 \\ 2 & 0 & 0 & 0 & 0 & 0 & 0 & 0 & 0 & 0 & 0 \\ 3 & 0 & 0 & 0 & 0 & 1 & 1 & 1 & 1 & 1 & 2 \\ 4 & 0 & 0 & 2 & 2 & 0 & 0 & 0 & 0 & 0 & 0 \\ 5 & 2 & 3 & 3 & 2 & 4 & 3 & 2 & 2 & 2 & 3\end{array}$

$\begin{array}{lllllllllll}1 & 0 & 0 & 0 & 0 & 0 & 0 & 0 & 0 & 0 & 0 \\ 2 & 1 & 0 & 0 & 1 & 0 & 0 & 0 & 0 & 0 & 0 \\ 3 & 0 & 0 & 0 & 0 & 0 & 0 & 0 & 0 & 0 & 0 \\ 4 & 0 & 0 & 0 & 0 & 1 & 1 & 1 & 0 & 0 & 0 \\ 5 & 0 & 0 & 0 & 0 & 0 & 0 & 0 & 0 & 0 & 0\end{array}$

$\begin{array}{lllllllllll}1 & 0 & 0 & 0 & 0 & 0 & 0 & 0 & 0 & 0 & 0 \\ 2 & 0 & 0 & 0 & 0 & 0 & 0 & 0 & 0 & 0 & 1 \\ 3 & 0 & 0 & 0 & 0 & 0 & 0 & 0 & 0 & 0 & 0 \\ 4 & 0 & 0 & 0 & 0 & 0 & 0 & 0 & 0 & 0 & 0 \\ 5 & 0 & 0 & 0 & 0 & 0 & 0 & 0 & 0 & 0 & 0\end{array}$ 
IABLE F.5. Daily Observations of R. abronius Floating on Surface During 10-Day Solid Phase Static Test, Richmond Harbor Program

Sediment

Treatment

COMP I

COMP I

COMP I

COMP I

COMP I

COMP II

COMP II

COMP II

COMP II

COMP II

COMP III

COMP III

COMP III

COMP II I

COMP III

TC-5 Upper Comp

TC-5 Upper Comp

TC-5 Upper Comp 3

TC-5 Upper Comp 4

TC-5 Upper Comp 5

COMP IV

COMP IV

COMP IV

COMP IV

COMP IV

COMP V

COMP V

COMP V

COMP V

COMP V

COMP VI

COMP VI

COMP VI

COMP V I

COMP VI

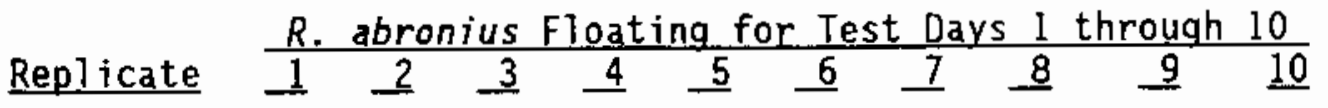

$\begin{array}{lllllllllll}1 & 0 & 0 & 1 & 0 & 2 & 0 & 0 & 0 & 3 & 3 \\ 2 & 2 & 6 & 2 & 2 & 4 & 1 & 0 & 0 & 4 & 1 \\ 3 & 1 & 0 & 1 & 3 & 1 & 0 & 1 & 0 & 3 & 2 \\ 4 & 2 & 1 & 1 & 4 & 2 & 0 & 1 & 1 & 3 & 3 \\ 5 & 0 & 1 & 0 & 2 & 1 & 0 & 0 & 0 & 2 & 1\end{array}$

$\begin{array}{lllllllllll}1 & 0 & 1 & 2 & 2 & 1 & 0 & 1 & 0 & 5 & 3 \\ 2 & 0 & 1 & 0 & 2 & 1 & 1 & 0 & 0 & 3 & 4 \\ 3 & 1 & 1 & 2 & 4 & 4 & 1 & 0 & 1 & 2 & 4 \\ 4 & 0 & 1 & 1 & 1 & 3 & 0 & 0 & 1 & 4 & 3 \\ 5 & 0 & 2 & 1 & 3 & 2 & 0 & 0 & 0 & 1 & 4\end{array}$

$\begin{array}{lllllllllll}1 & 0 & 0 & 1 & 0 & 2 & 0 & 0 & 0 & 2 & 1 \\ 2 & 0 & 1 & 1 & 0 & 1 & 0 & 0 & 0 & 4 & 4 \\ 3 & 0 & 0 & 1 & 1 & 2 & 0 & 0 & 0 & 4 & 4 \\ 4 & 0 & 2 & 1 & 2 & 0 & 0 & 0 & 1 & 3 & 3 \\ 5 & 0 & 0 & 1 & 1 & 0 & 0 & 0 & 0 & 1 & 0\end{array}$

$\begin{array}{lllllllllll}1 & 0 & 1 & 1 & 2 & 1 & 0 & 0 & 0 & 1 & 2 \\ 2 & 1 & 4 & 4 & 5 & 2 & 0 & 1 & 1 & 3 & 4 \\ 3 & 0 & 1 & 1 & 1 & 1 & 0 & 1 & 0 & 6 & 3 \\ 4 & 2 & 3 & 2 & 2 & 1 & 1 & 2 & 1 & 1 & 3 \\ 5 & 2 & 6 & 2 & 4 & 4 & 0 & 0 & 0 & 4 & 3\end{array}$

$\begin{array}{lllllllllll}1 & 0 & 0 & 4 & 1 & 0 & 0 & 0 & 1 & 4 & 4 \\ 2 & 2 & 0 & 3 & 4 & 4 & 0 & 0 & 0 & 2 & 3 \\ 3 & 1 & 0 & 0 & 0 & 1 & 0 & 0 & 1 & 6 & 2 \\ 4 & 1 & 2 & 3 & 4 & 4 & 0 & 0 & 0 & 6 & 1 \\ 5 & 2 & 2 & 2 & 5 & 4 & 0 & 0 & 0 & 9 & 5\end{array}$

$\begin{array}{lllllllllll}1 & 0 & 1 & 0 & 3 & 0 & 0 & 1 & 2 & 4 & 3 \\ 2 & 0 & 2 & 1 & 2 & 2 & 0 & 0 & 0 & 3 & 4 \\ 3 & 2 & 3 & 3 & 2 & 3 & 0 & 0 & 0 & 2 & 5 \\ 4 & 1 & 1 & 1 & 3 & 2 & 0 & 0 & 0 & 3 & 1 \\ 5 & 2 & 0 & 3 & 2 & 2 & 0 & 0 & 0 & 1 & 2\end{array}$

$\begin{array}{lllllllllll}1 & 0 & 1 & 0 & 0 & 0 & 0 & 0 & 0 & 1 & 1 \\ 2 & 0 & 1 & 3 & 2 & 4 & 0 & 0 & 1 & 2 & 1 \\ 3 & 0 & 0 & 2 & 3 & 5 & 0 & 0 & 0 & 6 & 4 \\ 4 & 0 & 1 & 0 & 0 & 2 & 0 & 0 & 0 & 1 & 2 \\ 5 & 0 & 0 & 1 & 2 & 0 & 1 & 0 & 0 & 2 & 2\end{array}$ 
TABLE F.5. (contd)

Sediment

Treatment

$R-A C$

$R-A C$

$\mathrm{R}-\mathrm{AC}$

$\mathrm{R}-\mathrm{AC}$

$\mathrm{R}-\mathrm{AC}$

$R-H M$
R-AM

R-AM

R-AM

R-AM

$R-B F$

$R-B F$

$R-B F$

$R-B F$

$R-B F$

R-OS

$R-0 S$

R-OS

R-OS

R-OS

$R-P F$

$R-P F$

$R-P F$

$R-P F$

$R-P F$

C-SB

$C-S B$

$C-S B$

C-SB

C-SB

C-WB

$C-W B$

$C-W B$

$C-W B$

C-WB

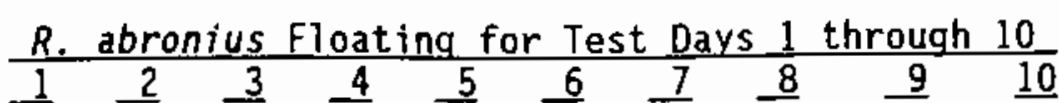

$\begin{array}{llllllllll}0 & 1 & 1 & 0 & 1 & 0 & 0 & 0 & 1 & 3 \\ 1 & 0 & 0 & 0 & 2 & 0 & 0 & 0 & 3 & 1 \\ 0 & 1 & 2 & 3 & 0 & 0 & 0 & 0 & 1 & 2 \\ 1 & 1 & 2 & 1 & 1 & 0 & 0 & 0 & 0 & 0 \\ 0 & 0 & 1 & 2 & 2 & 0 & 0 & 0 & 3 & 3\end{array}$

$\begin{array}{llllllllll}0 & 0 & 0 & 0 & 0 & 0 & 0 & 0 & 0 & 0 \\ 0 & 0 & 0 & 0 & 0 & 0 & 0 & 0 & 0 & 0 \\ 0 & 1 & 0 & 0 & 0 & 0 & 0 & 0 & 0 & 0 \\ 0 & 0 & 0 & 0 & 0 & 0 & 0 & 0 & 0 & 0 \\ 0 & 0 & 0 & 0 & 0 & 0 & 0 & 0 & 0 & 0\end{array}$

$\begin{array}{llllllllll}0 & 0 & 1 & 1 & 1 & 0 & 1 & 0 & 4 & 1 \\ 0 & 0 & 2 & 1 & 0 & 0 & 0 & 0 & 1 & 2 \\ 0 & 0 & 1 & 0 & 1 & 0 & 0 & 0 & 2 & 0 \\ 0 & 0 & 1 & 0 & 0 & 0 & 1 & 0 & 0 & 1 \\ 1 & 2 & 1 & 2 & 1 & 0 & 0 & 0 & 2 & 3\end{array}$

$\begin{array}{llllllllll}0 & 0 & 1 & 0 & 0 & 0 & 0 & 1 & 0 & 0\end{array}$

$\begin{array}{lllllllll}0 & 0 & 1 & 0 & 0 & 0 & 0 & 0 & 0 \\ 0 & 0 & 0 & 0 & 0 & 0 & 0 & 0 & 2\end{array}$

$\begin{array}{llllllllll}1 & 0 & 2 & 2 & 2 & 1 & 3 & 0 & 2 & 1 \\ 0 & 0 & 1 & 0 & 0 & 0 & 0 & 0 & 2 & 1\end{array}$

$\begin{array}{llllllllll}0 & 0 & 0 & 0 & 0 & 0 & 0 & 0 & 0 & 0\end{array}$

$\begin{array}{llllllllll}0 & 0 & 0 & 0 & 0 & 0 & 0 & I & 0 & 0\end{array}$

$\begin{array}{llllllllll}1 & 0 & 1 & 0 & 0 & 0 & 0 & 0 & 0 & 0\end{array}$

$\begin{array}{lllllllllll}4 & 1 & 0 & 1 & 0 & 0 & 0 & 0 & 0 & 0 & 0 \\ 5 & 0 & 0 & 0 & 1 & 0 & 0 & 0 & 0 & 0 & 0\end{array}$

$\begin{array}{lllllllllll}1 & 1 & 1 & 0 & 0 & 1 & 0 & 0 & 0 & 1 & 0 \\ 2 & 0 & 1 & 1 & 2 & 0 & 0 & 0 & 0 & 0 & 0 \\ 3 & 0 & 2 & 0 & 0 & 1 & 0 & 0 & 0 & 1 & 1 \\ 4 & 0 & 1 & 0 & 2 & 1 & 0 & 0 & 0 & 2 & 1 \\ 5 & 2 & 0 & 0 & 1 & 0 & 0 & 0 & 0 & 0 & 2\end{array}$

$\begin{array}{lllllllllll}1 & 0 & 0 & 0 & 0 & 0 & 0 & 0 & 0 & 0 & 0 \\ 2 & 0 & 0 & 0 & 0 & 0 & 0 & 0 & 0 & 0 & 0 \\ 3 & 0 & 0 & 0 & 0 & 0 & 0 & 0 & 0 & 0 & 0 \\ 4 & 0 & 0 & 0 & 0 & 0 & 0 & 0 & 0 & 0 & 0 \\ 5 & 0 & 0 & 0 & 0 & 0 & 0 & 0 & 0 & 0 & 0\end{array}$

F.8 
TABLE F.6. Test Resuit for 4-Day R. abronius Reference Toxicant Test, Richmond Harbor Program

\begin{tabular}{|c|c|c|c|c|}
\hline \multirow{2}{*}{$\begin{array}{l}\text { Cadmium } \\
\text { Concentration } \\
\text { (mg/L) }\end{array}$} & \multirow[b]{2}{*}{ Replicate } & \multicolumn{2}{|c|}{ R. abronius } & \multirow{2}{*}{$\begin{array}{c}\text { Mean } \\
\text { Proportion } \\
\text { Surviving } \\
\end{array}$} \\
\hline & & $\underline{\text { Live }}^{(\mathrm{a})}$ & $\begin{array}{c}\text { Dead } \\
\text { or Missing }\end{array}$ & \\
\hline $\begin{array}{l}0 \\
0 \\
0\end{array}$ & $\begin{array}{l}1 \\
2 \\
3\end{array}$ & $\begin{array}{l}17 \\
18 \\
16\end{array}$ & $\begin{array}{l}3 \\
2 \\
4\end{array}$ & 0.85 \\
\hline $\begin{array}{l}0.5 \\
0.5 \\
0.5\end{array}$ & $\begin{array}{l}1 \\
2 \\
3\end{array}$ & $\begin{array}{l}14 \\
15 \\
14\end{array}$ & $\begin{array}{l}6 \\
6 \\
6\end{array}$ & 0.72 \\
\hline $\begin{array}{l}1.00 \\
1.00 \\
1.00\end{array}$ & $\begin{array}{l}1 \\
2 \\
3\end{array}$ & $\begin{array}{r}12 \\
9 \\
8\end{array}$ & $\begin{array}{r}8 \\
11 \\
12\end{array}$ & 0.48 \\
\hline $\begin{array}{l}2.00 \\
2.00 \\
2.00\end{array}$ & $\begin{array}{l}1 \\
2 \\
3\end{array}$ & $\begin{array}{l}6 \\
2 \\
2\end{array}$ & $\begin{array}{l}14 \\
18 \\
18\end{array}$ & 0.17 \\
\hline $\begin{array}{l}4.00 \\
4.00 \\
4.00\end{array}$ & $\begin{array}{l}1 \\
2 \\
3\end{array}$ & $\begin{array}{l}0 \\
1 \\
0\end{array}$ & $\begin{array}{l}20 \\
19 \\
20\end{array}$ & 0.02 \\
\hline
\end{tabular}

(a) Survival based on initial exposure of 20 individuals per replicate. 
IABLE F.7. Rank Order Based on Mean Proportion Surviving 4-Day $R$. abronius Reference Toxicant Test, Richmond Harbor Program

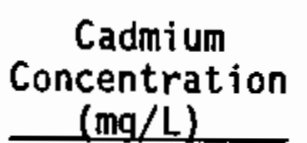

4.00

2.00

1.00

0.50

0.00

\author{
Mean \\ Proportion \\ Surviving
}

0.02

0.17

0.48

0.72

0.85 
IABLE F.8. Water Quality Summary for 4-Day $R$. abronius Reference Toxicant Test, Richmond Harbor Program

\begin{tabular}{l}
$\begin{array}{c}\text { Cadmium } \\
\text { Concentration } \\
(\mathrm{mg} / \mathrm{L})\end{array}$ \\
\hline $\begin{array}{l}\text { Acceptabie } \\
\text { Range }\end{array}$ \\
0.00 \\
0.50 \\
1.00 \\
2.00 \\
4.00
\end{tabular}

\begin{tabular}{|c|c|c|c|}
\hline \multicolumn{2}{|c|}{$\begin{array}{c}\text { Temperature } \\
\left({ }^{\circ} \mathrm{C}\right)\end{array}$} & \multicolumn{2}{|c|}{$\mathrm{OH}$} \\
\hline Min & $\operatorname{Max}$ & Min & $\operatorname{Max}$ \\
\hline 13.0 & 17.0 & 7.53 & 8.53 \\
\hline 14.9 & 15.3 & 7.81 & 8.24 \\
\hline 14.9 & 15.4 & 7.81 & 8.20 \\
\hline 14.9 & 15.8 & 7.78 & 8.18 \\
\hline 14.8 & .15 .4 & 7.70 & 8.14 \\
\hline 15.0 & 35.7 & 7.68 & 8.03 \\
\hline
\end{tabular}

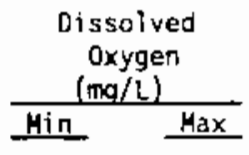

4.0 NA $(a)$

7.6

7.3

7.5

7.6

7.4

7.9
8.0
7.9
8.1
8.0

Salinity
$(0 / 00)$
Hin $\quad \operatorname{Max}$

30.2

34.2

$32.0 \quad 32.5$

$32.0 \quad 32.5$

$32.0 \quad 32.5$

$32.0 \quad 32.5$

$32.0 \quad 32.5$

(a) NA Not applicabie. 
IABLE F.9. Dajly Observations of $R$. abronius Floating on Surface During 4-Day Reference Toxicant Test, Richmond Harbor Program

Cadmium

Concentration

$(\mathrm{mg} / \mathrm{L})$

0.00

0.00

0.00

0.50

0.50

0.50

1.00

1.00

1.00

2.00

2.00

2.00

4.00

4.00

4.00
Replicate

1
2
3

1
2
3

1
2
3

1
2
3

1
2
3

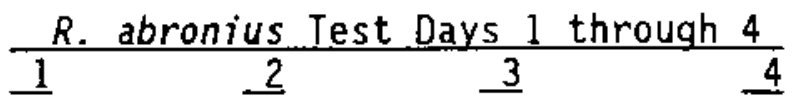

10

0

0

1

$\begin{array}{ll}2 & 1 \\ 4 & 3 \\ 0 & 3\end{array}$

1
1
4

1
2
2

2
4
2

0

1

$\begin{array}{llll}2 & 1 & 4 & 3\end{array}$

04

3

10

$2 \quad 0$

1

3

2
2
2
2

0

0

0

0

0

0

0

0 
APPENDIX G

BLOASSAY RESULTS FOR 96-HOUR SUSPENDED-PARTICULATE-PHASE TEST AND 96-HOUR BEFERENCE TOXICANT TEST FOR CITHARICHTHYS sitgmaeUS 
IABLE G.1. Test Results for 96-Hour C. stigmaeus SuspendedParticulate-Phase Test, Richmond Harbor Program

Sediment Treatment

$\begin{array}{lr}\text { COMP I } & 0 \\ \text { COMP I } & 0 \\ \text { COMP I } & 0 \\ \text { COMP I } & 0 \\ \text { COMP I } & 10 \\ \text { COMP I } & 10 \\ \text { COMP I } & 10 \\ \text { COMP I } & 10 \\ \text { COMP I } & \\ \text { COMP I } & 50 \\ \text { COMP I } & 50 \\ \text { COMP I } & 50 \\ \text { COMP I } & 50 \\ \text { COMP I } & \\ \text { COMP I } & 100 \\ \text { COMP I } & 100 \\ \text { COMP I } & 100 \\ \text { COMP II } & 100 \\ \text { COMP I } & 0 \\ \text { COMP I } & 0 \\ \text { COMP II } & 0 \\ \text { COMP I } & 0 \\ \text { COMP II } & \\ \text { COMP II } & 10 \\ \text { COMP I } & 10 \\ \text { COMP I } & 10 \\ \text { COMP I } & 10 \\ \text { COMP II } & 50 \\ \text { COMP I } & 50 \\ \text { COMP I } & 50 \\ \text { COMP I } & 50 \\ \text { COMP I } & 100 \\ & 100 \\ & 100 \\ & 100\end{array}$

$\frac{\text { C. stigmaeus }}{\text { Dead }} \begin{gathered}\text { Mean } \\ \text { Proportion }\end{gathered}$ Concentration (\%) Replicate Live ${ }^{(a)}$ or Missing Surviving

0

0

0

0

10

10

10

50

50

50

50

100

100

100

100

0

0

0

0

10

10

10

10

50

50

50

50

100

100

100
1

2

3

4

1

2

3

4

1

2

3

4

1

2

3

4

1
2
3
4

1

2

3

4

1

2

3

4

1

2

3

$\begin{array}{rl}9 & 1 \\ 10 & 0 \\ 10 & 0 \\ 9 & 1\end{array}$

0.95

9

10

10

0.98

9

9

10

0.95

10

10

10

0.98

10

10

10

0.95

2

9

10

10

0.95

0.93

8

2

$\begin{array}{rr}10 & 0 \\ 9 & 1 \\ 9 & 1 \\ 9 & 1\end{array}$

0.93

G.1 
IABLE G.1. (contd)

Sediment

Ireatment

\section{Concentration (\%) Replicate}

$\begin{array}{ll}\text { COMP II I } & \\ \text { COMP II I } \\ \text { COMP II I } \\ \text { COMP I I I } \\ \text { COMP II I } \\ \text { COMP I I I } & \\ \text { COMP I I } & 10 \\ \text { COMP I I I } & 10 \\ \text { COMP III } & 10 \\ \text { COMP III } & 50 \\ \text { COMP II I } & 50 \\ \text { COMP II I } & 50 \\ \text { COMP II I } & 100 \\ \text { COMP II I } & 100 \\ \text { COMP II I } & 100 \\ \text { COMP II I } & 100\end{array}$

TC-5 Upper Comp 0

TC-5 Upper Comp 0

TC-5 Upper Comp 0

TC-5 Upper Comp 0

TC-5 Upper Comp 10

TC-5 Upper Comp 10

TC -5 Upper Comp 10

TC -5 Upper Comp 10

TC-5 Upper Comp 50

TC-5 Upper Comp 50

TC-5 Upper Comp 50

TC-5 Upper Comp 50

TC-5 Upper Comp 100

TC-5 Upper Comp $\quad 100$

TC-5 Upper Comp 100

TC-5 Upper Comp 100 
IABLE G.1. (contd)

Sediment
Ireatment

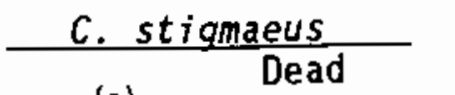

Mean

Dead Proportion

Concentration (\%) Replicate

Live(a) or Missing Surviving

COMP IV

COMP IV

COMP IV

COMP IV

0

9
10

1

10

0

10

0.98

COMP IV

COMP IV

COMP IV

COMP IV

10

10

10

10

9
10
10
7

1

1

3

COMP IV

COMP IV

COMP IV

COMP IV

50

50

50

50

COMP IV

COMP IV

COMP IV

COMP IV

100

100

100

100

COMP $V$

COMP V

COMP V

COMP V

0

0

0

COMP V

COMP V

COMP V

COMP V

1
2
3
4

10

9

10

0.95

0.90

3

0.90

0

1

1

$\begin{array}{rr}1 & 8 \\ 2 & 10\end{array}$

3

9

0.90

COMP V

COMP V

COMP V

COMP V

10

10

10

10

110

29

310

410

0.98

COMP V

COMP V

COMP V

COMP V

50

50

50

50

1
2
3
4

8

10

9
10

0.93

100

100

100

100

$\begin{array}{rr}1 & 10 \\ 2 & 9 \\ 3 & 10 \\ 4 & 10 \\ & \\ 1 & 8 \\ 2 & 10 \\ 3 & 9 \\ 4 & 10\end{array}$

0.98

8
10
9
10

0.93 
TABLE G.1. (contd)

\begin{tabular}{|c|c|c|c|c|c|}
\hline \multirow[b]{2}{*}{$\begin{array}{l}\text { Sediment } \\
\text { Ireatment }\end{array}$} & \multirow[b]{2}{*}{ Concentration $(\%)$} & \multirow[b]{2}{*}{ Replicate } & \multicolumn{2}{|c|}{ C. stigmaeus } & \multirow{2}{*}{$\begin{array}{l}\text { Mean } \\
\text { Proportion } \\
\text { Surviving }\end{array}$} \\
\hline & & & Live $^{(a)}$ & $\begin{array}{l}\text { Dead } \\
\text { or Missing }\end{array}$ & \\
\hline COMP VI & 0 & 1 & 9 & 1 & \\
\hline COMP VI & 0 & 2 & 9 & 1 & \\
\hline COMP VI & 0 & 3 & 10 & 0 & \\
\hline COMP VI & 0 & 4 & 10 & 0 & 0.95 \\
\hline COMP VI & 10 & 1 & 8 & 2 & \\
\hline COMP VI & 10 & 2 & 10 & 0 & \\
\hline COMP VI & 10 & 3 & 10 & 0 & \\
\hline COMP VI & 10 & 4 & 10 & 0 & 0.95 \\
\hline COMP VI & 50 & 1 & 10 & 0 & \\
\hline COMP VI & 50 & 2 & و & 1 & \\
\hline COMP VI & 50 & 3 & 10 & 0 & \\
\hline COMP VI & 50 & 4 & 10 & 0 & 0.98 \\
\hline СOMP VI & 100 & 1 & 10 & 0 & \\
\hline COMP VI & 100 & 2 & 10 & 0 & \\
\hline COMP VI & 100 & 3 & 10 & 0 & \\
\hline COMP VI & 100 & 4 & g & l & 0.98 \\
\hline
\end{tabular}

(a) Survival based on initial exposure of 10 individuals per replicate. 
IABLE G.2. Summary of Mean Proportion Surviving 96-Hour C. stigmaeus Suspended-Particulate-Phase Test, Richmond Harbor Program

\section{Sediment}

Treatment

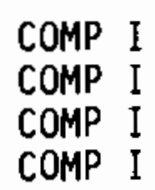

COMP II

COMP II

COMP II

COMP II

COMP III

COMP III

COMP III

COMP III

COMP IV

COMP IV

COMP IV

COMP IV

COMP V

COMP V

COMP V

COMP V

COMP VI

COMP VI

COMP VI

COMP VI

TC-5 Upper Comp

TC-5 Upper Comp

TC-5 Upper Comp

TC-5 Upper Comp
Concentration (\%)

\section{0}

10

50

100

0

10

50

100

0

10

50

100

0

10

50

100

0

10

50

100

0

10

50

100

0

10

50

100

\author{
Mean \\ Proportion \\ Surviving
}

0.95

0.98

0.95

0.98

0.95

0.95

0.93

0.93

0.93

0.98

0.95

1.00

0.98

0.90

0.95

0.90

0.98

0.93

0.98

0.93

0.95

0.95

0.98

0.98

1.00

1.00

0.90

0.23 
IABLE G.3. Water Quality Summary for 96-Hour C. stigmaeus Suspended-Particulate-Phase Test, Richmond Harbor Program

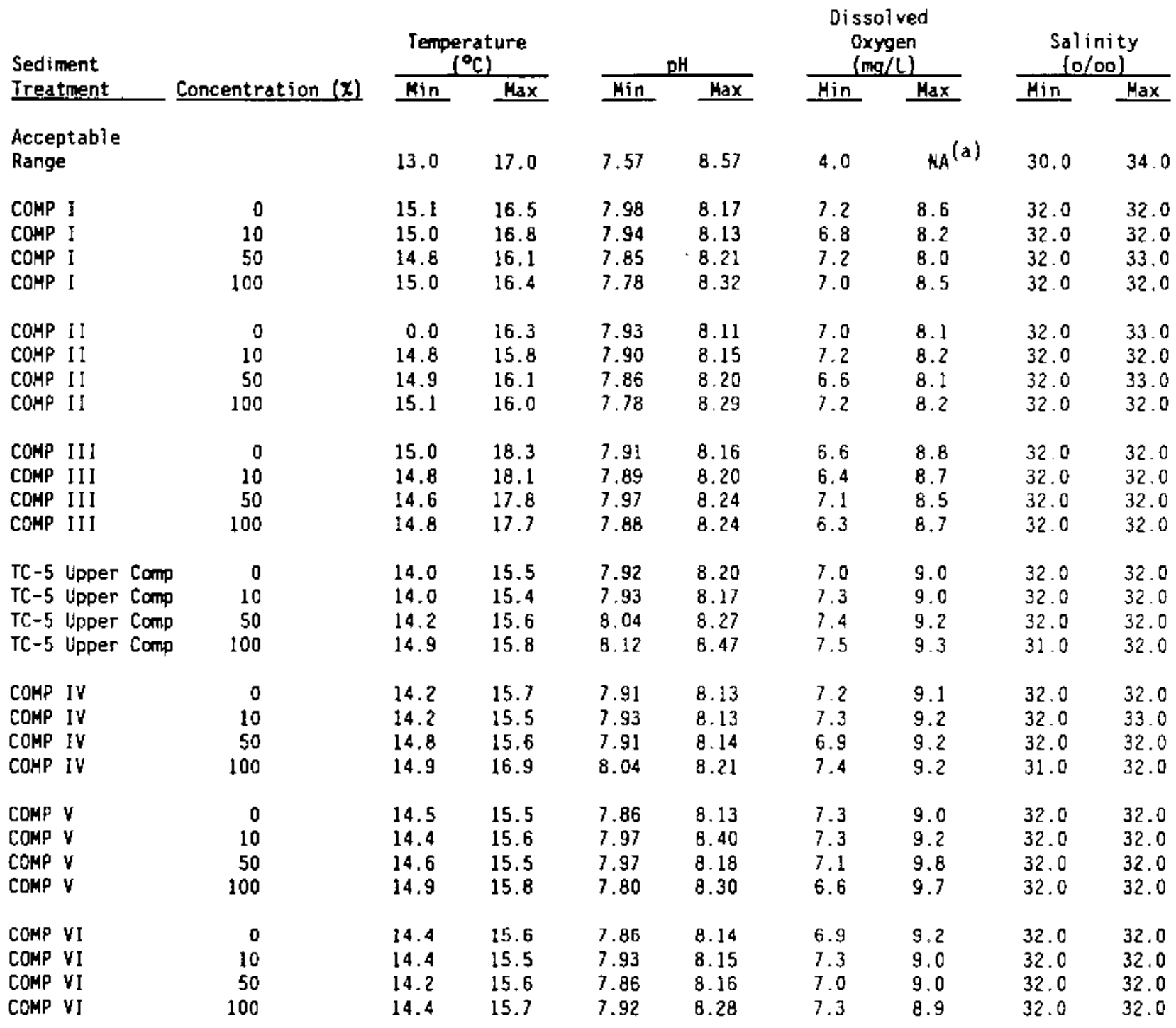

(a) NA Not applicable. 
IABLE G.4. Daily Observations of $C$. stigmaeus During 96-Hour Suspended-Particulate-Phase Test, Richmond Harbor Program

Sediment Treatment conP I COMP I COMP I COMP I

COMP I

COMP 1

COMP I

COMP I

COMP I

COMP I

COMP I

CDHP I

COMP 1

COMP I

COMP I

COMP I

COMP II

COMP II

COMP 11

COMP II

COMP II

COMP II

COMP II

COMP II

COMP II

COMP II

COMP II

COMP II

COMP II

COMP II

COMP II

COMP II

COMP III

COMP III

COMP III

COMP III

COMP III

COMP II I

COMP III

COMP III

COMP II I

COMP III

COMP III

COMP III $\frac{\text { C. stigmanss Live }}{\text { oh } 4 \mathrm{~h} \text { 24h } 48 \mathrm{~h} \text { I2h } \underline{96 \mathrm{~h}}}$ Concentration ( $\%$ ) Replicate

\section{0
0
0}

1
2
3
4

C. stigmaens Dead

$\begin{array}{rrrrrrrrrrrr}10 & 10 & 10 & 10 & 9 & 9 & 0 & 0 & 0 & 0 & 1 & 0 \\ 10 & 10 & 10 & 10 & 10 & 10 & 0 & 0 & 0 & 0 & 0 & 0 \\ 10 & 10 & 10 & 10 & 10 & 10 & 0 & 0 & 0 & 0 & 0 & 0 \\ 10 & 10 & 10 & 9 & 9 & 9 & 0 & 0 & 0 & 1 & 0 & 0\end{array}$

10

10

10

10

1
2
3
4

$\begin{array}{rrrrrrrrrrrr}10 & 10 & 10 & 10 & 10 & 9 & 0 & 0 & 0 & 0 & 0 & 1 \\ 10 & 10 & 10 & 10 & 10 & 10 & 0 & 0 & 0 & 0 & 0 & 0 \\ 10 & 10 & 10 & 10 & 10 & 10 & 0 & 0 & 0 & 0 & 0 & 0 \\ 10 & 10 & 10 & 10 & 10 & 10 & 0 & 0 & 0 & 0 & 0 & 0\end{array}$

$\begin{array}{ll}50 & 1 \\ 50 & 2 \\ 50 & 3 \\ 50 & 4\end{array}$

$$
\begin{array}{rrrrrrrrrrrr}
10 & 10 & 10 & 9 & 9 & 9 & 0 & 0 & 0 & 1 & 0 & 0 \\
10 & 10 & 10 & 10 & 10 & 9 & 0 & 0 & 0 & 0 & 0 & 1 \\
10 & 10 & 10 & 10 & 10 & 10 & 0 & 0 & 0 & 0 & 0 & 0 \\
10 & 10 & 10 & 10 & 10 & 10 & 0 & 0 & 0 & 0 & 0 & 0
\end{array}
$$

100

100

100

100

$\begin{array}{rrrrrrrrrrrr}10 & 10 & 10 & 10 & 10 & 10 & 0 & 0 & 0 & 0 & 0 & 0 \\ 10 & 10 & 10 & 10 & 10 & 10 & 0 & 0 & 0 & 0 & 0 & 0 \\ 10 & 10 & 10 & 10 & 10 & 10 & 0 & 0 & 0 & 0 & 0 & 0 \\ 10 & 10 & 10 & 9 & 9 & 9 & 0 & 0 & 0 & 1 & 0 & 0\end{array}$

$\begin{array}{rrrrrrrrrrrr}10 & 10 & 10 & 10 & 10 & 10 & 0 & 0 & 0 & 0 & 0 & 0 \\ 10 & 10 & 10 & 10 & 10 & 10 & 0 & 0 & 0 & 0 & 0 & 0 \\ 10 & 10 & 10 & 10 & 10 & 10 & 0 & 0 & 0 & 0 & 0 & 0 \\ 10 & 10 & 9 & 8 & 8 & 8 & 0 & 0 & 1 & 1 & 0 & 0\end{array}$

$\begin{array}{rrrrrrrrrrrr}10 & 10 & 10 & 9 & 9 & 9 & 0 & 0 & 0 & 1 & 0 & 0 \\ 10 & 10 & 10 & 10 & 10 & 10 & 0 & 0 & 0 & 0 & 0 & 0 \\ 10 & 10 & 10 & 10 & 10 & 10 & 0 & 0 & 0 & 0 & 0 & 0 \\ 10 & 10 & 10 & 9 & 9 & 9 & 0 & 0 & 0 & 1 & 0 & 0\end{array}$

10

50
50
50

50

100

100

100

100

$\begin{array}{rrrrrrrrrrrr}10 & 10 & 10 & 10 & 10 & 10 & 0 & 0 & 0 & 0 & 0 & 0 \\ 10 & 10 & 10 & 9 & 9 & 9 & 0 & 0 & 0 & 1 & 0 & 0 \\ 10 & 10 & 10 & 10 & 10 & 10 & 0 & 0 & 0 & 0 & 0 & 0 \\ 10 & 10 & 10 & 9 & 9 & 8 & 0 & 0 & 0 & 1 & 0 & 1\end{array}$

$\begin{array}{rrrrrrrrrrrr}10 & 10 & 10 & 10 & 10 & 10 & 0 & 0 & 0 & 0 & 0 & 0 \\ 10 & 10 & 10 & 9 & 9 & 9 & 0 & 0 & 0 & 1 & 0 & 0 \\ 10 & 10 & 10 & 9 & 9 & 9 & 0 & 0 & 0 & 1 & 0 & 0 \\ 10 & 10 & 10 & 10 & 9 & 9 & 0 & 0 & 0 & 0 & 1 & 0\end{array}$

$\begin{array}{rrrrrrrrrrrr}10 & 10 & 10 & 10 & 10 & 10 & 0 & 0 & 0 & 0 & 0 & 0 \\ 10 & 10 & 10 & 10 & 10 & 9 & 0 & 0 & 0 & 0 & 0 & 1 \\ 10 & 10 & 10 & 10 & 9 & 9 & 0 & 0 & 0 & 0 & 1 & 0 \\ 10 & 10 & 10 & 10 & 10 & 9 & 0 & 0 & 0 & 0 & 0 & 1\end{array}$

$\begin{array}{rrrrrrrrrrrr}10 & 10 & 10 & 10 & 9 & 9 & 0 & 0 & 0 & 0 & 1 & 0 \\ 10 & 10 & 10 & 10 & 10 & 10 & 0 & 0 & 0 & 0 & 0 & 0 \\ 10 & 10 & 10 & 10 & 10 & 10 & 0 & 0 & 0 & 0 & 0 & 0 \\ 10 & 10 & 10 & 10 & 10 & 10 & 0 & 0 & 0 & 0 & 0 & 0\end{array}$

$\begin{array}{rrrrrrrrrrrr}10 & 10 & 10 & 10 & 10 & 10 & 0 & 0 & 0 & 0 & 0 & 0 \\ 10 & 10 & 10 & 10 & 10 & 10 & 0 & 0 & 0 & 0 & 0 & 0 \\ 10 & 10 & 10 & 10 & 9 & 9 & 0 & 0 & 0 & 0 & 1 & 0 \\ 10 & 10 & 10 & 9 & 9 & 9 & 0 & 0 & 0 & 1 & 0 & 0\end{array}$ 


\section{IABLE G.4. (contd)}

Sediment

Ireatment

\section{COMP III}

COMP III

COMP III

COMP II I

TC-5 Upper Comp

IC-5 Upper Comp

IC-5 Upper Comp

TC-5 Upper Comp

TC-5 Upper Comp

TC-5 Upper Comp

TC-5 Upper Comp

TC-5 Upper Comp

TC-5 Upper Comp

TC-5 Upper Comp

TC-5 Upper Comp

TC-5 Upper Comp

TC-5 Upper Comp

TC-5 Upper Comp

IC-5 Upper Comp

TC-5 Upper Comp

COMP IV

COMP IV

COMP IV

COMP IV

COMP IV

COMP IV

COMP IV

COMP IV

COMP IV

COHP IV

COHP IV

COHP IV

COMP IV

COMP IV

COMP IV

COMP IV

COMP $V$

COHP $V$

COMP V

COMP $V$

COMP $V$

СОMP $V$

COMP $V$

COMP $V$

Concentration ( $\boldsymbol{x}$ ) Replicate

C. sigmaeus Live

Oh $4 \mathrm{~h}$ 24h 48h $2 \mathrm{hh}$ 96h oh 4h 24h 48h 72h g6h

\section{0}

100

100

100

$$
\begin{aligned}
& 0 \\
& 0 \\
& 0 \\
& 0
\end{aligned}
$$

10

10

10

10

50

so

50

50

100

100

100

100

$$
\begin{aligned}
& 0 \\
& 0 \\
& 0 \\
& 0
\end{aligned}
$$

10

10

10

10

50
50
50
50

100

100

100

100

$$
\begin{aligned}
& 0 \\
& 0 \\
& 0 \\
& 0
\end{aligned}
$$

10

10
10

10

1
2
3
4

$\begin{array}{llllllllllll}10 & 10 & 10 & 10 & 10 & 10 & 0 & 0 & 0 & 0 & 0 & 0 \\ 10 & 10 & 10 & 10 & 10 & 10 & 0 & 0 & 0 & 0 & 0 & 0 \\ 10 & 10 & 10 & 10 & 10 & 10 & 0 & 0 & 0 & 0 & 0 & 0 \\ 10 & 10 & 10 & 10 & 10 & 10 & 0 & 0 & 0 & 0 & 0 & 0\end{array}$

$\begin{array}{llllllllllll}10 & 10 & 10 & 10 & 10 & 10 & 0 & 0 & 0 & 0 & 0 & 0 \\ 10 & 10 & 10 & 10 & 10 & 10 & 0 & 0 & 0 & 0 & 0 & 0 \\ 10 & 10 & 10 & 10 & 10 & 10 & 0 & 0 & 0 & 0 & 0 & 0 \\ 10 & 10 & 10 & 10 & 10 & 10 & 0 & 0 & 0 & 0 & 0 & 0\end{array}$

$\begin{array}{llllllllllll}10 & 10 & 10 & 10 & 10 & 10 & 0 & 0 & 0 & 0 & 0 & 0 \\ 10 & 10 & 10 & 10 & 10 & 10 & 0 & 0 & 0 & 0 & 0 & 0 \\ 10 & 10 & 10 & 10 & 10 & 10 & 0 & 0 & 0 & 0 & 0 & 0 \\ 10 & 10 & 10 & 10 & 10 & 10 & 0 & 0 & 0 & 0 & 0 & 0\end{array}$

$\begin{array}{rrrrrrrrrrrr}10 & 10 & 10 & 10 & 9 & 8 & 0 & 0 & 0 & 0 & 1 & 1 \\ 10 & 10 & 10 & 8 & 8 & 8 & 0 & 0 & 0 & 2 & 0 & 0 \\ 10 & 10 & 10 & 10 & 10 & 10 & 0 & 0 & 0 & 0 & 0 & 0 \\ 10 & 10 & 10 & 10 & 10 & 10 & 0 & 0 & 0 & 0 & 0 & 0\end{array}$

$\begin{array}{llllllllllll}10 & 10 & 4 & 4 & 4 & 4 & 0 & 0 & 6 & 0 & 0 & 0 \\ 10 & 10 & 4 & 3 & 3 & 3 & 0 & 0 & 6 & 1 & 0 & 0 \\ 10 & 10 & 1 & 1 & 1 & 1 & 0 & 0 & 9 & 0 & 0 & 0 \\ 10 & 10 & 2 & 2 & 1 & 1 & 0 & 0 & 8 & 0 & 1 & 0\end{array}$

$\begin{array}{rrrrrrrrrrrr}10 & 10 & 10 & 9 & 9 & 9 & 0 & 0 & 0 & 1 & 0 & 0 \\ 10 & 10 & 10 & 10 & 10 & 10 & 0 & 0 & 0 & 0 & 0 & 0 \\ 10 & 10 & 10 & 10 & 10 & 10 & 0 & 0 & 0 & 0 & 0 & 0 \\ 10 & 10 & 10 & 10 & 10 & 10 & 0 & 0 & 0 & 0 & 0 & 0\end{array}$

$\begin{array}{rrrrrrrrrrrr}10 & 10 & 10 & 10 & 9 & 9 & 0 & 0 & 0 & 0 & \mathrm{i} & 0 \\ 10 & 10 & 10 & 10 & 10 & 10 & 0 & 0 & 0 & 0 & 0 & 0 \\ 10 & 10 & 10 & 10 & 10 & 10 & 0 & 0 & 0 & 0 & 0 & 0 \\ 10 & 10 & 9 & 9 & 8 & 7 & 0 & 0 & 1 & 0 & 1 & 1\end{array}$

$\begin{array}{rrrrrrrrrrrr}10 & 10 & 10 & 10 & 10 & 10 & 0 & 0 & 0 & 0 & 0 & 0 \\ 10 & 10 & 9 & 9 & 9 & 9 & 0 & 0 & 1 & 0 & 0 & 0 \\ 10 & 10 & 10 & 10 & 9 & 9 & 0 & 0 & 0 & 0 & 1 & 0 \\ 10 & 10 & 10 & 10 & 10 & 10 & 0 & 0 & 0 & 0 & 0 & 0\end{array}$

$\begin{array}{rrrrrrrrrrrr}10 & 9 & 9 & 8 & 8 & 8 & 0 & 1 & 0 & 1 & 0 & 0 \\ 10 & 10 & 10 & 10 & 10 & 10 & 0 & 0 & 0 & 0 & 0 & 0 \\ 10 & 10 & 9 & 9 & 9 & 9 & 0 & 0 & 1 & 0 & 0 & 0 \\ 10 & 10 & 10 & 10 & 9 & 9 & 0 & 0 & 0 & 0 & 1 & 0\end{array}$

$\begin{array}{llllllllllll}10 & 10 & 10 & 10 & 10 & 10 & 0 & 0 & 0 & 0 & 0 & 0\end{array}$

$\begin{array}{rrrrrrrrrrrr}10 & 10 & 9 & 9 & 9 & 9 & 0 & 0 & 1 & 0 & 0 & 0 \\ 10 & 10 & 10 & 10 & 10 & 10 & 0 & 0 & 0 & 0 & 0 & 0\end{array}$

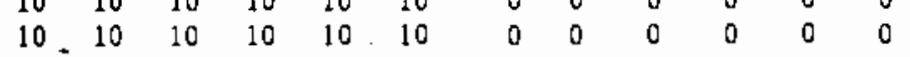

$\begin{array}{rrrrrrrrrrrr}10 & 10 & 10 & 9 & 8 & 8 & 0 & 0 & 0 & 1 & 1 & 0 \\ 10 & 10 & 10 & 10 & 10 & 10 & 0 & 0 & 0 & 0 & 0 & 0 \\ 10 & 10 & 10 & 9 & 9 & 9 & 0 & 0 & 0 & 1 & 0 & 0 \\ 10 & 10 & 10 & 10 & 10 & 10 & 0 & 0 & 0 & 0 & 0 & 0\end{array}$ 
IABLE G.4. (contd)

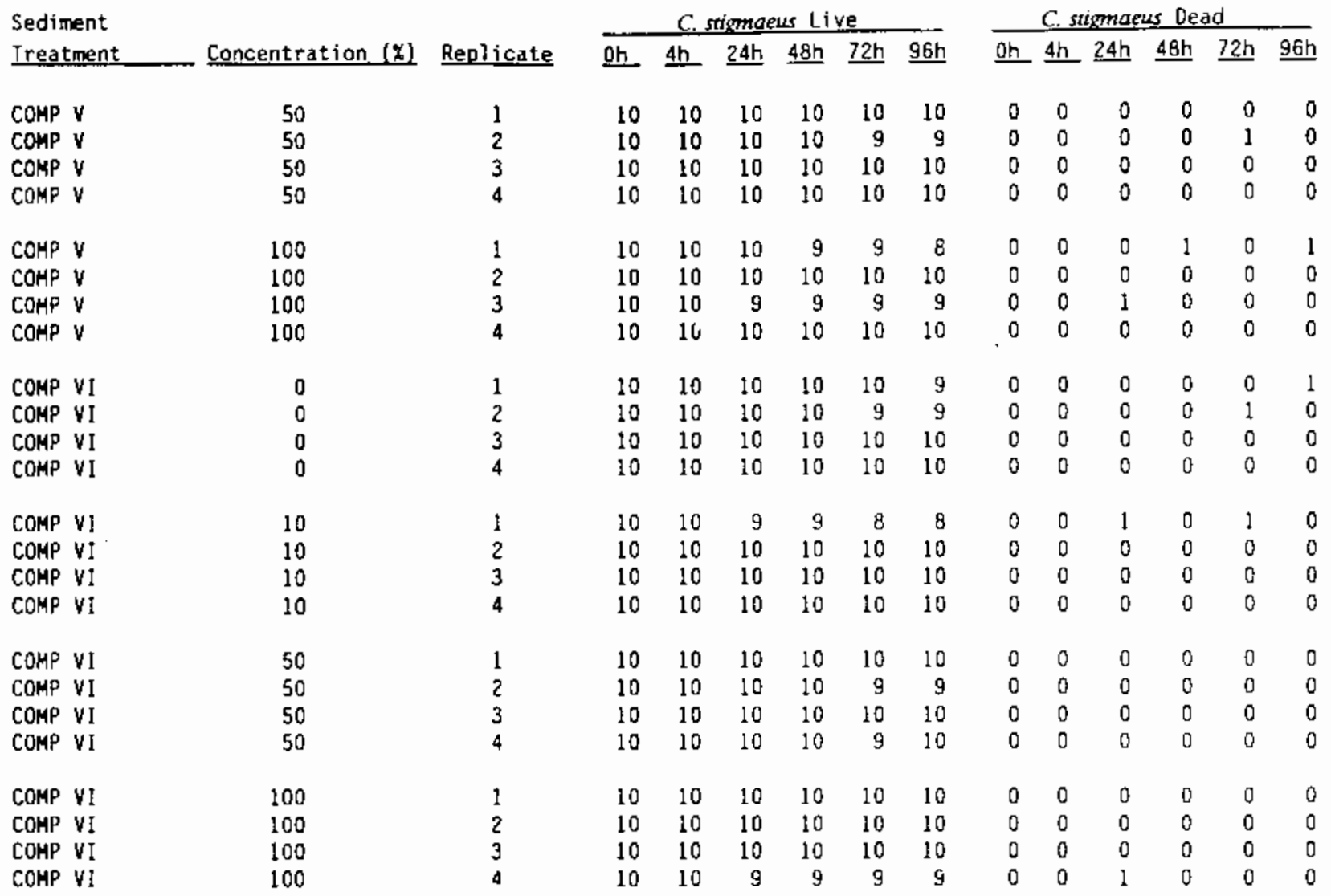


IABLE G.5. Survival Data for 96-Hour C. stigmaeus Reference Toxicant Test, Richmond Harbor Program

\begin{tabular}{|c|c|c|c|c|}
\hline \multirow{2}{*}{$\begin{array}{c}\text { Copper } \\
\text { Concentration } \\
(\mathrm{mg} / \mathrm{L}) \\
\end{array}$} & \multirow[b]{2}{*}{ Replicate } & \multicolumn{2}{|c|}{ C. stiqmaeus } & \multirow{2}{*}{$\begin{array}{c}\text { Mean } \\
\text { Proportion } \\
\text { Surviving } \\
\end{array}$} \\
\hline & & Live $^{(a)}$ & $\begin{array}{c}\text { Dead } \\
\text { or Missing }\end{array}$ & \\
\hline 0 & 1 & 10 & 0 & \\
\hline 0 & 2 & 10 & 0 & \\
\hline 0 & 3 & 10 & 0 & \\
\hline 0 & 4 & 10 & 0 & 1.00 \\
\hline 0.77 & 1 & 6 & 4 & \\
\hline 0.77 & 2 & 8 & 2 & \\
\hline 0.77 & 3 & 9 & 1 & 0.77 \\
\hline 0.96 & 1 & 9 & 1 & \\
\hline 0.96 & 2 & 7 & 3 & \\
\hline 0.96 & 3 & 7 & 3 & 0.77 \\
\hline 1.2 & 1 & 9 & 1 & \\
\hline 1.2 & 2 & 4 & 6 & \\
\hline 1.2 & 3 & 3 & 7 & 0.53 \\
\hline 1.5 & 1 & 0 & 10 & \\
\hline 1.5 & 2 & 0 & 10 & \\
\hline 1.5 & 3 & 8 & 2 & 0.27 \\
\hline
\end{tabular}

(a) Survival based on initial exposure of 10 individuals per replicate. 
TABLE G.6. Rank Order Based on Mean Proportion Surviving 96-Hour C. stigmaeus Reference Toxicant Test, Richmond Harbor Program

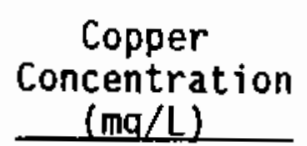

1.5

1.2

0.77

0.96

0
Mean

Proportion

Surviving

0.27

0.53

0.77

0.77

1.00

G.11 
IABLE G.7. Water Quality Summary for 96-Hour C. stigmaeus Reference Toxicant Test, Richmond Harbor Program

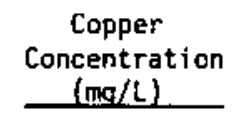

Acceptabie

Range

0

0.77

0.96

1.2

1.5

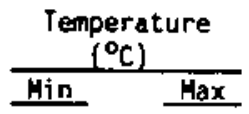

13.0

17.0

14.0

14.0

14.0

14.0

14.1

15.5

15.5

15.6

15.6

15.5

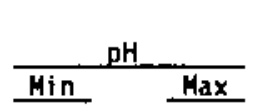

7.45

8.45

7.92

7.76

7.71

7.65

7.55

8.20

8.21

0.18

8.19

B. 24

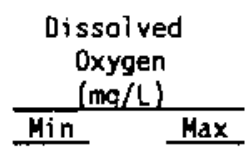

4.0

7.0

7.1

7.1

7.4

7.3

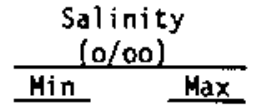

$30.1 \quad 34.1$

$32.0 \quad 32.0$

$32.0 \quad 32.5$

$32.0 \quad 32.5$

$32.0 \quad 33.0$

$32.0 \quad 33.0$

(a) NA Not applicabie. 
TABLE G.8. DaiTy Observations of C. stigmaeus During 96-Hour Reference Toxicant Test, Richmond Harbor Program

Copper

Concentration (ma/L)

0
0
0
0

0.77

0.77

0.77

0.96

0.96

0.96

1.2

1.2

1.2

1.5

1.5

1.5

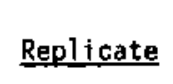

1
2
3
4

1

3

1

2

1
2
3

1

1
2
3

\section{C. strigmaew Live}

\begin{tabular}{ll}
\hline Ch & 4h \\
10 & 1 \\
10 & 10 \\
10 & 10 \\
10 & 10
\end{tabular}

\begin{abstract}
1010
\end{abstract}

10

$24 \mathrm{~h}$

$\begin{array}{llll}10 & 10 & 10 & 10 \\ 10 & 10 & 10 & 10 \\ 10 & 10 & 10 & 10 \\ 10 & 10 & 10 & 10\end{array}$

10

$\begin{array}{rrrrr}10 & 10 & 9 & 6 \\ 10 & 10 & 9 & 8 \\ 10 & 10 & 10 & 9\end{array}$

$\begin{array}{lllll}10 & 10 & 10 & 10 & 10\end{array}$

$\begin{array}{rrrrr}10 & 10 & 10 & 10 & 10 \\ 10 & 10 & 10 & 10 & 9 \\ 10 & 10 & 10 & 9 & 9\end{array}$

$10 \quad 10$

$\begin{array}{ll}10 & 10 \\ 10 & 10\end{array}$

$\begin{array}{rrrr}10 & 10 & 10 & 9 \\ 10 & 10 & 9 & 4 \\ 10 & 10 & 6 & 3\end{array}$

$\begin{array}{ll}10 & 10 \\ 10 & 10 \\ 10 & 10\end{array}$
C. stigmaess Dead

oh 4h 24h 48h $\underline{72 h \quad 96 h}$

$\begin{array}{llllll}0 & 0 & 0 & 0 & 0 & 0 \\ 0 & 0 & 0 & 0 & 0 & 0 \\ 0 & 0 & 0 & 0 & 0 & 0 \\ 0 & 0 & 0 & 0 & 0 & 0\end{array}$

$\begin{array}{llllll}0 & 0 & 0 & 0 & 1 & 3 \\ 0 & 0 & 0 & 0 & 1 & 1 \\ 0 & 0 & 0 & 0 & 0 & 1\end{array}$

$\begin{array}{llllll}0 & 0 & 0 & 0 & 0 & 1 \\ 0 & 0 & 0 & 0 & 1 & 2 \\ 0 & 0 & 0 & 1 & 1 & 2\end{array}$

$\begin{array}{llllll}0 & 0 & 0 & 0 & 0 & 1 \\ 0 & 0 & 0 & 0 & 1 & 5 \\ 0 & 0 & 0 & 0 & 4 & 3\end{array}$

$\begin{array}{rrrr}10 & 2 & 1 & 0 \\ 10 & 8 & 2 & 0 \\ 10 & 10 & 9 & 8\end{array}$

$\begin{array}{llllll}0 & 0 & 0 & 8 & 0 & 1 \\ 0 & 0 & 0 & 2 & 6 & 2 \\ 0 & 0 & 0 & 0 & 1 & 1\end{array}$ 

APPENDIX H

BLOASSAYRESULTS FOR 96-HOUR SUSPENDED-PARTICULATE-PHASE TEST AND 96-HOURREFERENCE TOXICANT TEST FOR HOLMESIMYSIS SCUlota 
IABLE H.1. Test Results for 96-Hour H. sculpta Suspended-ParticulatePhase Test, Richmond Harbor Program

\begin{tabular}{|c|c|c|c|c|c|}
\hline \multirow[b]{2}{*}{$\begin{array}{l}\text { Sediment } \\
\text { Ireatment }\end{array}$} & \multirow[b]{2}{*}{ Concentration (\%) } & \multirow[b]{2}{*}{ Replicate } & \multicolumn{2}{|c|}{ H. sculpta } & \multirow{2}{*}{$\begin{array}{c}\text { Mean } \\
\text { Proportion } \\
\text { Surviving }\end{array}$} \\
\hline & & & Live $^{(a)}$ & $\begin{array}{l}\text { Dead } \\
\text { or Missing }\end{array}$ & \\
\hline COMP I & 0 & 1 & 10 & 0 & \\
\hline COMP I & 0 & 2 & 10 & 0 & \\
\hline COMP I & 0 & 3 & 10 & 0 & \\
\hline COMP I & 0 & 4 & 10 & 0 & 1.00 \\
\hline COMP I & 10 & 1 & 6 & 4 & \\
\hline COMP I & 10 & 2 & 10 & 0 & \\
\hline COMP I & 10 & 3 & 10 & 0 & \\
\hline COMP I & 10 & 4 & 10 & 0 & 0.90 \\
\hline COMP I & 50 & 1 & 10 & 0 & \\
\hline COMP I & 50 & 2 & 10 & 0 & \\
\hline COMP I & 50 & 3 & 10 & 0 & \\
\hline COMP I & 50 & 4 & 10 & 0 & 1.00 \\
\hline COMP I & 100 & 1 & 10 & 0 & \\
\hline COMP I & 100 & 2 & 10 & 0 & \\
\hline COMP I & 100 & 3 & 9 & 1 & \\
\hline COMP I & 100 & 4 & 10 & 0 & 0.98 \\
\hline COMP II & 0 & 1 & 10 & 0 & \\
\hline COMP II & 0 & 2 & 10 & 0 & \\
\hline COMP II & 0 & 3 & 10 & 0 & \\
\hline COMP II & 0 & 4 & 10 & 0 & 1.00 \\
\hline COMP II & 10 & 1 & 10 & 0 & \\
\hline COMP II & 10 & 2 & 10 & 0 & \\
\hline COMP II & 10 & 3 & 10 & 0 & \\
\hline COMP II & 10 & 4 & 10 & 0 & 1.00 \\
\hline COMP II & 50 & 1 & 5 & 5 & \\
\hline COMP II & 50 & 2 & $\ddot{g}$ & 1 & \\
\hline COMP II & 50 & 3 & 6 & 4 & \\
\hline COMP II & 50 & 4 & 10 & 0 & 0.75 \\
\hline COMP II & 100 & 1 & 9 & l & \\
\hline COMP II & 100 & 2 & $-g$ & 1 & \\
\hline COMP II & 100 & 3 & 10 & 0 & \\
\hline COMP II & 100 & 4 & 10 & 0 & 0.95 \\
\hline
\end{tabular}


IABLE H.1. (contd)

Sediment

Ireatment

Concentration (\%) Replicate

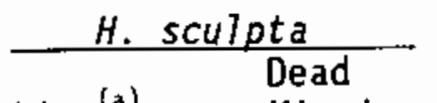

Live $^{(a)}$ or Missing

Mean

Proportion

COMP III

COMP III

COMP III

COMP III

0

0
0

0

10

10

10

1.00

COMP II I

COMP III

COMP II I

COMP II I

10

10

10

10

COMP III

COMP II I

COMP III

COMP II I

50

50

50

50

COMP III

COMP III

COMP III

COMP III

100

100

100

100

TC-5 Upper Comp 0

TC -5 Upper Comp

TC-5 Upper Comp

TC-5 Upper Comp

1
2
3
4

10

Surviving

10

9

10

0.95

$\begin{array}{rl}8 & 2 \\ 10 & 0 \\ 9 & 1 \\ 9 & 1\end{array}$

$10 \quad 0$

10

9

10

0.98

0.90

$10 \quad 0$

$10 \quad 0$

10

9

0.98

TC-5 Upper Comp 10

TC-5 Upper Comp 10

TC-5 Upper Comp 10

TC-5 Upper Comp 10

$10 \quad 0$

$10 \quad 0$

$10 \quad 0$

TC-5 Upper Comp 50

TC-5 Upper Comp 50

TC-5 Upper Comp 50

TC-5 Upper Comp 50

10

1.00

TC -5 Upper Comp 100

TC-5 Upper Comp 100

TC-5 Upper Comp 100

TC-5 Upper Comp 100

$\begin{array}{rl}9 & 1 \\ 10 & 0 \\ 10 & 0 \\ 10 & 0 \\ 10 & 0 \\ 10 & 0 \\ 10 & 0 \\ 8 & 2\end{array}$

0.98

110

0

0

2

0.95 
IABLE H.1. (contd)

Sediment

Treatment

\begin{tabular}{|c|c|c|}
\hline & ulpta & an \\
\hline$i v e^{l}$ & $\begin{array}{c}\text { Dead } \\
\text { or Missing }\end{array}$ & $\begin{array}{l}\text { Proportion } \\
\text { Surviving }\end{array}$ \\
\hline
\end{tabular}

COMP IV

COMP IV

COMP IV

COMP IV

COMP IV

COMP IV

COMP IV

COMP IV

COMP IV

COMP IV

COMP IV

COMP IV

COMP IV

COMP IV

COMP IV

COMP IV

COMP $V$

COMP V

COMP V

COMP V

COMP V

COMP V

COMP V

COMP V

COMP V

COMP $V$

COMP $V$

COMP V

COMP V

COMP $V$

COMP V

COMP $V$
Concentrat
0
0
0
0

10

10

10

10

50

50

50

50

100

100

100

100

\section{0}

0

0

10

10

10

10

50

50

50

50

100

100

100

100

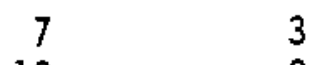

$10 \quad 0$

$10 \quad 0$

$10 \quad 0$

0.93

$10 \quad 0$

$10 \quad 0$

$10 \quad 0$

1.00

100

$10 \quad 0$

100

$\begin{array}{lll}9 & 1 & 0.98\end{array}$

100

$10 \quad 0$

$\begin{array}{rl}9 & 1 \\ 10 & 0\end{array}$

0.98

82

$10 \quad 0$

100

0.93

91

$10 \quad 0$

$10 \quad 0$

$\begin{array}{lll}10 & 0 & 0.98\end{array}$

$10 \quad 0$

$10 \quad 0$

$10 \quad 0$

$\begin{array}{lll}9 & 1 & 0.98\end{array}$

64

82

$10 \quad 0$

$10 \quad 0$

0.85 
TABLE H.1. (contd)

\begin{tabular}{|c|c|c|c|c|c|}
\hline \multirow[b]{2}{*}{$\begin{array}{l}\text { Sediment } \\
\text { Ireatment }\end{array}$} & \multirow[b]{2}{*}{ Concentration (\%) } & \multirow[b]{2}{*}{ Replicate } & \multicolumn{2}{|c|}{ H. sculpta } & \multirow{2}{*}{$\begin{array}{c}\text { Mean } \\
\text { Proportion } \\
\text { Surviving } \\
\end{array}$} \\
\hline & & & Live $^{(a)}$ & $\begin{array}{l}\text { Dead } \\
\text { or Missing }\end{array}$ & \\
\hline COMP VI & 0 & 1 & 9 & 1 & \\
\hline COMP VI & 0 & 2 & 10 & 0 & \\
\hline COMP VI & 0 & 3 & 10 & 0 & \\
\hline COMP VI & 0 & 4 & 9 & 1 & 0.95 \\
\hline COMP VI & 10 & 1 & 8 & 2 & \\
\hline COMP VI & 10 & 2 & 10 & 0 & \\
\hline COMP VI & 10 & 3 & 9 & 1 & \\
\hline COMP VI & 10 & 4 & 8 & 2 & 0.88 \\
\hline COMP VI & 50 & 1 & 8 & 2 & \\
\hline COMP VI & 50 & 2 & 9 & 1 & \\
\hline COMP VI & 50 & 3 & 9 & 1 & \\
\hline COMP VI & 50 & 4 & 10 & 0 & 0.90 \\
\hline COMP VI & 100 & 1 & 10 & 0 & \\
\hline COMP VI & 100 & 2 & 10 & 0 & \\
\hline COMP VI & 100 & 3 & 10 & 0 & \\
\hline COMP VI & 100 & 4 & 8 & 2 & 0.95 \\
\hline
\end{tabular}

(a) Survival based on initial exposure of 10 individuals per replicate. 
TABLE H.2. Summmary of Mean Proportion Surviving for 96-Hour H. sculpta Suspended-Particulate-Phase Test, Richmond Harbor Program

Sediment
Treatment

COMP I

COMP I

COMP I

COMP I

COMP II

COMP II

COMP II

COMP II

COMP III

COMP III

COMP II I

COMP III

COMP IV

COMP IV

COMP IV

COMP IV

COMP V

COMP $V$

COMP $V$

COMP $V$

COMP VI

COMP VI

COMP VI

COMP VI

TC-5 Upper Comp

TC-5 Upper Comp

TC-5 Upper Comp

TC-5 Upper Comp
Mean

Proportion

Concentration (\%)

\section{0}

10

50

100

\section{0}

10

50

100

0

10

50

100

0

10

50

100

0

10

50

100

0

10

50

100

0

10

50

100
Surviving

1.00

0.90

1.00

0.98

1.00

1.00

0.75

0.95

1.00

0.95

0.90

0.98

0.93

1.00

0.98

0.98

0.93

0.98

0.98

0.85

0.95

0.88

0.90

0.95

0.98

1.00

0.98

0.95 
IABLE H.3. Water Quality Summary for 96-Hour H. sculpta Suspended-Particulate-Phase Test, Richmond Harbor Program

\begin{tabular}{|c|c|}
\hline $\begin{array}{l}\text { Sediment } \\
\text { Treatment }\end{array}$ & Concentr \\
\hline Acceptable Range & \\
\hline СоMP 1 & \\
\hline Cosp I & 10 \\
\hline COMP I & 50 \\
\hline COHP I & 10 \\
\hline COMP II & \\
\hline COHP II & 10 \\
\hline COMP II & 5 \\
\hline COAP II & 100 \\
\hline COMP III & 0 \\
\hline COMP III & 10 \\
\hline COMP III & 5 \\
\hline COMP III & 100 \\
\hline IC-5 Upper Comp & \\
\hline IC-5 Upper Comp & 10 \\
\hline TC-5 Upper Comp & 50 \\
\hline TC-5 Upper Comp & 100 \\
\hline COHP IV & \\
\hline COMP IV & 10 \\
\hline COMP IV & 50 \\
\hline COMP IV & 100 \\
\hline COHP V & 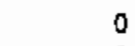 \\
\hline СОМР V & 10 \\
\hline COMP V & 50 \\
\hline COMP V & 100 \\
\hline COMP VI & 0 \\
\hline COHP VI & 10 \\
\hline COMP VI & 50 \\
\hline COHP VI & 100 \\
\hline
\end{tabular}

\begin{tabular}{|c|c|c|c|c|c|c|c|}
\hline \multicolumn{2}{|c|}{$\begin{array}{c}\text { Temperature } \\
\left({ }^{\circ} \mathrm{C}\right)\end{array}$} & \multicolumn{2}{|c|}{$\mathrm{pH}$} & \multicolumn{2}{|c|}{$\begin{array}{c}\text { Dissolved } \\
\text { oxygen } \\
\text { (mg/L) }\end{array}$} & \multicolumn{2}{|c|}{$\begin{array}{c}\text { Salinity } \\
(0 / 00)\end{array}$} \\
\hline Min & $\operatorname{Max}$ & Hin & $\operatorname{Max}$ & Min & Mex & Min & Max \\
\hline 13.0 & 17.0 & 7.54 & 8.54 & 4.0 & $N_{A}(a)$ & 30.2 & 34.2 \\
\hline $\begin{array}{l}14.6 \\
14.6 \\
14.6 \\
14.6\end{array}$ & $\begin{array}{l}15.2 \\
15.3 \\
15.3 \\
15.5\end{array}$ & $\begin{array}{l}7.90 \\
7.94 \\
7.83 \\
7.80\end{array}$ & $\begin{array}{l}8.23 \\
8.21 \\
8.24 \\
8.3 !\end{array}$ & $\begin{array}{l}7.5 \\
7.4 \\
7.4 \\
7.5\end{array}$ & $\begin{array}{l}8.2 \\
8.2 \\
8.2 \\
8.2\end{array}$ & $\begin{array}{l}31.5 \\
31.5 \\
31.5 \\
31.5\end{array}$ & $\begin{array}{l}32.5 \\
33.0 \\
33.0 \\
32.5\end{array}$ \\
\hline $\begin{array}{l}14.6 \\
14.3 \\
14.5 \\
14.6\end{array}$ & $\begin{array}{l}15.4 \\
15.2 \\
15.2 \\
15.2\end{array}$ & $\begin{array}{l}7.93 \\
7.92 \\
7.87 \\
7.81\end{array}$ & $\begin{array}{l}8.20 \\
8.19 \\
8.32 \\
8.33\end{array}$ & $\begin{array}{l}7.5 \\
7.3 \\
7.4 \\
7.4\end{array}$ & $\begin{array}{l}8.3 \\
8.2 \\
8.3 \\
8.2\end{array}$ & $\begin{array}{l}31.5 \\
31.5 \\
32.0 \\
31.5\end{array}$ & $\begin{array}{l}33.0 \\
33.0 \\
32.5 \\
32.5\end{array}$ \\
\hline $\begin{array}{l}14.6 \\
14.6 \\
14.8 \\
14.6\end{array}$ & $\begin{array}{l}15.2 \\
15.4 \\
15.3 \\
15.4\end{array}$ & $\begin{array}{l}7.86 \\
7.99 \\
8.05 \\
8.06\end{array}$ & $\begin{array}{l}8.19 \\
8.26 \\
8.26 \\
8.34\end{array}$ & $\begin{array}{l}7.5 \\
7.2 \\
7.3 \\
7.4\end{array}$ & $\begin{array}{l}8.1 \\
8.2 \\
8.2 \\
8.1\end{array}$ & $\begin{array}{l}32.0 \\
32.0 \\
31.5 \\
32.0\end{array}$ & $\begin{array}{l}33.5 \\
33.5 \\
33.0 \\
32.5\end{array}$ \\
\hline $\begin{array}{l}14.4 \\
14.3 \\
14.3 \\
14.4\end{array}$ & $\begin{array}{l}15.2 \\
15.1 \\
15.4 \\
15.2\end{array}$ & $\begin{array}{l}7.93 \\
7.95 \\
8.01 \\
8.04\end{array}$ & $\begin{array}{l}8.23 \\
8.22 \\
8.38 \\
8.45\end{array}$ & $\begin{array}{l}7.2 \\
7.2 \\
7.3 \\
7.4\end{array}$ & $\begin{array}{l}7.9 \\
8.1 \\
8.1 \\
8.1\end{array}$ & $\begin{array}{l}31.5 \\
31.5 \\
31.5 \\
32.0\end{array}$ & $\begin{array}{l}33.5 \\
33.0 \\
33.0 \\
33.5\end{array}$ \\
\hline $\begin{array}{l}14.7 \\
14.7 \\
14.7 \\
14.7\end{array}$ & $\begin{array}{l}15.0 \\
15.1 \\
15.2 \\
15.4\end{array}$ & $\begin{array}{l}7.88 \\
7.98 \\
8.03 \\
7.95\end{array}$ & $\begin{array}{l}8.27 \\
8.29 \\
8.25 \\
8.28\end{array}$ & $\begin{array}{l}7.6 \\
7.5 \\
7.4 \\
7.4\end{array}$ & $\begin{array}{l}8.2 \\
8.3 \\
8.2 \\
8.0\end{array}$ & $\begin{array}{l}31.5 \\
31.5 \\
32.0 \\
32.0\end{array}$ & $\begin{array}{l}33.5 \\
33.0 \\
33.5 \\
32.5\end{array}$ \\
\hline $\begin{array}{l}14.5 \\
14.4 \\
14.5 \\
14.6\end{array}$ & $\begin{array}{l}15.3 \\
15.2 \\
15.2 \\
15.5\end{array}$ & $\begin{array}{l}7.92 \\
7.94 \\
7.89 \\
7.83\end{array}$ & $\begin{array}{l}8.24 \\
8.21 \\
8.28 \\
8.31\end{array}$ & $\begin{array}{l}7.5 \\
7.4 \\
7.5 \\
7.3\end{array}$ & $\begin{array}{l}8.2 \\
8.3 \\
8.2 \\
8.2\end{array}$ & $\begin{array}{l}32.0 \\
31.5 \\
31.5 \\
31.5\end{array}$ & $\begin{array}{l}33.5 \\
33.0 \\
32.5 \\
32.5\end{array}$ \\
\hline $\begin{array}{l}14.9 \\
14.9 \\
14.9 \\
14.8\end{array}$ & $\begin{array}{l}15.3 \\
15.4 \\
15.3 \\
15.4\end{array}$ & $\begin{array}{l}7.90 \\
7.93 \\
7.84 \\
7.72\end{array}$ & $\begin{array}{l}8.32 \\
8.28 \\
8.30 \\
8.37\end{array}$ & $\begin{array}{l}7.4 \\
7.2 \\
7.3 \\
7.2\end{array}$ & $\begin{array}{l}8.4 \\
8.2 \\
8.1 \\
8.0\end{array}$ & $\begin{array}{l}31.5 \\
32.0 \\
31.5 \\
32.0\end{array}$ & $\begin{array}{l}32.5 \\
33.0 \\
32.0 \\
32.5\end{array}$ \\
\hline
\end{tabular}

(a) NA Not applicable. 
IABLE H.4. Daily Observations of 96-Hour H. sculpta Suspended-ParticulatePhase Test, Richmond Harbor Program

Sediment

H. sculpta Live Concentration ( $(\boldsymbol{)})$ Replicate oh $4 \mathrm{~h}$ 24h $\underline{48 \mathrm{~h}}$ 72h $\underline{96 h}$
H. sculpta Qead

$\underline{\text { oh }}$ 4h $\underline{24 h}$ 48h $\underline{72 h} \underline{96 h}$
COMP
COMP
COMP

COMP I

COMP I

COMP I

COMP I

COMP I

COMP I

COMP I

$\operatorname{com} 9$ I

COMP I

COMP I

COHP I

COMP I

COMP I

COMP II

COMP II

COMP II

COMP II

COMP II

COMP II

COMP II

$\operatorname{Com} 11$

COMP II

COMP II

COMP II

COMP II

COMP II

COHP II

COMP II

COMP II

COMP III

COMP III

СОMP III

COMP III

COMP III

COMP III

COMP II I

COMP I I I

COMP III

COMP II I

COMP II I

COMP III

$\begin{array}{llllllllllllll}0 & 1 & 10 & 10 & 10 & 10 & 10 & 10 & 0 & 0 & 0 & 0 & 0 & 0 \\ 0 & 2 & 10 & 10 & 10 & 10 & 10 & 10 & 0 & 0 & 0 & 0 & 0 & 0 \\ 0 & 3 & 10 & 10 & 10 & 10 & 10 & 10 & 0 & 0 & 0 & 0 & 0 & 0 \\ 0 & 4 & 10 & 10 & 10 & 10 & 10 & 10 & 0 & 0 & 0 & 0 & 0 & 0\end{array}$

10
10

10
10

50

50

50

50

$\begin{array}{rrrrrrr}1 & 10 & 10 & 10 & 9 & 7 & 6 \\ 2 & 10 & 10 & 10 & 10 & 10 & 10 \\ 3 & 10 & 10 & 10 & 10 & 10 & 10 \\ 4 & 10 & 10 & 10 & 10 & 10 & 10\end{array}$

0
0
0

$\begin{array}{lllllll}1 & 10 & 10 & 10 & 10 & 10 & 10 \\ 2 & 10 & 10 & 10 & 10 & 10 & 10 \\ 3 & 10 & 10 & 10 & 10 & 10 & 10\end{array}$

100

100

100

100

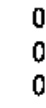

0
0
0
0

10

10

10
10

50

50

50

50

100

100

100

100

$$
\begin{array}{rrrrrrr}
1 & 10 & 10 & 10 & 10 & 10 & 10 \\
2 & 10 & 10 & 10 & 10 & 10 & 10 \\
3 & 10 & 10 & 10 & 9 & 9 & 9 \\
4 & 10 & 10 & 10 & 10 & 10 & 10
\end{array}
$$$$
\begin{array}{llllll}
0 & 0 & 0 & 0 & 0 & 0
\end{array}
$$$$
\begin{array}{lllllll}
1 & 10 & 10 & 10 & 10 & 10 & 10 \\
2 & 10 & 10 & 10 & 10 & 10 & 10 \\
3 & 10 & 10 & 10 & 10 & 10 & 10 \\
4 & 10 & 10 & 10 & 10 & 10 & 10
\end{array}
$$$$
\begin{array}{llllll}
0 & 0 & 0 & 0 & 0 & 0 \\
0 & 0 & 0 & 0 & 0 & 0 \\
0 & 0 & 0 & 0 & 0 & 0
\end{array}
$$

$\begin{array}{lllllll}1 & 10 & 10 & 10 & 10 & 10 & 10 \\ 2 & 10 & 10 & 10 & 10 & 10 & 10 \\ 3 & 10 & 10 & 10 & 10 & 10 & 10 \\ 4 & 10 & 10 & 10 & 10 & 10 & 10\end{array}$

$$
\begin{array}{llllll}
0 & 0 & 0 & 0 & 0 & 0 \\
0 & 0 & 0 & 0 & 0 & 0 \\
0 & 0 & 0 & 1 & 0 & 0 \\
0 & 0 & 0 & 0 & 0 & 0
\end{array}
$$

(n)

$\begin{array}{llllll}0 & 0 & 0 & 0 & 0 & 0 \\ 0 & 0 & 0 & 0 & 0 & 0 \\ 0 & 0 & 0 & 0 & 0 & 0 \\ 0 & 0 & 0 & 0 & 0 & 0\end{array}$

$\begin{array}{rrrrrrr}1 & 10 & 10 & 10 & 10 & 7 & 5 \\ 2 & 10 & 10 & 10 & 9 & 9 & 9 \\ 3 & 10 & 10 & 10 & 10 & 9 & 6 \\ 4 & 10 & 10 & 10 & 10 & 10 & 10\end{array}$

$\begin{array}{llllll}0 & 0 & 0 & 0 & 0 & 0 \\ 0 & 0 & 0 & 0 & 0 & 0 \\ 0 & 0 & 0 & 0 & 0 & 0 \\ 0 & 0 & 0 & 0 & 0 & 0\end{array}$

$$
\begin{aligned}
& 0 \\
& 0 \\
& 0 \\
& 0
\end{aligned}
$$

10

10

10

$\begin{array}{rrrrrrrrrrrrr}1 & 10 & 10 & 10 & 10 & 9 & 9 & 0 & 0 & 0 & 0 & 1 & 0 \\ 2 & 10 & 10 & 10 & 10 & 10 & 9 & 0 & 0 & 0 & 0 & 0 & 1 \\ 3 & 10 & 10 & 10 & 10 & 10 & 10 & 0 & 0 & 0 & 0 & 0 & 0 \\ 4 & 10 & 10 & 10 & 10 & 10 & 10 & 0 & 0 & 0 & 0 & 0 & 0\end{array}$

$\begin{array}{lllllllllllll}1 & 10 & 10 & 10 & 10 & 10 & 10 & 0 & 0 & 0 & 0 & 0 & 0 \\ 2 & 10 & 10 & 10 & 10 & 10 & 10 & 0 & 0 & 0 & 0 & 0 & 0 \\ 3 & 10 & 10 & 10 & 10 & 10 & 10 & 0 & 0 & 0 & 0 & 0 & 0 \\ 4 & 10 & 10 & 10 & 10 & 10 & 10 & 0 & 0 & 0 & 0 & 0 & 0\end{array}$

50

50

50

50 $\begin{array}{rrrrrrrrrrrrr}1 & 10 & 10 & 10 & 10 & 10 & 10 & 0 & 0 & 0 & 0 & 0 & 0 \\ 2 & 10 & 10 & 10 & 10 & 9 & 9 & 0 & 0 & 0 & 0 & 1 & 0 \\ 3 & 10 & 10 & 10 & 10 & 10 & 10 & 0 & 0 & 0 & 0 & 0 & 0 \\ 4 & 10 & 10 & 10 & 10 & 9 & 9 & 0 & 0 & 0 & 0 & 1 & 0\end{array}$

$\begin{array}{rrrrrrrrrrrrr}1 & 10 & 10 & 9 & 8 & 8 & 8 & 0 & 0 & 1 & 1 & 0 & 0 \\ 2 & 10 & 10 & 10 & 10 & 10 & 10 & 0 & 0 & 0 & 0 & 0 & 0 \\ 3 & 10 & 10 & 10 & 10 & 10 & 9 & 0 & 0 & 0 & 0 & 0 & 1 \\ 4 & 10 & 10 & 9 & 9 & 9 & 9 & 0 & 0 & 1 & 0 & 0 & 0\end{array}$ 
IABLE H.4. (contd)

Sediment

Ireatment

COMP III

COMP II I

COMP III

COMP III

TC-5 Upper Comp

TC-5 Upper Comp

TC-5 Upper Comp

TC-5 Upper Comp

TC-5 Upper Comp

TC-5 Upper Comp

TC-5 Upper Comp

TC-5 Upper Comp

TC-5 Upper Comp

TC-5 Upper Comp

TC-5 Upper Comp

TC-5 Upper Comp

TC -5 Upper Conp

TC -5 Upper Comp

TC-5 Upper Comp

TC-5 Upper Comp

COMP IV

COMP IV

COMP IV

COMP IV

COHP IV

COMP IV

COMP IV

COMP IV

conp IV

COMP IV

COHP IV

COMP IV

COMP IV

COMP IV

COMP IV

COHP IV

COMP V

COMP V

COMP $V$

COMP $V$
H. scupto Live

Concentration (x) Replicate $\underline{\text { Oh }}$ 4h $24 h$ 48h $\underline{72 h}$ 96h

100
100
100
100

$\begin{array}{lllllll}1 & 10 & 10 & 10 & 10 & 10 & 10\end{array}$

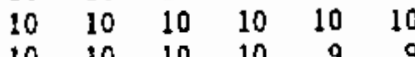

$\begin{array}{rrrrrr}10 & 10 & 10 & 10 & 9 & 9 \\ 10 & 10 & 10 & 10 & 10 & 10\end{array}$

0
0
0

0

10

10

10

10

50

50

50

50

100

100

100

100

0

0

0

10

10

10

10

50

50

50

50

100

100

100

100

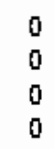

$\begin{array}{llllll}10 & 10 & 10 & 10 & 10 & 10\end{array}$

$\begin{array}{llllll}10 & 10 & 10 & 10 & 10 & 10\end{array}$

$\begin{array}{llllll}10 & 10 & 10 & 10 & 10 & 9\end{array}$

$\begin{array}{llllll}10 & 10 & 10 & 10 & 10 & 10\end{array}$

$\begin{array}{llllll}10 & 10 & 10 & 10 & 10 & 10\end{array}$

$\begin{array}{llllll}10 & 10 & 10 & 10 & 10 & 10\end{array}$

$\begin{array}{llllll}10 & 10 & 10 & 10 & 10 & 10\end{array}$

$\begin{array}{rrrrrr}10 & 10 & 10 & 10 & 9 & 9 \\ 10 & 10 & 10 & 10 & 10 & 10\end{array}$

$\begin{array}{llllll}10 & 10 & 10 & 10 & 10 & 10\end{array}$

$\begin{array}{llllll}10 & 10 & 10 & 10 & 10 & 10\end{array}$

$\begin{array}{llllll}10 & 10 & 10 & 10 & 10 & 10 \\ 10 & 10 & 10 & 10 & 10 & 10 \\ 10 & 10 & 10 & 10 & 10 & 10\end{array}$

$\begin{array}{rrrrrr}10 & 10 & 10 & 9 & 9 & 8\end{array}$

$\begin{array}{rrrrrr}10 & 10 & 10 & 10 & 9 & 7 \\ 10 & 10 & 10 & 10 & 10 & 10\end{array}$

$\begin{array}{llllll}10 & 10 & 10 & 10 & 10 & 10\end{array}$

$\begin{array}{llllll}10 & 10 & 10 & 10 & 10 & 10\end{array}$

$\begin{array}{llllll}10 & 10 & 10 & 10 & 10 & 10\end{array}$

$\begin{array}{llllll}10 & 10 & 10 & 10 & 10 & 10\end{array}$

$\begin{array}{llllll}10 & 10 & 10 & 10 & 10 & 10 \\ 10 & 10 & 10 & 10 & 10 & 10\end{array}$

$\begin{array}{llllll}10 & 10 & 10 & 10 & 10 & 10\end{array}$

$\begin{array}{llllll}10 & 10 & 10 & 10 & 10 & 10\end{array}$

$\begin{array}{rrrrrr}10 & 10 & 10 & 10 & 10 & 10 \\ 10 & 10 & 10 & 10 & 10 & 9\end{array}$

$\begin{array}{llllll}10 & 10 & 10 & 10 & 10 & 10\end{array}$

$\begin{array}{llllll}10 & 10 & 10 & 10 & 10 & 9\end{array}$

$\begin{array}{llllll}10 & 10 & 10 & 10 & 10 & 10\end{array}$

$\begin{array}{rrrrrr}10 & 10 & 10 & 10 & 9 & 8 \\ 10 & 10 & 10 & 10 & 10 & 10 \\ 10 & 10 & 10 & 10 & 10 & 10 \\ 10 & 10 & 10 & 10 & 10 & 9\end{array}$
H. sculpto Dead

oh $\underline{4 h}$ 24h 48h 72h 96h

$\begin{array}{llllll}10 & 10 & 10 & 10 & 10 & 10\end{array}$ $\begin{array}{llllll}0 & 0 & 0 & 0 & 0 & 0 \\ 0 & 0 & 0 & 0 & 0 & 0 \\ 0 & 0 & 0 & 0 & 1 & 0 \\ 0 & 0 & 0 & 0 & 0 & 0\end{array}$

$\begin{array}{llllll}0 & 0 & 0 & 0 & 0 & 0 \\ 0 & 0 & 0 & 0 & 0 & 0 \\ 0 & 0 & 0 & 0 & 0 & 0 \\ 0 & 0 & 0 & 0 & 0 & 1\end{array}$

$\begin{array}{llllll}0 & 0 & 0 & 0 & 0 & 0 \\ 0 & 0 & 0 & 0 & 0 & 0\end{array}$

$\begin{array}{llllll}0 & 0 & 0 & 0 & 0 & 0 \\ 0 & 0 & 0 & 0 & 0 & 0\end{array}$

$\begin{array}{llllll}0 & 0 & 0 & 0 & 0 & 0\end{array}$

$\begin{array}{llllll}0 & 0 & 0 & 0 & 1 & 0 \\ 0 & 0 & 0 & 0 & 0 & 0 \\ 0 & 0 & 0 & 0 & 0 & 0 \\ 0 & 0 & 0 & 0 & 0 & 0\end{array}$

$\begin{array}{llllll}0 & 0 & 0 & 0 & 0 & 0 \\ 0 & 0 & 0 & 0 & 0 & 0 \\ 0 & 0 & 0 & 0 & 0 & 0 \\ 0 & 0 & 0 & 1 & 0 & 1\end{array}$

$\begin{array}{llllll}0 & 0 & 0 & 0 & i & 2 \\ 0 & 0 & 0 & 0 & 0 & 0 \\ 0 & 0 & 0 & 0 & 0 & 0 \\ 0 & 0 & 0 & 0 & 0 & 0\end{array}$

$\begin{array}{llllll}0 & 0 & 0 & 0 & 0 & 0 \\ 0 & 0 & 0 & 0 & 0 & 0 \\ 0 & 0 & 0 & 0 & 0 & 0 \\ 0 & 0 & 0 & 0 & 0 & 0\end{array}$

$\begin{array}{llllll}0 & 0 & 0 & 0 & 0 & 0 \\ 0 & 0 & 0 & 0 & 0 & 0 \\ 0 & 0 & 0 & 0 & 0 & 0 \\ 0 & 0 & 0 & 0 & 0 & 1\end{array}$

$\begin{array}{llllll}0 & 0 & 0 & 0 & 0 & 0\end{array}$

$\begin{array}{llllll}0 & 0 & 0 & 0 & 0 & 0\end{array}$

$\begin{array}{llllll}0 & 0 & 0 & 0 & 0 & 1 \\ 0 & 0 & 0 & 0 & 0 & 0\end{array}$

$\begin{array}{llllll}0 & 0 & 0 & 0 & 1 & 1 \\ 0 & 0 & 0 & 0 & 0 & 0 \\ 0 & 0 & 0 & 0 & 0 & 0 \\ 0 & 0 & 0 & 0 & 0 & 1\end{array}$ 
TABLE H.4. (contd)

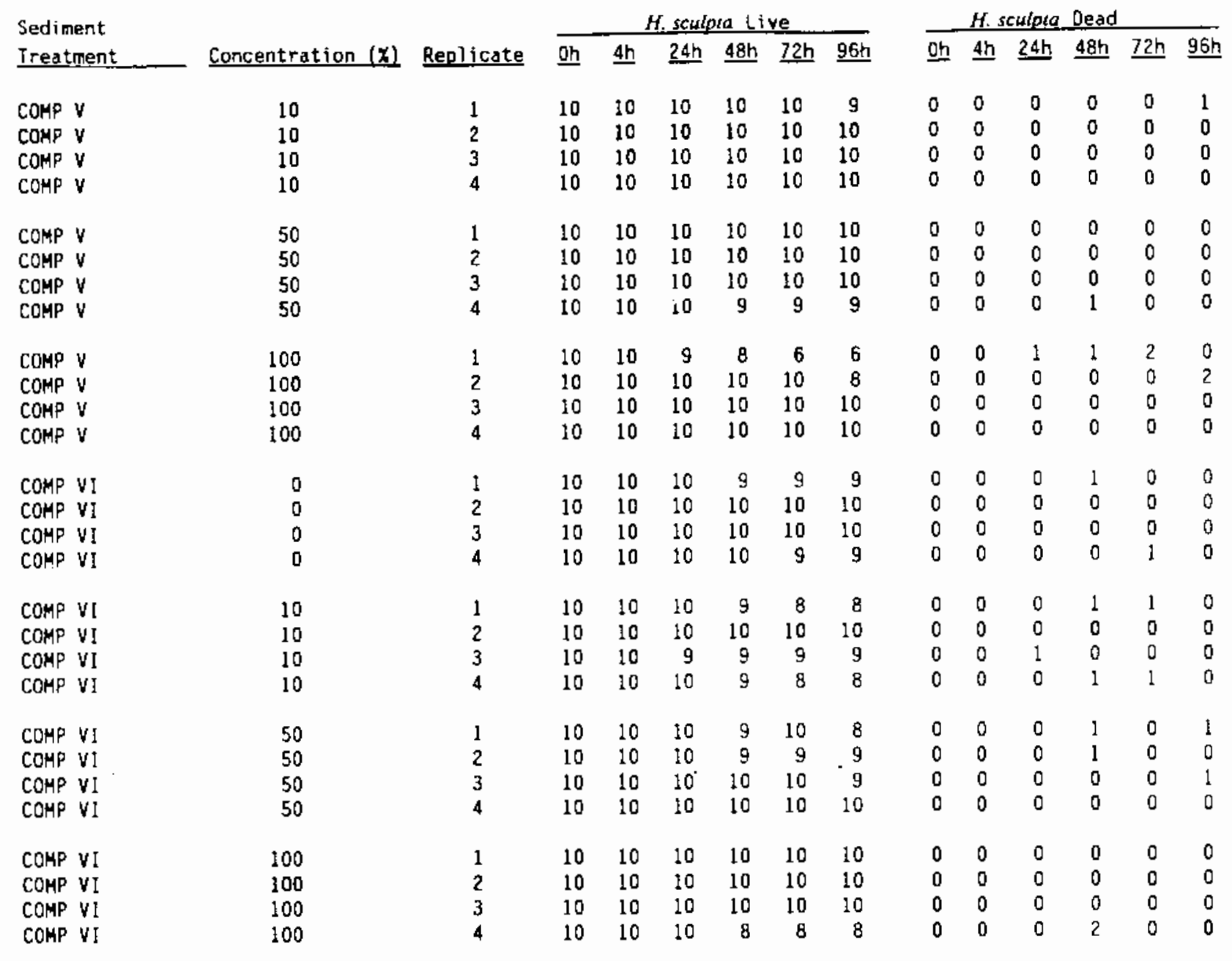


IABLE H.5. Test Results for 96-Hour H. sculpta Reference Toxicant Test, Richmond Harbor Program

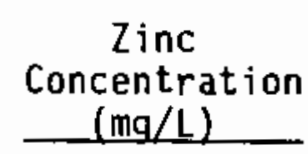

0

0

0

0.125

0.125

0.125

0.25

0.25

0.25

0.50

0.50

0.50

1.00

1.00

1.00

2.00

2.00

2.00
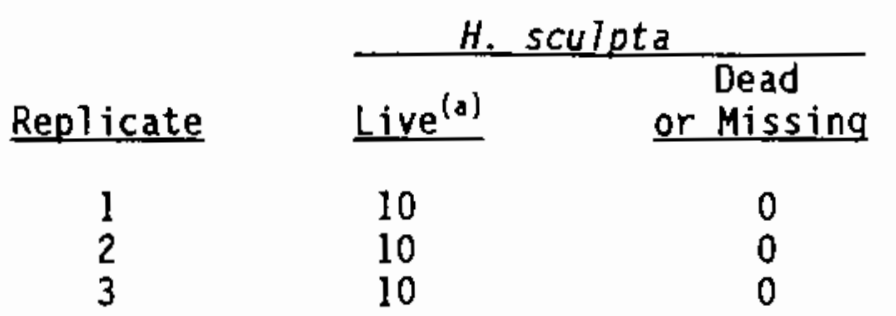

10

10

10

7

$\frac{1}{2}$

38

1

2

3

5
2

10

20

30

10

$2 \quad 0$

3

1

3
0

0

1.00

0.30

Mean

Proportion

Surviving

0.77

5

8

10

10

10

0.00

10

10

10

0.00

10

10

10

0.00

(a) Survival based on initial exposure of 10 individuals per replicate. 
IABLE H.6. Rank Order Based on Mean Proportion Surviving 96-Hour H. sculpta Reference Toxicant Test, Richmond Harbor Program

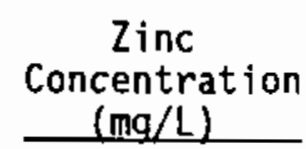

0.50

1.00

2.00

0.25

0.125

0

\author{
Mean \\ Proportion \\ Surviving
}

0.00
0.00
0.00
0.30
0.77
1.00

H.11 


\section{IABLE H.7. Water Quality Summary for 96-Hour H. sculpta Reference Toxicant Test, Richmond Harbor Program}

\begin{tabular}{|c|c|c|c|c|c|c|c|c|}
\hline \multirow{2}{*}{$\begin{array}{l}\text { Zinc } \\
\text { Concentration } \\
\text { (ma } / L) \\
\end{array}$} & \multicolumn{2}{|c|}{$\begin{array}{c}\text { Temperature } \\
\left({ }^{\circ} \mathrm{C}\right)\end{array}$} & \multicolumn{2}{|c|}{$\mathrm{pH}$} & \multicolumn{2}{|c|}{$\begin{array}{l}\text { Dissolved } \\
\text { Oxygen } \\
(\mathrm{mg} / \mathrm{L})\end{array}$} & \multicolumn{2}{|c|}{$\begin{array}{c}\text { Salinity } \\
\text { (o/oo) }\end{array}$} \\
\hline & Min & $\operatorname{Max}$ & Min & Max & Min & $\operatorname{Max}$ & Min & $\operatorname{Max}$ \\
\hline Acceptable Range & 13.0 & 17.0 & 7.53 & 8.53 & 4.0 & $N^{(a)}$ & 30.3 & 34.3 \\
\hline 0 & 14.7 & 15.3 & 7.93 & 8.21 & 7.4 & 8.0 & 32.0 & 33.0 \\
\hline 0.125 & 14.4 & 15.0 & 7.89 & 8.25 & 6.9 & 8.1 & 32.0 & 33.0 \\
\hline 0.25 & 14.4 & 15.2 & 7.95 & 8.25 & 7.4 & 8.2 & 32.0 & 33.0 \\
\hline 0.50 & 14.4 & 15.2 & 7.90 & 8.18 & 7.3 & 8.1 & 32.0 & 33.0 \\
\hline 1.00 & 14.4 & 15.1 & 7.93 & 8.24 & 4.0 & 8.2 & 32.0 & 32.0 \\
\hline 2.00 & 14.4 & 15.1 & 7.93 & 8.20 & 7.7 & 8.2 & 32.0 & 32.5 \\
\hline
\end{tabular}

(a) NA Not applicable. 
TABLE H.8. Daily Observations of H. sculpta During 96-Hour Reference Toxicant Test, Richmond Harbor Program

Zine

Concentration $(\mathrm{mg} / \mathrm{L})$

0
0

0.125

0.125

0.125

0.25

0.25

0.25

0.50

0.50

0.50

1. 00

1.00

1.00

2.00

2.00

2.00

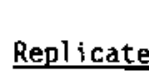

1
2
3

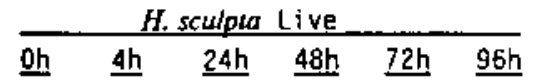

$\begin{array}{llllll}10 & 10 & 10 & 10 & 10 & 10 \\ 10 & 10 & 10 & 10 & 10 & 10 \\ 10 & 10 & 10 & 10 & 10 & 10\end{array}$

$\begin{array}{llllll}10 & 10 & 10 & 10 & 7 & 7\end{array}$

$\begin{array}{llllll}10 & 10 & 10 & 10 & 10 & 8 \\ 10 & 10 & 10 & 10 & 10 & 8\end{array}$

$\begin{array}{llllll}10 & 10 & 10 & 9 & 7 & 5 \\ 10 & 10 & 10 & 7 & 5 & 2 \\ 10 & 10 & 10 & 5 & 3 & 2\end{array}$

$\begin{array}{llllll}10 & 10 & 10 & 6 & 2 & 0\end{array}$

1
2

(1)

1
2
3

1
2
3

$\begin{array}{rrrrrr}10 & 10 & 10 & 5 & 1 & 0 \\ 10 & 10 & 10 & 5 & 0 & 0 \\ 10 & 10 & 10 & 1 & 0 & 0 \\ 10 & 10 & 7 & 1 & 0 & 0 \\ 10 & 10 & 9 & 0 & 0 & 0 \\ 10 & 10 & 5 & 0 & 0 & 0 \\ 10 & 10 & 5 & 0 & 0 & 0 \\ 10 & 10 & 3 & 0 & 0 & 0\end{array}$

H. sculpta Dead
oh $\underline{4 h}$ 24h $48 \mathrm{~h} \quad$ 72h $\underline{96 h}$

$\begin{array}{llllll}0 & 0 & 0 & 0 & 0 & 0 \\ 0 & 0 & 0 & 0 & 0 & 0 \\ 0 & 0 & 0 & 0 & 0 & 0\end{array}$

$\begin{array}{llllll}0 & 0 & 0 & 0 & 3 & 0\end{array}$

$\begin{array}{llllll}0 & 0 & 0 & 0 & 0 & 2 \\ 0 & 0 & 0 & 0 & 0 & 2\end{array}$

$\begin{array}{llllll}0 & 0 & 0 & 1 & 2 & 3 \\ 0 & 0 & 0 & 3 & 2 & 1 \\ 0 & 0 & 0 & 5 & 2 & 2\end{array}$

$\begin{array}{rrrrrr}0 & 0 & 0 & 4 & 4 & 1 \\ 0 & 0 & 0 & 5 & 4 & 10 \\ 0 & 0 & 0 & 5 & 5 & 10\end{array}$

$\begin{array}{rrrrrr}0 & 0 & 0 & 9 & 1 & 10 \\ 0 & 0 & 3 & 6 & 1 & 10 \\ 0 & 0 & 1 & 9 & 10 & 10\end{array}$

$\begin{array}{llllll}0 & 0 & 5 & 5 & 10 & 10 \\ 0 & 0 & 5 & 5 & 10 & 10 \\ 0 & 0 & 7 & 3 & 10 & 10\end{array}$ 
APPENDIX 1

BLOASSAY RESULTS FOR 48-HOUR SUSPENDED-PABTICUUATE-PHASE IEST AND 48-HOURBEFERENCE TOXICANT TEST FOR MYTILUS edulis 
IABLE I.1. Test Results for All Replicates in 48-Hour Larval M. edulis Suspended-Particulate-Phase Test, Richmond Harbor Program

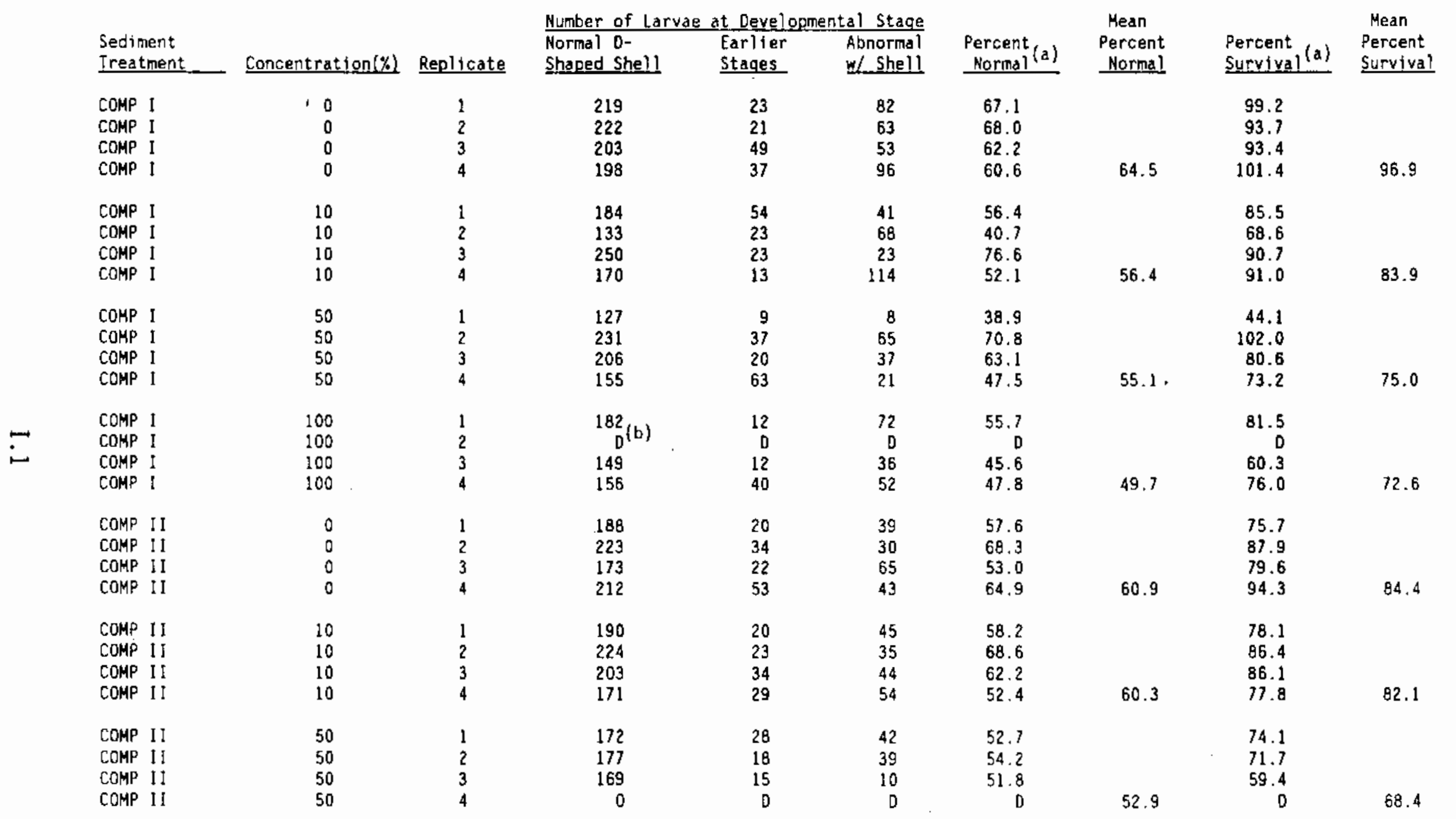


IABLE I.1. (contd)

Sediment
Treatment

COMP II

COMP II

COMP I

COMP II

COMP III

COMP III

COMP III

COMP III

CDMP III

COMP II I

COHP III

COMP III

COMP III

COMP 11 !

in $\quad$ COMP III

COMP III

COMP II I

COHP II I

COMP III

TC-5 upper Comp

TC-5 Upper Comp

TC-5 Upper Comp

TC-5 Upper Comp

TC-5 Upper Comp

IC-5 Upper Comp

TC-5 Upper Comp

TC-5 Upper Comp

\section{$\frac{\text { Number of Larvae at Oevelopmental Stage }}{\text { Normal D- }}$ Shaped shell \\ Stages \\ w/ Shell}

Percent
Mormal (a)

Mean

Percent

Nonnal

$D$
146
186
203

0
99
13
15

0
78
103
94

D
184
171

NO (c)

NO
ND
NO
ND

NO

190

142

214
44. 7

57.0

62.2

67.7

64.3

53.3

61.6

60.3

55.4

59.4

51.1

58.5

66.2

81.5

55.1

55.4

56.4

52.4

98

92.5
$54.6 \quad 95.6$

95.7

93.1

94.3

$61.7 \quad 92.1$

92.0

77.5

77.5

$\begin{array}{ll}56.6 & 90.7 \\ & 68.0\end{array}$

78.4

85.8

99.2

$\begin{array}{rr} & 101.1 \\ 65.3 & 92.8\end{array}$

94.7

93. 1

82.1
75.3

$54.7 \quad 75.3$

83.5

NO

NO

ND

NO

ND
ND
NO
ND

NO

58.2

43.5

52.1

65.5

82.7
83.6

$54.8 \quad 88.2$ 
TABLE 1.1. (contd)

Sediment Ireatment

TC-5 Upper Comp

TC-5 Upper Comp

TC-5 Upper Comp

TC-5 Upper Comp

TC-5 Upper Comp

TC-5 Upper Comp

TC-5 Upper Comp

TC-5 Upper Comp

COHP IV

COHP IV

COMP IV

COMP IV

COMP IV

COHP IV

COMP $1 \mathrm{~V}$

COHP IV

COHP IV

COMP IV

COMP IV

COMP IV

COMP IV

COHP IV

COMP IV

COMP IV

COMP $V$

CONP V

COMP V

COMP $V$

$\begin{array}{lll}\text { Number of Larvae at Developmental Stage } \\ \text { Normal } 0- & \text { Earlier } & \text { Abnorma } 1 \\ \text { Shaped Shell } & \text { Stages } & W / \text { Shell }\end{array}$

Cancentration $(\%)$ Replicate

Shaped Shell

181
144
166
141

100

100

100

100

0
0
0
0

50
50

50

1
2
3
4
1
3
2
4

181
144
166
141
2
7
7
13

233

211

166

178

192

186

192

199

178

193

166

193

179

158

186
194

194

176
197
175
222 \begin{tabular}{llll} 
Percent & $\begin{array}{l}\text { Mean } \\
\text { Normal (a) }\end{array}$ & $\begin{array}{l}\text { Percent } \\
\text { Normal }\end{array}$ & $\begin{array}{l}\text { Pean } \\
\text { Survival (a) }\end{array}$ \\
\hline
\end{tabular}

55.4

44.1

50.8
43.2

43.2

0.6

2.1

2.1
4.0

71.4

64.6

50.8

54.5

58. 8

57.0

58.8

54.5

59.1

50.8

59.1

54.8

48.4

57.0

59.4

53.9

60.3

53.6

68.0
79.6

85.8

68.9

$48.4 \quad 64.6$

74.7

79.3

68.9

$2.2 \quad 72.6$

76.0

101.1
98.6

70.8

$\begin{array}{ll}60.3 & 78.8\end{array}$

87.2

87.9

85.8

83.6

$\begin{array}{ll}58.9 & 96.5\end{array}$

88.4

85.8

85.5

67.1

82.7

85.1

79.0

93.4

$54.9 \quad 83.3$

85.2

69.8

106.6

79.3

$59.0 \quad 100.5$

89.1 
TABLE I.1. (contd)

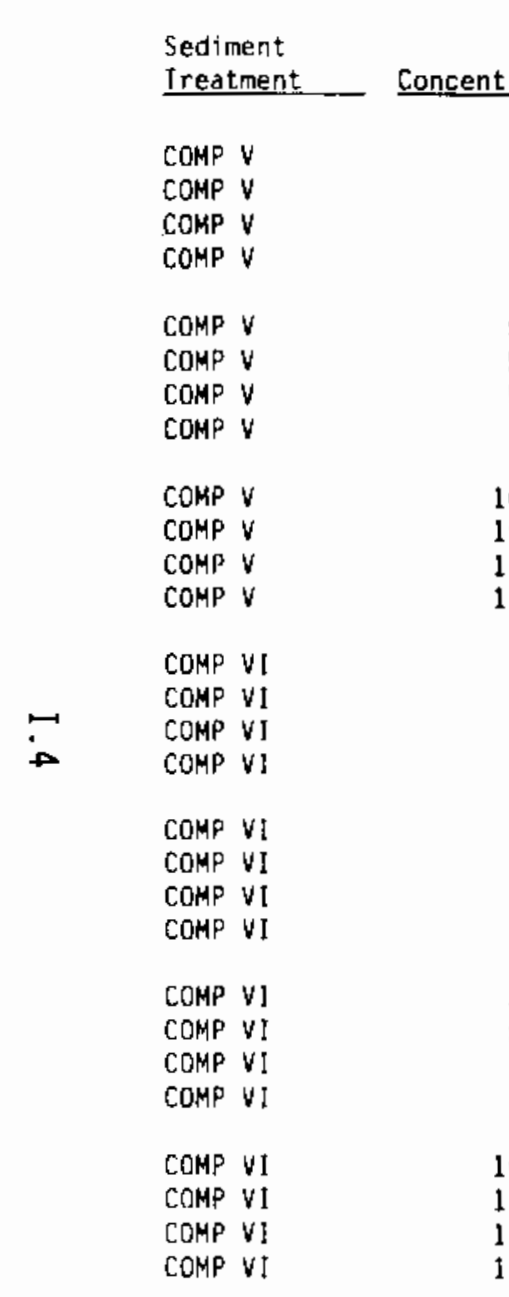

$\begin{array}{lll}\text { Number of Laryae at Oevelopmental Stage } \\ \text { Normal D- } & \text { Earlier } & \text { Abnormal } \\ \text { Shaped Shell } & \text { Stages } & \text { w/ Shell }\end{array}$

Percent (a)

Mean

Percent

Normal

Percent

Mean

Percent

$\operatorname{COMP} V$

$\begin{array}{ll}10 & 1 \\ 10 & 2 \\ 10 & 3 \\ 10 & 4\end{array}$

$\begin{array}{ll}190 & 25 \\ 172 & 14 \\ 192 & 36 \\ 186 & 17\end{array}$

58.2

52.7

58.8

77.5

57.0

56.7

186

49

56.7

53.0

173

23
22

30

D

58.5

56.0

77.2

76.8

$\begin{array}{llr}50 & 3 & 0 \\ 50 & 4 & 191\end{array}$

$$
27
$$$$
\text { B6 }
$$

$\begin{array}{rr}182 & 37 \\ 203 & 1 \\ 177 & 23 \\ 194 & 25\end{array}$

85
82

82

55.7

62.2

54.2

93.1

100

194

43

59.4

57.9

$$
87.6
$$

60.6

72.3

67.7

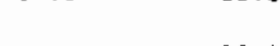

84.6

$\begin{array}{ll}198 & 32 \\ 236 & 27 \\ 221 & 31\end{array}$

55
65

63,1

65.

97.4

192

199

153

58.8

60.9

46.9

57.9

64.9

57.9
57.9

49.9

83.3

83.3

94.6

66.8

$56.1 \quad 87.0$

82.9

212
189
189

163

77.5

81.8

50

81

$57.7 \quad 91.3$

$\begin{array}{ll}100 & 1 \\ 100 & 2 \\ 100 & 3 \\ 100 & 4\end{array}$

$\begin{array}{lr}169 & 7 \\ 164 & 15 \\ 168 & 15 \\ 143 & 17\end{array}$

51.8

50.2

51.5

43.8

$\begin{array}{rr} & 89.1 \\ & 72.0 \\ & 78.7 \\ 49.3 & 75.0\end{array}$

(a) Percent normal and percent survival based on stocking density of 326.5 larvae per $10 \mathrm{~mL}$.

(b) Difficult to see because of particle debris.

(c) ND No data avaíable; sample nat taken. 


\section{IABLE I.2. Water Quality Summary for 48-Hour Larval M. edulis Suspended-Particulate-Phase Test, Richmond \\ Harbor Program}

\begin{tabular}{|c|c|c|c|c|c|c|c|c|c|}
\hline \multirow{2}{*}{$\begin{array}{l}\text { Sediment } \\
\text { Ireatment }\end{array}$} & \multirow[b]{2}{*}{ Concentration 8} & \multicolumn{2}{|c|}{$\begin{array}{l}\text { Temperature } \\
\left({ }^{\circ} \mathrm{C}\right)\end{array}$} & \multicolumn{2}{|c|}{$\mathrm{OH}$} & \multicolumn{2}{|c|}{$\begin{array}{c}\text { Dissolved } \\
\text { Oxygen } \\
(\mathrm{mg} / \mathrm{L})\end{array}$} & \multicolumn{2}{|c|}{$\begin{array}{c}\text { Salinity } \\
(0 / 00)\end{array}$} \\
\hline & & Min & $\operatorname{Max}$ & Min & $\max$ & Min & $\operatorname{Max}$ & Min & $\operatorname{Max}$ \\
\hline $\begin{array}{l}\text { Acceptable } \\
\text { Range }\end{array}$ & & 14.0 & 18.0 & 7.55 & 8.55 & 4.0 & $\mathrm{NA}(\mathrm{a})$ & 28.9 & 32.9 \\
\hline COMP I & 0 & 16.2 & 16.9 & 8.03 & 8.11 & 7.5 & 7.8 & 30.0 & 31.5 \\
\hline COMP I & 10 & 16.2 & 16.9 & 7.95 & 8.14 & 7.5 & 7.9 & 30.5 & 32.5 \\
\hline COMP I & 50 & 16.2 & 16.8 & 8.03 & 8.27 & 7.4 & 7.8 & 30.0 & 32.0 \\
\hline COMP I & 100 & 16.2 & 16.9 & 8.15 & 8.26 & 7.3 & 7.8 & 30.0 & 31.5 \\
\hline COMP II & 0 & 16.2 & 16.9 & 8.08 & 8.18 & 7.3 & 7.9 & 30.0 & 31.5 \\
\hline COMP II & 10 & 16.3 & 16.8 & 8.01 & 8.16 & 7.1 & 7.8 & 30.0 & 32.5 \\
\hline СOMP II & 50 & 16.2 & 16.8 & 8.11 & 8.27 & 7.3 & 7.8 & 30.0 & 32.0 \\
\hline COMP II & 100 & 16.3 & 16.8 & 7.88 & 8.26 & 7.4 & 7.7 & 30.0 & 31.5 \\
\hline COMP III & 0 & 16.2 & 16.9 & 8.02 & 8.11 & 7.5 & 7.9 & 30.0 & 32.0 \\
\hline COHF III & 10 & 16.3 & 16.8 & 8.01 & 8.18 & 7.5 & 7.8 & 30.0 & 32.5 \\
\hline COMP II! & 50 & 16.3 & 16.8 & 8. 06 & 8.24 & 7.4 & 7.8 & 31.0 & 32.0 \\
\hline COMP III & 100 & 16.3 & 16.9 & 8.17 & 8.35 & 7.4 & 7.8 & 30.0 & 31.0 \\
\hline TC-5 Upper Comp & 0 & 16.3 & 16.9 & 8.06 & 8.12 & 7.5 & 7.9 & 30.0 & 31.5 \\
\hline TC-5 Upper Comp & 10 & 16.3 & 17.0 & 8.04 & 8.14 & 7.6 & 7.8 & 31.0 & 32.5 \\
\hline IC-5 upper Comp & 50 & 16.2 & 16.8 & 8.15 & 8.24 & 7.1 & 7.7 & 30.0 & 31.5 \\
\hline TC-5 Upper Comp & 100 & 16.2 & 16.8 & 8.21 & 8.32 & 7.5 & 7.7 & 31.0 & 32.5 \\
\hline СОMP IV & 0 & 16.2 & 16.9 & 8.01 & 8.15 & 7.2 & 8.0 & 30.0 & 31.5 \\
\hline COMP IV & 10 & 16.3 & 16.8 & 8.01 & 8.16 & 7.6 & 7.9 & 30.0 & 32.0 \\
\hline COMP IV & 50 & 16.3 & 16.8 & 8.04 & 8.23 & 7.5 & 7.8 & 31.0 & 32.0 \\
\hline COMP IV & 100 & 16.2 & 16.8 & 7.83 & 8.23 & 7.5 & 7.8 & 30.0 & 31.5 \\
\hline COMP $V$ & 0 & 16.3 & 16.9 & 8.04 & 8.15 & 7.5 & 7.9 & 30.0 & 31.5 \\
\hline COMP V & 10 & 16.3 & 16.9 & 8.01 & 8.16 & 7.5 & 7.9 & 30.0 & 32.5 \\
\hline COMP V & 50 & 16.3 & 16.8 & 8.06 & 8.17 & 7.5 & 7.8 & 30.0 & 32.0 \\
\hline COMP V & 100 & 16.3 & 17.0 & 8.07 & 8.27 & 7.4 & 7.8 & 30.0 & 31.5 \\
\hline сомР VI & 0 & 16.2 & 16.8 & 8.04 & 8.13 & 7.5 & 8.0 & 30.0 & 31.5 \\
\hline COMP VI & 10 & 16.3 & 16.9 & 8.00 & 8.14 & 7.5 & 7.9 & 30.5 & 32.5 \\
\hline COMP VI & 50 & 16.3 & 16.8 & 8.07 & 8.19 & 7.4 & 7.7 & 31.0 & 32.5 \\
\hline COMP VI & 100 & 16.3 & 16.8 & 8.13 & 8.20 & 7.4 & 7.8 & 30.0 & 31.0 \\
\hline
\end{tabular}

(a) NA Not applicable. 
TABLE I.3. Survival Data for All Replicates in 48-Hour Larval $M$. edulis Reference Toxicant Test, Richmond Harbor Program

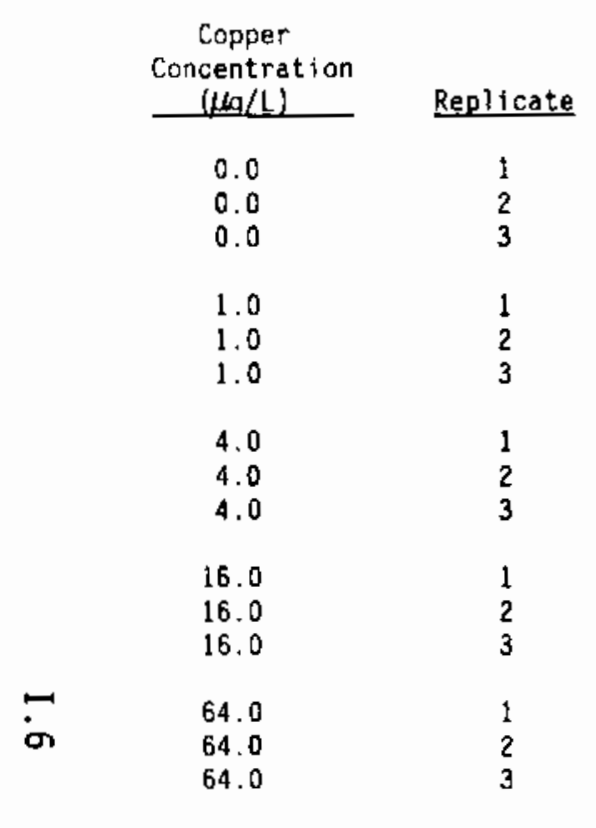

\begin{tabular}{|c|c|c|}
\hline $\begin{array}{l}\text { Normal o- } \\
\text { Shaped Shell }\end{array}$ & $\begin{array}{l}\text { Earlier } \\
\text { Stages }\end{array}$ & $\begin{array}{l}\text { Abnormal } \\
\text { I/ Shell }\end{array}$ \\
\hline $\begin{array}{l}167 \\
200 \\
185\end{array}$ & $\begin{array}{r}116 \\
30 \\
72\end{array}$ & $\begin{array}{l}26 \\
66 \\
24\end{array}$ \\
\hline $\begin{array}{l}166 \\
197 \\
165\end{array}$ & $\begin{array}{l}48 \\
76 \\
62\end{array}$ & $\begin{array}{l}21 \\
28 \\
67\end{array}$ \\
\hline $\begin{array}{l}184 \\
154 \\
128\end{array}$ & $\begin{array}{l}85 \\
70 \\
55\end{array}$ & $\begin{array}{l}77 \\
30 \\
25\end{array}$ \\
\hline $\begin{array}{l}0 \\
1 \\
2\end{array}$ & $\begin{array}{l}124 \\
126 \\
100\end{array}$ & $\begin{array}{r}4 \\
6 \\
53\end{array}$ \\
\hline $\begin{array}{l}N^{0}(b) \\
N D\end{array}$ & $\begin{array}{l}9 \\
\text { ND } \\
\text { ND }\end{array}$ & $\begin{array}{l}1 \\
\text { NO } \\
\text { NO }\end{array}$ \\
\hline
\end{tabular}

\begin{tabular}{c} 
Percent \\
Normal \\
\hline 51.1 \\
61.3 \\
56.7 \\
50.8 \\
60.3 \\
50.5 \\
56.4 \\
47.2 \\
39.2 \\
0.0 \\
0.3 \\
0.6 \\
0.0 \\
ND \\
ND
\end{tabular}

\section{Mean}

Percent

Norma 1

56.4

23.9

53.9

(10.6

47.6

0.3

0.3

0.0

\begin{tabular}{l} 
Percent (a) \\
Survival \\
\hline 94.6 \\
90.7 \\
86.1 \\
72.0 \\
92.2 \\
90.0 \\
106.0 \\
77.8 \\
63.7 \\
39.2 \\
40.7 \\
47.5 \\
3.1 \\
ND \\
ND
\end{tabular}

(a) Percent normal and percent survival based on stocking density of 326.5 larvae per $10 \mathrm{~mL}$.

(b) ND No data avaílable; sample not taken. 
APPENDIX $J$

IISSUE CHEMISTRYAND OUALITY ASSURANCE DATA

EORMACOMA nasuta 


\section{QA/QC SUMMARY}

PROGRAM:

PARAMETER:

LABORATORY:

MATRIX:

SAMPLE NUMBER:
Richmond Harbor Program

Polynuclear Aromatic Hydrocarbons (PAHs)

Battelle Ocean Sciences (Duxbury, Mass)

M. nasuta

\section{QA/QC REQUIREMENTS}

$\begin{array}{cccc}\begin{array}{c}\text { Reference } \\ \text { Method }\end{array} & \begin{array}{c}\text { Range of } \\ \text { Recovery }\end{array} & \begin{array}{c}\text { Relative } \\ \text { Rrecision }\end{array} & \begin{array}{c}\text { Detectlon } \\ \text { Limit_(wetwiw) }\end{array} \\ 8270 & 40 \%-120 \% & \pm 30 \% & 20 \mu \mathrm{g} / \mathrm{kg}\end{array}$

HOLDING TIMES Samples were frozen for up to 2 months prior to extraction. All four extraction batches were analyzed within the EPA extract holding time of 40 days (EPA 1986).

\section{DETECTION LIMITS Target detection limits were met for all PAH compounds.}

METHOD BLANKS Four method blanks were analyzed. Naphthalene was detected at low levels in all four method blanks at levels not sufficiently high to require data correction or flagging. Fluorene, anthracene, fluoranthene, chrysene, and benzo(k)fluoramthene also had detectable amounts in up to two of the method blanks; all values reported were below the method detection limit and no data were flagged or corrected. Only one HPAH compound, pyrene, was detected above the detection limit in two of the four blanks and the data were not flagged or blank corrected.

\section{MATRIX SPIKES}

Four sets of background samples were spiked in duplicate with all $16 \mathrm{PAH}$ compounds. One set of spikes was extracted and analyzed with each of the four batches of samples to assess accuracy and precision. Spike recoveries for LPAH compounds ranged from $98 \%$ to $128 \%$ with only acenaphthalene in both spikes for Batch A slightly exceeding the QAOC limits. Relative percent differences (RPDs) between spike duplicate recoveries ranged from $0 \%$ to $6 \%$ indicating acceptable precision of the method.

The HPAH spike recoveries ranged from $65 \%$ to $127 \%$. Four recoveries exceeded the upper OAOC range. These exceedences do not affect data quality or bias any sample results. The RPDs between spike recoveries ranged from $0 \%$ to $20 \%$, within the acceptable precision goal. 
REPLICATES

SRMs

SURROGATES
Four sample were analyzed in triplicate (COMP V, R-AM, R-BF, and C-SB). Precision was measured by Relative Standard Deviation (RSD) between results. The RSD values ranged from $6 \%$ to $60 \%$ for LPAHs detected in all triplicate analyses with only two measurements exceeding the precision goal. The HPAH RSD values ranged from $1 \%$ to $65 \%$, with only one RSD value exceeding the goal. Overall, these measurements indicate acceptable precision of the method.

Tissue sample SRM 1974 (NIST) was analyzed once with each extraction batch (a totnl of 4 analyses). This SRM was certified for 8 of the 16 PAH compounds measured. In general, values measured were near the certified values and all concentrations were within $\pm 30 \%$ of the certitied mean value with the exception of anthracene, benzo(a)pyrene, and benzo(ghi)perylene. No criteria was given for SRMs in the OA /QC Plan; therefore, values were not flagged.

Three radiolabelled PAH compounds (naphthalene $d 8$, acenaphthene d10, and benzo(a)pyrene d12) were added as surrogates to samples prior to analysis. Recoveries for most samples were within the QAOC requirements. Four samples had recoveries slightly below the $Q C$ limits for two of the three surrogates measured and one sample (a background clam sample) had all three surrogates below the lower $Q C$ limit. These recoveries were still all above $20 \%$, requiring no re-extractions. Results for these four samples may be biased low based on these recoveries. 


\section{QA/QC SUMMARY}

PROGRAM:

PARAMETER:

LABORATORY:

MATRIX:

SAMPLE NUMBER:
Richmond Harbor Program

Chlorinated Pesticides and PCBs

Battelle Ocean Sciences (Duxbury, Mass)

\section{QA/QC REQUIREMENTS:}

$\begin{array}{lcccc}\text { Reference } & \begin{array}{c}\text { Range of } \\ \text { Method }\end{array} & \begin{array}{c}\text { Relatlve } \\ \text { Recovery }\end{array} & \begin{array}{c}\text { Detection } \\ \text { Preclslon }\end{array} & \begin{array}{c}\text { Limit (wet wt) } \\ \text { Pesticides }\end{array} \\ \text { PCBs } & 8080 & 40 \%-120 \% & \pm 30 \% & 2.0 \mu \mathrm{g} / \mathrm{kg} \\ \text { PC } & 8080 & 40 \%-120 \% & \pm 30 \% & 20 \mu \mathrm{g} / \mathrm{kg}\end{array}$

\section{HOLDING TIMES}

Samples were frozen for up to 2 months prior to extraction. All sample extracts were analyzed within the EPA extract holding time of 40 days (EPA 1986).

DETECTION LIMITS Target detection limits for pesticides $(2 \mu \mathrm{g} / \mathrm{kg}$ wet weight, $30 \mu g / \mathrm{kg}$ for toxaphene) were met for all samples with the exception of chiordane. The detection limits for chlordane ranged from 2.214 to 7.023 . The elevated detection limits for chlordane reflect the multiple peak nature of the compound. Target $\mathrm{PCB}$ detection limits $(20 \mu \mathrm{g} / \mathrm{kg}$ wet weight $)$ were met for all samples.

\section{METHOD BLANKS}

One method blank was analyzed with each of the four extraction batches. Alpha, beta, delta, and gamma-BHC, 4,4'-DDE, and 4,4'-DDT were found in at least one method blank. However, in all cases, levels detected were low; therefore, data were flagged or blank corrected. No PCBs were detected in any of the method blanks.

Four background samples were spiked in duplicate with 18 pesticides and $1 \mathrm{PCB}$ (aroclor 1254). Pesticide spike recoveries ranged from $6 \%$ to $191 \%$. Endrin aldehyde produced low recoveries of $6 \%$ to $48 \%$ for all spikes. These low recoveries suggest that sample values for endrin aldehyde may be underestimated; however, endrin aldehyde is a breakdown product of endrin and was not found in any samples. Three pesticides (endosulfan I, endosulfan II, and endosulfan sulfate) exceeded the upper recovery limit for both spikes in Batch A (ranging from $122 \%$ to $140 \%$ ). The greatest spike recovery exceedences were for endosulfan II in Batch $\mathrm{C}$ with recoveries of $184 \%$ and $191 \%$. Because endosultan II was not detected above the method detection limit in any samples, this does not affect the quality of the data.

Aroclor 1254 spike recoveries ranged from $106 \%$ to $141 \%$. Batch $A$ and Batch B spike recoveries exceeded the upper QAOC requirements. Since the surrogate recoveries for these samples were not elevated above QAVC requirements, the high spike recoveries may reflect an inaccurate spiking concentration. 
Relative percent differences between spike duplicate recoveries for pesticides ranged from $0 \%$ to $60 \%$ with only 2 out of 64 calculations exceeding OAOC requirements. The exceedences were for endrin aldehyde.

Relative percent differences between spike duplicate recoveries for PCBs ranged from $2 \%$ to $4 \%$ and were within OAQC requirements.

SRMS

REPLICATES

SURROGATES
ADDITIONAL INFORMATION

\section{NOT APPLICABLE}

Four samples were analyzed in triplicate (COMP V, R-AM, F-PF, and C$\mathrm{SB}$ ), and precision was measured by cakculating the relative standard deviation (RSD) between the replicates. Pesticide ASD values ranged from $1 \%$ to $33 \%$ for samples having pesticides detected in all three replicates. All ASD values, with the exception of gamma-BHC in Batch C were within the precision goal of $\pm 30 \%$, indicating acceptable precision.

The PCB ASD values ranged from $4 \%$ to $8 \%$, indicating acceptable precision.

Two compounds, dibromooclaflourobiphenyl (DBOFB) and tetrachloronaphthalene (TCN), were added to all samples prior to extraction to assess the efficiency of the method. Recoveries for the samples were within the OAVC requirements, with the exception of DBOFB for one of the background samples. This recovery was above $20 \%$; therefore, re-extraction was not required.

An "E" flag was used to flag selected PCB/Pesticide data. This "E" flag indicates that the compound of interest was only detected on the primary column and was not confimed to be that compound on the second column. 


\section{QA/QC SUMMARY}

PROGRAM

PARAMETER:

LABORATORY:

MATRIX:

SAMPLE NUMBER:
Richmond Harbor Program

Metals (Ag, As, Cd, Cr, Cu, $\mathrm{Hg}, \mathrm{Ni}, \mathrm{Pb}, \mathrm{Se}$, and $\mathrm{Zn}$ )

Battelle/Marine Sciences Laboratory

M. nasuta

75

\section{QA/QC REQUIREMENTS}

$\begin{array}{lccccc} & \text { Analysls } & \begin{array}{c}\text { QA/QC } \\ \text { Decument }\end{array} & \begin{array}{c}\text { Range of } \\ \text { Recovery }\end{array} & \begin{array}{c}\text { Relative } \\ \text { Precislon }\end{array} & \begin{array}{c}\text { Detection } \\ \text { Lml_(dry wd }\end{array} \\ \text { Arsenic } & \text { XRF } & \text { PNL-SP-19 } & \text { NA } & \pm 20 \% & 1.0 \mathrm{mg} / \mathrm{kg} \\ \text { Cadmium } & \text { AA } & \text { MSL-M-33 } & 75 \%-125 \% & \pm 20 \% & 0.1 \mathrm{mg} / \mathrm{kg} \\ \text { Chromium } & \text { AA } & \text { PNL-SP-19 } & \text { NA } & \pm 20 \% & 1.0 \mathrm{mg} / \mathrm{kg} \\ \text { Copper } & \text { XRF } & \text { PNL-SP-19 } & \text { NA } & \pm 20 \% & 1.0 \mathrm{mg} / \mathrm{kg} \\ \text { Lead } & \text { AA } & \text { PNL-SP-19 } & \text { NA } & \pm 20 \% & 1.0 \mathrm{mg} / \mathrm{kg} \\ \text { Mercury } & \text { ICP-MS } & \text { MSL-M-11 } & 75 \%-125 \% & \pm 20 \% & 0.02 \mathrm{mg} / \mathrm{kg} \\ \text { Nickel } & \text { XRF } & \text { PNL-SP-19 } & \text { NA } & \pm 20 \% & 1.0 \mathrm{mg} / \mathrm{kg} \\ \text { Selenium } & \text { XRF } & \text { MSL-M-33 } & 75 \%-125 \% & \pm 20 \% & 0.5 \mathrm{mg} / \mathrm{kg} \\ \text { Silver } & \text { AA } & \text { MSL-M-33 } & 75 \%-125 \% & \pm 20 \% & 1.0 \mathrm{mg} / \mathrm{kg} \\ \text { Zinc } & \text { XRF } & \text { PNL-SP-19 } & \text { NA } & \pm 20 \% & 1.0 \mathrm{mg} / \mathrm{kg}\end{array}$

HOLDING TIMES

Recommended holding times for metals in tissues based on the 1991 Implementation Manual (EPAUSACE 1991) are 6 months $(<200 \mathrm{C}$ ) for all metals except $\mathrm{Hg}$, which is 28 days. After receipt at MSL, $M$. nasuta tissue samples for this project were held frozen for up to 4 weeks and then freeze dried and stored for up to 3 months in sealed containers. Holding times have not been established for samples held freeze dried; however, standard reference material (SRM) prepared by the U.S. National Institute of Standards and Technology (NIST) such as SRM 1566a (oyster tissue) have been issued for up to 10 years after freeze drying without changes to the certified concentrations including those for $\mathrm{Hg}$.

DETECTION LIMITS Achieved detection limits based on dry weight concentrations were lower than target detection limits for all metais.

METHOD BLANKS One method blank was analyzed with each of four batches. Low levels of $\mathrm{Ag}, \mathrm{Cd}$, and $\mathrm{Cr}$ were found in the blanks at levels slightly above the achieved detection but much less than the target detection limits. Tissue samples analyzed by AA or ICP-MS ( $\mathrm{Ag}, \mathrm{Cd}, \mathrm{Cr}, \mathrm{Hg}$, and $\mathrm{Pb}$ ) were corrected for the concentration of metals found in the corresponding blanks. Method blanks were not applicable to metals analyzed by XRF. 


\section{MATRIX SPIKES}

SRMS

REPLICATES

SURROGATES
Four samples (COMP II, COMP V, C-SB, and R-PF) were spiked with Ag, $\mathrm{Cd}, \mathrm{Cr}, \mathrm{Hg}$, and $\mathrm{Pb}$. Spikes were analyzed at a minimum of 1 per 20 samples. Recoveries ranged from $54 \%$ to $129 \%$. Silver recoveries for two out of the four spikes were below the QAOC requirements. Although no limits are given for $\mathrm{Pb}$, one out of the four spikes was above $125 \%$.

The SRM 1566 a (oyster tissue) was obtained from the U.S. National institute of Standards and Technology (NIST). This SRM was analyzed by AA or ICPMS at a minimum of 1 per 20 samples and 1 per 5 samples for metals analyses by XRF. $\mathrm{Ag}, \mathrm{Hg}, \mathrm{Ni}, \mathrm{Pb}$, and $\mathrm{Se}$ values exceeded the certified ranc e for at least two reps of the SRM. Experience has shown that $\mathrm{Hg}$ values are routinely lower than the certitied range. Six of the fourteen Ni measurements (pertormed by XRF) were outside of the certified range. Other QC measurements for this metal (i.e., spikes and replicates) are acceptable, indicating that the variability may be a result of non-homogeneity of the SRM rather than an arialytical bias. Although some metals exceeded certitied ranges, all values fell within $\pm 20 \%$ of the certitied mean.

Four samples (COMP II, COMP V, R-PF, and C-SB) were analyzed in triplicate for all metals. Precision was measured by Relative Standard Deviation (RSD) between replicate results. The RSDs ranged from $1 \%$ to $50 \%$. Eight out of forty calculated RSD values $(\mathrm{Ag}, \mathrm{Cd}, \mathrm{Cr}$, and $\mathrm{Se})$ exceeded the OAOC requirements.

NOT APPLICABLE 


\section{QA/QC SUMMARY}

PROGRAM:

PARAMETER:

LABORATORY:

MATRIX:

SAMPLE NUMBER:
Richmond Harbor Program

Butyltins

Battelle/Marine Sciences Laboratory

M. naserta

75

\section{QA/QC REQUIREMENTS:}

\section{Reference Method}

Monobutyltin

Dibutyltin

Tributyltin

$$
\begin{aligned}
& \text { MSL-M-4 } \\
& \text { MSL-M-4 } \\
& M S L-M-4
\end{aligned}
$$

\section{Range of Becovery}

$$
\begin{aligned}
& 40 \%-120 \% \\
& 40 \%-120 \%
\end{aligned}
$$

\section{Relative Precision}

$\pm 30 \%$

$\pm 30 \%$

$\pm 30 \%$

\section{Detection \\ Limit (wet wo)}

$10 \mu g / \mathrm{kg}$

$10 \mu g / \mathrm{kg}$

$10 \mu \mathrm{g} / \mathrm{kg}$

HOLDING TIMES No holding times have been established for butyttins in tissues; however, samples were kept frozen until used for analyses. All tissue samples were initially extracted in four batches and analyzed within 2 months. Because of low surrogate recoveries ( $<40 \%$ ), approximately $30 \%$ of the samples were re-extracted and re-analyzed approximately 2.5 months after receipt.

DETECTION LIMITS Target detection limits $(10 \mu \mathrm{g} / \mathrm{kg})$ were met for all butyltin tissue samples.

\section{METHOD BLANKS}

\section{MATRIX SPIKES}

A total of 11 method blanks were analyzed, a minimum of 1 blank per 20 samples. Butyltins were not detected in any method blanks.

Five samples (COMP IV, R-AM, COMP III, R-PF, and R-AC) were spked in duplicate to assess the accuracy and precision of the method. One set of spike and spike duplicate analyses was performed with each extraction batch. Recoveries for tri- and dibutyltin ranged from $30 \%$ to $77 \%$ with 42 of the 48 recoveries within the $Q A Q C$ requirements.

Relative percent difference (RPD) values were compared between spike and spike duplicate recoveries to assess precision. The RPD values for triand dibutyltin ranged from $10 \%$ to $39 \%$. Two sets of RPDs out of the six MS/MSD samples analyzed exceeded the QANCC requirements. In general, the precision of the analyses, based on spike duplicate recovery data, was acceptable.

NOT APPLICABLE 
REPLICATES

\section{SURROGATES}

Five samples (COMP III, TC-5 Upper Comp, R-OS, C-SB, and the MSL background) were analyzed in triplicate, one per each extraction batch. Batch A triplicates had bow surrogate recoveries and were not reported. Precision between triplicate analyses was measured by Relative Standard Deviation (RSD) and ranged from $3 \%$ to $28 \%$, which is within the QNOC requirements. Dibutyltin was not found in any of the triplicates; therefore, no RSDs were calculated.

Tripropythin was added as surrogate to each sample prior to extraction to assess extraction efticiency. Percent recoveries ranged from $30 \%$ to $76 \%$. Three recoveries were out of or below the $2 A N C$ requirements. These exceedences were all above $30 \%$, so no turther actions were required. 
IABLE J.1. Total Polynuclear Aromatic Hydrocarbons (PAHs), Dry Weight, in Tissue of M. nasuta, Richmond Harbor Program

\begin{tabular}{|c|c|c|c|c|c|}
\hline $\begin{array}{l}\text { Sediment } \\
\text { Ireatment }\end{array}$ & Replicate & $\begin{array}{c}\text { Analytical } \\
\text { Batch } \\
\end{array}$ & $\begin{array}{l}\text { M. nasuta P } \\
\text { Total Low } \\
\text { Molecular } \\
\text { Weight PAHs } \\
\end{array}$ & $\begin{array}{l}\mathrm{s}(\mu \mathrm{g} / \mathrm{kg} \text { dry } \\
\text { Total High } \\
\text { Molecular } \\
\text { Weight PAHS }\end{array}$ & $\begin{array}{r}\text { veight) } \\
\text { Total } \\
\text { PAHs } \\
\end{array}$ \\
\hline $\begin{array}{ll}\text { COMP } & \text { I } \\
\text { COMP } & \text { I } \\
\text { COMP } & \text { I } \\
\text { COMP } & I \\
\text { COMP } & \text { I }\end{array}$ & $\begin{array}{l}1 \\
2 \\
3 \\
4 \\
5\end{array}$ & $\begin{array}{l}D \\
D \\
A \\
B \\
A\end{array}$ & $\begin{array}{l}28.80 \\
35.59 \\
41.85 \\
37.60 \\
46.29\end{array}$ & $\begin{array}{l}157.27 \\
205.39 \\
178.58 \\
217.70 \\
218.29\end{array}$ & $\begin{array}{l}186.07 \\
240.98 \\
220.43 \\
255.30 \\
264.58\end{array}$ \\
\hline $\begin{array}{l}\text { COMP } \\
\text { COMP I I } \\
\text { COMP } \\
\text { COMP I I } \\
\text { COMP } \\
\text { I I }\end{array}$ & $\begin{array}{l}1 \\
2 \\
3 \\
4 \\
5\end{array}$ & $\begin{array}{l}D \\
A \\
C \\
D \\
C\end{array}$ & $\begin{array}{l}20.41 \\
42.03 \\
38.31 \\
22.88 \\
43.47\end{array}$ & $\begin{array}{l}110.58 \\
197.52 \\
120.12 \\
147.86 \\
168.68\end{array}$ & $\begin{array}{l}130.99 \\
239.55 \\
158.43 \\
170.74 \\
212.15\end{array}$ \\
\hline $\begin{array}{ll}\text { COMP } & \text { I I I } \\
\text { COMP } & \text { I I I } \\
\text { COMP } & \text { I I I } \\
\text { COMP } & \text { I I I } \\
\text { COMP } & \text { I I I }\end{array}$ & $\begin{array}{l}1 \\
2 \\
3 \\
4 \\
5\end{array}$ & $\begin{array}{l}C \\
C \\
A \\
D \\
C\end{array}$ & $\begin{array}{l}25.99 \\
27.43 \\
36.24 \\
21.27 \\
23.70\end{array}$ & $\begin{array}{l}17.47 \\
42.51 \\
57.19 \\
52.16 \\
33.90\end{array}$ & $\begin{array}{l}43.46 \\
69.94 \\
93.43 \\
73.43 \\
57.60\end{array}$ \\
\hline $\begin{array}{l}\text { TC-5 Upper Comp } \\
\text { TC-5 Upper Comp } \\
\text { TC-5 Upper Comp } \\
\text { TC-5 Upper Comp } \\
\text { TC-5 Upper Comp }\end{array}$ & $\begin{array}{l}1 \\
2 \\
3 \\
4 \\
5\end{array}$ & $\begin{array}{l}C \\
C \\
C \\
A \\
A\end{array}$ & $\begin{array}{l}70.67 \\
58.45 \\
72.38 \\
58.68 \\
52.67\end{array}$ & $\begin{array}{l}956.45 \\
843.73 \\
863.06 \\
659.41 \\
618.68\end{array}$ & $\begin{array}{r}1027.12 \\
902.18 \\
935.44 \\
718.09 \\
671.35\end{array}$ \\
\hline $\begin{array}{l}\text { COMP IV } \\
\text { COMP IV } \\
\text { COMP IV } \\
\text { COMP IV } \\
\text { COMP IV }\end{array}$ & $\begin{array}{l}1 \\
2 \\
3 \\
4 \\
5\end{array}$ & $\begin{array}{l}C \\
C \\
A \\
C \\
A\end{array}$ & $\begin{array}{l}32.29 \\
23.78 \\
29.18 \\
30.47 \\
38.64\end{array}$ & $\begin{array}{l}18.75 \\
12.54 \\
32.38 \\
12.56 \\
29.67\end{array}$ & $\begin{array}{l}51.04 \\
36.32 \\
61.56 \\
43.03 \\
68.31\end{array}$ \\
\hline $\begin{array}{l}\text { COMP } V \\
\text { COMP } V \\
\text { COMP } V \\
\text { COMP } V \\
\text { COMP } V \text { Replicate } 1 \\
\text { COMP } V \text { Replicate } 2 \\
\text { COMP } V \text { Replicate } 3\end{array}$ & $\begin{array}{l}1 \\
2 \\
3 \\
4 \\
5 \\
5 \\
5\end{array}$ & $\begin{array}{l}A \\
A \\
A \\
D \\
B \\
B \\
B\end{array}$ & $\begin{array}{l}35.99 \\
55.60 \\
49.38 \\
26.86 \\
73.86 \\
56.02 \\
34.39\end{array}$ & $\begin{array}{l}369.31 \\
435.19 \\
491.12 \\
281.23 \\
404.48 \\
415.43 \\
397.30\end{array}$ & $\begin{array}{l}405.30 \\
490.79 \\
540.50 \\
308.09 \\
478.34 \\
471.45 \\
431.69\end{array}$ \\
\hline $\begin{array}{l}\text { COMP VI } \\
\text { COMP VI } \\
\text { COMP VI } \\
\text { COMP VI } \\
\text { COMP VI }\end{array}$ & $\begin{array}{l}1 \\
2 \\
3 \\
4 \\
5\end{array}$ & $\begin{array}{l}C \\
A \\
B \\
A \\
D\end{array}$ & $\begin{array}{l}41.22 \\
43.84 \\
66.10 \\
56.53 \\
11.85\end{array}$ & $\begin{array}{l}288.05 \\
407.71 \\
487.84 \\
393.77 \\
326.66\end{array}$ & $\begin{array}{l}329.27 \\
451.55 \\
553.94 \\
450.30 \\
338.51\end{array}$ \\
\hline
\end{tabular}


IABLE J.1. (contd)

\begin{tabular}{|c|c|}
\hline $\begin{array}{l}R-A C \\
R-A C \\
R-A C \\
R-A C \\
R-A C\end{array}$ & \\
\hline $\begin{array}{l}\text { R-AM } \\
\text { R-AM } \\
\text { R-AM } \\
\text { R-AM } \\
\text { R-AM } \\
\text { R-AM } \\
\text { R-AM }\end{array}$ & $\begin{array}{l}\text { Replicate } 1 \\
\text { Repl icate } 2 \\
\text { Replicate } 3 \\
\end{array}$ \\
\hline $\begin{array}{l}R-B F \\
R-B F \\
R-B F \\
R-B F \\
R-B F\end{array}$ & \\
\hline $\begin{array}{l}R-O S \\
R-O S \\
R-O S \\
R-O S \\
R-O S\end{array}$ & \\
\hline $\begin{array}{l}R-P F \\
R-P F \\
R-P F \\
R-P F \\
R-P F \\
R-P F \\
R-P F\end{array}$ & $\begin{array}{l}\text { Replicate } 1 \\
\text { Replicate } 2 \\
\text { Replicate } 3\end{array}$ \\
\hline $\begin{array}{l}C-S B \\
C-S B \\
C-S B \\
C-S B \\
C-S B \\
C-S B \\
C-S B\end{array}$ & $\begin{array}{l}\text { Replicate } 1 \\
\text { Replicate } 2 \\
\text { Replicate } 3\end{array}$ \\
\hline
\end{tabular}

$\begin{array}{llll}\text { B } & 189.31 & 4979.20 & 5168.51 \\ \text { C } & 151.57 & 3180.60 & 3332.17 \\ \text { C } & 246.64 & 6922.55 & 7169.19 \\ \text { A } & 192.34 & 5950.02 & 6142.36 \\ \text { D } & 191.98 & 6074.82 & 6266.80\end{array}$

$\begin{array}{lrrr}\text { B } & 45.13 & 630.33 & 675.46 \\ \text { C } & 67.95 & 666.55 & 734.50 \\ \text { C } & 77.01 & 747.44 & 824.45 \\ \text { C } & 75.46 & 711.70 & 787.16 \\ \text { B } & 108.44 & 1600.96 & 1709.40 \\ \text { B } & 115.93 & 1885.00 & 2000.93 \\ \text { B } & 121.95 & 1327.63 & 1449.58\end{array}$

D 28.28

37.58

44.51

44.44

41.94

34.43

14.41

40.44

23.50

40.79

$144.25 \quad 172.53$

$285.96 \quad 323.54$

$248.48 \quad 292.99$

$237.82 \quad 282.26$

$221.90 \quad 263.84$

$\begin{array}{ll}56.36 & 90.79\end{array}$

$17.87 \quad 32.28$

$35.56 \quad 76.00$

$28.22 \quad 51.72$

$35.47 \quad 76.26$

$25.61 \quad 62.18$

$18.40 \quad 49.06$

$23.97 \quad 52.94$

$20.96 \quad 45.12$

$18.60 \quad 45.99$

$24.61 \quad 47.33$

$41.22 \quad 79.72$

$59.75 \quad 89.45$

$62.53 \quad 93.75$

$83.92 \quad 102.99$

$46.93 \quad 82.17$

$64.73 \quad 103.38$

$44.90 \quad 78.32$

$51.38 \quad 73.69$ 
IABLE J.1. (contd)

$\begin{array}{llllrr}\text { C-NE } & 1 & \mathrm{~B} & 51.00 & 51.06 & 102.06 \\ \text { C-NE } & 2 & \mathrm{~B} & 32.59 & 33.64 & 66.23 \\ \text { C-NE } & 3 & \mathrm{~B} & 24.81 & 40.73 & 65.54 \\ \text { C-NE } & 4 & \mathrm{~B} & 36.94 & 52.74 & 89.68 \\ \text { C-NE } & 5 & \mathrm{~B} & 36.03 & 46.26 & 82.29 \\ & & & & & \\ \text { MSL Background } & 1 & \mathrm{~A} & 48.37 & 159.17 & 207.54 \\ \text { MSL Background } & 2 & \mathrm{~B} & 25.89 & 154.68 & 180.57 \\ \text { MSL Background } & 3 & \mathrm{C} & 32.08 & 183.37 & 215.45 \\ \text { MSL 8ackground } & 4 & \mathrm{D} & 31.32 & 134.43 & 165.75 \\ \text { MSL Background } & 5 & \mathrm{D} & 21.65 & 195.26 & 216.91\end{array}$




\section{IABLE 0.2. Low Molecular Weight Polynuclear Aromatic Hydrocarbons (LPAHs), Dry Weight, in Tissue of $M$. nasuta, Richmond Harbor Program}

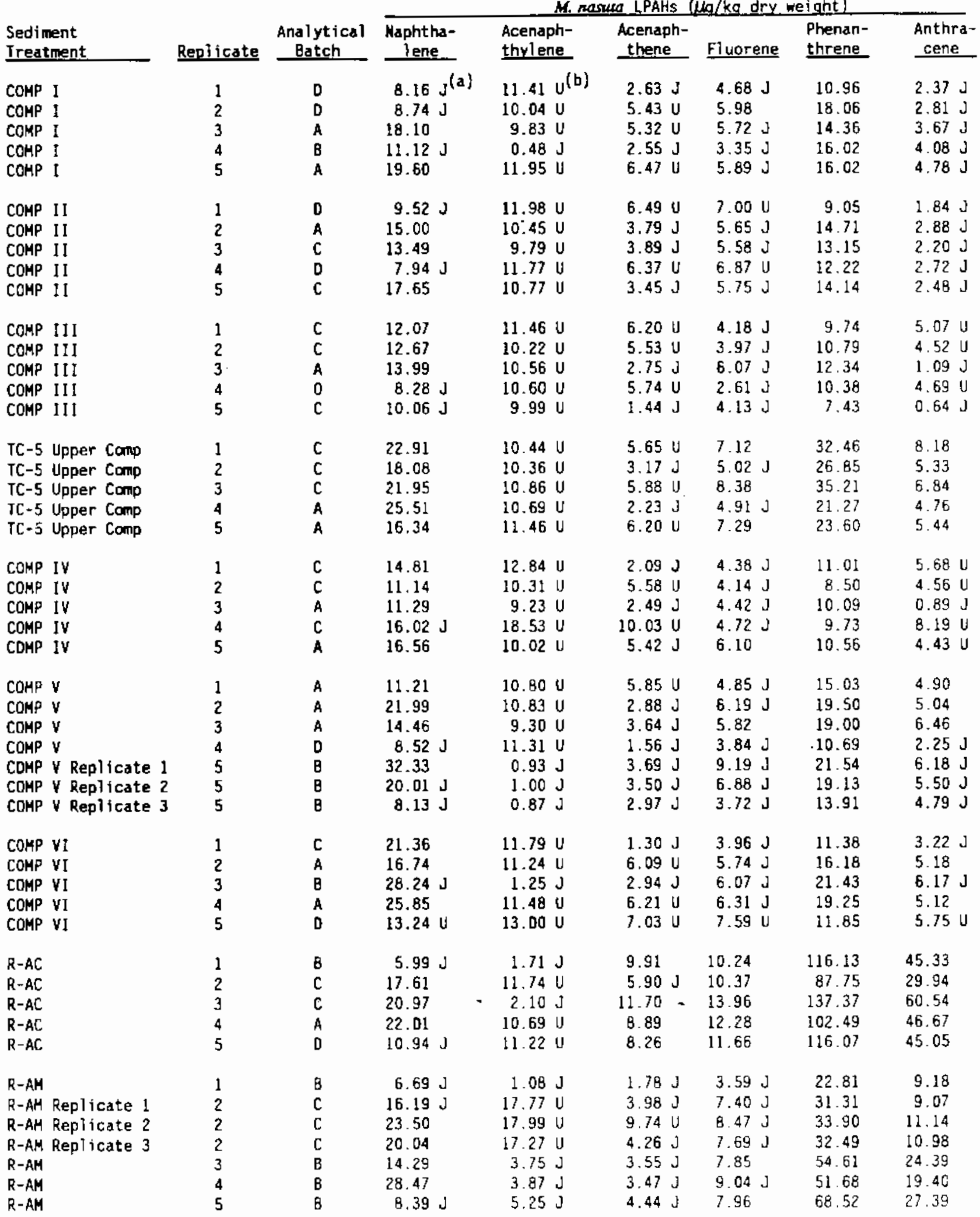


TABLE J.2. (contd)

\begin{tabular}{|c|c|c|c|c|c|c|c|c|}
\hline \multirow[b]{2}{*}{$\begin{array}{l}\text { Sediment } \\
\text { Treatment }\end{array}$} & \multirow[b]{2}{*}{ Replicate } & \multirow[b]{2}{*}{$\begin{array}{l}\text { Analytical } \\
\text { Batch } \\
\end{array}$} & \multicolumn{6}{|c|}{ M. naruta LPAHs ( $\mu \mathrm{g} / \mathrm{kg}$ dry weight) } \\
\hline & & & $\begin{array}{l}\text { Maphtha- } \\
\text { Iene } \\
\end{array}$ & $\begin{array}{l}\text { Acenaph- } \\
\text { thylene }\end{array}$ & $\begin{array}{l}\text { Acenaph- } \\
\text { thene }\end{array}$ & Fluorene & $\begin{array}{l}\text { Phenan- } \\
\text { threne }\end{array}$ & $\begin{array}{l}\text { Anthra- } \\
\text { cene }\end{array}$ \\
\hline $\begin{array}{l}R-B F \\
R-B F \\
R-B F \\
R-B F \\
R-B F\end{array}$ & $\begin{array}{l}1 \\
2 \\
3 \\
4 \\
5\end{array}$ & $\begin{array}{l}\text { D } \\
\text { B } \\
\text { B } \\
\text { A } \\
\text { A }\end{array}$ & $\begin{array}{l}11.66 \mathrm{~J} \\
11.68 \\
16.05 \\
20.74 \\
18.32\end{array}$ & $\begin{array}{r}13.04 \mathrm{U} \\
0.55 \mathrm{~J} \\
0.61 \mathrm{~J} \\
12.12 \mathrm{U} \\
9.33 \mathrm{U}\end{array}$ & $\begin{array}{l}7.06 \mathrm{U} \\
2.07 \mathrm{~J} \\
2.21 \mathrm{~J} \\
6.56 \mathrm{U} \\
5.05 \mathrm{U}\end{array}$ & $\begin{array}{l}3.82 \mathrm{~J} \\
4.34 \mathrm{~J} \\
5.38 \mathrm{~J} \\
6.68 \mathrm{~J} \\
5.59\end{array}$ & $\begin{array}{l}10.96 \\
14.77 \\
16.32 \\
13.30 \\
14.77\end{array}$ & $\begin{array}{l}1.84 \mathrm{~J} \\
4.17 \\
3.94 \mathrm{~J} \\
3.72 \mathrm{~J} \\
3.26 \mathrm{~J}\end{array}$ \\
\hline $\begin{array}{l}R-O S \\
R-O S \\
R-O S \\
R-O S \\
R-O S\end{array}$ & $\begin{array}{l}1 \\
2 \\
3 \\
4 \\
5\end{array}$ & $\begin{array}{l}B \\
0 \\
B \\
D \\
C\end{array}$ & $\begin{array}{r}13.24 \\
5.56 \mathrm{~J} \\
18.49 \\
6.97 \mathrm{~J} \\
17.91\end{array}$ & $\begin{array}{r}0.45 \mathrm{~J} \\
10.57 \mathrm{U} \\
10.63 \mathrm{U} \\
10.02 \mathrm{U} \\
9.64 \mathrm{U}\end{array}$ & $\begin{array}{l}2.14 \mathrm{~J} \\
5.72 \mathrm{~J} \\
2.07 \mathrm{~J} \\
3.86 \mathrm{~J} \\
5.49\end{array}$ & $\begin{array}{l}4.69 \mathrm{~J} \\
6.18 \mathrm{U} \\
5.43 \mathrm{~J} \\
4.12 \mathrm{~J} \\
4.78 \mathrm{~J}\end{array}$ & $\begin{array}{r}12.40 \\
8.85 \\
12.95 \\
8.55 \\
11.69\end{array}$ & $\begin{array}{l}1.51 \mathrm{~J} \\
4.67 \mathrm{U} \\
1.50 \mathrm{~J} \\
4.43 \mathrm{U} \\
0.92 \mathrm{~J}\end{array}$ \\
\hline $\begin{array}{l}R-P F \\
R-P F \\
R-P F \text { Replicate } 1 \\
R-P F \text { Replicate } 2 \\
R-P F \text { Replicate } 3 \\
R-P F \\
R-P F\end{array}$ & $\begin{array}{l}1 \\
2 \\
3 \\
3 \\
3 \\
4 \\
5\end{array}$ & $\begin{array}{l}\mathrm{C} \\
\mathrm{C} \\
\mathrm{D} \\
0 \\
0 \\
\mathrm{D} \\
\mathrm{A}\end{array}$ & $\begin{array}{c}18.54 \\
13.68 \\
14.69 \mathrm{~J} \\
12.15 \mathrm{~J} \\
12.28 \mathrm{~J} \\
8.75 \mathrm{~J} \\
12.76\end{array}$ & $\begin{array}{l}11.43 \mathrm{U} \\
10.96 \mathrm{U} \\
17.83 \mathrm{U} \\
17.36 \mathrm{~V} \\
17.79 \mathrm{~V} \\
13.19 \mathrm{~V} \\
10.27 \mathrm{~V}\end{array}$ & $\begin{array}{l}2.20 \mathrm{~J} \\
5.93 \mathrm{U} \\
9.65 \mathrm{U} \\
9.40 \mathrm{U} \\
9.63 \mathrm{U} \\
7.14 \mathrm{U} \\
3.21 \mathrm{~J}\end{array}$ & $\begin{array}{r}4.26 \mathrm{~J} \\
4.65 \mathrm{~J} \\
3.35 \mathrm{~J} \\
10.14 \mathrm{~J} \\
5.43 \mathrm{~J} \\
5.02 \mathrm{~J} \\
6.25\end{array}$ & $\begin{array}{r}10.42 \\
10.97 \\
10.93 \\
12.01 \\
9.68 \\
8.95 \\
14.66\end{array}$ & $\begin{array}{l}1.15 \mathrm{~J} \\
1.36 \mathrm{~J} \\
7.88 \mathrm{U} \\
7.67 \mathrm{U} \\
7.87 \mathrm{U} \\
5.83 \mathrm{U} \\
1.62 \mathrm{~J}\end{array}$ \\
\hline $\begin{array}{l}\text { C-SB } \\
\text { C-SB } \\
\text { C-SB } \\
\text { C-SB Replicate } 1 \\
\text { C-SB Replicate } 2 \\
\text { C-SB Replicate } 3 \\
\text { C-SB }\end{array}$ & $\begin{array}{l}1 \\
2 \\
3 \\
4 \\
4 \\
4 \\
5\end{array}$ & $\begin{array}{l}\text { C } \\
D \\
B \\
A \\
A \\
A \\
D\end{array}$ & $\begin{array}{r}8.93 \mathrm{~J} \\
10.29 \mathrm{~J} \\
4.58 \mathrm{~J} \\
20.24 \\
19.28 \\
17.78 \\
9.57 \mathrm{~J}\end{array}$ & $\begin{array}{l}9.26 \mathrm{U} \\
11.73 \mathrm{U} \\
11.11 \mathrm{U} \\
15.28 \mathrm{U} \\
14.85 \mathrm{U} \\
14.20 \mathrm{U} \\
12.45 \mathrm{U}\end{array}$ & $\begin{array}{l}2.45 \mathrm{~J} \\
4.28 \mathrm{~J} \\
1.42 \mathrm{~J} \\
2.34 \mathrm{~J} \\
8.04 \mathrm{U} \\
7.69 \mathrm{U} \\
6.74 \mathrm{U}\end{array}$ & $\begin{array}{l}4.22 \mathrm{~J} \\
4.81 \mathrm{~J} \\
3.06 \mathrm{~J} \\
8.93 \mathrm{U} \\
7.19 \mathrm{~J} \\
6.03 \mathrm{~J} \\
4.35 \mathrm{~J}\end{array}$ & $\begin{array}{r}12.08 \\
11.84 \\
8.77 \\
11.42 \\
12.18 \\
9.61 \\
8.39\end{array}$ & $\begin{array}{l}2.02 \mathrm{~J} \\
5.18 \mathrm{U} \\
1.24 \mathrm{~J} \\
1.24 \mathrm{~J} \\
6.56 \mathrm{U} \\
6.28 \mathrm{U} \\
5.50 \mathrm{U}\end{array}$ \\
\hline $\begin{array}{l}C-N E \\
C-N E \\
C-N E \\
C-N E \\
C-N E\end{array}$ & $\begin{array}{l}1 \\
2 \\
3 \\
4 \\
5\end{array}$ & $\begin{array}{l}\mathrm{B} \\
\mathrm{B} \\
\mathrm{B} \\
\mathrm{B} \\
\mathrm{B}\end{array}$ & $\begin{array}{c}20.73 \\
11.65 \\
5.09 \mathrm{~J} \\
11.77 \\
11.52\end{array}$ & $\begin{array}{r}10.61 \mathrm{U} \\
11.17 \mathrm{U} \\
9.42 \mathrm{U} \\
11.34 \mathrm{U} \\
9.83 \mathrm{U}\end{array}$ & $\begin{array}{l}2.8 \mathrm{~J} \\
2.54 \mathrm{~J} \\
2.09 \mathrm{~J} \\
2.54 \mathrm{~J} \\
2.09 \mathrm{~J}\end{array}$ & $\begin{array}{l}5.84 \mathrm{~J} \\
4.38 \mathrm{~J} \\
3.37 \mathrm{~J} \\
4.89 \mathrm{~J} \\
5.01 \mathrm{~J}\end{array}$ & $\begin{array}{l}20.13 \\
12.96 \\
13.34 \\
16.39 \\
16.10\end{array}$ & $\begin{array}{l}1.42 \mathrm{~J} \\
1.06 \mathrm{~J} \\
0.92 \mathrm{~J} \\
1.25 \mathrm{~J} \\
1.31 \mathrm{~J}\end{array}$ \\
\hline $\begin{array}{l}\text { MSL Background } \\
\text { HSL Background } \\
\text { HSL Background } \\
\text { MSL Background } \\
\text { HSL Background }\end{array}$ & $\begin{array}{l}1 \\
2 \\
3 \\
4 \\
5\end{array}$ & $\begin{array}{l}A \\
B \\
C \\
D \\
D\end{array}$ & $\begin{array}{r}14.96 \\
4.98 \mathrm{~J} \\
12.60 \\
9.66 \mathrm{~J} \\
5.67 \mathrm{~J}\end{array}$ & $\begin{array}{l}10.15 \mathrm{U} \\
11.12 \mathrm{U} \\
11.15 \mathrm{U} \\
10.99 \mathrm{U} \\
10.99 \mathrm{U}\end{array}$ & $\begin{array}{l}7.44 \\
2.43 \mathrm{~J} \\
6.03 \mathrm{U} \\
3.51 \mathrm{~J} \\
5.95 \mathrm{~J}\end{array}$ & $\begin{array}{l}5.92 \mathrm{~J} \\
3.40 \mathrm{~J} \\
4.93 \mathrm{~J} \\
3.20 \mathrm{~J} \\
2.11 \mathrm{~J}\end{array}$ & $\begin{array}{l}17.19 \\
14.00 \\
14.55 \\
14.95 \\
13.87\end{array}$ & $\begin{array}{l}2.86 \mathrm{~J} \\
1.08 \mathrm{~J} \\
4.93 \mathrm{U} \\
4.86 \mathrm{U} \\
4.86 \mathrm{~J}\end{array}$ \\
\hline
\end{tabular}

(a) J Analyte detected below method detection 1 imit (MOL). but above instrument detection limit (IDL).

(b) U The analyte was not present above the level of the associated vaiue. 
TABLE J.3. High Molecular Weight Polynuclear Aromatic Hydrocarbons (HPAHs), Dry Weight, in - Tissue of $M$. nasuta, Richmond Harbor Program

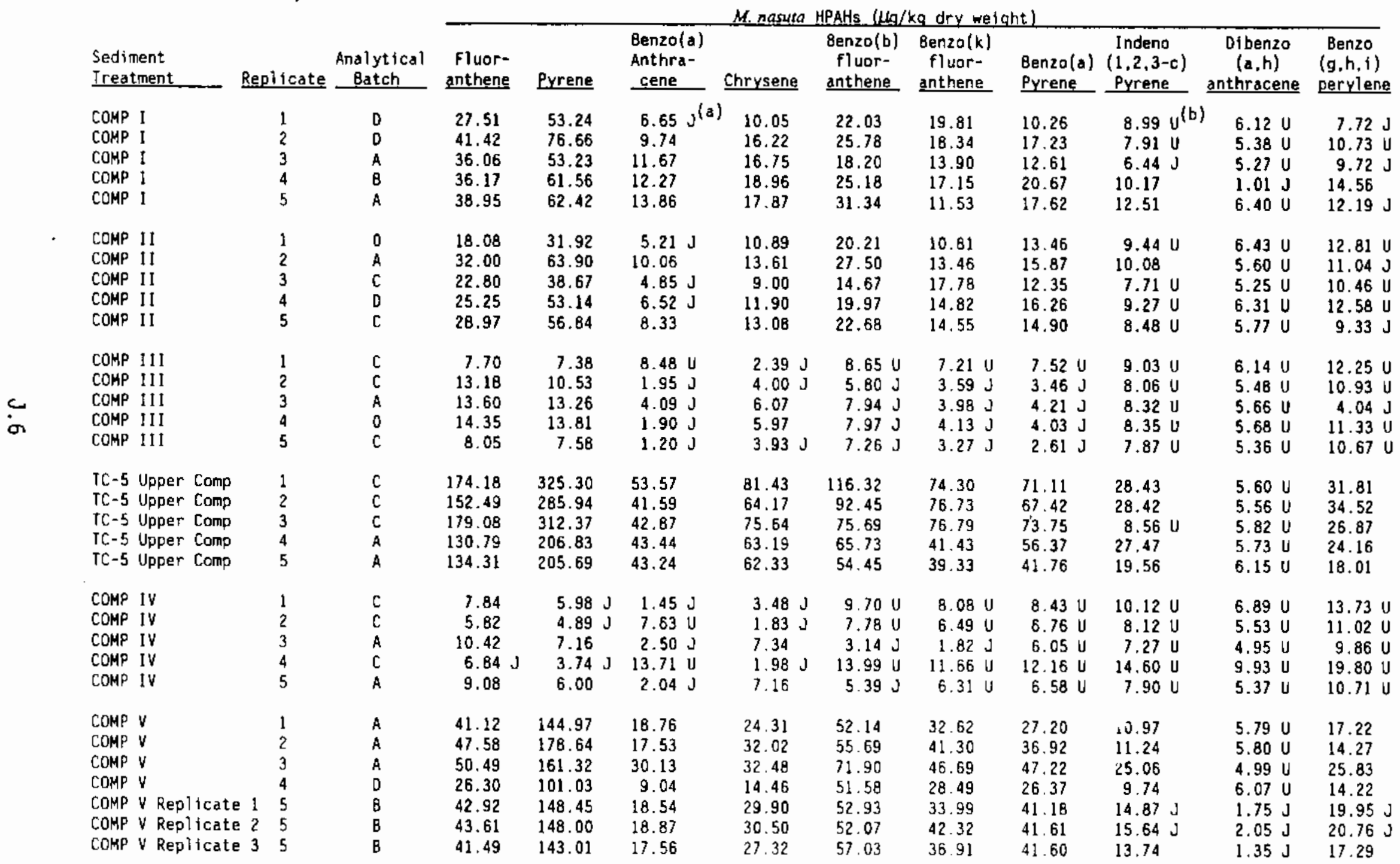


TABLE J.3. (contd)

\begin{tabular}{|c|c|c|c|c|c|c|c|c|c|c|c|c|}
\hline \multirow{2}{*}{$\begin{array}{l}\text { Sediment } \\
\text { Ireatment }\end{array}$} & \multirow[b]{2}{*}{ Replicate } & \multirow[b]{2}{*}{$\begin{array}{l}\text { Analytical } \\
\text { Bateh } \\
\end{array}$} & \multicolumn{9}{|c|}{ M. nouta HPAHs ( $\mu_{0} / \mathrm{kg}$ dry weight) } & \multirow[b]{2}{*}{$\begin{array}{l}\text { Benzo } \\
(g, h, 1) \\
\text { perylene }\end{array}$} \\
\hline & & & $\begin{array}{l}\text { Fluor- } \\
\text { anthene }\end{array}$ & Pyrene & $\begin{array}{l}\text { Benzo(a) } \\
\text { Anthra- } \\
\text { cene } \\
\end{array}$ & Chrysene & $\begin{array}{c}\text { Benzo }(b) \\
\text { fluor- } \\
\text { anthene }\end{array}$ & $\begin{array}{l}\text { Benzo(k) } \\
\text { fluor- } \\
\text { anthene }\end{array}$ & $\begin{array}{l}\text { genzo(a) } \\
\text { Pyrene }\end{array}$ & $\begin{array}{l}\text { Indeno } \\
(1,2,3-\mathrm{c}) \\
\text { Pyrene } \\
\end{array}$ & $\begin{array}{c}\text { Dibenzo } \\
(a, h) \\
\text { anthracene }\end{array}$ & \\
\hline $\begin{array}{l}\text { COMP VI } \\
\text { COMP VI } \\
\text { COMP VI } \\
\text { COMP VI } \\
\text { COMP VI }\end{array}$ & $\begin{array}{l}1 \\
2 \\
3 \\
4 \\
5\end{array}$ & $\begin{array}{l}C \\
A \\
B \\
A \\
0\end{array}$ & $\begin{array}{l}22.83 \\
38.42 \\
45.89 \\
37.43 \\
30.29\end{array}$ & $\begin{array}{l}110.09 \\
161.27 \\
182.55 \\
143.66 \\
150.58\end{array}$ & $\begin{array}{c}10.15 \\
25.05 \\
18.88 \mathrm{~J} \\
23.87 \\
9.77\end{array}$ & $\begin{array}{l}15.76 \\
28.65 \\
32.25 \\
28.29 \\
18.72\end{array}$ & $\begin{array}{l}50.03 \\
52.95 \\
71.90 \\
46.28 \\
54.01\end{array}$ & $\begin{array}{l}29.01 \\
39.03 \\
47.99 \\
45.69 \\
30.21\end{array}$ & $\begin{array}{l}23.95 \\
33.25 \\
47.83 \\
35.82 \\
33.08\end{array}$ & $\begin{array}{l}9.58 \\
13.44 \\
17.04 \mathrm{~J} \\
16.46 \\
10.24 \mathrm{U}\end{array}$ & $\begin{array}{l}6.32 \mathrm{U} \\
6.03 \mathrm{U} \\
1.92 \mathrm{~J} \\
6.15 \mathrm{U} \\
6.97 \mathrm{U}\end{array}$ & $\begin{array}{l}16.65 \\
15.65 \\
21.59 \mathrm{~J} \\
16.27 \\
13.89 \mathrm{U}\end{array}$ \\
\hline $\begin{array}{l}R-A C \\
R-A C \\
R-A C \\
R-A C \\
R-A C\end{array}$ & $\begin{array}{l}1 \\
2 \\
3 \\
4 \\
5\end{array}$ & $\begin{array}{l}B \\
C \\
C \\
A \\
D\end{array}$ & $\begin{array}{r}1032.19 \\
636.14 \\
1448.54 \\
1243.58 \\
1262.84\end{array}$ & $\begin{array}{l}2345.15 \\
1490.52 \\
3521.14 \\
2791.36 \\
2924.16\end{array}$ & $\begin{array}{l}224.75 \\
103.07 \\
258.21 \\
321.90 \\
302.35\end{array}$ & $\begin{array}{l}302.80 \\
147.79 \\
319.97 \\
352.76 \\
375.46\end{array}$ & $\begin{array}{l}287.11 \\
202.34 \\
451.28 \\
370.49 \\
326.20\end{array}$ & $\begin{array}{l}225.83 \\
249.31 \\
280.34 \\
221.94 \\
242.69\end{array}$ & $\begin{array}{l}346.82 \\
241.54 \\
435.06 \\
378.29 \\
392.56\end{array}$ & $\begin{array}{r}100.21 \\
50.94 \\
105.36 \\
141.71 \\
113.67\end{array}$ & $\begin{array}{l}5.39 \\
6.29 \mathrm{U} \\
5.59 \mathrm{U} \\
5.73 \mathrm{U} \\
7.03\end{array}$ & $\begin{array}{r}108.95 \\
58.95 \\
102.65 \\
127.99 \\
127.86\end{array}$ \\
\hline $\begin{array}{l}\text { R-AM } \\
\text { R-AM Replicate } \\
\text { R-AM Replicate } \\
\text { R-AM Replicate } \\
\text { R-AM } \\
\text { R-AM } \\
\text { R-AM }\end{array}$ & $\begin{array}{l}1 \\
2 \\
2 \\
2 \\
3 \\
4 \\
5\end{array}$ & $\begin{array}{l}B \\
C \\
C \\
C \\
B \\
B \\
B\end{array}$ & $\begin{array}{l}162.42 \\
203.36 \\
226.25 \\
216.37 \\
354.99 \\
391.35 \\
311.37\end{array}$ & $\begin{array}{l}171.26 \\
198.96 \\
230.78 \\
215.09 \\
395.26 \\
460.95 \\
338.03\end{array}$ & $\begin{array}{r}50.41 \\
44.60 \\
51.39 \\
45.16 \\
160.62 \\
186.37 \\
134.61\end{array}$ & $\begin{array}{r}86.61 \\
70.65 \\
93.71 \\
82.35 \\
233.78 \\
302.05 \\
209.50\end{array}$ & $\begin{array}{r}37.82 \\
38.28 \\
45.44 \\
34.51 \\
104.23 \\
120.31 \\
77.97\end{array}$ & $\begin{array}{r}44.61 \\
51.02 \\
44.10 \\
49.67 \\
117.42 \\
141.95 \\
82.04\end{array}$ & $\begin{array}{r}49.84 \\
45.45 \\
43.38 \\
53.14 \\
142.51 \\
177.52 \\
108.76\end{array}$ & $\begin{array}{l}12.26 \\
14.01 \mathrm{U} \\
14.18 \mathrm{U} \\
13.61 \mathrm{U} \\
44.59 \\
48.44 \\
29.88\end{array}$ & $\begin{array}{l}1.68 \mathrm{~J} \\
9.53 \mathrm{U} \\
9.65 \mathrm{U} \\
9.26 \mathrm{~J} \\
4.91 \mathrm{~J} \\
5.86 \mathrm{~J} \\
3.64 \mathrm{~J}\end{array}$ & $\begin{array}{l}13.42 \\
14.23 \mathrm{~J} \\
12.39 \mathrm{~J} \\
15.41 \mathrm{~J} \\
42.65 \\
50.20 \\
31.83\end{array}$ \\
\hline $\begin{array}{l}R-B F \\
R-B F \\
R-B F \\
R-B F \\
R-8 F\end{array}$ & $\begin{array}{l}1 \\
2 \\
3 \\
4 \\
5\end{array}$ & $\begin{array}{l}D \\
B \\
B \\
A \\
A\end{array}$ & $\begin{array}{l}26.28 \\
58.02 \\
48.81 \\
50.76 \\
44.60\end{array}$ & $\begin{array}{l}28.80 \\
63.86 \\
59.98 \\
47.60 \\
42.84\end{array}$ & $\begin{array}{r}7.76 \mathrm{~J} \\
14.10 \\
12.52 \\
15.75 \\
13.52\end{array}$ & $\begin{array}{l}13.73 \\
27.84 \\
23.16 \\
25.15 \\
21.37\end{array}$ & $\begin{array}{l}24.31 \\
39.53 \\
36.70 \\
33.36 \\
29.24\end{array}$ & $\begin{array}{l}10.39 \\
20.51 \\
21.81 \\
16.51 \\
18.70\end{array}$ & $\begin{array}{l}15.11 \\
27.88 \\
24.93 \\
20.17 \\
18.48\end{array}$ & $\begin{array}{r}7.50 \mathrm{~J} \\
12.22 \\
8.09 \mathrm{U} \\
12.23 \\
13.64\end{array}$ & $\begin{array}{l}6.99 \mathrm{U} \\
1.14 \mathrm{~J} \\
1.10 \mathrm{~J} \\
6.50 \mathrm{U} \\
5.00 \mathrm{U}\end{array}$ & $\begin{array}{l}10.37 \mathrm{~J} \\
20.86 \\
19.47 \\
16.29 \\
19.51\end{array}$ \\
\hline $\begin{array}{l}R-0 S \\
R-O S \\
R-O S \\
R-O S \\
R-O S\end{array}$ & $\begin{array}{l}1 \\
2 \\
3 \\
4 \\
5\end{array}$ & $\begin{array}{l}B \\
D \\
B \\
D \\
C\end{array}$ & $\begin{array}{r}20.42 \\
8.24 \\
10.60 \\
10.66 \\
11.65\end{array}$ & $\begin{array}{r}14.06 \\
5.72 \\
6.94 \\
8.27 \\
8.38\end{array}$ & $\begin{array}{l}3.06 \mathrm{~J} \\
7.82 \mathrm{~J} \\
2.58 \mathrm{~J} \\
1.10 \mathrm{~J} \\
4.76 \mathrm{~J}\end{array}$ & $\begin{array}{l}8.18 \\
3.91 \mathrm{~J} \\
5.57 \\
3.54 \mathrm{~J} \\
4.73 \mathrm{~J}\end{array}$ & $\begin{array}{l}3.64 \mathrm{~J} \\
7.98 \mathrm{U} \\
3.43 \mathrm{~J} \\
4.65 \mathrm{~J} \\
2.37 \mathrm{~J}\end{array}$ & $\begin{array}{l}1.60 \mathrm{~J} \\
6.65 \mathrm{U} \\
1.67 \mathrm{~J} \\
6.30 \mathrm{U} \\
2.10 \mathrm{~J}\end{array}$ & $\begin{array}{l}1.79 \mathrm{~J} \\
6.94 \mathrm{U} \\
1.80 \mathrm{~J} \\
6.57 \mathrm{U} \\
1.48 \mathrm{~J}\end{array}$ & $\begin{array}{l}1.38 \mathrm{~J} \\
9.33 \mathrm{U} \\
1.23 \mathrm{~J} \\
7.90 \mathrm{U} \\
7.60 \mathrm{U}\end{array}$ & $\begin{array}{l}5.53 \mathrm{U} \\
5.67 \mathrm{U} \\
5.70 \mathrm{U} \\
5.37 \mathrm{U} \\
5.17 \mathrm{U}\end{array}$ & $\begin{array}{r}2.23 \mathrm{~J} \\
11.30 \mathrm{U} \\
1.74 \mathrm{~J} \\
10.71 \mathrm{U} \\
10.31 \mathrm{U}\end{array}$ \\
\hline $\begin{array}{l}\text { R-PF } \\
\text { R-PF } \\
\text { R-PF Replicate } \\
\text { R-PF Replicate } \\
\text { R-PF Replicate } \\
\text { R-PF } \\
\text { R-PF }\end{array}$ & $\begin{array}{l}1 \\
2 \\
3 \\
3 \\
3 \\
4 \\
5\end{array}$ & $\begin{array}{l}C \\
C \\
0 \\
0 \\
D \\
D \\
A\end{array}$ & $\begin{array}{r}8.70 \\
8.24 \\
10.38 \\
9.39 \\
8.12 \\
8.99 \\
13.83\end{array}$ & $\begin{array}{l}7.29 \\
7.73 \\
8.91 \mathrm{~J} \\
8.22 \mathrm{~J} \\
7.48 \mathrm{~J} \\
6.61 \mathrm{~J} \\
8.28\end{array}$ & $\begin{array}{r}1.02 \mathrm{~J} \\
8.11 \mathrm{U} \\
13.19 \mathrm{U} \\
12.84 \mathrm{U} \\
13.16 \mathrm{U} \\
9.76 \mathrm{U} \\
2.80 \mathrm{~J}\end{array}$ & $\begin{array}{l}2.49 \mathrm{~J} \\
2.43 \mathrm{~J} \\
4.68 \mathrm{~J} \\
3.35 \mathrm{~J} \\
3.00 \mathrm{~J} \\
3.38 \mathrm{~J} \\
7.15\end{array}$ & $\begin{array}{r}3.89 \mathrm{~J} \\
8.28 \mathrm{U} \\
13.47 \mathrm{U} \\
13.11 \mathrm{U} \\
13.43 \mathrm{U} \\
4.43 \mathrm{~J} \\
4.89 \mathrm{~J}\end{array}$ & $\begin{array}{r}2.22 \mathrm{~J} \\
6.90 \mathrm{U} \\
11.22 \mathrm{U} \\
10.93 \mathrm{U} \\
11.20 \mathrm{U} \\
8.30 \mathrm{U} \\
2.21 \mathrm{~J}\end{array}$ & $\begin{array}{r}7.50 \mathrm{U} \\
7.19 \mathrm{U} \\
11.70 \mathrm{U} \\
11.39 \mathrm{U} \\
11.67 \mathrm{U} \\
1.20 \mathrm{~J} \\
2.06 \mathrm{~J}\end{array}$ & $\begin{array}{r}9.01 \mathrm{U} \\
8.64 \mathrm{U} \\
14.06 \mathrm{U} \\
13.68 \mathrm{U} \\
14.02 \mathrm{U} \\
10.40 \mathrm{U} \\
8.10 \mathrm{U}\end{array}$ & $\begin{array}{l}6.13 \mathrm{U} \\
5.8 B \mathrm{U} \\
9.56 \mathrm{U} \\
9.31 \mathrm{U} \\
9.54 \mathrm{U} \\
7.07 \mathrm{U} \\
5.51 \mathrm{U}\end{array}$ & $\begin{array}{l}12.22 \\
11.72 \mathrm{U} \\
19.06 \mathrm{U} \\
18.55 \\
19.02 \\
14.10 \mathrm{U} \\
10.98 \mathrm{U}\end{array}$ \\
\hline
\end{tabular}


JABLE J.3. (contd)

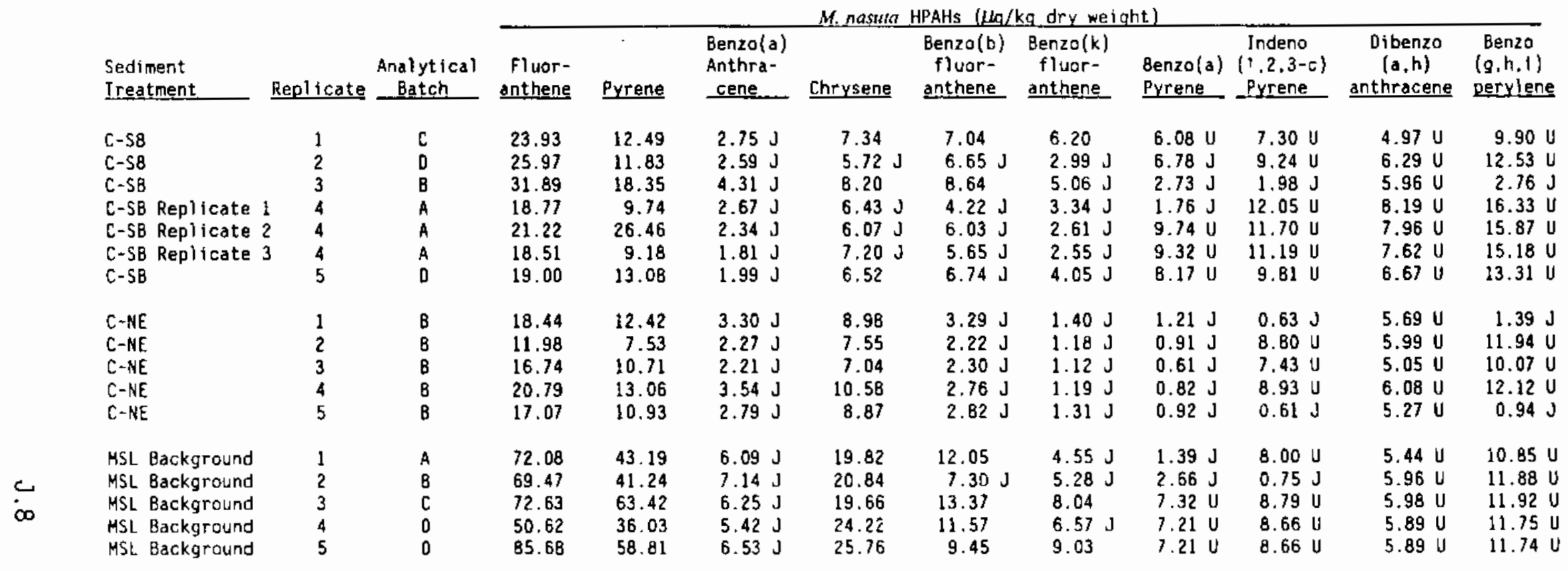

(a) J Analyte detected below methad detection 1 imit (MDL), but above instrument detection limit (IOL).

(b) $U$ The analyte was not present above the level of the assoctated value. 
IABLE J.4. Total Polynuclear Aromatic Hydrocarbons (PAHs), Wet Weight, in Tissue of M. nasuta, Richmond Harbor Program

\begin{tabular}{|c|c|c|c|c|c|c|}
\hline $\begin{array}{l}\text { Sediment } \\
\text { Ireatment }\end{array}$ & Replicate & $\begin{array}{c}\text { Analytical } \\
\text { Batch }\end{array}$ & $\begin{array}{l}\text { Percent } \\
\text { Ory Height }\end{array}$ & $\begin{array}{c}\text { Holecular } \\
\text { Height PAHs }\end{array}$ & $\begin{array}{l}\text { Molecular } \\
\text { Weight PAHs }\end{array}$ & $\begin{array}{r}\text { Total } \\
\text { PAHs } \\
\end{array}$ \\
\hline COMP I & 1 & D & 10.85 & 3.12 & 17.06 & 20.19 \\
\hline comp 1 & 2 & D & 12.31 & 4.38 & 25.29 & 29.67 \\
\hline COMP I & 3 & A & 12.58 & 5.26 & 22.46 & 27.72 \\
\hline COHP I & 4 & B & 10.95 & 4.12 & 23.83 & 27.94 \\
\hline COMP I & 5 & A & 12.42 & 5.75 & 27.12 & 32.87 \\
\hline cомp II & 1 & D & 9.87 & 2.01 & 10.91 & 12.93 \\
\hline COMP II & 2 & A & 11.86 & 4.99 & 23.43 & 28.41 \\
\hline СОНP II & 3 & c & 12.66 & 4.85 & 15.21 & 20.06 \\
\hline СОнР II & 4 & 0 & 10.52 & 2.41 & $-\quad 15.55$ & 17.95 \\
\hline СОНP II & 5 & $c$ & 10.91 & 4.74 & 18.40 & 23.14 \\
\hline COHP III & 1 & C & 10.74 & 2.79 & 1.88 & 4.67 \\
\hline COMP III & 2 & C & 12.02 & 3.30 & 5.11 & 8.41 \\
\hline COMP III & 3 & A & 11.73 & 4.25 & 6.71 & 10.96 \\
\hline COMP III & 4 & D & 11.69 & 2.49 & 6.10 & 8.58 \\
\hline COMP III & 5 & C & 12.22 & 2.90 & 4.14 & 7.04 \\
\hline TC-5 Upper Comp & 1 & c & 11.76 & 8.31 & 112.52 & 120.83 \\
\hline TC-5 Uррег Сотр & 2 & C & 11.72 & 6.85 & 98.86 & 105.71 \\
\hline TC-5 Upper Comp & 3 & $\mathrm{C}$ & 11.42 & 8.26 & 98.53 & 106.79 \\
\hline TC-5 Upper Comp & 4 & A & 12.42 & 8.62 & 82.62 & 91.23 \\
\hline TC-5 Upper Comp & 5 & A & 10.78 & 5.68 & 66.71 & 72.38 \\
\hline COMP IV & 1 & $\mathrm{C}$ & 9.62 & 3.11 & 1.80 & 4.91 \\
\hline Comp IV & 2 & C & 11.93 & 2.84 & 1.50 & 4.33 \\
\hline COMP IV & 3 & A & 13.03 & 3.80 & 4.22 & 8.02 \\
\hline COMP IV & 4 & c & 13.34 & 4.06 & 1.68 & 5.74 \\
\hline COMP IV & 5 & A & 12.31 & 4.76 & 3.65 & 8.41 \\
\hline $\operatorname{comp} V$ & 1 & $A$ & 11.44 & 4.12 & 42.23 & 46.35 \\
\hline COHP V & 2 & A & 13.28 & 7.39 & 57.81 & 65.20 \\
\hline $\operatorname{comp~V}$ & 3 & $A$ & 13.30 & 6.57 & 65.33 & 71.90 \\
\hline comp $v$ & 4 & $D$ & 10.90 & 2.93 & 30.66 & 33.59 \\
\hline COMP $V$ Replicate 1 & 5 & B & 12.39 & 9.15 & 50.11 & 59.26 \\
\hline comp $V$ Replicate 2 & 5 & 8 & 12.39 & 6.94 & 51.46 & 58.40 \\
\hline Comp V Replicate 3 & 5 & 8 & 12.39 & 4.26 & 49.22 & 53.48 \\
\hline СонP VI & 1 & C & 10.47 & 4.31 & 30.15 & 34.47 \\
\hline СОНP VI & 2 & A & 11.02 & 4.83 & 44.94 & 49.77 \\
\hline COMP VI & 3 & $\mathrm{~B}$ & 12.94 & 8.55 & 63.14 & 71.69 \\
\hline COMP VI & 4 & $A$ & 10.78 & 6.09 & 42.43 & 48.52 \\
\hline COMP VI & 5 & D & 9.48 & 1.12 & 30.96 & 32.08 \\
\hline $\mathrm{R}-\mathrm{AC}$ & 1 & 8 & 12.41 & 23.49 & 617.87 & 641.36 \\
\hline $\mathrm{R}-\mathrm{AC}$ & 2 & $\mathrm{C}$ & 10.54 & 15.97 & 335.11 & 351.08 \\
\hline$R-A C$ & 3 & $\mathrm{C}$ & 11.77 & 29.03 & 814.85 & 843.89 \\
\hline$R-A C$ & 4 & $A$ & 11.56 & 22.24 & 687.94 & 710.18 \\
\hline$R-A C$ & 5 & D & 11.02 & 21.16 & 669.63 & 690.79 \\
\hline$R-A M$ & 1 & $B$ & 10.05 & 4.54 & 63.36 & 67.90 \\
\hline R-AM Replicate 1 & 2 & $C$ & 10.33 & 7.02 & 68.87 & 75.90 \\
\hline R-AM Replicate 2 & 2 & C & 10.33 & 7.96 & 77.23 & 85.19 \\
\hline R-AM Replicate 3 & 2 & $\mathrm{C}$ & 10.33 & 7.80 & 73.54 & 81.34 \\
\hline$R-A M$ & 3 & $\mathrm{~B}$ & 12.31 & 13.34 & 197.00 & 210.34 \\
\hline$R-A M$ & 4 & $B$ & 12.40 & 14.37 & 233.68 & 248.06 \\
\hline
\end{tabular}




\section{IABLE J.4. (contd)}

\begin{tabular}{|c|c|c|c|c|c|c|}
\hline \multirow[b]{2}{*}{$\begin{array}{l}\text { Sediment } \\
\text { Ireatment }\end{array}$} & \multirow[b]{2}{*}{ Replicate } & \multirow[b]{2}{*}{$\begin{array}{l}\text { Analytical } \\
\text { Batch }\end{array}$} & \multirow[b]{2}{*}{$\begin{array}{c}\text { Percent } \\
\text { Dry Veight }\end{array}$} & \multicolumn{3}{|c|}{$M$. nasura PAHs $(\mu \mathrm{g} / \mathrm{kg}$ wet weight $)$} \\
\hline & & & & $\begin{array}{l}\text { Total Low } \\
\text { Molecular } \\
\text { Yeight PAHs }\end{array}$ & $\begin{array}{l}\text { Total High } \\
\text { Molecular } \\
\text { Yeight PaHs }\end{array}$ & $\begin{array}{r}\text { Total } \\
\text { PAHS } \\
\end{array}$ \\
\hline R-AM & 5 & 8 & 10.44 & 12.73 & 138.58 & 151.31 \\
\hline$R-B F$ & 1 & 0 & 11.13 & 3.15 & 16.05 & 19.20 \\
\hline $\mathrm{R}-\mathrm{BF}$ & 2 & B & 13.42 & 5.04 & 38.37 & 43.41 \\
\hline $\mathrm{R}-\mathrm{BF}$ & 3 & B & 12.07 & 5.37 & 29.99 & 35.38 \\
\hline $\mathrm{R}-\mathrm{BF}$ & 4 & A & 10.12 & 4.50 & 24.07 & 28.57 \\
\hline$R-E F$ & 5 & A & 12.83 & 5.38 & 28.47 & 33.85 \\
\hline$R \operatorname{OS}$ & 1 & B & 12.06 & 4.15 & 6.80 & 10.95 \\
\hline$R-O S$ & 2 & 0 & 11.53 & 1.66 & 2.06 & 3.72 \\
\hline$R-O S$ & 3 & B & 11.56 & 4.67 & 4.11 & 8.78 \\
\hline$R-O S$ & 4 & 0 & 12.33 & 2.90 & 3.48 & 6.36 \\
\hline$R=0 S$ & 5 & c & 12.74 & 5.20 & 4.52 & 9.71 \\
\hline$R-P F$ & 1 & c & 10.78 & 3.94 & 2.76 & 6.70 \\
\hline$R-P F$ & 2 & c & 11.26 & 3.45 & 2.07 & 5.53 \\
\hline R-PF Replicate 1 & 3 & 0 & 10.40 & 3.01 & 2.49 & 5.51 \\
\hline R-PF Replicate 2 & 3 & 0 & 10.40 & 2.51 & 2.18 & 4.69 \\
\hline R-PF Replicate 3 & 3 & 0 & 10.40 & 2.85 & 1.94 & 4.78 \\
\hline R-PF & 4 & 0 & 9.33 & 2,12 & 2.30 & 4.42 \\
\hline R-PF & 5 & A & 12.22 & 4.70 & 5.04 & 9.74 \\
\hline $\mathrm{C}-\mathrm{SB}$ & 1 & c & 12.45 & 3.70 & 7.44 & 11.14 \\
\hline $\mathrm{C}-\mathrm{SB}$ & 2 & 0 & 10.40 & 3.25 & 6.50 & 9.75 \\
\hline $\mathrm{C}-\mathrm{SB}$ & 3 & $B$ & 10.96 & 2.09 & 9.20 & 11.29 \\
\hline C-SB Replicate 1 & 4 & A & 11.33 & 3.99 & 5.32 & 9.31 \\
\hline C-SB Replicate 2 & 4 & A & 11.33 & 4.38 & 7.34 & 11.72 \\
\hline C-SB Replicate 3 & 4 & A & 11.33 & 3.79 & 5.09 & 8.88 \\
\hline$C-S B$ & 5 & 0 & 9.85 & 2.20 & 5.06 & 7.26 \\
\hline C-NE & 1 & $B$ & 11.64 & 5.93 & 5.94 & 11.88 \\
\hline C-KE & 2 & B & 10.40 & 3.39 & 3.50 & 6.89 \\
\hline $\mathrm{C}-\mathrm{NE}$ & 3 & B & 13.08 & 3.25 & 5.33 & B. 57) \\
\hline$C-N E$ & 4 & $B$ & 10.83 & 4.00 & 5.71 & 9.71 \\
\hline$C-N E$ & 5 & B & 12.59 & 45.25 & 58.10 & 203.35 \\
\hline MSL Background & 1 & A & 12.16 & 5.88 & 19.36 & 25.24 \\
\hline SSL Background & 2 & B & 10.85 & 2.81 & 16.78 & 19.58 \\
\hline HSL Background & 3 & c & 10.94 & 3.51 & 20.05 & 23.56 \\
\hline MSL Background & 4 & D & 11.08 & 3.47 & 14.89 & 18.36 \\
\hline MSL Background & 5 & 0 & 11.18 & 2.42 & 21.82 & 24.24 \\
\hline
\end{tabular}


TABLE J.5. Low Molecular Weight Polynuclear Aromatic Hydrocarbons (LPAHs), Wet Weight, in Tissue of M. nasuta, Richmond Harbor Program

\begin{tabular}{|c|c|c|c|c|c|c|c|c|c|c|}
\hline \multirow[b]{2}{*}{$\begin{array}{l}\text { Sediment } \\
\text { Ireatment }\end{array}$} & \multirow[b]{2}{*}{ Replicate } & \multirow[b]{2}{*}{$\begin{array}{l}\text { Analytical } \\
\text { Batch } \\
\end{array}$} & \multirow[b]{2}{*}{$\begin{array}{l}\text { Percent } \\
\text { Dry Weiqht }\end{array}$} & \multicolumn{7}{|c|}{ M. nasseg LPAHs $(\mu \mathrm{g} / \mathrm{kg}$ wet weight) } \\
\hline & & & & $\begin{array}{l}\text { Naphtha- } \\
\text { lene } \\
\end{array}$ & $\begin{array}{l}\text { Acenap } \\
\text { thylen } \\
\end{array}$ & ph- & $\begin{array}{l}\text { Acenaph- } \\
\text { thene }\end{array}$ & Fluorene & $\begin{array}{l}\text { Phenan- } \\
\text { threne }\end{array}$ & $\begin{array}{l}\text { Anthra- } \\
\text { cene } \\
\end{array}$ \\
\hline $\begin{array}{l}\text { Target } D(a) \\
\text { Achieved DL High } \\
\text { Achieved DL Low }\end{array}$ & & & & $\underset{N A}{20.0}(b)$ & $\begin{array}{l}20.0 \\
1.86 \\
1.15\end{array}$ & & $\begin{array}{l}20.0 \\
1.34 \\
0.64\end{array}$ & $\begin{array}{l}20.0 \\
1.05 \\
0.69\end{array}$ & $\begin{array}{r}20.0 \\
\text { NA } \\
\text { HA }\end{array}$ & $\begin{array}{l}20.0 \\
1.09 \\
0.54\end{array}$ \\
\hline $\begin{array}{l}\text { COMP I } \\
\text { COMP I } \\
\text { COMP I } \\
\text { COHP I } \\
\text { COHP I }\end{array}$ & $\begin{array}{l}1 \\
2 \\
3 \\
4 \\
5\end{array}$ & $\begin{array}{l}0 \\
0 \\
A \\
B \\
A\end{array}$ & $\begin{array}{l}10.85 \\
12.31 \\
12.58 \\
10.95 \\
12.42\end{array}$ & $\begin{array}{l}0.89 \mathrm{j}^{(\mathrm{c})} \\
1.08 \mathrm{~J} \\
2.28 \\
1.22 \mathrm{~J} \\
2.44\end{array}$ & $\begin{array}{l}1.24 \\
1.24 \\
1.24 \\
0.05 \\
1.48\end{array}$ & $\begin{array}{l}u^{(d)} \\
u \\
u \\
J \\
u\end{array}$ & $\begin{array}{ll}0.29 & \mathrm{~J} \\
0.67 & \mathrm{U} \\
0.67 & \mathrm{U} \\
0.28 \mathrm{~J} & \mathrm{~J} \\
0.80 & \mathrm{U}\end{array}$ & $\begin{array}{l}0.51 \mathrm{~J} \\
0.74 \\
0.72 \mathrm{~J} \\
0.37 \mathrm{~J} \\
0.73 \mathrm{~J}\end{array}$ & $\begin{array}{l}1.19 \\
2.22 \\
1.81 \\
1.75 \\
1.99\end{array}$ & $\begin{array}{l}0.26 \mathrm{~J} \\
0.35 \mathrm{~J} \\
0.46 \mathrm{~J} \\
0.45 \mathrm{~J} \\
0.59 \mathrm{~J}\end{array}$ \\
\hline $\begin{array}{l}\text { СОНP II } \\
\text { СOMP II } \\
\text { COMP II } \\
\text { СОMP II } \\
\text { СОMP II }\end{array}$ & $\begin{array}{l}1 \\
2 \\
3 \\
4 \\
5\end{array}$ & $\begin{array}{l}0 \\
A \\
C \\
0 \\
C\end{array}$ & $\begin{array}{r}9.87 \\
11.86 \\
12.66 \\
10.52 \\
10.91\end{array}$ & $\begin{array}{l}0.94 \mathrm{~J} \\
1.78 \\
1.71 \\
0.83 \mathrm{~J} \\
1.92\end{array}$ & $\begin{array}{l}1.18 \\
1.24 \\
1.24 \\
1.24 \\
1.17\end{array}$ & $\begin{array}{l}\mathrm{U} \\
\mathrm{U} \\
\mathrm{U} \\
\mathrm{U} \\
\mathrm{U}\end{array}$ & $\begin{array}{ll}0.64 & \mathrm{~J} \\
0.45 & \mathrm{~J} \\
0.49 & \mathrm{~J} \\
0.67 & \mathrm{U} \\
0.38 \mathrm{~J}\end{array}$ & $\begin{array}{ll}0.69 & \mathrm{U} \\
0.67 & \mathrm{~J} \\
0.71 \mathrm{~J} & \mathrm{~J} \\
0.72 \mathrm{U} \\
0.63 & \mathrm{~J}\end{array}$ & $\begin{array}{l}0.89 \\
1.74 \\
1.67 \\
1.28 \\
1.54\end{array}$ & $\begin{array}{ll}0.18 & \mathrm{~J} \\
0.34 & \mathrm{~J} \\
0.28 & \mathrm{~J} \\
0.29 \mathrm{~J} \\
0.27 \mathrm{~J}\end{array}$ \\
\hline $\begin{array}{l}\text { СOHP III } \\
\text { COMP III } \\
\text { COHP III } \\
\text { COMP III } \\
\text { COMP III }\end{array}$ & $\begin{array}{l}1 \\
2 \\
3 \\
4 \\
5\end{array}$ & $\begin{array}{l}C \\
C \\
A \\
D \\
C\end{array}$ & $\begin{array}{l}10.74 \\
12.02 \\
11.73 \\
11.69 \\
12.22\end{array}$ & $\begin{array}{l}1.30 \\
1.52 \\
1.64 \\
0.97 \mathrm{~J} \\
1.23 \mathrm{~J}\end{array}$ & $\begin{array}{l}1.23 \\
1.23 \\
1.24 \\
1.24 \\
1.22\end{array}$ & $\begin{array}{l}U \\
U \\
U \\
U \\
U\end{array}$ & $\begin{array}{ll}0.67 & \mathrm{U} \\
0.66 & \mathrm{U} \\
0.32 & \mathrm{~J} \\
0.67 & \mathrm{U} \\
0.18 & \mathrm{~J}\end{array}$ & $\begin{array}{l}0.45 \mathrm{~J} \\
0.48 \mathrm{~J} \\
0.71 \mathrm{~J} \\
0.31 \mathrm{~J} \\
0.50 \mathrm{~J}\end{array}$ & $\begin{array}{l}1.05 \\
1.30 \\
1.45 \\
1.21 \\
0.91\end{array}$ & $\begin{array}{l}0.54 \mathrm{U} \\
0.54 \mathrm{U} \\
0.13 \mathrm{~J} \\
0.55 \mathrm{U} \\
0.08 \mathrm{~J}\end{array}$ \\
\hline $\begin{array}{l}\text { TC-5 Upper Comp } \\
\text { TC-5 Upper Comp } \\
\text { TC-5 Upper Comp } \\
\text { TC-5 Upper Comp } \\
\text { TC-5 Upper Comp }\end{array}$ & $\begin{array}{l}1 \\
2 \\
3 \\
4 \\
5\end{array}$ & $\begin{array}{l}\text { C } \\
\text { C } \\
\text { C } \\
\text { A } \\
\text { A }\end{array}$ & $\begin{array}{l}11.76 \\
11.72 \\
11.42 \\
12.42 \\
10.78\end{array}$ & $\begin{array}{l}2.70 \\
2.12 \\
2.51 \\
3.17 \\
1.76\end{array}$ & $\begin{array}{l}1.23 \\
1.21 \\
1.24 \\
1.33 \\
1.24\end{array}$ & $\begin{array}{l}u \\
U \\
u \\
U \\
u\end{array}$ & $\begin{array}{l}0.66 \mathrm{~J} \\
0.37 \mathrm{~J} \\
0.67 \mathrm{U} \\
0.28 \mathrm{~J} \\
0.67 \mathrm{U}\end{array}$ & $\begin{array}{l}0.84 \\
0.59 \mathrm{~J} \\
0.96 \\
0.61 \mathrm{~J} \\
0.79\end{array}$ & $\begin{array}{l}3.82 \\
3.15 \\
4.02 \\
2.64 \\
2.54\end{array}$ & $\begin{array}{l}0.98 \\
0.62 \\
0.78 \\
0.59 \\
0.59\end{array}$ \\
\hline $\begin{array}{l}\text { COHP IV } \\
\text { COHP IV } \\
\text { COHP IV } \\
\text { COHP IV } \\
\text { COMP IV }\end{array}$ & $\begin{array}{l}1 \\
2 \\
3 \\
4 \\
5\end{array}$ & $\begin{array}{l}\text { C } \\
\text { C } \\
\text { A } \\
\text { C } \\
\text { A }\end{array}$ & $\begin{array}{r}9.62 \\
11.93 \\
13.03 \\
13.34 \\
12.31\end{array}$ & $\begin{array}{l}1.42 \\
1.33 \\
1.47 \\
2.14 \mathrm{~J} \\
2.04\end{array}$ & $\begin{array}{l}1.24 \\
1.23 \\
1.20 \\
2.47 \\
1.23\end{array}$ & $\begin{array}{l}U \\
U \\
U \\
U \\
U\end{array}$ & $\begin{array}{l}0.20 \mathrm{~J} \\
0.67 \mathrm{U} \\
0.32 \mathrm{~J} \\
1.34 \mathrm{U} \\
0.67 \mathrm{~J}\end{array}$ & $\begin{array}{l}0.42 \mathrm{~J} \\
0.49 \mathrm{~J} \\
0.58 \mathrm{~J} \\
0.63 \mathrm{~J} \\
0.75\end{array}$ & $\begin{array}{l}1.06 \\
1.01 \\
1.31 \\
1.30 \\
1.30\end{array}$ & $\begin{array}{l}0.55 \mathrm{U} \\
0.54 \mathrm{U} \\
0.12 \mathrm{~J} \\
\mathrm{I} .09 \mathrm{U} \\
0.55 \mathrm{U}\end{array}$ \\
\hline $\begin{array}{l}\text { COMP V } \\
\text { COMP V } \\
\text { COMP V } \\
\text { COMP V } \\
\text { COMP V Replicate } 1 \\
\text { COMP V Replicate } 2 \\
\text { COMP V Replicate } 3\end{array}$ & $\begin{array}{l}1 \\
2 \\
3 \\
4 \\
5 \\
5 \\
5\end{array}$ & $\begin{array}{l}A \\
A \\
A \\
D \\
B \\
B \\
B\end{array}$ & $\begin{array}{l}11.44 \\
13.28 \\
13.30 \\
10.90 \\
12.39 \\
12.39 \\
12.39\end{array}$ & $\begin{array}{l}1.28 \\
2.92 \\
1.92 \\
0.93 \mathrm{~J} \\
4.01 \\
2.48 \mathrm{~J} \\
1.01 \mathrm{~J}\end{array}$ & $\begin{array}{l}1.24 \\
1.44 \\
1.24 \\
1.23 \\
0.12 \\
0.12 \\
0.11\end{array}$ & $\begin{array}{l}U \\
U \\
U \\
U \\
J \\
J \\
J\end{array}$ & $\begin{array}{l}0.67 \mathrm{~J} \\
0.38 \mathrm{~J} \\
0.48 \mathrm{~J} \\
0.17 \mathrm{~J} \\
0.46 \mathrm{~J} \\
0.43 \mathrm{~J} \\
0.37 \mathrm{~J}\end{array}$ & $\begin{array}{l}0.55 \mathrm{~J} \\
0.82 \mathrm{~J} \\
0.77 \\
0.42 \mathrm{~J} \\
1.14 \mathrm{~J} \\
0.85 \mathrm{~J} \\
0.46 \mathrm{~J}\end{array}$ & $\begin{array}{l}1.72 \\
2.59 \\
2.53 \\
1.17 \\
2.67 \\
2.37 \\
1.72\end{array}$ & $\begin{array}{l}0.56 \\
0.67 \\
0.86 \\
0.25 \mathrm{~J} \\
0.77 \mathrm{~J} \\
0.68 \mathrm{~J} \\
0.59 \mathrm{~J}\end{array}$ \\
\hline $\begin{array}{l}\text { COHP VI } \\
\text { COHP VI } \\
\text { COMP VI } \\
\text { COMP VI } \\
\text { COHP VI }\end{array}$ & $\begin{array}{l}1 \\
2 \\
3 \\
4 \\
5\end{array}$ & $\begin{array}{l}C \\
A \\
B \\
A \\
D\end{array}$ & $\begin{array}{r}10.47 \\
11.02 \\
12.94 \\
10.78 \\
9.48\end{array}$ & $\begin{array}{l}2.24 \\
1.85 \\
3.65 \mathrm{~J} \\
2.79 \\
1.25 \mathrm{U}\end{array}$ & $\begin{array}{l}1.23 \\
1.24 \\
0.16 \\
1.24 \\
1.23\end{array}$ & $\begin{array}{l}U \\
U \\
J \\
U \\
U\end{array}$ & $\begin{array}{l}0.14 \mathrm{~J} \\
0.67 \mathrm{U} \\
0.38 \mathrm{~J} \\
0.67 \mathrm{U} \\
0.67 \mathrm{U}\end{array}$ & $\begin{array}{ll}0.41 & \mathrm{~J} \\
0.63 \mathrm{~J} & \mathrm{~J} \\
0.79 & \mathrm{~J} \\
0.68 \mathrm{~J} & \mathrm{~J} \\
0.72 \mathrm{~J}\end{array}$ & $\begin{array}{l}1.19 \\
1.78 \\
2.77 \\
2.07 \\
1.12\end{array}$ & $\begin{array}{l}0.34 \mathrm{~J} \\
0.57 \\
0.80 \mathrm{~J} \\
0.55 \mathrm{H} \\
0.54 \mathrm{H}\end{array}$ \\
\hline $\begin{array}{l}R-A C \\
R-A C \\
R-A C \\
R-A C \\
R-A C\end{array}$ & $\begin{array}{l}1 \\
2 \\
3 \\
4 \\
5\end{array}$ & $\begin{array}{l}B \\
C \\
C \\
A \\
D\end{array}$ & $\begin{array}{l}12.41 \\
10.54 \\
11.77 \\
11.56 \\
11.02\end{array}$ & $\begin{array}{l}0.74 \mathrm{~J} \\
1.86 \\
2.47 \\
2.54 \\
1.21 \mathrm{~J}\end{array}$ & $\begin{array}{l}0.21 \\
1.24 \\
0.25 \\
1.24 \\
1.24\end{array}$ & $\begin{array}{l}J \\
U \\
J \\
U \\
U\end{array}$ & $\begin{array}{l}1.23 \\
0.62 \mathrm{~J} \\
1.38 \\
1.03 \\
0.91\end{array}$ & $\begin{array}{l}1.27 \\
1.09 \\
1.64 \\
1.42 \\
1.29\end{array}$ & $\begin{array}{r}14.41 \\
9.25 \\
16.17 \\
11.85 \\
12.79\end{array}$ & $\begin{array}{l}5.62 \\
3.15 \\
7.13 \\
5.40 \\
4.97\end{array}$ \\
\hline
\end{tabular}


IABLE J.5. (contd)

\begin{tabular}{|c|c|c|c|c|c|c|c|c|c|}
\hline \multirow[b]{2}{*}{$\begin{array}{l}\text { Sediment } \\
\text { Ireatment }\end{array}$} & \multirow[b]{2}{*}{ Replicate } & \multirow[b]{2}{*}{$\begin{array}{l}\text { Analytical } \\
\text { Batch } \\
\end{array}$} & \multirow[b]{2}{*}{$\begin{array}{l}\text { Percent } \\
\text { Dry Weight }\end{array}$} & \multicolumn{6}{|c|}{ M. Masuta LPAHs $(\mathrm{kg} / \mathrm{kq}$ wet weight) } \\
\hline & & & & $\begin{array}{l}\text { Haphtha- } \\
\text { lene } \\
\end{array}$ & $\begin{array}{l}\text { Acenaph- } \\
\text { thylene }\end{array}$ & $\begin{array}{l}\text { Acenaph- } \\
\text { thene }\end{array}$ & Fluorene & $\begin{array}{l}\text { Phenan- } \\
\text { threne }\end{array}$ & $\begin{array}{l}\text { Anthra- } \\
\text { cene }\end{array}$ \\
\hline $\begin{array}{l}R-A H \\
R-A M \text { Replicate } 1 \\
R-A M \text { Replicate } 2 \\
R-A H \text { Replicate } 3 \\
R-A M \\
R-A M \\
R-A M\end{array}$ & $\begin{array}{l}1 \\
2 \\
2 \\
2 \\
3 \\
4 \\
5\end{array}$ & $\begin{array}{l}B \\
C \\
C \\
C \\
8 \\
B \\
B\end{array}$ & $\begin{array}{l}10.05 \\
10.33 \\
10.33 \\
10.33 \\
12.31 \\
12.40 \\
10.44\end{array}$ & $\begin{array}{l}0.67 \mathrm{~J} \\
1.67 \mathrm{~J} \\
2.43 \\
2.07 \\
1.76 \\
3.53 \\
0.88 \mathrm{~J}\end{array}$ & $\begin{array}{l}0.11 \mathrm{~J} \\
1.84 \mathrm{U} \\
1.86 \mathrm{U} \\
1.78 \mathrm{U} \\
0.46 \mathrm{~J} \\
0.48 \mathrm{~J} \\
0.55 \mathrm{~J}\end{array}$ & $\begin{array}{l}0.18 \mathrm{~J} \\
0.41 \mathrm{~J} \\
1.01 \mathrm{~J} \\
0.44 \mathrm{~J} \\
0.44 \mathrm{~J} \\
0.43 \mathrm{~J} \\
0.46 \mathrm{~J}\end{array}$ & $\begin{array}{l}0.36 \mathrm{~J} \\
0.76 \mathrm{~J} \\
0.88 \mathrm{~J} \\
0.79 \mathrm{~J} \\
0.97 \\
1.12 \mathrm{~J} \\
0.83\end{array}$ & $\begin{array}{l}2.29 \\
3.24 \\
3.50 \\
3.36 \\
6.72 \\
6.41 \\
7.15\end{array}$ & $\begin{array}{l}0.92 \\
0.94 \\
1.15 \\
1.13 \\
3.00 \\
2.41 \\
2.86\end{array}$ \\
\hline $\begin{array}{l}R-B F \\
R-B F \\
R-B F \\
R-B F \\
R-B F\end{array}$ & $\begin{array}{l}1 \\
2 \\
3 \\
4 \\
5\end{array}$ & $\begin{array}{l}0 \\
B \\
\text { B } \\
\text { A } \\
\text { A }\end{array}$ & $\begin{array}{l}11.13 \\
13.42 \\
12.07 \\
10.12 \\
12.83\end{array}$ & $\begin{array}{l}1.30 \mathrm{~J} \\
1.57 \\
1.94 \\
2.10 \\
2.35\end{array}$ & $\begin{array}{l}1.45 \mathrm{U} \\
0.07 \mathrm{~J} \\
0.07 \mathrm{~J} \\
1.23 \mathrm{U} \\
1.20 \mathrm{U}\end{array}$ & $\begin{array}{l}0.79 \mathrm{U} \\
0.28 \mathrm{~J} \\
0.27 \mathrm{~J} \\
0.66 \mathrm{U} \\
0.65 \mathrm{U}\end{array}$ & $\begin{array}{l}0.43 \mathrm{~J} \\
0.58 \mathrm{~J} \\
0.65 \mathrm{~J} \\
0.68 \mathrm{~J} \\
0.72\end{array}$ & $\begin{array}{l}1.22 \\
1.98 \\
1.97 \\
1.35 \\
1.89\end{array}$ & $\begin{array}{l}0.20 \\
0.56 \\
0.48 \\
0.38 \\
0.42\end{array}$ \\
\hline $\begin{array}{l}R-O S \\
R-O S \\
R-O S \\
R-O S \\
R-O S\end{array}$ & $\begin{array}{l}1 \\
2 \\
3 \\
4 \\
5\end{array}$ & $\begin{array}{l}B \\
D \\
B \\
0 \\
C\end{array}$ & $\begin{array}{l}12.06 \\
11.53 \\
11.56 \\
12.33 \\
12.74\end{array}$ & $\begin{array}{l}1.60 \\
0.64 \mathrm{~J} \\
2.14 \\
0.86 \mathrm{~J} \\
2.28\end{array}$ & $\begin{array}{l}0.05 \mathrm{~J} \\
1.22 \mathrm{U} \\
1.23 \mathrm{U} \\
1.24 \mathrm{U} \\
1.23 \mathrm{U}\end{array}$ & $\begin{array}{l}0.26 \mathrm{~J} \\
0.66 \mathrm{~J} \\
0.24 \mathrm{~J} \\
0.48 \mathrm{~J} \\
0.70\end{array}$ & $\begin{array}{l}0.57 \mathrm{~J} \\
0.71 \mathrm{U} \\
0.63 \mathrm{~J} \\
0.51 \mathrm{~J} \\
0.61 \mathrm{~J}\end{array}$ & $\begin{array}{l}1.50 \\
1.02 \\
1.50 \\
1.05 \\
1.49\end{array}$ & $\begin{array}{l}0.18 \mathrm{~J} \\
0.54 \\
0.17 \mathrm{~J} \\
0.55 \mathrm{I} \\
0.12 \mathrm{~J}\end{array}$ \\
\hline $\begin{array}{l}\text { R-PF } \\
\text { R-PF } \\
\text { R-PF Replicate } 1 \\
\text { R-PF Replicate } 2 \\
\text { R-PF Replicate } 3 \\
\text { R-PF } \\
\text { R-PF }\end{array}$ & $\begin{array}{l}1 \\
2 \\
3 \\
3 \\
3 \\
4 \\
5\end{array}$ & $\begin{array}{l}C \\
C \\
D \\
0 \\
0 \\
D \\
A\end{array}$ & $\begin{array}{r}10.78 \\
11.26 \\
10.40 \\
10.40 \\
10.40 \\
9.33 \\
12.22\end{array}$ & $\begin{array}{l}2.00 \\
1.54 \\
1.53 \mathrm{~J} \\
1.26 \mathrm{~J} \\
1.28 \mathrm{~J} \\
0.82 \mathrm{~J} \\
1.56\end{array}$ & $\begin{array}{l}1.23 \mathrm{U} \\
1.23 \mathrm{U} \\
1.86 \mathrm{U} \\
1.81 \mathrm{U} \\
1.85 \mathrm{U} \\
1.23 \mathrm{U} \\
1.25 \mathrm{U}\end{array}$ & $\begin{array}{l}0.24 \mathrm{~J} \\
0.67 \mathrm{U} \\
1.00 \mathrm{U} \\
0.98 \mathrm{U} \\
1.00 \mathrm{U} \\
0.67 \mathrm{U} \\
0.39 \mathrm{~J}\end{array}$ & $\begin{array}{l}0.46 \mathrm{~J} \\
0.52 \mathrm{~J} \\
0.35 \mathrm{~J} \\
1.05 \mathrm{U} \\
0.56 \mathrm{~J} \\
0.47 \mathrm{~J} \\
0.76\end{array}$ & $\begin{array}{l}1.12 \\
1.24 \\
1.14 \\
1.25 \\
1.01 \\
0.84 \\
1.79\end{array}$ & $\begin{array}{l}0.12 \mathrm{~J} \\
0.15 \mathrm{~J} \\
0.82 \\
0.80 \\
0.82 \\
0.54 \\
0.20\end{array}$ \\
\hline $\begin{array}{l}\text { C-SB } \\
\text { C-SB } \\
\text { C-SB } \\
\text { C-SB Replicate } 1 \\
\text { C-SB Replicate } 2 \\
\text { C-SB Replicate } 3 \\
\text { C-SB }\end{array}$ & $\begin{array}{l}1 \\
2 \\
3 \\
4 \\
4 \\
4 \\
5\end{array}$ & $\begin{array}{l}C \\
0 \\
B \\
A \\
A \\
A \\
D\end{array}$ & $\begin{array}{r}12.45 \\
10.40 \\
10.96 \\
11.33 \\
11.33 \\
11.33 \\
9.85\end{array}$ & $\begin{array}{l}1.11 \mathrm{~J} \\
1.07 \mathrm{~J} \\
0.50 \mathrm{~J} \\
2.29 \\
2.19 \\
2.02 \\
0.94 \mathrm{~J}\end{array}$ & $\begin{array}{l}1.15 \mathrm{U} \\
1.22 \mathrm{U} \\
1.22 \mathrm{U} \\
1.73 \mathrm{U} \\
1.68 \mathrm{U} \\
1.61 \mathrm{U} \\
1.23 \mathrm{U}\end{array}$ & $\begin{array}{l}0.31 \mathrm{~J} \\
0.44 \mathrm{~J} \\
0.16 \mathrm{~J} \\
0.27 \mathrm{~J} \\
0.91 \mathrm{U} \\
0.87 \mathrm{U} \\
0.66 \mathrm{~J}\end{array}$ & $\begin{array}{l}0.53 \mathrm{~J} \\
0.50 \mathrm{~J} \\
0.34 \mathrm{~J} \\
1.01 \mathrm{U} \\
0.81 \mathrm{~J} \\
0.68 \mathrm{~J} \\
0.43 \mathrm{~J}\end{array}$ & $\begin{array}{l}1.50 \\
1.23 \\
0.96 \\
1.29 \\
1.38 \\
1.09 \\
0.83\end{array}$ & $\begin{array}{l}0.25 \mathrm{~J} \\
0.54 \mathrm{~J} \\
0.14 \mathrm{~J} \\
0.14 \mathrm{~J} \\
0.74 \mathrm{U} \\
0.71 \mathrm{U} \\
0.54 \mathrm{U}\end{array}$ \\
\hline $\begin{array}{l}\text { C-NE } \\
C-N E \\
C-N E \\
C-N E \\
C-N E\end{array}$ & $\begin{array}{l}1 \\
2 \\
3 \\
4 \\
5\end{array}$ & $\begin{array}{l}B \\
B \\
B \\
B \\
B\end{array}$ & $\begin{array}{l}11.64 \\
10.40 \\
13.08 \\
10.83 \\
12.59\end{array}$ & $\begin{array}{l}2.41 \\
1.21 \\
0.67 \mathrm{~J} \\
1.27 \\
1.45\end{array}$ & $\begin{array}{l}1.23 \mathrm{U} \\
1.16 \mathrm{U} \\
1.23 \mathrm{U} \\
1.23 \mathrm{U} \\
1.24 \mathrm{U}\end{array}$ & $\begin{array}{ll}0.34 & \mathrm{~J} \\
0.26 \mathrm{~J} \\
0.27 \mathrm{~J} \\
0.29 \mathrm{~J} \\
0.26 \mathrm{~J}\end{array}$ & $\begin{array}{l}0.68 \mathrm{~J} \\
0.46 \mathrm{~J} \\
0.44 \mathrm{~J} \\
0.53 \mathrm{~J} \\
0.63 \mathrm{~J}\end{array}$ & $\begin{array}{l}2.34 \\
1.35 \\
1.75 \\
1.77 \\
2.03\end{array}$ & $\begin{array}{l}0.17 \mathrm{~J} \\
0.11 \mathrm{~J} \\
0.12 \mathrm{~J} \\
0.14 \mathrm{~J} \\
0.16 \mathrm{~J}\end{array}$ \\
\hline $\begin{array}{l}\text { HSL Background } \\
\text { HSL Background } \\
\text { MSL Background } \\
\text { MSL Background } \\
\text { HSL Background }\end{array}$ & $\begin{array}{l}1 \\
2 \\
3 \\
4 \\
5\end{array}$ & $\begin{array}{l}A \\
B \\
C \\
0 \\
D\end{array}$ & $\begin{array}{l}12.16 \\
10.85 \\
10.94 \\
11.08 \\
11.18\end{array}$ & $\begin{array}{l}1.82 \\
0.54 \mathrm{~J} \\
1.38 \\
1.07 \mathrm{~J} \\
0.63 \mathrm{~J}\end{array}$ & $\begin{array}{l}1.23 \mathrm{U} \\
1.21 \mathrm{U} \\
1.22 \mathrm{U} \\
1.22 \mathrm{~J} \\
1.23 \mathrm{~J}\end{array}$ & $\begin{array}{l}0.90 \\
0.26 \mathrm{~J} \\
0.66 \mathrm{U} \\
0.39 \mathrm{~J} \\
0.66 \mathrm{U}\end{array}$ & $\begin{array}{l}0.72 \mathrm{~J} \\
0.37 \mathrm{~J} \\
0.54 \mathrm{~J} \\
0.35 \mathrm{~J} \\
0.24 \mathrm{~J}\end{array}$ & $\begin{array}{l}2.09 \\
1.52 \\
1.59 \\
1.66 \\
1.55\end{array}$ & $\begin{array}{l}0.35 \mathrm{~J} \\
0.12 \mathrm{~J} \\
0.54 \mathrm{U} \\
0.54 \mathrm{U} \\
0.54 \mathrm{U}\end{array}$ \\
\hline
\end{tabular}

\footnotetext{
(a) DL Detection limit.

(b) NA Not applicable; anaiyte detected in all samples.

(c) J Analyte detected below method detection limit (HOL). but above instrument detection limit (IOL).

(d) U The analyte was not present above the level of the associated value.
} 
TABLE J.6. High Molecular Weight Polynuclear Aromatic Hydrocarbons (HPAHs), Wet Weight, in Tissue of M. nasuta, Richmond Harbor Program

\begin{tabular}{|c|c|c|c|c|c|c|c|c|c|c|c|c|c|}
\hline & & & & & & & nasut & PAHs & $\mathrm{kg}$ wet & t) & & & \\
\hline $\begin{array}{l}\text { Sediment } \\
\text { Treatment }\end{array}$ & eplicate & $\begin{array}{l}\text { Analytical } \\
\text { Batch } \\
\end{array}$ & $\begin{array}{c}\text { Percent } \\
\text { Dry Nelaht }\end{array}$ & $\begin{array}{c}\text { Fluor- } \\
\text { anthene }\end{array}$ & Pyrene & $\begin{array}{l}\text { Benzo(a) } \\
\text { Anthra- } \\
\text { cene } \\
\end{array}$ & Chrysene & $\begin{array}{c}\text { Benzo(b) } \\
\text { Fluor- } \\
\text { anthene }\end{array}$ & $\begin{array}{l}\text { Benzo(k) } \\
\text { Fivor- } \\
\text { anthene }\end{array}$ & $\begin{array}{l}\text { Benzo(a) } \\
\text { Pyrene }\end{array}$ & $\begin{array}{l}\text { Indeno } \\
(1,2,3-\mathrm{cd}) \\
\text { Pyrene ar }\end{array}$ & $\begin{array}{c}\text { Dibenzo } \\
(\mathrm{a}, \mathrm{h}) \\
\text { anthracene }\end{array}$ & $\begin{array}{r}\text { Benzo } \\
(g, h, i) \\
\text { pervlene }\end{array}$ \\
\hline $\begin{array}{l}\text { Target } \mathrm{DL}(\mathrm{a}) \\
\text { Achieved High DL } \\
\text { Achieved Low OL }\end{array}$ & & & & $\begin{array}{c}20.0 \\
K A \\
N A\end{array}$ & $\begin{array}{r}20.0 \\
\text { NA } \\
\text { NA }\end{array}$ & $\begin{array}{l}20.0 \\
1.83 \\
0.91\end{array}$ & $\begin{array}{r}20.0 \\
\mathrm{NA} \\
\mathrm{NA}\end{array}$ & $\begin{array}{l}20.0 \\
1.87 \\
0.92\end{array}$ & $\begin{array}{l}20.0 \\
1.17 \\
0.77\end{array}$ & $\begin{array}{l}20.0 \\
1.62 \\
0.76\end{array}$ & $\begin{array}{l}20.0 \\
1.95 \\
0.92\end{array}$ & $\begin{array}{l}20.0 \\
1.32 \\
0.62\end{array}$ & $\begin{array}{l}20.0 \\
2.64 \\
1.23\end{array}$ \\
\hline $\begin{array}{l}\text { СOMP I } \\
\text { COMP I } \\
\text { COMP I } \\
\text { COMP I } \\
\text { СOMP I }\end{array}$ & $\begin{array}{r}1 \\
2 \\
3 \\
4 \\
+5\end{array}$ & $\begin{array}{l}\text { D } \\
\text { D } \\
\text { A } \\
B \\
A\end{array}$ & $\begin{array}{l}10.85 \\
12.31 \\
12.58 \\
10.95 \\
12.42\end{array}$ & $\begin{array}{l}2.90 \\
5.10 \\
4.53 \\
3.96 \\
4.84\end{array}$ & $\begin{array}{l}5.78 \\
9.44 \\
6.69 \\
6.74 \\
7.76\end{array}$ & $\begin{array}{l}0.72 \mathrm{~J}^{(\mathrm{c})} \\
1.20 \\
1.47 \\
1.34 \\
1.72\end{array}$ & $\begin{array}{l}1.09 \\
2.00 \\
2.11 \\
2.08 \\
2.22\end{array}$ & $\begin{array}{l}2.39 \\
3.17 \\
2.29 \\
2.76 \\
3.89\end{array}$ & $\begin{array}{l}2.15 \\
2.26 \\
1.75 \\
1.88 \\
1.43\end{array}$ & $\begin{array}{l}1.11 \\
2.12 \\
1.59 \\
2.26 \\
2.19\end{array}$ & $\begin{array}{l}0.98 \mathrm{U}^{(\mathrm{d})} \\
0.97 \mathrm{U} \\
0.81 \mathrm{~J} \\
1.11 \\
1.55\end{array}$ & d) $\begin{array}{l}0.66 \mathrm{U} \\
0.66 \mathrm{U} \\
0.66 \mathrm{U} \\
0.11 \mathrm{~J} \\
0.80 \mathrm{U}\end{array}$ & $\begin{array}{l}0.84 \mathrm{~J} \\
1.32 \mathrm{~J} \\
1.22 \mathrm{~J} \\
1.59 \\
1.51 \mathrm{~J}\end{array}$ \\
\hline $\begin{array}{ll}\text { СомP } & \text { II } \\
\text { COMP } & \text { II } \\
\text { COMP } & \text { II } \\
\text { COMP } & \text { II } \\
\text { COMP } & \text { II }\end{array}$ & $\begin{array}{l}1 \\
2 \\
3 \\
4 \\
5\end{array}$ & $\begin{array}{l}0 \\
A \\
C \\
0 \\
C\end{array}$ & $\begin{array}{r}9.87 \\
11.86 \\
12.66 \\
10.52 \\
10.91\end{array}$ & $\begin{array}{l}1.78 \\
3.80 \\
2.89 \\
2.66 \\
3.16\end{array}$ & $\begin{array}{l}3.15 \\
7.58 \\
4.90 \\
5.59 \\
6.20\end{array}$ & $\begin{array}{l}0.51 \mathrm{~J} \\
1.19 \\
0.61 \mathrm{~J} \\
0.69 \mathrm{~J} \\
0.91\end{array}$ & $\begin{array}{l}1.07 \\
1.61 \\
1.14 \\
1.25 \\
1.43\end{array}$ & $\begin{array}{l}1.99 \\
3.26 \\
1.86 \\
2.10 \\
2.47\end{array}$ & $\begin{array}{l}1.07 \\
1.60 \\
2.25 \\
1.56 \\
1.59\end{array}$ & $\begin{array}{l}1.33 \\
1.88 \\
1.56 \\
1.71 \\
1.62\end{array}$ & $\begin{array}{l}0.93 \mathrm{U} \\
1.20 \\
0.98 \mathrm{U} \\
0.97 \mathrm{U} \\
0.92 \mathrm{U}\end{array}$ & $\begin{array}{l}0.63 \mathrm{U} \\
0.66 \mathrm{U} \\
0.66 \mathrm{U} \\
0.66 \mathrm{U} \\
0.63 \mathrm{U}\end{array}$ & $\begin{array}{l}1.26 \mathrm{U} \\
1.31 \mathrm{~J} \\
1.32 \mathrm{U} \\
1.32 \mathrm{U} \\
1.02 \mathrm{~J}\end{array}$ \\
\hline $\begin{array}{l}\text { COMP I I I } \\
\text { COMP II I } \\
\text { COMP II I } \\
\text { COMP I II } \\
\text { COMP II I }\end{array}$ & $\begin{array}{l}1 \\
2 \\
3 \\
4 \\
5\end{array}$ & $\begin{array}{l}C \\
C \\
A \\
D \\
C\end{array}$ & $\begin{array}{l}10.74 \\
12.02 \\
11.73 \\
11.69 \\
12.22\end{array}$ & $\begin{array}{l}0.83 \\
1.58 \\
1.60 \\
1.68 \\
0.98\end{array}$ & $\begin{array}{l}0.79 \\
1.27 \\
1.56 \\
1.61 \\
0.93\end{array}$ & $\begin{array}{l}0.91 \mathrm{U} \\
0.23 \mathrm{~J} \\
0.48 \mathrm{~J} \\
0.22 \mathrm{~J} \\
0.15 \mathrm{~J}\end{array}$ & $\begin{array}{l}0.25 \mathrm{~J} \\
0.48 \mathrm{~J} \\
0.71 \\
0.70 \\
0.48 \mathrm{~J}\end{array}$ & $\begin{array}{l}0.93 \mathrm{~J} \\
0.70 \mathrm{~J} \\
0.93 \mathrm{~J} \\
0.93 \mathrm{~J} \\
0.89 \mathrm{~J}\end{array}$ & $\begin{array}{l}0.77 \mathrm{U} \\
0.43 \mathrm{~J} \\
0.47 \mathrm{~J} \\
0.48 \mathrm{~J} \\
0.40 \mathrm{~J}\end{array}$ & $\begin{array}{ll}0.81 & \mathrm{U} \\
0.42 & \mathrm{~J} \\
0.49 & \mathrm{~J} \\
0.47 \mathrm{~J} \\
0.32 \mathrm{~J}\end{array}$ & $\begin{array}{l}0.97 \mathrm{U} \\
0.97 \mathrm{U} \\
0.98 \mathrm{U} \\
0.98 \mathrm{U} \\
0.96 \mathrm{U}\end{array}$ & $\begin{array}{l}0.66 \mathrm{U} \\
0.66 \mathrm{U} \\
0.66 \mathrm{U} \\
0.66 \mathrm{U} \\
0.66 \mathrm{U}\end{array}$ & $\begin{array}{l}1.32 \mathrm{U} \\
1.31 \mathrm{U} \\
0.47 \mathrm{~J} \\
1.32 \mathrm{U} \\
1.30 \mathrm{U}\end{array}$ \\
\hline $\begin{array}{l}\text { TC-5 Upper Comp } \\
\text { TC-5 Upper Comp } \\
\text { TC-5 Upper Comp } \\
\text { TC-5 Upper Comp } \\
\text { TC-5 Upper Comp }\end{array}$ & $\begin{array}{l}1 \\
2 \\
3 \\
4 \\
5\end{array}$ & $\begin{array}{l}C \\
C \\
C \\
A \\
A\end{array}$ & $\begin{array}{l}11.76 \\
11.72 \\
11.42 \\
12.42 \\
10.78\end{array}$ & $\begin{array}{l}20.49 \\
17.87 \\
20.44 \\
16.25 \\
14.48\end{array}$ & $\begin{array}{l}38.27 \\
33.50 \\
35.66 \\
25.69 \\
22.18\end{array}$ & $\begin{array}{l}6.30 \\
4.87 \\
4.89 \\
5.40 \\
4.66\end{array}$ & $\begin{array}{l}9.58 \\
7.52 \\
8.64 \\
7.85 \\
6.72\end{array}$ & $\begin{array}{r}13.68 \\
10.83 \\
8.64 \\
8.16 \\
5.87\end{array}$ & $\begin{array}{l}8.74 \\
8.99 \\
8.77 \\
5.15 \\
4.24\end{array}$ & $\begin{array}{l}8.37 \\
7.90 \\
8.42 \\
7.00 \\
4.50\end{array}$ & $\begin{array}{l}3.34 \\
3.33 \\
0.98 \mathrm{U} \\
3.41 \\
2.11\end{array}$ & $\begin{array}{l}0.66 \mathrm{U} \\
0.65 \mathrm{U} \\
0.66 \mathrm{U} \\
0.71 \mathrm{U} \\
0.66 \mathrm{U}\end{array}$ & $\begin{array}{l}3.74 \\
4.04 \\
3.07 \\
3.00 \\
1.94\end{array}$ \\
\hline $\begin{array}{l}\text { COMP IV } \\
\text { COMP IV } \\
\text { COMP IV } \\
\text { COMP IV } \\
\text { COMP IV }\end{array}$ & $\begin{array}{r}1 \\
2 \\
3 \\
4 \\
5\end{array}$ & $\begin{array}{l}\text { C } \\
\text { C } \\
\text { A } \\
\text { C } \\
\text { A }\end{array}$ & $\begin{array}{r}9.62 \\
11.93 \\
13.03 \\
13.34 \\
12.31\end{array}$ & $\begin{array}{l}0.75 \\
0.69 \\
1.36 \\
0.91 \mathrm{~J} \\
1.12\end{array}$ & $\begin{array}{l}0.58 \mathrm{~J} \\
0.58 \mathrm{~J} \\
0.93 \\
0.50 \mathrm{~J} \\
0.74\end{array}$ & $\begin{array}{l}0.14 \mathrm{~J} \\
0.91 \mathrm{U} \\
0.33 \mathrm{~J} \\
1.83 \mathrm{~J} \\
0.25 \mathrm{~J}\end{array}$ & $\begin{array}{l}0.33 \mathrm{~J} \\
0.22 \mathrm{~J} \\
0.96 \\
0.26 \mathrm{~J} \\
0.88\end{array}$ & $\begin{array}{l}0.93 \mathrm{U} \\
0.93 \mathrm{U} \\
0.41 \mathrm{~J} \\
1.87 \mathrm{U} \\
0.66 \mathrm{~J}\end{array}$ & $\begin{array}{l}0.78 \mathrm{U} \\
0.77 \mathrm{U} \\
0.24 \mathrm{~J} \\
1.55 \mathrm{U} \\
0.78 \mathrm{U}\end{array}$ & $\begin{array}{ll}0.81 & U \\
0.81 & U \\
0.79 & U \\
1.62 & U \\
0.81 & U\end{array}$ & $\begin{array}{l}0.97 \mathrm{U} \\
0.97 \mathrm{U} \\
0.95 \mathrm{U} \\
1.95 \mathrm{U} \\
0.97 \mathrm{U}\end{array}$ & $\begin{array}{l}0.66 \mathrm{U} \\
0.66 \mathrm{U} \\
0.64 \mathrm{U} \\
1.32 \mathrm{U} \\
0.66 \mathrm{U}\end{array}$ & $\begin{array}{l}1.32 \mathrm{U} \\
1.31 \mathrm{U} \\
1.28 \mathrm{U} \\
2.64 \mathrm{U} \\
1.32 \mathrm{U}\end{array}$ \\
\hline $\begin{array}{l}\text { COMP } v \\
\text { COMP } v \\
\text { COMP } v \\
\text { COMP } v\end{array}$ & $\begin{array}{l}1 \\
2 \\
3 \\
4\end{array}$ & $\begin{array}{l}A \\
A \\
A \\
D\end{array}$ & $\begin{array}{l}11.44 \\
13.28 \\
13.30 \\
10.90\end{array}$ & $\begin{array}{l}4.70 \\
6.32 \\
6.72 \\
2.87\end{array}$ & $\begin{array}{l}16.58 \\
23.73 \\
21.46 \\
11.02\end{array}$ & $\begin{array}{l}2.15 \\
2.33 \\
4.01 \\
0.99\end{array}$ & $\begin{array}{l}2.78 \\
4.25 \\
4.32 \\
1.58\end{array}$ & $\begin{array}{l}5.96 \\
7.40 \\
9.56 \\
5.62\end{array}$ & $\begin{array}{l}3.73 \\
5.49 \\
6.21 \\
3.11\end{array}$ & $\begin{array}{l}3.11 \\
4.90 \\
6.28 \\
2.88\end{array}$ & $\begin{array}{l}1.25 \\
1.49 \\
3.33 \\
1.06\end{array}$ & $\begin{array}{l}0.66 \mathrm{U} \\
0.77 \mathrm{U} \\
0.66 \mathrm{U} \\
0.66 \mathrm{U}\end{array}$ & $\begin{array}{l}1.97 \\
1.90 \\
3.44 \\
1.55\end{array}$ \\
\hline
\end{tabular}


IABLE J.6. (contd)

\begin{tabular}{|c|c|c|c|c|c|c|c|c|c|c|c|c|c|}
\hline & & & & & & & naspito & HPAHS ( $\mu$ g & . & |qht) & & & \\
\hline $\begin{array}{l}\text { Sediment } \\
\text { Ireatment }\end{array}$ & Replicate & $\begin{array}{l}\text { Analytfcal } \\
\text { Bateh } \\
\end{array}$ & $\begin{array}{l}\text { Percent } \\
\text { Dry Weight }\end{array}$ & $\begin{array}{l}\text { Fluor- } \\
\text { anthene }\end{array}$ & Pyrene & $\begin{array}{l}\text { Benzo(a) } \\
\text { Anthra- } \\
\text { cene } \\
\end{array}$ & Chrysene & $\begin{array}{l}\text { Benzo(b) } \\
\text { Fluor- } \\
\text { anthene }\end{array}$ & $\begin{array}{l}\text { Benzo(k) } \\
\text { Fluor- } \\
\text { anthene }\end{array}$ & $\begin{array}{l}\text { Benzo(a) } \\
\text { Pyrene } \\
\end{array}$ & $\begin{array}{c}\text { Indeno } \\
(1,2,3-\mathrm{cd}) \\
\text { Pyrene } \\
\end{array}$ & $\begin{array}{c}\begin{array}{c}\text { Dibenzo } \\
(\mathrm{a}, \mathrm{h}) \\
\text { anthracene }\end{array} \\
\end{array}$ & $\begin{array}{r}\text { Benzo } \\
(g, h, i) \\
\text { perylene }\end{array}$ \\
\hline $\begin{array}{l}\text { COMP V Repl icate } 1 \\
\text { COMP V Repl icate } 2 \\
\text { COMP V Repl icate } 3\end{array}$ & $\begin{array}{l}5 \\
5 \\
5\end{array}$ & $\begin{array}{l}\mathrm{B} \\
\mathrm{B} \\
\mathrm{B}\end{array}$ & $\begin{array}{l}12.39 \\
12.39 \\
12.39\end{array}$ & $\begin{array}{l}5.32 \\
5.40 \\
5.14\end{array}$ & $\begin{array}{l}18.39 \\
18.33 \\
17.72\end{array}$ & $\begin{array}{l}2.30 \\
2.34 \\
2.18\end{array}$ & $\begin{array}{l}3.70 \\
3.78 \\
3.38\end{array}$ & $\begin{array}{l}6.56 \\
6.45 \\
7.06\end{array}$ & $\begin{array}{l}4.21 \\
5.24 \\
4.57\end{array}$ & $\begin{array}{l}5.10 \\
5.15 \\
5.15\end{array}$ & $\begin{array}{l}1.84 \mathrm{~J} \\
1.94 \mathrm{~J} \\
1.70\end{array}$ & $\begin{array}{l}0.22 \mathrm{~J} \\
0.25 \mathrm{~J} \\
0.17 \mathrm{~J}\end{array}$ & $\begin{array}{l}2.47 \mathrm{~J} \\
2.57 \mathrm{~J} \\
2.14\end{array}$ \\
\hline $\begin{array}{l}\text { COMP VI } \\
\text { COMP VI } \\
\text { COMP VI } \\
\text { COMP VI } \\
\text { COMP VI }\end{array}$ & $\begin{array}{l}1 \\
2 \\
3 \\
4 \\
5\end{array}$ & $\begin{array}{l}C \\
A \\
B \\
A \\
D\end{array}$ & $\begin{array}{r}10.47 \\
11.02 \\
12.94 \\
10.78 \\
9.48\end{array}$ & $\begin{array}{l}2.39 \\
4.23 \\
5.94 \\
4.03 \\
2.87\end{array}$ & $\begin{array}{l}11.52 \\
17.78 \\
23.63 \\
15.48 \\
14.27\end{array}$ & $\begin{array}{l}1.06 \\
2.76 \\
2.44 \\
2.57 \\
0.93\end{array}$ & $\begin{array}{l}1.65 \\
3.16 \\
4.17 \\
3.05 \\
1.77\end{array}$ & $\begin{array}{l}5.24 \\
5.84 \\
9.31 \\
4.99 \\
5.12\end{array}$ & $\begin{array}{l}3.04 \\
4.30 \\
6.21 \\
4.92 \\
2.86\end{array}$ & $\begin{array}{l}2.51 \\
3.66 \\
6.19 \\
3.86 \\
3.14\end{array}$ & $\begin{array}{l}1.00 \\
1.48 \\
2.21 \mathrm{~J} \\
1.77 \\
0.97 \mathrm{U}\end{array}$ & $\begin{array}{l}0.66 \mathrm{U} \\
0.66 \mathrm{U} \\
0.25 \mathrm{~J} \\
0.66 \mathrm{U} \\
0.66 \mathrm{U}\end{array}$ & $\begin{array}{l}1.74 \\
1.72 \\
2.79 \mathrm{~J} \\
1.75 \\
1.32 \mathrm{U}\end{array}$ \\
\hline $\begin{array}{l}R-A C \\
R-A C \\
R-A C \\
R-A C \\
R-A C\end{array}$ & $\begin{array}{r}1 \\
2 \\
3 \\
4 \\
+5\end{array}$ & $\begin{array}{l}B \\
C \\
C \\
A \\
D\end{array}$ & $\begin{array}{l}12.41 \\
10.54 \\
11.77 \\
11.56 \\
11.02\end{array}$ & $\begin{array}{r}128.08 \\
67.02 \\
170.31 \\
143.78 \\
139.20\end{array}$ & $\begin{array}{l}291.01 \\
157.04 \\
414.47 \\
322.74 \\
322.33\end{array}$ & $\begin{array}{l}27.89 \\
10.86 \\
30.39 \\
37.22 \\
33.33\end{array}$ & $\begin{array}{l}37.57 \\
15.57 \\
37.66 \\
40.79 \\
41.39\end{array}$ & $\begin{array}{l}35.63 \\
21.32 \\
53.12 \\
42.84 \\
35.96\end{array}$ & $\begin{array}{l}28.02 \\
26.27 \\
33.00 \\
25.66 \\
26.75\end{array}$ & $\begin{array}{l}43.04 \\
25.45 \\
51.21 \\
43.74 \\
43.27\end{array}$ & $\begin{array}{r}12.44 \\
5.37 \\
12.40 \\
16.38 \\
12.53\end{array}$ & $\begin{array}{l}0.67 \\
0.66 \mathrm{U} \\
0.66 \mathrm{U} \\
0.66 \mathrm{U} \\
0.77\end{array}$ & $\begin{array}{r}13.52 \\
6.21 \\
12.08 \\
14.80 \\
14.09\end{array}$ \\
\hline $\begin{array}{l}\text { R-AH } \\
R \text {-AM Replicate } 1 \\
\text { R-AH Replicate } 2 \\
\text { R-AH Replicate } 3 \\
\text { R-AM } \\
\text { R-AM } \\
\text { R-AM }\end{array}$ & $\begin{array}{l}1 \\
2 \\
2 \\
2 \\
3 \\
4 \\
5\end{array}$ & $\begin{array}{l}B \\
C \\
C \\
C \\
8 \\
8 \\
B\end{array}$ & $\begin{array}{l}10.05 \\
10.33 \\
10.33 \\
10.33 \\
12.31 \\
12.40 \\
10.44\end{array}$ & $\begin{array}{l}16.33 \\
21.01 \\
23.38 \\
22.36 \\
43.68 \\
48.52 \\
32.50\end{array}$ & $\begin{array}{l}17.22 \\
20.56 \\
23.85 \\
22.23 \\
48.64 \\
57.14 \\
35.28\end{array}$ & $\begin{array}{r}5.07 \\
4.61 \\
5.31 \\
4.67 \\
19.76 \\
23.10 \\
14.05\end{array}$ & $\begin{array}{r}8.71 \\
7.30 \\
9.68 \\
8.51 \\
28.77 \\
37.45 \\
21.87\end{array}$ & $\begin{array}{r}3.80 \\
3.96 \\
4.70 \\
3.57 \\
12.83 \\
14.91 \\
8.14\end{array}$ & $\begin{array}{r}4.48 \\
5.27 \\
4.56 \\
5.13 \\
14.45 \\
17.60 \\
8.56\end{array}$ & $\begin{array}{r}5.01 \\
4.70 \\
4.48 \\
5.49 \\
17.54 \\
22.01 \\
11.35\end{array}$ & $\begin{array}{l}1.23 \\
1.45 \mathrm{U} \\
1.47 \mathrm{U} \\
1.41 \mathrm{U} \\
5.49 \\
6.01 \\
3.12\end{array}$ & $\begin{array}{l}0.17 \mathrm{~J} \\
0.98 \mathrm{U} \\
1.00 \mathrm{U} \\
0.96 \mathrm{U} \\
0.60 \mathrm{~J} \\
0.73 \mathrm{~J} \\
0.38 \mathrm{~J}\end{array}$ & $\begin{array}{l}1.35 \\
1.47 \mathrm{~J} \\
1.28 \mathrm{~J} \\
1.59 \mathrm{~J} \\
5.25 \\
6.22 \\
3.32\end{array}$ \\
\hline $\begin{array}{l}R-B F \\
R-B F \\
R-B F \\
R-B F \\
R-B F\end{array}$ & $\begin{array}{l}1 \\
2 \\
3 \\
4 \\
5\end{array}$ & $\begin{array}{l}D \\
B \\
B \\
A \\
A\end{array}$ & $\begin{array}{l}11.13 \\
13.42 \\
12.07 \\
10.12 \\
12.83\end{array}$ & $\begin{array}{l}2.92 \\
7.79 \\
5.89 \\
5.14 \\
5.72\end{array}$ & $\begin{array}{l}3.20 \\
8.57 \\
7.24 \\
4.82 \\
5.50\end{array}$ & $\begin{array}{l}0.86 \mathrm{~J} \\
1.89 \\
1.51 \\
1.59 \\
1.73\end{array}$ & $\begin{array}{l}1.53 \\
3.74 \\
2.79 \\
2.55 \\
2.74\end{array}$ & $\begin{array}{l}2.70 \\
5.30 \\
4.43 \\
3.38 \\
3.75\end{array}$ & $\begin{array}{l}1.16 \\
2.75 \\
2.63 \\
1.67 \\
2.40\end{array}$ & $\begin{array}{l}1.68 \\
3.74 \\
3.01 \\
2.04 \\
2.37\end{array}$ & $\begin{array}{l}0.83 \mathrm{~J} \\
1.64 \\
0.98 \mathrm{~J} \\
1.24 \\
1.75\end{array}$ & $\begin{array}{l}0.78 \mathrm{U} \\
0.15 \mathrm{~J} \\
0.13 \mathrm{~J} \\
0.66 \mathrm{U} \\
0.64 \mathrm{U}\end{array}$ & $\begin{array}{l}1.15 \mathrm{~J} \\
2.80 \\
2.35 \\
1.65 \\
2.50\end{array}$ \\
\hline $\begin{array}{l}R-O S \\
R-O S \\
R-O S \\
R-O S \\
R-O S\end{array}$ & $\begin{array}{l}1 \\
2 \\
3 \\
4 \\
5\end{array}$ & $\begin{array}{l}B \\
D \\
B \\
D \\
C\end{array}$ & $\begin{array}{l}12.06 \\
11.53 \\
11.56 \\
12.33 \\
12.74\end{array}$ & $\begin{array}{l}2.46 \\
0.95 \\
1.23 \\
1.31 \\
1.48\end{array}$ & $\begin{array}{l}1.70 \\
0.66 \\
0.80 \\
1.02 \\
1.07\end{array}$ & $\begin{array}{l}0.37 \mathrm{~J} \\
0.90 \mathrm{~J} \\
0.30 \mathrm{~J} \\
0.14 \mathrm{~J} \\
0.61 \mathrm{~J}\end{array}$ & $\begin{array}{l}0.99 \\
0.45 \mathrm{~J} \\
0.64 \\
0.44 \mathrm{~J} \\
0.60 \mathrm{~J}\end{array}$ & $\begin{array}{l}0.44 \mathrm{~J} \\
0.92 \mathrm{U} \\
0.40 \mathrm{~J} \\
0.57 \mathrm{~J} \\
0.30 \mathrm{~J}\end{array}$ & $\begin{array}{l}0.19 \mathrm{~J} \\
0.77 \mathrm{~J} \\
0.19 \mathrm{~J} \\
0.78 \mathrm{~J} \\
0.27 \mathrm{~J}\end{array}$ & $\begin{array}{lll}0.22 & \mathrm{~J} \\
0.80 & \mathrm{U} \\
0.21 & \mathrm{~J} \\
0.81 \mathrm{U} & \\
0.19 \mathrm{~J}\end{array}$ & $\begin{array}{l}0.17 \mathrm{~J} \\
0.96 \mathrm{U} \\
0.14 \mathrm{~J} \\
0.97 \mathrm{U} \\
0.97 \mathrm{U}\end{array}$ & $\begin{array}{l}0.67 \mathrm{U} \\
0.65 \mathrm{U} \\
0.66 \mathrm{U} \\
0.66 \mathrm{U} \\
0.66 \mathrm{U}\end{array}$ & $\begin{array}{l}0.27 \mathrm{~J} \\
1.30 \mathrm{U} \\
0.20 \mathrm{~J} \\
1.32 \mathrm{U} \\
1.31 \mathrm{U}\end{array}$ \\
\hline
\end{tabular}


TABLE J.6. (contd)

\begin{tabular}{|c|c|c|c|c|c|c|c|c|c|c|c|c|c|c|}
\hline & & & & & & & & 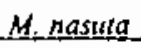 & aHS 1 & $\mathrm{~kg}$ wet & (ght) & & & \\
\hline & $\begin{array}{l}\text { Sediment } \\
\text { Ireatment }\end{array}$ & Replicate & $\begin{array}{l}\text { Analytical } \\
\text { Batch } \\
\end{array}$ & $\begin{array}{c}\text { Percent } \\
\text { Dry. Wetght }\end{array}$ & $\begin{array}{l}\text { Fluor- } \\
\text { anthene }\end{array}$ & Pyrene & $\begin{array}{l}\text { Benzo (a) } \\
\text { Anthra- } \\
\text { Cene. }\end{array}$ & Chrysene & $\begin{array}{c}\text { Benzo(b) } \\
\text { Fivor- } \\
\text { anthene }\end{array}$ & $\begin{array}{c}\text { Benzo(k) } \\
\text { Fluor- } \\
\text { anthene }\end{array}$ & $\begin{array}{l}\text { Benzo(a) } \\
\text { Pyrene }\end{array}$ & $\begin{array}{c}\text { Indeno } \\
\{1,2,3-c d) \\
\text { Pyrene }\end{array}$ & $\begin{array}{c}\begin{array}{c}\text { Dabenzo } \\
(a, h)\end{array} \\
\text { anthracene }\end{array}$ & $\begin{array}{r}\text { Benzo } \\
(\mathrm{g}, \mathrm{h}, \mathrm{i}) \\
\text { pervlene }\end{array}$ \\
\hline & $\begin{array}{l}\text { R-PF } \\
\text { R-PF } \\
\text { R-PF Replicate } 1 \\
\text { R-PF Replicate } 2 \\
\text { R-PF Replicate } 3 \\
\text { R-PF } \\
\text { R-PF }\end{array}$ & $\begin{array}{l}1 \\
2 \\
3 \\
3 \\
3 \\
4 \\
5\end{array}$ & $\begin{array}{l}C \\
C \\
D \\
D \\
D \\
D \\
A\end{array}$ & $\begin{array}{r}10.78 \\
11.26 \\
10.40 \\
10.40 \\
10.40 \\
9.33 \\
12.22\end{array}$ & $\begin{array}{l}0.94 \\
0.93 \\
1.08 \\
0.98 \\
0.84 \\
0.84 \\
1.69\end{array}$ & $\begin{array}{l}0.79 \\
0.87 \\
0.93 \mathrm{~J} \\
0.86 \mathrm{~J} \\
0.78 \mathrm{~J} \\
0.62 \mathrm{~J} \\
1.01\end{array}$ & $\begin{array}{l}0.11 \mathrm{~J} \\
0.91 \mathrm{U} \\
1.37 \mathrm{U} \\
1.34 \mathrm{U} \\
1.37 \mathrm{U} \\
0.91 \mathrm{U} \\
0.34 \mathrm{~J}\end{array}$ & $\begin{array}{l}0.27 \mathrm{~J} \\
0.27 \mathrm{~J} \\
0.49 \mathrm{~J} \\
0.35 \mathrm{~J} \\
0.31 \mathrm{~J} \\
0.32 \mathrm{~J} \\
0.87\end{array}$ & $\begin{array}{l}0.42 \mathrm{~J} \\
0.93 \mathrm{U} \\
1.40 \mathrm{U} \\
1.36 \mathrm{U} \\
1.40 \mathrm{U} \\
0.41 \mathrm{~J} \\
0.60 \mathrm{~J}\end{array}$ & $\begin{array}{l}0.24 \mathrm{~J} \\
0.78 \mathrm{U} \\
1.17 \mathrm{U} \\
1.14 \mathrm{U} \\
1.17 \mathrm{U} \\
0.77 \mathrm{U} \\
0.27 \mathrm{~J}\end{array}$ & $\begin{array}{l}0.81 \mathrm{U} \\
0.81 \mathrm{U} \\
1.22 \mathrm{U} \\
1.19 \mathrm{U} \\
1.21 \mathrm{U} \\
0.11 \mathrm{~J} \\
0.25 \mathrm{~J}\end{array}$ & $\begin{array}{l}0.97 \mathrm{U} \\
0.97 \mathrm{U} \\
1.46 \mathrm{U} \\
1.42 \mathrm{U} \\
1.46 \mathrm{U} \\
0.97 \mathrm{U} \\
0.99 \mathrm{U}\end{array}$ & $\begin{array}{l}0.66 \mathrm{U} \\
0.66 \mathrm{U} \\
0.99 \mathrm{U} \\
0.97 \mathrm{U} \\
0.99 \mathrm{U} \\
0.66 \mathrm{U} \\
0.67 \mathrm{U}\end{array}$ & $\begin{array}{l}1.32 \mathrm{U} \\
1.32 \mathrm{U} \\
1.98 \mathrm{U} \\
1.93 \mathrm{U} \\
1.98 \mathrm{U} \\
1.32 \mathrm{U} \\
1.34 \mathrm{U}\end{array}$ \\
\hline & $\begin{array}{l}\text { C-SB } \\
\text { C-SB } \\
\text { C-SB } \\
\text { C-S8 Replicate } 1 \\
\text { C-S8 Replicate } 2 \\
\text { C-SB Replicate } 3 \\
\text { C-SB }\end{array}$ & $\begin{array}{r}1 \\
2 \\
3 \\
4 \\
4 \\
4 \\
5\end{array}$ & $\begin{array}{l}C \\
D \\
B \\
A \\
A \\
A \\
D\end{array}$ & $\begin{array}{r}12.45 \\
10.40 \\
10.96 \\
11.33 \\
11.33 \\
11.33 \\
9.85\end{array}$ & $\begin{array}{l}2.98 \\
2.70 \\
3.50 \\
2.13 \\
2.41 \\
2.10 \\
1.87\end{array}$ & $\begin{array}{l}1.56 \\
1.23 \\
2.01 \\
1.10 \\
3.00 \\
1.04 \\
1.29\end{array}$ & $\begin{array}{l}0.34 \mathrm{~J} \\
0.27 \mathrm{~J} \\
0.47 \mathrm{~J} \\
0.30 \mathrm{~J} \\
0.27 \mathrm{~J} \\
0.21 \mathrm{~J} \\
0.20 \mathrm{~J}\end{array}$ & $\begin{array}{l}0.91 \\
0.59 \mathrm{~J} \\
0.90 \\
0.73 \mathrm{~J} \\
0.69 \mathrm{~J} \\
0.82 \mathrm{~J} \\
0.64\end{array}$ & $\begin{array}{l}0.88 \\
0.69 \mathrm{~J} \\
0.95 \\
0.48 \mathrm{~J} \\
0.68 \mathrm{~J} \\
0.64 \mathrm{~J} \\
0.66 \mathrm{~J}\end{array}$ & $\begin{array}{l}0.77 \\
0.31 \mathrm{~J} \\
0.55 \mathrm{~J} \\
0.38 \mathrm{~J} \\
0.30 \mathrm{~J} \\
0.29 \mathrm{~J} \\
0.40 \mathrm{~J}\end{array}$ & $\begin{array}{l}0.76 \mathrm{U} \\
0.70 \mathrm{~J} \\
0.30 \mathrm{~J} \\
0.20 \mathrm{~J} \\
1.10 \mathrm{U} \\
1.06 \mathrm{U} \\
0.80 \mathrm{U}\end{array}$ & $\begin{array}{ll}0.91 & U \\
0.96 & U \\
0.22 & J \\
1.37 & U \\
1.33 & U \\
1.27 & U \\
0.97 & U\end{array}$ & $\begin{array}{l}0.62 \mathrm{U} \\
0.65 \mathrm{U} \\
0.65 \mathrm{U} \\
0.93 \mathrm{U} \\
0.90 \mathrm{U} \\
0.86 \mathrm{U} \\
0.66 \mathrm{U}\end{array}$ & $\begin{array}{l}1.23 \mathrm{U} \\
1.30 \mathrm{U} \\
0.30 \mathrm{~J} \\
1.85 \mathrm{U} \\
1.80 \mathrm{U} \\
1.72 \mathrm{U} \\
1.31 \mathrm{U}\end{array}$ \\
\hline N & $\begin{array}{l}C-N E \\
C-N E \\
C-N E \\
C-N E \\
C-N E\end{array}$ & $\begin{array}{l}1 \\
2 \\
3 \\
4 \\
5\end{array}$ & $\begin{array}{l}8 \\
6 \\
8 \\
8 \\
8\end{array}$ & $\begin{array}{l}11.64 \\
10.40 \\
13.08 \\
10.83 \\
12.59\end{array}$ & $\begin{array}{l}2.15 \\
1.25 \\
2.19 \\
2.25 \\
2.15\end{array}$ & $\begin{array}{l}1.45 \\
0.78 \\
1.40 \\
1.41 \\
1.38\end{array}$ & $\begin{array}{l}0.38 \mathrm{~J} \\
0.24 \mathrm{~J} \\
0.29 \mathrm{~J} \\
0.38 \mathrm{~J} \\
0.35 \mathrm{~J}\end{array}$ & $\begin{array}{l}1.05 \\
0.79 \\
0.92 \\
1.15 \\
1.12\end{array}$ & $\begin{array}{l}0.38 \mathrm{~J} \\
0.23 \mathrm{~J} \\
0.30 \mathrm{~J} \\
0.30 \mathrm{~J} \\
0.36 \mathrm{~J}\end{array}$ & $\begin{array}{l}0.16 \mathrm{~J} \\
0.12 \mathrm{~J} \\
0.15 \mathrm{~J} \\
0.13 \mathrm{~J} \\
0.16 \mathrm{~J}\end{array}$ & $\begin{array}{l}0.14 \mathrm{~J} \\
0.09 \mathrm{~J} \\
0.08 \mathrm{~J} \\
0.09 \mathrm{~J} \\
0.12 \mathrm{~J}\end{array}$ & $\begin{array}{l}0.07 \mathrm{~J} \\
0.92 \mathrm{U} \\
0.97 \mathrm{U} \\
0.97 \mathrm{U} \\
0.08 \mathrm{~J}\end{array}$ & $\begin{array}{l}0.66 \mathrm{U} \\
0.62 \mathrm{U} \\
0.66 \mathrm{U} \\
0.66 \mathrm{U} \\
0.66 \mathrm{U}\end{array}$ & $\begin{array}{l}0.16 \mathrm{~J} \\
1.24 \mathrm{U} \\
1.32 \mathrm{U} \\
1.31 \mathrm{U} \\
0.12 \mathrm{~J}\end{array}$ \\
\hline & $\begin{array}{l}\text { MSL Background } \\
\text { MSL Background } \\
\text { MSL Background } \\
\text { MSL Background } \\
\text { MSL Background }\end{array}$ & $\begin{array}{l}1 \\
2 \\
3 \\
4 \\
5\end{array}$ & $\begin{array}{l}A \\
B \\
C \\
0 \\
D\end{array}$ & $\begin{array}{l}12.16 \\
10.85 \\
10.94 \\
11.08 \\
11.18\end{array}$ & $\begin{array}{l}8.76 \\
7.53 \\
7.94 \\
5.61 \\
9.58\end{array}$ & $\begin{array}{l}5.25 \\
4.47 \\
6.93 \\
3.99 \\
6.57\end{array}$ & $\begin{array}{l}0.74 \mathrm{~J} \\
0.77 \mathrm{~J} \\
0.68 \mathrm{~J} \\
0.60 \mathrm{~J} \\
0.73 \mathrm{~J}\end{array}$ & $\begin{array}{l}2.41 \\
2.26 \\
2.15 \\
2.68 \\
2.88\end{array}$ & $\begin{array}{l}1.47 \\
0.79 \mathrm{~J} \\
1.46 \\
1.28 \\
1.06\end{array}$ & $\begin{array}{l}0.55 \mathrm{~J} \\
0.57 \mathrm{~J} \\
0.88 \\
0.73 \mathrm{~J} \\
1.01\end{array}$ & $\begin{array}{l}0.17 \mathrm{~J} \\
0.29 \mathrm{~J} \\
0.80 \mathrm{U} \\
0.80 \mathrm{U} \\
0.81 \mathrm{U}\end{array}$ & $\begin{array}{l}0.97 \mathrm{U} \\
0.08 \mathrm{~J} \\
0.96 \mathrm{U} \\
0.96 \mathrm{U} \\
0.97 \mathrm{U}\end{array}$ & $\begin{array}{l}0.66 \mathrm{U} \\
0.65 \mathrm{U} \\
0.65 \mathrm{U} \\
0.65 \mathrm{U} \\
0.66 \mathrm{U}\end{array}$ & $\begin{array}{l}1.320 \\
1.29 u \\
1.30 u \\
1.300 \\
1.31 U\end{array}$ \\
\hline
\end{tabular}

(a) DL Detection limit.

(b) NA Not applicable; analyte detected in all samples.

(c) J Analyte detected below method detection limit (MDL), but above instrument detection limit (IDL).

(d) $U$ The analyte was not present above the level of the associated value. 
IABLE J.7. Quality Control Data for Low Molecular Weight Polynuclear Aromatic Hydrocarbons (LPAHs), Dry Weight, in Tissue of M. nasuta, Richmond Harbor Program

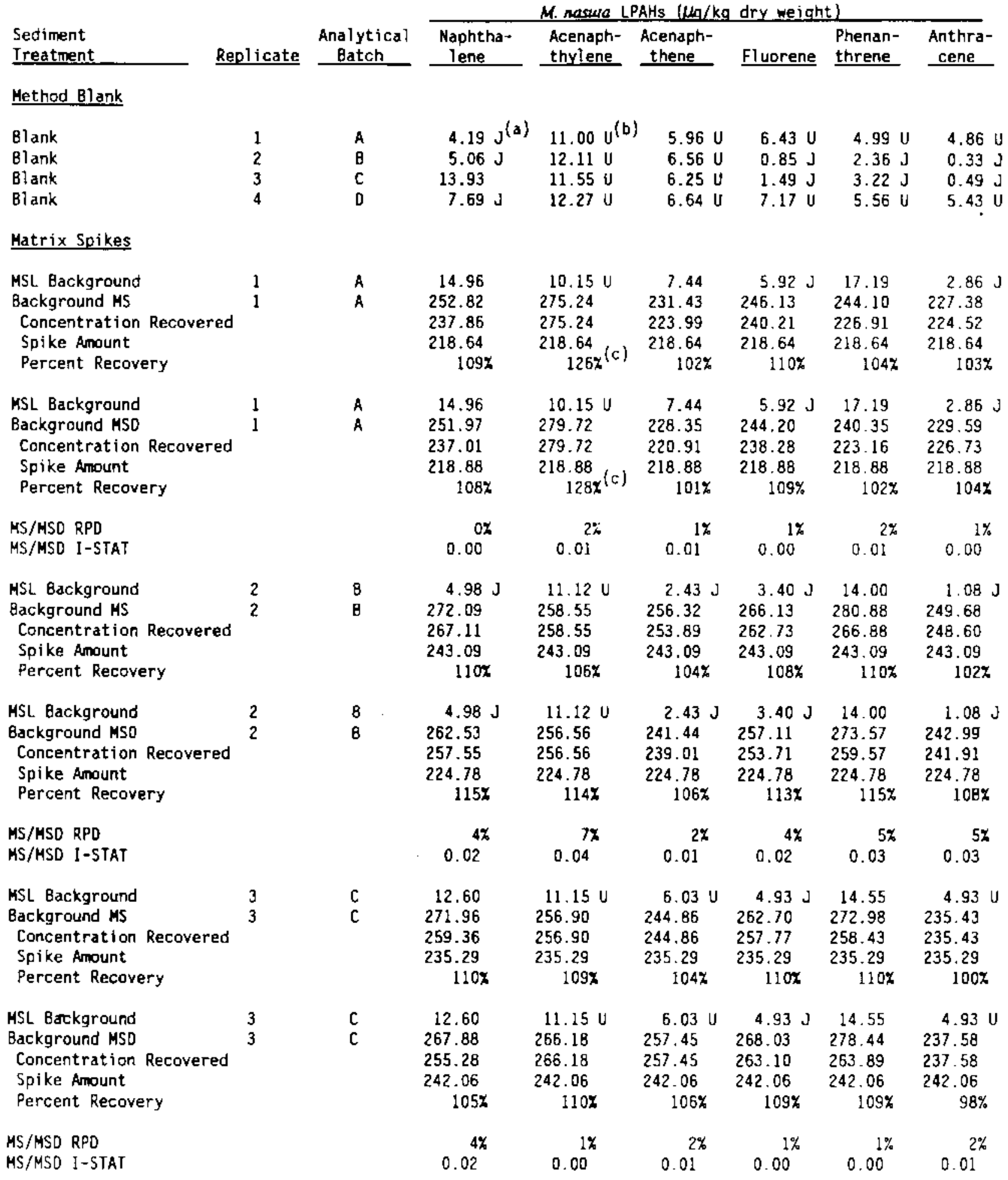


IABLE J.7. (contd)

\begin{tabular}{|c|c|c|c|c|c|c|c|c|}
\hline \multirow[b]{2}{*}{$\begin{array}{l}\text { Sediment } \\
\text { Ireatment }\end{array}$} & \multirow[b]{2}{*}{ Replicate } & \multirow[b]{2}{*}{$\begin{array}{l}\text { Analytical } \\
\text { Batch } \\
\end{array}$} & \multicolumn{6}{|c|}{$M$. narura LPAHs $(\mu \mathrm{k} / \mathrm{kg}$ dry weight) } \\
\hline & & & $\begin{array}{l}\text { Naphtha- } \\
\text { lene }\end{array}$ & $\begin{array}{l}\text { Acenaph- } \\
\text { thylene }\end{array}$ & $\begin{array}{l}\text { Acenaph- } \\
\text { thene }\end{array}$ & Fluorene & $\begin{array}{l}\text { Phenan- } \\
\text { threne }\end{array}$ & $\begin{array}{l}\text { Anthra- } \\
\text { cene } \\
\end{array}$ \\
\hline $\begin{array}{l}\text { HSL Background } \\
\text { Background HS } \\
\text { Concentration Recoveres } \\
\text { Spike Amount } \\
\text { Percent Recovery }\end{array}$ & $\begin{array}{r}4 \\
4\end{array}$ & $\begin{array}{l}D \\
D\end{array}$ & $\begin{array}{c}9.66 \mathrm{~J} \\
265.44 \\
255.78 \\
239.52 \\
107 \%\end{array}$ & $\begin{array}{l}10.99 \mathrm{U} \\
270.31 \\
270.31 \\
239.52 \\
1137\end{array}$ & $\begin{array}{r}3.51 \mathrm{~J} \\
264.35 \\
260.84 \\
239.52 \\
109 x\end{array}$ & $\begin{array}{c}3.20 \mathrm{~J} \\
267.88 \\
264.68 \\
239.52 \\
111 x\end{array}$ & $\begin{array}{r}14.95 \\
261.50 \\
246.55 \\
239.52 \\
103 x\end{array}$ & $\begin{array}{r}4.86 \mathrm{U} \\
233.69 \\
233.69 \\
239.52 \\
987\end{array}$ \\
\hline $\begin{array}{l}\text { MSL Background } \\
\text { 8ackground HSD } \\
\text { Concentration Recoverec } \\
\text { Spike Amount } \\
\text { Percent Recovery }\end{array}$ & $\begin{array}{r}4 \\
4\end{array}$ & $\begin{array}{l}0 \\
D\end{array}$ & $\begin{array}{c}9.66 \mathrm{~J} \\
266.44 \\
256.78 \\
238.81 \\
108 \%\end{array}$ & $\begin{array}{c}10.99 u \\
279.55 \\
279.55 \\
238.81 \\
117 \%\end{array}$ & $\begin{array}{l}3.51 \mathrm{~J} \\
261.76 \\
258.25 \\
238.81 \\
108 \%\end{array}$ & $\begin{array}{c}3.20 \mathrm{~J} \\
262.75 \\
259.55 \\
238.81 \\
1097\end{array}$ & $\begin{array}{r}14.95 \\
255.56 \\
240.61 \\
238.81 \\
101 \%\end{array}$ & $\begin{array}{r}4.86 u \\
223.43 \\
223.43 \\
238.81 \\
94 \%\end{array}$ \\
\hline $\begin{array}{l}\text { MS/MSO RPO } \\
\text { MS/HSO I-STAT }\end{array}$ & & & $0.00^{1 \%}$ & $0.02^{4 x}$ & $0.00^{1 .}$ & 0.01 & 0.01 & $0.02^{4 \%}$ \\
\hline \multicolumn{9}{|c|}{ Standard Reference Material } \\
\hline Certified Value & & & $N C^{(d)}$ & NC & NC & NC & $\begin{array}{l}45.00 \\
\pm 11.0\end{array}$ & $\begin{array}{l}6.10 \\
\pm 1.7\end{array}$ \\
\hline $\begin{array}{ll}\text { SRM } & 1974 \\
\text { SRH } & 1974 \\
\text { SRM } & 1974 \\
\text { SRM } & 1974\end{array}$ & & $\begin{array}{l}A \\
B \\
C \\
D\end{array}$ & $\begin{array}{l}\text { NA } \\
\text { NA } \\
\text { NA } \\
\text { NA }\end{array}$ & $\begin{array}{l}\text { NA } \\
\text { NA } \\
\text { NA } \\
\text { NA }\end{array}$ & $\begin{array}{l}\text { NA } \\
\text { NA } \\
\text { NA } \\
\text { HA }\end{array}$ & $\begin{array}{l}\text { NA } \\
\text { NA } \\
\text { NA } \\
\text { NA }\end{array}$ & $\begin{array}{l}48.06 \\
55.57 \\
44.53 \\
39.14\end{array}$ & $\begin{array}{r}10.84 \mathrm{~J} \\
9.83 \mathrm{~J} \\
5.51 \mathrm{~J} \\
2.80 \mathrm{~J}\end{array}$ \\
\hline \multicolumn{9}{|l|}{ Analytical Replicates } \\
\hline $\begin{array}{l}\text { COMP V Repl icate } 1 \\
\text { COMP V Replicate } 2 \\
\text { COMP V Replicate } 3 \\
\text { RSD }\end{array}$ & $\begin{array}{l}5 \\
5 \\
5\end{array}$ & $\begin{array}{l}B \\
B \\
B\end{array}$ & $\begin{array}{l}32.33 \\
20.01 \mathrm{~J} \\
8.13 \mathrm{~J} \\
60 \%\end{array}$ & $\begin{array}{l}0.93 \mathrm{~J} \\
1.00 \mathrm{~J} \\
0.87 \mathrm{~J} \\
7 \%\end{array}$ & $\begin{array}{c}3.69 \mathrm{~J} \\
3.50 \mathrm{~J} \\
2.97 \mathrm{~J} \\
11 \%\end{array}$ & $\begin{array}{l}9.19 \mathrm{~J} \\
6.88 \mathrm{~J} \\
3.72 \mathrm{~J} \\
42 \%\end{array}$ & $\begin{array}{l}21.54 \\
19.13 \\
13.91 \\
21 \%\end{array}$ & $\begin{array}{l}6.18 \mathrm{~J} \\
5.50 \mathrm{~J} \\
4.79 \mathrm{~J} \\
13 \%\end{array}$ \\
\hline $\begin{array}{l}\text { R-AH Replicate } 1 \\
\text { R-AM Replicate } 2 \\
\text { R-AM Replicate } 3 \\
\text { RSO }\end{array}$ & $\begin{array}{l}2 \\
2 \\
2\end{array}$ & $\begin{array}{l}\mathrm{C} \\
\mathrm{C} \\
\mathrm{C}\end{array}$ & $\begin{array}{l}16.19 \mathrm{~J} \\
23.50 \\
20.04 \\
18 x\end{array}$ & $\begin{array}{l}17.77 \mathrm{U} \\
17.99 \mathrm{U} \\
17.27 \mathrm{U} \\
\text { NA }\end{array}$ & $\begin{array}{l}3.98 \mathrm{~J} \\
9.74 \mathrm{U} \\
4.26 \mathrm{~J} \\
\text { HA }\end{array}$ & $\begin{array}{c}7.40 \mathrm{~J} \\
8.47 \mathrm{~J} \\
7.69 \mathrm{~J} \\
7 \%\end{array}$ & $\begin{array}{r}31.31 \\
33.90 \\
32.49 \\
4 \%\end{array}$ & $\begin{array}{r}9.07 \\
11.14 \\
10.98 \\
11 \%\end{array}$ \\
\hline $\begin{array}{l}\text { R-PF Repl icate } 1 \\
\text { R-PF Repl icate } 2 \\
\text { R-PF Repl icate } 3 \\
\text { RSD }\end{array}$ & $\begin{array}{l}3 \\
3 \\
3\end{array}$ & $\begin{array}{l}0 \\
D \\
D\end{array}$ & $\begin{array}{c}14.69 \mathrm{~J} \\
12.15 \mathrm{~J} \\
12.28 \mathrm{~J} \\
11 \%\end{array}$ & $\begin{array}{l}17.83 \mathrm{U} \\
17.36 \mathrm{U} \\
17.79 \mathrm{U} \\
\text { NA }\end{array}$ & $\begin{array}{l}9.65 \mathrm{U} \\
9.40 \mathrm{U} \\
9.63 \mathrm{U} \\
\text { NA }\end{array}$ & $\begin{array}{r}3.35 \mathrm{~J} \\
10.14 \mathrm{U} \\
5.43 \mathrm{~J} \\
\text { NA }\end{array}$ & $\begin{array}{r}10.93 \\
12.01 \\
9.68 \\
11 \%\end{array}$ & $\begin{array}{l}7.88 \mathrm{U} \\
7.67 \mathrm{U} \\
7.87 \mathrm{U} \\
\text { NA }\end{array}$ \\
\hline $\begin{array}{l}\text { C-SB Replicate } 1 \\
\text { C-SB Replicate } 2 \\
\text { C-SB Replicate } 3 \\
\text { RSD }\end{array}$ & $\begin{array}{l}4 \\
4 \\
4\end{array}$ & $\begin{array}{l}A \\
A \\
A\end{array}$ & $\begin{array}{r}20.24 \\
19.28 \\
17.78 \\
6 \%\end{array}$ & $\begin{array}{c}15.28 \mathrm{U} \\
14.85 \mathrm{U} \\
14.20 \mathrm{U} \\
\text { NA }\end{array}$ & $\begin{array}{l}2.34 \mathrm{~J} \\
8.04 \mathrm{U} \\
7.69 \mathrm{U} \\
\text { NA }\end{array}$ & $\begin{array}{l}8.93 \mathrm{U} \\
7.19 \mathrm{~J} \\
6.03 \mathrm{~J} \\
\text { NA }\end{array}$ & $\begin{array}{c}11.42 \\
12.18 \\
9.61 \\
12 \%\end{array}$ & $\begin{array}{l}1.24 \mathrm{~J} \\
6.56 \mathrm{U} \\
6.28 \mathrm{U} \\
\text { NA }\end{array}$ \\
\hline
\end{tabular}

(a) I Analyte detected below method detection 1 imit (MOL). but above instrument detection limit (IDL).

(b) $U$ The analyte was not present above the level of the associated value.

(c) Recovery outside quality control range (40\%-120x).

(d) NC Not certified.

(e) NA Not applicable.

(f) Value exceeds relative precision range of $30 x$. 
TABLE J.8. Quality Control Data for High Molecular Weight Polynuclear Aromatic Hydrocarbons (HPAHs), Dry Weight, in Tissue of M. nasuta, Richmond Harbor Program.

\begin{tabular}{|c|c|c|c|c|c|c|c|c|c|c|c|c|}
\hline $\begin{array}{l}\text { Sediment } \\
\text { Ireatment }\end{array}$ & Replicate & $\begin{array}{c}\text { Analytical } \\
\text { Batch } \\
\end{array}$ & $\begin{array}{l}\text { Fluor- } \\
\text { anthene }\end{array}$ & Pyrene. & $\begin{array}{l}\text { Benzo(a) } \\
\text { Anthra- } \\
\text { cene } \\
\end{array}$ & Chrysene & $\begin{array}{l}\text { Benzo(b) } \\
\text { Fluor- } \\
\text { anthene }\end{array}$ & $\begin{array}{l}\text { Benzo(k) } \\
\text { Fluor- } \\
\text { anthene }\end{array}$ & $\begin{array}{l}\text { Benzo(a) } \\
\text { Pyrene } \\
\end{array}$ & $\begin{array}{l}\text { Indeno } \\
(1,2,3-c d) \\
\text { Pyrene }\end{array}$ & $\begin{array}{c}\text { Dibenzo } \\
(a, h) \\
\text { anthracene }\end{array}$ & $\begin{array}{l}\text { Benzo } \\
(g, h, i) \\
\text { peryiene }\end{array}$ \\
\hline \multicolumn{13}{|c|}{ Method Blank } \\
\hline $\begin{array}{l}\text { Blank } \\
\text { Blank } \\
\text { 8lank } \\
\text { 8lank }\end{array}$ & $\begin{array}{l}1 \\
2 \\
3 \\
4\end{array}$ & $\begin{array}{l}A \\
B \\
C \\
D\end{array}$ & $\begin{array}{l}4.74 \mathrm{~J}^{(\mathrm{a})} \\
2.19 \mathrm{~J} \\
1.50 \mathrm{~J} \\
1.88 \mathrm{~J}\end{array}$ & $\begin{array}{l}1.93 \mathrm{~J}^{(\mathrm{b})} \\
8.30 \\
3.83 \mathrm{~J} \\
8.94\end{array}$ & $\begin{array}{l}8.14 \mathrm{U} \\
8.96 \mathrm{U} \\
8.54 \mathrm{U} \\
9.08 \mathrm{U}\end{array}$ & $\begin{array}{l}5.70 \mathrm{U} \\
0.49 \mathrm{~J} \\
5.98 \mathrm{U} \\
6.35 \mathrm{U}\end{array}$ & $\begin{array}{l}8.31 \mathrm{U} \\
0.36 \mathrm{~J} \\
8.72 \mathrm{U} \\
9.27 \mathrm{~J}\end{array}$ & $\begin{array}{l}6.92 \mathrm{U} \\
0.20 \mathrm{~J} \\
7.27 \mathrm{U} \\
7.72 \mathrm{U}\end{array}$ & $\begin{array}{l}7.22 \mathrm{U} \\
7.95 \mathrm{U} \\
7.58 \mathrm{U} \\
8.05 \mathrm{U}\end{array}$ & $\begin{array}{l}8.67 \mathrm{U} \\
9.55 \mathrm{U} \\
9.10 \mathrm{U} \\
9.67 \mathrm{U}\end{array}$ & $\begin{array}{l}5.90 \mathrm{U} \\
6.50 \mathrm{U} \\
6.19 \mathrm{U} \\
6.58 \mathrm{U}\end{array}$ & $\begin{array}{l}11.76 \mathrm{U} \\
12.94 \mathrm{U} \\
12.34 \mathrm{U} \\
13.12 \mathrm{U}\end{array}$ \\
\hline
\end{tabular}

Hatrix Spikes

MSL Background

Background MS

Concentration Recovered

Spike Anount

Percent Recovery

$\begin{array}{ll}\text { MSL Background } & 1 \\ \text { Background MSO } & 1\end{array}$

Concentration Recovered

Spike Amount

Percent Recovery

MS/MSO RPD

MS/MSO I-STAT

MSt Background

Background $H S$

Concentration Recovered

Spike Amount

Percent Recovery

Background MSO

Concentration Recovered

Spike Amount

Percent Recovery

72.08
316.80

316.88
244.80

218.64

$112 \%$

43.19

267.72

224.53

218.64

$\begin{array}{rr}6.09 \mathrm{~J} & 19.82 \\ 245.36 & 218.03 \\ 239.27 & 198.21 \\ 218.64 & 218.64\end{array}$

12.05

$4.55 \mathrm{~J} \quad 1.39 \mathrm{~J}$

8.00 U 5.44 U $10.85 \mathrm{U}$ 246.67

234.62

$103 x$

$109 x$ $91 x$

232.42

197.48

237.26

211.32

217.62

$107 \%$

237.26

$211.32 \quad 217.62$

72.08

43.19

324.20

252.12

218.88

277.50

234.31

$6.09 \mathrm{~J} \quad 19.82$
258.42

$258.42 \quad 218.64$

12.05

$106 x$

$90 x$

$109 \%$

$97 \% \quad 218.64$

$115 \%$

$107 \%$

218. 88

245.09

233.04

$4.55 \mathrm{~J} \quad 1.39 \mathrm{~d}$

$8.00 \mathrm{U} \quad 5.44 \mathrm{U} \quad 10.85 \mathrm{~L}$

$\begin{array}{lllll}248.91 & 196.04 & 245.71 & 198.07 & 220.39\end{array}$

$\begin{array}{lllll}244.36 & 194.65 & 245.71 & 198.07 & 220.39\end{array}$

$0.01^{3 \%}$

$115 \%$

$91 \%$
98

$106 \%$
108

18.88

218.88

20.39

0.02

$\begin{array}{cc}5 \% & 0 \% \\ 0.03 & 0.00\end{array}$

0.00

$5 \%$

$89 \%$

$112 \%$

\begin{tabular}{l}
$90 \%$ \\
\hline
\end{tabular}

$101 \%$

$69.47 \quad 41.24$

41.24
308.58

267.34

$7.14 \mathrm{~J} \quad 20.84$

$262.20 \quad 275.66$

265.53

243.09

243.09

$255.06 \quad 254.82$

$7.30 \mathrm{~J}$

0.02

$0.00^{1 \%}$

0.02

0.03

$1 \%$

260.47

$5.28 \mathrm{~d}$

$2.66 \mathrm{~J}$

$0.75 \mathrm{~J}$

$5.96 \mathrm{U}$

$11.88 \mathrm{U}$

$281.36 \quad 250.75$

230.88

3.96

214.38

$\begin{array}{llllll}259.17 & 276.08 & 248.09 & 230.13 & 234.65 & 214.38\end{array}$

$109 \%$

$110 \%$

$105 \% \quad 243.09$

$107 \%$

$102 \%$

.09

243.09

243.09

69.47

333.46

41.24

$7.14 \mathrm{~J} \quad 20.84$

$7.30 \mathrm{~J}$

$5.28 \mathrm{~J} \quad 2.66 \mathrm{~J}$

$0.75 \mathrm{~J}$

$97 \%$

$88 \%$

263.99

224.78

262.97

272.01

249.83

259.97

229.35

$5.96 \cup \quad 11.88$

224.78

$251.86 \quad 251.17$

$117 \%$

$112 \% \quad 224.78$

0.04

$6 \%$

MS/MSD I-STAT

0.03

$0.03 \quad 0.03$

$108 \%$

$254.69 \quad 235.30$

$210.45 \quad 222.79$

$210.45 \quad 222.79$

$\begin{array}{rrrrr}113 \% & 224.78 & 224.78 & 224.78 & 224.78 \\ & 105 \% & 102 \% & 94 \% & 99 \%\end{array}$

0.01

0.00

$0.3 \%$

0.04

$0.02 \quad 12 \%$ 
TABLE J.8. (contd)

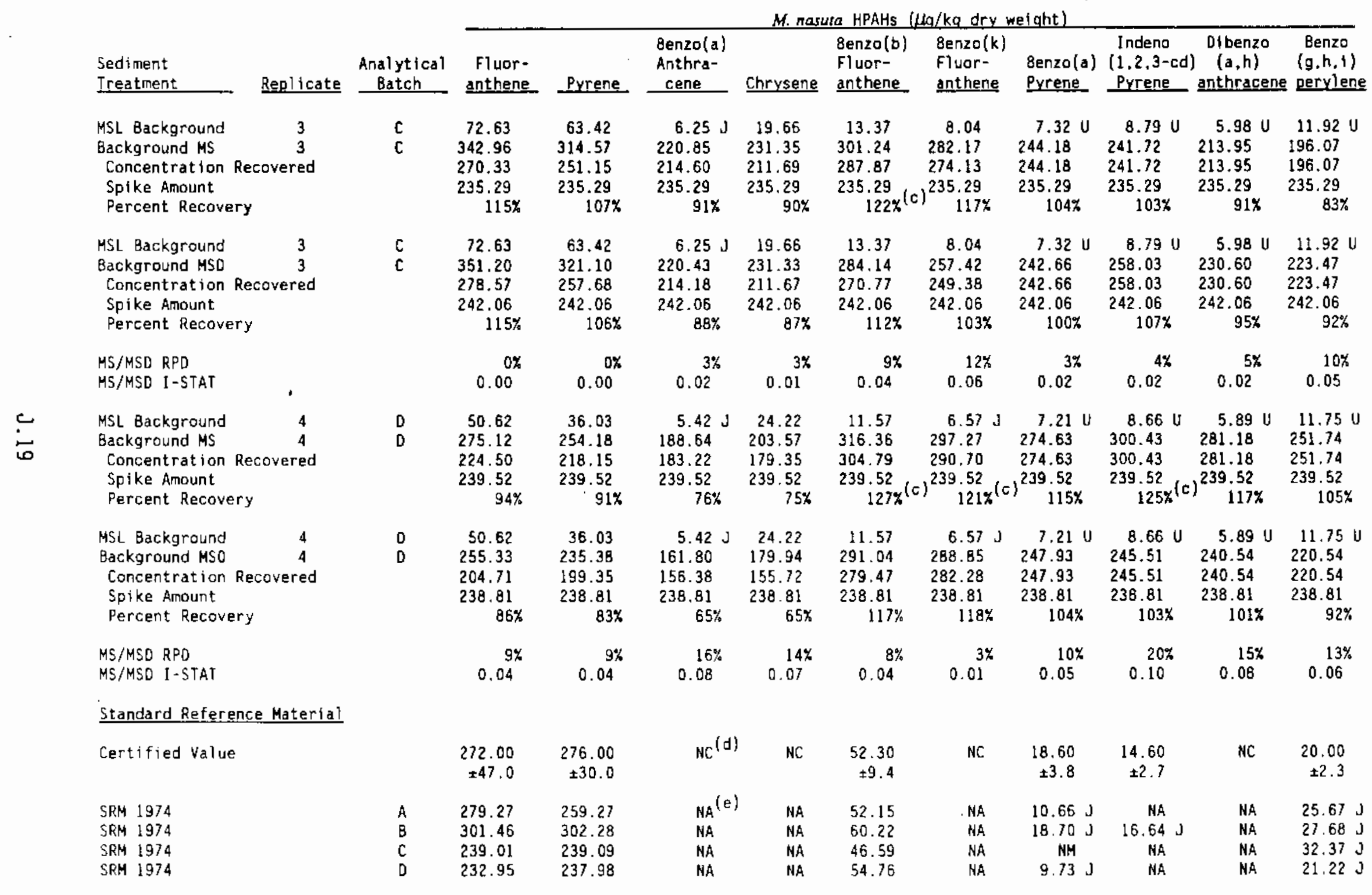




\section{TABLE J.8. (contd)}

\begin{tabular}{|c|c|c|c|c|c|c|c|c|c|c|c|c|}
\hline & & & & & & M. na & HPAHS & $\mathrm{kg} \mathrm{dry}$ & ght & & & \\
\hline $\begin{array}{l}\text { ediment } \\
\text { reatment }\end{array}$ & Reolicate & $\begin{array}{c}\text { Analytical } \\
\text { Batch }\end{array}$ & $\begin{array}{l}\text { Fluor- } \\
\text { anthene }\end{array}$ & Pyrene & $\begin{array}{c}\text { Benzo(a) } \\
\text { Anthra- } \\
\text { Cene }\end{array}$ & Chrysene & $\begin{array}{l}\text { Benzo }(b) \\
\text { Fluor- } \\
\text { anthene }\end{array}$ & $\begin{array}{l}\text { Benzo(k) } \\
\text { Fluor- } \\
\text { anthene }\end{array}$ & $\begin{array}{l}\text { Benzo (a) } \\
\text { Pyrene }\end{array}$ & $\begin{array}{l}\text { Indeno } \\
(1,2,3-\mathrm{cd}\} \\
\text { Pyrene }\end{array}$ & $\begin{array}{c}\text { Dibenzo } \\
(a, h) \\
\text { anthracene }\end{array}$ & $\begin{array}{l}\text { Benzo } \\
(g, h, i) \\
\text { perylene }\end{array}$ \\
\hline
\end{tabular}

\section{Analytical Replicates}

$\begin{array}{lll}\text { COMP V Replicate } 1 & 5 \\ \text { COMP V Replicate } 2 & 5 \\ \text { COMP V Replicate } 3 & 5 \\ \text { RSD }\end{array}$

R-AM Replicate

R-AM Replicate 2

R-AM Replicate 3

RSD

$\begin{array}{rr}42.92 & 148.45 \\ 43.61 & 148.00 \\ 41.49 & 143.01 \\ 3 \% & 2 \% \\ & \\ 203.36 & 198.96 \\ 226.25 & 230.78 \\ 216.37 & 215.09 \\ 5 \% & 7 \%\end{array}$

18.54
18.87
17.56
$4 \%$

29.90
30.50
27.32
$6 \%$

$\begin{array}{rl}52.93 & 33.99 \\ 52.07 & 42.32 \\ 57.03 & 36.91 \\ 5 \% & 11 \%\end{array}$

41.18

41.61

14.87

15.64

$1.75 \mathrm{~J}$

$1 \%$

3.74

$2.05 \mathrm{~J} 20.76 \mathrm{~J}$

$2 \%$

$44.60 \quad 70.65$

$38.28 \quad 51.02$

45.45

$14.01 \mathrm{U}$

$20 x \quad 9 \%$

R-PF Replicate 1

R-PF Replicate 2

$5 x$

51.39

93.71

45.44

51.02
44.10
49.67

$9.53 \mathrm{~V} \quad 14.23 \mathrm{~J}$

$8 \%$

$14 \%$

$14 \%$

67
$8 \%$

53.14

13.61

$7 \%$

$13.19 \mathrm{U} \quad 4.68 \mathrm{~J}$

$13.47 \mathrm{U} \quad 11.22 \mathrm{U} \quad 11.70 \mathrm{U}$

R-Pr Replicate 3

10.38
9.39

$8.91 \mathrm{~J}$

$7.48 \mathrm{~J}$

$13.16 \mathrm{U}$

$3.35 \mathrm{~J}$
$3.00 \mathrm{~J}$

127

9X

NA

$24 \%$

13.43

$10.93 \mathrm{U}$
$11.20 \mathrm{U}$

$1.70 \mathrm{U}$
$11.39 \mathrm{U}$

NA

i2.39 $\mathrm{J}$

$9.26 \mathrm{U} \quad 15.41 \mathrm{~J}$

18.77

9.74
26.46
9.18
$65 \times(f)$

$2.67 \mathrm{~J}$

$6.43 \mathrm{~J}$

NA

NA

$14.05 \mathrm{U}$

$11 \%$

C-SB Replicate

C-SB Replicate 2
C-SB Replicate 3

21.22
18.51

$2.34 \mathrm{~J} \quad 6.07 \mathrm{~J}$

$4.22 \mathrm{~J}$

$3.34 \mathrm{~J}$

NA

$13.68 \mathrm{U}$
$14.02 \mathrm{U}$

$9.56 \mathrm{U} \quad 19.06 \mathrm{~V}$

$.31 \mathrm{v} 18.55 \mathrm{U}$

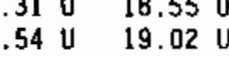

RSD

Bx

$65 x^{10}(f)$

$19 \%$

$7.20 \mathrm{~J}$
$9 \%$

$5.65 \mathrm{~J}$

$2.61 \mathrm{~J}$

$1.76 \mathrm{~J} \quad 12.05 \mathrm{U}$

NA

(a) I The analyte was not present above the level of the associated value.

(b) J Analyte detected below method detection linit (MOL), but above instrunent detection limit (IDL).

(c) Recovery outside quality control range (40\%-120\%).

(d) NC Not certified.

(e) NA Not applicable.

(f) Value exceeds relative precision range of $30 \%$. 
TABLE J.9. Surrogate Recoveries for Polynuclear Aromatic Hydrocarbons (PAHs) Including Quality Control Data, in Tissue of M. nasuta, Richmond Harbor Program

\begin{tabular}{|c|c|c|c|c|c|}
\hline $\begin{array}{l}\text { Sediment } \\
\text { Treatment }\end{array}$ & Replicate & $\begin{array}{l}\text { Analytical } \\
\text { Batch } \\
\end{array}$ & $\begin{array}{l}\text { 1. nasuta } \\
\text { Naphtha- } \\
\text { lene } \\
\text { d8 } \\
\end{array}$ & $\begin{array}{l}\text { Acenaph- } \\
\text { thene } \\
\text { d10 }\end{array}$ & $\begin{array}{l}\text { Recoveries } \\
\text { Benzo(a) } \\
\text { Pyrene } \\
\text { d12 } \\
\end{array}$ \\
\hline $\begin{array}{l}\text { COMP I } \\
\text { COMP I } \\
\text { COMP I } \\
\text { COMP I } \\
\text { COMP }\end{array}$ & $\begin{array}{l}1 \\
2 \\
3 \\
4 \\
5\end{array}$ & $\begin{array}{l}D \\
D \\
A \\
B \\
A\end{array}$ & $\begin{array}{l}58.18 \\
39.63^{(a)} \\
65.86 \\
79.67 \\
69.73\end{array}$ & $\begin{array}{l}69.48 \\
42.89 \\
63.21 \\
77.94 \\
69.18\end{array}$ & $\begin{array}{l}55.99 \\
35.12^{(a)} \\
66.91 \\
73.71 \\
69.24\end{array}$ \\
\hline $\begin{array}{l}\text { COMP } \text { II } \\
\text { COMP II } \\
\text { COMP II } \\
\text { COMP II } \\
\text { COMP II }\end{array}$ & $\begin{array}{l}1 \\
2 \\
3 \\
4 \\
5\end{array}$ & $\begin{array}{l}\text { D } \\
\text { A } \\
\text { C } \\
\text { D } \\
\text { C }\end{array}$ & $\begin{array}{l}63.27 \\
66.20 \\
52.59 \\
55.47 \\
60.29\end{array}$ & $\begin{array}{l}75.07 \\
67.12 \\
56.12 \\
61.35 \\
58.13\end{array}$ & $\begin{array}{l}66.80 \\
69.78 \\
42.98 \\
53.69 \\
50.99\end{array}$ \\
\hline $\begin{array}{l}\text { COMP II I } \\
\text { COMP II I } \\
\text { COMP II I } \\
\text { COMP II I } \\
\text { COMP II I }\end{array}$ & $\begin{array}{l}1 \\
2 \\
3 \\
4 \\
5\end{array}$ & $\begin{array}{l}C \\
C \\
A \\
D \\
C\end{array}$ & $\begin{array}{l}58.30 \\
62.52 \\
64.12 \\
59.73 \\
69.76\end{array}$ & $\begin{array}{l}61.97 \\
66.69 \\
64.70 \\
60.97 \\
77.23\end{array}$ & $\begin{array}{l}44.68 \\
53.60 \\
62.93 \\
46.44 \\
56.56\end{array}$ \\
\hline $\begin{array}{l}\text { TC-5 Upper Comp } \\
\text { TC-5 Upper Comp } \\
\text { TC-5 Upper Comp } \\
\text { TC-5 Upper Comp } \\
\text { TC-5 Upper Comp }\end{array}$ & $\begin{array}{l}1 \\
2 \\
3 \\
4 \\
5\end{array}$ & $\begin{array}{l}\text { C } \\
\text { C } \\
\text { C } \\
A \\
A\end{array}$ & $\begin{array}{l}57.85 \\
61.45 \\
52.55 \\
61.16 \\
65.12\end{array}$ & $\begin{array}{l}60.65 \\
66.10 \\
58.27 \\
63.42 \\
67.71\end{array}$ & $\begin{array}{l}54.97 \\
50.08 \\
51.36 \\
63.50 \\
64.08\end{array}$ \\
\hline $\begin{array}{l}\text { COMP IV } \\
\text { COMP IV } \\
\text { COMP IV } \\
\text { COMP IV } \\
\text { COMP IV }\end{array}$ & $\begin{array}{r}1 \\
2 \\
3 \\
4 \\
5\end{array}$ & $\begin{array}{l}\text { C } \\
C \\
A \\
C \\
A\end{array}$ & $\begin{array}{l}61.14 \\
53.13 \\
65.58 \\
59.28 \\
60.66\end{array}$ & $\begin{array}{l}64.81 \\
64.68 \\
71.42 \\
65.70 \\
61.35\end{array}$ & $\begin{array}{l}54.43 \\
57.12 \\
64.36 \\
50.21 \\
60.27\end{array}$ \\
\hline $\begin{array}{l}\text { COMP V } \\
\text { COMP V } \\
\text { COMP V } \\
\text { COMP V } \\
\text { COMP V Replicate } 1 \\
\text { COMP V Replicate } 2 \\
\text { COMP V Replicate } 3\end{array}$ & $\begin{array}{l}1 \\
2 \\
3 \\
4 \\
5 \\
5 \\
5\end{array}$ & $\begin{array}{l}\text { A } \\
A \\
A \\
D \\
B \\
B \\
B\end{array}$ & $\begin{array}{l}55.51 \\
64.51 \\
64.45 \\
70.92 \\
79.63 \\
78.34 \\
78.69\end{array}$ & $\begin{array}{l}58.74 \\
66.56 \\
67.00 \\
76.58 \\
77.13 \\
74.81 \\
77.90\end{array}$ & $\begin{array}{l}63.28 \\
64.23 \\
64.34 \\
55.85 \\
75.05 \\
74.30 \\
75.44\end{array}$ \\
\hline
\end{tabular}


TABLE J.9. (contd)

Sediment

Treatment

COMP VI

COMP VI

COMP VI

COMP VI

COMP VI

$\mathrm{R}-\mathrm{AC}$

$\mathrm{R}-\mathrm{AC}$

$R-A C$

$R-A C$

$\mathrm{R}-\mathrm{AC}$

$R-A M$

R-AM Replicate 1

R-AM Replicate 2

R-AM Replicate 3

$\mathrm{R}-\mathrm{AM}$

R-AM

$\mathrm{R}-\mathrm{AM}$

$R-B F$

$R-B F$

$R-B F$

$R-B F$

$R-B F$

R-OS

$\mathrm{R}-0 \mathrm{~S}$

R-OS

$\mathrm{R}-\mathrm{OS}$

R-OS

$R-P F$

$R-P F$

R-PF Replicate 1

R-PF Replicate 2

R-PF Replicate 3

$R-P F$

$R \cdot P F$

C-SB

$C-S B$

$\mathrm{C}-\mathrm{SB}$

\section{Replicate}

1
2
3
4
5

1

2

3

5

1
2
2
2
3
4
5

1

3

4

5

1

2

3

4

1

2

3

3

3

4

5

1
2
3
M. nasuta S NaphthaAnalytical lene

Batch $d 8$

C
A
$B$
$A$
$D$

62.57

56.78

78.02

59.02

$36.34^{(a)}$

76.94

57.38

65.10

61.63

63.87

78.00

66.26

57.24

58.39

78.71

64.52

77.60

67.04

80.12

79.24

58.78

61.99

79.83

44.27

65.35

72.42

57.92

66.57

55.12

61.34

59.60

66.24

68.56

57.85

65.81

57.09

69.42

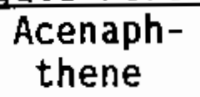

thene

dlo

65.67

58.56

76.83

58.81

40.57

76.67

69.18

67.14

63.43

67.60

76.10

69.56

56.77

58.99

77.43

62.76

76.98

71.15

78.82

79.06

59.60

62.26

77.70

48.56

63.88

81.86

59.65

70.73

60.01

61.99

62.54

70.07

72.43

59.71

71.86

63.49

67.22
Recoveries

Benzo(a)

Pyrene

d12

57.04

56.47

73.39

63.90

$35.04^{(a)}$

73.89

65.02

66.82

70.13

68.84

70.39

50.31

54.39

51.39

75.33

62.99

78.10

56.70

74.31

75.82

58.08

61.59

76.84

$39.35^{(a)}$

61.18

60.07

45.66

53.62

41.47

52.90

43.65

48.67

57.42

46.68

52.75

50.60

64.93 
TABLE J.9. (contd)

Sediment

Treatment

C-SB Replicate 1

C-SB Replicate 2

C-SB Rep] icate 3

C-SB

C-NE

$\mathrm{C}-\mathrm{NE}$

$\mathrm{C}-\mathrm{NE}$

$\mathrm{C}-\mathrm{NE}$

$\mathrm{C}-\mathrm{NE}$

MSL Background

MSL Background

MSL. Background

MSL Background

MSL Background

Quality Control Data

Method Blank

Blank

Blank

BTank

Blank

\section{Matrix Spikes}

MSL Background MS

MSL Background MSD

MS/MSD RPD

MS/MSD I-STAT

MSL Background MS

MSL Background MSD

MS/MSD RPD

MS/MSD I-STAT

MSL Background MS

MSL Background MSD

MS/MSD RPD

MS/MSD I -STAT

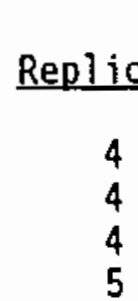

4
4
4
5

1

2

3

4

5

1
2
3
4
5

\section{M.}

Analytical Batch

$\begin{array}{ll}\text { A } & 65.06 \\ \text { A } & 64.01 \\ \text { A } & 63.32 \\ \text { D } & 62.57\end{array}$

B

B

B

B

B

$\begin{array}{ll}\text { A } & 64.89 \\ \text { B } & 80.61 \\ \text { C } & 60.19 \\ \text { D } & 33.30^{(a)} \\ \text { D } & 40.91\end{array}$

77.70

77.01

75.41

80.30

75.09

64.89

60.19

40.91
Acenaph -

thene

d 10

65.54

67.39

63.50

73.46

75.48

76.82

78.70

79.43

74.67

64.98

78.97

70.06

$38.12^{(a)}$

49.03
Recoveries

Benzo(a)

Pyrene

d12

64.50

63.49

59.47

62.99

74.07

74.07

77.26

74.88

73.75

61.06

75.73

56.76

$28.47^{(a)}$ $31.00^{(a)}$

$\begin{array}{llll}A & 20.01^{(a)} & 18.41^{(a)} & 18.27^{(a)} \\ B & 24.95^{(a)} & 25.04^{(a)} & 25.15^{(a)} \\ C & 18.69^{(a)} & 18.34^{(a)} & 16.94^{(a)} \\ D & 21.50^{(a)} & 20.38^{(a)} & 18.33^{(a)}\end{array}$

A

65

63

70

68

72

73

0.02

0.01

0.01

B

82

77

82

81

B

77

78

6
0.03

0.6

4
0.02

C 67

70

65

C

68

69

66

0.01

0.01

0.01 
TABLE J.9. (contd)

Sediment

Ireatment

Replicate

H. nasut NaphthaAnalytical lene Batch d8

$D$
$D$ 61
56

68

MSL Background MSD

9
0.04

0.01

6
0.03

MS/MSD I-STAT

Standard Reference Material

SRM 1974
SRM 1974
SRM 1974
SRM 1974

$\begin{array}{ll}\text { A } & 67.08 \\ \text { B } & 76.15 \\ \text { C } & 68.11 \\ \text { D } & 67.07\end{array}$

69.33

77.43

75.31

69.59

61.56

74.27

59.62

54.39

Analytical Replicates

$\begin{array}{lll}\text { COMP V Replicate } 1 & \mathbf{5} \\ \text { COMP V Replicate 2 } & 5 \\ \text { COMP V Replicate } 3 & 5 \\ \text { RSD } & \end{array}$

$\begin{array}{lr}\text { B } & 79.63 \\ \text { B } & 78.34 \\ \text { B } & 78.69 \\ & 1\end{array}$

77.13

74.81

77.90

74.30

75.44

$\begin{array}{ll}\text { R-AM Replicate } 1 & 2 \\ \text { R-AM Replicate } 2 & 2 \\ \text { R-AM Replicate } 3 & 2\end{array}$

C $\quad 66.26$

57.24

58.39

RSD

c

- 8

R-PF Replicate 1

R-PF Replicate 2

R-PF Replicate 3

3
3
3

$D$
$D$
$D$

61.34

59.60

66.24

RSD

6

69.56

56.77

58.99

11

61.99

62.54

70.07

65.06

64.01

63.32

$\begin{array}{lr}\text { A } & 65.06 \\ \text { A } & 64.01 \\ \text { A } & 63.32 \\ & 1\end{array}$

65.54

67.39

63.50

50.31

54.39

51.39

4

C-SB Replicate 1

C-SB Replicate 3

RSD

4
4
4

52.90

43.65

48.67 10

64.50

63.49

59.47

(a) Recovery outside quality control range (40\%-120\%). 
TABLE J.10. Chlorinated Pesticides (alphabetical, Aldrin - 4'4-DDT), Dry Weight, in Tissue of M. nasuta, Richmond Harbor Program

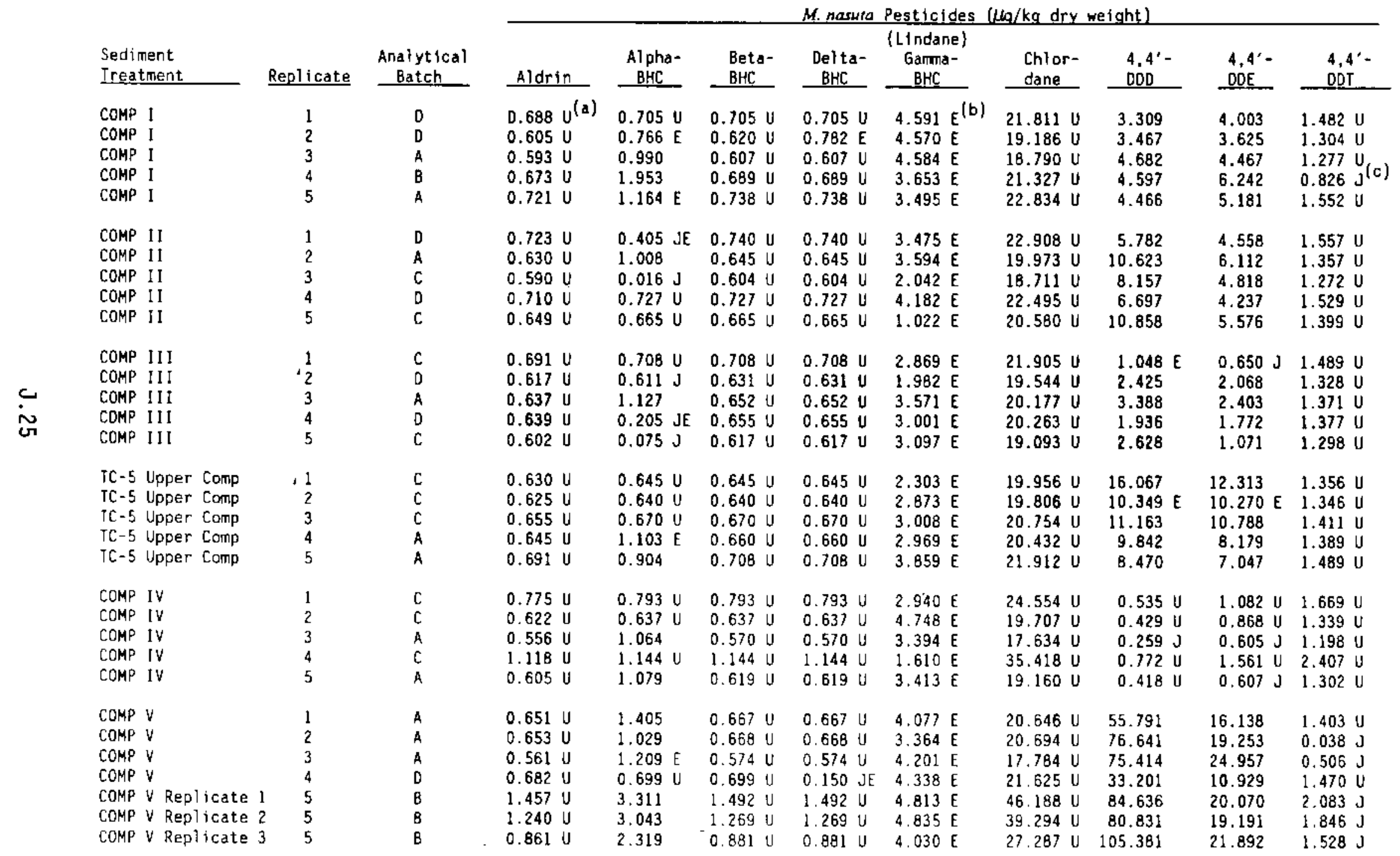


TABLE J.10. (contd)

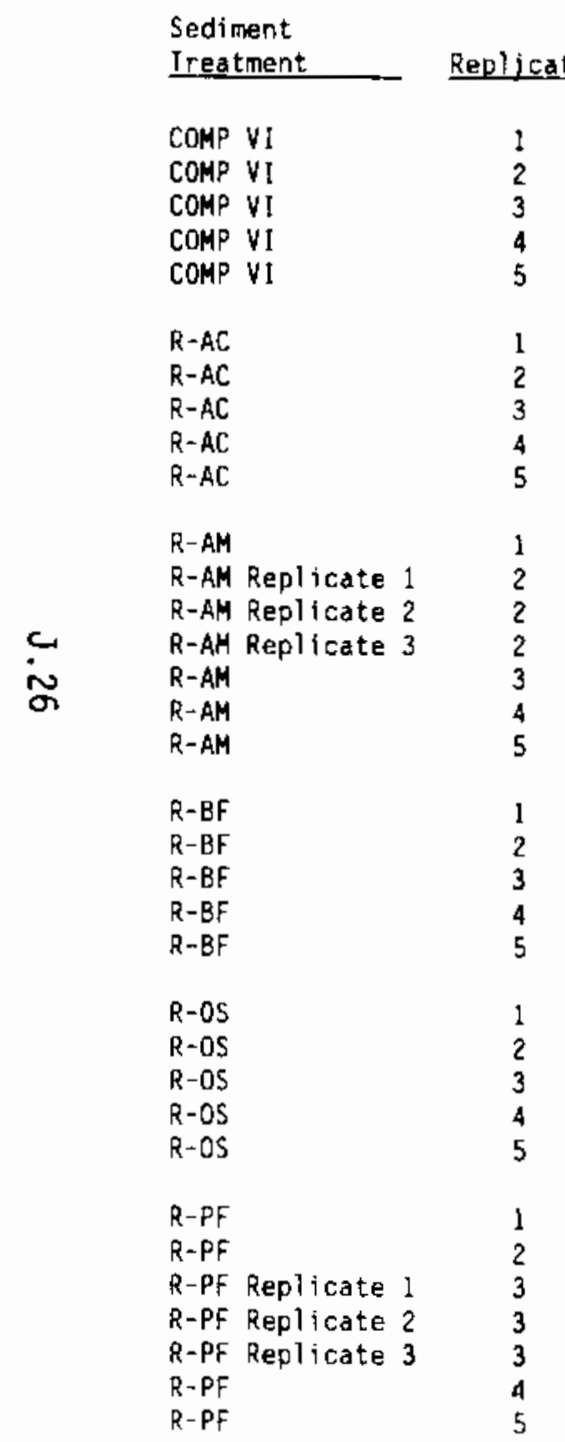

M. Masuta Pesticldes $(\mu \mathrm{g} / \mathrm{kg}$ dry welaht)

Analytical Batch.

$C$
$A$
$B$
$A$
$D$

8

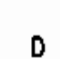

$D$
$B$
$B$
$A$
$A$

$B$
$D$
$B$
$D$
$C$

\begin{tabular}{|c|c|c|c|c|c|c|c|c|}
\hline Aldrin & $\begin{array}{l}\text { Alpha- } \\
\text { BHC }\end{array}$ & $\begin{array}{l}\text { Beta- } \\
8 \mathrm{HC} \\
\end{array}$ & $\begin{array}{l}\text { Oelta- } \\
\text { BHC }\end{array}$ & $\begin{array}{c}\text { (Lindane) } \\
\text { Ganma- } \\
B H C \\
\end{array}$ & $\begin{array}{l}\text { Chlor- } \\
\text { dane }\end{array}$ & $\begin{array}{l}4,4^{\prime}- \\
D D D \\
\end{array}$ & $\begin{array}{l}4,4^{\prime}- \\
D D E \\
\end{array}$ & $\begin{array}{l}4,4^{\prime}- \\
\mathrm{OOT}\end{array}$ \\
\hline $\begin{array}{l}0.711 \mathrm{U} \\
0.678 \mathrm{U} \\
1.712 \mathrm{U} \\
0.692 \mathrm{U} \\
0.784 \mathrm{U}\end{array}$ & $\begin{array}{l}0.728 \mathrm{U} \\
1.409 \\
4.429 \\
1.176 \\
1.218 \mathrm{E}\end{array}$ & $\begin{array}{l}0.728 \mathrm{U} \\
0.694 \mathrm{U} \\
1.753 \mathrm{U} \\
0.709 \mathrm{U} \\
0.803 \mathrm{U}\end{array}$ & $\begin{array}{l}0.728 \mathrm{U} \\
0.694 \mathrm{U} \\
1.753 \mathrm{U} \\
0.709 \mathrm{U} \\
0.224 \mathrm{JE}\end{array}$ & $\begin{array}{l}2.694 \mathrm{E} \\
3.656 \mathrm{E} \\
5.696 \mathrm{E} \\
4.655 \mathrm{E} \\
6.106 \mathrm{E}\end{array}$ & $\begin{array}{l}22.537 \mathrm{U} \\
21.495 \mathrm{U} \\
54.262 \mathrm{U} \\
21.939 \mathrm{U} \\
24.846 \mathrm{U}\end{array}$ & $\begin{array}{r}48.761 \\
75.795 \\
156.357 \\
72.746 \\
45.508\end{array}$ & $\begin{array}{l}16.522 \\
17.724 \\
28.138 \\
17.565 \\
12.755 \mathrm{E}\end{array}$ & $\begin{array}{l}1.532 \mathrm{U} \\
1.461 \mathrm{U} \\
2.937 \mathrm{~J} \\
0.377 \mathrm{~J} \\
0.039 \mathrm{~J}\end{array}$ \\
\hline $\begin{array}{l}0.591 \mathrm{U} \\
0.708 \mathrm{U} \\
0.629 \mathrm{U} \\
0.645 \mathrm{U} \\
0.677 \mathrm{U}\end{array}$ & $\begin{array}{l}1.830 \\
0.725 \mathrm{U} \\
0.235 \mathrm{JE} \\
1.454 \\
0.732 \mathrm{E}\end{array}$ & $\begin{array}{l}0.605 \mathrm{U} \\
0.725 \mathrm{U} \\
0.643 \mathrm{U} \\
0.660 \mathrm{U} \\
0.693 \mathrm{U}\end{array}$ & $\begin{array}{l}0.605 \mathrm{U} \\
0.725 \mathrm{U} \\
0.643 \mathrm{U} \\
0.660 \mathrm{U} \\
0.029 \mathrm{JE}\end{array}$ & $\begin{array}{l}3.356 \mathrm{E} \\
3.340 \mathrm{E} \\
3.419 \mathrm{E} \\
3.866 \mathrm{E} \\
3.991 \mathrm{E}\end{array}$ & $\begin{array}{l}18.736 \mathrm{U} \\
22.438 \mathrm{U} \\
19.922 \mathrm{U} \\
20.432 \mathrm{U} \\
21.456 \mathrm{U}\end{array}$ & $\begin{array}{l}5.003 \\
2.935 \\
5.597 \\
6.001 \\
3.904\end{array}$ & $\begin{array}{l}5.117 \\
2.320 \\
4.256 \\
4.275 \\
3.618\end{array}$ & $\begin{array}{l}1.273 \mathrm{U} \\
1.525 \mathrm{U} \\
1.354 \mathrm{U} \\
1.389 \mathrm{U} \\
1.458 \mathrm{U}\end{array}$ \\
\hline $\begin{array}{l}0.695 \mathrm{U} \\
1.072 \mathrm{U} \\
1.085 \mathrm{U} \\
1.042 \mathrm{U} \\
0.751 \mathrm{U} \\
1.374 \mathrm{U} \\
0.700 \mathrm{U}\end{array}$ & $\begin{array}{l}1.848 \\
1.098 \mathrm{U} \\
1.111 \mathrm{U} \\
1.066 \mathrm{U} \\
2.117 \\
3.206 \\
1.944\end{array}$ & $\begin{array}{l}0.711 \mathrm{U} \\
1.098 \mathrm{U} \\
1.111 \mathrm{U} \\
1.066 \mathrm{U} \\
0.769 \mathrm{U} \\
1.406 \mathrm{U} \\
0.716 \mathrm{U}\end{array}$ & $\begin{array}{l}0.711 \mathrm{U} \\
1.098 \mathrm{U} \\
1.111 \mathrm{U} \\
1.066 \mathrm{U} \\
0.769 \mathrm{U} \\
1.406 \mathrm{U} \\
0.716 \mathrm{U}\end{array}$ & $\begin{array}{l}3.624 \mathrm{E} \\
1.071 \mathrm{JE} \\
1.825 \mathrm{E} \\
2.138 \mathrm{E} \\
3.949 \mathrm{E} \\
4.919 \mathrm{E} \\
3.656 \mathrm{E}\end{array}$ & $\begin{array}{l}22.028 \mathrm{U} \\
33.978 \mathrm{U} \\
34.389 \mathrm{U} \\
33.016 \mathrm{U} \\
23.813 \mathrm{U} \\
43.529 \mathrm{U} \\
22.172 \mathrm{U}\end{array}$ & $\begin{array}{l}0.480 \mathrm{U} \\
0.740 \mathrm{U} \\
0.749 \mathrm{U} \\
0.719 \mathrm{U} \\
0.012 \mathrm{~J} \\
0.949 \mathrm{U} \\
0.483 \mathrm{U}\end{array}$ & $\begin{array}{l}1.909 \\
1.497 \mathrm{U} \\
1.515 \mathrm{U} \\
1.455 \mathrm{U} \\
2.814 \\
3.665 \\
2.190\end{array}$ & $\begin{array}{l}1.497 \mathrm{U} \\
2.309 \mathrm{U} \\
2.337 \mathrm{U} \\
2.244 \mathrm{U} \\
1.315 \mathrm{~J} \\
1.999 \mathrm{~J} \\
0.951 \mathrm{~J}\end{array}$ \\
\hline $\begin{array}{l}0.787 \mathrm{U} \\
0.556 \mathrm{U} \\
0.619 \mathrm{U} \\
0.731 \mathrm{U} \\
0.563 \mathrm{U}\end{array}$ & $\begin{array}{l}0.805 \mathrm{~J} \\
1.725 \\
1.822 \\
1.192 \\
1.151\end{array}$ & $\begin{array}{l}0.805 \mathrm{U} \\
0.569 \mathrm{U} \\
0.634 \mathrm{U} \\
0.749 \mathrm{U} \\
0.576 \mathrm{U}\end{array}$ & $\begin{array}{l}0.805 \mathrm{U} \\
0.569 \mathrm{U} \\
0.634 \mathrm{U} \\
0.749 \mathrm{U} \\
0.576 \mathrm{U}\end{array}$ & $\begin{array}{l}3.323 \mathrm{E} \\
4.494 \mathrm{E} \\
4.103 \mathrm{E} \\
3.278 \mathrm{E} \\
2.947 \mathrm{E}\end{array}$ & $\begin{array}{l}24.933 \mathrm{U} \\
17.630 \mathrm{U} \\
19.615 \mathrm{U} \\
23.177 \mathrm{U} \\
17.842 \mathrm{U}\end{array}$ & $\begin{array}{l}1.401 \mathrm{E} \\
2.657 \\
2.724 \\
2.883 \\
3.046\end{array}$ & $\begin{array}{l}2.132 \\
5.246 \\
5.486 \\
3.420 \\
3.386\end{array}$ & $\begin{array}{l}1.694 \mathrm{U} \\
1.198 \mathrm{U} \\
1.333 \mathrm{U} \\
1.575 \mathrm{U} \\
1.213 \mathrm{U}\end{array}$ \\
\hline $\begin{array}{l}0.622 \text { U } \\
0.638 \mathrm{U} \\
0.641 \mathrm{U} \\
0.604 \mathrm{U} \\
0.582 \mathrm{U}\end{array}$ & $\begin{array}{l}1.904 \\
0.961 \mathrm{E} \\
1.772 \\
0.148 \mathrm{~J} \\
0.748 \mathrm{E}\end{array}$ & $\begin{array}{l}0.637 \mathrm{U} \\
0.653 \mathrm{U} \\
0.657 \mathrm{U} \\
0.619 \mathrm{U} \\
0.595 \mathrm{U}\end{array}$ & $\begin{array}{l}0.637 \mathrm{U} \\
0.219 \mathrm{JE} \\
0.657 \mathrm{U} \\
0.460 \mathrm{JE} \\
0.595 \mathrm{U}\end{array}$ & $\begin{array}{l}3.430 \mathrm{E} \\
6.363 \mathrm{E} \\
3.564 \mathrm{E} \\
3.289 \mathrm{E} \\
3.824 \mathrm{E}\end{array}$ & $\begin{array}{l}19.712 \mathrm{U} \\
20.211 \mathrm{U} \\
20.327 \mathrm{U} \\
19.150 \mathrm{U} \\
18.434 \mathrm{U}\end{array}$ & $\begin{array}{l}0.430 \mathrm{U} \\
0.834 \\
0.443 \mathrm{U} \\
0.417 \mathrm{U} \\
0.402 \mathrm{U}\end{array}$ & $\begin{array}{l}4.416 \\
4.615 \\
4.060 \\
3.569 \\
3.293 \mathrm{E}\end{array}$ & $\begin{array}{l}1.340 \mathrm{U} \\
1.374 \mathrm{U} \\
1.381 \mathrm{U} \\
1.301 \mathrm{U} \\
1.253 \mathrm{U}\end{array}$ \\
\hline $\begin{array}{l}0.690 \mathrm{U} \\
0.661 \mathrm{U} \\
1.076 \mathrm{U} \\
1.047 \mathrm{U} \\
1.073 \mathrm{U} \\
0.796 \mathrm{U} \\
0.620 \mathrm{U}\end{array}$ & $\begin{array}{l}0.706 \mathrm{U} \\
0.677 \mathrm{U} \\
1.101 \mathrm{U} \\
1.072 \mathrm{U} \\
1.099 \mathrm{U} \\
0.212 \mathrm{JE} \\
1.077\end{array}$ & $\begin{array}{l}0.706 \mathrm{U} \\
0.677 \mathrm{U} \\
1.101 \mathrm{U} \\
1.072 \mathrm{U} \\
1.099 \mathrm{U} \\
0.814 \mathrm{U} \\
0.634 \mathrm{U}\end{array}$ & $\begin{array}{l}0.706 \mathrm{U} \\
0.677 \mathrm{~J} \\
1.101 \mathrm{U} \\
1.072 \mathrm{~J} \\
1.099 \mathrm{~J} \\
0.227 \mathrm{JE} \\
0.634 \mathrm{U}\end{array}$ & $\begin{array}{l}2.670 \mathrm{E} \\
3.002 \mathrm{E} \\
3.015 \mathrm{E} \\
2.161 \mathrm{E} \\
3.105 \mathrm{E} \\
3.607 \mathrm{E} \\
4.393 \mathrm{E}\end{array}$ & $\begin{array}{l}21.858 \mathrm{U} \\
20.956 \mathrm{U} \\
34.093 \mathrm{U} \\
33.185 \mathrm{U} \\
34.011 \mathrm{U} \\
25.216 \mathrm{U} \\
19.636 \mathrm{U}\end{array}$ & $\begin{array}{l}0.476 \mathrm{U} \\
0.457 \mathrm{U} \\
0.743 \mathrm{U} \\
0.723 \mathrm{U} \\
0.741 \mathrm{U} \\
0.549 \mathrm{U} \\
0.428 \mathrm{U}\end{array}$ & $\begin{array}{l}4.091 \\
3.753 \\
3.708 \\
5.011 \\
4.986 \\
4.151 \\
5.668\end{array}$ & $\begin{array}{l}1.486 \mathrm{U} \\
1.424 \mathrm{U} \\
2.317 \mathrm{U} \\
2.255 \mathrm{U} \\
2.311 \mathrm{U} \\
1.714 \mathrm{U} \\
1.335 \mathrm{U}\end{array}$ \\
\hline
\end{tabular}




\section{IABLE J.10. (contd)}

\begin{tabular}{|c|c|c|c|c|c|c|c|c|c|c|c|}
\hline \\
\hline $\begin{array}{l}\text { Sediment } \\
\text { Ireatment }\end{array}$ & $\underline{\text { Repl icate }}$ & $\begin{array}{l}\text { Analytical } \\
\text { Batch } \\
\end{array}$ & Aldrin & $\begin{array}{c}\text { Alpha- } \\
\text { BHC } \\
\end{array}$ & $\begin{array}{l}\text { Beta- } \\
\text { BHC }\end{array}$ & $\begin{array}{l}\text { Delta- } \\
\text { BHC } \\
\end{array}$ & $\begin{array}{c}\text { (Lindane) } \\
\text { Gamma- } \\
\text { BHC } \\
\end{array}$ & $\begin{array}{l}\text { Chlor- } \\
\text { dane }\end{array}$ & $\begin{array}{l}4,4^{\prime}- \\
000 \\
\end{array}$ & $\begin{array}{l}4.4^{\prime}- \\
D Q E \\
\end{array}$ & $\begin{array}{l}4,4^{\prime}- \\
\text { OOT }\end{array}$ \\
\hline $\begin{array}{l}\text { C-SB } \\
\text { C-SB } \\
\text { C-SB } \\
\text { C-SB Replicate } 1 \\
\text { C-SB Replicate 2 } \\
\text { C-SB Replicate } 3 \\
\text { C-SB }\end{array}$ & $\begin{array}{l}1 \\
2 \\
3 \\
4 \\
4 \\
4 \\
5\end{array}$ & $\begin{array}{l}C \\
D \\
B \\
A \\
A \\
A \\
D\end{array}$ & $\begin{array}{l}0.559 \mathrm{U} \\
0.707 \mathrm{U} \\
0.670 \mathrm{U} \\
0.922 \mathrm{U} \\
0.896 \mathrm{U} \\
0.857 \mathrm{U} \\
0.751 \mathrm{U}\end{array}$ & $\begin{array}{l}0.073 \mathrm{~J} \\
0.724 \mathrm{U} \\
2.065 \\
1.386 \\
2.066 \\
1.202 \\
0.361 \mathrm{JE}\end{array}$ & $\begin{array}{l}0.572 \mathrm{U} \\
0.724 \mathrm{U} \\
0.686 \mathrm{U} \\
0.944 \mathrm{U} \\
0.917 \mathrm{U} \\
0.877 \mathrm{U} \\
0.769 \mathrm{U}\end{array}$ & $\begin{array}{l}0.572 \mathrm{U} \\
0.724 \mathrm{U} \\
0.686 \mathrm{U} \\
0.944 \mathrm{U} \\
0.917 \mathrm{U} \\
0.877 \mathrm{U} \\
0.769 \mathrm{U}\end{array}$ & $\begin{array}{l}3.636 \mathrm{E} \\
4.009 \mathrm{E} \\
3.327 \mathrm{E} \\
2.647 \mathrm{E} \\
2.788 \mathrm{E} \\
3.020 \mathrm{E} \\
3.960 \mathrm{U}\end{array}$ & $\begin{array}{l}17.709 \mathrm{U} \\
22.417 \mathrm{U} \\
21.238 \mathrm{U} \\
29.216 \mathrm{U} \\
28.388 \mathrm{U} \\
27.152 \mathrm{U} \\
23.797 \mathrm{U}\end{array}$ & $\begin{array}{ll}0.386 & \mathrm{U} \\
0.488 \mathrm{U} \\
0.463 \mathrm{U} \\
0.637 \mathrm{U} \\
0.619 \mathrm{U} \\
0.592 \mathrm{U} \\
0.519 \mathrm{U}\end{array}$ & $\begin{array}{l}0.780 \mathrm{~J} \\
0.837 \mathrm{~J} \\
2.623 \\
1.109 \mathrm{~J} \\
0.902 \mathrm{~J} \\
0.889 \mathrm{~J} \\
0.494 \mathrm{~J}\end{array}$ & $\begin{array}{l}1.204 \mathrm{U} \\
1.523 \mathrm{U} \\
1.443 \mathrm{U} \\
1.986 \mathrm{U} \\
1.929 \mathrm{U} \\
1.845 \mathrm{U} \\
1.617 \mathrm{U}\end{array}$ \\
\hline $\begin{array}{l}\mathrm{C}-\mathrm{NE} \\
\mathrm{C}-\mathrm{NE} \\
\mathrm{C}-\mathrm{NE} \\
\mathrm{C}-\mathrm{NE} \\
\mathrm{C}-\mathrm{NE}\end{array}$ & $\begin{array}{l}1 \\
2 \\
3 \\
4 \\
5\end{array}$ & $\begin{array}{l}B \\
B \\
B \\
B \\
B\end{array}$ & $\begin{array}{l}0.640 \mathrm{U} \\
0.674 \mathrm{U} \\
0.568 \mathrm{U} \\
0.684 \mathrm{U} \\
0.593 \mathrm{U}\end{array}$ & $\begin{array}{l}2.130 \\
1.936 \\
1.961 \\
2.200 \\
2.011\end{array}$ & $\begin{array}{l}0.655 \mathrm{U} \\
0.690 \mathrm{U} \\
0.582 \mathrm{U} \\
0.700 \mathrm{U} \\
0.607 \mathrm{U}\end{array}$ & $\begin{array}{l}0.655 \mathrm{U} \\
0.690 \mathrm{U} \\
0.582 \mathrm{U} \\
0.700 \mathrm{U} \\
0.607 \mathrm{U}\end{array}$ & $\begin{array}{l}3.941 E \\
3.847 \mathrm{E} \\
3.387 \mathrm{E} \\
4.440 \mathrm{E} \\
3.499 \mathrm{E}\end{array}$ & $\begin{array}{l}20.280 \mathrm{U} \\
21.353 \mathrm{U} \\
18.014 \mathrm{U} \\
21.672 \mathrm{U} \\
18.795 \mathrm{U}\end{array}$ & $\begin{array}{l}0.442 \mathrm{U} \\
0.465 \mathrm{U} \\
0.393 \mathrm{U} \\
0.472 \mathrm{U} \\
0.410 \mathrm{U}\end{array}$ & $\begin{array}{l}2.602 \\
2.265 \\
2.422 \\
3.041 \\
2.118\end{array}$ & $\begin{array}{l}1.378 \mathrm{U} \\
1.451 \mathrm{U} \\
1.224 \mathrm{U} \\
1.473 \mathrm{U} \\
1.169 \mathrm{~J}\end{array}$ \\
\hline $\begin{array}{l}\text { MSL Background } \\
\text { MSL Background } \\
\text { MSL Background } \\
\text { MSL Background } \\
\text { MSL. Background }\end{array}$ & $\begin{array}{l}1 \\
2 \\
3 \\
4 \\
5\end{array}$ & $\begin{array}{l}A \\
B \\
C \\
0 \\
0\end{array}$ & $\begin{array}{l}0.612 \mathrm{U} \\
0.671 \mathrm{U} \\
0.673 \mathrm{U} \\
0.663 \mathrm{U} \\
0.663 \mathrm{U}\end{array}$ & $\begin{array}{l}1.200 \\
1.840 \\
0.688 \mathrm{U} \\
0.252 \mathrm{JE} \\
0.678 \mathrm{U}\end{array}$ & $\begin{array}{l}0.627 \mathrm{U} \\
0.686 \mathrm{U} \\
0.688 \mathrm{U} \\
0.679 \mathrm{U} \\
0.678 \mathrm{U}\end{array}$ & $\begin{array}{l}0.627 \mathrm{U} \\
0.686 \mathrm{U} \\
0.688 \mathrm{U} \\
0.679 \mathrm{U} \\
0.305 \mathrm{JE}\end{array}$ & $\begin{array}{l}3.390 \mathrm{E} \\
3.542 \mathrm{E} \\
3.524 \mathrm{E} \\
4.480 \mathrm{E} \\
3.829 \mathrm{E}\end{array}$ & $\begin{array}{l}19.400 \mathrm{U} \\
21.251 \mathrm{U} \\
21.314 \mathrm{U} \\
21.012 \mathrm{U} \\
20.999 \mathrm{U}\end{array}$ & $\begin{array}{l}0.938 \\
0.463 \mathrm{U} \\
0.464 \mathrm{U} \\
0.458 \mathrm{U} \\
0.458 \mathrm{U}\end{array}$ & $\begin{array}{l}0.436 \mathrm{~J} \\
1.764 \\
0.939 \mathrm{U} \\
0.926 \mathrm{U} \\
0.925 \mathrm{~V}\end{array}$ & $\begin{array}{l}1.319 \mathrm{U} \\
1.444 \mathrm{U} \\
1.449 \mathrm{U} \\
1.42 \mathrm{U} \\
1.427 \mathrm{U}\end{array}$ \\
\hline
\end{tabular}

(a) U The analyte was not present above the level of the associated value.

(b) E Value an estimate; analyte not detected on confirmation column.

(c) J Analyte detected below method detection 1 tmit (MOL), but above instrument detection 11mit (IDL). 
IABLE J.11. Chiorinated Pesticides (alphabetical, Dieldrin - Toxaphene), Dry Weight, in Tissue of M. nasuta, Richmond Harbor Program

\begin{tabular}{|c|c|c|c|c|c|c|c|c|c|c|}
\hline & & & & & 2.0 & tuo & $y$ weto & & & \\
\hline $\begin{array}{l}\text { Sediment } \\
\text { Treatment }\end{array}$ & $\begin{array}{l}\text { Analytical } \\
\text { Batch }\end{array}$ & Dieldrin & $\begin{array}{l}\text { Endo- } \\
\text { sulfan_I }\end{array}$ & $\begin{array}{l}\text { Endo- } \\
\text { sulfan II }\end{array}$ & $\begin{array}{r}\text { Endo- } \\
\text { sulfan } \\
\text { Sulfate } \\
\end{array}$ & Endrin & $\begin{array}{l}\text { Endrin } \\
\text { aldehyde }\end{array}$ & $\begin{array}{l}\text { Hepta- } \\
\text { chlor }\end{array}$ & $\begin{array}{l}\text { Hepta- } \\
\text { chlor- } \\
\text { epoxide }\end{array}$ & $\begin{array}{l}\text { Toxa- } \\
\text { phene }\end{array}$ \\
\hline $\begin{array}{l}\text { COMP } 1 \\
\text { COMP } 1 \\
\text { COMP } 1 \\
\text { COMP } 1 \\
\text { COMP } 1\end{array}$ & $\begin{array}{l}1 \\
2 \\
3 \\
4 \\
5\end{array}$ & $\begin{array}{l}0.766 \mathrm{~J}^{(\mathrm{a})} \\
0.472 \mathrm{~J} \\
0.508 \mathrm{~J} \\
1.363 \mathrm{~J} \\
0.333 \mathrm{~J}\end{array}$ & $\begin{array}{l}2.181 \mathrm{U}^{(\mathrm{b})} \\
1.918 \mathrm{U} \\
1.879 \mathrm{U} \\
2.133 \mathrm{U} \\
2.283 \mathrm{U}\end{array}$ & $\begin{array}{l}2.181 \mathrm{U} \\
1.918 \mathrm{U} \\
1.879 \mathrm{U} \\
2.133 \mathrm{U} \\
2.283 \mathrm{U}\end{array}$ & $\begin{array}{l}2.181 \mathrm{U} \\
1.918 \mathrm{U} \\
1.879 \mathrm{U} \\
2.133 \mathrm{U} \\
2.283 \mathrm{U}\end{array}$ & $\begin{array}{l}6.932 \mathrm{U} \\
6.098 \mathrm{U} \\
5.972 \mathrm{U} \\
6.778 \mathrm{U} \\
7.257 \mathrm{~J}\end{array}$ & $\begin{array}{l}2.181 \mathrm{U} \\
1.918 \mathrm{U} \\
1.879 \mathrm{U} \\
2.133 \mathrm{U} \\
2.283 \mathrm{U}\end{array}$ & $\begin{array}{l}1.439 \mathrm{U} \\
1.266 \mathrm{U} \\
1.240 \mathrm{U} \\
1.407 \mathrm{U} \\
1.507 \mathrm{U}\end{array}$ & $\begin{array}{l}0.790 \mathrm{U} \\
0.694 \mathrm{U} \\
0.680 \mathrm{U} \\
0.772 \mathrm{U} \\
0.827 \mathrm{U}\end{array}$ & $\begin{array}{l}21.811 \mathrm{U} \\
19.186 \mathrm{U} \\
18.790 \mathrm{U} \\
21.327 \mathrm{U} \\
22.834 \mathrm{U}\end{array}$ \\
\hline $\begin{array}{l}\text { COMP II } \\
\text { COMP II } \\
\text { COMP II } \\
\text { COMP II } \\
\text { COMP II }\end{array}$ & $\begin{array}{l}\text { D } \\
A \\
C \\
D \\
C\end{array}$ & $\begin{array}{l}1.277 \mathrm{~J} \\
1.400 \mathrm{~J} \\
1.319 \mathrm{~J} \\
1.074 \mathrm{JE} \\
0.968 \mathrm{~J}\end{array}$ & $\begin{array}{l}2.291 \mathrm{U} \\
1.997 \mathrm{U} \\
1.871 \mathrm{U} \\
2.249 \mathrm{U} \\
2.058 \mathrm{U}\end{array}$ & $\begin{array}{l}0.155 \mathrm{JE}(\mathrm{c}) \\
1.997 \mathrm{U} \\
1.871 \mathrm{U} \\
0.264 \mathrm{JE} \\
2.058 \mathrm{~J}\end{array}$ & $\begin{array}{l}2.291 \mathrm{U} \\
1.997 \mathrm{U} \\
1.871 \mathrm{U} \\
2.249 \mathrm{U} \\
2.058 \mathrm{U}\end{array}$ & $\begin{array}{l}7.281 \mathrm{U} \\
6.348 \mathrm{U} \\
5.947 \mathrm{U} \\
7.149 \mathrm{U} \\
6.541 \mathrm{U}\end{array}$ & $\begin{array}{l}2.291 \mathrm{U} \\
1.997 \mathrm{U} \\
1.871 \mathrm{U} \\
2.249 \mathrm{U} \\
2.058 \mathrm{U}\end{array}$ & $\begin{array}{l}1.512 \mathrm{~J} \\
1.318 \mathrm{U} \\
1.235 \mathrm{U} \\
1.484 \mathrm{U} \\
1.358 \mathrm{U}\end{array}$ & $\begin{array}{l}0.829 \mathrm{U} \\
0.723 \mathrm{U} \\
0.677 \mathrm{U} \\
0.814 \mathrm{U} \\
0.745 \mathrm{U}\end{array}$ & $\begin{array}{l}22.908 \mathrm{U} \\
19.973 \mathrm{U} \\
18.711 \mathrm{U} \\
22.495 \mathrm{U} \\
20.580 \mathrm{U}\end{array}$ \\
\hline $\begin{array}{l}\text { COMP II I } \\
\text { COMP II I } \\
\text { COMP II I } \\
\text { COMP II I } \\
\text { COMP III }\end{array}$ & $\begin{array}{l}C \\
D \\
A \\
D \\
C\end{array}$ & $\begin{array}{l}7.384 \mathrm{U} \\
0.681 \mathrm{~J} \\
0.288 \mathrm{~J} \\
0.557 \mathrm{~J} \\
6.436 \mathrm{~J}\end{array}$ & $\begin{array}{l}2.190 \mathrm{U} \\
1.954 \mathrm{U} \\
2.018 \mathrm{U} \\
2.026 \mathrm{U} \\
1.909 \mathrm{U}\end{array}$ & $\begin{array}{l}2.190 \mathrm{U} \\
1.954 \mathrm{U} \\
2.018 \mathrm{U} \\
2.026 \mathrm{U} \\
1.909 \mathrm{U}\end{array}$ & $\begin{array}{l}2.190 \mathrm{U} \\
1.954 \mathrm{U} \\
2.018 \mathrm{U} \\
2.025 \mathrm{U} \\
1.909 \mathrm{U}\end{array}$ & $\begin{array}{l}6.962 \mathrm{U} \\
6.212 \mathrm{U} \\
6.413 \mathrm{U} \\
6.440 \mathrm{U} \\
6.068 \mathrm{U}\end{array}$ & $\begin{array}{l}2.190 \mathrm{U} \\
1.954 \mathrm{U} \\
2.018 \mathrm{U} \\
2.026 \mathrm{U} \\
1.909 \mathrm{U}\end{array}$ & $\begin{array}{l}1.446 \mathrm{U} \\
1.290 \mathrm{U} \\
1.332 \mathrm{U} \\
1.337 \mathrm{U} \\
1.260 \mathrm{U}\end{array}$ & $\begin{array}{l}0.793 \mathrm{U} \\
0.707 \mathrm{U} \\
0.730 \mathrm{U} \\
0.733 \mathrm{U} \\
0.691 \mathrm{U}\end{array}$ & $\begin{array}{l}21.905 \mathrm{U} \\
19.544 \mathrm{U} \\
20.177 \mathrm{U} \\
20.263 \mathrm{U} \\
19.093 \mathrm{U}\end{array}$ \\
\hline $\begin{array}{l}\text { TC-5 Upper Comp } \\
\text { TC-5 Upper Comp } \\
\text { IC-5 Upper Comp } \\
\text { IC-5 Upper Comp } \\
\text { TC-5 Upper Comp }\end{array}$ & $\begin{array}{l}\text { C } \\
\text { C } \\
\text { C } \\
\text { A } \\
\text { A }\end{array}$ & $\begin{array}{l}2.949 \mathrm{~J} \\
2.039 \mathrm{JE} \\
2.441 \mathrm{~J} \\
1.493 \mathrm{~J} \\
1.483 \mathrm{~J}\end{array}$ & $\begin{array}{l}1.996 \mathrm{U} \\
1.980 \mathrm{U} \\
2.075 \mathrm{U} \\
2.043 \mathrm{U} \\
2.191 \mathrm{U}\end{array}$ & $\begin{array}{l}1.996 \mathrm{U} \\
1.980 \mathrm{U} \\
2.075 \mathrm{U} \\
2.043 \mathrm{U} \\
2.191 \mathrm{U}\end{array}$ & $\begin{array}{l}2.228 \mathrm{E} \\
1.980 \mathrm{~J} \\
2.022 \mathrm{JE} \\
2.043 \mathrm{U} \\
2.191 \mathrm{U}\end{array}$ & $\begin{array}{l}6.343 \mathrm{U} \\
6.295 \mathrm{U} \\
6.596 \mathrm{U} \\
6.494 \mathrm{U} \\
6.964 \mathrm{U}\end{array}$ & $\begin{array}{l}1.996 \mathrm{U} \\
1.980 \mathrm{U} \\
2.075 \mathrm{U} \\
2.043 \mathrm{U} \\
2.191 \mathrm{U}\end{array}$ & $\begin{array}{l}1.317 \mathrm{U} \\
1.307 \mathrm{U} \\
1.370 \mathrm{U} \\
1.348 \mathrm{U} \\
1.446 \mathrm{U}\end{array}$ & $\begin{array}{l}0.722 \mathrm{U} \\
0.717 \mathrm{U} \\
0.751 \mathrm{U} \\
0.740 \mathrm{U} \\
0.793 \mathrm{U}\end{array}$ & $\begin{array}{l}19.956 \mathrm{U} \\
19.806 \mathrm{U} \\
20.754 \mathrm{U} \\
20.432 \mathrm{U} \\
21.912 \mathrm{U}\end{array}$ \\
\hline $\begin{array}{l}\text { COMP IV } \\
\text { COMP IV } \\
\text { COMP IV } \\
\text { COMP IV } \\
\text { COMP IV }\end{array}$ & $\begin{array}{l}C \\
C \\
A \\
C \\
A\end{array}$ & $\begin{array}{r}8.276 \mathrm{U} \\
6.643 \mathrm{U} \\
5.944 \mathrm{U} \\
11.938 \mathrm{U} \\
6.458 \mathrm{U}\end{array}$ & $\begin{array}{l}2.455 \mathrm{U} \\
1.971 \mathrm{U} \\
1.763 \mathrm{U} \\
3.542 \mathrm{U} \\
1.916 \mathrm{U}\end{array}$ & $\begin{array}{l}2.455 \mathrm{U} \\
1.971 \mathrm{U} \\
1.763 \mathrm{U} \\
3.542 \mathrm{U} \\
1.916 \mathrm{U}\end{array}$ & $\begin{array}{l}2.455 \mathrm{U} \\
1.971 \mathrm{U} \\
1.763 \mathrm{U} \\
3.542 \mathrm{U} \\
1.916 \mathrm{U}\end{array}$ & $\begin{array}{r}7.804 \mathrm{U} \\
6.263 \mathrm{U} \\
5.605 \mathrm{U} \\
11.257 \mathrm{U} \\
6.089 \mathrm{U}\end{array}$ & $\begin{array}{l}2.455 \mathrm{U} \\
1.971 \mathrm{U} \\
1.763 \mathrm{U} \\
3.542 \mathrm{U} \\
1.916 \mathrm{U}\end{array}$ & $\begin{array}{l}1.620 \mathrm{U} \\
1.301 \mathrm{U} \\
1.164 \mathrm{U} \\
2.337 \mathrm{U} \\
1.264 \mathrm{U}\end{array}$ & $\begin{array}{l}0.889 \mathrm{U} \\
0.713 \mathrm{U} \\
0.638 \mathrm{U} \\
1.282 \mathrm{U} \\
0.694 \mathrm{U}\end{array}$ & $\begin{array}{l}24.554 \mathrm{U} \\
19.107 \mathrm{U} \\
17.634 \mathrm{U} \\
35.418 \mathrm{U} \\
19.160 \mathrm{U}\end{array}$ \\
\hline $\begin{array}{l}\text { COMP } V \\
\text { COMP V } \\
\text { COMP V } \\
\text { COMP } V \\
\text { COMP V Replicate } 1 \\
\text { COMP } V \text { Replicate } 2 \\
\text { COMP } V \text { Replicate } 3\end{array}$ & $\begin{array}{l}A \\
A \\
A \\
D \\
B \\
8 \\
B\end{array}$ & $\begin{array}{l}5.231 \mathrm{~J} \\
6.186 \mathrm{~J} \\
6.859 \\
5.534 \mathrm{~J} \\
7.507 \mathrm{~J} \\
7.322 \mathrm{~J} \\
7.417 \mathrm{~J}\end{array}$ & $\begin{array}{l}2.064 \mathrm{U} \\
2.069 \mathrm{U} \\
1.778 \mathrm{U} \\
2.162 \mathrm{U} \\
4.619 \mathrm{U} \\
3.929 \mathrm{U} \\
2.729 \mathrm{U}\end{array}$ & $\begin{array}{l}2.064 \mathrm{~J} \\
2.069 \mathrm{~J} \\
1.778 \mathrm{U} \\
0.549 \mathrm{JE} \\
0.997 \mathrm{~J} \\
0.652 \mathrm{~J} \\
1.137 \mathrm{~J}\end{array}$ & $\begin{array}{l}2.064 \mathrm{U} \\
2.069 \mathrm{U} \\
1.778 \mathrm{U} \\
2.162 \mathrm{U} \\
4.619 \mathrm{U} \\
3.929 \mathrm{U} \\
2.729 \mathrm{U}\end{array}$ & $\begin{array}{r}6.562 \mathrm{U} \\
6.577 \mathrm{U} \\
5.652 \mathrm{U} \\
6.873 \mathrm{U} \\
14.680 \mathrm{U} \\
12.489 \mathrm{U} \\
8.673 \mathrm{U}\end{array}$ & $\begin{array}{l}2.064 \mathrm{U} \\
2.069 \mathrm{U} \\
1.778 \mathrm{U} \\
2.162 \mathrm{U} \\
4.619 \mathrm{U} \\
3.929 \mathrm{U} \\
2.729 \mathrm{U}\end{array}$ & $\begin{array}{l}1.362 \mathrm{U} \\
1.366 \mathrm{U} \\
1.174 \mathrm{U} \\
1.427 \mathrm{U} \\
3.048 \mathrm{U} \\
2.593 \mathrm{U} \\
1.801 \mathrm{U}\end{array}$ & $\begin{array}{l}0.747 \mathrm{U} \\
0.749 \mathrm{U} \\
0.644 \mathrm{U} \\
0.783 \mathrm{U} \\
1.672 \mathrm{U} \\
1.422 \mathrm{U} \\
0.988 \mathrm{U}\end{array}$ & $\begin{array}{l}20.646 \mathrm{U} \\
20.694 \mathrm{U} \\
17.784 \mathrm{U} \\
21.625 \mathrm{U} \\
46.188 \mathrm{U} \\
39.294 \mathrm{U} \\
27.287 \mathrm{U}\end{array}$ \\
\hline
\end{tabular}


IABLE J.11. (contd)

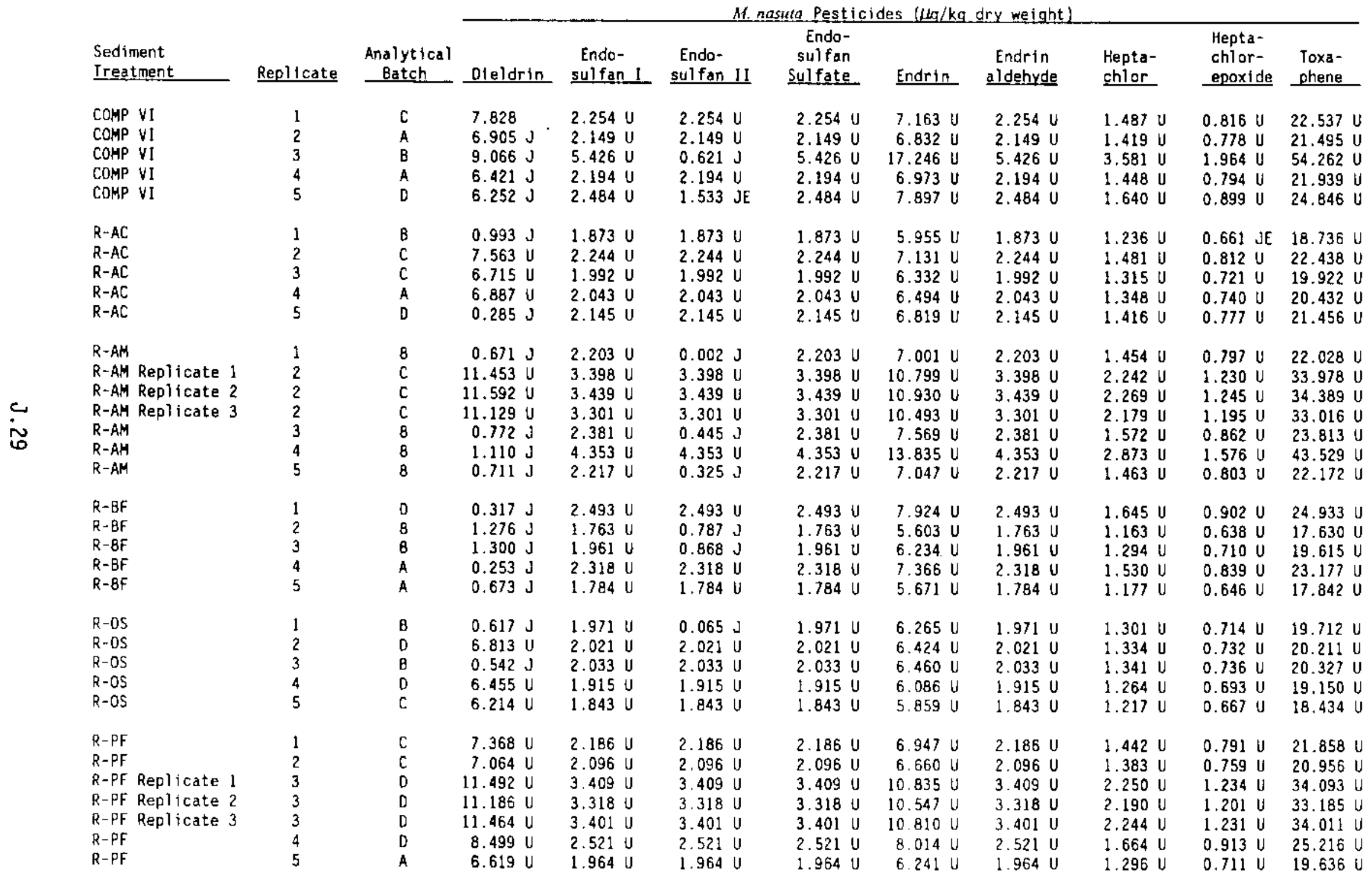


IABLE J.11. (contd)

\begin{tabular}{|c|c|c|c|c|c|c|c|c|c|c|c|}
\hline \multirow[b]{2}{*}{$\begin{array}{l}\text { Sediment } \\
\text { Ireatment }\end{array}$} & \multirow[b]{2}{*}{ Replicate } & \multirow[b]{2}{*}{$\begin{array}{l}\text { Analyt lcal } \\
\text { Batch } \\
\end{array}$} & \multicolumn{9}{|c|}{ M. nasura Pesticides $(\mu \mathrm{a} / \mathrm{kg}$ dry weight) } \\
\hline & & & Dieldtín & $\begin{array}{c}\begin{array}{c}\text { Endo- } \\
\text { sulfan } 1\end{array} \\
\end{array}$ & $\begin{array}{l}\text { Endo- } \\
\text { sulfan 11 }\end{array}$ & $\begin{array}{r}\text { Endo- } \\
\text { sulfan } \\
\text { Sulfate } \\
\end{array}$ & Endrin & $\begin{array}{c}\begin{array}{c}\text { Endrín } \\
\text { aldehyde }\end{array} \\
\end{array}$ & $\begin{array}{l}\text { Hepta- } \\
\text { chlor }\end{array}$ & $\begin{array}{l}\text { Hepta- } \\
\text { chlor- } \\
\text { epoxide }\end{array}$ & $\begin{array}{l}\text { Toxa - } \\
\text { phene }\end{array}$ \\
\hline $\begin{array}{l}\text { C-SB } \\
C-S B \\
\text { C-SB } \\
\text { C-SB Replicate } 1 \\
\text { C-SB Replicate ? } \\
\text { C-SB Replicate } 3 \\
\text { C-SB }\end{array}$ & $\begin{array}{l}1 \\
2 \\
3 \\
4 \\
4 \\
4 \\
5\end{array}$ & $\begin{array}{l}C \\
D \\
B \\
A \\
A \\
A \\
D\end{array}$ & $\begin{array}{l}5.969 \mathrm{U} \\
7.556 \mathrm{U} \\
0.631 \mathrm{~J} \\
9.848 \mathrm{U} \\
9.569 \mathrm{U} \\
9.152 \mathrm{U} \\
8.021 \mathrm{U}\end{array}$ & $\begin{array}{l}1.771 \mathrm{U} \\
2.242 \mathrm{U} \\
2.124 \mathrm{U} \\
2.921 \mathrm{U} \\
2.839 \mathrm{U} \\
2.715 \mathrm{U} \\
2.380 \mathrm{U}\end{array}$ & $\begin{array}{l}1.771 \mathrm{U} \\
2.242 \mathrm{U} \\
2.124 \mathrm{U} \\
2.921 \mathrm{U} \\
2.839 \mathrm{U} \\
2.715 \mathrm{U} \\
2.380 \mathrm{U}\end{array}$ & $\begin{array}{l}1.771 \mathrm{U} \\
2.242 \mathrm{U} \\
2.124 \mathrm{U} \\
2.921 \mathrm{U} \\
2.839 \mathrm{U} \\
2.715 \mathrm{U} \\
2.380 \mathrm{U}\end{array}$ & $\begin{array}{l}5.628 \mathrm{U} \\
7.125 \mathrm{U} \\
6.750 \mathrm{U} \\
9.286 \mathrm{U} \\
9.022 \mathrm{~J} \\
8.629 \mathrm{U} \\
7.563 \mathrm{U}\end{array}$ & $\begin{array}{l}1.771 \mathrm{U} \\
2.242 \mathrm{U} \\
2.124 \mathrm{U} \\
2.921 \mathrm{U} \\
2.839 \mathrm{U} \\
2.715 \mathrm{U} \\
2.380 \mathrm{U}\end{array}$ & $\begin{array}{l}1.169 \mathrm{U} \\
1.479 \mathrm{U} \\
1.402 \mathrm{U} \\
1.928 \mathrm{U} \\
1.873 \mathrm{U} \\
1.792 \mathrm{U} \\
1.570 \mathrm{U}\end{array}$ & $\begin{array}{l}0.641 \mathrm{U} \\
0.811 \mathrm{U} \\
0.769 \mathrm{U} \\
1.058 \mathrm{U} \\
1.028 \mathrm{U} \\
0.983 \mathrm{U} \\
0.861 \mathrm{U}\end{array}$ & $\begin{array}{l}17.709 \mathrm{U} \\
22.417 \mathrm{U} \\
21.238 \mathrm{U} \\
29.216 \mathrm{U} \\
28.388 \mathrm{U} \\
27.152 \mathrm{U} \\
23.797 \mathrm{U}\end{array}$ \\
\hline $\begin{array}{l}C-N E \\
C-N E \\
C-N E \\
C-N E \\
C-N E\end{array}$ & $\begin{array}{l}1 \\
2 \\
3 \\
4 \\
5\end{array}$ & $\begin{array}{l}B \\
B \\
8 \\
B \\
B\end{array}$ & $\begin{array}{l}0.739 \mathrm{~J} \\
0.668 \mathrm{~J} \\
0.699 \mathrm{~J} \\
0.814 \mathrm{~J} \\
0.621 \mathrm{~J}\end{array}$ & $\begin{array}{l}2.028 \mathrm{U} \\
2.135 \mathrm{U} \\
1.801 \mathrm{U} \\
2.167 \mathrm{U} \\
1.879 \mathrm{U}\end{array}$ & $\begin{array}{l}2.028 \mathrm{U} \\
2.135 \mathrm{U} \\
1.801 \mathrm{U} \\
2.167 \mathrm{U} \\
0.318 \mathrm{~J}\end{array}$ & $\begin{array}{l}2.028 \mathrm{U} \\
2.135 \mathrm{U} \\
1.801 \mathrm{U} \\
2.167 \mathrm{U} \\
1.879 \mathrm{U}\end{array}$ & $\begin{array}{l}6.446 \mathrm{U} \\
6.786 \mathrm{U} \\
5.725 \mathrm{U} \\
6.888 \mathrm{U} \\
5.974 \mathrm{U}\end{array}$ & $\begin{array}{l}2.028 \mathrm{U} \\
2.135 \mathrm{U} \\
1.801 \mathrm{U} \\
2.167 \mathrm{U} \\
1.879 \mathrm{U}\end{array}$ & $\begin{array}{l}1.338 \mathrm{U} \\
1.409 \mathrm{U} \\
1.189 \mathrm{U} \\
1.430 \mathrm{U} \\
1.240 \mathrm{U}\end{array}$ & $\begin{array}{l}0.734 \mathrm{U} \\
0.773 \mathrm{U} \\
0.652 \mathrm{U} \\
0.784 \mathrm{U} \\
0.680 \mathrm{U}\end{array}$ & $\begin{array}{l}20.280 \mathrm{U} \\
21.353 \mathrm{U} \\
18.014 \mathrm{U} \\
21.672 \mathrm{U} \\
18.795 \mathrm{U}\end{array}$ \\
\hline $\begin{array}{l}\text { MSL Background } \\
\text { MSL Background } \\
\text { MSL Background } \\
\text { MSL Background } \\
\text { MSL Background }\end{array}$ & $\begin{array}{l}1 \\
2 \\
3 \\
4 \\
5\end{array}$ & $\begin{array}{l}A \\
B \\
C \\
D \\
D\end{array}$ & $\begin{array}{l}6.539 \mathrm{U} \\
0.755 \mathrm{~J} \\
7.184 \mathrm{U} \\
7.082 \mathrm{U} \\
7.078 \mathrm{U}\end{array}$ & $\begin{array}{l}1.940 \mathrm{U} \\
2.125 \mathrm{U} \\
2.131 \mathrm{U} \\
2.101 \mathrm{U} \\
2.100 \mathrm{U}\end{array}$ & $\begin{array}{l}1.940 \mathrm{U} \\
0.008 \mathrm{~J} \\
2.131 . \mathrm{U} \\
2.101 \mathrm{U} \\
2.100 \mathrm{U}\end{array}$ & $\begin{array}{l}1.940 \mathrm{U} \\
2.125 \mathrm{U} \\
2.131 \mathrm{U} \\
2.101 \mathrm{U} \\
2.100 \mathrm{U}\end{array}$ & $\begin{array}{l}6.156 \mathrm{U} \\
6.754 \mathrm{U} \\
6.774 \mathrm{U} \\
6.678 \mathrm{U} \\
6.674 \mathrm{U}\end{array}$ & $\begin{array}{l}1.940 \mathrm{U} \\
2.125 \mathrm{U} \\
2.131 \mathrm{U} \\
2.101 \mathrm{U} \\
2.100 \mathrm{U}\end{array}$ & $\begin{array}{l}1.280 \mathrm{U} \\
1.402 \mathrm{U} \\
1.407 \mathrm{U} \\
1.387 \mathrm{U} \\
1.386 \mathrm{U}\end{array}$ & $\begin{array}{l}0.702 \mathrm{U} \\
0.769 \mathrm{U} \\
0.772 \mathrm{U} \\
0.761 \mathrm{U} \\
0.760 \mathrm{U}\end{array}$ & $\begin{array}{l}19.400 \mathrm{U} \\
21.251 \mathrm{U} \\
21.314 \mathrm{U} \\
21.012 \mathrm{U} \\
20.999 \mathrm{U}\end{array}$ \\
\hline
\end{tabular}

(a) J Analyte detected below method detection 1 imit (MOL), but above instrument detection 1 imit (lDL).

(b) U The analyte was not present above the level of the assoclated value.

(c) E Value an estimate; analyte not detected on confirmation column. 
IABLE J, 12. Chlorinated Pesticides (alphabetical, Aldrin - 4'4-DDT), Wet Weight, in Tissue of $M$. nasuta, Richmond Harbor Program

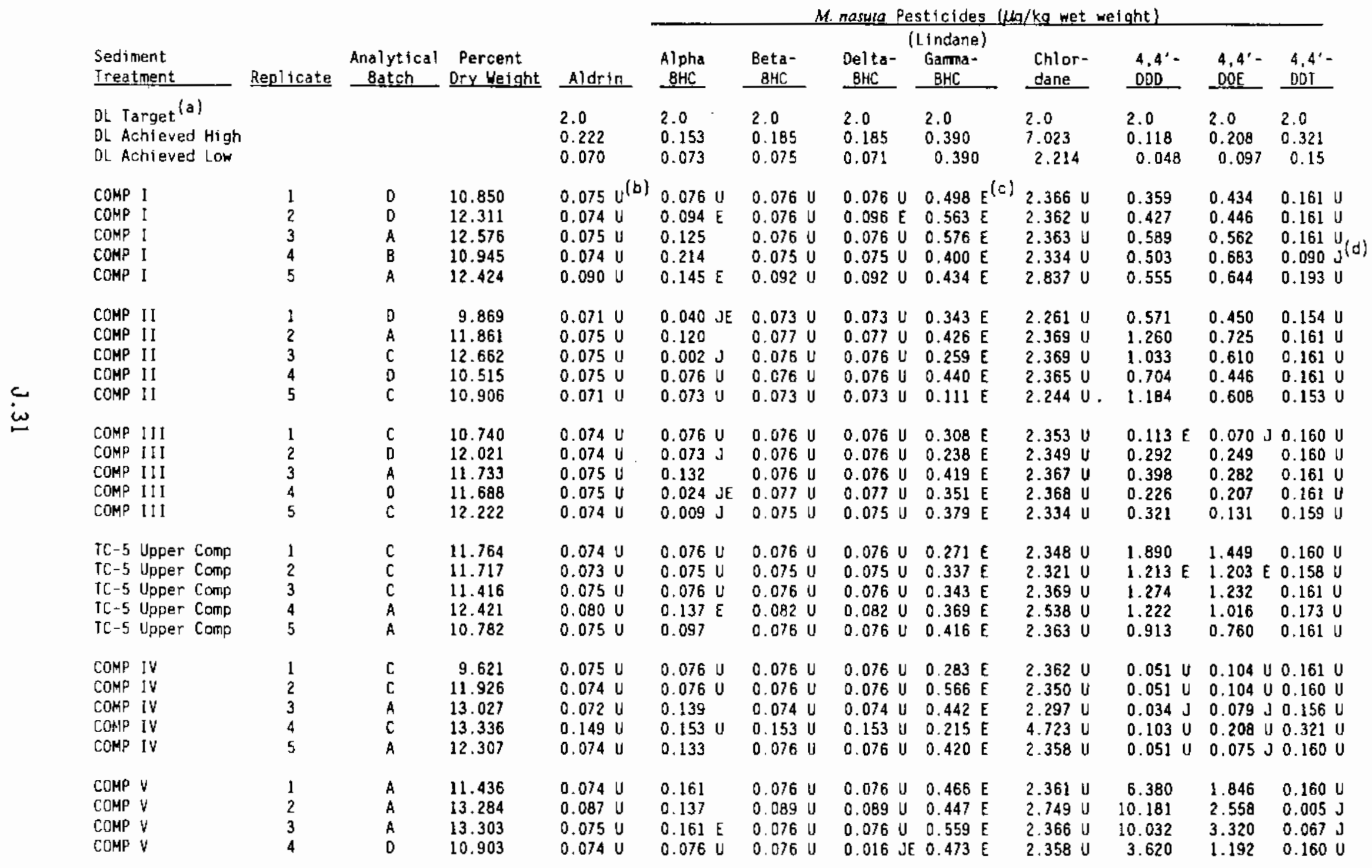


TABLE J.12. (contd)

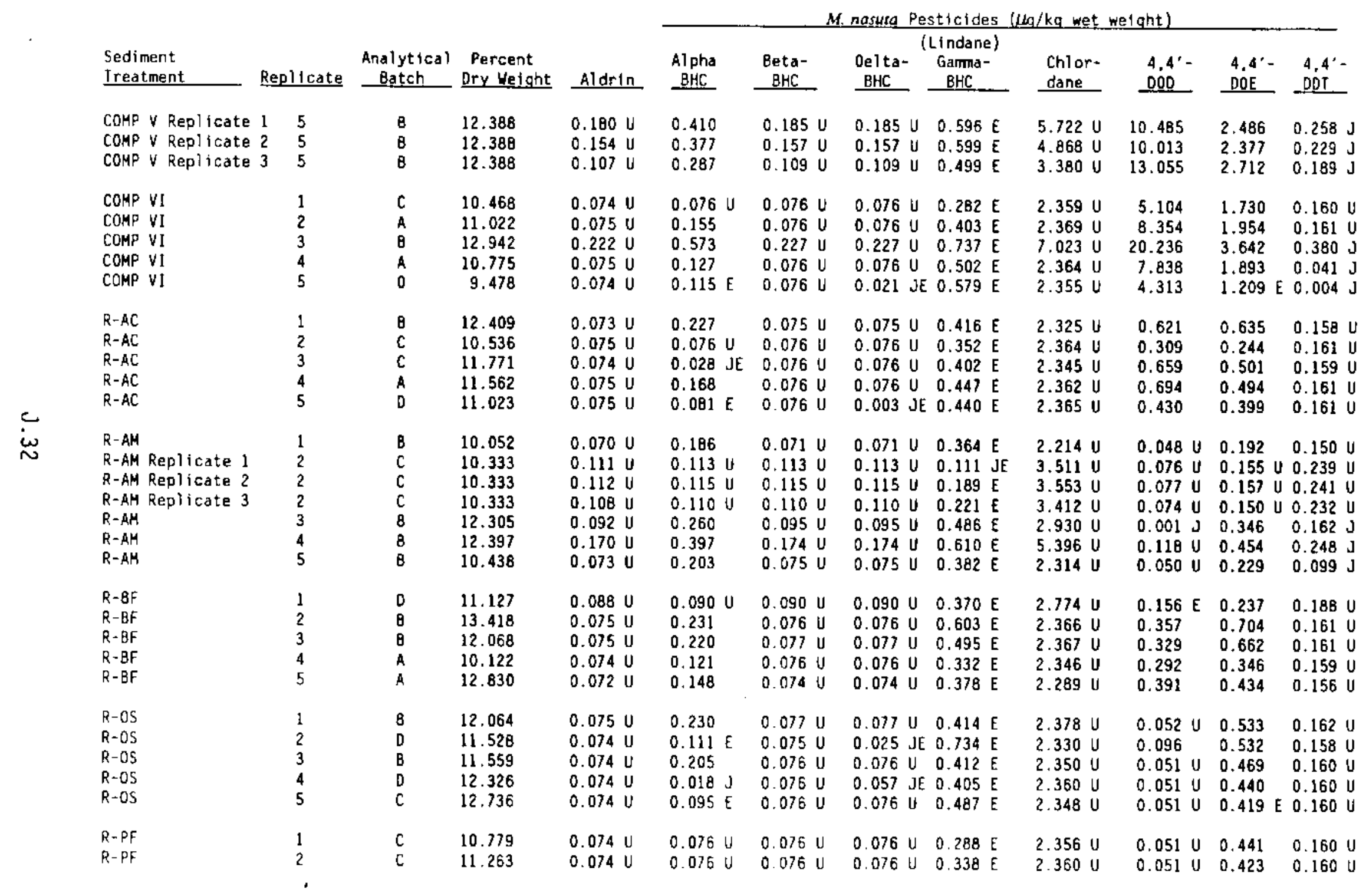


IABLE 3.12. (contd)

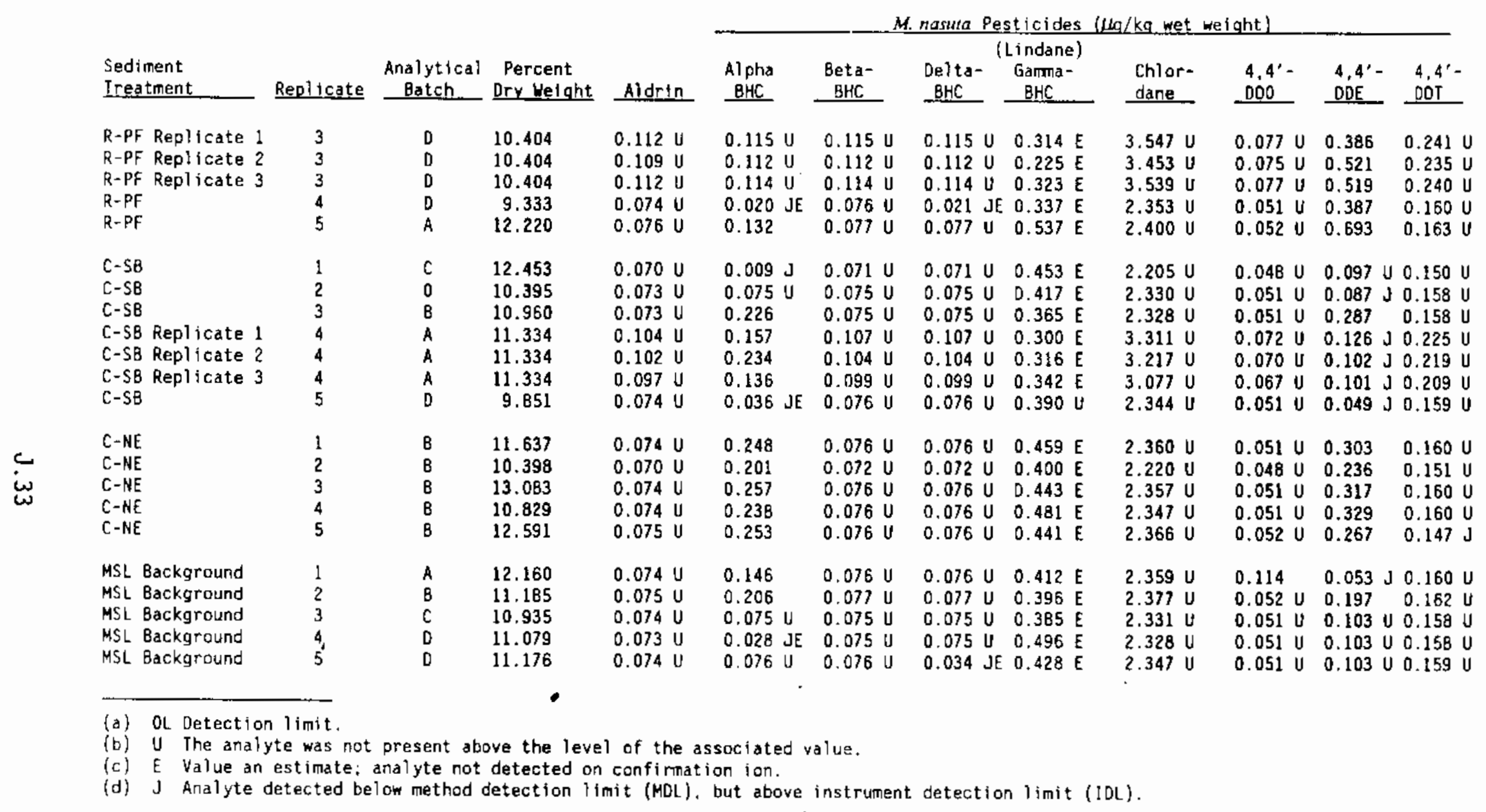


IABLE J.13. Chlorinated Pesticides (alphabetical, Dieldrin - Toxaphene), Wet Weight, in Tissue of M. nasuta, Richmond Harbor Program

\begin{tabular}{|c|c|c|c|c|c|c|c|c|c|c|c|}
\hline & & & & & suta & 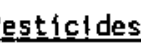 & 4 & 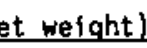 & & & \\
\hline $\begin{array}{l}\text { Sediment } \\
\text { Ireatment }\end{array}$ & Replicate & $\begin{array}{l}\text { Analytical Percent } \\
\text { Batch Dry Welaht } \\
\end{array}$ & Dieldrin & $\begin{array}{l}\text { Endo- } \\
\text { sulfan } 1\end{array}$ & $\begin{array}{l}\begin{array}{c}\text { Endo- } \\
\text { sulfan II }\end{array} \\
\end{array}$ & $\begin{array}{l}\text { Endo- } \\
\text { sulfan } \\
\text { Sulfate } \\
\end{array}$ & Endrin & $\begin{array}{l}\text { Endrin } \\
\text { aldehyde }\end{array}$ & $\begin{array}{l}\text { Hepta- } \\
\text { chlor }\end{array}$ & $\begin{array}{l}\text { Hepta- } \\
\text { chlor- } \\
\text { epoxide }\end{array}$ & $\begin{array}{c}\text { Toxa- } \\
\text { phene } \\
\end{array}$ \\
\hline $\begin{array}{l}\text { Target DL (a) } \\
\text { Achieved DL High } \\
\text { Achieved DL Low }\end{array}$ & & & $\begin{array}{l}2.0 \\
1.592 \\
0.743\end{array}$ & $\begin{array}{l}2.0 \\
0.702 \\
0.221\end{array}$ & $\begin{array}{l}2.0 \\
0.472 \\
0.221\end{array}$ & $\begin{array}{l}2.0 \\
0.702 \\
0.221\end{array}$ & $\begin{array}{l}2.0 \\
1.819 \\
0.706\end{array}$ & $\begin{array}{l}2.0 \\
0.702 \\
0.221\end{array}$ & $\begin{array}{l}2.0 \\
0.463 \\
0.146\end{array}$ & $\begin{array}{l}2.0 \\
0.254 \\
0.080\end{array}$ & $\begin{array}{c}30.0 \\
7.023 \\
2.205\end{array}$ \\
\hline $\begin{array}{l}\text { COMP I } \\
\text { COMP } \\
\text { COMP } \\
\text { COMP I } \\
\text { COMP }\end{array}$ & $\begin{array}{l}1 \\
2 \\
3 \\
4 \\
5\end{array}$ & $\begin{array}{l}10.850 \\
12.311 \\
12.576 \\
10.945 \\
12.424\end{array}$ & $\begin{array}{l}0.083 \mathrm{~J}^{(\mathrm{b})} \\
0.058 \mathrm{~J} \\
0.064 \mathrm{~J} \\
0.149 \mathrm{~J} \\
0.041 \mathrm{~J}\end{array}$ & $\begin{array}{l}0.237 \mathrm{U}^{(c)} \\
0.236 \mathrm{U} \\
0.236 \mathrm{U} \\
0.233 \mathrm{U} \\
0.284 \mathrm{U}\end{array}$ & $\begin{array}{l}0.237 \mathrm{U} \\
0.236 \mathrm{U} \\
0.236 \mathrm{U} \\
0.233 \mathrm{U} \\
0.284 \mathrm{U}\end{array}$ & $\begin{array}{l}0.237 \mathrm{U} \\
0.236 \mathrm{U} \\
0.236 \mathrm{U} \\
0.233 \mathrm{U} \\
0.284 \mathrm{U}\end{array}$ & $\begin{array}{ll}0.752 & \mathrm{U} \\
0.751 & \mathrm{U} \\
0.751 & \mathrm{U} \\
0.742 & \mathrm{U} \\
0.902 & \mathrm{U}\end{array}$ & $\begin{array}{l}0.237 \\
0.236 \\
0.236 \\
0.233 \\
0.284 \\
0.28\end{array}$ & $\begin{array}{l}0.156 \\
0.156 \\
0.156 \\
0.154 \\
0.187\end{array}$ & 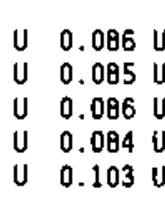 & $\begin{array}{l}2.366 \mathrm{U} \\
2.362 \mathrm{U} \\
2.363 \mathrm{U} \\
2.334 \mathrm{U} \\
2.837 \mathrm{U}\end{array}$ \\
\hline $\begin{array}{l}\text { COMP II } \\
\text { COMP } \\
\text { COMP } \\
\text { II } \\
\text { COMP } \\
\text { COMP } \\
\text { II }\end{array}$ & $\begin{array}{l}1 \\
2 \\
3 \\
4 \\
5\end{array}$ & $\begin{array}{r}9.869 \\
11.861 \\
12.662 \\
10.515 \\
10.906\end{array}$ & $\begin{array}{l}0.126 \mathrm{~J} \\
0.167 \mathrm{~J} \\
0.167 \mathrm{~J} \\
0.113 \mathrm{JE} \\
0.106 \mathrm{~J}\end{array}$ & $\begin{array}{l}0.226 \mathrm{U} \\
0.237 \mathrm{U} \\
0.237 \mathrm{U} \\
0.236 \mathrm{U} \\
0.224 \mathrm{U}\end{array}$ & $\begin{array}{l}0.015 \mathrm{JE}^{(\mathrm{d})} \\
0.237 \mathrm{U} \\
0.237 \mathrm{U} \\
0.02 \theta \mathrm{JE} \\
0.224 \mathrm{U}\end{array}$ & $\begin{array}{l}0.226 \mathrm{U} \\
0.237 \mathrm{U} \\
0.237 \mathrm{U} \\
0.236 \mathrm{U} \\
0.224 \mathrm{U}\end{array}$ & $\begin{array}{l}0.719 \mathrm{U} \\
0.753 \mathrm{U} \\
0.753 \mathrm{U} \\
0.752 \mathrm{U} \\
0.713 \mathrm{U}\end{array}$ & $\begin{array}{l}0.226 \mathrm{U} \\
0.237 \mathrm{U} \\
0.237 \mathrm{U} \\
0.236 \mathrm{U} \\
0.224 \mathrm{U}\end{array}$ & $\begin{array}{l}0.149 \\
0.156 \\
0.156 \\
0.156 \\
0.148\end{array}$ & $\begin{array}{ll}U & 0.082 U \\
U & 0.086 U \\
U & 0.086 U \\
U & 0.086 U \\
U & 0.081\end{array}$ & $\begin{array}{l}2.261 \mathrm{U} \\
2.369 \mathrm{U} \\
2.369 \mathrm{U} \\
2.365 \mathrm{U} \\
2.244 \mathrm{U}\end{array}$ \\
\hline $\begin{array}{l}\text { COMP II I } \\
\text { COMP III } \\
\text { COMP III } \\
\text { COMP III } \\
\text { COMP III }\end{array}$ & $\begin{array}{l}1 \\
2 \\
3 \\
4 \\
5\end{array}$ & $\begin{array}{l}10.740 \\
12.021 \\
11.733 \\
11.688 \\
12.222\end{array}$ & $\begin{array}{ll}0.793 & \mathrm{U} \\
0.082 & \mathrm{~J} \\
0.034 & \mathrm{~J} \\
0.065 \mathrm{~J} & 0.787 \mathrm{U}\end{array}$ & $\begin{array}{l}0.235 \mathrm{U} \\
0.235 \mathrm{U} \\
0.237 \mathrm{U} \\
0.237 \mathrm{U} \\
0.233 \mathrm{U}\end{array}$ & $\begin{array}{l}0.235 \mathrm{U} \\
0.235 \mathrm{U} \\
0.237 \mathrm{U} \\
0.237 \mathrm{U} \\
0.233 \mathrm{U}\end{array}$ & $\begin{array}{l}0.235 \mathrm{U} \\
0.235 \mathrm{U} \\
0.237 \mathrm{U} \\
0.237 \mathrm{U} \\
0.233 \mathrm{U}\end{array}$ & $\begin{array}{ll}0.748 & \mathrm{U} \\
0.747 & \mathrm{U} \\
0.752 & \mathrm{U} \\
0.753 \mathrm{U} & \\
0.742 \mathrm{U}\end{array}$ & $\begin{array}{l}0.235 \mathrm{U} \\
0.235 \mathrm{U} \\
0.237 \mathrm{U} \\
0.237 \mathrm{U} \\
0.233 \mathrm{U}\end{array}$ & $\begin{array}{l}0.155 \\
0.155 \\
0.156 \\
0.156 \\
0.154\end{array}$ & $\begin{array}{ll}U & 0.085 U \\
U & 0.085 U \\
U & 0.086 U \\
U & 0.086 U \\
U & 0.084 U\end{array}$ & $\begin{array}{l}2.353 \mathrm{U} \\
2.349 \mathrm{U} \\
2.367 \mathrm{U} \\
2.368 \mathrm{U} \\
2.334 \mathrm{U}\end{array}$ \\
\hline $\begin{array}{l}\text { TC-5 Upper Comp } \\
\text { TC-5 Upper Comp } \\
\text { TC-5 Upper Comp } \\
\text { TC-5 Upper Comp } \\
\text { TC-5 Upper Comp }\end{array}$ & $\begin{array}{l}1 \\
2 \\
3 \\
4 \\
5\end{array}$ & $\begin{array}{l}11.764 \\
11.717 \\
11.416 \\
12.421 \\
10.782\end{array}$ & $\begin{array}{l}0.347 \mathrm{~J} \\
0.239 \mathrm{JE} \\
0.279 \mathrm{~J} \\
0.185 \mathrm{~J} \\
0.160 \mathrm{~J}\end{array}$ & $\begin{array}{l}0.235 \mathrm{U} \\
0.232 \mathrm{U} \\
0.237 \mathrm{U} \\
0.254 \mathrm{U} \\
0.236 \mathrm{U}\end{array}$ & $\begin{array}{l}0.235 \mathrm{U} \\
0.232 \mathrm{U} \\
0.237 \mathrm{U} \\
0.254 \mathrm{U} \\
0.236 \mathrm{U}\end{array}$ & $\begin{array}{l}0.262 \\
0.232 \mathrm{U} \\
0.231 \mathrm{JE} \\
0.254 \mathrm{U} \\
0.236 \mathrm{U}\end{array}$ & $\begin{array}{l}0.746 \mathrm{U} \\
0.738 \mathrm{U} \\
0.753 \mathrm{U} \\
0.807 \mathrm{U} \\
0.751 \mathrm{U}\end{array}$ & $\begin{array}{l}0.235 \mathrm{U} \\
0.232 \mathrm{U} \\
0.237 \mathrm{U} \\
0.254 \mathrm{U} \\
0.236 \mathrm{U}\end{array}$ & $\begin{array}{l}0.155 \\
0.153 \\
0.156 \\
0.167 \\
0.156\end{array}$ & 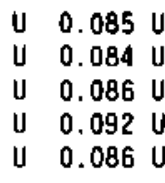 & $\begin{array}{l}2.348 \mathrm{U} \\
2.321 \mathrm{U} \\
2.369 \mathrm{U} \\
2.538 \mathrm{U} \\
2.363 \mathrm{U}\end{array}$ \\
\hline $\begin{array}{l}\text { СOMP IV } \\
\text { COMP IV } \\
\text { СOMP IV } \\
\text { СOMP IV } \\
\text { COMP IV }\end{array}$ & $\begin{array}{l}1 \\
2 \\
3 \\
4 \\
5\end{array}$ & $\begin{array}{r}9.621 \\
11.926 \\
13.027 \\
13.336 \\
12.307\end{array}$ & $\begin{array}{l}0.796 \mathrm{U} \\
0.792 \mathrm{U} \\
0.774 \mathrm{U} \\
1.592 \mathrm{U} \\
0.795 \mathrm{U}\end{array}$ & $\begin{array}{l}0.236 \mathrm{U} \\
0.235 \mathrm{U} \\
0.230 \mathrm{U} \\
0.472 \mathrm{U} \\
0.236 \mathrm{U}\end{array}$ & $\begin{array}{l}0.236 \mathrm{U} \\
0.235 \mathrm{U} \\
0.230 \mathrm{U} \\
0.472 \mathrm{U} \\
0.236 \mathrm{U}\end{array}$ & $\begin{array}{l}0.236 \mathrm{U} \\
0.235 \mathrm{U} \\
0.230 \mathrm{U} \\
0.472 \mathrm{U} \\
0.235 \mathrm{U}\end{array}$ & $\begin{array}{l}0.751 \mathrm{U} \\
0.747 \mathrm{U} \\
0.730 \mathrm{U} \\
1.501 \mathrm{U} \\
0.749 \mathrm{U}\end{array}$ & $\begin{array}{l}0.236 \mathrm{U} \\
0.235 \mathrm{U} \\
0.230 \mathrm{U} \\
0.472 \mathrm{U} \\
0.236 \mathrm{U}\end{array}$ & $\begin{array}{l}0.156 \\
0.155 \\
0.152 \\
0.312 \\
0.156\end{array}$ & 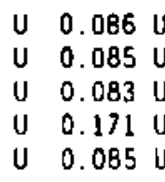 & $\begin{array}{l}2.362 \mathrm{U} \\
2.350 \mathrm{U} \\
2.297 \mathrm{U} \\
4.723 \mathrm{U} \\
2.358 \mathrm{U}\end{array}$ \\
\hline $\begin{array}{l}\text { COMP V } \\
\text { COMP V } \\
\text { COMP V } \\
\text { COMP V }\end{array}$ & $\begin{array}{l}1 \\
2 \\
3 \\
4\end{array}$ & $\begin{array}{l}11.436 \\
13.284 \\
13.303 \\
10.903\end{array}$ & $\begin{array}{l}0.598 \mathrm{~J} \\
0.822 \mathrm{~J} \\
0.912 \\
0.603 \mathrm{~J}\end{array}$ & $\begin{array}{l}0.236 \mathrm{U} \\
0.275 \mathrm{U} \\
0.237 \mathrm{U} \\
0.236 \mathrm{U}\end{array}$ & $\begin{array}{l}0.236 \mathrm{U} \\
0.275 \mathrm{U} \\
0.237 \mathrm{U} \\
0.060 \mathrm{JE}\end{array}$ & $\begin{array}{l}0.236 \mathrm{U} \\
0.275 \mathrm{U} \\
0.237 \mathrm{U} \\
0.236 . \mathrm{U}\end{array}$ & $\begin{array}{l}0.750 \mathrm{U} \\
0.874 \mathrm{U} \\
0.752 \mathrm{U} \\
0.749 \mathrm{U}\end{array}$ & $\begin{array}{l}0.236 \mathrm{U} \\
0.275 \mathrm{U} \\
0.237 \mathrm{U} \\
0.236 \mathrm{U}\end{array}$ & $\begin{array}{l}0.156 \\
0.181 \\
0.156 \\
0.156\end{array}$ & $\begin{array}{lll}U & 0.085 & 1 \\
U & 0.099 & U \\
U & 0.086 & \mathrm{U} \\
\mathrm{U} & 0.085 & \mathrm{U}\end{array}$ & $\begin{array}{l}2.361 \mathrm{U} \\
2.749 \mathrm{U} \\
2.366 \mathrm{U} \\
2.35 \mathrm{~B}\end{array}$ \\
\hline
\end{tabular}


IABLE J.13. (contd)

M. nasuta Pesticides $(\mu \mathrm{kg} / \mathrm{kg}$ wet weight)

\begin{tabular}{|c|c|c|c|c|c|c|c|c|c|c|c|c|}
\hline \multirow[b]{2}{*}{$\begin{array}{l}\text { Sediment } \\
\text { Treatment }\end{array}$} & \multirow[b]{2}{*}{ Repl icate } & \multirow[b]{2}{*}{$\begin{array}{l}\text { Anaiytical } \\
\text { Eatch } \\
\end{array}$} & \multirow[b]{2}{*}{$\begin{array}{l}\text { Percent } \\
\text { Ory Weight }\end{array}$} & \\
\hline & & & & Dteldrin & $\begin{array}{l}\text { Endo- } \\
\text { sulfan I }\end{array}$ & $\begin{array}{c}\begin{array}{c}\text { Endo- } \\
\text { sulfan II }\end{array} \\
\end{array}$ & $\begin{array}{l}\text { Endo- } \\
\text { sulfan } \\
\text { Sulfate } \\
\end{array}$ & Endrin & $\begin{array}{c}\text { Endrin } \\
\text { aldehyde }\end{array}$ & $\begin{array}{l}\text { Hepta- } \\
\text { chlor }\end{array}$ & $\begin{array}{l}\text { Hepta- } \\
\text { chlor- } \\
\text { epoxide }\end{array}$ & $\begin{array}{r}\text { Toxa- } \\
\text { phene }\end{array}$ \\
\hline \multirow{3}{*}{\multicolumn{2}{|c|}{$\begin{array}{lll}\text { COMP V Replicate } & 1 & 5 \\
\text { COMP V Repl fcate } 2 & 5 \\
\text { COMP V Replicate } 3 & 5\end{array}$}} & B & 12.388 & $0.930 \mathrm{~J}$ & $0.572 U$ & $0.124 \mathrm{~J}$ & $0.572 \mathrm{U}$ & $1.819 \mathrm{~V}$ & $0.572 \mathrm{U}$ & $0.378 U$ & $0.207 \mathrm{U}$ & $5.722 \mathrm{U}$ \\
\hline & & $B$ & 12.388 & $0.907 \mathrm{~J}$ & $0.487 \mathrm{U}$ & $0.081 \mathrm{~J}$ & $0.487 \mathrm{U}$ & $1.547 \mathrm{U}$ & $0.487 \mathrm{U}$ & $0.321 \mathrm{U}$ & $0.176 \mathrm{U}$ & $4.868 \mathrm{~J}$ \\
\hline & & $B$ & $12.38 B$ & $0.919 \mathrm{~J}$ & 0.3380 & $0.141 \mathrm{~J}$ & 0.338 u & $1.074 \mathrm{U}$ & $0.338 \mathrm{U}$ & $0.223 \mathrm{U}$ & $0.122 \mathrm{U}$ & $3.380 \mathrm{~V}$ \\
\hline COMP VI & 1 & c & 10.468 & 0.819 & $0.236 \mathrm{U}$ & $0.236 \mathrm{U}$ & $0.236 \mathrm{U}$ & $0.750 \mathrm{U}$ & $0.236 U$ & $0.156 \mathrm{U}$ & J $0.085 \mathrm{U}$ & $2.359 \mathrm{U}$ \\
\hline COMP VI & 2 & A & 11.022 & $0.761 \mathrm{~J}$ & $0.237 \mathrm{U}$ & $0.237 \mathrm{U}$ & $0.237 \mathrm{U}$ & $0.753 \mathrm{U}$ & $0.237 \mathrm{U}$ & $0.156 \mathrm{U}$ & & $2.369 \mathrm{U}$ \\
\hline COMP VI & 3 & B & 12.942 & $1.173 \mathrm{~J}$ & $0.702 \mathrm{U}$ & $0.080 \mathrm{~J}$ & $0.702 \mathrm{U}$ & $2.232 \mathrm{~J}$ & $0.702 \mathrm{U}$ & $0.463 \mathrm{U}$ & $0.254 \mathrm{U}$ & $7.023 \mathrm{U}$ \\
\hline COMP VI & 4 & A & 10.775 & $0.692 \mathrm{~J}$ & $0.236 \mathrm{U}$ & $0.236 \mathrm{U}$ & $0.236 \mathrm{U}$ & $0.751 \mathrm{U}$ & $0.236 \mathrm{U}$ & $0.156 \mathrm{U}$ & J $0.086 \mathrm{U}$ & $2.364 \mathrm{~V}$ \\
\hline COMP VI & 5 & 0 & 9.478 & $0.593 \mathrm{~J}$ & $0.235 \mathrm{U}$ & $0.145 \mathrm{JE}$ & $0.235 \mathrm{~V}$ & $0.748 \mathrm{U}$ & $0.235 \mathrm{U}$ & $0.155 \mathrm{U}$ & $0.085 \mathrm{U}$ & 2.355 \\
\hline$-A C$ & 1 & B & 12.409 & $3 \mathrm{~J}$ & $0.232 \mathrm{U}$ & $0.232 \mathrm{U}$ & $32 \mathrm{U}$ & $0.739 \mathrm{U}$ & $0.232 \mathrm{U}$ & 0. & JE & 1 \\
\hline$R-A C$ & 2 & c & 10.536 & $\mathrm{u}$ & $0.236 \mathrm{U}$ & $0.236 \mathrm{U}$ & $0.236 \mathrm{U}$ & $0.751 \mathrm{U}$ & $0.236 \mathrm{U}$ & $6 \mathrm{U}$ & & 2. \\
\hline $\mathrm{R}-\mathrm{AC}$ & 3 & C & 11.771 & $0.790 \mathrm{U}$ & $0.234 \mathrm{U}$ & $0.234 \mathrm{~J}$ & $0.234 \mathrm{U}$ & $0.745 \mathrm{U}$ & $0.234 \mathrm{U}$ & $0.155 \mathrm{U}$ & J 0. & 2.3 \\
\hline$R-A C$ & 4 & A & 11.562 & $0.796 \mathrm{U}$ & $0.236 \mathrm{U}$ & $0.236 \mathrm{U}$ & $0.236 \mathrm{U}$ & $0.751 \mathrm{U}$ & $0.236 \mathrm{U}$ & $0.156 \mathrm{U}$ & $0.086 \mathrm{U}$ & $2.362 \mathrm{~L}$ \\
\hline$R-A C$ & 5 & 0 & 11.023 & $0.031 \mathrm{~J}$ & $0.236 \mathrm{U}$ & $0.236 \mathrm{U}$ & $0.236 \mathrm{U}$ & $0.752 \mathrm{U}$ & $0.236 \mathrm{U}$ & 0. & & 2.365 \\
\hline B-AH & 1 & B & 10. & 0.067 & $u$ & 0.000 & u & 0. & u & 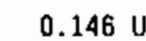 & & $\mathrm{u}$ \\
\hline R-AM R & 12 & $c$ & 10.3 & 13 & $0.351 \mathrm{U}$ & $0.351 U$ & 10 & $1.116 \mathrm{U}$ & 0.3 & & & 3 \\
\hline R-AM Replicate 2 & 22 & c & 10.333 & $1.198 \mathrm{U}$ & $0.355 \mathrm{U}$ & $0.355 \mathrm{U}$ & $0.355 \mathrm{U}$ & $1.129 \mathrm{~V}$ & $0.355 \mathrm{U}$ & & & 3.5 \\
\hline R-AM Replicate 3 & 32 & C & 10.333 & $1.150 \mathrm{U}$ & $0.341 \mathrm{U}$ & $0.341 \mathrm{U}$ & $0.341 \mathrm{U}$ & $1.084 \mathrm{~J}$ & $0.341 \mathrm{U}$ & $25 \mathrm{U}$ & & 3.412 \\
\hline$R-A M$ & 3 & 8 & 12.305 & $0.095 \mathrm{~J}$ & $0.293 \mathrm{U}$ & $0.055 \mathrm{~J}$ & $0.293 \mathrm{U}$ & $0.931 \mathrm{~J}$ & $0.293 \mathrm{U}$ & $0.193 \mathrm{U}$ & $0.106 \mathrm{U}$ & $2.930 \mathrm{U}$ \\
\hline R-AM & 4 & 8 & 12.397 & $0.138 \mathrm{~J}$ & $0.540 \mathrm{U}$ & $0.540 \mathrm{U}$ & $0.540 \mathrm{U}$ & $1.715 \mathrm{U}$ & $0.540 \mathrm{U}$ & $0.356 \mathrm{U}$ & & $5.396 \mathrm{U}$ \\
\hline R-AM & 5 & 8 & 10.438 & 0 & $0.231 \mathrm{U}$ & $0.034 \mathrm{~J}$ & $0.231 \mathrm{U}$ & $0.736 \mathrm{U}$ & $0.231 \mathrm{U}$ & $0.153 \mathrm{U}$ & 0.084 U & 2.314 \\
\hline$R-B$ & 1 & D & 1 & & 70 & 0.2 & $0.277 \mathrm{U}$ & $0.882 \mathrm{U}$ & $0.2+3-1$ & $0.183 \mathrm{U}$ & & L \\
\hline$R-B F$ & 2 & 8 & 13.418 & $\mathrm{~J}$ & $0.237 \mathrm{U}$ & & $0.237 \mathrm{U}$ & & & & & \\
\hline$R-B F$ & 3 & 8 & 12.068 & $0.157 \mathrm{~J}$ & $0.237 \mathrm{U}$ & $0.105 \mathrm{~J}$ & $0.237 \mathrm{U}$ & $0.752 \mathrm{U}$ & $0.237 \mathrm{U}$ & $0.156 \mathrm{U}$ & 0 . 0 . & $2.367 \mathrm{u}$ \\
\hline$R-B F$ & 4 & A & 10.122 & $0.026 \mathrm{~J}$ & $0.235 \mathrm{U}$ & & & $0.746 \mathrm{U}$ & $0.235 \mathrm{U}$ & $0.155 \mathrm{U}$ & 0 . & $2.346 \mathrm{U}$ \\
\hline$R-B F$ & 5 & A & 12.830 & $0.086 \mathrm{~J}$ & $0.229 \mathrm{U}$ & $0.229 \mathrm{U}$ & $0.229 \mathrm{U}$ & $0.728 \mathrm{U}$ & $0.229 \mathrm{U}$ & $0.151 \mathrm{~V}$ & $0.083 \mathrm{U}$ & $2.289 u$ \\
\hline$R-C$ & 1 & 8 & & & & & & & & 0. & & \\
\hline$R-C$ & 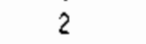 & D & 11. & & 0.2 & $0.233 \mathrm{U}$ & $0.233 \mathrm{U}$ & $0.741 \mathrm{~J}$ & & & & \\
\hline$R-0 S$ & 3 & B & 11.559 & $0.063 \mathrm{~J}$ & $0.235 \mathrm{U}$ & $0.235 \mathrm{U}$ & $0.235 \mathrm{U}$ & $0.747 \mathrm{U}$ & $0.235 \mathrm{U}$ & $0.155 \mathrm{U}$ & 0. & 2.350 \\
\hline$R-0 S$ & 4 & 0 & 12.3 & & 0.2 & & & $0 \mathrm{U}$ & $0.236 \mathrm{U}$ & 0. & $J$ & $2.360 \mathrm{~L}$ \\
\hline$R-0 S$ & 5 & c & 12.736 & $0.791 \mathrm{U}$ & $0.235 \mathrm{U}$ & $0.235 \mathrm{U}$ & $0.235 U$ & $0.746 \mathrm{U}$ & $0.235 \mathrm{~V}$ & $0.155 \mathrm{U}$ & $\mathrm{J} 0.085 \mathrm{U}$ & $2.34 \mathrm{~B} \mathrm{C}$ \\
\hline
\end{tabular}


TABLE $] .13 . \quad$ (contd)

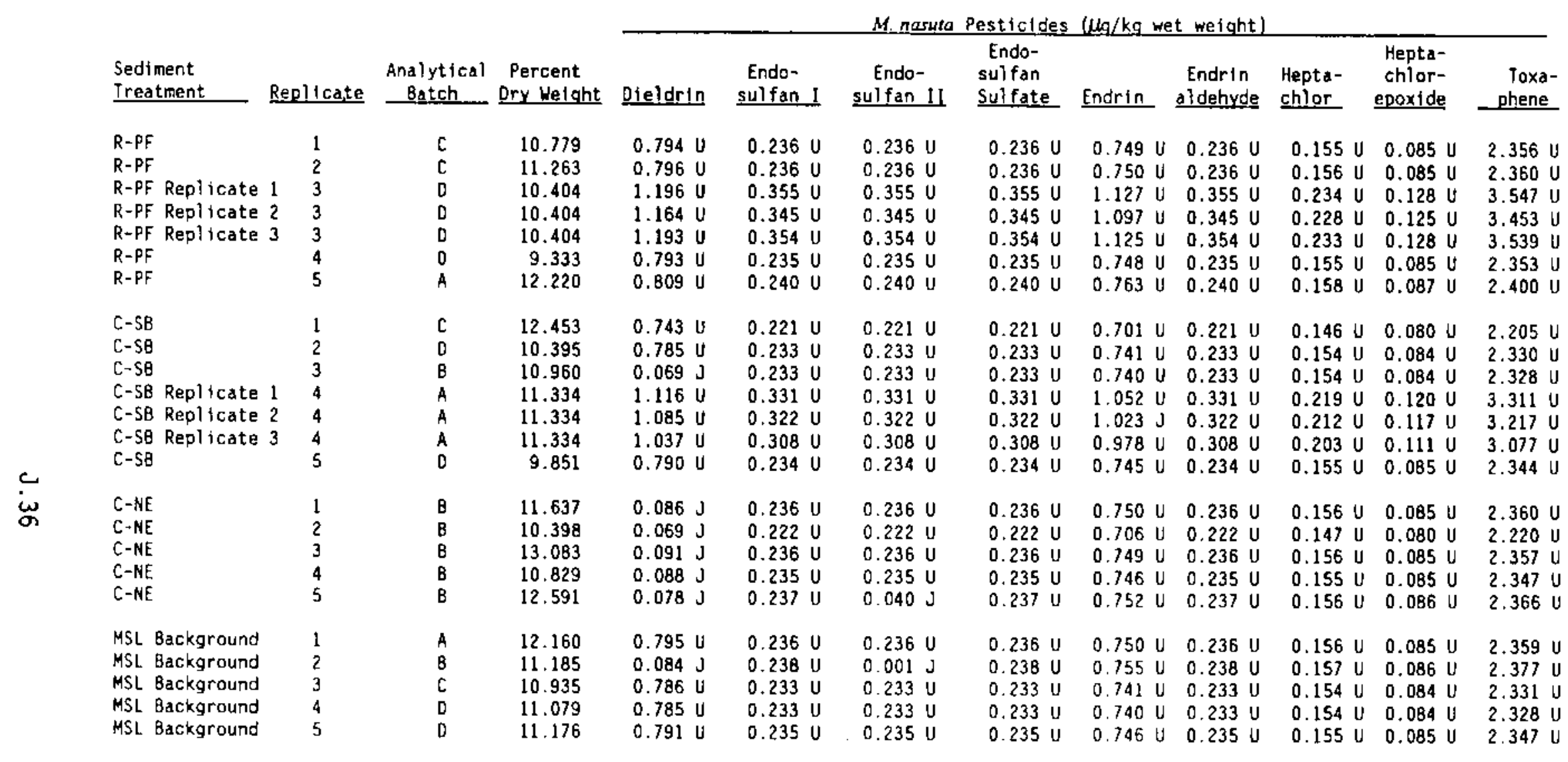

(a) DL Detection limit.

(b) J Analyte detected below method detection 1 imit (MDL), but above instrument detection limit (IDL).

(c) U The analyte was not present above the level of the assaciated value.

(d) $\mathrm{E}$ Value an estimate; analyte not detected on confirmation column. 
IABLE J.14. Quality Control Data for Chlorinated Pesticides (alphabetical, Aldrin - 4,4'-DDT), Dry Weight, in Tissue of $M$. nasuta, Richmond Harbor Program

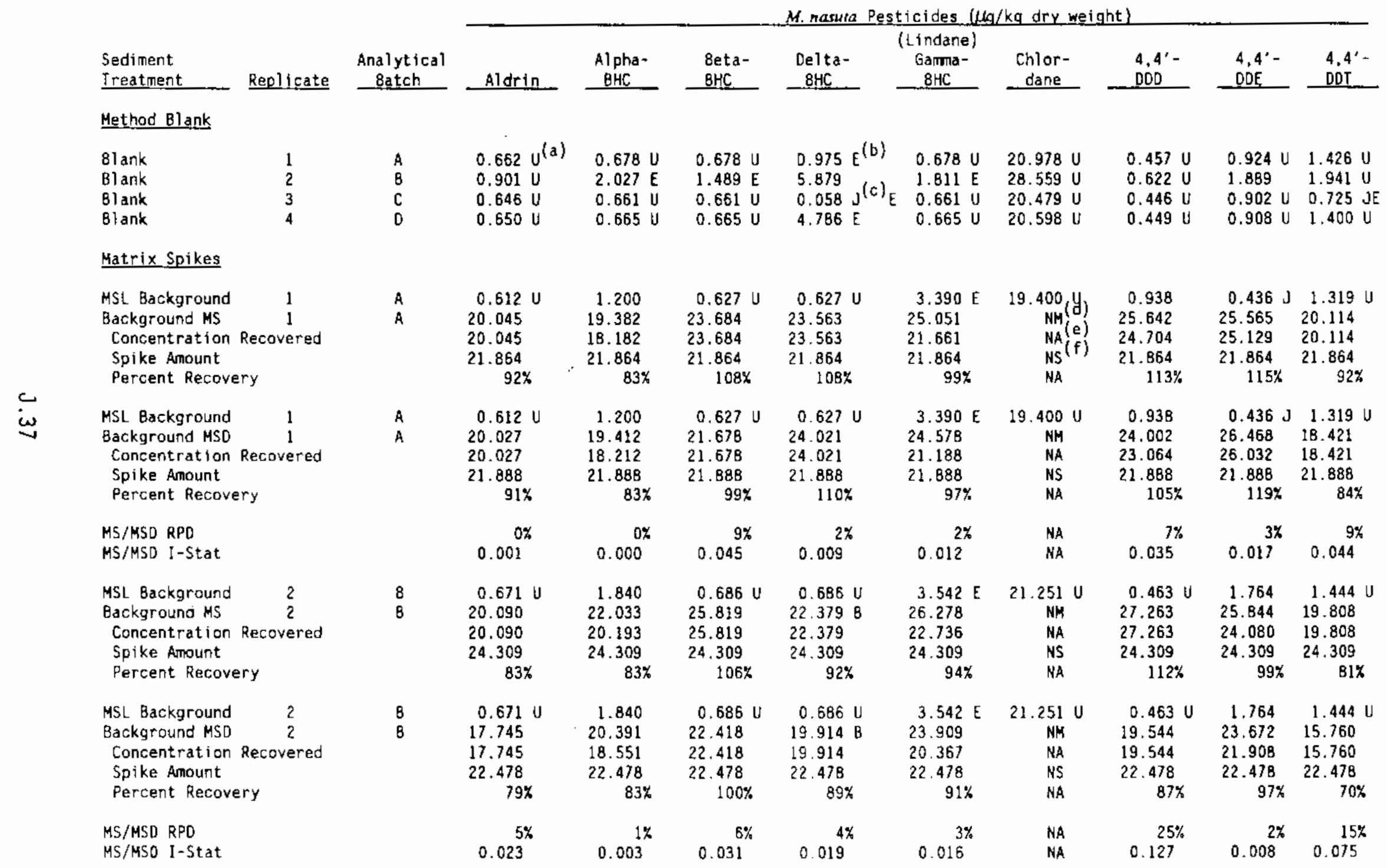


TABLE J.14. (contd)

M. nasuta Pesticides ( $\mu$ a/kq dry weight)

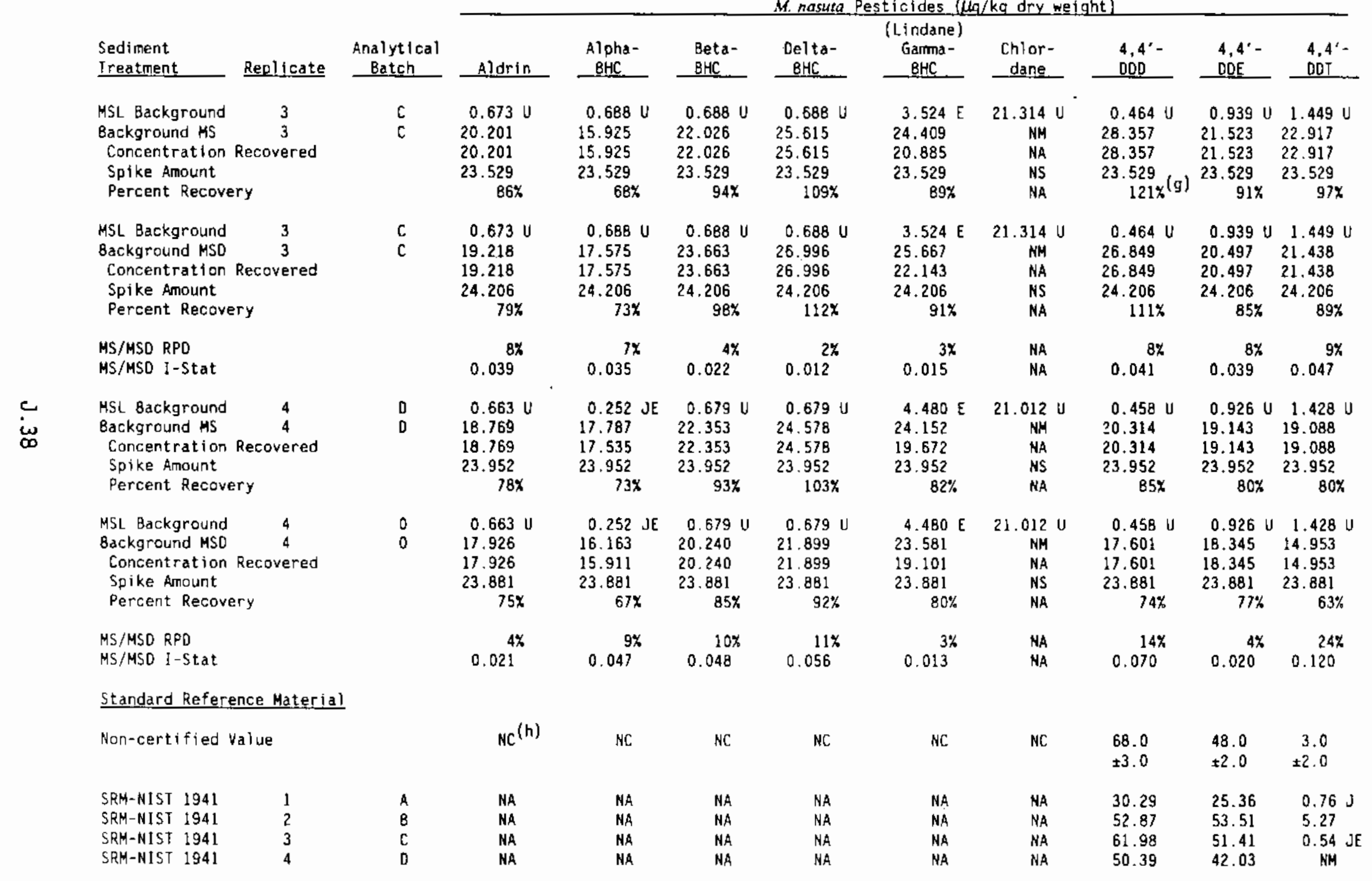


TABLE J.14. (contd)

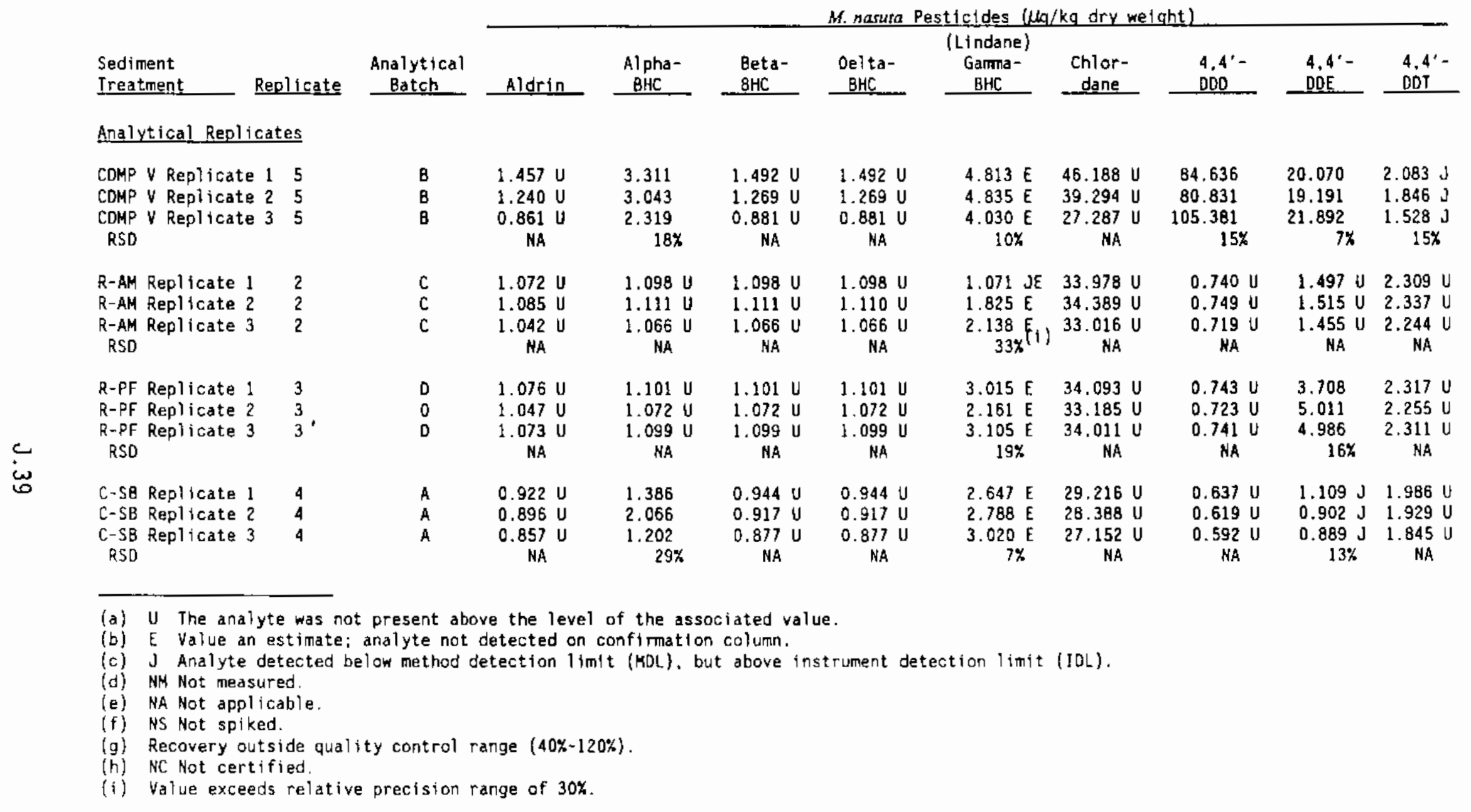


IABLE 3.15. Quality Control Data for Chlorinated Pesticides (alphabetical, Dieldrin - Toxaphene), Dry Weight, in Tissue of M. nasuta, Richmond Harbor Program

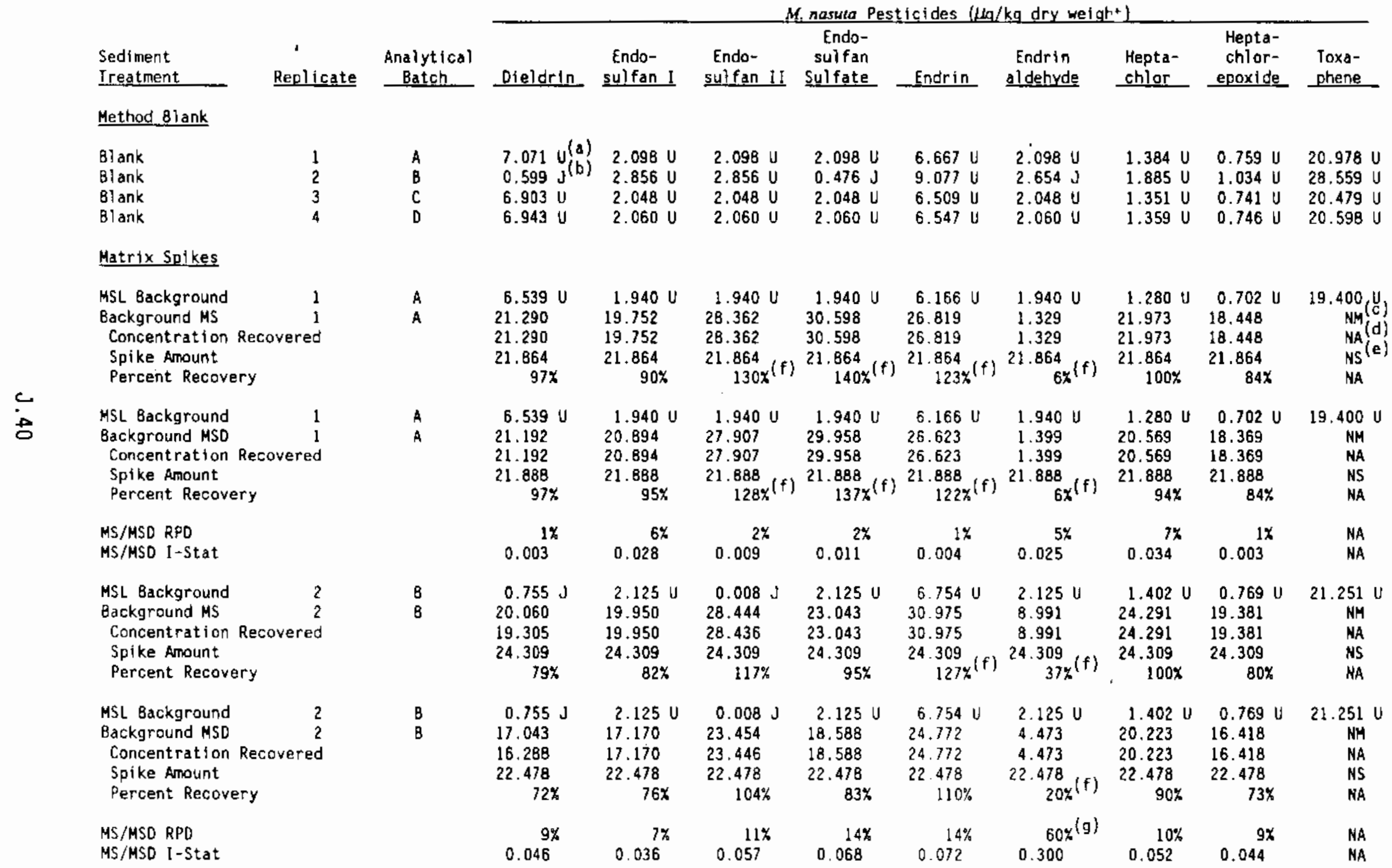


IABLE J.15. (contd)

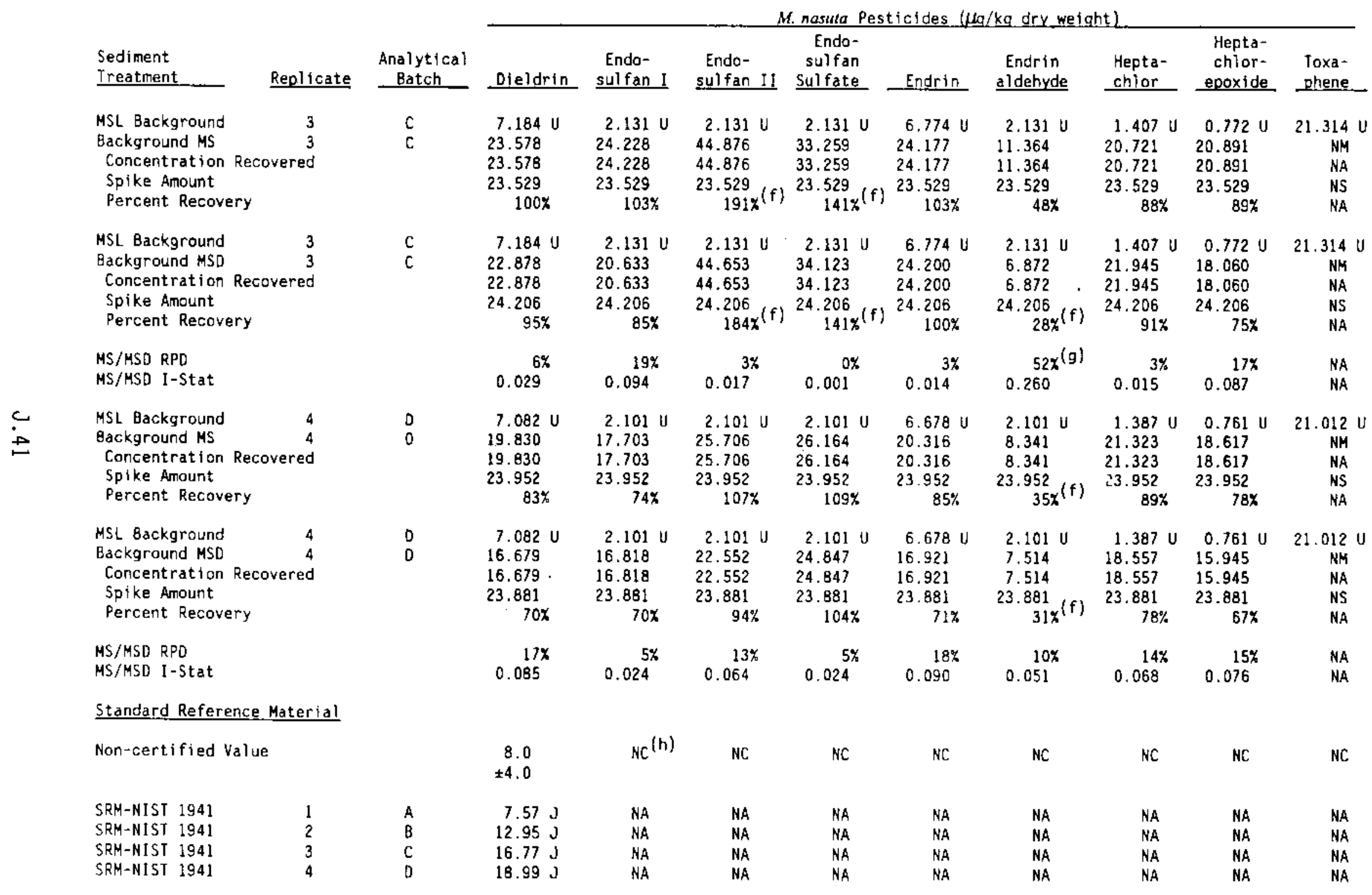


TABLE J.15. (contd)

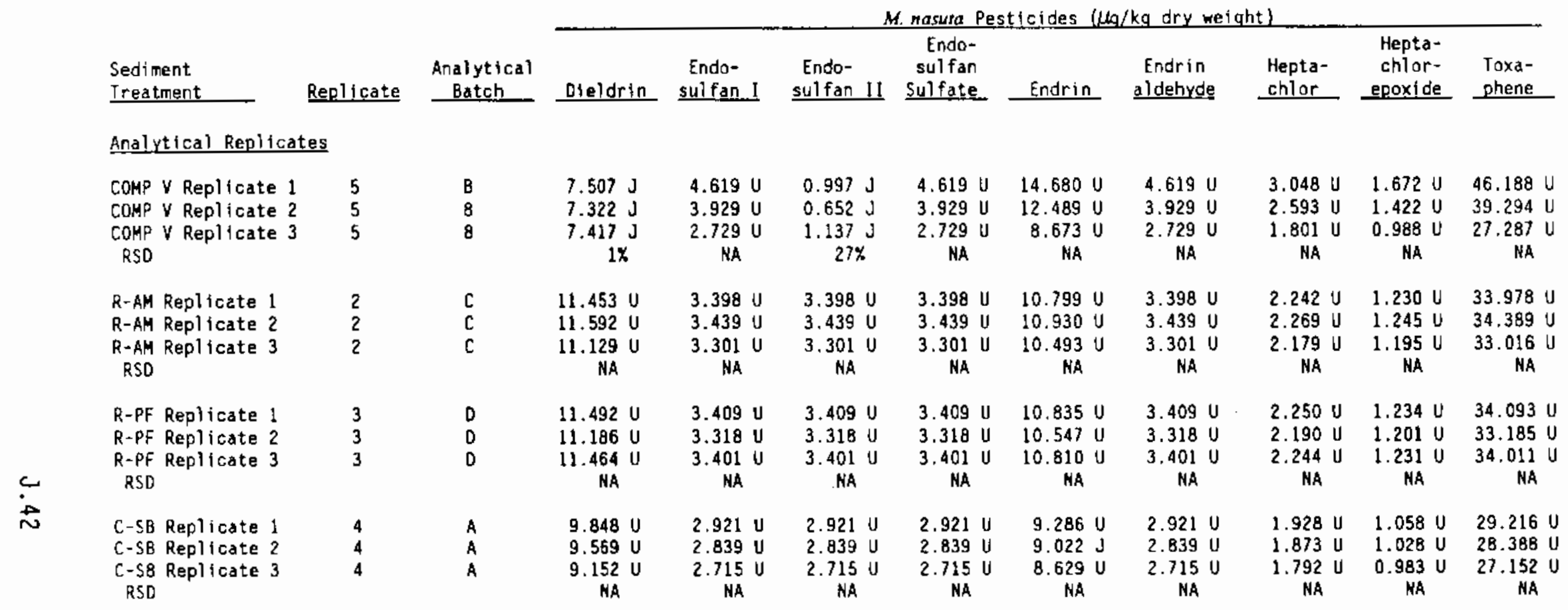

(a) U The analyte was not present above the level of the associated value.

(b) J Analyte detected below method detection limit (MOL), but above instrument detection limit (IDL).

(c) NM Not measured.

(d) NA Not applicable.

(e) NS Not spiked.

(f) Recovery outside quality control range (40\%-120x).

(g) Value exceeds relative precision range of $30 \%$.

(h) NC Not certified. 


\section{TABLE J.16. Polychorinated Biphenyls (PCBs), Dry Weight, in Tissue of \\ M. nasuta, Richmond Harbor Program}

Sediment

Treatment

COMP I

COMP I

COMP I

COMP I

COMP I

COMP II

COMP II

COMP II

COMP II

COMP II

COMP II:

COMP III

COMP II

COMP 111

COMP 111

TC-5 Upper Comp

IC-5 Upper Comp

TC-5 Upper Comp

TC-5 Upper Comp

TC-5 Upper Comp

COMP IV

COMP IV

COMP IV

COMP IV

COMP IV

COMP V

COMP V

COMP $V$

COMP $V$

COMP V Replicate 1

COMP V Replicate 2

CDMP $\vee$ Replicate 3

COMP VI

COMP VI

COMP VI

COMP VI

COMP VI

$R-A C$

$R-A C$

$R-A C$

$R-A C$

$R-A C$

R-AM

R-AM Replicate 1

R-AM Replicate 2

R-AM Replicate 3

$R-A M$

R-AM

R-AH
Analytical

Replicate Batch

$\begin{array}{ll}1 & 0 \\ 2 & 0 \\ 3 & \text { A } \\ 4 & \text { B } \\ 5 & \text { A }\end{array}$

1

2

3

4

5

1

2

3

5

1

2

3

4

A

2

3

4

2

3

4

5

5

1

2

3

4

1

2

3

5

1

1
2
2

2

2

3

\begin{tabular}{|c|c|c|c|}
\hline $\begin{array}{c}\text { Aroclor } \\
1242\end{array}$ & $\begin{array}{c}\text { Aroclor } \\
1248\end{array}$ & $\begin{array}{c}\text { Aroclor } \\
1254 \\
\end{array}$ & $\begin{array}{c}\text { Aroclor } \\
1260\end{array}$ \\
\hline $\begin{array}{l}21.811 \mathrm{U}^{(\mathrm{d})} \\
19.186 \mathrm{U}^{(19.790 \mathrm{U}} \\
18.727 \mathrm{U} \\
21.327 \\
22.834 \mathrm{U}\end{array}$ & $\begin{array}{l}21.811 \mathrm{U} \\
19.186 \mathrm{U} \\
18.790 \mathrm{U} \\
21.327 \mathrm{U} \\
22.834 \mathrm{U}\end{array}$ & $\begin{array}{l}70.323 \\
80.239 \\
82.272 \\
74.656 \\
82.577\end{array}$ & $\begin{array}{l}21.811 \\
19.186 \\
18.790 \\
21.327 \\
22.834\end{array}$ \\
\hline $\begin{array}{l}22.908 \mathrm{U} \\
19.973 \mathrm{U} \\
18.711 \mathrm{U} \\
22.495 \mathrm{U} \\
20.580 \mathrm{U}\end{array}$ & $\begin{array}{l}22.908 \mathrm{U} \\
19.973 \mathrm{U} \\
18.711 \mathrm{U} \\
22.495 \mathrm{U} \\
20.580 \mathrm{U}\end{array}$ & $\begin{array}{r}86.264 \\
106.675 \\
91.115 \\
78.429 \\
97.712\end{array}$ & $\begin{array}{l}22.908 \\
19.973 \\
18.711 \\
22.495 \\
20.580\end{array}$ \\
\hline $\begin{array}{l}21.905 \mathrm{U} \\
19.544 \mathrm{U} \\
20.177 \mathrm{U} \\
20.263 \mathrm{U} \\
19.093 \mathrm{U}\end{array}$ & $\begin{array}{l}21.905 \mathrm{U} \\
19.544 \mathrm{U} \\
20.177 \mathrm{U} \\
20.263 \mathrm{U} \\
19.093 \mathrm{U}\end{array}$ & $\begin{array}{l}64.938 \\
62.334 \\
65.176 \\
43.677 \\
57.537\end{array}$ & $\begin{array}{l}21.905 \\
19.544 \\
20.177 \\
20.263 \\
19.093\end{array}$ \\
\hline $\begin{array}{l}19.956 \mathrm{U} \\
19.806 \mathrm{U} \\
20.754 \mathrm{U} \\
20.432 \mathrm{U} \\
21.912 \mathrm{U}\end{array}$ & $\begin{array}{l}19.956 \mathrm{U} \\
19.806 \mathrm{U} \\
20.754 \mathrm{U} \\
20.432 \mathrm{U} \\
21.912 \mathrm{U}\end{array}$ & $\begin{array}{l}188.164 \\
184.500 \\
212.688 \\
142.585 \\
139.686\end{array}$ & $\begin{array}{l}19.956 \mathrm{~L} \\
19.806 \mathrm{~L} \\
20.754 \mathrm{~L} \\
20.432 \mathrm{~L} \\
21.912 \mathrm{~L}\end{array}$ \\
\hline $\begin{array}{l}24.554 \mathrm{U} \\
19.707 \mathrm{U} \\
17.634 \mathrm{U} \\
35.418 \mathrm{U} \\
19.160 \mathrm{U}\end{array}$ & $\begin{array}{l}24.554 \mathrm{U} \\
19.707 \mathrm{U} \\
17.634 \mathrm{U} \\
35.418 \mathrm{U} \\
19.160 \mathrm{U}\end{array}$ & $\begin{array}{l}24.554 \mathrm{U} \\
40.840 \\
39.416 \\
35.418 \mathrm{U} \\
48.761\end{array}$ & $\begin{array}{l}24.554 \\
19.707 \\
17.634 \\
35.418 \\
19.160\end{array}$ \\
\hline $\begin{array}{l}20.646 \mathrm{U} \\
20.694 \mathrm{U} \\
17.784 \mathrm{U} \\
21.625 \mathrm{U} \\
46.188 \mathrm{U} \\
39.294 \mathrm{U} \\
27.287 \mathrm{U}\end{array}$ & $\begin{array}{l}20.646 \mathrm{U} \\
20.694 \mathrm{U} \\
17.784 \mathrm{U} \\
21.625 \mathrm{U} \\
46.188 \mathrm{U} \\
39.294 \mathrm{U} \\
27.287 \mathrm{U}\end{array}$ & $\begin{array}{l}175.972 \\
163.323 \\
174.219 \\
128.288 \\
143.548 \\
156.695 \\
155.426\end{array}$ & $\begin{array}{l}20.646 \\
20.694 \\
17.784 \\
21.625 \\
46.188 \\
39.294 \\
27.287\end{array}$ \\
\hline $\begin{array}{l}22.537 \mathrm{U} \\
21.495 \mathrm{U} \\
54.262 \mathrm{U} \\
21.939 \mathrm{U} \\
24.846 \mathrm{U}\end{array}$ & $\begin{array}{l}22.537 \mathrm{U} \\
21.495 \mathrm{U} \\
54.262 \mathrm{U} \\
21.939 \mathrm{U} \\
24.846 \mathrm{U}\end{array}$ & $\begin{array}{l}201.989 \\
154.013 \\
251.080 \\
213.081 \\
193.302\end{array}$ & $\begin{array}{l}22.537 \quad u \\
21.495 \mathrm{U} \\
54.262 \mathrm{U} \\
21.939 \mathrm{U} \\
24.846 \mathrm{U}\end{array}$ \\
\hline $\begin{array}{l}18.736 \mathrm{U} \\
22.438 \mathrm{U} \\
19.922 \mathrm{U} \\
20.432 \mathrm{U} \\
21.456 \mathrm{U}\end{array}$ & $\begin{array}{l}18.736 \mathrm{U} \\
22.438 \mathrm{U} \\
19.922 \mathrm{U} \\
20.432 \mathrm{U} \\
21.456 \mathrm{U}\end{array}$ & $\begin{array}{r}94.512 \\
128.6 \mathrm{~B} 8 \\
181.823 \\
157.103 \\
85.992\end{array}$ & $\begin{array}{l}18.736 \\
22.438 \\
19.922 \\
20.432 \\
21.456\end{array}$ \\
\hline $\begin{array}{l}22.028 \mathrm{U} \\
33.978 \mathrm{U} \\
34.389 \mathrm{U} \\
33.016 \mathrm{U} \\
23.813 \mathrm{U} \\
43.529 \mathrm{U} \\
22.172 \mathrm{U}\end{array}$ & $\begin{array}{l}22.028 \mathrm{U} \\
33.978 \mathrm{U} \\
34.389 \mathrm{U} \\
33.016 \mathrm{U} \\
23.813 \mathrm{U} \\
43.529 \mathrm{U} \\
22.172 \mathrm{U}\end{array}$ & $\begin{array}{r}59.169 \\
80.162 \\
78.654 \\
91.345 \\
115.442 \\
118.580 \\
66.193\end{array}$ & $\begin{array}{l}22.028 \\
33.978 \\
34.389 \\
33.016 \\
23.813 \\
43.529 \\
22.172\end{array}$ \\
\hline
\end{tabular}


TABLE J.16. (contd)

Sediment

ireatment

R-BF

$R-B F$

$R-B F$

$R-B F$

$R-B F$

$R-O S$

$R-0 S$

R-OS

$\mathrm{R}-\mathrm{OS}$

$R+O S$

$R+P F$

$R-P F$

R-PF Repi icate 1

$R$-PF Replicate 2

R-PF

$\mathrm{R}-\mathrm{PF}$

$C-\$ B$

$\mathrm{C}-\mathrm{SB}$

C-58

C-S8 Peplicate 1

C-SB Replicate 2

C-S8 Replicate 3

$\mathrm{C}-\mathrm{SB}$

$\mathrm{C}-\mathrm{NE}$

C-NE

C-ME

C-ASE

C-NE

MSL Background

HSL Background

MSL Background

HSL Background

HSL Background
$R-P F$ Replicate 3

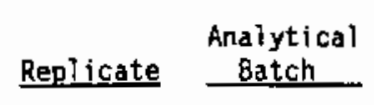

D
B
B
A
A

$B$
$D$
$B$
0
$C$

$C$
$C$
$D$
$D$
$D$
$D$
$A$

\section{c}

1
2
3
4
4
4
5

1
2
3
4
5

$\begin{array}{ll}1 & A \\ 2 & B \\ 3 & C \\ 4 & D \\ 5 & \text { D }\end{array}$

M. narma PCBs $(\mu \mathrm{g} / \mathrm{kq}$ dry weight)

\begin{tabular}{ccccc}
\hline $\begin{array}{c}\text { Aroclor } \\
1242\end{array}$ & $\begin{array}{c}\text { Aroclor } \\
1248\end{array}$ & $\begin{array}{c}\text { Aroclor } \\
1254\end{array}$ & $\begin{array}{c}\text { Aroclor } \\
1260\end{array}$ \\
\cline { 1 - 1 } & & & & \\
$24.933 \mathrm{U}$ & $24.933 \mathrm{U}$ & 69.236 & $24.933 \mathrm{U}$ \\
$17.630 \mathrm{U}$ & $17.630 \mathrm{U}$ & 115.933 & $17.630 \mathrm{U}$ \\
$19.615 \mathrm{U}$ & $19.615 \mathrm{U}$ & 114.900 & $19.615 \mathrm{U}$ \\
$23.177 \mathrm{U}$ & $23.177 \mathrm{U}$ & 106.710 & $23.177 \mathrm{U}$ \\
$17.842 \mathrm{U}$ & $17.842 \mathrm{U}$ & 91.766 & $17.842 \mathrm{U}$ \\
& & & & \\
$19.712 \mathrm{U}$ & $19.712 \mathrm{U}$ & 25.119 & $19.712 \mathrm{U}$ \\
$20.211 \mathrm{U}$ & $20.211 \mathrm{U}$ & $20.211 \mathrm{U}$ & $20.211 \mathrm{U}$ \\
$20.327 \mathrm{U}$ & $20.327 \mathrm{U}$ & 22.374 & $20.327 \mathrm{U}$ \\
$19.150 \mathrm{U}$ & $19.150 \mathrm{U}$ & 27.999 & $19.150 \mathrm{U}$ \\
$18.434 \mathrm{U}$ & $18.434 \mathrm{U}$ & $18.434 \mathrm{U}$ & $18.434 \mathrm{U}$ \\
& & & & \\
$21.858 \mathrm{U}$ & $21.858 \mathrm{U}$ & $21.858 \mathrm{U}$ & $21.858 \mathrm{U}$ \\
$20.956 \mathrm{U}$ & $20.956 \mathrm{U}$ & 38.246 & $20.956 \mathrm{U}$ \\
$34.093 \mathrm{U}$ & $34.093 \mathrm{U}$ & $34.093 \mathrm{U}$ & $34.093 \mathrm{U}$ \\
$33.185 \mathrm{U}$ & $33.185 \mathrm{U}$ & $33.185 \mathrm{U}$ & $33.185 \mathrm{U}$ \\
$34.011 \mathrm{U}$ & $34.011 \mathrm{U}$ & $34.011 \mathrm{U}$ & $34.011 \mathrm{U}$ \\
$25.216 \mathrm{U}$ & $25.216 \mathrm{U}$ & 32.682 & $25.216 \mathrm{U}$ \\
$19.636 \mathrm{U}$ & $19.636 \mathrm{U}$ & 51.277 & $19.636 \mathrm{U}$ \\
& & & & \\
$17.709 \mathrm{U}$ & $17.709 \mathrm{U}$ & 42.084 & $17.709 \mathrm{U}$ \\
$22.417 \mathrm{U}$ & $22.417 \mathrm{U}$ & 31.549 & $22.417 \mathrm{U}$ \\
$21.238 \mathrm{U}$ & $21.238 \mathrm{U}$ & 38.957 & $21.238 \mathrm{U}$ \\
$29.216 \mathrm{U}$ & $29.216 \mathrm{U}$ & 35.074 & $29.216 \mathrm{U}$ \\
$28.388 \mathrm{U}$ & $28.388 \mathrm{U}$ & 37.273 & $28.388 \mathrm{U}$ \\
$27.152 \mathrm{U}$ & $27.152 \mathrm{U}$ & 37.331 & $27.152 \mathrm{U}$ \\
$23.797 \mathrm{U}$ & $23.797 \mathrm{U}$ & 33.199 & $23.797 \mathrm{U}$ \\
& & & & \\
$20.280 \mathrm{U}$ & $20.280 \mathrm{U}$ & 41.367 & $20.280 \mathrm{U}$ \\
$21.353 \mathrm{U}$ & $21.353 \mathrm{U}$ & 42.943 & $21.353 \mathrm{U}$ \\
$18.014 \mathrm{U}$ & $18.014 \mathrm{U}$ & 47.330 & $18.014 \mathrm{U}$ \\
$21.672 \mathrm{U}$ & $21.672 \mathrm{U}$ & 48.628 & $21.672 \mathrm{U}$ \\
$18.795 \mathrm{U}$ & $18.795 \mathrm{U}$ & 49.805 & $18.795 \mathrm{U}$ \\
& & & & \\
$19.400 \mathrm{U}$ & $19.400 \mathrm{U}$ & $19.400 \mathrm{U}$ & $19.400 \mathrm{U}$ \\
$21.251 \mathrm{U}$ & $21.251 \mathrm{U}$ & 22.598 & $21.251 \mathrm{U}$ \\
$21.314 \mathrm{U}$ & $21.314 \mathrm{U}$ & $21.314 \mathrm{U}$ & $21.314 \mathrm{U}$ \\
$21.012 \mathrm{U}$ & $21.012 \mathrm{U}$ & $21.012 \mathrm{U}$ & $21.012 \mathrm{U}$ \\
$20.999 \mathrm{U}$ & $20.999 \mathrm{U}$ & 34.739 & $20.999 \mathrm{U}$
\end{tabular}

(a) U The analyte was not present above the level of the associated value. 
IABLE J.17. Polychlorinated Biphenyls (PCBs), Wet Weight, in Tissue of M. nasuta, Richmond Harbor Program

\begin{tabular}{|c|c|c|c|c|c|c|c|c|c|}
\hline \multirow[b]{2}{*}{$\begin{array}{l}\text { Sediment } \\
\text { Treatment }\end{array}$} & \multirow[b]{2}{*}{ Replicate } & \multirow[b]{2}{*}{$\begin{array}{l}\text { Analytical } \\
\text { Batch }\end{array}$} & \multirow[b]{2}{*}{$\begin{array}{l}\text { Percent } \\
\text { Dry Height }\end{array}$} & \multicolumn{6}{|c|}{ M. nasuta PCBs $(\mu \mathrm{g} / \mathrm{kg}$ wet weight $)$} \\
\hline & & & & $\begin{array}{l}\text { Aroclor } \\
1242 \\
\end{array}$ & & $\begin{array}{l}\text { Arocior } \\
1248 \\
\end{array}$ & & $\begin{array}{l}\text { Aroclor } \\
1254 \\
\end{array}$ & $\begin{array}{l}\text { Aroclor } \\
1260 \\
\end{array}$ \\
\hline $\begin{array}{l}\text { Target OL (a) } \\
\text { Achieved OL High } \\
\text { Achieved DL Low }\end{array}$ & & & & $\begin{array}{r}20.0 \\
7.023 \\
2.244\end{array}$ & & $\begin{array}{l}20.0 \\
7.023 \\
2.244\end{array}$ & & $\begin{array}{r}20.0 \\
4.723 \\
2.728\end{array}$ & $\begin{array}{r}20.0 \\
7.023 \\
2.244\end{array}$ \\
\hline $\begin{array}{l}\text { COMP I } \\
\text { COMP I } \\
\text { COMP I } \\
\text { COMP I } \\
\text { COMP I }\end{array}$ & $\begin{array}{l}1 \\
2 \\
3 \\
4 \\
5\end{array}$ & $\begin{array}{l}D \\
D \\
A \\
B \\
A\end{array}$ & $\begin{array}{l}10.850 \\
12.311 \\
12.576 \\
10.945 \\
12.424\end{array}$ & $\begin{array}{l}2.366 \\
2.362 \\
2.363 \\
2.334 \\
2.837\end{array}$ & $\begin{array}{l}u^{(b)} \\
u \\
u \\
u \\
u\end{array}$ & $\begin{array}{l}2.366 \\
2.362 \\
2.363 \\
2.334 \\
2.837\end{array}$ & $\begin{array}{l}u \\
u \\
u \\
u \\
u\end{array}$ & $\begin{array}{r}7.630 \\
9.878 \\
10.347 \\
8.171 \\
10.259\end{array}$ & $\begin{array}{l}2.366 \mathrm{U} \\
2.362 \mathrm{U} \\
2.363 \mathrm{U} \\
2.334 \mathrm{U} \\
2.837 \mathrm{U}\end{array}$ \\
\hline $\begin{array}{l}\text { СOMP II } \\
\text { СОMP II } \\
\text { COMP II } \\
\text { СОMP II } \\
\text { СОMP II }\end{array}$ & $\begin{array}{l}1 \\
2 \\
3 \\
4 \\
5\end{array}$ & $\begin{array}{l}\text { D } \\
A \\
C \\
D \\
C\end{array}$ & $\begin{array}{r}9.869 \\
11.861 \\
12.662 \\
10.515 \\
10.906\end{array}$ & $\begin{array}{l}2.261 \\
2.369 \\
2.369 \\
2.365 \\
2.244\end{array}$ & $\begin{array}{l}U \\
U \\
U \\
U \\
U\end{array}$ & $\begin{array}{l}2.261 \\
2.369 \\
2.369 \\
2.3651 \\
2.244\end{array}$ & $\begin{array}{l}U \\
U \\
U \\
U \\
U\end{array}$ & $\begin{array}{r}8.513 \\
12.653 \\
11.537 \\
8.247 \\
10.656\end{array}$ & $\begin{array}{l}2.261 \mathrm{U} \\
2.369 \mathrm{U} \\
2.369 \mathrm{U} \\
2.365 \mathrm{U} \\
2.244 \mathrm{U}\end{array}$ \\
\hline $\begin{array}{l}\text { COMP III } \\
\text { COMP III } \\
\text { COMP III } \\
\text { COMP III } \\
\text { COMP III }\end{array}$ & $\begin{array}{l}1 \\
2 \\
3 \\
4 \\
5\end{array}$ & $\begin{array}{l}C \\
D \\
A \\
D \\
C\end{array}$ & $\begin{array}{l}10.740 \\
12.021 \\
11.733 \\
11.688 \\
12.222\end{array}$ & $\begin{array}{l}2.353 \\
2.349 \\
2.367 \\
2.368 \\
2.334\end{array}$ & $\begin{array}{l}\mathrm{U} \\
\mathrm{U} \\
\mathrm{U} \\
\mathrm{U} \\
\mathrm{U}\end{array}$ & $\begin{array}{l}2.353 \\
2.349 \\
2.367 \\
2.368 \\
2.334\end{array}$ & $\begin{array}{l}u \\
U \\
u \\
u \\
U\end{array}$ & $\begin{array}{l}6.974 \\
7.493 \\
7.647 \\
5.105 \\
7.032\end{array}$ & $\begin{array}{l}2.353 \mathrm{U} \\
2.349 \mathrm{U} \\
2.367 \mathrm{U} \\
2.368 \mathrm{U} \\
2.334 \mathrm{U}\end{array}$ \\
\hline $\begin{array}{l}\text { TC-5 Upper Comp } \\
\text { TC-5 Upper Comp } \\
\text { TC-5 Upper Comp } \\
\text { TC-5 Upper Comp } \\
\text { TC-5 Upper Comp }\end{array}$ & $\begin{array}{l}1 \\
2 \\
3 \\
4 \\
5\end{array}$ & $\begin{array}{l}\text { C } \\
\text { C } \\
\text { C } \\
\text { A } \\
\text { A }\end{array}$ & $\begin{array}{l}11.764 \\
11.717 \\
11.416 \\
12.421 \\
10.782\end{array}$ & $\begin{array}{l}2.348 \\
2.321 \\
2.369 \\
2.538 \\
2.363\end{array}$ & $\begin{array}{l}U \\
U \\
U \\
U \\
U\end{array}$ & $\begin{array}{l}2.348 \\
2.321 \\
2.369 \\
2.538 \\
2.363\end{array}$ & $\begin{array}{l}U \\
U \\
U \\
U \\
U \\
U\end{array}$ & $\begin{array}{l}22.136 \\
21.618 \\
24.280 \\
17.710 \\
15.061\end{array}$ & $\begin{array}{l}2.348 \mathrm{U} \\
2.321 \mathrm{U} \\
2.369 \mathrm{U} \\
2.538 \mathrm{U} \\
2.363 \mathrm{U}\end{array}$ \\
\hline $\begin{array}{l}\text { COMP IV } \\
\text { COMP IV } \\
\text { COMP IV } \\
\text { COMP IV } \\
\text { COHP IV }\end{array}$ & $\begin{array}{l}1 \\
2 \\
3 \\
4 \\
5\end{array}$ & $\begin{array}{l}\text { C } \\
C \\
A \\
C \\
A\end{array}$ & $\begin{array}{r}9.621 \\
11.926 \\
13.027 \\
13.336 \\
12.307\end{array}$ & $\begin{array}{l}2.362 \\
2.350 \\
2.297 \\
4.723 \\
2.358\end{array}$ & $\begin{array}{l}U \\
U \\
U \\
U \\
U\end{array}$ & $\begin{array}{l}2.362 \\
2.350 \\
2.297 \\
4.723 \\
2.358\end{array}$ & $\begin{array}{l}U \\
U \\
U \\
U \\
U\end{array}$ & $\begin{array}{l}2.362 \mathrm{U} \\
4.871 \\
5.135 \\
4.723 \mathrm{U} \\
6.001\end{array}$ & $\begin{array}{l}2.362 \mathrm{U} \\
2.350 \mathrm{U} \\
2.297 \mathrm{U} \\
4.723 \mathrm{U} \\
2.358 \mathrm{U}\end{array}$ \\
\hline $\begin{array}{l}\text { COMP } \checkmark \\
\text { COMP } \checkmark \\
\text { COMP } \checkmark \\
\text { COMP } \checkmark \\
\text { COMP } \checkmark \text { Replicate } 1 \\
\text { COMP } \checkmark \text { Repl icate } 2 \\
\text { COMP } \checkmark \text { Repl icate } 3\end{array}$ & $\begin{array}{l}1 \\
2 \\
3 \\
4 \\
5 \\
5 \\
5\end{array}$ & $\begin{array}{l}A \\
A \\
A \\
D \\
B \\
B \\
B\end{array}$ & $\begin{array}{l}11.436 \\
13.284 \\
13.303 \\
10.903 \\
12.388 \\
12.388 \\
12.388\end{array}$ & $\begin{array}{l}2.361 \\
2.749 \\
2.366 \\
2.358 \\
5.722 \\
4.868 \\
3.380\end{array}$ & $\begin{array}{l}U \\
U \\
U \\
U \\
U \\
U \\
U\end{array}$ & $\begin{array}{l}2.361 \\
2.749 \\
2.366 \\
2.358 \\
5.722 \\
4.868 \\
3.380\end{array}$ & $\begin{array}{l}U \\
U \\
U \\
U \\
U \\
U \\
U\end{array}$ & $\begin{array}{l}20.124 \\
21.696 \\
23.176 \\
13.987 \\
17.783 \\
19.411 \\
19.254\end{array}$ & $\begin{array}{l}2.361 \mathrm{U} \\
2.749 \mathrm{U} \\
2.366 \mathrm{U} \\
2.358 \mathrm{U} \\
5.722 \mathrm{U} \\
4.868 \mathrm{U} \\
3.380 \mathrm{U}\end{array}$ \\
\hline $\begin{array}{l}\text { COMP VI } \\
\text { COMP VI } \\
\text { COMP VI } \\
\text { COMP VI } \\
\text { COMP VI }\end{array}$ & $\begin{array}{l}1 \\
2 \\
3 \\
4 \\
5\end{array}$ & $\begin{array}{l}\mathrm{C} \\
\mathrm{A} \\
\mathrm{B} \\
\mathrm{A} \\
\mathrm{D}\end{array}$ & $\begin{array}{r}10.468 \\
11.022 \\
12.942 \\
10.775 \\
9.478\end{array}$ & $\begin{array}{r}2.359 \\
2.369 \\
7.023 \\
2.364 \\
-2.355\end{array}$ & $\begin{array}{l}U \\
U \\
U \\
U \\
U\end{array}$ & $\begin{array}{l}2.359 \\
2.369 \\
7.023 \\
2.364 \\
2.355\end{array}$ & $\begin{array}{l}U \\
U \\
u \\
U \\
U\end{array}$ & $\begin{array}{l}21.144 \\
17.063 \\
32.495 \\
22.959 \\
18.321\end{array}$ & $\begin{array}{l}2.359 \mathrm{U} \\
2.369 \mathrm{U} \\
7.023 \mathrm{U} \\
2.364 \mathrm{U} \\
2.355 \mathrm{U}\end{array}$ \\
\hline $\begin{array}{l}R-A C \\
R-A C \\
R-A C \\
R-A C \\
R-A C\end{array}$ & $\begin{array}{l}1 \\
2 \\
3 \\
4 \\
5\end{array}$ & $\begin{array}{l}8 \\
C \\
C \\
A \\
D\end{array}$ & $\begin{array}{l}12.409 \\
10.536 \\
11.771 \\
11.562 \\
11.023\end{array}$ & $\begin{array}{l}2.325 \\
2.364 \\
2.345 \\
2.362 \\
2.365\end{array}$ & $\begin{array}{l}U \\
U \\
U \\
U \\
U\end{array}$ & $\begin{array}{l}2.325 \\
2.364 \\
2.345 \\
2.362 \\
2.365\end{array}$ & $\begin{array}{l}u \\
u \\
u \\
u \\
u\end{array}$ & $\begin{array}{r}11.728 \\
13.559 \\
21.402 \\
18.164 \\
9.479\end{array}$ & $\begin{array}{l}2.325 \mathrm{U} \\
2.364 \mathrm{U} \\
2.345 \mathrm{U} \\
2.362 \mathrm{U} \\
2.365 \mathrm{U}\end{array}$ \\
\hline $\begin{array}{l}\text { R-AM } \\
\text { R-AM Replicate } 1 \\
\text { R-AM Repl icate } 2\end{array}$ & $\begin{array}{l}1 \\
2 \\
2\end{array}$ & $\begin{array}{l}8 \\
\mathrm{C} \\
\mathrm{C}\end{array}$ & $\begin{array}{l}10.052 \\
10.333 \\
10.333\end{array}$ & $\begin{array}{l}2.214 \\
3.511 \\
3.553\end{array}$ & $\begin{array}{l}\mathrm{U} \\
\mathrm{U} \\
\mathrm{U}\end{array}$ & $\begin{array}{l}2.214 \\
3.511 \\
3.553\end{array}$ & $\begin{array}{l}U \\
U \\
U\end{array}$ & $\begin{array}{l}5.948 \\
8.283 \\
8.127\end{array}$ & $\begin{array}{l}2.214 \mathrm{U} \\
3.511 \mathrm{U} \\
3.553 \mathrm{U}\end{array}$ \\
\hline
\end{tabular}


TABLE J.17. (contd)

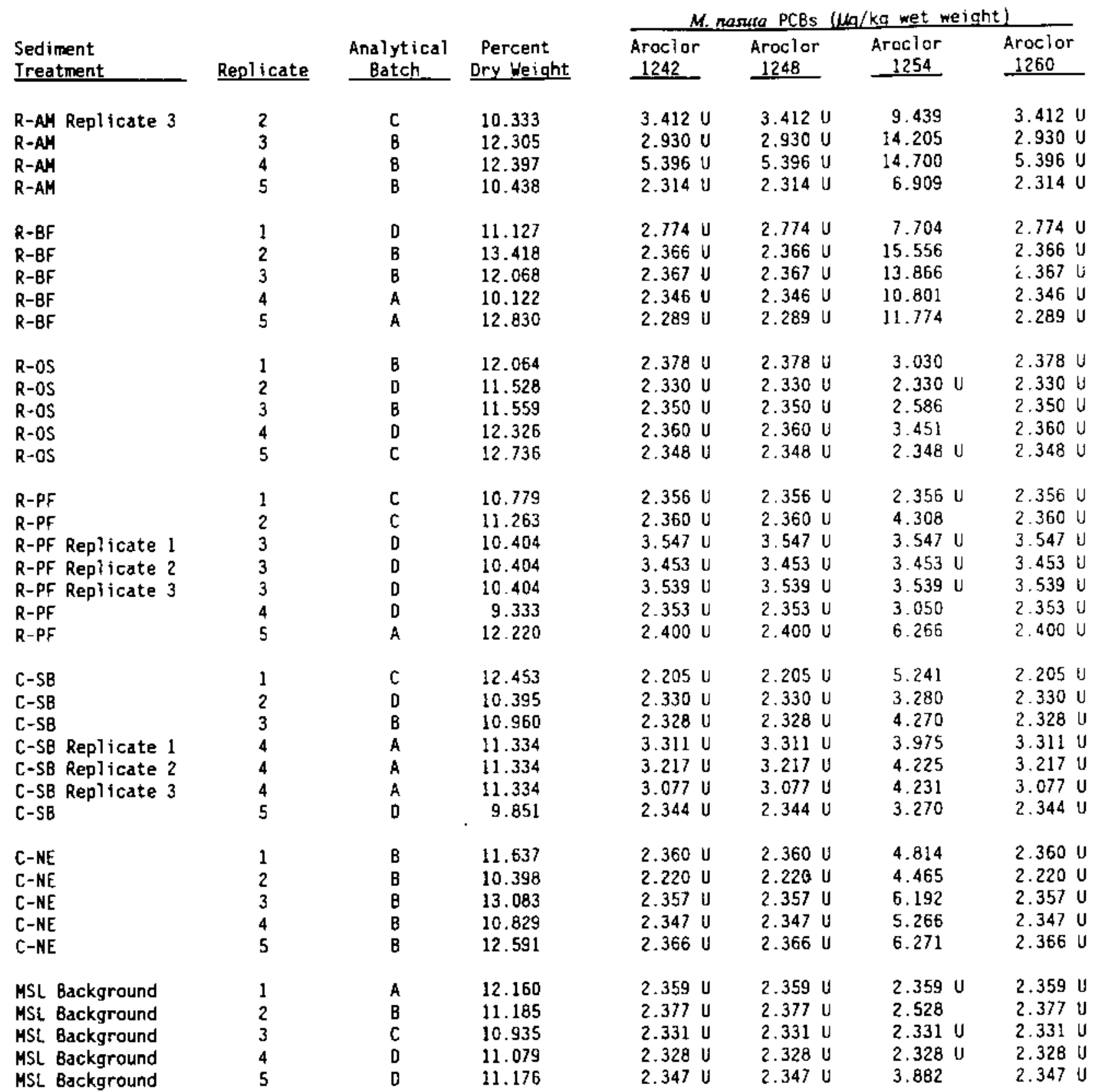

(a) DL Detection Iimit.

(b) U The analyte was. not present above the level of the associated value. 
IABLE J.18. Quality Control Data for Polychiorinated Biphenyls (PCBs), Ory Weight, in Tissue of M. nasuta, Richmond Harbor Program

\begin{tabular}{|c|c|c|c|c|c|c|}
\hline \multirow[b]{2}{*}{$\begin{array}{l}\text { Sediment } \\
\text { Ireatment }\end{array}$} & \multirow[b]{2}{*}{ Repl icate } & \multirow[b]{2}{*}{$\begin{array}{l}\text { Analytical } \\
\text { Batch } \\
\end{array}$} & \multicolumn{4}{|c|}{$M$. nasua PCBs ( $\mu \mathrm{g} / \mathrm{kg}$ dry wejght) } \\
\hline & & & $\begin{array}{l}\text { Aroclor } \\
1242 \\
\end{array}$ & $\begin{array}{c}\text { Aroclor } \\
1248 \\
\end{array}$ & $\begin{array}{c}\text { Arocior } \\
1254 \\
\end{array}$ & $\begin{array}{c}\text { Arocior } \\
1260 \\
\end{array}$ \\
\hline \multicolumn{7}{|l|}{ Method Blank } \\
\hline $\begin{array}{l}\text { Blank } \\
\text { Blank } \\
\text { Blank } \\
\text { Blank }\end{array}$ & $\begin{array}{l}1 \\
2 \\
3 \\
4\end{array}$ & $\begin{array}{l}A \\
B \\
C \\
D\end{array}$ & $\begin{array}{l}20.978 u^{(a)} \\
28.559 u \\
20.479 u \\
20.598 \mathrm{U}\end{array}$ & $\begin{array}{l}20.978 \mathrm{U} \\
28.559 \mathrm{U} \\
20.479 \mathrm{U} \\
20.598 \mathrm{U}\end{array}$ & $\begin{array}{l}20.978 \mathrm{U} \\
28.559 \mathrm{U} \\
20.479 \mathrm{U} \\
20.598 \mathrm{U}\end{array}$ & $\begin{array}{l}20.978 \mathrm{U} \\
28.559 \mathrm{U} \\
20.479 \mathrm{U} \\
20.598 \mathrm{U}\end{array}$ \\
\hline \multicolumn{7}{|l|}{ Matrix Spikes } \\
\hline $\begin{array}{l}\text { HSL Background } \\
\text { Background HS } \\
\text { Concentration Recovered } \\
\text { Spike Amount } \\
\text { Percent Recovery }\end{array}$ & $\begin{array}{l}1 \\
1\end{array}$ & $\begin{array}{l}\mathrm{A} \\
\mathrm{A}\end{array}$ & $\begin{array}{l}19.400(f) \\
N H(c) \\
N A(d) \\
N S^{(d)} \\
N A\end{array}$ & $\begin{array}{c}19.400 \mathrm{~J} \\
\text { NH } \\
\text { NA } \\
\text { NS } \\
\text { NA }\end{array}$ & $\begin{array}{l}19.400 \mathrm{U} \\
662.871 \\
662.871 \\
546.597 \\
121 \%(\mathrm{e})\end{array}$ & $\begin{array}{r}19.400 \mathrm{U} \\
\text { NH } \\
\text { NA } \\
\text { NS } \\
\text { NA }\end{array}$ \\
\hline $\begin{array}{l}\text { MSL Background } \\
\text { Background HSO } \\
\text { Concentration Recovered } \\
\text { Spike Anount } \\
\text { Percent Recovery }\end{array}$ & $\begin{array}{l}1 \\
1\end{array}$ & $\begin{array}{l}A \\
A\end{array}$ & $\begin{array}{c}19.400 \mathrm{U} \\
\text { NM } \\
\text { NA } \\
\text { NS } \\
\text { NA }\end{array}$ & $\begin{array}{c}19.400 \mathrm{U} \\
\text { NH } \\
\text { NA } \\
\text { NS } \\
\text { NA }\end{array}$ & $\begin{array}{l}19.400 \mathrm{U} \\
673.581 \\
673.581 \\
546.597 \\
123 x^{(\mathrm{e})}\end{array}$ & $\begin{array}{c}19.400 \cup \\
N H \\
N A \\
N S \\
N A\end{array}$ \\
\hline $\begin{array}{l}\text { MS/HSD RPD } \\
\text { MS/HSD I-Stat }\end{array}$ & & & $\begin{array}{l}\text { NA } \\
\text { NA }\end{array}$ & $\begin{array}{l}\text { NA } \\
\text { NA }\end{array}$ & $0.008^{2 \%}$ & $\begin{array}{l}\text { NA } \\
\text { HA }\end{array}$ \\
\hline $\begin{array}{l}\text { MSL Background } \\
\text { Background MS } \\
\text { Concentration Recovered } \\
\text { Spike Amount } \\
\text { Percent Recovery }\end{array}$ & $\begin{array}{l}2 \\
2\end{array}$ & $\begin{array}{l}\mathrm{B} \\
\mathrm{B}\end{array}$ & $\begin{array}{c}21.251 \mathrm{U} \\
\text { NM } \\
\text { NA } \\
\text { NS } \\
\text { NA }\end{array}$ & $\begin{array}{c}21.251 \mathrm{U} \\
\text { NH } \\
\text { NA } \\
\text { NS } \\
\text { NA }\end{array}$ & $\begin{array}{l}22.598 \\
846.425 \\
823.827 \\
607.718 \\
136 \%(\mathrm{e})\end{array}$ & $\begin{array}{r}21.251 \mathrm{U} \\
\mathrm{NH} \\
\mathrm{NA} \\
\mathrm{NS} \\
\mathrm{NA}\end{array}$ \\
\hline $\begin{array}{l}\text { HSL Background } \\
\text { Background MSD } \\
\text { Concentration Recovered } \\
\text { Spike Anount } \\
\text { Percent Recovery }\end{array}$ & $\begin{array}{l}2 \\
2\end{array}$ & $\begin{array}{l}B \\
8\end{array}$ & $\begin{array}{c}21.251 \mathrm{U} \\
\text { NH } \\
\text { NA } \\
\text { NS } \\
\text { NA }\end{array}$ & $\begin{array}{c}21.251 \mathrm{U} \\
\text { NM } \\
\text { NA } \\
\text { NS } \\
\text { NA }\end{array}$ & $\begin{array}{r}22.598 \\
815.759 \\
793.161 \\
561.956 \\
141 \%^{(e)}\end{array}$ & $\begin{array}{r}21.251 \mathrm{U} \\
\text { NM } \\
\text { NA } \\
\text { NS } \\
\text { NA }\end{array}$ \\
\hline $\begin{array}{l}\text { MS/MSD RPD } \\
\text { MS/KSD i-Stat }\end{array}$ & & & $\begin{array}{l}\text { NA } \\
\text { NA }\end{array}$ & $\begin{array}{l}\text { NA } \\
\text { NA }\end{array}$ & $0.020^{4 \%}$ & $\begin{array}{l}\text { NA } \\
\text { NA }\end{array}$ \\
\hline $\begin{array}{l}\text { MSL Background } \\
\text { Background MS } \\
\text { Concentration Recovered } \\
\text { Spike Amount } \\
\text { Percent Recovery }\end{array}$ & $\begin{array}{l}3 \\
3\end{array}$ & $\begin{array}{l}\mathrm{C} \\
\mathrm{C}\end{array}$ & $\begin{array}{c}21.314 \mathrm{U} \\
\text { NH } \\
\text { NA } \\
\text { NS } \\
\text { NA }\end{array}$ & $\begin{array}{l}21.314 \mathrm{U} \\
\text { NM } \\
\text { NA } \\
\text { NS } \\
\text { NA }\end{array}$ & $\begin{array}{c}21.314 \mathrm{~J} \\
659.04 \\
659.04 \\
588.235 \\
112 \%\end{array}$ & $\begin{array}{c}21.314 \mathrm{U} \\
\mathrm{NH} \\
\mathrm{NA} \\
\mathrm{NS} \\
\mathrm{NA}\end{array}$ \\
\hline $\begin{array}{l}\text { HSL Background } \\
\text { Background HSD } \\
\text { Concentration Recovered } \\
\text { Spike Anount } \\
\text { Percent Recovery }\end{array}$ & $\begin{array}{l}3 \\
3\end{array}$ & $\begin{array}{l}c \\
c\end{array}$ & $\begin{array}{c}21.314 \mathrm{U} \\
\text { NM } \\
\text { NA } \\
\text { NS } \\
\text { NA }\end{array}$ & $\begin{array}{c}21.314 \mathrm{U} \\
\text { NH } \\
\text { NA } \\
\text { NS } \\
\text { NA }\end{array}$ & $\begin{array}{c}21.314 \mathrm{U} \\
694.211 \\
694.211 \\
605.144 \\
115 \%\end{array}$ & $\begin{array}{c}21.314 \mathrm{U} \\
\text { NH } \\
\text { NA } \\
\text { NS } \\
\text { NA }\end{array}$ \\
\hline $\begin{array}{l}\text { HS/MSD RPD } \\
\text { MS/MSO I-Stat }\end{array}$ & & & $\begin{array}{l}\text { NA } \\
\text { NA }\end{array}$ & $\begin{array}{l}\text { NA } \\
\text { NA }\end{array}$ & $0.012^{2 \%}$ & $\begin{array}{l}\text { NA } \\
\text { NA }\end{array}$ \\
\hline
\end{tabular}


TABLE J.18. (contd)

Sediment

Treatment

MSL Background

Background HS

Concentration Recovered

Spike Amount

Percent Recovery

HSt Background

Background MSD

Concentration Recovered

Spike Amount.

Percent Recovery

MS/MSO RPD

MS/MSO I-Stat

Standard Reference Material

No Certified vaiues for PCBs

Analytical Replicates

COMP V Replicate 1
COMP V Replicate 2
COMP V Replicate 3
RSD
R-AH Replicate 1
R-AM Replicate 2
R-AH Replicate 3
RSD
R-PF Replicate 1
R-PF Replicate 2
R-PF Replicate 3
RSO
C-S8 Replicate 1
C-SB Replicate 2
C-SB Replicate 3
RSD

\begin{tabular}{|c|c|c|c|c|}
\hline \multirow[b]{2}{*}{$\begin{array}{c}\text { Analytical } \\
\text { Batch }\end{array}$} & \multicolumn{4}{|c|}{ M. nasuta $P C B s(\mu \mathrm{q} / \mathrm{kq}$ dry weight) } \\
\hline & $\begin{array}{c}\text { Aroclor } \\
1242\end{array}$ & $\begin{array}{c}\text { Aroclor } \\
1248\end{array}$ & $\begin{array}{c}\text { Aroclor } \\
1254\end{array}$ & $\begin{array}{l}\text { Aroclor } \\
1260\end{array}$ \\
\hline
\end{tabular}

$\begin{array}{rrrrrr}4 & 0 & 21.012 \mathrm{U} & 21.012 \mathrm{U} & 21.012 \mathrm{U} & 21.012 \mathrm{U} \\ 4 & \text { NH } & \text { NH } & 633.08 & \text { NH } \\ & \text { NA } & \text { NA } & 633.08 & \text { NA } \\ & \text { NS } & \text { NS } & 598.802 & \text { NS } \\ & \text { NA } & \text { NA } & 106 \% & \text { NA }\end{array}$

$\begin{array}{ll}4 & 0 \\ 4 & 0\end{array}$
21.012
NA
NA

$21.012 \mathrm{U}$

$21.012 \mathrm{U}$

641.432

641.432

597.015

$107 \%$

$21.012 \mathrm{U}$

NA

NA

NH
NA
NA

NA

NS

NA

NA

$0.008^{2 \%}$

NA

NA

5
5
5

$\mathrm{B}$
$\mathrm{B}$
$\mathrm{B}$
$46.188 \mathrm{U}$
$39.294 \mathrm{U}$
$27.287 \mathrm{U}$
NA

C
C

$33.978 \mathrm{U}$
$34.389 \mathrm{U}$

$33.016 \mathrm{U}$

NA

$34.093 \mathrm{U}$
$33.185 \mathrm{U}$
$34.011 \mathrm{U}$

NA

$29.216 \mathrm{U}$
$28.388 \mathrm{U}$
$27.152 \mathrm{U}$

NA
$46.188 \mathrm{U}$

$39.294 \mathrm{U}$

$27.287 \mathrm{U}$

NA

$33.978 \mathrm{~V}$

$34.389 \mathrm{~V}$

$33.016 \mathrm{U}$

NA

$34.093 \mathrm{U}$
$33.185 \mathrm{U}$
$34.011 \mathrm{U}$

NA

$29.216 \mathrm{U}$
$28.388 \mathrm{U}$
$27.152 \mathrm{U}$

NA
143.548
156.695
155.126
$5 \%$

80.162

78.654

91.345

$8 \%$

$34.093 \mathrm{U}$

$33.185 \mathrm{U}$

$34.011 \mathrm{U}$

NA

35.074

37.273

37.331

$4 \%$
$46.188 \mathrm{U}$

$39.294 \mathrm{U}$

$27.287 \mathrm{U}$

NA

$33.978 \mathrm{U}$

$34.389 \mathrm{U}$

$33.016 \mathrm{U}$

NA

$34.093 \mathrm{U}$ $33.185 \mathrm{~V}$ $34.011 \mathrm{U}$

NÁ

$29.216 \mathrm{U}$ $28.388 \mathrm{U}$ $27.152 \mathrm{U}$ NA

(a) $U$ The analyte was not present above the level of the associated value.

(b) NM Not measured.

(c) NA Not applicable.

(d) NS Not Spiked.

(e) Recovery outside quality control range (40x-120x), 
IABLE J.19. Surrogate Recoveries for Chlorinated Pesticides and Polychlorinated Biphenyls (PCBs) in Tissue of M. nasuta, Richmond Harbor Program

\begin{tabular}{|c|c|c|c|c|}
\hline Sediment & & Analytical & Surrogat & Recovery \\
\hline Treatment & Replicate & Batch & DBOFB & TCN \\
\hline $\begin{array}{l}\text { COMP I } \\
\text { COMP I } \\
\text { COMP I } \\
\text { LOMP I } \\
\text { COMP I }\end{array}$ & $\begin{array}{l}1 \\
2 \\
3 \\
4 \\
5\end{array}$ & $\begin{array}{l}\text { D } \\
\text { D } \\
A \\
B \\
A\end{array}$ & $\begin{array}{l}73.958 \\
44.052 \\
74.311 \\
93.979 \\
80.131\end{array}$ & $\begin{array}{r}89.862 \\
57.056 \\
101.509 \\
106.291 \\
106.685\end{array}$ \\
\hline $\begin{array}{ll}\text { COMP } & \text { II } \\
\text { COMP } & \text { I I } \\
\text { COMP } & \text { II } \\
\text { COMP } & \text { II } \\
\text { COMP } & \text { II }\end{array}$ & $\begin{array}{l}1 \\
2 \\
3 \\
4 \\
5\end{array}$ & $\begin{array}{l}D \\
A \\
C \\
D \\
C\end{array}$ & $\begin{array}{l}77.673 \\
72.945 \\
66.501 \\
72.314 \\
66.809\end{array}$ & $\begin{array}{l}91.675 \\
99.969 \\
68.764 \\
79.506 \\
66.244\end{array}$ \\
\hline $\begin{array}{l}\text { COMP I II } \\
\text { COMP III } \\
\text { COMP III } \\
\text { COMP II I } \\
\text { COMP III }\end{array}$ & $\begin{array}{l}1 \\
2 \\
3 \\
4 \\
5\end{array}$ & $\begin{array}{l}C \\
D \\
A \\
D \\
C\end{array}$ & $\begin{array}{l}55.983 \\
67.317 \\
76.876 \\
61.257 \\
64.811\end{array}$ & $\begin{array}{r}64.514 \\
78.306 \\
107.110 \\
70.445 \\
77.106\end{array}$ \\
\hline $\begin{array}{l}\text { TC-5 Upper Comp } \\
\text { TC-5 Upper Comp } \\
\text { TC-5 Upper Comp } \\
\text { TC-5 Upper Comp } \\
\text { TC-5 Upper Comp }\end{array}$ & $\begin{array}{l}1 \\
2 \\
3 \\
4 \\
5\end{array}$ & $\begin{array}{l}\text { C } \\
C \\
C \\
A \\
A\end{array}$ & $\begin{array}{l}63.608 \\
67.543 \\
52.637 \\
65.665 \\
69.885\end{array}$ & $\begin{array}{r}81.253 \\
79.137 \\
72.186 \\
93.888 \\
102.495\end{array}$ \\
\hline $\begin{array}{ll}\text { COMP } & \text { IV } \\
\text { COMP } & \text { IV } \\
\text { COMP } & \text { IV } \\
\text { COMP } & \text { IV } \\
\text { COMP } & \text { IV }\end{array}$ & $\begin{array}{l}1 \\
2 \\
3 \\
4 \\
5\end{array}$ & $\begin{array}{l}\text { C } \\
\text { C } \\
A \\
C \\
A\end{array}$ & $\begin{array}{l}59.026 \\
64.634 \\
83.092 \\
59.805 \\
66.830\end{array}$ & $\begin{array}{r}69.762 \\
74.316 \\
105.025 \\
66.002 \\
96.818\end{array}$ \\
\hline $\begin{array}{l}\text { COMP } V \\
\text { COMP } V \\
\text { COMP } V \\
\text { COMP } V \\
\text { COMP } V \text { Replicate } 1 \\
\text { COMP } \vee \text { Replicate } 2 \\
\text { COMP } V \text { Replicate } 3\end{array}$ & $\begin{array}{l}1 \\
2 \\
3 \\
4 \\
5 \\
5 \\
5\end{array}$ & $\begin{array}{l}A \\
A \\
A \\
D \\
B \\
B \\
B\end{array}$ & $\begin{array}{l}75.840 \\
90.469 \\
75.459 \\
75.677 \\
97.706 \\
82.195 \\
84.010\end{array}$ & $\begin{array}{r}117.362 \\
117.189 \\
108.339 \\
95.320 \\
103.744 \\
95.571 \\
95.385\end{array}$ \\
\hline $\begin{array}{l}\text { СOMP VI } \\
\text { СOMP VI } \\
\text { COMP VI } \\
\text { COMP VI } \\
\text { COMP VI }\end{array}$ & $\begin{array}{l}1 \\
2 \\
3 \\
4 \\
5\end{array}$ & $\begin{array}{l}\text { C } \\
A \\
B \\
A \\
D\end{array}$ & $\begin{array}{l}56.487 \\
80.613 \\
87.886 \\
71.986 \\
40.061\end{array}$ & $\begin{array}{r}76.190 \\
106.862 \\
116.971 \\
119.622 \\
57.722\end{array}$ \\
\hline
\end{tabular}


IABLE J.19. (contd)

Sediment

Ireatment

$R-A C$

$\mathrm{R}-\mathrm{AC}$

$\mathrm{R}-\mathrm{AC}$

$\mathrm{R}-\mathrm{AC}$

$R-A C$

R-AM

R-AM Replicate 1

R-AM Replicate 2

R-AM Replicate 3

$\mathrm{R}-\mathrm{AM}$

R-AM

$\mathrm{R}-\mathrm{AM}$

$R-B F$

$R-B F$

$R-B F$

$R-B F$

$R-B F$

R-OS

R-OS

$\mathrm{R}-\mathrm{OS}$

R-OS

R-OS

$R-P F$

$R-P F$

R-PF Replicate I

R-PF Replicate 2

R-PF Replicate 3

$R-P F$

$R-P F$

C-SB

$C-S B$

$\mathrm{C}-\mathrm{SB}$

C-SB Replicate 1

C-SB Replicate 2

C-SB Replicate 3 C-SB
Analytical

Replicate

1
2
3
4
5

1

2

2

2

4

5

1
2
3
4
5

1

2

3

4

5

]

2

3

3

3

4

5

1
2
3
4
4
4
5
M. nasuta

Surrogate Percent Recovery DBOFB

92.877

62.539

62.284

67.424

72.942

85.728

56.787

50.724

51.339

100.600

67.588

81.752

75.820

96.515

93.050

69.126

80.330

86.714

46.578

94.763

76.732

56.185

59.432

53.061

57.505

71.265

62.892

71.865

66.545

61.254

63.942

7]. 885

65.422

67.402

67.114

77.865
ICN

98.417

70.164

74.313

94.632

83.891

106.179

60.135

62.912

64.821

104.931

104.892

108.997

82.407

104.515

95.968

94.229

97.490

110.233

65.956

103.869

82.497

66.132

69.197

56.900

69.072

72.888

68.938

86.022

93.758

67.955

76.852

108.790

86.468

89.751

92.119

89.590 
TABLE J.19. (contd)

Sediment

Treatment

C-NE

C-NE

C-NE

C-NE

C-NE

MSL Background

MSL Background

MSL Background

MSL Background

MSL Background

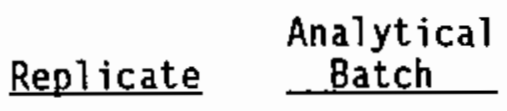

1

2

3

4

5

1

2

3

4

5
B

B

B

B

B

A

B

C

D

D
M. nasuta Surrogate Percent Recovery DBOFB

93.084

91.824

92.632

93.620

75.419

75.591

95.127

56.393

$36.791^{(a)}$

45.415 TCN

110.167

94.418

105.890

94.008

99.739

103.588

106.594

69.214

49.650

65.707

QuaTity Control Data

Method Blank

Blank

Blank

Bl ank

Blank

1
2
3
4

$18.689^{(a)}$

$29.412^{(a)}$

$22.702^{(a)}$

$18.566^{(a)}$

$22.536^{(a)}$

$38.543^{(a)}$

$21.231^{(a)}$

C

$19.728^{(a)}$

\section{Matrix Spikes}

MSL Background MS

A

69

87

MSL Background MSD

A

65

81

MS/MSD RPD

MS/MSD I-STAT

2

0.03

2
0.04

MSL Background MS

2
2

B

79

84

109

MSL Background MSD

B

119

MS/MSD RPD

MS/MSD I -STAT

0.03

2
0.04

MSL Background MS

3

C

89

88

MSL Background MSD

3

C

74

78

MS/MSD RPD

MS/MSD I-STAT

0.03

5
0.09

MSL Background MS

4
4

D

67

74

61

70

MS/MSD RPD

MS/MSD I-STAT

0.05

0.03 
IABLE J.19. (contd)

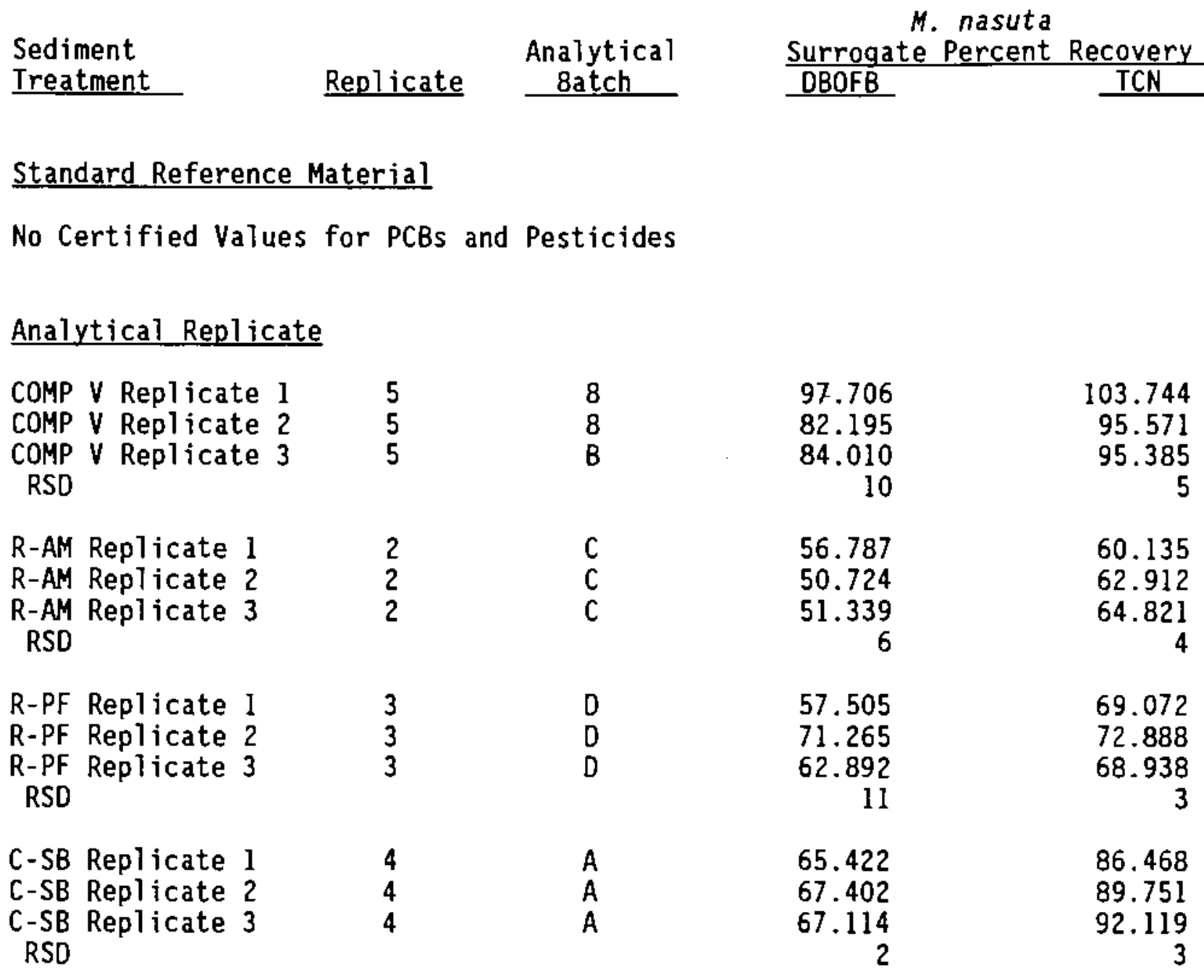

(a) Recovery outside quality control range (40\%-120\%). 
IABLE J.20. Metals, Dry Weight, in Tissue of M. nasuta, Richmond Harbor Program

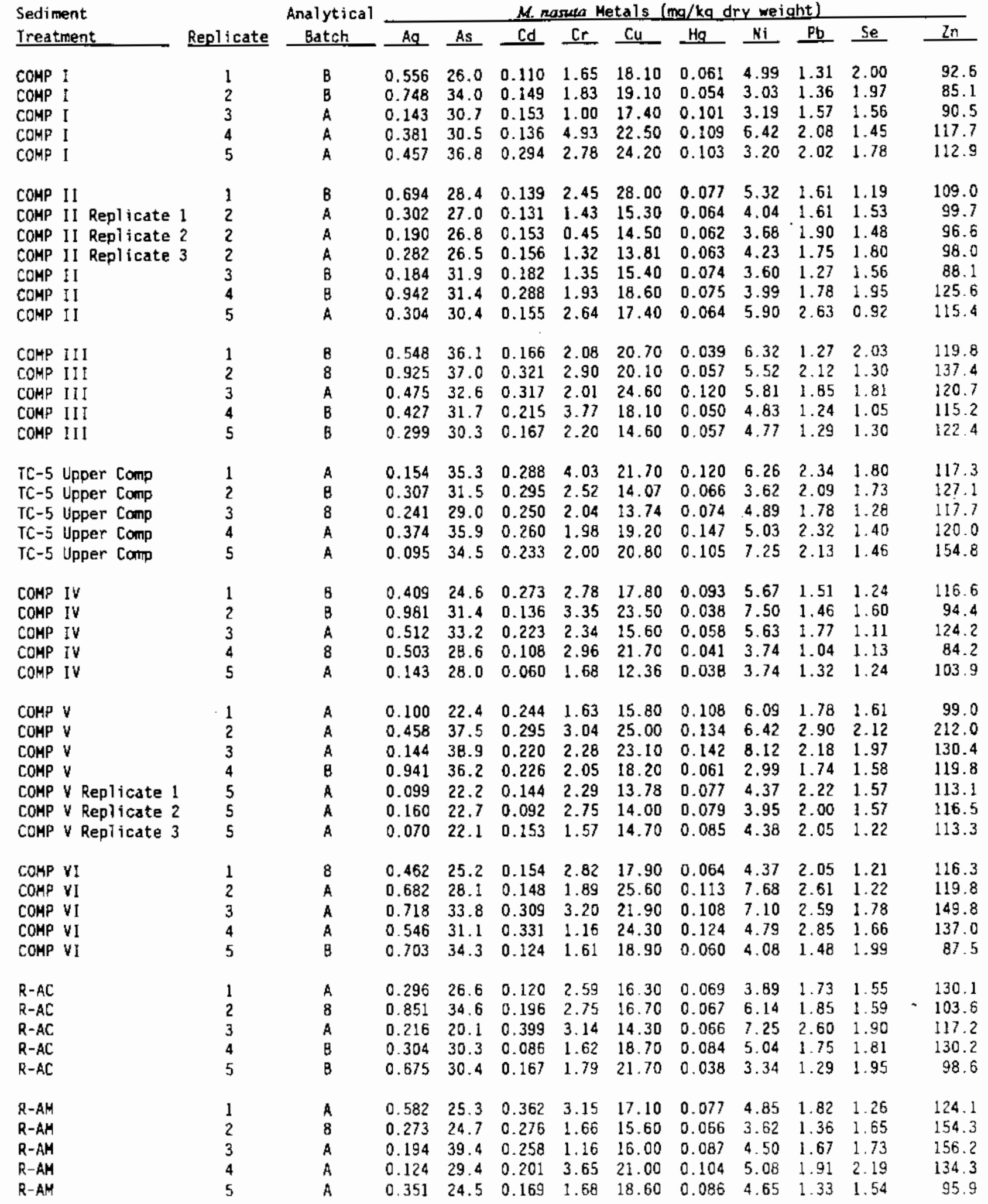


IABLE J.20. (contd)

\begin{tabular}{|c|c|c|c|c|c|c|c|c|c|c|c|c|}
\hline \multirow{2}{*}{$\begin{array}{l}\text { Sediment } \\
\text { Ireatment }\end{array}$} & \multirow[b]{2}{*}{ Replicate } & \multirow{2}{*}{$\begin{array}{c}\text { Analytical } \\
\text { Batch } \\
\end{array}$} & \multicolumn{10}{|c|}{ M. masuta Metals $(\mathrm{mg} / \mathrm{kq}$ dry weight) } \\
\hline & & & $\mathrm{Ag}$ & As & $\mathrm{Cd}$ & $\mathrm{Cr}$ & $\mathrm{Cu}$ & $\mathrm{Hg}$ & $\mathrm{Ni}$ & $\mathrm{Pb}$ & Se & $2 \pi$ \\
\hline $\begin{array}{l}R-B F \\
R-B F \\
R-B F \\
R-B F \\
R-B F\end{array}$ & $\begin{array}{l}1 \\
2 \\
3 \\
4 \\
5\end{array}$ & $\begin{array}{l}B \\
A \\
A \\
A \\
A\end{array}$ & $\begin{array}{l}0.583 \\
0.117 \\
0.079 \\
0.261 \\
0.174\end{array}$ & $\begin{array}{l}22.9 \\
29.1 \\
33.0 \\
27.1 \\
29.3\end{array}$ & $\begin{array}{l}0.345 \\
0.271 \\
0.288 \\
0.240 \\
0.153\end{array}$ & $\begin{array}{l}1.96 \\
1.45 \\
2.10 \\
2.06 \\
2.18\end{array}$ & $\begin{array}{l}17.10 \\
17.10 \\
16.70 \\
21.90 \\
14.90\end{array}$ & $\begin{array}{l}0.073 \\
0.119 \\
0.097 \\
0.106 \\
0.109\end{array}$ & $\begin{array}{l}4.47 \\
6.56 \\
4.91 \\
4.99 \\
4.91\end{array}$ & $\begin{array}{l}1.64 \\
2.20 \\
2.56 \\
1.91 \\
1.83\end{array}$ & $\begin{array}{l}1.83 \\
1.64 \\
1.07 \\
2.05 \\
1.42\end{array}$ & $\begin{array}{r}119.2 \\
165.5 \\
114.7 \\
135.2 \\
97.2\end{array}$ \\
\hline $\begin{array}{l}R-O S \\
R-O S \\
R-O S \\
R-O S \\
R-O S\end{array}$ & $\begin{array}{l}1 \\
2 \\
3 \\
4 \\
5\end{array}$ & $\begin{array}{l}A \\
B \\
A \\
B \\
B\end{array}$ & $\begin{array}{l}0.354 \\
0.813 \\
0.971 \\
0.162 \\
0.212\end{array}$ & $\begin{array}{l}31.6 \\
30.9 \\
24.4 \\
22.6 \\
25.4\end{array}$ & $\begin{array}{l}0.285 \\
0.160 \\
0.194 \\
0.301 \\
0.169\end{array}$ & $\begin{array}{l}2.43 \\
2.46 \\
3.65 \\
2.51 \\
2.50\end{array}$ & $\begin{array}{l}13.64 \\
16.20 \\
16.70 \\
11.88 \\
15.10\end{array}$ & $\begin{array}{l}0.075 \\
0.057 \\
0.062 \\
0.090 \\
0.046\end{array}$ & $\begin{array}{l}6.81 \\
5.19 \\
4.94 \\
6.24 \\
4.90\end{array}$ & $\begin{array}{l}1.59 \\
1.15 \\
1.34 \\
1.10 \\
0.92\end{array}$ & $\begin{array}{l}1.71 \\
1.48 \\
1.69 \\
2.10 \\
1.26\end{array}$ & $\begin{array}{r}93.0 \\
78.2 \\
114.9 \\
102.6 \\
95.7\end{array}$ \\
\hline $\begin{array}{l}\text { R-PF } \\
\text { R-PF } \\
\text { R-PF Replicate } 1 \\
R-P F \text { Replicate } 2 \\
\text { R-PF Replicate } 3 \\
\text { R-PF } \\
\text { R-PF }\end{array}$ & $\begin{array}{l}1 \\
2 \\
3 \\
3 \\
3 \\
4 \\
5\end{array}$ & $\begin{array}{l}\text { B } \\
\text { B } \\
\text { B } \\
8 \\
\text { B } \\
\text { B } \\
\text { A }\end{array}$ & $\begin{array}{l}0.220 \\
0.536 \\
0.109 \\
0.128 \\
0.112 \\
0.846 \\
0.099\end{array}$ & $\begin{array}{l}25.9 \\
31.4 \\
22.7 \\
22.9 \\
22.3 \\
31.9 \\
33.7\end{array}$ & $\begin{array}{l}0.305 \\
0.338 \\
0.203 \\
0.160 \\
0.235 \\
0.535 \\
0.311\end{array}$ & $\begin{array}{l}2.90 \\
2.28 \\
3.60 \\
3.83 \\
3.16 \\
2.84 \\
3.23\end{array}$ & $\begin{array}{l}17.20 \\
12.85 \\
12.52 \\
12.20 \\
12.52 \\
20.70 \\
19.10\end{array}$ & $\begin{array}{l}0.059 \\
0.062 \\
0.065 \\
0.066 \\
0.064 \\
0.067 \\
0.127\end{array}$ & $\begin{array}{l}4.71 \\
3.76 \\
5.65 \\
4.73 \\
4.26 \\
4.99 \\
5.79\end{array}$ & $\begin{array}{l}1.16 \\
1.19 \\
1.04 \\
1.10 \\
1.07 \\
1.38 \\
1.22\end{array}$ & $\begin{array}{l}1.16 \\
1.29 \\
0.67 \\
1.50 \\
1.71 \\
1.45 \\
1.94\end{array}$ & 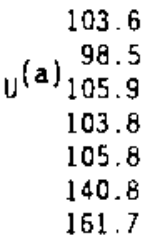 \\
\hline $\begin{array}{l}\text { C-58 Replicate } 1 \\
\text { C-S8 Replicate } 2 \\
\text { C-SB Replicate } 3 \\
\text { C-SB } \\
\text { C-SB } \\
\text { C-SB } \\
\text { C-SB }\end{array}$ & $\begin{array}{l}1 \\
1 \\
1 \\
2 \\
3 \\
4 \\
5\end{array}$ & $\begin{array}{l}B \\
B \\
B \\
8 \\
A \\
A \\
B\end{array}$ & $\begin{array}{l}0.286 \\
0.377 \\
0.350 \\
0.949 \\
0.160 \\
0.260 \\
0.288\end{array}$ & $\begin{array}{l}32.7 \\
32.7 \\
31.9 \\
30.7 \\
34.8 \\
25.4 \\
29.1\end{array}$ & $\begin{array}{l}0.090 \\
0.157 \\
0.169 \\
0.201 \\
0.143 \\
0.342 \\
0.121\end{array}$ & $\begin{array}{l}1.78 \\
1.79 \\
1.58 \\
1.54 \\
1.57 \\
1.35 \\
1.71\end{array}$ & $\begin{array}{l}14.00 \\
14.70 \\
14.80 \\
19.50 \\
38.60 \\
17.30 \\
16.80\end{array}$ & $\begin{array}{l}0.065 \\
0.062 \\
0.067 \\
0.067 \\
0.100 \\
0.064 \\
0.054\end{array}$ & $\begin{array}{l}3.79 \\
4.16 \\
4.72 \\
3.12 \\
3.85 \\
3.01 \\
4.84\end{array}$ & $\begin{array}{l}1.28 \\
1.28 \\
1.33 \\
1.50 \\
1.58 \\
1.79 \\
1.35\end{array}$ & $\begin{array}{l}1.91 \\
1.36 \\
0.98 \\
1.53 \\
1.73 \\
1.85 \\
1.90\end{array}$ & $\begin{array}{r}98.3 \\
98.0 \\
98.8 \\
138.5 \\
119.7 \\
130.9 \\
.85 .6\end{array}$ \\
\hline $\begin{array}{l}C-N E \\
C-N E \\
C-N E \\
C-N E \\
C-N E\end{array}$ & $\begin{array}{l}1 \\
2 \\
3 \\
4 \\
5\end{array}$ & $\begin{array}{l}A \\
A \\
A \\
A \\
A\end{array}$ & $\begin{array}{l}0.327 \\
0.320 \\
0.255 \\
0.182 \\
0.474\end{array}$ & $\begin{array}{l}35.0 \\
23.4 \\
34.7 \\
28.9 \\
28.4\end{array}$ & $\begin{array}{l}0.288 \\
0.356 \\
0.320 \\
0.212 \\
0.301\end{array}$ & $\begin{array}{l}1.29 \\
2.59 \\
1.54 \\
1.74 \\
1.70\end{array}$ & $\begin{array}{l}24.30 \\
15.30 \\
23.10 \\
18.50 \\
18.50\end{array}$ & $\begin{array}{l}0.101 \\
0.076 \\
0.132 \\
0.102 \\
0.098\end{array}$ & $\begin{array}{l}4.43 \\
4.23 \\
4.87 \\
3.25 \\
6.10\end{array}$ & $\begin{array}{l}1.90 \\
1.10 \\
1.69 \\
0.92 \\
1.60\end{array}$ & $\begin{array}{l}1.44 \\
1.38 \\
1.98 \\
1.24 \\
2.42\end{array}$ & $\begin{array}{l}124.6 \\
103.5 \\
162.1 \\
131.5 \\
152.4\end{array}$ \\
\hline $\begin{array}{l}\text { HSL Background } \\
\text { HSL Background } \\
\text { MSL Background } \\
\text { HSL Background } \\
\text { HSL Background }\end{array}$ & $\begin{array}{l}1 \\
2 \\
3 \\
4 \\
5\end{array}$ & $\begin{array}{l}B \\
B \\
B \\
B \\
B\end{array}$ & $\begin{array}{l}0.748 \\
1.087 \\
1.080 \\
0.592 \\
0.839\end{array}$ & $\begin{array}{l}31.5 \\
29.8 \\
29.9 \\
28.7 \\
31.1\end{array}$ & $\begin{array}{l}0.363 \\
0.188 \\
0.374 \\
0.487 \\
0.184\end{array}$ & $\begin{array}{l}2.00 \\
1.04 \\
0.70 \\
8.17 \\
1.12\end{array}$ & $\begin{array}{l}21.10 \\
27.00 \\
24.70 \\
16.40 \\
27.30\end{array}$ & $\begin{array}{l}0.082 \\
0.070 \\
0.092 \\
0.054 \\
0.056\end{array}$ & $\begin{array}{l}5.06 \\
2.59 \\
3.62 \\
3.38 \\
2.80\end{array}$ & $\begin{array}{l}2.41 \\
2.32 \\
2.26 \\
1.96 \\
2.98\end{array}$ & $\begin{array}{l}1.47 \\
1.76 \\
1.33 \\
1.04 \\
1.62\end{array}$ & $\begin{array}{l}140.7 \\
134.2 \\
127.1 \\
133.9 \\
127.2\end{array}$ \\
\hline
\end{tabular}

(a) U The analyte was not present above the level of the associated value. 
IABLE J.21. Metals, Wet Weight, in Tissue of M. nasuta, Richmond Harbor Program

Sediment
Treatment
Target DL (a)
Achieved DL
COMP I
COMP I
COMP I
COMP I
COMP I
COMP II
COMP II Replicate 1
COMP II Replicate 2
COMP II Replicate 3
COMP II
COMP II
COMP II
COMP III
COMP II I
COMP II I
COMP III
COMP II
TC-5 Upper Comp
TC-5 Upper Comp
TC-5 Upper Comp
TC-5 Upper Comp
TC-5 Upper Comp
COMP IV
COMP IV
COMP IV
COMP IV
COMP IV
COMP V
COMP V
COMP V
COMP V
COMP V Replicate 1
COMP V Replíate 2
COMP V Replicate 3

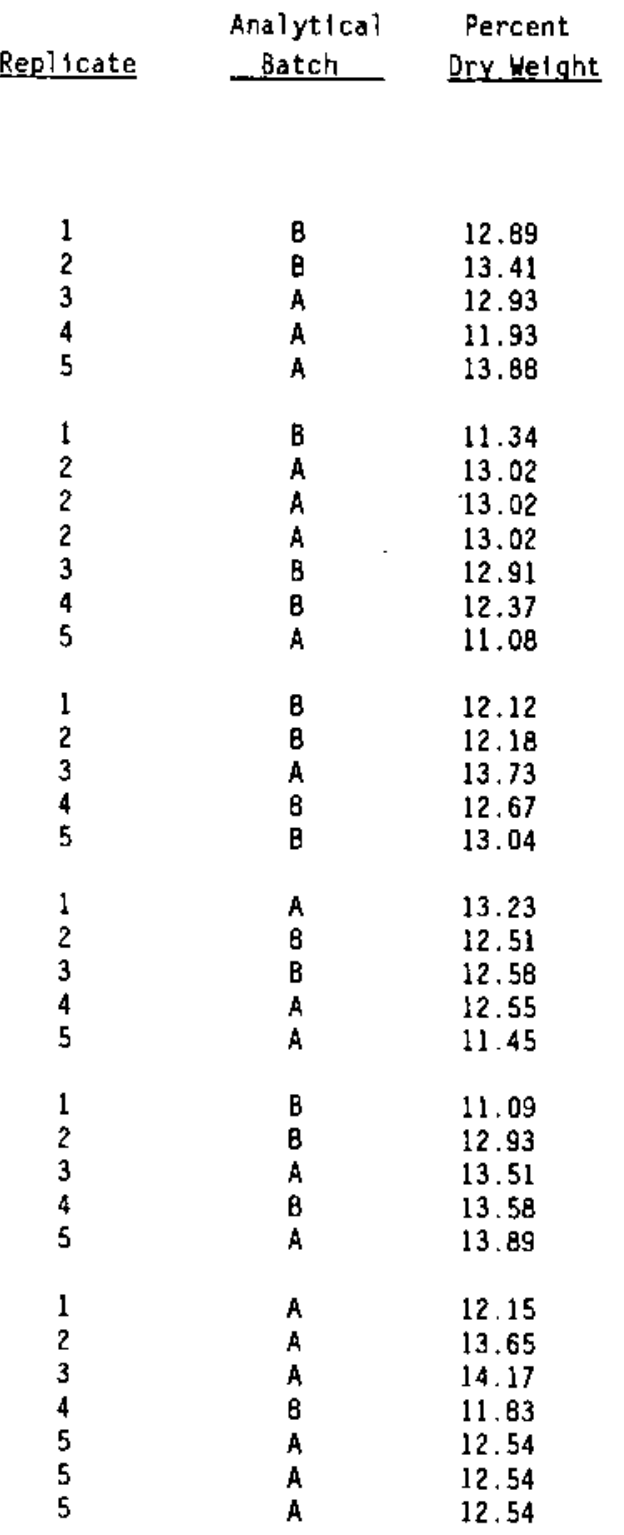

\begin{tabular}{|c|c|c|c|c|c|c|c|c|c|}
\hline $\mathrm{Ag}$ & As & $\mathrm{Cd}$ & $\underline{C_{\Gamma}}$ & $\mathrm{Cu}$ & $\mathrm{Hq}$ & $\mathrm{Ni}$ & $\mathrm{Pb}$ & Se & $\mathrm{Zm}$ \\
\hline $\begin{array}{l}1.0 \\
0.007\end{array}$ & $\begin{array}{l}1.0 \\
1.0\end{array}$ & $\begin{array}{l}0.1 \\
0.05\end{array}$ & $\begin{array}{l}1.0 \\
0.08\end{array}$ & $\begin{array}{l}1.0 \\
1.0\end{array}$ & $\begin{array}{l}0.02 \\
0.00012\end{array}$ & $\begin{array}{l}1.0 \\
1.0\end{array}$ & $\begin{array}{l}1.0 \\
0.01\end{array}$ & $\begin{array}{l}0.5 \\
0.5\end{array}$ & $\begin{array}{l}1.0 \\
1.0\end{array}$ \\
\hline $\begin{array}{l}0.072 \\
0.100 \\
0.018 \\
0.045 \\
0.063\end{array}$ & $\begin{array}{l}3.4 \\
4.6 \\
4.0 \\
3.6 \\
5.1\end{array}$ & $\begin{array}{l}0.014 \\
0.020 \\
0.020 \\
0.016 \\
0.041\end{array}$ & $\begin{array}{l}0.21 \\
0.25 \\
0.13 \\
0.59 \\
0.39\end{array}$ & $\begin{array}{l}2.33 \\
2.56 \\
2.25 \\
2.68 \\
3.36\end{array}$ & $\begin{array}{l}0.008 \\
0.007 \\
0.013 \\
0.013 \\
0.014\end{array}$ & $\begin{array}{l}0.64 \\
0.41 \\
0.41 \\
0.77 \\
0.44\end{array}$ & $\begin{array}{l}0.17 \\
0.18 \\
0.20 \\
0.25 \\
0.28\end{array}$ & $\begin{array}{l}0.26 \\
0.26 \\
0.20 \\
0.17 \\
0.25\end{array}$ & $\begin{array}{l}11.9 \\
11.4 \\
11.7 \\
14.0 \\
15.7\end{array}$ \\
\hline $\begin{array}{l}0.079 \\
0.039 \\
0.025 \\
0.037 \\
0.024 \\
0.117 \\
0.034\end{array}$ & $\begin{array}{l}3.2 \\
3.5 \\
3.5 \\
3.5 \\
4.1 \\
3.9 \\
3.4\end{array}$ & $\begin{array}{l}0.016 \\
0.017 \\
0.020 \\
0.020 \\
0.023 \\
0.036 \\
0.017\end{array}$ & $\begin{array}{l}0.28 \\
0.19 \\
0.06 \\
0.17 \\
0.17 \\
0.24 \\
0.29\end{array}$ & $\begin{array}{l}3.18 \\
1.99 \\
1.89 \\
1.80 \\
1.99 \\
2.30 \\
1.93\end{array}$ & $\begin{array}{l}0.009 \\
0.008 \\
0.008 \\
0.008 \\
0.010 \\
0.009 \\
0.007\end{array}$ & $\begin{array}{l}0.60 \\
0.53 \\
0.48 \\
0.55 \\
0.46 \\
0.49 \\
0.65\end{array}$ & $\begin{array}{l}0.18 \\
0.21 \\
0.25 \\
0.23 \\
0.16 \\
0.22 \\
0.29\end{array}$ & $\begin{array}{l}0.13 \\
0.20 \\
0.19 \\
0.23 \\
0.20 \\
0.24 \\
0.10\end{array}$ & $\begin{array}{l}12.4 \\
13.0 \\
12.6 \\
12.8 \\
11.4 \\
15.5 \\
12.8\end{array}$ \\
\hline $\begin{array}{l}0.056 \\
0.113 \\
0.065 \\
0.054 \\
0.039\end{array}$ & $\begin{array}{l}4.4 \\
4.5 \\
4.5 \\
4.0 \\
4.0\end{array}$ & $\begin{array}{l}0.020 \\
0.039 \\
0.044 \\
0.027 \\
0.022\end{array}$ & $\begin{array}{l}0.25 \\
0.35 \\
0.28 \\
0.48 \\
0.29\end{array}$ & $\begin{array}{l}2.51 \\
2.45 \\
3.38 \\
2.29 \\
1.90\end{array}$ & $\begin{array}{l}0.005 \\
0.007 \\
0.016 \\
0.006 \\
0.007\end{array}$ & $\begin{array}{l}0.77 \\
0.67 \\
0.80 \\
0.61 \\
0.62\end{array}$ & $\begin{array}{l}0.15 \\
0.26 \\
0.25 \\
0.16 \\
0.17\end{array}$ & $\begin{array}{l}0.25 \\
0.16 \\
0.25 \\
0.13 \\
0.17\end{array}$ & $\begin{array}{l}14.5 \\
16.7 \\
16.6 \\
14.6 \\
16.0\end{array}$ \\
\hline $\begin{array}{l}0.020 \\
0.038 \\
0.030 \\
0.047 \\
0.011\end{array}$ & $\begin{array}{l}4.7 \\
3.9 \\
3.6 \\
4.5 \\
4.0\end{array}$ & $\begin{array}{l}0.038 \\
0.037 \\
0.031 \\
0.033 \\
0.027\end{array}$ & $\begin{array}{l}0.53 \\
0.32 \\
0.26 \\
0.25 \\
0.23\end{array}$ & $\begin{array}{l}2.87 \\
1.76 \\
1.73 \\
2.41 \\
2.38\end{array}$ & $\begin{array}{l}0.016 \\
0.008 \\
0.009 \\
0.018 \\
0.012\end{array}$ & $\begin{array}{l}0.83 \\
0.45 \\
0.62 \\
0.63 \\
0.83\end{array}$ & $\begin{array}{l}0.31 \\
0.26 \\
0.22 \\
0.29 \\
0.24\end{array}$ & $\begin{array}{l}0.24 \\
0.22 \\
0.16 \\
0.18 \\
0.17\end{array}$ & $\begin{array}{l}15.5 \\
15.9 \\
14.8 \\
15.1 \\
17.7\end{array}$ \\
\hline $\begin{array}{l}0.045 \\
0.127 \\
0.069 \\
0.068 \\
0.020\end{array}$ & $\begin{array}{l}2.7 \\
4.1 \\
4.5 \\
3.9 \\
3.9\end{array}$ & $\begin{array}{l}0.030 \\
0.018 \\
0.030 \\
0.015 \\
0.008\end{array}$ & $\begin{array}{l}0.31 \\
0.43 \\
0.32 \\
0.40 \\
0.23\end{array}$ & $\begin{array}{l}1.97 \\
3.04 \\
2.11 \\
2.95 \\
1.72\end{array}$ & $\begin{array}{l}0.010 \\
0.005 \\
0.008 \\
0.006 \\
0.005\end{array}$ & $\begin{array}{l}0.63 \\
0.97 \\
0.76 \\
0.51 \\
0.52\end{array}$ & $\begin{array}{l}0.17 \\
0.19 \\
0.24 \\
0.14 \\
0.18\end{array}$ & $\begin{array}{l}0.14 \\
0.21 \\
0.15 \\
0.15 \\
0.17\end{array}$ & $\begin{array}{l}12.9 \\
12.2 \\
16.8 \\
11.4 \\
14.4\end{array}$ \\
\hline $\begin{array}{l}0.012 \\
0.063 \\
0.020 \\
0.111 \\
0.012 \\
0.020 \\
0.009\end{array}$ & $\begin{array}{l}2.7 \\
5.1 \\
5.5 \\
4.3 \\
2.8 \\
2.8 \\
2.8\end{array}$ & $\begin{array}{l}0.030 \\
0.040 \\
0.031 \\
0.027 \\
0.018 \\
0.012 \\
0.019\end{array}$ & $\begin{array}{l}0.20 \\
0.41 \\
0.32 \\
0.24 \\
0.29 \\
0.34 \\
0.20\end{array}$ & $\begin{array}{l}1.92 \\
3.41 \\
3.27 \\
2.15 \\
1.73 \\
1.76 \\
1.84\end{array}$ & $\begin{array}{l}0.013 \\
0.018 \\
0.020 \\
0.007 \\
0.010 \\
0.010 \\
0.011\end{array}$ & $\begin{array}{l}0.74 \\
0.88 \\
1.15 \\
0.35 \\
0.55 \\
0.50 \\
0.55\end{array}$ & $\begin{array}{l}0.22 \\
0.40 \\
0.31 \\
0.21 \\
0.28 \\
0.25 \\
0.26\end{array}$ & $\begin{array}{l}0.20 \\
0.29 \\
0.28 \\
0.19 \\
0.20 \\
0.20 \\
0.15\end{array}$ & $\begin{array}{l}12.0 \\
28.9 \\
18.5 \\
14.2 \\
14.2 \\
14.6 \\
14.2\end{array}$ \\
\hline
\end{tabular}


TABLE J.21. (contd)

Sediment

Ireatment

COHP VI

COHP VI

COMP VI

COMP VI

COHP VI

$R-A C$

$R-A C$

$R-A C$

$R-A C$

$R-A C$

$R-A M$

$\mathrm{R}-\mathrm{AH}$

$\mathrm{R}-\mathrm{AH}$

$R-A M$

c

$R-B F$

$R-B F$
$R-B F$

$R-B F$

$R-B F$

$R-B F$

$R-0 S$

$R-0 S$

$R-0 S$

$R-0 S$

$R-0 S$

$R-P F$

$R-P F$

R-PF Replicate

R-PF Replicate ?

$R-P F$ Repilicate 3

$R-P F$

$R-P F$

C-SB Replicate 1

C-SB Replicate 2

C-SB Replicate 3
Analytical

Percent Dry Welght

11.33

16.25
12.86

12.27

11.91

13.43

11.50

9.43

13.97

11.22

11.61

13.58
14.26

11.36

13.05

13.74

13.28

11.62
13.18

48

12.49
12.00

12.00
12.23

13.34

13.22

11.21
13.61

13.61
11.72

11.72

11.72

12.40
13.22

12.24

12.24

12.24
12.24

\begin{tabular}{|c|c|c|c|c|c|c|c|c|c|}
\hline $\mathrm{Ag}$ & As & $\mathrm{Cd}$ & $\mathrm{Cr}$ & $\mathrm{Cu}$ & $\mathrm{Hq}$ & $\mathrm{N}$ & $\mathrm{Pb}$ & $\underline{\mathrm{Se}}$ & $\underline{\underline{Z}} \underline{n}$ \\
\hline $\begin{array}{l}0.052 \\
0.111 \\
0.092 \\
0.067 \\
0.084\end{array}$ & $\begin{array}{l}2.9 \\
4.6 \\
4.3 \\
3.8 \\
4.1\end{array}$ & $\begin{array}{l}0.017 \\
0.024 \\
0.040 \\
0.041 \\
0.015\end{array}$ & $\begin{array}{l}0.32 \\
0.31 \\
0.41 \\
0.14 \\
0.19\end{array}$ & $\begin{array}{l}2.03 \\
4.16 \\
2.82 \\
2.98 \\
2.25\end{array}$ & $\begin{array}{l}0.007 \\
0.018 \\
0.014 \\
0.015 \\
0.007\end{array}$ & $\begin{array}{l}0.50 \\
1.25 \\
0.91 \\
0.59 \\
0.49\end{array}$ & $\begin{array}{l}0.23 \\
0.42 \\
0.33 \\
0.35 \\
0.18\end{array}$ & $\begin{array}{l}0.14 \\
0.20 \\
0.23 \\
0.20 \\
0.24\end{array}$ & $\begin{array}{l}13.2 \\
19.5 \\
19.3 \\
16.8 \\
10.4\end{array}$ \\
\hline $\begin{array}{l}0.040 \\
0.098 \\
0.025 \\
0.029 \\
0.094\end{array}$ & $\begin{array}{l}3.6 \\
4.0 \\
2.3 \\
2.9 \\
4.2\end{array}$ & $\begin{array}{l}0.016 \\
0.023 \\
0.047 \\
0.008 \\
0.023\end{array}$ & $\begin{array}{l}0.35 \\
0.32 \\
0.37 \\
0.15 \\
0.25\end{array}$ & $\begin{array}{l}2.19 \\
1.92 \\
1.67 \\
1.76 \\
3.03\end{array}$ & $\begin{array}{l}0.009 \\
0.008 \\
0.008 \\
0.008 \\
0.005\end{array}$ & $\begin{array}{l}0.52 \\
0.71 \\
0.85 \\
0.48 \\
0.47\end{array}$ & $\begin{array}{l}0.23 \\
0.21 \\
0.30 \\
0.17 \\
0.18\end{array}$ & $\begin{array}{l}0.21 \\
0.18 \\
0.22 \\
0.17 \\
0.27\end{array}$ & $\begin{array}{l}17.5 \\
11.9 \\
13.7 \\
12.3 \\
13.8\end{array}$ \\
\hline $\begin{array}{l}0.065 \\
0.032 \\
0.026 \\
0.018 \\
0.040\end{array}$ & $\begin{array}{l}2.8 \\
2.9 \\
5.4 \\
4.2 \\
2.8\end{array}$ & $\begin{array}{l}0.041 \\
0.032 \\
0.035 \\
0.029 \\
0.019\end{array}$ & $\begin{array}{l}0.35 \\
0.19 \\
0.16 \\
0.52 \\
0.19\end{array}$ & $\begin{array}{l}1.92 \\
1.81 \\
2.17 \\
2.99 \\
2.11\end{array}$ & $\begin{array}{l}0.009 \\
0.008 \\
0.012 \\
0.015 \\
0.010\end{array}$ & $\begin{array}{l}0.54 \\
0.42 \\
0.61 \\
0.72 \\
0.53\end{array}$ & $\begin{array}{l}0.20 \\
0.16 \\
0.23 \\
0.27 \\
0.15\end{array}$ & & $\begin{array}{l}13.9 \\
17.9 \\
21.2 \\
19.2 \\
10.9\end{array}$ \\
\hline $\begin{array}{l}0.076 \\
0.016 \\
0.010 \\
0.030 \\
0.023\end{array}$ & $\begin{array}{l}3.0 \\
4.0 \\
4.4 \\
3.1 \\
3.0\end{array}$ & $\begin{array}{l}0.045 \\
0.037 \\
0.038 \\
0.028 \\
0.020\end{array}$ & $\begin{array}{l}0.26 \\
0.20 \\
0.28 \\
0.24 \\
0.29\end{array}$ & $\begin{array}{l}2.23 \\
2.35 \\
2.22 \\
2.54 \\
1.96\end{array}$ & $\begin{array}{l}0.010 \\
0.016 \\
0.013 \\
0.012 \\
0.014\end{array}$ & $\begin{array}{l}0.58 \\
0.90 \\
0.65 \\
0.58 \\
0.65\end{array}$ & $\begin{array}{l}0.21 \\
0.30 \\
0.34 \\
0.22 \\
0.24\end{array}$ & $\begin{array}{l}0.24 \\
0.23 \\
0.14 \\
0.24 \\
0.19\end{array}$ & $\begin{array}{l}15.6 \\
22.7 \\
15.2 \\
15.7 \\
12.8\end{array}$ \\
\hline $\begin{array}{l}0.044 \\
0.098 \\
0.119 \\
0.022 \\
0.028\end{array}$ & $\begin{array}{l}3.9 \\
3.7 \\
3.0 \\
3.0 \\
3.4\end{array}$ & $\begin{array}{l}0.036 \\
0.019 \\
0.024 \\
0.040 \\
0.022\end{array}$ & $\begin{array}{l}0.30 \\
0.30 \\
0.45 \\
0.33 \\
0.33\end{array}$ & $\begin{array}{l}1.70 \\
1.94 \\
2.04 \\
1.58 \\
2.00\end{array}$ & $\begin{array}{l}0.009 \\
0.007 \\
0.008 \\
0.012 \\
0.006\end{array}$ & $\begin{array}{l}0.85 \\
0.62 \\
0.60 \\
0.83 \\
0.65\end{array}$ & $\begin{array}{l}0.20 \\
0.14 \\
0.16 \\
0.15 \\
0.12\end{array}$ & $\begin{array}{l}0.21 \\
0.18 \\
0.21 \\
0.28 \\
0.17\end{array}$ & $\begin{array}{r}11.6 \\
9.4 \\
14.1 \\
13.7 \\
12.7\end{array}$ \\
\hline $\begin{array}{l}0.025 \\
0.073 \\
0.013 \\
0.015 \\
0.013 \\
0.105 \\
0.013\end{array}$ & $\begin{array}{l}2.9 \\
4.3 \\
2.7 \\
2.7 \\
2.6 \\
4.0 \\
4.5\end{array}$ & $\begin{array}{l}0.034 \\
0.046 \\
0.024 \\
0.019 \\
0.028 \\
0.066 \\
0.041\end{array}$ & $\begin{array}{l}0.33 \\
0.31 \\
0.42 \\
0.45 \\
0.37 \\
0.35 \\
0.43\end{array}$ & $\begin{array}{l}1.93 \\
1.75 \\
1.47 \\
1.43 \\
1.47 \\
2.57 \\
2.53\end{array}$ & $\begin{array}{l}0.007 \\
0.008 \\
0.008 \\
0.008 \\
0.008 \\
0.008 \\
0.017\end{array}$ & $\begin{array}{l}0.53 \\
0.51 \\
0.66 \\
0.55 \\
0.50 \\
0.62 \\
0.77\end{array}$ & $\begin{array}{l}0.13 \\
0.16 \\
0.12 \\
0.13 \\
0.13 \\
0.17 \\
0.16\end{array}$ & $\begin{array}{l}0.13 \\
0.18 \\
0.08 u^{(b)} \\
0.18 \\
0.20 \\
0.18 \\
0.26\end{array}$ & $\begin{array}{l}11.6 \\
13.4 \\
12.4 \\
12.2 \\
12.4 \\
17.5 \\
21.4\end{array}$ \\
\hline $\begin{array}{l}0.035 \\
0.046 \\
0.043\end{array}$ & $\begin{array}{l}4.0 \\
4.0 \\
3.9\end{array}$ & $\begin{array}{l}0.011 \\
0.019 \\
0.021\end{array}$ & $\begin{array}{l}0.22 \\
0.22 \\
0.19\end{array}$ & $\begin{array}{l}1.71 \\
1.80 \\
1.81\end{array}$ & $\begin{array}{l}0.008 \\
0.008 \\
0.008\end{array}$ & $\begin{array}{l}0.46 \\
0.51 \\
0.58\end{array}$ & $\begin{array}{l}0.16 \\
0.16 \\
0.16\end{array}$ & $\begin{array}{l}0.23 \\
0.17 \\
0.12\end{array}$ & $\begin{array}{l}12.0 \\
12.0 \\
12.1\end{array}$ \\
\hline
\end{tabular}


IABLE J.21. (contd)

Sediment

Ireatment

$C-S B$

$\mathrm{C}-\mathrm{SB}$

C-SB

C-SB

$C-N E$

$C-N E$

$\mathrm{C}-\mathrm{NE}$

$C-N E$

C-NE

MSL Background

MSL eackground

MSL Background

MSL Background

MSL Background

\begin{tabular}{l} 
Repl fcate \\
\hline 2 \\
3 \\
4 \\
5 \\
1 \\
2 \\
3 \\
4 \\
5
\end{tabular}

Analytical Percent Batch Dry Weight

$\begin{array}{ll}\text { B } & 11.33 \\ A & 13.05 \\ \text { A } & 14.02 \\ \text { B } & 13.47 \\ \text { A } & 12.49 \\ \text { A } & 11.26 \\ \text { A } & 13.29 \\ \text { A } & 11.54 \\ \text { A } & 12.74 \\ \text { B } & 13.66 \\ \text { B } & 13.32 \\ \text { B } & 13.10 \\ \text { B } & 12.67 \\ \text { B } & 14.05\end{array}$

M. nasuma Metals (mg/kq wet weight)

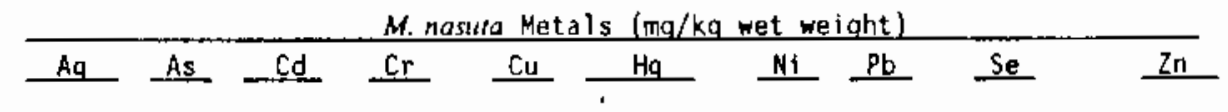

$\begin{array}{llllll}0.108 & 3.5 & 0.023 & 0.17 & 2.21 & 0.008\end{array}$

$\begin{array}{llllll}0.021 & 4.5 & 0.019 & 0.20 & 5.04 & 0.013\end{array}$

$\begin{array}{llllll}0.036 & 3.6 & 0.048 & 0.19 & 2.43 & 0.009\end{array}$

$\begin{array}{llllll}0.039 & 3.9 & 0.016 & 0.23 & 2.26 & 0.007\end{array}$

$\begin{array}{lll}0.35 & 0.17 & 0.17\end{array}$

$\begin{array}{lll}0.50 & 0.21 & 0.23\end{array}$

$\begin{array}{lll}0.42 & 0.25 & 0.26\end{array}$

$\begin{array}{lll}0.65 & 0.18 & 0.26\end{array}$

15.7

15.6

$\begin{array}{llllllllll}0.041 & 4.4 & 0.036 & 0.16 & 3.04 & 0.013 & 0.55 & 0.24 & 0.18 & 15.6\end{array}$

$\begin{array}{llllllllll}0.036 & 2.6 & 0.040 & 0.29 & 1.72 & 0.009 & 0.48 & 0.12 & 0.16 & 11.7\end{array}$

$\begin{array}{llllllllll}0.034 & 4.6 & 0.043 & 0.20 & 3.07 & 0.018 & 0.65 & 0.22 & 0.26 & 21.5\end{array}$

$\begin{array}{llllllllll}0.021 & 3.3 & 0.024 & 0.20 & 2.13 & 0.012 & 0.38 & 0.11 & 0.14 & 15.2\end{array}$

$\begin{array}{llllllllll}0.060 & 3.6 & 0.038 & 0.22 & 2.36 & 0.012 & 0.78 & 0.20 & 0.31 & 19.4\end{array}$

$\begin{array}{llllllllll}0.102 & 4.3 & 0.050 & 0.27 & 2.88 & 0.011 & 0.69 & 0.33 & 0.20 & 19.2\end{array}$

$\begin{array}{llllllllll}0.145 & 4.0 & 0.025 & 0.14 & 3.60 & 0.009 & 0.34 & 0.31 & 0.23 & 17.9\end{array}$

$\begin{array}{llllllllll}0.141 & 3.9 & 0.049 & 0.09 & 3.24 & 0.012 & 0.47 & 0.30 & 0.17 & 16.7\end{array}$

$\begin{array}{llllllllll}0.075 & 3.6 & 0.062 & 1.04 & 2.08 & 0.007 & 0.43 & 0.25 & 0.13 & 17.0\end{array}$

$\begin{array}{llllllllll}0.118 & 4.4 & 0.026 & 0.16 & 3.84 & 0.008 & 0.39 & 0.42 & 0.23 & 17.9\end{array}$

in

(a) OL Detection limit.

(b) U The analyte was not present above the level of the associated value. 
IABLE J.22. Quality Control Data for Metals, Ory Weight, in Tissue of M. nasuta, Richmond Harbor Program

Sediment Replicate $\begin{aligned} & \text { Analytical } \\ & \text { Batch }\end{aligned}$

Treatment

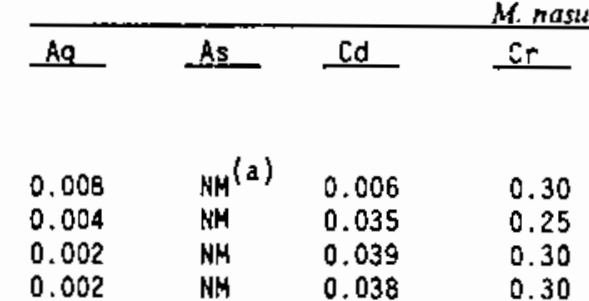

Method Blanks

Blank

Blank

81 ank

Blank

$\begin{array}{ll}\text { A } & 0.008 \\ 8 & 0.004 \\ \text { C } & 0.002 \\ 0 & 0.002\end{array}$

Matrix Spikes

comp II $(\mathrm{c})$

COMP II MS

A

\begin{tabular}{|c|c|c|c|}
\hline $\begin{array}{l}0.510 \\
1.584 \\
1.073 \\
2.000\end{array}$ & $\begin{array}{l}\text { NH } \\
\text { NA } \\
\text { NA } \\
\text { NS }(e)\end{array}$ & $\begin{array}{l}0.190 \\
4.635 \\
4.445 \\
5.000\end{array}$ & $\begin{array}{r}3.39 \\
11.30 \\
7.91 \\
10.00\end{array}$ \\
\hline
\end{tabular}

Spike Amount

Percent Recovery

$\begin{array}{llr} & \operatorname{COMP} V(c) \\ c & \operatorname{COMPVMS} & 5 \\ \text { in } & \text { Concentration Recovered } \\ & \text { Spike Amount } \\ & \text { Percent Recovery }\end{array}$

$C-S B(C)$

$\mathrm{C}-\mathrm{SB}$ HS

Concentration Recovered

Spike Amount

Percent Recovery

$R-P F(C)$

R-PF MS

Concentration Recovered

Spike Amount

Percent Recovery

Standard Reference Material

Certified Value 1566 a

$\begin{array}{rrr}14.0 & 4.15 & 1.43 \\ \pm 1.2 & \pm 0.38 & \pm 0.46 \\ & & \\ 14.67 & 4.500 & 1.65 \\ 13.98 & \text { NM } & \text { NM } \\ 13.72 & \text { NM } & \text { NM } \\ 14.05 & \text { NM } & \text { NM }\end{array}$

NH
NH
NM
NM

$\begin{array}{ll}0.0002 U^{(b)} & \text { NH } \\ 0.0000 U & \text { NM } \\ 0.0000 \mathrm{U} & \text { NM } \\ 0.0023 & \text { NM }\end{array}$

0.01

0.01

$0.0023 \quad \mathrm{NM}$

0.01

NM

$N M$

NM

NH

NM

SRM 1566

SRH 1566

SRH 1566

SRM 1566

\begin{tabular}{|c|c|c|c|c|}
\hline $\begin{array}{l}A \\
A\end{array}$ & $\begin{array}{l}0.665 \\
1.808 \\
1.143 \\
2.000 \\
\quad 57 q^{(f)}\end{array}$ & $\begin{array}{l}\text { NM } \\
\text { NA } \\
\text { NA } \\
\text { NS } \\
\text { NA }\end{array}$ & $\begin{array}{r}0.156 \\
4.563 \\
4.407 \\
5.000 \\
88 \%\end{array}$ & $\begin{array}{r}2.88 \\
10.83 \\
7.95 \\
10.00 \\
79 \%\end{array}$ \\
\hline $\begin{array}{l}B \\
B\end{array}$ & $\begin{array}{l}0.197 \\
2.543 \\
2.346 \\
2.000 \\
117 \%\end{array}$ & $\begin{array}{l}\text { NH } \\
\text { NA } \\
\text { NA } \\
\text { NS } \\
\text { NA }\end{array}$ & $\begin{array}{r}0.245 \\
4.599 \\
4.354 \\
5.000 \\
87 \%\end{array}$ & $\begin{array}{r}2.16 \\
12.50 \\
10.34 \\
10.00 \\
103 \%\end{array}$ \\
\hline $\begin{array}{l}B \\
B\end{array}$ & $\begin{array}{l}0.116 \\
2.502 \\
2.386 \\
2.000 \\
119 x\end{array}$ & $\begin{array}{l}\text { NM } \\
\text { NA } \\
\text { NA } \\
\text { NS } \\
\text { NA }\end{array}$ & $\begin{array}{r}0.199 \\
5.148 \\
4.949 \\
5.000 \\
99 \%\end{array}$ & $\begin{array}{r}3.53 \\
13.00 \\
9.47 \\
10.00 \\
95 \%\end{array}$ \\
\hline
\end{tabular}

\begin{tabular}{|c|c|c|c|c|c|}
\hline NH & 0.096 & $\mathrm{NH}$ & 1.90 & NH & NH \\
\hline NA & 0.975 & NA & 12.70 & HA & NA \\
\hline$N A$ & 0.879 & NA & 10.80 & HA & NA \\
\hline NS & 0.998 & NS & 10.00 & NS & HS \\
\hline $\mathrm{NA}$ & $88 x$ & NA & $108 \%$ & NA & NA \\
\hline NH & 0.046 & NM & 1.42 & NM & NH \\
\hline NA & 0.934 & NA & 14.30 & HA & NA \\
\hline NA & 0.888 & NA & 12.88 & NA & NA \\
\hline NS & 0.998 & NS & 10.00 & NS & NS \\
\hline NA & $89 x$ & NA & $129 x^{(t)}$ & NA & NA \\
\hline NH & 0.086 & $\mathrm{NH}$ & 1.65 & NM & NK \\
\hline $\mathrm{NA}$ & 0.920 & NA & 10.50 & NA & NA \\
\hline NA & 0.834 & NA & 8.85 & NA & NA \\
\hline NS & 0.995 & NS & 10.00 & NS & NS \\
\hline NA & $84 \%$ & NA & $89 \%$ & NA & $N A$ \\
\hline NM & 0.065 & NH & 1.07 & NM & NM \\
\hline NA & 0.952 & NA & 9.68 & NA & NA \\
\hline NA & 0.887 & NA & 8.61 & NA & NA \\
\hline NS & 0.997 & NS & 10.00 & NS & NS \\
\hline$N A$ & $89 \%$ & NA & $86 \%$ & NA & NA \\
\hline
\end{tabular}

$\pm 0.15$

66.3
\pm 4.3
66.5
66.0
63.2
65.8

0.064

$\begin{array}{lll}2.25 & 0.371 & 2.21\end{array}$

2.21
+0.24

830.0

1.980

NM

14.05

0.054

$\begin{array}{ll}1.47 & 0.37\end{array}$

2.40

$\pm 57.0$

NM $\quad 2.25 \quad 822$.

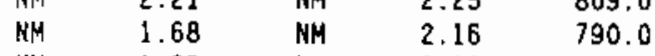


IABLE J.22. (contd)

Sediment

Ireatment

SRM 1566

SRM 1566

SRM 1566

SRM 1566

SRM 1566

SRM 1566

SRM 1566

SRN 1566

SRM 1566

SRM 1566

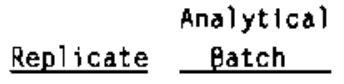

$\begin{array}{ll}1 & \text { E } \\ 2 & \text { A } \\ 2 & \text { B } \\ 2 & \text { C } \\ 2 & 0 \\ 3 & \text { A } \\ 3 & 8 \\ 4 & \text { A } \\ 4 & 8 \\ 4 & \text { C }\end{array}$

\begin{tabular}{r}
\hline$A q$ \\
NM \\
1.676 \\
NM \\
NM \\
NM \\
1.523 \\
NH \\
1.686 \\
NM \\
NM
\end{tabular}

$\mathrm{Mr}$

$\begin{array}{lr}14.67 & \text { NM } \\ 14.31 & 4.158 \\ 14.84 & \text { NM } \\ 14.05 & \text { NM } \\ 14.78 & \text { NH } \\ 14.23 & 4.455 \\ 14.43 & \text { NM } \\ 14.25 & 4.095 \\ 14.20 & \text { NM } \\ 14.62 & \text { NM }\end{array}$

Analytical Replicates

\section{COMP II Replicate 1 \\ COHP II Replicate 2 \\ COHP II Replicate 3}

RSO

in

\begin{tabular}{|c|c|c|c|c|c|c|c|}
\hline $\begin{array}{l}\text { COMP } \\
\text { COMP } \\
\text { COMP } \\
\text { RSO }\end{array}$ & $\begin{array}{l}V \text { Replicate } 1 \\
V \text { Replicate } 2 \\
V \text { Replicate } 3\end{array}$ & & $\begin{array}{l}5 \\
5 \\
5\end{array}$ & $\begin{array}{l}\text { A } \\
\text { A } \\
\text { A }\end{array}$ & $\begin{array}{l}0.099 \\
0.160 \\
0.070 \\
\quad 42 x^{(g)}\end{array}$ & $\begin{array}{l}22.2 \\
22.7 \\
22.1 \\
1 \%\end{array}$ & $\begin{array}{l}0.144 \\
0.092 \\
0.153(g) \\
\quad 25 \%\end{array}$ \\
\hline $\begin{array}{r}R-P F \\
R-P F \\
R-P F \\
R S D\end{array}$ & $\begin{array}{l}\text { Replicate } 1 \\
\text { Replicate } 2 \\
\text { Replicate } 3\end{array}$ & & $\begin{array}{l}3 \\
3 \\
3\end{array}$ & $\begin{array}{l}\text { A } \\
\text { A } \\
\text { A }\end{array}$ & $\begin{array}{r}0.109 \\
0.128 \\
0.112 \\
9 \%\end{array}$ & $\begin{array}{r}22.7 \\
22.9 \\
22.3 \\
17\end{array}$ & $\begin{array}{c}0.203 \\
0.160 \\
0.235 \\
19 \%\end{array}$ \\
\hline $\begin{array}{r}C-S B \\
C-S B \\
C-S B \\
R S D\end{array}$ & $\begin{array}{l}\text { Replicate } 1 \\
\text { Replicate } 2 \\
\text { Replicate } 3\end{array}$ & 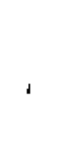 & $\begin{array}{l}1 \\
1 \\
1\end{array}$ & $\begin{array}{l}B \\
B \\
8\end{array}$ & $\begin{array}{r}0.286 \\
0.377 \\
0.350 \\
14 \%\end{array}$ & $\begin{array}{l}32.7 \\
32.7 \\
31.9 \\
1 \%\end{array}$ & $\begin{array}{l}0.090 \\
0.157 \\
0.169 \\
31 \%(g)\end{array}$ \\
\hline $\begin{array}{l}\text { (a) } \\
\text { (b) } \\
\text { (c) } \\
\text { (d) } \\
\text { (e) } \\
\text { (f) } \\
\text { (g) }\end{array}$ & $\begin{array}{l}\text { NM Not measured } \\
\text { U The analyte } \\
\text { Average values } \\
\text { NA Not applicab } \\
\text { NS Not spiked. } \\
\text { Recovery outsid } \\
\text { Value exceeds }\end{array}$ & $\begin{array}{l}\text { was } \\
\text { are } \\
\text { le. }\end{array}$ & $\begin{array}{l}\text { not present } \\
\text { an average o }\end{array}$ & $\begin{array}{l}\text { above } \\
\text { of the }\end{array}$ & $\begin{array}{l}\text { the level of } \\
\text { repticates. } \\
\text { ge }(75 \%-125 \%) \\
\text { ge of } 20 \% \text {. }\end{array}$ & the $a$ & sociated.v \\
\hline
\end{tabular}

$$
\begin{array}{lrrlr}
0.302 & 27.0 & 0.131 & 1.43 & 15.30 \\
0.190 & 26.8 & 0.153 & 0.45 & 14.50 \\
0.282 & 26.5 & 0.156 & 1.32 & 13.81 \\
23 \%(g) & 1 \% & 9 \% & 50 \%(g) & 5 \% \\
0.099 & 22.2 & 0.144 & 2.29 & 13.78 \\
0.160 & 22.7 & 0.092 & 2.75 & 14.00 \\
0.070 & 22.1 & 0.153 & 1.57 & 14.70 \\
42 \%(g) & 1 \% & 25 \%(g) & 27 \%(g) & 3 \% \\
& & & & \\
0.109 & 22.7 & 0.203 & 3.60 & 12.52 \\
0.128 & 22.9 & 0.160 & 3.83 & 12.20 \\
0.112 & 22.3 & 0.235 & 3.16 & 12.52 \\
9 \% & 1 \% & 19 \% & 10 \% & 1 \%
\end{array}
$$$$
50 x(9)
$$$$
14.50
$$$$
13.81
$$$$
14.00
$$$$
3 \%
$$$$
12.20
$$$$
12.52
$$$$
14.00
$$$$
14.70
$$$$
\begin{array}{r}
14.80 \\
3 \%
\end{array}
$$

$\begin{array}{lr}64.7 & \text { NM } \\ 63.8 & 0.052 \\ 65.3 & \text { NM } \\ 65.6 & \text { NH } \\ 64.6 & \text { NH } \\ 66.3 & 0.049 \\ 66.6 & \text { NM } \\ 64.8 & 0.058 \\ 64.2 & \text { NM } \\ 63.7 & \text { NM }\end{array}$

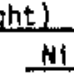

$\begin{array}{lr}3.03 & \\ 2.03 & 0.31 \\ 1.75 & \mathrm{NH} \\ 2.02 & \mathrm{NH} \\ 2.59 & \mathrm{NM} \\ 2.59 & 0.32 \\ 1.99 & \mathrm{NM} \\ 1.76 & 0.38 \\ 2.20 & \mathrm{NM} \\ 1.77 & \mathrm{NM}\end{array}$
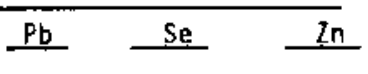

$1.80 \quad 815.0$

$2.24 \quad 816.0$

$1.99 \quad 823.0$

$2.29 \quad 818.0$

$2.35 \quad 827.0$

$\begin{array}{ll}1.76 & 828.0 \\ 2.07 & 827.0\end{array}$

$1.95 \quad 807.0$

$1.92 \quad 799.0$

2.14810 .0

$\begin{array}{lllll}0.064 & 4.04 & 1.61 & 1.53 & 99.7\end{array}$

$\begin{array}{lllll}0.062 & 3.68 & 1.90 & 1.48 & 96.6\end{array}$

$\begin{array}{lllll}0.063 & 4.23 & 1.75 & 1.80 & 98.0\end{array}$

$\begin{array}{lllll}0.077 & 4.37 & 2.22 & 1.57 & 113.1\end{array}$

$\begin{array}{lllll}0.079 & 3.95 & 2.00 & 1.57 & 116.5\end{array}$

$\begin{array}{lllll}0.079 & 3.95 & 2.00 & 1.57 & 116.5 \\ 0.085 & 4.38 & 2.05 & 1.22 & 113.3\end{array}$

$\begin{array}{rrrrr}5 \% & 6 \% & 6 \% & 14 \% & 2 \%\end{array}$

$\begin{array}{llllll}0.065 & 5.65 & 1.04 & 0.67 & \mathrm{U} & 105.9\end{array}$

$\begin{array}{lllll}0.066 & 4.73 & 1.10 & 1.50 & 103.8\end{array}$

$\begin{array}{rrrrr}0.064 & 4.26 & 1.07 & 1.71 & 105.8 \\ 2 \% & 14 \% & 3 \% & 43 \% & 1 \%\end{array}$

$\begin{array}{lllll}0.065 & 3.79 & 1.28 & 1.91 & 98.3 \\ 0.062 & 4.16 & 1.28 & 1.36 & 98.0\end{array}$

$\begin{array}{lllll}0.062 & 4.16 & 1.28 & 1.36 & 98.0\end{array}$

$\begin{array}{rrrrr}.067 & 4.72 & 1.33 & 0.98 & 98.8 \\ 4 \% & 11 \% & 2 \% & 33 \%(g) & 0 \%\end{array}$

(g) Value exceeds relative precision range of $20 x$. 
TABLE J.23. Butyltin Results, Dry and Wet Weight, in Tissue of M. nasuta, Richmond Harbor Program Tri-

pentyltin Butyltin. Species $\left(\mu \mathrm{g} / \mathrm{kg}\right.$ dry weight) Percent $\frac{\text { 8utyitin Specles }(\mu \mathrm{g} / \mathrm{kg} \text { wet weight) }}{\text { Tetra- }}$

Sediment Ireatment

Target $\mathrm{DL}$ (a)

Achieved DL High
Achieved DL Low

$\underline{\text { Repl Icate }}$

Analytical Recoveryz butyltin butyltin butyitin butyltin Weight butyltin butyltin butyltin butyltin

Achieved DL Low

COMP I

COMP I

COMP I

COMP

COMP I

COHP II

COMP II

COMP II

COMP II

COMP 1

COMP III
COMP III
COMP II
COMP III Replicate 1
COMP III Replicate 2
COMP III Replicate 3
COMP II
TC-5 Upper Comp
TC-5 Upper Comp
TC-5 Upper Comp Replicate 1
TC-5 Upper Comp Replicate 2
TC-5 Upper Comp Replicate 3
IC-5 Upper Comp
TC-5 Upper Comp
COMP IV
COMP IV
COMP IV
COMP IV
COMP IV

\section{Batch}

42.62
30.19
50.31
51.75
44.37
45.40
63.13
49.02
66.62
50.79

61.99
66.90
48.32
47.30
47.23
45.54
46.17

52.59
55.78
57.34
46.53
48.27
45.17
41.04
46.39
40.34
49.19
56.19
44.01

\begin{tabular}{|c|c|c|c|c|}
\hline & $\begin{array}{l}10 \\
0.74 \\
0.03\end{array}$ & $\begin{array}{l}10 \\
{ }_{N A}\end{array}$ & $\begin{array}{r}10 \\
1.25 \\
0.25\end{array}$ & $\begin{array}{r}10 \\
0.45 \\
0.24\end{array}$ \\
\hline .89 & $0.55 \mathrm{U}$ & 5.84 & $0.34 \mathrm{~V}$ & $0.34 \mathrm{U}$ \\
\hline 13.41 & $0.55 \mathrm{U}$ & 3.50 & $0.34 U$ & $0.34 \mathrm{U}$ \\
\hline 12.93 & $0.57 \mathrm{U}$ & 5.08 & $0.35 \mathrm{U}$ & $0.35 \mathrm{U}$ \\
\hline 11.93 & $0.45 \mathrm{U}$ & 5.55 & $0.27 \mathrm{U}$ & $0.27 U$ \\
\hline 13.88 & $0.58 v$ & 4.94 & $0.35 \mathrm{U}$ & $0.35 \mathrm{U}$ \\
\hline 11.34 & $0.39 \mathrm{U}$ & 6.70 & 1.04 & $0.24 U$ \\
\hline 13 & $0.59 \mathrm{U}$ & 8.89 & $0.35 \mathrm{U}$ & $0.35 \mathrm{U}$ \\
\hline 12.91 & $0.48 U$ & 8.33 & 1.17 & $0.28 \mathrm{U}$ \\
\hline 12.37 & $0.49 U$ & 6.51 & $1.25 \mathrm{U}$ & $0.30 \mathrm{U}$ \\
\hline 11.08 & $0.52 \mathrm{U}$ & 5.47 & $0.31 \cup$ & $0.31 \mathrm{U}$ \\
\hline 12.12 & $0.52 \mathrm{U}$ & 5.73 & $0.32 \mathrm{U}$ & $0.32 \mathrm{U}$ \\
\hline & $0.4 B U$ & 8.77 & 1.71 & \\
\hline 13.73 & $0.59 \mathrm{U}$ & 6.67 & $0.36 \mathrm{U}$ & $0.36 \mathrm{U}$ \\
\hline 12.67 & $0.54 \mathrm{U}$ & 5.64 & $0.33 U$ & $0.33 \mathrm{U}$ \\
\hline & $0.56 \mathrm{U}$ & 5.35 & $0.34 \mathrm{U}$ & $0.34 \mathrm{U}$ \\
\hline 12.67 & $0.52 \mathrm{U}$ & 5.47 & $0.32 \mathrm{U}$ & $0.32 \mathrm{U}$ \\
\hline 13.04 & $0.52 \mathrm{U}$ & 7.55 & $0.31 \mathrm{U}$ & 0.31 v \\
\hline 13.23 & $0.53 \mathrm{U}$ & 7.06 & 1.38 & $0.32 \mathrm{U}$ \\
\hline 12.51 & $0.03 \mathrm{U}$ & 7.31 & 1.69 & $0.29 \mathrm{U}$ \\
\hline 12.58 & $0.53 \mathrm{U}$ & 7.46 & 1.57 & $0.31 \mathrm{U}$ \\
\hline 12.58 & $0.50 \mathrm{U}$ & 6.65 & 1.96 & $0.30 \mathrm{~V}$ \\
\hline 12.58 & $0.42 U$ & 6.84 & $0.25 \mathrm{U}$ & $0.25 \mathrm{U}$ \\
\hline & $0.49 \mathrm{U}$ & 7.44 & 1.77 & $0.30 \mathrm{U}$ \\
\hline 11 & $0.45 \mathrm{U}$ & 4.68 & $0.27 \mathrm{U}$ & $0.27 \mathrm{U}$ \\
\hline & & & 1.34 & \\
\hline 12.93 & $0.53 \mathrm{U}$ & 5.83 & $0.32 \mathrm{U}$ & $0.32 \mathrm{U}$ \\
\hline & $0.51 \mathrm{U}$ & 11.04 & 1.35 & $0.31 \mathrm{U}$ \\
\hline & 0.561 & 9.28 & 1.49 & $0.34 \mathrm{U}$ \\
\hline & 0.581 & 5.65 & 1.69 & $0.36 U$ \\
\hline
\end{tabular}


IABLE J.23. (contd)

Tri-

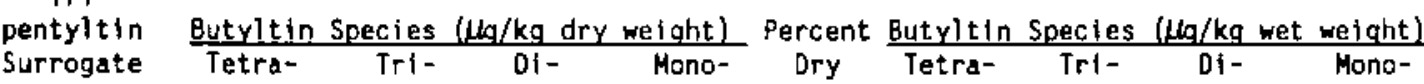

Sediment

Analytical Surrogate

Mono-

Mono-

COMP $V$

COMP $V$

COMP $V$

COMP V

COMP V

COHP VI

COMP VI

COMP V!

COMP VI

COMP $V I$

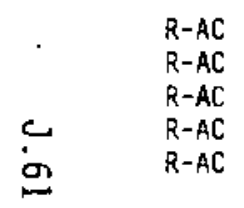

$R-A M$

R-AM

$R-A M$

R-AM

$\mathrm{R}-\mathrm{BF}$

$\mathrm{R}-\mathrm{BF}$
$\mathrm{R}-\mathrm{BF}$

$R-8 F$

$R-8 F$

$R-B F$

R-OS

R-OS Replicate

R-OS Replicate 2

R-OS Replicate 3

$\mathrm{R}-\mathrm{OS}$

$R-O S$
Replicate

55.54
50.62
55.83
60.50
68.09

44.61
56.30
62.87
56.80
49.55

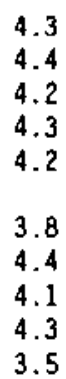

$4.3 \mathrm{~V}$

\section{3}

48.4

55.3

4.3 U 47.1

$4.2 \mathrm{U}$

78.7

$\begin{array}{ll}3.8 \mathrm{U} & 48.8 \\ 4.4 \mathrm{U} & 36.0\end{array}$

4.1 U 70.5

$4.3 \mathrm{U} \quad 42.1$

39.51 (d)

39.51

54.98
76.85

76.85
56.50

79.61

48.64

68.91

44.24

59.82

54.04

43.51

73.73
70.75

70.75

43.73

42.43

69.05

41.96

76.36

46.32

76.69

46.09

45.41
4.

$4.2 \mathrm{U}$

3.911

$4.3 \mathrm{U} \quad 93.9$

$4.3 \mathrm{~V} 100$.

$5.3 \cup \quad 74.3$

$4.4 \mathrm{U} \quad 52.6$

$4.0 \mathrm{U} \quad 94.1$

$3.6 \mathrm{U}$

$4.3 \cup 69.8$

$4.4 \mathrm{U} \quad 51.0$

$4.3 \mathrm{U} \quad 89.8$

4.4 U 83.5

$4.04 \quad 69.4$

$3.5 \% 60.7$

$3.8 \cup \quad 30.0$

$4.4 \mathrm{U} 76.7$

45.4

$4.1 \mathrm{U} \quad 51.2$ $\begin{array}{ll}4.2 & \mathrm{U} \\ 4.2 \mathrm{U} & 38.5\end{array}$

$\begin{array}{rl}2.6 \mathrm{U} & 2.6 \mathrm{U} \\ 2.6 \mathrm{U} & 2.6 \mathrm{U} \\ 10.5 \mathrm{U} & 2.5 \mathrm{U} \\ 2.6 \mathrm{U} & 2.6 \mathrm{U}\end{array}$

$2.6 \mathrm{~V} \quad 2.6 \mathrm{~V}$

$13.7 \quad 2.5 \mathrm{U}$

$\begin{array}{lll}2.3 & U & 2.3 \mathrm{U} \\ 2.7 & \mathrm{U} & 2.7 \mathrm{U}\end{array}$

$14.2 \quad 2.5 \mathrm{U}$

$2.6 \mathrm{U} \quad 2.6 \mathrm{U}$

$2.1 \mathrm{U} \quad 2.1 \mathrm{U}$

$2.5 \mathrm{U} \quad 2.5 \mathrm{U}$

$11.4 \quad 2.4 \mathrm{U}$

$15.9 \quad 2.6 \mathrm{~J}$

$\begin{array}{ll}15.0 & 2.6 \mathrm{U} \\ 14.7 & 3.2 \mathrm{U}\end{array}$

$2.6 \mathrm{~V} 2.6 \mathrm{U}$

$2.6 \mathrm{~V} 2.6 \mathrm{U}$

16.7

$2.4 \mathrm{U}$
$2.2 \mathrm{U}$

$2.2 \mathrm{U}$
$2.6 \mathrm{U}$

$2.5 \mathrm{U}$

12.4

$2.6 \mathrm{U} 2.6 \mathrm{U}$

$2.6 \mathrm{U}$
$2.6 \mathrm{U}$

$2.7 \mathrm{U}$

$2.5 \mathrm{U} 2.5 \mathrm{U}$

$2.4 \mathrm{U} 2.4 \mathrm{U}$

22.5

10.4

$2.1 \mathrm{U}$

2. $3 \mathrm{U}$

$2.6 \mathrm{U}$

$2.6 \mathrm{U} \quad 2.6 \mathrm{U}$

$14.9 \quad 2.6 \mathrm{U}$

$2.5 \mathrm{U} \quad 2.5 \mathrm{U}$

$2.5 \mathrm{~V} \quad 2.5 \mathrm{U}$ $\begin{array}{llll}12.15 & 0.52 \cup & 5.75\end{array}$

$13.65 \quad 0.60 \mathrm{U} \quad 6.61$

$\begin{array}{llll}14.17 & 0.60 \mathrm{U} & 7.84\end{array}$

$\begin{array}{lllll}1.83 & 0.51 & \cup & 5.57\end{array}$

$\begin{array}{lllll}12.54 & 0.53 \cup & 9.87\end{array}$

$\begin{array}{lllll}11.33 & 0.43 & \mathrm{U} & 5.53\end{array}$

$\begin{array}{lllll}16.25 & 0.72 \cup & 5.85\end{array}$

$\begin{array}{lllll}12.85 & 0.53 & \cup & 9.07\end{array}$

$\begin{array}{llll}12.27 & 0.53 \cup & 5.17\end{array}$

$11.910 .42 \cup \quad 3.85$

$\begin{array}{llll}13.43 & 0.56 \cup & 7.76\end{array}$

$\begin{array}{llll}11.50 & 0.45 \mathrm{U} & 7.08\end{array}$

$11.67 \quad 0.50 \mathrm{~V} \quad 10.96$

$\begin{array}{rrrr}9.43 & 0.41 & \text { U } & 9.44 \\ 13.97 & 0.74 & \text { U } & 10.38\end{array}$

$11.22 \quad 0.49$ U $\quad 5.90$

$\begin{array}{lllll}11.61 & 0.46 \cup & 10.93\end{array}$

$\begin{array}{rrrr}13.58 & 0.49 \cup & 10.10\end{array}$

$\begin{array}{lllll}14.26 & 0.61 & \cup & 9.95 \\ 1.36 & 0.47 & \cup & 8.83\end{array}$

$\begin{array}{llll}13.05 & 0.57 \cup & 6.66\end{array}$

$\begin{array}{llll}13.74 & 0.59 \cup & 12.34\end{array}$

$13.28 \quad 0.58 \cup 11.12$

$\begin{array}{llll}11.62 & 0.48 \cup \quad 5.02\end{array}$

$\begin{array}{lll}13.18 & 0.53 \cup & 9.15\end{array}$

$12.49 \quad 0.44 \cup \quad 7.58$

$12.00 \quad 0.46 \cup \quad 3.60$

$\begin{array}{llll}12.23 & 0.54 & \mathrm{U} & 9.38\end{array}$

$\begin{array}{llll}12.23 & 0.53 \mathrm{U} & 5.55\end{array}$

$\begin{array}{lllll}12.23 & 0.51 \cup & 0.60\end{array}$

$13.34 \quad 0.56$ U 4.30

$\begin{array}{llll}13.22 & 0.54 & \cup & 6.77\end{array}$
$0.32 \mathrm{U} \quad 0.32 \mathrm{U}$

$0.35 \mathrm{U} \quad 0.35 \mathrm{U}$

$1.490 .35 \mathrm{U}$

$0.31 \mathrm{U} \quad 0.31 \mathrm{U}$

$1.720 .31 \mathrm{U}$

$0.26 \mathrm{U} \quad 0.26 \mathrm{U}$

$0.44 \mathrm{U} \quad 0.44 \mathrm{U}$

$1.83 \quad 0.32 \mathrm{U}$

$0.32 \mathrm{U} \quad 0.32 \mathrm{U}$

$0.25 \mathrm{U} \quad 0.25 \mathrm{U}$

$0.34 \mathrm{U} \quad 0.34 \mathrm{U}$

$1.310 .28 \mathrm{U}$

$1.86 \quad 0.30 \mathrm{U}$

$\begin{array}{ll}1.41 & 0.25 \mathrm{U} \\ 2.05 & 0.45 \mathrm{U}\end{array}$

$0.29 \mathrm{U} \quad 0.29 \mathrm{U}$

$1.94 \mathrm{U} \quad 0.28 \mathrm{U}$

$\begin{array}{ll}1.25 & 0.30 \mathrm{~V}\end{array}$

$\begin{array}{ll}1.40 & 0.37 \mathrm{U}\end{array}$

$0.34 \mathrm{U} \quad 0.34 \mathrm{U}$

$1.47 \quad 0.36 \mathrm{U}$

$2.22 \quad 0.36 \mathrm{U}$

$0.29 \mathrm{U} \quad 0.29 \mathrm{U}$

$0.32 \mathrm{U} \quad 0.32 \mathrm{~J}$

$2.81 \quad 0.26 \mathrm{U}$

$1.25 \quad 0.28 \mathrm{U}$

$1.220 .32 \mathrm{U}$

$0.32 \mathrm{U}$

$1.82 \quad 0.32 \mathrm{U}$

$\begin{array}{lll}0.33 & \mathrm{U} & 0.33 \mathrm{U} \\ 0.33 \mathrm{U} & 0.33 \mathrm{U}\end{array}$ 
IABLE J.23. (contd)

Trit-

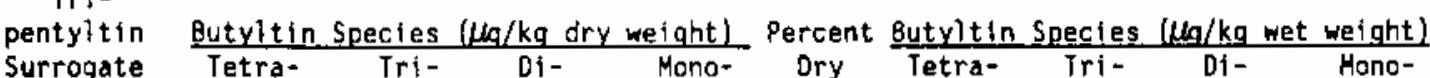

Sediment

Analytical Surrogate

Replicate Batch Recovery butyltin butyitin butyltin butyltin veight butyltin butyltin butyltin butyltin

$R-P F$
$R-P F$
$R-P F$
$R-P F$
$R-P F$
$C-S B$
$C-S B$
$C-S B$
$C-S B$ Replicate 1
C-SB Replicate 2
C-SB Replicate 3
C-SB
C-NE
C-NE
C-NE
C-NE
$C-N E$

1
2
3
4
5
1
2
3
4
4
4
5
1
2
3
4
5

$\begin{array}{lll}41.65 & 4.1 \mathrm{U} & 40.5 \\ 58.60 & 5.0 \mathrm{U} & 55.0 \\ 46.74 & 4.5 \mathrm{U} & 37.2 \\ 43.79 & 3.7 \mathrm{U} & 26.3 \\ 57.64 & 4.6 \mathrm{U} & 66.3 \\ & & \\ 43.77 & 3.9 \mathrm{U} & 46.2 \\ 43.62 & 4.2 \mathrm{U} & 41.0 \\ 62.40 & 4.1 \mathrm{U} & 80.4 \\ 59.08 & 4.3 \mathrm{U} & 35.7 \\ 68.98 & 4.2 \mathrm{U} & 45.6 \\ 58.65 & 4.2 \mathrm{U} & 34.8 \\ 70.04 & 4.2 \mathrm{U} & 44.1\end{array}$

$2.5 \mathrm{U} \quad 2.5 \mathrm{U}$

$11.21 \quad 0.46 \cup \quad 4.54$

$0.28 \mathrm{U} \quad 0.28 \mathrm{U}$

$3.7 \mathrm{u}$

$2.7 \mathrm{U}$

$2.3 \mathrm{U} \quad 2.3 \mathrm{U}$

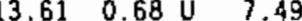

$0.42 \mathrm{U}$

$\begin{array}{lllllll}11.72 & 0.53 & \mathrm{U} & 4.36 & 0.32 \mathrm{U} & 0.32 \mathrm{U} \\ 12.40 & 0.46 \mathrm{U} & 3.26 & 0.29 \mathrm{U} & 0.29 \mathrm{U}\end{array}$

$\begin{array}{lllllll}11.72 & 0.53 & \mathrm{U} & 4.36 & 0.32 \mathrm{U} & 0.32 \mathrm{U} \\ 12.40 & 0.46 \mathrm{U} & 3.26 & 0.29 \mathrm{U} & 0.29 \mathrm{U}\end{array}$

$\begin{array}{llllll}13.22 & 0.61 \cup & 8.76 & 0.37 \cup & 0.37 \mathrm{U}\end{array}$

MSL Background

MSL Back.ground

MSL Background Replicate 1

MSL Background Replicate?

MSL Background Replicate 3

MSL Background

MSL Background

1
2
3
3
3
4
5

\begin{tabular}{|c|c|}
\hline $\begin{array}{l}70.55 \\
63.02 \\
56.04 \\
70.78 \\
47.61\end{array}$ & $\begin{array}{l}3.6 \mathrm{U} \\
4.3 \mathrm{U} \\
4.5 \mathrm{U} \\
4.3 \mathrm{U} \\
3.6 \mathrm{U}\end{array}$ \\
\hline $\begin{array}{l}40.30 \\
42.00 \\
35.59 \text { (d) } \\
40.53 \\
52.21 \\
40.76\end{array}$ & $\begin{array}{l}4.3 U \\
4.4 U \\
4.0 U \\
4.1 U \\
4.0 U \\
4.0 U\end{array}$ \\
\hline
\end{tabular}

$2.4 \mathrm{U} \quad 2.4 \mathrm{U}$

$12.24 \quad 0.48 \cup \quad 5.65$

$\begin{array}{llll}11.33 & 0.48 \mathrm{U} & 4.65\end{array}$

$0.29 \mathrm{U} \quad 0.29 \mathrm{U}$

$\begin{array}{rrrrr}2.6 \mathrm{~V} & 2.6 \mathrm{U} & 11.33 & 0.48 \mathrm{U} & 4.65 \\ 2.5 \mathrm{~V} & 2.5 \mathrm{U} & 13.05 & 0.54 \mathrm{U} & 10.49\end{array}$

$\begin{array}{rrrrr}2.5 \mathrm{U} & 2.5 \mathrm{U} & 13.05 & 0.54 \mathrm{U} & 10.49 \\ 11.9 & 2.6 \mathrm{U} & 14.02 & 0.60 \mathrm{U} & 5.01\end{array}$

$0.33 \mathrm{U} \quad 0.33 \mathrm{U}$

$2.5 \mathrm{U}=2.5 \mathrm{~V} \quad 14.020 .59 \mathrm{~V} \quad 4.88$

$\begin{array}{lllllll}11.4 & 2.5 \mathrm{U} & 13.47 & 0.57 \mathrm{U} & 5.94 & 1.54 & 0.34 \mathrm{U}\end{array}$

(a) DL Detection Iimit

(b) NA Not applicable.

(c) U The analyte was not present above the level of the associated value.

(d) Recovery outside quality control range of (40\%-120\%). 
TABLE J.24. Quality Control Data for Butyltin Results, Dry Weight, in Tissue of M. nasuta, Richmond Harbor Program

Sediment

Treatment

Method Blanks

Blank

Blank

Blank

8lank

Blank

Blank

Blank

Blank

Blank

B?ank

Blank

\section{Matrix Spikes}

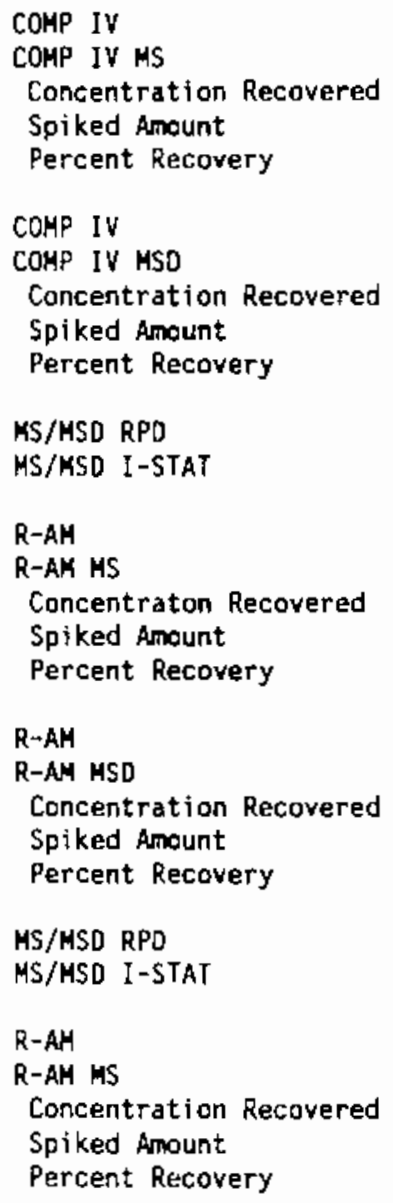

Tripentyltin \begin{tabular}{c}
$\begin{array}{c}\text { Analytical } \\
\text { Batch }\end{array}$ Recovogate \\
\hline
\end{tabular} Replicate Batch

\begin{tabular}{|c|c|c|c|}
\hline $\begin{array}{l}\text { Tetra- } \\
\text { butyltin }\end{array}$ & $\begin{array}{c}\text { Tri- } \\
\text { butyltin }\end{array}$ & $\begin{array}{c}\mathrm{Di}= \\
\text { butyltin }\end{array}$ & $\begin{array}{c}\text { Hono- } \\
\text { butyltin }\end{array}$ \\
\hline
\end{tabular}

\begin{tabular}{|c|c|c|c|c|c|c|}
\hline & A & 41.29 & $3.6 u^{(a)}$ & $2.7 \mathrm{U}$ & $2.2 \mathrm{U}$ & $2.2 \mathrm{U}$ \\
\hline $1-R^{(b)}$ & $\mathrm{E}$ & 48.46 & $4.8 \mathrm{U}$ & $3.6 \mathrm{~V}$ & $2.9 \mathrm{U}$ & $2.9 \mathrm{U}$ \\
\hline 2 & A & $37.97^{(c)}$ & $3.8 \mathrm{U}$ & $2.8 \mathrm{U}$ & $2.3 \mathrm{U}$ & $2.3 \mathrm{U}$ \\
\hline $2-R$ & $E$ & 79.97 & $4.4 \mathrm{U}$ & $3.3 \mathrm{U}$ & $2.7 \mathrm{U}$ & $2.7 \mathrm{U}$ \\
\hline 3 & $B$ & $53.32(\mathrm{c})$ & $3.8 \mathrm{U}$ & $2.8 \mathrm{U}$ & 2.34 & $2.3 \mathrm{U}$ \\
\hline $3-R$ & $F$ & $22.12^{(\mathrm{c})}$ & $4.0 \mathrm{U}$ & $3.0 \mathrm{U}$ & $2.4 \mathrm{~V}$ & 2.4 \\
\hline 4 & C & 43.29 & $3.8 \mathrm{~V}$ & $2.9 \mathrm{U}$ & $2.3 \mathrm{U}$ & $2.3 \mathrm{U}$ \\
\hline $4-R$ & $F$ & $41.08 \mathrm{dcl}$ & $4.2 U$ & $3.1 \mathrm{U}$ & $2.5 \mathrm{U}$ & $2.5 \mathrm{U}$ \\
\hline 5 & $C$ & $35.25^{(\mathrm{c})}$ & $3.5 \mathrm{U}$ & $2.6 \mathrm{U}$ & $2.1 \mathrm{U}$ & $2.1 \mathrm{U}$ \\
\hline 6 & $D$ & 58.37 & $3.9 \mathrm{U}$ & $2.9 \mathrm{U}$ & $2.3 \mathrm{U}$ & 2.3 \\
\hline 7 & $D$ & $36.41(C)$ & $3.7 U$ & $2.8 \mathrm{~J}$ & $2.2 \mathrm{U}$ & 2.2 \\
\hline
\end{tabular}

5

E

$\begin{array}{lrrrr}27 \% & 4.2 \mathrm{v} & 40.7 & 12.2 & 2.6 \mathrm{U} \\ \text { NA } & 692.7 & 457.4 & 457.7 & 93.4 \\ \text { NA } & 692.7 & 416.7 & 445.5 & 93.4 \\ \text { NS (e) } & 1408.45 & 1408.45 & 1408.45 & 1408.45 \\ \text { NA } & 49 \% & 30 \%(c) & 32 \%(c) & 7 \%\end{array}$

5

E

$\begin{array}{lllll}41 \% & 4.2 \mathrm{U} & 40.7 & 12.2 & 2.6 \mathrm{U}\end{array}$

$\begin{array}{lllll}\text { NA } & 974.5 & 665.5 & 662 & 149.7\end{array}$

$\begin{array}{lllll}\text { NA } & 974.5 & 624.8 & 649.8 & 149.7\end{array}$

$\begin{array}{lrrrr}\text { NS } & 1428.57 & 1428.57 & 1428.57 & 1428.57 \\ \text { NA } & 68 \% & 44 \% & 45 \% & 10 \mathrm{C}^{(\mathrm{c})}\end{array}$

$\begin{array}{lllll}\text { NA } & 32 x^{(f)} & 39 x^{(f)} & 36 x^{(f)} & 45 x^{(f)} \\ \text { NA } & 0.16 & 0.19 & 0.18 & 0.22\end{array}$

$5 \quad$ E

54.04

$04-4.1 \mathrm{U}$

77.7

1046.3

968.6

HA 1037.2

NS 1639.34

NA $63 \%$

1639.34

12.4

$899.3 \quad 182.4$

$1639.34 \quad 1639.34$ (c)

$\begin{array}{ll}5 & E \\ 5 & A\end{array}$

$54.04 \quad 4.1$

2.4

1223.1

1223.1

$\begin{array}{lr}\text { NS } & 1666.67 \\ \text { NA } & 73 x\end{array}$

77.7
1314.1

1236.4
1666.67

$\begin{array}{cc}7 \% & 15 \% \\ 0.14 & 0.07\end{array}$

$74 x$

12.4
1179.6

1167.2

1666.67

$70 \%$

$2.5 \mathrm{U}$

198

198
1666.67

${ }_{12 x^{(c)}}$

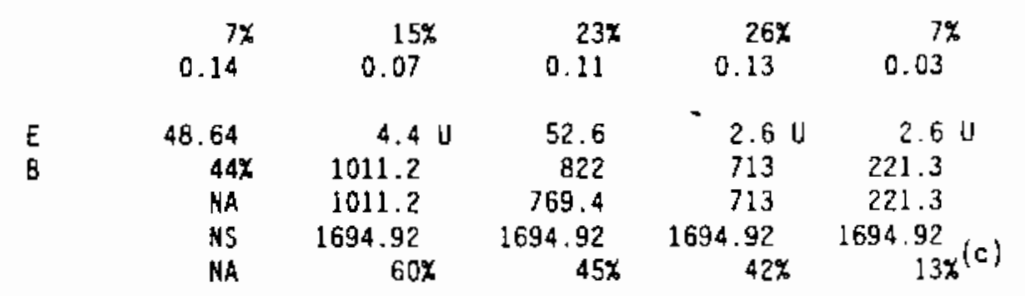


IABLE J.24. (contd)

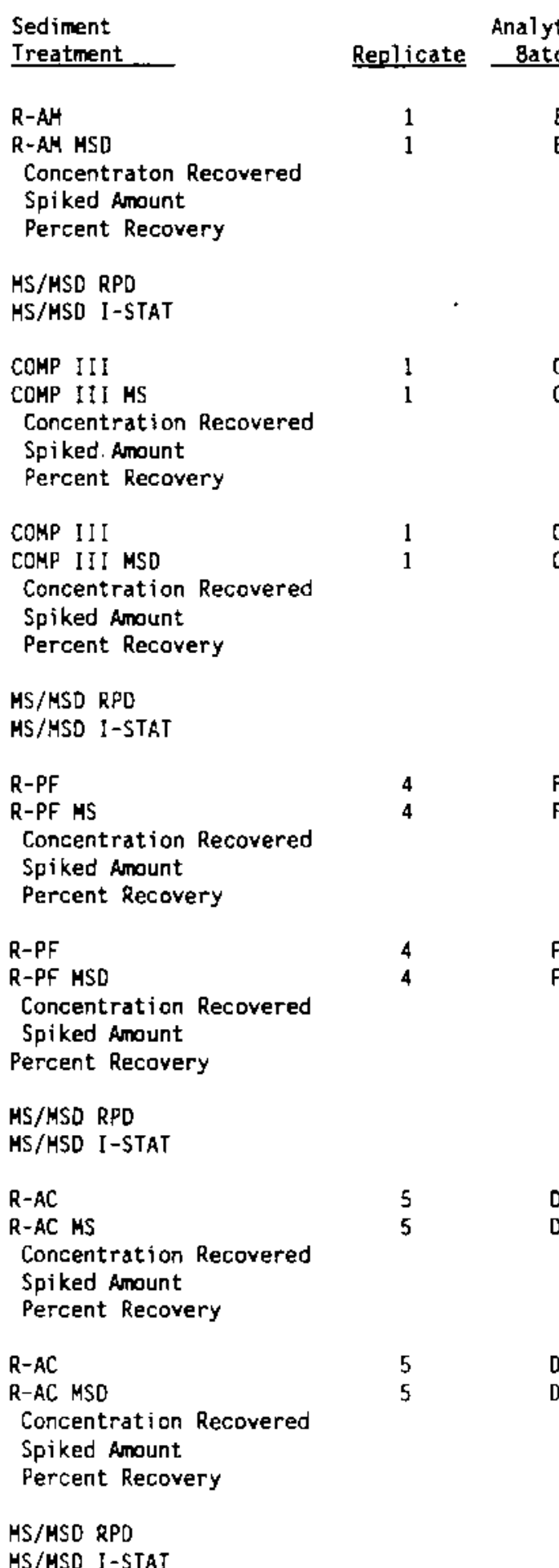

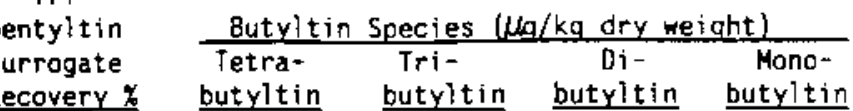

$\begin{array}{llrrr}48.64 & 4.4 \mathrm{~J} & 52.6 & 2.6 \mathrm{U} & 2.6 \mathrm{U}\end{array}$ $\begin{array}{lllll}66 \% & 982.5 & 1200.4 & 1058.9 & 286.2\end{array}$

$\begin{array}{lrrrr}\text { NA } & 982.5 & 1147.8 & 1058.9 & 286.2\end{array}$

$\begin{array}{rrrrr}\text { NS } & 1724.14 & 1724.14 & 1724.14 & 1724.14 \\ \text { HA } & 57 \% & 67 \% & 61 \% & 17 \%(c)\end{array}$

$10 \% \quad 5 \% \quad 38 \%^{(f)} \quad 37 \%^{(f)} \quad 24 \%$

$\begin{array}{lllll}0.20 & 0.02 & 0.19 & 0.19 & 0.12\end{array}$

$\begin{array}{lrrrrr}C & 61.99 & 4.3 \mathrm{U} & 47.3 & 2.6 \mathrm{U} & 2.6 \mathrm{U}\end{array}$

$\begin{array}{lllll}76 \% & 1060.6 & 1196.5 & 1042.9 & 244.5\end{array}$

NA $\quad 1060.6 \quad 1149.2 \quad 1042.9 \quad 244.5$

$\begin{array}{rrrrr}\text { NS } & 1666.67 & 1666.67 & 1666.67 & 1666.67 \\ \text { NA } & 64 \% & 69 \% & 63 \% & 15 \%\end{array}$

$\begin{array}{llllll}\mathrm{C} & 61.99 & 4.3 \mathrm{U} & 47.3 & 2.6 \mathrm{U} & 2.6 \mathrm{U}\end{array}$

$\begin{array}{llllll}\text { C } & 72 \% & 1036.3 & 1353.5 & 1177.8 & 197\end{array}$

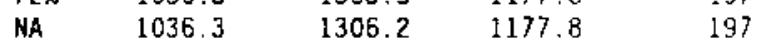

$\begin{array}{rrrrr}\text { NS } & 1694.92 & 1694.92 & 1694.92 & 1694.92 \\ \text { NA } & 61 \% & 77 \% & 69 \% & 12 \%(c)\end{array}$

$\begin{array}{ccccc}1 \% & 4 \% & 11 \% & 10 \% & 23 \% \\ 0.03 & 0.02 & 0.06 & 0.05 & 0.12\end{array}$

$\begin{array}{llllll}F & 43.79 & 3.7 U & 26.3 & 2.3 U & 2.3 U\end{array}$

497 $888.5 \quad 775.2 \quad 829.5 \quad 127.8$

$\begin{array}{lllll}\text { NA } & 888.5 & 748.9 & 829.5 & 127.8\end{array}$

$\begin{array}{lrrrr}\text { NS } & 1587.3 & 1587.3 & 1587.3 & 1587.3\end{array}$

NA $56 \% \quad 47 \% \quad 52 \% \quad 8 \%$

$\begin{array}{llllll}F & 43.79 & 3.7 \mathrm{U} & 26.3 & 2.3 \mathrm{U} & 2.3 \mathrm{U}\end{array}$

$\begin{array}{lllll}63 \% & 718.3 & 979.9 & 994.5 & 194.7\end{array}$

$\begin{array}{lllll}\text { NA } & 718.3 & 953.6 & 994.5 & 194.7\end{array}$

$\begin{array}{lrrrr}\text { NS } & 1587.3 & 1587.3 & 1587.3 & 1587.3 \\ \text { NA } & 45 \% & 60 \% & 63 \% & 12 \%^{(c)}\end{array}$

$6 \% \quad 21 \% \quad 24 \% \quad 18 \% \quad 41 \%(f)$

$\begin{array}{lllll}0.13 & 0.11 & 0.12 & 0.09 & 0.21\end{array}$

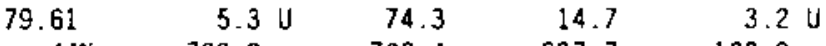

$\begin{array}{lllll}44 \% & 728.2 & 706.4 & 637.7 & 129.9\end{array}$

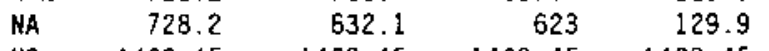

$\begin{array}{rrrrr}\text { NS } & 1408.45 & 1408.45 & 1408.45 & 1408.45 \text { (c) } \\ \text { NA } & 52 \% & 45 \% & 44 \% & 9 \%\end{array}$

$\begin{array}{lllll}9.61 & 5.3 \mathrm{U} & 74.3 & 14.7 & 3.2 \mathrm{U}\end{array}$

$\begin{array}{lllll}-387 & 675.8 & 545.6 & 473.8 & 104.7\end{array}$

$\begin{array}{lllll}\text { NA } & 675.8 & 471.3 & 459.1 & 104.7\end{array}$

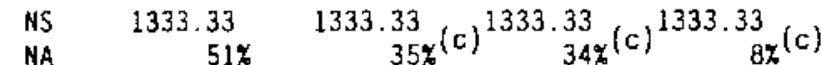

$\begin{array}{ccccc}4 \% & 2 \% & 24 \% & 25 \% & 16 \% \\ 0.07 & 0.01 & 0.12 & 0.12 & 0.08\end{array}$ 
IABLE J.24. (contd)

Sediment

Treatment
Tripentylitin Analytical Surrogate
Batch
Butyltin Species ( $\mu / k / k 0$ dry weight)

\begin{tabular}{cccc}
\hline $\begin{array}{c}\text { Tetra- } \\
\text { butyltin }\end{array}$ butyltin butyltin butyltin \\
\hline
\end{tabular}

\section{Analytical Replicates}

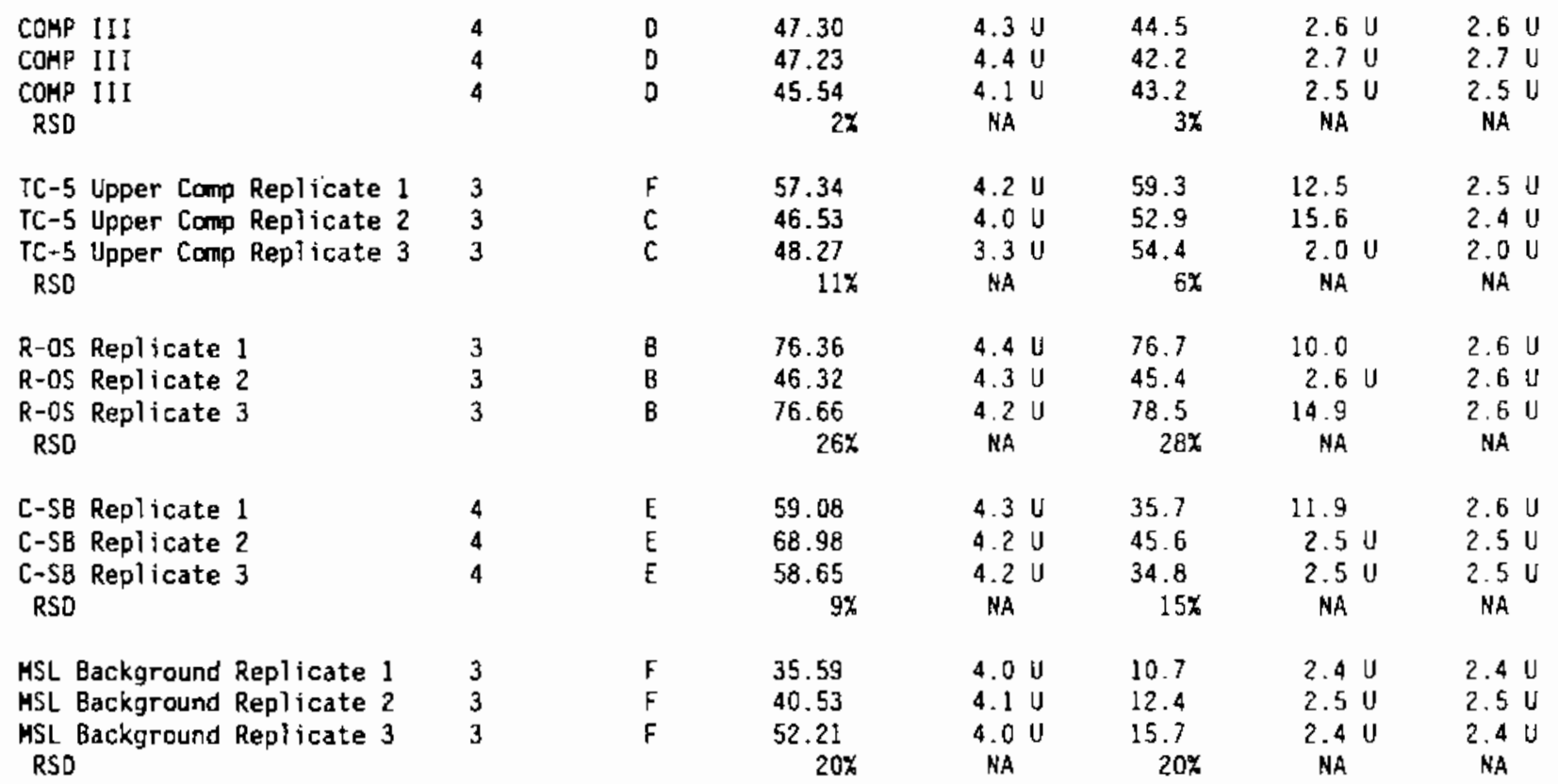

(a) U The analyte was not present above the level of the associated value.

(b) R Sample was reanalyzed.

(c) Recovery outside quality control range (40\%-120\%).

(d) NA Not applicable.

(e) NS Not spiked.

(f) Value exceeds relative precision range of $30 \%$. 


\section{APPENDIX $X$}

IISSUE CHEMISTRY AND QUALITY ASSURANCE DATA

FOR NEPHTYS caecoides 


\section{QA/QC SUMMARY}

PROGRAM:

PARAMETER:

LABORATORY:

MATRIX:

SAMPLE NUMBER:
Richmond Harbor Program

Polynuclear Aromatic Hydrocarbons (PAHs)

Battelle Ocean Sciences (Duxbury, Mass.)

N. caecoides

75

\section{QA/QC REQUIREMENTS}

\section{Reterence \\ Method}

8270

\section{Range of \\ Recovery}

$40 \%-120 \%$
Relative
Precision

$\pm 30 \%$
Detectlon

Limit (wet wt)

$20 \mu \mathrm{g} / \mathrm{kg}$

HOLDING TIMES Samples were held frozen for up to 2 months prior to extraction and were analyzed within the EPA extract holding time of 40 days (EPA 1986). Samples were extracted in four batches.

DETECTION LIMITS Target detection limits ranged from 1.6 to $29.9 \mu \mathrm{g} / \mathrm{kg}$ for LPAHs and from 1.5 to $31.4 \mu \mathrm{g} / \mathrm{kg}$ for HPAHs. Target detection limits (20 $\mu \mathrm{g} / \mathrm{kg}$ wet $w \mathrm{t}$.) were exceeded for 11 samples due to the small quantity of available tissue for analyses.

METHOD BLANKS Four method blanks were analyzed, one with each extraction batch. Naphthalene, phenanthrene, fluoranthene, chrysene, benzo(b) fluoranthene, and pyrene were detected in all four method blanks; however, because levels were low, no data were corrected or flagged.

\section{MATRIX SPIKES}

Four sets of background samples were spiked in duplicate with all $16 \mathrm{PAH}$ compounds. One set of spikes was extracted with each batch for samples to assess accuracy and precision. Spike recoveries for LPAH compounds ranged from $87 \%$ to $123 \%$ with only acenaphthalene in one spike for Batch $C$ slightly exceeding the QAVC requirements. Relative percent differences (RPDs) between spike duplicate recoveries ranged from $0 \%$ to $4 \%$, indicating acceptable precision of the method.

The HPAH spike recoveries ranged from $90 \%$ to $126 \%$. Four recoveries out of eighty exceeded the upper QAVOC requirements for Batch $\mathrm{C}$. The RPDs between spike recoveries ranged from $0 \%$ to $7 \%$ and were within the $O A O C$ requirements, indicating acceptable precision.

REPLICATES

Four samples (COMP I, COMP IV, R-AM, and R-OS) were analyzed in triplicate. Precision was measured by Relative Standard Deviation (RSD) between duplicate results. The RSD values ranged from $6 \%$ to $55 \%$ for LPAHs with only one naphthalene RSD exceeding QAVC requirements. The HPAH RSD values ranged from $2 \%$ to $21 \%$, all within the QAQC requirements. Overall, these measurements indicate acceptable precision of the method. 
batch (a total of 4 analyses). This SRM is certilied for 8 of the $16 \mathrm{PAH}$ compounds. In general, values measured were within the certified range and all concentrations were within $\pm 30 \%$ of the certified mean value with the exception of benzo(a)pyrene. No criteria was given for SRMs in the QAVC plan; therefore, no values were flagged.

SURROGATES

Three radiolabelled PAH compounds (naphthalene d8, acenapthlene d10, and benzo(a)pyrene d12) were added as surtogates to samples prior to analysis. Recoveries for all samples were within the QACC requirements. 


\section{OA/OC SUMMARY}

PROGRAM:

PARAMETER:

LABORATORY:

MATRIX:

SAMPLE NUMBER:
Richmond Harbor Program

Chlorinated Pesticides and PCBs

Battelle Ocean Sciences (Duxbury, Mass.)

N. caecoides

\section{QA/OC REQUIREMENTS}

$\begin{array}{lcccc} & \begin{array}{c}\text { Reference } \\ \text { Method }\end{array} & \begin{array}{c}\text { Range of } \\ \text { Recovery }\end{array} & \begin{array}{c}\text { Relative } \\ \text { Preclsion }\end{array} & \begin{array}{c}\text { Detection } \\ \text { Limlt_dry wt) }\end{array} \\ \text { Pesticides } & 8080 & 40 \%-120 \% & \pm 30 \% & 2.0 \mu \mathrm{g} / \mathrm{kg} \\ \text { PCBs } & 8080 & 40 \%-120 \% & \pm 30 \% & 20 \mu \mathrm{kg} / \mathrm{kg}\end{array}$

HOLDING TIMES

DETECTION LIMITS

METHOD BLANKS
Samples were held frozen for up to 2 months prior to extraction. All sample extracts were analyzed within the EPA extract holding time of 40 days (EPA 1986).

Target detection limits for pesticides $(2 \mu \mathrm{g} / \mathrm{kg}$ wet weight, $30 \mu \mathrm{g} / \mathrm{kg}$ for toxaphene) were met. The PCB detection limits ranged from 4.7 to 52 $\mu \mathrm{g} / \mathrm{kg}$ (wet weight). Target detection limits of $20 \mu \mathrm{g} / \mathrm{kg}$ wet weight were exceeded for 11 out of 75 samples due to limited tissue avallable for analysis.

Four method blanks were analyzed, one with each extraction batch. Beta-BHC and aldrin were found in two of the blanks at levels below the detection limits. Delta-BHC and lindane were found at levels slightly above the detection limits; however, these compounds were not flagged or blank corrected. No PCBs were detected in the method blanks.

Four background samples were spiked in duplicate with 18 pesticides and $1 \mathrm{PCB}$ (aroclor 1254). Pesticide spike recoveries ranged from $13 \%$ to $215 \%$. However, the majority of the spike recoveries were within the QAOC requirements. Spike recoveries for endosulfan II and endosulfan sulfate ranged from $125 \%$ to $174 \%$; however, neither of these compounds were detected above detection limits or confirmed on a second column in any of the tissue samples. The recoveries of the matrix spikes would suggest that any tissue values reported would be biased high. Spike recoveries of endrin for Batches $B$ and $C$ ranged from $142 \%$ to $215 \%$; however, endrin was rot detected in any samples. Low spike recoveries were found for endrin aldehyde, with recoveries ranging from $13 \%$ to $65 \%$, and again, this compound was not detected in any samples.

Relative percent differences (RPD) between spike and spike duplicates were within QAQC requirements from 143 out 144 calculations, indicating acceptable precision for this method. 
REPLICATES

SRMS

SURROGATES
Aroclor 1254 spike recoveries ranged from $103 \%$ to $136 \%$. Four out of the eight recoveries slightly exceeded the OAQC requirements. These were not batch specific and do not indicate a significant bias in the data. The RPDs between spike and spike duplicate recoveries for PCBs ranged from $4 \%$ to $13 \%$, indicating acceptable precision for the method.

Four samples (COMP I, COMP IV, R-AM, and R-OS) were analyzed in triplicate. Three pesticides were detected for two of the triplicate anatyses. Precision for these measurements was determined by calculating relative standard deviation (RSDs). The RSDs ranged from $4 \%$ to $22 \%$, and were within the OAOC requirements, indicating acceptable precision.

The PCB RSDs were measured for two of the four sets of triplicates. The RSDs were $23 \%$ and $28 \%$ and also indicate acceptable precision.

The SRM 1974 (obtained from NIST) was analyzed four times, once with each extraction batch. No pesticide values are certified; however, consensus values were given for four pesticides.

Two compounds, dibromooctaflourobiphenyl (DBOFB) and tetrachloronaphthalene (TCN), were added to all samples prior to extraction to assess the efficiency of the method. Recoveries for DBOBF were within the OAQC requirements, with the exception of one sample (R-AM with a recovery of $122 \%$ ). Recoveries for TCN ranged from $64 \%$ to $144 \%$. A total of 31 out of 75 sample recoveries for $\mathrm{TCN}$ were above the $\mathrm{OA} Q \mathrm{C}$ requirements. In most cases, this was due to interference of the spiked PCB congener peak, which coeluted with the surrogate. These exceedences do not reflect recovery problems associated with the sample analysis and therefore do not affect data qualify. 


\section{QA/QC SUMMARY}

PROGRAM

PARAMETER:

LABORATORY:

MATRIX:

SAMPLE NUMBER:
Richmond Harbor Program

Metals (Ag, As, Cd, $\mathrm{Cr}, \mathrm{Cu}, \mathrm{Hg}, \mathrm{Ni}, \mathrm{Pb}, \mathrm{Se}$, and $\mathrm{Zn}$ )

Battelie/Marine Sciences Laboratory

$N$ caocoides

75

\section{QA/QC REQUIREMENTS}

$\begin{array}{lccccc}\text { Analysis } & \begin{array}{c}\text { QA/OC } \\ \text { Methed }\end{array} & \begin{array}{c}\text { Range of } \\ \text { Recument }\end{array} & \begin{array}{c}\text { Relative } \\ \text { Recovery }\end{array} & \begin{array}{c}\text { Detection } \\ \text { Limit (dry wt) }\end{array} \\ \text { Arsenic } & \text { XRF } & \text { PNL-SP-19 } & \text { NA } & \pm 20 \% & 1.0 \mathrm{mg} / \mathrm{kg} \\ \text { Cadmium } & \text { ICP-MS } & \text { MSL-M-33 } & 75 \%-125 \% & \pm 20 \% & 0.1 \mathrm{mg} / \mathrm{kg} \\ \text { Chromium } & \text { ICP-MS } & \text { PNL-SP-19 } & 75 \%-125 \% & \pm 20 \% & 1.0 \mathrm{mg} / \mathrm{kg} \\ \text { Copper } & \text { XRF } & \text { PNL-SP-19 } & \text { NA } & \pm 20 \% & 1.0 \mathrm{mg} / \mathrm{kg} \\ \text { Lead } & \text { ICP-MS } & \text { PNL-SP-19 } & 75 \%-125 \% & \pm 20 \% & 1.0 \mathrm{mg} / \mathrm{kg} \\ \text { Mercury } & \text { CVAA } & \text { MSL-M-11 } & 75 \%-125 \% & \pm 20 \% & 0.02 \mathrm{mg} / \mathrm{kg} \\ \text { Nickel } & \text { ICP-MS } & \text { PNL-SP-19 } & 75 \%-125 \% & \pm 20 \% & 1.0 \mathrm{mg} / \mathrm{kg} \\ \text { Selenium } & \text { XRF } & \text { PNL-SP-19 } & 75 \%-125 \% & \pm 20 \% & 0.5 \mathrm{mg} / \mathrm{kg} \\ \text { Silver } & \text { ICP-MS } & \text { MSL-M-33 } & 75 \%-125 \% & \pm 20 \% & 1.0 \mathrm{mg} / \mathrm{kg} \\ \text { Zinc } & \text { XRF } & \text { PNL-SP-19 } & \text { NA } & \pm 20 \% & 1.0 \mathrm{mg} / \mathrm{kg}\end{array}$

HOLDING TIMES

Recommended holding times for metals in tissues based on the 1991 Implementation Manual (EPAUSACE 1991) are 6 months frozen $\left(<20^{\circ} \mathrm{C}\right)$ for all metals except $\mathrm{Hg}$, which is 28 days after receipt at the MSL. $N$. caecoides samples for this project were held frozen for up to 4 weeks and were then freeze dried and stored for up to 3 months in sealed containers. Holding times have not been established for samples held freeze dried; however, standard reference material (SRM) prepared by the U.S. National Institute of Standards and Technology (NIST) such as SRM 1566a (oyster tissue), which is freeze dried, has been issued tor up to 10 years without changes to the certified concentrations, including those for $\mathrm{Hg}$.

$N$. caecoides were digested in two batches for metals analyzed by $A A$ and ICP/MS. The QAOC samples were analyzed at a minimum of 1 per 20.

Samples analyzed by XRF were not treated prior to XRF analysis (other than freeze drying and grinding). All analytical measurements occurred in single batches and were generally performed at a frequency of 1 per 20 samples.

DETECTION LIMITS Detection limits, based on dry weight concentrations, were acceptable for all metals.

METHOD BLANKS Four method blanks were analyzed with $N$. caecoides samples for this project 1 per 20 samples). Low levels of $\mathrm{Ag}, \mathrm{Cd}, \mathrm{Cr}, \mathrm{Ni}$, and $\mathrm{Pb}$ were found in blanks; sample metals anatyzed by $\mathrm{AA}$ or ICP-MS ( $\mathrm{Ag}, \mathrm{Cd}, \mathrm{Cr}, \mathrm{Ni}$, and $\mathrm{Pb}$ ) were corrected for concentrations contained in the blanks. Method blanks are not applicable to metals analyzed by XRF.

MATRIX SPIKES Four samples (COMP V, C-NE, COMP II, and R-PF) were spiked in duplicate 
SRMS

REPLICATES

\section{SURROGATES}

with metals analyzed by $\mathrm{AA}$ or ICP-MS ( $\mathrm{Ag}, \mathrm{Cd}, \mathrm{Cr}, \mathrm{Hg}, \mathrm{Ni}$, and $\mathrm{Pb}$ ). Spikes were analyzed a minimum of 1 in 20 samples and recoveries ranged from $58 \%$ to $121 \%$. $\mathrm{Cd}, \mathrm{Cu}, \mathrm{Ni}$, and $\mathrm{Pb}$ recoveries for one spike duplicate were bolow the QAQC requirements. Replicate and SRM results for these metals were within all $Q A O C$ guidelines and indicate that these spike recoveries do not reflect a bias in the data. Cd, however, in one spike was recovered at $185 \%$ and was probably double spiked, which would affect data quality.

Relative precision difference values between spike and spike duplicate recoveries ranged from $1 \%$ to $43 \%$. Most values were within precision guidelines of $\pm 20 \%$. Overall, RPDs between spikes and spike duplicates indicate acceptable accuracy of the method.

The SRM 1566a, oyster tissue, was obtained from the NIST. This SRM was analyzed by AA or ICPMS at a minimum of 1 per 20 samples, and more frequently (1 per 5 samples) for XRF analyses. $\mathrm{Cr}, \mathrm{Hg}$, and Ni values exceeded the certified range for the initial SRM analyzed. Experience has shown that $\mathrm{Hg}$ values are routinely lower than the certified range. Eight of the 32 Se measurements for the SRM (performed by XRF) were outside of the certified range. These exceedences indicate slightly more variability in XRF measurement of Se than other metals; however, other QACC measurements for this metal (i.e., spikes and replicates) are acceptable, indicating that the variability may be a result of non-homogeneity of the SRM rather than an analytical bias.

Five samples (TC-5 Upper Comp, R-PF, R-AM, R-OS, and C-SB) were analyzed in triplicate for all metals. Precision was measured by Relative Standard Deviation (RSD) between replicate results. The RSDs ranged from $1 \%$ to $42 \%$. Four metals, $\mathrm{As}, \mathrm{Cd}, \mathrm{Hg}$, and $\mathrm{Se}$, exceeded the precision guideline in one of the four sets of triplicates. Silver exceeded the precision guideline for three of five triplicate analyses, suggesting that siver analyses may be more variable and less precise than the other metals.

NOT APPLICABLE 


\section{QA/QC SUMMARY}

PROGRAM

PARAMETER:

LABORATORY:

MATRIX:

SAMPLE NUMBER:
Richmond Harbor Program

Butyltins

Battelle/Marine Sciences Laboratory

N. caecoides

75

\section{QA/QC REQUIREMENTS}

$\begin{array}{lcccc}\begin{array}{c}\text { Reference } \\ \text { Method }\end{array} & \begin{array}{c}\text { Range of } \\ \text { Becovery }\end{array} & \begin{array}{c}\text { Relative } \\ \text { Preclslon }\end{array} & \begin{array}{c}\text { Detectlon } \\ \text { Lmit_wet_wt) }\end{array} \\ \begin{array}{l}\text { Monobutyltin } \\ \text { Dibutyltin }\end{array} & \text { MSL-M-4 } & - & \pm 30 \% & 10 \mu \mathrm{g} / \mathrm{kg} \\ \text { Tribulyltin } & \text { MSL-M-4 } & 40 \%-120 \% & \pm 30 \% & 10 \mu \mathrm{g} / \mathrm{kg} \\ & \text { MSL-M-4 } & 40 \%-120 \% & \pm 30 \% & 10 \mu \mathrm{g} / \mathrm{kg}\end{array}$

HOLDING TIMES

DETECTION LIMITS

METHOD BLANKS

MATRIX SPIKES
No holding times have been established for butylins in tissues. Samples were kept frozen, extracted in four batches, and analyzed within 2 months of receipt at the laboratory.

Detection limits ranged from 4.2 to $51.7 \mu \mathrm{g} / \mathrm{kg}$ wet wt and exceeded the target detection limits $(10 \mu \mathrm{g} / \mathrm{kg}$ wet $w$ ) for the majority of samples analyzed due to limited tissue available for extraction.

Four method blanks were analyzed, one per extraction batch. Butyltins were not detected in the method blanks with the exception of monobutyltin, which was observed below the detection limit in the blank from Batch $\mathrm{C}$.

Four background samples were spiked in duplicate to assess the accuracy and precision of the method. One set of spike and spike duplicate analyses was performed with each extraction batch. Although tri-, di-, and monobutyltins were used as spiking compounds, recovery and precision criteria are provided for the tri- and dibutyltins only. Recoveries for TBT ranged from $22 \%$ to $112 \%$. Recoveries for DBT ranged from $57 \%$ to $96 \%$. Four spike recoveries for TBT were below the QAOC requirements.

Relative percent ditferences (RPD) were compared between spike and spike duplicate recoveries to assess precision. The RPD values for tributyltin ranged from $18 \%$ to $39 \%$ and dibutyltin RPDs ranged from $2 \%$ to $12 \%$. Seven out of eight RPDs were within the QAQC requirements. In general, the precision of the analyses, based on spike duplicate recovery data, was acceptable.

SRMS NOT APPLICABLE 
REPLICATES

SURROGATES
Four samples (COMP I, TC-5 Upper Comp, COMP VI, and R-PC) were analyzed in triplicate, one per each extraction batch. Precision between triplicate analyses was measured by Relative Standard Deviation (RSD). One RSD value was calculated for TBT at $47 \%$ (other RSDs could not be calculated due to undetected values). Precision, based on the triplicate data available, appear to be low; this is due to the fact that the levels detected in the samples were near or below the detection limits.

Tripropyltin was added as a surrogate to each sample prior to extraction to assess extraction efficiency. Percent recoveries ranged from $0 \%$ to $283 \%$. Appruximately $45 \%$ of the recoveries were outside of the QANCC requirements. The cause of the variability of the surrogate recoveries appears to be a problem with the surrogate compound itself, rather than with the analysis. Recoveries for this compound in the past have been low and quite variable and may be due to the relatively high volatility of this compound compared to tri- and dibutytins. This surrogate does not reflect the behavior of the butyltin compounds of interest; therefore, a more representative compound, tripentyltin, is currently being implemented to assess the efficiency of the extraction and analysis. Because of limited tissue amounts, no re-extractions could be performed. 
IABLE K.1. Total Polynuclear Aromatic Hydrocarbons (PAHs), Dry Weight, in Tissue of $N$. caecoides, Richmond Harbor Program

\begin{tabular}{|c|c|c|c|c|c|c|}
\hline \multirow[b]{2}{*}{$\begin{array}{l}\text { Sediment } \\
\text { Ireatment }\end{array}$} & \multirow[b]{2}{*}{ Replicate } & \multirow[b]{2}{*}{$\begin{array}{l}\text { Analytical } \\
\text { Batch } \\
\end{array}$} & \multirow[b]{2}{*}{$\begin{array}{l}\text { Percent } \\
\text { Dry Weight }\end{array}$} & \multicolumn{3}{|c|}{ N. caecoides ( $\mu \mathrm{g} / \mathrm{kg}$ dry meight) } \\
\hline & & & & $\begin{array}{l}\text { Total Low } \\
\text { Molecular } \\
\text { Height PAHS }\end{array}$ & $\begin{array}{l}\text { Total High } \\
\text { Molecular } \\
\text { Height PAHS }\end{array}$ & $\begin{array}{l}\text { Total } \\
\text { PAHs } \\
\end{array}$ \\
\hline comp I & 1 & D & 16.00 & 97.23 & 793.32 & 890.55 \\
\hline COMP : & 2 & 0 & 15.28 & 60.50 & 169.97 & 230.47 \\
\hline COMP 1 & 3 & A & $16.50^{(a)}$ & 40.32 & 36,43 & 76.75 \\
\hline COHP I & 4 & $B$ & 17.16 & 37.65 & 74.24 & 111.89 \\
\hline COMP I Replicate 1 & 5 & A & 17.54 & 115.86 & 692.10 & 807.96 \\
\hline COHP I Replicate 2 & 5 & A & 17.54 & 685.63 & 10604.51 & 11290.14 \\
\hline COHP I Replicate 3 & 5 & A & 17.54 & 40.93 & 238.17 & 279.10 \\
\hline COMP II & 1 & D & 15.12 & 27.96 & 50.62 & 78.58 \\
\hline COMP II & 2 & A & 17.08 & 56.61 & 37.43 & 94.04 \\
\hline сонр 11 & 3 & C & 17.30 & 39.46 & 215.23 & 254.69 \\
\hline COMP II & 4 & D & 15.82 & 32.00 & 78.73 & 110.73 \\
\hline conp II & 5 & $\mathrm{C}$ & 16.64 & 38.41 & 256.92 & 295.33 \\
\hline COMP III & 1 & $c$ & 14.77 & 48.33 & 232.09 & 280.42 \\
\hline COMP III & 2 & D & 16.64 & 50.39 & 120.08 & 170.47 \\
\hline COMP III & 3 & $A$ & 15.35 & 39.93 & 36.68 & 76.61 \\
\hline COMP III & 4 & 0 & 16.35 & 74.08 & 44.04 & 118.12 \\
\hline COMP III & 5 & C & 15.26 & 41.56 & 223.76 & 265.32 \\
\hline TC-5 Upper Comp & 1 & c & 15.40 & 90.88 & 76.97 & 167.84 \\
\hline TC-5 Upper Comp & 2 & C & 15.92 & 54.62 & 90.99 & 145.61 \\
\hline TC-5 Upper Comp & 3 & $c$ & 16.93 & 56.21 & 100.97 & 157.18 \\
\hline TC-5 Upper Comp & 4 & A & 15.87 & 59.55 & 37.11 & 96.66 \\
\hline TC-5 Upper Comp & 5 & A & 16.58 & 129.47 & 455.31 & 584.78 \\
\hline COMP IV & 1 & C & 16.16 & 46.49 & 25.52 & 72.01 \\
\hline COMP IV Replicate 1 & 2 & c & 16.46 & 60.44 & 275.50 & 335.94 \\
\hline COMP IV Replicate 2 & 2 & C & 16.46 & 76.29 & 62.94 & 139.23 \\
\hline COMP IV Replicate 3 & 2 & $c$ & 16.46 & 67.96 & 44.97 & 112.93 \\
\hline COMP IV & 3 & A & 11.15 & 116.68 & 115.45 & 232.12 \\
\hline COMP IV & 4 & C & 16.04 & 94.28 & 474.78 & 569.07 \\
\hline COMP IV & 5 & A & 13.09 & 56.96 & 45.98 & 102.95 \\
\hline COMP V & 1 & A & 15.27 & 73.73 & 124.21 & 197.94 \\
\hline COMP V & 2 & A & 14.83 & 58.04 & 33.59 & 91.63 \\
\hline COMP V & 3 & A & 17.13 & 53.13 & 32.26 & 85.39 \\
\hline COMP V & 4 & 0 & 15.44 & 69.42 & 250.52 & 319.94 \\
\hline COMP V & 5 & B & 17.14 & 77.03 & 30.36 & 107.39 \\
\hline COMP VI & 1 & $c$ & 15.08 & 111.34 & 485.14 & 596.47 \\
\hline COMP VI & 2 & A & 15.83 & 370.14 & 6241.10 & 6611.24 \\
\hline COMP VI & 3 & 8 & 16.25 & 188.52 & 90.15 & 278.67 \\
\hline COMP VI & 4 & A & 15.89 & 283.56 & 580.43 & 864.00 \\
\hline COMP VI & 5 & 0 & 16.24 & 293.44 & 413.97 & 707.41 \\
\hline$R-A C$ & 1 & $B$ & 15.84 & 130.46 & 608.97 & 739.43 \\
\hline $\mathrm{R}-\mathrm{AC}$ & 2 & C & 16.14 & 107.47 & 886.10 & 993.57 \\
\hline$R-A C$ & 3 & C & 16.16 & 40.72 & 43.81 & 84.53 \\
\hline$R-A C$ & 4 & A & 13.29 & 356.44 & 8445.67 & $8 B 02.10$ \\
\hline $\mathrm{R}-\mathrm{AC}$ & 5 & 0 & 16.75 & 40.69 & 115.32 & 156.01 \\
\hline R-AM & 1 & B & 17.29 & 121.01 & 98.99 & 220.00 \\
\hline R-A.H & 2 & $\mathrm{C}$ & 16.62 & 44.44 & 68.44 & 112.88 \\
\hline R-AM & 3 & 8 & 16.26 & 49.14 & 202.65 & 251.79 \\
\hline
\end{tabular}


IABLE K.1. (contd)

\begin{tabular}{|c|c|c|c|c|c|c|}
\hline \multirow[b]{2}{*}{$\begin{array}{l}\text { Sediment } \\
\text { Ireatment }\end{array}$} & \multirow[b]{2}{*}{ Replicate } & \multirow[b]{2}{*}{$\begin{array}{l}\text { Analytical } \\
\text { Batch } \\
\end{array}$} & \multirow[b]{2}{*}{$\begin{array}{l}\text { Percent } \\
\text { Dry Weight }\end{array}$} & \multicolumn{3}{|c|}{$N$ coecoides ( $\mu \mathrm{g} / \mathrm{kg}$ dry weight $)$} \\
\hline & & & & $\begin{array}{l}\text { Total Low } \\
\text { Holecular } \\
\text { Height PAHs } \\
\end{array}$ & $\begin{array}{l}\text { Total High } \\
\text { Holecular } \\
\text { Weight PAHs } \\
\end{array}$ & $\begin{array}{l}\text { Total } \\
\text { PAHs } \\
\end{array}$ \\
\hline $\begin{array}{l}\text { R-AM Replicate } 1 \\
\text { R-AM Replicate } 2 \\
\text { R-AM Replicate } 3 \\
\text { R-AM }\end{array}$ & $\begin{array}{l}4 \\
4 \\
4 \\
5\end{array}$ & $\begin{array}{l}B \\
B \\
B \\
B\end{array}$ & $\begin{array}{l}16.61 \\
16.61 \\
16.61 \\
11.30\end{array}$ & $\begin{array}{l}42.20 \\
39.19 \\
92.02 \\
76.90\end{array}$ & $\begin{array}{r}44.76 \\
30.85 \\
894.54 \\
343.56\end{array}$ & $\begin{array}{r}86.96 \\
70.04 \\
986.56 \\
420.46\end{array}$ \\
\hline $\begin{array}{l}R-B F \\
R-B F \\
R-B F \\
R-B F \\
R-B F\end{array}$ & $\begin{array}{l}1 \\
2 \\
3 \\
4 \\
5\end{array}$ & $\begin{array}{l}D \\
B \\
B \\
A \\
A\end{array}$ & $\begin{array}{l}16.72 \\
13.79 \\
15.57 \\
15.24 \\
16.05\end{array}$ & $\begin{array}{r}53.71 \\
105.08 \\
43.99 \\
49.56 \\
31.05\end{array}$ & $\begin{array}{r}45.17 \\
1028.17 \\
91.91 \\
42.38 \\
23.38\end{array}$ & $\begin{array}{r}98.89 \\
1133.25 \\
135.90 \\
91.94 \\
54.43\end{array}$ \\
\hline $\begin{array}{l}\text { R-OS } \\
\text { R-OS Replicate } 1 \\
\text { R-OS Replicate } 2 \\
\text { R-OS Repl icate } 3 \\
\text { R-OS } \\
\text { R-OS } \\
\text { R-OS }\end{array}$ & $\begin{array}{l}1 \\
2 \\
2 \\
2 \\
3 \\
4 \\
5\end{array}$ & $\begin{array}{l}B \\
D \\
D \\
D \\
B \\
0 \\
C\end{array}$ & $\begin{array}{l}15.79 \\
16.53 \\
16.53 \\
16.53 \\
15.02 \\
17.85 \\
17.02\end{array}$ & $\begin{array}{r}435.69 \\
81.59 \\
78.80 \\
95.32 \\
30.83 \\
32.94 \\
27.90\end{array}$ & $\begin{array}{r}6038.41 \\
54.43 \\
32.08 \\
36.45 \\
37.62 \\
32.82 \\
22.97\end{array}$ & $\begin{array}{r}6474.10 \\
136.03 \\
110.87 \\
131.77 \\
68.45 \\
65.76 \\
50.87\end{array}$ \\
\hline $\begin{array}{l}R-P F \\
R-P F \\
R-P F \\
R-P F \\
R-P F\end{array}$ & $\begin{array}{l}1 \\
2 \\
3 \\
4 \\
5\end{array}$ & $\begin{array}{l}C \\
C \\
0 \\
D \\
A\end{array}$ & $\begin{array}{l}13.90 \\
13.46 \\
16.88 \\
16.74 \\
16.47\end{array}$ & $\begin{array}{l}37.62 \\
42.75 \\
37.81 \\
38.76 \\
25.20\end{array}$ & $\begin{array}{r}56.71 \\
286.79 \\
86.25 \\
78.95 \\
31.68\end{array}$ & $\begin{array}{r}94.32 \\
329.53 \\
124.06 \\
117.70 \\
56.88\end{array}$ \\
\hline $\begin{array}{l}C-S B \\
C-S B \\
C-S B \\
C-S B \\
C-S B\end{array}$ & $\begin{array}{l}1 \\
2 \\
3 \\
4 \\
5\end{array}$ & $\begin{array}{l}C \\
D \\
B \\
A \\
D\end{array}$ & $\begin{array}{l}14.29 \\
16.03 \\
15.65 \\
16.06 \\
16.46\end{array}$ & $\begin{array}{r}33.33 \\
533.97 \\
32.75 \\
54.89 \\
85.34\end{array}$ & $\begin{array}{r}34.95 \\
10924.42 \\
59.78 \\
130.42 \\
123.89\end{array}$ & $\begin{array}{r}68.28 \\
11458.39 \\
92.53 \\
185.32 \\
209.23\end{array}$ \\
\hline $\begin{array}{l}C-N E \\
C-N E \\
C-N E \\
C-N E \\
C-N E\end{array}$ & $\begin{array}{l}1 \\
2 \\
3 \\
4 \\
5\end{array}$ & $\begin{array}{l}B \\
B \\
B \\
B \\
B\end{array}$ & $\begin{array}{l}15.94 \\
18.40 \\
16.01 \\
15.81 \\
15.28\end{array}$ & $\begin{array}{l}86.91 \\
99.51 \\
52.51 \\
52.45 \\
51.72\end{array}$ & $\begin{array}{r}135.67 \\
337.13 \\
57.71 \\
35.63 \\
39.62\end{array}$ & $\begin{array}{r}222.58 \\
436.64 \\
110.22 \\
88.08 \\
91.35\end{array}$ \\
\hline $\begin{array}{l}\text { MSL Background } \\
\text { MSL Background } \\
\text { MSL Background } \\
\text { MSL Background } \\
\text { MSL Background }\end{array}$ & $\begin{array}{l}1 \\
2 \\
3 \\
4 \\
5\end{array}$ & $\begin{array}{l}E \\
E \\
E \\
E \\
E\end{array}$ & $\begin{array}{l}19.82 \\
19.82 \\
19.82 \\
19.82 \\
19.82\end{array}$ & $\begin{array}{l}41.98 \\
47.07 \\
48.94 \\
42.79 \\
44.75\end{array}$ & $\begin{array}{l}31.08 \\
30.63 \\
27.95 \\
27.09 \\
33.20\end{array}$ & $\begin{array}{l}73.06 \\
77.70 \\
76.89 \\
69.88 \\
77.95\end{array}$ \\
\hline
\end{tabular}

(a) Percent dry weight averaged from the other four Replicates of CoMP 1 . 
IABLE K.2. Low Molecular Weight Polynuclear Aromatic Hydrocarbons (LPAHs), Dry Weight, in Tissue of A?cHecoides, Richmond Harbor Program

\begin{tabular}{|c|c|c|c|c|c|c|c|c|c|}
\hline & & & & & N.co & LPAHS \& & kq dry wei & & \\
\hline $\begin{array}{l}\text { Sediment } \\
\text { Ireatment }\end{array}$ & Repl tcate & $\begin{array}{l}\text { Analytical } \\
\text { Batch } \\
\end{array}$ & $\begin{array}{c}\text { Percent } \\
\text { Pry Weight }\end{array}$ & $\begin{array}{l}\text { Naphtha- } \\
\text { lene }\end{array}$ & $\begin{array}{l}\text { Acenaph- } \\
\text { thylene } \\
\end{array}$ & $\begin{array}{l}\text { Acenaph- } \\
\text { thene }\end{array}$ & Eluorene & $\begin{array}{l}\text { Phenan- } \\
\text { threne }\end{array}$ & $\begin{array}{c}\text { Anthra- } \\
\text { cene } \\
\end{array}$ \\
\hline $\begin{array}{l}\text { COMP I } \\
\text { COMP I } \\
\text { COMP I } \\
\text { COMP I } \\
\text { COMP I Repl I cate } 1 \\
\text { COMP I RepI Icate } 2 \\
\text { COMP I Rep I Icate } 3\end{array}$ & $\begin{array}{l}1 \\
2 \\
3 \\
4 \\
5 \\
5 \\
5\end{array}$ & $\begin{array}{l}D \\
D \\
A \\
8 \\
A \\
A \\
A\end{array}$ & $\begin{array}{l}16.00 \\
15.28 \\
16.50 \\
17.16 \\
17.54 \\
17.54 \\
17.54\end{array}$ & $\begin{array}{l}15.31 \mathrm{~J}(\mathrm{a}) \\
35.14 \\
15.82 \mathrm{~J} \\
139.10 \\
48.57 \mathrm{~J} \\
33.58 \mathrm{~J} \\
34.72 \mathrm{~J}\end{array}$ & $\begin{aligned} 40.50 \mathrm{U}^{(b)} \\
3.08 \mathrm{~J} \\
31.03 \mathrm{U} \\
109.85 \mathrm{U} \\
120.47 \mathrm{U} \\
110.83 \mathrm{U} \\
81.64 \mathrm{U}\end{aligned}$ & $\begin{array}{rl}21.88 & \mathrm{U} \\
7.98 \mathrm{~J} \\
16.73 \mathrm{U} \\
59.32 \mathrm{U} \\
65.05 \mathrm{U} \\
59.86 \mathrm{U} \\
44.13 \mathrm{U}\end{array}$ & $\begin{array}{r}6.63 \mathrm{~J} \\
8.84 \mathrm{~J} \\
18.12 \mathrm{U} \\
14.04 \mathrm{~J} \\
11.86 \mathrm{~J} \\
64.82 \mathrm{U} \\
47.72 \mathrm{U}\end{array}$ & $\begin{array}{l}15.88 \mathrm{~J} \\
27.03 \\
16.18 \\
28.21 \mathrm{~J} \\
30.44 \mathrm{~J} \\
21.04 \mathrm{~J} \\
21.49 \mathrm{~J}\end{array}$ & $\begin{array}{r}17.94 \mathrm{U} \\
4.84 \mathrm{~J} \\
13.76 \mathrm{U} \\
7.17 \mathrm{~J} \\
53.31 \mathrm{U} \\
49.09 \mathrm{U} \\
36.15 \mathrm{U}\end{array}$ \\
\hline $\begin{array}{l}\text { COMP II } \\
\text { COMP II } \\
\text { COMP II } \\
\text { COMP II } \\
\text { COMP II }\end{array}$ & $\begin{array}{l}1 \\
2 \\
3 \\
4 \\
5\end{array}$ & $\begin{array}{l}D \\
A \\
C \\
D \\
C\end{array}$ & $\begin{array}{l}15.12 \\
17.08 \\
17.30 \\
15.82 \\
16.64\end{array}$ & $\begin{array}{l}22.35 \mathrm{~J} \\
11.71 \mathrm{~J} \\
10.75 \mathrm{~J} \\
42.16 \\
10.94 \mathrm{~J}\end{array}$ & $\begin{array}{l}25.99 \mathrm{U} \\
49.00 \mathrm{U} \\
26.71 \mathrm{U} \\
35.52 \mathrm{U} \\
27.04 \mathrm{U}\end{array}$ & $\begin{array}{r}6.15 \mathrm{~J} \\
26.46 \mathrm{U} \\
4.22 \mathrm{~J} \\
6.19 \mathrm{~J} \\
4.15 \mathrm{~J}\end{array}$ & $\begin{array}{l}6.15 \mathrm{~J} \\
7.38 \mathrm{~J} \\
6.65 \mathrm{~J} \\
7.77 \mathrm{~J} \\
6.25 \mathrm{~J}\end{array}$ & $\begin{array}{l}18.12 \\
15.93 \mathrm{~J} \\
19.60 \\
25.47 \\
16.77\end{array}$ & $\begin{array}{l}2.12 \mathrm{~J} \\
2.63 \mathrm{~J} \\
2.77 \mathrm{~J} \\
3.73 \mathrm{~J} \\
2.58 \mathrm{~d}\end{array}$ \\
\hline $\begin{array}{l}\operatorname{COMP} \text { III } \\
\text { CONP III } \\
\text { COMP II } \\
\text { COMP II I } \\
\text { CONP III }\end{array}$ & $\begin{array}{l}1 \\
2 \\
3 \\
4 \\
5\end{array}$ & $\begin{array}{l}C \\
D \\
A \\
D \\
C\end{array}$ & $\begin{array}{l}14.77 \\
16.64 \\
15.35 \\
16.35 \\
15.26\end{array}$ & $\begin{array}{r}19.43 \mathrm{~J} \\
9.92 \mathrm{~J} \\
19.15 \mathrm{~J} \\
8.56 \mathrm{~J} \\
14.88 \mathrm{~J}\end{array}$ & $\begin{array}{l}37.64 \mathrm{U} \\
31.37 \mathrm{U} \\
28.08 \mathrm{U} \\
29.36 \mathrm{U} \\
38.07 \mathrm{U}\end{array}$ & $\begin{array}{r}4.13 \mathrm{~J} \\
16.95 \mathrm{U} \\
15.18 \mathrm{U} \\
15.84 \mathrm{U} \\
3.47 \mathrm{~J}\end{array}$ & $\begin{array}{l}6.91 \mathrm{~J} \\
4.87 \mathrm{~J} \\
5.60 \mathrm{~J} \\
4.71 \mathrm{~J} \\
6.55 \mathrm{~J}\end{array}$ & $\begin{array}{l}17.60 \\
16.05 \\
15.18 \\
11.93 \mathrm{~J} \\
16.32 \mathrm{~J}\end{array}$ & $\begin{array}{r}1.49 \mathrm{~J} \\
13.88 \mathrm{U} \\
12.44 \mathrm{U} \\
12.97 \mathrm{U} \\
0.98 \mathrm{~J}\end{array}$ \\
\hline $\begin{array}{l}\text { TC-5 Upper Comp } \\
\text { TC-5 Upper Comp } \\
\text { TC-5 Upper Comp } \\
\text { TC-5 Upper Comp } \\
\text { TC-5 Upper Comp }\end{array}$ & $\begin{array}{l}1 \\
2 \\
3 \\
4 \\
5\end{array}$ & $\begin{array}{l}C \\
C \\
C \\
A \\
A\end{array}$ & $\begin{array}{l}15.40 \\
15.92 \\
16.93 \\
15.87 \\
16.58\end{array}$ & $\begin{array}{l}28.44 \mathrm{~J} \\
14.32 \mathrm{~J} \\
14.24 \mathrm{~J} \\
16.07 \mathrm{~J} \\
50.18 \mathrm{~J}\end{array}$ & $\begin{array}{r}51.75 \mathrm{U} \\
30.46 \mathrm{U} \\
41.64 \mathrm{U} \\
43.86 \mathrm{U} \\
143.85 \mathrm{U}\end{array}$ & $\begin{array}{r}5.32 \mathrm{~J} \\
16.46 \mathrm{U} \\
4.84 \mathrm{~J} \\
23.69 \mathrm{U} \\
77.68 \mathrm{U}\end{array}$ & $\begin{array}{l}11.56 \mathrm{~J} \\
11.18 \mathrm{~J} \\
13.11 \mathrm{~J} \\
11.15 \mathrm{~J} \\
84.14 \mathrm{U}\end{array}$ & $\begin{array}{l}52.86 \\
56.16 \\
61.84 \\
58.03 \\
54.10 \mathrm{~J}\end{array}$ & $\begin{array}{r}9.29 \mathrm{~J} \\
10.36 \mathrm{~J} \\
11.05 \mathrm{~J} \\
11.97 \mathrm{~J} \\
11.58 \mathrm{~J}\end{array}$ \\
\hline $\begin{array}{l}\text { COMP IV } \\
\text { COMP IV Replicate } 1 \\
\text { COMP IV Replicate } 2 \\
\text { COMP IV Replicate } 3 \\
\text { COMP IV } \\
\text { COMP IV } \\
\text { COMP IV }\end{array}$ & $\begin{array}{l}1 \\
2 \\
2 \\
2 \\
3 \\
4 \\
5\end{array}$ & $\begin{array}{l}\text { C } \\
C \\
C \\
C \\
A \\
C \\
A\end{array}$ & $\begin{array}{l}16.16 \\
16.46 \\
16.46 \\
16.46 \\
11.15 \\
16.04 \\
13.09\end{array}$ & $\begin{array}{r}14.17 \mathrm{~J} \\
39.55 \mathrm{~J} \\
46.42 \mathrm{~J} \\
50.61 \mathrm{~J} \\
36.05 \mathrm{~J} \\
9.98 \mathrm{~J} \\
26.97 \mathrm{~J}\end{array}$ & $\begin{array}{rl}29.70 & \mathrm{U} \\
126.12 \mathrm{U} \\
160.02 \mathrm{U} \\
112.52 \mathrm{U} \\
80.36 \mathrm{U} \\
35.60 \mathrm{U} \\
75.86 \mathrm{U}\end{array}$ & $\begin{array}{r}3.47 \mathrm{~J} \\
6.74 \mathrm{~J} \\
86.45 \mathrm{U} \\
6.68 \mathrm{~J} \\
43.41 \mathrm{U} \\
2.81 \mathrm{~J} \\
40.95 \mathrm{U}\end{array}$ & $\begin{array}{r}5.45 \mathrm{~J} \\
11.79 \mathrm{~J} \\
12.76 \mathrm{~J} \\
11.60 \mathrm{~J} \\
10.58 \mathrm{~J} \\
5.17 \mathrm{~J} \\
7.79 \mathrm{~J}\end{array}$ & $\begin{array}{l}16.34 \\
23.51 \mathrm{~J} \\
19.62 \mathrm{~J} \\
26.43 \mathrm{~J} \\
27.44 \mathrm{~J} \\
13.09 \mathrm{~J} \\
21.85 \mathrm{~J}\end{array}$ & $\begin{array}{r}1.30 \mathrm{~J} \\
55.83 \mathrm{U} \\
70.84 \mathrm{U} \\
49.82 \mathrm{U} \\
35.61 \mathrm{U} \\
15.77 \mathrm{U} \\
33.61 \mathrm{U}\end{array}$ \\
\hline $\begin{array}{l}\text { CONP V } \\
\text { COKP V } \\
\text { COMP V } \\
\text { COMP V } \\
\text { COMP V }\end{array}$ & $\begin{array}{l}1 \\
2 \\
3 \\
4 \\
5\end{array}$ & $\begin{array}{l}A \\
A \\
A \\
D \\
B\end{array}$ & $\begin{array}{l}15.27 \\
14.83 \\
17.13 \\
15.44 \\
17.14\end{array}$ & $\begin{array}{l}23.77 \mathrm{~J} \\
12.41 \mathrm{~J} \\
12.67 \mathrm{~J} \\
13.28 \mathrm{~J} \\
22.52\end{array}$ & $\begin{array}{l}33.66 \mathrm{U} \\
40.05 \mathrm{U} \\
24.28 \mathrm{U} \\
38.02 \mathrm{U} \\
21.47 \mathrm{U}\end{array}$ & $\begin{array}{r}18.21 \mathrm{U} \\
21.65 \mathrm{U} \\
13.13 \mathrm{U} \\
20.53 \mathrm{U} \\
4.03 \mathrm{~J}\end{array}$ & $\begin{array}{r}19.71 \mathrm{~J} \\
4.99 \mathrm{~J} \\
6.89 \mathrm{~J} \\
5.57 \mathrm{~J} \\
6.07 \mathrm{~J}\end{array}$ & $\begin{array}{l}19.71 \\
19.42 \\
17.22 \\
21.50 \\
22.35\end{array}$ & $\begin{array}{l}4.85 \mathrm{~J} \\
4.11 \mathrm{~J} \\
4.79 \mathrm{~J} \\
2.40 \mathrm{~J} \\
5.48 \mathrm{~J}\end{array}$ \\
\hline
\end{tabular}


IABLE K.2. (contd)

\begin{tabular}{|c|c|c|c|c|c|c|c|c|c|}
\hline \multirow[b]{2}{*}{$\begin{array}{l}\text { Sediment } \\
\text { Ireatment }\end{array}$} & \multirow[b]{2}{*}{ Replicate } & \multirow[b]{2}{*}{$\begin{array}{l}\text { Analyt1cal } \\
\text { Batch } \\
\end{array}$} & \multirow[b]{2}{*}{$\begin{array}{l}\text { Percent } \\
\text { Dry Velght }\end{array}$} & \multicolumn{6}{|c|}{ N. caecoides LPAHs $\left(\mu_{\mathrm{g}} / \mathrm{kg}\right.$ dry weight) } \\
\hline & & & & $\begin{array}{l}\text { Naphtha- } \\
\text { lene }\end{array}$ & $\begin{array}{l}\text { Acenaph- } \\
\text { thylene }\end{array}$ & $\begin{array}{l}\text { Acenaph- } \\
\text { thene }\end{array}$ & Fluorene & $\begin{array}{l}\text { Phenan- } \\
\text { threne }\end{array}$ & $\begin{array}{c}\text { Anthra- } \\
\text { cene }\end{array}$ \\
\hline COMP VI & 1 & c & 15.08 & $14.06 \mathrm{~J}$ & $1.79 \mathrm{~J}$ & $3.12 \mathrm{~J}$ & $6.37 \mathrm{~J}$ & $17.64 \mathrm{~J}$ & $6.17 \mathrm{~J}$ \\
\hline COKP VI & 2 & A & 15.83 & $11.43 \mathrm{~J}$ & $30.70 \mathrm{U}$ & $16.55 \mathrm{U}$ & $5.94 \mathrm{~J}$ & 17.44 & $3.60 \mathrm{~J}$ \\
\hline COMP VI & 3 & B & 16.25 & $34.28 \mathrm{~J}$ & $34.71 \mathrm{U}$ & $18.77 \mathrm{~V}$ & $7.63 \mathrm{~J}$ & 23.82 & $3.69 \mathrm{~J}$ \\
\hline COMP VI & 4 & A & 15.89 & $19.76 \mathrm{~J}$ & $35.81 \mathrm{U}$ & $19.32 \mathrm{U}$ & $20.96 U$ & 19.70 & $15.86 \mathrm{U}$ \\
\hline COMP VI & 5 & D & 16.24 & $59.73 \mathrm{~J}$ & $107.70 \mathrm{U}$ & $58.19 \mathrm{U}$ & $9.73 \mathrm{~J}$ & $25.68 \mathrm{~J}$ & $4.37 \mathrm{~J}$ \\
\hline$R-A C$ & 1 & B & 15.84 & 49.37 & $47.92 U$ & $12.18 \mathrm{~J}$ & $24.37 \mathrm{~J}$ & 238.45 & 45.77 \\
\hline$R-A C$ & 2 & c & 16.14 & $41.45 \mathrm{~J}$ & $105.27 \mathrm{U}$ & $20.38 \mathrm{~J}$ & $33.09 \mathrm{~J}$ & 291.39 & 49,38 \\
\hline$R-A C$ & 3 & c & 16.16 & $17.14 \mathrm{~J}$ & $2.78 \mathrm{~J}$ & $14.17 \mathrm{~J}$ & 26.67 & 236.70 & 58.97 \\
\hline$R-A C$ & 4 & A & 13.29 & $32.88 \mathrm{~J}$ & $44.09 \mathrm{U}$ & 42.59 & 59.67 & 454.78 & 95.71 \\
\hline$R-A C$ & 5 & D & 16.75 & $8.48 \mathrm{~J}$ & $27.28 \mathrm{U}$ & 32.06 & 39.88 & 377.01 & 76.54 \\
\hline R-AM & 1 & $\theta$ & 17.29 & 33.02 & $29.15 \mathrm{~V}$ & $15.73 \mathrm{U}$ & $9.14 \mathrm{~J}$ & 60.27 & $8.91 \mathrm{~J}$ \\
\hline R-AM & 2 & c & 16.62 & $12.39 \mathrm{~J}$ & $1.81 \mathrm{~J}$ & $4.45 \mathrm{~J}$ & $8.24 \mathrm{~J}$ & 41.88 & $8.12 \mathrm{~J}$ \\
\hline$R-A M$ & 3 & $B$ & 16.26 & $21.53 \mathrm{~J}$ & $24.17 \mathrm{U}$ & $5.66 \mathrm{~J}$ & $7.81 \mathrm{~J}$ & 50.37 & $8.92 \mathrm{~J}$ \\
\hline R-AM Replicate 1 & 4 & 8 & 16.61 & 190.01 & $115.47 \mathrm{~V}$ & $62.37 \mathrm{U}$ & $9.39 \mathrm{~J}$ & 68.45 & $15.71 \mathrm{~J}$ \\
\hline R-AM Replicate 2 & 4 & B & 16.61 & 190.91 & $176.52 \mathrm{U}$ & $95.36 \mathrm{U}$ & $103.19 \mathrm{U}$ & 83.14 & $19.39 \mathrm{~J}$ \\
\hline R-AM Replicate 3 & 4 & B & 16.61 & $53.16 \mathrm{~J}$ & $63.21 \mathrm{~V}$ & $34.14 \mathrm{U}$ & $8.97 \mathrm{~J}$ & 59.78 & $8.55 \mathrm{~J}$ \\
\hline$R-A M$ & 5 & $\theta$ & 11.30 & $28.76 \mathrm{~J}$ & $38.05 \mathrm{U}$ & $8.50 \mathrm{~J}$ & $9.82 \mathrm{~J}$ & 67.52 & $14.87 \mathrm{~J}$ \\
\hline$R-B F$ & 1 & 0 & 16.72 & $16.21 \mathrm{~J}$ & $45.04 \mathrm{U}$ & $24.34 \mathrm{U}$ & $5.68 \mathrm{~J}$ & $16.87 \mathrm{~J}$ & $19.92 \mathrm{U}$ \\
\hline$R-B F$ & 2 & B & 13.79 & 75.63 & $63.23 \mathrm{~V}$ & $34.16 \mathrm{U}$ & $11.39 \mathrm{~J}$ & $25.45 \mathrm{~J}$ & $4.21 \mathrm{~J}$ \\
\hline$R-B F$ & 3 & $B$ & 15.57 & 33.78 & $31.92 \mathrm{~V}$ & $17.21 \mathrm{u}$ & $8.48 \mathrm{~J}$ & 25.43 & $6.04 \mathrm{~J}$ \\
\hline$R-B F$ & 4 & A & 15.24 & $20.14 \mathrm{~J}$ & $39.76 \mathrm{U}$ & $21.52 \mathrm{U}$ & $6.50 \mathrm{~J}$ & 20.80 & $2.95 \mathrm{~J}$ \\
\hline$R-B F$ & 5 & A & 16.05 & $11.96 \mathrm{~J}$ & $38.38 \mathrm{U}$ & $20.75 \mathrm{U}$ & $7.41 \mathrm{~J}$ & 36.76 & $4.36 \mathrm{~J}$ \\
\hline$R-0 S$ & 1 & B & 15.79 & $24.64 \mathrm{~J}$ & $28.50 \mathrm{U}$ & $15.39 \mathrm{U}$ & $4.94 \mathrm{~J}$ & 15.20 & $1.71 \mathrm{~J}$ \\
\hline R-OS Replicate 1 & 2 & D & 16.53 & $28.25 \mathrm{~J}$ & $96.01 \mathrm{U}$ & $51.85 \mathrm{U}$ & $7.08 \mathrm{~J}$ & $17.18 \mathrm{~J}$ & $42.47 \mathrm{U}$ \\
\hline R-OS Replicate? & 2 & D & 16.53 & $28.86 \mathrm{~J}$ & $77.86 \mathrm{U}$ & $42.04 \mathrm{U}$ & $7.99 \mathrm{~J}$ & $13.37 \mathrm{~J}$ & $2.24 \mathrm{~J}$ \\
\hline R-OS Replicate 3 & 2 & 0 & 16.53 & $29.52 \mathrm{~J}$ & $94.13 \mathrm{U}$ & $50.82 u$ & $8.35 \mathrm{~J}$ & $13.85 \mathrm{~J}$ & $41.68 \mathrm{U}$ \\
\hline$R-0 S$ & 3 & $B$ & 15.02 & 39.01 & $31.49 \mathrm{U}$ & $7.39 \mathrm{~J}$ & $5.59 \mathrm{~J}$ & 22.17 & $2.86 \mathrm{~J}$ \\
\hline$R-O S$ & 4 & D & 17.85 & $11.54 \mathrm{~d}$ & $29.08 \mathrm{U}$ & $15.69 \mathrm{U}$ & $5.04 \mathrm{~J}$ & $11.32 \mathrm{~J}$ & $12.89 \mathrm{U}$ \\
\hline$R-O S$ & 5 & c & 17.02 & $13.10 \mathrm{~J}$ & 29.85 u & $3.06 \mathrm{~J}$ & $5.93 \mathrm{~J}$ & 15.69 & $1.41 \mathrm{~J}$ \\
\hline R-PF & 1 & C & 13.90 & 50.07 & $37.34 U$ & $11.87 \mathrm{~J}$ & $11.01 \mathrm{~J}$ & 45.40 & $2.66 \mathrm{~J}$ \\
\hline$R-P F$ & 2 & C & 13.46 & $16.20 \mathrm{~J}$ & $43.68 \mathrm{~V}$ & $4.38 \mathrm{~J}$ & $8.62 \mathrm{~J}$ & 22.88 & $1.63 \mathrm{~J}$ \\
\hline$R-P F$ & 3 & 0 & 16.88 & $9.30 \mathrm{~J}$ & $28.32 \mathrm{U}$ & $4.09 \mathrm{~J}$ & $5.15 \mathrm{~J}$ & 14.40 & $12.56 \mathrm{U}$ \\
\hline$R-P F$ & 4 & $D$ & 16.74 & $9.32 \mathrm{~J}$ & $24.37 \mathrm{U}$ & $4.54 \mathrm{~J}$ & $5.26 \mathrm{~J}$ & 14.22 & $10.75 \mathrm{~V}$ \\
\hline $\mathrm{R}-\mathrm{PF}$ & 5 & A & 16.47 & $14.39 \mathrm{~J}$ & $36.31 \mathrm{U}$ & $19.61 \mathrm{U}$ & $6.19 \mathrm{~J}$ & 18.46 & $1.28 \mathrm{~J}$ \\
\hline
\end{tabular}




\section{IABLE K.2. (contd)}

Sediment
Ireatment

$\mathrm{C}-\mathrm{SB}$
$\mathrm{C}-\mathrm{SB}$

C-SB

$\mathrm{C}-\mathrm{SB}$
$\mathrm{C}-\mathrm{SB}$

C-ME

C-NE

$C-N E$
$C-N E$

C-NE

C-NE

MSL Background

MSL Background

MSL Background

MSL Background

ir

Replicate
1
2
3
4
5
1
2
3
4
5

Analytical

Batch

C
D
$B$
A
D

Percent

Dry Weight

14.29
16.03
15.65
16.06
16.46

15.94
18.40
16.01
15.81
15.28
19.82
19.82
19.82
19.82
19.82

Naphtha-
lene

$14.70 \mathrm{~J}$

$12.16 \mathrm{~J}$
44.35

$12.52 \mathrm{~J}$

$10.33 \mathrm{~J}$

23.40

$22.77 \mathrm{~J}$

28.61
$22.07 \mathrm{~J}$

$25.92 \mathrm{~J}$

$13.02 \mathrm{~J}$
17.71
17.86
15.19
13.98

N.coe

Acenaph-

thylene

$35.13 \mathrm{U}$

$32.69 \mathrm{U}$

$37.12 \mathrm{U}$

$25.03 \mathrm{U}$

$27.04 \mathrm{U}$

$22.58 \mathrm{U}$

$22.99 \mathrm{U}$

$26.05 \mathrm{U}$

$29.48 \mathrm{U}$

$33.57 \mathrm{U}$

$13.32 \mathrm{U}$

$13.37 \mathrm{~V}$

$13.37 \mathrm{U}$

$13.47 \mathrm{U}$

$13.37 \mathrm{U}$
Acenaph-

thene

$4.20 \mathrm{~J}$

$5.18 \mathrm{~J}$
$20.06 \mathrm{~J}$

$20.06 \mathrm{U}$

$3.04 \mathrm{~J}$

$4.39 \mathrm{~J}$

$4.57 \mathrm{~J}$
5.87

$15.94 \mathrm{U}$

$18.13 \mathrm{U}$

$2.77 \mathrm{~J}$

$2.72 \mathrm{~J}$

$\begin{array}{ll}2.47 & \mathrm{~J} \\ 2.27 \mathrm{~J}\end{array}$

$2.47 \mathrm{~J}$
Phenan-

Elvorene threme

$6.79 \mathrm{~J} \quad 17.2$

$14.35, \quad 1.54$

$\begin{array}{lll}5.93 \mathrm{~J} & 14.35 \mathrm{~J} & 14.47\end{array}$

$6.84 \mathrm{~J} \quad 20.89 \quad 4.22 \mathrm{~J}$

$14.63 \mathrm{U} \quad 15.44 \quad 11.08 \mathrm{U}$

$\begin{array}{lll}4.56 \mathrm{~J} & 12.94 & 1.88 \mathrm{~J}\end{array}$

$6.02 \mathrm{~J} \quad 23.15 \quad 9.97 \mathrm{U}$

$6.85 \mathrm{~J} \quad 23.86 \quad 10.16 \mathrm{~J}$

$7.06 \mathrm{~J} \quad 24.48 \quad 1.94 \mathrm{~J}$

$6.20 \mathrm{~J} \quad 24.86 \quad 13.03 \mathrm{U}$

$7.53 \mathrm{~J} \quad 26.11 \quad 14.86 \mathrm{U}$

$7.16 \mathrm{~J} \quad 16.95$

$6.46 \mathrm{~J} \quad 18.37 \mathrm{~J} \quad 1.82 \mathrm{~J}$

$6.61 \mathrm{~J} \quad 18.57 \quad 3.43 \mathrm{~J}$

$6.56 \mathrm{~J} \quad 16.85 \quad 1.92 \mathrm{~J}$

$\begin{array}{lll}7.06 \mathrm{~J} & 19.27 & 1.92 \mathrm{~J}\end{array}$

(a) J Analyte detected below method detection $1 \mathrm{imit}$ ( $\mathrm{MOL}$ ), but above instrument detection limit (IOL).

(b) U The analyte was not present above the level of the associated value.

(c) Percent dry weight was averaged from the other four replicates of COMP 1 . 
IABLE K.3. High Molecular Weight Polynuclear Aromatic Hydrocarbons (HPAHs), Dry Weight, in Tissue of $N$. caecoides, Richmond Harbor Program

\begin{tabular}{|c|c|c|c|c|c|c|c|c|c|c|c|c|c|}
\hline $\begin{array}{l}\text { Sediment } \\
\text { Ireatment }\end{array}$ & Replicate & $\begin{array}{c}\text { Analytical } \\
\text { oatch } \\
\end{array}$ & $\begin{array}{l}\text { Percent } \\
\text { Ory Weight }\end{array}$ & $\begin{array}{l}\text { Fiuoran- } \\
\text { thene }\end{array}$ & Pyrene & $\begin{array}{l}\text { 8enzo(a) } \\
\text { anthra* } \\
\text { cene } \\
\end{array}$ & Chrysene & $\begin{array}{l}\text { Benzo(b) } \\
\text { Fluoran- } \\
\text { thene } \\
\end{array}$ & $\begin{array}{c}\text { Benzo(k) } \\
\text { Fluoran- } \\
\text { thene } \\
\end{array}$ & $\begin{array}{l}\text { Benzo(a) } \\
\text { Dyrene }\end{array}$ & \multicolumn{2}{|c|}{$\begin{array}{l}\text { Indeno Dibenzo } \\
(1,2,3-\text { (a,h) } \\
-c, d) \text { Anthra- } \\
\text { Dyrene cene } \\
\end{array}$} & $\begin{array}{l}\text { Benzo } \\
(g, h, i) \\
\text { Perylene }\end{array}$ \\
\hline $\begin{array}{l}\text { COMP I } \\
\text { COMP I } \\
\text { COMP I } \\
\text { COMP I } \\
\text { COMP I Replicate } 1 \\
\text { COMP I Replicate } 2 \\
\text { COMP I Replicate } 3\end{array}$ & $\begin{array}{l}1 \\
2 \\
3 \\
4 \\
5 \\
5 \\
5\end{array}$ & $\begin{array}{l}0 \\
D \\
A \\
B \\
A \\
A \\
A\end{array}$ & $\begin{array}{l}16.00 \\
15.28 \\
16.50(c) \\
17.16 \\
17.54 \\
17.54 \\
17.54\end{array}$ & $\begin{array}{l}11.81 \\
26.96 \\
18.42 \\
21.21 \mathrm{~J} \\
19.95 \mathrm{~J} \\
21.95 \mathrm{~J} \\
23.03 \mathrm{~J}\end{array}$ & $\begin{array}{l}57.00 \\
76.37 \\
47.45 \\
56.47 \\
46.07 \\
57.81 \\
65.28\end{array}$ & $\begin{array}{l}29.94 \mathrm{U}^{(\mathrm{a})} \\
3.27 \mathrm{~J} \\
22.91 \mathrm{~J} \\
\mathrm{~J} 81.18 \mathrm{U} \\
\mathrm{J} 89.05 \mathrm{U} \\
\mathrm{J} 81.93 \mathrm{U} \\
60.38 \mathrm{U}\end{array}$ & $\begin{array}{l}11.44 \mathrm{~J}(\mathrm{~b}) \\
18.06 \\
12.85 \\
12.47 \mathrm{~J} \\
10.95 \mathrm{~J} \\
11.23 \mathrm{~J} \\
12.66 \mathrm{~J}\end{array}$ & $\begin{array}{r}30.56 \mathrm{U} \\
4.25 \mathrm{~J} \\
23.39 \mathrm{~J} \\
82.87 \mathrm{U} \\
90.88 \mathrm{U} \\
83.64 \mathrm{U} \\
61.63 \mathrm{U}\end{array}$ & $\begin{array}{rl}25.56 & \mathrm{U} \\
3.14 \mathrm{~J} \\
19.64 \mathrm{~J} \\
69.41 \mathrm{U} \\
76.11 \mathrm{U} \\
70.07 \mathrm{U} \\
51.60 \mathrm{U}\end{array}$ & $\begin{array}{r}26.63 \mathrm{U} \\
2.75 \mathrm{~J} \\
20.42 \mathrm{~J} \\
72.26 \mathrm{U} \\
79.30 \mathrm{U} \\
72.92 \mathrm{U} \\
53.76 \mathrm{U}\end{array}$ & $\begin{array}{l}31.94 U \\
21.47 U \\
24.48 U \\
86.66 U \\
95.04 U \\
87.46 U \\
64.42 \mathrm{U}\end{array}$ & 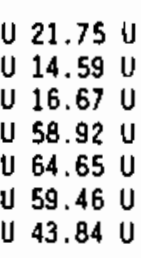 & 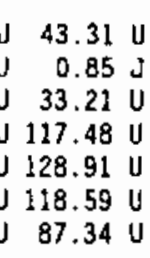 \\
\hline $\begin{array}{l}\text { COMP II } \\
\text { COMP II } \\
\text { COMP II } \\
\text { COMP II } \\
\text { COMP II }\end{array}$ & $\begin{array}{l}1 \\
2 \\
3 \\
4 \\
5\end{array}$ & $\begin{array}{l}D \\
A \\
C \\
D \\
C\end{array}$ & $\begin{array}{l}15.12 \\
17.08 \\
17.30 \\
15.82 \\
16.64\end{array}$ & $\begin{array}{l}23.68 \\
16.69 \mathrm{~J} \\
19.48 \\
23.45 \\
23.56\end{array}$ & $\begin{array}{l}86.18 \\
45.90 \\
54.86 \\
80.09 \\
70.37\end{array}$ & $\begin{array}{r}1.32 \mathrm{~J} \\
0.94 \mathrm{~J} \\
1.27 \mathrm{~J} \\
26.30 \mathrm{~J} \\
1.02 \mathrm{~J}\end{array}$ & $\begin{array}{l}16.87 \\
10.71 \mathrm{~J} \\
13.64 \mathrm{~J} \\
17.38 \mathrm{~J} \\
14.48\end{array}$ & $\begin{array}{r}1.46 \mathrm{~J} \\
37.00 \mathrm{U} \\
1.04 \mathrm{~J} \\
1.90 \mathrm{~J} \\
1.86 \mathrm{~J}\end{array}$ & $\begin{array}{r}0.93 \mathrm{~J} \\
30.97 \mathrm{~J} \\
0.98 \mathrm{~J} \\
1.07 \mathrm{~J} \\
0.84 \mathrm{~J}\end{array}$ & $\begin{array}{r}17.13 \mathrm{U} \\
32.26 \mathrm{U} \\
0.64 \mathrm{~J} \\
23.39 \mathrm{U} \\
0.66 \mathrm{~J}\end{array}$ & $\begin{array}{l}20.50 \mathrm{U} \\
38.70 \mathrm{U} \\
21.10 \mathrm{U} \\
28.07 \mathrm{U} \\
21.33 \mathrm{U}\end{array}$ & $\begin{array}{llll}U & 13.96 & U \\
U & 26.29 & U \\
U & 14.34 & U \\
U & 19.09 & U \\
U & 14.48 & U\end{array}$ & $\begin{array}{r}27.84 \\
52.46 \\
28.61 \\
38.05 \\
2.52 \\
J\end{array}$ \\
\hline $\begin{array}{l}\text { СОMP III } \\
\text { СОMP II } \\
\text { СОMP III } \\
\text { СОMP II } \\
\text { СОMP III }\end{array}$ & $\begin{array}{l}1 \\
2 \\
3 \\
4 \\
5\end{array}$ & $\begin{array}{l}\text { C } \\
0 \\
A \\
D \\
C\end{array}$ & $\begin{array}{l}14.77 \\
16.64 \\
15.35 \\
16.35 \\
15.26\end{array}$ & $\begin{array}{r}13.20 \mathrm{~J} \\
11.66 \mathrm{~J} \\
11.86 \mathrm{~J} \\
9.11 \mathrm{~J} \\
14.29 \mathrm{~J}\end{array}$ & $\begin{array}{l}20.51 \\
19.83 \\
19.02 \\
17.43 \\
21.43\end{array}$ & $\begin{array}{r}0.74 \mathrm{~J} \\
23.20 \mathrm{U} \\
0.52 \mathrm{~J} \\
21.71 \mathrm{U} \\
0.79 \mathrm{~J}\end{array}$ & $\begin{array}{l}6.30 \mathrm{~J} \\
6.13 \mathrm{~J} \\
5.28 \mathrm{~J} \\
5.14 \mathrm{~J} \\
6.55 \mathrm{~J}\end{array}$ & $\begin{array}{r}1.08 \mathrm{~J} \\
23.68 \mathrm{U} \\
21.17 \mathrm{U} \\
22.14 \mathrm{U} \\
0.92 \mathrm{~J}\end{array}$ & $\begin{array}{r}0.54 \mathrm{~J} \\
19.83 \mathrm{U} \\
17.72 \mathrm{U} \\
18.53 \mathrm{U} \\
0.79 \mathrm{~J}\end{array}$ & $\begin{array}{l}24.78 \mathrm{U} \\
20.67 \mathrm{U} \\
18.44 \mathrm{U} \\
19.33 \mathrm{U} \\
25.03 \mathrm{U}\end{array}$ & $\begin{array}{l}29.65 U \\
24.76 U \\
22.15 U \\
23.12 U \\
30.01 U\end{array}$ & $\begin{array}{llll}U & 20.18 & U \\
U & 16.83 & U \\
U & 15.05 & U \\
U & 15.72 & U \\
U & 20.45 & U\end{array}$ & $\begin{array}{lll} & 40.28 \\
33.53 \\
30.03 \\
31.38 \\
U \\
40.76\end{array}$ \\
\hline $\begin{array}{l}\text { TC-5 Upper Comp } \\
\text { TC-5 Upper Comp } \\
\text { TC-5 Upper Comp } \\
\text { TC-5 Upper Comp } \\
\text { TC-5 Upper Comp }\end{array}$ & $\begin{array}{l}1 \\
2 \\
3 \\
4 \\
5\end{array}$ & $\begin{array}{l}\text { C } \\
\text { C } \\
\text { C } \\
\text { A } \\
\text { A }\end{array}$ & $\begin{array}{l}15.40 \\
15.92 \\
16.93 \\
15.87 \\
16.58\end{array}$ & $\begin{array}{l}219.61 \\
224.18 \\
258.12 \\
186.26 \\
162.67\end{array}$ & $\begin{array}{l}505.97 \\
529.59 \\
575.19 \\
452.30 \\
395.24\end{array}$ & $\begin{array}{l}20.00 \mathrm{~J} \\
16.71 \mathrm{~J} \\
24.04 \mathrm{~J} \\
17.58 \mathrm{~J} \\
18.46 \mathrm{~J}\end{array}$ & $\begin{array}{r}90.26 \\
86.75 \\
102.54 \\
81.98 \\
76.66\end{array}$ & $\begin{array}{l}17.27 \mathrm{~J} \\
15.26 \mathrm{~J} \\
25.22 \mathrm{~J} \\
15.94 \mathrm{~J} \\
13.15 \mathrm{~J}\end{array}$ & $\begin{array}{l}7.99 \mathrm{~J} \\
7.47 \mathrm{~J} \\
9.21 \mathrm{~J} \\
5.73 \mathrm{~J} \\
6.45 \mathrm{~J}\end{array}$ & $\begin{array}{r}10.52 \mathrm{~J} \\
7.22 \mathrm{~J} \\
13.17 \mathrm{~J} \\
8.82 \mathrm{~J} \\
8.38 \mathrm{~J}\end{array}$ & $\begin{array}{r}2.73 \mathrm{~J} \\
24.06 \mathrm{U} \\
4.13 \mathrm{~J} \\
34.59 \mathrm{U} \\
113.51 \mathrm{U}\end{array}$ & $\begin{array}{lrl}\mathrm{J} & 27.79 & \mathrm{U} \\
\mathrm{U} & 16.33 & \mathrm{U} \\
\mathrm{J} & 0.95 & \mathrm{~J} \\
\mathrm{U} & 23.50 \mathrm{U} \\
\mathrm{U} & 77.20 \mathrm{U}\end{array}$ & $\begin{array}{r}11.75 \mathrm{~J} \\
\mathrm{~J} \\
7.35 \mathrm{~J} \\
\mathrm{~J} \\
15.59 \mathrm{~J} \\
\mathrm{U} \\
24.70 \mathrm{~J} \\
\mathrm{~J} \\
11.10 \mathrm{~J}\end{array}$ \\
\hline $\begin{array}{l}\text { COMP IV } \\
\text { COMP IV Replicate } 1 \\
\text { COMP IV Replicate } \\
\text { COMP IV Replicate } 3 \\
\text { COMP IV } \\
\text { COMP IV } \\
\text { COMP IV }\end{array}$ & $\begin{array}{ll} & 1 \\
1 & 2 \\
2 & 2 \\
3 & 2 \\
& 3 \\
& 3 \\
& 4 \\
& 5\end{array}$ & $\begin{array}{l}C \\
C \\
C \\
C \\
A \\
C \\
A\end{array}$ & $\begin{array}{l}16.16 \\
16.46 \\
16.46 \\
16.46 \\
11.15 \\
16.04 \\
13.09\end{array}$ & $\begin{array}{r}9.72 \mathrm{~J} \\
13.55 \mathrm{~J} \\
12.58 \mathrm{~J} \\
14.34 \mathrm{~J} \\
17.94 \mathrm{~J} \\
8.98 \mathrm{~J} \\
13.06 \mathrm{~J}\end{array}$ & $\begin{array}{l}11.70 \\
16.83 \\
14.34 \\
16.77 \\
20.18 \\
10.60 \\
18.79\end{array}$ & $\begin{array}{lll}\mathrm{J} & 0.80 & \mathrm{~J} \\
\mathrm{~J} & 93.26 & \mathrm{U} \\
\mathrm{J} 118.35 & \mathrm{U} \\
\mathrm{J} & 83.23 & \mathrm{U} \\
\mathrm{J} & 59.46 & \mathrm{U} \\
\mathrm{J} & 26.31 & \mathrm{U} \\
\mathrm{J} & 56.07 & \mathrm{U}\end{array}$ & $\begin{array}{l}3.77 \mathrm{~J} \\
5.41 \mathrm{~J} \\
5.16 \mathrm{~J} \\
5.35 \mathrm{~J} \\
5.92 \mathrm{~J} \\
3.18 \mathrm{~J} \\
5.58 \mathrm{~J}\end{array}$ & $\begin{array}{r}0.80 \mathrm{~J} \\
95.14 \mathrm{U} \\
120.78 \mathrm{U} \\
84.93 \mathrm{U} \\
60.63 \mathrm{U} \\
0.62 \mathrm{~J} \\
57.22 \mathrm{U}\end{array}$ & $\begin{array}{r}0.62 \mathrm{~J} \\
79.71 \mathrm{U} \\
101.15 \mathrm{U} \\
71.14 \mathrm{U} \\
50.76 \mathrm{U} \\
22.51 \mathrm{U} \\
47.98 \mathrm{U}\end{array}$ & $\begin{array}{r}19.55 \mathrm{U} \\
82.99 \mathrm{U} \\
105.35 \mathrm{U} \\
74.06 \mathrm{U} \\
52.91 \mathrm{U} \\
23.44 \mathrm{U} \\
49.96 \mathrm{U}\end{array}$ & $\begin{array}{r}23.45 \\
99.51 \\
126.25 \\
88.82 \\
63.41 \\
28.05 \mathrm{U} \\
59.89\end{array}$ & $\begin{array}{lll}U & 15.90 & \mathrm{~J} \\
U & 67.68 \mathrm{U} \\
\mathrm{U} & 85.84 \mathrm{U} \\
U & 60.39 \mathrm{U} \\
\mathrm{U} & 43.14 \mathrm{U} \\
\mathrm{U} & 19.08 \mathrm{U} \\
\mathrm{U} & 40.72 \mathrm{U}\end{array}$ & $\begin{array}{lrl}J & 0.50 & \mathrm{~J} \\
\mathrm{U} & 18.65 & \\
U & 171.20 \\
U & 120.41 \\
\begin{array}{l}\mathrm{U} \\
\mathrm{U}\end{array} & 86.01 \\
U & 38.09 & \mathrm{U} \\
\mathrm{U} & 81.21 & \mathrm{U}\end{array}$ \\
\hline $\begin{array}{l}\text { COMP V } \\
\text { COMP V } \\
\text { COMP V } \\
\text { COMP V } \\
\text { COMP V }\end{array}$ & $\begin{array}{l}1 \\
2 \\
3 \\
4 \\
5\end{array}$ & $\begin{array}{l}A \\
A \\
A \\
0 \\
B\end{array}$ & $\begin{array}{l}15.27 \\
14.83 \\
17.13 \\
15.44 \\
17.14\end{array}$ & $\begin{array}{l}27.37 \\
25.42 \\
24.69 \\
32.58 \\
32.15\end{array}$ & $\begin{array}{l}173.87 \\
177.21 \\
169.35 \\
209.13 \\
210.79\end{array}$ & $\begin{array}{rl}24.89 & \mathrm{U} \\
2.02 \mathrm{~J} \\
1.98 \mathrm{~J} \\
28.11 \mathrm{U} \\
15.87 \mathrm{U}\end{array}$ & $\begin{array}{l}23.58 \\
24.48 \\
22.36 \\
30.63 \\
27.07\end{array}$ & $\begin{array}{l}4.45 \mathrm{~J} \\
3.98 \mathrm{~J} \\
2.45 \mathrm{~J} \\
4.21 \mathrm{~J} \\
2.57 \mathrm{~J}\end{array}$ & $\begin{array}{l}2.82 \mathrm{~J} \\
2.29 \mathrm{~J} \\
2.10 \mathrm{~J} \\
4.60 \mathrm{~J} \\
2.92 \mathrm{~J}\end{array}$ & $\begin{array}{r}22.13 \mathrm{U} \\
26.37 \mathrm{U} \\
0.82 \mathrm{~J} \\
3.11 \mathrm{~J} \\
14.12 \mathrm{U}\end{array}$ & $\begin{array}{r}26.59 \\
31.63 \\
19.15 \\
2.53 \\
16.92\end{array}$ & $\begin{array}{llll}U & 18.07 & U \\
U & 21.51 & U \\
U & 13.02 & U \\
J & 20.40 & U \\
U & 11.55 & U\end{array}$ & $\begin{array}{lr}U & 36.02 \\
U & 2.76 \\
U & 25.98 \\
U & 40.74 \\
U & 22.99\end{array}$ \\
\hline
\end{tabular}


IABLE K.3. (contd)

$N$ caecoides HPAMs ( $\mathrm{kg} / \mathrm{kg}$ dry weight)

\begin{tabular}{|c|c|c|c|c|c|c|c|c|c|c|c|c|c|}
\hline \multirow[b]{2}{*}{$\begin{array}{l}\text { Sediment } \\
\text { Ireatment }\end{array}$} & \multirow[b]{2}{*}{ Replicate } & \multirow[b]{2}{*}{$\begin{array}{l}\text { Analytical } \\
\text { Batch }\end{array}$} & \multirow[b]{2}{*}{$\begin{array}{c}\text { Percent } \\
\text { Dry Weight }\end{array}$} & \multirow[b]{2}{*}{$\begin{array}{l}\text { Fluoran- } \\
\text { thene } \\
\end{array}$} & \multicolumn{6}{|c|}{ N. caecoides HPAMs $(\mu \mathrm{k} / \mathrm{kg}$ dry weight) } & \multirow{2}{*}{\multicolumn{2}{|c|}{$\begin{array}{l}\text { Indeno 0ibenzo } \\
(1,2,3-\text { (a,h) } \\
-c, d) \text { Anthra- } \\
\text { pyrene cene }\end{array}$}} & \multirow[b]{2}{*}{$\begin{array}{l}\text { Benzo } \\
(g, h, 1) \\
\text { Perylene }\end{array}$} \\
\hline & & & & & Pyrene & $\begin{array}{l}\text { Benzo(a) } \\
\text { anthra- } \\
\text { cene } \\
\end{array}$ & Chrysene & $\begin{array}{l}\text { Benzo(b) } \\
\text { Fluoran- } \\
\text { thene. }\end{array}$ & $\begin{array}{c}\text { Denzo }(k) \\
\text { Fluoran- } \\
\text { thene }\end{array}$ & $\begin{array}{l}\text { ) } \\
\text { - 8enzo(a) } \\
\text { - pyrene } \\
\end{array}$ & & & \\
\hline $\begin{array}{l}\text { COMP VI } \\
\text { COMP VI } \\
\text { COMP VI } \\
\text { COMP VI } \\
\text { COMP VI }\end{array}$ & $\begin{array}{l}1 \\
2 \\
3 \\
4 \\
5\end{array}$ & $\begin{array}{l}C \\
A \\
B \\
A \\
D\end{array}$ & $\begin{array}{l}15.08 \\
15.83 \\
16.25 \\
15.89 \\
16.24\end{array}$ & $\begin{array}{l}22.21 \\
26.85 \\
28.43 \\
26.31 \\
38.73 \mathrm{~J}\end{array}$ & $\begin{array}{l}149.54 \\
193.24 \\
192.74 \\
159.41 \\
263.12\end{array}$ & $\begin{array}{r}1.66 \mathrm{~J} \\
2.34 \mathrm{~J} \\
25.66 \mathrm{~V} \\
26.49 \mathrm{U} \\
79.62 \mathrm{U}\end{array}$ & $\begin{array}{l}23.01 \\
25.08 \\
23.32 \\
20.64 \\
35.28 \mathrm{~J}\end{array}$ & $\begin{array}{r}2.85 \mathrm{~J} \\
3.47 \mathrm{~J} \\
4.37 \mathrm{~J} \\
5.35 \mathrm{~J} \\
81.28 \mathrm{U}\end{array}$ & $\begin{array}{r}2.19 \mathrm{~J} \\
2.40 \mathrm{~J} \\
1.66 \mathrm{~J} \\
3.52 \mathrm{~J} \\
68.04 \mathrm{U}\end{array}$ & $\begin{array}{r}1.19 \mathrm{~J} \\
1.58 \mathrm{~J} \\
22.83 \mathrm{U} \\
23.60 \mathrm{U} \\
70.87 \mathrm{U}\end{array}$ & $\begin{array}{l}31.56 \\
24.19 \\
27.38 \\
28.26 \\
84.98\end{array}$ & $\begin{array}{ll}U & 21.49 \\
U & 16.49 \\
U & 18.65 \\
U & 19.19 \\
U & 57.82\end{array}$ & $\begin{array}{lrr}U & 42.84 & U \\
U & 1.96 & J \\
U & 37.11 & \\
U & 38.33 & U \\
U & 115.27 & \end{array}$ \\
\hline $\begin{array}{l}R-A C \\
R-A C \\
R-A C \\
R-A C \\
R-A C\end{array}$ & $\begin{array}{l}1 \\
2 \\
3 \\
4 \\
5\end{array}$ & $\begin{array}{l}8 \\
C \\
C \\
A \\
D\end{array}$ & $\begin{array}{l}15.84 \\
16.14 \\
16.16 \\
13.29 \\
16.75\end{array}$ & $\begin{array}{l}1375.95 \\
1298.57 \\
2042.20 \\
2400.98 \\
2626.57\end{array}$ & $\begin{array}{l}4497.66 \\
4217.53 \\
5721.66 \\
7624.91 \\
7477.67\end{array}$ & $\begin{array}{r}45.96 \\
226.89 \\
105.63 \\
83.37 \\
119.34\end{array}$ & $\begin{array}{l}248.11 \\
225.28 \\
365.04 \\
346.35 \\
409.01\end{array}$ & $\begin{array}{r}30.49 \mathrm{~J} \\
28.56 \mathrm{~J} \\
70.17 \\
50.41 \\
112.90\end{array}$ & $\begin{array}{r}14.84 \mathrm{~J} \\
16.54 \mathrm{~J} \\
27.29 \\
27.24 \mathrm{~J} \\
105.97\end{array}$ & $\begin{array}{l}17.36 \mathrm{~J} \\
15.06 \mathrm{~J} \\
66.77 \\
42.29 \\
48.00\end{array}$ & $\begin{array}{r}37.82 \mathrm{U} \\
83.02 \mathrm{U} \\
3.40 \mathrm{~J} \\
34.76 \mathrm{U} \\
21.55 \mathrm{U}\end{array}$ & $\begin{array}{rrr}U & 25.69 \\
U & 56.51 \\
J & 0.74 \\
U & 23.63 \\
U & 14.63 & U\end{array}$ & $\begin{array}{lrr}\mathrm{U} & 10.73 & \mathrm{~J} \\
\mathrm{U} & 9.98 & \mathrm{~J} \\
\mathrm{~J} & 42.76 \\
\mathrm{U} & 28.97 & \mathrm{~J} \\
\mathrm{U} & 24.96 & \mathrm{~J}\end{array}$ \\
\hline $\begin{array}{l}\text { R-AM } \\
\text { R-AM } \\
\text { R-AM } \\
\text { R-AM Repl icate } 1 \\
\text { R-AM Replicate } 2 \\
\text { R-AM Replicate } 3 \\
\text { R-AM }\end{array}$ & $\begin{array}{l}1 \\
2 \\
3 \\
4 \\
4 \\
4 \\
5\end{array}$ & $\begin{array}{l}B \\
C \\
B \\
8 \\
B \\
B \\
B\end{array}$ & $\begin{array}{l}17.29 \\
16.62 \\
16.26 \\
16.61 \\
16.61 \\
16.61 \\
11.30\end{array}$ & $\begin{array}{r}145.69 \\
82.07 \\
114.21 \\
190.55 \\
136.06 \\
172.49 \\
119.73\end{array}$ & $\begin{array}{l}286.81 \\
205.60 \\
290.47 \\
325.71 \\
234.50 \\
361.29 \\
277.26\end{array}$ & $\begin{array}{r}3.99 \mathrm{~J} \\
4.93 \mathrm{~J} \\
6.70 \mathrm{~J} \\
85.37 \mathrm{~J} \\
130.52 \mathrm{U} \\
6.92 \mathrm{~J} \\
5.22 \mathrm{~J}\end{array}$ & $\begin{array}{l}43.96 \\
46.15 \\
59.23 \\
64.18 \\
43.41 \mathrm{~J} \\
61.89 \\
53.10\end{array}$ & $\begin{array}{r}3.30 \mathrm{~J} \\
1.81 \mathrm{~J} \\
1.48 \mathrm{~J} \\
87.12 \mathrm{U} \\
133.23 \mathrm{U} \\
4.15 \mathrm{~J} \\
28.67 \mathrm{U}\end{array}$ & $\begin{array}{r}1.39 \mathrm{~J} \\
1.38 \mathrm{~J} \\
2.71 \mathrm{~J} \\
72.97 \mathrm{U} \\
111.56 \mathrm{U} \\
2.23 \mathrm{~J} \\
24.07 \mathrm{U}\end{array}$ & $\begin{aligned} 19.20 \mathrm{U} \\
0.90 \mathrm{~J} \\
15.93 \mathrm{U} \\
75.98 \mathrm{U} \\
116.20 \mathrm{U} \\
41.60 \mathrm{U} \\
25.04 \mathrm{U}\end{aligned}$ & $\begin{array}{r}22.96 \mathrm{U} \\
18.65 \mathrm{U} \\
19.07 \mathrm{U} \\
91.09 \mathrm{U} \\
139.25 \mathrm{U} \\
49.91 \mathrm{U} \\
30.00 \mathrm{U}\end{array}$ & $\begin{array}{llll}U & 15.62 & U \\
U & 12.70 & U \\
U & 12.98 & U \\
U & 61.95 & U \\
U & 94.70 & U \\
U & 33.96 & U \\
U & 20.44 & U\end{array}$ & $\begin{array}{lrr}U & 31.17 & U \\
U & 0.72 & \mathrm{~J} \\
\mathrm{U} & 25.89 & \mathrm{U} \\
\mathrm{U} & 25.89 & \mathrm{U} \\
\mathrm{U} & 123.54 & \mathrm{U} \\
\mathrm{U} & 188.86 & \mathrm{U} \\
\mathrm{U} & 67.67 & \mathrm{U} \\
\mathrm{U} & 40.71 & \mathrm{U}\end{array}$ \\
\hline $\begin{array}{l}R-B F \\
R-8 F \\
R-8 F \\
R-B F \\
R-B F\end{array}$ & $\begin{array}{l}1 \\
2 \\
3 \\
4 \\
5\end{array}$ & $\begin{array}{l}0 \\
B \\
8 \\
A \\
A\end{array}$ & $\begin{array}{l}16.72 \\
13.79 \\
15.57 \\
15.24 \\
16.05\end{array}$ & $\begin{array}{l}19.14 \mathrm{~J} \\
26.76 \mathrm{~J} \\
27.62 \\
29.99 \\
42.06\end{array}$ & $\begin{array}{l}45.45 \\
51.78 \\
55.68 \\
66.34 \\
59.25\end{array}$ & $\begin{array}{r}33.31 \mathrm{~J} \\
46.77 \mathrm{~J} \\
6.42 \mathrm{~J} \\
1.84 \mathrm{~J} \\
6.23 \mathrm{~J}\end{array}$ & $\begin{array}{l}14.35 \mathrm{~J} \\
16.32 \mathrm{~J} \\
19.46 \\
18.57 \mathrm{~J} \\
26.79\end{array}$ & $\begin{array}{r}33.97 \mathrm{U} \\
6.96 \mathrm{~J} \\
5.20 \mathrm{~J} \\
1.71 \mathrm{~J} \\
10.90 \mathrm{~J}\end{array}$ & $\begin{array}{r}28.47 \mathrm{U} \\
39.96 \mathrm{U} \\
4.95 \mathrm{~J} \\
1.64 \mathrm{~J} \\
8.79 \mathrm{~J}\end{array}$ & $\begin{array}{r}29.67 \mathrm{U} \\
41.62 \mathrm{U} \\
4.88 \mathrm{~J} \\
26.18 \mathrm{U} \\
25.30 \mathrm{U}\end{array}$ & $\begin{array}{r}35.53 \\
49.89 \\
25.18 \\
31.43 \\
5.79\end{array}$ & $\begin{array}{rrr}U & 17.15 \\
U & 21.33 \\
\mathrm{~J} & 3.36 & \mathrm{~J}\end{array}$ & $\begin{array}{rr}U & 48.21 \\
U & 13.63 \\
U & 34.10 \\
U & 42.59 \\
\mathrm{~J} & 6.79\end{array}$ \\
\hline $\begin{array}{l}\text { R-OS } \\
\text { R-OS Replicate } 1 \\
\text { R-OS Replicate } 2 \\
\text { R-OS Replicate } 3 \\
\text { R-OS } \\
\text { R-OS } \\
\text { R-OS }\end{array}$ & $\begin{array}{l}1 \\
2 \\
2 \\
2 \\
3 \\
4 \\
5\end{array}$ & $\begin{array}{l}B \\
D \\
D \\
D \\
B \\
D \\
C\end{array}$ & $\begin{array}{l}15.79 \\
16.53 \\
16.53 \\
16.53 \\
15.02 \\
17.85 \\
17.02\end{array}$ & $\begin{array}{r}10.26 \mathrm{~J} \\
15.18 \mathrm{~J} \\
14.52 \mathrm{~J} \\
16.09 \mathrm{~J} \\
10.19 \mathrm{~J} \\
8.24 \mathrm{~J} \\
11.81 \mathrm{~J}\end{array}$ & $\begin{array}{l}11.27 \mathrm{~J} \\
22.26 \mathrm{~J} \\
16.15 \mathrm{~J} \\
16.82 \mathrm{~J} \\
15.11 \mathrm{~J} \\
10.81 \mathrm{~J} \\
13.04 \mathrm{~J}\end{array}$ & $\begin{array}{lll}J & 21.09 & U \\
J & 70.96 & U \\
J & 57.53 & U \\
J & 69.57 & U \\
J & 23.30 & U \\
J & 21.51 & U \\
J & 0.65 & J\end{array}$ & $\begin{array}{r}3.99 \mathrm{~J} \\
49.73 \mathrm{U} \\
4.96 \mathrm{~J} \\
6.72 \mathrm{~J} \\
5.06 \mathrm{~J} \\
3.92 \mathrm{~J} \\
3.94 \mathrm{~J}\end{array}$ & $\begin{array}{r}21.53 \mathrm{U} \\
72.41 \mathrm{U} \\
58.74 \mathrm{U} \\
71.02 \mathrm{U} \\
23.77 \mathrm{U} \\
21.90 \mathrm{U} \\
1.06 \mathrm{~J}\end{array}$ & $\begin{array}{r}18.05 \mathrm{U} \\
60.68 \mathrm{U} \\
49.18 \mathrm{U} \\
59.47 \mathrm{U} \\
19.91 \mathrm{U} \\
18.38 \mathrm{U} \\
0.35 \mathrm{~J}\end{array}$ & $\begin{array}{l}18.75 \mathrm{U} \\
63.16 \mathrm{U} \\
51.24 \mathrm{U} \\
61.95 \mathrm{U} \\
20.71 \mathrm{U} \\
19.10 \mathrm{U} \\
19.62 \mathrm{U}\end{array}$ & $\begin{array}{l}22.48 \\
75.74 \\
61.40 \\
74.29 \\
24.83 \\
22.91 \\
23.56\end{array}$ & $\begin{array}{ll}U & 15.33 \\
\text { U } & 51.48 \\
\text { U } & 41.74 \\
\text { U } & 50.51 \\
\text { U } & 16.91 \\
\text { U } & 15.57 \\
\text { U } & 16.04\end{array}$ & $\begin{array}{lr}U & 30.53 \\
U & 20.27 \\
U & 83.30 \\
U & 100.73 \\
U & 33.69 \\
U & 31.09 \\
U & 31.96\end{array}$ \\
\hline $\begin{array}{l}R-P F \\
R-P F \\
R-P F \\
R-P F \\
R-P F\end{array}$ & $\begin{array}{l}1 \\
2 \\
3 \\
4 \\
5\end{array}$ & $\begin{array}{l}C \\
C \\
0 \\
0 \\
A\end{array}$ & $\begin{array}{l}13.90 \\
13.46 \\
16.88 \\
16.74 \\
16.47\end{array}$ & $\begin{array}{l}34.89 \\
19.09 \\
11.97 \mathrm{~J} \\
13.08 \\
13.66 \mathrm{~J}\end{array}$ & $\begin{array}{l}31.08 \\
18.72 \mathrm{~J} \\
16.00 \\
16.19 \\
16.70 \mathrm{~J}\end{array}$ & $\begin{array}{r}6.69 \mathrm{~J} \\
32.24 \mathrm{U} \\
20.97 \mathrm{U} \\
17.98 \mathrm{U} \\
\mathrm{J} 26.84 \mathrm{U}\end{array}$ & $\begin{array}{r}11.22 \mathrm{~J} \\
6.09 \mathrm{~J} \\
4.86 \mathrm{~J} \\
5.68 \mathrm{~J} \\
4.74 \mathrm{~J}\end{array}$ & $\begin{array}{r}4.89 \mathrm{~J} \\
1.26 \mathrm{~J} \\
21.39 \mathrm{U} \\
18.40 \mathrm{U} \\
1.34 \mathrm{~J}\end{array}$ & $\begin{array}{r}2.95 \mathrm{~J} \\
27.56 \mathrm{U} \\
17.89 \mathrm{U} \\
15.41 \mathrm{U} \\
22.95 \mathrm{U}\end{array}$ & $\begin{array}{r}4.46 \mathrm{~J} \\
28.75 \mathrm{U} \\
18.66 \mathrm{U} \\
16.01 \mathrm{U} \\
23.92 \mathrm{U}\end{array}$ & $\begin{array}{l}29.50 \\
34.47 \\
22.33 \\
19.24 \\
28.66\end{array}$ & $\begin{array}{ll}U & 20.07 \\
U & 23.40 \\
U & 15.23 \\
U & 13.08 \\
U & 19.49\end{array}$ & $\begin{array}{lrl}U & 2.81 & J \\
U & 46.73 & U \\
U & 30.33 & U \\
U & 26.05 & \\
U & 38.86 & U\end{array}$ \\
\hline
\end{tabular}


IABLE K.3. (contd)

\begin{tabular}{|c|c|c|c|c|c|c|c|c|c|c|c|c|c|}
\hline \multirow[b]{2}{*}{$\begin{array}{l}\text { Sediment } \\
\text { Ireatment }\end{array}$} & \multirow[b]{2}{*}{ Repliçate } & \multirow[b]{2}{*}{$\begin{array}{l}\text { Analytical } \\
\text { Batch }\end{array}$} & \multirow[b]{2}{*}{$\begin{array}{c}\text { Percent } \\
\text { Ory Yeight } \\
\end{array}$} & \multicolumn{7}{|c|}{ N. caecoides HeAHs ( $\mu \mathrm{g} / \mathrm{kg}$ dry weight) } & \multirow{2}{*}{\multicolumn{2}{|c|}{$\begin{array}{l}\text { Indeno Dibenzo } \\
(1,2,3-(a, h) \\
-c, d) \text { Anthra- } \\
\text { Dyrene cene }\end{array}$}} & \multirow[b]{2}{*}{$\begin{array}{l}\text { Benzo } \\
(g, h, i) \\
\text { Perylene } \\
\end{array}$} \\
\hline & & & & $\begin{array}{l}\text { Fluoran- } \\
\text { thene }\end{array}$ & Pyrene & $\begin{array}{c}\text { Benzo(a) } \\
\text { anthra- } \\
\text { cene } \\
\end{array}$ & Chrysene & $\begin{array}{c}\text { Benzo(b) } \\
\text { Fluoran- } \\
\text { thene }\end{array}$ & $\begin{array}{c}\text { Benzo(k) } \\
\text { Fluoran- } \\
\text { thene. }\end{array}$ & $\begin{array}{l}\text { Benzo (a) } \\
\text { pyrene }\end{array}$ & & & \\
\hline $\begin{array}{l}C-S B \\
C-S B \\
C-S B \\
C-S B \\
C-S B\end{array}$ & $\begin{array}{l}1 \\
2 \\
3 \\
4 \\
5\end{array}$ & $\begin{array}{l}C \\
0 \\
B \\
A \\
0\end{array}$ & $\begin{array}{l}14.29 \\
16.03 \\
15.65 \\
16.06 \\
16.46\end{array}$ & $\begin{array}{l}25.05 \\
20.59 \\
25.18 \\
20.30 \\
23.27\end{array}$ & $\begin{array}{l}30.16 \\
26.70 \\
28.56 \\
23.10 \\
28.13\end{array}$ & $\begin{array}{r}1.40 \mathrm{~J} \\
24.20 \mathrm{U} \\
27.48 \mathrm{U} \\
18.49 \mathrm{U} \\
19.99 \mathrm{U}\end{array}$ & $\begin{array}{l}9.59 \mathrm{~J} \\
9.42 \mathrm{~J} \\
9.20 \mathrm{~J} \\
7.22 \mathrm{~J} \\
8.38 \mathrm{~J}\end{array}$ & $\begin{array}{l}1.12 \mathrm{~J} \\
24.70 \mathrm{U} \\
27.99 \mathrm{U} \\
18.87 \mathrm{U} \\
20.41 \mathrm{U}\end{array}$ & $\begin{array}{r}0.55 \mathrm{~J} \\
20.65 \mathrm{U} \\
23.45 \mathrm{U} \\
15.82 \mathrm{U} \\
17.07 \mathrm{U}\end{array}$ & $\begin{array}{r}0.56 \mathrm{~J} \\
21.52 \mathrm{U} \\
24.41 \mathrm{U} \\
16.50 \mathrm{U} \\
17.80 \mathrm{U}\end{array}$ & $\begin{array}{l}27.71 \mathrm{U} \\
25.83 \mathrm{U} \\
29.27 \mathrm{U} \\
19.74 \mathrm{U} \\
21.32 \mathrm{U}\end{array}$ & $\begin{array}{l}18.82 \mathrm{U} \\
17.53 \mathrm{U} \\
19.94 \mathrm{U} \\
13.45 \mathrm{U} \\
14.52 \mathrm{U}\end{array}$ & $\begin{array}{l}37.58 \mathrm{U} \\
35.00 \mathrm{U} \\
39.74 \mathrm{U} \\
26.77 \mathrm{U} \\
28.92 \mathrm{U}\end{array}$ \\
\hline $\begin{array}{l}\mathrm{C}-\mathrm{NE} \\
\mathrm{C}-\mathrm{NE} \\
\mathrm{C}-\mathrm{NE} \\
\mathrm{C}-\mathrm{NE} \\
\mathrm{C}-\mathrm{NE}\end{array}$ & $\begin{array}{l}1 \\
2 \\
3 \\
4 \\
5\end{array}$ & $\begin{array}{l}B \\
8 \\
B \\
B \\
8\end{array}$ & $\begin{array}{l}15.94 \\
18.40 \\
16.01 \\
15.81 \\
15.28\end{array}$ & $\begin{array}{l}17.38 \\
12.93 \\
17.61 \\
11.76 \mathrm{~J} \\
13.87 \mathrm{~J}\end{array}$ & $\begin{array}{l}17.63 \\
14.95 \\
18.80 \\
14.61 \\
17.08\end{array}$ & $\begin{array}{r}5.58 \mathrm{~J} \\
17.01 \mathrm{U} \\
1.62 \mathrm{~J} \\
\mathrm{~J} 21.82 \mathrm{U} \\
\mathrm{J} 24.87 \mathrm{U}\end{array}$ & $\begin{array}{l}5.40 \mathrm{~J} \\
5.71 \mathrm{~J} \\
5.93 \mathrm{~J} \\
5.88 \mathrm{~J} \\
6.15 \mathrm{~J}\end{array}$ & $\begin{array}{r}17.00 \mathrm{U} \\
17.34 \mathrm{U} \\
1.00 \mathrm{~J} \\
22.26 \mathrm{U} \\
25.33 \mathrm{U}\end{array}$ & $\begin{array}{l}14.24 \mathrm{U} \\
14.57 \mathrm{U} \\
16.43 \mathrm{U} \\
18.66 \mathrm{U} \\
21.27 \mathrm{U}\end{array}$ & $\begin{array}{l}14.87 \mathrm{U} \\
15.16 \mathrm{U} \\
17.11 \mathrm{U} \\
19.42 \mathrm{U} \\
22.12 \mathrm{U}\end{array}$ & $\begin{array}{l}17.82 \mathrm{U} \\
18.15 \mathrm{U} \\
20.55 \mathrm{U} \\
23.28 \mathrm{U} \\
26.51 \mathrm{U}\end{array}$ & $\begin{array}{l}12.11 \mathrm{U} \\
12.34 \mathrm{U} \\
13.99 \mathrm{U} \\
15.81 \mathrm{U} \\
18.06 \mathrm{U}\end{array}$ & $\begin{array}{l}24.15 \mathrm{U} \\
24.62 \mathrm{U} \\
27.86 \mathrm{U} \\
31.56 \mathrm{U} \\
35.93 \mathrm{U}\end{array}$ \\
\hline $\begin{array}{l}\text { MSL Background } \\
\text { MSL Background } \\
\text { MSL Background } \\
\text { HSL Background } \\
\text { MSL Background }\end{array}$ & $\begin{array}{l}1 \\
2 \\
3 \\
4 \\
5\end{array}$ & $\begin{array}{l}E \\
E \\
E \\
E \\
E\end{array}$ & $\begin{array}{l}19.82 \\
19.82 \\
19.82 \\
19.82 \\
19.82\end{array}$ & $\begin{array}{r}10.04 \\
9.54 \\
12.56 \\
9.64 \\
10.14\end{array}$ & $\begin{array}{l}10.85 \\
10.54 \\
11.30 \\
10.60 \\
11.60\end{array}$ & $\begin{array}{l}1.16 \mathrm{~J} \\
1.26 \mathrm{~J} \\
1.21 \mathrm{~J} \\
1.01 \mathrm{~J} \\
1.31 \mathrm{~J}\end{array}$ & $\begin{array}{l}4.04 \mathrm{~J} \\
7.42 \\
6.91 \mathrm{U} \\
3.99 \mathrm{~J} \\
4.14 \mathrm{~J}\end{array}$ & $\begin{array}{l}1.51 \mathrm{~J} \\
1.36 \mathrm{~J} \\
1.11 \mathrm{~J} \\
1.36 \mathrm{~J} \\
2.22 \mathrm{~J}\end{array}$ & $\begin{array}{l}0.81 \mathrm{~J} \\
0.50 \mathrm{~J} \\
0.96 \mathrm{~J} \\
0.50 \mathrm{~J} \\
1.21 \mathrm{~J}\end{array}$ & $\begin{array}{l}8.78 \mathrm{U} \\
8.78 \mathrm{U} \\
8.78 \mathrm{U} \\
8.88 \mathrm{U} \\
8.78 \mathrm{U}\end{array}$ & $\begin{array}{r}10.49 \mathrm{U} \\
10.54 \mathrm{U} \\
10.54 \mathrm{U} \\
10.65 \mathrm{U} \\
1.16 \mathrm{~J}\end{array}$ & $\begin{array}{l}7.16 \mathrm{U} \\
7.16 \mathrm{U} \\
7.16 \mathrm{U} \\
7.21 \mathrm{U} \\
7.16 \mathrm{U}\end{array}$ & $\begin{array}{r}2.67 \mathrm{~J} \\
14.33 \mathrm{~J} \\
0.81 \mathrm{~J} \\
14.43 \mathrm{U} \\
1.41 \mathrm{~J}\end{array}$ \\
\hline
\end{tabular}

(a) U The analyte was not present above the level of the associated value.

(b) J Analyte detected below method detection 11 mit (MDL), but above instrument detection 11 mit (IOL).

(c) Percent dry weight was averaged from other four replicates of COMP 1 . 
TABLE K.4. Total Polynuclear Aromatic Hydrocarbons (PAHs), Wet Weight, in Tissue of $N$. caecoides, Richmond Harbor Program

\begin{tabular}{|c|c|c|c|c|c|}
\hline $\begin{array}{l}\text { Sediment } \\
\text { Ireatment }\end{array}$ & Replicate & $\begin{array}{c}\text { Analytical } \\
\text { Batch } \\
\end{array}$ & $\begin{array}{l}\text { N. caecoide } \\
\text { Total Low } \\
\text { Molecular } \\
\text { Weight PAHS }\end{array}$ & $\begin{array}{l}\frac{s(\mu \mathrm{g} / \mathrm{kg} \text { wet }}{\text { Total High }} \\
\text { Molecular } \\
\text { Weight PAHs }\end{array}$ & $\begin{array}{l}\text { eight) } \\
\text { Total } \\
\text { PAHs } \\
\end{array}$ \\
\hline $\begin{array}{l}\text { COMP I } \\
\text { COMP I } \\
\text { COMP I } \\
\text { COMP I } \\
\text { COMP I Replicate } 1 \\
\text { COMP I Replicate } 2 \\
\text { COMP I Replicate } 3\end{array}$ & $\begin{array}{l}1 \\
2 \\
3 \\
4 \\
5 \\
5 \\
5\end{array}$ & $\begin{array}{l}\text { D } \\
\text { D } \\
\text { A } \\
\text { B } \\
\text { A } \\
\text { A } \\
\text { A }\end{array}$ & $\begin{array}{r}6.05 \\
13.28 \\
5.28 \\
32.35 \\
15.94 \\
9.58 \\
9.86\end{array}$ & $\begin{array}{l}13.80 \\
20.73 \\
12.99 \\
15.47 \\
13.50 \\
15.96 \\
17.71\end{array}$ & $\begin{array}{l}19.85 \\
34.01 \\
18.27 \\
47.82 \\
29.44 \\
25.54 \\
27.57\end{array}$ \\
\hline $\begin{array}{l}\text { COMP II } \\
\text { COMP II } \\
\text { COMP II } \\
\text { COMP II } \\
\text { COMP II }\end{array}$ & $\begin{array}{l}1 \\
2 \\
3 \\
4 \\
5\end{array}$ & $\begin{array}{l}0 \\
A \\
C \\
0 \\
C\end{array}$ & $\begin{array}{r}8.30 \\
6.43 \\
7.61 \\
13.50 \\
6.77\end{array}$ & $\begin{array}{l}19.72 \\
12.68 \\
15.90 \\
19.60 \\
19.19\end{array}$ & $\begin{array}{l}28.02 \\
19.11 \\
23.51 \\
33.10 \\
25.96\end{array}$ \\
\hline $\begin{array}{l}\text { COMP III } \\
\text { COMP III } \\
\text { COMP III } \\
\text { COMP III } \\
\text { COMP III }\end{array}$ & $\begin{array}{l}1 \\
2 \\
3 \\
4 \\
5\end{array}$ & $\begin{array}{l}C \\
D \\
A \\
D \\
C\end{array}$ & $\begin{array}{l}7.32 \\
5.13 \\
6.13 \\
4.12 \\
6.44\end{array}$ & $\begin{array}{l}6.26 \\
6.26 \\
5.63 \\
5.18 \\
6.83\end{array}$ & $\begin{array}{r}13.58 \\
11.39 \\
11.76 \\
9.30 \\
13.27\end{array}$ \\
\hline $\begin{array}{l}\text { TC-5 Upper Comp } \\
\text { TC-5 Upper Comp } \\
\text { TC-5 Upper Comp } \\
\text { TC-5 Upper Comp } \\
\text { TC-5 Upper Comp }\end{array}$ & $\begin{array}{l}1 \\
2 \\
3 \\
4 \\
5\end{array}$ & $\begin{array}{l}\text { C } \\
C \\
C \\
A \\
A\end{array}$ & $\begin{array}{l}16.55 \\
14.65 \\
17.79 \\
15.43 \\
19.21\end{array}$ & $\begin{array}{l}136.46 \\
142.41 \\
174.07 \\
125.90 \\
114.75\end{array}$ & $\begin{array}{l}153.01 \\
157.06 \\
191.86 \\
141.33 \\
133.96\end{array}$ \\
\hline $\begin{array}{l}\text { COMP IV } \\
\text { COMP IV Replicate } 1 \\
\text { COMP IV Replicate } 2 \\
\text { COMP IV RepTicate } 3 \\
\text { COMP IV } \\
\text { COMP IV } \\
\text { COMP IV }\end{array}$ & $\begin{array}{l}1 \\
2 \\
2 \\
2 \\
3 \\
4 \\
5\end{array}$ & $\begin{array}{l}C \\
C \\
C \\
C \\
A \\
C \\
A\end{array}$ & $\begin{array}{r}6.58 \\
13.43 \\
12.97 \\
15.69 \\
8.26 \\
4.98 \\
7.41\end{array}$ & $\begin{array}{l}7.08 \\
8.96 \\
5.28 \\
6.00 \\
4.91 \\
3.75 \\
4.90\end{array}$ & $\begin{array}{r}13.66 \\
22.39 \\
18.25 \\
21.69 \\
13.17 \\
8.73 \\
12.31\end{array}$ \\
\hline $\begin{array}{l}\text { COMP } V \\
\text { COMP V } \\
\text { COMP } V \\
\text { COMP } V \\
\text { COMP } V\end{array}$ & $\begin{array}{l}1 \\
2 \\
3 \\
4 \\
5\end{array}$ & $\begin{array}{l}\text { A } \\
\text { A } \\
A \\
D \\
B\end{array}$ & $\begin{array}{r}7.38 \\
6.07 \\
7.12 \\
6.60 \\
10.36\end{array}$ & $\begin{array}{l}35.44 \\
35.32 \\
38.33 \\
44.28 \\
47.22\end{array}$ & $\begin{array}{l}42.82 \\
41.39 \\
45.45 \\
50.88 \\
57.58\end{array}$ \\
\hline $\begin{array}{l}\text { COMP VI } \\
\text { COMP VI } \\
\text { COMP VI }\end{array}$ & $\begin{array}{l}1 \\
2 \\
3\end{array}$ & $\begin{array}{l}C \\
A \\
B\end{array}$ & $\begin{array}{r}7.41 \\
6.08 \\
11.28\end{array}$ & $\begin{array}{l}30.56 \\
40.67 \\
40.71\end{array}$ & $\begin{array}{l}37.97 \\
46.75 \\
51.99\end{array}$ \\
\hline
\end{tabular}


IABLE K.4. (contd)

Sediment

Treatment

COMP VI
COMP VI
$R-A C$
$R-A C$
$R-A C$
$R-A C$
$R-A C$

$\mathrm{R}-\mathrm{AC}$

R-AM
R-AM
R-AM Replicate 1
R-AM Replicate 2
R-AM Replicate 3
R-AM Replicate
R-AM

$R-B F$

$R-B F$

$R-B F$

$R-B F$

$\mathrm{R}-\mathrm{BF}$

R-OS

R-OS Replicate 1

R-OS Replicate 2

R-OS Replicate 3

$\mathrm{R}-\mathrm{OS}$

R-OS

R-OS

$R-P F$

$R-P F$

$R-P F$

$R-P F$

$R-P F$

C-SB

$C-S B$

C-SB

$C-S B$

C-SB

$C-N E$

C-NE

$\mathrm{C}-\mathrm{NE}$
Replicate

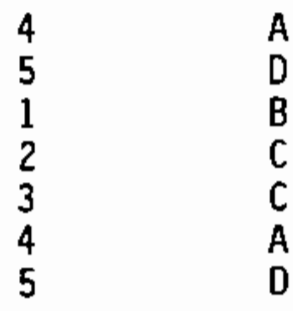

2

3

4

5

1

2

2

2

3

4

5

1
2
3
4
5

4
5

1

2

3

4

5

1

2

3
Analytical

Batch

A

6.27

16.16

58.63

70.32

57.60

91.12

89.44

19.25

12.78

15.33

47.10

48.74

21.67

14.63

6.48

16.09

11.48

7.68

9.71

7.34

8.68

8.67

8.55

11.57

4.98

6.67

16.82

7.23

5.56

5.58

6.64

6.35

6.03

11.94

4.49

5.39

9.08

10.68

10.88
34.20

54.75

988.59

974.60

1364.82

1409.34

1829.84

83.88

57.10

77.20

96.41

68.76

101.15

51.45

13.20

15.92

19.34

18.30

27.28

4.03

9.54

5.89

6.55

4.56

4.10

5.25

13.76

6.08

5.54

5.85

6.00

9.78

9.09

9.85

8.13

9.84

7.33

6.18

7.20
Total

PAHS

40.47

70.91

1047.22

1044.92

1422.42

1500.46

1919.28

103.13

69.88

92.53

143.51

117.50

122.82

66.08

19.68

32.01

30.82

25.98

36.99

11.37

18.22

14.56

15.10

16.13

9.08

11.92

30.58

13.31

11.10

11.43

12.64

16.13

15.12

21.79

12.62

15.23

16.41

16.86

18.08 
TABLE_K.4. (contd)

Sediment

Ireatment

$\mathrm{C}-\mathrm{NE}$

C-NE

MSL Background

MSL Background

MSL Background

MSL Background

MSL Background
$\frac{N \text {. caecoides }(\mu \mathrm{g} / \mathrm{kg} \text { wet weight) }}{\text { Total Low Total High }}$

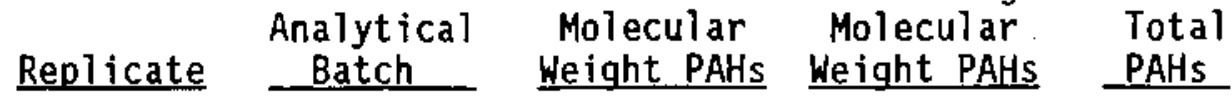

8.40

5.10

9.10

5.67

13.50

B

832

9.33

9.70

8.48

8.87
6.16

6.07

5.54

5.37

6.58
14.77

E

14.48

15.40

15.24

13.85

5

15.45 
TABLE K.5. Low Molecular Weight Polynuclear Aromatic Hydrocarbons (LPAHs), Wet Weight, in Tissue of $N$. caecoides, Richmond Harbor Program

\begin{tabular}{|c|c|c|c|c|c|c|c|c|}
\hline \multirow[b]{2}{*}{$\begin{array}{l}\text { Sediment } \\
\text { Ireatment }\end{array}$} & \multirow[b]{2}{*}{ Replicate } & \multirow[b]{2}{*}{$\begin{array}{l}\text { Analytical } \\
\text { Batch } \\
\end{array}$} & \multicolumn{6}{|c|}{$N$ caecoides LPAHs $(\mu \mathrm{g} / \mathrm{kq}$ wet weight) } \\
\hline & & & $\begin{array}{l}\text { Naphtha- } \\
\text { lene }\end{array}$ & $\begin{array}{l}\text { Acenaph- } \\
\text { thylene }\end{array}$ & $\begin{array}{l}\text { Acenaph- } \\
\text { thene }\end{array}$ & Fluorene & $\begin{array}{l}\text { Phenan- } \\
\text { threne }\end{array}$ & $\begin{array}{l}\text { Anthra- } \\
\text { cene }\end{array}$ \\
\hline $\begin{array}{l}\text { Target DL (a) } \\
\text { Achieved OL High } \\
\text { Achieved DL Low }\end{array}$ & & & $\begin{array}{l}20 \\
N A \\
N A\end{array}$ & $\begin{array}{r}20 \\
29.32 \\
3.60\end{array}$ & $\begin{array}{r}20 \\
15.84 \\
2.17\end{array}$ & $\begin{array}{r}20 \\
17.14 \\
2.35\end{array}$ & $\begin{array}{l}20 \\
\text { NA } \\
\text { NA }\end{array}$ & $\begin{array}{r}20 \\
11.66 \\
1.59\end{array}$ \\
\hline $\begin{array}{l}\text { COMP I } \\
\text { COMP I } \\
\text { COMP I } \\
\text { COMP I } \\
\text { COMP I Repl icate } 1 \\
\text { COMP I Repi icate } 2 \\
\text { COMP I Replicate } 3\end{array}$ & $\begin{array}{l}1 \\
2 \\
3 \\
4 \\
5 \\
5 \\
5\end{array}$ & $\begin{array}{l}D \\
D \\
A \\
B \\
A \\
A \\
A\end{array}$ & $\begin{array}{l}2.45 \mathrm{~J}^{(\mathrm{c})} \\
5.37 \\
2.61 \mathrm{~J} \\
23.87 \\
8.52 \mathrm{~J} \\
5.89 \mathrm{~J} \\
6.09 \mathrm{~J}\end{array}$ & $\begin{array}{l}6.48 \mathrm{U}^{(\mathrm{d})} \\
0.47 \mathrm{~J} \\
5.12 \mathrm{U} \\
18.85 \mathrm{U} \\
21.13 \mathrm{U} \\
19.44 \mathrm{U} \\
14.32 \mathrm{U}\end{array}$ & $\begin{aligned} 3.50 \mathrm{U} \\
1.22 \mathrm{~J} \\
2.76 \mathrm{U} \\
10.18 \mathrm{U} \\
11.41 \mathrm{U} \\
10.50 \mathrm{U} \\
7.74 \mathrm{U}\end{aligned}$ & $\begin{array}{r}1.06 \mathrm{~J} \\
1.35 \mathrm{~J} \\
2.99 \mathrm{U} \\
2.41 \mathrm{~J} \\
2.08 \mathrm{~J} \\
11.37 \mathrm{U} \\
8.37 \mathrm{U}\end{array}$ & $\begin{array}{l}2.54 \mathrm{~J} \\
4.13 \\
2.67 \\
4.84 \mathrm{~J} \\
5.34 \mathrm{~J} \\
3.69 \mathrm{~J} \\
3.77 \mathrm{~J}\end{array}$ & $\begin{array}{l}2.87 \mathrm{U} \\
0.74 \mathrm{~J} \\
2.27 \mathrm{U} \\
1.23 \mathrm{~J} \\
9.35 \mathrm{U} \\
8.61 \mathrm{U} \\
6.34 \mathrm{U}\end{array}$ \\
\hline $\begin{array}{ll}\text { COHP II } \\
\text { COHP } \\
\text { COMP II } \\
\text { COMP II } \\
\text { COMP II }\end{array}$ & $\begin{array}{l}1 \\
2 \\
3 \\
4 \\
5\end{array}$ & $\begin{array}{l}D \\
A \\
C \\
0 \\
C\end{array}$ & $\begin{array}{l}3.38 \mathrm{~J} \\
2.00 \mathrm{~J} \\
1.86 \mathrm{~J} \\
6.67 \\
1.82 \mathrm{~J}\end{array}$ & $\begin{array}{l}3.93 \mathrm{U} \\
8.37 \mathrm{U} \\
4.62 \mathrm{U} \\
5.62 \mathrm{U} \\
4.50 \mathrm{~V}\end{array}$ & $\begin{array}{l}0.93 \mathrm{~J} \\
4.52 \mathrm{U} \\
0.73 \mathrm{~J} \\
0.98 \mathrm{~J} \\
0.69 \mathrm{~J}\end{array}$ & $\begin{array}{l}0.93 \mathrm{~J} \\
1.26 \mathrm{~J} \\
1.15 \mathrm{~J} \\
1.23 \mathrm{~J} \\
1.04 \mathrm{~J}\end{array}$ & $\begin{array}{l}2.74 \\
2.72 \mathrm{~J} \\
3.39 \\
4.03 \\
2.79\end{array}$ & $\begin{array}{l}0.32 \mathrm{~J} \\
0.45 \mathrm{~J} \\
0.48 \mathrm{~J} \\
0.59 \mathrm{~J} \\
0.43 \mathrm{~J}\end{array}$ \\
\hline $\begin{array}{l}\text { COMP II } \\
\text { COMP II I } \\
\text { COMP II I } \\
\text { COMP III } \\
\text { COMP I II }\end{array}$ & $\begin{array}{l}1 \\
2 \\
3 \\
4 \\
5\end{array}$ & $\begin{array}{l}\text { C } \\
\text { D } \\
\text { A } \\
\text { D } \\
\text { C }\end{array}$ & $\begin{array}{l}2.87 \mathrm{~J} \\
1.65 \mathrm{~J} \\
2.94 \mathrm{~J} \\
1.40 \mathrm{~J} \\
2.27 \mathrm{~J}\end{array}$ & $\begin{array}{l}5.56 \mathrm{U} \\
5.22 \mathrm{U} \\
4.31 \mathrm{U} \\
4.80 \mathrm{U} \\
5.81 \mathrm{U}\end{array}$ & $\begin{array}{l}0.61 \mathrm{~J} \\
2.82 \mathrm{U} \\
2.33 \mathrm{U} \\
2.59 \mathrm{U} \\
0.53 \mathrm{~J}\end{array}$ & $\begin{array}{l}1.02 \mathrm{~J} \\
0.81 \mathrm{~J} \\
0.86 \mathrm{~J} \\
0.77 \mathrm{~J} \\
1.00 \mathrm{~J}\end{array}$ & $\begin{array}{l}2.60 \\
2.67 \\
2.33 \\
1.95 \mathrm{~J} \\
2.49 \mathrm{~J}\end{array}$ & $\begin{array}{l}0.22 \mathrm{~J} \\
2.31 \mathrm{U} \\
1.91 \mathrm{U} \\
2.12 \mathrm{U} \\
0.15 \mathrm{~J}\end{array}$ \\
\hline $\begin{array}{l}\text { TC-5 Upper Comp } \\
\text { TC-5 Upper Comp } \\
\text { TC-5 Upper Comp } \\
\text { TC-5 Upper Comp } \\
\text { TC-5 Upper Comp }\end{array}$ & $\begin{array}{l}1 \\
2 \\
3 \\
4 \\
5\end{array}$ & $\begin{array}{l}\text { C } \\
\text { C } \\
\text { C } \\
A \\
A\end{array}$ & $\begin{array}{l}4.38 \mathrm{~J} \\
2.28 \mathrm{~J} \\
2.41 \mathrm{~J} \\
2.55 \mathrm{~J} \\
8.32 \mathrm{~J}\end{array}$ & $\begin{array}{r}7.97 \mathrm{U} \\
4.85 \mathrm{U} \\
7.05 \mathrm{U} \\
6.96 \mathrm{U} \\
23.85 \mathrm{U}\end{array}$ & $\begin{array}{r}0.82 \mathrm{~J} \\
2.62 \mathrm{U} \\
0.82 \mathrm{~J} \\
3.76 \mathrm{U} \\
12.88 \mathrm{U}\end{array}$ & $\begin{array}{r}1.78 \mathrm{~J} \\
1.78 \mathrm{~J} \\
2.22 \mathrm{~J} \\
1.77 \mathrm{~J} \\
13.95 \mathrm{U}\end{array}$ & $\begin{array}{r}8.14 \\
8.94 \\
10.47 \\
9.21 \\
8.97 \mathrm{~d}\end{array}$ & $\begin{array}{l}1.43 \mathrm{~J} \\
1.65 \mathrm{~J} \\
1.87 \mathrm{~J} \\
1.90 \mathrm{~J} \\
1.92 \mathrm{~J}\end{array}$ \\
\hline $\begin{array}{l}\text { COMP IV } \\
\text { COMP IV Replicate } 1 \\
\text { COMP IV Repl icate } 2 \\
\text { CDHP IV Replicate } 3 \\
\text { COMP IV } \\
\text { COMP IV } \\
\text { COMP IV }\end{array}$ & $\begin{array}{l}1 \\
2 \\
2 \\
2 \\
3 \\
4 \\
5\end{array}$ & $\begin{array}{l}C \\
C \\
C \\
C \\
A \\
C \\
A\end{array}$ & $\begin{array}{l}2.29 \mathrm{~J} \\
6.51 \mathrm{~J} \\
7.64 \mathrm{~J} \\
8.33 \mathrm{~J} \\
4.02 \mathrm{~J} \\
1.60 \mathrm{~J} \\
3.53 \mathrm{~J}\end{array}$ & $\begin{array}{r}4.80 \mathrm{U} \\
20.76 \mathrm{U} \\
26.34 \mathrm{U} \\
18.52 \mathrm{U} \\
8.96 \mathrm{U} \\
5.71 \mathrm{U} \\
9.93 \mathrm{U}\end{array}$ & $\begin{array}{r}0.56 \mathrm{~J} \\
1.11 \mathrm{~J} \\
14.23 \mathrm{U} \\
1.10 \mathrm{~J} \\
4.84 \mathrm{U} \\
0.45 \mathrm{~J} \\
5.36 \mathrm{U}\end{array}$ & $\begin{array}{l}0.88 \mathrm{~J} \\
1.94 \mathrm{~J} \\
2.10 \mathrm{~J} \\
1.91 \mathrm{~J} \\
1.18 \mathrm{~J} \\
0.83 \mathrm{~J} \\
1.02 \mathrm{~J}\end{array}$ & $\begin{array}{l}2.64 \\
3.87 \mathrm{~J} \\
3.23 \mathrm{~J} \\
4.35 \mathrm{~J} \\
3.06 \mathrm{~J} \\
2.10 \mathrm{~J} \\
2.86 \mathrm{~J}\end{array}$ & $\begin{array}{r}0.21 \mathrm{~J} \\
9.19 \mathrm{U} \\
11.66 \mathrm{U} \\
8.20 \mathrm{U} \\
3.97 \mathrm{U} \\
2.53 \mathrm{U} \\
4.40 \mathrm{U}\end{array}$ \\
\hline $\begin{array}{l}\text { COMP V } \\
\text { COMP V } \\
\text { COHP V } \\
\text { COHP V } \\
\text { COHP V }\end{array}$ & $\begin{array}{l}1 \\
2 \\
3 \\
4 \\
5\end{array}$ & $\begin{array}{l}A \\
A \\
A \\
D \\
B\end{array}$ & $\begin{array}{l}3.63 \mathrm{~J} \\
1.84 \mathrm{~J} \\
2.17 \mathrm{~J} \\
2.05 \mathrm{~J} \\
3.86\end{array}$ & $\begin{array}{l}5.14 \mathrm{U} \\
5.94 \mathrm{U} \\
4.16 \mathrm{U} \\
5.87 \mathrm{U} \\
3.68 \mathrm{U}\end{array}$ & $\begin{array}{l}2.78 \mathrm{U} \\
3.21 \mathrm{U} \\
2.25 \mathrm{U} \\
3.17 \mathrm{U} \\
0.69 \mathrm{~J}\end{array}$ & $\begin{array}{l}3.01 \mathrm{U} \\
0.74 \mathrm{~J} \\
1.18 \mathrm{~J} \\
0.86 \mathrm{~J} \\
1.04 \mathrm{~J}\end{array}$ & $\begin{array}{l}3.01 \\
2.88 \\
2.95 \\
3.32 \\
3.83\end{array}$ & $\begin{array}{ll}0.74 & \mathrm{~J} \\
0.61 \mathrm{~J} \\
0.82 \mathrm{~J} \\
0.37 \mathrm{~J} \\
0.94 \mathrm{~J}\end{array}$ \\
\hline $\begin{array}{l}\text { COMP VI } \\
\text { COMP VI } \\
\text { COMP VI } \\
\text { COMP VI } \\
\text { COMP VI }\end{array}$ & $\begin{array}{l}1 \\
2 \\
3 \\
4 \\
5\end{array}$ & $\begin{array}{l}C \\
A \\
8 \\
A \\
0\end{array}$ & $\begin{array}{l}2.12 \mathrm{~J} \\
1.81 \mathrm{~J} \\
5.57 \mathrm{~J} \\
3.14 \mathrm{~J} \\
9.70 \mathrm{~J}\end{array}$ & $\begin{array}{r}0.27 \mathrm{~J} \\
4.86 \mathrm{U} \\
5.64 \mathrm{U} \\
5.69 \mathrm{U} \\
17.49 \mathrm{U}\end{array}$ & $\begin{array}{l}0.47 \mathrm{~J} \\
2.62 \mathrm{U} \\
3.05 \mathrm{U} \\
3.07 \mathrm{U} \\
9.45 \mathrm{U}\end{array}$ & $\begin{array}{l}0.96 \mathrm{~J} \\
0.94 \mathrm{~J} \\
1.24 \mathrm{~J} \\
3.33 \mathrm{U} \\
1.58 \mathrm{~J}\end{array}$ & $\begin{array}{l}2.66 \mathrm{~J} \\
2.76 \\
3.87 \\
3.13 \\
4.17 \mathrm{~J}\end{array}$ & $\begin{array}{l}0.93 \mathrm{~J} \\
0.57 \mathrm{~J} \\
0.60 \mathrm{~J} \\
2.52 \mathrm{U} \\
0.71 \mathrm{~J}\end{array}$ \\
\hline $\begin{array}{l}R-A C \\
R-A C \\
R-A C \\
R-A C \\
R-A C\end{array}$ & $\begin{array}{l}1 \\
2 \\
3 \\
4 \\
5\end{array}$ & $\begin{array}{l}B \\
C \\
C \\
A \\
D\end{array}$ & $\begin{array}{l}7.82 \\
6.69 \mathrm{~J} \\
2.77 \mathrm{~J} \\
4.37 \mathrm{~J} \\
1.42 \mathrm{~J}\end{array}$ & $\begin{array}{r}7.59 \mathrm{U} \\
16.99 \mathrm{U} \\
0.45 \mathrm{~J} \\
5.86 \mathrm{U} \\
4.57 \mathrm{U}\end{array}$ & $\begin{array}{l}1.93 \mathrm{~J} \\
3.29 \mathrm{~J} \\
2.29 \mathrm{~J} \\
5.66 \\
5.37\end{array}$ & $\begin{array}{l}3.86 \mathrm{~J} \\
5.34 \mathrm{~J} \\
4.31 \\
7.93 \\
6.68\end{array}$ & $\begin{array}{l}37.77 \\
47.03 \\
38.25 \\
60.44 \\
63.15\end{array}$ & $\begin{array}{r}7.25 \\
7.97 \\
9.53 \\
12.72 \\
12.82\end{array}$ \\
\hline
\end{tabular}


TABLE K.5. (contd)

\begin{tabular}{|c|c|c|c|c|c|c|c|c|}
\hline \multirow[b]{2}{*}{$\begin{array}{l}\text { Sediment } \\
\text { Ireatment }\end{array}$} & \multirow[b]{2}{*}{ Repijcate } & \multirow[b]{2}{*}{$\begin{array}{l}\text { Analytical } \\
\text { Batch } \\
\end{array}$} & \multicolumn{6}{|c|}{$N$. caecoides L.PAHs ( $\mu \mathrm{k} / \mathrm{kg}$ wet weight) } \\
\hline & & & $\begin{array}{l}\text { Naphtha- } \\
\text { lene }\end{array}$ & $\begin{array}{l}\text { Acenaph- } \\
\text { thylene }\end{array}$ & $\begin{array}{l}\text { Acenaph- } \\
\text { thene }\end{array}$ & Fluorene & $\begin{array}{l}\text { Phenan- } \\
\text { threne }\end{array}$ & $\begin{array}{l}\text { Anthra- } \\
\text { cene } \\
\end{array}$ \\
\hline $\begin{array}{l}\text { R-AM } \\
\text { R-AH } \\
\text { R-AM } \\
\text { R-AH Replicate } 1 \\
\text { R-AM Replicate } 2 \\
\text { R-AM Replicate } 3 \\
\text { R-AH }\end{array}$ & $\begin{array}{l}1 \\
2 \\
3 \\
4 \\
4 \\
4 \\
5\end{array}$ & $\begin{array}{l}\text { B } \\
\text { C } \\
\text { B } \\
B \\
B \\
B \\
B\end{array}$ & $\begin{array}{l}5.71 \\
2.06 \mathrm{~J} \\
3.50 \mathrm{~J} \\
31.56 \\
31.71 \\
8.83 \mathrm{~J} \\
3.25 \mathrm{~J}\end{array}$ & $\begin{array}{r}5.04 \mathrm{U} \\
0.30 \mathrm{~J} \\
3.93 \mathrm{U} \\
19.18 \mathrm{U} \\
29.32 \mathrm{U} \\
10.50 \mathrm{U} \\
4.30 \mathrm{U}\end{array}$ & $\begin{array}{r}2.72 \mathrm{U} \\
0.74 \mathrm{~J} \\
0.92 \mathrm{~J} \\
10.36 \mathrm{U} \\
15.84 \mathrm{U} \\
5.67 \mathrm{U} \\
0.96 \mathrm{~J}\end{array}$ & $\begin{array}{r}1.58 \mathrm{~J} \\
1.37 \mathrm{~J} \\
1.27 \mathrm{~J} \\
1.56 \mathrm{~J} \\
17.14 \mathrm{~J} \\
1.49 \mathrm{~J} \\
1.11 \mathrm{~J}\end{array}$ & $\begin{array}{r}10.42 \\
6.96 \\
8.19 \\
11.37 \\
13.81 \\
9.93 \\
7.63\end{array}$ & $\begin{array}{l}1.54 \mathrm{~J} \\
1.35 \mathrm{~J} \\
1.45 \mathrm{~J} \\
2.61 \mathrm{~J} \\
3.22 \mathrm{~J} \\
1.42 \mathrm{~J} \\
1.68 \mathrm{~J}\end{array}$ \\
\hline $\begin{array}{l}R-B F \\
R-B F \\
R-B F \\
R-B F \\
R-B F\end{array}$ & $\begin{array}{l}1 \\
2 \\
3 \\
4 \\
5\end{array}$ & $\begin{array}{l}D \\
B \\
B \\
A \\
A\end{array}$ & $\begin{array}{l}2.71 \mathrm{~J} \\
10.43 \\
5.26 \\
3.07 \mathrm{~J} \\
1.92 \mathrm{~J}\end{array}$ & $\begin{array}{l}7.53 \mathrm{U} \\
8.72 \mathrm{U} \\
4.97 \mathrm{U} \\
6.06 \mathrm{U} \\
6.16 \mathrm{U}\end{array}$ & $\begin{array}{l}4.07 \mathrm{U} \\
4.71 \mathrm{U} \\
2.68 \mathrm{U} \\
3.28 \mathrm{U} \\
3.33 \mathrm{U}\end{array}$ & $\begin{array}{l}0.95 \mathrm{~J} \\
1.57 \mathrm{~J} \\
1.32 \mathrm{~J} \\
0.99 \mathrm{~J} \\
1.19 \mathrm{~J}\end{array}$ & $\begin{array}{l}2.82 \mathrm{~J} \\
3.51 \mathrm{~J} \\
3.96 \\
3.17 \\
5.90\end{array}$ & $\begin{array}{l}3.33 \mathrm{U} \\
0.58 \mathrm{~J} \\
0.94 \mathrm{~J} \\
0.45 \mathrm{~J} \\
0.70 \mathrm{~J}\end{array}$ \\
\hline $\begin{array}{l}\text { R-OS } \\
\text { R-OS Replicate } 1 \\
\text { R-OS Replicate } 2 \\
\text { R-OS Replicate } 3 \\
\text { R-OS } \\
\text { R-OS } \\
\text { R-OS }\end{array}$ & $\begin{array}{l}1 \\
2 \\
2 \\
2 \\
3 \\
4 \\
5\end{array}$ & $\begin{array}{l}8 \\
0 \\
0 \\
0 \\
8 \\
0 \\
C\end{array}$ & $\begin{array}{l}3.89 \mathrm{~J} \\
4.67 \mathrm{~J} \\
4.77 \mathrm{~J} \\
4.88 \mathrm{~J} \\
5.86 \\
2.06 \mathrm{~J} \\
2.23 \mathrm{~J}\end{array}$ & $\begin{array}{r}4.50 \mathrm{U} \\
15.87 \mathrm{U} \\
12.87 \mathrm{U} \\
15.56 \mathrm{U} \\
4.73 \mathrm{U} \\
5.19 \mathrm{U} \\
5.08 \mathrm{U}\end{array}$ & $\begin{array}{l}2.43 \mathrm{U} \\
8.57 \mathrm{U} \\
6.95 \mathrm{U} \\
8.40 \mathrm{U} \\
1.11 \mathrm{~J} \\
2.80 \mathrm{U} \\
0.52 \mathrm{~J}\end{array}$ & $\begin{array}{l}0.78 \mathrm{~J} \\
1.17 \mathrm{~J} \\
1.32 \mathrm{~J} \\
1.38 \mathrm{~J} \\
0.84 \mathrm{~J} \\
0.90 \mathrm{~J} \\
1.01 \mathrm{~J}\end{array}$ & $\begin{array}{l}2.40 \\
2.84 \mathrm{~J} \\
2.21 \mathrm{~J} \\
2.29 \mathrm{~J} \\
3.33 \\
2.02 \mathrm{~J} \\
2.67\end{array}$ & $\begin{array}{l}0.27 \mathrm{~J} \\
7.02 \mathrm{U} \\
0.37 \mathrm{~J} \\
6.89 \mathrm{U} \\
0.43 \mathrm{~J} \\
2.30 \mathrm{U} \\
0.24 \mathrm{~J}\end{array}$ \\
\hline $\begin{array}{l}R-P F \\
R-P F \\
R-P F \\
R-P F \\
R-P F\end{array}$ & $\begin{array}{l}1 \\
2 \\
3 \\
4 \\
5\end{array}$ & $\begin{array}{l}C \\
C \\
D \\
D \\
A\end{array}$ & $\begin{array}{l}6.96 \\
2.18 \mathrm{~J} \\
1.57 \mathrm{~J} \\
1.56 \mathrm{~J} \\
2.37 \mathrm{~J}\end{array}$ & $\begin{array}{l}5.19 \mathrm{U} \\
5.88 \mathrm{U} \\
4.78 \mathrm{U} \\
4.08 \mathrm{U} \\
5.98 \mathrm{U}\end{array}$ & $\begin{array}{l}1.65 \mathrm{~J} \\
0.59 \mathrm{~J} \\
0.69 \mathrm{~J} \\
0.76 \mathrm{~J} \\
3.23 \mathrm{~J}\end{array}$ & $\begin{array}{l}1.53 \mathrm{~J} \\
1.16 \mathrm{~J} \\
0.87 \mathrm{~J} \\
0.88 \mathrm{~J} \\
1.02 \mathrm{~J}\end{array}$ & $\begin{array}{l}6.31 \\
3.08 \\
2.43 \\
2.38 \\
3.04\end{array}$ & $\begin{array}{l}0.37 \mathrm{~J} \\
0.22 \mathrm{~J} \\
2.12 \mathrm{U} \\
1.80 \mathrm{U} \\
0.21 \mathrm{~J}\end{array}$ \\
\hline $\begin{array}{l}C-S B \\
C-S B \\
C-S B \\
C-S B \\
C-S B\end{array}$ & $\begin{array}{l}1 \\
2 \\
3 \\
4 \\
5\end{array}$ & $\begin{array}{l}C \\
D \\
B \\
A \\
D\end{array}$ & $\begin{array}{l}2.10 \mathrm{~J} \\
1.95 \mathrm{~J} \\
6.94 \\
2.01 \mathrm{~J} \\
1.70 \mathrm{~J}\end{array}$ & $\begin{array}{l}5.02 \mathrm{U} \\
5.24 \mathrm{U} \\
5.81 \mathrm{U} \\
4.02 \mathrm{U} \\
4.45 \mathrm{U}\end{array}$ & $\begin{array}{l}0.60 \mathrm{~J} \\
0.83 \mathrm{~J} \\
3.14 \mathrm{U} \\
2.17 \mathrm{U} \\
0.50 \mathrm{~J}\end{array}$ & $\begin{array}{l}0.97 \mathrm{~J} \\
0.95 \mathrm{~J} \\
1.07 \mathrm{~J} \\
2.35 \mathrm{~J} \\
0.75 \mathrm{~J}\end{array}$ & $\begin{array}{l}2.46 \\
2.30 \mathrm{~J} \\
3.27 \\
2.48 \\
2.13\end{array}$ & $\begin{array}{l}0.22 \mathrm{~J} \\
2.32 \mathrm{U} \\
0.66 \mathrm{~J} \\
1.78 \mathrm{U} \\
0.31 \mathrm{~J}\end{array}$ \\
\hline $\begin{array}{l}\text { C-NE } \\
\text { C-NE } \\
\text { C-NE } \\
\text { C-NE } \\
\text { C-NE }\end{array}$ & $\begin{array}{l}1 \\
2 \\
3 \\
4 \\
5\end{array}$ & $\begin{array}{l}B \\
B \\
B \\
B \\
B\end{array}$ & $\begin{array}{l}3.73 \\
4.19 \mathrm{~J} \\
4.58 \\
3.49 \mathrm{~J} \\
3.96 \mathrm{~J}\end{array}$ & $\begin{array}{l}3.60 \mathrm{U} \\
4.23 \mathrm{U} \\
4.17 \mathrm{U} \\
4.66 \mathrm{U} \\
5.13 \mathrm{U}\end{array}$ & $\begin{array}{l}0.70 \mathrm{~J} \\
0.84 \mathrm{~J} \\
0.94 \mathrm{~J} \\
2.52 \mathrm{~J} \\
2.77 \mathrm{U}\end{array}$ & $\begin{array}{l}0.96 \mathrm{~J} \\
1.26 \mathrm{~J} \\
1.13 \mathrm{~J} \\
0.98 \mathrm{~J} \\
1.15 \mathrm{~J}\end{array}$ & $\begin{array}{l}3.69 \\
4.39 \\
3.92 \\
3.93 \\
3.99\end{array}$ & $\begin{array}{l}1.59 \mathrm{U} \\
1.87 \mathrm{U} \\
0.31 \mathrm{~J} \\
2.06 \mathrm{U} \\
2.27 \mathrm{U}\end{array}$ \\
\hline $\begin{array}{l}\text { MSL Background } \\
\text { MSL Background } \\
\text { MSL Background } \\
\text { MSL Background } \\
\text { MSL Background }\end{array}$ & $\begin{array}{l}1 \\
2 \\
3 \\
4 \\
5\end{array}$ & $\begin{array}{l}E \\
E \\
E \\
E \\
E\end{array}$ & $\begin{array}{l}2.58 \mathrm{~J} \\
3.51 \\
3.54 \\
3.01 \\
2.77\end{array}$ & $\begin{array}{l}2.64 \mathrm{U} \\
2.65 \mathrm{U} \\
2.65 \mathrm{U} \\
2.67 \mathrm{U} \\
2.65 \mathrm{U}\end{array}$ & $\begin{array}{l}0.55 \mathrm{~J} \\
0.54 \mathrm{~J} \\
0.49 \mathrm{~J} \\
0.45 \mathrm{~J} \\
0.49 \mathrm{~J}\end{array}$ & $\begin{array}{r}1.42 \mathrm{~J} \\
1.28 \mathrm{~J} \\
1.31 \mathrm{~J} \\
1.3 \mathrm{~J} \\
1.4 \mathrm{~J}\end{array}$ & $\begin{array}{l}3.36 \\
3.64 \mathrm{~J} \\
3.68 \\
3.34 \\
3.82\end{array}$ & $\begin{array}{l}0.41 \mathrm{~J} \\
0.36 \mathrm{~J} \\
0.68 \mathrm{~J} \\
0.38 \mathrm{~J} \\
0.39 \mathrm{~J}\end{array}$ \\
\hline
\end{tabular}

(a) DL Detection fimit.

(b) NA Not applicabie.

(c) J Analyte detected below method detection limit (MDL), but above instrument detection limit (IDL).

(d) U The analyte was not present above the level of the associated value. 
TABLE K.6. High Molecular Weight Polynuclear Aromatic Hydrocarbons (HPAHs), Wet Weight, in Tissue of $N$. caecoides, Richmond Harbor Program

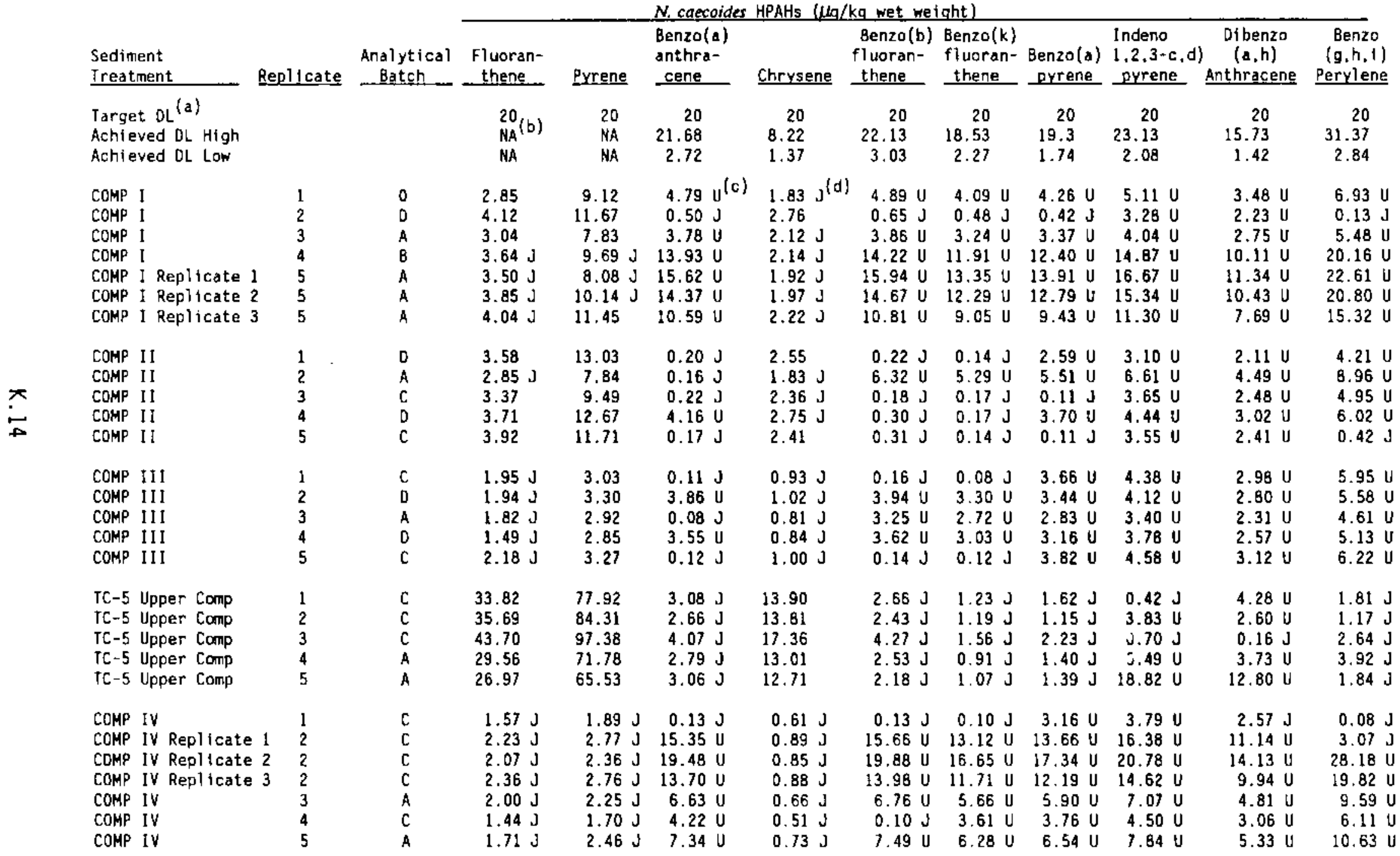


IABLE K.6. (contd)

N. caecoides HPAHs $(\mu \mathrm{kg} / \mathrm{kq}$ wet weight

\begin{tabular}{|c|c|c|c|c|c|c|c|c|c|c|c|c|}
\hline & & & & & N. caecoit & HPAHs $(\mu \mathrm{kg}$ & $1 \mathrm{kq}$ wet wei & (aht) & & & & \\
\hline $\begin{array}{l}\text { Sediment } \\
\text { Ireatment }\end{array}$ & Replicate & $\begin{array}{l}\text { Analytical } \\
\text { Batch } \\
\end{array}$ & $\begin{array}{c}\text { Fluoran- } \\
\text { thene } \\
\end{array}$ & Prrene & $\begin{array}{l}\text { Benzo(a) } \\
\text { anthra- } \\
\text { cene } \\
\end{array}$ & Chrysene & $\begin{array}{l}\text { Benzo(b) } \\
\text { fluoran- } \\
\text { thene } \\
\end{array}$ & $\begin{array}{l}\text { Benzo(k) } \\
\text { fluoran- } \\
\text { thene }\end{array}$ & $\begin{array}{c}\text { Benzo (a) } \\
\text { pyrene }\end{array}$ & $\begin{array}{l}\text { Indeno } \\
1,2,3-c, d) \\
\text { pyrene }\end{array}$ & $\begin{array}{c}\text { Dibenzo } \\
(a, h) \\
\text { Anthracene }\end{array}$ & $\begin{array}{r}\text { Benzo } \\
(g, h, i) \\
\text { Perylene }\end{array}$ \\
\hline
\end{tabular}

\section{COMP $V$ \\ COMP $V$ \\ COMP $V$ \\ COMP $V$ \\ COMP $\vee$}

COMP VI

COMP VI

COMP VI

COMP Y

COMP VI

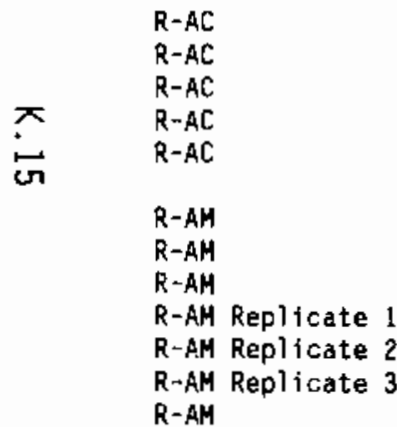

$R-B F$

$R-B F$

$R-B F$

$R-B F$

$R-B F$

$R-0 S$

R-OS Replicate 1 R-OS Replicate 2 R-OS Replicate 3 $R-O S$

$R-0 S$

R-DS

$\begin{array}{lrr}4.18 & 26.55 & 3.80 \mathrm{U} \\ 3.77 & 26.28 & 0.30 \mathrm{~J} \\ 4.23 & 29.01 & 0.34 \mathrm{~J} \\ 5.03 & 32.29 & 4.34 \mathrm{U} \\ 5.51 & 36.13 & 2.72 \mathrm{U} \\ & & \\ 3.35 & 22.55 & 0.25 \mathrm{~J} \\ 4.25 & 30.59 & 0.37 \mathrm{~J} \\ 4.62 & 31.32 & 4.17 \mathrm{U} \\ 4.18 & 25.33 & 4.21 \mathrm{U} \\ 6.29 \mathrm{~J} & 42.73 & 12.93 \mathrm{U} \\ & & \\ 217.95 & 712.43 & 7.28 \\ 209.59 & 680.71 & 36.62 \\ 330.02 & 924.62 & 17.07 \\ 319.09 & 1013.35 & 11.08 \\ 439.95 & 1252.51 & 19.99 \\ & & \\ 25.19 & 49.59 & 0.69 \mathrm{~J} \\ 13.64 & 34.17 & 0.82 \mathrm{~J} \\ 18.57 & 47.23 & 1.09 \mathrm{~J} \\ 31.65 & 54.10 & 14.18 \mathrm{U} \\ 22.60 & 38.95 & 21.68 \mathrm{U} \\ 28.65 & 60.01 & 1.15 \mathrm{~J} \\ 13.53 & 31.33 & 0.59 \mathrm{~J} \\ & & \\ 3.20 \mathrm{~J} & 7.60 & 5.57 \mathrm{U} \\ 3.69 \mathrm{~J} & 7.14 & 6.45 \mathrm{U} \\ 4.30 & 8.67 & 1.00 \mathrm{~J} \\ 4.57 & 10.11 & 0.28 \mathrm{~J} \\ 6.75 & 9.51 & 1.00 \mathrm{~J} \\ & & \\ 1.62 \mathrm{~J} & 1.78 \mathrm{~J} & 3.33 \mathrm{U} \\ 2.51 \mathrm{~J} & 3.68 \mathrm{~J} & 11.73 \mathrm{U} \\ 2.40 \mathrm{~J} & 2.67 \mathrm{~J} & 9.51 \mathrm{U} \\ 2.66 \mathrm{~J} & 2.78 \mathrm{~J} & 11.50 \mathrm{U} \\ 1.53 \mathrm{~J} & 2.27 \mathrm{~J} & 3.50 \mathrm{U} \\ 1.47 \mathrm{~J} & 1.93 \mathrm{~J} & 3.84 \mathrm{U} \\ 2.01 \mathrm{~J} & 2.22 \mathrm{~J} & 0.11 \mathrm{~J}\end{array}$

3.60
3.53
3.83
4.73
4.64

3.47
3.97
3.79
3.28
$5.73 \mathrm{~J}$

39.30
36.36
58.99
46.03
68.51

7.60
7.67
9.63
10.66
$7.21 \mathrm{~J}$
10.28
6.00

$2.40 \mathrm{~J}$
$2.25 \mathrm{~J}$
3.03
$2.83 \mathrm{~J}$
4.30

$0.63 \mathrm{~J}$
$8.22 \mathrm{U}$
$0.82 \mathrm{~J}$
$1.11 \mathrm{~J}$
$0.76 \mathrm{~J}$
$0.70 \mathrm{~J}$
$0.67 \mathrm{~J}$

0.60

$\begin{array}{lllll}0.59 \mathrm{~J} & 0.43 \mathrm{~J} & 3.38 \mathrm{U} & 4.06 \mathrm{U}\end{array}$

$\begin{array}{llllll}0.42 \mathrm{~J} & 0.36 \mathrm{~J} & 0.14 \mathrm{~J} & 3.28 \mathrm{U}\end{array}$

$0.65 \mathrm{~J} \quad 0.71 \mathrm{~J} \quad 0.48 \mathrm{~J} \quad 0.39 \mathrm{~J}$

$\begin{array}{lllll}0.44 \mathrm{~J} & 0.50 \mathrm{~J} & 2.42 \mathrm{~J} & 2.90 \mathrm{U}\end{array}$

$\begin{array}{llllll}0.43 \mathrm{~J} & 0.33 \mathrm{~J} & 0.18 \mathrm{~J} & 4.76 \mathrm{~J}\end{array}$

$\begin{array}{llllll}0.55 \mathrm{~J} & 0.38 \mathrm{~J} & 0.25 \mathrm{~J} & 3.83 \mathrm{U}\end{array}$

$0.71 \mathrm{~J} \quad 0.27 \mathrm{~J} \quad 3.71 \mathrm{U} \quad 4.45 \mathrm{U}$

$0.85 \mathrm{~J} \quad 0.56 \mathrm{~J} \quad 3.75 \mathrm{U} \quad 4.49 \mathrm{U}$

$13.20 \mathrm{U} \quad 11.05 \mathrm{U} 11.51 \mathrm{U} 13.80 \mathrm{U}$

$4.83 \mathrm{~J} \quad 2.35 \mathrm{~J} \quad 2.75 \mathrm{~J} \quad 5.99 \mathrm{U}$

$4.61 \mathrm{~J} \quad 2.67 \mathrm{~J} \quad 2.43 \mathrm{~J} \quad 13.40 \mathrm{U}$

$\begin{array}{lllll}11.34 & 4.41 & 10.79 & 0.55 \mathrm{~J}\end{array}$

$\begin{array}{rrr}6.70 & 3.62 \mathrm{~J} \quad 5.62 & 4.62 \mathrm{U}\end{array}$

$\begin{array}{llll}18.91 & 17.75 & 8.04 & 3.61 \mathrm{U}\end{array}$

$\begin{array}{lllll}0.57 \mathrm{~J} & 0.24 \mathrm{~J} & 3.32 \mathrm{U} & 3.97 \mathrm{U}\end{array}$

$\begin{array}{lllll}0.30 \mathrm{~J} & 0.23 \mathrm{~J} & 0.15 \mathrm{~J} & 3.10 \mathrm{U}\end{array}$

$0.24 \mathrm{~J} \quad 0.44 \mathrm{~J} \quad 2.59 \mathrm{U} \quad 3.10 \mathrm{U}$

$14.47 \mathrm{U} \quad 12.12 \mathrm{U} \quad 12.62 \mathrm{U} \quad 15.13 \mathrm{U}$

$22.13 \mathrm{U} \quad 18.53$ U $19.30 \mathrm{U} 23.13 \mathrm{U}$

$\begin{array}{llllll}0.69 \mathrm{~J} & 0.37 \mathrm{~J} & 6.91 \mathrm{U} & 8.29 \mathrm{U} & \\ 3.24 & 2.72 \mathrm{~J} & 2.83 & \mathrm{U} & 3.39 \mathrm{U}\end{array}$

3.24

2.72

2.83

$5.68 \mathrm{U} \quad 4.76 \mathrm{U} \quad 4.96 \mathrm{U} \quad 5.94 \mathrm{U}$

$0.96 \mathrm{~J} \quad 5.51 \mathrm{U} \quad 5.74 \mathrm{U} \quad 6.88 \mathrm{U}$

$\begin{array}{lllllll}0.81 \mathrm{~J} & 0.77 \mathrm{~J} & 0.76 \mathrm{~J} & 3.92 \mathrm{U}\end{array}$

$\begin{array}{lllll}0.26 \mathrm{~J} & 0.25 \mathrm{~J} & 3.99 \mathrm{U} & 4.79 \mathrm{U}\end{array}$

$1.75 \mathrm{~J} \quad 1.41 \mathrm{~J} \quad 4.06 \mathrm{U} \quad 0.93 \mathrm{~J}$

$\begin{array}{llll}3.40 \mathrm{U} & 2.85 \mathrm{~V} & 2.96 \mathrm{U} & 3.55 \mathrm{U}\end{array}$

$11.97 \mathrm{U} \quad 10.03 \mathrm{U} \quad 10.44 \mathrm{U} 12.52 \mathrm{U}$

$9.71 \mathrm{U} \quad 8.13 \mathrm{U} \quad 8.47 \mathrm{U} \quad 10.15 \mathrm{U}$

$11.74 \mathrm{U} \quad 9.83 \mathrm{U} \quad 10.24 \mathrm{U} 12.28 \mathrm{U}$

3.57 U $2.99 \mathrm{U} \quad 3.11 \mathrm{U} \quad 3.73 \mathrm{U}$

$3.91 \mathrm{U} \quad 3.28 \mathrm{U} \quad 3.41 \mathrm{U} \quad 4.09 \mathrm{U}$

$0.18 \mathrm{~J} \quad 0.06 \mathrm{~J} \quad 3.34 \mathrm{U} \quad 4.01 \mathrm{U}$
$2.76 \mathrm{U} \quad 5.50 \mathrm{U}$

$3.19 \mathrm{U} \quad 0.41 \mathrm{~J}$

$2.23 \mathrm{U} \quad 4.45 \mathrm{U}$

$3.15 \mathrm{U} \quad 6.29 \mathrm{~V}$

$1.98 \mathrm{U} \quad 3.94 \mathrm{U}$

$3.24 \mathrm{U} \quad 6.46 \mathrm{U}$

$2.61 \mathrm{U} \quad 0.31 \mathrm{~J}$

$3.03 \mathrm{U} \quad 6.03 \mathrm{~J}$

$3.05 \mathrm{U} \quad 6.09 \mathrm{~V}$

$4.07 \mathrm{U} \quad 1.70 \mathrm{~J}$

$9.12 \mathrm{U} \quad 1.61 \mathrm{~J}$

$0.12 \mathrm{~J} \quad 6.91$

$3.14 \mathrm{U} \quad 3.85 \mathrm{~J}$

$2.45 \mathrm{U} \quad 4.18 \mathrm{~J}$

$2.70 \mathrm{U} \quad 5.39$

$2.11 \mathrm{U} \quad 0.12 \mathrm{~J}$

$2.11 \mathrm{U} \quad 4.21 \mathrm{U}$

$10.29 \mathrm{U} 20.52 \mathrm{U}$

$15.73 \mathrm{U} \quad 31.37 \mathrm{U}$

$5.64 \mathrm{U} \quad 11.24 \mathrm{~V}$

$2.31 \mathrm{U} \quad 4.60 \mathrm{U}$

$4.04 \mathrm{U} \quad 8.06 \mathrm{U}$

$4.68 \mathrm{U} \quad 1.88 \mathrm{~J}$

$2.67 \mathrm{U} \quad 5.31 \mathrm{U}$

$3.25 \mathrm{U} \quad 6.49$

$0.54 \mathrm{~J} \quad 1.09 \mathrm{~J}$

$2.42 \mathrm{U} \quad 4.82 \mathrm{IJ}$

$8.51 \mathrm{U} \quad 3.35 \mathrm{~J}$

$6.90 \mathrm{U} \quad 13.77 \mathrm{U}$

$8.35 \mathrm{U} \quad 16.65 \mathrm{U}$

$2.54 \mathrm{U} \quad 5.06 \mathrm{U}$

$2.78 \mathrm{U} \quad 5.55 \mathrm{U}$

$2.73 \mathrm{U} \quad 5.44 \mathrm{U}$ 
TABLE K.6. (contd)

\begin{tabular}{|c|c|c|c|c|c|c|c|c|c|c|c|c|}
\hline $\begin{array}{l}\text { Sediment } \\
\text { Ireatment }\end{array}$ & Replicate & $\begin{array}{l}\text { Analytical } \\
\text { Batch } \\
\end{array}$ & $\begin{array}{c}\begin{array}{c}\text { Fluoran- } \\
\text { thene }\end{array} \\
\end{array}$ & Pyrene & $\begin{array}{l}\text { 8enzo(a) } \\
\text { anthra- } \\
\text { cene } \\
\end{array}$ & Chrysene & $\begin{array}{l}\text { Benzo(b) } \\
\text { fluoran- } \\
\text { thene } \\
\end{array}$ & $\begin{array}{l}\text { Benzo(k) } \\
\text { fluoran- } \\
\text { thene }\end{array}$ & $\begin{array}{l}\text { 8enzo(a) } \\
\text { Drrene } \\
\end{array}$ & $\begin{array}{l}\text { Indeno } \\
1,2,3-c . d) \\
\text { prrene }\end{array}$ & $\begin{array}{c}\text { O1benzo } \\
(a, h) \\
\text { Anthracene }\end{array}$ & $\begin{array}{r}\text { Benzo } \\
(g, h, 1) \\
\text { Perylene } \\
\end{array}$ \\
\hline $\begin{array}{l}R-P F \\
R-P F \\
R-P F \\
R-P F \\
R-P F\end{array}$ & $\begin{array}{l}1 \\
2 \\
3 \\
4 \\
5\end{array}$ & $\begin{array}{l}C \\
C \\
0 \\
0 \\
A\end{array}$ & $\begin{array}{l}4.85 \\
2.57 \\
2.02 \mathrm{~J} \\
2.19 \\
2.25 \mathrm{~J}\end{array}$ & $\begin{array}{l}4.32 \\
2.52 \mathrm{~J} \\
2.70 \\
2.71 \\
2.75 \mathrm{~J}\end{array}$ & $\begin{array}{l}0.93 \mathrm{~J} \\
4.34 \mathrm{U} \\
3.54 \mathrm{U} \\
3.01 \mathrm{U} \\
4.42 \mathrm{U}\end{array}$ & $\begin{array}{l}1.56 \mathrm{~J} \\
0.82 \mathrm{~J} \\
0.82 \mathrm{~J} \\
0.95 \mathrm{~J} \\
0.78 \mathrm{~J}\end{array}$ & $\begin{array}{l}0.68 \mathrm{~J} \\
0.17 \mathrm{~J} \\
3.61 \mathrm{U} \\
3.08 \mathrm{U} \\
0.22 \mathrm{~J}\end{array}$ & $\begin{array}{ll}0.41 & \mathrm{~J} \\
3.71 & \mathrm{U} \\
3.02 & \mathrm{U} \\
2.58 \mathrm{U} \\
3.78 \mathrm{U}\end{array}$ & $\begin{array}{ll}0.62 & \mathrm{~J} \\
3.87 & \mathrm{U} \\
3.15 & \mathrm{U} \\
2.68 \mathrm{U} \\
3.94 & \mathrm{U}\end{array}$ & $\begin{array}{l}4.10 \mathrm{U} \\
4.64 \mathrm{U} \\
3.77 \mathrm{U} \\
3.22 \mathrm{U} \\
4.72 \mathrm{U}\end{array}$ & $\begin{array}{l}2.79 \mathrm{U} \\
3.15 \mathrm{U} \\
2.57 \mathrm{U} \\
2.19 \mathrm{U} \\
3.21 \mathrm{U}\end{array}$ & $\begin{array}{l}0.39 \mathrm{~J} \\
6.29 \mathrm{U} \\
5.12 \mathrm{U} \\
4.36 \mathrm{U} \\
6.40 \mathrm{U}\end{array}$ \\
\hline $\begin{array}{l}C-S B \\
C-S B \\
C-S B \\
C-S B \\
C-S B\end{array}$ & $\begin{array}{l}1 \\
2 \\
3 \\
4 \\
5\end{array}$ & $\begin{array}{l}C \\
D \\
B \\
A \\
D\end{array}$ & $\begin{array}{l}3.58 \\
3.30 \\
3.94 \\
3.26 \\
3.83\end{array}$ & $\begin{array}{l}4.31 \\
4.28 \\
4.47 \\
3.71 \\
4.63\end{array}$ & $\begin{array}{l}0.20 \mathrm{~J} \\
3.8 \mathrm{U} \\
4.30 \mathrm{U} \\
2.97 \mathrm{U} \\
3.29 \mathrm{U}\end{array}$ & $\begin{array}{l}1.37 \mathrm{~J} \\
1.51 \mathrm{~J} \\
1.44 \mathrm{~J} \\
1.16 \mathrm{~J} \\
1.38 \mathrm{~J}\end{array}$ & $\begin{array}{l}0.16 \mathrm{~J} \\
3.96 \mathrm{U} \\
4.38 \mathrm{U} \\
3.03 \mathrm{U} \\
3.36 \mathrm{U}\end{array}$ & $\begin{array}{l}0.08 \mathrm{~J} \\
3.31 \mathrm{U} \\
3.67 \mathrm{U} \\
2.54 \mathrm{U} \\
2.81 \mathrm{U}\end{array}$ & $\begin{array}{l}0.08 \mathrm{~J} \\
3.45 \mathrm{U} \\
3.82 \mathrm{U} \\
2.65 \mathrm{U} \\
2.93 \mathrm{U}\end{array}$ & $\begin{array}{l}7.96 \mathrm{U} \\
4.14 \mathrm{U} \\
4.58 \mathrm{U} \\
3.17 \mathrm{U} \\
3.51 \mathrm{U}\end{array}$ & $\begin{array}{l}2.69 \mathrm{U} \\
2.81 \mathrm{U} \\
3.12 \mathrm{U} \\
2.16 \mathrm{U} \\
2.39 \mathrm{U}\end{array}$ & $\begin{array}{l}5.37 \mathrm{U} \\
5.61 \mathrm{U} \\
6.22 \mathrm{U} \\
4.30 \mathrm{U} \\
4.76 \mathrm{U}\end{array}$ \\
\hline $\begin{array}{l}C-N E \\
C-N E \\
C-N E \\
C-N E \\
C-N E\end{array}$ & $\begin{array}{l}1 \\
2 \\
3 \\
4 \\
5\end{array}$ & $\begin{array}{l}B \\
B \\
9 \\
B \\
B\end{array}$ & $\begin{array}{l}2.77 \\
2.38 \\
2.82 \\
1.86 \mathrm{~J} \\
2.12 \mathrm{~J}\end{array}$ & $\begin{array}{l}2.81 \\
2.75 \\
3.01 \\
2.31 \mathrm{~J} \\
2.61 \mathrm{~J}\end{array}$ & $\begin{array}{l}0.89 \mathrm{~J} \\
3.13 \mathrm{U} \\
0.26 \mathrm{~J} \\
3.45 \mathrm{U} \\
3.80 \mathrm{U}\end{array}$ & $\begin{array}{l}0.86 \mathrm{~J} \\
1.05 \mathrm{~J} \\
0.95 \mathrm{~J} \\
0.93 \mathrm{~J} \\
0.94 \mathrm{~J}\end{array}$ & $\begin{array}{l}2.71 \mathrm{U} \\
3.19 \mathrm{U} \\
0.16 \mathrm{~J} \\
3.52 \mathrm{U} \\
3.87 \mathrm{U}\end{array}$ & $\begin{array}{l}2.27 \mathrm{U} \\
2.68 \mathrm{U} \\
2.63 \mathrm{U} \\
2.95 \mathrm{U} \\
3.25 \mathrm{U}\end{array}$ & $\begin{array}{l}2.37 \mathrm{U} \\
2.79 \mathrm{U} \\
2.74 \mathrm{U} \\
3.07 \mathrm{U} \\
3.38 \mathrm{U}\end{array}$ & $\begin{array}{l}2.84 \mathrm{U} \\
3.34 \mathrm{U} \\
3.29 \mathrm{U} \\
3.68 \mathrm{U} \\
4.05 \mathrm{U}\end{array}$ & $\begin{array}{l}1.93 \mathrm{U} \\
2.27 \mathrm{U} \\
2.24 \mathrm{U} \\
2.50 \mathrm{U} \\
2.76 \mathrm{U}\end{array}$ & $\begin{array}{l}3.85 \mathrm{U} \\
4.53 \mathrm{U} \\
4.46 \mathrm{U} \\
4.99 \mathrm{U} \\
5.49 \mathrm{U}\end{array}$ \\
\hline $\begin{array}{l}\text { MSL Background } \\
\text { MSL Background } \\
\text { MSL Background } \\
\text { MSL. 8ackground } \\
\text { MSL. Background }\end{array}$ & $\begin{array}{l}1 \\
2 \\
3 \\
4 \\
5\end{array}$ & $\begin{array}{l}E \\
E \\
E \\
E \\
E\end{array}$ & $\begin{array}{l}1.99 \\
1.89 \\
2.49 \\
1.91 \\
2.01\end{array}$ & $\begin{array}{r}2.15 \\
2.09 \\
2.24 \\
2.1 \\
2.3\end{array}$ & $\begin{array}{r}0.23 \mathrm{~J} \\
0.25 \mathrm{~J} \\
0.24 \mathrm{~J} \\
0.2 \mathrm{~J} \\
0.26 \mathrm{~J}\end{array}$ & $\begin{array}{l}0.8 \mathrm{~J} \\
1.47 \\
1.37 \mathrm{U} \\
0.79 \mathrm{~J} \\
0.82 \mathrm{~J}\end{array}$ & 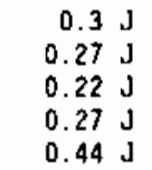 & $\begin{array}{l}0.16 \mathrm{~J} \\
0.1 \mathrm{~J} \\
0.19 \mathrm{~J} \\
0.1 \mathrm{~J} \\
0.24 \mathrm{~J}\end{array}$ & $\begin{array}{l}1.74 \mathrm{U} \\
1.74 \mathrm{U} \\
1.74 \mathrm{U} \\
1.76 \mathrm{U} \\
1.74 \mathrm{U}\end{array}$ & $\begin{array}{l}2.08 \mathrm{U} \\
2.09 \mathrm{U} \\
2.09 \mathrm{U} \\
2.11 \mathrm{U} \\
0.23 \mathrm{~J}\end{array}$ & $\begin{array}{l}1.42 \mathrm{U} \\
1.42 \mathrm{U} \\
1.42 \mathrm{U} \\
1.43 \mathrm{U} \\
1.42 \mathrm{U}\end{array}$ & $\begin{array}{l}0.53 \mathrm{~J} \\
2.84 \mathrm{U} \\
0.16 \mathrm{~J} \\
2.86 \mathrm{U} \\
0.28 \mathrm{~J}\end{array}$ \\
\hline
\end{tabular}

\footnotetext{
(a) DL Detection limit.

(b) NA Not applicable.

(c) U The analyte was not present above the level of the assoctated value.

(d) J Analyte detected beiow method detection 11 mit (MOL). but above instrument detection limit (IDL).
} 
IABLE K.7. Quality Control Data for Low Molecular Weight Polynuclear Aromatic Hydrocarbons (LPAHs), Wet Weight, in Tissue of $N$. caecoides, Richmond Harbor Program

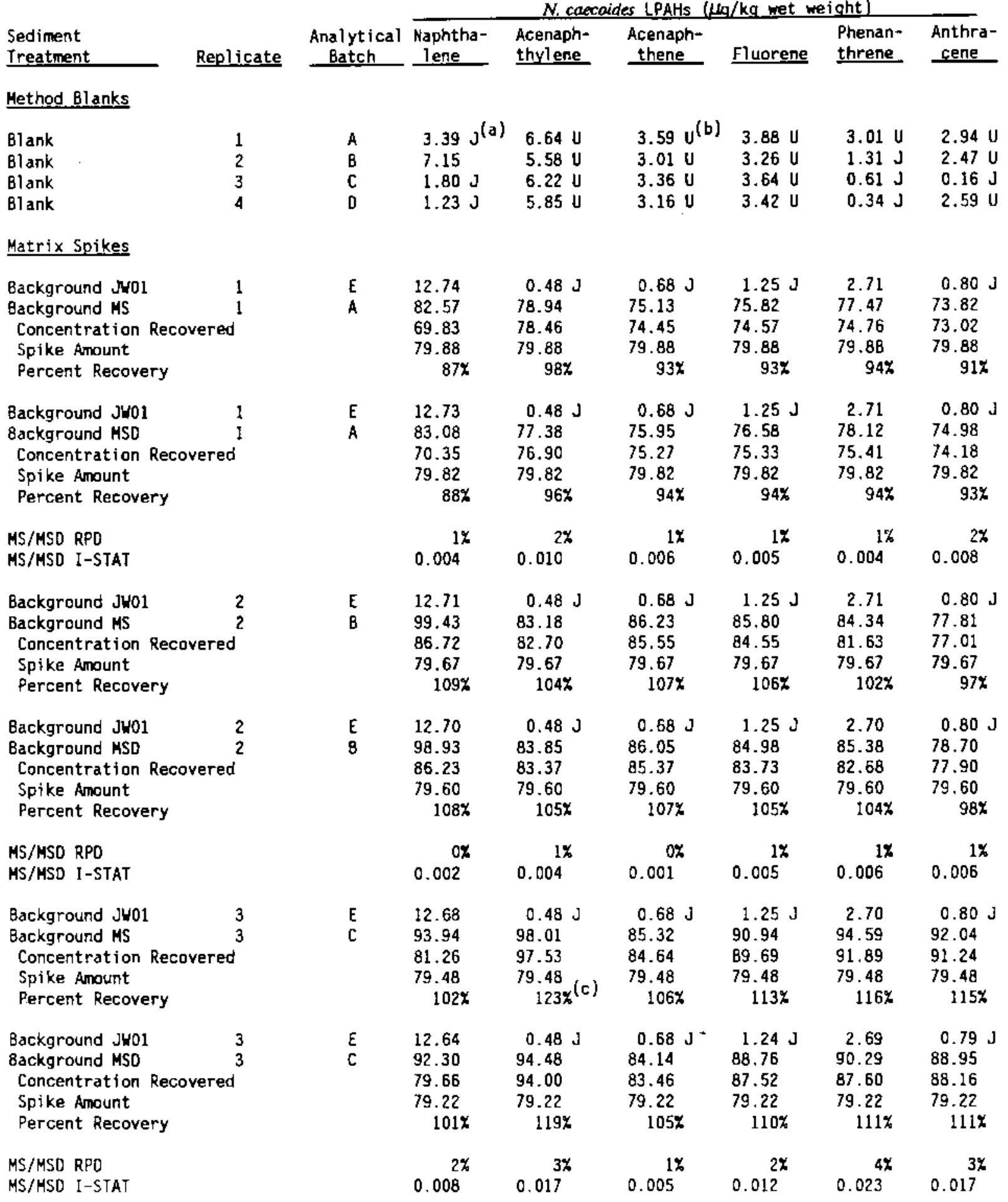


IABLE K.7. (contd)

\begin{tabular}{|c|c|c|c|c|c|c|c|c|}
\hline \multirow{2}{*}{$\begin{array}{l}\text { Sediment } \\
\text { Ireatment }\end{array}$} & \multirow[b]{2}{*}{ Replicate } & \multirow[b]{2}{*}{$\begin{array}{l}\text { Analytical } \\
\text { Batch } \\
\end{array}$} & \multicolumn{6}{|c|}{ N. caecoides LPAHs ( $(\mathrm{ld} / \mathrm{kg}$ wet weight) } \\
\hline & & & $\begin{array}{l}\text { Naphtha- } \\
\text { lene }\end{array}$ & $\begin{array}{l}\text { Acenaph- } \\
\text { thylene } \\
\end{array}$ & $\begin{array}{l}\text { Acenaph- } \\
\text { thene }\end{array}$ & Fluorene & $\begin{array}{l}\text { Phenan- } \\
\text { threne }\end{array}$ & $\begin{array}{l}\text { Anthra- } \\
\text { cene } \\
\end{array}$ \\
\hline $\begin{array}{l}\text { Background WO1 } \\
\text { Background MS } \\
\text { Concentration Reco } \\
\text { Spike Amount } \\
\text { Percent Recovery }\end{array}$ & $\begin{array}{r}4 \\
4 \\
\text { svered }\end{array}$ & $\begin{array}{l}E \\
0\end{array}$ & $\begin{array}{l}12.73 \\
89.36 \\
76.63 \\
79.78 \\
96 \%\end{array}$ & $\begin{array}{c}0.48 \mathrm{~J} \\
84.72 \\
84.24 \\
79.78 \\
106 \%\end{array}$ & $\begin{array}{c}0.68 \mathrm{~J} \\
83.23 \\
82.55 \\
79.78 \\
103 x\end{array}$ & $\begin{array}{c}1.25 \mathrm{~J} \\
81.57 \\
80.32 \\
79.78 \\
101 \mathrm{x}\end{array}$ & $\begin{array}{r}2.71 \\
86.37 \\
83.66 \\
79.78 \\
105 \%\end{array}$ & $\begin{array}{c}0.80 \mathrm{~J} \\
79.80 \\
79.00 \\
79.78 \\
99 \%\end{array}$ \\
\hline $\begin{array}{l}\text { Background JWOI } \\
\text { Background HSD } \\
\text { Concentratian Reco } \\
\text { Spike Amount } \\
\text { Percent Recovery }\end{array}$ & vered & $\begin{array}{l}E \\
D\end{array}$ & $\begin{array}{r}12.42 \\
86.14 \\
73.72 \\
77.85 \\
95 \%\end{array}$ & $\begin{array}{l}0.47 \mathrm{~J} \\
80.16 \\
79.69 \\
77.85 \\
102 \%\end{array}$ & $\begin{array}{l}0.66 \mathrm{~J} \\
81.16 \\
80.50 \\
77.85 \\
103 \mathrm{x}\end{array}$ & $\begin{array}{c}1.22 \mathrm{~J} \\
79.48 \\
78.26 \\
77.85 \\
101 \mathrm{x}\end{array}$ & $\begin{array}{r}2.65 \\
83.90 \\
81.25 \\
77.85 \\
104 \%\end{array}$ & $\begin{array}{c}0.78 \mathrm{~J} \\
77.13 \\
76.35 \\
77.85 \\
98 \%\end{array}$ \\
\hline $\begin{array}{l}\text { MS/MSD RPD } \\
\text { MS/ KSD I-STAT }\end{array}$ & & & $0.007^{1 x}$ & $0.015^{3 x}$ & $0.000^{0 x}$ & $0.013^{D \%}$ & $0.015^{08}$ & $0.017^{12}$ \\
\hline \multicolumn{9}{|c|}{ Standard Reference Material } \\
\hline Certified Value & & & $N C^{(d)}$ & NC & NC & NC & $\begin{array}{r}5.6 \\
+1.4\end{array}$ & $\begin{array}{r}0.75 \\
\pm 0.21\end{array}$ \\
\hline $\begin{array}{ll}\text { SRM } & 1974 \\
\text { SRH } & 1974 \\
\text { SRH } & 1974 \\
\text { SRM } & 1974\end{array}$ & $\begin{array}{l}1 \\
2 \\
3 \\
4\end{array}$ & $\begin{array}{l}A \\
\mathrm{~B} \\
\mathrm{C} \\
0\end{array}$ & $\begin{array}{l}\text { NA }(e) \\
\text { NA } \\
\text { NA } \\
\text { NA }\end{array}$ & $\begin{array}{l}\text { NA } \\
\text { NA } \\
\text { NA } \\
\text { NA }\end{array}$ & $\begin{array}{l}\text { NA } \\
\text { NA } \\
\text { NA } \\
\text { NA }\end{array}$ & $\begin{array}{l}\text { NA } \\
\text { NA } \\
\text { NA } \\
\text { NA }\end{array}$ & $\begin{array}{l}4.48 \\
4.76 \\
4.74 \\
4.87\end{array}$ & $\begin{array}{l}0.77 \mathrm{~J} \\
0.64 \mathrm{~J} \\
1.12 \mathrm{~J} \\
0.49 \mathrm{~J}\end{array}$ \\
\hline \multicolumn{9}{|l|}{ Analytical Replicates } \\
\hline $\begin{array}{l}\text { COMP I Replicate } 1 \\
\text { COMP I Replicate } 2 \\
\text { COMP I Replicate } 3 \\
\text { RSD }\end{array}$ & $\begin{array}{l}5 \\
5 \\
5\end{array}$ & $\begin{array}{l}A \\
A \\
A\end{array}$ & $\begin{array}{l}8.52 \mathrm{~J} \\
5.89 \mathrm{~J} \\
6.09 \mathrm{~J} \\
21 \mathrm{X}\end{array}$ & $\begin{array}{l}21.13 \mathrm{U} \\
19.44 \mathrm{U} \\
14.32 \mathrm{U} \\
\text { NA }\end{array}$ & $\begin{aligned} 11.41 \mathrm{U} \\
10.50 \mathrm{~V} \\
7.74 \mathrm{U} \\
\text { NA }\end{aligned}$ & $\begin{array}{r}2.08 \mathrm{~J} \\
11.37 \mathrm{U} \\
8.37 \mathrm{U} \\
\text { NA }\end{array}$ & $\begin{array}{l}5.34 \mathrm{~J} \\
3.69 \mathrm{~J} \\
3.77 \mathrm{~J} \\
22 \mathrm{x}\end{array}$ & $\begin{array}{l}9.35 \mathrm{U} \\
8.61 \mathrm{U} \\
6.34 \mathrm{U} \\
\text { NA }\end{array}$ \\
\hline $\begin{array}{l}\text { COMP IV Replicate } 1 \\
\text { COMP IV Replicate } 2 \\
\text { COMP IV Replicate } 3 \\
\text { RSD }\end{array}$ & $\begin{array}{l}2 \\
2 \\
2\end{array}$ & $\begin{array}{l}\mathrm{C} \\
\mathrm{C} \\
\mathrm{C}\end{array}$ & $\begin{array}{c}6.51 \mathrm{~J} \\
7.64 \mathrm{~J} \\
8.33 \mathrm{~J} \\
12 \mathrm{x}\end{array}$ & $\begin{array}{l}20.76 \mathrm{U} \\
26.34 \mathrm{U} \\
18.52 \mathrm{U} \\
\text { NA }\end{array}$ & $\begin{array}{r}1.11 \mathrm{~J} \\
14.23 \mathrm{U} \\
1.10 \mathrm{~J} \\
\mathrm{NA}\end{array}$ & $\begin{array}{l}1.94 \mathrm{~J} \\
2.10 \mathrm{~J} \\
1.91 \mathrm{~J} \\
5 \%\end{array}$ & $\begin{array}{l}3.87 \mathrm{~J} \\
3.23 \mathrm{~J} \\
4.35 \mathrm{~J} \\
15 \mathrm{z}\end{array}$ & $\begin{array}{r}9.19 \mathrm{U} \\
11.66 \mathrm{U} \\
8.20 \mathrm{U} \\
\text { NA }\end{array}$ \\
\hline $\begin{array}{l}\text { R-AH Repi icate } 1 \\
\text { R-AH Replicate } 2 \\
\text { R-AM Replicate } 3 \\
\text { RSO }\end{array}$ & $\begin{array}{l}4 \\
4 \\
4\end{array}$ & $\begin{array}{l}B \\
B \\
B\end{array}$ & $\begin{array}{l}31.56 \\
31.71 \\
8.83 \mathrm{~J}(\mathrm{f}) \\
55 \%\end{array}$ & $\begin{array}{c}19.18 \mathrm{U} \\
29.32 \mathrm{U} \\
10.50 \mathrm{U} \\
\text { NA }\end{array}$ & $\begin{array}{rl}10.36 & \mathrm{U} \\
15.84 \mathrm{U} \\
5.67 \mathrm{U} \\
\text { NA }\end{array}$ & $\begin{array}{r}1.56 \mathrm{~J} \\
17.14 \mathrm{U} \\
1.49 \mathrm{~J} \\
\text { NA }\end{array}$ & $\begin{array}{c}11.37 \\
13.81 \\
9.93 \\
177\end{array}$ & $\begin{array}{l}2.61 \mathrm{~J} \\
3.22 \mathrm{~J} \\
1.42 \mathrm{~J} \\
38 \mathrm{X}^{(f)}\end{array}$ \\
\hline $\begin{array}{l}\text { R-OS Replicate } 1 \\
\text { R-OS Replicate } 2 \\
\text { R-OS Repl icate } 3 \\
\text { RSD }\end{array}$ & $\begin{array}{l}2 \\
2 \\
2\end{array}$ & $\begin{array}{l}0 \\
0 \\
0\end{array}$ & $\begin{array}{c}4.67 \mathrm{~J} \\
4.77 \mathrm{~J} \\
4.88 \mathrm{~J} \\
2 \%\end{array}$ & $\begin{array}{c}15.87 \mathrm{U} \\
12.87 \mathrm{U} \\
15.56 \mathrm{U} \\
\text { NA }\end{array}$ & $\begin{array}{l}8.57 \mathrm{U} \\
6.95 \mathrm{U} \\
8.40 \mathrm{U} \\
\text { NA }\end{array}$ & $\begin{array}{l}1.17 \mathrm{~J} \\
1.32 \mathrm{~J} \\
1.38 \mathrm{~J} \\
8 \%\end{array}$ & $\begin{array}{l}2.84 \mathrm{~J} \\
2.21 \mathrm{~J} \\
2.29 \mathrm{~J} \\
14 \mathrm{X}\end{array}$ & $\begin{array}{l}7.02 \mathrm{U} \\
0.37 \mathrm{~J} \\
6.89 \mathrm{U} \\
\mathrm{NA}\end{array}$ \\
\hline
\end{tabular}

(a) J Analyte detected below method detection 1 imit (HDL), but above instrument detection limit (IOL).

(b) U The analyte was not present above the level of the associated value.

(c) Recovery outside quality control range $(40 x-120 x)$.

(d) NC Not certified.

(e) NA Not applicable.

(f) Value exceeds relative precision range of $30 x$. 
TABLE K.8. Quality Control Data for High Molecular Weight Polynuclear Aromatic Hydrocarbons (HPAHs), Wet Weight, in Tissue of $N$. caecoides, Richmond Harbor Program

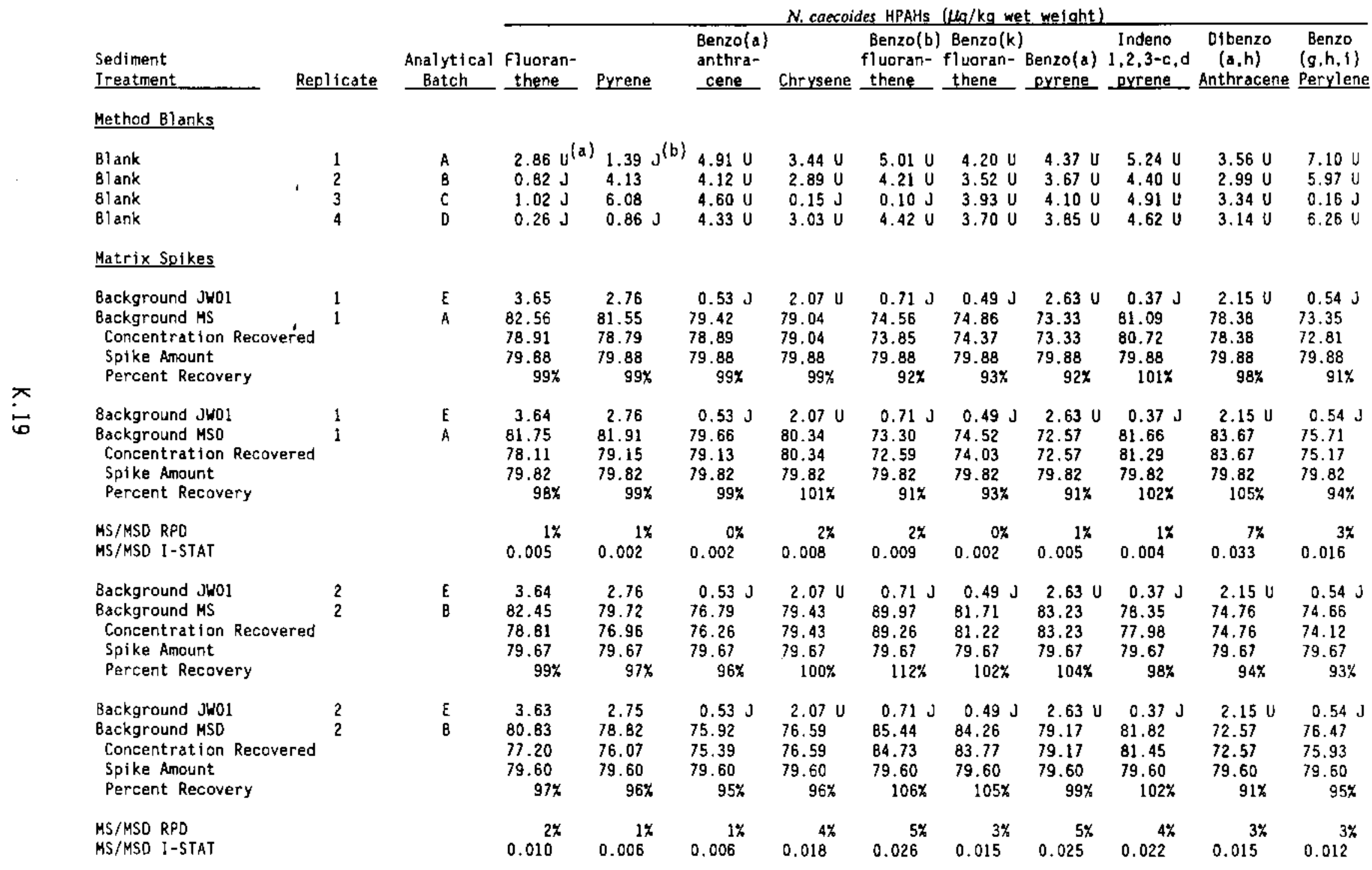


IABLE K.8. (contd)

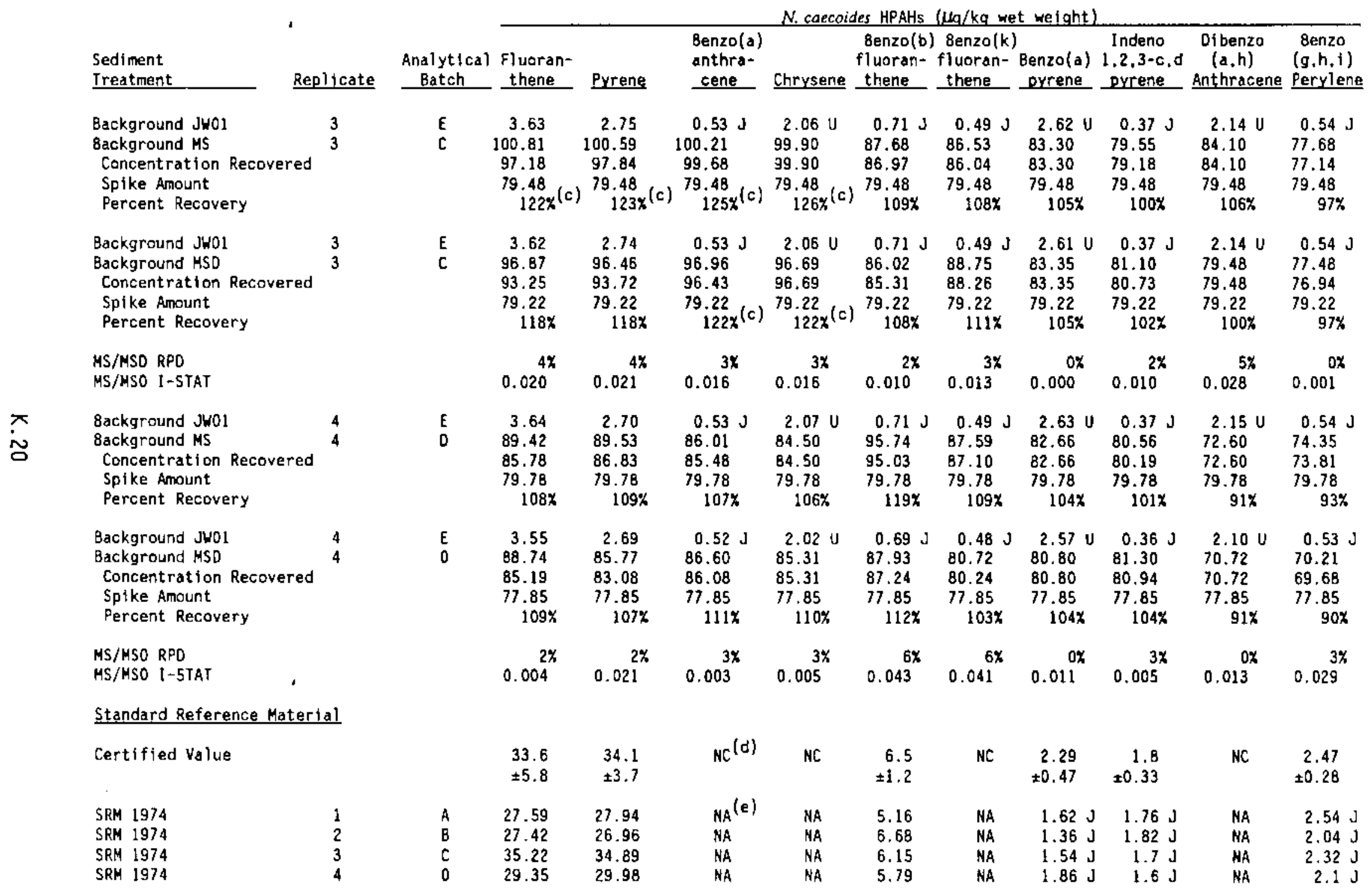


IABLE K.8. (contd)

\begin{tabular}{|c|c|c|c|c|c|c|c|c|c|c|c|c|}
\hline \multirow[b]{2}{*}{$\begin{array}{l}\text { Sediment } \\
\text { Ireatment }\end{array}$} & \multirow[b]{2}{*}{ Replicate } & \multirow[b]{2}{*}{$\begin{array}{l}\text { Analytical } \\
\text { Batch }\end{array}$} & \multicolumn{10}{|c|}{ N. caecoides HPAMs ( $1 \mathrm{~g} / \mathrm{kg}$ ret weight) } \\
\hline & & & $\begin{array}{l}\text { Fluoran- } \\
\text { thene }\end{array}$ & Pyrene & $\begin{array}{l}\text { Benzo(a) } \\
\text { anthra- } \\
\text { cene } \\
\end{array}$ & Chrysene & $\begin{array}{l}\text { Benzo(b) } \\
\text { fluoran- } \\
\text { thene }\end{array}$ & $\begin{array}{l}\text { Benzo(k) } \\
\text { fluoran- } \\
\text { thene }\end{array}$ & $\begin{array}{l}\text { Benzo(a) } \\
\text { Pyrene }\end{array}$ & $\begin{array}{l}\text { Indeno } \\
1.2 .3 \cdot c . d \\
\text { prrene } \\
\end{array}$ & $\begin{array}{c}\text { Dibenzo } \\
(a, h) \\
\text { Anthracene }\end{array}$ & $\begin{array}{l}\text { 8enzo } \\
(g, h, i) \\
\text { Perylene } \\
\end{array}$ \\
\hline Analytical Replicate & & & & & & & & & & & & \\
\hline $\begin{array}{l}\text { COMP I Replicate } 1 \\
\text { COMP I Rep]icate } 2 \\
\text { COMP I Replicate } 3 \\
\text { RSD }\end{array}$ & $\begin{array}{l}5 \\
5 \\
5\end{array}$ & $\begin{array}{l}\mathrm{A} \\
\mathrm{A} \\
\mathrm{A}\end{array}$ & $\begin{array}{c}3.50 \mathrm{~J} \\
3.85 \mathrm{~J} \\
4.04 \mathrm{~J} \\
7 \%\end{array}$ & $\begin{array}{c}8.08 \mathrm{~J} \\
10.14 \mathrm{~J} \\
11.45 \\
17 \%\end{array}$ & $\begin{array}{l}15.62 \mathrm{U} \\
14.37 \mathrm{U} \\
10.59 \mathrm{U} \\
\text { NA }\end{array}$ & $\begin{array}{c}1.92 \mathrm{~J} \\
1.97 \mathrm{~J} \\
2.22 \mathrm{~J} \\
8 \%\end{array}$ & $\begin{array}{c}15.94 \mathrm{U} \\
14.67 \mathrm{U} \\
10.81 \mathrm{U} \\
\mathrm{NA}\end{array}$ & $\begin{array}{c}13.35 \mathrm{U} \\
12.29 \mathrm{U} \\
9.05 \mathrm{U} \\
\text { NA }\end{array}$ & $\begin{array}{r}13.91 \mathrm{U} \\
12.79 \mathrm{U} \\
9.43 \mathrm{U} \\
\text { NA }\end{array}$ & $\begin{array}{l}16.67 \mathrm{U} \\
15.34 \mathrm{U} \\
11.30 \mathrm{U} \\
\mathrm{NA}\end{array}$ & $\begin{array}{c}11.34 \mathrm{U} \\
10.43 \mathrm{U} \\
7.69 \mathrm{U} \\
\mathrm{NA}\end{array}$ & $\begin{array}{l}22.61 \mathrm{U} \\
20.80 \mathrm{U} \\
15.32 \mathrm{U} \\
\text { NA }\end{array}$ \\
\hline $\begin{array}{l}\text { COMP IV Replicate } 1 \\
\text { COMP IV Repl icate } 2 \\
\text { COMP IV Repl icate } 3 \\
\text { RSD }\end{array}$ & $\begin{array}{l}2 \\
2 \\
2\end{array}$ & $\begin{array}{l}c \\
C \\
C\end{array}$ & $\begin{array}{c}2.23 \mathrm{~J} \\
2.07 \mathrm{~J} \\
2.36 \mathrm{~J} \\
7 \%\end{array}$ & $\begin{array}{c}2.77 \mathrm{~J} \\
2.36 \mathrm{~J} \\
2.76 \mathrm{~J} \\
9 \%\end{array}$ & $\begin{array}{l}15.35 \mathrm{U} \\
19.48 \mathrm{U} \\
13.70 \mathrm{U} \\
\text { NA }\end{array}$ & $\begin{array}{c}0.89 \mathrm{~J} \\
0.85 \mathrm{~J} \\
0.88 \mathrm{~J} \\
2 \%\end{array}$ & $\begin{array}{l}15.66 \mathrm{U} \\
19.88 \mathrm{U} \\
13.98 \mathrm{U} \\
\text { NA }\end{array}$ & $\begin{array}{l}13.12 \mathrm{U} \\
16.65 \mathrm{U} \\
11.71 \mathrm{U} \\
\text { NA }\end{array}$ & $\begin{array}{l}13.66 \mathrm{U} \\
17.34 \mathrm{U} \\
12.19 \mathrm{U} \\
\mathrm{NA}\end{array}$ & $\begin{array}{l}16.38 \mathrm{U} \\
20.78 \mathrm{U} \\
14.62 \mathrm{U} \\
\text { NA }\end{array}$ & $\begin{array}{c}11.14 \mathrm{U} \\
14.13 \mathrm{U} \\
9.94 \mathrm{U} \\
\text { NA }\end{array}$ & $\begin{array}{rl}3.07 & \mathrm{~J} \\
28.18 \mathrm{U} \\
19.82 \mathrm{U} \\
\text { NA }\end{array}$ \\
\hline $\begin{array}{l}\text { R-AM Replicate } 1 \\
\text { R-AM Replicate } 2 \\
\text { R-AM Replicate } 3 \\
\text { RSD }\end{array}$ & $\begin{array}{l}4 \\
4 \\
4\end{array}$ & $\begin{array}{l}8 \\
8 \\
B\end{array}$ & $\begin{array}{r}31.65 \\
22.60 \\
28.65 \\
17 \%\end{array}$ & $\begin{array}{r}54.10 \\
38.95 \\
60.01 \\
21 \%\end{array}$ & $\begin{array}{c}14.18 \mathrm{U} \\
21.68 \mathrm{U} \\
1.15 \mathrm{~J} \\
\mathrm{NA}\end{array}$ & $\begin{array}{c}10.66 \\
7.21 \mathrm{~J} \\
10.28 \\
20 \%\end{array}$ & $\begin{array}{c}14.47 \mathrm{U} \\
22.13 \mathrm{U} \\
0.69 \mathrm{~J} \\
\text { NA }\end{array}$ & $\begin{array}{r}12.12 \mathrm{U} \\
18.53 \mathrm{U} \\
0.37 \mathrm{~J} \\
\text { NA }\end{array}$ & $\begin{array}{c}12.62 \mathrm{U} \\
19.30 \mathrm{U} \\
6.91 \mathrm{U} \\
\mathrm{NA}\end{array}$ & $\begin{array}{c}15.13 \mathrm{U} \\
23.13 \mathrm{U} \\
8.29 \mathrm{U} \\
\mathrm{NA}\end{array}$ & $\begin{array}{c}10.29 \mathrm{U} \\
15.73 \mathrm{U} \\
5.64 \mathrm{U} \\
\text { NA }\end{array}$ & $\begin{array}{l}20.52 \mathrm{U} \\
31.37 \mathrm{U} \\
11.24 \mathrm{U} \\
\text { NA }\end{array}$ \\
\hline $\begin{array}{l}\text { R-OS Replicate } 1 \\
\text { R-OS Replicate } 2 \\
\text { R-OS Replicate } 3 \\
\text { RSD }\end{array}$ & $\begin{array}{l}2 \\
2 \\
2\end{array}$ & $\begin{array}{l}0 \\
0 \\
0\end{array}$ & $\begin{array}{l}2.51 \mathrm{~J} \\
2.40 \mathrm{~J} \\
2.66 \mathrm{~J} \\
5 \%\end{array}$ & $\begin{array}{l}3.68 \mathrm{~J} \\
2.67 \mathrm{~J} \\
2.78 \mathrm{~J} \\
18 \%\end{array}$ & $\begin{array}{r}11.73 \mathrm{U} \\
9.51 \mathrm{U} \\
11.50 \mathrm{U} \\
\text { NA }\end{array}$ & $\begin{array}{l}8.22 \mathrm{U} \\
0.82 \mathrm{~J} \\
1.11 \mathrm{~J} \\
\text { NA }\end{array}$ & $\begin{array}{rl}11.97 & \mathrm{U} \\
9.71 \mathrm{U} \\
11.74 \mathrm{U} \\
\text { NA }\end{array}$ & $\begin{array}{c}10.03 \mathrm{U} \\
8.13 \mathrm{U} \\
9.83 \mathrm{U} \\
\mathrm{NA}\end{array}$ & $\begin{array}{r}10.44 \mathrm{U} \\
8.47 \mathrm{U} \\
10.24 \mathrm{U} \\
\text { NA }\end{array}$ & $\begin{array}{l}12.52 \mathrm{U} \\
10.15 \mathrm{U} \\
12.28 \mathrm{U} \\
\text { NA }\end{array}$ & $\begin{array}{l}8.51 U \\
6.90 \mathrm{U} \\
8.35 \mathrm{U} \\
\text { NA }\end{array}$ & $\begin{aligned} 3.35 \mathrm{~J} \\
13.77 \mathrm{U} \\
16.65 \mathrm{U} \\
\text { NA }\end{aligned}$ \\
\hline
\end{tabular}

(a) U The analyte was not present above the level of the associated value.

(b) J Analyte detected below method detection limit (MDL). but above instrument detection limit (IDL).

(c) Recovery outside quality control range (40\%-120\%)

(d) NC Not certified.

(e) NA Not applicable. 
TABLE K.9. Surrogate Recoveries for Polynuclear Aromatic Hydrocarbons (PAHs) Including Quality Control Data in Tissue of $N$. caecoides, Richmond Harbor Program

Sediment

Ireatment

\section{COMP I}

COMP I

COMP I

COMP I

COMP I Replicate 1

COMP I Replicate 2

COMP I Replicate 3

COMP II

COMP II

COMP II

COMP II

COMP II

COMP III

COMP III

COMP III

COMP II I

COMP III

TC-5 Upper Comp

TC-5 Upper Comp

TC-5 Upper Comp

TC-5 Upper Comp

TC-5 Upper Comp

COMP IV

COMP IV Replicate 1

COMP IV Replicate 2

COMP IV Replicate 3

COMP IV

COMP IV

COMP IV

COMP V

COMP V

COMP V

COMP V

COMP V

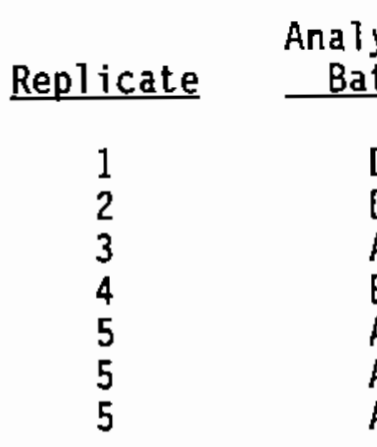

1

2

3

4
5

1

2

3

4

5

1

2

3

4

5

1

2

2

2

3

4
5

1

2

3

4
5

Surrogate Percent Recoveries Naphtha- Acenaph- Benzo(a) lene thene pyrene $\mathrm{d} 8 \quad \mathrm{~d} 10 \quad \mathrm{~d} 12$

D

D

B

A

A

A

D

A

C

D

C

C

0

A

D

C

C
C
C
A
A

C

C

C

A

C

A

A

A

A

0

B
64.76

58.96

78.35

70.39

80.10

82.11

77.49

58.62

80.95

61.09

67.58

72.19

70.39

61.43

79.11

69.95

64.78

67.65

71.85

70.03

84.13

79.98

65.13

70.88

68.41

73.04

83.40

64.03

78.20

74.13

82.12

60.98

66.39

42.36
69.93

69.19

87.12

79.20

84.50

81.61

79.97

66.56

82.84

65.55

69.53

75.77

75.34

66.31

86.58

69.78

73.34

71.20

73.51

72.64

85.76

83.11

66.17

73.11

71.51

77.52

86.94

69.48

82.52

87.41

85.31

66.42

69.58

56.23
66.49

66.99

94.32

66.06

85.26

87.31

85.65

64.18

87.41

75.30

68.93

76.63

76.95

70.88

89.13

65.91

76.61

75.77

74.38

72.38

89.05

85.54

74.17

74.87

74.32

78.68

84.59

73.56

87.64

89.34

89.45

71.20

65.47

65.45 
IABLE K.9. (contd)

\begin{tabular}{l} 
Sediment \\
Treatment \\
\hline
\end{tabular}

COMP VI
COMP VI
COMP VI
COMP VI
COMP VI

$R-A C$

$\mathrm{R}-\mathrm{AC}$

$\mathrm{R}-\mathrm{AC}$

$\mathrm{R}-\mathrm{AC}$

$\mathrm{R}-\mathrm{AC}$

R-AM
R-AM
R-AM
R-AM Replicate 1
R-AM Replicate 2
R-AM Replicate 3
R-AM

$R-B F$

$R-B F$

$\mathrm{R}-\mathrm{BF}$

$\mathrm{R}-\mathrm{BF}$

$R-B F$

R-OS

R-OS Replicate 1

R-OS Replicate 2

R-OS Replicate 3

$\mathrm{R}-\mathrm{OS}$

R-OS

R-OS

$\mathrm{R}-\mathrm{PF}$

$R-P F$

$R-P F$

$R-P F$

$R-P F$

C-SB

C-SB

$C-S B$

C-SB

C-SB

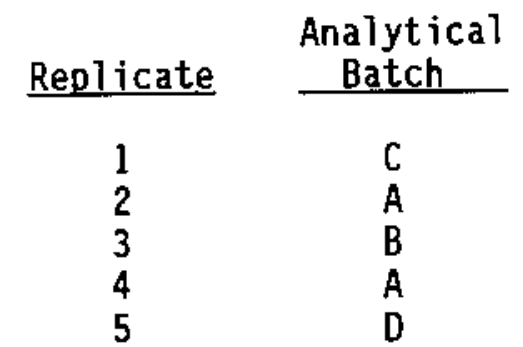

$\begin{array}{ll}1 & \text { B } \\ 2 & \text { C } \\ 3 & \text { C } \\ 4 & \text { A } \\ 5 & \text { D }\end{array}$

1
2
3
4
4
4
5

5

1
2
3
4
5

1
2
2
2
3
4
5

I

1
2
3
4
5

1
2
3
4
5
Surrogate Percent Recoveries

Naphtha- Acenaph- Benzo(a) lene thene pyrene $\mathrm{d} 8 \quad \mathrm{~d} 10 \quad \mathrm{~d} 12$ $\begin{array}{lll}64.85 & 73.29 & 74.92\end{array}$

$83.20 \quad 86.20 \quad 89.71$

$\begin{array}{lll}56.62 & 67.58 & 43.37\end{array}$

$\begin{array}{lll}68.48 & 81.64 & 85.39\end{array}$

$\begin{array}{lll}60.41 & 67.13 & 59.31\end{array}$

$\begin{array}{lll}57.84 & 63.54 & 72.95\end{array}$

$\begin{array}{lll}72.21 & 74.16 & 77.47\end{array}$

$\begin{array}{lll}71.26 & 73.59 & 78.47\end{array}$

$\begin{array}{lll}80.62 & 86.91 & 91.51\end{array}$

$\begin{array}{lll}71.93 & 70.37 & 69.14\end{array}$

$\begin{array}{lll}34.73^{(a)} & 37.03^{(a)} & 41.97 \\ 58.98 & 65.94 & 74.39 \\ 50.36 & 64.69 & 77.59 \\ 67.89 & 75.63 & 63.79 \\ 66.83 & 75.12 & 63.03 \\ 73.85 & 72.67 & 78.46 \\ 64.77 & 75.60 & 82.79\end{array}$

$\begin{array}{lll}61.36 & 67.28 & 67.86\end{array}$

$\begin{array}{lll}70.76 & 81.95 & 73.09\end{array}$

$\begin{array}{lll}57.80 & 66.44 & 69.41\end{array}$

$\begin{array}{lll}73.57 & 80.29 & 85.12\end{array}$

$\begin{array}{lll}62.92 & 81.07 & 88.08\end{array}$

$\begin{array}{lll}64.94 & 72.18 & 76.05\end{array}$

$\begin{array}{lll}64.67 & 71.62 & 59.98\end{array}$

$58.34 \quad 66.24 \quad 58.92$

$\begin{array}{lll}56.46 & 64.80 & 54.39\end{array}$

$56.07 \quad 64.83 \quad 76.13$

$61.03 \quad 71.28 \quad 64.30$

$\begin{array}{lll}63.74 & 66.06 & 77.34\end{array}$

$\begin{array}{lll}40.26 & 42.86 & 42.88\end{array}$

$\begin{array}{lll}57.07 & 61.53 & 71.30\end{array}$

$\begin{array}{lll}64.11 & 68.78 & 72.92\end{array}$

$\begin{array}{lll}58.25 & 67.31 & 73.45\end{array}$

$\begin{array}{lll}81.33 & 85.64 & 91.60\end{array}$

$\begin{array}{lll}64.62 & 73.52 & 75.51\end{array}$

$\begin{array}{lll}68.20 & 69.38 & 68.84\end{array}$

$\begin{array}{lll}53.05 & 66.43 & 75.22\end{array}$

$61.02 \quad 73.57-73.11$

$\begin{array}{lll}60.65 & 68.61 & 66.07\end{array}$ 
TABLE K.9. (contd)

Sediment

Treatment

C-NE

$\mathrm{C}-\mathrm{NE}$

$\mathrm{C}-\mathrm{NE}$

$C-N E$

C-NE

MSL Background

MSL Background

MSL Background

MSL Background

MSL Background

Qual ity Control Data

Method Blanks

Blank

Bl ank

Blank

Blank

Matrix Spikes

\section{Background MS}

Background MSD

MS/MSD RPD

MS/MSD I-STAT

Background MS

Background MSD

MS/MSD RPD

MS/MSD I-STAT

Background MS

Background MSO

MS/MSD RPD

MS/MSD I-STAT

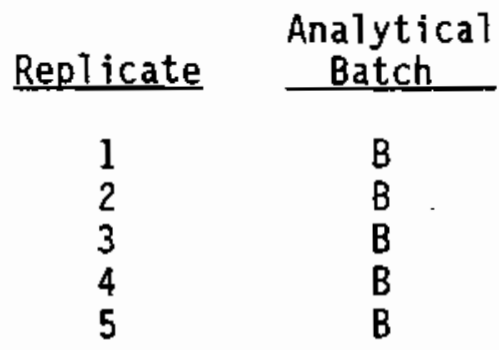

1

$E$
$E$
$E$
$E$
$E$

A

B

C

11.37

10.44

8.94

10.47

41.08

41.98

50.10

50.86

51.65

66

74

73

73

74
Surrogate Percent Recoveries tha- Acenaph- Benzo(a) thene pyrene d 10 d12

54.95

55.33

66.34

64.62

67.66

56.06

63.45

76.55

73.54

75.68

63

57

71

63

63

64

71

70

\section{3
3
6}$$
64
$$ 
TABLE K.9. (contd)

Sediment

Treatment

Background MS

Background MSD

MS/MSD RPD

MS/MSD I-STAT

Analytical Replicates

COMP I Replicate 1

COMP I Replicate 2

COMP I Replicate 3

RSD

COMP IV Replicate 1

COMP IV Replicate 2

COMP IV Replicate 3

RSD

R-AM Replicate 1
R-AM Replicate 2
R-AM Replicate 3
RSD

R-OS Replicate 1

R-OS Replicate 2

R-OS Replicate 3

RSD

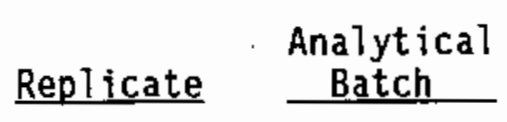

4

D

$A$
$A$
$A$

80.10

82.11

77.49

3

$c$
$c$
$c$

70.88

68.41

73.04

3

$\begin{array}{ll}4 & \text { B } \\ 4 & \text { B } \\ 4 & \text { B }\end{array}$

67.89

66.83

73.85

$$
5
$$

64.67

58.34

56.46

D
84.50

81.61

79.97

3

73.11

71.51

77.52

75.63

75.12

72.67

2

71.62

66.24

64.80

5
85.26

87.31

85.65

1

74.87

74.32

78.68

3

63.79

63.03

78.46

13

59.98

58.92

54.39

(a) Recovery outside quality control range (40\%-120\%). 
TABLE K.10. Chlorinated Pesticides (alphabetical, Aldrin-4,4-DDT), Dry Weight, in Tissue of N. caecoides, Richmond Harbor Program

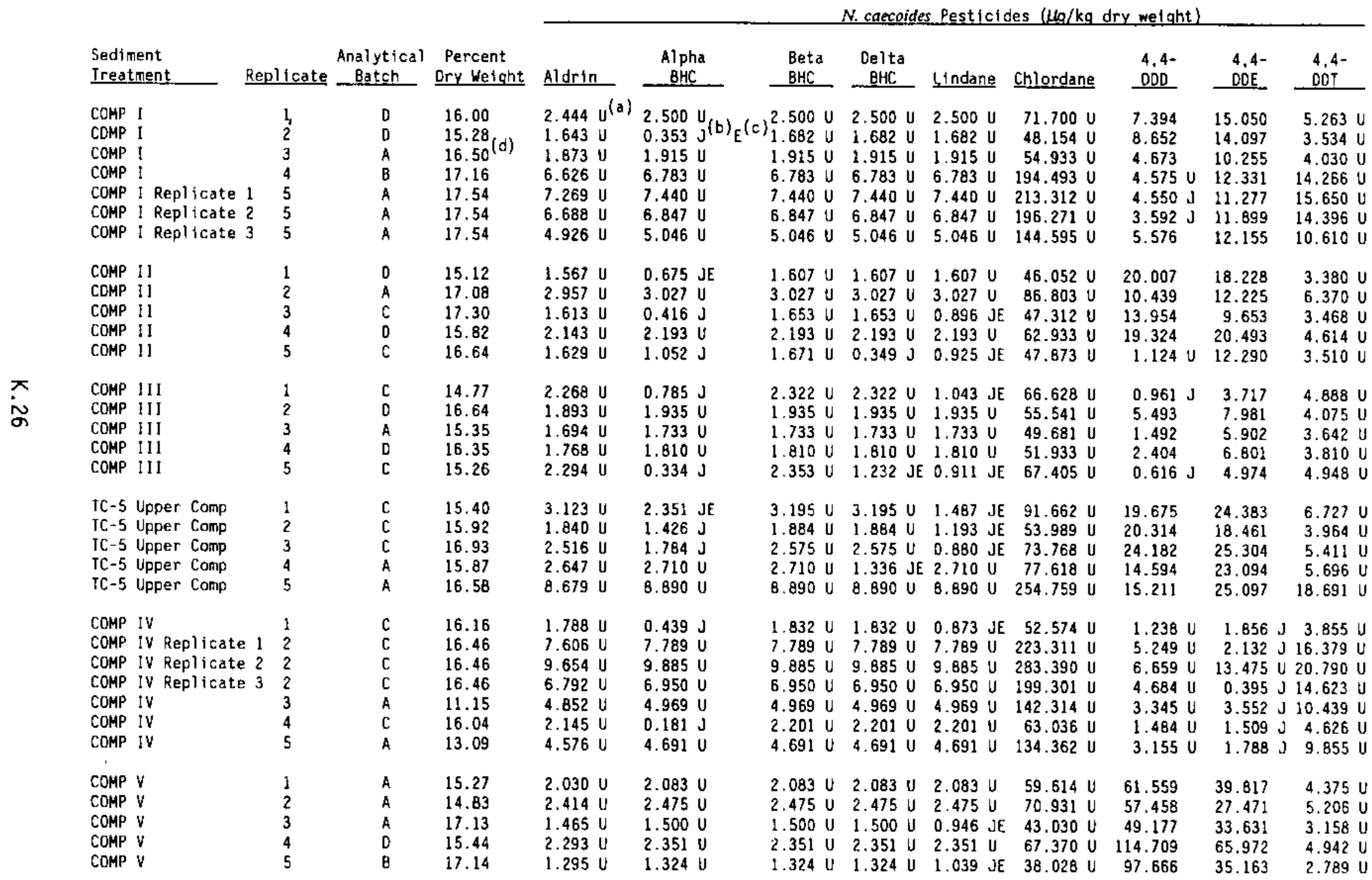


TABLE K.10. (contd)

\begin{tabular}{|c|c|c|c|c|c|c|c|c|c|c|c|c|c|}
\hline \multirow[b]{2}{*}{$\begin{array}{l}\text { Sediment } \\
\text { Ireatment }\end{array}$} & \multirow[b]{2}{*}{ Replicate } & \multirow[b]{2}{*}{$\begin{array}{l}\text { Anaiytical } \\
\text { Eatch }\end{array}$} & \multirow[b]{2}{*}{$\begin{array}{c}\text { Percent } \\
\text { Ory Weight }\end{array}$} & \multicolumn{10}{|c|}{$N$ coecoides Pesticides ( $(\mathrm{g} / \mathrm{kg}$ dry weight) } \\
\hline & & & & Aldrin & $\begin{array}{c}\text { Alpha } \\
\text { BHC } \\
\end{array}$ & $\begin{array}{l}\text { Eeta } \\
\text { BHC }\end{array}$ & $\begin{array}{c}\text { Oeita } \\
\text { BHC } \\
\end{array}$ & Lindane & & Chlordane & $\begin{array}{l}4,4- \\
000 \\
\end{array}$ & $\begin{array}{l}4,4- \\
\text { ODE } \\
\end{array}$ & $\begin{array}{l}4,4- \\
\text { DOT } \\
\end{array}$ \\
\hline $\begin{array}{l}\text { COMP VI } \\
\text { COMP VI } \\
\text { COMP VI } \\
\text { COMP VI } \\
\text { COMP VI }\end{array}$ & $\begin{array}{l}1 \\
2 \\
3 \\
4 \\
5\end{array}$ & $\begin{array}{l}C \\
A \\
8 \\
A \\
D\end{array}$ & $\begin{array}{l}15.08 \\
15.83 \\
16.25 \\
15.89 \\
16.24\end{array}$ & $\begin{array}{l}2.414 \mathrm{U} \\
1.851 \mathrm{U} \\
2.092 \mathrm{U} \\
2.159 \mathrm{U} \\
6.496 \mathrm{U}\end{array}$ & $\begin{array}{l}0.782 \mathrm{~J} \\
0.133 \mathrm{JE} \\
2.142 \mathrm{U} \\
2.215 \mathrm{U} \\
6.656 \mathrm{U}\end{array}$ & $\begin{array}{l}2.473 \mathrm{U} \\
1.895 \mathrm{U} \\
2.142 \mathrm{U} \\
2.215 \mathrm{U} \\
6.656 \mathrm{U}\end{array}$ & $\begin{array}{lll}U & 2.473 & U \\
U & 1.895 & U \\
U & 2.142 & U \\
U & 2.215 & U \\
U & 6.656\end{array}$ & $\begin{array}{ll}\mathrm{U} & 1.088 \\
\mathrm{U} & 1.895 \\
\mathrm{U} & 1.428 \\
\mathrm{U} & 2.215 \\
\mathrm{U} & 6.656\end{array}$ & $\begin{array}{l}\mathrm{JE} \\
\mathrm{U} \\
\mathrm{JE} \\
\mathrm{U} \\
\mathrm{U}\end{array}$ & $\begin{array}{r}70.889 \mathrm{U} \\
54.327 \mathrm{U} \\
61.458 \mathrm{U} \\
63.411 \mathrm{U} \\
190.739 \mathrm{U}\end{array}$ & $\begin{array}{r}107.633 \\
56.342 \\
143.834 \\
67.911 \\
151.675\end{array}$ & $\begin{array}{l}32.798 \\
23.689 \\
38.154 \\
37.036 \\
54.957\end{array}$ & $\begin{array}{r}5.199 U \\
3.986 U \\
4.511 U \\
4.651 U \\
13.990 \mathrm{U}\end{array}$ \\
\hline $\begin{array}{l}R-A C \\
R-A C \\
R-A C \\
R-A C \\
R-A C\end{array}$ & $\begin{array}{l}1 \\
2 \\
3 \\
4 \\
5\end{array}$ & $\begin{array}{l}B \\
C \\
C \\
A \\
D\end{array}$ & $\begin{array}{l}15.84 \\
16.14 \\
16.16 \\
13.29 \\
16.75\end{array}$ & $\begin{array}{l}2.891 \mathrm{U} \\
6.351 \mathrm{U} \\
1.999 \mathrm{U} \\
2.656 \mathrm{U} \\
1.648 \mathrm{U}\end{array}$ & $\begin{array}{l}2.961 \mathrm{~J} \\
0.155 \mathrm{~J} \\
2.048 \mathrm{U} \\
0.324 \mathrm{JE} \\
1.690 \mathrm{U}\end{array}$ & $\begin{array}{l}2.961 \mathrm{U} \\
6.506 \mathrm{U} \\
2.048 \mathrm{U} \\
2.724 \mathrm{U} \\
1.690 \mathrm{U}\end{array}$ & $\begin{array}{lll}U & 2.961 & U \\
U & 6.506 & U \\
U & 2.048 & \\
U & 2.724 & U \\
U & 1.690 & U\end{array}$ & $\begin{array}{ll}U & 2.961 \\
U & 6.506 \\
U & 0.978 \\
U & 2.724 \\
U & 1.690\end{array}$ & $\begin{array}{l}\mathrm{U} \\
\mathrm{U} \\
\mathrm{JE} \\
\mathrm{U} \\
\mathrm{U}\end{array}$ & $\begin{array}{r}84.855 \mathrm{U} \\
186.394 \mathrm{U} \\
58.645 \mathrm{U} \\
78.051 \mathrm{U} \\
48.352 \mathrm{U}\end{array}$ & $\begin{array}{l}9.186 \mathrm{~J} \\
4.380 \mathrm{U} \\
5.037 \\
4.695 \\
6.257\end{array}$ & $\begin{array}{r}12.835 \\
6.437 \\
7.902 \\
10.662 \\
12.269\end{array}$ & $\begin{array}{r}6.225 \mathrm{U} \\
\mathrm{J} 13.674 \mathrm{U} \\
4.301 \mathrm{U} \\
\mathrm{E} \quad 5.726 \mathrm{U} \\
3.546 \mathrm{U}\end{array}$ \\
\hline $\begin{array}{l}\text { R-AM } \\
\text { R-AM } \\
\text { R-AM } \\
\text { R-AM Replicate } 1 \\
\text { R-AM Replicate } 2 \\
\text { R-AM Replicate } 3 \\
\text { R-AM }\end{array}$ & $\begin{array}{l}1 \\
2 \\
3 \\
4 \\
4 \\
4 \\
5\end{array}$ & $\begin{array}{l}B \\
C \\
8 \\
B \\
8 \\
8 \\
8\end{array}$ & $\begin{array}{l}17.29 \\
16.62 \\
16.26 \\
16.61 \\
16.61 \\
16.61 \\
11.30\end{array}$ & $\begin{array}{r}1.758 \mathrm{U} \\
1.426 \mathrm{U} \\
1.458 \mathrm{U} \\
6.966 \mathrm{U} \\
10.650 \mathrm{U} \\
3.817 \mathrm{U} \\
2.292 \mathrm{U}\end{array}$ & $\begin{array}{r}1.799 \mathrm{U} \\
0.650 \mathrm{JE} \\
1.494 \mathrm{U} \\
7.134 \mathrm{U} \\
10.909 \mathrm{U} \\
3.907 \mathrm{U} \\
2.345 \mathrm{U}\end{array}$ & $\begin{array}{r}1.799 U \\
1.456 U \\
1.494 U \\
7.134 U \\
10.909 U \\
3.907 U \\
2.345 U\end{array}$ & $\begin{array}{lrr}U & 1.799 & U \\
U & 1.456 & U \\
U & 1.494 & U \\
U & 7.134 & U \\
U & 10.909 & U \\
U & 3.907 & U \\
U & 2.345 & U\end{array}$ & $\begin{array}{lr}U & 1.799 \\
U & 0.746 \\
\text { U } & 0.584 \\
U & 7.134 \\
\text { U } & 10.909 \\
U & 3.907 \\
\text { U } & 1.788\end{array}$ & $\begin{array}{l}\mathrm{U} \\
\mathrm{JE} \\
\mathrm{JE} \\
\mathrm{U} \\
\mathrm{U} \\
\mathrm{U} \\
\mathrm{J} \mathrm{J}\end{array}$ & $\begin{array}{r}51.579 \mathrm{U} \\
41.793 \mathrm{U} \\
42.841 \mathrm{U} \\
204.485 \mathrm{U} \\
312.631 \mathrm{U} \\
111.981 \mathrm{U} \\
67.319 \mathrm{U}\end{array}$ & $\begin{array}{l}1.215 \mathrm{U} \\
0.981 \mathrm{U} \\
1.009 \mathrm{U} \\
4.804 \mathrm{U} \\
7.351 \mathrm{U} \\
2.631 \mathrm{U} \\
1.584 \mathrm{U}\end{array}$ & $\begin{array}{r}3.725 \\
2.990 \\
3.555 \\
4.214 \\
14.865 \\
\text { U U } \\
3.329 \\
7.673\end{array}$ & $\begin{array}{rr} & 3.783 \mathrm{U} \\
& 3.069 \mathrm{U} \\
& 3.143 \mathrm{U} \\
\mathrm{J} & 15.003 \mathrm{U} \\
\mathrm{U} & 22.932 \mathrm{U} \\
\mathrm{J} & 8.212 \mathrm{U} \\
& 4.938 \mathrm{U}\end{array}$ \\
\hline $\begin{array}{l}R-B F \\
R-B F \\
R-B F \\
R-B F \\
R-B F\end{array}$ & $\begin{array}{l}1 \\
2 . \\
3 \\
4 \\
5\end{array}$ & $\begin{array}{l}0 \\
B \\
B \\
A \\
A\end{array}$ & $\begin{array}{l}16.72 \\
13.79 \\
15.57 \\
15.24 \\
16.05\end{array}$ & $\begin{array}{l}2.715 \mathrm{U} \\
3.814 \mathrm{U} \\
1.927 \mathrm{U} \\
2.402 \mathrm{U} \\
2.318 \mathrm{U}\end{array}$ & $\begin{array}{l}2.781 \mathrm{U} \\
3.909 \mathrm{U} \\
1.972 \mathrm{U} \\
2.461 \mathrm{U} \\
2.374 \mathrm{U}\end{array}$ & $\begin{array}{l}2.781 \mathrm{U} \\
3.909 \mathrm{U} \\
1.972 \mathrm{U} \\
2.461 \mathrm{U} \\
2.374 \mathrm{U}\end{array}$ & $\begin{array}{lll}U & 2.781 & U \\
U & 3.909 & U \\
U & 1.972 & U \\
U & 2.461 & U \\
U & 2.374 & U\end{array}$ & $\begin{array}{ll}\text { U } & 2.781 \\
\text { U } & 1.827 \\
\text { U } & 0.822 \\
\text { U } & 2.461 \\
\text { U } & 2.374\end{array}$ & $\begin{array}{l}\mathrm{U} \\
\mathrm{JE} \\
\mathrm{JE} \\
\mathrm{U} \\
\mathrm{U}\end{array}$ & $\begin{array}{r}79.755 \mathrm{U} \\
111.972 \mathrm{U} \\
56.480 \mathrm{U} \\
70.472 \mathrm{U} \\
68.019 \mathrm{U}\end{array}$ & $\begin{array}{l}3.272 \\
0.232 \\
2.800 \\
4.167 \\
3.427\end{array}$ & $\begin{array}{r}10.795 \\
6.831 \\
9.891 \\
10.801 \\
8.667\end{array}$ & $\begin{array}{l}5.849 \mathrm{U} \\
8.216 \mathrm{U} \\
4.143 \mathrm{U} \\
5.171 \mathrm{U} \\
4.991 \mathrm{U}\end{array}$ \\
\hline $\begin{array}{l}R-O S \\
R-O S \text { Replicate } 1 \\
R-O S \text { Replicate } 2 \\
R-O S \text { Replicate } 3 \\
R-0 S \\
R-O S \\
R-O S\end{array}$ & $\begin{array}{l}1 \\
2 \\
2 \\
2 \\
3 \\
4 \\
5\end{array}$ & $\begin{array}{l}8 \\
0 \\
0 \\
0 \\
8 \\
0 \\
C\end{array}$ & $\begin{array}{l}15.79 \\
16.53 \\
16.53 \\
16.53 \\
15.02 \\
17.85 \\
17.02\end{array}$ & $\begin{array}{l}1.723 \mathrm{U} \\
5.789 \mathrm{U} \\
4.694 \mathrm{U} \\
5.681 \mathrm{U} \\
1.897 \mathrm{U} \\
1.754 \mathrm{U} \\
1.804 \mathrm{U}\end{array}$ & $\begin{array}{l}1.761 \mathrm{U} \\
5.929 \mathrm{U} \\
4.809 \mathrm{U} \\
5.814 \mathrm{U} \\
1.944 \mathrm{U} \\
1.793 \mathrm{U} \\
0.082 \mathrm{~J}\end{array}$ & $\begin{array}{l}1.761 \mathrm{U} \\
5.929 \mathrm{U} \\
4.809 \mathrm{U} \\
5.814 \mathrm{U} \\
1.944 \mathrm{U} \\
1.793 \mathrm{U} \\
1.845 \mathrm{U}\end{array}$ & $\begin{array}{lll}U & 1.761 & U \\
U & 5.929 & U \\
U & 4.809 & U \\
U & 5.814 & U \\
U & 1.944 & U \\
U & 1.793 & U \\
U & 1.845 & U\end{array}$ & $\begin{array}{ll}\mathrm{J} & 1.355 \\
\mathrm{U} & 5.929 \\
\mathrm{U} & 4.809 \\
\mathrm{U} & 5.814 \\
\mathrm{U} & 1.944 \\
\mathrm{U} & 1.793 \\
\mathrm{U} & 1.069\end{array}$ & $\begin{array}{l}\text { JE } \\
U \\
U \\
U \\
U \\
U \\
J E\end{array}$ & $\begin{array}{r}50.481 \mathrm{U} \\
169.982 \mathrm{U} \\
137.840 \mathrm{U} \\
166.691 \mathrm{U} \\
55.772 \mathrm{U} \\
51.468 \mathrm{U} \\
52.861 \mathrm{U}\end{array}$ & $\begin{array}{l}1.184 \mathrm{U} \\
3.993 \mathrm{U} \\
3.243 \mathrm{U} \\
3.920 \mathrm{U} \\
1.312 \mathrm{U} \\
1.210 \mathrm{U} \\
1.240 \mathrm{U}\end{array}$ & $\begin{array}{rr} & 7.638 \\
d & 13.134 \\
U & 11.113 \\
U & 10.430 \\
\text { U } & 7.011 \\
\text { U } & 7.961 \\
& 5.535\end{array}$ & $\begin{array}{r}3.705 \mathrm{U} \\
12.468 \mathrm{U} \\
10.109 \mathrm{U} \\
12.226 \mathrm{U} \\
4.095 \mathrm{U} \\
3.776 \mathrm{U} \\
3.878 \mathrm{U}\end{array}$ \\
\hline $\begin{array}{l}R-P F \\
R-P F \\
R-P F \\
R-P F \\
R-P F\end{array}$ & $\begin{array}{l}1 \\
2 \\
3 \\
4 \\
5\end{array}$ & $\begin{array}{l}C \\
C \\
0 \\
0 \\
A\end{array}$ & $\begin{array}{l}13.90 \\
13.46 \\
16.88 \\
16.74 \\
16.47\end{array}$ & $\begin{array}{l}2.252 \mathrm{U} \\
2.637 \mathrm{U} \\
1.712 \mathrm{U} \\
1.470 \mathrm{U} \\
0.152 \mathrm{JE}\end{array}$ & $\begin{array}{l}2.309 \mathrm{U} \\
0.386 \mathrm{JE} \\
1.754 \mathrm{U} \\
1.505 \mathrm{~V} \\
2.240 \mathrm{U}\end{array}$ & $\begin{array}{l}2.309 \\
2.697 \\
1.754 \\
1.505 \\
2.240\end{array}$ & $\begin{array}{lll}U & 1.194 & J \\
U & 2.697 & U \\
U & 1.754 & U \\
U & 1.505 \\
U & 2.240 & U\end{array}$ & $\begin{array}{ll}J & 1.417 \\
\text { U } & 1.352 \\
\text { U } & 1.754 \\
\text { U } & 1.505 \\
\text { U } & 2.240\end{array}$ & $\begin{array}{l}J E \\
J E \\
U \\
U \\
U\end{array}$ & $\begin{array}{l}66.144 \mathrm{U} \\
77.303 \mathrm{U} \\
50.190 \mathrm{U} \\
43.124 \mathrm{U} \\
64.299 \mathrm{U}\end{array}$ & $\begin{array}{l}1.554 \\
1.820 \\
1.179 \\
1.016 \\
1.512\end{array}$ & $\begin{array}{rr}\text { U } & 8.288 \\
\text { U } & 8.418 \\
\text { U } & 12.050 \\
\text { U } & 9.313 \\
\text { U } & 6.242\end{array}$ & $\begin{array}{l}4.849 \mathrm{U} \\
5.669 \mathrm{U} \\
3.679 \mathrm{U} \\
3.166 \mathrm{U} \\
4.718 \mathrm{U}\end{array}$ \\
\hline
\end{tabular}


TABLE K.10. (contd)

$N$ caecoides Pesticides (Ug/kg dry weight)

Sediment

Ireatment

Analyt
Repllcate
Bat
1
2
3
4
5
1
2
3
4
5

Analytical Percent

Alpha

Beta Delta

Dry Weight Aldrin

BHC B BHC Lindane Chlordane

4,4-

$4,4+4,4-$

$C-S B$

$\mathrm{C}-\mathrm{SB}$

C-SB

$\mathrm{C}-\mathrm{SB}$
$\mathrm{C}-\mathrm{SB}$

14.29

$2.120 \mathrm{U} \quad 2.169 \mathrm{U}$

$2.169 \mathrm{U} \quad 0.455 \mathrm{JE} \quad 0.980 \mathrm{JE} \quad 62.204 \mathrm{~J}$

DOD

DDE

OOT

$\begin{array}{llll}16.03 & 1.971 \mathrm{U} & 2.021 \mathrm{U} \\ 15.65 & 2.243 \mathrm{U} & 2.294 \mathrm{U} \\ 16.06 & 1.513 \mathrm{U} & 1.544 \mathrm{U}\end{array}$

2.021 U 2.021 U 2.021 U $57.916 U$

$1.463 \mathrm{U} \quad 3.268$

$1.360 \mathrm{~V} \quad 3.337$

$4.563 \mathrm{U}$

$\begin{array}{llll}2.294 \mathrm{~J} & 2.294 \mathrm{U} & 2.294 \mathrm{U} & 65.744 \mathrm{U}\end{array}$

$1.546 \mathrm{U} \quad 4.300$

$4.248 \mathrm{U}$

$16.46 \quad 1.634 \mathrm{U} \quad 0.158 \mathrm{~J}$

$1.671 \mathrm{U} \quad 1.671 \mathrm{U} \quad 1.671 \mathrm{U} \quad 47.892 \mathrm{U}$

$1.040 \mathrm{U} \quad 3.848$

$4.824 \mathrm{U}$

C-NE

C-NE

C-NE

$C-N E$

C-NE

$15.94 \quad 1.361 \mathrm{U} \quad 1.393 \mathrm{U}$

$18.40 \quad 1.386 \mathrm{U} \quad 1.424 \mathrm{U}$

$1.393 \cup 1.393 \cup \quad 1.393$ U $39.962 U$

$1.124 \mathrm{U} \quad 5.626$

$3.250 \mathrm{U}$

$\begin{array}{lll}18.40 & 1.386 \mathrm{U} & 1.424 \mathrm{U} \\ 16.01 & 1.568 \mathrm{U} & 1.605 \mathrm{U}\end{array}$

$\begin{array}{llllll}1.424 & \mathrm{U} & 1.424 \mathrm{U} & 1.424 \mathrm{U} & 40.739 \mathrm{U}\end{array}$

$1.605 \mathrm{U} \quad 1.605 \mathrm{U} \quad 1.243 \mathrm{JE} \quad 46.077 \mathrm{U}$

$1.822 \mathrm{U} \quad 1.822 \mathrm{U} \quad 0.664 \mathrm{JE} \quad 52.226 \mathrm{U}$

0.941 U 3.965

$2.930 \mathrm{U}$

$\begin{array}{lll}16.01 & 1.568 \mathrm{U} & 1.605 \mathrm{U} \\ 15.81 & 1.777 \mathrm{~V} & 1.822 \mathrm{U}\end{array}$

$\begin{array}{lll}15.28 & 2.029 \mathrm{U} & 2.075 \mathrm{U}\end{array}$

$2.075 \mathrm{U} \quad 2.075 \mathrm{U} \quad 2.075 \mathrm{~V} \quad 59.503 \mathrm{U}$

0.957 U 4.571

$2.989 \mathrm{U}$

$\begin{array}{llll}1.081 & 4 & 4.266 & 3.379 \mathrm{U}\end{array}$

$1.227 \mathrm{U} \quad 5.136 \quad 3.833 \mathrm{U}$

HSL Background

MSL Background

$19.82 \quad 0.802 \cup \quad 0.822 U$

$\begin{array}{lll}19.82 & 0.807 \mathrm{U} & 0.827 \mathrm{U}\end{array}$

$0.822 \cup 0.822 \cup 0.822 \cup \quad 23.572 \mathrm{U}$

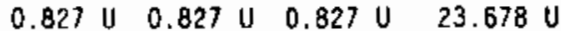

$1.401 \mathrm{U} \quad 5.020$

$4.365 \mathrm{U}$

MSL Background

HSL Background

19.82

$\begin{array}{lll}0.807 & U & 0.827 \\ 0.807 & 0.822 \mathrm{U}\end{array}$

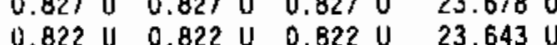

0.832 U 0.832 U 0.832 U 23.880 U

0.555 U 3.355

$17.306 \mathrm{U}$

$\begin{array}{lll}0.807 & U & 0.822 \\ 0.812 & U & 0.832 U\end{array}$

$0.822 \cup 0.822 \cup 0.822 \cup \quad 23.633 \cup$

$0.555 \mathrm{~J} \quad 3.254 \quad 1.736 \mathrm{U}$

$0.555 \mathrm{U} \quad 1.761 \quad 1.736 \mathrm{U}$

$\begin{array}{lll}19.82 & 0.812 \mathrm{U} & 0.832 \mathrm{U} \\ 19.82 & 0.807 \mathrm{U} & 0.822 \mathrm{U}\end{array}$

0.560 U 3.845

$17.508 \mathrm{~V}$

(a) U The analyte was not present above the level of the associated value.

(b) J Analyte detected below method detection 11 mit (MDL), but above instrument detection 1 imit (1DL).

(c) $\varepsilon$ Value an estimate; analyte not detected on confimation column

(d) Percent dry weight was averaged from the other four replicates of CoMp I. 
IABLE K.11. Chlorinated Pesticides (alphabetical, Dieldrin - Toxaphene), Dry Weight, in Tissue of N. caecoides, Richmond Harbor Program

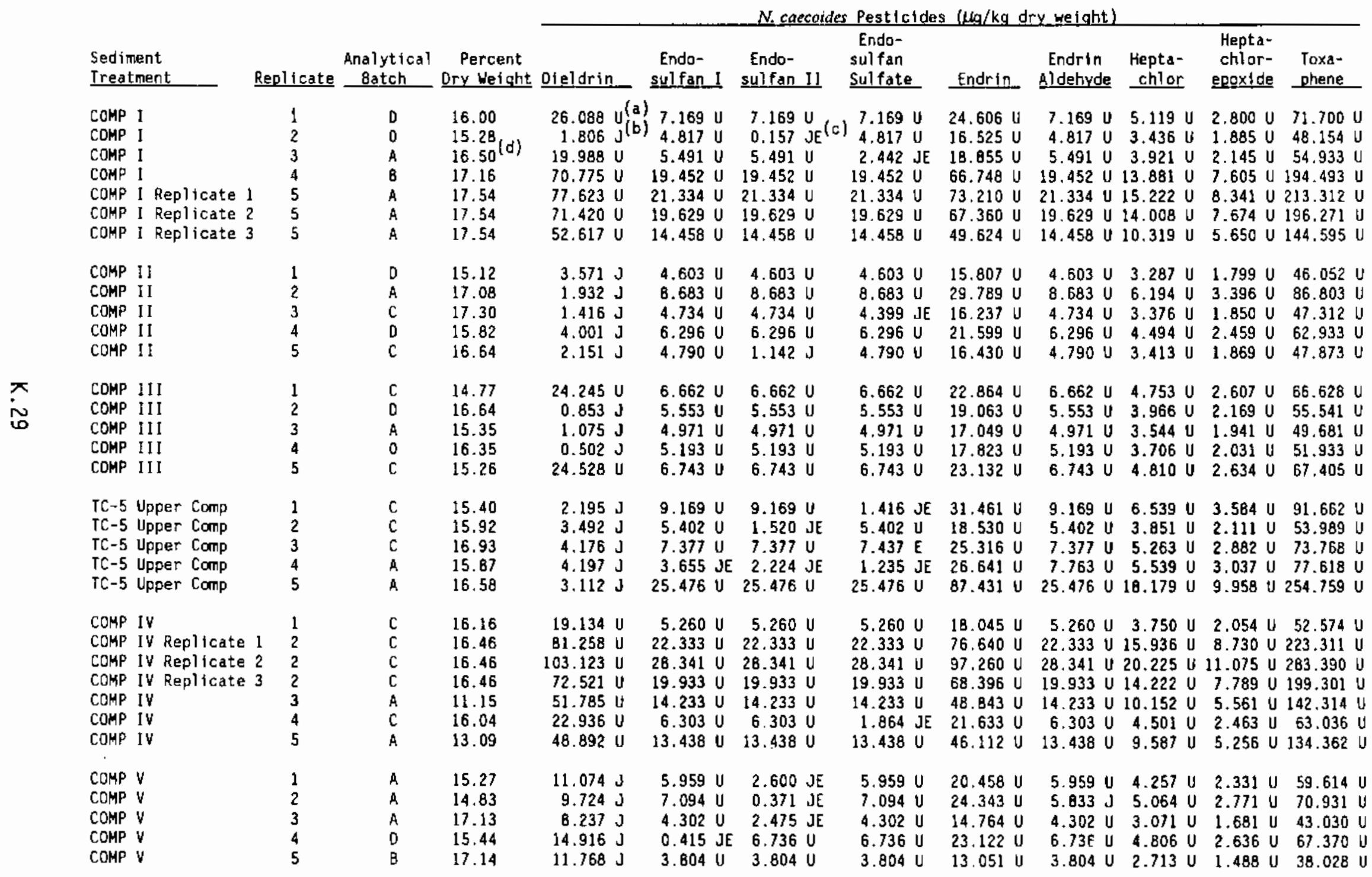


IABLE K.11. (contd)

\begin{tabular}{|c|c|c|c|c|c|c|c|c|c|c|c|c|}
\hline \multirow[b]{2}{*}{$\begin{array}{l}\text { Sediment } \\
\text { Ireatment }\end{array}$} & \multirow[b]{2}{*}{ Replicate } & \multirow[b]{2}{*}{$\begin{array}{l}\text { Analytical } \\
\text { Batch } \\
\end{array}$} & \multirow[b]{2}{*}{$\begin{array}{c}\text { Percent } \\
\text { Dry Wetaht }\end{array}$} & \multicolumn{9}{|c|}{$N$. caecoides Pesticides $(\mu \mathrm{q} / \mathrm{kg}$ dry weight $)$} \\
\hline & & & & Oielorin & $\begin{array}{l}\text { Endo- } \\
\text { sulfan I }\end{array}$ & $\begin{array}{l}\text { Endo- } \\
\text { sulfan II }\end{array}$ & $\begin{array}{l}\text { Endo- } \\
\text { sulfan } \\
\text { Sulfate } \\
\end{array}$ & Endrin & $\begin{array}{c}\text { Endrin } \\
\text { Al dehyde }\end{array}$ & $\begin{array}{l}\text { Hepta- } \\
\text { e chlor } \\
\end{array}$ & $\begin{array}{l}\text { Hepta- } \\
\text { chlor- } \\
\text { epoxide }\end{array}$ & $\begin{array}{l}\text { Toxa- } \\
\text { phene }\end{array}$ \\
\hline $\begin{array}{l}\text { COMP VI } \\
\text { COMP VI } \\
\text { COMP VI } \\
\text { COMP VI } \\
\text { COMP VI }\end{array}$ & $\begin{array}{l}1 \\
2 \\
3 \\
4 \\
5\end{array}$ & $\begin{array}{l}C \\
A \\
8 \\
A \\
D\end{array}$ & $\begin{array}{l}15.08 \\
15.83 \\
16.25 \\
15.89 \\
16.24\end{array}$ & $\begin{array}{r}9.344 \mathrm{~J} \\
10.859 \mathrm{~J} \\
13.120 \mathrm{~J} \\
4.481 \mathrm{~J} \\
20.794 \mathrm{~J}\end{array}$ & $\begin{array}{c}7.089 \mathrm{U} \\
1.364 \mathrm{JE} \\
6.148 \mathrm{U} \\
6.344 \mathrm{U} \\
19.076 \mathrm{U}\end{array}$ & $\begin{array}{l}2.341 \mathrm{JE} \\
0.992 \mathrm{JE} \\
0.615 \mathrm{JE} \\
6.344 \mathrm{U} \\
19.076 \mathrm{U}\end{array}$ & $\begin{array}{r}7.089 \mathrm{U} \\
5.433 \mathrm{U} \\
6.148 \mathrm{U} \\
6.344 \mathrm{U} \\
19.076 \mathrm{U}\end{array}$ & $\begin{array}{l}24.330 \mathrm{U} \\
18.642 \mathrm{U} \\
21.095 \mathrm{U} \\
21.762 \mathrm{U} \\
65.462 \mathrm{U}\end{array}$ & $\begin{array}{r}7.089 \mathrm{U} \\
2.021 \mathrm{~J} \\
6.148 \mathrm{U} \\
6.344 \mathrm{U} \\
19.076 \mathrm{U}\end{array}$ & $\begin{array}{lrl}U & 5.060 & U \\
J & 3.879 & U \\
U & 4.388 & U \\
U & 4.525 & U \\
U & 13.608 & U\end{array}$ & $\begin{array}{lll}U & 2.772 & U \\
U & 2.123 & U \\
U & 2.400 & U \\
U & 2.480 & U \\
U & 7.457 & U\end{array}$ & $\begin{array}{lr}U & 70.889 \\
U & 54.327 \\
U & 61.458 \\
U & 63.411 \\
U & 190.739\end{array}$ \\
\hline $\begin{array}{l}R-A C \\
R-A C \\
R-A C \\
R-A C \\
R-A C\end{array}$ & $\begin{array}{l}1 \\
2 \\
3 \\
4 \\
5\end{array}$ & $\begin{array}{l}B \\
C \\
C \\
A \\
D\end{array}$ & $\begin{array}{l}15.84 \\
16.14 \\
16.16 \\
13.29 \\
16.75\end{array}$ & $\begin{array}{r}30.878 \mathrm{U} \\
67.825 \mathrm{U} \\
21.343 \mathrm{U} \\
28.405 \mathrm{U} \\
0.985 \mathrm{~J}\end{array}$ & $\begin{array}{r}8.485 \mathrm{U} \\
18.637 \mathrm{U} \\
5.866 \mathrm{U} \\
7.803 \mathrm{U} \\
4.836 \mathrm{U}\end{array}$ & $\begin{array}{r}8.485 \mathrm{U} \\
18.637 \mathrm{U} \\
5.866 \mathrm{U} \\
7.803 \mathrm{U} \\
4.836 \mathrm{U}\end{array}$ & $\begin{array}{r}8.485 \mathrm{U} \\
18.637 \mathrm{U} \\
5.866 \mathrm{U} \\
7.803 \mathrm{U} \\
4.836 \mathrm{U}\end{array}$ & $\begin{array}{l}29.122 \mathrm{U} \\
63.971 \mathrm{U} \\
20.124 \mathrm{U} \\
26.787 \mathrm{U} \\
16.591 \mathrm{U}\end{array}$ & $\begin{array}{r}8.485 \mathrm{U} \\
18.637 \mathrm{U} \\
5.866 \mathrm{U} \\
7.803 \mathrm{U} \\
4.836 \mathrm{U}\end{array}$ & $\begin{array}{lrr}U & 6.054 & U \\
U & 13.302 & U \\
U & 4.183 & U \\
U & 5.568 & U \\
U & 3.451 & U\end{array}$ & $\begin{array}{llll}U & 3.314 & U \\
U & 7.286 & U \\
U & 0.285 & \\
U & 3.055 & U \\
U & 1.893 & U\end{array}$ & $\begin{array}{lr}U & 84.855 \\
U & 186.394 \\
\text { JE } & 58.645 \\
U & 78.051 \\
U & 48.352\end{array}$ \\
\hline $\begin{array}{l}\text { R-AM } \\
\text { R-AM } \\
\text { R-AM } \\
\text { R-AM Replicate } 1 \\
\text { R-AM Replicate } 2 \\
\text { R-AM Replicate } 3 \\
\text { R-AM }\end{array}$ & $\begin{array}{l}1 \\
2 \\
3 \\
4 \\
4 \\
4 \\
5\end{array}$ & $\begin{array}{l}B \\
C \\
B \\
B \\
B \\
B \\
B\end{array}$ & $\begin{array}{l}17.29 \\
16.62 \\
16.26 \\
16.61 \\
16.61 \\
16.61 \\
11.30\end{array}$ & $\begin{array}{r}18.768 \mathrm{U} \\
15.211 \mathrm{U} \\
15.590 \mathrm{U} \\
74.407 \mathrm{U} \\
113.763 \mathrm{U} \\
40.747 \mathrm{U} \\
24.496 \mathrm{U}\end{array}$ & $\begin{array}{r}5.159 \mathrm{U} \\
4.182 \mathrm{U} \\
4.287 \mathrm{U} \\
20.452 \mathrm{U} \\
31.264 \mathrm{U} \\
11.198 \mathrm{U} \\
6.735 \mathrm{U}\end{array}$ & $\begin{array}{r}5.159 \mathrm{U} \\
4.182 \mathrm{U} \\
4.287 \mathrm{U} \\
20.452 \mathrm{U} \\
31.264 \mathrm{U} \\
11.198 \mathrm{U} \\
6.735 \mathrm{U}\end{array}$ & $\begin{array}{r}5.159 \mathrm{U} \\
4.182 \mathrm{U} \\
4.287 \mathrm{U} \\
20.452 \mathrm{U} \\
31.264 \mathrm{U} \\
11.198 \mathrm{U} \\
6.735 \mathrm{U}\end{array}$ & $\begin{array}{r}17.704 \mathrm{U} \\
14.344 \mathrm{U} \\
14.705 \mathrm{U} \\
70.175 \mathrm{U} \\
107.291 \mathrm{U} \\
38.429 \mathrm{U} \\
23.106 \mathrm{U}\end{array}$ & $\begin{array}{r}5.159 \mathrm{U} \\
4.182 \mathrm{U} \\
4.287 \mathrm{U} \\
20.452 \mathrm{U} \\
31.264 \mathrm{U} \\
11.198 \mathrm{U} \\
6.735 \mathrm{U}\end{array}$ & $\begin{array}{rrr}U & 3.678 & U \\
U & 2.984 & U \\
U & 3.057 & U \\
U & 14.594 & U \\
& 22.312 & U \\
U & 7.989 & U \\
U & 4.805 & U\end{array}$ & $\begin{array}{lrl}U & 2.019 & U \\
U & 1.637 & U \\
U & 1.673 & U \\
U & 7.995 & U \\
U & 12.222 & U \\
U & 4.377 & U \\
U & 2.628 & U\end{array}$ & $\begin{array}{lrll}U & 51.579 & U \\
U & 41.793 & \\
U & 42.841 & \\
U & 204.485 & \\
U & 312.631 & \\
U & 111.981 & \\
U & 67.319 & \end{array}$ \\
\hline $\begin{array}{l}R-B F \\
R-B F \\
R-B F \\
R-B F \\
R-B F\end{array}$ & $\begin{array}{l}1 \\
2 \\
3 \\
4 \\
5\end{array}$ & $\begin{array}{l}0 \\
B \\
B \\
A \\
A\end{array}$ & $\begin{array}{l}16.72 \\
13.79 \\
15.57 \\
15.24 \\
16.05\end{array}$ & $\begin{array}{r}0.520 \mathrm{~J} \\
40.747 \mathrm{U} \\
1.175 \mathrm{JE} \\
1.870 \mathrm{~J} \\
1.601 \mathrm{~J}\end{array}$ & $\begin{array}{r}7.978 \mathrm{U} \\
11.197 \mathrm{U} \\
5.645 \mathrm{U} \\
7.047 \mathrm{U} \\
6.804 \mathrm{U}\end{array}$ & $\begin{array}{r}7.978 \mathrm{U} \\
11.197 \mathrm{U} \\
5.645 \mathrm{U} \\
1.017 \mathrm{JE} \\
6.804 \mathrm{U}\end{array}$ & $\begin{array}{r}7.978 \mathrm{U} \\
11.197 \mathrm{U} \\
5.645 \mathrm{U} \\
7.047 \mathrm{U} \\
3.595 \mathrm{JE}\end{array}$ & $\begin{array}{l}27.368 \mathrm{U} \\
38.426 \mathrm{U} \\
19.383 \mathrm{U} \\
24.186 \mathrm{U} \\
23.340 \mathrm{U}\end{array}$ & $\begin{array}{r}7.978 \mathrm{U} \\
11.197 \mathrm{U} \\
5.645 \mathrm{U} \\
7.047 \mathrm{U} \\
6.804 \mathrm{U}\end{array}$ & $\begin{array}{lll}U & 5.694 & U \\
U & 7.991 & U \\
U & 4.033 & U \\
U & 5.026 & U \\
U & 4.854 & U\end{array}$ & $\begin{array}{lll}U & 3.116 & U \\
U & 4.380 & U \\
U & 2.209 & U \\
U & 2.756 & U \\
U & 2.660 & U\end{array}$ & $\begin{array}{lr}U & 79.755 \\
U & 111.972 \\
U & 56.480 \\
U & 70.472 \\
U & 68.019\end{array}$ \\
\hline $\begin{array}{l}\text { R-OS } \\
\text { R-OS Replicate } 1 \\
\text { R-OS Replicate } 2 \\
\text { R-OS Replicate } 3 \\
\text { R-OS } \\
\text { R-OS } \\
\text { R-OS }\end{array}$ & $\begin{array}{l}1 \\
2 \\
2 \\
2 \\
3 \\
4 \\
5\end{array}$ & $\begin{array}{l}B \\
D \\
0 \\
0 \\
B \\
0 \\
C\end{array}$ & $\begin{array}{l}15.79 \\
16.53 \\
16.53 \\
16.53 \\
15.02 \\
17.85 \\
17.02\end{array}$ & $\begin{array}{l}18.372 \mathrm{U} \\
61.857 \mathrm{U} \\
50.157 \mathrm{U} \\
60.653 \mathrm{U} \\
20.293 \mathrm{U} \\
18.728 \mathrm{U} \\
19.236 \mathrm{U}\end{array}$ & $\begin{array}{r}5.047 \mathrm{U} \\
16.999 \mathrm{U} \\
13.787 \mathrm{U} \\
16.667 \mathrm{U} \\
5.579 \mathrm{U} \\
5.148 \mathrm{U} \\
5.288 \mathrm{U}\end{array}$ & $\begin{array}{r}5.047 \mathrm{U} \\
16.999 \mathrm{U} \\
13.787 \mathrm{U} \\
16.667 \mathrm{U} \\
5.579 \mathrm{U} \\
5.148 \mathrm{U} \\
5.288 \mathrm{U}\end{array}$ & $\begin{array}{r}5.047 \mathrm{U} \\
16.999 \mathrm{U} \\
13.787 \mathrm{U} \\
16.667 \mathrm{U} \\
5.579 \mathrm{U} \\
5.148 \mathrm{U} \\
5.288 \mathrm{U}\end{array}$ & $\begin{array}{l}17.327 \mathrm{U} \\
58.336 \mathrm{U} \\
47.308 \mathrm{U} \\
57.205 \mathrm{U} \\
19.141 \mathrm{U} \\
17.664 \mathrm{U} \\
18.143 \mathrm{U}\end{array}$ & $\begin{array}{r}5.047 \mathrm{U} \\
16.999 \mathrm{U} \\
13.787 \mathrm{U} \\
16.667 \mathrm{U} \\
5.579 \mathrm{U} \\
5.148 \mathrm{U} \\
5.288 \mathrm{U}\end{array}$ & $\begin{array}{rrr}U & 3.604 & U \\
U & 12.129 & U \\
U & 9.837 & U \\
U & 11.894 & U \\
U & 3.981 & U \\
U & 3.675 & U \\
U & 3.772 & U\end{array}$ & $\begin{array}{llll}U & 1.976 & U \\
U & 6.642 & U \\
U & 5.390 & U \\
U & 6.515 & U \\
U & 2.177 & U \\
U & 2.011 & U \\
U & 2.068 & U\end{array}$ & $\begin{array}{lrl}U & 50.481 \\
U & 169.982 \\
U & 137.840 \\
U & 166.691 \\
U & 55.772 \\
U & 51.468 \\
U & 52.861\end{array}$ \\
\hline $\begin{array}{l}R-P F \\
R-P F \\
R-P F \\
R-P F \\
R-P F\end{array}$ & $\begin{array}{l}1 \\
2 \\
3 \\
4 \\
5\end{array}$ & $\begin{array}{l}C \\
C \\
0 \\
0 \\
A\end{array}$ & $\begin{array}{l}13.90 \\
13.46 \\
16.88 \\
16.74 \\
16.47\end{array}$ & $\begin{array}{l}24.072 \mathrm{U} \\
28.128 \mathrm{U} \\
18.264 \mathrm{U} \\
15.693 \mathrm{U} \\
23.394 \mathrm{U}\end{array}$ & $\begin{array}{l}6.612 \mathrm{U} \\
7.734 \mathrm{U} \\
5.018 \mathrm{U} \\
4.313 \mathrm{U} \\
6.430 \mathrm{U}\end{array}$ & $\begin{array}{l}6.612 \mathrm{U} \\
7.734 \mathrm{U} \\
5.018 \mathrm{U} \\
4.313 \mathrm{U} \\
6.430 \mathrm{U}\end{array}$ & $\begin{array}{l}6.612 \mathrm{U} \\
7.734 \mathrm{U} \\
5.018 \mathrm{U} \\
4.313 \mathrm{U} \\
6.430 \mathrm{U}\end{array}$ & $\begin{array}{l}22.698 \mathrm{U} \\
26.530 \mathrm{U} \\
17.227 \mathrm{U} \\
14.797 \mathrm{U} \\
22.064 \mathrm{U}\end{array}$ & $\begin{array}{l}6.612 \mathrm{U} \\
7.734 \mathrm{U} \\
5.018 \mathrm{U} \\
4.313 \mathrm{U} \\
6.430 \mathrm{U}\end{array}$ & $\begin{array}{lll}U & 4.719 & U \\
U & 5.520 & U \\
U & 3.584 & U \\
U & 3.076 & U \\
U & 4.590 & U\end{array}$ & $\begin{array}{lll}U & 2.583 & U \\
U & 3.024 & U \\
U & 1.961 & \\
U & 1.685 & U \\
U & 2.514 & U\end{array}$ & $\begin{array}{ll}U & 66.144 \\
U & 77.303 \\
U & 50.190 \\
U & 43.124 \\
U & 64.299\end{array}$ \\
\hline
\end{tabular}


IABLE K.11. (contd)

N. caecoides Pesticides $(\mu \mathrm{d} / \mathrm{kg}$ dry weight $)$

\begin{tabular}{|c|c|c|c|c|c|c|c|c|c|c|c|c|}
\hline \multirow[b]{2}{*}{$\begin{array}{l}\text { Sediment } \\
\text { Ireatment }\end{array}$} & \multirow[b]{2}{*}{ Replicate } & \multirow[b]{2}{*}{$\begin{array}{l}\text { Analytical } \\
\text { Batch }\end{array}$} & \multirow[b]{2}{*}{$\begin{array}{c}\text { Percent } \\
\text { Dry Welght } \\
\end{array}$} & \multicolumn{9}{|c|}{ N. caecoides Pesticides $(\mu \mathrm{g} / \mathrm{kg}$ dry weight $)$} \\
\hline & & & & Dieldrin. & $\begin{array}{l}\begin{array}{c}\text { Endo- } \\
\text { sulfan I }\end{array} \\
\end{array}$ & $\begin{array}{l}\text { Endo- } \\
\text { sulfan II }\end{array}$ & $\begin{array}{l}\begin{array}{l}\text { Endo- } \\
\text { sulfan } \\
\text { Sulfate }\end{array} \\
\end{array}$ & Endrin & $\begin{array}{c}\text { Endrin } \\
\text { Aldehyde }\end{array}$ & $\begin{array}{l}\text { Hepta- } \\
\text { chlor }\end{array}$ & $\begin{array}{l}\text { Hepta- } \\
\text { chlor- } \\
\text { epoxide }\end{array}$ & $\begin{array}{l}\text { Toxa- } \\
\text { phene }\end{array}$ \\
\hline $\mathrm{C}-\mathrm{SB}$ & 1 & c & 14.29 & $22.638 \mathrm{U}$ & $6.221 \mathrm{U}$ & $6.221 \mathrm{U}$ & $6.221 \mathrm{U}$ & $21.351 \mathrm{U}$ & $6.221 \mathrm{U}$ & $4.437 \mathrm{U}$ & $2.435 \mathrm{~J}$ & $62.204 \mathrm{U}$ \\
\hline$c-s B$ & 2 & 0 & 16.03 & $21.073 \mathrm{U}$ & $5.789 \mathrm{U}$ & $5.789 \mathrm{U}$ & $5.789 \mathrm{U}$ & $19.875 \mathrm{U}$ & $5.789 \mathrm{U}$ & $4.136 \mathrm{U}$ & $2.265 \mathrm{U}$ & $57.916 \mathrm{U}$ \\
\hline$c-58$ & 3 & $\mathrm{~B}$ & 15.65 & $23.923 \mathrm{U}$ & $6.575 \mathrm{U}$ & $6.575 \mathrm{u}$ & $6.575 \mathrm{u}$ & $22.562 \mathrm{U}$ & $6.575 \mathrm{U}$ & $4.690 \mathrm{U}$ & $2.569 \mathrm{U}$ & $65.744 \mathrm{U}$ \\
\hline $\mathrm{C}-\mathrm{SB}$ & 4 & A & 16.06 & $16.133 \mathrm{U}$ & $4.433 \mathrm{U}$ & $4.433 \mathrm{U}$ & $4.433 \mathrm{U}$ & $15.218 \mathrm{U}$ & 4.433 U & $3.163 \mathrm{U}$ & $1.731 \mathrm{U}$ & $44.346 \mathrm{U}$ \\
\hline$c-5 B$ & 5 & D & 16.46 & $17.424 \mathrm{U}$ & $4.787 \mathrm{U}$ & $4.787 \mathrm{U}$ & $4.787 \mathrm{U}$ & $16.434 \mathrm{U}$ & $4.787 \mathrm{U}$ & $3.420 \mathrm{U}$ & $1.871 \mathrm{U}$ & $47.892 \mathrm{U}$ \\
\hline $\mathrm{C}-\mathrm{NE}$ & 1 & B & 15.94 & $14.542 \mathrm{U}$ & $3.996 \mathrm{U}$ & $3.996 \mathrm{U}$ & $3.996 \mathrm{U}$ & $13.714 \mathrm{U}$ & $3.996 U$ & $2.854 \mathrm{U}$ & $1.562 \mathrm{U}$ & $39.962 \mathrm{U}$ \\
\hline $\mathrm{C}-\mathrm{NE}$ & 2 & 8 & 18.40 & $14.826 \mathrm{U}$ & $4.076 \mathrm{U}$ & $4.076 \mathrm{U}$ & $4.076 \mathrm{U}$ & $13.984 \mathrm{U}$ & $4.076 U$ & $2.908 \mathrm{U}$ & $1.592 \mathrm{U}$ & $40.739 \mathrm{U}$ \\
\hline $\mathrm{C}-\mathrm{NE}$ & 3 & B & 16.01 & $16.771 \mathrm{U}$ & $4.610 \mathrm{U}$ & $4.610 \mathrm{U}$ & $4.610 \mathrm{U}$ & $15.815 \mathrm{U}$ & $4.610 \mathrm{U}$ & $3.285 \mathrm{U}$ & $1.799 \mathrm{U}$ & 46.077 U \\
\hline $\mathrm{C}-\mathrm{NE}$ & 4 & B & 15.81 & $19.001 \mathrm{U}$ & $5.225 \mathrm{U}$ & $5.225 \mathrm{U}$ & $5.225 \mathrm{U}$ & $17.925 \mathrm{U}$ & $5.225 \mathrm{U}$ & $3.725 \mathrm{U}$ & $2.043 \mathrm{U}$ & $52.226 \mathrm{U}$ \\
\hline $\mathrm{C}-\mathrm{NE}$ & 5 & B & 15.28 & $21.649 \mathrm{U}$ & $5.949 \mathrm{U}$ & $5.949 \mathrm{U}$ & $5.949 \mathrm{U}$ & $20.419 \mathrm{U}$ & $5.949 \mathrm{U}$ & $4.247 \mathrm{U}$ & $2.323 \mathrm{U}$ & $59.503 \mathrm{U}$ \\
\hline MSL Backgroun & 1 & $E$ & 19.82 & $8.577 \mathrm{U}$ & $2.356 U$ & $2.356 U$ & $2.356 U$ & $8.088 \mathrm{U}$ & $2.356 \mathrm{U}$ & $1.680 \mathrm{U}$ & $0.923 \mathrm{U}$ & $23.572 \mathrm{U}$ \\
\hline MSL Backg & 2 & E & 19.82 & $8.618 \mathrm{U}$ & $2.366 \mathrm{U}$ & $2.366 \mathrm{U}$ & $2.366 \mathrm{U}$ & $8.128 \mathrm{U}$ & $2.366 \mathrm{U}$ & $1.690 \mathrm{U}$ & $0.923 \mathrm{U}$ & $23.678 \mathrm{U}$ \\
\hline MSL Background & 3 & E & 19.82 & $8.602 \mathrm{U}$ & $2.366 \mathrm{U}$ & $2.366 U$ & $2.366 \mathrm{U}$ & $8.113 \mathrm{U}$ & $2.366 \mathrm{U}$ & $1.685 \mathrm{U}$ & $0.923 \mathrm{U}$ & $23.643 \mathrm{U}$ \\
\hline MSL Background & 4 & E & 19.82 & $8.688 \cup$ & $2.386 \mathrm{U}$ & $2.386 U$ & $2.386 U$ & $8.194 \mathrm{U}$ & $2.386 \mathrm{U}$ & $1.705 \mathrm{U}$ & $0.933 \mathrm{U}$ & $23.880 \mathrm{U}$ \\
\hline MSL Background & 5 & $\mathrm{E}$ & 19.82 & $8.602 \mathrm{U}$ & $2.361 \mathrm{U}$ & $2.361 \mathrm{U}$ & $2.361 \mathrm{U}$ & $8.113 \mathrm{U}$ & $2.361 U$ & $1.685 \mathrm{U}$ & $0.923 \mathrm{U}$ & 23.633 \\
\hline
\end{tabular}

(a) $U$ The analyte was not present above the level of the assoclated value.

(b) J Analyte detected below method detection 1 imit (MOL), but above instrument detection 11 mit (IDL).

(c) E Value an est /mate; analyte nat detected on confirmation column.

(d) Percent dry weight was averaged from the other fouf replicates of COMP 1 . 
TABLE K.12. Chlorinated Pesticides (alphabetical, Aldrin - 4,4-DDT), Wet Weight, in Tissue of N. caecoides, Richmond Harbor Program

\begin{tabular}{|c|c|c|c|c|c|c|c|c|c|c|c|}
\hline \multirow[b]{2}{*}{$\begin{array}{l}\text { Sediment } \\
\text { Treatment }\end{array}$} & \multirow[b]{2}{*}{ Replicate } & \multirow[b]{2}{*}{$\begin{array}{l}\text { Analytical } \\
\text { Qatch } \\
\end{array}$} & \multicolumn{9}{|c|}{$N$ caecoides Pesticides $(\mu \mathrm{g} / \mathrm{kg}$ wet welght) } \\
\hline & & & Aldrin & $\begin{array}{c}\text { Alpha } \\
\text { BHC }\end{array}$ & $\begin{array}{r}\text { 8eta } \\
\text { 8HC } \\
\end{array}$ & $\begin{array}{l}\text { Delta } \\
\text { BHC } \\
\end{array}$ & Lindane & Chlordane & $\begin{array}{l}4.4- \\
000 \\
\end{array}$ & $\begin{array}{l}4.4- \\
\mathrm{DDE}\end{array}$ & $\begin{array}{l}4,4- \\
\text { DDT } \\
\end{array}$ \\
\hline $\begin{array}{l}\text { Target } \mathrm{DL}(\mathrm{a}) \\
\text { Achleved DL Low } \\
\text { Achieved DL High }\end{array}$ & $\cdot$ & & $\begin{array}{r}2.0 \\
0.159 \\
1.769\end{array}$ & $\begin{array}{r}2.0 \\
0.163 \\
1.812\end{array}$ & $\begin{array}{r}2.0 \\
0.163 \\
1.812\end{array}$ & $\begin{array}{r}2.0 \\
0.163 \\
1.812\end{array}$ & $\begin{array}{r}2.0 \\
0.163 \\
1.812\end{array}$ & $\begin{array}{r}2.0 \\
4.672 \\
51.928\end{array}$ & $\begin{array}{r}2.0 \\
0.110 \\
1.221\end{array}$ & $\begin{array}{r}2.0 \\
2.218 \\
2.469\end{array}$ & $\begin{array}{r}2.0 \\
0.344 \\
3.809\end{array}$ \\
\hline $\begin{array}{l}\text { COMP I } \\
\text { COMP I } \\
\text { COMP I } \\
\text { COMP I } \\
\text { COMP I Repl I cate } 1 \\
\text { COMP I Repl icate } 2 \\
\text { COMP I Repl icate } 3\end{array}$ & $\begin{array}{r}1 \\
2 \\
3 \\
4 \\
5 \\
5 \\
5\end{array}$ & $\begin{array}{l}\text { D } \\
D \\
A \\
B \\
A \\
A \\
A\end{array}$ & $\begin{array}{ll}0.391 & U \\
0.251 & U \\
0.309 & U \\
1.137 & U \\
1.275 & U \\
1.173 & U \\
0.864 & U\end{array}$ & 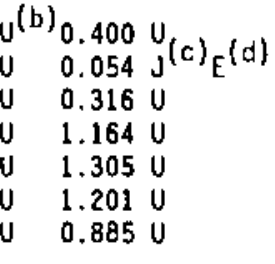 & $\begin{array}{l}0.400 \mathrm{U} \\
0.257 \mathrm{U} \\
0.316 \mathrm{U} \\
1.164 \mathrm{U} \\
1.305 \mathrm{U} \\
1.201 \mathrm{U} \\
0.885 \mathrm{U}\end{array}$ & $\begin{array}{l}0.400 \mathrm{U} \\
0.257 \mathrm{U} \\
0.316 \mathrm{U} \\
1.164 \mathrm{U} \\
1.305 \mathrm{U} \\
1.201 \mathrm{U} \\
0.885 \mathrm{U}\end{array}$ & $\begin{array}{l}0.400 \mathrm{U} \\
0.257 \mathrm{U} \\
0.316 \mathrm{U} \\
1.164 \mathrm{U} \\
1.305 \mathrm{U} \\
1.201 \mathrm{U} \\
0.885 \mathrm{U}\end{array}$ & $\begin{array}{rl}11.472 & \mathrm{U} \\
7.358 \mathrm{U} \\
9.064 \mathrm{U} \\
33.375 \mathrm{U} \\
37.415 \mathrm{U} \\
34.426 \mathrm{U} \\
25.362 \mathrm{U}\end{array}$ & $\begin{array}{l}1.183 \\
1.322 \\
0.771 \\
0.785 \mathrm{~J} \\
0.798 \mathrm{~J} \\
0.630 \mathrm{~J} \\
0.978\end{array}$ & $\begin{array}{l}2.408 \\
2.154 \\
1.692 \\
2.116 \\
1.978 \\
2.087 \\
2.132\end{array}$ & $\begin{array}{l}0.842 \mathrm{U} \\
0.540 \mathrm{U} \\
0.665 \mathrm{U} \\
2.448 \mathrm{U} \\
2.745 \mathrm{U} \\
2.525 \mathrm{U} \\
1.861 \mathrm{U}\end{array}$ \\
\hline $\begin{array}{l}\text { COMP II } \\
\text { COMP II } \\
\text { COMP II } \\
\text { COMP II } \\
\text { COMP II }\end{array}$ & $\begin{array}{l}1 \\
2 \\
3 \\
4 \\
5\end{array}$ & $\begin{array}{l}D \\
A \\
C \\
D \\
C\end{array}$ & $\begin{array}{l}0.237 \mathrm{U} \\
0.505 \mathrm{U} \\
0.279 \mathrm{U} \\
0.339 \mathrm{U} \\
0.271 \mathrm{U}\end{array}$ & $\begin{array}{ll}U & 0.102 \mathrm{JE} \\
U & 0.517 \mathrm{U} \\
\mathrm{U} & 0.072 \mathrm{~J} \\
U & 0.347 \mathrm{U} \\
U & 0.175 \mathrm{~J}\end{array}$ & $\begin{array}{l}0.243 \mathrm{U} \\
0.517 \mathrm{U} \\
0.286 \mathrm{U} \\
0.347 \mathrm{U} \\
0.278 \mathrm{U}\end{array}$ & $\begin{array}{ll}0.243 & \mathrm{U} \\
0.517 & \mathrm{U} \\
0.286 & \mathrm{U} \\
0.347 & \mathrm{U} \\
0.058 \mathrm{~J}\end{array}$ & $\begin{array}{l}0.243 \mathrm{U} \\
0.517 \mathrm{U} \\
0.155 \mathrm{JE} \\
0.347 \mathrm{U} \\
0.154 \mathrm{JE}\end{array}$ & $\begin{array}{r}6.963 \mathrm{U} \\
14.826 \mathrm{U} \\
8.185 \mathrm{U} \\
9.956 \mathrm{U} \\
7.966 \mathrm{U}\end{array}$ & $\begin{array}{l}3.025 \\
1.783 \\
2.414 \\
3.057 \\
0.187 \mathrm{U}\end{array}$ & $\begin{array}{l}2.756 \\
2.088 \\
1.670 \\
3.242 \\
2.045\end{array}$ & $\begin{array}{l}0.511 \mathrm{U} \\
1.088 \mathrm{U} \\
0.600 \mathrm{U} \\
0.730 \mathrm{U} \\
0.584 \mathrm{U}\end{array}$ \\
\hline $\begin{array}{l}\text { COMP II } \\
\text { COMP I I } \\
\text { COMP II } \\
\text { COMP II I } \\
\text { COMP III }\end{array}$ & $\begin{array}{l}1 \\
2 \\
3 \\
4 \\
5\end{array}$ & $\begin{array}{l}\text { C } \\
\text { D } \\
\text { A } \\
\text { D } \\
\text { C }\end{array}$ & $\begin{array}{l}0.335 \mathrm{U} \\
0.315 \mathrm{U} \\
0.260 \mathrm{U} \\
0.269 \mathrm{U} \\
0.350 \mathrm{U}\end{array}$ & $\begin{array}{l}0.116 \mathrm{~J} \\
0.322 \mathrm{U} \\
0.266 \mathrm{U} \\
0.296 \mathrm{U} \\
0.051 \mathrm{~J}\end{array}$ & $\begin{array}{l}0.343 \mathrm{U} \\
0.322 \mathrm{U} \\
0.266 \mathrm{U} \\
0.296 \mathrm{U} \\
0.359 \mathrm{U}\end{array}$ & $\begin{array}{l}0.343 \mathrm{U} \\
0.322 \mathrm{U} \\
0.266 \mathrm{U} \\
0.296 \mathrm{U} \\
0.188 \mathrm{JE}\end{array}$ & $\begin{array}{l}0.154 \mathrm{JE} \\
0.322 \mathrm{U} \\
0.266 \mathrm{U} \\
0.296 \mathrm{U} \\
0.139 \mathrm{JE}\end{array}$ & $\begin{array}{r}9.841 \mathrm{U} \\
9.242 \mathrm{U} \\
7.626 \mathrm{U} \\
8.491 \mathrm{U} \\
10.286 \mathrm{U}\end{array}$ & $\begin{array}{l}0.142 \mathrm{~J} \\
0.914 \\
0.229 \\
0.393 \\
0.094 \mathrm{~J}\end{array}$ & $\begin{array}{l}0.549 \\
1.328 \\
0.906 \\
1.112 \\
0.759\end{array}$ & $\begin{array}{l}0.722 \mathrm{U} \\
0.67 \mathrm{U} \\
0.559 \mathrm{U} \\
0.623 \mathrm{U} \\
0.755 \mathrm{U}\end{array}$ \\
\hline $\begin{array}{l}\text { TC-5 Upper Comp } \\
\text { TC-5 Upper Comp } \\
\text { TC-5 Upper Comp } \\
\text { TC-5 Upper Comp } \\
\text { TC-5 Upper Comp }\end{array}$ & $\begin{array}{l}1 \\
2 \\
3 \\
4 \\
5\end{array}$ & $\begin{array}{l}\text { C } \\
\text { C } \\
\text { C } \\
A \\
\text { A }\end{array}$ & $\begin{array}{l}0.481 \mathrm{U} \\
0.293 \mathrm{U} \\
0.426 \mathrm{U} \\
0.420 \mathrm{U} \\
1.439 \mathrm{U}\end{array}$ & $\begin{array}{l}0.362 \mathrm{JE} \\
0.227 \mathrm{~J} \\
0.302 \mathrm{~J} \\
0.430 \mathrm{U} \\
1.474 \mathrm{U}\end{array}$ & $\begin{array}{l}0.492 \mathrm{U} \\
0.300 \mathrm{U} \\
0.436 \mathrm{U} \\
0.430 \mathrm{U} \\
1.474 \mathrm{U}\end{array}$ & $\begin{array}{l}0.492 \mathrm{U} \\
0.300 \mathrm{U} \\
0.436 \mathrm{U} \\
0.212 \mathrm{JE} \\
1.474 \mathrm{U}\end{array}$ & $\begin{array}{l}0.229 \mathrm{JE} \\
0.190 \mathrm{JE} \\
0.149 \mathrm{JE} \\
0.430 \mathrm{U} \\
1.474 \mathrm{U}\end{array}$ & $\begin{array}{r}14.116 \mathrm{U} \\
8.595 \mathrm{U} \\
12.489 \mathrm{U} \\
12.318 \mathrm{U} \\
42.239 \mathrm{U}\end{array}$ & $\begin{array}{l}3.030 \\
3.234 \\
4.094 \\
2.316 \\
2.522\end{array}$ & $\begin{array}{l}3.755 \\
2.939 \\
4.284 \\
3.665 \\
4.161\end{array}$ & $\begin{array}{l}1.036 \mathrm{U} \\
0.631 \mathrm{U} \\
0.916 \mathrm{U} \\
0.904 \mathrm{U} \\
3.099 \mathrm{U}\end{array}$ \\
\hline $\begin{array}{l}\text { COMP IV } \\
\text { COMP IV Replicate } 1 \\
\text { COMP IV Replicate } 2 \\
\text { COMP IV Replicate } 3 \\
\text { COMP IV } \\
\text { COMP IV } \\
\text { COMP IV }\end{array}$ & $\begin{array}{l}1 \\
2 \\
2 \\
2 \\
3 \\
4 \\
5\end{array}$ & $\begin{array}{l}\text { C } \\
C \\
C \\
C \\
A \\
C \\
A\end{array}$ & $\begin{array}{l}0.289 \mathrm{U} \\
1.252 \mathrm{U} \\
1.589 \mathrm{U} \\
1.118 \mathrm{U} \\
0.541 \mathrm{U} \\
0.344 \mathrm{U} \\
0.599 \mathrm{U}\end{array}$ & $\begin{array}{ll}\mathrm{U} & 0.071 \mathrm{~J} \\
\mathrm{U} & 1.282 \mathrm{U} \\
\mathrm{U} & 1.627 \mathrm{U} \\
\mathrm{U} & 1.144 \mathrm{U} \\
\mathrm{U} & 0.554 \mathrm{U} \\
\mathrm{U} & 0.029 \mathrm{~J} \\
\mathrm{U} & 0.614 \mathrm{U}\end{array}$ & $\begin{array}{l}0.296 \mathrm{U} \\
1.282 \mathrm{U} \\
1.627 \mathrm{U} \\
1.144 \mathrm{U} \\
0.554 \mathrm{U} \\
0.353 \mathrm{U} \\
0.614 \mathrm{U}\end{array}$ & $\begin{array}{l}0.296 \mathrm{U} \\
1.282 \mathrm{U} \\
1.627 \mathrm{U} \\
1.144 \mathrm{U} \\
0.554 \mathrm{U} \\
0.353 \mathrm{U} \\
0.614 \mathrm{U}\end{array}$ & $\begin{array}{l}0.141 \mathrm{JE} \\
1.282 \mathrm{U} \\
1.627 \mathrm{U} \\
1.144 \mathrm{U} \\
0.554 \mathrm{U} \\
0.353 \mathrm{U} \\
0.614 \mathrm{U}\end{array}$ & $\begin{array}{r}8.496 \mathrm{U} \\
36.757 \mathrm{U} \\
46.646 \mathrm{U} \\
32.805 \mathrm{U} \\
15.868 \mathrm{U} \\
10.111 \mathrm{U} \\
17.588 \mathrm{U}\end{array}$ & $\begin{array}{l}0.200 \mathrm{U} \\
0.864 \mathrm{U} \\
1.096 \mathrm{U} \\
0.771 \mathrm{U} \\
0.373 \mathrm{U} \\
0.238 \mathrm{U} \\
0.413 \mathrm{U}\end{array}$ & $\begin{array}{l}0.300 \mathrm{~J} \\
0.351 \mathrm{~J} \\
2.218 \mathrm{U} \\
0.065 \mathrm{~J} \\
0.396 \mathrm{~J} \\
0.242 \mathrm{~J} \\
0.234 \mathrm{~J}\end{array}$ & $\begin{array}{l}0.623 \mathrm{U} \\
2.696 \mathrm{U} \\
3.422 \mathrm{U} \\
2.407 \mathrm{U} \\
1.164 \mathrm{U} \\
0.742 \mathrm{U} \\
1.290 \mathrm{U}\end{array}$ \\
\hline
\end{tabular}




\section{TABLE_K.12. (contd)}

Sediment

Ireatment

COMP $V$

COMP V

COMP V

COMP

COMP V

COMP VI

COMP VI

СОHP VI

COHP VI

COMP VI

$R-A C$

$R-A C$

$R-A C$

त

R-AM

$R-A M$

R-AM Replicate

R-AM Replicate

R-AM Replicate

$R-A M$

$R-B F$

$R-B F$

$R-8 F$

$R-B F$
$R-B F$

$R-O S$

R-OS Replicate 1

R-OS Replicate

R-OS Replicate

$R-O S$

$R-0 S$

R-OS

\begin{tabular}{|c|c|c|c|}
\hline Replicate & $\begin{array}{l}\text { Analytical } \\
\text { Batch }\end{array}$ & Aldrin & $\begin{array}{l}\text { Alpha } \\
\text { BHC }\end{array}$ \\
\hline 1 & A & $0.310 \mathrm{U}$ & $0.318 \mathrm{U}$ \\
\hline 2 & A & $0.358 \mathrm{U}$ & $0.367 \mathrm{U}$ \\
\hline 3 & A & $0.251 \mathrm{U}$ & $0.257 \mathrm{U}$ \\
\hline 4 & $D$ & $0.354 \mathrm{U}$ & $0.363 \mathrm{U}$ \\
\hline 5 & $B$ & $0.222 \mathrm{U}$ & $0.227 \mathrm{U}$ \\
\hline 1 & C & $0.364 \mathrm{U}$ & $0.118 \mathrm{~J}$ \\
\hline 2 & A & 0.2930 & $0.021 \mathrm{JE}$ \\
\hline 3 & 8 & $0.340 \mathrm{~V}$ & $0.348 \mathrm{U}$ \\
\hline 4 & $A$ & $0.343 \mathrm{U}$ & $0.352 \mathrm{U}$ \\
\hline 5 & 0 & $1.055 \mathrm{U}$ & $1.081 \mathrm{U}$ \\
\hline 1 & 8 & $0.458 \mathrm{U}$ & $0.469 \mathrm{U}$ \\
\hline 2 & C & $1.025 \mathrm{U}$ & $0.025 \mathrm{~J}$ \\
\hline 3 & C & $0.323 \mathrm{U}$ & $0.331 \mathrm{U}$ \\
\hline 4 & A & $0.353 \mathrm{U}$ & $0.043 \mathrm{JE}$ \\
\hline 5 & 0 & $0.276 \mathrm{U}$ & $0.283 \mathrm{U}$ \\
\hline 1 & 8 & $0.304 \mathrm{U}$ & $0.311 \mathrm{U}$ \\
\hline 2 & C & $0.237 \mathrm{U}$ & $0.108 \mathrm{JE}$ \\
\hline 3 & 8 & $0.237 \mathrm{U}$ & $0.243 \mathrm{U}$ \\
\hline 4 & $\theta$ & $1.157 \mathrm{U}$ & $1.185 \mathrm{U}$ \\
\hline 4 & $\theta$ & $1.769 \mathrm{U}$ & $1.812 \mathrm{U}$ \\
\hline 4 & a & $0.634 \mathrm{U}$ & $0.649 \mathrm{U}$ \\
\hline 5 & $B$ & $0.259 \mathrm{U}$ & $0.265 \mathrm{U}$ \\
\hline 1 & D & $0.454 \mathrm{U}$ & $0.465 \mathrm{U}$ \\
\hline 2 & 8 & $0.526 \mathrm{U}$ & $0.539 \mathrm{U}$ \\
\hline 3 & B & $0.300 \mathrm{~V}$ & $0.307 \mathrm{U}$ \\
\hline 4 & A & $0.366 \mathrm{U}$ & $0.375 \mathrm{U}$ \\
\hline 5 & A & $0.372 \mathrm{~V}$ & $0.381 \mathrm{U}$ \\
\hline 1 & 8 & $0.272 \mathrm{U}$ & $0.278 \mathrm{U}$ \\
\hline 2 & 0 & $0.957 \mathrm{U}$ & $0.980 \mathrm{U}$ \\
\hline 2 & 0 & $0.776 \mathrm{U}$ & 0.7950 \\
\hline 2 & 0 & $0.939 \mathrm{U}$ & $0.961 \cup$ \\
\hline 3 & 8 & $0.285 \mathrm{U}$ & $0.292 \mathrm{U}$ \\
\hline 4 & 0 & $0.313 \mathrm{U}$ & $0.320 \mathrm{U}$ \\
\hline 5 & C & $0.307 \mathrm{U}$ & $0.014 \mathrm{~J}$ \\
\hline
\end{tabular}

N. caecor

\begin{tabular}{|c|c|c|c|c|c|c|}
\hline $\begin{array}{l}\text { Beta } \\
\text { BHC }\end{array}$ & $\begin{array}{l}\text { Delta } \\
\text { BHC }\end{array}$ & Lindane & Chlordane & $\begin{array}{l}4,4- \\
\text { DDD }\end{array}$ & $\begin{array}{l}4.4- \\
\text { ODE }\end{array}$ & $\begin{array}{l}4,4- \\
\text { DDT }\end{array}$ \\
\hline $\begin{array}{l}0.318 U \\
0.367 U \\
0.257 \mathrm{U} \\
0.363 \mathrm{U} \\
0.227 \mathrm{U}\end{array}$ & $\begin{array}{l}0.318 \mathrm{U} \\
0.367 \mathrm{U} \\
0.257 \mathrm{U} \\
0.363 \mathrm{U} \\
0.227 \mathrm{U}\end{array}$ & $\begin{array}{l}0.318 \mathrm{~J} \\
0.367 \mathrm{~J} \\
0.162 \mathrm{JE} \\
0.363 \mathrm{U} \\
0.176 \mathrm{JE}\end{array}$ & $\begin{array}{r}9.103 \mathrm{U} \\
10.519 \mathrm{U} \\
7.371 \mathrm{U} \\
10.402 \mathrm{U} \\
5.518 \mathrm{U}\end{array}$ & $\begin{array}{r}9.400 \\
8.521 \\
6.424 \\
17.711 \\
16.740\end{array}$ & $\begin{array}{r}6.080 \\
4.074 \\
5.761 \\
10.186 \\
6.027\end{array}$ & $\begin{array}{l}0.668 \\
0.772 \\
0.541 \\
0.763 \\
0.478\end{array}$ \\
\hline $\begin{array}{l}0.373 U \\
0.300 U \\
0.346 U \\
0.352 U \\
1.081 U\end{array}$ & $\begin{array}{l}0.373 \mathrm{U} \\
0.300 \mathrm{U} \\
0.348 \mathrm{U} \\
0.352 \mathrm{U} \\
1.081 \mathrm{U}\end{array}$ & $\begin{array}{l}0.164 \mathrm{JE} \\
0.300 \mathrm{U} \\
0.232 \mathrm{dE} \\
0.352 \mathrm{U} \\
1.081 \mathrm{U}\end{array}$ & $\begin{array}{r}10.690 \mathrm{U} \\
8.600 \mathrm{U} \\
9.987 \mathrm{U} \\
10.076 \mathrm{U} \\
30.976 \mathrm{U}\end{array}$ & $\begin{array}{r}16.231 \\
8.919 \\
23.373 \\
10.791 \\
24.632\end{array}$ & $\begin{array}{l}4.946 \\
3.750 \\
6.200 \\
5.885 \\
8.925\end{array}$ & $\begin{array}{l}0.784 \\
0.631 \\
0.733 \\
0.739 \\
2.272\end{array}$ \\
\hline $\begin{array}{l}0.469 \mathrm{U} \\
1.050 \mathrm{U} \\
0.331 \mathrm{U} \\
0.362 \mathrm{U} \\
0.283 \mathrm{U}\end{array}$ & $\begin{array}{l}0.469 \mathrm{U} \\
1.050 \mathrm{U} \\
0.331 \mathrm{U} \\
0.362 \mathrm{U} \\
0.283 \mathrm{U}\end{array}$ & $\begin{array}{l}0.469 \mathrm{U} \\
1.050 \mathrm{U} \\
0.158 \mathrm{JE} \\
0.362 \mathrm{U} \\
0.283 \mathrm{U}\end{array}$ & $\begin{array}{r}13.441 \mathrm{U} \\
30.084 \mathrm{U} \\
9.477 \mathrm{U} \\
10.373 \mathrm{U} \\
8.099 \mathrm{U}\end{array}$ & $\begin{array}{l}1.455 \mathrm{~J} \\
0.707 \mathrm{U} \\
0.814 \\
0.624 \\
1.048\end{array}$ & $\begin{array}{l}2.033 \\
1.039 \mathrm{~J} \\
1.277 \\
1.417 \mathrm{E} \\
2.055\end{array}$ & $\begin{array}{l}0.986 \\
2.207 \\
0.695 \\
0.761 \\
0.594\end{array}$ \\
\hline $\begin{array}{l}0.311 \mathrm{U} \\
0.242 \mathrm{U} \\
0.243 \mathrm{U} \\
1.185 \mathrm{U} \\
1.812 \mathrm{U} \\
0.649 \mathrm{U} \\
0.265 \mathrm{U}\end{array}$ & $\begin{array}{l}0.311 \mathrm{U} \\
0.242 \mathrm{U} \\
0.243 \mathrm{U} \\
1.185 \mathrm{U} \\
1.812 \mathrm{U} \\
0.649 \mathrm{U} \\
0.265 \mathrm{U}\end{array}$ & $\begin{array}{l}0.311 \mathrm{U} \\
0.124 \mathrm{JE} \\
0.095 \mathrm{JE} \\
1.185 \mathrm{U} \\
1.812 \mathrm{U} \\
0.649 \mathrm{U} \\
0.202 \mathrm{JE}\end{array}$ & $\begin{array}{r}8.918 \mathrm{U} \\
6.946 \mathrm{U} \\
6.966 \mathrm{U} \\
33.965 \mathrm{U} \\
51.928 \mathrm{U} \\
18.600 \mathrm{U} \\
7.607 \mathrm{U}\end{array}$ & $\begin{array}{l}0.210 \mathrm{U} \\
0.163 \mathrm{U} \\
0.164 \mathrm{U} \\
0.798 \mathrm{U} \\
1.221 \mathrm{U} \\
0.437 \mathrm{U} \\
1.179 \mathrm{U}\end{array}$ & $\begin{array}{l}0.644 \\
0.497 \\
0.578 \\
0.700 \mathrm{~J} \\
2.469 \mathrm{U} \\
0.553 \mathrm{~J} \\
0.867\end{array}$ & $\begin{array}{l}0.654 \\
0.510 \\
0.511 \\
2.492 \\
3.809 \\
1.364 \\
0.558\end{array}$ \\
\hline $\begin{array}{l}0.465 \mathrm{U} \\
0.539 \mathrm{U} \\
0.307 \mathrm{U} \\
0.375 \mathrm{U} \\
0.381 \mathrm{U}\end{array}$ & $\begin{array}{l}0.465 \mathrm{U} \\
0.539 \mathrm{U} \\
0.307 \mathrm{U} \\
0.375 \mathrm{U} \\
0.381 \mathrm{U}\end{array}$ & $\begin{array}{l}0.465 \mathrm{U} \\
0.252 \mathrm{JE} \\
0.12 \mathrm{~B} \mathrm{JE} \\
0.375 \mathrm{U} \\
0.3 \mathrm{~B} 1 \mathrm{U}\end{array}$ & $\begin{array}{r}13.335 \mathrm{U} \\
15.441 \mathrm{U} \\
8.794 \mathrm{U} \\
10.740 \mathrm{U} \\
10.917 \mathrm{U}\end{array}$ & $\begin{array}{l}0.547 \\
0.032 \mathrm{~J} \\
0.436 \\
0.635 \\
0.550\end{array}$ & $\begin{array}{l}1.805 \\
0.942 \\
1.540 \\
1.646 \\
1.391\end{array}$ & $\begin{array}{l}0.978 \\
1.133 \\
0.645 \\
0.788 \\
0.801\end{array}$ \\
\hline $\begin{array}{l}0.278 \mathrm{U} \\
0.980 \mathrm{U} \\
0.795 \mathrm{U} \\
0.961 \mathrm{U} \\
0.292 \mathrm{U} \\
0.320 \mathrm{U} \\
0.314 \mathrm{U}\end{array}$ & $\begin{array}{l}0.278 \mathrm{U} \\
0.980 \mathrm{U} \\
0.795 \mathrm{U} \\
0.961 \mathrm{U} \\
0.292 \mathrm{U} \\
0.320 \mathrm{U} \\
0.314 \mathrm{U}\end{array}$ & $\begin{array}{l}0.214 \mathrm{JE} \\
0.980 \mathrm{U} \\
0.795 \mathrm{U} \\
0.961 \mathrm{U} \\
0.292 \mathrm{U} \\
0.320 \mathrm{U} \\
0.182 \mathrm{JE}\end{array}$ & $\begin{array}{r}7.971 \mathrm{U} \\
28.098 \mathrm{U} \\
22.785 \mathrm{U} \\
27.554 \mathrm{U} \\
8.377 \mathrm{U} \\
9.187 \mathrm{U} \\
8.997 \mathrm{U}\end{array}$ & $\begin{array}{ll}0.187 & \mathrm{U} \\
0.660 \mathrm{U} & \mathrm{U} \\
0.536 \mathrm{U} \\
0.648 \mathrm{U} \\
0.197 \mathrm{U} \\
0.216 \mathrm{U} \\
0.211 \mathrm{U}\end{array}$ & $\begin{array}{l}1.206 \\
2.171 \\
1.837 \\
1.724 \\
1.053 \\
1.421 \\
0.942\end{array}$ & $\begin{array}{l}0.585 \\
2.061 \\
1.671 \\
2.021 \\
0.615 \\
0.674 \\
0.660\end{array}$ \\
\hline
\end{tabular}




\section{TABLE K.12. (contd)}

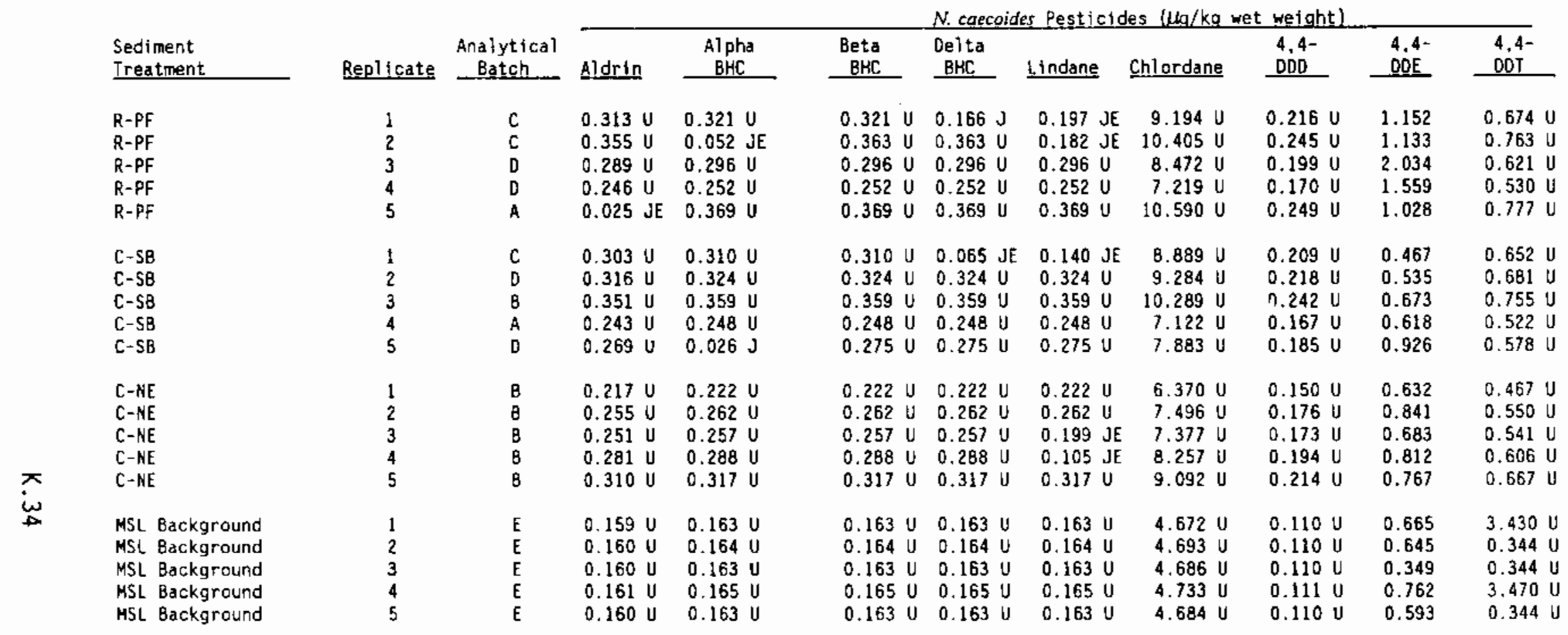

(a) DL Detection limit.

(b) U The analyte was not present above the level of the associated value.

(c) J Analyte detected below method detection limit (MDL), but above instrunent detection limit (IDL).

(d) $E$ Value an estimate; analyte not detected on confimation column. 
IABLE K.13. Chlorinated Pesticides (alphabetical, Dieldrin - Toxaphene), Wet Weight, in Tissue of PDNcaecoides, Richmond Harbor Program

\begin{tabular}{|c|c|c|c|c|c|c|c|c|c|c|c|}
\hline & & & & & $N_{1}$ caecoides $P_{6}$ & Pesticides & $(\mu \mathrm{q} / \mathrm{kq}$ wet & $\mathrm{t}$ weight) & & & \\
\hline $\begin{array}{l}\text { Sediment } \\
\text { Ireatment }\end{array}$ & Repltcate & $\begin{array}{l}\text { Analytical } \\
\text { Batch } \\
\end{array}$ & Dieldrin & $\begin{array}{c}\text { Endo- } \\
\text { sulfan I } \\
\end{array}$ & $\begin{array}{l}\text { Endo- } \\
\text { sulfan_II }\end{array}$ & $\begin{array}{l}\text { Endo- } \\
\text { sulfan } \\
\text { Sulfate }\end{array}$ & Endritn & $\begin{array}{c}\text { Endrin } \\
\text { Aldehyde }\end{array}$ & $\begin{array}{l}\text { Hepta- } \\
\text { chlor } \\
\end{array}$ & $\begin{array}{l}\text { Hepta- } \\
\text { chlor- } \\
\text { epoxide }\end{array}$ & $\begin{array}{c}\text { Toxa- } \\
\text { phene }\end{array}$ \\
\hline $\begin{array}{l}\text { Target DL (a) } \\
\text { Achteved OL Low } \\
\text { Achieved OL High }\end{array}$ & & & $\begin{array}{r}2.0 \\
1.700 \\
18.896\end{array}$ & $\begin{array}{r}2.0 \\
0.467 \\
5.193\end{array}$ & $\begin{array}{r}2.0 \\
0.467 \\
5.193\end{array}$ & $\begin{array}{r}2.0 \\
0.467 \\
5.493\end{array}$ & $\begin{array}{r}2.0 \\
1.603 \\
17.821\end{array}$ & $\begin{array}{r}2.0 \\
0.467 \\
5.193\end{array}$ & $\begin{array}{r}2.0 \\
0.333 \\
3.706\end{array}$ & $\begin{array}{r}2.0 \\
0.183 \\
2.030\end{array}$ & $\begin{array}{r}30.0 \\
4.672 \\
51.928\end{array}$ \\
\hline COMP I & 1 & 0 & $4.174 u^{(b)}$ & $1.147 \mathrm{U}$ & $1.147 \mathrm{U}$ & $1.147 \mathrm{U}$ & $3.937 \mathrm{U}$ & $1,147 \mathrm{U}$ & $0.819 \mathrm{U}$ & $0.448 \mathrm{U}$ & 11.472 \\
\hline COMP I & 2 & 0 & $0.276 \mathrm{~J}(\mathrm{c})$ & $0.736 \mathrm{U}$ & $0.024 \mathrm{JE}^{(\mathrm{d})}$ & $0.736 \mathrm{U}$ & $2.525 \mathrm{U}$ & $0.736 \mathrm{U}$ & $0.525 \mathrm{U}$ & $0.288 \mathrm{U}$ & 7.3580 \\
\hline COMP I & 3 & A & $3.298 \mathrm{U}$ & $0.906 \mathrm{U}$ & $0.906 \mathrm{U}$ & $0.403 \mathrm{JE}$ & $3.111 \mathrm{U}$ & $0.906 \mathrm{U}$ & $0.647 \mathrm{U}$ & $0.354 \mathrm{U}$ & 9.064 \\
\hline COMP I Replicate 2 & 5 & A & $12.527 \mathrm{U}$ & $3.443 \mathrm{~V}$ & $3.443 \mathrm{U}$ & $3.443 \mathrm{U}$ & $11.815 \mathrm{U}$ & $3.443 \mathrm{U}$ & $2.457 \mathrm{U}$ & $1.346 \mathrm{U}$ & $34.426 \mathrm{U}$ \\
\hline COMP I Replicate 3 & 5 & A & $9.229 \mathrm{U}$ & $2.536 \mathrm{U}$ & $2.536 \mathrm{U}$ & $2.536 \mathrm{U}$ & $8.704 \mathrm{U}$ & $2.536 \mathrm{U}$ & $1.810 \mathrm{U}$ & $0.991 \mathrm{U}$ & $25.362 \mathrm{U}$ \\
\hline COMP 11 & 1 & D & $0.540 \mathrm{~J}$ & 0.696 U & $0.696 \mathrm{U}$ & $0.696 \mathrm{U}$ & $2.390 \mathrm{U}$ & $0.696 \mathrm{U}$ & $0.497 \mathrm{U}$ & $0.272 \mathrm{U}$ & $6.963 \mathrm{U}$ \\
\hline COMP II & 2 & A & $0.330 \mathrm{~J}$ & $1.483 \mathrm{U}$ & $1.483 \mathrm{~V}$ & $1.483 \mathrm{U}$ & $5.088 \mathrm{U}$ & $1.483 \mathrm{U}$ & $1.058 \mathrm{U}$ & $0.580 \mathrm{U}$ & $14.826 \mathrm{~V}$ \\
\hline COMP 11 & 3 & c & $0.245 \mathrm{~J}$ & $0.819 \mathrm{U}$ & $0.819 \mathrm{U}$ & $0.761 \mathrm{JE}$ & $2.809 \mathrm{U}$ & $0.819 \mathrm{U}$ & $0.584 U$ & $0.320 \mathrm{U}$ & $8.185 \mathrm{U}$ \\
\hline COMP II & 4 & 0 & $0.633 \mathrm{~J}$ & $0.996 \mathrm{U}$ & $0.996 \mathrm{U}$ & $0.996 \mathrm{U}$ & $3.417 \mathrm{U}$ & $0.996 \mathrm{U}$ & $0.711 \mathrm{U}$ & $0.389 \mathrm{U}$ & $9.956 \mathrm{~L}$ \\
\hline COMP II & 5 & c & $0.358 \mathrm{~J}$ & $0.797 \mathrm{U}$ & $0.190 \mathrm{~J}$ & $0.797 \mathrm{U}$ & $2.734 \mathrm{U}$ & $0.797 \mathrm{U}$ & $0.568 \mathrm{U}$ & $0.311 \mathrm{U}$ & $7.966 \mathrm{~L}$ \\
\hline COMP III & 2 & D & $0.142 \mathrm{~J}$ & $0.924 \mathrm{U}$ & $0.924 \mathrm{U}$ & $0.924 \mathrm{U}$ & $3.172 \mathrm{U}$ & $0.924 \mathrm{U}$ & $0.660 \mathrm{U}$ & $0.361 \mathrm{u}$ & 9.242 \\
\hline COMP 111 & 3 & A & $0.165 \mathrm{~J}$ & $0.763 \mathrm{U}$ & $0.763 \mathrm{U}$ & $0.763 \mathrm{U}$ & $2.617 \mathrm{U}$ & $0.763 \mathrm{U}$ & $0.544 \mathrm{U}$ & $0.298 \mathrm{U}$ & 7.626 \\
\hline COMP III & 4 & D & $0.082 \mathrm{~J}$ & $0.849 \mathrm{U}$ & $0.849 \mathrm{U}$ & $0.849 \mathrm{U}$ & $2.914 \mathrm{U}$ & $0.849 \mathrm{U}$ & $0.606 \mathrm{U}$ & $0.332 \mathrm{U}$ & $8.491 \mathrm{~L}$ \\
\hline COMP III & 5 & $\mathrm{c}$ & $3.743 \mathrm{v}$ & $1.029 \mathrm{U}$ & $1.029 \mathrm{U}$ & $1.029 \mathrm{U}$ & $3.530 \mathrm{U}$ & 1.0290 & $0.734 \mathrm{U}$ & $0.402 \mathrm{U}$ & $10.286 \mathrm{U}$ \\
\hline TC-5 Upper Comp & 1 & c & 0.338 & $1.412 \mathrm{U}$ & 1.4 & $0.218 \mathrm{JE}$ & $4.845 U$ & $1.412 \mathrm{U}$ & $1.007 \mathrm{U}$ & $0.552 \mathrm{U}$ & $14.116 V$ \\
\hline ic-5 Upper Comp & 2 & c & $0.556 \mathrm{~J}$ & $0.860 \mathrm{U}$ & $0.242 \mathrm{JE}$ & $0.860 \mathrm{v}$ & $2.950 \mathrm{U}$ & $0.860 \mathrm{U}$ & & & 8.5950 \\
\hline TC-5 Upper Comp & 3 & c & $0.707 \mathrm{~J}$ & $1.249 \mathrm{U}$ & $1.249 \mathrm{U}$ & $1.259 \mathrm{E}$ & $4.286 \mathrm{U}$ & $1.249 \mathrm{U}$ & $0.891 \mathrm{U}$ & $0.488 \mathrm{U}$ & $12.489 \mathrm{U}$ \\
\hline TC-5 Upper Comp & 4 & A & $0.666 \mathrm{~J}$ & $0.580 \mathrm{JE}$ & $0.353 \mathrm{JE}$ & $0.196 \mathrm{JE}$ & $4.228 \mathrm{~V}$ & $1.232 \mathrm{U}$ & $0.879 \mathrm{U}$ & $0.482 \mathrm{U}$ & 12.318 \\
\hline TC-5 Upper Comp & 5 & A & $0.516 \mathrm{~J}$ & $4.224 \mathrm{U}$ & $4.224 \mathrm{U}$ & $4.224 \mathrm{U}$ & $14.496 \mathrm{U}$ & $4.224 \mathrm{U}$ & $3.014 \mathrm{U}$ & $1.651 \mathrm{U}$ & $42.239 \mathrm{U}$ \\
\hline COMP IV & 1 & c & $3.092 \mathrm{U}$ & $0.850 \mathrm{U}$ & $0.850 \mathrm{U}$ & $0.850 \mathrm{U}$ & $2.916 \mathrm{U}$ & $0.850 \mathrm{U}$ & $0.606 U$ & $0.332 \mathrm{U}$ & 8.496 \\
\hline COMP IV Replicate 1 & 2 & c & $13.375 \mathrm{U}$ & $3.676 \mathrm{U}$ & $3.676 \mathrm{U}$ & $3.676 \mathrm{~V}$ & $12.615 \mathrm{U}$ & $3.676 \mathrm{U}$ & $2.623 \mathrm{U}$ & $1.437 \mathrm{U}$ & $36.757 \mathrm{~L}$ \\
\hline COHP IV Replicate 2 & 2 & c & $16.974 \mathrm{U}$ & $4.665 \mathrm{U}$ & $4.665 \mathrm{U}$ & $4.665 \mathrm{U}$ & $16.009 \mathrm{U}$ & $4.665 \mathrm{U}$ & $3.329 \mathrm{U}$ & $1.823 \mathrm{U}$ & $46.646 \mathrm{I}$ \\
\hline COMP IV Replicate 3 & 2 & c & $11.937 \mathrm{U}$ & $3.281 \mathrm{v}$ & $3.281 \mathrm{U}$ & $3.281 \mathrm{U}$ & $11.258 \mathrm{U}$ & $3.281 \mathrm{U}$ & $2.341 \mathrm{U}$ & $1.282 \mathrm{U}$ & 32.805 \\
\hline COHP IV & 3 & A & $5.774 \mathrm{U}$ & $1.587 \mathrm{U}$ & $1.587 \mathrm{U}$ & $1.587 \mathrm{U}$ & $5.446 \mathrm{U}$ & $1.587 \mathrm{U}$ & $1.132 \mathrm{U}$ & $0.620 u$ & $15.868 \mathrm{l}$ \\
\hline COMP IV & 4 & c & $3.679 \mathrm{U}$ & $1.011 \mathrm{~V}$ & $1.011 \mathrm{U}$ & $0.299 \mathrm{JE}$ & $3.470 \mathrm{U}$ & $1.011 \mathrm{U}$ & $0.722 \mathrm{U}$ & $0.395 \mathrm{U}$ & $10.111 \mathrm{~L}$ \\
\hline COMP IV & 5 & A & $6.400 \mathrm{U}$ & $1.759 \mathrm{U}$ & $1.759 \mathrm{U}$ & $1.759 \mathrm{U}$ & $6.036 \mathrm{U}$ & $1.759 \mathrm{U}$ & $1.255 \mathrm{U}$ & $0.688 \mathrm{U}$ & 17.586 \\
\hline
\end{tabular}


IABLE K.13. (contd)

\begin{tabular}{|c|c|c|c|c|c|c|c|c|c|c|c|c|}
\hline & & & & & 1. caecoic & esticide & $\mathrm{tg} / \mathrm{kg}$ & melqht & & & & \\
\hline $\begin{array}{l}\text { Sediment } \\
\text { Ireatment }\end{array}$ & Replicate & $\begin{array}{c}\text { Analytical } \\
\text { Batch } \\
\end{array}$ & Dieldrin & $\begin{array}{c}\text { Endo- } \\
\text { sulfan I }\end{array}$ & $\begin{array}{l}\text { Endo- } \\
\text { sulfan } 11\end{array}$ & $\begin{array}{l}\text { Endo- } \\
\text { sulfan } \\
\text { Sulfate }\end{array}$ & Endr1n & $\begin{array}{c}\text { Endrín } \\
\text { Aldehyde }\end{array}$ & $\begin{array}{l}\text { Hepta - } \\
\text { chlor }\end{array}$ & $\begin{array}{l}\text { Hepta- } \\
\text { chlor- } \\
\text { epoxide }\end{array}$ & $\begin{array}{l}\text { Toxa- } \\
\text { phene }\end{array}$ & \\
\hline $\begin{array}{l}\text { COMP V } \\
\text { COMP V } \\
\text { COMP V } \\
\text { COMP V } \\
\text { COMP V }\end{array}$ & $\begin{array}{l}1 \\
2 \\
3 \\
4 \\
5\end{array}$ & $\begin{array}{l}A \\
A \\
A \\
D \\
B\end{array}$ & $\begin{array}{l}1.691 \mathrm{~J} \\
1.442 \mathrm{~J} \\
1.411 \mathrm{~J} \\
2.303 \mathrm{~J} \\
2.017 \mathrm{~J}\end{array}$ & $\begin{array}{l}0.910 \mathrm{U} \\
1.052 \mathrm{U} \\
0.737 \mathrm{U} \\
0.064 \mathrm{JE} \\
0.652 \mathrm{U}\end{array}$ & $\begin{array}{l}0.397 \mathrm{JE} \\
0.055 \mathrm{JE} \\
0.424 \mathrm{JE} \\
1.040 \mathrm{U} \\
0.652 \mathrm{U}\end{array}$ & $\begin{array}{l}0.910 \mathrm{U} \\
1.052 \mathrm{U} \\
0.737 \mathrm{U} \\
1.040 \mathrm{U} \\
0.652 \mathrm{U}\end{array}$ & $\begin{array}{l}3.124 \mathrm{U} \\
3.610 \mathrm{U} \\
2.529 \mathrm{U} \\
3.570 \mathrm{U} \\
2.237 \mathrm{U}\end{array}$ & $\begin{array}{lll}U & 0.910 & U \\
U & 0.865 & J \\
U & 0.737 & U \\
U & 1.040 & U \\
U & 0.652 & U\end{array}$ & $\begin{array}{l}0.650 \mathrm{U} \\
0.751 \mathrm{U} \\
0.526 \mathrm{U} \\
0.742 \mathrm{U} \\
0.465 \mathrm{U}\end{array}$ & $\begin{array}{l}0.356 \mathrm{U} \\
0.411 \mathrm{U} \\
0.288 \mathrm{U} \\
0.407 \mathrm{U} \\
0.255 \mathrm{U}\end{array}$ & $\begin{array}{r}9.103 \\
10.519 \\
7.371 \\
10.402 \\
6.518\end{array}$ & $\begin{array}{l}\mathrm{U} \\
\mathrm{U} \\
\mathrm{U} \\
\mathrm{U} \\
\mathrm{U}\end{array}$ \\
\hline $\begin{array}{l}\text { COMP VI } \\
\text { COMP VI } \\
\text { COHP VI } \\
\text { COMP VI } \\
\text { COMP VI }\end{array}$ & $\begin{array}{l}1 \\
2 \\
3 \\
4 \\
5\end{array}$ & $\begin{array}{l}C \\
A \\
B \\
A \\
D\end{array}$ & $\begin{array}{l}1.409 \mathrm{~J} \\
1.719 \mathrm{~J} \\
2.132 \mathrm{~J} \\
0.712 \mathrm{~J} \\
3.377 \mathrm{~J}\end{array}$ & $\begin{array}{l}1.069 \mathrm{U} \\
0.216 \mathrm{JE} \\
0.999 \mathrm{U} \\
1.008 \mathrm{U} \\
3.098 \mathrm{U}\end{array}$ & $\begin{array}{l}0.353 \mathrm{JE} \\
0.157 \mathrm{JE} \\
0.100 \mathrm{JE} \\
1.008 \mathrm{U} \\
3.098 \mathrm{U}\end{array}$ & $\begin{array}{l}1.069 \mathrm{U} \\
0.860 \mathrm{U} \\
0.999 \mathrm{U} \\
1.008 \mathrm{U} \\
3.098 \mathrm{U}\end{array}$ & $\begin{array}{r}3.669 \mathrm{U} \\
2.951 \mathrm{U} \\
3.428 \\
3.458 \mathrm{U} \\
10.631 \mathrm{U}\end{array}$ & $\begin{array}{ll}1.069 & U \\
0.320 \mathrm{~J} \\
\mathrm{U} \\
0.999 \mathrm{U} \\
1.008 \mathrm{U} \\
\mathbf{3}\end{array}$ & $\begin{array}{l}0.763 \mathrm{U} \\
0.614 \mathrm{U} \\
0.713 \mathrm{U} \\
0.719 \mathrm{U} \\
2.210 \mathrm{U}\end{array}$ & $\begin{array}{l}0.418 \mathrm{U} \\
0.336 \mathrm{U} \\
0.390 \mathrm{U} \\
0.394 \mathrm{U} \\
1.211 \mathrm{U}\end{array}$ & $\begin{array}{r}10.690 \\
8.600 \\
9.987 \\
10.076 \\
30.976\end{array}$ & $\begin{array}{l}U \\
U \\
U \\
U \\
U \\
U\end{array}$ \\
\hline $\begin{array}{l}R-A C \\
R-A C \\
R-A C \\
R-A C \\
R-A C\end{array}$ & $\begin{array}{l}1 \\
2 \\
3 \\
4 \\
5\end{array}$ & $\begin{array}{l}B \\
C \\
C \\
A \\
D\end{array}$ & $\begin{array}{r}4.891 \mathrm{U} \\
10.947 \mathrm{U} \\
3.449 \mathrm{U} \\
3.775 \mathrm{U} \\
0.165 \mathrm{~J}\end{array}$ & $\begin{array}{l}1.344 \mathrm{U} \\
3.008 \mathrm{U} \\
0.948 \mathrm{U} \\
1.037 \mathrm{U} \\
0.810 \mathrm{U}\end{array}$ & $\begin{array}{l}1.344 \mathrm{U} \\
3.008 \mathrm{U} \\
0.948 \mathrm{U} \\
1.037 \mathrm{U} \\
0.810 \mathrm{U}\end{array}$ & $\begin{array}{l}1.344 \mathrm{U} \\
3.008 \mathrm{U} \\
0.948 \mathrm{U} \\
1.037 \mathrm{U} \\
0.810 \mathrm{U}\end{array}$ & $\begin{array}{r}4.613 \mathrm{U} \\
10.325 \mathrm{U} \\
3.252 \mathrm{U} \\
3.560 \mathrm{U} \\
2.779 \mathrm{U}\end{array}$ & $\begin{array}{llll}U & 1.344 & U \\
U & 3.008 & U \\
U & 0.948 & U \\
U & 1.037 & U \\
U & 0.810 & U\end{array}$ & $\begin{array}{l}0.959 \mathrm{U} \\
2.147 \mathrm{U} \\
0.676 \mathrm{U} \\
0.740 \mathrm{U} \\
0.578 \mathrm{U}\end{array}$ & $\begin{array}{l}0.525 \mathrm{U} \\
1.176 \mathrm{U} \\
0.046 \mathrm{JE} \\
0.406 \mathrm{U} \\
0.317 \mathrm{U}\end{array}$ & $\begin{array}{r}13.441 \\
30.084 \\
9.477 \\
10.373 \\
8.099\end{array}$ & $\begin{array}{l}U \\
U \\
U \\
U \\
U\end{array}$ \\
\hline $\begin{array}{l}\text { R-AM } \\
\text { R-AM } \\
\text { R-AM } \\
\text { R-AM Replicate } 1 \\
\text { R-AM Replicate } 2 \\
\text { R-AM Replicate } 3 \\
\text { R-AH }\end{array}$ & $\begin{array}{l}1 \\
2 \\
3 \\
4 \\
4 \\
4 \\
5\end{array}$ & $\begin{array}{l}8 \\
C \\
8 \\
8 \\
8 \\
B \\
B\end{array}$ & $\begin{array}{r}3.245 \mathrm{U} \\
2.528 \mathrm{U} \\
2.535 \mathrm{U} \\
12.359 \mathrm{U} \\
18.896 \mathrm{U} \\
6.768 \mathrm{U} \\
2.768 \mathrm{U}\end{array}$ & $\begin{array}{l}0.892 \mathrm{U} \\
0.695 \mathrm{U} \\
0.697 \mathrm{U} \\
3.397 \mathrm{U} \\
5.193 \mathrm{U} \\
1.860 \mathrm{U} \\
0.761 \mathrm{U}\end{array}$ & $\begin{array}{l}0.892 \mathrm{U} \\
0.695 \mathrm{U} \\
0.697 \mathrm{U} \\
3.397 \mathrm{U} \\
5.193 \mathrm{U} \\
1.860 \mathrm{U} \\
0.761 \mathrm{U}\end{array}$ & $\begin{array}{l}0.892 \mathrm{U} \\
0.695 \mathrm{U} \\
0.697 \mathrm{U} \\
3.397 \mathrm{U} \\
5.193 \mathrm{U} \\
1.860 \mathrm{U} \\
0.761 \mathrm{U}\end{array}$ & $\begin{array}{r}3.061 \mathrm{U} \\
2.384 \mathrm{U} \\
2.391 \mathrm{U} \\
11.656 \mathrm{U} \\
17.821 \mathrm{U} \\
6.383 \mathrm{U} \\
2.611 \mathrm{U}\end{array}$ & $\begin{array}{lll}U & 0.892 & U \\
U & 0.695 & U \\
U & 0.697 & U \\
U & 3.397 & U \\
U & 5.193 & U \\
U & 1.860 & U \\
U & 0.761 & U\end{array}$ & $\begin{array}{l}0.636 \mathrm{U} \\
0.496 \mathrm{U} \\
0.497 \mathrm{U} \\
2.424 \mathrm{U} \\
3.706 \mathrm{U} \\
1.327 \mathrm{U} \\
0.543 \mathrm{U}\end{array}$ & $\begin{array}{l}0.349 \mathrm{U} \\
0.272 \mathrm{U} \\
0.272 \mathrm{U} \\
1.328 \mathrm{U} \\
2.030 \mathrm{U} \\
0.727 \mathrm{U} \\
0.297 \mathrm{U}\end{array}$ & $\begin{array}{r}8.918 \\
6.946 \\
6.966 \\
33.965 \\
51.928 \\
18.600 \\
7.607\end{array}$ & $\begin{array}{l}u \\
U \\
u \\
u \\
u \\
u \\
u\end{array}$ \\
\hline $\begin{array}{l}R-8 F \\
R-8 F \\
R-B F \\
R-B F \\
R-B F\end{array}$ & $\begin{array}{l}1 \\
2 \\
3 \\
4 \\
5\end{array}$ & $\begin{array}{l}D \\
B \\
B \\
A \\
A\end{array}$ & $\begin{array}{l}0.087 \mathrm{~J} \\
5.619 \mathrm{U} \\
0.183 \mathrm{JE} \\
0.285 \mathrm{~J} \\
0.257 \mathrm{~J}\end{array}$ & $\begin{array}{l}1.334 \mathrm{U} \\
1.544 \mathrm{U} \\
0.879 \mathrm{U} \\
1.074 \mathrm{U} \\
1.092 \mathrm{U}\end{array}$ & $\begin{array}{l}1.334 \mathrm{U} \\
1.544 \mathrm{U} \\
0.879 \mathrm{U} \\
0.155 \mathrm{JE} \\
1.092 \mathrm{U}\end{array}$ & $\begin{array}{l}1.334 \mathrm{U} \\
1.544 \mathrm{U} \\
0.879 \mathrm{U} \\
1.074 \mathrm{U} \\
0.577 \mathrm{JE}\end{array}$ & $\begin{array}{l}4.576 \mathrm{U} \\
5.299 \mathrm{U} \\
3.018 \mathrm{U} \\
3.686 \mathrm{U} \\
3.746 \mathrm{U}\end{array}$ & $\begin{array}{lll}U & 1.334 & U \\
U & 1.544 & U \\
U & 0.879 & U \\
U & 1.074 & U \\
U & 1.092 & U\end{array}$ & $\begin{array}{l}0.952 \mathrm{U} \\
1.102 \mathrm{U} \\
0.628 \mathrm{U} \\
0.766 \mathrm{U} \\
0.779 \mathrm{U}\end{array}$ & $\begin{array}{l}0.521 \mathrm{U} \\
0.604 \mathrm{U} \\
0.344 \mathrm{U} \\
0.420 \mathrm{U} \\
0.427 \mathrm{U}\end{array}$ & $\begin{array}{r}13.335 \\
15.441 \\
8.794 \\
10.740 \\
10.917\end{array}$ & $\begin{array}{l}U \\
U \\
U \\
U \\
U \\
U\end{array}$ \\
\hline $\begin{array}{l}\text { R-OS } \\
\text { R-OS Repl icate } 1 \\
\text { R-OS Repl icate } 2 \\
\text { R-OS Repl icate } 3 \\
\text { R-05 } \\
\text { R-OS } \\
\text { R-OS }\end{array}$ & $\begin{array}{l}1 \\
2 \\
2 \\
2 \\
3 \\
4 \\
5\end{array}$ & $\begin{array}{l}B \\
0 \\
0 \\
0 \\
0 \\
0 \\
C\end{array}$ & $\begin{array}{r}2.901 \mathrm{U} \\
10.225 \mathrm{U} \\
8.291 \mathrm{U} \\
10.026 \mathrm{U} \\
3.048 \mathrm{U} \\
3.343 \mathrm{U} \\
3.274 \mathrm{U}\end{array}$ & $\begin{array}{l}0.797 \mathrm{U} \\
2.810 \mathrm{U} \\
2.279 \mathrm{U} \\
2.755 \mathrm{U} \\
0.838 \mathrm{U} \\
0.919 \mathrm{U} \\
0.900 \mathrm{U}\end{array}$ & $\begin{array}{l}0.797 \mathrm{U} \\
2.810 \mathrm{U} \\
2.279 \mathrm{U} \\
2.755 \mathrm{U} \\
0.838 \mathrm{U} \\
0.919 \mathrm{U} \\
0.900 \mathrm{U}\end{array}$ & $\begin{array}{l}0.797 \mathrm{U} \\
2.810 \mathrm{U} \\
2.279 \mathrm{U} \\
2.755 \mathrm{U} \\
0.838 \mathrm{U} \\
0.919 \mathrm{U} \\
0.900 \mathrm{U}\end{array}$ & $\begin{array}{l}2.736 \mathrm{U} \\
9.643 \mathrm{U} \\
7.820 \mathrm{U} \\
9.456 \mathrm{U} \\
2.875 \mathrm{U} \\
3.153 \mathrm{U} \\
3.088 \mathrm{U}\end{array}$ & $\begin{array}{lll}U & 0.797 & U \\
U & 2.810 & U \\
U & 2.279 & U \\
U & 2.755 & U \\
U & 0.838 & U \\
U & 0.919 & U \\
U & 0.900 & U\end{array}$ & $\begin{array}{l}0.569 \mathrm{U} \\
2.005 \mathrm{U} \\
1.626 \mathrm{U} \\
1.966 \mathrm{U} \\
0.598 \mathrm{U} \\
0.656 \mathrm{U} \\
0.642 \mathrm{U}\end{array}$ & $\begin{array}{ll}0.312 & \mathrm{U} \\
1.098 \mathrm{U} \\
0.891 \mathrm{U} \\
1.077 \mathrm{U} \\
0.327 \mathrm{U} \\
0.359 \mathrm{U} \\
0.352 \mathrm{U}\end{array}$ & $\begin{array}{r}7.971 \\
28.098 \\
22.785 \\
27.554 \\
8.377 \\
9.187 \\
8.997\end{array}$ & $\begin{array}{l}u \\
U \\
U \\
U \\
U \\
U \\
U\end{array}$ \\
\hline
\end{tabular}


TABLE_K.13. (contd)

$N$ coecoides Pesticides $(\mu \mathrm{g} / \mathrm{kg}$ wet weight)

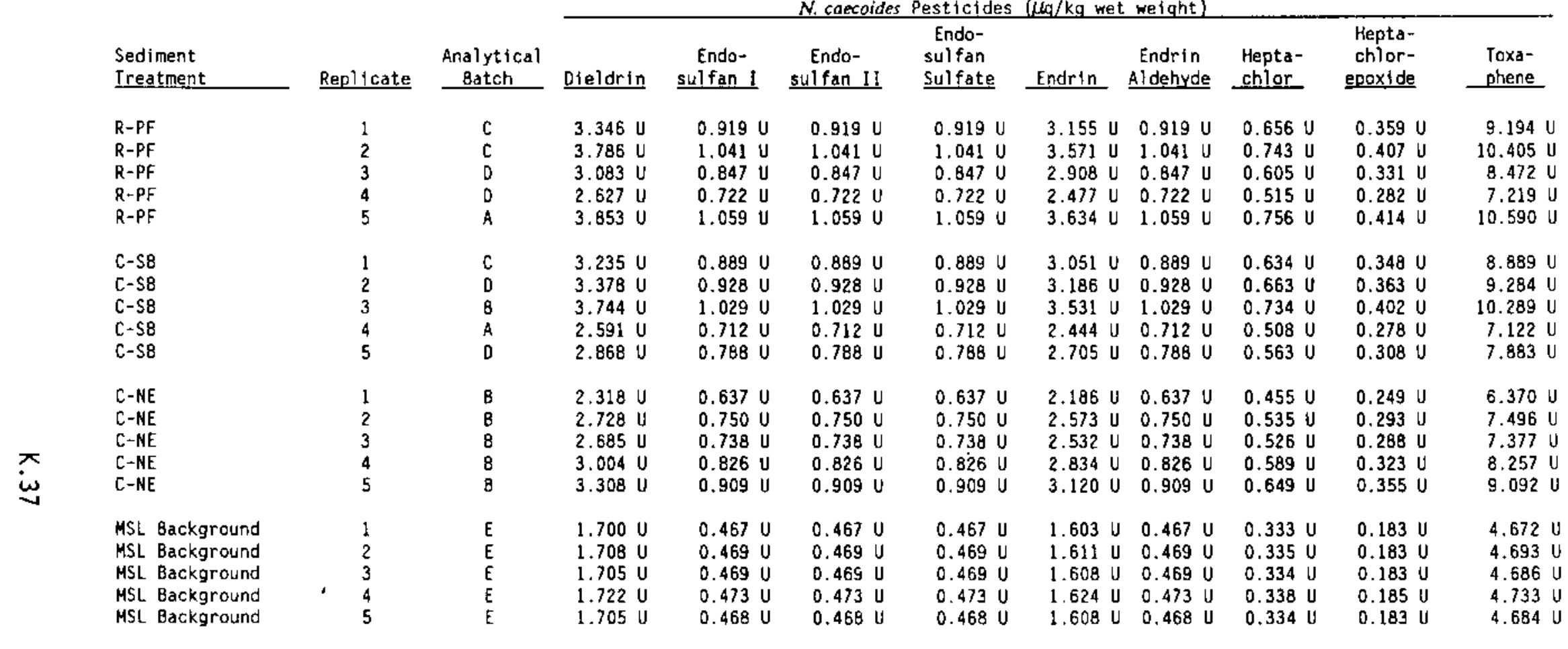

(a) DL Detection limit.

(b) U The analyte was not present above the level of the associated value.

(c) J Analyte detected below method detection hmit (MOL), but above instrument detection limit (IDL).

(d) $E$ Value an estimate: analyte not detected on confirmation column. 
TABLE_K.14. Quality Control Data for Pesticides (alphabetical, Aldrin - 4,4-DDT), Wet Weight, in Tissue of $N$. caecoides, Richmond Harbor Program

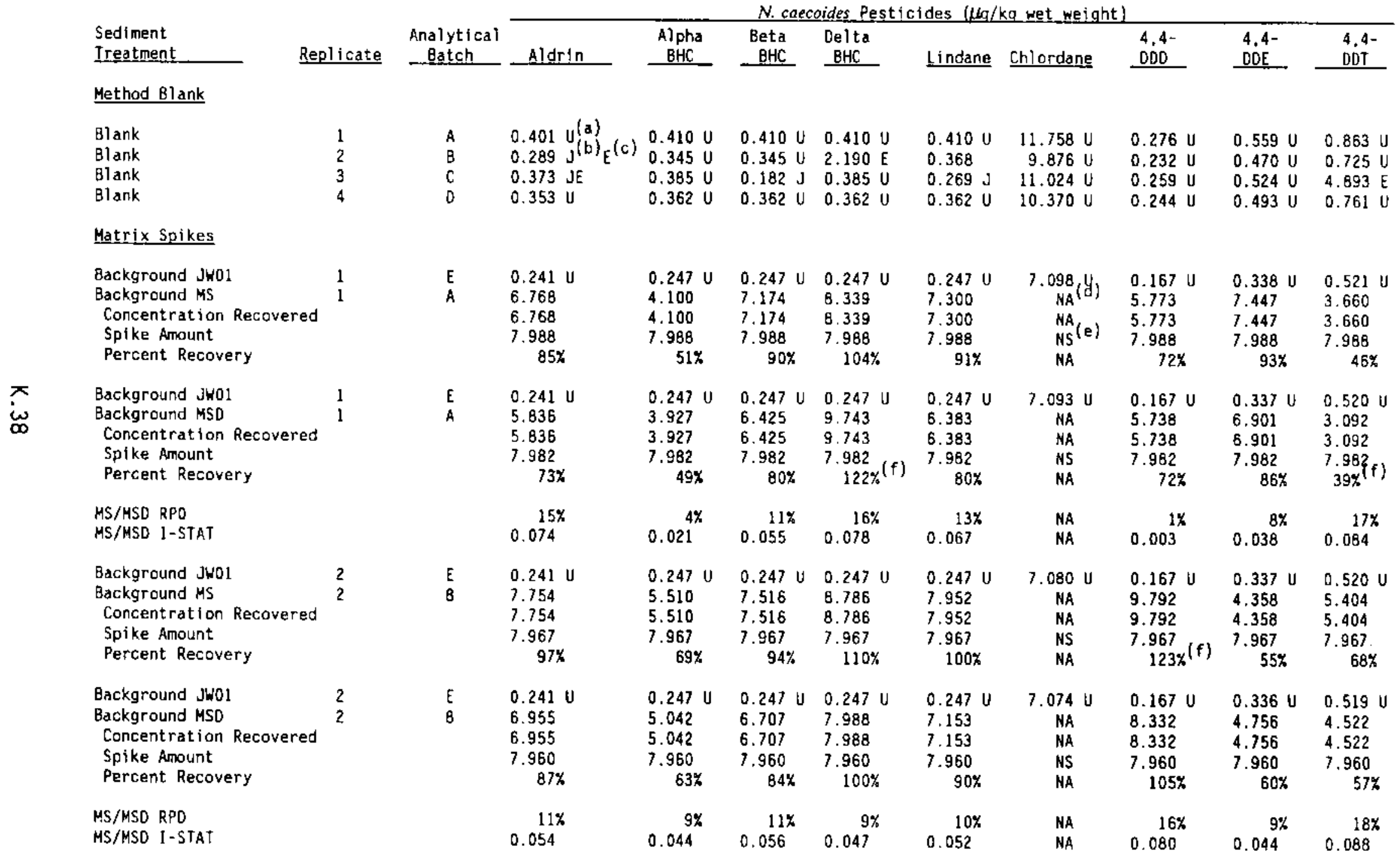


TABLE K.14. (contd)

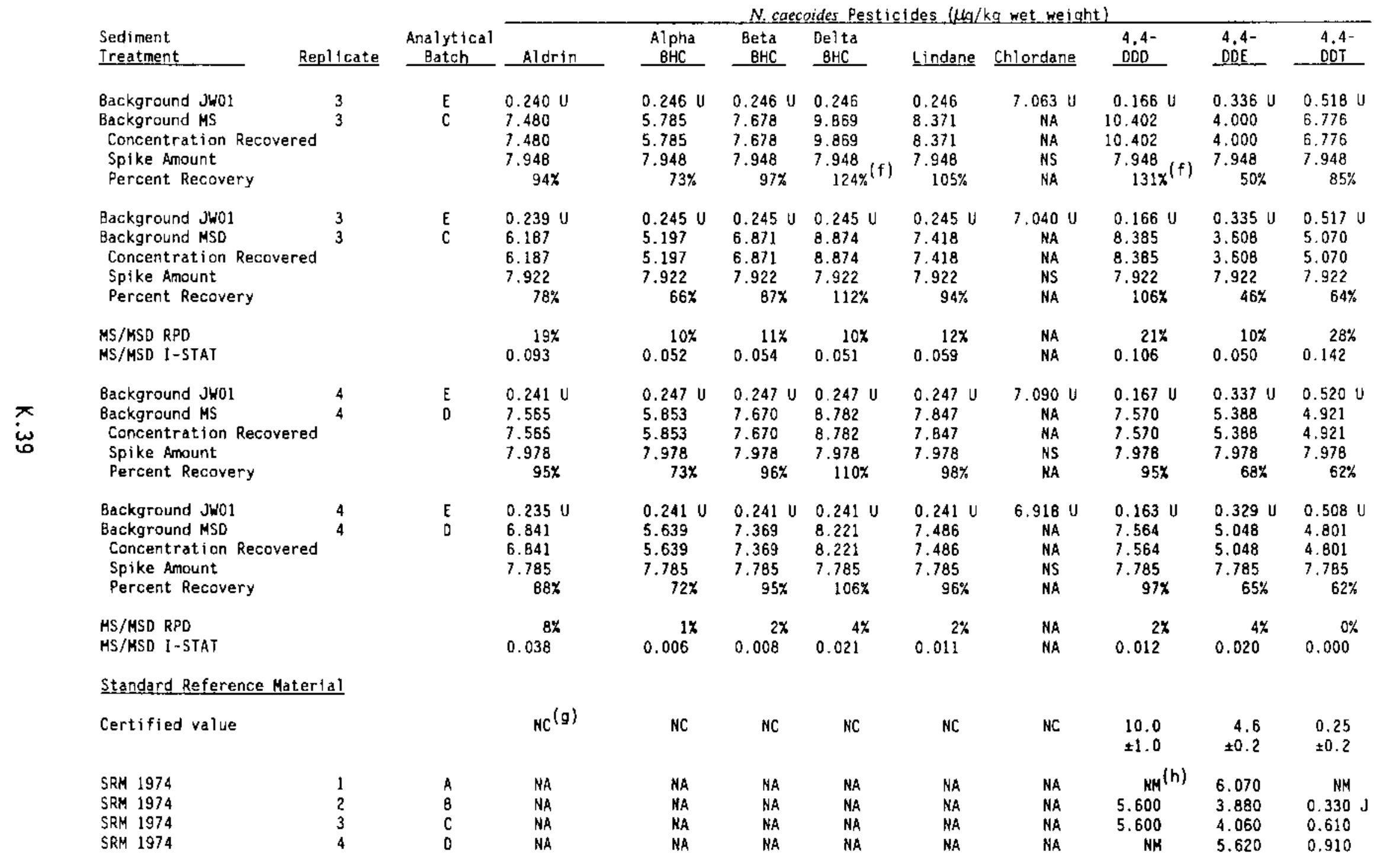


IABLE K.14. (contd)

\begin{tabular}{|c|c|c|c|c|c|c|c|c|c|c|c|}
\hline \multirow[b]{2}{*}{$\begin{array}{l}\text { Sediment } \\
\text { Ireatment }\end{array}$} & \multirow[b]{2}{*}{ Replicate } & \multirow[b]{2}{*}{$\begin{array}{l}\text { Analytical } \\
\text { Batch } \\
\end{array}$} & \multicolumn{9}{|c|}{$N$ crecoides Pesticides $(\mu \mathrm{h} / \mathrm{kg}$ wet weight) } \\
\hline & & & Aldrin & $\begin{array}{c}\text { Alpha } \\
\text { BHC } \\
\end{array}$ & $\begin{array}{r}\text { Beta } \\
\text { BHC } \\
\end{array}$ & $\begin{array}{l}\text { Delta } \\
\text { BHC }\end{array}$ & Lindane & Chlordane & $\begin{array}{l}4,4- \\
\mathrm{DOD} \\
\end{array}$ & $\begin{array}{l}4,4- \\
O D E \\
\end{array}$ & $\begin{array}{r}4,4- \\
\text { DDI } \\
\end{array}$ \\
\hline \multicolumn{12}{|l|}{ Analytical Replicates } \\
\hline $\begin{aligned} \text { COMP I Replicate } 1 \\
\text { COMP I Replicate } 2 \\
\text { COMP I Repl I cate } 3 \\
\text { RSD }\end{aligned}$ & $\begin{array}{l}5 \\
5 \\
5\end{array}$ & $\begin{array}{l}A \\
A \\
A\end{array}$ & $\begin{array}{l}1.275 \mathrm{U} \\
1.173 \mathrm{U} \\
0.864 \mathrm{U} \\
\mathrm{NA}\end{array}$ & $\begin{array}{c}1.305 \mathrm{U} \\
1.201 \mathrm{U} \\
0.885 \mathrm{U} \\
\mathrm{NA}\end{array}$ & $\begin{array}{c}1.305 \mathrm{U} \\
1.201 \mathrm{U} \\
0.885 \mathrm{U} \\
\mathrm{NA}\end{array}$ & $\begin{array}{l}1.305 \mathrm{U} \\
1.201 \mathrm{U} \\
0.885 \mathrm{U} \\
\mathrm{NA}\end{array}$ & $\begin{array}{l}1.305 \mathrm{U} \\
1.201 \mathrm{U} \\
0.885 \mathrm{U} \\
\text { NA }\end{array}$ & $\begin{array}{c}37.415 \mathrm{U} \\
34.426 \mathrm{U} \\
25.362 \mathrm{U} \\
\text { NA }\end{array}$ & $\begin{array}{l}0.798 \mathrm{~J} \\
0.630 \mathrm{~J} \\
0.978 \\
\quad 22 \%\end{array}$ & $\begin{array}{r}1.978 \\
2.087 \\
2.132 \\
4 \%\end{array}$ & $\begin{array}{c}2.745 \mathrm{U} \\
2.525 \mathrm{U} \\
1.861 \mathrm{U} \\
\text { NA }\end{array}$ \\
\hline $\begin{array}{l}\text { COMP IV Replicate } 1 \\
\text { COMP IV Replicate } 2 \\
\text { COMP IV Replicate } 3 \\
\text { RSD }\end{array}$ & $\begin{array}{l}2 \\
2 \\
2\end{array}$ & $\begin{array}{l}\mathrm{C} \\
\mathrm{C} \\
\mathrm{C}\end{array}$ & $\begin{array}{c}1.252 \mathrm{U} \\
1.589 \mathrm{U} \\
1.118 \mathrm{U} \\
\mathrm{NA}\end{array}$ & $\begin{array}{c}1.282 \mathrm{U} \\
1.627 \mathrm{U} \\
1.144 \mathrm{U} \\
\text { NA }\end{array}$ & $\begin{array}{c}1.282 \mathrm{U} \\
1.627 \mathrm{U} \\
1.144 \mathrm{U} \\
\mathrm{NA}\end{array}$ & $\begin{array}{c}1.282 \mathrm{U} \\
1.627 \mathrm{U} \\
1.144 \mathrm{U} \\
\text { NA }\end{array}$ & $\begin{array}{c}1.282 \mathrm{U} \\
1.627 \mathrm{U} \\
1.144 \mathrm{U} \\
\text { NA }\end{array}$ & $\begin{array}{c}36.757 \mathrm{U} \\
46.646 \mathrm{U} \\
32.805 \mathrm{U} \\
\text { NA }\end{array}$ & $\begin{array}{l}0.864 \mathrm{U} \\
1.096 \mathrm{U} \\
0.771 \mathrm{U} \\
\text { NA }\end{array}$ & $\begin{array}{c}0.351 \mathrm{~J} \\
2.218 \mathrm{U} \\
0.065 \mathrm{~J} \\
\text { NA }\end{array}$ & $\begin{array}{c}2.696 \mathrm{U} \\
3.422 \mathrm{U} \\
2.407 \mathrm{U} \\
\text { NA }\end{array}$ \\
\hline $\begin{array}{l}\text { R-AM Replicate } 1 \\
\text { R-AM Replicate } 2 \\
\text { R-AM Replicate } 3 \\
\text { RSD }\end{array}$ & $\begin{array}{l}4 \\
4 \\
4\end{array}$ & $\begin{array}{l}\mathrm{B} \\
\mathrm{B} \\
8\end{array}$ & $\begin{array}{c}1.157 \mathrm{U} \\
1.769 \mathrm{U} \\
0.634 \mathrm{U} \\
\mathrm{HA}\end{array}$ & $\begin{array}{c}1.185 \mathrm{U} \\
1.812 \mathrm{U} \\
0.649 \mathrm{~J} \\
\text { NA }\end{array}$ & $\begin{array}{c}1.185 \mathrm{U} \\
1.812 \mathrm{U} \\
0.649 \mathrm{U} \\
\text { NA }\end{array}$ & $\begin{array}{c}1.185 \mathrm{U} \\
1.812 \mathrm{U} \\
0.649 \mathrm{U} \\
\mathrm{NA}\end{array}$ & $\begin{array}{c}1.185 \mathrm{U} \\
1.812 \mathrm{U} \\
0.649 \mathrm{U} \\
\text { NA }\end{array}$ & $\begin{array}{c}33.965 \mathrm{U} \\
51.928 \mathrm{U} \\
18.600 \mathrm{U} \\
\text { MA }\end{array}$ & $\begin{array}{c}0.798 \mathrm{U} \\
1.221 \mathrm{U} \\
0.437 \mathrm{U} \\
\mathrm{NA}\end{array}$ & $\begin{array}{c}0.700 \mathrm{~J} \\
2.469 \mathrm{~J} \\
0.553 \mathrm{~J} \\
H A\end{array}$ & $\begin{array}{c}2.492 \mathrm{U} \\
3.809 \mathrm{U} \\
1.364 \mathrm{U} \\
\text { NA }\end{array}$ \\
\hline $\begin{array}{l}\text { R-OS Replicate } 1 \\
\text { R-OS Repl I cate } 2 \\
\text { R-OS Replicate } 3 \\
\text { RSD }\end{array}$ & $\begin{array}{l}2 \\
2 \\
2\end{array}$ & $\begin{array}{l}0 \\
0 \\
0\end{array}$ & $\begin{array}{c}0.957 \mathrm{U} \\
0.776 \mathrm{~J} \\
0.939 \mathrm{U} \\
\text { NA }\end{array}$ & $\begin{array}{c}0.980 \mathrm{U} \\
0.795 \mathrm{U} \\
0.961 \mathrm{U} \\
\text { NA }\end{array}$ & $\begin{array}{c}0.980 \mathrm{U} \\
0.795 \mathrm{U} \\
0.961 \mathrm{U} \\
\mathrm{NA}\end{array}$ & $\begin{array}{c}0.980 \mathrm{U} \\
0.795 \mathrm{U} \\
0.961 \mathrm{U} \\
\mathrm{NA}\end{array}$ & $\begin{array}{l}0.980 \mathrm{U} \\
0.795 \mathrm{U} \\
0.961 \mathrm{U} \\
\mathrm{HA}\end{array}$ & $\begin{array}{c}28.098 \mathrm{U} \\
22.785 \mathrm{U} \\
27.554 \mathrm{U} \\
\text { NA }\end{array}$ & $\begin{array}{c}0.660 \mathrm{U} \\
0.536 \mathrm{U} \\
0.648 \mathrm{U} \\
\text { NA }\end{array}$ & $\begin{array}{r}2.171 \\
1.837 \\
1.724 \\
12 \%\end{array}$ & $\begin{array}{c}2.061 \mathrm{U} \\
1.671 \mathrm{U} \\
2.021 \mathrm{U} \\
\text { NA }\end{array}$ \\
\hline
\end{tabular}

(a) U The analyte was not present above the level of the associated value.

(b) J Analyte detected below method detection limit (HDL). but above instrument detection 1 imit (IDL).

(c) E Value an estimate; analyte not detected on confimation column.

(d) NA Not appl lcable.

(e) NS Not spiked.

(f) Recovery outside quality control range $(40 \%-120 \%$.

(g) NC Not certified.

(h) NM Not measured. 
TABLE K.15. Quality Control Data for Pesticides (alphabetical, Dieldrin - Toxaphene), Wet Weight, in Tissue of $N$. caecoides, Richmond Harbor Program

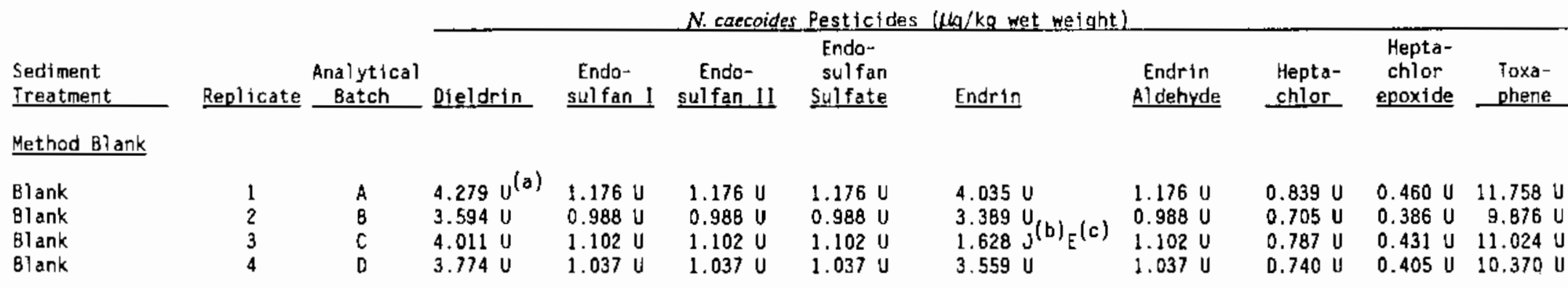

Matrix Spikes

Background MS

Concentration Recovered

Spike Amount

Percent Recovery
E

$2.583 \mathrm{U}$

6.142

6.142

6.142

7.988
$77 \%$

$77 \%$

E $\quad 2.581 \mathrm{U}$

5.685

5.685

7.982

Percent Recovery

MS/MSD RPD

MS/MSD I-STAT

Background JW01

Background MS

Concentration Recovered

Spike Amount

Percent Recovery

Background JwOl

Background MSO

Concentration Recovered

Spike Amount

Percent Recovery

MS/MSO RPD

MS/MSD I-STAT

$8 \%$

0.038

7.087

7.087

$89 \%$

$2.574 \mathrm{U}$

6.016

6.016

7.960

$76 \%$

$16 \%$

\subsection{U $\quad 0.710$ U $\quad 0.710$ U}

4.699

4.699

7.988

11.385

11.385

11.016

$59 \%$

$143 \%^{(f)} \quad{ }_{138 \%}^{7.988}(f)$

$0.710 \mathrm{U}$

6.735

6.735
7.982

$0.710 \mathrm{U} \quad 0.710 \mathrm{U}$

$9.950 \quad 10.739$

9.950

10.739

$84 \%$

$125 \%(f)$

$36 x^{(g)}$
0.178

$13 \%$

${ }_{135 \%}(f)$

$0.708 \mathrm{U}$

6.841

6.841

7.967

$86 \%$

$0.708 \mathrm{U}$

0.012

12.246

$0.708 \mathrm{U}$

10.701

7.967

$154 \mathrm{f}^{(f)} \quad 7.967$ (f)

$0.708 \mathrm{U}$

0.7084

$134 \%(f)$

5.818

0.708
10.372
10.372

$0.708 \mathrm{U}$

7.960

.960
$73 \%$

7.960

7.960 (f)

9.337

7.960

$16 \%$

0.082

$14 \%$
0.068

0.080
$2.436 \mathrm{U}$

7.907

7.907

7.988
$99 \%$

$434 \mathrm{~V}$

7.004

7.004
7.004

7.982

$88 \%$

$12 \%$

0.060

$2.430 \mathrm{~V}$

14.769

14.769

.967 (f)

$2.427 \mathrm{U}$

11.343

11.343

7.960 (f)

0.131

$0.710 u$
5.194
5.194
7.988
$65 \%$

$0.507 \mathrm{U}$

$8.261 \quad 6.079$

$8.261 \quad 6.079$

$\begin{array}{ll}8.261 & 6.079 \\ 7.988 & 7.988\end{array}$

$103 x \quad 76 \%$

$\begin{array}{lllll}0.710 \cup & 0.506 \cup & 0.277 & 0 & 7.093\end{array}$

$\begin{array}{lll}4.959 & 7.590 & 5.382\end{array}$

$4.959 \quad 7.590 \quad 5.382$

7.98

$62 \%$

7.982

$0.023^{5 \%}$

0.042

$12 \%$

$0.708 \mathrm{U}$

2.865

2.865

7. 967 (f)

0.505

8.965

8.965

0.2770

7.458
7.458

7.458

$113 \%$

$0.708 \mathrm{U}$

2.173

2.173

7.960

$27 \%$ (f)

$0.505 \mathrm{~V}$

8.180

$27 \%$

0.137

$8.180 \quad 6.249$

6.249
6.249

7.960

$103 \%$

$79 \%$

$\begin{array}{cc}9 x & 18 \% \\ 0.045 & 0.088\end{array}$

NA 
IABLE K.15. (contd)

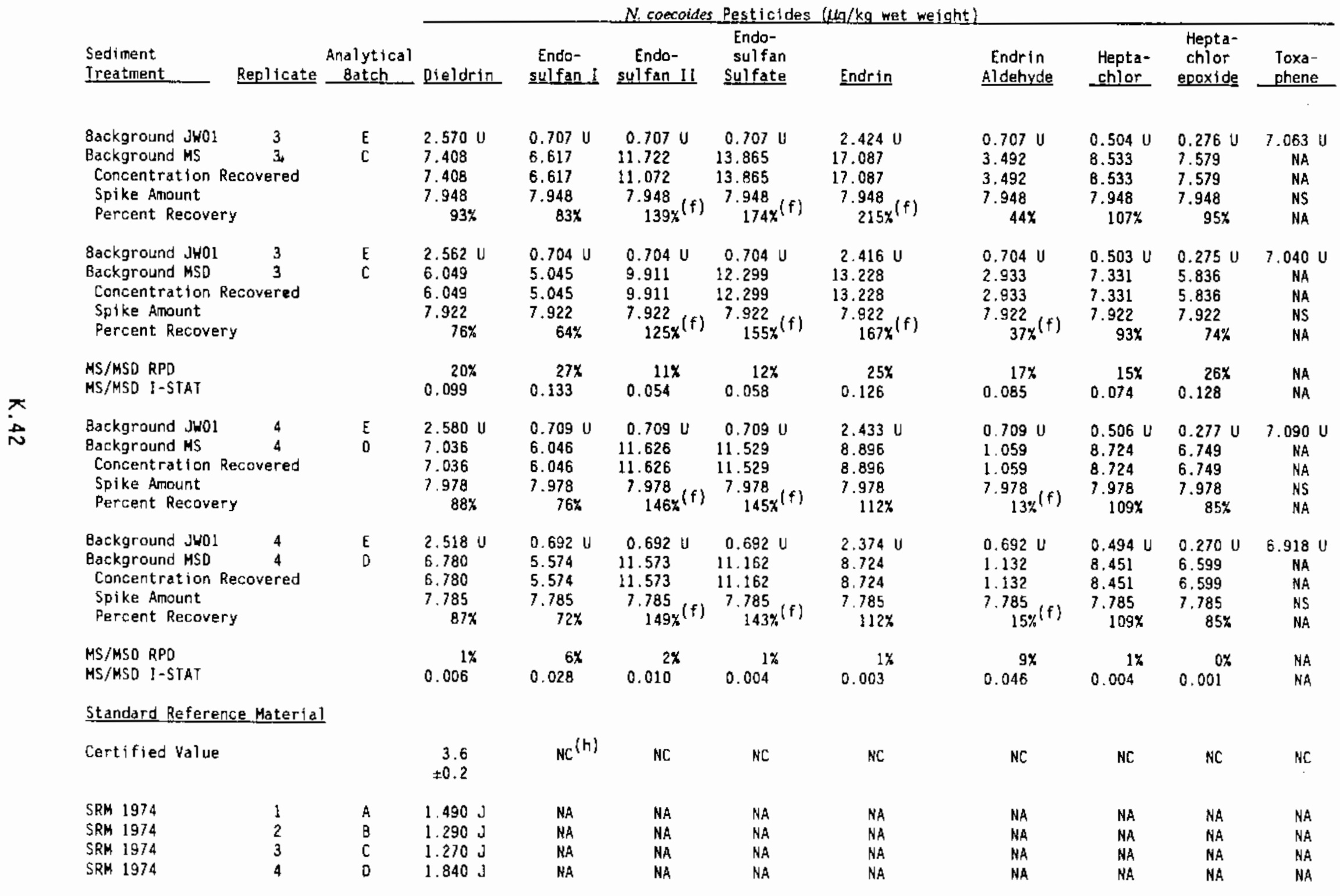


TABLEKK.15. (contd)

$N$ coecoides Pesticldes ( $\mu \mathrm{g} / \mathrm{kg}$, wet weight)

\begin{tabular}{|c|c|c|c|c|c|c|c|c|c|c|c|}
\hline \multirow[b]{2}{*}{$\begin{array}{l}\text { Sediment } \\
\text { Ireatment }\end{array}$} & \multirow[b]{2}{*}{ plicate } & \multirow[b]{2}{*}{$\begin{array}{l}\text { Analytical } \\
\text { Batch }\end{array}$} & \multicolumn{7}{|c|}{ N. caecoides Pesticldes ( $\mu \mathrm{g} / \mathrm{kg}$ wet weight) } & \multirow[b]{2}{*}{$\begin{array}{l}\text { Hepta- } \\
\text { chlor } \\
\text { epoxide }\end{array}$} & \multirow[b]{2}{*}{$\begin{array}{l}\text { Toxa- } \\
\text { phene }\end{array}$} \\
\hline & & & Qteldrin & $\begin{array}{l}\text { Endo- } \\
\text { sulfan. I } \\
\end{array}$ & $\begin{array}{c}\text { Endo- } \\
\text { sulfan } 11\end{array}$ & $\begin{array}{l}\text { Endo- } \\
\text { sulfan } \\
\text { Sulfate }\end{array}$ & Endrin & $\begin{array}{c}\text { Endrín } \\
\text { Aldehyde }\end{array}$ & $\begin{array}{l}\text { Hepta- } \\
\text { chlor } \\
\end{array}$ & & \\
\hline \multicolumn{12}{|l|}{ Analytical Replicates } \\
\hline $\begin{array}{cc}\text { COMP I Replicate } 1 \\
\text { COMP I Replicate } 2 \\
\text { COMP I Replicate } 3 \\
\text { RSD }\end{array}$ & $\begin{array}{l}5 \\
5 \\
5\end{array}$ & $\begin{array}{l}A \\
A \\
A\end{array}$ & $\begin{array}{c}13.615 \mathrm{U} \\
12.527 \mathrm{U} \\
9.229 \mathrm{U} \\
\mathrm{NA}\end{array}$ & $\begin{array}{c}3.742 \mathrm{U} \\
3.443 \mathrm{U} \\
2.536 \mathrm{U} \\
\mathrm{NA}\end{array}$ & $\begin{array}{c}3.742 \mathrm{U} \\
3.443 \mathrm{U} \\
2.536 \mathrm{U} \\
\mathrm{NA}\end{array}$ & $\begin{array}{c}3.742 \mathrm{U} \\
3.443 \mathrm{U} \\
2.536 \mathrm{U} \\
\mathrm{NA}\end{array}$ & $\begin{array}{c}12.841 \mathrm{U} \\
11.815 \mathrm{U} \\
8.704 \mathrm{U} \\
\mathrm{NA}\end{array}$ & $\begin{array}{c}3.742 \mathrm{U} \\
3.443 \mathrm{U} \\
2.536 \mathrm{U} \\
\text { NA }\end{array}$ & $\begin{array}{l}2.670 \mathrm{U} \\
2.457 \mathrm{U} \\
1.810 \mathrm{U} \\
\text { NA }\end{array}$ & $\begin{array}{l}1.463 \mathrm{U} \\
1.346 \mathrm{U} \\
0.991 \mathrm{U} \\
\text { NA }\end{array}$ & $\begin{array}{c}37.415 \mathrm{U} \\
34.426 \mathrm{U} \\
25.362 \mathrm{U} \\
\text { NA }\end{array}$ \\
\hline $\begin{array}{l}\text { COMP IV Replicate } 1 \\
\text { COMP IV Replicate } 2 \\
\text { COMP IV Replicate } 3 \\
\text { RSD }\end{array}$ & $\begin{array}{l}2 \\
2 \\
2\end{array}$ & $\begin{array}{l}c \\
c \\
c\end{array}$ & $\begin{array}{c}13.375 \mathrm{U} \\
16.974 \mathrm{U} \\
11.937 \mathrm{U} \\
\text { NA }\end{array}$ & $\begin{array}{c}3.676 \mathrm{U} \\
4.665 \mathrm{U} \\
3.281 \mathrm{U} \\
\mathrm{HA}\end{array}$ & $\begin{array}{c}3.676 \mathrm{U} \\
4.665 \mathrm{U} \\
3.281 \mathrm{U} \\
\text { NA }\end{array}$ & $\begin{array}{c}3.676 \mathrm{U} \\
4.665 \mathrm{U} \\
3.281 \mathrm{U} \\
\mathrm{NA}\end{array}$ & $\begin{array}{c}12.615 \mathrm{U} \\
16.009 \mathrm{U} \\
11.258 \mathrm{U} \\
\text { NA }\end{array}$ & $\begin{array}{c}3.676 \mathrm{U} \\
4.665 \mathrm{U} \\
3.281 \mathrm{U} \\
\text { NA }\end{array}$ & $\begin{array}{c}2.623 \mathrm{U} \\
3.329 \mathrm{~V} \\
2.341 \mathrm{U} \\
\text { NA }\end{array}$ & $\begin{array}{c}1.437 \mathrm{U} \\
1.823 \mathrm{U} \\
1.282 \mathrm{U} \\
\text { NA }\end{array}$ & $\begin{array}{c}36.757 \mathrm{U} \\
46.646 \mathrm{U} \\
32.805 \mathrm{U} \\
\text { NA }\end{array}$ \\
\hline $\begin{array}{l}\text { R-AM Replicate } 1 \\
\text { R-AM Replicate } 2 \\
\text { R-AM Replicate } 3 \\
\text { RSO }\end{array}$ & $\begin{array}{l}4 \\
4 \\
4\end{array}$ & $\begin{array}{l}8 \\
8 \\
8\end{array}$ & $\begin{array}{c}12.359 \mathrm{U} \\
18.896 \mathrm{U} \\
6.768 \mathrm{U} \\
\mathrm{NA}\end{array}$ & $\begin{array}{c}3.397 \mathrm{U} \\
5.193 \mathrm{U} \\
1.860 \mathrm{U} \\
\text { NA }\end{array}$ & $\begin{array}{c}3.397 \mathrm{U} \\
5.193 \mathrm{U} \\
1.860 \mathrm{U} \\
\text { NA }\end{array}$ & $\begin{array}{c}3.397 \mathrm{U} \\
5.193 \mathrm{U} \\
1.860 \mathrm{U} \\
\mathrm{NA}\end{array}$ & $\begin{array}{c}11.656 \mathrm{U} \\
17.821 \mathrm{U} \\
6.383 \mathrm{U} \\
\text { NA }\end{array}$ & $\begin{array}{c}3.397 \mathrm{U} \\
5.193 \mathrm{U} \\
1.860 \mathrm{U} \\
\text { NA }\end{array}$ & $\begin{array}{l}2.424 \mathrm{U} \\
3.706 \mathrm{U} \\
1.327 \mathrm{U} \\
\text { NA }\end{array}$ & $\begin{array}{c}1.328 \mathrm{U} \\
2.030 \mathrm{U} \\
0.727 \mathrm{U} \\
\text { NA }\end{array}$ & $\begin{array}{c}33.965 \mathrm{U} \\
51.928 \mathrm{U} \\
18.600 \mathrm{U} \\
\text { NA }\end{array}$ \\
\hline $\begin{array}{l}\text { R-OS Replicate } 1 \\
\text { R-0S Replicate } 2 \\
\text { R-0S Replicate } 3 \\
\text { RSD }\end{array}$ & $\begin{array}{l}2 \\
2 \\
2\end{array}$ & $\begin{array}{l}0 \\
0 \\
0\end{array}$ & $\begin{array}{r}10.225 \mathrm{U} \\
8.291 \mathrm{U} \\
10.026 \mathrm{U} \\
\mathrm{NA}\end{array}$ & $\begin{array}{c}2.810 \mathrm{U} \\
2.279 \mathrm{U} \\
2.755 \mathrm{U} \\
\text { NA }\end{array}$ & $\begin{array}{l}2.810 \mathrm{U} \\
2.279 \mathrm{U} \\
2.755 \mathrm{U} \\
\mathrm{NA}\end{array}$ & $\begin{array}{l}2.810 \mathrm{U} \\
2.279 \mathrm{U} \\
2.755 \mathrm{U} \\
\mathrm{NA}\end{array}$ & $\begin{array}{c}9.643 \mathrm{U} \\
7.820 \mathrm{U} \\
9.456 \mathrm{U} \\
\text { NA }\end{array}$ & $\begin{array}{c}2.810 \mathrm{U} \\
2.279 \mathrm{U} \\
2.755 \mathrm{U} \\
\mathrm{NA}\end{array}$ & $\begin{array}{c}2.005 \mathrm{U} \\
1.626 \mathrm{U} \\
1.966 \mathrm{U} \\
\text { NA }\end{array}$ & $\begin{array}{c}1.098 \mathrm{U} \\
0.891 \mathrm{U} \\
1.077 \mathrm{U} \\
\mathrm{NA}\end{array}$ & $\begin{array}{c}28.098 \mathrm{U} \\
22.785 \mathrm{U} \\
27.554 \mathrm{U} \\
\mathrm{NA}\end{array}$ \\
\hline
\end{tabular}

(a) $U$ The analyte was not present above the level of the associated value.

(b) J Analyte detected below method detection 1 imit (MDL), but above instrument detection $11 \mathrm{mit}$ (IDL).

(c) E Value an estimate: analyte not detected on confirmation column.

(d) NA Not applicable.

(e) NS Not spiked.

(f) Recovery outside quality control range $(40 \%-120 \%)$.

(g) Value exceeds relative precision range of $30 \%$.

(h) NC Not certified. 
TABLE K.16. Polychlorinated Biphenyls (PCBs), Dry Weight, in Tissue of N. caecoides, Richmond Harbor Program

\begin{tabular}{|c|c|c|c|c|c|c|c|}
\hline \multirow[b]{2}{*}{$\begin{array}{l}\text { Sediment } \\
\text { Irreatment }\end{array}$} & \multirow[b]{2}{*}{ Replicate } & \multirow[b]{2}{*}{$\begin{array}{c}\text { Analytical } \\
\text { Batch } \\
\end{array}$} & \multirow[b]{2}{*}{$\begin{array}{c}\text { Percent } \\
\text { Dry Height }\end{array}$} & \multicolumn{4}{|c|}{ 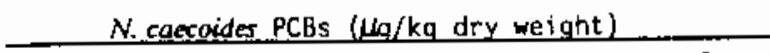 } \\
\hline & & & & $\begin{array}{l}\text { Aroclor- } \\
1242\end{array}$ & $\begin{array}{c}\text { Aroclor- } \\
1248 \\
\end{array}$ & $\begin{array}{c}\text { Aroclor- } \\
1254 \\
\end{array}$ & $\begin{array}{c}\text { Aroclor- } \\
1260 \\
\end{array}$ \\
\hline COMP I & 1 & D & 16.00 & $71.700 \mathrm{ve}^{(\mathrm{a})}$ & $71.700 \mathrm{U}$ & 86.325 & $71.700 \mathrm{u}$ \\
\hline COMP I & 2 & D & 15.28 & $48.154 \mathrm{U}$ & $48.154 \mathrm{U}$ & 134.889 & $48.154 U$ \\
\hline COMPI & 3 & A & $16.50^{(b)}$ & $54.933 \mathrm{U}$ & $54.933 \mathrm{U}$ & $54.933 \mathrm{U} / \mathrm{cl}$ & $54.933 \mathrm{U}$ \\
\hline COMP I & 4 & a & 17.16 & $194.493 \mathrm{U}$ & $194.493 \mathrm{U}$ & $96.929 j^{(c)}$ & $194.493 U$ \\
\hline COMP I Replicate I & 5 & A & 17.54 & $213.312 \mathrm{U}$ & 213.312 U & $70.678 \mathrm{~J}$ & $213.312 U$ \\
\hline СОНP I Replicate 2 & 5 & A & 17.54 & $196.271 \mathrm{U}$ & $196.271 \mathrm{U}$ & $111.608 \mathrm{~J}$ & $196.271 \mathrm{U}$ \\
\hline COMP I Replicate 3 & 5 & A & 17.54 & $144.595 \mathrm{~V}$ & $144.595 \mathrm{U}$ & $105.838 \mathrm{~J}$ & $144.595 \mathrm{U}$ \\
\hline СОНР II & 1 & 0 & 15.12 & $46.052 \mathrm{U}$ & 46.052 U & 144.405 & $46.052 \mathrm{U}$ \\
\hline COMP II & 2 & A & 17.08 & $86.803 \mathrm{U}$ & $86.803 \mathrm{U}$ & 144.865 & $86.803 \mathrm{U}$ \\
\hline СOMP II & 3 & c & 17.30 & $47.312 \mathrm{U}$ & $47.312 \mathrm{U}$ & 181.416 & $47.312 u$ \\
\hline COMP II & 4 & D & 15.82 & $62.933 \mathrm{U}$ & $62.933 \mathrm{U}$ & 194.362 & $62.933 \mathrm{~V}$ \\
\hline COMP II & 5 & c & 16.64 & $47.873 \mathrm{U}$ & $47.873 \mathrm{U}$ & 196.064 & $47.873 \mathrm{U}$ \\
\hline COMP III & 1 & $c$ & 14.77 & $66.628 \mathrm{U}$ & $66.628 \mathrm{U}$ & 99.127 & $66.628 \mathrm{U}$ \\
\hline COMP III & 2 & D & 16.64 & $55.541 \mathrm{U}$ & $55.541 \cup$ & 67.464 & $55.541 \cup$ \\
\hline COMP II I & 3 & A & 15.35 & $49.681 \mathrm{U}$ & $49.681 \mathrm{U}$ & 59.954 & $49.681 \mathrm{U}$ \\
\hline СОНР III & 4 & 0 & 16.35 & $51.933 U$ & $51.933 \mathrm{U}$ & 66.043 & $51.933 \mathrm{U}$ \\
\hline COMP III & 5 & c & 15.26 & $67.405 \mathrm{U}$ & $67.405 \mathrm{U}$ & 85.046 & $67.405 \mathrm{U}$ \\
\hline TC-5 Upper Comp & 1 & c & 15.40 & $91.662 \mathrm{U}$ & $91.662 \mathrm{U}$ & 485.675 & $91.662 \mathrm{u}$ \\
\hline TC-5 Upper Comp & 2 & c & 15.92 & $53.989 \mathrm{U}$ & $53.989 u$ & 407.104 & $53.989 \mathrm{U}$ \\
\hline TC-5 Upper Comp & 3 & $\mathrm{c}$ & 16.93 & $73.768 \mathrm{U}$ & $73.768 \mathrm{U}$ & 498.494 & $73.768 \mathrm{U}$ \\
\hline TC-5 Upper Comp & 4 & A & 15.87 & $77.618 \mathrm{U}$ & $77.618 \mathrm{U}$ & 337.051 & $77.618 \mathrm{U}$ \\
\hline TC-5 Upper Comp & 5 & A & 16.58 & $254.759 \mathrm{U}$ & $254.759 \mathrm{U}$ & 323.764 & 254.759 \\
\hline COMP IV & 1 & c & 16.16 & $52.574 \mathrm{U}$ & $52.574 \mathrm{U}$ & $50.000 \mathrm{~J}$ & $52.574 \mathrm{U}$ \\
\hline COMP IV Replicate 1 & 2 & C & 16.46 & $223.311 \mathrm{U}$ & $223.311 \mathrm{U}$ & $223.311 \mathrm{U}$ & 223.3110 \\
\hline COMP IV Replifate ? & 2 & c & 16.46 & $283.390 \mathrm{U}$ & $283.390 \mathrm{U}$ & $283.390 \mathrm{U}$ & $283.390 \mathrm{U}$ \\
\hline COMP IV Replicate 3 & 2 & $c$ & 16.46 & $199.301 \mathrm{U}$ & $199.301 \mathrm{U}$ & $199.301 \mathrm{U}$ & $199.301 \mathrm{U}$ \\
\hline COMP iv & 3 & A & 11.15 & $142.314 U$ & $142.314 \mathrm{U}$ & $142.314 \mathrm{U}$ & $142.314 \mathrm{~V}$ \\
\hline COMP iv & 4 & $\ddot{c}$ & 16.04 & $63.036 \mathrm{U}$ & $63.036 \mathrm{U}$ & $63.036 \mathrm{U}$ & $63.036 \mathrm{U}$ \\
\hline COMP iV & 5 & A & 13.09 & $134.362 \mathrm{U}$ & $134.362 \mathrm{U}$ & $134.362 \mathrm{U}$ & $134.362 U$ \\
\hline COMP $V$ & 1 & A & 15.27 & $59.614 \mathrm{U}$ & $59.614 \cup$ & 375.403 & $59.614 \mathrm{U}$ \\
\hline $\operatorname{comp} v$ & 2 & A & 14.83 & $70.931 \mathrm{v}$ & $70.931 \mathrm{U}$ & 333.196 & $70.931 \mathrm{U}$ \\
\hline $\operatorname{com} P V$ & 3 & A & 17.13 & $43.030 \mathrm{U}$ & $43.030 \mathrm{U}$ & 282.703 & $43.030 \mathrm{U}$ \\
\hline COMP $V$ & 4 & D & 15.44 & $67.370 \mathrm{U}$ & $67.370 \mathrm{U}$ & 242.817 & $67.370 \mathrm{U}$ \\
\hline COMP V & 5 & B & 17.14 & $38.028 \mathrm{U}$ & $38.028 \mathrm{U}$ & 354.947 & $38.028 u$ \\
\hline COMP VI & 1 & c & 15.08 & $70.889 \mathrm{U}$ & $70.889 \mathrm{U}$ & 369.503 & $70.889 \mathrm{U}$ \\
\hline COMP VI & 2 & A & 15.83 & $54.327 \mathrm{U}$ & $54.327 \cup$ & 338.661 & $54.327 \mathrm{U}$ \\
\hline COMP VI & 3 & 8 & 16.25 & $61.458 \mathrm{U}$ & $61.458 \mathrm{U}$ & 338.437 & 61.4580 \\
\hline СОМР VI & 4 & A & 15.89 & $63.411 \mathrm{U}$ & $63.411 \mathrm{U}$ & 310.818 & $63.411 \mathrm{v}$ \\
\hline сонP VI & 5 & D & 16.24 & $190.739 \mathrm{~J}$ & $190.739 \mathrm{U}$ & 456.299 & $190.739 \mathrm{U}$ \\
\hline$R-A C$ & 1 & 8 & 15.84 & $84.855 \mathrm{U}$ & $84.855 \mathrm{U}$ & 274.318 & $84.855 \mathrm{U}$ \\
\hline$R-A C$ & 2 & c & 16.14 & $186.394 \mathrm{U}$ & $186.394 \mathrm{U}$ & 214.572 & $186.394 \mathrm{U}$ \\
\hline$R-A C$ & 3 & C & 16.16 & $58.645 \mathrm{U}$ & $58.645 \mathrm{U}$ & 204.969 & $58.645 \mathrm{U}$ \\
\hline$R-A C$ & 4 & A & 13.29 & $78.051 \mathrm{U}$ & $78.051 \mathrm{U}$ & $78.051 \mathrm{U}$ & $78.051 \mathrm{U}$ \\
\hline $\mathrm{R}-\mathrm{AC}$ & 5 & D & 16.75 & $48.352 \mathrm{U}$ & $48.352 \cup$ & 160.436 & $48.352 U$ \\
\hline$R-A \mathbf{H}$ & 1 & 8 & 17.29 & $51.579 \mathrm{U}$ & $51.579 \mathrm{U}$ & $51.579 U$ & $51.579 u$ \\
\hline$R-A M$ & 2 & C & 16.62 & $41.793 \mathrm{U}$ & $41.793 \mathrm{U}$ & 97.497 & 41.793 \\
\hline R-AM & 3 & B & 16.26 & $42.841 \mathrm{U}$ & $42.841 \mathrm{U}$ & 97.638 & $42.841 \mathrm{U}$ \\
\hline
\end{tabular}


IABLE K.16. (contd)

Sediment

Ireatment

R-AM Replicate 1

R-AM Replicate 2

R-AM Replicate 3

R-AK

$R-B F$

$R-B F$

$\mathrm{R}-\mathrm{BF}$

$R-B F$

$R-B F$

R-OS

R-OS Replicate 1

R-OS Repi icate 2

R-OS Replicate 3

R-OS

$R-O S$

$R-0 S$

$R-P F$

$R-P F$

$R-P F$

$R-P F$

$R+P F$

C-SB

$\mathrm{C}-\mathrm{SB}$

C-SB

$\mathrm{C}-\mathrm{SB}$

C-SB

C-NE

$\mathrm{C}-\mathrm{NE}$

$\mathrm{C}-\mathrm{NE}$

C-NE

$C-N E$

MSL 8ackground HSL Background MSL Background MSL Background MSL Background

Repl

N. caecoides PCBs $\mu \mathrm{g} / \mathrm{kg}$ dry weight

\begin{tabular}{|c|c|c|c|}
\hline $\begin{array}{l}\text { Aroclor- } \\
1242 \\
\end{array}$ & $\begin{array}{c}\text { Aroclar- } \\
1248 \\
\end{array}$ & $\begin{array}{c}\text { Aroclor- } \\
1254 \\
\end{array}$ & $\begin{array}{c}\text { Aracior- } \\
1260 \\
\end{array}$ \\
\hline $\begin{array}{r}204.485 \mathrm{U} \\
312.631 \mathrm{U} \\
111.981 \mathrm{U} \\
67.319 \mathrm{U}\end{array}$ & $\begin{array}{r}204.485 \mathrm{U} \\
312.631 \mathrm{U} \\
111.981 \mathrm{U} \\
67.319 \mathrm{U}\end{array}$ & $\begin{array}{r}132.715 \mathrm{~J} \\
104.371 \mathrm{~J} \\
74.485 \mathrm{~J} \\
133.115\end{array}$ & $\begin{array}{r}204.485 \\
312.631 \\
111.981 \\
67.319\end{array}$ \\
\hline
\end{tabular}

1
2
3
4
5

D $\quad 16.72$

13.79

$79.755 \mathrm{U}$

$111.972 \mathrm{U}$

$56.480 \mathrm{U}$

$70.472 \mathrm{U}$

$79.755 \mathrm{U}$

111.417

$79.755 \mathrm{U}$

15.57

15.24

$68.019 \mathrm{U}$

56.480

222.255

132.177

70.472 U 189.573

$111.972 \mathrm{U}$

$56.480 \mathrm{U}$

$70.472 \mathrm{U}$

$68.019 \mathrm{U} \quad 104.125$

$68.019 \mathrm{~J}$

15.79

$50.481 \mathrm{U}$

$50.481 \mathrm{U}$

$50.481 \mathrm{~V}$

16.53

16.53

$169.982 \mathrm{U}$

$137.840 \mathrm{~V}$

$169.982 \mathrm{U}$

$169.982 \mathrm{U}$

16.53

15.02

$166.691 \mathrm{U}$

$137.840 \mathrm{U}$

$137.840 \mathrm{~J}$

$166.691 \mathrm{U} \quad 166.691 \mathrm{U}$

$55.772 \mathrm{U}$

$55.772 \mathrm{U}$

$166.691 \mathrm{U}$
$55.772 \mathrm{U}$

17.85

$51.468 \mathrm{U}$

$51.468 \mathrm{U}$

$51.468 \mathrm{U}$

$52.861 \mathrm{U}$

$52.861 \mathrm{U}$

$50.481 \mathrm{U}$

$169.982 \mathrm{U}$

$137.840 \mathrm{~V}$

$166.691 \mathrm{U}$

$55.772 \mathrm{U}$

$51.468 \mathrm{U}$

$52.861 \mathrm{U}$

$66.144 \mathrm{U}$

66.144

$66.144 \mathrm{U}$

$77.303 \mathrm{U} \quad 77.303 \mathrm{~V}$

$66.144 \mathrm{U}$

13.46

16.88

$77.303 \mathrm{U}$

$50.190 \mathrm{U}$

$50.190 \mathrm{U}$

$43.124 \mathrm{U}$

$43.124 \mathrm{U}$

$43.124 \mathrm{U}$

16.47

64.299 U

$64.299 \mathrm{U}$

$64.299 \mathrm{U}$

$77.303 \mathrm{~V}$

$50.190 \mathrm{U}$

$43.124 \mathrm{~V}$

$64.299 \mathrm{U}$

$62.204 \mathrm{~V}$

$57.916 \mathrm{U}$

$62.204 \mathrm{U} \quad 62.204 \mathrm{U}$

14.29

16.03

$65.744 \mathrm{U}$

$57.916 \mathrm{U}$

$62.204 \mathrm{U}$

$62.204 \mathrm{U}$

15.65

16.06

$44.346 \cup$

$65.744 \mathrm{U}$

$17.169 \mathrm{~J}$

$44.346 \mathrm{U} \quad 44.346 \mathrm{U}$

$57.916 \mathrm{U}$

$65.744 \mathrm{U}$

$47.892 \mathrm{U}$

$47.892 U$

$35.571 \mathrm{~J}$

$44.346 \mathrm{U}$

$47.892 \mathrm{U}$

$\begin{array}{ll}\text { B } & 15.94 \\ \text { B } & 18.40 \\ \text { B } & 16.01 \\ \text { B } & 15.81 \\ \text { B } & 15.28 \\ & \\ \text { E } & 19.82 \\ \text { E } & 19.82 \\ \text { E } & 19.82 \\ \text { E } & 19.82 \\ \text { E } & 19.82\end{array}$

$39.962 \mathrm{~V}$

$39.962 v$

$39.962 \mathrm{~V}$

$40.739 \mathrm{~J}$

$40.739 \mathrm{U}$

$40.739 \mathrm{U}$

$46.077 \mathrm{U}$

$46.077 \mathrm{~V}$

$23.348 \mathrm{~J}$

$52.226 \mathrm{~V}$

$52.226 \mathrm{U}$

$52.226 \mathrm{U}$

$59.503 \mathrm{U}$

$59.503 \mathrm{U}$

57.788

$39.962 \mathrm{U}$

$40.739 \mathrm{~V}$

$46.077 \mathrm{U}$

$52.226 \mathrm{U}$

$59.503 \mathrm{U}$

$23.572 \mathrm{U}$
$23.678 \mathrm{U}$
$23.643 \mathrm{U}$
$23.880 \mathrm{U}$
$23.633 \mathrm{U}$

$23.572 \mathrm{~V}$

$23.572 \mathrm{~V}$

$23.678 \mathrm{~V}$

$23.678 \mathrm{~V}$

$23.643 \mathrm{~J}$

$23.643 \mathrm{~V}$

$23.880 \mathrm{~V}$

$23.880 \mathrm{~V}$

$23.633 \mathrm{~V}$

$23.633 \mathrm{U}$

$23.572 \mathrm{U}$ $23.678 \mathrm{~V}$ $23.643 \mathrm{U}$ $23.880 \mathrm{U}$ $23.633 \mathrm{U}$

(a) $\mathrm{U}$ The analyte was not present above the level of the associated value.

(b) Percent dry weight was averaged from the other four replicates of COMP I.

(c) J Analyte detected below method detection limit (MOL). but above instrument detection limit (IDL). 
IABLE K.17. Polychlorinated Biphenyls (PCBs), Wet Weight, in Tissue of N. caecoides, Richmond Harbor Program

\begin{tabular}{|c|c|c|c|c|c|c|}
\hline \multirow[b]{2}{*}{$\begin{array}{l}\text { Sediment } \\
\text { Ireatment }\end{array}$} & \multirow[b]{2}{*}{ Replicate } & \multirow[b]{2}{*}{$\begin{array}{l}\text { Analytical } \\
\text { Batch } \\
\end{array}$} & \multicolumn{4}{|c|}{$N$ coecoides $\mathrm{PCBS}(\mu \mathrm{g} / \mathrm{kg}$ wet weight $)$} \\
\hline & & & $\begin{array}{c}\text { Aroclor- } \\
1242 \\
\end{array}$ & $\begin{array}{c}\text { Aroclor- } \\
1248 \\
\end{array}$ & $\begin{array}{l}\text { Arocior- } \\
1254 \\
\end{array}$ & $\begin{array}{l}\text { Aroclor } \\
1260 \\
\end{array}$ \\
\hline $\begin{array}{l}\text { Target OL (a) } \\
\text { Achieved OL Low } \\
\text { Achieved OL High }\end{array}$ & & & $\begin{array}{r}20.0 \\
4.672 \\
51.928\end{array}$ & $\begin{array}{r}20.0 \\
4.672 \\
51.928\end{array}$ & $\begin{array}{r}20.0 \\
4.672 \\
46.646\end{array}$ & $\begin{array}{r}20.0 \\
4.672 \\
51.928\end{array}$ \\
\hline $\begin{array}{l}\text { COMP I } \\
\text { COMP I } \\
\text { COMP I } \\
\text { COMP I } \\
\text { COMP I Replicate I } \\
\text { COMP I Replicate } 2 \\
\text { COMP I Replicate } 3\end{array}$ & $\begin{array}{l}1 \\
2 \\
3 \\
4 \\
5 \\
5 \\
5\end{array}$ & $\begin{array}{l}D \\
D \\
A \\
B \\
A \\
A \\
A\end{array}$ & $\begin{aligned} 11.472 \mathrm{U}^{(\mathrm{b})} \\
7.358 \mathrm{U} \\
9.064 \mathrm{U} \\
33.375 \mathrm{U} \\
37.415 \mathrm{U} \\
34.426 \mathrm{U} \\
25.362 \mathrm{U}\end{aligned}$ & $\begin{array}{r}11.472 \mathrm{U} \\
7.358 \mathrm{U} \\
9.064 \mathrm{U} \\
33.375 \mathrm{U} \\
37.415 \mathrm{U} \\
34.426 \mathrm{U} \\
25.362 \mathrm{U}\end{array}$ & $\begin{array}{l}13.812 \\
20.611 \\
9.064 \mathrm{~J}(\mathrm{c}) \\
16.633 \mathrm{~J} \\
12.397 \mathrm{~J} \\
19.576 \mathrm{~J} \\
18.564 \mathrm{~J}\end{array}$ & $\begin{array}{rl}11.472 & \mathrm{U} \\
7.358 \mathrm{U} \\
9.064 \mathrm{U} \\
33.375 \mathrm{U} \\
37.415 \mathrm{U} \\
34.426 \mathrm{U} \\
25.362 \mathrm{U}\end{array}$ \\
\hline $\begin{array}{l}\text { COMP II } \\
\text { COMP II } \\
\text { COMP II } \\
\text { COMP II } \\
\text { CONP II }\end{array}$ & $\begin{array}{l}1 \\
2 \\
3 \\
4 \\
5\end{array}$ & $\begin{array}{l}0 \\
A \\
C \\
0 \\
C\end{array}$ & $\begin{array}{r}6.963 \mathrm{U} \\
14.826 \mathrm{U} \\
8.185 \mathrm{U} \\
9.956 \mathrm{U} \\
7.966 \mathrm{U}\end{array}$ & $\begin{array}{r}6.963 \mathrm{U} \\
14.826 \mathrm{U} \\
8.185 \mathrm{U} \\
9.956 \mathrm{U} \\
7.966 \mathrm{U}\end{array}$ & $\begin{array}{l}21.834 \\
24.743 \\
31.385 \\
30.748 \\
32.625\end{array}$ & $\begin{array}{r}6.963 \mathrm{U} \\
14.826 \mathrm{U} \\
8.185 \mathrm{U} \\
9.956 \mathrm{U} \\
7.966 \mathrm{U}\end{array}$ \\
\hline $\begin{array}{l}\text { COMP II I } \\
\text { COMP II I } \\
\text { COMP II I } \\
\text { COMP II I } \\
\text { COMP II I }\end{array}$ & $\begin{array}{l}1 \\
2 \\
3 \\
4 \\
5\end{array}$ & $\begin{array}{l}\text { C } \\
\text { D } \\
\text { A } \\
\text { D } \\
\text { C }\end{array}$ & $\begin{array}{r}9.841 \mathrm{U} \\
9.242 \mathrm{U} \\
7.626 \mathrm{U} \\
8.491 \mathrm{U} \\
10.286 \mathrm{U}\end{array}$ & $\begin{array}{r}9.841 \mathrm{U} \\
9.242 \mathrm{U} \\
7.626 \mathrm{U} \\
8.491 \mathrm{U} \\
10.286 \mathrm{U}\end{array}$ & $\begin{array}{r}14.641 \\
11.226 \\
9.203 \\
10.798 \\
12.078\end{array}$ & $\begin{array}{r}9.841 \mathrm{U} \\
9.242 \mathrm{U} \\
7.626 \mathrm{U} \\
8.491 \mathrm{U} \\
10.286 \mathrm{U}\end{array}$ \\
\hline $\begin{array}{l}\text { TC-5 Upper Comp } \\
\text { TC-5 Upper Comp } \\
\text { TC-5 Upper Conp } \\
\text { TC-5 Upper Comp } \\
\text { TC-5 Upper Comp }\end{array}$ & $\begin{array}{l}1 \\
2 \\
3 \\
4 \\
5\end{array}$ & $\begin{array}{l}C \\
C \\
C \\
A \\
A\end{array}$ & $\begin{array}{r}14.116 \mathrm{U} \\
8.595 \mathrm{U} \\
12.489 \mathrm{U} \\
12.318 \mathrm{U} \\
42.239 \mathrm{U}\end{array}$ & $\begin{array}{r}14.116 \mathrm{U} \\
8.595 \mathrm{U} \\
12.489 \mathrm{U} \\
12.318 \mathrm{U} \\
42.239 \mathrm{U}\end{array}$ & $\begin{array}{l}74.794 \\
64.811 \\
84.395 \\
53.490 \\
53.680\end{array}$ & $\begin{array}{r}14.116 \mathrm{U} \\
8.595 \mathrm{U} \\
12.489 \mathrm{U} \\
12.318 \mathrm{U} \\
42.239 \mathrm{U}\end{array}$ \\
\hline $\begin{array}{l}\text { COMP IV } \\
\text { COMP IV Replicate } 1 \\
\text { COMP IV Replicate } 2 \\
\text { COMP IV Replicate } 3 \\
\text { COMP IV } \\
\text { COMP IV } \\
\text { COMP IV }\end{array}$ & $\begin{array}{l}1 \\
2 \\
2 \\
2 \\
3 \\
4 \\
5\end{array}$ & $\begin{array}{l}\text { C } \\
\text { C } \\
\text { C } \\
\text { C } \\
\text { A } \\
\text { C } \\
\text { A }\end{array}$ & $\begin{array}{l}8.496 \mathrm{U} \\
36.757 \mathrm{U} \\
46.646 \mathrm{U} \\
32.805 \mathrm{U} \\
15.868 \mathrm{U} \\
10.111 \mathrm{U} \\
17.588 \mathrm{U}\end{array}$ & $\begin{array}{l}8.496 \mathrm{U} \\
36.757 \mathrm{U} \\
46.646 \mathrm{U} \\
32.805 \mathrm{U} \\
15.868 \mathrm{U} \\
10.111 \mathrm{U} \\
17.588 \mathrm{U}\end{array}$ & $\begin{array}{l}8.080 \mathrm{~J} \\
36.757 \mathrm{U} \\
46.646 \mathrm{U} \\
32.805 \mathrm{U} \\
15.868 \mathrm{U} \\
10.111 \mathrm{U} \\
17.588 \mathrm{U}\end{array}$ & $\begin{array}{rl}8.496 & \mathrm{U} \\
36.757 \mathrm{U} \\
46.646 \mathrm{U} \\
32.805 \mathrm{U} \\
15.868 \mathrm{U} \\
10.111 \mathrm{U} \\
17.588 \mathrm{U}\end{array}$ \\
\hline $\begin{array}{l}\text { СОНР V } \\
\text { СОНP V } \\
\text { СОМР V } \\
\text { СОМР V } \\
\text { СОМP V }\end{array}$ & $\begin{array}{l}1 \\
2 \\
3 \\
4 \\
5\end{array}$ & $\begin{array}{l}\text { A } \\
\text { A } \\
\text { A } \\
\text { D } \\
\text { B }\end{array}$ & $\begin{array}{r}9.103 \mathrm{U} \\
10.519 \mathrm{U} \\
7.371 \mathrm{U} \\
10.402 \mathrm{U} \\
6.518 \mathrm{U}\end{array}$ & $\begin{array}{r}9.103 \mathrm{U} \\
10.519 \mathrm{U} \\
7.371 \mathrm{U} \\
10.402 \mathrm{U} \\
6.518 \mathrm{U}\end{array}$ & $\begin{array}{l}57.324 \\
49.413 \\
48.427 \\
37.491 \\
60.838\end{array}$ & $\begin{array}{r}9.103 \mathrm{U} \\
10.519 \mathrm{U} \\
7.371 \mathrm{U} \\
10.402 \mathrm{U} \\
6.518 \mathrm{U}\end{array}$ \\
\hline $\begin{array}{l}\text { COMP VI } \\
\text { COMP VI } \\
\text { COMP VI } \\
\text { COMP VI } \\
\text { COMP VI }\end{array}$ & $\begin{array}{l}1 \\
2 \\
3 \\
4 \\
5\end{array}$ & $\begin{array}{l}\text { C } \\
A \\
B \\
A \\
D\end{array}$ & $\begin{array}{r}10.690 \mathrm{U} \\
8.600 \mathrm{U} \\
9.987 \mathrm{U} \\
10.076 \mathrm{U} \\
30.976 \mathrm{U}\end{array}$ & $\begin{array}{r}10.690 \mathrm{U} \\
8.600 \mathrm{U} \\
9.987 \mathrm{U} \\
10.076 \mathrm{U} \\
30.976 \mathrm{U}\end{array}$ & $\begin{array}{l}55.721 \\
53.610 \\
54.996 \\
49.389 \\
74.103\end{array}$ & $\begin{array}{r}10.690 \mathrm{U} \\
8.600 \mathrm{U} \\
9.987 \mathrm{U} \\
10.076 \mathrm{U} \\
30.976 \mathrm{U}\end{array}$ \\
\hline $\begin{array}{l}R-A C \\
R-A C \\
R-A C \\
R-A C \\
R-A C\end{array}$ & $\begin{array}{l}1 \\
2 \\
3 \\
4 \\
5\end{array}$ & $\begin{array}{l}B \\
C \\
C \\
A \\
D\end{array}$ & $\begin{array}{r}13.441 \mathrm{U} \\
30.084 \mathrm{U} \\
9.477 \mathrm{U} \\
10.373 \mathrm{U} \\
8.099 \mathrm{U}\end{array}$ & $\begin{array}{r}13.441 \mathrm{U} \\
30.084 \mathrm{U} \\
9.477 \mathrm{U} \\
10.373 \mathrm{U} \\
8.099 \mathrm{U}\end{array}$ & $\begin{array}{l}43.452 \\
34.632 \\
33.123 \\
10.373 \mathrm{U} \\
26.873\end{array}$ & $\begin{array}{r}13.441 \mathrm{U} \\
30.084 \mathrm{U} \\
9.477 \mathrm{U} \\
10.373 \mathrm{U} \\
8.099 \mathrm{U}\end{array}$ \\
\hline
\end{tabular}


IABLE K.17. (contd)

\begin{tabular}{|c|c|c|c|c|c|c|}
\hline \multirow[b]{2}{*}{$\begin{array}{l}\text { Sediment } \\
\text { Ireatment }\end{array}$} & \multirow[b]{2}{*}{ Replicate } & \multirow[b]{2}{*}{$\begin{array}{l}\text { Analytical } \\
\text { Batch } \\
\end{array}$} & \multicolumn{4}{|c|}{ N. coecoides $\mathrm{PC} 8 \mathrm{~s}$ ( $\mu \mathrm{g} / \mathrm{kg}$ wet weight) } \\
\hline & & & $\begin{array}{c}\text { Aroclor- } \\
1242 \\
\end{array}$ & $\begin{array}{l}\text { Aroclor- } \\
1248 \\
\end{array}$ & $\begin{array}{c}\text { Aroclor- } \\
1254 \\
\end{array}$ & $\begin{array}{l}\text { Aroclor- } \\
1260\end{array}$ \\
\hline $\begin{array}{l}\text { R-AM } \\
\text { R-AM } \\
\text { R-AM } \\
\text { R-AM Repl icate } 1 \\
\text { R-AM Repl i cate } 2 \\
\text { R-AM Repl icate } 3 \\
\text { R-AM }\end{array}$ & $\begin{array}{l}1 \\
2 \\
3 \\
4 \\
4 \\
4 \\
5\end{array}$ & $\begin{array}{l}\text { B } \\
\mathrm{C} \\
\mathrm{B} \\
8 \\
8 \\
\mathrm{~B} \\
\mathrm{~B}\end{array}$ & $\begin{array}{r}8.918 \mathrm{U} \\
6.946 \mathrm{U} \\
6.966 \mathrm{U} \\
33.965 \mathrm{U} \\
51.928 \mathrm{U} \\
18.600 \mathrm{U} \\
7.607 \mathrm{U}\end{array}$ & $\begin{array}{r}8.918 \mathrm{U} \\
6.946 \mathrm{U} \\
6.966 \mathrm{U} \\
33.965 \mathrm{U} \\
51.928 \mathrm{U} \\
18.600 \mathrm{U} \\
7.607 \mathrm{U}\end{array}$ & $\begin{array}{l}8.918 \mathrm{~J} \\
16.204 \\
15.876 \\
22.044 \mathrm{~J} \\
17.336 \mathrm{~J} \\
12.372 \mathrm{~J} \\
15.042\end{array}$ & $\begin{array}{r}8.918 \mathrm{U} \\
6.946 \mathrm{U} \\
6.966 \mathrm{U} \\
33.965 \mathrm{U} \\
51.928 \mathrm{U} \\
18.600 \mathrm{U} \\
7.607 \mathrm{U}\end{array}$ \\
\hline $\begin{array}{l}R-B F \\
R-B F \\
R-B F \\
R-B F \\
R-B F\end{array}$ & $\begin{array}{l}1 \\
2 \\
3 \\
4 \\
5\end{array}$ & $\begin{array}{l}\text { D } \\
\text { B } \\
\text { B } \\
\text { A } \\
\text { A }\end{array}$ & $\begin{array}{r}13.335 \mathrm{U} \\
15.441 \mathrm{U} \\
8.794 \mathrm{U} \\
10.740 \mathrm{U} \\
10.917 \mathrm{U}\end{array}$ & $\begin{array}{r}13.335 \mathrm{U} \\
15.441 \mathrm{U} \\
8.794 \mathrm{U} \\
10.740 \mathrm{U} \\
10.917 \mathrm{U}\end{array}$ & $\begin{array}{l}18.629 \\
30.649 \\
20.580 \\
28.891 \\
16.712\end{array}$ & $\begin{array}{r}13.335 \mathrm{U} \\
15.441 \mathrm{U} \\
8.794 \mathrm{U} \\
10.740 \mathrm{U} \\
10.917 \mathrm{U}\end{array}$ \\
\hline $\begin{array}{l}\text { R-OS } \\
\text { R-OS Replicate } 1 \\
\text { R-OS Repl icate } 2 \\
\text { R-OS Replicate } 3 \\
\text { R-OS } \\
\text { R-OS } \\
\text { R-OS }\end{array}$ & $\begin{array}{l}1 \\
2 \\
2 \\
2 \\
3 \\
4 \\
5\end{array}$ & $\begin{array}{l}8 \\
0 \\
0 \\
0 \\
B \\
D \\
C\end{array}$ & $\begin{array}{rl}7.971 & \mathrm{U} \\
28.098 \mathrm{U} \\
22.785 \mathrm{U} \\
27.554 \mathrm{U} \\
8.377 \mathrm{U} \\
9.187 \mathrm{U} \\
8.997 \mathrm{U}\end{array}$ & $\begin{array}{r}7.971 \mathrm{U} \\
28.098 \mathrm{U} \\
22.785 \mathrm{U} \\
27.554 \mathrm{U} \\
8.377 \mathrm{U} \\
9.187 \mathrm{U} \\
8.997 \mathrm{U}\end{array}$ & $\begin{array}{r}7.971 \mathrm{U} \\
28.098 \mathrm{U} \\
22.785 \mathrm{U} \\
27.554 \mathrm{U} \\
8.377 \mathrm{U} \\
9.187 \mathrm{U} \\
8.997 \mathrm{U}\end{array}$ & $\begin{array}{r}7.971 \mathrm{U} \\
28.098 \mathrm{U} \\
22.785 \mathrm{U} \\
27.554 \mathrm{U} \\
8.377 \mathrm{U} \\
9.187 \mathrm{U} \\
8.997 \mathrm{U}\end{array}$ \\
\hline $\begin{array}{l}R-P F \\
R-P F \\
R-P F \\
R-P F \\
R-P F\end{array}$ & $\begin{array}{l}1 \\
2 \\
3 \\
4 \\
5\end{array}$ & $\begin{array}{l}C \\
C \\
D \\
D \\
A\end{array}$ & $\begin{array}{r}9.194 \mathrm{U} \\
10.405 \mathrm{U} \\
8.472 \mathrm{U} \\
7.219 \mathrm{U} \\
10.590 \mathrm{U}\end{array}$ & $\begin{array}{r}9.194 \mathrm{U} \\
10.405 \mathrm{U} \\
8.472 \mathrm{U} \\
7.219 \mathrm{U} \\
10.590 \mathrm{U}\end{array}$ & $\begin{array}{r}9.194 \mathrm{U} \\
10.405 \mathrm{U} \\
8.472 \mathrm{U} \\
7.219 \mathrm{U} \\
10.590 \mathrm{U}\end{array}$ & $\begin{array}{r}9.194 \mathrm{U} \\
10.405 \mathrm{U} \\
8.472 \mathrm{U} \\
7.219 \mathrm{U} \\
10.590 \mathrm{U}\end{array}$ \\
\hline $\begin{array}{l}\mathrm{C}-58 \\
\mathrm{C}-58 \\
\mathrm{C}-58 \\
\mathrm{C}-58 \\
\mathrm{C}-58\end{array}$ & $\begin{array}{l}1 \\
2 \\
3 \\
4 \\
5\end{array}$ & $\begin{array}{l}C \\
D \\
B \\
A \\
D\end{array}$ & $\begin{array}{r}8.889 \mathrm{U} \\
9.284 \mathrm{U} \\
10.289 \mathrm{U} \\
7.122 \mathrm{U} \\
7.883 \mathrm{U}\end{array}$ & $\begin{array}{r}8.889 \mathrm{U} \\
9.284 \mathrm{U} \\
10.289 \mathrm{U} \\
7.122 \mathrm{U} \\
7.883 \mathrm{U}\end{array}$ & $\begin{array}{l}8.889 \mathrm{U} \\
9.284 \mathrm{U} \\
2.687 \mathrm{~J} \\
7.122 \mathrm{U} \\
5.855 \mathrm{~J}\end{array}$ & $\begin{array}{r}8.889 \mathrm{U} \\
9.284 \mathrm{U} \\
10.289 \mathrm{U} \\
7.122 \mathrm{U} \\
7.883 \mathrm{U}\end{array}$ \\
\hline $\begin{array}{l}C-N E \\
C-N E \\
C-N E \\
C-N E \\
C-N E\end{array}$ & $\begin{array}{l}1 \\
2 \\
3 \\
4 \\
5\end{array}$ & $\begin{array}{l}\text { B } \\
\text { B } \\
\text { B } \\
\text { B } \\
\text { B }\end{array}$ & $\begin{array}{l}6.370 \mathrm{U} \\
7.496 \mathrm{U} \\
7.377 \mathrm{U} \\
8.257 \mathrm{U} \\
9.092 \mathrm{U}\end{array}$ & $\begin{array}{l}6.370 \mathrm{U} \\
7.496 \mathrm{U} \\
7.377 \mathrm{U} \\
8.257 \mathrm{U} \\
9.092 \mathrm{U}\end{array}$ & $\begin{array}{l}6.370 \mathrm{U} \\
7.496 \mathrm{U} \\
3.738 \mathrm{~J} \\
8.257 \mathrm{U} \\
8.830\end{array}$ & $\begin{array}{l}6.370 \mathrm{U} \\
7.496 \mathrm{U} \\
7.377 \mathrm{U} \\
8.257 \mathrm{U} \\
9.092 \mathrm{U}\end{array}$ \\
\hline $\begin{array}{l}\text { MSL Background } \\
\text { MSL Background } \\
\text { MSL Background } \\
\text { MSL Background } \\
\text { MSL Background }\end{array}$ & $\begin{array}{l}1 \\
2 \\
3 \\
4 \\
5\end{array}$ & $\begin{array}{l}E \\
E \\
E \\
E \\
E\end{array}$ & $\begin{array}{l}4.672 \mathrm{U} \\
4.693 \mathrm{U} \\
4.686 \mathrm{U} \\
4.733 \mathrm{U} \\
4.684 \mathrm{U}\end{array}$ & $\begin{array}{l}4.672 \mathrm{U} \\
4.693 \mathrm{U} \\
4.686 \mathrm{U} \\
4.733 \mathrm{U} \\
4.684 \mathrm{U}\end{array}$ & $\begin{array}{l}4.672 \mathrm{U} \\
4.693 \mathrm{U} \\
4.686 \mathrm{U} \\
4.733 \mathrm{U} \\
4.684 \mathrm{U}\end{array}$ & $\begin{array}{l}4.672 \mathrm{U} \\
4.693 \mathrm{U} \\
4.686 \mathrm{U} \\
4.733 \mathrm{U} \\
4.684 \mathrm{U}\end{array}$ \\
\hline
\end{tabular}

(a) DL Detection limit.

(b) U The anaiyte was not present above the level of the associated value.

(c) J Analyte detected below method detection limit (MOL). but above instrument detection 1 imit (IDL). 
IABLE K.18. Quality Control Data for Polychlorinated Biphenyls (PCBs), Wet Weight, in Tissue of $N$. caecoides, Richmond Harbor Program

Sediment
Treatment
Method Blank
8lank
81 ank
Blank
Blank
Matrix Spikes
Background JuO1
Background MS
Concentration Recovered
Spike Anount
Percent Recovery

Background JWO1
Background MSO
Concentration Recovered
Spike Anount
Percent Recovery

MS/HSO RPD

MS/NSO I-STAT
Background MS
Concentration Recovered
Spike Amount
Percent Recovery

Background JW01
Background MSD
Concentration Recovered
Spike Amount
Percent Recovery

MS/HSD RPD

MS/MSD I STAT

Background No1

Background HS

Concentration Recovered

Spike Amount

Percent Recovery

Background JW01

Background MSD 3

Concentration Recovered

Spike Amount

Percent Recovery

MS/MSD RPD

MS/MSD I-STAT

2

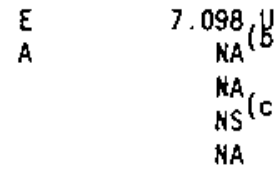

E

$\begin{array}{cc} & \text { NA } \\ & \text { NS } \\ & \text { NA } \\ & \text { HA } \\ & \text { NA } \\ & \\ & \\ & 7.080 \mathrm{U} \\ & \text { NA } \\ & \text { NA } \\ & \text { NS } \\ & \text { NA }\end{array}$

E $\quad 7.074 \mathrm{U}$

$B$

(1)

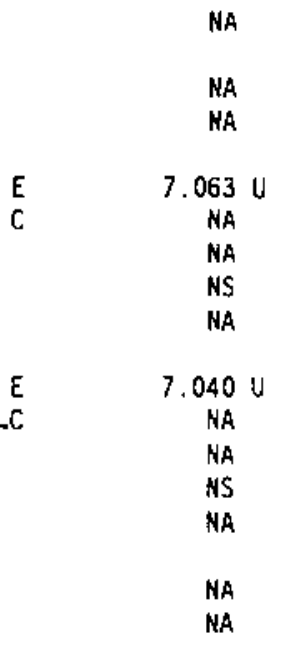

$N$ caecoides PCBs ( $1 \mathrm{~g} / \mathrm{kq}$ wet weight)

\begin{tabular}{cccc}
\hline Aroclor & Aroclor- & Aroclor & Aroclor - \\
1242 & 1248 & 1254 & 1260 \\
\hline
\end{tabular}

$\begin{array}{rrrr}11.758 \mathrm{U}^{(\mathrm{a})} & 11.758 \mathrm{U} & 11.758 \mathrm{U} & 11.758 \mathrm{U} \\ 9.876 \mathrm{U} & 9.876 \mathrm{U} & 9.876 \mathrm{U} & 9.876 \mathrm{U} \\ 11.024 \mathrm{U} & 11.024 \mathrm{U} & 11.024 \mathrm{U} & 11.024 \mathrm{U} \\ 10.370 \mathrm{U} & 10.370 \mathrm{U} & 10.370 \mathrm{U} & 10.370 \mathrm{U}\end{array}$

7.098 U
NA
NA
NS
NA

$7.093 \mathrm{U}$

NA

NA

NS

HA

NA

NA

$7.080 \mathrm{U}$

NA

NA

NS

HA

$7.074 \mathrm{U}$

NA

NA

NA

NA

NA

$7.063 \mathrm{U}$

NA

NA

NS

NA

$7.040 \mathrm{U}$

NA

NA

NS

NA

NA
$7.098 \mathrm{U}$

204.861

204.861

199.700

$103 \%$

$7.093 \mathrm{~V}$

217.575

217.575

199. 561

$109 \%$

$$
0.030^{6 \%}
$$

$7.080 \mathrm{~V}$

236.945

236.945

199.183

$119 \%$

$$
7.074 \mathrm{U}
$$

258.947

258.947

190.386

$136 \%^{(d)}$

$13 \%$

0.067

$7.063 \mathrm{U}$

250.742

250.742

198.708

$126 \%^{(d)}$

$7.040 \mathrm{U}$

233.677

233.677

$\$ 98.059$

$118 \%$

0.034
$7.098 \mathrm{U}$

NA

NA

NS

NA

$7.093 \mathrm{U}$

NA

NA

NS

NA

NA

NA

$7.080 \mathrm{U}$

NA

NA

NS

NA

$7.074 \mathrm{U}$

NA

NA

NS

NA

NA

NA

$7.063 \mathrm{U}$

NA

NA

NS

NA

$7.040 \mathrm{U}$

NA

NA

NS

NA

NA 


\section{TABLE K.18. (contd)}

\begin{tabular}{l} 
Sediment \\
Ireatment \\
\hline
\end{tabular}

Standard Reference Material

Certified Value

No certified values for PCBs

Analytical Replicates

\begin{tabular}{|c|c|c|c|c|}
\hline \multirow[b]{2}{*}{$\begin{array}{l}\text { Analytical } \\
\text { Batch }\end{array}$} & \multicolumn{4}{|c|}{$N$. caecoides $\mathrm{PCBS}(\mathrm{L \textrm {g }} / \mathrm{kq}$ wet weight $)$} \\
\hline & $\begin{array}{c}\text { Aroclor- } \\
1242 \\
\end{array}$ & $\begin{array}{c}\text { Arocior- } \\
1248 \\
\end{array}$ & $\begin{array}{l}\text { Aroclor- } \\
1254\end{array}$ & $\begin{array}{l}\text { Aroctor- } \\
1260 \\
\end{array}$ \\
\hline $\begin{array}{l}E \\
D\end{array}$ & $\begin{array}{c}7.090 \mathrm{U} \\
\text { NA } \\
\text { NA } \\
\text { NS } \\
\text { HA }\end{array}$ & $\begin{array}{c}7.090 \mathrm{U} \\
\text { NA } \\
\text { NA } \\
\text { NS } \\
\text { NA }\end{array}$ & $\begin{array}{c}7.090 \mathrm{U} \\
260.392 \\
260.392 \\
199.461 \\
131 \mathrm{z}^{(d)}\end{array}$ & $\begin{array}{c}7.090 \mathrm{U} \\
N A \\
N A \\
N S \\
N A\end{array}$ \\
\hline $\begin{array}{l}E \\
0\end{array}$ & $\begin{array}{c}6.918 \mathrm{U} \\
\mathrm{NA} \\
\mathrm{NA} \\
\mathrm{NS} \\
\mathrm{NA}\end{array}$ & $\begin{array}{c}6.918 \mathrm{U} \\
\text { NA } \\
\text { NA } \\
\text { NS } \\
\text { NA }\end{array}$ & $\begin{array}{c}6.918 \mathrm{U} \\
265.016 \\
265.016 \\
194.628 \\
136 \%\end{array}$ & $\begin{array}{r}6.918 \mathrm{U} \\
\text { NA } \\
\text { NA } \\
\text { NS } \\
\text { NA }\end{array}$ \\
\hline & $\begin{array}{l}\text { KA } \\
\text { NA }\end{array}$ & $\begin{array}{l}\text { NA } \\
\text { NA }\end{array}$ & $0.021^{4 \%}$ & $\begin{array}{l}N A \\
N A\end{array}$ \\
\hline
\end{tabular}

$N^{(e)}$

NC

MC

NC

\begin{tabular}{|c|c|c|c|c|c|c|c|}
\hline $\begin{array}{l}\text { COMP } \\
\text { COMP } \\
\text { COMP } \\
\text { RSD }\end{array}$ & $\begin{array}{l}\text { I Repijicate } 1 \\
\text { I Replicate } 2 \\
\text { I Replicate } 3\end{array}$ & $\begin{array}{l}5 \\
5 \\
5\end{array}$ & $\begin{array}{l}\text { A } \\
\text { A } \\
\text { A }\end{array}$ & $\begin{array}{c}37.415 \mathrm{U} \\
34.426 \mathrm{U} \\
25.362 \mathrm{U} \\
\text { NA }\end{array}$ & $\begin{array}{c}37.415 \mathrm{U} \\
34.426 \mathrm{U} \\
25.362 \mathrm{U} \\
\text { NA }\end{array}$ & $\begin{array}{c}12.397 \mathrm{~J} \\
19.576 \mathrm{~J} \\
18.564 \mathrm{~J} \\
23 \%\end{array}$ & $\begin{array}{c}37.415 \mathrm{U} \\
34.426 \mathrm{U} \\
25.362 \mathrm{U} \\
\text { NA }\end{array}$ \\
\hline $\begin{array}{l}\text { COMP } \\
\text { COMP } \\
\text { COMP } \\
\text { RSD }\end{array}$ & $\begin{array}{l}\text { IV Replicate } 1 \\
\text { IV Replicate } 2 \\
\text { IV Replicate } 3\end{array}$ & $\begin{array}{l}2 \\
2 \\
2\end{array}$ & $\begin{array}{l}c \\
c \\
c\end{array}$ & $\begin{array}{c}36.757 \mathrm{U} \\
46.646 \mathrm{U} \\
32.805 \mathrm{U} \\
\text { NA }\end{array}$ & $\begin{array}{c}36.757 \mathrm{U} \\
46.646 \mathrm{U} \\
32.805 \mathrm{U} \\
\text { NA }\end{array}$ & $\begin{array}{c}36.757 \mathrm{U} \\
46.646 \mathrm{U} \\
32.805 \mathrm{U} \\
\text { NA }\end{array}$ & $\begin{array}{c}36.757 \mathrm{U} \\
46.646 \mathrm{U} \\
32.805 \mathrm{U} \\
\text { NA }\end{array}$ \\
\hline $\begin{array}{r}R-A H \\
R-A M \\
R-A H \\
\text { RSD }\end{array}$ & $\begin{array}{l}\text { Replicate } 1 \\
\text { Replicate } 2 \\
\text { Replicate } 3\end{array}$ & $\begin{array}{l}4 \\
4 \\
4\end{array}$ & $\begin{array}{l}\text { B } \\
B \\
B\end{array}$ & $\begin{array}{c}33.965 \mathrm{U} \\
51.926 \mathrm{U} \\
18.600 \mathrm{U} \\
\text { NA }\end{array}$ & $\begin{array}{c}33.965 \mathrm{U} \\
51.928 \mathrm{U} \\
18.600 \mathrm{U} \\
\text { NA }\end{array}$ & $\begin{array}{c}22.044 \mathrm{~J} \\
17.336 \mathrm{~J} \\
12.372 \mathrm{~J} \\
28 \%\end{array}$ & $\begin{array}{c}33.965 \mathrm{U} \\
51.926 \mathrm{U} \\
18.600 \mathrm{U} \\
\text { NA }\end{array}$ \\
\hline $\begin{array}{r}R-O S \\
R-0 S \\
R-0 S \\
\text { RSD }\end{array}$ & $\begin{array}{l}\text { Repl icate } 1 \\
\text { Repl icate } 2 \\
\text { Repl icate } 3\end{array}$ & $\begin{array}{l}2 \\
2 \\
2\end{array}$ & $\begin{array}{l}0 \\
0 \\
0\end{array}$ & $\begin{array}{c}28.098 \mathrm{U} \\
22.785 \mathrm{U} \\
27.554 \mathrm{U} \\
\text { NA }\end{array}$ & $\begin{array}{c}28.098 \mathrm{U} \\
22.785 \mathrm{U} \\
27.554 \mathrm{U} \\
\text { NA }\end{array}$ & $\begin{array}{l}28.098 \mathrm{U} \\
22.785 \mathrm{U} \\
27.554 \mathrm{U} \\
\text { NA }\end{array}$ & $\begin{array}{c}28.098 \mathrm{U} \\
22.785 \mathrm{U} \\
27.554 \mathrm{U} \\
\text { NA }\end{array}$ \\
\hline
\end{tabular}

(a) U The anaiyte was not present above the level of the associated value.

(b) NA Not appiicabie.

(c) NS Not spiked.

(d) Hecovery outside quality control range $(40 \%-120 \%)$.

(e) NC Not certified. 
IABLEEK.19. Surrogate Recoveries for Chlorinated Pesticides and Polyclorinated Biphenyls (PCBs), in Tissue of N. caecoides, Richmond Harbor Program

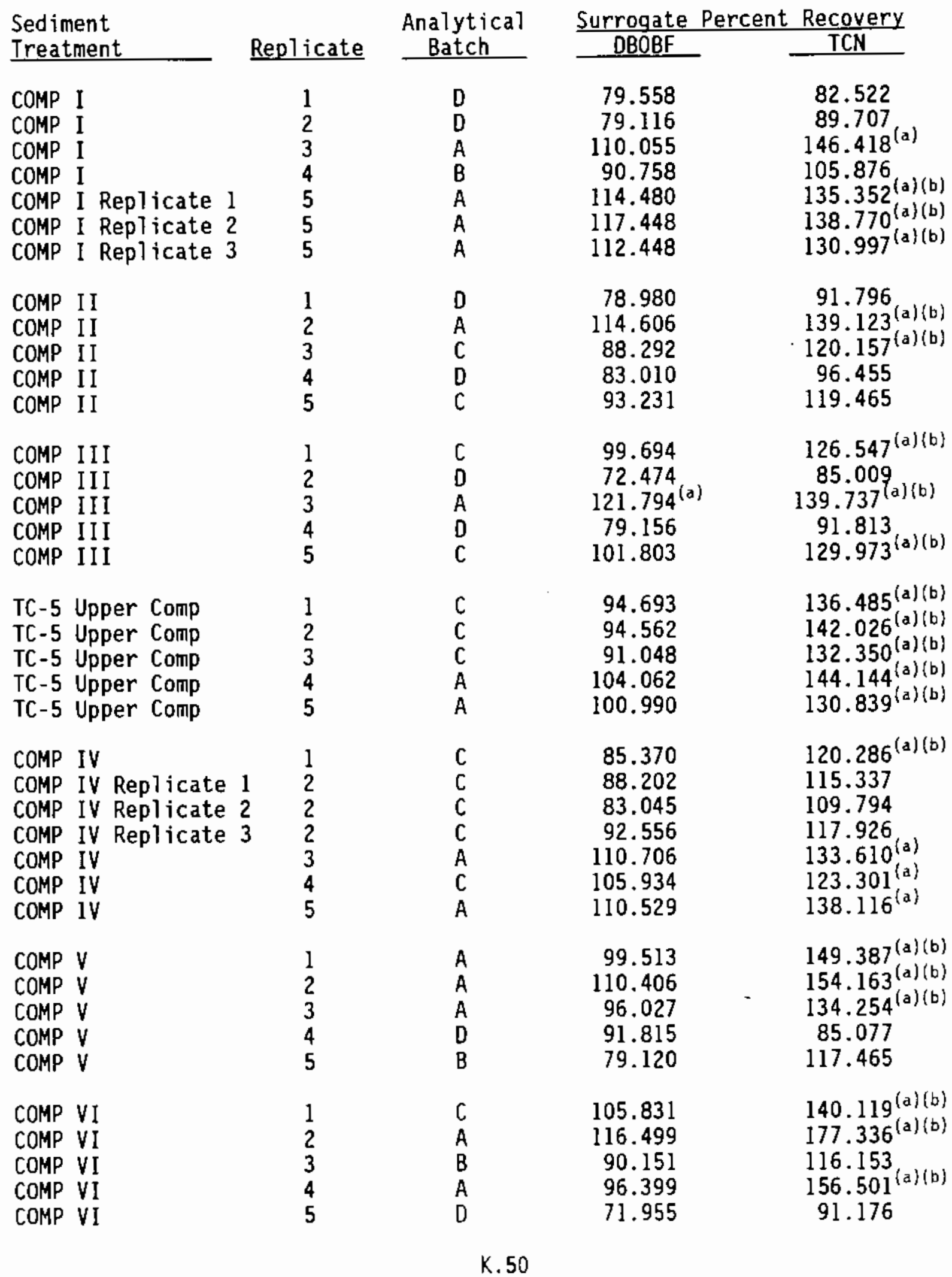


IABLE K.19. (contd)

Sediment

Ireatment

$R-A C$

$\mathrm{R}-\mathrm{AC}$

$\mathrm{R}-\mathrm{AC}$

$\mathrm{R}-\mathrm{AC}$

$\mathrm{R}-\mathrm{AC}$

$\mathrm{R}-\mathrm{AM}$

$\mathrm{R}-\mathrm{AM}$

$\mathrm{R}-\mathrm{AM}$

R-AM Replicate 1

R-AM Replicate 2

R-AM Replicate 3

$\mathrm{R}-\mathrm{AM}$

$R-\dot{B} F$

$R-B F$

$R-B F$

$R-B F$

$R-B F$

$R-0 S$

R-OS Replicate 1

R-OS Replicate 2

R-OS Replicate 3

$\mathrm{R}-\mathrm{OS}$

$\mathrm{R}-\mathrm{OS}$

R-OS

$R-P F$

$R-P F$

$R-P F$

$R-P F$

$R-P F$

C-SB

C-SB

$C-S B$

$C-S B$

$C-S B$

$C-N E$

$C-N E$

$C-N E$

$\mathrm{C}-\mathrm{NE}$

$\mathrm{C}-\mathrm{NE}$

$\begin{array}{cc}\text { Replicate } & \text { Anal Ba } \\ 1 & \\ 2 & \\ 3 & \\ 4 & \\ 5 & \\ 1 & \\ 2 & \\ 3 & \\ 4 & \\ 4 & \\ 4 & \end{array}$

I

3

4

5

1

2

2

2

3

4

5

1

2

3

4

5

1

2

3

4
5

5

1
2
3
4
5
Analytical Batch

$B$
$C$
$C$
$A$
$D$
$B$
$B$
$C$
$B$
$B$
$B$
$B$
$B$

D

B

B

A

A

B

D

D

D

D

C

C

C

D

D

A

C

D

$B$

A

D

$B$
$B$
$B$
$B$
$B$
Surrogate Percent Recovery DBOBF

82.153

92.926

98.454

103.461

85.729

50.485

84.851

89.180

84.863

78.798

101.092

91.903

77.419

90.541

99.397

105.398

107.930

89.635

80.542

73.741

71.339

88.998

79.790

91.504

48.913

80.523

78.791

76.737

116.966

96.642

85.009

90.497

84.891

$82.06 \tilde{3}$

71.347

73.486

94.479

87.336

91.895
109.391

119.690

$130.892^{(a)(b)}$

$148.186^{(a)}$

102.436

63.866

114.813

113.874

104.307

98.497

118.056

119.754

84.715

115.737

109.551

$135.470^{(a)(b)}$

$132.623^{(a)\{b)}$

109.906

87.989

B4. 256

80.159

108.127

82.199

110.396

69.752

103.443

81.126

85.517

$137.199^{(a)}$

$125.829^{(a)(b)}$

89.897

107.592

109.098

86.285

86.517

92.614

109.883

107.508

116.073 
IABLE K.19. (contd)

Sediment

Treatment

MSL Background

MSL Background

MSL Background

MSL Background

MSL Background

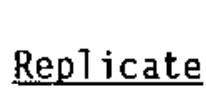

\section{1}

2

3

4

5

\section{Analytical}

Batch

$E$
$E$
$E$
$E$
Surrogate Percent Recovery $\mathrm{DBOBF}$

65.000

68.000

79.000

87.000

73.000
TCN

78.000

79.000

$121.000^{(\mathrm{d})}$

82.000

Quality Control Data

Method Blank

Blank

Blank

Blank

Blank

Matrix_Spikes

Background MS

Background MSD

MS/MSD RPD

MS/MSD I-STAT

Background MS

Background MSD

MS/MSD RPD

MS/MSD I-STAT

Background MS

Background MSD

MS/MSD RPD

MS/MSD I-STAT

Background MS

Background MSD

MS/MSD RPD

MS/MSD I-STAT
A $\quad 12.665$

B $\quad 11.536$

$\begin{array}{ll}\text { C } & 12.087\end{array}$

D $\quad 11.868$
16.875

11.487

11.326

12.430

Standard Reference Material

No SRM data provided for Aroclors

NA

NA 
IABLE K.19. (contd)

Sediment

Treatment
Analytical Surrogate Percent Recovery

Replicate Batch $-\mathrm{TBN}$

Analytical Replicates

\begin{tabular}{|c|c|c|c|c|}
\hline $\begin{array}{c}\text { COMP I Replicate } 1 \\
\text { COMP I Replicate } 2 \\
\text { COMP I Replicate } 3 \\
\text { RSD }\end{array}$ & $\begin{array}{l}5 \\
5 \\
5\end{array}$ & $\begin{array}{l}A \\
A \\
A\end{array}$ & $\begin{array}{r}114.480 \\
117.448 \\
112.448 \\
2\end{array}$ & $\begin{array}{c}135.352^{(\mathrm{a})(\mathrm{b})} \\
138.770^{(\mathrm{a})(\mathrm{b})} \\
130.997^{(\mathrm{a})(\mathrm{b})} \\
3\end{array}$ \\
\hline $\begin{array}{c}\text { COMP IV Replicate } 1 \\
\text { COMP IV Replicate } 2 \\
\text { COMP IV Replicate } 3 \\
\text { RSD }\end{array}$ & $\begin{array}{l}2 \\
2 \\
2\end{array}$ & $\begin{array}{l}c \\
c \\
c\end{array}$ & $\begin{array}{r}88.202 \\
83.045 \\
92.556 \\
5\end{array}$ & $\begin{array}{r}115.337 \\
109.794 \\
117.926 \\
4\end{array}$ \\
\hline $\begin{array}{l}\text { R-AM Rep] icate } 1 \\
\text { R-AM Replicate } 2 \\
\text { R-AM Replicate } 3 \\
\text { RSD }\end{array}$ & $\begin{array}{l}4 \\
4 \\
4\end{array}$ & $\begin{array}{l}\mathrm{B} \\
\mathrm{B} \\
\mathrm{B}\end{array}$ & $\begin{array}{r}84.863 \\
78.798 \\
101.092 \\
13\end{array}$ & $\begin{array}{r}104.307 \\
98.497 \\
118.056 \\
9\end{array}$ \\
\hline $\begin{array}{l}\text { R-OS Replicate } 1 \\
\text { R-0S Replicate } 2 \\
\text { R-0S Replicate } 3 \\
\text { RSD }\end{array}$ & $\begin{array}{l}2 \\
2 \\
2\end{array}$ & $\begin{array}{l}D \\
D \\
D\end{array}$ & $\begin{array}{r}80.542 \\
73.741 \\
71.339 \\
6\end{array}$ & $\begin{array}{r}87.989 \\
84.256 \\
80.159 \\
5\end{array}$ \\
\hline
\end{tabular}

(a) Recovery outside quality control range (40\%-120\%).

(b) I Elevated surrogate percent recoveries due to coelution of PCB congener peak.

(c) NA Not applicable. 
TABLE K.20. Metals, Dry Weight, in Tissue of $N$. caecoides, Richmond Harbor Program

\begin{tabular}{|c|c|c|c|c|c|c|c|c|c|c|c|c|}
\hline \multirow{2}{*}{$\begin{array}{l}\text { Sediment } \\
\text { Ireatment }\end{array}$} & \multirow[b]{2}{*}{ Replicate } & \multirow{2}{*}{$\begin{array}{l}\text { Analytical } \\
\text { Batch }\end{array}$} & \multicolumn{10}{|c|}{$N$ caecoides Metals $(\mathrm{mg} / \mathrm{kg}$ dry weight) } \\
\hline & & & Aq_. & As & $\mathrm{cd}$ & $\mathrm{Cr}$ & Cu & $\mathrm{Hg}$ & $\mathrm{Ni}$ & $\mathrm{Pb}$ & Se & $\mathrm{Zn}$ \\
\hline $\begin{array}{l}\text { Target } O L(a) \\
\text { Achíeved } D L\end{array}$ & & & $\begin{array}{r}1.0 \\
0.001\end{array}$ & $\begin{array}{l}1.0 \\
1.0\end{array}$ & $\begin{array}{r}0.1 \\
0.014\end{array}$ & $\begin{array}{l}1.0 \\
0.05\end{array}$ & $\begin{array}{l}1.0 \\
1.0\end{array}$ & $\begin{array}{l}0.00012 \\
0.00015\end{array}$ & $\begin{array}{r}1.0 \\
0.006\end{array}$ & $\begin{array}{r}1.0 \\
0.001\end{array}$ & $\begin{array}{l}0.5 \\
0.5\end{array}$ & $\begin{array}{l}1.0 \\
1.0\end{array}$ \\
\hline $\begin{array}{l}\text { COMP I } \\
\text { COMP I } \\
\text { COMP I } \\
\text { COMP I } \\
\text { COMP I }\end{array}$ & $\begin{array}{l}1 \\
2 \\
3 \\
4 \\
5\end{array}$ & $\begin{array}{l}\text { B } \\
\text { B } \\
A \\
A \\
A\end{array}$ & $\begin{array}{l}0.036 \\
0.023 \\
0.017 \\
0.056 \\
0.035\end{array}$ & $\begin{array}{l}40.8 \\
33.8 \\
33.6 \\
30.8 \\
34.4\end{array}$ & $\begin{array}{l}1.056 \\
1.144 \\
1.496 \\
1.091 \\
1.056\end{array}$ & $\begin{array}{l}0.98 \\
0.61 \\
0.82 \\
0.68 \\
0.74\end{array}$ & $\begin{array}{l}12.00 \\
13.70 \\
14.30 \\
16.90 \\
13.90\end{array}$ & $\begin{array}{l}0.083 \\
0.088 \\
0.077 \\
0.058 \\
0.093\end{array}$ & $\begin{array}{l}5.73 \\
4.59 \\
4.05 \\
4.34 \\
4.56\end{array}$ & $\begin{array}{l}1.08 \\
1.10 \\
1.00 \\
1.05 \\
1.02\end{array}$ & $\begin{array}{l}1.65 \\
1.39 \\
2.45 \\
0.95 \\
2.36\end{array}$ & $\begin{array}{l}196.0 \\
207.0 \\
218.0 \\
182.3 \\
200.0\end{array}$ \\
\hline $\begin{array}{l}\text { СОMP II } \\
\text { СOMP II } \\
\text { COMP II } \\
\text { COMP II } \\
\text { COMP II }\end{array}$ & $\begin{array}{l}1 \\
2 \\
3 \\
4 \\
5\end{array}$ & $\begin{array}{l}B \\
A \\
B \\
B \\
B\end{array}$ & $\begin{array}{l}0.045 \\
0.037 \\
0.029 \\
0.050 \\
0.081\end{array}$ & $\begin{array}{l}26.8 \\
28.9 \\
33.0 \\
37.4 \\
29.6\end{array}$ & $\begin{array}{l}0.800 \\
1.267 \\
1.112 \\
1.232 \\
1.136\end{array}$ & $\begin{array}{l}0.56 \\
0.22 \\
0.68 \\
0.86 \\
1.04\end{array}$ & $\begin{array}{l}13.00 \\
14.30 \\
10.90 \\
17.10 \\
13.80\end{array}$ & $\begin{array}{l}0.048 \\
0.084 \\
0.083 \\
0.095 \\
0.063\end{array}$ & $\begin{array}{l}6.00 \\
3.64 \\
6.14 \\
6.30 \\
6.84\end{array}$ & $\begin{array}{l}1.02 \\
1.11 \\
0.79 \\
1.17 \\
0.71\end{array}$ & $\begin{array}{l}0.96 \mathrm{U}^{(b)} \\
1.69 \\
1.45 \\
1.72 \\
1.45\end{array}$ & $\begin{array}{l}172.2 \\
222.0 \\
205.0 \\
229.0 \\
187.5\end{array}$ \\
\hline $\begin{array}{l}\text { COMP II } \\
\text { COMP III } \\
\text { COMP III } \\
\text { COMP III } \\
\text { COMP III }\end{array}$ & $\begin{array}{l}1 \\
2 \\
3 \\
4 \\
5\end{array}$ & $\begin{array}{l}B \\
8 \\
A \\
8 \\
B\end{array}$ & $\begin{array}{l}0.027 \\
0.041 \\
0.026 \\
0.027 \\
0.029\end{array}$ & $\begin{array}{l}23.4 \\
29.2 \\
32.7 \\
28.0 \\
27.4\end{array}$ & $\begin{array}{l}1.096 \\
1.080 \\
0.870 \\
1.216 \\
0.920\end{array}$ & $\begin{array}{l}0.66 \\
0.97 \\
0.84 \\
0.62 \\
1.15\end{array}$ & $\begin{array}{l}10.05 \\
12.80 \\
10.81 \\
10.72 \\
11.40\end{array}$ & $\begin{array}{l}0.080 \\
0.088 \\
0.073 \\
0.083 \\
0.072\end{array}$ & $\begin{array}{l}5.79 \\
6.33 \\
4.70 \\
5.27 \\
6.40\end{array}$ & $\begin{array}{l}0.71 \\
0.67 \\
0.84 \\
0.70 \\
0.78\end{array}$ & $\begin{array}{l}1.79 \\
1.18 \\
1.73 \\
1.13 \\
0.99 \mathrm{v}\end{array}$ & $\begin{array}{l}198.0 \\
202.0 \\
184.1 \\
203.0 \\
187.5\end{array}$ \\
\hline $\begin{array}{l}\text { TC-5 Upper Comp } \\
\text { TC-5 Upper Comp } \\
\text { TC-5 Upper Comp } \\
\text { TC-5 Upper Comp } \\
\text { TC-5 Upper Comp Replicate } 1 \\
\text { TC-5 Upper Comp Repli icate } 2 \\
\text { TC-5 Upper Comp Replicate } 3\end{array}$ & $\begin{array}{l}1 \\
2 \\
3 \\
4 \\
5 \\
5 \\
5\end{array}$ & $\begin{array}{l}\text { B } \\
\text { B } \\
\text { B } \\
\text { A } \\
\text { A } \\
\text { A } \\
\text { A }\end{array}$ & $\begin{array}{l}0.093 \\
0.036 \\
0.024 \\
0.059 \\
0.024(0) \\
\text { NA }\end{array}$ & $\begin{array}{l}39.4 \\
33.4 \\
44.1 \\
32.8 \\
40.3 \\
24.9 \\
23.3\end{array}$ & $\begin{array}{r}0.928 \\
0.840 \\
0.770 \\
1.399 \\
0.924 \\
\text { NA } \\
\text { NA }\end{array}$ & $\begin{array}{l}1.11 \\
0.90 \\
0.89 \\
1.92 \\
0.97 \\
\text { NA } \\
\text { NA }\end{array}$ & $\begin{array}{r}13.50 \\
9.08 \\
13.30 \\
11.57 \\
10.88 \\
10.22 \\
9.83\end{array}$ & $\begin{array}{r}0.069 \\
0.063 \\
0.058 \\
0.063 \\
0.066 \\
\text { NA } \\
\text { NA }\end{array}$ & $\begin{array}{l}6.53 \\
5.94 \\
6.10 \\
4.55 \\
4.29 \\
\text { NA } \\
\text { NA }\end{array}$ & $\begin{array}{l}1.09 \\
1.76 \\
1.26 \\
1.23 \\
0.97 \\
\text { NA } \\
\text { NA }\end{array}$ & $\begin{array}{l}1.90 \\
1.70 \\
2.18 \\
2.28 \\
2.81 \\
1.28 \\
2.30\end{array}$ & $\begin{array}{l}193.6 \\
178.7 \\
202.0 \\
216.0 \\
189.7 \\
172.5 \\
162.8\end{array}$ \\
\hline $\begin{array}{l}\text { COMP IV } \\
\text { COMP IV } \\
\text { COMP IV } \\
\text { COMP IV } \\
\text { COMP IV }\end{array}$ & $\begin{array}{l}1 \\
2 \\
3 \\
4 \\
5\end{array}$ & $\begin{array}{l}B \\
B \\
A \\
B \\
A\end{array}$ & $\begin{array}{l}0.027 \\
0.042 \\
0.010 \\
0.029 \\
0.014\end{array}$ & $\begin{array}{l}30.9 \\
36.4 \\
22.2 \\
25.8 \\
25.7\end{array}$ & $\begin{array}{l}1.152 \\
1.032 \\
1.364 \\
0.764 \\
1.267\end{array}$ & $\begin{array}{l}0.58 \\
0.78 \\
0.75 \\
0.53 \\
0.83\end{array}$ & $\begin{array}{r}11.60 \\
13.80 \\
10.75 \\
9.71 \\
11.60\end{array}$ & $\begin{array}{l}0.055 \\
0.076 \\
0.081 \\
0.069 \\
0.064\end{array}$ & $\begin{array}{l}5.68 \\
6.10 \\
4.16 \\
6.69 \\
4.76\end{array}$ & $\begin{array}{l}0.48 \\
0.73 \\
0.63 \\
0.52 \\
0.72\end{array}$ & $\begin{array}{l}0.95 \mathrm{U} \\
2.08 \\
2.10 \\
1.04 \\
1.76\end{array}$ & $\begin{array}{l}182.9 \\
204.0 \\
186.9 \\
166.1 \\
207.0\end{array}$ \\
\hline $\begin{array}{l}\text { COMP V } \\
\text { COMP V } \\
\text { COMP V } \\
\text { COMP V } \\
\text { COMP V }\end{array}$ & $\begin{array}{l}1 \\
2 \\
3 \\
4 \\
5\end{array}$ & $\begin{array}{l}A \\
A \\
A \\
B \\
A\end{array}$ & $\begin{array}{l}0.024 \\
0.027 \\
0.012 \\
0.032 \\
0.053\end{array}$ & $\begin{array}{l}35.4 \\
29.4 \\
28.8 \\
31.2 \\
30.5\end{array}$ & $\begin{array}{l}0.858 \\
1.514 \\
0.898 \\
0.888 \\
1.232\end{array}$ & $\begin{array}{l}0.81 \\
1.02 \\
0.36 \\
0.76 \\
0.72\end{array}$ & $\begin{array}{l}10.40 \\
13.20 \\
10.10 \\
11.50 \\
14.00\end{array}$ & $\begin{array}{l}0.077 \\
0.059 \\
0.060 \\
0.079 \\
0.049\end{array}$ & $\begin{array}{l}3.30 \\
3.80 \\
3.10 \\
5.01 \\
3.60\end{array}$ & $\begin{array}{l}1.11 \\
1.31 \\
1.04 \\
1.03 \\
1.12\end{array}$ & $\begin{array}{l}2.16 \\
1.41 \\
2.48 \\
1.95 \\
1.40\end{array}$ & $\begin{array}{l}180.0 \\
219.0 \\
199.0 \\
178.9 \\
177.7\end{array}$ \\
\hline
\end{tabular}


IABLE K.20. (contd)

Sediment

Ireatment

\section{COMP VI}

COMP VI

COMP VI

COMP VI

$\mathrm{R}-\mathrm{AC}$

$R-A C$

$\mathrm{R}-\mathrm{AC}$

$\mathrm{R}-\mathrm{AC}$

$\mathrm{R}-\mathrm{AC}$

$R-A M$

R-AH

R-AM Replicate 1

R-AM Replicate ?

R-AM Replicate 3

ir $\quad R-A M$

G $R-A M$

R-BF

$R-B F$
$R-8 F$

$R-B F$

$\mathrm{R}-\mathrm{8F}$

R-OS

$R-0 S$

$R-0 S$
$R-O S$

R-OS Replicate 1

R-OS Replicate

R-OS Replicate 3

$R-P F$

R-PF Replicate 1

R-PF Replicate 2

R-PF Replicate 3

\begin{tabular}{c} 
Replicate \\
\hline 1 \\
2 \\
3 \\
4 \\
4 \\
\\
1 \\
2 \\
3 \\
4 \\
5 \\
1 \\
1 \\
2 \\
3 \\
3 \\
3 \\
4 \\
5 \\
1 \\
2 \\
3 \\
4 \\
5 \\
1 \\
1 \\
3 \\
4 \\
5 \\
5 \\
5 \\
1 \\
2 \\
3 \\
4 \\
5 \\
5 \\
5 \\
\end{tabular}

\begin{tabular}{|c|c|c|c|c|c|c|c|c|c|c|}
\hline \multirow{2}{*}{$\begin{array}{l}\text { Analytical } \\
\text { Batch } \\
\end{array}$} & \multicolumn{10}{|c|}{$N$ caecoides Metals $(\mathrm{mq} / \mathrm{kg}$ dry weight.) } \\
\hline & Ag_. & As & Cd. & $\mathrm{Cr}$ & Cu & $\mathrm{Hg}$ & $\mathrm{Ni}$ & $\mathrm{Pb}$ & Se & $\mathrm{Zn}$ \\
\hline $\begin{array}{l}\text { B } \\
A \\
A \\
A \\
B\end{array}$ & $\begin{array}{l}0.029 \\
0.040 \\
0.051 \\
0.015 \\
0.038\end{array}$ & $\begin{array}{l}32.7 \\
31.1 \\
43.8 \\
28.2 \\
28.2\end{array}$ & $\begin{array}{l}0.976 \\
1.311 \\
1.426 \\
1.170 \\
0.952\end{array}$ & $\begin{array}{l}1.46 \\
0.85 \\
0.65 \\
0.79 \\
0.70\end{array}$ & $\begin{array}{l}12.20 \\
13.80 \\
14.00 \\
11.90 \\
14.10\end{array}$ & $\begin{array}{l}0.075 \\
0.069 \\
0.070 \\
0.075 \\
0.056\end{array}$ & $\begin{array}{l}6.62 \\
3.88 \\
4.44 \\
4.34 \\
5.13\end{array}$ & $\begin{array}{l}0.97 \\
1.51 \\
1.41 \\
1.18 \\
1.12\end{array}$ & $\begin{array}{l}1.72 \\
2.55 \\
1.11 \\
1.48 \\
1.54\end{array}$ & $\begin{array}{l}213.0 \\
227.0 \\
186.6 \\
195.0 \\
186.2\end{array}$ \\
\hline $\begin{array}{l}A \\
B \\
B \\
A \\
B\end{array}$ & $\begin{array}{l}0.042 \\
0.027 \\
0.047 \\
0.039 \\
0.035\end{array}$ & $\begin{array}{l}27.8 \\
32.5 \\
30.6 \\
27.3 \\
24.4\end{array}$ & $\begin{array}{l}0.950 \\
0.944 \\
1.352 \\
1.302 \\
1.288\end{array}$ & $\begin{array}{l}0.62 \\
0.91 \\
0.86 \\
0.67 \\
0.81\end{array}$ & $\begin{array}{l}11.73 \\
11.80 \\
15.20 \\
13.80 \\
13.50\end{array}$ & $\begin{array}{l}0.077 \\
0.070 \\
0.057 \\
0.057 \\
0.048\end{array}$ & $\begin{array}{l}4.34 \\
5.87 \\
6.82 \\
4.13 \\
6.06\end{array}$ & $\begin{array}{l}0.99 \\
0.86 \\
0.69 \\
1.14 \\
1.10\end{array}$ & $\begin{array}{l}1.94 \\
2.11 \\
1.23 \\
2.09 \\
1.24\end{array}$ & $\begin{array}{l}167.3 \\
207.0 \\
205.0 \\
247.0 \\
196.0\end{array}$ \\
\hline $\begin{array}{l}A \\
B \\
A \\
A \\
A \\
B \\
A\end{array}$ & $\begin{array}{l}0.070 \\
0.069 \\
0.031 \\
0.041 \\
0.048 \\
0.065 \\
0.035\end{array}$ & $\begin{array}{l}24.6 \\
22.2 \\
22.2 \\
22.4 \\
22.6 \\
28.1 \\
20.0\end{array}$ & $\begin{array}{l}1.302 \\
1.056 \\
1.170 \\
0.701 \\
1.206 \\
1.320 \\
1.197\end{array}$ & $\begin{array}{l}0.65 \\
0.83 \\
0.79 \\
0.90 \\
0.91 \\
1.17 \\
0.69\end{array}$ & $\begin{array}{r}17.00 \\
11.30 \\
12.78 \\
12.60 \\
12.20 \\
10.31 \\
9.20\end{array}$ & $\begin{array}{l}0.071 \\
0.070 \\
0.068 \\
0.072 \\
0.066 \\
0.099 \\
0.080\end{array}$ & $\begin{array}{l}4.38 \\
6.91 \\
4.33 \\
4.56 \\
5.10 \\
7.22 \\
4.65\end{array}$ & $\begin{array}{l}0.65 \\
0.54 \\
0.65 \\
0.70 \\
0.55 \\
0.58 \\
0.68\end{array}$ & $\begin{array}{l}1.53 \\
0.91 \mathrm{U} \\
2.08 \\
2.14 \\
1.66 \\
1.57 \\
1.87\end{array}$ & $\begin{array}{l}198.0 \\
190.5 \\
201.0 \\
194.3 \\
192.7 \\
211.0 \\
188.0\end{array}$ \\
\hline $\begin{array}{l}8 \\
A \\
A \\
A \\
A\end{array}$ & $\begin{array}{l}0.015 \\
0.049 \\
0.036 \\
0.024 \\
0.030\end{array}$ & $\begin{array}{l}32.7 \\
26.0 \\
31.4 \\
27.0 \\
31.1\end{array}$ & $\begin{array}{l}1.024 \\
1.144 \\
0.898 \\
0.836 \\
0.846\end{array}$ & $\begin{array}{l}0.87 \\
0.69 \\
0.65 \\
1.00 \\
1.34\end{array}$ & $\begin{array}{r}11.99 \\
11.03 \\
9.97 \\
9.81 \\
11.20\end{array}$ & $\begin{array}{l}0.080 \\
0.094 \\
0.078 \\
0.085 \\
0.083\end{array}$ & $\begin{array}{l}6.15 \\
3.79 \\
3.71 \\
3.46 \\
4.92\end{array}$ & $\begin{array}{l}1.01 \\
1.00 \\
1.07 \\
1.05 \\
1.20\end{array}$ & $\begin{array}{l}1.82 \\
1.49 \\
0.88 \mathrm{U} \\
2.13 \\
0.99 \mathrm{U}\end{array}$ & $\begin{array}{l}195.1 \\
170.6 \\
180.5 \\
186.7 \\
197.0\end{array}$ \\
\hline $\begin{array}{l}A \\
B \\
A \\
B \\
B \\
B \\
B\end{array}$ & $\begin{array}{l}0.026 \\
0.068 \\
0.033 \\
0.040 \\
0.045 \\
0.036 \\
0.039\end{array}$ & $\begin{array}{r}18.3 \\
23.7 \\
25.0 \\
27.5 \\
26.0 \\
\text { NA } \\
\text { NA }\end{array}$ & $\begin{array}{l}0.959 \\
1.296 \\
1.170 \\
1.312 \\
0.928 \\
1.128 \\
1.060\end{array}$ & $\begin{array}{l}0.87 \\
0.66 \\
0.54 \\
1.02 \\
1.08 \\
1.49 \\
1.07\end{array}$ & $\begin{array}{r}10.81 \\
11.37 \\
13.80 \\
12.10 \\
11.23 \\
\text { NA } \\
\text { NA }\end{array}$ & $\begin{array}{l}0.069 \\
0.065 \\
0.083 \\
0.073 \\
0.077 \\
0.080 \\
0.084\end{array}$ & $\begin{array}{l}3.91 \\
6.06 \\
3.58 \\
6.76 \\
6.26 \\
6.30 \\
6.44\end{array}$ & $\begin{array}{l}0.57 \\
0.57 \\
0.61 \\
0.74 \\
0.51 \\
0.66 \\
0.68\end{array}$ & $\begin{array}{r}1.85 \\
1.01 \\
2.11 \\
2.36 \\
2.03 \\
\text { NA } \\
\text { NA }\end{array}$ & $\begin{array}{r}182.9 \\
166.8 \\
194.4 \\
184.5 \\
181.7 \\
\text { NA } \\
\text { NA }\end{array}$ \\
\hline $\begin{array}{l}\text { B } \\
\text { B } \\
\text { B } \\
B \\
A \\
\text { A } \\
\text { A }\end{array}$ & $\begin{array}{l}0.020 \\
0.020 \\
0.038 \\
0.036 \\
0.044 \\
0.026 \\
0.020\end{array}$ & $\begin{array}{l}30.0 \\
22.4 \\
24.5 \\
23.6 \\
27.8 \\
27.0 \\
27.3\end{array}$ & $\begin{array}{l}1.144 \\
1.056 \\
1.144 \\
1.088 \\
1.223 \\
1.082 \\
1.038\end{array}$ & $\begin{array}{l}1.12 \\
0.88 \\
0.71 \\
0.95 \\
0.55 \\
0.82 \\
0.87\end{array}$ & $\begin{array}{l}14.40 \\
10.90 \\
11.01 \\
12.30 \\
11.00 \\
10.62 \\
10.80\end{array}$ & $\begin{array}{l}0.086 \\
0.067 \\
0.085 \\
0.065 \\
0.091 \\
0.087 \\
0.088\end{array}$ & $\begin{array}{l}6.41 \\
5.32 \\
5.49 \\
5.50 \\
3.95 \\
3.68 \\
3.66\end{array}$ & $\begin{array}{l}0.42 \\
0.44 \\
0.59 \\
5.08 \\
0.64 \\
0.65 \\
0.78\end{array}$ & $\begin{array}{l}1.55 \\
1.35 \\
0.98 \quad 1 \\
1.60 \\
1.88 \\
2.05 \\
1.83\end{array}$ & $\begin{array}{l}205.0 \\
184.9 \\
174.6 \\
175.7 \\
190.6 \\
186.1 \\
198.0\end{array}$ \\
\hline
\end{tabular}


TABLE K.20. (contd)

Sediment

Ireatment

\section{C-S8}

C-SB

$\mathrm{C}-\mathrm{S} 8$

$\mathrm{C}-\mathrm{SB}$

C-SB Replícate 1

C-S8 Replicate 2

C-SB Replicate 3

C-NE

C-NE

C-NE

$\mathrm{C}-\mathrm{NE}$
Replicate

1
2
3
4
5
5
5

1
2
3
4
5

Analytical Batch

$$
\begin{aligned}
& \text { B } \\
& \text { B } \\
& A \\
& A \\
& \text { B } \\
& \text { B } \\
& \text { B } \\
& \text { A } \\
& \text { A } \\
& \text { A } \\
& \text { A } \\
& \text { A }
\end{aligned}
$$

$N$. caecoides Hetals (mo/kg dry weight)

\begin{tabular}{|c|c|c|c|c|c|c|c|c|c|}
\hline $\mathrm{Aq}$ & As & $\mathrm{Cd}$ & $\mathrm{Cr}$ & $\mathrm{Cu}$ & $\mathrm{Hq}$ & $\mathrm{Ni}$ & $\mathrm{Pb}$ & $\mathrm{Se}$ & $\mathrm{Zn}$ \\
\hline $\begin{array}{l}0.027 \\
0.027 \\
0.055 \\
0.024 \\
0.029 \\
0.047 \\
0.032\end{array}$ & $\begin{array}{l}30.2 \\
29.2 \\
25.4 \\
26.8 \\
24.3 \\
23.7 \\
24.0\end{array}$ & $\begin{array}{l}0.757 \\
1.000 \\
1.179 \\
1.038 \\
1.032 \\
0.968 \\
0.936\end{array}$ & $\begin{array}{l}1.06 \\
0.67 \\
0.71 \\
1.11 \\
1.00 \\
1.28 \\
1.11\end{array}$ & $\begin{array}{l}12.90 \\
12.20 \\
13.00 \\
10.42 \\
12.80 \\
12.50 \\
12.50\end{array}$ & $\begin{array}{l}0.060 \\
0.048 \\
0.050 \\
0.047 \\
0.021 \\
0.033 \\
0.030\end{array}$ & $\begin{array}{l}6.56 \\
5.21 \\
3.95 \\
4.02 \\
5.38 \\
5.50 \\
5.48\end{array}$ & $\begin{array}{l}0.58 \\
0.59 \\
0.77 \\
0.69 \\
0.69 \\
0.81 \\
0.72\end{array}$ & $\begin{array}{l}1.47 \\
2.22 \\
2.44 \\
1.66 \\
1.59 \\
1.88 \\
1.90\end{array}$ & $\begin{array}{l}206.0 \\
188.4 \\
175.0 \\
181.8 \\
184.5 \\
183.6 \\
177.1\end{array}$ \\
\hline $\begin{array}{l}0.038 \\
0.049 \\
0.017 \\
0.045 \\
0.026\end{array}$ & $\begin{array}{l}22.9 \\
21.9 \\
24.4 \\
33.1 \\
21.5\end{array}$ & $\begin{array}{l}1.355 \\
1.012 \\
1.382 \\
1.038 \\
0.968\end{array}$ & $\begin{array}{l}0.67 \\
0.84 \\
0.71 \\
0.57 \\
0.78\end{array}$ & $\begin{array}{l}14.80 \\
12.63 \\
13.30 \\
13.40 \\
13.10\end{array}$ & $\begin{array}{l}0.068 \\
0.061 \\
0.076 \\
0.062 \\
0.077\end{array}$ & $\begin{array}{l}4.02 \\
4.39 \\
4.07 \\
3.64 \\
3.25\end{array}$ & $\begin{array}{l}0.70 \\
0.66 \\
0.55 \\
0.67 \\
0.51\end{array}$ & $\begin{array}{l}0.88 \mathrm{U} \\
1.55 \\
1.21 \\
2.26 \\
1.27\end{array}$ & $\begin{array}{l}173.9 \\
163.0 \\
175.8 \\
181.2 \\
171.0\end{array}$ \\
\hline
\end{tabular}

NOTE: Background Nephtys Tissue was not analyzed for metals.

T. (a) OL Detection 1imit.

in (b) U The analyte was not present above the level of the associated value. 
TABLE K.21. Metals, Wet Weight, in Tissue of N. caecoides, Richmond Harbor Program

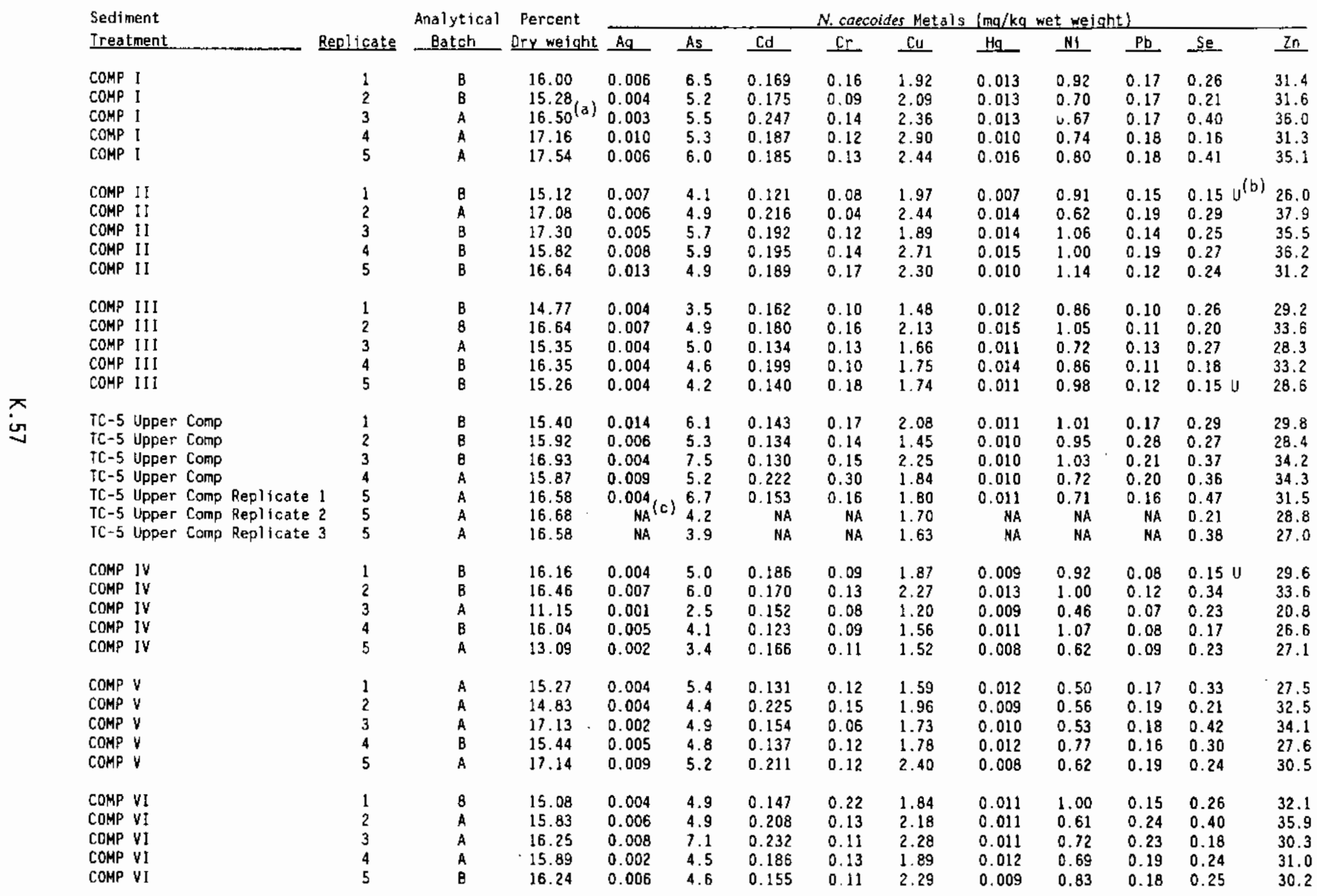


IABLE K.21. (contd)

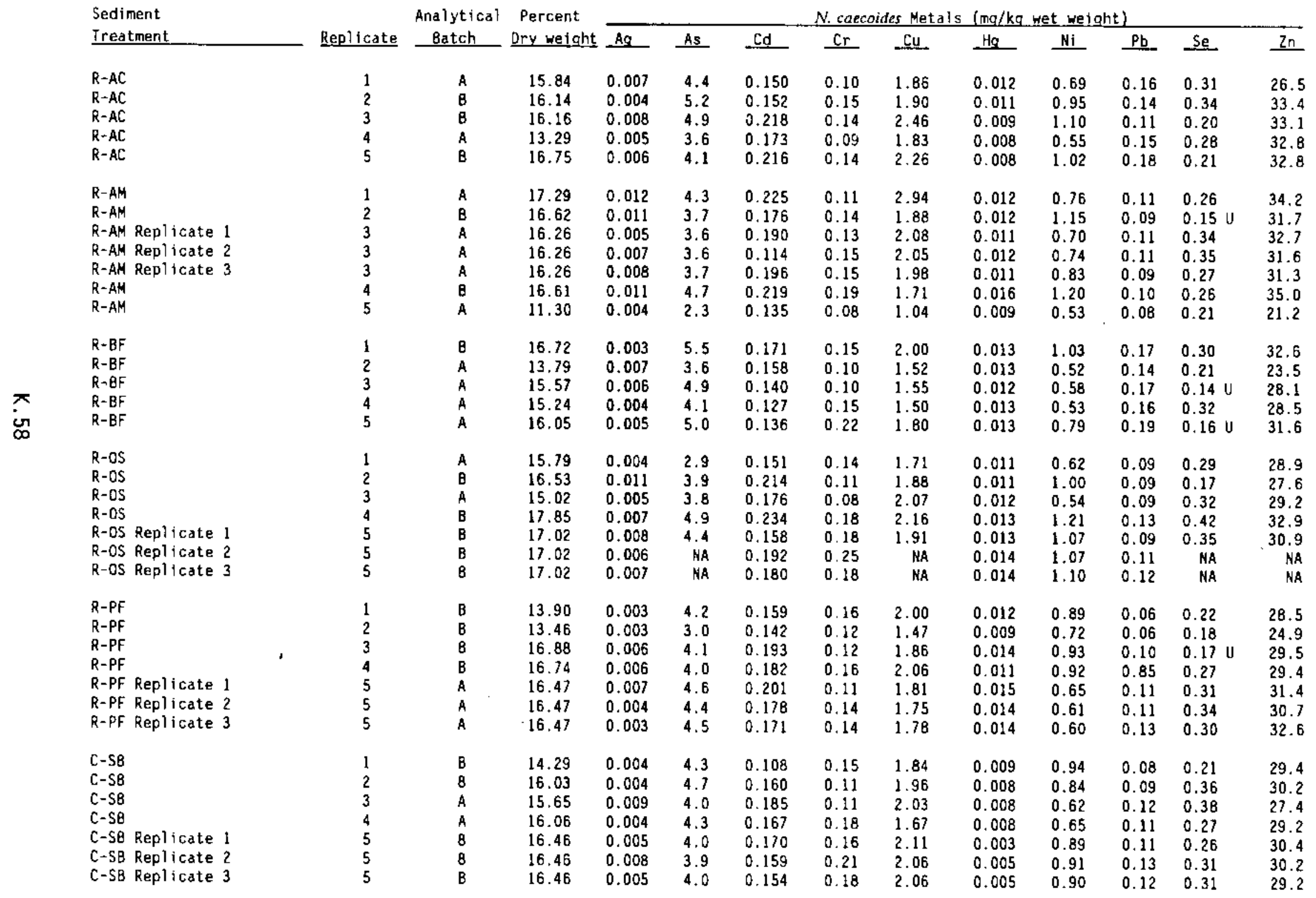


TABLE K.21. (contd)

Sediment Ireatment

$C-N E$

$C-N E$

C-NE

$C-N E$

$\mathrm{C}-\mathrm{NE}$
Analytical Percent Replicate

$\begin{array}{ll}1 & A \\ 2 & A \\ 3 & A \\ 4 & A \\ 5 & A\end{array}$

NOTE: Background $N$. caecoides Tissue was not analyzed for metals.

(a) Percent dry weight was averaged from the four replicates of COMP 1

(b) U The analyte was not present above the level of the associated value.

(c) NA Not applicable.
N. caecoides Metals $(\mathrm{mg} / \mathrm{kg}$ wet weight)

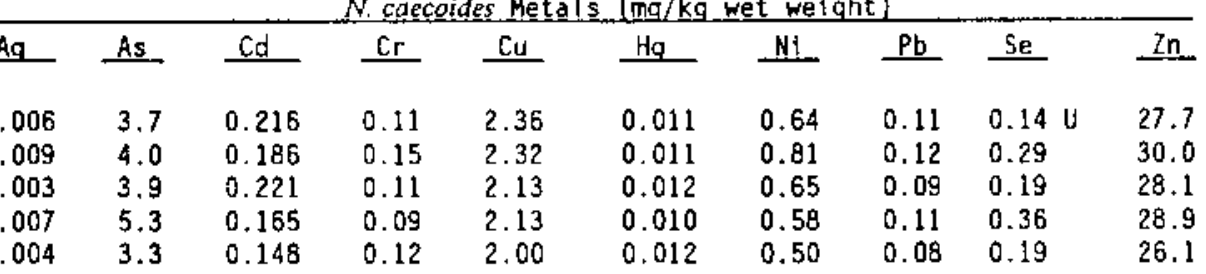


TABLE K.22. Quality Control Data for Metals, Dry Weight, in Tissue of N. caecoides, Richmond Harbor Program

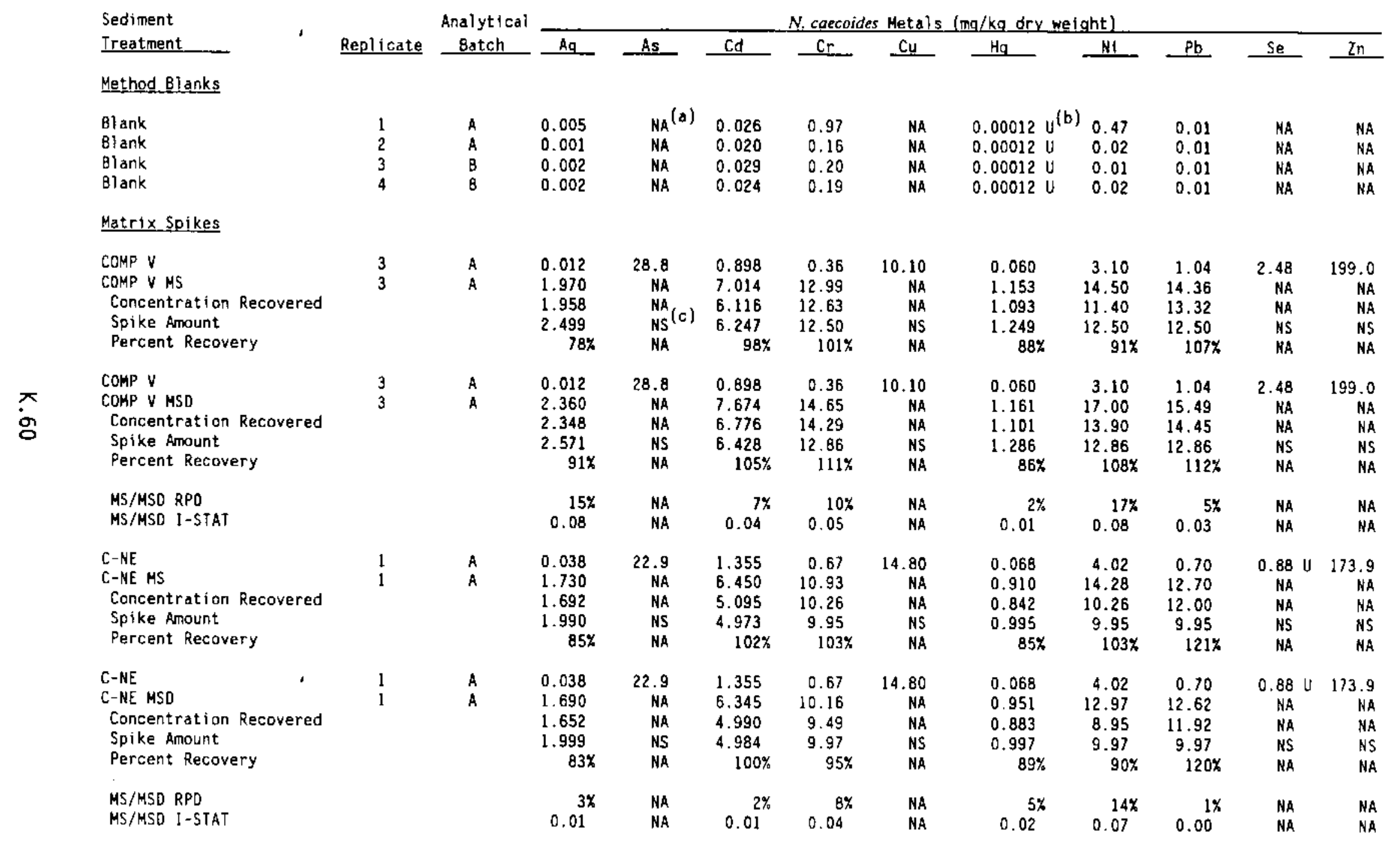


IABLE K.22. (contd)

Sediment Treatment.

COMP II

Comp II mS (d)

Concentration Recovered

Spike Amount

Percent Recovery

COMP II

COMP II MSD (d)

Concentration Recovered

Spike Amount.

Percent Recovery

MS/MSO RPD

MS/MSO I-STAT

$R-P F$

R-PF HS

T Concentration Recovered

Spike Amount

Percent Recovery

\section{$R-P F$}

$R-P F$ MSD

Concentration Recovered

Spike Amount

Percent Recovery

MS/MSD RPD

MS/MSD I -STAT

\section{Standard Reference Material}

Certified Value

SRM 1566

SRM 1566

SRM 1566

SRM 1566

SRN 1566

SRH 1566

SRM 1566

SRM 1566

\begin{tabular}{|c|c|c|c|c|c|c|c|c|c|c|c|}
\hline \multirow[b]{2}{*}{ Replicate } & \multirow{2}{*}{$\begin{array}{l}\text { Anaiytical } \\
\text { Batch } \\
\end{array}$} & \multicolumn{10}{|c|}{ N. caecoides Meta)s (mq/kq dry weight) } \\
\hline & & $\mathrm{Ag}$ & As & $\mathrm{Cd}$ & $\mathrm{Cr}$ & $\mathrm{Cu}$ & $\mathrm{Hg}$ & $\mathrm{Ni}$ & $\mathrm{Pb}$ & $\mathrm{Se}$ & $\mathrm{Zn}$ \\
\hline $\begin{array}{l}3 \\
3\end{array}$ & $\begin{array}{l}B \\
8\end{array}$ & $\begin{array}{r}0.029 \\
2.189 \\
2.160 \\
2.417 \\
89 \%\end{array}$ & $\begin{array}{r}33.0 \\
\text { NA } \\
\text { NA } \\
\text { NS } \\
\text { NA }\end{array}$ & $\begin{array}{r}1.112 \\
6.224 \\
5.112 \\
6.042 \\
85 \%\end{array}$ & $\begin{array}{r}0.68 \\
11.90 \\
11.22 \\
12.08 \\
93 \%\end{array}$ & $\begin{array}{r}10.90 \\
N A \\
N A \\
N S \\
\text { NA }\end{array}$ & $\begin{array}{r}0.083 \\
1.141 \\
1.058 \\
1.208 \\
88 \%\end{array}$ & $\begin{array}{r}6.14 \\
17.70 \\
11.56 \\
12.08 \\
96 \%\end{array}$ & $\begin{array}{r}0.79 \\
12.20 \\
11.41 \\
12.08 \\
94 \%\end{array}$ & $\begin{array}{r}1.45 \\
\text { NA } \\
\text { NA } \\
\text { NS } \\
\text { NA }\end{array}$ & $\begin{array}{r}205.0 \\
N A \\
N A \\
\text { NS } \\
N A\end{array}$ \\
\hline $\begin{array}{l}3 \\
3\end{array}$ & $\begin{array}{l}8 \\
8\end{array}$ & $\begin{array}{r}0.029 \\
2.394 \\
2.365 \\
2.452 \\
96 \%\end{array}$ & $\begin{array}{r}33.0 \\
N A \\
\text { NA } \\
N S \\
N A\end{array}$ & $\begin{array}{c}1.112 \\
12.480 \\
11.368 \\
6.131 \\
185 \%\end{array}$ & $\begin{array}{r}0.68 \\
12.30 \\
11.62 \\
12.26 \\
95 \%\end{array}$ & $\begin{array}{r}10.90 \\
\text { NA } \\
\text { NA } \\
\text { NS } \\
\text { NA }\end{array}$ & $\begin{array}{r}0.083 \\
1.112 \\
1.029 \\
1.226 \\
84 \%\end{array}$ & $\begin{array}{r}6.14 \\
17.60 \\
11.46 \\
12.26 \\
93 \%\end{array}$ & $\begin{array}{c}0.79 \\
13.70 \\
12.91 \\
12.26 \\
105 \%\end{array}$ & $\begin{array}{r}1.45 \\
\text { NA } \\
\text { NA } \\
\text { NS } \\
\text { NA }\end{array}$ & $\begin{array}{r}205.0 \\
\text { NA } \\
\text { NA } \\
\text { NS } \\
\text { NA }\end{array}$ \\
\hline & & $0.0 \%$ & $\begin{array}{l}\text { NA } \\
\text { NA }\end{array}$ & $\begin{array}{l}75 \%^{1 f} \\
0.37\end{array}$ & $0.01^{2 \%}$ & $\begin{array}{l}\text { NA } \\
\text { NA }\end{array}$ & 0.02 & $0.01^{2 x}$ & 0.05 & $\begin{array}{l}N A \\
N A\end{array}$ & $\begin{array}{l}\text { NA } \\
\text { NA }\end{array}$ \\
\hline $\begin{array}{l}3 \\
3\end{array}$ & $\begin{array}{l}8 \\
8\end{array}$ & $\begin{array}{r}0.038 \\
1.958 \\
1.920 \\
2.456 \\
78 \%\end{array}$ & $\begin{array}{r}24.5 \\
\text { NA } \\
\text { NA } \\
\text { NS } \\
\text { NA }\end{array}$ & $\begin{array}{l}1.144 \\
5.040 \\
3.896 \\
6.140 \\
63 \%\end{array}$ & $\begin{array}{c}0.71 \\
9.38 \\
8.67 \\
12.28 \\
71 \%(\mathrm{e})\end{array}$ & $\begin{array}{r}11.01 \\
\text { HA } \\
\text { HA } \\
\text { NS } \\
\text { NA }\end{array}$ & $\begin{array}{r}0.085 \\
1.255 \\
1.170 \\
1.228 \\
95 \%\end{array}$ & $\begin{array}{r}5.49 \\
12.60 \\
7.11 \\
12.28 \\
58 \%\end{array}$ & $\begin{array}{c}0.59 \\
9.55 \\
8.96 \\
12.28 \\
73 \%(\mathrm{e})\end{array}$ & $\begin{array}{l}0.98 \mathrm{U} \\
\text { NA } \\
\text { NA } \\
\text { NS } \\
\text { NA }\end{array}$ & $\begin{array}{r}174.6 \\
\text { NA } \\
\text { NA } \\
\text { NS } \\
\text { NA }\end{array}$ \\
\hline $\begin{array}{l}3 \\
3\end{array}$ & $\begin{array}{l}8 \\
8\end{array}$ & $\begin{array}{l}0.038 \\
2.726 \\
2.688 \\
2.234 \\
120 \%\end{array}$ & $\begin{array}{r}24.5 \\
\text { NA } \\
\text { NA } \\
\text { NS } \\
\text { NA }\end{array}$ & $\begin{array}{r}1.144 \\
6.336 \\
5.192 \\
5.585 \\
93 \%\end{array}$ & $\begin{array}{c}0.71 \\
12.00 \\
11.29 \\
11.17 \\
101 \%\end{array}$ & $\begin{array}{r}11.01 \\
\text { NA } \\
\text { NA } \\
\text { NS } \\
\text { NA }\end{array}$ & $\begin{array}{r}0.085 \\
1.113 \\
1.028 \\
1.117 \\
92 \%\end{array}$ & $\begin{array}{r}5.49 \\
18.30 \\
12.81 \\
11.17 \\
115 \%\end{array}$ & $\begin{array}{c}0.59 \\
13.20 \\
12.61 \\
11.17 \\
113 \%\end{array}$ & $\begin{array}{l}0.98 U \\
\text { NA } \\
\text { NA } \\
\text { NS } \\
\text { NA }\end{array}$ & $\begin{array}{r}174.6 \\
\text { NA } \\
\text { NA } \\
\text { NS } \\
\text { NA }\end{array}$ \\
\hline & & $0.21 x^{4 f}$ & $\begin{array}{l}N A \\
N A\end{array}$ & ${ }_{0.19}^{38 x^{(f}}$ & $\begin{array}{l}35 x^{(} \\
0.18\end{array}$ & $\begin{array}{l}N A \\
N A\end{array}$ & 0.02 & $\begin{array}{l}66 \% \\
0.33\end{array}$ & $0.23 \%^{\text {(f }}$ & $\begin{array}{l}\text { NA } \\
\text { NA }\end{array}$ & $\begin{array}{l}\text { NA } \\
\text { NA }\end{array}$ \\
\hline
\end{tabular}

1.68
\pm 0.15

14
\pm 1.2
14.93
14.24
14.93
14.55
15.00
13.57
14.31
14.66
1.43
\pm 0.46
2.12
NA
NA
NA
NA
NA
NA
NA

66.3
\pm 4.3
65.9
69.7
65.9
65.
65.
61.
66.
66.
0.0642

$\pm .0067$

0.056

NA

NA

NA

NA

NA

$\begin{array}{rrrr}2.25 & 0.37 & 2.21 & 830.0 \\ \pm 0.44 & \pm 0.014 & \pm 0.24 & \pm 57.0 \\ 3.2 & 0.36 & 2.53 & 849.0 \\ \text { NA } & \text { NA } & 1.84 & 862.0 \\ \text { NA } & \text { NA } & 2.53 & 849.0 \\ \text { HA } & \text { NA } & 1.84 & 835.0 \\ \text { NA } & \text { NA } & 2.00 & 854.0 \\ \text { NA } & \text { NA } & 2.17 & 785.0 \\ \text { NA } & \text { NA } & 2.36 & 806.0 \\ \text { NA } & \text { NA } & 2.45 & 848.0\end{array}$


IABLE_K.22. (contd)

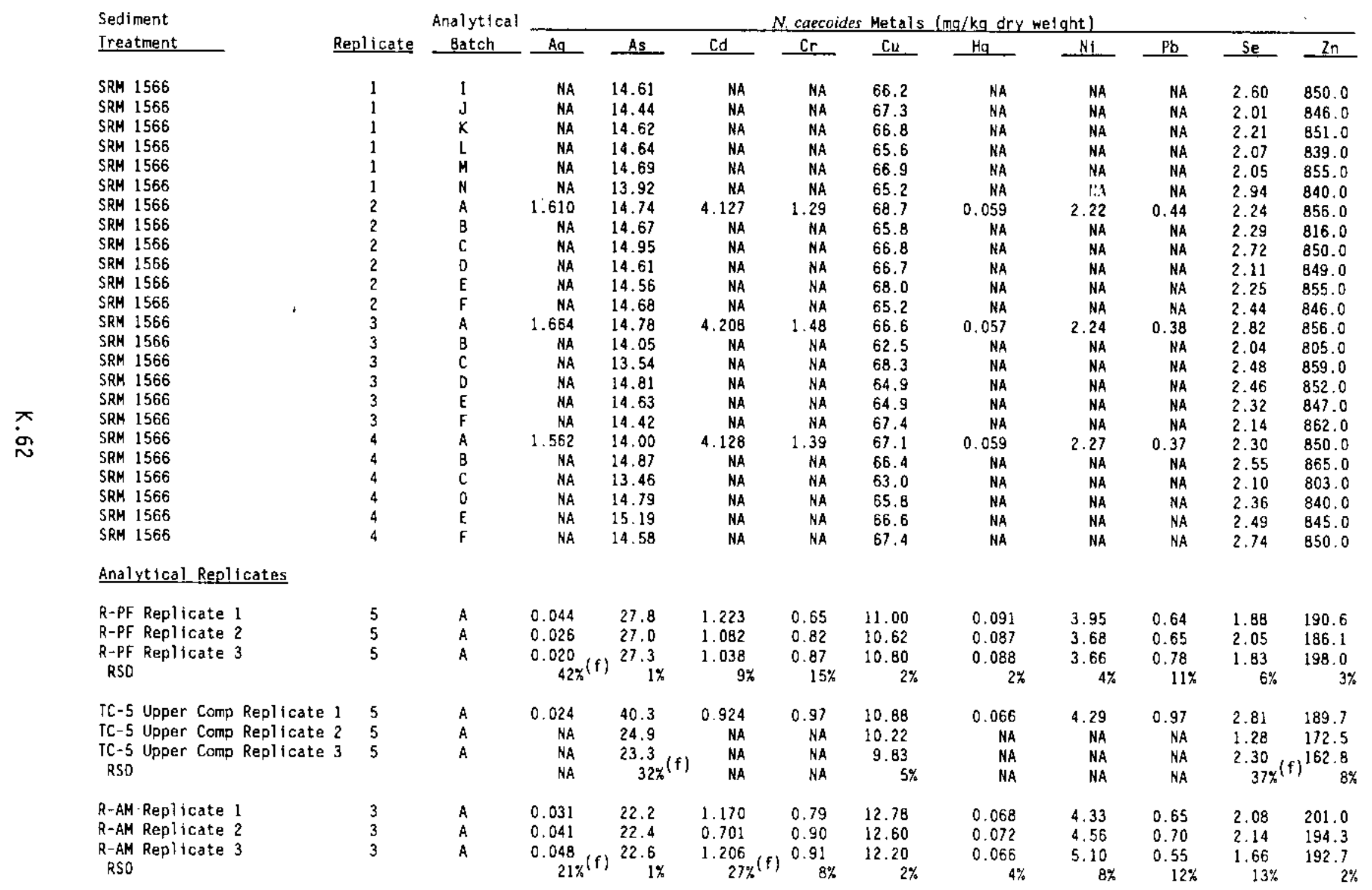


TABLE K.22. (contd)

Sediment

\section{Ireatment}

R-OS Replicate

R-OS Replicate

R-OS Replicate 3

RSD

C-SB Replicate 1

C-SB Replicate 2

C-SB Replicate 3

RSD
Analytical

\section{Replicate}

$$
\begin{aligned}
& 5 \\
& 5 \\
& 5
\end{aligned}
$$

Batch

B

8

\begin{tabular}{|c|c|c|c|c|c|c|c|c|c|}
\hline $\mathrm{Ag}$ & As & $\mathrm{Cd}$ & $\mathrm{Cr}$ & $\mathrm{Cu}$ & $\mathrm{Ha}$ & $\mathrm{Ni}$ & $\mathrm{Pb}$ & Se & $\mathrm{Zn}$ \\
\hline 0.045 & 26.0 & 0.928 & 1.08 & 11.23 & 0.077 & 6.26 & 0.51 & 2.03 & 181.7 \\
\hline 0.036 & NA & 1.128 & 1.49 & NA & 0.080 & 6.30 & 0.66 & $\mathrm{NA}$ & NA \\
\hline 0.039 & NA & 1.060 & 1.07 & NA & 0.084 & 6.44 & 0.68 & NA & NA \\
\hline $11 \%$ & NA & $10 \%$ & $20 \%$ & NA & $4 \%$ & $1 *$ & $15 \%$ & NA & NA \\
\hline $\begin{array}{l}0.029 \\
0.047\end{array}$ & $\begin{array}{l}24.3 \\
23.7\end{array}$ & $\begin{array}{l}1.032 \\
0.968\end{array}$ & $\begin{array}{l}1.00 \\
1.28\end{array}$ & $\begin{array}{l}12.80 \\
12.50\end{array}$ & $\begin{array}{l}0.021 \\
0.033\end{array}$ & $\begin{array}{l}5.38 \\
5.50\end{array}$ & $\begin{array}{l}0.69 \\
0.81\end{array}$ & $\begin{array}{l}1.59 \\
1.88\end{array}$ & $\begin{array}{l}184.5 \\
183.6\end{array}$ \\
\hline 0.032 (f) & 24.0 & 0.936 & 1.11 & 12.50 & 0.030 & 5.48 & 0.72 & 1.90 & 177.1 \\
\hline $27 \%^{(f)}$ & $1 \%$ & $5 \%$ & $12 \%$ & $1 \%$ & $22 \%^{(f)}$ & $1 \%$ & $8 \%$ & $10 \%$ & $2 \%$ \\
\hline
\end{tabular}

N. caecoides

(a) NA Not applicable.

(b) U The analyte was not present above the level of the associated value.

(c) NS Not splked.

(d) COMP II MS/MSO appears to be doubled spiked with Cd.

(e) Recovery aut of quality control range of $(75 \%-125 \%)$.

(g) SRM 1566-1A appears to be contaminated with $\mathrm{Cr}$ and $\mathrm{Ni}$. 
TABLE K.23. Buty't in Results, Wet and Dry Weight, in Tissue of N. caecoides, Richmond Harbor Program

Sediment Treatment

Target DL (a)

Achieved OL Low

Achieved DL High

COMP I

COMP I

COMP I

COMP I Replicate

COMP I Replicate ?

COMP I Replicate 3

COMP I

COMP II

COMP 1 I

COMP II

COMP II

주

of COMP III

COHP II I

COMP II I

COHP III

COMP III

TC-5 Upper Comp

TC-5 Upper Comp

JC-5 Upper Comp

TC-5 Upper Comp

TC-5 Upper Comp Replicate

TC-5 Upper Comp Replicate

TC-5 Upper Comp Replicate 3

COMP IV

COMF IV

COMP IV

COMP IV

COMP IV
Anaiy- Tri- $\frac{\text { Butyltin Species }(\mu \mathrm{g} / \mathrm{kq} \text { wet wetght })}{\text { tical propyltin }}$ Percent

$\frac{\text { Butyltin Soecies }(\mu \mathrm{g} / \mathrm{kg} \text { dry weight })}{\text { Tetra- }}$ Replicate Batch zSurroqate butylin butyitin butylin butyltin Dry Weight butyltin butyitin butyltin butyltin

$\begin{array}{rrrr}10 & 10 & 10 & 10 \\ 5.211 & 9.847 & 4.636 & 4.2199 \\ 27.349 & 51.678 & 24.329 & 22.147\end{array}$

133 (b) $\quad 18.744 \quad 57.094 \quad 7.899 \mathrm{u}^{(\mathrm{c})} 11.458 \mathrm{u}^{(\mathrm{d})} 16.00$

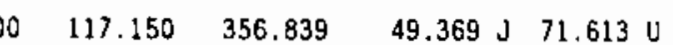

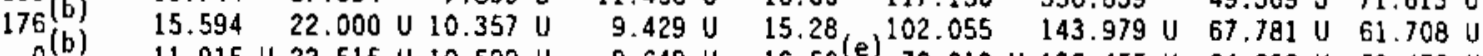
(b) $\quad 11.915 \cup 22.515 \cup 10.599$ U 9.649 U $16.50($ e $) 72.212$ U 136.455 U 64.236 U $58.479 \mathrm{U}$ $72 \quad 18.693$ U 35.321 U 16.628 U 15.138 U $17.16 \quad 108.934$ U 205.833 U 96.900 U 88.217 U

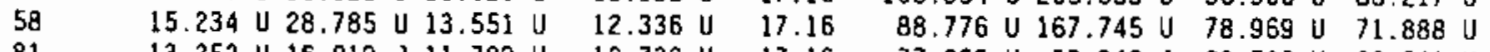

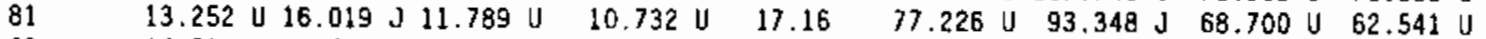

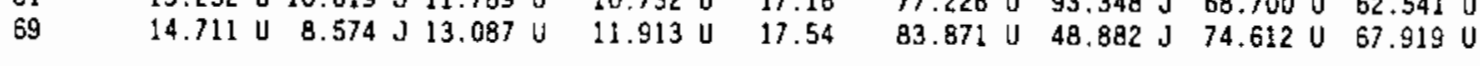

$72 \quad 8.019 \mathrm{~J} \quad 6.739 \mathrm{~J} 13.376 \mathrm{~V}$ 65 (b) $14(b)$

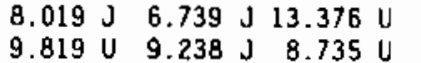
$13.955 \mathrm{U} \quad 8.034 \mathrm{~J} 12.414 \mathrm{U}$ 20.477 U 38.693 U $18.216 \mathrm{U}$ $12.177 \mathrm{U}$ 0 (b) $16.043 \cup 30.315 \cup 14.272 \cup$

$11.3010 \quad 17.30$

$53.038 \mathrm{~J} \quad 44.571 \mathrm{~J} \quad 88.466 \mathrm{U} \quad 80.536 \mathrm{U}$

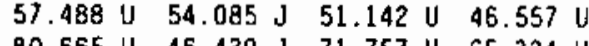
$80.665 \mathrm{U} \quad 46.439 \mathrm{~J} \quad 71.757 \mathrm{U} \quad 65.324 \mathrm{U}$ 129.437 U 244.583 U 115.145 U 104.823 U 96.412 U 182.181 U 85.769 U $9.075 \mathrm{~J}$

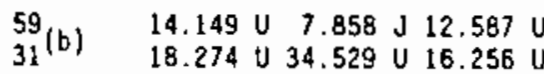
${ }^{80}(\mathrm{~b})$ $18.274 \cup 34.529 \cup 16.256 \mathrm{U}$

$1.510 \mathrm{~J}$

11.458 U 14.77

14.798 U $\quad 16.64$

95.796 U $53.200 \mathrm{~J} \quad 85.220 \mathrm{U} \quad 77.576 \mathrm{U}$ 14.872 U 28.102 U 13.230 U 12.044 U 15.35 10.925 U 20.643 U 9.718 U 8.847 U 16.35 63

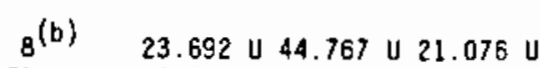
13.908 U $6.729 \mathrm{~J} 12.372 \mathrm{U}$ $16.498 \mathrm{U} 10.147 \mathrm{~J} 14.676$ $15.856 \mathrm{U} 8.682 \mathrm{~J} 14.105 \mathrm{U}$ $22.148 \cup \quad 15.26$

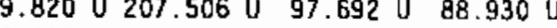
96.886 U 183.075 U 86.189 U 78.463 U 66.820 บ 126.257 ป 59.437 U 54.110 U $179.220 \cup 338.650$ U $159.430 \cup 145.138 \mathrm{U}$

$19.186 \cup \quad 15.40$ $11.263 \mathrm{U} \quad 15.92$ $13.360 \mathrm{U} \quad 16.93$ $12.840 \mathrm{U} \quad 15.87$ $6.954 \mathrm{U} \quad 6.185 \mathrm{~J} 6.186 \mathrm{U} \quad 5.631 \mathrm{U} \quad 16.58$ $22.971 \cup 43.405 \cup 20.434 \cup \quad 18.602 \cup \quad 16.58$ 13.520 U $7.285 \mathrm{~J} 12.027$ U 10.949 U 16.58

153.844 U 290.695 U 136.857 U 124.584 U $87.362 \mathrm{U} \quad 42.267 \mathrm{~J} \quad 77.714 \mathrm{U} \quad 70.747 \mathrm{U}$ 97.448 U $59.936 \mathrm{~J} \quad 86.686$ U $78.913 \mathrm{U}$ 99.912 U $54.705 \mathrm{~J} \quad 88.878$ U $80.907 \mathrm{U}$ $41.942 \mathrm{U} \quad 37.303 \mathrm{~J} \quad 37.310 \mathrm{U} \quad 33.963 \mathrm{U}$ $138.546 \cup 261.791 \cup 123.245 \cup 112.195 \cup$ $81.544 \mathrm{U} \quad 43.939 \mathrm{~J} 72.539 \mathrm{U} 66.037 \mathrm{~J}$

$11.985 \mathrm{~V} 5.371 \mathrm{~J} 3.419 \mathrm{~J}$

$9.706 \cup 16.16$ $11.544 \mathrm{~V} 21.813 \mathrm{U} 10.269 \mathrm{~V} \quad 9.348 \mathrm{~V} \quad 16.46$ $17.267 \cup 32.627 \cup 15.360$ U 13.983 U 11.15 $\begin{array}{llllll}12.695 \mathrm{~V} & 4.377 & 1.628 & 1.495 \mathrm{~J} & 16.04\end{array}$

$74.165 \mathrm{U} \quad 33.236 \mathrm{~J} 21.157 \mathrm{~J} \quad 60.062 \mathrm{U}$ 70.134 U 132.521 U 62.388 U 56.792 U $154.861 \cup 292.619 \cup 137.758 \cup 125.408 \cup$

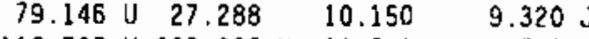
14.502 U 27.402 U 12.900 U 11.744 U 13.09

110.787 U 209.335 U 98.549 U 89.717 U 
IABLE K.23. (contd)

Sediment

Ireatment

COMP $v$
COMP $v$
COMP $v$
COMP V
COMP $V$

COHP VI

COMP VI

COHP VI

COMP VI

COMP VI Replicate

COMP VI Replicate

COMP VI Replicate 3

R-AC

R-AC Replicate

त R-AC Replicate

on R-AC Replicate 3

of $R-A C$

$R-A C$

$R-A C$

$\mathrm{R}-\mathrm{AH}$

$R-A M$

$R-A M$

R-AM

$\mathrm{R}-\mathrm{AM}$

$R-B F$

$R-B F$

$R-B F$

$R-B F$

$R-B F$

R-os

$R-0 S$

R-OS

$R-0 S$
$R-0 S$

Analy- Tri- 8utyltin Species_( $\mu \mathrm{g} / \mathrm{kg}$. wet weight

tical propyltin Tetra Tri- Oi- Mono Replicate Batch gSurrogate butyltin butyltin butyltin butyltin Pry Height butyltin butyltin butyitin butyltin

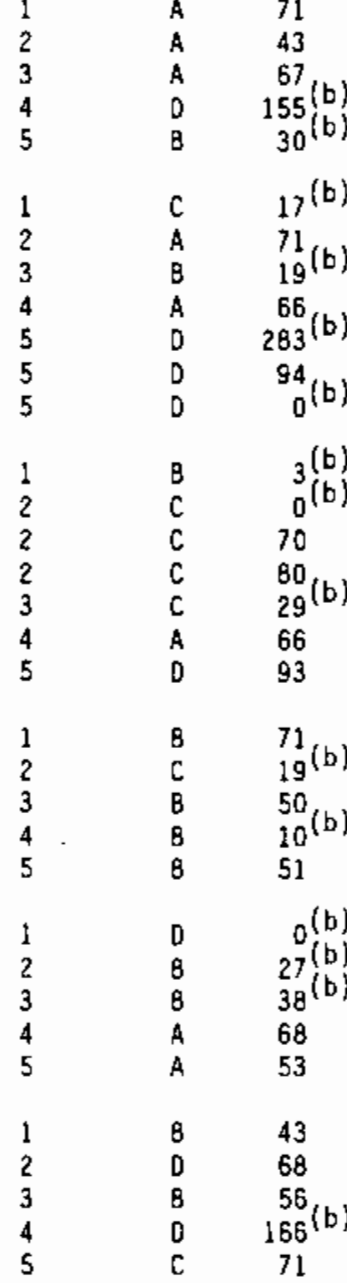

12.855 U $8.869 \mathrm{~J} 4.968 \mathrm{~J}$ 14.199 U $9.919 \mathrm{~J} 12.631 \mathrm{U}$

11.257 U 21.271 U $10.014 \mathrm{U}$

$\begin{array}{lll}9.540 & 22.561 \quad 5.864 \mathrm{~J}\end{array}$

$11.288 \cup 15.813 \quad 5.838$

10.410 U 15.27

$9.018 \quad 14.83$

$9.116 \mathrm{U} \quad 17.13$

$6.962 \cup 15.44$

$9.141 \cup \quad 17.14$

$9.963 \cup 9.062 \quad 8.863 \mathrm{~L}$

14.298 U $10.649 \mathrm{~J} 12.719 \mathrm{~V}$

8. $068 \mathrm{U}$

$11.579 \mathrm{U}$

$8.919 \mathrm{U} \quad 16.25$

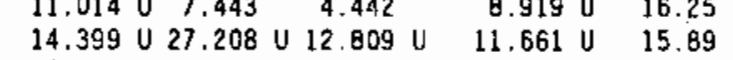

$\begin{array}{llllll}45.349 & 37.745 & \mathrm{U} & 17.770 \mathrm{U} & 16.176 \mathrm{U} & 16.24\end{array}$

$\begin{array}{lllrl}24.703 & 16.259 \mathrm{~J} & 6.308 \mathrm{~J} & 18.655 \mathrm{~J} & 16.24 \\ 12.070 \mathrm{U} 20.213 & 6.492 \mathrm{~J} & 2.947 \mathrm{~J} & 16.24\end{array}$

16.24

3 (b) $\quad 19.131 \mathrm{U} \quad 5.070 \mathrm{~J} 17.019 \mathrm{U}$

$1.270 \mathrm{~J} 3.564 \mathrm{~J} 1.296 \mathrm{~J}$

$13.579 \mathrm{U} 8.344 \mathrm{~J} 12.079 \mathrm{U}$

$1.276 \mathrm{~J}$

$1.632 \mathrm{~J}$

15.84

16.14

16.14

$9.940 \mathrm{U} \quad 16.14$

14.732 U 16.16

$18.192 \mathrm{U} 9.592 \mathrm{~J} 16.183 \mathrm{U}$

9.611 U $11.776 \mathrm{~J} 8.550 \mathrm{U}$

$15.180 \quad 26.448 \quad 11.018 \mathrm{U}$

10.030

16.16
13.29

16.75

9.679 U $22.797 \quad 8.610 \mathrm{U}$

$\begin{array}{ll}11.014 \mathrm{U} 13.241 & 9.797 \mathrm{~J}\end{array}$

7.689 U $18.817 \quad 2.252 \mathrm{~J}$

$7.838 \cup \quad 17.29$

B.919 U 16.62

6.226 U 16.26

$5.344 \mathrm{~J}$

16.26
16.61

$5.152 \mathrm{~J} 24.783 \quad 6.956$

$12.274 \cup 23.193$ U 4.835

$19.686 \cup 37.198 \cup 17.512 \mathrm{U}$

$21.791 \mathrm{U} \quad 9.834 \mathrm{~J} \quad 6.372 \mathrm{~J}$

$9.749 \cup 18.421 \cup 8.672$ U

$3.585 \mathrm{~J}$

$9.940 \mathrm{~V}$

$15.942 \mathrm{~V}$

$17.647 \mathrm{U}$

$7.895 \mathrm{U}$

$9.792 U$

$12.992 \mathrm{U}$

$12.805 \quad 18.459 \mathrm{~J} 14.272 \mathrm{U}$

$16.633 \mathrm{~V} 19.223 \quad 14.796 \mathrm{~V}$

$20.477 \quad 19.321 \mathrm{~J} 12.900 \mathrm{U}$

$13.469 \mathrm{U}$

$11.744 \mathrm{U}$

$10.443 \mathrm{U}$
$84.185 \mathrm{U} \quad 58.079 \mathrm{~J} 32.534 \mathrm{~J} \quad 68.173 \mathrm{U}$

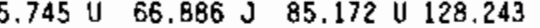

65.715 U 124.174 U 58.459 U 53.217 U $\begin{array}{lllll}61.788 & 146.120 & 37.979 \mathrm{~J} & 45.091 \mathrm{~V}\end{array}$

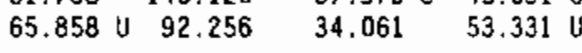

66.068 U $60.094 \quad 58.773$ U 53.501 U 90.322 U $67.268 \mathrm{~J} \quad 80.347$ U $73.146 \mathrm{U}$ 67.778 U $45.805 \quad 27.334 \quad 54.886 \mathrm{U}$ 90.617 U 171.227 U 80.610 U 73.386 U $279.243 \quad 232.420$ U 109.421 U $99.606 \mathrm{~V}$ $152.113100 .118 \mathrm{~J} 38.844 \mathrm{~J} 114.871 \mathrm{~J}$ $74.323 \mathrm{U} 124.464 \quad 39.975 \mathrm{~J} \quad 18.147 \mathrm{~J}$

120.777 U $32.008 \mathrm{~J} 107.443 \mathrm{U} \quad 8.056 \mathrm{~J}$ $7.869 \mathrm{~J} 22.082 \mathrm{~J} 8.030 \mathrm{~J} 10.112 \mathrm{~J}$ $84.133 \mathrm{U} \quad 51.698 \mathrm{~J} 74.839 \mathrm{U} 68.129 \mathrm{U}$ $76.047 \mathrm{U} \quad 64.709 \mathrm{~J} \quad 67.652$ U $61.586 \mathrm{U}$ 112.574 U $59.358 \mathrm{~J} 100.142 \mathrm{U} 91.163 \mathrm{U}$ 72.318 U 68.611 J 64.334 U 58.563 U $\begin{array}{lllll}90.629 & 157.900 & 65.779 & \mathrm{U} & 59.881\end{array}$

55.980 U $131.853 \quad 49.798$ U 45.333 U $66.270 \cup 79.666 \quad 58.947$ U $53.664 \mathrm{U}$ 47.288 \& $115.723 \quad 13.847 \mathrm{~J} 38.290 \mathrm{U}$ 63.721 U $32.615 \quad 56.689$ บ 51.601 U 118.628 U $235.28247 .295 \mathrm{~J} 96.062 \mathrm{U}$

$30.813 \mathrm{~J} 148.224 \quad 41.603 \mathrm{~J} 21.441 \mathrm{~J}$ 89.007 U 168.187 U $35.065 \quad 72.081$ U $126.435 \cup 238.908$ U $112.473 \cup 102.389$ U $142.986 \mathrm{U} \quad 64.529 \mathrm{~J} 41.813 \mathrm{~J} 115.794 \mathrm{U}$ 60.741 U 114.773 U 54.031 U 49.190 U

$76.580 \cup 144.706$ U 68.125 U 62.014 U $\begin{array}{lllll}77.466 & 111.671 \mathrm{~J} & 86.340 \mathrm{U} & 78.596 \mathrm{U} & \mathrm{U}\end{array}$ 110.739 U $127.980 \quad 98.509$ U 89.674 U $114.717 \quad 108.241 \mathrm{~J} 72.269$ U $65.793 \mathrm{U}$

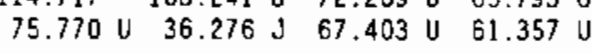




\section{TABLE K.23. (contd)}

Sediment

Treatment

\section{$R-P F$}

$R-P F$

$R-P F$

$R-P F$

R-PF

$C-S B$
$C-S B$
$C-S B$

$\mathrm{C}-\mathrm{SB}$

$C-S B$

$\mathrm{C}-\mathrm{SB}$

C-NE

$C-N E$

$\mathrm{C}-\mathrm{NE}$

$C-N E$

त् $\mathrm{C}-\mathrm{NE}$

का

MSL Background

MSL Background

MSL Background

MSL Background

MSL Background

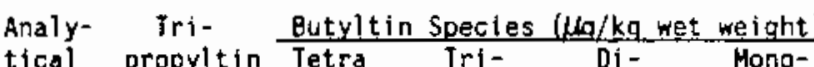

Percent

Butyltin Species $(\mu \mathrm{g} / \mathrm{kg}$ dry weight) Replicate batch qSurroqate butyltin butyltin butyltin butyltin ory Yeight butyltin butyltin butyltin butyltin

\section{$1 \quad C \quad 134$ (b) $\quad 8.579 \mathrm{U} \quad 6.209 \mathrm{~J} \quad 1.931 \mathrm{~J}$}

$6.947 \mathrm{U} \quad 13.90$

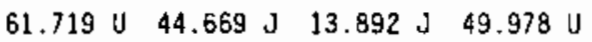
56 (b) $\quad 12.424 \mathrm{U} \quad 6.366 \mathrm{~J} 11.052 \mathrm{U}$

${ }_{165}^{133}(b)$

$10.994 \quad 16.983 \mathrm{~J} \quad 9.490 \mathrm{U}$

10.061 U 13.46

$92.303 \mathrm{U} \quad 47.292 \mathrm{~J} 82.110 \mathrm{U} 74.747 \mathrm{U}$

$165^{(b)}$

$25.214 \quad 33.772$ y 15.899 U

8.639 U 16.88

$55.130 \quad 100.610 \mathrm{~J} 56.220 \mathrm{U} \quad 51.179 \mathrm{VJ}$

61

6.724 U $8.175 \quad 1.709 \mathrm{~J}$

4.474

16.74

$150.621201 .744 \mathrm{~V} 94.976 \mathrm{~J} \quad 86.454 \mathrm{~V}$

$37^{\text {(b) }} \quad 15.856$ U 29.961 U $14.105 \mathrm{v}$

101 (b)

$6.520 \mathrm{~J} 11.025 \mathrm{~J} 6.664 \mathrm{U}$

$5.446 \mathrm{~V}-16.47$

40.826 \& 49.637

$10.374 \mathrm{~J} 33.066 \mathrm{U}$

68

$13.908 \mathrm{U} 4.840 \mathrm{~J} 3.836 \mathrm{~J}$

$12.840 \mathrm{U} \quad 14.29$

110.959 U 209.664 U 98.705 U 89.853 U

$40.671 \mathrm{~J} \quad 68.778 \mathrm{~J} \quad 41.572 \mathrm{U} \quad 37.842 \mathrm{U}$

$88.869 \mathrm{U} \quad 30.927 \mathrm{~J} 24.511 \mathrm{~J} 71.968 \mathrm{U}$

$46.389 \mathrm{U} \quad 66.433 \quad 41.264 \mathrm{U} \quad 37.565 \mathrm{U}$

$21.389 \mathrm{~J} 153.882$ U 72.442 U $65.948 \mathrm{U}$

$3.521 \mathrm{~J} 25.329$ U $11.924 \mathrm{U}$

$6.033 \mathrm{U} \quad 16.06$

16.46

$4.220 \mathrm{U} \quad 15.94$

5.211 U 9.847 U 4.636

10.749 U 18.40

$32.691 \cup \quad 61.775$ U $29.084 \cup \quad 26.474 U$

$9.565 \mathrm{U} \quad 16.01$

11.812 U $22.319 \mathrm{U} 10.507 \mathrm{U}$

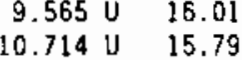

$105.805 \quad 64.174$ U $58.418 \mathrm{U}$

33.779 U 139.407 U 65.628 U 59.744 U

$\begin{array}{rrrrr}49.941 & \mathrm{U} & 94.365 \mathrm{U} & 44.535 \mathrm{U} & 67.853 \mathrm{U} \\ 44.424 & 40.445 \mathrm{U}\end{array}$

$7.631 \cup 14.419$ U $6.788 \mathrm{~V}$

$6.180 \mathrm{U} \quad 15.28$

$2.710 \cup \quad 5.120 \cup \quad 4.283$

2.700 U 5.102 U 3.068

$3.345 \mathrm{U} \quad 6.321 \mathrm{U} \quad 1.325 \mathrm{~d}$

2.194 U 19.82

13.673 U 25.832 U $21.609 \quad 11.070 \mathrm{U}$

$\begin{array}{llllllll}2.187 & \mathrm{~V} & 19.82 & 13.623 \mathrm{U} & 25.742 \mathrm{U} & 15.479 & 11.034 \mathrm{U}\end{array}$

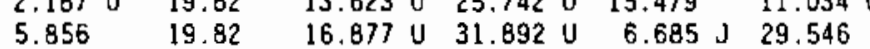

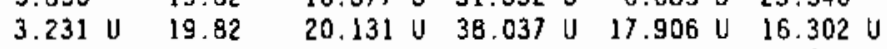

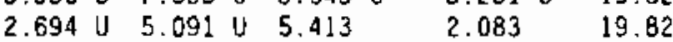

13.592 U 25.686 U 27.311

10.510

(a) DL Detection limit.

(b) Recovery outside quality control range $(40 \%-120 \%)$.

(c) J Analyte detected below method detection limit (MOL). but above instrument detection limit (IDL)

(d) The analyte was not present above the level of the associated value.

(e) Percent dry weight was averaged from the other four replicates of COMP I. 
TABLE K.24. Quality Control Data for Butyltins, Wet Weight, in Tissue of N. caecoides, Richmond Harbor Program

Sediment

Treatment

Method Blanks

Blank

B? ank

Blank

B] ank

Matrix Spikes

Background Jw05

Background MS

Concentration Recovered

Anount Spiked

Percent Recovery

Background JW0S

Background MSD

Concentration Recovered

Anount Spiked

Percent Recovery

MS/MSD RPD

MS/MSD I-STAT

Background JW05

Background MS

Concentration Recovered

Amount Spiked

Percent Recovery

Background Jw05

Background MSD

Concentration Recovered

Amount Spiked

Percent Recovery

MS/HSD RPD

MS/MSD I-STAT

8ackground JW05

Background MS

Concentration Recovered

Anount Spiked

Percent Recovery

8ackground JW05

Background MSO

Concentration Recovered

Amount Spiked

Percent Recovery

MS/MSD RPD

MS/MSD I-STAT
Butyltin Species ( $/ \mathrm{g} / \mathrm{kg}$ wet weight)

Analytical Iripropyltin Tetra- Tri- Di- Mono-

Replicate $\begin{gathered}\text { Batch } \\ \text { \% Surrogate butyltin butyltin butyltin butyltin }\end{gathered}$

$\begin{array}{rrllll}\text { A } & 27(\mathrm{a}) & 40.75 \mathrm{U}^{(\mathrm{b})} & 77 \mathrm{U} & 36.25 \mathrm{U} & 33 \mathrm{U} \\ \mathrm{B} & 0(\mathrm{a}) & 40.75 \mathrm{U} & 77 \mathrm{U} & 36.25 \mathrm{U} & 33 \mathrm{U}(\mathrm{c}) \\ \mathrm{C} & 1(\mathrm{a}) & 40.75 \mathrm{U} & 77 \mathrm{U} & 36.25 \mathrm{U} & 2.281 \mathrm{~J}^{(\mathrm{U})} \\ \mathrm{D} & \mathrm{O}^{(\mathrm{a})} & 58.473 & 77 \mathrm{U} & 36.25 \mathrm{U} & 33 \mathrm{U}\end{array}$

$\begin{array}{cccc}4.065 \mathrm{U} & 7.682 \mathrm{U} & 3.616 \mathrm{U} & 3.399 \\ 3.651 \mathrm{U} & 13.808 & 15.373 & 2.957 \\ \text { NA } & 13.808 & 15.370 & \text { NA } \\ \text { NS } & 29.498 & 24.247 & \text { NS } \\ \text { NA } & 47 \% & 63 \% & \text { NA }\end{array}$

$\begin{array}{lllll}4.065 \mathrm{U} & 7.682 \mathrm{U} & 3.616 \mathrm{U} & 3.399\end{array}$

$\begin{array}{llll}3.486 \mathrm{U} & 10.698 & 14.898 & 2.823 \mathrm{U}\end{array}$

NA $10.698 \quad 14.898 \quad$ NA

NS $\quad 28.161$ (a) $\begin{array}{ccc}23.148 & \text { NA } \\ \text { NA } & 38 \%(a) & \text { NA }\end{array}$

NA $\quad 21 \% \quad 2 \% \quad$ NA

$\begin{array}{llll}\text { NA } & 0.10 & 0.01 & \text { NA }\end{array}$

4.065 U $\quad 7.682$ U $\quad 3.616$ U $\quad 3.399$

$3.933 \mathrm{U} \quad 35.558 \quad 22.592 \quad 3.185 \mathrm{U}$

$\begin{array}{llll}\text { NA } & 35.558 & 22.592 & \text { NA }\end{array}$

$\begin{array}{llrl}\text { NS } & 31.776 & 26.120 & \text { NS } \\ \text { NA } & 112 \% & 85 \% & \text { NA }\end{array}$

4.065 U $\quad 7.682 \cup \quad 3.616$ U 3.399

$\begin{array}{rrrr}3.05 \mathrm{U} & 22.931 & 18.280 & 2.47 \mathrm{U}\end{array}$

ND $22.931 \quad 18.280 \quad$ NA

NS $24.641 \quad 20.254$ NS

NA $\quad 93 \% \quad 90 \%$ NA

$\begin{array}{cccc}\text { NA } & 18 \% & \mathbf{4 \%} & \text { NA } \\ \text { NA } & 0.09 & 0.02 & \text { NA }\end{array}$

4.065 U $\quad 7.682$ ป 3.616 ป 3.399

$\begin{array}{llll}2.221 \mathrm{U} & 7.315 & 9.511 & 1.798 \mathrm{U}\end{array}$

NA $\quad 7.315 \quad 9.511$ NA

$\begin{array}{llll}\text { NS } & 17.940 & 14.747 & \text { NS }\end{array}$

NA $41 \% \quad 64 \% \quad$ NA

$\begin{array}{lllll}4.065 & \text { U } & 7.682 \text { U } & 3.616 \text { U } & 3.399\end{array}$

$\begin{array}{llll}5.855 \mathrm{U} & 12.937 & 22.156 & 1.64 \mathrm{~J}\end{array}$

$\begin{array}{llll}\text { NA } & 12.937 & 22.156 & 1.64\end{array}$

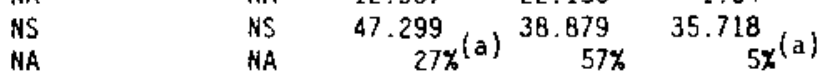

NA NA $\quad 39 \%^{\text {(f) }} \quad 12 \%$ NA 


\section{TABLE K.24. (contd)}

Sediment

Treatment

Background JW05

Background MS

Concentration Recovered

Amount Spiked

Percent Recovery

Background JW05

Background MSD

Concentration Recovered

Anount Spiked

Percent Recovery

MS/MSO RPD

MS/MSD I-STAI

Analytical Replicates

\begin{tabular}{|c|c|c|c|c|c|c|}
\hline \multirow[b]{2}{*}{ Replicate } & \multirow[b]{2}{*}{$\begin{array}{l}\text { Analytical } \\
\text { Batch } \\
\end{array}$} & \multirow[b]{2}{*}{$\begin{array}{l}\text { Tripropyltin } \\
\text { X_Surrogate }\end{array}$} & \multicolumn{4}{|c|}{ Butyltin Species $(\mu \mathrm{g} / \mathrm{kq}$ wet weight $)$} \\
\hline & & & $\begin{array}{l}\text { Tetra- } \\
\text { butyltin }\end{array}$ & $\begin{array}{c}\text { Tri- } \\
\text { butyltin }\end{array}$ & $\begin{array}{c}\text { Di- } \\
\text { butyltin }\end{array}$ & $\begin{array}{c}\text { Mono- } \\
\text { butyltin }\end{array}$ \\
\hline 4 & $\begin{array}{l}E \\
D\end{array}$ & $\begin{array}{l}72(a) \\
\text { NA } \\
\text { NS } \\
\text { NA }\end{array}$ & $\begin{array}{c}4.065 \mathrm{U} \\
6.747 \mathrm{U} \\
\text { NA } \\
\text { NS } \\
\text { NA }\end{array}$ & $\begin{array}{c}7.682 \text { u } \\
15.419 \\
15.419 \\
54.503 \\
28 \%(\mathrm{a})\end{array}$ & $\begin{array}{c}3.616 \mathrm{U} \\
43.172 \\
43.172 \\
44.801 \\
96 \%\end{array}$ & $\begin{array}{l}3.399 \\
2.679 \mathrm{~J} \\
2.679 \\
41.159 \\
7 \%(\mathrm{a})\end{array}$ \\
\hline $\begin{array}{l}4 \\
4\end{array}$ & $\begin{array}{l}E \\
D\end{array}$ & $\begin{array}{l}72 \\
0 \\
\text { NA } \\
\text { NS } \\
\text { NA }\end{array}$ & $\begin{array}{c}4.065 \mathrm{U} \\
6.637 \mathrm{U} \\
\text { NA } \\
\text { NS } \\
\text { NA }\end{array}$ & $\begin{array}{c}7.682 \mathrm{U} \\
11.91 \\
11.91 \\
53.616 \\
22 \mathrm{x}^{(a)}\end{array}$ & $\begin{array}{c}3.616 \mathrm{U} \\
38.611 \\
38.611 \\
44.072 \\
88 \%\end{array}$ & $\begin{array}{c}3.399 \\
2.249 \mathrm{~J} \\
2.249 \\
40.489 \\
6 \mathrm{x}^{(\mathrm{a})}\end{array}$ \\
\hline & & $\begin{array}{l}\text { NA } \\
\text { NA }\end{array}$ & $\begin{array}{l}\text { NA } \\
\text { NA }\end{array}$ & $\begin{array}{l}24 \% \\
0.12\end{array}$ & $\begin{array}{l}10 \% \\
0.05\end{array}$ & $\begin{array}{l}16 \% \\
0.08\end{array}$ \\
\hline
\end{tabular}

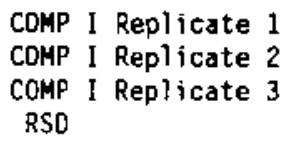

TC-E Upper Comp Replicate

IC-5 Upper Comp Replicate 2

TC-5 Upper Comp Replicate 3 RSO

COMP VI Replicate 1 COMP VI Replicate 2 COMP VI Replicate 3 RSD

R-AC Replicate 1 R-AC Replicate 2 R-AC Reolicate 3 RSD

4
4
4

5
5
5

$\begin{array}{ll}\text { A } & 76 \\ \text { A } & 42 \\ \text { A } & 69\end{array}$

$18.693 \mathrm{U}$
$15.234 \mathrm{u}$
$13.252 \mathrm{U}$

NA
16.628 U $15.138 \mathrm{U}$

13.551 u $12.336 \mathrm{U}$

$28.785 \mathrm{U} 13.551 \mathrm{U} 12.336 \mathrm{U}$

$16.019 \mathrm{~J}$

NA

NA

NA

(a) Recovery outside quality control range (40x-120x).

(b) U The anaiyte was not present above the level of the associated value.

(c) J Analyte detected was below method detection limits (MOL), but above

(d) NA Not applicable. instrument detection limit (IDL).

(e) NS Not spiked.

(f) Value exceeds relative precision range of (30x). 
APPENDIX L

MEAN CONCENTRATIONS AND STATISTICAL GROUPING'

FOR M. nasuta 
IABLE L.1. Mean Concentrations and Statistical Grouping for Naphthalene in M.nasuta Tissues, Richmond Harbor Program

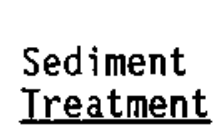

R-OS

COMP III

COMP II

COMP I

$\mathrm{R}-\mathrm{PF}$

$\mathrm{R}-\mathrm{AM}$

COMP IV

$\mathrm{R}-\mathrm{AC}$

COMP V

$\mathrm{R}-\mathrm{BF}$

COMP VI

TC-5 Upper Comp

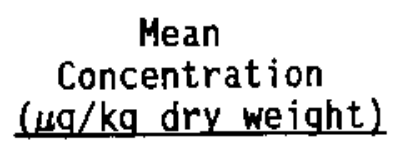

12.43

11.41

12.72

13.14

13.35

15.55

13.96

15.50

15.27

15.69

21.09

20.96
Statistical

Grouping

A

A

A

A

A

A

A

A

A

$A$

A

TABLE L.2. ANOVA Results for Naphthalene in $M$. nasuta Tissues, Richmond Harbor Program

\begin{tabular}{lccccc}
$\begin{array}{l}\text { Source of } \\
\text { Variation }\end{array}$ & $\begin{array}{c}\text { Sum of } \\
\text { Squares }\end{array}$ & d.f. & $\begin{array}{c}\text { Mean } \\
\text { Square }\end{array}$ & $\underline{\text { F-Ratio }}$ & $\begin{array}{c}\text { Significance } \\
\text { Level }\end{array}$ \\
\cline { 2 - 5 } & 2.204 & 11 & 0.200 & 1.377 & 0.2144 \\
Treatment & 6.985 & 48 & 0.146 & &
\end{tabular}


TABLE L.3. Mean Concentrations and Statistical Grouping for Fluorene in M. nasuta Tissues, Richmond Harbor Program

\begin{tabular}{lcc}
$\begin{array}{c}\text { Sediment } \\
\text { Ireatment }\end{array}$ & $\begin{array}{c}\text { Mean } \\
\text { Concentration } \\
(\mu \mathrm{g} / \mathrm{kg} \text { dry weight })\end{array}$ & $\begin{array}{c}\text { Statistical } \\
\text { Grouping }\end{array}$ \\
\cline { 2 - 3 } COMP IV & $4.75 \mathrm{U}^{(\mathrm{a})} \mathrm{J}^{(\mathrm{b})}$ & $\mathrm{A}$ \\
R-OS & 5.04 & $\mathrm{~A}$ \\
COMP I & 5.12 & $\mathrm{~A}$ \\
R-BF & 5.16 & $\mathrm{~A}$ \\
R-PF & 5.30 & $\mathrm{~A}$ \\
COMP V & 5.46 & $\mathrm{~A}$ \\
TC-5 Upper Comp & 6.54 & $\mathrm{~A}$ \\
R-AM & 7.26 & $\mathrm{~A}$ \\
R-AC & 11.70 & $\mathrm{~B}$
\end{tabular}

(a) U The analyte was not present above the level of the associated value.

(b) J Analyte detected below method detection limit (MOL), but above instrument detection level (IDL).

TABLE L.4. ANOVA Results for Fluorene in M. nasuta Tissues, Richmond Harbor Program

\begin{tabular}{|c|c|c|c|c|c|}
\hline $\begin{array}{l}\text { Source of } \\
\text { Variation }\end{array}$ & $\begin{array}{l}\text { Sum of } \\
\text { Squares }\end{array}$ & d.f. & $\begin{array}{l}\text { Mean } \\
\text { Square }\end{array}$ & F-Ratio & $\begin{array}{c}\begin{array}{c}\text { Significance } \\
\text { Level }\end{array} \\
\end{array}$ \\
\hline $\begin{array}{l}\text { Treatment } \\
\text { Residual }\end{array}$ & $\begin{array}{l}3.242 \\
1.779\end{array}$ & $\begin{array}{r}8 \\
36\end{array}$ & $\begin{array}{l}0.405 \\
0.049\end{array}$ & 8.199 & 0.0001 \\
\hline
\end{tabular}


TABLE L.5. Mean Concentrations and Statistical Grouping for Phenanthrene in $M$. nasuta Tissues, Richmond Harbor Program

Sediment
Ireatment
COMP IV
COMP III
R-OS
R-PF
COMP II
R-BF
COMP I
COMP VI
COMP V
TC-5 Upper Comp
R-AM
R-AC

$\begin{gathered}\text { Mean } \\ \text { Concentration } \\ (\mu \mathrm{g} / \mathrm{kg} \text { dry weight })\end{gathered}$
9.98
10.14
10.89
11.17
12.65
14.02
15.08
16.02
16.48
27.88
46.04
111.96

\begin{tabular}{c} 
Statistical \\
Grouping \\
\hline
\end{tabular}

A

A

A

A

A

A

A

A

A

B

B

C

IABLE L.6. ANOVA Results for Phenanthrene in $M$. nasuta Tissues, Richmond Harbor Program

\begin{tabular}{|c|c|c|c|c|c|}
\hline $\begin{array}{l}\text { Source of } \\
\text { Variation }\end{array}$ & $\begin{array}{r}\text { Sum of } \\
\text { Squares }\end{array}$ & d.f. & $\begin{array}{l}\text { Mean } \\
\text { Square }\end{array}$ & F-Ratio & $\begin{array}{c}\text { Significance } \\
\text { Level }\end{array}$ \\
\hline $\begin{array}{l}\text { Treatment } \\
\text { Residual }\end{array}$ & $\begin{array}{r}28.454 \\
2.495\end{array}$ & $\begin{array}{l}11 \\
48\end{array}$ & $\begin{array}{l}2.587 \\
0.052\end{array}$ & 49.762 & 0.0001 \\
\hline
\end{tabular}


TABLE L.7. Mean Concentrations and Statistical Grouping for Anthracene in $M$. nasuta Tissues, Richmond Harbor Program

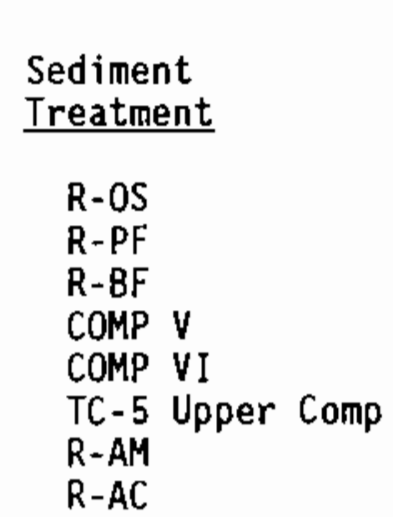

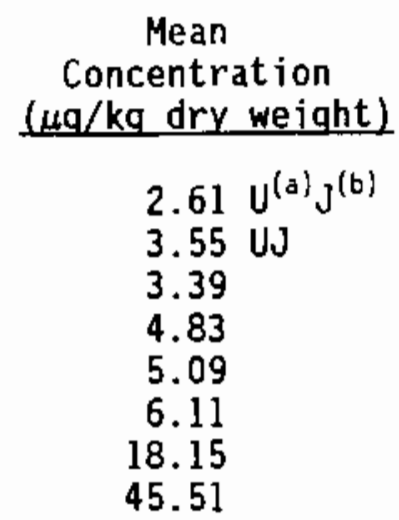

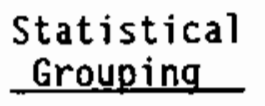

A

$A B$

$A B$

$A B$

$A B$

$B$

c

(a) U The analyte was not present above the level of the associated value.

(b) J Analyte detected below method detection limit (MDL), but above instrument detection level (IDL).

TABLE L.8. ANOVA Results for Anthracene in M. nasuta Tissues, Richmond Harbor Program

\begin{tabular}{|c|c|c|c|c|c|}
\hline $\begin{array}{l}\text { Source of } \\
\text { Variation }\end{array}$ & $\begin{array}{r}\text { Sum of } \\
\text { Squares }\end{array}$ & d.f. & $\begin{array}{c}\text { Mean } \\
\text { Square }\end{array}$ & F-Ratio & $\begin{array}{c}\begin{array}{c}\text { Significance } \\
\text { Leve] }\end{array} \\
\end{array}$ \\
\hline $\begin{array}{l}\text { Treatment } \\
\text { Residual }\end{array}$ & $\begin{array}{r}36.500 \\
8.070\end{array}$ & $\begin{array}{r}7 \\
32\end{array}$ & $\begin{array}{l}5.214 \\
0.252\end{array}$ & 20.677 & 0.0001 \\
\hline
\end{tabular}


TABLE L.9. Mean Concentrations and Statistical Grouping for Fluoranthene in $M$. nasuta Tissues, Richmond Harbor Program

\section{Sediment \\ Treatment}

COMP IV
R-PF
COMP III
R-OS
COMP II
COMP VI
COMP I
COMP V
R-BF
TC-5 Upper Comp
R-AM
R-AC

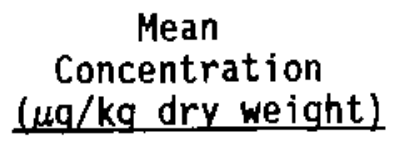

8.00

9.81

11.38

12.31

25.42

34.97

36.02

41.63

45.69

154.17

287.09

1124.66
Statistical

Grouping

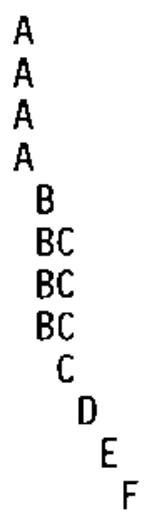

TABLE L.10. ANOVA Results for Fluoranthene in M. nasuta Tissues, Richmond Harbor Program

\begin{tabular}{|c|c|c|c|c|c|}
\hline $\begin{array}{l}\text { Source of } \\
\text { Variation }\end{array}$ & $\begin{array}{r}\text { Sum of } \\
\text { Squares }\end{array}$ & d.f. & $\begin{array}{l}\text { Mean } \\
\text { Square }\end{array}$ & F-Ratio & $\begin{array}{c}\begin{array}{c}\text { Significance } \\
\text { Level }\end{array} \\
\end{array}$ \\
\hline $\begin{array}{l}\text { Treatment } \\
\text { Residual }\end{array}$ & $\begin{array}{r}122.479 \\
3.467\end{array}$ & $\begin{array}{l}11 \\
48\end{array}$ & $\begin{array}{r}11.134 \\
0.072\end{array}$ & .140 & 1 \\
\hline
\end{tabular}


TABLE L.11. Mean Concentrations and Statistical Grouping for Pyrene in $M$. nasuta Tissues, Richmond Harbor Program

Sediment
Treatment

COMP IV
R-PF
R-OS
COMP III
R-BF
COMP II
COMP I
COMP V
COMP VI
TC-5 Upper Comp
R-AM
R-AC

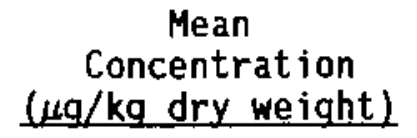

5.55

7.62

8.67

10.51

48.62

48.89

61.42

146.49

149.63

267.23

316.09

2614.47
Statistical

Grouping

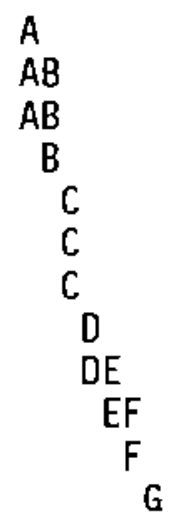

IABLE L.12. ANOVA Results for Pyrene in M. nasuta Tissues, Richmond Harbor Program

\begin{tabular}{|c|c|c|c|c|c|}
\hline $\begin{array}{l}\text { Source of } \\
\text { Variation }\end{array}$ & $\begin{array}{r}\text { Sum of } \\
\text { Squares }\end{array}$ & $\underline{d . f}$. & $\begin{array}{c}\text { Mean } \\
\text { Square }\end{array}$ & $\underline{\text { F-Ratio }}$ & $\begin{array}{c}\begin{array}{c}\text { Significance } \\
\text { Level }\end{array} \\
\end{array}$ \\
\hline $\begin{array}{l}\text { Treatment } \\
\text { Residual }\end{array}$ & $\begin{array}{r}187.444 \\
3.549\end{array}$ & $\begin{array}{l}11 \\
48\end{array}$ & $\begin{array}{r}17.040 \\
0.074\end{array}$ & 230.457 & 0.0001 \\
\hline
\end{tabular}


TABLE L.13. Mean Concentrations and Statistical Grouping for Benzo(a) anthracene in $M$. nasuta Tissues, Richmond Harbor Program

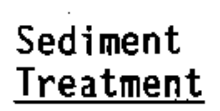

R-OS

$\mathrm{R}-\mathrm{PF}$

COMP II

COMP I

$\mathrm{R}-\mathrm{BF}$

COHP VI

COMP $V$

TC-5 Upper Comp

R-AM

$\mathrm{R}-\mathrm{AC}$

$\begin{gathered}\text { Mean } \\ \text { Concentration } \\ (\mu \mathrm{g} / \mathrm{kg} \text { dry weight })\end{gathered}$
$3.86 \mathrm{u}^{(\mathrm{a})} \mathrm{J}^{(\mathrm{b})}$
$6.95 \mathrm{UJ}$
6.99
10.84
12.73
17.54
18.76
44.94
115.81
242.06

Srouping

$A$

$A B$

$A B C$

$B C$

$B C$

$\mathrm{CD}$

$\mathrm{CD}$

$\mathrm{DE}$

(a) $U$ The analyte was not present above the level of the associated value.

(b) J Analyte detected below method detection limit (MDL), but above instrument detection level (IDL).

TABLE L.14. ANOVA Results for Benzo(a) anthracene in M. nasuta Tissues, Richmond Harbor Program

\begin{tabular}{|c|c|c|c|c|c|}
\hline $\begin{array}{l}\text { Source of } \\
\text { Variation }\end{array}$ & $\begin{array}{r}\text { Sum of } \\
\text { Squares }\end{array}$ & d.f. & $\begin{array}{c}\text { Hean } \\
\text { Square }\end{array}$ & F-Ratio & $\begin{array}{c}\text { Significance } \\
\text { Level }\end{array}$ \\
\hline $\begin{array}{l}\text { Treatment } \\
\text { Residual }\end{array}$ & $\begin{array}{l}80.983 \\
11.813\end{array}$ & $\begin{array}{r}9 \\
40\end{array}$ & $\begin{array}{l}8.998 \\
0.295\end{array}$ & 30.467 & 0.0001 \\
\hline
\end{tabular}


IABLE L.15. Mean Concentrations and Statistical Grouping for Chrysene in M. nasuta Tissues, Richmond Harbor Program

\begin{tabular}{l} 
Sediment \\
Treatment \\
\hline R-PF \\
COMP IV \\
COMP II I \\
R-OS \\
COMP II \\
COMP I \\
R-BF \\
COMP VI \\
COMP V \\
TC-5 Upper Comp \\
R-AM \\
R-AC
\end{tabular}

$\begin{array}{cc}\begin{array}{c}\text { Mean } \\ \begin{array}{c}\text { Concentration } \\ (\mu \mathrm{g} / \mathrm{kg} \text { dry weight })\end{array}\end{array} & \begin{array}{c}\text { Statist } \\ \text { Groupi }\end{array} \\ 3.83 & \mathrm{~A} \\ 4.36 & \mathrm{~A} \\ 4.47 & \mathrm{~A} \\ 5.19 & \mathrm{~A} \\ 11.70 & \mathrm{~B} \\ 15.97 & \mathrm{~B} \\ 22.25 & \mathrm{~B} \\ 24.73 & \mathrm{~B} \\ 26.50 & \mathrm{~B} \\ 69.35 & \mathrm{C} \\ 182.84 & \mathrm{D} \\ 299.76 & \mathrm{D}\end{array}$

TABLE L.16. ANOVA Results for Chrysene in M. nasuta Tissues, Richmond Harbor Program

\begin{tabular}{|c|c|c|c|c|c|}
\hline $\begin{array}{l}\text { Source of } \\
\text { Variation }\end{array}$ & $\begin{array}{r}\text { Sum of } \\
\text { Squares }\end{array}$ & d.f. & $\begin{array}{l}\text { Mean } \\
\text { Square }\end{array}$ & F-Ratio & $\begin{array}{c}\text { Significance } \\
\text { Level }\end{array}$ \\
\hline $\begin{array}{l}\text { Treatment } \\
\text { Residual }\end{array}$ & $\begin{array}{r}118.034 \\
7.150\end{array}$ & $\begin{array}{l}11 \\
48\end{array}$ & $\begin{array}{r}10.730 \\
0.149\end{array}$ & 72.031 & 0.0001 \\
\hline
\end{tabular}


TABLE L.17. Mean Concentrations and Statistical Grouping for Benzo(b)fluoranthene in M. nasuta Tissues, Richmond Harbor Program

Sediment
Ireatment

R-OS
R-PF
COMP II
COMP I
R-BF
COMP VI
COMP V
R-AM
TC-5 Upper Comp
R-AC

Mean Concentration $(\mu \mathrm{g} / \mathrm{kg} \mathrm{dry}$ weight $)$

$$
4.41 \mathrm{U}^{(\mathrm{a})} \mathrm{J}^{(\mathrm{b})}
$$$$
6.97 \mathrm{UJ}
$$

21.01

24.51

32.63

55.03

57.06

75.95

80.93

327.48
Statistical

Grouping

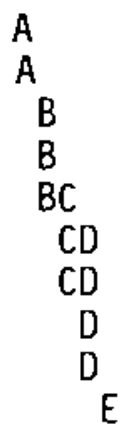

(a) U The analyte was not present above the level of the associated value.
(b) J Analyte detected below method detection limit (MDL), but above
instrument detection level (IDL).

TABLE L.18. ANOVA Resuits for Benzo(b)fluoranthene in M. nasuta Tissues, Richmond Harbor Program

$\begin{array}{lrrrrrr}\begin{array}{c}\text { Source of } \\ \text { Variation }\end{array} & \begin{array}{r}\text { Sum of } \\ \text { Squares }\end{array} & \text { d.f. } & \begin{array}{c}\text { Mean } \\ \text { Square }\end{array} & \text { F-Ratio } & \frac{\begin{array}{c}\text { Significance } \\ \text { Level }\end{array}}{} \\ \text { Treatment } & 72.054 & 9 & & 8.006 & 71.793 & 0.0001 \\ \text { Residual } & 4.461 & 40 & 0.112 & & \end{array}$


TABLE L.19. Mean Concentrations and Statistical Grouping for Benzo(k)fluoranthene in M. nasuta Tissues, Richmond Harbor Program

Sediment

Ireatment

R-OS
R-PF
COMP II
COMP I
R-BF
COMP V
COMP VI
TC-5 Upper Comp
R-AM
R-AC

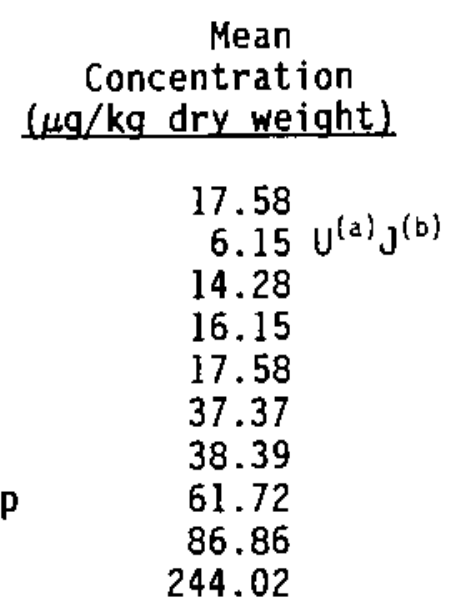

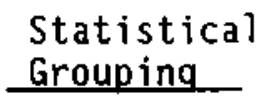

A

A

$B$

$8 C$

$\mathrm{BC}$

$\mathrm{CO}$

$\mathrm{CO}$

0

E

(a) U The analyte was not present above the level of the associated value.

(b) J Analyte detected below method detection limit (MDL), but above instrument detection level (IDL).

IABLE L.20. ANOVA Results for Benzo(k)fluoranthene in M. nasuta Tissues, Richmond Harbor Program

\begin{tabular}{|c|c|c|c|c|c|}
\hline $\begin{array}{l}\text { Source of } \\
\text { Variation }\end{array}$ & $\begin{array}{r}\text { Sum of } \\
\text { Squares }\end{array}$ & d.f. & $\begin{array}{c}\text { Mean } \\
\text { Souare }\end{array}$ & F-Ratio & $\begin{array}{c}\begin{array}{c}\text { Significance } \\
\text { Level }\end{array} \\
\end{array}$ \\
\hline $\begin{array}{l}\text { Treatment } \\
\text { Residual }\end{array}$ & $\begin{array}{r}76.695 \\
7.016\end{array}$ & $\begin{array}{r}9 \\
40\end{array}$ & $\begin{array}{l}8.522 \\
0.175\end{array}$ & 48.585 & 0.0001 \\
\hline
\end{tabular}




\section{TABLE L.21. Mean Concentrations and Statistical Grouping for Benzo(a)pyrene in M. nasuta Tissues, Richmond Harbor Program}

\section{Sediment \\ Treatment}

R-OS
R-PF
COMP II
COMP I
R-BF
COMP VI
COMP V
TC-5 Upper Comp
R-AM
R-AC

Mean Concentration ( $\mu \mathrm{g} / \mathrm{kg}$ dry weight)

$3.72 \mathrm{v}^{(\mathrm{a})} \mathrm{J}^{(\mathrm{b})}$ $5.91 \mathrm{UJ}$

14.57

15.68

21.31

34.79

35.83

62.08

105.19

358.85
Statistical Grouping
A
B
A
B
B
$B C$
$B C D$
$C D$
E

(a) $U$ The analyte was not present above the level of the associated value.

(b) $J$ Analyte detected below method detection limit (MDL), but above instrument detection level (IDL).

TABLE L.22. ANOVA Results for Benzo(a)pyrene $M$ nasuta in Tissues, Richmond Harbor Program

\begin{tabular}{|c|c|c|c|c|c|}
\hline $\begin{array}{l}\text { Source of } \\
\text { Variation }\end{array}$ & $\begin{array}{l}\text { Sum of } \\
\text { Squares }\end{array}$ & d.f. & $\begin{array}{c}\text { Mean } \\
\text { Square }\end{array}$ & F-Ratio & $\begin{array}{l}\text { Significance } \\
\text { Level }\end{array}$ \\
\hline $\begin{array}{l}\text { Treatment } \\
\text { Residua } 1\end{array}$ & $\begin{array}{r}89.609 \\
9.081\end{array}$ & $\begin{array}{r}9 \\
40\end{array}$ & $\begin{array}{l}9.957 \\
0.227\end{array}$ & 43.856 & 0.0001 \\
\hline
\end{tabular}


IABLE L.23. Mean Concentrations and Statistical Grouping for Indeno(1,2,3-cd)pyrene in $M$. nasuta Tissues, Richmond Harbor Program

Sediment
Treatment

R-OS

COMP II

COMP I

$\mathrm{R}-\mathrm{PF}$

$R-B F$

COMP VI

COMP $V$

TC-5 Upper Comp

$\mathrm{R}-\mathrm{AM}$

$R-A C$
Mean

Concentration

$(\mu \mathrm{g} / \mathrm{kg}$ dry weight)

$5.29 \mathrm{U}^{(\mathrm{a})} \mathrm{J}^{(\mathrm{b})}$

9.00

9.20

$10.01 \mathrm{U}$

10.74

13.35

14.35

22.49

29.82

102.38
Statistical

Grouping

A

$A B$

$A B$

$A B C$

$B C$

$B C$

$B C$

$\mathrm{BC}$

C

(a) $U$ The analyte was not present above the level of the associated value.

(b) J Analyte detected below method detection limit (MDL), but above instrument detection level (IDL).

TABLE L.24. ANOVA Results for Indeno(1,2,3-cd)pyrene in M. nasuta Tissues, Richmond Harbor Program

Source of Sum of

Variation Squares

Treatment

Residua 1
32.731

8.863
Mean

d.f.

9
Square

3.637

0.222
Significance

F-Ratio

Level

16.413

0.0001 
IABLE L.25. Mean Concentrations and Statistical Grouping for Benzo( $g, h, i)$ perylene in $M$. nasuta $T i$ ssues, Richmond Harbor Program

\begin{tabular}{l} 
Sediment \\
Treatment \\
\hline R-OS \\
COMP I \\
R-PF \\
COMP VI \\
R-BF \\
COMP V \\
TC-5 Upper Comp \\
R-AM \\
R-AC
\end{tabular}

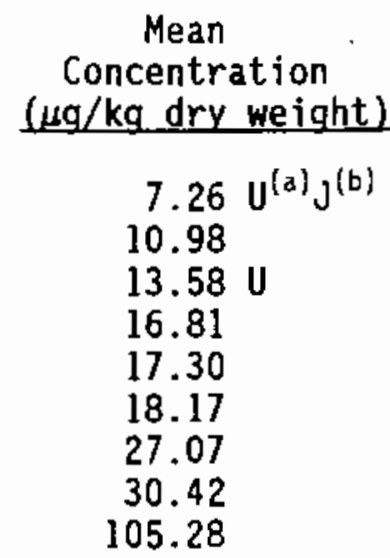

Statistical Grouping

$A$ $A B$ $B C$ $\mathrm{BC}$ $B C$ $B C$ $\mathrm{C}$ C

(a) U The analyte was not present above the level of the associated value.

(b) J Analyte detected below method detection limit (MDL), but above instrument detection level (IDL).

TABLE L.26. ANOVA Results for Benzo(g,h,i)perylene in $M$. nasuta Tissues, Richmond Harbor Program

\begin{tabular}{lrrrrr}
$\begin{array}{l}\text { Source of } \\
\text { Variation }\end{array}$ & $\begin{array}{r}\text { Sum of } \\
\text { Squares }\end{array}$ & $\underline{\text { d.f. }}$ & $\begin{array}{c}\text { Mean } \\
\text { Square }\end{array}$ & $\underline{\text { F-Ratio }}$ & $\begin{array}{c}\text { Significance } \\
\text { Level }\end{array}$ \\
\cline { 2 - 4 } & 25.375 & 8 & 3.172 & 16.821 & 0.0001 \\
Treatment & 6.789 & 36 & 0.189 & &
\end{tabular}


TABLE L.27. Mean Concentrations and Statistical Grouping for Aroclor 1254 in M. nasuta Tissues, Richmond Harbor Program

Sediment
Treatment
R-OS
R-PF
COMP IV
COMP III
COMP I
R-AM
COMP II
R-BF
R-AC
COMP V
TC-5 Upper Comp
COMP VI

$\begin{array}{cc}\begin{array}{c}\text { Mean } \\ \begin{array}{c}\text { Concentration } \\ (\mu \mathrm{g} / \mathrm{kg} \text { dry weight) }\end{array}\end{array} & \begin{array}{c}\text { Statistical } \\ \text { Grouping }\end{array} \\ 22.827 & \mathrm{~A} \\ 35.565 & \mathrm{AB} \\ 37.798 & \mathrm{C} \\ 58.732 & \mathrm{CD} \\ 78.013 & \mathrm{DE} \\ 88.554 & \mathrm{DEF} \\ 92.039 & \mathrm{DEF} \\ 99.709 & \mathrm{EF} \\ 129.624 & \mathrm{FG} \\ 158.738 & \mathrm{GH} \\ 173.525 & \mathrm{GH} \\ 202.853 & \mathrm{H}\end{array}$

TABLE L.28. ANOVA Results for Aroclor 1254 in M. nasuta Tissues, Richmond Harbor Program

\begin{tabular}{lrcccc}
$\begin{array}{l}\text { Source of } \\
\text { Variation }\end{array}$ & $\begin{array}{r}\text { Sum of } \\
\text { Squares }\end{array}$ & d.f. & Square & F-Ratio & $\begin{array}{c}\text { Significance } \\
\text { Level }\end{array}$ \\
\cline { 2 - 5 } & 25.813 & 11 & 2.347 & 49.852 & 0.0001 \\
Treatment & 2.259 & 48 & 0.042 & &
\end{tabular}


TABLE L.29. Mean Concentrations and Statistical Grouping for Alpha-BHC in M. nasuta Tissues, Richmond Harbor Program

\begin{tabular}{ccc}
$\begin{array}{c}\text { Sediment } \\
\text { Ireatment }\end{array}$ & $\begin{array}{c}\text { Mean } \\
\text { Concentration } \\
(\mu \mathrm{g} / \mathrm{kg} \text { dry weight })\end{array}$ & $\begin{array}{c}\text { Statistical } \\
\text { Grouping }\end{array}$ \\
\cline { 2 - 3 } COMP II & 0.564 & $\mathrm{~A}$ \\
COMP III & 0.545 & $\mathrm{AB}$ \\
R-PF & 0.753 & $\mathrm{AB}$ \\
TC-5 Upper Comp & 0.792 & $\mathrm{AB}$ \\
R-AC & 0.995 & $\mathrm{AB}$ \\
R-OS & 1.107 & $\mathrm{AB}$ \\
COMP IV & 0.943 & $\mathrm{AB}$ \\
COMP V & 1.447 & $\mathrm{AB}$ \\
COMP I & 1.116 & $\mathrm{AB}$ \\
R-BF & 1.339 & $\mathrm{AB}$ \\
COMP VI & 1.792 & $\mathrm{AB}$ \\
R-AM & 2.041 & $\mathrm{~B}$
\end{tabular}

TABLE L.30. ANOVA Results for Alpha-BHC in M. nasuta Tissues, Richmond Harbor Program

\begin{tabular}{|c|c|c|c|c|c|}
\hline $\begin{array}{l}\text { Source of } \\
\text { Variation }\end{array}$ & $\begin{array}{r}\text { Sum of } \\
\text { Squares }\end{array}$ & d.f. & $\begin{array}{c}\text { Mean } \\
\text { Square }\end{array}$ & F-Ratio & $\begin{array}{c}\begin{array}{c}\text { Significance } \\
\text { Level }\end{array} \\
\end{array}$ \\
\hline $\begin{array}{l}\text { Treatment } \\
\text { Residual }\end{array}$ & $\begin{array}{l}15.361 \\
30.046\end{array}$ & $\begin{array}{l}11 \\
48\end{array}$ & $\begin{array}{l}1.396 \\
0.626\end{array}$ & 2.231 & 0.0279 \\
\hline
\end{tabular}


TABLE L.31. Mean Concentrations and Statistical Grouping for Delta-BHC in $M$. nasuta Tissues, Richmond Harbor Program

\begin{tabular}{ccc}
$\begin{array}{c}\text { Sediment } \\
\text { Treatment }\end{array}$ & $\begin{array}{c}\text { Mean } \\
\text { Concentration } \\
(\mu \mathrm{g} / \mathrm{kg} \text { dry weight })\end{array}$ & $\begin{array}{c}\text { Statistical } \\
\text { Grouping }\end{array}$ \\
\hline R-AC & $0.532 \mathrm{U}^{(a)} \mathrm{J}^{(b)} \mathrm{E}^{(\mathrm{c})}$ & $\mathrm{A}$ \\
COMP & $0.655 \mathrm{UJE}$ & $\mathrm{A}$ \\
R-OS & $0.514 \mathrm{UJE}$ & $\mathrm{A}$ \\
R-PF & $0.667 \mathrm{UJE}$ & $\mathrm{A}$ \\
R-BF & $0.667 \mathrm{U}$ & $\mathrm{A}$ \\
COMP VI & $0.822 \mathrm{UJE}$ & $\mathrm{A}$ \\
COMP I & $0.704 \mathrm{UE}$ & $\mathrm{A}$ \\
R-AM & $0.939 \mathrm{U}$ & $\mathrm{A}$
\end{tabular}

(a) $U$ The analyte was not present above the level of the associated value.

(b) $J$ Analyte detected below method detection limit (MDL), but above instrument detection level (IDL).

(c) E Value an estimate, analyte not detected on confirmation column.

TABLE L.32. ANOVA Results for Delta-BHC in $M$. nasuta Tissues, Richmond Harbor Program

\begin{tabular}{lrrrrr}
$\begin{array}{l}\text { Source of } \\
\text { Variation }\end{array}$ & $\begin{array}{c}\text { Sum of } \\
\text { Squares }\end{array}$ & d.f. & $\begin{array}{c}\text { Mean } \\
\text { Square }\end{array}$ & $\underline{\text { F-Ratio }}$ & $\begin{array}{c}\text { Significance } \\
\text { Level }\end{array}$ \\
\cline { 2 - 5 } & 2.802 & 7 & 0.400 & 0.853 & 0.5531 \\
$\begin{array}{l}\text { Treatment } \\
\text { Residual }\end{array}$ & 15.99 & 32 & 0.469 & &
\end{tabular}


TABLE L.33. Mean Concentrations and Statistical Grouping for Gamma-BHC in M. nasuta Tissues, Richmond Harbor Program

\begin{tabular}{l} 
Sediment \\
Treatment \\
\hline COMP I I \\
COMP I I \\
TC-5 Upper Comp \\
COMP IV \\
R-PF \\
R-AC \\
R-BF \\
R-AM \\
R-OS \\
COMP V \\
COMP I \\
COMP VI
\end{tabular}

\begin{tabular}{|c|}
\hline $\begin{array}{c}\text { Mean } \\
\text { Concentration } \\
(\mu \mathrm{g} / \mathrm{kg} \text { dry weigh }\end{array}$ \\
\hline $\begin{array}{ll}2.863 & \mathrm{E}^{(a)} \\
2.904 & \mathrm{E} \\
3.002 & \mathrm{E} \\
3.221 & \mathrm{E} \\
3.286 & \mathrm{E} \\
3.594 & \mathrm{E} \\
3.629 & \mathrm{E} \\
3.565 \mathrm{~J}^{(b)} \\
4.094 & \\
4.108 & \mathrm{E} \\
4.179 & \mathrm{E} \\
4.561 & \mathrm{E}\end{array}$ \\
\hline
\end{tabular}

$\begin{array}{r}\text { Statistical } \\ \text { Grouping } \\ \hline\end{array}$

A

A

A

A

A

A

A

A

A

A

A

A

(a) E Value an estimate, analyte not detected on confirmation column.

(b) J Analyte detected below method detection limit (MDL), but above instrument detection level (IDL).

TABLE L.34. ANOVA Results for Gamma-BHC in M. nasuta Tissues, Richmond Harbor Program

\begin{tabular}{|c|c|c|c|c|c|}
\hline $\begin{array}{l}\text { Source of } \\
\text { Variation }\end{array}$ & $\begin{array}{r}\text { Sum of } \\
\text { Squares }\end{array}$ & d.f. & $\begin{array}{l}\text { Mean } \\
\text { Square }\end{array}$ & F-Ratio & $\begin{array}{c}\begin{array}{c}\text { Significance } \\
\text { Level }\end{array} \\
\end{array}$ \\
\hline $\begin{array}{l}\text { Treatment } \\
\text { Residual }\end{array}$ & $\begin{array}{l}1.555 \\
4.163\end{array}$ & $\begin{array}{l}11 \\
48\end{array}$ & $\begin{array}{l}0.141 \\
0.087\end{array}$ & 1.630 & 01205 \\
\hline
\end{tabular}


TABLE L.35. Mean Concentrations and Statistical Grouping for $4,4^{\prime}-\mathrm{DDD}$ in $M$. nasuta Tissues, Richmond Harbor Program

\begin{tabular}{l} 
Sediment \\
Ireatment \\
\hline R-AM \\
R-PF \\
R-OS \\
COMP II \\
R-BF \\
COMP I \\
R-AC \\
COMP II \\
TC-5 Upper Comp \\
COMP V \\
COMP VI
\end{tabular}

Mean

Concentration ( $\mu \mathrm{g} / \mathrm{kg}$ dry weight)

$0.532 \mathrm{u}^{(\mathrm{a})} \mathrm{J}^{(b)}$
0.529
0.505
2.285
2.542
4.104
4.688
8.423
11.178
66.266
79.833

Statistical

Grouping
A
A
A
B
B
$B C$
$B C$
$B C$
D

(a) $U$ The analyte was not present above the level of the associated value.

(b) J Analyte detected below method detection limit (MDL), but above instrument detection level (IDL).

TABLE L.36. ANOVA Results for $4,4^{\prime}-D D D$ in $M$. nasuta Tissues, Richmond Harbor Program

\begin{tabular}{lrcccc}
$\begin{array}{c}\text { Source of } \\
\text { Variation }\end{array}$ & $\begin{array}{r}\text { Sum of } \\
\text { Squares }\end{array}$ & d.f. & Square & F-Ratio & $\begin{array}{c}\text { Significance } \\
\text { Level }\end{array}$ \\
\hline Treatment & 168.211 & 10 & 16.821 & 42.868 & 0.0001 \\
Residual & 17.265 & 44 & 0.392 & & -
\end{tabular}


IABLE L.37. Mean Concentrations and Statistical Grouping for $4,4^{\prime}$-DDE in M. nasuta Tissues, Richmond Harbor Program

\begin{tabular}{l} 
Sediment \\
Treatment \\
\hline COMP II I \\
R-AM \\
R-BF \\
R-AC \\
R-OS \\
R-PF \\
COMP I \\
COMP II \\
TC-5 Upper Comp \\
COMP V \\
Comp VI
\end{tabular}

Mean
Concentration
$(\mathrm{ag} / \mathrm{kg}$ dry weight)
1.593
2.413
3.934
3.917
3.991
4.446
4.704
5.060
9.719
18.332
18.541

Statistical
Grouping

A

$A B$

$B C$

$B C$

$\mathrm{BC}$

$\mathrm{BC}$

$\mathrm{C}$

CD

$\mathrm{DE}$

E

TABLE L.38. ANOVA Results for 4,4'-DDE in $M$. nasuta Tissues, Richmond Harbor Program

\begin{tabular}{lrcccc}
$\begin{array}{l}\text { Source of } \\
\text { Variation }\end{array}$ & $\begin{array}{r}\text { Sum of } \\
\text { Squares }\end{array}$ & d.f. & Square & F-Ratio & $\begin{array}{c}\text { Significance } \\
\text { Level }\end{array}$ \\
\cline { 2 - 5 } & 30.189 & 10 & 3.019 & 33.515 & 0.0001 \\
$\begin{array}{l}\text { Treatment } \\
\text { Residual }\end{array}$ & 3.963 & 44 & 0.090 & &
\end{tabular}


IABLE L.39. Mean Concentrations and Statistical Grouping for $4,4^{\prime}$-DDT in $M$. nasuta Tissues, Richmond Harbor Program

\section{Sediment \\ $\underline{\text { Treatment }}$}

$$
\begin{aligned}
& \text { COMP V } \\
& R-O S \\
& R-B F \\
& R-A C \\
& R-A M \\
& R-P F
\end{aligned}
$$

$\begin{gathered}\text { Mean } \\ \text { Concentration } \\ (\mu \mathrm{g} / \mathrm{kg} d r y \text { weight })\end{gathered}$
$1.047 \mathrm{U}^{(\mathrm{a})} \mathrm{J}^{(\mathrm{b})} \mathrm{E}^{(\mathrm{c})}$
$1.330 \mathrm{U}$
$1.403 \mathrm{U}$
$1.400 \mathrm{U}$
1.612
1.651

Statistical Grouping
A
A
A
A
A
A

(a) $U$ The analyte was not present above the level of the associated value.

(b) J Analyte detected below method detection limit (MDL), but above instrument detection level (IDL).

(c) E Value an estimate, analyte not detected on confirmation column.

IABLE L.40. ANOVA Results for $4,4^{\prime}-$ DDT in $M$. nasuta Tissues, Richmond Harbor Program

$\begin{array}{lrrrrr}\begin{array}{l}\text { Source of } \\ \text { Variation }\end{array} & \begin{array}{r}\text { Sum of } \\ \text { Squares }\end{array} & \text { d.f. } & \begin{array}{c}\text { Mean } \\ \text { Square }\end{array} & \text { F-Ratio } & \frac{\begin{array}{c}\text { Significance } \\ \text { Level }\end{array}}{\text { Treatment }} \\ \begin{array}{l}\text { Treatidual } \\ \text { Resides }\end{array} & 11.189 & 24 & \begin{array}{l}0.698 \\ 0.466\end{array} & 1.497 & 0.2280\end{array}$


IABLE L.41. Mean Concentrations and Statistical Grouping for Dieldrin in $M$. nasuta Tissues, Richmond Harbor Program

\begin{tabular}{lcc}
$\begin{array}{c}\text { Sediment } \\
\text { Treatment }\end{array}$ & $\begin{array}{c}\text { Mean } \\
\text { Concentration } \\
(\mu \mathrm{g} / \mathrm{kg} \text { dry weight) }\end{array}$ & $\begin{array}{c}\text { Statistical } \\
\text { Grouping }\end{array}$ \\
\cline { 2 - 3 } & $0.764 \mathrm{~J}^{(\mathrm{a})}$ & $\mathrm{A}$ \\
R-BF & $2.931 \mathrm{U}^{(\mathrm{b})} \mathrm{J}$ & $\mathrm{AB}$ \\
R-AM & $1.209 \mathrm{JE}^{(\mathrm{c})}$ & $\mathrm{ABC}$ \\
COMP II & $2.081 \mathrm{JE}$ & $\mathrm{ABC}$ \\
TC-5 Upper Comp & $4.128 \mathrm{UJ}$ & $\mathrm{ABC}$ \\
R-OS & $4.489 \mathrm{UJ}$ & $\mathrm{ABC}$ \\
R-AC & 6.245 & $\mathrm{BC}$ \\
COMP V & 7.294 & $\mathrm{BC}$ \\
COMP VI & $8.186 \mathrm{U}$ & $\mathrm{C}$ \\
R-PF & &
\end{tabular}
(a) J Analyte detected below method detection limit (MDL), but above instrument detection level (IDL).
(b) $U$ The analyte was not present above the level of the associated value.
(c) E Value an estimate, analyte not detected on confirmation column.

IABLE L.42. ANOVA Results for Dieldrin in M. nasuta Tissues, Richmond Harbor
Program

\begin{tabular}{|c|c|c|c|c|c|}
\hline $\begin{array}{l}\text { Source of } \\
\text { Variation }\end{array}$ & $\begin{array}{r}\text { Sum of } \\
\text { Squares }\end{array}$ & d.f. & $\begin{array}{c}\text { Mean } \\
\text { Square }\end{array}$ & F-Ratio & $\begin{array}{c}\text { Significance } \\
\text { Level }\end{array}$ \\
\hline $\begin{array}{l}\text { Treatment } \\
\text { Residual }\end{array}$ & $\begin{array}{l}31.127 \\
24.778\end{array}$ & $\begin{array}{r}8 \\
36\end{array}$ & $\begin{array}{l}3.891 \\
0.688\end{array}$ & 5.653 & 0.0001 \\
\hline
\end{tabular}


TABLE L.43. Mean Concentrations and Statistical Grouping for Endosulfan II in M. nasuta Tissues, Richmond Harbor Program

$\begin{array}{lcc}\begin{array}{c}\text { Sediment } \\ \text { Ireatment }\end{array} & \begin{array}{c}\text { Mean } \\ \text { Concentration } \\ (\mu \mathrm{g} / \mathrm{kg} \text { dry weight })\end{array} & \begin{array}{c}\text { Statistical } \\ \text { Grouping }\end{array} \\ \text { R-AM } & 1.701 \mathrm{U}^{(a) \mathrm{J}^{(b)}} & \mathrm{A} \\ \text { COMP II } & 1.269 \mathrm{UJE}^{(\mathrm{c})} & \mathrm{A} \\ \text { R-OS } & 1.575 \mathrm{UJ} & \mathrm{A} \\ \text { COMP V } & 1.478 \mathrm{UJE} & \mathrm{A} \\ \text { R-BF } & 1.650 \mathrm{UJ} & \mathrm{A} \\ \text { COMP VI } & 1.750 \mathrm{UJE} & \mathrm{A} \\ \text { R-AC } & 2.059 \mathrm{U} & \mathrm{A} \\ \text { R-PF } & 2.429 \mathrm{U} & \mathrm{A}\end{array}$

\footnotetext{
(a) U The analyte was not present above the level of the associated value.

(b) J Analyte detected below method detection limit (MDL), but above instrument detection level (IDL).

(c) E Value an estimate, analyte not detected on confirmation column.
}

TABLE L.44. ANOVA Results for Endosulfan II in $M$. nasuta Tissues, Richmond Harbor Program

\begin{tabular}{|c|c|c|c|c|c|}
\hline $\begin{array}{l}\text { Source of } \\
\text { Variation }\end{array}$ & $\begin{array}{r}\text { Sum of } \\
\text { Squares }\end{array}$ & d.f. & $\begin{array}{c}\text { Mean } \\
\text { Square }\end{array}$ & F-Ratio & $\begin{array}{c}\begin{array}{c}\text { Significance } \\
\text { Leve? }\end{array} \\
\end{array}$ \\
\hline $\begin{array}{l}\text { Treatment } \\
\text { Residual }\end{array}$ & $\begin{array}{l}13.604 \\
57.851\end{array}$ & $\begin{array}{r}7 \\
32\end{array}$ & $\begin{array}{l}1.943 \\
1.808\end{array}$ & 1.075 & 0.4 \\
\hline
\end{tabular}


IABLE L.45. Mean Concentrations and Statistical Grouping for Silver in M. nasuta Tissues, Richmond Harbor Program

$\begin{array}{lcc}\begin{array}{c}\text { Sediment } \\ \text { Ireatment }\end{array} & \begin{array}{c}\text { Mean } \\ \text { Concentration } \\ \text { (mg/kg dry weight) }\end{array} & \begin{array}{c}\text { Statistical } \\ \text { Grouping }\end{array} \\ \text { R-BF } & 0.243 & \\ \text { TC-5 Upper Comp } & 0.234 & \mathrm{~A} \\ \text { COMP V } & 0.351 & \mathrm{~A} \\ \text { R-PF } & 0.363 & \mathrm{~A} \\ \text { R-AM } & 0.305 & \mathrm{~A} \\ \text { COMP II } & 0.476 & \mathrm{~A} \\ \text { R-OS } & 0.502 & \mathrm{~A} \\ \text { COMP I } & 0.457 & \mathrm{~A} \\ \text { R-AC } & 0.468 & \mathrm{~A} \\ \text { COMP IV } & 0.510 & \mathrm{~A} \\ \text { COMP III } & 0.535 & \mathrm{~A} \\ \text { COMP VI } & 0.622 & \mathrm{~A}\end{array}$

TABLE L.46. ANOVA Results for Silver in M. nasuta Tissues, Richmond Harbor Program

\begin{tabular}{|c|c|c|c|c|c|}
\hline $\begin{array}{l}\text { Source of } \\
\text { Variation }\end{array}$ & $\begin{array}{r}\text { Sum of } \\
\text { Squares }\end{array}$ & d.f. & $\begin{array}{c}\text { Mean } \\
\text { Square }\end{array}$ & F-Ratio & $\begin{array}{c}\begin{array}{c}\text { Significance } \\
\text { Level }\end{array} \\
\end{array}$ \\
\hline $\begin{array}{l}\text { Treatment } \\
\text { Residual }\end{array}$ & $\begin{array}{r}7.536 \\
22.582\end{array}$ & $\begin{array}{l}11 \\
48\end{array}$ & $\begin{array}{l}0.685 \\
0.470\end{array}$ & 1.456 & 0.1797 \\
\hline
\end{tabular}


TABLE L.47. Mean Concentrations and Statistical Grouping for Arsenic in M. nasuta Tissues, Richmond Harbor Program

Sediment
Ireatment
R-OS
R-AC
R-AM
R-BF
COMP IV
R-PF
COMP VI
COMP II
COMP V
COMP I
TC-5 Upper Comp
COMP III

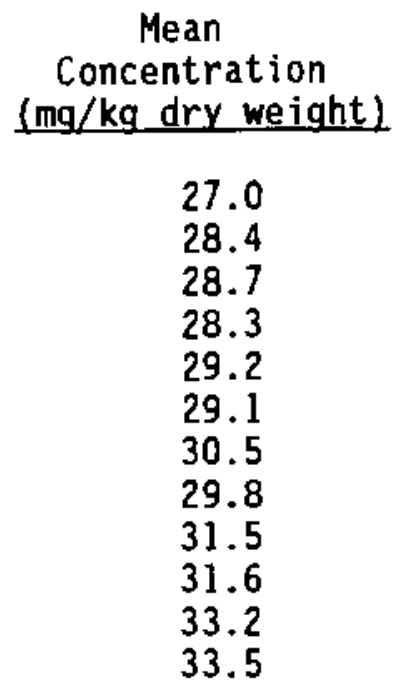

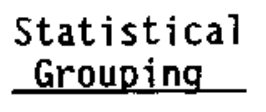

A

A

A

A

A

A

A

A

A

A

A

TABLE L.48. ANOVA Results for Arsenic in $M$. nasuta Tissues, Richmond Harbor Program

\begin{tabular}{|c|c|c|c|c|c|}
\hline $\begin{array}{l}\text { Source of } \\
\text { Variation }\end{array}$ & $\begin{array}{r}\text { Sum of } \\
\text { Squares }\end{array}$ & d.f. & $\begin{array}{c}\text { Mean } \\
\text { Square }\end{array}$ & F-Ratio & $\begin{array}{c}\begin{array}{c}\text { Significance } \\
\text { Level }\end{array} \\
\end{array}$ \\
\hline $\begin{array}{l}\text { Treatment } \\
\text { Residual }\end{array}$ & $\begin{array}{l}0.281 \\
1.268\end{array}$ & $\begin{array}{l}11 \\
48\end{array}$ & $\begin{array}{l}0.026 \\
0.026\end{array}$ & 0.968 & 0.4872 \\
\hline
\end{tabular}


IABLE L.49. Mean Concentrations and Statistical Grouping for Cadmium in M. nasuta Tissues, Richmond Harbor Program

Sediment
Treatment
COMP IV
COMP I
R-AC
COMP II
COMP VI
R-OS
COMP V
COMP II I
R-AM
R-BF
TC-5 Upper Comp
R-PF

$\begin{gathered}\text { Mean } \\ \text { Concentration } \\ \text { (mg/kg_dry weight) }\end{gathered}$
0.160
0.168
0.194
0.182
0.213
0.222
0.223
0.237
0.253
0.259
0.265
0.338

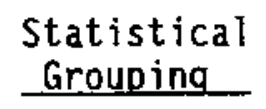

A

$A B$

$A B$

$A B$

$A B$

$A B$

$A B$

$A B$

$A B$

$A B$

$A B$

B

TABLE L.50. ANOVA Results for Cadmium in M. nasuta Tissues, Richmond Harbor Program

Source of Sum of

Variation Squares

Treatment

Residual
3.126

6.904
Mean

Square

0.284

0.144
Significance

F-Ratio

1.975

11

48 Leve1

0.0524 
TABLE L.51. Mean Concentrations and Statistical Grouping for Chromium in $M$. nasuta Tissues, Richmond Harbor Program

\begin{tabular}{l} 
Sediment \\
Ireatment \\
\hline \\
COMP II \\
R-BF \\
COMP VI \\
R-AM \\
COMP I \\
COMP V \\
R-AC \\
TC-5 Upper Comp \\
COMP III \\
COMP IV \\
R-OS \\
R-PF
\end{tabular}

$\begin{gathered}\text { Mean } \\ \text { Concentration } \\ \text { (mg/kg dry weight) }\end{gathered}$
1.89
1.95
2.14
2.26
2.44
2.24
2.38
2.51
2.59
2.62
2.71
2.96

Statistical
Grouping

A

A

A

A

A

A

A

A

A

A

A

A

TABLE L.52. ANOVA Results for Chromium in M. nasuta Tissues, Richmond Harbor Program

\begin{tabular}{|c|c|c|c|c|c|}
\hline $\begin{array}{l}\text { Source of } \\
\text { Variation }\end{array}$ & $\begin{array}{r}\text { Sum of } \\
\text { Squares }\end{array}$ & d.f. & $\begin{array}{c}\text { Mean } \\
\text { Square }\end{array}$ & F-Ratio & $\begin{array}{c}\text { Significance } \\
\text { Level }\end{array}$ \\
\hline $\begin{array}{l}\text { Treatment } \\
\text { Residual }\end{array}$ & $\begin{array}{l}1.173 \\
5.457\end{array}$ & $\begin{array}{l}11 \\
48\end{array}$ & $\begin{array}{l}0.107 \\
0.114\end{array}$ & 0.938 & 0.5133 \\
\hline
\end{tabular}


IABLE L.53. Mean Concentrations and Statistical Grouping for Copper in M. nasuta Tissues, Richmond Harbor Program

Sediment
Ireatment
R-OS
R-PF
R-AC
R-BF
TC-5 Upper Comp
R-AM
COMP IV
COMP I I
COMP V
COMP I I
COMP I
COMP VI

\begin{tabular}{c}
$\begin{array}{c}\text { Mean } \\
\text { Concentration } \\
\text { (mg/kg dry weight) }\end{array}$ \\
\hline 14.70 \\
16.45 \\
17.54 \\
17.54 \\
17.90 \\
17.66 \\
18.19 \\
18.79 \\
19.25 \\
19.62 \\
20.26 \\
21.72
\end{tabular}
Statistical
Grouping

A
A
$A$
$A$
$A$
$A$
$A$
$A$
$A$
$A$
$A$
$A$

IABLE L.54. ANOVA Results for Copper in M. nasuta Tissues, Richmond Harbor Program

\begin{tabular}{|c|c|c|c|c|c|}
\hline $\begin{array}{l}\text { Source of } \\
\text { Variation }\end{array}$ & $\begin{array}{r}\text { Sum of } \\
\text { Squares }\end{array}$ & d.f. & $\begin{array}{c}\text { Mean } \\
\text { Square }\end{array}$ & F-Ratio & $\begin{array}{c}\begin{array}{c}\text { Significance } \\
\text { [eve] }\end{array} \\
\end{array}$ \\
\hline $\begin{array}{l}\text { Treatment } \\
\text { Residual }\end{array}$ & $\begin{array}{l}0.559 \\
1.821\end{array}$ & $\begin{array}{l}11 \\
56\end{array}$ & $\begin{array}{l}0.051 \\
0.038\end{array}$ & 1.340 & 0.2327 \\
\hline
\end{tabular}


IABLE L.55. Mean Concentrations and Statistical Grouping for Mercury in M. nasuta Tissues, Richmond Harbor Program

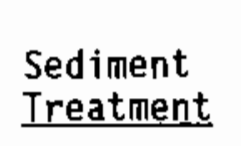

COMP IV
COMP III
R-AC
R-OS
COMP II
R-PF
COMP I
R-AM
COMP VI
TC-5 Upper Comp
R-BF
COMP V

$\begin{gathered}\text { Mean } \\ \text { Concentration } \\ \text { (mq/kg dry weight) }\end{gathered}$
0.054
0.065
0.065
0.066
0.071
0.076
0.086
0.084
0.094
0.102
0.101
0.105

Statistica]

Grouping
A
$A B$
$A B$
$A B$
$A B$
$A B$
$A B$
$A B$
$A B$
B
$\mathrm{B}$
B

IABLE L.56. ANOVA Results for Mercury in M. nasuta Tissues, Richmond Harbor Program

$\begin{array}{lrrrrr}\begin{array}{c}\text { Source of } \\ \text { Variation }\end{array} & \begin{array}{c}\text { Sum of } \\ \text { Squares }\end{array} & \text { d.f. } & \begin{array}{c}\text { Mean } \\ \text { Square }\end{array} & \text { F-Ratio } & \begin{array}{c}\text { Significance } \\ \text { Level }\end{array} \\ \begin{array}{l}\text { Treatment } \\ \text { Residual }\end{array} & 2.785 & 11 & 0.253 & 2.721 & 0.0082 \\ & 4.467 & 48 & 0.093 & & \end{array}$


TABLE L.57. Mean Concentrations and Statistical Grouping for Nickel in $M$. nasuta Tissues, Richmond Harbor Program

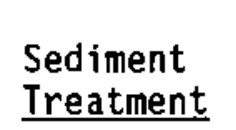

COMP I
COMP II
R-AM
R-PF
R-AC
COMP IV
R-BF
COMP V
TC-5 Upper Comp
COMP III
COMP VI
R-OS

\author{
Mean \\ Concentration \\ $(\mathrm{mg} / \mathrm{kg}$ dry weight)
}

4.17

4.56

4.54

4.83

5.13

5.26

5.17

5.57

5.41

5.45

5.60

5.62
Statistical

Grouping

TABLE L.58. ANOVA Results for Nickel in $H$. nasuta Tissues, Richmond Harbor Program

\begin{tabular}{lrrrrr}
$\begin{array}{l}\text { Source of } \\
\text { Variation }\end{array}$ & $\begin{array}{r}\text { Sum of } \\
\text { Squares }\end{array}$ & d.f. & $\begin{array}{c}\text { Mean } \\
\text { Square }\end{array}$ & $\underline{\text { F-Ratio }}$ & $\begin{array}{c}\text { Significance } \\
\text { Level }\end{array}$ \\
\hline $\begin{array}{l}\text { Treatment } \\
\text { Residual }\end{array}$ & 0.539 & 11 & 0.049 & 0.781 & 0.6569 \\
S.010 & 48 & 0.063 & &
\end{tabular}


TABLE L.59. Mean Concentrations and Statistical Grouping for Lead in M. nasuta Tissues, Richmond Harbor Program

\begin{tabular}{l} 
Sediment \\
Ireatment \\
\hline R-PF \\
R-OS \\
COMP IV \\
COMP II \\
R-AM \\
COMP I \\
COMP II \\
R-AC \\
R-BF \\
COMP V \\
TC-5 Upper Comp \\
COMP VI
\end{tabular}

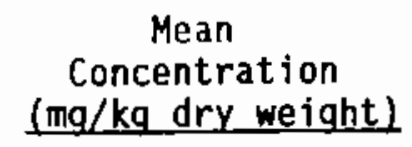

1.20

1.22

1.42

1.55

1.62

1.67

1.81

1.84

2.03

2.14

2.13

2.32
Statistical

Grouping

A

A

AB

$A B C$

$A B C$

$A B C$

$A B C$

$A B C$

$B C$

$B C$

$B C$

TABLE L.60. ANOVA Results for Lead in M. nasuta Tissues, Richmond Harbor Program

\begin{tabular}{|c|c|c|c|c|c|}
\hline $\begin{array}{l}\text { Source of } \\
\text { Variation }\end{array}$ & $\begin{array}{r}\text { Sum of } \\
\text { Squares }\end{array}$ & d.f. & $\begin{array}{c}\text { Mean } \\
\text { Square }\end{array}$ & F-Ratio & $\begin{array}{c}\begin{array}{c}\text { Significance } \\
\text { Level }\end{array} \\
\end{array}$ \\
\hline $\begin{array}{l}\text { Treatment } \\
\text { Residual }\end{array}$ & $\begin{array}{l}2.519 \\
2.047\end{array}$ & $\begin{array}{l}11 \\
48\end{array}$ & $\begin{array}{l}0.229 \\
0.043\end{array}$ & 5.369 & 0.0001 \\
\hline
\end{tabular}


TABLE L.61. Mean Concentrations and Statistical Grouping for Selenium in M. nasuta Tissues, Richmond Harbor Program

\begin{tabular}{ccc}
$\begin{array}{c}\text { Sediment } \\
\text { Ireatment }\end{array}$ & $\begin{array}{c}\text { Mean } \\
\text { Concentration } \\
\text { (mg/kg dry weight) }\end{array}$ & $\begin{array}{c}\text { Statistical } \\
\text { Grouping_ }\end{array}$ \\
\cline { 2 - 3 } COMP IV & 1.26 & $\mathrm{~A}$ \\
COMP II & 1.44 & $\mathrm{~A}$ \\
R-PF & 1.43 & $\mathrm{~A}$ \\
COMP III & 1.50 & $\mathrm{~A}$ \\
TC-5 Upper Comp & 1.53 & $\mathrm{~A}$ \\
COMP VI & 1.57 & $\mathrm{~A}$ \\
R-BF & 1.60 & $\mathrm{~A}$ \\
R-OS & 1.65 & $\mathrm{~A}$ \\
R-AM & 1.67 & $\mathrm{~A}$ \\
COMP V & 1.75 & $\mathrm{~A}$ \\
COMP I & 1.75 & $\mathrm{~A}$ \\
R-AC & 1.76 &
\end{tabular}

TABLE L.62. ANOVA Results for Selenium in M. nasuta Tissues, Richmond Harbor Program

\begin{tabular}{|c|c|c|c|c|c|}
\hline $\begin{array}{l}\text { Source of } \\
\text { Variation }\end{array}$ & $\begin{array}{r}\text { Sum of } \\
\text { Squares }\end{array}$ & d.f. & $\begin{array}{c}\text { Mean } \\
\text { Square }\end{array}$ & F-Ratio & $\begin{array}{c}\begin{array}{c}\text { Significance } \\
\text { Level }\end{array} \\
\end{array}$ \\
\hline $\begin{array}{l}\text { Treatment } \\
\text { Residual }\end{array}$ & $\begin{array}{r}.579 \\
1.943\end{array}$ & $\begin{array}{l}11 \\
48\end{array}$ & $\begin{array}{l}0.053 \\
0.040\end{array}$ & 1.300 & 0.2536 \\
\hline
\end{tabular}


TABLE L.63. Mean Concentrations and Statistical Grouping for Zinc in M. nasuta Tissues, Richmond Harbor Program

$\begin{array}{lcc}\begin{array}{c}\text { Sediment } \\ \text { Treatment }\end{array} & \begin{array}{c}\text { Mean } \\ \text { Concentration } \\ \text { (mg/kg dry weight) }\end{array} & \begin{array}{c}\text { Statistical } \\ \text { Grouping }\end{array} \\ \text { R-OS } & 96.9 & \mathrm{~A} \\ \text { COMP I } & 99.8 & \mathrm{~A} \\ \text { COMP IV } & 104.7 & \mathrm{~A} \\ \text { COMP II } & 107.2 & \mathrm{~A} \\ \text { R-AC } & 115.9 & \mathrm{~A} \\ \text { R-PF } & 122.0 & \mathrm{~A} \\ \text { COMP VI } & 122.1 & \mathrm{~A} \\ \text { COMP III } & 123.1 & \mathrm{~A} \\ \text { R-BF } & 126.4 & \mathrm{~A} \\ \text { TC-5 Upper Comp } & 127.4 & \mathrm{~A} \\ \text { R-AM } & 133.0 & \mathrm{~A} \\ \text { COMP V } & 135.1 & \mathrm{~A}\end{array}$

TABLE L.64. ANOVA Results for Zinc in M. nasuta Tissues, Richmond Harbor Program

\begin{tabular}{lrcccc}
$\begin{array}{l}\text { Source of } \\
\text { Variation }\end{array}$ & $\begin{array}{c}\text { Sum of } \\
\text { Squares }\end{array}$ & $\underline{\text { d.f. }}$ & $\begin{array}{c}\text { Mean } \\
\text { Square }\end{array}$ & $\underline{\text { F-Ratio }}$ & $\begin{array}{c}\text { Significance } \\
\text { Level }\end{array}$ \\
\cline { 2 - 3 } & 0.714 & 11 & 0.065 & 2.082 & 0.0403 \\
Treaidual & 1.496 & 48 & 0.031 & &
\end{tabular}


TABLE L.65. Mean Concentrations and Statistical Grouping for Tributyltin in M. nasuta Tissues, Richmond Harbor Program

\begin{tabular}{l} 
Sediment \\
Treatment \\
\hline \\
COMP I \\
R-PF \\
COMP VI \\
R-OS \\
TC-5 Upper Comp \\
COMP III \\
COMP IV \\
COMP V \\
COMP II \\
R-BF \\
R-AM \\
R-AC
\end{tabular}

\begin{tabular}{cc}
$\begin{array}{c}\text { Mean } \\
\begin{array}{c}\text { Concentration } \\
(\mu \mathrm{g} / \mathrm{kg} \text { dry weight })\end{array}\end{array}$ & $\begin{array}{r}\text { Statist } \\
\text { Group }\end{array}$ \\
\cline { 3 - 3 } 38.6 & $\mathrm{~A}$ \\
45.1 & $\mathrm{AB}$ \\
45.9 & $\mathrm{ABC}$ \\
48.2 & $\mathrm{ABC}$ \\
53.5 & $\mathrm{ABC}$ \\
53.8 & $\mathrm{ABC}$ \\
56.9 & $\mathrm{ABC}$ \\
55.4 & $\mathrm{ABC}$ \\
58.8 & $\mathrm{ABC}$ \\
67.4 & $\mathrm{ABC}$ \\
73.7 & $\mathrm{BC}$ \\
77.5 & $\mathrm{C}$
\end{tabular}

IABLE L.66. ANOVA Results for Tributyltin in M. nasuta Tissues, Richmond Harbor Program

\begin{tabular}{lrrrrr}
$\begin{array}{l}\text { Source of } \\
\text { Variation }\end{array}$ & $\begin{array}{r}\text { Sum of } \\
\text { Squares }\end{array}$ & d.f. & Square & F-Ratio & $\begin{array}{c}\text { Significance } \\
\text { Level }\end{array}$ \\
\cline { 2 - 5 } & 2.358 & 11 & 0.214 & 3.252 & 0.0022 \\
$\begin{array}{l}\text { Treatment } \\
\text { Residual }\end{array}$ & 3.164 & 48 & 0.066 & &
\end{tabular}


IABLE L.67. Mean Concentrations and Statistical Grouping for Dibutyltin in M. nasuta Tissues, Richmond Harbor Program

Sediment
Ireatment
R-PF
COMP VI
COMP II
R-BF
COMP V
COMP II
R-OS
COMP IV
TC-5 Upper Comp
R-AM
R-AC

$\begin{gathered}\text { Mean } \\ \text { Concentration } \\ (\mu \mathrm{g} / \mathrm{kg} \text { dry weight })\end{gathered}$
$2.7 \mathrm{U}^{(\mathrm{a})}$
4.8
4.8
7.0
6.4
6.8
9.4
9.6
10.1
10.1
11.9

Statistical

Grouping

A

A

A

A

A

A

A

A

A

A

A

(a) $U$ The analyte was not present above the level of the associated value.

IABLE L.68. ANOVA Results for Dibutyltin in M. nasuta Tissues, Richmond Harbor Program

\begin{tabular}{lrrrrr}
$\begin{array}{l}\text { Source of } \\
\text { Variation }\end{array}$ & $\begin{array}{r}\text { Sum of } \\
\text { Squares }\end{array}$ & $\underline{\text { d.f. }}$ & $\underline{\text { Square }}$ & $\underline{\text { F-Ratio }}$ & $\begin{array}{c}\text { Significance } \\
\text { Level }\end{array}$ \\
\hline $\begin{array}{l}\text { Treatment } \\
\text { Residual }\end{array}$ & 9.521 & 10 & 0.952 & 1.683 & 0.1154
\end{tabular}


APPENDIX $M$

MEAN CONCENTRATIONS AND STATISTICAL GROUPING

FOR $N$. caecoides 
IABLE M.1. Mean Concentrations and Statistical Grouping for Naphthalene in $N$. caecoides Tissues, Richmond Harbor Program

\begin{tabular}{|c|c|c|}
\hline $\begin{array}{l}\text { Sediment } \\
\text { Ireatment }\end{array}$ & $\begin{array}{c}\text { Mean } \\
\text { Concentration } \\
(\mu \mathrm{g} / \mathrm{kg} \text { dry weight })\end{array}$ & $\begin{array}{l}\text { Statistical } \\
\text { Grouping } \\
\end{array}$ \\
\hline $\begin{array}{l}\text { R-PF } \\
\text { COMP V } \\
\text { COMP II } \\
\text { R-OS } \\
\text { R-AC } \\
\text { R-BF } \\
\text { R-AM } \\
\text { COMP I }\end{array}$ & $\begin{array}{l}19.86 \\
16.93 \\
19.58 \\
23.43 \\
29.86 \\
31.55 \\
48.08 \\
48.87\end{array}$ & $\begin{array}{l}A \\
A \\
A \\
A \\
A \\
A \\
A \\
A\end{array}$ \\
\hline
\end{tabular}

TABLE M.2. ANOVA Results for Naphthalene in N. caecoides Tissues, Richmond Harbor Program

\begin{tabular}{|c|c|c|c|c|c|}
\hline $\begin{array}{l}\text { Source of } \\
\text { Variation }\end{array}$ & $\begin{array}{l}\text { Sum of } \\
\text { Squares }\end{array}$ & d.f. & $\begin{array}{c}\text { Mean } \\
\text { Square }\end{array}$ & F-Ratio & $\begin{array}{c}\text { Significance } \\
\text { Level }\end{array}$ \\
\hline $\begin{array}{l}\text { Treatment } \\
\text { Residua] }\end{array}$ & $\begin{array}{r}3.279 \\
15.597\end{array}$ & $\begin{array}{r}7 \\
32\end{array}$ & $\begin{array}{l}0.468 \\
0.487\end{array}$ & 0.961 & 0.4754 \\
\hline
\end{tabular}

M. 1 


\section{TABLE M.3. Mean Concentrations and Statistical Grouping for Phenanthrene in $N$. caecoides Tissues, Richmond Harbor Program}

Sediment
Ireatment
COMP III
R-OS
COMP II
COMP IV
COMP V
COMP VI
R-PF
COMP I
R-BF
TC-5 Upper Comp
R-AM
R-AC

\begin{tabular}{|c|}
\hline $\begin{array}{c}\text { Mean } \\
\text { Concentration } \\
(\mu \mathrm{g} / \mathrm{kg} \text { dry weight })\end{array}$ \\
\hline $\begin{array}{r}15.41 \\
15.84 \\
19.18 \\
20.38 \\
20.04 \\
20.85 \\
23.07 \\
22.32 \\
25.06 \\
56.60 \\
58.10 \\
319.66\end{array}$ \\
\hline
\end{tabular}

\begin{tabular}{c} 
Statistical \\
Grouping \\
\hline$A$ \\
$A$ \\
$A B$ \\
$A B$ \\
$A B$ \\
$A B$ \\
$A B$ \\
$A B$ \\
$B$ \\
$C$ \\
$C$ \\
$D$
\end{tabular}

TABLE M.5. ANOVA Results for Phenanthrene in N. caecoides Tissues, Richmond Harbor Program

\begin{tabular}{|c|c|c|c|c|c|}
\hline $\begin{array}{l}\text { Source of } \\
\text { Variation }\end{array}$ & $\begin{array}{r}\text { Sum of } \\
\text { Squares }\end{array}$ & d.f. & $\begin{array}{c}\text { Mean } \\
\text { SQuare }\end{array}$ & F-Ratio & $\begin{array}{c}\begin{array}{c}\text { Significance } \\
\text { Level }\end{array} \\
\end{array}$ \\
\hline $\begin{array}{l}\text { Treatment } \\
\text { Residual }\end{array}$ & $\begin{array}{r}40.557 \\
3.073\end{array}$ & $\begin{array}{l}11 \\
48\end{array}$ & $\begin{array}{l}3.687 \\
0.064\end{array}$ & 57.598 & 00 \\
\hline
\end{tabular}


TABLE M.6. Mean Concentrations and Statistical Grouping for Fluoranthene in $N$. caecoides Tissues, Richmond Harbor Program

Sediment
Ireatment
R-OS
R-PF
COMP I
COMP II
COMP VI
R-BF
COMP V
R-AM U U T Comp
TC-5 Upper Co
R-AC

Mean $(\mu \mathrm{g} / \mathrm{kg}$ dry weight $)$ Concentration

Statistica] Grouping

$11.15 \mathrm{~J}^{(\mathrm{a})}$

18.54

21.21

21.37

28.51

29.11

28.44

125.61

210.17

1948.85

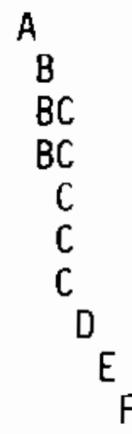

(a) J Analyte detected below method detection 7 imit (MDL) but above instrument detection 1 imit (1DL).

TABLE M.7. ANOVA Results for Fluoranthene in N. caecoides Tissues, Richmond Harbor Program

Source of Sum of

Variation Squares

Treatment $\quad 109.526$

Residual

2.550

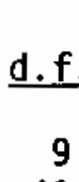

40
Mean

Square

12.170

0.064
Significance

F-Ratio Leve]

190.872

0.0001 
TABLE M.8. Mean Concentrations and Statistical Grouping for Pyrene in N. caecoides Tissues, Richmond Harbor Program

Sediment
Treatment
R-OS
R-PF
COMP III
R-BF
COMP I
COMP II
COMP V
COMP VI
R-AM
TC-5 Upper Comp
R-AC
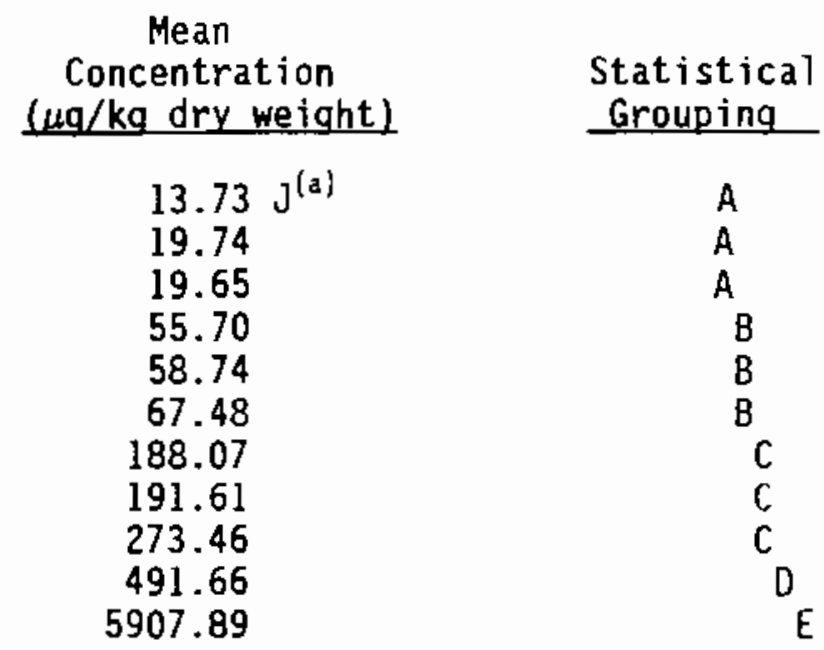

(a) J Analyte detected below method detection limit (MDL) but above instrument detection limit (IDL).

TABLE M.9. ANOVA Results for Pyrene in N. caecoides Tissues, Richmond Harbor Program

\begin{tabular}{|c|c|c|c|c|c|}
\hline $\begin{array}{l}\text { Source of } \\
\text { Variation }\end{array}$ & $\begin{array}{r}\text { Sum of } \\
\text { Squares }\end{array}$ & d.f. & $\begin{array}{c}\text { Mean } \\
\text { Square }\end{array}$ & F-Ratio & $\begin{array}{c}\text { Significance } \\
\text { Level }\end{array}$ \\
\hline $\begin{array}{l}\text { Treatment } \\
\text { Residual }\end{array}$ & $\begin{array}{r}154.155 \\
1.732\end{array}$ & $\begin{array}{l}10 \\
44\end{array}$ & $\begin{array}{r}15.415 \\
0.039\end{array}$ & 391.508 & 0.0001 \\
\hline
\end{tabular}


IABLE M.10. Mean Concentrations and Statistical Grouping for Chrysene in $N$. caecoides Tissues, Richmond Harbor Program

Sediment

Treatment

$\mathrm{R}-\mathrm{OS}$

$\mathrm{R}-\mathrm{PF}$

COMP I

COMP II

$\mathrm{R}-\mathrm{BF}$

COMP VI

COMP V

R-AM

TC-5 Upper Comp

$\mathrm{R}-\mathrm{AC}$
Mean

Concentration

( $\mu \mathrm{g} / \mathrm{kg}$ dry weight)

$7.48 \mathrm{U}^{(\mathrm{a})} \mathrm{J}^{(\mathrm{b})}$

$6.52 \mathrm{~J}$

13.290

14.62

19.106

25.47

25.62

51.78

87.64

318.76
Statistical

Grouping

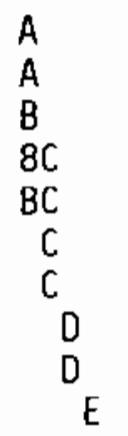

(a) $U$ The analyte was not present above the level of the associated value.

(b) J Analyte detected below method detection limit (MDL) but above instrument detection limit (IOL).

TABLE M.11. ANOVA Results for Chrysene in N. caecoides Tissues, Richmond Harbor Program

\begin{tabular}{|c|c|c|c|c|c|}
\hline $\begin{array}{l}\text { Source of } \\
\text { Variation }\end{array}$ & $\begin{array}{r}\text { Sum of } \\
\text { Squares }\end{array}$ & d.f. & $\begin{array}{l}\text { Mean } \\
\text { Square }\end{array}$ & F-Ratio & $\begin{array}{c}\begin{array}{c}\text { Significance } \\
\text { Level }\end{array} \\
\end{array}$ \\
\hline $\begin{array}{l}\text { Treatment } \\
\text { Residual }\end{array}$ & $\begin{array}{r}66.674 \\
3.666\end{array}$ & $\begin{array}{r}9 \\
40\end{array}$ & $\begin{array}{l}7.408 \\
0.092\end{array}$ & 80.834 & 0.0001 \\
\hline
\end{tabular}


TABLE M.12. Mean Concentrations and Statistical Grouping for Aroclor 1254 in $N$. caecoides Tissues, Richmond Harbor Program

Sediment

Treatment

$\mathrm{R}-\mathrm{PF}$

$\mathrm{R}-\mathrm{OS}$

COMP III

COMP I

R-AM

R-BF

COMP II

$\mathrm{R}-\mathrm{AC}$

COMP V

COMP VI

TC-5 Upper Comp
Mean

Concentration

( $\mu \mathrm{g} / \mathrm{kg}$ dry weight)

$60.21 \mathrm{U}^{(a)}$

$73.75 \mathrm{U}$

75.53

93.82

96.74

151.91

172.22

186.47

317.81

362.74

410.42
Statistical

Grouping

A

A

$A B$

$A B C$

$A B C$

$B C$

$\mathrm{CD}$

$\mathrm{CD}$

$\mathrm{DE}$

E

(a) U The analyte was not present above the level of the associated value.

TABLE M.13. ANOVA Results for Aroclor 1254 in N. caecoides Tissues, Richmond Harbor Program

\begin{tabular}{|c|c|c|c|c|c|}
\hline $\begin{array}{l}\text { Source of } \\
\text { Variation }\end{array}$ & $\begin{array}{r}\text { Sum of } \\
\text { Squares }\end{array}$ & d.f. & $\begin{array}{l}\text { Mean } \\
\text { Square }\end{array}$ & F-Ratio & $\begin{array}{c}\begin{array}{c}\text { Significance } \\
\text { Level }\end{array} \\
\end{array}$ \\
\hline $\begin{array}{l}\text { Treatment } \\
\text { Residua? }\end{array}$ & $\begin{array}{r}24.187 \\
4.112\end{array}$ & $\begin{array}{l}10 \\
44\end{array}$ & $\begin{array}{l}2.419 \\
0.093\end{array}$ & 25.880 & 0.0001 \\
\hline
\end{tabular}


TABLE M.14. Mean Concentrations and Statistical Grouping for $4,4^{\prime}$-DDD in $N$. caecoides Tissues, Richmond Harbor Program

Sediment
Treatment
R-PF
R-OS
R-AM
COMP III
R-BF
R-AC
COMP I
COMP II
TC-5 Upper Comp
COMP V
COMP VI

$\begin{gathered}\text { Mean } \\ \text { Concentration } \\ (\mu \mathrm{g} / \mathrm{kg} \text { dry weight })\end{gathered}$
$1.42 \mathrm{U}^{(\mathrm{a})}$
$1.73 \mathrm{U}$
$1.94 \mathrm{U}$
2.19
2.78
5.91
5.97
12.97
18.80
76.11
105.48

Statistical Grouping

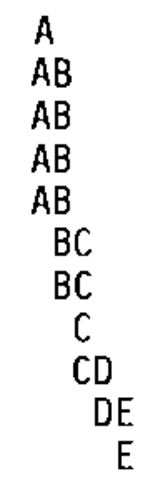

(a) $U$ The analyte was not present above the level of the associated value.

TABLE M.15. ANOVA Results for $4,4^{\prime}-$ DDD in $N$. caecoides Tissues, Richmond Harbor Program

\begin{tabular}{lrrrrr}
$\begin{array}{l}\text { Source of } \\
\text { Variation }\end{array}$ & $\begin{array}{r}\text { Sum of } \\
\text { Squares }\end{array}$ & d.f. & $\begin{array}{c}\text { Mean } \\
\text { Square }\end{array}$ & $\underline{\text { F-Ratio }}$ & $\begin{array}{c}\text { Significance } \\
\text { Leve] }\end{array}$ \\
\hline Treatment & 120.746 & 10 & 12.075 & 26.955 & 0.0001 \\
Residual & 19.710 & 44 & 0.448 & &
\end{tabular}


TABLE M.16. Mean Concentrations and Statistical Grouping for $4,4^{\prime}$-DDE in $N$. caecoides Tissues, Richmond Harbor Program

Sediment
Treatment
R-AM
COMP III
R-OS
R-PF
R-BF
R-AC
COMP I
CDMP II
TC-5 Upper Comp
COMP VI
COMP V

\begin{tabular}{c}
$\begin{array}{c}\text { Mean } \\
\text { Concentration } \\
(\mu \mathrm{k} / \mathrm{kg} \text { dry weight })\end{array}$ \\
\hline 5.08 \\
5.88 \\
7.94 \\
8.86 \\
9.40 \\
10.02 \\
12.70 \\
14.58 \\
23.27 \\
37.33 \\
40.41
\end{tabular}

IABLE M.17. ANOVA Results for $4,4^{\prime}-$ DDE in N. caecoides Tissues, Richmond Harbor Program

\begin{tabular}{|c|c|c|c|c|c|}
\hline $\begin{array}{l}\text { Source of } \\
\text { Variation }\end{array}$ & $\begin{array}{l}\text { Sum of } \\
\text { Squares }\end{array}$ & d.f. & $\begin{array}{l}\text { Mean } \\
\text { Square }\end{array}$ & F-Ratio & $\begin{array}{c}\text { Significance } \\
\text { Leve] }\end{array}$ \\
\hline $\begin{array}{l}\text { Treatment } \\
\text { Residual }\end{array}$ & $\begin{array}{r}24.395 \\
3.496\end{array}$ & $\begin{array}{l}10 \\
44\end{array}$ & $\begin{array}{l}2.439 \\
0.079\end{array}$ & 30.703 & 0.0001 \\
\hline
\end{tabular}


TABLE M.18. Mean Concentrations and Statistical Grouping for Silver in $N$. caecoides Tissues, Richmond Harbor Program

$\begin{array}{lcc}\begin{array}{c}\text { Sediment } \\ \text { Ireatment }\end{array} & \begin{array}{c}\text { Mean } \\ \text { Concentration } \\ \text { (mg/kg dry weight) }\end{array} & \begin{array}{c}\text { Statistical } \\ \text { Grouping }\end{array} \\ \text { COMP IV } & 0.024 & \mathrm{~A} \\ \text { COMP V } & 0.030 & \mathrm{AB} \\ \text { R-PF } & 0.029 & \mathrm{AB} \\ \text { R-BF } & 0.031 & \mathrm{AB} \\ \text { COMP III } & 0.030 & \mathrm{AB} \\ \text { COMP I } & 0.033 & \mathrm{AB} \\ \text { COMP VI } & 0.035 & \mathrm{AB} \\ \text { R-AC } & 0.038 & \mathrm{AB} \\ \text { R-0S } & 0.041 & \mathrm{AB} \\ \text { TC-5 Upper Comp } & 0.047 & \mathrm{AB} \\ \text { COMP I I } & 0.048 & \mathrm{AB} \\ \text { R-AM } & 0.056 & \mathrm{~B}\end{array}$

TABLE M.19. ANOVA Results for Silver in $N$. caecoides Tissues, Richmond Harbor Program

\begin{tabular}{lccccc}
$\begin{array}{l}\text { Source of } \\
\text { Variation }\end{array}$ & $\begin{array}{c}\text { Sum of } \\
\text { Squares }\end{array}$ & d.f. & $\begin{array}{c}\text { Mean } \\
\text { Square }\end{array}$ & $\underline{\text { F-Ratio }}$ & $\begin{array}{c}\text { Significance } \\
\text { Level }\end{array}$ \\
\cline { 2 - 5 } & 3.633 & 11 & 0.330 & 1.831 & 0.0745 \\
Treatment & 8.656 & 48 & 0.180 & &
\end{tabular}


IABLE M.20. Mean Concentrations and Statistical Grouping for Arsenic in N. caecoides Tissues, Richmond Harbor Program

Sediment
Ireatment
R-AM
R-OS
R-PF
COMP IV
COMP III
R-AC
R-BF
COMP II
COMP V
COMP VI
COMP I
TC-5 Upper Comp

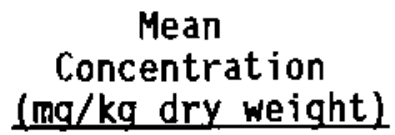

23.5

24.1

25.6

28.2

28.1

28.5

29.6

31.1

31.1

32.8

34.7

35.8
Statistical

Grouping

A

A

$A B$

$A B C$

$A B C$

$A B C$

$A B C$

$\mathrm{ABC}$

$A B C$

$\mathrm{BC}$

C

C

TABLE M.21. ANOVA Results for Arsenic in N. caecoides Tissues, Richmond Harbor Program

Source of Sum of

Variation Squares

Treatment Residua]
0.990

0.886
Mean

$\underline{\text { d.f. }}$

11

48
Square

0.090

0.018
F-Ratio

4.873

Significance Leve]

0.0001 
TABLE M.22. Mean Concentrations and Statistical Grouping for Cadmium in N. caecoides Tissues, Richmond Harbor Program

Sediment
Treatment
R-BF
TC-5 Upper Comp
COMP III
COMP V
COMP IV
COMP II
R-PF
R-OS
R-AC
COMP VI
COMP I
R-AM

$\begin{gathered}\text { Mean } \\ \text { Concentrat } \\ \text { (mg } / \mathrm{kg} \text { dry }\end{gathered}$
0.95
0.97
1.04
1.08
1.12
1.11
1.11
1.16
1.17
1.17
1.17
1.18

A

A

A

A

A

A

A

A

A

A

A

A

TABLE M.23. ANOVA Results for Cadmium in N. caecoides Tissues, Richmond Harbor Program

\begin{tabular}{lccccc}
$\begin{array}{c}\text { Source of } \\
\text { Variation }\end{array}$ & $\begin{array}{c}\text { Sum of } \\
\text { Squares }\end{array}$ & $\underline{\text { d.f. }}$ & $\begin{array}{c}\text { Mean } \\
\text { Square }\end{array}$ & E-Ratio & $\begin{array}{c}\text { Significance } \\
\text { Level }\end{array}$ \\
\cline { 2 - 5 } & 0.313 & 11 & 0.028 & 0.954 & 0.4994 \\
Treatment & 0.330 & 48 & 0.030 & &
\end{tabular}


TABLE M.24. Hean Concentrations and Statistical Grouping for Chromium in N. caecoides Tissues, Richmond Harbor Program

Sediment
Treatment
COMP II
COMP IV
COMP V
COMP I
R-AC
R-AM
R-OS
COMP III
COMP VI
R-PF
R-BF
TC-5 Upper Comp

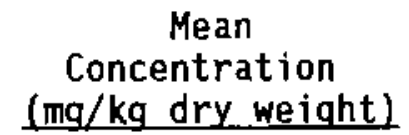

0.67

0.69

0.73

0.77

0.77

0.84

0.86

0.85

0.89

0.89

0.91

1.16
Statistical
Grouping

A

A

A

A

A

A

A

A

A

A

A

TABLE M.25. ANOVA Results for Chromium in N. caecoides Tissues, Richmond Harbor Program

Source of Sum of

Variation Squares

Treatment

Residual
1.326

4.663
Mean

Square

11

48

0.121

0.097
Significance

F-Ratio Level

1.241

0.2871 
IABLE M.26. Mean Concentrations and Statistical Grouping for Copper in $N$. caecoides Tissues, Richmond Harbor Program

Sediment
Treatment
R-BF
COMP III
COMP IV
TC-5 Upper Comp
COMP V
R-AM
R-PF
R-OS
R-AC
COMP VI
COMP II
COMP I

$\begin{array}{cr}\begin{array}{c}\text { Mean } \\ \begin{array}{c}\text { Concentration } \\ \text { (ma/kg dry weight) }\end{array}\end{array} & \begin{array}{r}\text { Statist } \\ \text { Group }\end{array} \\ 10.80 & \mathrm{~A} \\ 11.16 & \mathrm{~A} \\ 11.49 & \mathrm{~A} \\ 11.55 & \mathrm{~A} \\ 11.84 & \mathrm{~A} \\ 12.07 & \mathrm{~A} \\ 11.88 & \mathrm{~A} \\ 11.86 & \mathrm{~A} \\ 13.21 & \mathrm{~A} \\ 13.20 & \mathrm{~A} \\ 13.82 & \mathrm{~A} \\ 14.16 & \mathrm{~A}\end{array}$

TABLE M.27. ANOVA Results for Copper in N. caecoides Tissues, Richmond Harbor Program

\begin{tabular}{|c|c|c|c|c|c|}
\hline $\begin{array}{l}\text { Source of } \\
\text { Variation }\end{array}$ & $\begin{array}{r}\text { Sum of } \\
\text { Squares }\end{array}$ & $\underline{d . f}$. & $\begin{array}{c}\text { Mean } \\
\text { Square }\end{array}$ & F-Ratio & $\begin{array}{c}\text { Significance } \\
\text { Level }\end{array}$ \\
\hline $\begin{array}{l}\text { Treatment } \\
\text { Residual }\end{array}$ & .409 & $\begin{array}{l}11 \\
48\end{array}$ & $\begin{array}{l}0.037 \\
0.018\end{array}$ & .025 & 0.0464 \\
\hline
\end{tabular}


TABLE M.28. Mean Concentrations and Statistical Grouping for Mercury in $N$. caecoides Tissues, Richmond Harbor Program

Sediment
Ireatment
R-AC
TC-5 Upper Comp
COMP V
COMP IV
COMP VI
COMP II
R-OS
R-AM
R-PF
COMP I
COMP III
R-BF

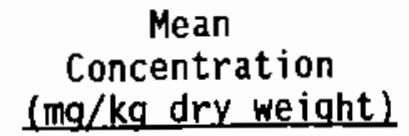

0.062

0.064

0.065

0.069

0.069

0.075

0.074

0.078

0.078

0.080

0.079

0.084
Statistical

Grouping

A

A

A

A

A

A

A

A

A

A

A

A

TABLE M.29. ANOVA Results for Mercury in N. caecoides Tissues, Richmond Harbor Program

\begin{tabular}{|c|c|c|c|c|c|}
\hline $\begin{array}{l}\text { Source of } \\
\text { Variation }\end{array}$ & $\begin{array}{r}\text { Sum of } \\
\text { Squares }\end{array}$ & $\mathrm{d}, \mathrm{f}$, & $\begin{array}{c}\text { Mean } \\
\text { Square }\end{array}$ & F-Ratio & $\begin{array}{c}\text { Significance } \\
\text { Level }\end{array}$ \\
\hline $\begin{array}{l}\text { Treatment } \\
\text { Residual }\end{array}$ & $\begin{array}{l}0.566 \\
1.181\end{array}$ & $\begin{array}{l}11 \\
48\end{array}$ & $\begin{array}{l}0.051 \\
0.025\end{array}$ & 2.091 & 0.0394 \\
\hline
\end{tabular}


IABLE M,30. Mean Concentrations and Statistical Grouping for Nickel in $N$. caecoides Tissues, Richmond Harbor Program

Sediment
Treatment
COMP V
R-BF
COMP I
COMP VI
R-OS
R-PF
R-AC
COMP IV
TC-5 Upper Comp
R-AM
COMP I I
COMP I I

Mean

Concentration

(mq/kg dry weight)

3.76

4.41

4.65

4.88

5.33

5.30

5.44

5.48

5.48

5.56

5.78

5.70
Statistical

Grouping

A

A

A

A

A

A

A

A

A

A

A

TABLE M.31. ANOVA Results for Nickel in N. caecoides Tissues, Richmond Harbor Program

\begin{tabular}{lccccc}
$\begin{array}{l}\text { Source of } \\
\text { Variation }\end{array}$ & $\begin{array}{c}\text { Sum of } \\
\text { Squares }\end{array}$ & $\underline{\text { d.f. }}$ & $\begin{array}{c}\text { Mean } \\
\text { Square }\end{array}$ & $\underline{\text { F-Ratio }}$ & $\begin{array}{c}\text { Significance } \\
\text { Leve] }\end{array}$ \\
\hline Treatment & 0.882 & Il & 0.080 & 1.792 & 0.0819 \\
Residual & 2.148 & 48 & 0.045 & &
\end{tabular}




\section{TABLE M.32. Mean Concentrations and Statistical Grouping for Lead in N. caecoides Tissues, Richmond Harbor Program}

$\begin{array}{lcc}\begin{array}{l}\text { Sediment } \\ \text { Ireatment }\end{array} & \begin{array}{c}\text { Mean } \\ \text { Concentration } \\ \text { (mg/kgdry weight) }\end{array} & \begin{array}{c}\text { Statistical } \\ \text { Grouping }\end{array} \\ \text { COMP IV } & 0.62 & \\ \text { R-AM } & 0.62 & A \\ \text { R-OS } & 0.62 & A B \\ \text { COMP II } & 0.74 & A B \\ \text { R-PF } & 1.44 & A B \\ \text { R-AC } & 0.96 & A B \\ \text { COMP II } & 0.96 & A B \\ \text { COMP I } & 1.05 & A B \\ \text { R-BF V } & 1.07 & A B \\ \text { COMP V } & 1.12 & A B \\ \text { COMP VI } & 1.24 & A B \\ \text { TC-5 Upper Comp } & 1.26 & A B \\ & & B\end{array}$

TABLE M.33. ANOVA Results for Lead in N. caecoides Tissues, Richmond Harbor Program

\begin{tabular}{|c|c|c|c|c|c|}
\hline $\begin{array}{l}\text { Source of } \\
\text { Variation }\end{array}$ & $\begin{array}{r}\text { Sum of } \\
\text { Squares }\end{array}$ & d.f. & $\begin{array}{c}\text { Mean } \\
\text { Square }\end{array}$ & F-Ratio & $\begin{array}{c}\text { Significance } \\
\text { Level }\end{array}$ \\
\hline $\begin{array}{l}\text { Treatment } \\
\text { Residual }\end{array}$ & $\begin{array}{l}3.912 \\
5.306\end{array}$ & $\begin{array}{l}11 \\
48\end{array}$ & $\begin{array}{l}0.356 \\
0.111\end{array}$ & 3.217 & 0.0 \\
\hline
\end{tabular}


TABLE M.34. Mean Concentrations and Statistical Grouping for Selenium in $N$. caecoides Tissues, Richmond Harbor Program

Sediment

Ireatment

COMP III

$\mathrm{R}-\mathrm{BF}$

COMP II

$\mathrm{R}-\mathrm{PF}$

COMP IV

R-AM

COMP VI

COMP I

$\mathrm{R}-\mathrm{AC}$

$\mathrm{R}-\mathrm{OS}$

COMP $V$

TC-5 Upper Comp

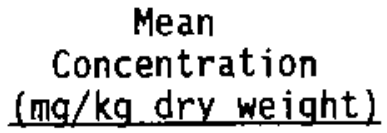

1.36

1.46

1.45

1.48

1.59

1. 57

1.68

1.76

1.72

1.87

1.88

2.04
Statistical

Grouping.

A

A

A

A

A

A

A

A

A

A

A

IABLE M.35. ANOVA Results for Selenium in N. caecoides Tissues, Richmond Harbor Program

\begin{tabular}{lccccc}
$\begin{array}{l}\text { Source of } \\
\text { Variation }\end{array}$ & $\begin{array}{c}\text { Sum of } \\
\text { Squares }\end{array}$ & $\underline{\text { d.f. }}$ & $\begin{array}{c}\text { Mean } \\
\text { Square }\end{array}$ & $\underline{\text { F-Ratio }}$ & $\begin{array}{c}\text { Significance } \\
\text { Leve] }\end{array}$ \\
\cline { 2 - 5 } & 0.894 & 11 & 0.081 & 0.894 & 0.5522 \\
Treatment & 0.360 & 48 & 0.091 & &
\end{tabular}


TABLE M.36. Mean Concentrations and Statistical Grouping for Zinc in N. caecoides Tissues, Richmond Harbor Program

Sediment
Ireatment
R-OS
R-BF
R-PF
COMP IV
COMP V
TC-5 Upper Comp
COMP III
R-AM
COMP I
COMP VI
COMP II
R-AC

\begin{tabular}{c}
$\begin{array}{c}\text { Mean } \\
\text { Concentration } \\
\text { (mg/kg dry weight) }\end{array}$ \\
\hline 182.1 \\
186.0 \\
186.4 \\
189.4 \\
190.9 \\
193.1 \\
194.9 \\
196.7 \\
200.7 \\
201.6 \\
203.1 \\
204.5
\end{tabular}

Statistica]

Grouping

A

A

A

A

A

A

A

A

A

A

A

A

TABLE M.37. ANOVA Results for Zinc in N. caecoides Tissues, Richmond Harbor Program

\begin{tabular}{|c|c|c|c|c|c|}
\hline $\begin{array}{l}\text { Source of } \\
\text { Variation }\end{array}$ & $\begin{array}{r}\text { Sum of } \\
\text { Squares }\end{array}$ & d.f. & $\begin{array}{c}\text { Mean } \\
\text { Square }\end{array}$ & F-Ratio & $\begin{array}{c}\begin{array}{c}\text { Significance } \\
\text { Level }\end{array} \\
\end{array}$ \\
\hline $\begin{array}{l}\text { Treatment } \\
\text { Residual }\end{array}$ & $\begin{array}{l}0.075 \\
0.336\end{array}$ & $\begin{array}{l}11 \\
48\end{array}$ & $\begin{array}{l}0.007 \\
0.007\end{array}$ & .9 & 0.4 \\
\hline
\end{tabular}


TABLE M.38. Mean Concentrations and Statistical Grouping for Dibutyltin in N. caecoides Tissues, Richmond Harbor Program

Sediment

Treatment

$\mathrm{R}-\mathrm{PF}$

R-AM

COMP V

$\mathrm{R}-\mathrm{BF}$

COMP VI

$\mathrm{R}-\mathrm{AC}$

R-OS
Mean

Concentration ( $\mu \mathrm{g} / \mathrm{kg}$ dry weight)

$51.51 \mathrm{U}^{(\mathrm{a})} \mathrm{J}^{(\mathrm{b})}$

45.31 UJ

49.64

57.60

61.96

$77.57 \mathrm{UJ}$

$78.53 \mathrm{U}$
Statistical

Grouping

A

A

A

A

A

A

A

(a) $U$ The analyte was not present above the level of the associated value.

(b) J Analyte detected below method detection limit (MDL) but above instrument detection 1 imit (IDL).

TABLE M.39. ANOVA Results for Dibutylt in in N. caecoides Tissues, Richmond Harbor Program

Source of Sum of

Variation squares

Treatment

Residual
2.521

8.582
Mean

Square

0.420

0.306
F-Ratio

1.371

d.f.
6
28

Significance Level

0.2605 
IABLE M.40. Mean Concentrations and Statistical Grouping for Tributyltin in $N$. caecoides Tissues, Richmond Harbor Program

Sediment
Treatment

$R-A C$

R-PF

COMP VI

COMP $V$

$R-0 S$

R-AM

$\mathrm{R}-\mathrm{BF}$

COMP I

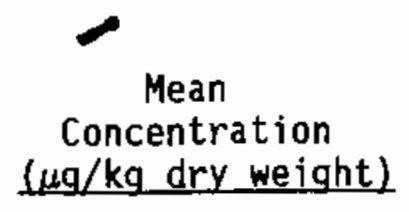

76.81

88.79

99.35

97.50

105.77

119.03

$146.92 \mathrm{U}^{(\mathrm{a})} \mathrm{J}^{(\mathrm{b})}$

171.81
Statistical

Grouping

$A$
$A$
$A$
$A$
$A$
$A$
$A$
$A$

(a) $U$ The analyte was not present above the level of the associated value. (b) J Analyte detected below method detection limit (MDL) but above instrument detection 1 imit (IDL).

TABLE M.41. ANOVA Results for Dibutyltin in N. caecoides Tissues, Richmond Harbor Program

\begin{tabular}{|c|c|c|c|c|c|}
\hline $\begin{array}{l}\text { Source of } \\
\text { Variation }\end{array}$ & $\begin{array}{r}\text { Sum of } \\
\text { Soguares }\end{array}$ & d.f. & $\begin{array}{c}\text { Mean } \\
\text { Square }\end{array}$ & F-Ratio & $\begin{array}{c}\begin{array}{c}\text { Significance } \\
\text { Level }\end{array} \\
\end{array}$ \\
\hline $\begin{array}{l}\text { Treatment } \\
\text { Residual }\end{array}$ & $\begin{array}{r}2.527 \\
11.563\end{array}$ & $\begin{array}{r}7 \\
32\end{array}$ & $\begin{array}{l}0.361 \\
0.361\end{array}$ & 0.999 & 0.4499 \\
\hline
\end{tabular}


PNL -8389

\section{DISTRIBUTION}

No. of

Copies

\section{OFFSITE}

2 DOE/0ffice of Scientific and Technical Information

2 R. Chisholm

U.S. Army Corps of Engineers San Francisco District

211 Main Street

San Francisco, CA 94105

S. Clark Ocean Protection Section W71

U.S. EPA Region 9

75 Hawthorne Street

San Francisco, CA 94105-3901

R. Giachino

U.S. Army Corps of Engineers

San Francisco District

211 Main Street

San Francisco, CA 94105

$5 \quad$ K. Guy

U.S. Army Corps of Engineers

San Francisco District

211 Main Street

San Francisco, CA 94105

A. Lincoff

Superfund

$\mathrm{H} 63$

U.S. EPA Region 9

75 Hawthorne Street

San Francisco, CA 94105-3901

B. Opton

U.S. Army Corps of Engineers

San Francisco District

211 Main Street

San Francisco, CA 94105
No. of

Copies

B. Ross

Wetlands and Coastal

Protection Section

W74

U.S. EPA Region 9

75 Hawthorne Street

San Francisco, CA 94105-3901

2 G. Serex

1411 Harbor Way South

P.0. Box 4046

Richmond, CA 94804

\section{ONSITE}

DOE Richland Field office

P. W. Kruger

A5-90

33 Pacific Northwest Laboratory

E. S. Barrows

SEQUI

R. Cuel1o

SEQUI

R. M. Ecker

SEQUI

M. R. Finney

SEQUI

W. R. Gorst

K6-86

N. P. Kohn

SEQUI

L. F. Lefkovitz SEQUI

H. L. Mayhew

SEQUI

M. R. Pinza (5)

J. A. Trelstad (2)

SEQUI

J. A. Ward

J. Q. Word (10)

Publishing Coordination

Technical Report Files (5)

SEQUI

SEQUI

SEQUI

$\underline{\text { Routing }}$

M. J. Graham

K6-80

C. J. Hostetler

$K 6-81$

P. M. Irving

K6-98

R. L. Skaggs

$\mathrm{K} 6-77$

C. S. Sloane

K6-04

P. C. Hays (1 ast)

K6-86 
